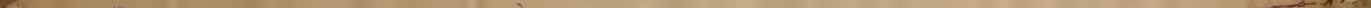



Verlag von J. F. Bergmann in Wiesbaden.

Soeben erschien:

\title{
Einführung
}

in die

\section{Experimentelle Entwickelungsséeschichte}

\section{(Entwickelungsmechanik).}

\author{
Von \\ Dr. Otto Maas, \\ a. o. Professor an der Unirersität München. \\ Mut 135 Figuren im Text. - Preis: Mk. 7.-.
}

\section{Auszug aus Besprechungen:}

... Der Verf, welcher selber einige wertvolle Experimente auf dem Gebiete der Entwickelungsmechanik gemacht hat, bietet uns ein kleines, aber seinem Zwecke der Einführung in das Gebiet der Entwickelungsmechanik entsprechendes Buch dar. Es ist aus Vorlesungen hervorgegangen, die der Autor in der gleichen Absicht gehaiten hat; und $\mathrm{M}$ a as war zweckmässigerweise bestrebt, besonders die bereits ermittelten $\mathrm{T}$ atsachen, weniger die verschiedenen zu ihrer Erklärung aufgestellten Theorien deu Lesern vorzuführen.

Man darf sagen, dass Maas die Aufgabe, die er sich gestellt hat, im ganzen gut gelöst hat. Die Darstellung ist klar, die Einleitung der Kapitel setzt zumeist in sehr gut einfiihrender Weise auseinander, worum es sich handelt und gibt die allgenneine Bedeutung des zu erwähnenden Details geschickt an ...

... Zum erstenmal in einem zusammenfassenden Werk wird hier auch die funktionelle Anpassung mehr als ganz aphoristisch behandelt. Das ist verdienstlich; und $\mathrm{M}$ a a s bringt auch einige Beispiele seiver eigenen Beobachtung und interessiert sich offenbar für dies Gebiet . . .

... Sehen wir zum Schluss von den mancherlei Vervollständigungen und Änderungen, die wir dem Buche $\mathrm{Ma}$ as' für seine folgenden Auflagen wünschen, ab, so ist das Buch doch im ganzen als ein den Leser von den meisten Hauptsachen des neuen Gebietes in gewaudter, leicht verständlicher und interessanter Darstellung unterrichtendes Werk zu bezeichnen. Wir begrüssen es daher als eine erfreuliche und nützliche Bereicherung der Literatur unseres Forschungsgebietes. ... Prof. Roux im Archiv f. Entwickelungsmechanik der Organismen. 


\section{OSMOTISCHER DRUCK}

UND

\section{IONENLEHRE}

IN DEN

MEDICINISCHEN WISSENSCHAFTEN.

ZUGLEICH

LEHRBUCH PHYSIKALISCH-CHEMISCHER METHODEN. 



\title{
OSMOTISCHER DRUCK
}

UND

\section{IONENLEHRE}

IN DEN

\section{MEDICINISCHEN WISSENSCHAFTEN.}

\author{
ZUGLEICH
}

LEHRBUCH PHYSIKALISCH-CHEMISCHER METHODEN.

VON

DR. CHEM. ET MED. H. J. HAMBURGER,

PROFESSOR DER PHYSIOLOGIEAN DER REICHSUNIVERSITÄT GRONINGEN.

BAND III :

ISOLIRTE ZELLEN, COLLOIDE UND FERMENTE. MUSKEL- UND NERYENPHYSIOLOGIE. OPHTALMOLOGIE. GESCHMACK. EMBRYOLOGIE. PHARMAROLOGIE. BALNEOLOGIE. BACTERIOLOGIE. HISTOLOGIE.

MIT 1 TAFEL UND 8 ABBILDUNGEN IM TEXT.

\section{WIESBADEN.}

VERLAG VON J. F. BERGMANN. 
Nachdruck verboten.

Uebersetzungen, auch ins Ungarische, vorbehalten.

Druck der Kgl. Universitatsdruckerei von H. Stürtz in Würzburg.

Printed in Germany 


\section{Vorwort zum II. und III. Bande.}

Mit dem vorliegenden Bande ist das Buch, dessen ersten Band ich im Februar 1902 dem Publicum vorlegen konnte und dessen zweiten ich im Mai dieses Jahres folgen liess, zum Abschluss gebracht. Mein ursprünglicher Plan, das Werk in zwei Bänden erscheinen zu lassen, musste eine Aenderung erfahren. Der Zufluss von Material während der Bearbeitung veranlasste eine so erhebliche Ausdehnung, dass eine Vertheilung über drei Bände nothwendig erschien. Es war nicht möglich, diesen Zufluss durch Abkürzung der Behandlungsweise auszugleichen, wollte ich mein Buch in demselben Geiste weiter führen, in dem der erste Band verfasst war.

Wie dort, so wurde nämlich auch im zweiten und dritten Bande eine historisch-kritische Behandlungsweise befolgt und bemühte ich mich wieder, dem Leser durchweg ein selbstständiges Urtheil über meine eigenen Arbeiten und die denselben zu Theil gewordene Kritik, sowie über die Arbeiten Anderer und die Richtigkeit meiner Bemerkungen zu diesen, zu ermöglichen. Fs liegt auf der Hand, dass diese Behandlungsweise eine nicht zu beschränkte Vorführung von Thatsachen-Material erforderte.

Ferner entsprang eine gewisse Breite der Darstellung aus meinem Wunsch, dem Buche auch weiterhin den Charakter eines Lehrbuchs physikalisch-chemischer Methoden zu wahren. Dementsprechend sollten wieder an allen einschlägigen Stellen so genaue Beschreibungen gegeben werden, dass man olıne Weiteres im Stande sein würde, im Laboratorium danach zu arbeiten; ich verweise in dieser Beziehung beispielsweise auf die während der Bearbeitung nothwendig gewordene Behandlung der elektrochemischen Aciditätsbestimmung (Bd. II, S. 330-391).

Auch erschien es mehrfach nothwendig, Auseinandersetzungen, die von Chemikern oder für Chemiker geschrieben und in denen mathema- 
tische Entwicklungen als bekannt rorausgesetzt waren, in dieser Beziehung zu ergänzen und ins Einzelne auszuarbeiten. Olne das wären die betreffenden Untersuchungen wohl für einen grossen Theil der Mediciner fast unverständlich geblieben.

Fügt man noch hinzu, dass während der Bearbeitung wiederholt sich Fragen erhoben, die eine sofortige experimentelle Prüfung unerlässlich erscheinen liessen und die ich deshalb selbst bearbeitete oder von meinen Schülern bearbeiten liess, so wird man es verstehen, dass das Werk einen grösseren Umfang erhielt, als anfänglich in meiner Absicht lag.

Ich hoffe, dass mein Buch dazu beitragen wird, die Anwendung der physikalischen Chemie, die doch das wesentliche Verdienst hat, tiefer in die Vorgänge der Materie einzudringen, in den medicinischen Wissenschaften zu fördern. Aber ich hoffe auch, dass es dazu beitragen wird, die Ueberschätzung zu beschränken, die jede neue Strömung in einer Wissenschaft im Anfang so leicht erfährt und von der fast immer eine zeitweilige Geringschätzung die Folge zu sein ptlegt.

Wiederum hatte ich mich der Mitwirkung des Herrn Dr. L. Gr ünhut, Docenten und Abtheilungsvorsteher am chemischen Laboratorium Fresenius in Wiesbaden zu erfreuen. Die Correctur einer Arbeit aus sprachlichem Gesichtspunkte kann wohl kaum in gehöriger Weise erledigt werden, wenn man sich nicht genau in den Gedankengang des Verfassers eingearbeitet hat. Diese für einen Nichtmediziner besonders in Band II und III sehr schwierige Aufgabe hat Herr Dr. Grünhut in musterhafter Weise erfüllt. Oft hatte ich Gelegenheit, den grossen Scharfsinn zu bewundern, mit dem er in das Wesen ihm ferner stehender Probleme sich vertiefte. Zweifellos ist das dem Werke zu Gute gekommen. Auch für die sachverständige Controlle vieler Rechnungen spreche ich Herrn Dr. Grü nhut hier meinen wärmsten Dank aus.

Schliesslich sei es inir erlaubt, auch dem Verleger, Herrn J. F. Bergmann, meinen verbindlichsten Dank für die der Ausstattung des Werkes zugewendete Sorgfalt auszusprechen, sowie für die liebenswürdige Weise, in welcher er jedem Wunsche meinerseits entgegengekommen ist. Es war mir in jeder Hinsicht eine Freude nit ihm zusammen zu arbeiten.

Groningen, Juni 1904.

\section{H. J. Hamburger.}




\section{Inhalts-Verzeichniss.}

I. Ka pitel.

Osmotisches Verhalten verschiedener isolirter Zellen

1. Spermatozoen . . . . . . . . . . . . . . . . . . . . 2

a) Beeinflussung der Beweglichkeit durch Salze . . . 2

b) Volumänderungen durch anisotonische Salzlösungen 4

2. Epithel . . . . . . . . . . . . . . . . . 7

Volnuänderungen isolirter Fpithelzellen und dereu Kerue dnrch anisotonische Lösungen . . . . . . . . . . . . . . 7

a) Darmepithel . . . . . . . . . . . . . 8

Discussion der Resultate . . . . . . . . . . 18

Mikroskopische Messung der Zellkerne . . . . . . . 19

b) Fliminerepithel . . . . . . . . . . . . 21

Mikroskopische Messung der Zellkerne . . . . . . . . 23

c) Blasenepithel . . . . . . . . . . . . . . . . 24

Mikroskopische Messung der Zellkerne . . . . . . . . 26

d) Oesophagusepithel . . . . . . . . . . . . 30

e) Kritik, Zusammenfassung und Discussion . . . . 33

3. Lyuphdrïsenzellen . . . . . . . . . . . . . . 37

Ihre Permeabilität fïr Anionen von Natrimmsalzen . . . . . . 37

a) Permeabilität für $\mathrm{Cl}^{\prime}$. . . . . . . . . . . . 38

b) Permeabilität für $\mathrm{SO}_{4}{ }^{\prime \prime}$. . . . . . . . . . 40

c) Permeabilität für $\mathrm{NO}_{3}{ }^{\prime}$. . . . . . . . . . . . 41

d) Permeabilität für anderweitige elektronegative Ionen 42

c) für $\mathrm{J}^{\prime}$. . . . . . . . . . . . . 43

3) für $\mathrm{PO}_{t}^{\prime \prime \prime}$. . . . . . . . . . . . . . . . . . . 43

y) für $\mathrm{Br}^{*}$. . . . . . . . . . . . . . . . . 44 44

б) für $(\mathrm{COO})_{2}$ " Oxalsäureanion . . . . . . . . . . . . 45

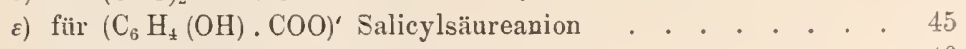

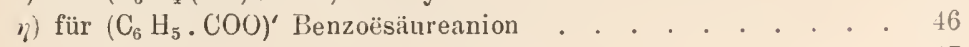

e) Zusammenfassung und Schluss . . . . . . . . 47

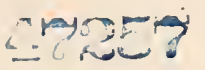


4. Leber-, Milz- nnd Nierenparenchymzellen

Einfluss von Säuren und Alkalien auf deren Volumen. Parenchymatöse Schwellnng . . . . . . . . . . . . . . . . 49

a) Leberzellen . . . . . . . . . . . . . . 50

b) Milzzellen................ . . . 52

c) Nierenzellen . . . . . . . . . . . . . . . . . . . . . . 52

Froscheier in Salzlösungen . . . . . . . . . . . . . . . . 54

II. K a pitel.

Bemerkungen über Colloide und Fermente . . . . . . . . . . . 59

1. Die Natur der Colloide: Lösnng oder Snspension . . . . . . 60

2. Znstandänderungen organischer Colloide . . . . . . . . . 65

a) durch den galvanischen Strom . . . . . . . . . . . . . 66

b) durch Hinzufügung von Ionen (in Säuren, Basen und Salzen) . . 69

3. Metallische Colloide . . . . . . . . . . . . 80

a) Herstellung von Metallsolen durch elektrische Zerstäubung . . . . . . . . . . . 82

b) Katalytische Wirkung der colloidalen Metalle... 84

c) Eigenschaften des Silbersols......... . . 88

d) Vergleichung der Katalyse durch Platin und durch organische Fermente . . . . . . . . . . 91 Ausführungen von Visser . . . . . . . . . . . . 97

e) Ansichten über das Wesender Katalyse . . . . . 104

\section{Ka pitel.}

Zur Muskel- und Nervenphysiologie . . . . . . . . . . . . . . 107

1. Verhalten von Froschmnskeln in Salzlösungen . . . . . . 108

a) Untersuchungen von Nasse . . . . . . . 108

b) Untersuchungen von J. Loeb. . . . . . . 110

a) über den Wassergehalt der Muskeln unter dem Einfluss von

Säuren . . . . . . . . . . . . . . 111

B) Einfluss von Basen . . . . . . . . . . . . . . . . 115

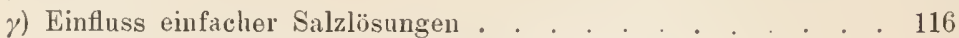

ઈ) Spontane rhytlımische Skelettmuskelzuckungen . . . . . 118

ह) Reizbarkeit durch Contact („Contact-irritability ${ }^{4}$. . . . . 119

ๆ) Ionenproteide und ihre Bedeutung. Giftigkeit einfacher reiner

Salzlösungen . . . . . . . . . . . . 120

1. für Fundulus (Seefisch) . . . . . . . . . . . . . 120

2. für Gonionemus (Meduse) . . . . . . . . . . . . 121

3. für das Herz . . . . . . . . . . . . . . . . 122

Ђ) Hrklärung der unter $\eta$ erwälnten Giftwirkungen und deren Aufheloung mittelst der elektrischen Ladung der Ionen . . . 125

Winige kritische Bemerkungen. Schluss . . . . . . . 128

c) Untersuchungenvou Overton . . . . . . . . 133

a) Verhalten von Muskeln in Salzlösungen . . . . . . . . . 133 
1. in isotonischer NaCl-Lösung - Seite

2. in hypisotonischer Lösung . . . . . . . . . . . . 135

3. in hyperisotonischer Lösung . . . . . . . . . . . 137

ß) Permeabilität der lebenden Muskelfaser für organische, sowie einige anorganische Verbindungen . . . . . . . . . 139

Kritische Bemerkung . . . . . . . . . . . . . . . 144

$\gamma)$ Bedeutung der $\mathrm{Na}$-Ionen für den Contractionsact des Muskels 144

2. Elektromotorische Erscheinumgen an ruhenden Froschunskel 147

a) Demarcationstrom bei künstlichem Querschnitt (T's chagowetseh) . . . . . . . . . . . . 148

b) Allgemeine Bemerkungen über Concentrationsketten 149

a) Wesen der Kette . . . . . . . . . . . . . . 149

ß) Beispiale von Ketten und ihre elektromotorische Krraft . . . 150

y) Constanz der Concentrationsketten . . . . . . . . . . 151

$\delta)$ Einfluss der Permeabilität der Berührungsfläche für Ionen auf die Constanz der Kette . . . . . . . . . . . 152

c) Demarcationstrom durch örtliche Application verschiedener Flüssigkeiten auf den Muskel (Oker Brom) 153

3. Zur Kenntuiss der Nervenreizung . . . . . . . . . . 156

IV. Kapitel.

Ophthalmologisches . . . . . . . . . . . . . . . 161

1. Thränenfliissigkeit . . . . . . . . . . . . . 161

2. Humor aquaens . . . . . . . . . . . . . . . . 163

3. Glaskörper . . . . . . . . . . . . . . 165

4. Linse . . . . . . . . . . . . . . . . . . 166

V. Ka pitel.

Geschmack . . . . . . . . . . . . . . . . . . 169

1. Säıren . . . . . . . . . . . . . . . . 169

2. Langen . . . . . . . . . . . . . . . . . 170

3. Salze . . . . . . . . . . . . . . . . 171

VI. Kapitel.

Embryologisches . . . . . . . . . . . . . . 175

1. Kiinstliche Parthenogenesis . . . . . . . . . . . 176

a) durch Steigerung des osmotischen Drucks . . . . 176

b) durch Ionen . . . . . . . . . . . . . 176

c) Vergleichung des Entwicklungsganges der Eier nach künstlicher Parthenogenesis und nach natürlicher Befruchtung mit Spermatozoen . . . . . . . 178

d) Bedeutung der kïnstlichen Parthenogenesis für die A uffassung der natürlichen Befruchtung und der Lebenserscheinungen im Allgemeinen . . . . . . 179 
2. Intrauterine Verhältuisse

a) Osmotische und osmotisch-chemische Analyse des Blutes bei Mutter und Frucht. Zur Kenntniss des St offaustausches zwischen beiden . . . . . . 182

a) Untersuchungen von Veit . . . . . . . . . . 184 Blutgewinnung . . . . . . . . . . . . . . 184

Resultate . . . . . . . . . . . . . . . . . 184

ß) Untersuchungen von $\mathrm{Kr}$ önig und Fueth...... . 185

$\gamma$ ) Untersuchungen von $\mathrm{Hamburger}$ und $\mathrm{Ubbels} . . . .186$

Untersuchungsmethoden . . . . . . . . . . . . . . 189

1. Gewinnung des Naterials . . . . . . . . . . . 189

2. Farbstoffaustritt . . . . . . . . . . 189

3. Osmotischer Druck . . . . . . . . . . . . . . 190

4. Volumänderungen der Blutkörperchen durch Salzlösungen . 191

5. Elektrisches Leitvermögen von Serum und Blut . . . . 192

6. Chlorbestimmung . . . . . . . . . . . . . 193

7. Alkalinität . . . . . . . . . . . . . . 194

8. Feste Bestandtheile . . . . . . . . . . . . . 195

Versuche . . . . . . . . . . . . . . 195

Discussion del Resultate . . . . . . . . . . . 202

b) Osmotische und osmotisch-chemische Analyse des

Fruchtwassers . . . . . . . . . . . . . 205

c) Untersuchungen von Jacqué über die Genese des

Fruchtwassers. . . . . . . . . . . 2 209

a) beim Schaf . . . . . . . . . . . . 209

в) bei Kuh und Schwein . . . . . . . . . . . . 215

y) beim Menschen . . . . . . . . . . . . . 216

d) Zusammenfassung und Schlussbetrachtung . . . . 218

VII. K a p itel.

\section{Pharmakologisches}

1. Untersuchungen an Pflanzenzellen zur Erforschung der Eindringungsfähigkeit von Substanzen in das Protoplasma und zur Ermittlung von deren Giftigkeit

a) Eindringungsfähigkeit von Substanzen in das Protoplasma von Pflanzenzellen (Untersuchungen von Overton)

œ) osmotometrische (plasmolytische) Methode....... . 226

B) Methode der gerbstoffhaltigen Zellen . . . . . . . . . 230

b) Giftigkeit von Substanzen für das Protoplasma von $\mathrm{Pfl}$ a nzenzellen (Untersuchungen von Vandevelde) . . . . . 232

2. Dosirung von Medicamenten . . . . . . . . . . 237

3. Die Ionenlehre in der Homoeopathie . . . . . . . . . 240

4. Kum Mechanismus der Narkose . . . . . . . . . . . 242

a) Acltere Ansichten . . . . . . . . . . 243

b) Hypothesevon R. Dubors . . . . . . . . 244

c) Hypothesevon H. Neyer und E. Overton . . . . 245 
a) Theorie der Theilungscoeffizientell . . . . . . . . . . 246

ß) Ermittlung des Theilungscoeffizienten bei Narkotica . . . . 247

y) Bedeutung der Theilungscoeffizienten für dio Auffassung des Wirkungsmechanismus von indifferenten Narkotica . . . . 249

ઈ) Wirkung basischer Narkotica . . . . . . . . . . . . 252

5. Pharmakologische Bedeutung von complexen Salzen, erläutert an der therapentischen Anwendung des Quecksilbers . . . . 253

6. Die Lehre von der Desinfection iu Lichte der Theorie der elektrolytischen Dissociation . . . . . . . . . . . 256

a) Salze . . . . . . . . . . . . . . . . . . 257

a) Abschwächung der desinficirenden Wirkung von Salzen durch

Hinzufïgung bestimmter Ionen . . . . . . . . . 260

b) Säuren . . . . . . . . . . . . . . . . . . . . 262

c) Basen . . . . . . . . . . . . . . . . . . . . . 264

d) Halogene . . . . . . . . . . . . . . . . . . . . . . 264

e) Phenol, Lysol, Creolin und andere organische Desinfectionsmittel . . . . . . . . . . . . 264

f) Alkohol und Aether als Lösungsmittel; ihr Einfluss auf das desinficirende Vermögen . . . . . . . . 266

g) Anderweitige Abweichungen, Schlussbetrachtung . . 267

7. Löslichkeitsverhältnisse von Harnsänre mnd harnsauren SaIzen und ihre therapentische Beclentung fïr die Anflösung ron Concrementen

a) Löslichkeitsverhältnisse . . . . . . . . . . . . . . . . 271

b) Bedeutung für die Auflösung von Concrementen im Organisinus . . . . . . . . . . . . . .

8. Begïnstigung der Bromwirkung durch Enthaltung von C'hlor

VIII. Ka pite l.

Balneologisches

1. Osmotische und osmotisch-chemische Untersnchung der Mineralwässer

a) Specifische Leitfähigkeit und Gefrierpunkterniedrigung einiger Mineralwässer . . . . . . . . . . 283

b) Eingehende Untersuchung von drei Mineralwässern . $2 \diamond 9$

c) Liebensteiner Stahlwasser . . . . . . . . . . . . . 289

1. Gefrierpunkterniedrigung . . . . . . . . . . . . . 289

2. Elektrische Leitfähigkeit . . . . . . . . . . . . 291

3. Vergleichung der chemischen mit del osmotischen Analyse 292

ß) Rhenser Sprudel . . . . . . . . . . . . . . 294

1. Gefrierpunkterniedrigung . . . . . . . . . . . . . 294

2. Elektrische Leitfähigkeit . . . . . . . . . . . 296

3. Vergleichung der chemischen und osmotischen Analyse . . 299

y) Grosser Sprudel zu Bad Neuenahr . . . . . . . . . . 303

c) Zusammenfassung und schlussbetrachtung . . . . . 306 
2. Einflnss der Mineralwässer auf die osmotiseh-ehemisehe Beschaffenheit von Körperfliissigkeiten . . . . . . . . . 313

a) Einfluss a uf das Blut . . . . . . . . . . . . 313

b) Einfluss a f den Harn . . . . . . . . . . . 318

c) Mineralwässer im Magen . . . . . . . . . . 318

d) Einfluss a uf die Milch . . . . . . . . . . 322

IX. Kapitel.

Bacteriologisches

1. Die Beweglichkeit von Bacterien in Salzlösungen versehiedener Coneentration

a) Untersuchungen von Massart . . . . . . . . . . 325

b) Untersuchungen von Wladimiroff . . . . . . . 328

2. Morphologische Veränderungen der Baeterien in Salzlösungen versehiedener Coneentration (Bekämpfung der Alexinlehre) • 333

3. Die Hänolyse . . . . . . . . . . . . . . . . . . 339

a) Eintheilung der Hämolysine. . . . . . . . . 340

b) Anschaungen über die Entstehung von Hämolysin durch Einverleibung fremden Blutes und über den Mechanismus der Hämolyse . . . . . . . . . . 344

«) Die Theorie von Bordet . . . . . . . . . 344

ß) Die Theorie von Ehrlich . . . . . . . . . . . 345

1. Die Seitenkettentheorie . . . . . . . . . . . 345

2. Anwendung der Seitenkettentheorie auf die Erklärung der Hämolysinwirkung . . . . . . . . . . . . 346

3. Immunisirung gegen die Hämolysinwirkung. Entstehen von Antikörpern . . . . . . . . . . . . . . . .

$\gamma)$ Zusammenfassung. Discussion über die Ansichten Bordet's und Ehrlich's . . . . . . . . . . 354

ઈ) Die Ansichten von Baumgarten's . . . . . . . 357

c) Reactionsgeschwindigkeit bei der Hämolyse durch Bacteriengifte. . . . . . . . . . . . . 363

4. Bindmugsverhältnisse bei der Neutralisirnng ron Toxin durch Antitoxin. Bekiimpfnng ron Elrlicli's Giftspectrmm . . . . 368

j. Bindungsverhältnisse des Agglntinins (und des Hämolysins) vom Standpmkt des Theilnngsprincips . . . . . . . . 382

6. Verbindnugswäme von Tetanolysin und Antitetanolysin . . 386

7. Moleculargewicht von Diphtherietoxin . . . . . . . . 386

8. Ansichten von R. Sleeswyk iiber das Wesen von Infeetion und Immunität

X. Kapitel.

Histologisches

1. Fixirnng der Gewehe . . . . . . . . . . . . . 397

a) Structurbildung in Colloidlösungen beim Uebergang von $\mathrm{Hydrosol}$ in $\mathrm{Hydrogel}$ 
b) Weiteres über den Uebergang von Hydrosol in $\mathrm{Hy} \mathrm{drogel} \mathrm{..............} \mathrm{.} \mathrm{.} \mathrm{.} 401$

a) Colloide, deren Hydrogele durch Hitze umkehrbar sind . . . 401

B) Colloide, deren Hydrogele durch Hitze nicht umkehrbar sind . 402

c) Volumverhältnisse (rother Blutkörperchen) bei Fixirung durch Formalin und andere Mittel . . 4 405

2. Theorie der Färbung fixirter Gewebe . . . . . . . . . . 412

a) Physikalische Theorie (Adsorption) . . . . . . . 413

b) Physikalisch-chemische Theorie. Das Theilungsprincip 415

c) Chemische Theorie . . . . . . . . . . . . 421

3. Färbung lebender Zellen (Intravitale Färbung) . . . . . . 424

Autoren-Register . . . . . . . . . . . . . . . . . . . . . . . 429

Sach-Register . . . . . . . . . . . . . . . . . 442 

Erstes Kapitel.

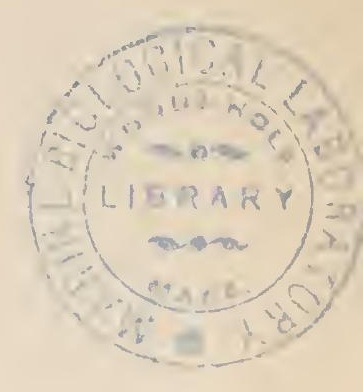

\section{Osmotisches Verhalten versehiedener isolirter Zellen.}

\section{Litteratur.}

1. Moleschott und Ricchetti, Compt. rend. de l'acad. d. Sciences de Paris. 26 Mars 1855.

2. Koelliker, Zeitschr. f. wissensch. Zoologie. 7. 1856. S. 201.

3. Hamburger, Archiv f. (Anat. u.) Physiol. 1898. S. 317.

4. Galeotti, Riv di Scienzi biologiche. 2. 1901. fasc. ${ }^{11} / 12$. (Ref. aus dem Centralbl. f. Physiol. 15. 1902. S. 154).

5. Hamburger, Archiv f. (Anat. u.) Physiol. 1899. Supplem. 1899. S. 431.

6. Fusari et Marfori, Archives Ital. de Biol. 23. Fasc. 1 et 2.

7. R. Heidenhain, Pfl ü ger's Archiv. 43. 1888. Supplementheft.

8. R. Höber, P flü ge r's Archiv. 74. 1899. S. 269.

9. Buitschli, Untersuchungen über mikroskopische Schäume und über das Protoplasma. Leipzig. 1882.

10. Hamburger, Archiv f. (Anat. u.) Physiol. 1898. S. 339.

11. Hamburger und van der Schroeff, Archiv f. (Anat. u.) Physiol. 1902. S. 119.

12. Virchow, Cellulare Pathologie. 4. Aufl. 1871. S. 376.

13. J. Cohnheim, Vorlesungen über allgem. Pathol. 2. Aufl. Th. 2. 1882. S. 570.

14. Hamburger; Over troebele zwelling. F'eestbundel voor S. T a lma 1901. p. 349.

15. A. Loewy, Centralbl. f. Physiol. Mai 1903.

Von den einzelnen Zellen habe ich im ersten Band die rothen und weissen Blutkörperchen in Beziehung auf ihre osmotischen Eigenschaften bereits einer ausführlichen Besprechung unterzogen. Im Folgenden behandle ich noch Spermatozoen, isolirte Epithelzellen, Lymphdrüsenzellen, Leber-, Milz- und Nierenzellen. 


\section{Spermatozoen.}

\section{a) Beeinflussung der Beweglichkeit durch Salze.}

Bereits lange Zeit, bevor an osmotischen Druck und Ionenlehre gedacht wurde, haben, unabhängig von einander, Moleschott und Ricchetti [1] sowie Koelliker [2] festzustellen gesucht, ob eine gesetzmässige Beziehung zwischen den Concentrationen der Salzlösungen besteht, welche die Bewegung der Spermatozoen regeln. Nach Moleschott und Ricchetti waren $\mathrm{Na}_{2} \mathrm{CO}_{3}, \mathrm{Na}_{2} \mathrm{SO}_{4} \mathrm{Na}_{2} \mathrm{HPO}_{4}$ in Lösungen von $5 \%$ sowie auch $\mathrm{NaCl}$-Lösung von $1 \%$ mächtige bewegungserregende Mittel für Froschspermatozoen.

Nach Koelliker wirkten $\mathrm{NaCl}, \mathrm{KCl}, \mathrm{NaNO}_{3}, \mathrm{KNO}_{3},\left(\mathrm{NH}_{4}\right) \mathrm{Cl}$ in $1 \%$ oiger

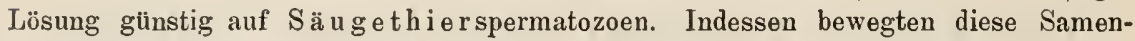
fäden sich auch noch in $2 \%$ igen, $3 \%$ igen und $4 \%$ igen Lösungen, während in $5 \%$ igen gewöhnlich und in $10 \%$ igen Lösungen stets jede Bewegung ausgelöscht war.

In 5\% Liger Lösung unschädlich verhielten sich:

$$
\mathrm{Na}_{2} \mathrm{HPO}_{4}, \mathrm{Na}_{2} \mathrm{SO}_{4}, \mathrm{MgSO}_{4}, \mathrm{BaCl}_{2}
$$

Nach K o elliker unterscheiden sich die Samenfäden der Vögel nur insofern von denen der Säugethiere, als $\mathrm{Na}_{2} \mathrm{HPO}_{4}$ und $\mathrm{MgSO}_{4}$ bereits in schwächerer Concentration wirksam sind. So bewegten sie sich bereits vortrefflich in $1 \%$ igen Lösungen dieser Salze. günstig:

Endlich wirken nach Koelliker auf die Spermatozoen des Frosches sehr

$0,5 \%$ ige Lösungen von $\mathrm{NaCl}, \mathrm{KCl}, \mathrm{NaNO}_{3}, \mathrm{KNO}_{3}, \mathrm{Na}_{2} \mathrm{CO}_{3}$ und $\mathrm{NH}_{4} \mathrm{Cl}$;

$1 \%$ ige Lösungen von $\mathrm{Na}_{2} \mathrm{HPO}_{4}, \mathrm{Na}_{2} \mathrm{SO}_{4}, \mathrm{MgSO}_{4}, \mathrm{BaCl}_{2}, \mathrm{CaCl}_{2}$, Natriumacetat.

Schädlich wirkte in allen Concentrationen $\left(0,5,1\right.$ und $2 \%$ das $\left(\mathrm{NH}_{4}\right) \mathrm{CO}_{3}$; hierin bildeten die Fäden in sehr kurzer Zeit Oesen.

In $\mathrm{KOH}-L o ̈$ sungen von $1 / 4$ bis $1 / 32 \%$ waren die Bewegungen wunderschön.

Nachdem ich die scharfe Gesetzmässigkeit gefunden hatte, nach welcher die Blutkörperchen gegen verschiedene Salzlösungen Farbstoff abzugeben anfingen, resp. ihr unverändertes Volumen beibehielten, schien es mir interessant zu untersuchen, ob vielleicht auch bei den Spermatozoen das Gesetz der isotonischen Coefficienten wiederzufinden war. Zu diesem 'Zweck wurde eine Kochsalzlösung von $0,6 \%$ sowie Lösungen von verschiedenen andern Salzen bereitet, welche mit der $0,6 \%$ igen NaCl im Sinne von de Vries isotonisch waren. Dann wurde ein Testikel eines sich paarenden Frosches genommen. Solch ein Testikel ist reif und weich. Es wurde ein capillar ausgezogenes Glasrohr in denselben eingesteckt und der Inhalt in sehr kleine Reagensröhrchen ausgeblasen, die je mit ein wenig Salzlösung beschickt waren. 
Nach Vermischung wurde nach verschiedenen Zeiten ein Tropfen mikroskopisch untersucht (natürlich unter Benutzung eines Paraffinleistchens zur Verhinderung der Verdampfung).

Von den verschiedenen NaCl-Lösungen hatte sich die $0,6 \%$ ige als die Optimumlösung erwiesen, $d$. h. in dieser blieben die Samenfäden am längsten beweglich. Hätte auch hier das Gesetz der isotonischen Coefficienten gegolten, so würden die damit isosmotischen Lösungen von andern Salzen ebenfalls Optimumlösungen gewesen sein. Die Abweichungen waren aber so bedeutend, dass ich erkannte, dass lier Complicationen vorliegen mussten, die wahrscheinlich von specifischen Wirkungen der Salze herrührten, die in die Zellen eingedrungen sein mochten. Bei meinem Wunsch, zuerst die Lebenserscheinungen ausfindig zu machen, bei denen die isotonischen Coefficienten rein $\mathrm{zu}$ T'age traten, verliess ich den Gegenstand und mass ihm nicht so viel Interesse bei, um die Ergebnisse zu veröffentlichen. Sie stammen aus dem Jahre 1887.

Später habe ich in anderer Richtung Versuche iuber Spermatozoen angestellt [3], nämlich über deren Volumverhältnisse in Salzlösungen. Hiervon wird sofort die Rede sein; doch erwähne ich zuerst noch die Untersuchungen Galeotti's.

Neuerdings hat sich namentlich Galeotti [4] wieder mit dem Gegenstand beschäftigt.

Der Verfasser ermittelte für Spermatozoen von verschiedenen Thieren die Grenzen des maximalen osmotischen Drucks, mit welchem das Leben der Spermatozoen rerträglich ist. Diese Grenzen erwiesen sich für jede Thierart verschieden und wurden von Galeotti als eine biologische Eigenschaft der verschiedenen Spermatozoen aufgefasst.

Auffallend war, dass die Spermatozoen der Säugethiere und der Vögel, bei denen die Begattung sich in der Art vollzieht, dass die Sexualzellen direkt von einem Organismus in den anderen, ohne Veränderung des osmotischen Drucks übergehen, sich sehr wenig widerstandsfähig gegen Veränderungen des osmotischen Drucks zeigten. Die Spermatozoen der Amphibien dagegen, die gewöhnlich in salzarmen Wassern leben, bleiben auch in destillirten Wasser lange lebendig. Dagegen widerstehen die Spermatozoen der Levia calaritana, eines in relativ concentrirtem Seewasser lebenden Fisches, auch Lösungen von starkem osmotischem Druck.

Aus diesen Thatsachen zieht Galeotti den Schluss, dass die Widerstandsfähigkeit des Protoplasma gegen Veränderungen des osmo- 
tischen Drucks eine durch Anpassung erworbene biologische Eigenschaft ist, in derselben Art wie die Anpassung an hohe und niedrige Temperatur und an starken hydrostatischen Druck erworben ist.

\section{b) Die Volumänderungen der Spermatozoen unter dem Einfluss hyperisotonischer und hypisotonischer Salzlösungen.}

Nachdem sich an den rothen, kernlosen Blutzellen gezeigt hatte, dass der Zellleib ans zwei Substanzen zusammengesetzt gedacht werden kann, einem Gerüst und einer intracellularen Flüssigkeit ${ }^{1}$ ), die sich in Beziehung auf Wasseranziehung verschieden verhalten, war es dann weiter die Frage, ob nicht etwa ein gleichartiges Verhältniss bei dem

1) Wie in dem Kapitel "Histologisches" unter: "1. Fixirung der Gewebe" noch näher erörtert werden wird, sind von botanischer Seite Stimmen laut geworden die eine Differenzirung der Zellen in Gerüst und intracellulare Flüssigkeit als Kunstproduct betrachten. Hingehende Versuche hat auch $\mathrm{H}$ ar dy angestellt. Dieser Verfasser wies nach, dass bei der Einwirkung von Fixirmitteln auf Colloidlösungen eine Netzstructur von gleichem Aussehen sichtbar wird, wie wenn das Colloid durch Kälte erstarrt. Immer handelt es sich, sowohl nach der Fixirung, wie nach der Erstarrung durch Abkühlung, um die Bildung von zwei Phasen, eine feste (Gerüst) und eine flüssige Phase (intracellulare Flüssigkeit). Eine ganz ähnliche Fixirung in zwei Phasen findet nun nach $\mathrm{H}$ ardy auch beim Absterben von Zellen statt. Die Netz- oder Wabenstructur der Zellen ist nach $\mathrm{Hardy}$ also ein Product, das intra vitam nicht besteht. Während des Lebens bildet das Protoplasma eine ho mogene structurlose Masse. So wird auch die Präexistenz von Kerntheilungsfiguren angezweifelt. Es würde sich hier um Druckverhältnisse in bestimmten Richtungen handeln, die durch Fixation festzulegen sind, aber als präexistirendes Ger ü st nicht vorhanden sind. Und wenn Bütschli angiebt, dass eine "Wabenstructur" oft auch an der lebenden Zelle deutlich sichtbar ist, so meint $\mathrm{H}$ a r d y annehmen zu dürfen, dass Bütschli's Zellen schon im Absterben begriffen waren. Hardy hat vor drei Jahren versprochen diesen wichtigen Punkt noch näher zu untersuchen, bis jetzt aber nichts hierüber hören lassen. Sonach würde man sich nach $\mathrm{H}$ ardy vorzustellen haben, dass während des Lebens der Zellinhalt aus einer protoplasmatischen Collo idlösung besteht, in der die Krystalloide gelöst sind und dass beim Absterben zwei Phasen auftreten: ein Netzwerk, das fast ausschliesslich aus einem Stroma von eiweissartigen Stoffen besteht und einer in deren Maschen angehäuften Flüssigkeit, die die Krystalloide und auch ein wenig Eiweiss enthält.

Es ergiebt sich nun die folgende Frage:

Wenn in der That ein Gerüst während des Lebens nicht besteht, behalten dann meine Zahlen für das Volumen des Stroma- (Gerüst) der Blutzellen doch noch einigen Worth? Allerdings! Man hat nur den Ausdruck "Gerüstvolumen " durch "Volumen der Colloidtheilchen" zu ersetzen. Im Wesentlichen kann es für die Rechnung doch gleichgültig seiu, ob die an der wasseranziehenden Kraft des Zellinhalts wenig betheiligten Colloidtheilchen zu einem Netz in der Krystalloidlüsung angeordnet oder zu einer homogenen Masse darin vertheilt sind. 
Kern vorlag. Es fragte sich also, ob es sich hier nicht um zwei Substanzen handelte, die sich in Beziehung auf die Wasseranziehung verschieden verhielten. Hier beim Kern könnten diese Substanzen Kerngerüst und intranucleare Flüssigkeit sein. Für diesen Fragepunkt eigneten sich gerade die Spermatozoen sehr gut, da sie Zellen bilden, die fast ausschliesslich aus Kernsubstanz bestehen. Am meisten empfahlen sich Froschspermatozoen, weil diese in so gut wie reinem Zustande, d. h. ohne Beimischung anderer Zellen zu haben sind. Man hat nur den Testikel aus der Bauchhöhle zu nehmen, in einige Stücke zu zerschneiden und mit ein wenig 0,6\% igen Kochsalzlösung zu schütteln. Man bekommt dann eine weisse milchartige Flüssigkeit, welche nach Coliren durch nicht-präparirte Gaze unmittelbar zum Gebrauch geeignet ist. Von dieser Lösung werden gleiche Mengen mit grössern Quantitäten verschiedener $\mathrm{NaCl}$-Lösungen versetzt und von diesen Gemischen gleiche Mengen centrifugirt.

Die U'eberlegung war dieselbe, wie die bei den Blutkörperchen erwähnte. Wenn man annimmt, dass die betreffende Zelle ein einfaches semipermeables Bläschen bildet, mit einer 0,6\% \% Kochsalzlösung als Inhalt, und man denkt sich diese Zelle in eine 0,9\% versetzt, so wird der Inhalt des Bläschens so lange Wasser abgeben, bis der Inhalt auch eine 0,9\%ige $\mathrm{NaCl}$-Lösung geworden ist. Die Volumabnalıme der Zelle wird $\frac{0,9-0,6}{0,6} \times 100=50 \%$ betragen.

Wenn sich nun aber in der Wirklichkeit herausstellt, dass die procentische Volumabnahme der Spermatozoen geringer ist, so geht daraus hervor, dass das Spermatozon nicht einfach als ein Bläschen mit Flüssigkeit betrachtet werden darf, sondern dass in dieser Flïssigkeit auch noch eine Substanz vertheilt ist, die an der Wasseranziehung nicht oder kaum betheiligt ist. Das ist das Kerngerüst. Welche Configuration dieses Gerüst besitzt, ist einerlei Je mehr Gerüst vorhanden ist, um so kleiner wird die durch $0,9 \%$ ige NaCl-Lösung herbeigeführte Volumabnahme sein. Man sieht leicht ein, dass die thatsächliche Volumabnahme ein Maass für die Menge der Gerüstsubstanz ist, oder wenn man sich auf dem Standpunkt Hardy's stellt und eine Trennung von Gerüstsubstanz und intracellularer Flüssigkeit intra vitam nicht annimmt, ein Maass für das Volumen der Colloidtheilchen.

1) Die für die Volumbestimmungen erforderlichen trichterförmigen calibrirten Röhrchen (B. I. S. 284, 337 u. 379) sind nicht mehr bei der früheren Adresse, sondern bei der Firma Franz Hugershoff, Leipzig, zu haben. 
Ich lasse hier in einer Tabelle einige Versuche zur Bestimmung der procentischen Gerüstsubstanz (procentisches Volumen der Colloidtheilchen) der Spermatozoen folgen. In derselben Tabelle ist zu gleicher Zeit die Gerïstsubstanz der rothen Blutkörperchen der Frösche ermittelt.

Die Einrichtung der Tabelle bedarf keiner Erläuterung; ebensowenig die Berechnung der Gerüstsubstanz. Für beides verweise ich auf Bd. 1, S. $341 \mathrm{ff}$.

Reife Spermatozoen und Blutkörperchen des Frosches.

\begin{tabular}{|c|c|c|c|c|c|c|c|c|c|}
\hline Zellenart & & Flüssigkei & iten & & 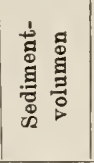 & $\begin{array}{r}\text { Gerüs } \\
\text { volume } \\
\text { berechnet } \\
\text { aus }\end{array}$ & st- & 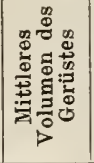 & 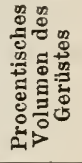 \\
\hline Spermatozoen & $\begin{array}{l}\text { a) } \\
\text { b) } \\
\text { c) } \\
\text { d) }\end{array}$ & 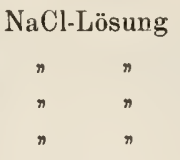 & $\begin{array}{l}0,35 \\
0,5 \\
0,6 \\
1\end{array}$ & $\begin{array}{l}\text { Proc. } \\
\qquad \\
n \\
n\end{array}$ & $\begin{array}{l}34 \\
30,5 \\
\mathbf{2 8 , 5} \\
25,5\end{array}$ & $\begin{array}{ccc}a & \text { und } & d \\
b & n & d \\
a & n & c\end{array}$ & $\begin{array}{l}20,92 \\
20,5 \\
20,8\end{array}$ & 20,74 & 72,8 \\
\hline Blutkörperchen & $\begin{array}{l}\text { a) } \\
\text { b) } \\
\text { c) } \\
\text { d) }\end{array}$ & $\begin{array}{cc}\text { NaCl-Lösung } \\
n & n \\
n & n \\
n & n\end{array}$ & $\begin{array}{l}0,35 \\
0,5 \\
0,6 \\
\mathbf{1}\end{array}$ & $\begin{array}{l}\text { Proc. } \\
\qquad n \\
n \\
n\end{array}$ & \begin{tabular}{l|}
41,75 \\
36,75 \\
$\mathbf{3 4 , 7 5}$ \\
31,5
\end{tabular} & $\begin{array}{lll}a & \text { und } & d \\
b & n & d \\
a & n & c\end{array}$ & $\begin{array}{l}25,9 \\
26,24 \\
24,96\end{array}$ & 25,7 & 73,9 \\
\hline Spermatozıen & $\begin{array}{l}\text { a) } \\
\text { b) } \\
\text { c) } \\
\text { d) }\end{array}$ & $\begin{array}{c}\text { NaCl-Lösung } \\
n \\
n \\
n\end{array}$ & $\begin{array}{l}0,35 \\
0,5 \\
0,6 \\
1\end{array}$ & $\begin{array}{c}\text { Proc. } \\
n \\
n \\
n\end{array}$ & \begin{tabular}{|l|}
39 \\
34,25 \\
$\mathbf{3 2}, \mathbf{5}$ \\
28,75
\end{tabular} & $\begin{array}{lll}a & \text { und } & d \\
b & n & d \\
a & n & c\end{array}$ & $\begin{array}{l}23,23 \\
23,40 \\
23,26\end{array}$ & 23,29 & 71,6 \\
\hline Blutkörperchen & $\begin{array}{l}\text { a) } \\
\text { b) } \\
\text { c) } \\
\text { d) }\end{array}$ & $\begin{array}{c}\text { NaCl-Lösung } \\
\begin{array}{cc}n & n \\
n & n \\
n & n\end{array}\end{array}$ & $\begin{array}{l}0,35 \\
0,5 \\
0,6 \\
1\end{array}$ & $\begin{array}{c}\text { Proc. } \\
n \\
n \\
n\end{array}$ & $\begin{array}{l}33,75 \\
29 \\
\mathbf{2 8} \\
24,75\end{array}$ & $\begin{array}{lll}a & \text { und } & d \\
b & & d \\
a & n & c\end{array}$ & $\begin{array}{l}19,9 \\
19,96 \\
20,5\end{array}$ & 20,12 & 73 \\
\hline
\end{tabular}

Diese Tabelle lehrt unzweideutig, dass die in 0,6\%iger $\mathrm{NaCl}$ Lösung liegenden Spermatozoen durch hypisotonische Lösungen von $\mathrm{NaCl}$ $(0,35 \%$ und $0,5 \%)$ quellen und durch eine hyperisotonische Lösung $(1 \%)$ schrumpfen, ebenso wie das bei den rothen Blutkörperchen geschieht.

Berechnet man nun weiter die procentische Quellung, resp. Schrumpfung, so stellt sich heraus, dass diese viel kleiner ist als sie sein würde, wenn die Spermatozoiden ganz und ausschliesslich aus einem mit wäss- 
riger Flüssigkeit bestehenden Bläschen beständen. Die Berechnung lehrt übereinstimmend aus dem Umfang der Quellung, wie aus dem der Schrumpfung, dass die Gerüstsubstanz (Colloidsubstanz) hier ein sehr grosses Volumen einnehmen muss, d. h. mehr als 70\% des Gesammtvolumens der Zelle. Dass das Volumen der intranuclearen Flüssigkeit so gering ist, scheint mir sehr zweckmässig zu sein, denn dadurch kann die absolute Volumvermehrung des Spermatozoons, wenn dasselbe nach der Ejaculation mit Wasser in Berührung kommt, nicht gross sein und hierdurch wird die Möglichkeit einer zu grossen Ausdehmung der äusseren Protoplasmaschicht relativ gering.

Merkwürdigerweise findet man bei den entsprechenden rothen Blutkörperchen nahezu dieselbe Zahl für die procentische Quellung und Schrumpfung.

So z. B. ist die procentische Schrumpfung der Spermatozoen nach Ueberführung aus einer $0,6 \%$ igen NaCl-Lösung in eine $1 \%$ ige; $\frac{28,5-25,5}{28,5} \times 100=10,5 \%$ und bei einer ähnlichen Ueberführung der rothen Blutkörperchen $\frac{34,75-31,5}{34,75} \times 100=9,4 \%$.

Ich erinnere in dieser Beziehung an die Thatsache, dass ich auch für die rothen und die weissen Blutkörperchen des Pferdes ein gleiches procentisches Gerüstvolumen $( \pm 55 \%)$ fand, sodass man sich unwillkürlich fragt, ob vielleicht nicht bei einer und derselben Thierart, im Zellkern dasselbe Volumverhältniss zwischen Gerüst und intranuclearer Flüssigkeit besteht, wie es auch im eigentlichen Zellkörper zwischen Gerüst und intracellularer Flüssigkeit obwaltet.

Es wäre erwünscht auch bei Warmblütern die procentische Volumzunahme der Spermatozoen und Blutkörperchen durch dieselbe hypisotonische Lösung oder die procentische Volumabnahme durch dieselbe hyperisotonische Lösung zu vergleichen. Vielleicht ergiebt sich auch hier, ebenso wie beim Frosch, Uebereinstimmung zwischen beiden Zellenarten.

\section{Epithel。}

Die Volumveränderungen isolirter Epithelzellen und deren Kerne unter dem Einfluss anisotonischer Salzlösungen.

Ich bespreche jetzt die Untersuchungen, die an Epithelzellen von vier verschiedenen Stellen: Darm, Trachea, Harnblase und Oesophagus, angestellt wurden. 
Das Epithel wurde stets so erhalten, dass man es beim frisch getödteten Thier vorsichtig vom Organ abschabte. Das Schabsel wurde in ein wenig frischem Blutserums oder in einer $0,9 \% \mathrm{NaCl}$-Lösung vertheilt und dann durch ein Filter von nichtpräparirter Gaze colirt. Durch letztere Manipulation wurde erzielt, dass die Zellen theilweise in isolirtem Zustande, anderentheils böchstens in kleinen Aggregaten vorhanden waren. Von der gewonnenen trüben Flüssigkeit wurden mittelst einer fein ausgezogenen Pipette gleiche Volumina $(0,25 \mathrm{cc})$ abgemessen und in Reagenscylinder gebracht, in welchen sich gleiche Quantitäten $(10$ bis $15 \mathrm{cc}$ ) der Salzlösungen befanden, deren Einfluss die Epithelzellen ausgesetzt werden soliten. Nach halbstündiger Einwirkung wurden gleiche Volumina der Gemische in die bekannten trichterförmigen Röhrchen gebracht und centrifugirt. Wenn das Niveau des Sediments constant geworden war, wurde das Volumen der Epithelsäule festgestellt. Wenn bereits nach kurzem Centrifugiren die Zellensäule nicht vollkommen homogen aussah, wurde die klare Flüssigkeit grösstentheils abpipetirt, die Säule mit der zurückgebliebenen Flüssigkeit mittelst eines Platindrahtes zu einem homogenen Gemisch durchgerührt und wieder auf's Neue centrifugirt. War dies bei einem der Röhrchen nothwendig, so wurde dasselbe auch mit den beiden anderen vorgenommen.

\section{a) Darmepithel.}

\section{Versnch I.}

Epithel des Dünndarmes eines Pferdes, etwa $0,5 \mathrm{~cm}$ vom Pylorus entfernt. Das Epithel war in Blutserum des nämlichen Thieres vertheilt.

\begin{tabular}{|c|c|}
\hline Salzlösungen & Volumen des Epithels \\
\hline $\begin{array}{cccc}\mathrm{NaCl} \text {-Lösung von } & 0,7 & \text { Procent } \\
\pi & n & 0,9 & \\
\pi & n & 1,0 & n \\
& n & 1,5 & \pi\end{array}$ & $\begin{array}{l}35,5 \\
34 \\
33 \\
29\end{array}$ \\
\hline
\end{tabular}

Aus dieser Tabelle geht hervor, dass das Volumen des Epithels ziemlich regelmässig abnimmt, wenn die Concentration der Salzlösung zunimmt.

A priori hätte man ein anders Ergebniss erwarten können. Darf doch die Darmucosa als ein treffliches Resorptionsorgan betrachtet werd en und es werden, wie die Erfahrung lehrt, dementsprechend verdünnte $\mathrm{NaCl}$ Lösungen äusserst leicht aufgenommen. Hiernach liess sich erwarten, dass die Zellen des abgeschabten Darmepithels, wenn sie in grosse Quantitäten $\mathrm{NaCl}-\mathrm{L}$ ösung verschiedener Concentration vertheilt werden, sich mit den betreffenden Lösungen tränken, sodass von einer Differen\% in osmotischem Druck zwischen Zellinhalt and Umgebung bald nicht mehr die Rede sein würde. Man hätte also erwarten können, dass das Volumen des Darmepithels sich unter dem Einfluss 
von Salzlösungen rerschiedener Concentration nicht oder wenig ändern würde.

Das folgende auf dieselbe Weise und mit derselben Epithelart ausgeführte Experiment gab jedoch ein ganz anderes Resultat als der erste Versuch.

\section{Versuch II.}

Epithel des Dünndarmes eines Pferdes, etwa $0,5 \mathrm{~m}$ vom Pylorus entfernt. Das Epithel ist im Blutserum des nämlichen Thieres vertheilt.

\begin{tabular}{ccccc}
\hline \multicolumn{2}{c}{ Salzlösungen } & Volumen des Epithels \\
\hline \multicolumn{2}{c}{ NaCl-Lösung von } & 0,5 & Procent & 106 \\
$\pi$ & $n$ & 0,7 & $n$ & 103 \\
$n$ & $n$ & 0,9 & $n$ & 103 \\
$n$ & $n$ & 1,5 & $n$ & 105
\end{tabular}

Bei diesem Versuch blieb das Volumen des Epithels in allen vier Salzlösungen ungefähr gleich.

Der Gegensatz zwischen den Resultaten der beiden Versuche machte es erwünscht, dieselben $\mathrm{zu}$ wiederholen.

\section{Versuch III.}

Epithel des Dünndarmes eines Schweines, etwa 0,25 m vom Pylorus entfernt. Das Epithel ist in $\mathrm{NaCl} 0,9 \%$ vertheilt.

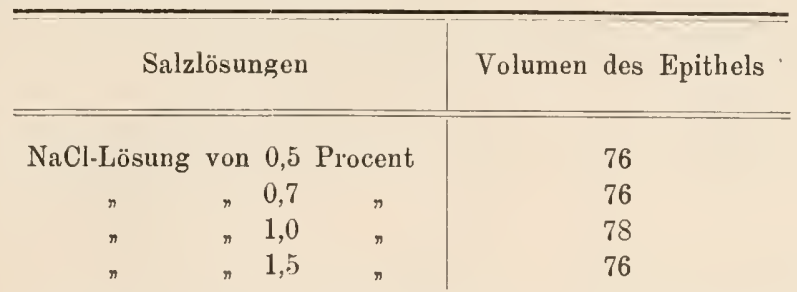

Wie ersichtlich, hat die Concentration der Salzlösung keinen Einfluss auf das Volumen ausgeübt. Von den vielen Experimenten haben noch drei ein entsprechendes Resultat ergeben. Ich lasse dieselben weiter unerwähnt und theile die anderen Versuche mit, welche im Gegensatz hierzu einen Einfluss der Concentration sehr wohl darthaten.

In der ersten Spalte der nächstfolgenden Tabelle findet man die benutzte Salzlösung angegeben, in der zweiten das Volumen des Sediments; in der dritten Spalte habe ich, um die Grösse der durch die Salzlösungen herbeigeführten Volumänderungen anzugeben, den Volum- 
unterschied der Zellen in $\mathrm{NaCl} 0,7 \%$ und $1,5 \%$ in Procenten ausgedrüickt.

Auf den ersten Blick erscheint es willkürlich, hier die beiden genannten Lösungen zu wählen. Ich nahm gerade diese beiden, weil sie am weitesten auseinander liegen und die Fehler dadurch relativ weniger in's Gewicht fallen. In allen Versuchen stammt das Epithel vom Schweinedarm, etwa $0,25 \mathrm{~m}$ vom Pylorus.

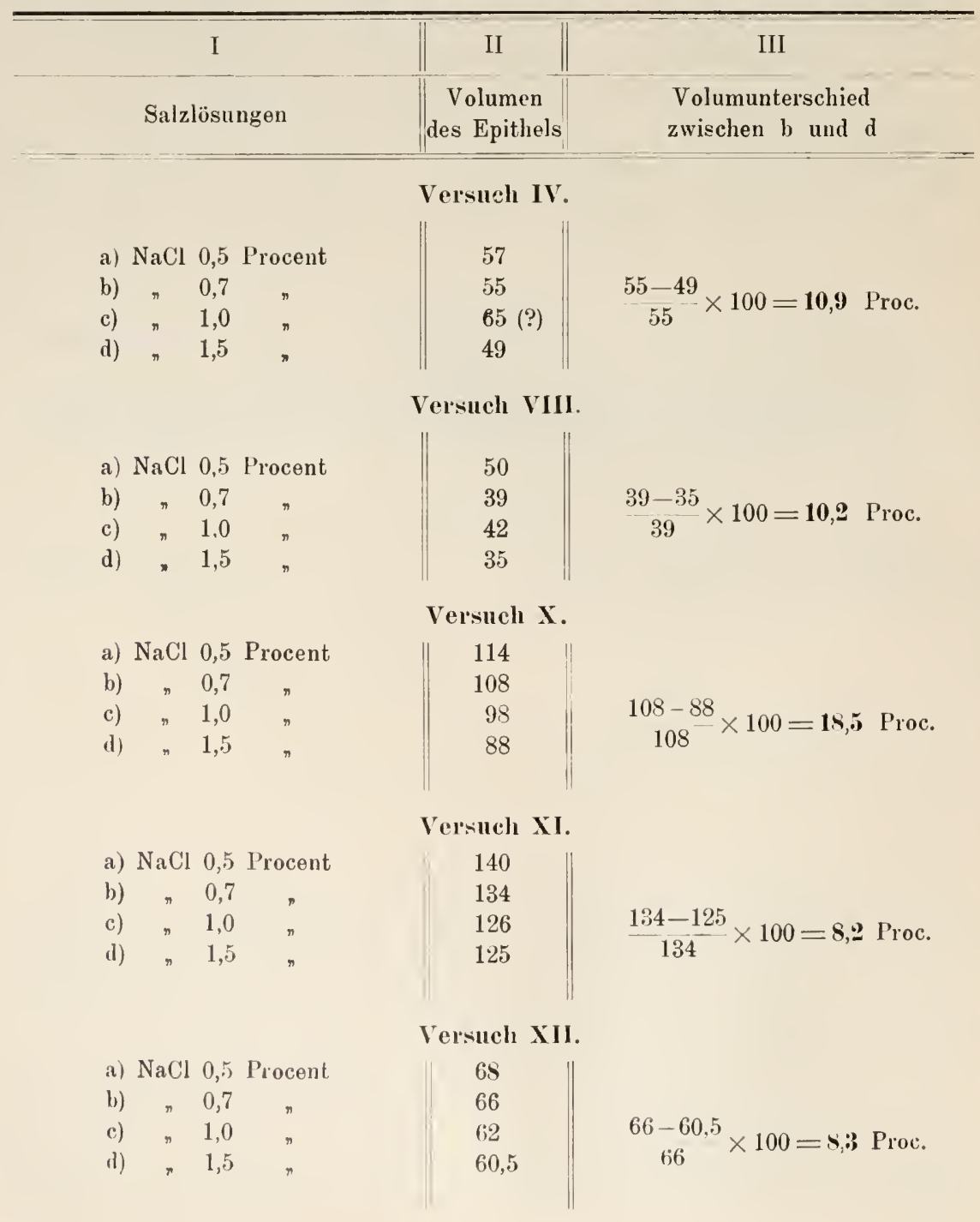




\begin{tabular}{c|cc}
\hline \hline I & II & III \\
\hline Salzlösungen & $\begin{array}{c}\text { Volumen } \\
\text { des Epithels }\end{array}$ & Volumunterschied \\
\hline
\end{tabular}

Versuch XIII.

a) $\mathrm{NaCl} 0,5$ Procent

b) $, 0,7$,

c) $\quad 1,0$,

d) $n 1,5 \quad$,

a) $\mathrm{NaCl} 0,5$ Procent

b) $, 0,7$,

c) $\pi 1,0 \quad$,

d) $, 1,5 \quad$,
69

64

60

54
Versuch $\mathrm{XV}$.

\begin{tabular}{l||}
74 \\
72,5 \\
69 \\
66
\end{tabular}

$\frac{72,5-66}{72,5} \times 100=8,9$ Proc.

In Beziehung auf die sieben anderen Versuche will jch nur erwähnen, dass die Volumunterschiede in NaCl-Lösung von 0,7 und von $1,5 \% 17,9,10,8,11,2,9,2,8,7,9,8$ und $10,5 \%$ betrugen.

Fassen wir die Versuchsresultate zusammen, so erhellt, dass der Volumunterschied zwischen den Zellen in $\mathrm{NaCl}$ von 0,7 und $1,5 \%$ in den meisten Fällen zwischen 10,9 und $8,2 \%$ schwankt; in vier Fällen beträgt die betreffende Differenz 18,8 bis $15,6 \%$.

Wie sind diese Abweichungen zu erklären? Meines Erachtens kann man hier an zwei Möglichkeiten denken: entweder die Untersuchungsmethode ist nicht zuverlässig, oder das in den verschiedenen Versuchen von entsprechenden Stellen bezogene Epithel befand sich nicht immer in demselben /ustand.

Die erste Möglichkeit ist zu verwerfen, weil meine Methode bei den rothen und weissen Blutkörperchen, bei den Spermatozoen und anch bei dem ebenfalls durch Abschaben erhaltenen Blasen- und Oesophagusepithel übereinstimmende Resultate gegeben hat.

Es bleibt also nichts anderes übrig, als anzunehmen, dass das Darmepithel sich nicht immer in demselben Zustand der Permeabilität befindet. machen.

In dieser Hinsicht kann man sich wieder zwei Torstellungen

a) Man kann sich denken, dass in den Fällen, in denen sich die betreffende Procentzahl um 18,5 bewegt, die Zellen vor dem Centrifugiren 
nicht lange genug in den Salzlösungen verweilt haben, um sich mit denselben zu tränken. Wenn das wirklich der Fall ist, so muss bei längerem Verweilen der Procentgehalt abnehmen und etwa 10 werden;

b) das Epithel befindet sich zuweilen in einem besonderen Zustand der nur unter bestimmten Einflïssen aufgehoben werden kann.

Die Möglichkeit a) war nicht schwer zu prüfen.

$\mathrm{Zn}$ diesem Zweck fertigte ich Mischungen von Epithel und Salzlösung an und centrifugirte nach verschiedenen Zeiten.

Aus der folgenden Tabelle ist das Resultat ersichtlich:

\section{Versuch XXVII.}

Epithel des Dünndarmes eines Schweines, etwa $0,25 \mathrm{~m}$ vom Pylorus. Das Epithel ist vertheilt in $\mathrm{NaCl}$ von $0,9 \%$. Es wurden Mischungen hergestellt, welche 1/2 Stunde, 1, 2 und 3 Strnden sich selbst überlassen wurden $\left.{ }^{1}\right)$ :

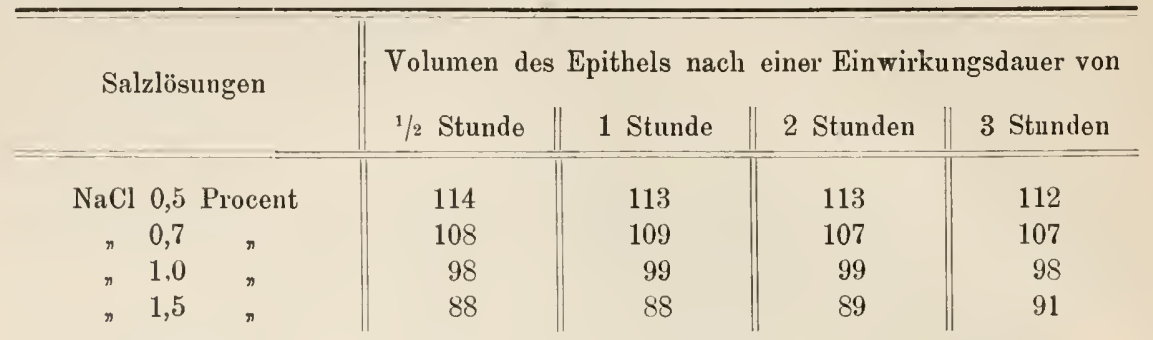

Man sieht, dass die Einwirkungsdauer keinen wesentlichen Einfluss auf das Volumen ausgeiibt hat.

Ich will noch ein paar von den vielen Versuchen erwähnen, welche ich behufs Klärung des vorliegenden Fragepunktes angestellt habe.

Versuch XVIII.

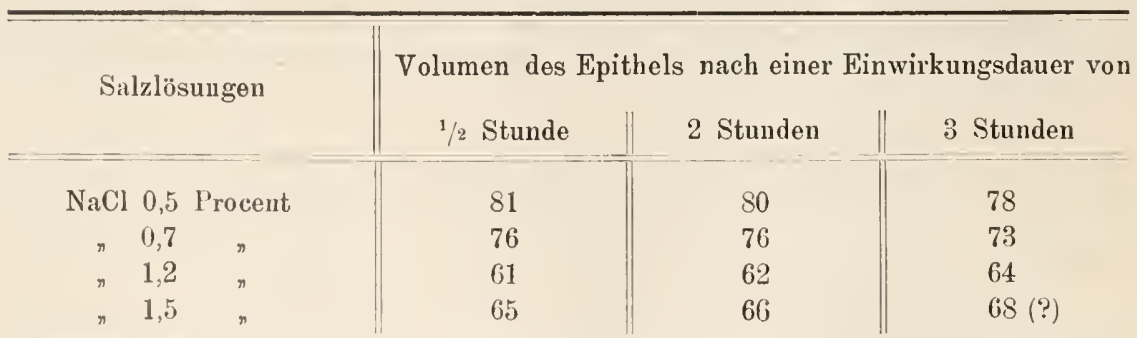

1) Wenn ich hier von einer Einwirkungsdauer von $1 / 2$ Stunde spreche, so denke jch an die Zeit, welche zwischen der Anfertigung der Gemische und dem Anfang des Centrifugirens liegt. Also die Zeitdauer des Centrifugirens wird ausser Betracht gelassen. Das ist zwar nicht ganz correct, aber die Epithelzellen werden nach dem Beginn des Centrifugirens so rasch gegeneinander gelegt, dass von einer merklichen Einwirkung der umgebenden Salzlösung auf die Zellen innerhalb weniger Minuten kaum die Rede mehr ist. 
Versuch XXXI.

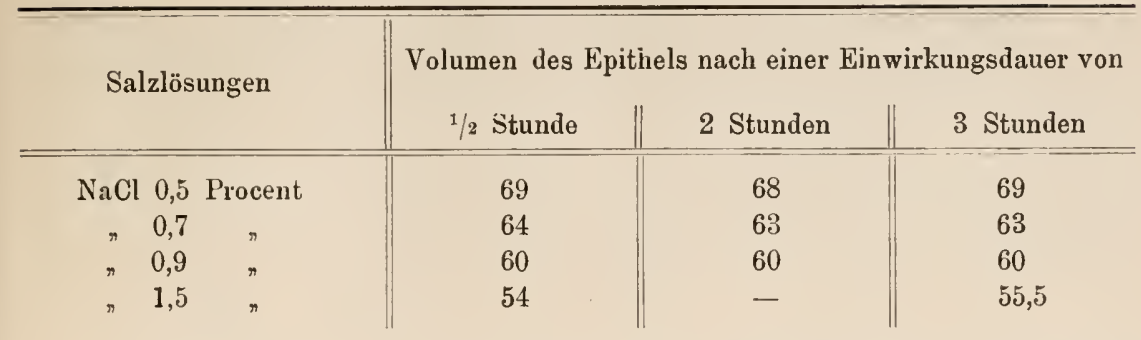

Auch in diesen zwei Versuchen hat eine längere Einwirkung, kaum einigen Einfluss auf das Volumen ausgeübt.

Man darf also schliessen, dass sich der Einfluss der Kochsalcconcentration auf das Epithelvolumen in demselben Maasse geäussert hat, bereits nach halbstündiger Einwirkung, wie dieser Einfluss sich nach mehrstündiger Einwirkung offenbart.

Hierdurch wird die Erklärung a auf S. 11 hinfällig und es erübrigt per exclusionem noch die Erklärung $b$.

Nach dieser befände sich das Epithel zuweilen in einem besonderen physiologischen Zustand, in welchem die Durchlässigkeit für Kochsalzlösungen verringert ist.

Dass nun wirklich das Darmepithel mit Beziehung auf seine Permeabilität in einen anderen Zustand gerathen kann, lehren uns die sorgfältigen Untersuchungen Hay's ${ }^{1}$ ). Durch diese wurde nachgewiesen, dass die purgative Wirkung des $\mathrm{MgSO}_{4}$ theilweise auf einer Abnahme des resorbirenden Vermögens der Darmmucosa beruht, was dann die Verflïssigung der Fäcalstoffe befördert. H a y hat gezeigt, dass das Thier nach Aufnahıne von $\mathrm{MgSO}_{4}$ Strychninmengen verträgt, durch die es sonst fast unmittelbar verendet.

Ich habe nun versucht, auch in vitro die Permeabilität des Darmepithels mittelst $\mathrm{MgSO}_{4}$ zu modificiren.

Versuche, um die Permeabilität des isolirten Darmepithels $\mathrm{zu}$ modificiren.

Zu diesem Zweck nahm ich Darmepithel, welches sich, wie z. B. in Versuch XII, nur in geringem Maasse durch die Concentration der Kochsalzungen beeinflussen liess, und versetzte dasselbe mit $\mathrm{MgSO}_{4}$ Lösungen verschiedener Stärke.

1) M. Hay, Journal of Anatomy and Physiology 1882. 


\section{Versuch XXXII.}

Epithel des Dünndarmes eines Pferdes, 0,5 m vom Pylorus. Die Zellen sind in ein wenig $\mathrm{MgSO}_{4}$-Lösung vertheilt, die mit $0,9 \%$ oiger NaCl-Lösung isotonisch ist.

\begin{tabular}{c||c}
\hline Sa l z lösungen & Volumen der Epithelzellen \\
\hline
\end{tabular}

$\mathrm{MgSO}_{4}$-Lüsung isotonisch mit $\mathrm{NaCl} 0,7$ Procent

45

60

51

64

\section{Versuch XXXIII.}

Epithel des Colon eines Pferdes, 0,5 m vom Pylorus. Die Zellen sind in ein wenig $\mathrm{NaCl}$ von $0,9 \%$ vertheilt.

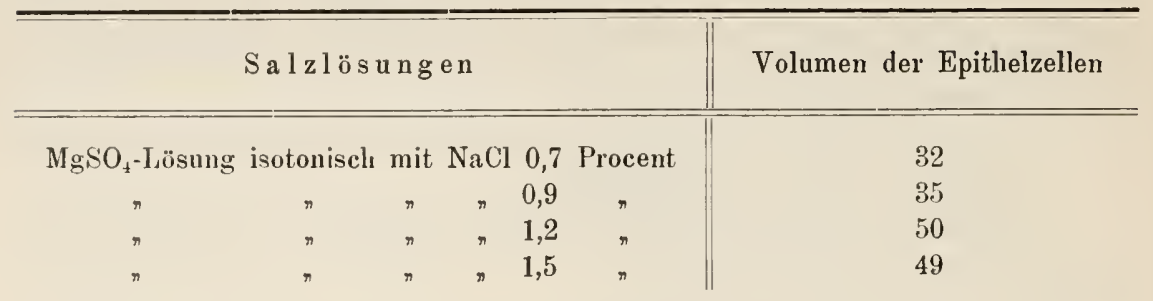

\section{Versuch XXXIV.}

Epithel des Dünndarmes eines Schweines. Die Zellen sind in ein wenig $\mathrm{NaCl}$ von $0,9 \%$ vertheilt.

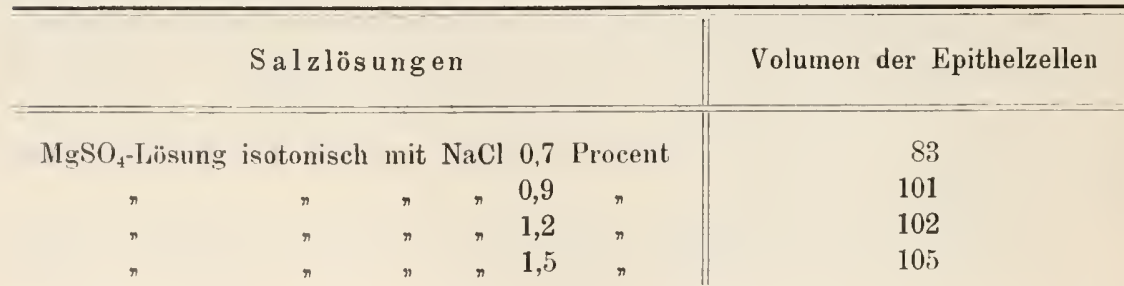

Es ist mir nicht möglich, aus diesen Versuchen einen bestimmten

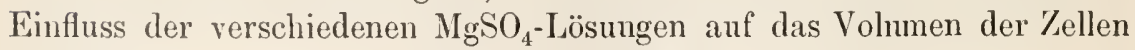
z.u erkennen. In allen drei Versuchen findet man das Zellvolumen in derjenigen $\mathrm{MgSO}_{4}$-Lösung am kleinsten, welche mit $\mathrm{NaCl}$ ron $0,7 \%$ isotonisch ist. Das Gegentheil hätte man erwarten dürfen. Bei näherer mikroskopischer und makroskopischer Betrachtung stellte sich aber heraus, dass die letztgenannte $\mathrm{MgSO}_{4}$-Lösung anch die einzige war, in welcher sich kein Schleim gebildet hatte. In den drei übrigen Lösungen latte 
das Epithel in so bedeutendem Maasse Schleim abgeschieden, dass die Zellenmasse ein ganz anderes Aussehen hatte wie in der ersten. Die sonderbaren Volumenverhältnisse sind wohl hieraus zu erklären.

Beim Durchsuchen der Litteratur ergab sich, dass die Eigenschaft von $\mathrm{MgSO}_{4^{-}}$ Lösungen, Schleimabsonderung aus Darmepithelien herbeizuführen, schon früher studirt worden ist. Fusari und Marfori fanden nänlich, dass nach der Aufnahme von purgirenden Mittelsalzen eine so bedeutende Schleimabsonderung stattfand, dass die Zotten ganz mit Schleim bedeckt waren und die Resorption des flüssigen Darminhaltes gehemmt wurde.

Indessen ist das Darmepithel nicht die einzige Zellenart, welche unter dem Einfluss von $\mathrm{MgSO}_{4}$ Schleim absondert. Ich konnte das Gleiche beim Harnblasenepithel konstatieren. Als ich dasselbe nach Zusatz zu $\mathrm{MgSO}_{4}$-Lösungen centrifugirte, die mit $\mathrm{NaCl}$ von $0,7,0,9,1,2$ und $1,5 \%$ isotonisch waren, setzten die Zellen sich nur in der ersten Lösung gut ab. In der übrigen Flüssigkeit war die Beschaffenheit des Epithels so schleimig, dass von einer Ablesung des Niveaus nicht die Rede sein konnte.

Ich beschloss nun, die Versuche mit Darmepithel derart zu wiederholen, dass die Zellen erst eine kurze Zeit mit einer $\mathrm{MgSO}_{4}$-Lösung in Berïhrung blieben und dann dem Einfluss von NaCl-Lösungen ausgesetzt wuiden.

\section{Versuch XXXV.}

Epithel des Dünndarmes des Sclıweines, $0,25 \mathrm{~m}$ vom Pylorus. Die abgeschabte Masse wurde in ein wenig NaCl-Lösung von $0,9 \%$ vertheilt. Dann wurde das Gemisch in zwei Theile getrennt. Die eine Hälfte wurde sich selbst überlassen, die andere Hälfte $(10 \mathrm{cc})$ wurde mit 1 cc einer $15 \%$ igen $\mathrm{MgSO}_{4}$-Lösung versetzt. Nachher wurden von beiden Antheilen gleiche Portionen abgemessen und in $\mathrm{NaCl}$ Lösungen von $0,7 \%$ und $1,5 \%$ gebracht. Nach einer halben Stunde wurde centrifugirt.

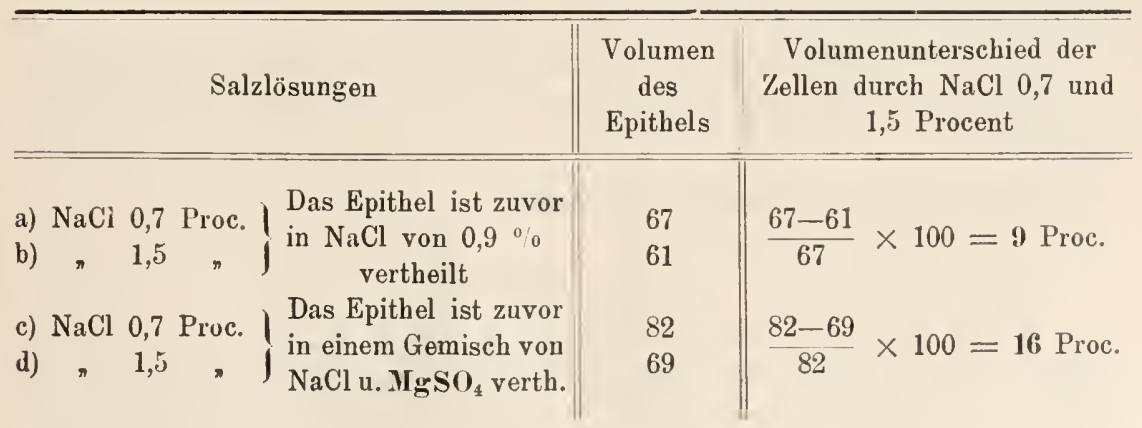

Durch Berührung mit $\mathrm{MgSO}_{4}$ hat das Epithel also eine grössere Empfindlichkeit für Concentrationsverschiedenheiten bekommen. 


\section{Versuch XXXvI.}

Der folgende Versuch wurde in gleicher Weise ausgeführt wie der vorige.

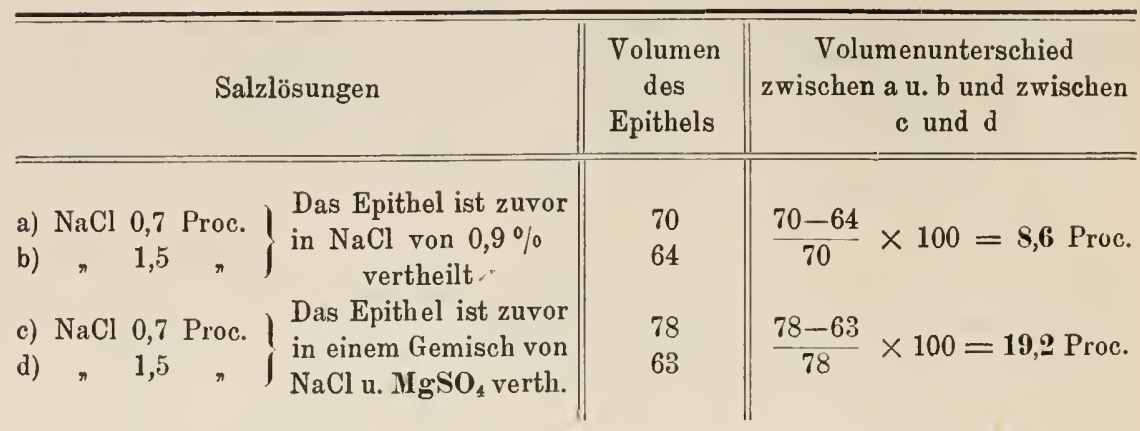

\section{Versuch XXXVII.}

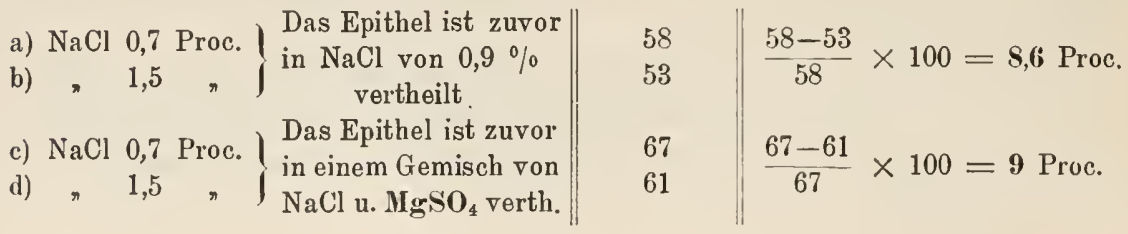

Während also in Versuch XXXV und XXXVI das $\mathrm{MgSO}_{4}$ eine bedeutende Permeabilitätsänderung hervorgerufen hat, ist in Versuch XXXVII nichts davon zu constatiren. Andere Experimente gaben ein gleichartiges Resultat.

Man kann also sagen, das $\mathrm{MgSO}_{4}$ besitzt das Vermögen, Darmepithel in einen modificirten Permeabilitätszustand überzuführen, diese Erscheinung bleibt aber auch bisweilen aus.

Von den Stoffen, deren Einfluss ich auf gleiche Weise wie den des $\mathrm{MgSO}_{4}$ prüfte, gab verdünnte $\mathrm{Schwefelsäure} \mathrm{ein} \mathrm{positives}$ Resultat.

Ich lasse ein Versuchspaar folgen.

\section{Versuch XXXVIII.}

Epithel des Dünndarmes des Schweines, 0,25 m vom Pylorus. Die abgeschabten Zellen werden in wenig $\mathrm{NaCl}$ ron $0,9 \%$ vertheilt. Von diesem Gemisch wird die eine Hälfte mit $\mathrm{NaCl}$ von $0,9 \%$ versetzt, die andere Hälfte mit einem Gemisch von $10 \mathrm{cc} \mathrm{NaCl}$ von $0,9 \%$ und $1 \mathrm{cc}^{1} / 10$ norm $\mathrm{H}_{2} \mathrm{SO}_{4}$. Von den beiden angefertigten Epithelgemischen werden gleiche Portionen in NaCl-Lösungen von 0,5, 0,7,1 und $1,5 \%$ gebraclıt und $1 / 2$ Stunde später centrifugirt. 


\begin{tabular}{|c|c|c|}
\hline Salzlösungen & $\begin{array}{l}\text { Volumen des Epithels } \\
\text { (Vertheilung in NaCl } \\
\text { von } 0,9 \% \text { ) }\end{array}$ & $\begin{array}{l}\text { Volumen des Epithels } \\
\text { (Vertheil, in einem Gemisch v. } \\
10 \text { cc } \mathrm{NaCl}+1 \text { ce } \mathrm{H}_{2} \mathrm{SO}_{4}^{1 / 10} \mathrm{n}\end{array}$ \\
\hline $\mathrm{NaCl} 0,5$ Proc. & 88 & 96 \\
\hline$\Rightarrow 0,7 \pi$ & 84 & 75 \\
\hline ᄁ 1,0 , & 81 & 71 \\
\hline 1,5 त & 78 & 63 \\
\hline
\end{tabular}

Betrachtet man die Resultate dieser Versuchsreihe, so ergiebt sich dass die Zugabe einer geringen Menge $\mathrm{H}_{2} \mathrm{SO}_{4}$ die Empfindlichkeit des Darmepithels für Concentrationsunterschiede erheblich vermehrt, mit anderen Worten, die Permeabilität für $\mathrm{NaCl}$ herabgesetzt hat.

Es zog mich wenig an, noch weiter im Dunkeln zu tasten und den Einfluss anderer Stoffe auf die Durchlässigkeit des Epithels für $\mathrm{NaCl}$ zu priifen. Es mag für jetzt geniigen, constatiren zu können, dass es gelingt, mittelst chemischer Agentien, also auf künstlichem Wege das Epithel in einen derartigen veränderten Zustand zu versetzen, dass der Einfluss der Concentration auf das Volumen erheblich steigt. Hierdurch gewinnt die per exclusionem aufgestellte Erklärung für das verschiedenartige Verhalten des abgeschabten Darmepithels gegen Salzlösungen in hohem Maasse an Wahrscheinlichkeit, die Erklärung nämlich, dass das abgeschabte Darmepithel nicht immer in demselben physiologischen Zustand sich befindet, d. l. nicht immer eine gleiche Durchlässigkeit für Kochsalzlösungen zeigt ${ }^{1}$ ).

1) Es sei hier bemerkt, dass dieses Resultat keineswegs mit meiner früher ausgesprochenen Ansicht im Widerspruch steht, nach welcher die bis damals bekannten Resorptionserscheinungen auf physikalischem Wege erklärt werden können. Im Gegentheil, ich habe damals mit Nachdruck betont, dass ich „nicht daran denke, behaupten zu wollen, dass das Leben auf den Resorptionsprocess keinen Einfluss ausüben kann und es auch wirklich nicht thut. Unter physiologischen und pathologischen Bedingungen können zweifellos in lebendigen Membranen fein nuancirte Veränderungen hervortreten, welche auf die darin statthabenden physikalischen $V$ or gänge einen nicht geringen Einfluss haben. Hierdurch hören aber diese Vorgänge selbst nicht auf, rein physikalische Processe zu sein." (Vergl. Bd. II, S. 218).

"Der arterielle Blutdruck wird durch Zusammenziehung des linken Ventrikels herbeigeführt; das ist eine Thatsache, welche aus einem rein physikalischen Gesichtspunkte für Jeden verständlich ist. Aber wenn irgend eine Ursache auf das Leben des Herzmuskels derart einwirkt, dass dieser fettig degenerirt, so ändert sich der Blutdruck. In dieser Thatsache kann doch kein Grund liegen, den Zusammenhang zwischen Herzcontraction und Blutdruck nun nicht mehr als einen rein physikalischen aufzufassen. 
Das Wesen der Veränderung, welche die Zellen durch die kur\%dauernde Einwirkung von $\mathrm{MgSO}_{4}$ oder $\mathrm{H}_{2} \mathrm{SO}_{4}$ erfahren, ist uns unbekannt geblieben.

Unwillkürlich denkt man hierbei an die Versuche Heidenhain's über die Permeabilität der zwischen den Darmepithelzellen liegenden Kittsubstanz. Als er beim lebenden Thier Methylenblau in den Darm gebracht hatte und nachher das Epithel mikroskopisch untersuchte, sah er, dass in einem und demselben Gesichtsfelde zwischen vielen Zellen die Kittsubstanz blau gefärbt war, während zwischen anderen danebenliegenden Zellen die Substanz ganz farblos war.

Heidenhain denkt hierbei an die Wahrscheinlichkeit, dass die Kittsubstanz sich zwischen den Zellen nicht überall im gleichen Zustand befindet und erinnert bei dieser Gelegenheit an eine gleichartige von ihm beobachtete Thatsache, dass nämlich nach Einverleibung von indigoschwefelsaurem Natron ein Theil des Nierenepithels blau gefärbt wird, während andere, dazwischenliegende Epithelzellen farblos bleiben.

\section{Discussion der Resultate.}

Fassen wir nun zusammen, was die Experimente über den Einfluss von Kochsalzlösungen auf das Volumen des Darmepithels gelehrt haben, so lassen sich die Resultate zu drei Fällen ordnen:

1. Die Concentration der Salzlösung hat auf das Volumen der Zellen absolut keinen Einfluss ausgeïbt. Das geschah nur selten.

2. Die Concentration der Salzlösung zeigt einen geringen Einfluss (die Volumdifferenz des Epithels in $\mathrm{NaCl}$ von 1,5 und $0,7 \%$ beträgt $9 \%$. Das ist das normale Verhältniss.

3. Die Concentration der Salzlösung übt einen bedeutenden Einfluss auf das Volumen des Epithels aus (die Volumdifferenz in NaCl von 1,5 und $0,7 \%$ beträgt 15 bis $19 \%$ ).

Dieses Resultat bekommt man von Zeit zu /eit.

Lassen wir den erstgenannten, relativ selten beobachteten Fall ausser Betracht, so ergiebt sich also, dass die Salzlösungen das Volumen des Darmepithels beeinflussen. Gewöhnlich ist der Einfluss geringfügig, zuweilen aber ist derselbe bedeutend. Im letzteren Falle handelt es sich höchstwahrscheinlich um einen besonderen physiologischen \%ustand des Epithels und es ist sogar gelungen, denselben mittelst $\mathrm{MgSO}_{4}$ und $\mathrm{H}_{2} \mathrm{SO}_{4}$ künstlich hervorzurufen (vgl. S. 13 und 16).

1)ie unter 2 genannte Erscheinung entspricht somit dem normalen Verhalten.

Es schien mir nicht überflüssig, noch einmal hierauf hinzuweisen, weil einige Autoren mir in den Mund gelegt haben, dass iclı mit Beziehung auf den Resorptionsvorgang den lebendeu Darm mit einer todten Membran gleichstellte. Eine derartige Auffassung meinerseits hätte man mit Recht als unpluysiologisch zu bezeichnen. 
Wir fragen nun, was uns dieses Ergebniss über die Permeabilität des Epithels für Salzlösungen aussagt. Darf man das abgeschabte Darmepithel als durchlässig für Kochsalz betrachten. Hiergegen scheint die Thatsache zu sprechen, dass die Concentration einen, wenn auch geringen, so doch jedenfalls merklichen Einfluss auf das Volumen des Epithels ausïbt, einen Einfluss, der auch nach längerer Einwirkung nicht verschwindet.

Anfangs meinte ich den betreffenden Einfluss der Salzconcentration einer Vermischung des Epithels mit Zellen zuschreiben zu müssen, die ebenso wie die rothen und weissen Blutkörperchen für Salz impermeabel sind, z. B. einer Vermischung mit lymphoiden Zellen, welche zugleich mit dem Epithel abgeschabt worden waren. Ich glaubte hierzu umsomehr berechtigt zu sein, weil in den vier Versuchen von Fall 1 (vgl. S. 18) gar kein Einfluss auf das Zellvolumen bemerkbar war.

Als mir aber die grosse Uebereinstimmung zwischen den sub. 2 zusammengestellten Volumdifferenzen (S. 18) aufgefallen war, schien es mir doch gewagt, anzunehmen, dass jedes Mal nahezu dieselbe Menge lymphoide Zellen abgeschabt worden'sei. Ausserdem lehrte die mikroskopische Untersuchung, dass die Menge dieser Zellen gering war. Deshalb dachte ich an die Kerne der Epithelzellen. "War es nicht möglich, dass die Kerne eine relativ geringe Durchlässigkeit für Kochsalz besässen und so durch ihreSchrumpfung und Quellung für die Volumänderung der Zellenmasse im Ganzen verantwortlich gemacht werden mïssten?"

Um diese Frage zu prüfen, war es erforderlich, die Grösse der Kerne unter dem Einfluss verschiedener Concentrationen mit einander $\mathrm{zu}$ vergleichen.

Von Volumbestimmungen der isolirten Kerne konnte natürlich nicht die Rede sein. Es blieb also nichts anderes übrig, als mikroskopische Messungen von zwei Dimensionen auszuführen.

\section{Mikroskopische Messung der Zellkerne.}

Zu diesem Zweck wurde die Darmmucosa des eben getödteten Thieres mit $\mathrm{NaCl}$ von $0,9 \%$ abgespült; dann wurde die Schleimhaut abgeschabt, das Epithel in ein wenig $\mathrm{NaCl}$ von $0,9 \%$ vertheilt und von diesem Gemisch je ein wenig mit $\mathrm{NaCl}$ von $0,7 \%$ und $1,5 \%$ versetzt. Nach bestimmten Einwirkungszeiten wurden Präparate angefertigt und in Paraffinleistchen eingeschlossen.

Von jedem Kerne wurde Längs- und Querachse gemessen, und zwar mittelst Ocularmikrometer $2^{1 / 2}$ Obj. F. Ze is s.

Da natïrlıch die Finwirkungsdauer bei dem zuletzt gemessenen Präparate die grösste sein musste, wurde, um diesen Factor bei den vergleichenden Bestimmungen 
zn eliminiren, abwechselnd 30 Zellkerne in 0,7 und 30 Zellkerne in $1,5 \% \mathrm{NaCl}$ Lösung untersucht.

\section{Versuch XLI.}

Das Epithel stammte vom Schweinedarm, ungefähr $0,25 \mathrm{~m}$ vom Pylorus entfernt. Die Messungen wurden vier Stunden nach der Vermischung des Épithels mit den 0,7 und $1,5 \%$ igen Salzlösungen begonnen.

\begin{tabular}{|c|c|c|c|c|c|}
\hline I & II & III & IV & V & VI \\
\hline Salzlösungen & $\begin{array}{c}\text { Gesammtdimension } \\
\text { der Längsachsen } \\
\text { v. je } 30 \text { Kelnen }\end{array}$ & $\begin{array}{c}\text { Ges.- } \\
\text { Dimens } \\
\text { der } \\
\text { Längs- } \\
\text { achsen } \\
\text { v.120 l. }\end{array}$ & $\begin{array}{l}\text { Gesammtdimension } \\
\text { der Breiteachsen } \\
\text { von je } 30 \text { Kernen }\end{array}$ & $\begin{array}{l}\text { Ges.: } \\
\text { Dimens } \\
\text { der } \\
\text { Breite } \\
\text { achsen } \\
\text { v. } 120 \mathrm{~K} \text {. }\end{array}$ & $\begin{array}{l}\text { Gesamtflachen- } \\
\text { durchischnitt v. } \\
120 \text { Kernen } \\
(I I I \times V)\end{array}$ \\
\hline $\begin{array}{c}\mathrm{NaCl} \\
n \quad 1,5 \% \\
n\end{array}$ & $\left|\begin{array}{c}200-209-205-199 \\
180,5-176-175-172,25\end{array}\right|$ & $\begin{array}{c}\$ 13 \\
703,75\end{array}$ & $\left\{\begin{array}{c}132-135-132-139 \\
131-127-125,5-130,5\end{array}\right.$ & $\begin{array}{l}5835 \\
514\end{array}$ & $\begin{array}{c}437394 \\
361797,5\end{array}$ \\
\hline
\end{tabular}

\section{Versuch XIII.}

Wiederholung des vorigen Versuches; anderes Schwein. Mit den Messungen wurde nach 6 stündiger Einwirkung der Salzlösungen begonnen.

\begin{tabular}{|c|c|c|c|c|}
\hline $\begin{array}{c}\mathrm{NaCl} 0,7^{\circ} \% \\
\eta \quad 1,5\end{array}$ & $\begin{array}{l}213,75-210-207-215 \\
203-199,75-206-195\end{array}$ & $\begin{array}{l}\$ 45,75 \\
803,75\end{array}$ & $\begin{array}{c}129,5-125-125,5-122 \\
119,5-126-120-119\end{array}$ & $\begin{array}{r}502 \\
484,5\end{array}$ \\
\hline
\end{tabular}

\section{Versuch XLIII.}

Wiederholung des vorigen Versuches mit Pferdedarm.

\begin{tabular}{cc|c|c||c||c||c||}
$\mathrm{NaCl}$ & $0,7 \%$ & $211 \cdot 217,5-209-212$ & $\mathbf{S 4 9 , 5}$ & $\mathbf{1 2 3 - 1 2 8 - 1 2 6 - 1 2 5 , 5}$ & $\mathbf{5 0 2}, 5$ & $\mathbf{4 2 6 5 7 3}$ \\
$n$ & 1,5, & $203-206-201-197$ & $\mathbf{S 0 5}$ & $\mathbf{1 2 4 - 1 1 9 - 1 2 2 - 1 2 4}$ & $\mathbf{4 8 9}$ & $\mathbf{3 9 3 6 4 5}$
\end{tabular}

Wie ersichtlich, hat die Salzconcentration einen deutlichen Einfluss auf die zwei linearen Dimensionen und also auch auf den Fläcliendurchschnitt (Spalte VI) der Kerne ausgeübt. Wenn das der Fall ist, muss der Einfluss auf das Volumen der Kerne noch grösser sein. Man darf wohl schliessen, dass bei dem nicht geringen Antheil, welchen der Kern am Volumen der Gesammtzelle hat, die Salzconcentration einen deutlichen Einfluss auf das Totalvolumen der Zelle ausiiben muss.

Ich glaube also, die Resultate der bis jetzt beschriebenen Untersuchungen in folgender Weise deuten zu müssen:

1. Der Zellenleib des abgeschabten Darmepithels ist für Kochsalz in hohem II asse permeabel, der Kern hingegen wenig oder nicht.

2. Zuweilen befindet sich das Darmepithel in einem "/ustande, in welchem nicht nur der kern, sondernauch der Zellenleib für Kochsalz wenig permeabel ist. 
Höber [8] hat im Züricher physiologischen Institute beiläufig versucht, die Frage zu beantworten, ob im Darme ausser der zwischen den Epithelzellen gelegenen Kittsubstanz auch die Zellen selbst für gelöste Stoffe durchlässig seien. Der Verfasser konnte auf seine Frage keine Antwort erhalten. Ich glaube, dass die oben mitgetheilten Versuche eine solche ertheilen.

\section{b) Flimmerepithel.}

Die zweite Epithelart, welche ich untersuchte, ist das Flimmerepithel aus der Trachea. Diese Zellenart gewälırt den Vortheil, dass man während der ganzen Versuchsdauer Sicherheit erlangen kann, ob das Object sich noch im lebendigen Zustande befindet.

Nachdem die Zellen die erforderliche Zeit mit der gebrauchten Salzlösungen in Berührung gewesen waren, konnte man im Engelmannschen Gaskämmerchen unter Anwendung von Körpertemperatur die Cilien vieler Zellen noch in Bewegung sehen, oder durch Reizung in Bewegung versetzen.

Da die Versuche in gleicher Weise wie beim Darmepithel angestellt wurden, wird die Mittheilung der Resultate genügen.

\section{Versuch XLIV}

Flimmerepithel aus der Trachea eines eben getödteten Pferdes. Das Epithel ist in ein wenig $\mathrm{NaCl}$-Lösung von $0,9 \%$ vertheilt. Unmittelbar nachher werden gleiche Mengen der Aufschwemmung mit 15 cc einer 0,7 bis 0,9 und $1,2 \%$ igen $\mathrm{NaCl}$ Lösung in Berührung gebracht. Nach halbstündiger Einwirkung wurde centrifugirt.

\begin{tabular}{cc||c}
\hline Salzlösungen & Volumen des Epithels \\
\hline \hline NaCl-Lösung von 0,7 Proc. & 86 \\
" $0,9,1,2$, & 81 \\
& " & 74
\end{tabular}

Vergleicht man die nach Einwirkung von $\mathrm{NaCl}$ von $0,7 \%$ und 1,2\% erhaltenen Zahlen, so ergiebt sich ein Volumunterschied von $\frac{86-74}{86} \times 100$ $=14 \%$. Dieser Betrag erinnert an die Werthe, die bei den für $\mathrm{NaCl}$ impermeablen rothen und weissen Blutkörperchen gefunden wurden und nun fragt es sich, ob das Flimmerepithel die Eigenschaft der Undurchlässigkeit für $\mathrm{NaCl}$ mit den genannten Zellen theilt, oder ob dasselbe 
im Gegentheil NaCl-Lösungen durchtreten lässt, ebenso wie das Darmepithel, aber langsamer. Letzteres war nicht schwer zu prüfen. Ich verfügte noch über einen Theil der Gemische des vorigen Versuches und wartete mit dem Centrifugiren, bis dieselben während zwei Stunden sich selbst überlassen gewesen waren.

Wiederholung des vorigen Versuches; jedoch bei zweistündiger Einwirkungsdauer statt halbstündiger.

\begin{tabular}{cc||c}
\hline \hline Salzlösungen & Volumen des Epithels \\
\hline \hline NaCl.Lösung von 0,7 Proc. & 84 \\
" $\quad$ " $0,9 \%$ & 82 \\
& 1,2, & 80
\end{tabular}

Jetzt ist der Volumunterschied $\frac{84-80}{84} \times 100=\mathbf{4 , 8} \%$ geworden, statt $14 \%$.

Es schien mir nun von Interesse, weiter zu untersuchen, ob bei noch längerer Einwirkung als zwei Stunden der Unterschied vielleicht ganz verschwinden wïrde.

$\mathrm{Zu}$ diesem Zwecke wurden die Sedimente mit den überstehenden Flüssigkeiten mittelst eines Platindrahtes gut gemischt. ${ }^{3}{ }_{4}$ Stunde später wurde wieder centrifugirt. l's stellte sich heraus, dass die zuvor erhaltenen Volumunterschiede nicht verschwanden, vielmehr nahezu unverändert blieben.

Die acht anderen Versuche, welche in derselben Weise ausgeführt wurden und deren ich hier der Kürze halber nur noch einen er'wähne, ergaben dasselbe Resultat.

\section{Versuch XIV.}

Epithel aus der Trachea eines eben getödteten Pferdes, vertheilt in ein wenig Pferdeserum.

\begin{tabular}{|c|c|c|c|c|}
\hline \multirow{2}{*}{ Salzlösungen } & \multicolumn{4}{|c|}{ Volumen des Epithels nach einer Eiuwirkungsdauer von } \\
\hline & $1 / 2$ Stunde & 2 Stunden & 3 Stunden & 4 Stunden \\
\hline $\mathrm{NaCl} 0,7$ Proc. & 68 & 66 & 62 & 62 \\
\hline ^ 0,9 , & 63 & 64 & 61 & 61 \\
\hline 1,2 & 57 & 9 & 57 & 57 \\
\hline$\Rightarrow \quad 1,5 \quad$, & 54 & 57 & 57 & 56 \\
\hline
\end{tabular}

Aus dieser 'Tabelle geht hervor, dass nach halbstiindiger Einwirkung der Einfluss der Salzconcentration bedeutend ist, und dass derselbe mit der Zeit abnimmt, um danu konstant zu werden. 
Nach dem beim Darmepithel Besprochenen, liegt es anf der Hand, diese Thatsachen in der Weise zu interpretiren, dass der Z ell körper des Flimmerepithels, wenn auch nichtso rasch, wie der des Darmepithels, doch im Stande ist, Kochsalzlösungen verschiedener Concentration durchtreten zu lassen, sodass schliesslich von einer osmotischen Druckdifferenz zwischen Zellkörperinhalt und Umgebung nicht mehr die Rede ist. Der Kern ist für Kochsalz nicht, oder schwer durchlässig und dieser ist also für die definitive Volumdifferenzder Gesammtzellenmasse verantwortlich zu machen.

Die Permeabilität des Tracheaepithels wird sich natïrlich in situ kräftiger aussprechen, wie im isolirten Zustande, weil die einerseits in die Zellen aufgenommene Flüssigkeit an der anderen Seite durch Lymphund Blutstrom entfernt wird. Das Ergebniss steht röllig in Uebereinstimmung mit der klinischen Erfahrung, dass intratracheal injicirte Medicamente sehr rasch resorbirt werden.

Dass nun in der That der Kern unter dem Einflusse verschiedener Salzconcentrationen erhebliche Dimensionsschwankungen zeigt, konnte ich ebenso wie beim Darmepithel auch beim Flimmerepithel mittelst mikroskopischer Messungen feststellen.

Mikroskopische Messung der Zellkerne.

\section{Versuch LII.}

Tracheaepitleel des Pferdes. Zwei Stunden nach der Vermischung mit den Salzlösungen, $\mathrm{NaCl} 0,7$ und $1,5 \%$, wurde mit den Messungen der Längsachse der Kerne begonnen.

\begin{tabular}{c||c||c}
\hline Salzlösungen & $\begin{array}{c}\text { Gesamtlängsachse von je } \\
30 \text { Kernen }\end{array}$ & $\begin{array}{c}\text { Gesamtlängsachse von } \\
120 \text { Kernen }\end{array}$ \\
\hline \hline NaCl 0,7 Procent & $176-171,25-173,5-179$ & $\mathbf{6 9 9 , 7 5}$ \\
n 1,5 n & $165-168,25-166,5-163$ & $\mathbf{6 6 2 , 7 5}$
\end{tabular}

\section{Versuch LIII.}

Wiederholung des vorigen Experimentes; nur begannen die Messungen erst vier Stunden nach Vermischung mit den Salzlösungen.
$\mathrm{NaCl} 0,7$ Procent
$166,5-161-162-167$
$6.56,5$
1,5 n
$154-154,25-151-158$
617,25 


\section{Versuch LIV und LV.}

Wiederholung des vorigen Experimentes. Beginn der Messungen naeh sechsstündiger Einwirkung der Salzlösungen.

\begin{tabular}{c|c|c}
\hline Salzlösungen & $\begin{array}{c}\text { Gesamtlängsachse von je } \\
30 \text { Kernen }\end{array}$ & $\begin{array}{c}\text { Gesamtlängsachse von } \\
120 \text { Kernen }\end{array}$ \\
\hline \hline $\mathrm{NaCl} 0,7$ Procent & $178-170-173-171,5$ & $\mathbf{6 9 2}, 5$ \\
\% $1,5 \pi$ & $156-161,25-165-161$ & $\mathbf{6 4 3 , 2 5}$ \\
$\mathrm{NaCl} 0,7$ Procent & $181,25-183-182-184$ & $\mathbf{7 3 2}, 25$ \\
$\pi 1,5 \quad \pi$ & $166-173,5-169-171$ & $\mathbf{6 7 9 , 5}$
\end{tabular}

\section{c) Blasenepithel.}

Handelte es sich beim Darm- und Tracheaepithel um Zellen, welche erwarten liessen, dass sie leicht Salze durchgehen lassen können, so liess das Blasenepithel das Gegentheil vermuthen. In der That würde die Blase ihrer Bestimmung sehr schlecht entsprechen, wenn sie eine erhebliche Permeabilität für gelöste Stoffe besitzen würde.

Bekanntlich ist die Blase von innen mit einer vierfachen Epithelschicht ausgekleidet. Beim Schwein lässt sich dieselbe leicht entfernen Es zeigte sich nothwendig, vor der Entfernung des Epithels die Schleimhant sorgfältig mit 0,9\% NaCl-Lösnng abzuspülen, weil sich beim Schwein nicht selten und beim Pferd gewöhnlich Sediment auf der Schleimhaut befindet.

\section{Versuch LVI.}

Blasenepithel eines eben geschlachteten Schweines, vertheilt in ein wenig $0,9 \% \mathrm{NaCl}-\mathrm{L}$ ösung. Von dem Gemisch wurden gleiche Volumen mit NaCl-Lösung von $0,7,0,9,1,2$ und $1,5 \%$ versetzt.

Nachdem ungefähr zwei Stunden centrifugirt worden war, wurde die Epithelsäule mittelst eines Platindrahtes wieder gut mit der überstehenden Flüssigkeit vermischt, das Gemisch eine Stunde sich selbst überlassen und dann wieder centrifugirt. Er sollte hierdurch in gleicher Weise, wie beim Flimmerepithel festgestellt werden, ob zur Erzielung eines constanten Zellenvolumens eine längere Einwirkungsdauer als eine halbe Stunde erforderlich war.

\begin{tabular}{|c|c|c|c|}
\hline \multirow{2}{*}{\multicolumn{2}{|c|}{ Salzlösungen }} & \multicolumn{2}{|c|}{$\begin{array}{l}\text { Volumen des Epithels nach einer } \\
\text { Einwirkungsdauer von }\end{array}$} \\
\hline & & $1 / 2$ Stunde & $1^{1 / 2}$ Stunde \\
\hline $\mathrm{NaCl}$ & 0,7 Procent & 78 & 78 \\
\hline$\eta$ & 0,9 & 70 & 70,5 \\
\hline 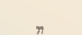 & 1,2 & 62,5 & 62 \\
\hline n & 1,5 & 58 & 58 \\
\hline
\end{tabular}


Aus dieser Tabelle geht hervor, dass das Volumen des Epithels regelmässig und erhebiich mit der Steigerung der Salzconcentration abnimmt und dass, im Gegensatz zu dem, beim Tracheaepithel beobachteten, die nach $1 \frac{1}{2}$ stündiger Einwirkung erhaltenen Zahlen annähernd die gleichen sind, wie die nach halbstündiger Einwirkung gefundenen.

Auf Grund analoger Ergebnisse bei den rothen und weissen Blutkörperchen und Spermatozoen schloss ich früher, dass diese Zellen aus zwei Substanzen bestehen, welche sich in Beziehung auf ihr wasseranziehendes Vermögen verschieden verhalten: eine protoplasmatische Substanz, welche am wasseranziehenden Vermögen der Zelle nicht oder kaum betheiligt ist und eine intracellulare und intranucleare Flüssigkeit, welche praktisch das ganze Wasseranziehungsvermögen der Zelle repräsentirt.

Es entstand nun der Gedanke, zu untersuchen, inwieweit bei demselben Individuum Uebereinstimmung zwischen dem procentischen Protoplasmagehalt des Blasenepithels und dem der rothen Blutkörperchen zu beobachten sein würde.

Durch äussere Umstände war es jedoch schwierig, Blasenepithel von frisch getödteten Pferden zu bekommen. Die meisten der betreffenden Untersuchungen wurden deshalb an Material vom Schwein ausgeführt.

Da die Centrifuge nur vier Röhrchen fassen konnte, so habe ich nur mit zwei Salzlösungen gearbeitet, und zwar mit einer $0,7 \%$ und einer 1,5\% NaCl-Lösung. Für beide Zellenarten berechnete ich dann den procentischen Volumenunterschied.

Versuch LxVIII.

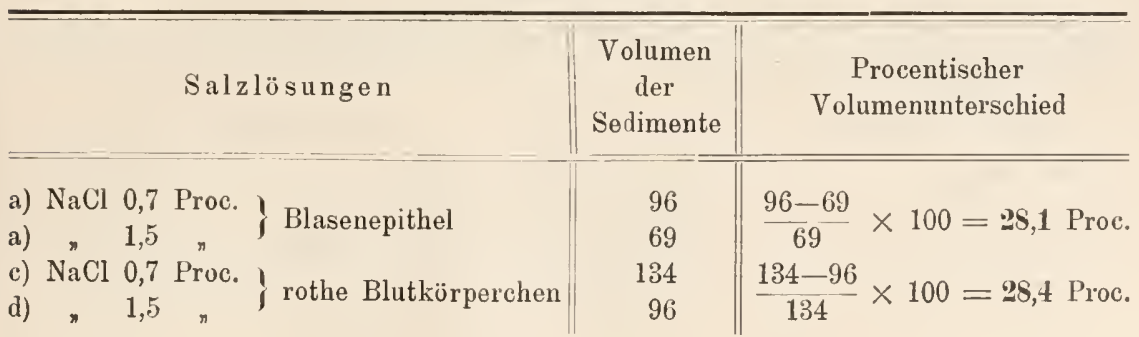

Wenn man anmimmt, dass die intracellulare Flüssigkeit des Blasenepithels isotonisch ist mit der der rothen Blutzellen, so geht aus diesem Versuche hervor, dass bei demselben Individuum der Procentgehalt an 
protoplasmatischem Gerïst (bezw. das procentische Volumen der Colloïdtheilchen) bei Blasenepithel und rothen Blutkörperchen sehr gut ïbereinstimmen.

Nach demselben Plane sind noch viele andere Versuche angeführt worden.

Die durch $\mathrm{NaCl}$ v on $0,7 \%$ und $1,5 \%$ verursachten Volumdifferenzen bewegten sich zwischen $25,4 \%$ und $29 \%$. Jedoch gelangten auch Fälle zur Beobachtung, in denen die Uebereinstimmung zwischen der Volumänderung von Blasenepithel und Blutkörperchen vermisst wurde. In zwei Experimenten betrug nämlich die Volumänderung für das Blasenepithel bloss 10,3 und 13 , wälrend dieselbe in einem dritten Versuch $17,9 \%$ betrug.

Diese drei Abweichungen lassen sich aber dadurch erklären, dass, wie die mikroskopische Untersuchung lehrte, in den beiden ersten Versuchen fast alle und im dritten Versuch ein grosser Theil der Kerne frei lagen, während die Zellenleiber in Körnchen auseinandergefallen waren, sodass in den beiden ersten Versuchen die Volumänderungen ausschliesslich von den Kernen und im letzten Versuch von den Kernen und den nicht zerfallenen Zellieibern herbeigeführt wurden.

Dass in der That auch die Kerne des Blasenepithels an den Volumänderungen betheiligt sind, hat sich unzweifelhaft aus mikroskopischen Messungen ilhrer Dimensionen ergeben.

\section{Mikroskopische Messung der Zellkerne.}

Zu diesem Zwecke wurde die Blasenmucosa eines eben getödteten Schweines mit $\mathrm{NaCl}$ von $0,9 \%$ abgespült; dann wurde die Schleimhaut abgeschabt, das Epithel ein wenig $\mathrm{NaCl}$ von $0,9^{\%}$ vertheilt und von diesem Gemisch ein wenig mit $\mathrm{NaCl}$ von $0,5,0,7$ und $2,4 \%$ versetzt.

Die Länge und Breite stimmten ziemlich genau miteinander überein; trotzdem wurden doch beide Dimensionen gemessen und von beiden der Mittelwerth genommen.

F. Zeiss

Die IIessungen geschahen mittelst Ocularmikrometer $2^{1 / 2}$, Obj.

Versuch LXXVII.

\begin{tabular}{|c|c|c|}
\hline Salzlösungen & $\begin{array}{l}\text { Gesamtdimension von } \\
\text { je } 30 \text { Kernen }\end{array}$ & $\begin{array}{l}\text { Totaldimension von } \\
120 \text { Kernen }\end{array}$ \\
\hline $\mathrm{NaCl} 0,5$ Procent & $280-295-297--298$ & 1180 \\
\hline » 0,7 & $282-294-274-292$ & 1142 \\
\hline$n \quad 0,9$ & $266-273-275-272$ & 1086 \\
\hline$n \quad 2,4$ & $232-241-246-240$ & 959 \\
\hline
\end{tabular}


Man sieht, dass die Dimensionen der Kerne mit der Concentrationszunahme der Salzlösungen abnehmen.

\section{Versuch LXXVIII.}

Dieser Versuch wurde in gleicher Weise angestellt wie der vorige, jedoch an einem anderen Thier.

\begin{tabular}{c|c|c}
\hline Salzlösungen & $\begin{array}{c}\text { Gesammtdimension von } \\
\text { je } 30 \text { Kernen }\end{array}$ & $\begin{array}{c}\text { Totaldimension von } \\
\text { 120 Kernen }\end{array}$ \\
\hline \hline $\mathrm{NaCl} 0,7$ Procent & $249-240-246-247$ & $\mathbf{9 8 2}$ \\
$1,5 \quad n$ & $238-229-237-231$ & $\mathbf{9 3 5}$ \\
$2,4 \quad$ & $255-246-243-250$ & $\mathbf{9 9 4}$
\end{tabular}

Dieser Versuch zeigt, ebenso wie der vorige, dass die Dimension der Kerne in einer 1,5\% NaCl-Lösung kleiner ist als in einer $0,7 \%$ $\mathrm{NaCl-Lösung.}$

Im Gegensatz hierzu stellte sich aber heraus, dass in der NaClLösung von 2,4\% die Kerne am grössten sind. Höchstwahrscheinlich haben dieselben aber in letzterer Lösung eine wesentliche Veränderung erfahren, denn sie erscheinen sehr blass und zeigen hier und da eine wellenförmige, d. h. abnorme Begrenzung. Die Bilder erinnern an die, welche man beobachtet, wenn rothe Blutkörperchen, insbesondere Froschblutkörperchen in starken NaCl-Lösungen verweilt haben (NaCl-Lösungen von 2-3\%). Auch die Blutkörperchen quellen dann zu grossen blassen Kingeln auf.

Ich will noch ein paar Versuche mit $\mathrm{NaCl}$ von $0,7,1$ und $1,5 \%$ erwähnen. Im letzten Versuche sind nur freiliegende Kerne gemessen.

Versuch LXXIX.

\begin{tabular}{|c|c|c|}
\hline Salzlösungen & $\begin{array}{c}\text { Gesammtdimension von } \\
\text { je } 30 \text { Kernen }\end{array}$ & $\begin{array}{l}\text { Totaldimension von } \\
120 \text { Kernen }\end{array}$ \\
\hline $\begin{array}{ccc}\mathrm{NaCl} & 0,7 & \text { Procent } \\
& 1,0 & \\
& 1,5 & \end{array}$ & $\begin{array}{l}270-271-276-269 \\
262--259-254-265 \\
250-246-251-244\end{array}$ & $\begin{array}{r}1006 \\
1030 \\
991\end{array}$ \\
\hline $\begin{array}{ccc}\mathrm{NaCl} & 0,7 & \text { Procent } \\
, & 1,0 & \\
, & 1,5 & \end{array}$ & $\begin{array}{l}\text { Versuch LXXX. } \\
254-259-253-263 \\
251-248-246-249 \\
239-242-238-240\end{array}$ & $\begin{array}{r}1029 \\
994 \\
959\end{array}$ \\
\hline
\end{tabular}


Aus diesen Versuchen geht deutlich hervor, dass die Dimension der Kernemit der Concentrationszunahme der umgebenden Salzlösungen abnimmt.

Man darf also schliessen: wenn sich das abgeschabte Blasenepithel nicht gerade in zerfallenem Zustande befindet, so stimmen die durch Salzlösungen herbeigeführten Volumänderungen genau mit den bei den entsprechenden rothen Blutkörperchen beobachteten überein.

Nun könnte man die Bemerkung machen, dass bei der Entfernung des Epithels doch wohl immer ein gewisser Theil der Zellen lädirt wird. In der That ist diese Möglichkeit auch nicht auszuschliessen. Indessen lehrt das Experiment, dass diese Lüsionen, bei denen z. B. ein Theil des Zellenleibes abgerissen wird, auf das Resultat der Bestimmungen keinen wesentlichen Einfluss ausiiben.

Hackt man nämlich abgeschabtes Blasenepithel mit einem scharfen Rasirmesser während einer halben Stunde, wie man dies zur Anfertigung von Netzhautpräparaten zu thun pflegt, und prïft nachher den Einfluss von Salzlösungen auf das Volumen, so ergiebt sich, dass das Hacken nur einen geringen Einfluss ausgeübt hat.

Ich lasse zum Beweise drei Versuche folgen.

\section{Versuch I.XXXI.}

Blasenepithel des Schweines wurde in wenig $\mathrm{NaCl}$ von $0,9 \%$ vertheilt. Ein Theil des Gemisches wurde mit scharfem Rasirmesser eine halbe Stunde gebracht; dann wurden gleiche Mengen dieser gehackten Masse mit gleichen Volumen einer $0,7 \%$ igen und $1,5 \%$ igen NaCl-Lösung versetzt. Genau dasselbe geschah mit dem nicht gehackten Antheile.

\begin{tabular}{|c|c|c|}
\hline Salzlösungen & $\begin{array}{c}\text { Volumen des } \\
\text { Epithels }\end{array}$ & $\begin{array}{c}\text { Procentischer } \\
\text { Volumunterschied }\end{array}$ \\
\hline $\begin{array}{l}\text { a) } \mathrm{NaCl} 0,7 \text { Proc. } \\
\text { b) } \$ \text { gehackt } \\
\text { c) } \mathrm{NaCl} 0,7 \text { Proc. } \\
\text { d) }, 1,5, \$ \text { nicht gehackt }\end{array}$ & $\begin{array}{l}85 \\
66 \\
94 \\
69\end{array}$ & $\begin{array}{l}\frac{85-66}{85} \times 100=\mathbf{2}, \mathbf{3} \text { Proc. } \\
\frac{94-69}{94} \times 100=\mathbf{2 6 , 6} \text { Proc. }\end{array}$ \\
\hline
\end{tabular}

Versuch LxxxiI.

\begin{tabular}{|c|c|c|}
\hline Salzlösungen & $\begin{array}{l}\text { Volumen des } \\
\text { Epithels }\end{array}$ & $\begin{array}{c}\text { Procentischer } \\
\text { Volumunterschied }\end{array}$ \\
\hline 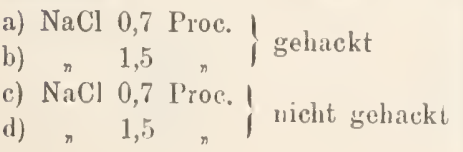 & $\begin{array}{l}74 \\
55,5 \\
85,5 \\
61\end{array}$ & 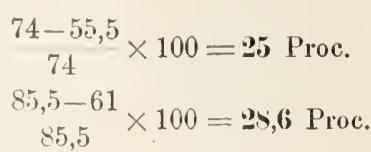 \\
\hline
\end{tabular}


Versuch IXXXIII.

\begin{tabular}{|c|c|c|}
\hline Salzlösungen. & $\begin{array}{l}\text { Volumen des } \\
\text { Epithels }\end{array}$ & $\begin{array}{l}\text { Procentischer } \\
\text { Volumunterschied }\end{array}$ \\
\hline 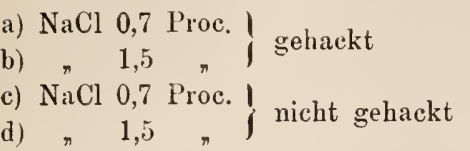 & $\begin{array}{c}59,5 \\
45,5 \\
107 \\
76\end{array}$ & $\begin{array}{l}\frac{59,5-45,5}{59,5} \times 100=\mathbf{9 3 , 5} \text { Proc. } \\
\frac{104-76}{104} \times 100=\mathbf{2 7} \text { Proc. }\end{array}$ \\
\hline
\end{tabular}

Man sieht, dass nach dem Hacken der Volumunterschied des Epithels in $\mathrm{NaCl}$ von 0,7 und $1,5 \%$ fast ebenso gross ist wie zuvor. Soweit ich sehe, kann das nur daher rühren, dass der Zellleib des Blasenepithels nach der Vorstellung B ütschli's [9] schon während des Lebens, bezw. nach der Vorstellung Hardy's nach dem Absterben, aus einem protoplasmatischen Schaum besteht, dessen Waben geschlossen sind und die intracellulare Flüssigkeit enthalten. Nach dieser Vorstellung werden beim Durchschneiden einer Zelle zwar viele Waben geöffnet, aber jede der zwei Hälften bildet wieder ein feines geschlossenes Wabenwerk. Wenn alle Waben mit einander communicirten, so würde nach einer Durchschneidung oder einer anderen Läsion der Zelle die intracellulare Flüssigkeit sich mit der sie umgebenden Salzlösung vermischen und der Zellenleib würde nicht mehr quellen oder schrumpfen. Wenn das nun nach dem Hacken doch geschieht, so ist das ungekehrt eine Stiitze für die Wabenstructurhypothese Bütschli's resp. Hardy's ${ }^{1}$ ). Da immerhin doch eine Anzahl Waben geöffnet wurden, so muss natïrlich der durch Salzlösungen herbeigeführte Volumunterschied doch etwas kleiner ausfallen, als wenn die Zellen unversehrt geblieben wären, was denn auch aus den Versuchen LXXXI-LXXXIII deutlich hervorgeht.

Wie man aber auch über die Interpretation der aufgefundenen Thatsachen denken mag, jedenfalls berechtigt die Beobachtung, dass das Volumen des abgeschabten Epithels sogar durch langwährendes Hacken wenig beeinflusst wird, zu dem Schluss, dass die Verletzung der Zellen durch einfaches Abschaben noch weniger Einfluss auf das Volumen ausüben wird.

Doch sieht man zuweilen, (wie in den drei erwähnten Versuchen), bei anscheinend gesunden Blasen, dass nach einfacher Entfernung des Epithels und Versetzung mit $\mathrm{NaCl}$ von $0,9 \%$ der ganze Zellenleib in

1) Hardy beobachtete bei einigen Colloiden nach dem Uebergang in den Gelzustand geschlossene, bei anderen offene Netze. Vergl. weiter die Kapitel "Bemerkungen über Colloïde" und „Histologisches" unter 1. 
Körnchen zerfällt. Warum das geschieht, vermag ich nicht zu erklären. Handelt es sich hier vielleicht um einen besonderen Zustand des Epithels?

Vielleicht wird die Bemerkung gemacht werden, dass auch nach langem Hacken die Zellen in eine Körnchenmasse verändert sein können. Das ist abes - man kann sich durch das Mikroskop leicht davon überzeugen - keineswegs der Fall. Ich denke das rührt daher, dass die Zellen so leicht unter dem Rasirmesser hinwegschlüpfen.

Als allgemeines Endresultat der über das Blasenepithel angestellten Versuche ergiebt sich, dass die Zellen sich in Beziehung auf Permeabilität und Volumänderung gegen Kochsalzlösungen ebenso verhalten, wie die rothen und weissen Blutkörperchen.

\section{d) Oesophagusepithel.}

Ich wollte noch eine Epithelart untersuchen, an welcher ebenso wie am Blasenepithel Undurchlässigkeit für Salze erwartet werden konnte. $\mathrm{Zu}$ diesem Zweck priifte ich das Epithel des Oesophagus, also eines Organs, das ebensowenig wie die Blase auf Resorption angewiesen ist.

Was man hier abschabt, sind sehr grosse, meist platte Zellen, in welchen nicht selten eine erhebliche Anzahl runde und ovale Körnchen vorlanden sind, welche den Eindruck von Bakterien erwecken und sich auch mit alkalischen Anilinfarbstoffen intensiv tingiren lassen.

In vielen Fällen gelang es nicht, eine genügende Menge zu gewinnen, denn die Zellen pflegen fest an einander und an der Unterlage zu haften.

Die Experimente wurden in gleicher Weise wie beim Darm-, Trachea- und Blasenepithel ausgefiihrt.

Ich lasse hier einen Versuch folgen.

Versuch LXXXIV.

Oesophagusepithel eines frisch getödteten jungen Hundes, vertheilt in ein

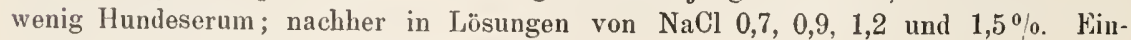
wirkungsdauer 1/2 Stunde; dann centrifugirt.

\begin{tabular}{|c|c|c|}
\hline \multicolumn{2}{|r|}{ Salzlösungen } & Volumen des Epithels \\
\hline a) & $\mathrm{NaCl} 0,7$ Procent & 44,5 \\
\hline b) & » $\quad 0,9$ & 38,5 \\
\hline c) & $\quad 1,2$ & 33 \\
\hline d) & $\leadsto \quad 1,5$ & 30,5 \\
\hline
\end{tabular}

Es ergah sich also eine regelmässige und erhebliche Abnahme des Yolumen bei Steigerung der Salzoncentration. 
Ebenso wie beim Blasenepithel, stellte ich auch hier eine Anzahl von Experimenten an, um zu untersuchen, wieweit bei demselben Individuum Uebereinstimmung zwischen der procentischen Volumänderung des Oesophagusepithels und derjenigen der rothen Blutkörperchen durch die gleiche Salzlösung zu beobachten sein würde.

Oft ereignete es sich wie gesagt, dass ich den betreffenden Versuch nicht auszuführen im Stande waren, weil die Epithelzellen zu fest an der Unterlage oder an einander hafteten.

Versuch LXXXVI.

\begin{tabular}{l|c|c}
\hline Salzlösungen & $\begin{array}{c}\text { Volumen } \\
\text { des } \\
\text { Sediments }\end{array}$ & $\begin{array}{c}\text { Procentischer } \\
\text { Volumunterschied }\end{array}$ \\
\hline
\end{tabular}
a) $\mathrm{NaCl} 0,7$ Proc. Y Oesophagusepithel
42
b) $, 1,5,1$ (Hund)
27,5
c) $\mathrm{NaCl} 0,7$ Proc. ; rothe Biutkörperchen
64
31.5
$\frac{42-27,5}{42} \times 100=34,5$ Proc. $\frac{64-31,5}{64} \times 100=50,5$ Proc.

\section{Versuch IAXXVII.}

a) $\mathrm{NaCl} 0,7$ Proc. । Oesophagusep,ithel

b) $, 1,5,1 \quad$ (Schwein)

c) $\mathrm{NaCl} 0,7$ Proc. ; rothe Blutkörperchen
38

17,5

72,5

33

$$
\begin{aligned}
& \frac{38-17,5}{38} \times 100=53,9 \text { Proc. } \\
& \underset{72,5}{72,5-33} \times 100=5 \mathbf{5}, \mathbf{4} \text { Proc. }
\end{aligned}
$$

\section{Versuch IXXXVIII.}
a) $\mathrm{NaCl} 0,7$ Proc. , Oesophagusepithel
46,5
b) $, 1,5,1$ (Hund)
24
69
c) $\mathrm{NaCl} 0,7$ Proc. ; rothe Blutkörperchen
35
$46,5-24$
46,5
$69-35$
69

Versuch LXXXIX.
a) $\mathrm{NaCl} 0,7$ Proc. Yesophagusepithel
b) $\approx 1,5,1$ (Pferd)
49
25
$\frac{49-25}{49} \times 100=45,9$ Proc.
c) $\mathrm{NaCl} 0,7$ Proc. ; rothe Blutkörperchen
59,5
26,5
$\frac{59,5-26,5}{59,5} \times 1(0=55,4$ Proc

Versuch XC.
a) $\mathrm{NaCl} 0,7$ Proc. Oesophagusepithel
44
b) $, 1,5,1$ (Rind)
22
c) $\mathrm{NaCl} 0,7$ Proc. \& rothe Blutkörperchen
71
32,5
$\frac{44-22}{44} \times 100=50$ Proc.
$\begin{gathered}71-32,5 \\ 71\end{gathered} \times 100=54,2$ Proc.


Versuch XCI.

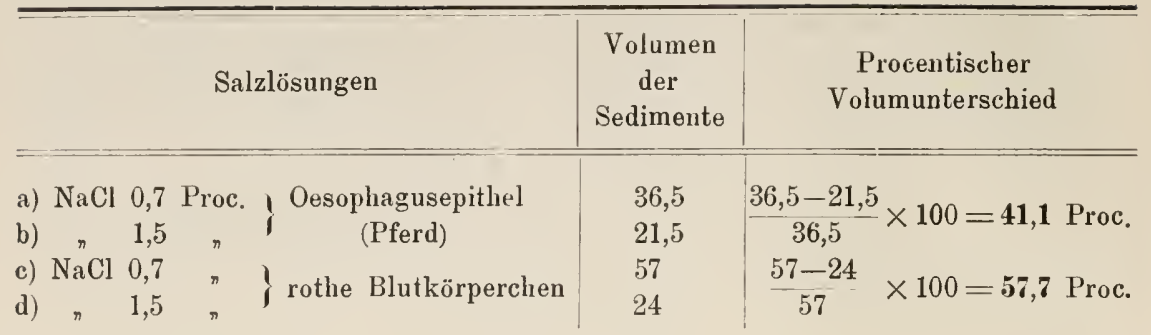

\section{Versuch XCII.}

a) $\mathrm{NaCl} 0,7$ Proc. , Oesophagusepithel

b) $\pi 1,5,1$ (Pferd)

c) $\mathrm{NaCl} 0,7$ Proc. ; rothe Blutkörperchen
40,5

17

56

23

$$
\begin{aligned}
& \frac{40,5-17}{40,5} \times 100=5 \text { S Proc. }
\end{aligned}
$$

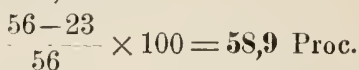

\section{Versuch XciII.}

a) $\mathrm{NaCl}$ 0,7 Proc. Oesophagusepithel

b) $n 1,5,1$ (Schwein)

c) $\mathrm{NaCl} 0,7$ Proc. $\}$ rothe Blutkörperchen
52

24,5

67,5

31,5

$$
\begin{aligned}
& \frac{52-24,5}{52} \times 106=52,8 \text { Proc. } \\
& \frac{67,5-31,5}{67,5} \times 100=53,3 \text { Proc. }
\end{aligned}
$$

Betrachtet man die Tabellen, so ergeben sich folgende Resultate:

1. In den Versuchen LXXXVII, LXXXVIII, XC, XCII und XCIII stimmt der Volumunterschied des Oesophagusepithels in $\mathrm{NaCl}$ von $0,7 \%$ und $1,5 \%$ mit dem der entprechenden rothen Blutkörperchen überein.

2. In den übrigen drei Versuchen LXXXVI, LXXXIX uud XCI aber zeigt das Oesephagusepithel einen viel geringeren Volumunterschied als die entsprechenden Blutkörperchen.

Woher rülırt dieser Gegensatz?

Handelt es sich im zweiten Falle vielleicht um einen Zerfall des 'ellkörpers, wie derselbe auch beim Blasenepithel zu beobachten war?

Davon war nicht die Rede.

Ein aufmerksames Studium der Versuchsprotokolle hat den Gegensatz auf befriedigende Weise aufgeklärt. Es fiel mir nämlich auf, dass gerade bei den letztgenannten drei Experimenten, in den Zellen eine grosse Anzahl Körnchen vorhanden war (vgl. S. 30); in den unter 1 angeführten Versuchen dagegen nicht oder nur sehr wenig. Nun liegt es auf der Hand, dass die Salzlösungen einen um so geringeren Finfluss auf das Zellvolumen ausüben müssen, je melır der Raum der 
intracellularen (wasseranziehenden) Flüssigkeit von Körnchen eingenommen wird.

Wenn also im Oesophagusepithel keine besonderen Ablagerungen vorhanden sind, so verhalten sich die Zellen gegenüber Kochsalzlösungen ebenso wie die Blutkörperchen und das Blasenepithel.

Was diese Ablagerungen bedeuten, vermag ich nicht zu sagen, ebensowenig, an welche Umstände ihr Vorkommen geknüpft ist.

\section{e) Kritik, Zusammenfassung und Discussion.}

Als die Absicht bei mir entstand, den Einfluss der Salzconcentration auf das Volumen von Epithelzellen zu untersuchen, wurde es bald deutlich, dass von quantitativen Bestimmungen an den Zellen in situ nicht die Rede sein konnte, sondern dass die Experimente an isolirten oder höchstens zu kleinen Aggregaten zusammengefügten Zellen ausgeführt werden mussten. Zu diesem Zwecke war ich genöthigt, die Zellen durch vorsichtiges Abschaben von der Unterlage zu entfernen.

Ich muss aber gestehen, dass ich nicht ohne Widerwillen an diese Methode herantrat. Liegt nicht die Möglichkeit, sogar die Wahrscheinlichkeit vor, dass man beim Abschaben auch andere Gewebstheile entfernt und ausserdem eine Anzahl der doch zarten Epithelzellen beschädigt?

Was den ersten Punkt anbetrifft, nämlich das Yorhandensein von anderen Gewebstheilen zwischen der Epithelmasse, so braucht man darüber nicht im Unklaren zu bleiben; das Mikroskop kann unmittelbaren Aufschluss geben.

Ich habe denn auch keinen Versuch angestellt, bei dem ich mir nicht auch aus anderweitigen Gründen die allerdings geringe Mïhe nahm, ein oder mehrere Präparate der zu centrifugirenden Giemischs unter dem Mikroskope zu betrachten. Hierbei hat es mich geradezu frappirt, wie wenig Gewebsfetzen in den Präparaten zu erkennen waren.

Was aber gar nicht selten vorkam, war eine sichtbare Beschädigung der Zellen, wodurch sogar oft Kerne isolirt worden waren.

Nun müssen wir in dieser Beziehung einen wesentlichen Unterschied zwischen den Fällen machen, in denen das Protoplasmagerüst aller oder fast aller Zellenleiber, selbst nach sorgfältigster Abschabung und vorsichtiger Vermischung mit den Salzlösungen in Körnchen zerfällt, sodass schliesslich nur freie Kerne und Protoplasmakörnchen vorhanden sind (vgl. S. 26), und jenen Fällen, in welchen unter den nämlichen Manipulationen nur ein kleiner Theil der Zellen sichtlich lädirt wurde und 
von einem Zerfalle in Körnchen absolut nicht die Rede ist. Wie sich herausstellte, iibt in den ersteren Fällen die Disgregation des Protoplasmagerüstes einen bedeutenden verkleinernden Einfluss auf den Betrag der durch Salzlösungen herbeigeführten Volumänderungen aus. Und das liegt auf der Hand, denn es sind dann bloss die Kerne, welche schrumpfen und quellen, während die Körnchenmasse, welche sich an den Volumänderungen nicht betheiligt, die Totalschwankungen herabdrückt.

Ich glaube aber nicht, dass in der zweiten Reihe von Fällen die Läsion der Zellen einen bedeutenden Einfluss auf die Volumschwankungen ausgeübt haben wird. Dies folgt schon daraus, dass die Resultate der verschiedenen Versuche gut mit einander übereinstimmen. Ausserdem stellte sich noch heraus, dass bei Blasenepithel der durch $\mathrm{NaCl}$ von 0,7 und $1,5 \%$ herbeigeführte Volumunterschied nahezu ebensogross bleibt, ob man das Epithel zuvor mit einem scharfen Rasirmesser gehackt oder ob man den Versuch mit dem ursprünglichen Epithel angestellt hatte (vgl. S. 28).

Dieses Resultat scheintmir, wenigstens für das Blasenepithel, die Vorstellung einer intravitalen oder jedenfalls postmortalen Wabenstruktur (vgl. S. 29) zu stützen.

Nach diesen kritischen Bemerkungen seien die Hauptergebnisse erwälınt, zu welchen die vorliegenden Untersuchungen geführt haben.

Dieselben sind kurz die folgenden:

1. Die vier untersuchten Epithelarten schrumpfen durch hyperisotonische und quellen durch hypisotonische NaCl-Lös sun gen.

Beim Darm- und Tracheaepithel sind die Volumänderungen gering, beim Blasenepithel dagegen bedentend.

2. Letztere Thatsachelässt sich dadurch erklären, dass beim Darm- und Tracheaepithel ausschliesslich der Kern, beim Blasen- nnd Oesophagusepithel auch der Zellkörper an den Volumänderungen betheiligt ist.

Mit anderen Worten: Der Zellkörper der beiden ersten Epithelarten ist für Koclisalz durchlässig, der der beiden let\%teren nicht.

Es steht dies wieder in Einklang mit dem bedeutenden Resorptionsvermögen von Blase und Oesopliagus andererseits.

3. Yuweilen zeigt sich das Darmepithel, im Gegensatz zu dem unter 1. und 2. erwähnten, für Kochsalz wenig permeabel. Das rührt daher, dass das Epithel in solchen 
Fällen sich in eınem besonderen physiologischen Zustand befindet: nichtselten gelang es denselben kiinstlich hervorzurufen (vgl. S. 13).

4. A us dem Betrag der durcli verschiedene NaCl-Lösungen herbeigeführten Volumänderungen lässt sichebenso wie das früher bei rothen und weissen Blutkörperchen geschah, auch beim Blasen- und beim Oesophagusepithel das Verhältniss zwisclien dem Volumen des Protoplasmagerïstes (incl. Kerngerüst) und der intracellularen (incl. intranuclearer) Substanz berechnen (vgl. Bd. I S. 339 ff. und S. 419 ff.).

5. Vergleicht man die an diesen beiden Epithelarten gewonnenen Zahlen mit den an den Blutkörperchen desselben Thieres erhaltenen, so ergiebt sich eine merkwürdige Uebereinstimmung.

So betrug beim Blasenepithel des Schweines die Volumdifferenz der Gerüstsubstanz in $\mathrm{NaCl}$ von 0,7 und 1,5\% 25,7-28,6\%, während dieselbe bei den rothen Blutkörperchen derselben Thierspecies 25,4 bis $29 \%$ betrug (vgl. S. 26).

Vergleicht man nun die im vorliegenden Abschnitte beschriebenen Resultate mit den in der ersten Mittheilung [10] erhaltenen, so erkennt man, dass die procentische Volumänderung der weissen Blutkörperchen, der Spermatozoen, des Blasen- und Oesophagusepithels nach Einwirkung der gleichen Salzlösung in treffender Weise mit der Volumänderung der entsprechenden rothen Blutkörperchen übereinstimmt. Man fragt sicl, ob es sich hier nicht um eine allgemeine Erscheinung handelt, welche also auch für andere Zellen des Körpers Gültigkeit besitzt. Sollte in der That in allen Zellen eines Individuums ein gleiches procentisches Volumverhältniss zwischen Colloidtheilchen und Wasser bestehen?

Bei dieser Frage denke ich unwillkürlich an das Befremden zurück, welches die aufgefundene Uebereinstimmung während der Untersuchuıgen bei jeder Zellenart auf's Neue bei nir erweckte. Dies begann schon bei der Vergleichung der rothen und weissen Blutkörperchen, zweier Zellenarten, welche einander äusserlich absolut nicht gleichen, die eine homogen und kernlos, die andere körnig und kernhaltend. Ich war denn auch sehr geneigt, die procentische Gleichheit des Protoplasmagerïstes bezw. der Volumänderung einem Zufalle zuzuschreiben. Vielleicht hatte der Kern der Leukocyten ein dichteres, der Zellkörper dagegen ein dünneres Gerüst als das entsprechende kernlose Blutkörperchen, und waren die quantitativen Verhältnisse nur zufälliger Weise derart, dass schliesslich das Gesammtgerüst der Leukocyten mit dem Gerüst der Erythrocyten übereinkam. Als sich aber später herausstellte, dass die fast ausschliesslich aus Kernsubstanz bestehenden Spermatozoen des Frosches 
dasselbe Gerüstvolumen besitzen, wie die grösstentheils aus Zellkörper bestehenden rothen Blutkörperchen derselben Thierspecies, schien es mir doch wohl etwas gewagt, auch hier wieder an einen Zufall zu denken und der Gedanke an einen Zufall verlor noch mehr an Wahrscheinlicbkeit, als auch das Blasen- und das Oesophagusepithel dasselbe procentische Gerüstvolum zeigte, wie die entsprechenden Errythrocyten.

Bei diesem Sachverhalt blieb nichts anderes übrig, als die Hypothese aufzustellen, dass Kern und Zellkörper ein entsprechendes procentisches Gerüstrolumen (Colloidv olumen) besitzen. Zu dieser Hypothese war ich umsomehr berechtigt, als sich durch direkte mikroskopische Messungen heransgestellt hatte, dass auch der Kern an den durch Salzlösungen herbeigefïhrten Volumänderungen betheiligt ist (S. 19, 23 u. 26).

Nun wird es Vielen ganz natïrlich erscheinen, dass das Gerïstvolumen einer Tochterzelle mit dem der Mutterzelle übereinstimmt wenn die Tochterzelle auf dieselbe Function angewiesen bleibt, wie die Mutterzelle. Wo dies aber, wie man es bei der embryonalen Entwicklung fortwährend beobachtet, nicht der Fall ist, da wird der genannte Befund als ein ganz unerwarteter anzusehen sein. So muss ich gestehen, dass es mich beim ersten Anblick sogar befremdet hat, dass z. B. das Oesophagus-Plattenepithel dasselbe procentische Gerïstvolumen aufweist, wie die rothen und weissen Blutkörperchen. Lag es nicht nahe, bei der platten Gestalt des Oesophagusepithels an eine Zusammenpressung und im Zusammenhang damit an eine Vermehrung der Dichte des Gerüstes zu denken?

Bei näherer Betrachtung wurde es mir aber deutlich, dass von einer durch die Function herbeigeführten Zusammenpressung nicht die Rede sein kann, denn man findet die platte Gestalt bereits während der embryonalen Entwicklung, und zwar nicht nur beim Oesophagus, sondern auch an der Haut, an der Cornea, an der Vaginalschleimhaut u. s. w. Gegen eine Zusammenpressung sprechen auch die Verhältnisse beim Pferdemagen, dessen innere Schleimhautwand zu einem grossen, scharf begrenzten Theil aus geschichtetem Plattenepithel besteht, von derselben Ciestalt. wie es beim Oesophagus gefunden wird, und zum anderen Theil ans einschichtigem, hohem Cylinderepithel, welches dem Drucke des Mageninhaltes doch ebensogut unterworfen ist, wie das Plattenepithel.

Bei näherer Betrachtung scheint mir also kein genügender Grund vorhanden zu sein, die platte Gestalt des inneren Oesophagusepithels einer mechanischen Zusammenpressung zuzuschreiben. Welche dann wohl die physiologische Bedeutung der platten Form der imeren Schichten sein mag, kann ich nicht sagen, und das ist liier auch nicht nothwendig. 
Indessen brauche ich kaum darauf hinzuweisen, dass man erst dann berechtigt sein wird, die Uebereinstimmung zwischen dem procentischen Gerüstvolumen (bezw. Colloidvolumen) von Kern und Zellkörper, sowie auch der ganzen Zellen bei demselben Thier oder derselben Thierspecies) als eine allgemein gültige Erscheinung aufzufassen, wenn noch eine grosse Anzahl anderer Zellen mit gleichem Resultat in derselben Richtung untersucht sein werden. Viele Zellen eignen sich zu diesen Untersuchungen nicht. Zellen, wie Darm- und Tracheaepithel, welche für Salzlösungen verschiedener Concentration permeabel sind, sind selbstverständlich ausgeschlossen.

\section{Lymphdrüsenzellen.}

\section{Ihre Permeabilität fiir Anionen von Natrinmsalzen.}

In Bd. 1, S. 423 wurden Versuche mitgetheilt, die ich in Gemeinschaft mit Dr. van der Schroeff angestellt habe, um die Permeabilität von Leukocyten zu untersuchen. Gleichzeitig wurden nach demselben Verfahren ähnliche Experimente zur Erforschung der Permeabilität von Lymphdrüsenzellen angestellt.

\section{Gewinnung der Lyuphdriisenzellen.}

Um Lymphdrüsenzellen zu isoliren, wurden Lymphdrüsen (meist mesenteriale) zerschnitten, gehackt und dann ausgewaschen. Hierzu benutzte ich Traubenzuckerlösung von 4,15\%, Blutserum oder Kochsalzlösung. Beim Auswaschen mit Traubenzuckerlösung hat man in Besonderen darauf zu achten, dass die Auswaschung schnell geschieht. Dauert die Behandlung z. B. einen Tag, so sind viele Zellen zerfallen und, was ganz merkwürdig ist, die Traubenzuckerlösung reagiert sauer. Man verfährt in folgender Weise.

Die gehackte Masse wird in der Flüssigkeit vertheilt, geschüttelt und durch nicht präparirte Gaze colirt. Das trübe Filtrat enthält dann unversehrte und zerstörte Zellen, bezw. Gewebepartikelchen. Ueberlässt man nun das Filtrat sich selbst, so senken sich die unzerstörten Zellen, während eine milchige Flüssigkeit daräber stehen bleibt. Diese hebt man ab, ersetzt dieselbe durch neue Flüssigkeit und wiederholt dieses Verfahren, bis die überstehende Flüssigkeit klar ist. Das Sediment enthält dann lediglich unzerstörte Lymphdrüsenzellen.

Will man die Sedimentirung der Lymphzellen beschleunigen, so kann dies durch Centrifugiren geschehen. Es sei aber mit Nachdruck hervorgehoben, dass kräftiges Centrifugiren schadet, denn dadurch ballen sich die Zellen zu Fäden und Flocken zusammen und sind später nicht melır von einander zu isoliren.

Die Methoden, mittelst deren ich die Permeabilität dieser Zellenart untersucht habe, sind vollkommen dieselben, welche für die Leukocyten angewandt wurden. Es genügt also betreffs dieses Punktes auf das in Bd. I S. 424 ff. Gesagte hinzuweisen, und ich kann unmittelbar zur Mittheilung einiger Versuche schreiten. 


\section{a) Permeabilität für Chlorionen.}

Versuch I.

Lymphdrüsenzellen wurden drei Mal mit 4,15\% iger Traubenzuckerlösung ausgewaschen bis eine reine Aufschwemmung von Zellen in dieser Flüssigkeit erhalten wurde. Diese Lösuug wurde abcentrifugirt und durch eine $1 \%$ ige NaCl-Lösung ersetzt. In $11 \mathrm{cc}$ der auf diese Weise erhaltenen Aufschwemmung sind etwa $2 \mathrm{cc}$ Zellen vorbanden.

5 cc Aufschwemmung wurden mit 12 cc $\mathrm{CO}_{2}$ geschüttelt, 5 cc dienten direct zum Gegenversuch. Beide wurden centrifugirt und von der überstehenden Flüssigkeit je $4 \mathrm{cc}$ genommen. Von diesen wurde erst der Alkalinität mittelst 1/20 normal$\mathrm{HNO}_{3}$ bestimmt und in der so erhaltenen neutralisirten Flüssigkeit der Chlorgehalt ermittelt.

Das Resultat ist:

\begin{tabular}{|c|c|c|c|}
\hline I & II & III & IV \\
\hline 4 cc Flüssigkeit & Alkalinität & Chlorgehalt & $\begin{array}{c}\text { Flüssigkeit in gleichen } \\
\text { Volumen } \\
\text { der Suspensionen }\end{array}$ \\
\hline $\begin{array}{l}\text { der normalen Zellen } \\
\text { der mit } \mathrm{CO}_{2} \text { ge- } \\
\text { schüttelten Zellen }\end{array}$ & $\begin{array}{l}0,1 \mathrm{cc}^{1} / 20 \mathrm{n} . \mathrm{HNO}_{3} \\
0,23 \text { " },\end{array}$ & $\left\{\begin{array}{l}4,11 \mathrm{cc}^{1} / 10 \mathrm{n} \cdot \mathrm{AgNO}_{3} \\
3,67, \cdots\end{array}\right.$ & $\begin{array}{l}75,6 \\
75\end{array}$ \\
\hline
\end{tabular}

Nach Berticksichtigung der Empfindlichkeit des Lakmoidpapieres (vergl. Bd. I S. 242 und S. 424) und der Volumverhältnisse für die Zahlen von Spalte II, und der Volumenveränderungen allein für die Zahlen von Spalte III, sind die Lirgebnisse folgende:

\begin{tabular}{|c|c|c|}
\hline 4 ec Flüssigkeit & Alkalinität & Chlorgehalt \\
\hline $\begin{array}{l}\text { der normalen Zellen } \\
\text { der mit } \mathrm{CO}_{2} \text { geschüttelten }\end{array}$ & 0,02 ce $1 / 20$ n. $\mathrm{HNO}_{3}$ & 4,11 cc $1 / 10$ n. $\mathrm{AgNO}_{3}$ \\
\hline Zellen & 0,15 , & 3,65 , \\
\hline
\end{tabular}

Aus dieser Versuchsgruppe geht hervor, dass unter dem Einfluss ron Kohlensäure Chlor in die Lymphdrüsenzellen eintritt und Alkali dieselben verlässt.

Es war nun die Frage, ob das unter dem Einfluss von $\mathrm{CO}_{2}$ in die Lymphdrüsenzellen eingedrungene Chlor und eingetretene Alkali, dem umgekehrten Weg folgen würde, wenn die $\mathrm{CO}_{2}$ ganz oder theilweise vertrieben wurde, m. a. W. ob der Process umkehrbar war. 
Umkehrbarkeit des Processes.

\section{Versuch V.}

Lymphdrüsenzellen wurden wiederholte Male mit $1 \%$ igem $\mathrm{NaCl}$ ausgewaschen, bis eine reine Aufschwemmung von Zellen in der Lösung erthalten wurde. Die Aufschwemmung wurde abcentrifugirt und auf's Neue $1 \%$ iges $\mathrm{NaCl}$ hinzugefügt. In $45 \mathrm{cc}$ Aufschwemmung sind etwa 6 cc Zellen vorhanden. $15 \mathrm{cc}$ der Aufschwemmung wurden mit $20 \mathrm{cc} \mathrm{CO}_{2}$ geschüttelt, $15 \mathrm{cc}$ wurden ebenso mit $20 \mathrm{cc} \mathrm{CO}_{2}$ und danach mit Luft geschüttelt, so dass die Kohlensäure jedenfalls theilweise entfernt wurde. $15 \mathrm{cc}$ blieben olne jede weitere Behandlung. Die drei Aufschwemmungen wurden centrifugirt und von der obenstehenden Flüssigkeit je $10 \mathrm{cc}$ weggenommen. Von diesen wurde erst die Alkalinität mittelst $1 / 30$ normal $\mathrm{HNO}_{3}$ bestimmt, und in der so erhaltenen neutralisirten F'lüssigkeit der Chlorgehalt ermittelt.

Das Resultat war:

\begin{tabular}{c||c||cc||c}
\hline \multicolumn{1}{c||}{ I } & II & & III & IV \\
\hline 10 cc Flüssigkeit & Alkalinität & & Chlorgehalt & $\begin{array}{c}\text { Flüssigkeit in gleichen } \\
\text { Volumen } \\
\text { der Suspensionen }\end{array}$ \\
\hline \hline $\begin{array}{l}\text { der normalen Zellen } \\
\text { der mit } \mathrm{CO}_{2} \text { ge- } \\
\text { schüttelten Zellen } \\
\text { der mit } \mathrm{CO}_{2} \text { u. Luft } \\
\text { geschüttelten Zellen }\end{array}$ & $0,44 \mathrm{cc}^{1 / 20} \mathrm{n} . \mathrm{HNO}_{3}$ & $11,68 \mathrm{cc}^{1 / 10} \mathrm{n} . \mathrm{AgNO}_{3}$ & 130 \\
\hline
\end{tabular}

Nach Berücksichtigung der Empfindlichkeit des Lakmoidpapieres und der Volumverhältnisse für die Zahlen von Spalte II, und der Volumveränderungen allein für die Zahlen von Spalte III, sind die Ergebnisse folgende:

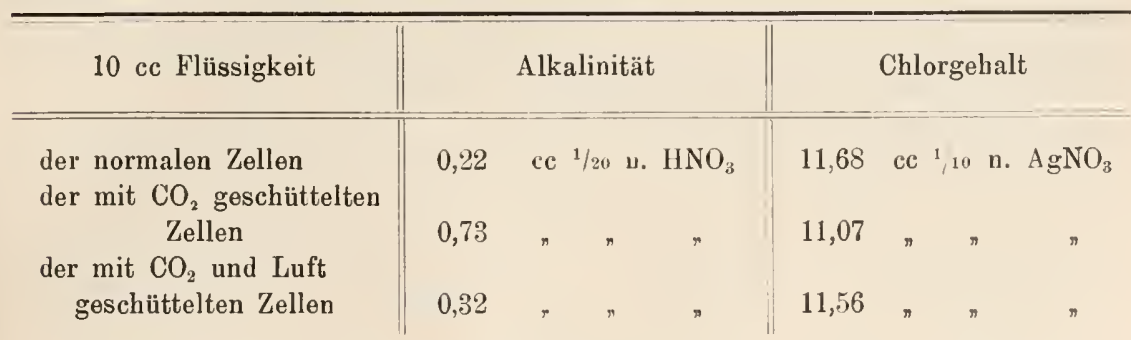

Aus dieser Versuchsgruppe erhellt, dass unter dem EinfIuss von $\mathrm{CO}_{2} \mathrm{Chlor}$ in die Lymphdrüsenzellen eindringt und Alkali dieselben verlässt. Durch Schütteln mit Luft tritt Chlorwieder in die Flïssigkeit zur ück, währendalkalische Affinitäten dieselbe verlassen. Der Process ist also ein umkehrbarer. 


\section{Schlussfolgerung.}

Aus den vorliegenden Versuchen geht unzweifelhaft hervor, dass beim Schütteln einer Aufschwemmung von Lymphdrüsenzellen in $\mathrm{NaCl}$ Lösung mit $\mathrm{CO}_{2}$ Chlor in die Zellen eintritt und $\mathrm{CO}_{3}$ " sie verlässt, sodass die vorher neutrale NaCl-Lösung durch Bildung von $\mathrm{Na}_{2} \mathrm{CO}_{3}$ alkalisch wird.

Weiter stellt sich heraus, dass nach Herbeiführung des genannten Austansches, Vertreibung von $\mathrm{CO}_{2}$ aus der Suspension mittelst Luftschïttelung den ursprünglichen Zustand nahezu vollständig wieder herstellt. Der Process ist also auch hier umkehrbar. Die hinzugefügte Kohlensäure hat somit auch auf die Lymphdrïsenzellen keinen zerstörenden Einfluss ausgeübt, sie hat nur die Permeabilität für Säure-Ionen in ausgiebigem Maasse zum Ausdruck gebracht.

\section{b) Permeabilitiit fiiir $\mathrm{SO}_{4}{ }^{\prime \prime}=$ Ionen.}

Das folgende Experiment dient der Untersuchung, ob $\mathrm{SO}_{4}$ " in die Lymphdrüsenzellen einzudringen im Stande ist, und ob der Process umkehrbar ist.

\section{Versuch.}

Lymphdrüsenzellen wurden drei Mal mit einer isotonischen Natriumsulfatlösung ausgewaschen, bis eine reine Aufschwemmung von Zellen in dieser Flüssig. keit erhalten wurde. Diese wurde abcentrifugirt und auf's Neue durch Sulfatlösung ersetzt. In 25 ce der auf diese Weise erhaltenen Aufschwemmung sind etwa 4 cc Zellen vorhanden. $8 \mathrm{cc}$ wurden mit $17 \mathrm{cc} \mathrm{CO}_{2}$ geschüttelt, $8 \mathrm{cc}$ wurden gleichfalls mit $17 \mathrm{ec} \mathrm{CO}_{2}$ und dann mit Luft geschüttelt, so dass alle Kohlensäure entfernt wurde. Weitere $8 \mathrm{ce}$ wurden nicht mit $\mathrm{CO}_{2}$ beliandelt. Die drei Aufschwemmungen wurden abcentrifugirt und von der überstehenden Flüssigkeit je $4 \mathrm{cc}$ weggenommen. Von diesen wurde erst die Alkalinität mittelst ${ }^{1} / 20$ normal $\mathrm{HNO}_{3}$ bestimmt, und von der so erhaltenen noutralisirten Flüssigkeit der Sulfatgehalt.

Das Resultat ist :

\begin{tabular}{|c|c|c|c|}
\hline I & II & III & IV \\
\hline 4 cc Flüssigkeit & Alkalinität & Sulfatgehalt & $\begin{array}{c}\text { Flüssigkeit in gleichen } \\
\text { Volumen } \\
\text { der Suspensionen }\end{array}$ \\
\hline $\begin{array}{l}\text { der normalen Zellen } \\
\text { der mit } \mathrm{CO}_{2} \text { ge- } \\
\text { schüittelten Zellen } \\
\text { der mit } \mathrm{CO}_{2} \text { und } \\
\text { danach mit Luft ge- } \\
\text { schüittelten Zellen }\end{array}$ & $\begin{array}{l}0,18 \text { ce }^{1 / 20} \text { n. } \mathrm{HNO}_{3} \\
0,28, \cdots \\
0,24,66\end{array}$ & $\begin{array}{lll}3,6 & \text { cc } & \mathrm{Ba} \mathrm{Cl}_{2} \\
3,48 & n & \\
3,5 & n & \end{array}$ & $\begin{array}{l}72 \\
73\end{array}$ \\
\hline
\end{tabular}


Nach Berücksichtigung der Empfindlichkeit des Lakmoidpapieres und der Volumverhältnisse für die Zahlen von Spalte II, und der Volumveränderungen allein für die Zahlen von Spalte III, sind die Ergebnisse folgende:

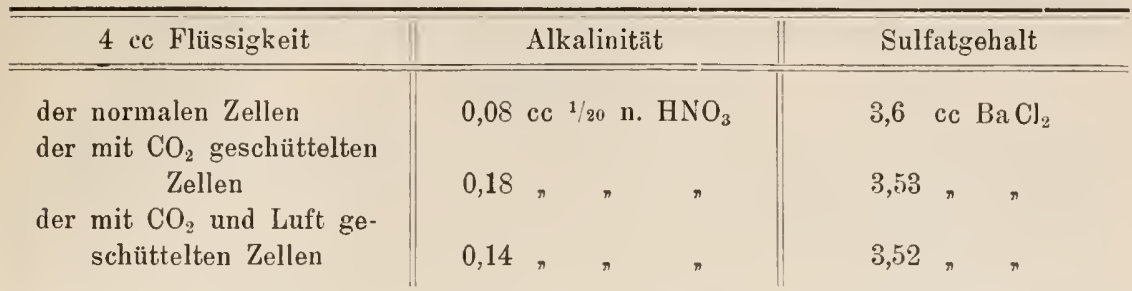

Aus dieser Versuchsgruppe geht hervor, dass unter dem Einfluss von Kohlensäure, $\mathrm{SO}_{4}{ }^{\prime \prime}$ in die Lymphdrüsenzellen eingedrungen ist und $\mathrm{CO}_{3}$ " dieselben verlassen hat. Nachdem Schütteln mit Luft verschwindet Alkali wieder aus der Flüsigkeit und $\mathrm{SO}_{4}$ " kehrt in dieselbe zurück. Auch hier ist also der Process unkehrbar.

Aehnliche Untersuchungen wurden mit $\mathrm{NO}_{3}{ }^{\prime}$-Ionen angestellt.

\section{c) Permeabilität für $\mathrm{NO}_{3}{ }^{\prime}$-Ionen.}

Auch hier führe ich nur ein Experiment als Beispiel an, das zu gleicher Zeit auch die Umkehrbarkeit nachweisen soll.

\section{Versuch.}

Lymphdrüsenzellen wurden drei Mal mit einer 4,15\% igen Traubenzuckerlösung ausgewaschen, bis eine reine Aufschwemmung von Zellen in der Flüssigkeit erhalten wurde. Diese wurde abcentrifugirt und durch eine isotonische $\mathrm{NaNO}_{3}$-Lösung ersetzt. In $31 \mathrm{cc}$ der auf diese Weise erhaltenen Aufschwemmung sind etwa 6 cc Zellen vorhanden. $10 \mathrm{cc}$ Aufschwemmung werden mit $7 \mathrm{cc} \mathrm{CO}_{3}$ geschüttelt, $10 \mathrm{cc}$ werden mit 7 ec $\mathrm{CO}_{2}$ und dann mit Luft geschüttelt, bis alle Kohlensäure entwichen ist; 10 ec werden nicht weiter behandelt, sondern direct untersucht. Die drei Aufschwemmungen werden centrifugirt und von der überstehenden Flüssigkeit je 5 cc genommen. In diesen wird erst die Alkalinität mittelst ${ }^{1} / 10$ normal Oxalsäure bestimmt, und in der so erhaltenen neutralisirten Flüssigkeit der Nitratgehalt.

Das Resultat war:

\begin{tabular}{|c|c|c|c|}
\hline I & II & III & IV \\
\hline 5 cc Flüssigkeit & Alkalinität & Nitratgehalt & $\begin{array}{c}\text { Flüssigkeit in gleichen } \\
\text { Volumen } \\
\text { der Suspensionen }\end{array}$ \\
\hline $\begin{array}{l}\text { der normalen } \\
\text { Zellen } \\
\text { der mit } \mathrm{CO}_{2} \text { ge- } \\
\text { schüttelten Zellen } \\
\text { der mit } \mathrm{CO}_{2} \text { u. Luft } \\
\text { geschüttelten Zelleu }\end{array}$ & $\begin{array}{l}0,1 \quad \text { cc } 1 / 10 \text { n. Oxal- } \\
\text { säure } \\
0,175 \text { cc } 1 / 10 \text { n. Oxal- } \\
\text { säure } \\
0,15 \text { cc } 1 / 10 \text { n. Oxal- } \\
\text { säure }\end{array}$ & 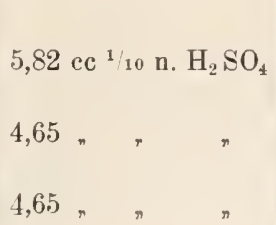 & $\begin{array}{l}91,88 \\
91,25 \\
88,75\end{array}$ \\
\hline
\end{tabular}


Nach Berücksichtigung der Empfindlichkeit des Lakmoidpapieres und der Volumverhältnisse für die Zahlen von Spalte II, und der Volumveränderungen allein für die Zahlen von Spalte III, sind die Ergebnisse folgende:

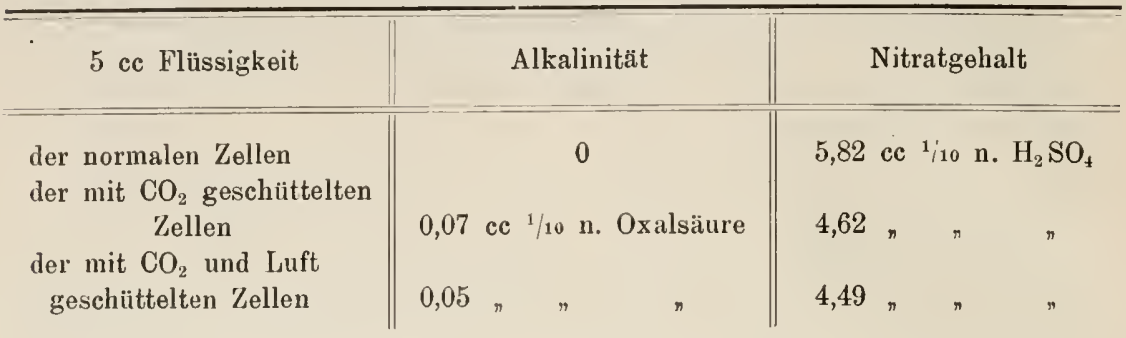

Aus dieser Versuchsgruppe erhellt, dass unter dem Einfluss von Kohlensäure, $\mathrm{NO}_{3}^{\prime}$ in die Lymphdrüsenzellen eingedrungen ist und Alkali dieselben verlassen hat. Weiter ergiebt sich, dass durch Schütteln mit Luft eine umgekehrte Bewegung stattfindet: Alkaliverlässt die Flüssigkeit wieder, während $\mathrm{NO}_{3}{ }^{\prime}$ in sie zurückkehrt. Der Process ist also ein umkehrbarer.

\section{d) Permenbilitiit der Iymphdriisenzellen fiir anderweitige elektro- negative Ionen.}

Nachdem sich so durch quantitative chemische Analysen ergeben hatte, dass bei der Einwirkung von neutralen Natriumsalzen auf kohlensäurehaltige weisse Blutkörperchen, mit dem Eintritt der elektronegativen $\left(\mathrm{Cl}^{\circ}\right.$-, $\mathrm{SO}_{4}{ }^{\prime \prime}$ - und $\left.\mathrm{NO}_{3}{ }^{\prime}\right)$ Ionen immer ein Austritt des elektronegativen Ions $\left(\mathrm{CO}_{3}{ }^{\prime \prime}\right)$ aus den genannten Zellen parallel geht, schien es mir, auch auf Grund theoretischer Erwägungen, nicht gewagt, im Allgemeinen den Satz auszusprechen, dass, wenn ein beliebiges neutrales Natriumsalz nach Hinzusetzung von kohlensäurehaltigen Leukocyten alkalisch wird, das entsprechende elektronegative Ion des Salzes eingewandert sein muss. War das Natriumsalz nicht neutral, sondern bereits alkalisch, so musste nach dieser Vorstellung eine Steigerung der alkalischen Reaction dasselbe bedeuten, wie bei der neutralen Lösung ein Auftreten derselben.

Von diesem Gesichtspunkte aus habe ich verschiedene Natriumsalze geprüft, und immer die Alkalinität quantitativ bestimmt. Dies war selbstverständlich für neutrale Lösungen eigentlich nicht streng nothwendig, wohl aber für diejenigen Salzlösungen, die von Haus aus alkalisch reagirten. Dass ich hierbei auf die mehrerwähnten Volum- 
änderungen und die Empfindlichkeit des Lakmoidpapieres Rücksicht nahm, braucht kaum gesagt zu werden.

In der Mittheilung der Versuche kann ich kurz sein.

\section{a) Permeabilität für $\mathbf{J}^{\prime}$ (Jodnatrium).}

Lymphdrüsenzellen werden drei Mal mit einer $0,9 \%$ igen $\mathrm{NaCl-Lösung} \mathrm{aus-}$ gewaschen bis eine reine Aufschwemmung der Zellen in dieser Flüssigkeit erhalten wird. Diese Lösung wird abcentrifugirt und durch eine damit isotonische Jodnatriumlösung ersetzt. In $21 \mathrm{cc}$ der auf diese Weise erhaltenen Aufschwemmung sind etwa 4 cc Zellen vorhanden. 10 cc Aufschwemmung werden mit $20 \mathrm{cc} \mathrm{CO}_{2}$ geschüttelt. weitere $10 \mathrm{cc}$ dagegen nicht. Beide Suspensionen werden centrifugirt und von der überstehenden Flüssigkeit je 5 cc zur Alkalinitätbestimmung mittelst ${ }^{1 / 20}$ normal $\mathrm{HNO}_{3}$ weggenommen.

Das Resultat ist:

\begin{tabular}{c||c||c}
\hline \hline I & II & III \\
\hline 5 cc Flüssigkeit & Alkalinität & $\begin{array}{c}\text { Flüssigkeit in gleichen } \\
\text { Volumen der Suspensionen }\end{array}$ \\
\hline $\begin{array}{c}\text { der normalen Zellen } \\
\text { der mit } \begin{array}{c}\mathrm{CO}_{2} \text { geschüttelten } \\
\text { Zellen }\end{array}\end{array}$ & $0,12 \mathrm{cc}^{1 / 20} \mathrm{n} . \mathrm{HNO}_{3}$ & 90,5 \\
$0,27, n, \quad$, & 88
\end{tabular}

Nach Berücksichtigung der Empfindlichkeit des Lakmoidpapieres und der Volumverhältnisse sind die Ergebnisse folgende:

\begin{tabular}{c|c}
\hline 5 cc Flüssigkeit & Alkalinität \\
\hline $\begin{array}{c}\text { der normalen Zellen } \\
\text { der mit } \mathrm{CO}_{2} \text { geschüttelten Zellen }\end{array}$ & 0 \\
0,15 cc $^{1 / 20} \mathrm{n} . \mathrm{HNO}_{b}$
\end{tabular}

Aus dieser Versuchsgruppe geht hervor, dass unter Einfluss von $\mathrm{CO}_{2}$ Alkali die Lymphdrüsenzellen verlässt, wodurch die Flüssigkeit alkalisch wird.

\section{ß) $\mathrm{PO}_{t}^{\prime \prime \prime}$ (Phosphorsaures Natron).}

Versuch.

Lymphdrüsenzellen werden drei Mal mit $1 \%$ igem $\mathrm{NaCl}$ ausgewaschen bis eine reine Aufschwemmung der Zellen in der Flüssigkeit erhalten wird. Diese wird abcentrifugirt und durch eine mit dem Blutserum isotonische Natriumphosphatlösung ersetzt. In $21 \mathrm{cc}$ der auf diese Weise erhaltenen Aufschwemmung sind etwa $4 \mathrm{cc}$ Zellen vorhanden. $10 \mathrm{cc}$ werden mit $12 \mathrm{cc} \mathrm{CO}_{2}$ geschüttelt, andere $10 \mathrm{cc}$ nicht. Beide werden centrifugirt und von der überstehenden Flüssigkeit je 5 cc zur Alkalibestimmung mittelst ${ }^{1 / 20}$ normal $\mathrm{HNO}_{3}$ weggenommen. 
Das Resultat ist:

\begin{tabular}{|c|c|c|}
\hline I & II & III \\
\hline 5 cc Flüssigkeit & Alkalinität & $\begin{array}{l}\text { Flüssigkeit in gleichen } \\
\text { Volumen der Suspensionen }\end{array}$ \\
\hline $\begin{array}{l}\text { der normalen Zellen } \\
\text { der mit } \mathrm{CO}_{2} \text { geschüttelten } \\
\text { Zellen }\end{array}$ & $\begin{array}{l}8,72 \text { cc } \frac{1 / 20}{} \text { n. } \mathrm{HNO}_{3} \\
8,6 \quad n \quad \pi \quad n\end{array}$ & $\begin{array}{l}75 \\
82,5\end{array}$ \\
\hline
\end{tabular}

Nach Berücksichtigung der Empfindlichkeit des Lakmoidpapieres und der Volumverhältnisse für die Zahlen von Spalte II sind die Ergebnisse folgende:

\begin{tabular}{|c|c|}
\hline 5 cc Flüssigkeit & Alkalinität \\
\hline $\begin{array}{l}\text { der normalen Zellen } \\
\text { der mit } \mathrm{CO}_{2} \text { geschüttelten Zellen }\end{array}$ & $\begin{array}{llll}8,6 & \text { cc } & 1 / 20 & \text { n. } \\
9,33 & \mathrm{HNO}_{3} \\
& & \end{array}$ \\
\hline
\end{tabular}

Aus dieser Versuchsgruppe geht hervor, dass unter dem Einfluss von Kohlensäure, Alkali die Lymphdrïsenzellen verlässt, wodurch die Flüssigkeit stärker alkalisch wird.

\section{$\gamma) \mathrm{Br}^{\prime}$ (Bromnatrium).}

Versuch.

Lymphdrüsenzellen werden drei Mal mit Blutserum ausgewaschen, bis eine reine Aufschwemmung der Zellen in der Flüssigkeit erhalten wird. Diese wurde abcentrifugirt und durch eine isotonische Bromnatriumlösung ersetzt. In 15 cc der auf diese Weise erhaltenen Aufschwemmung sind etwa $3 \mathrm{cc}$ Zellen vorhanden. $7 \mathrm{cc}$ derselben werden mit $15 \mathrm{cc} \mathrm{CO}_{2}$ geschüttelt, andere $7 \mathrm{cc}$ nicht. Beide werden centrifugirt und von der obenstehenden Flüssigkeit je 4 cc zur Alkalinitätsbestimmung mittelst ${ }^{1} / 20$ normal $\mathrm{HNO}_{3}$ weggenommen.

Das Resultat ist:

\begin{tabular}{|c|c|c|}
\hline 1 & Il & III \\
\hline $4 \mathrm{cc}$ Flüssigkeit & Alkalinität & $\begin{array}{l}\text { Flüssigkeit in gleichen } \\
\text { Volumen der Suspensionen }\end{array}$ \\
\hline $\begin{array}{c}\text { der normalen \%ellen } \\
\text { der mit } \mathrm{CO}_{2} \text { gescluüttelten } \\
\text { Zellen }\end{array}$ & $\begin{array}{llll}0,3 & \text { ce }{ }^{1}, 20 & \text { n. } \mathrm{HNO}_{3} \\
0,41 & \Uparrow & \pi & n\end{array}$ & $\begin{array}{l}57,4 \\
63\end{array}$ \\
\hline
\end{tabular}

Unter Beriicksichtigung der Empfindlichkeit des Lakmoidpapieres und der Volumverbältnisse für die Zahlen von Spalte II sind die Érgebnisse folgende:

\begin{tabular}{|c|c|}
\hline 4 cc Flüussigkeit & Alkalinität \\
\hline $\begin{array}{l}\text { der normalen Zellen } \\
\text { der mit } \mathrm{CO}_{2} \text { geschüttelten Zellen }\end{array}$ & $\begin{array}{lccc}0,2 & \mathrm{cc} & { }^{1}, 20 & \mathrm{n} . \mathrm{HNO}_{3} \\
0,34 & & & \end{array}$ \\
\hline
\end{tabular}


Auch nach Vermischung der Zellen mit Bromnatrium verlässt hiernach Alkali unter Einfluss von Kohlensäure die Lymphdrüsenzellen.

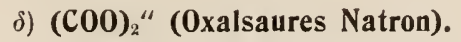

Lymphdriisenzellen werden drei Mal mit Blutserum ausgewaschen, bis eine reine Aufschwemmung der Zellen in der Flüssigkeit resultirte. Diese wurde abcentrifugirt und durch eine mit ilrr isotonische Natriumoxalatlösung ersetzt. In $10 \mathrm{cc}$ der auf diese Weise erhaltenen Flüssigkeit waren etwa 1,5 cc Zellen vorhanden. 5 cc wurden mit 5 cc $\mathrm{CO}_{2}$ geschüttelt, andere 5 cc nicht. Beide wurden centrifugirt. Von der überstehenden Flüssigkeit wurden je 2,5 ec für die Alkalinitätsbestimmung entnommen.

Das Resultat war:

\begin{tabular}{|c|c|c|}
\hline I & Il & III \\
\hline $2, \check{c}$ cc Flliissigkeit & Alkalinität & $\begin{array}{l}\text { Flüssigkeit in gleichen } \\
\text { Volumen der Suspensionen }\end{array}$ \\
\hline $\begin{array}{l}\text { der normalen Zellen } \\
\text { der mit } \mathrm{CO}_{2} \text { geschnittelten }\end{array}$ & 0,56 cc $^{1 / 20}$ n. $\mathrm{HNO}_{3}$ & 45,4 \\
\hline Zellen & 0,56 & 46,6 \\
\hline
\end{tabular}

Nach Berücksichtigung der Empfindlichkeit des Lakmoidpapieres und der Volumverliältnisse sind die Ergebnisse folgende:

\begin{tabular}{|c|c|}
\hline 2,5 cc Flüssigkeit & Alkalinität \\
\hline $\begin{array}{l}\text { der normalen Zellen } \\
\text { der mit } \mathrm{CO}_{2} \text { geschüttelten Zellen }\end{array}$ & $\begin{array}{lccc}0,5 & \text { cс } & 1 / 20 & \text { и. } \\
0,51 & \mathrm{HNO}_{3} \\
& \pi & \eta\end{array}$ \\
\hline
\end{tabular}

Aus dieser Versuchsgruppe erhellt, dass unter Finfluss von Kohlensäure Alkali die Kellen verlässt.

\section{ह) $\left(\mathrm{C}_{6} \mathrm{H}_{4}(\mathrm{OH}) \mathrm{COO}\right)^{\prime}$ (Salicylsaures Natron).}

Lymphdrüsenzellen wurden drei Mal mit 4,15\% iger Glykoselösung ausgewaschen, bis eine reine Aufschwemmung der Zellen in der Flüssigkeit erhalten wurde. Diese wurde abcentrifugirt und durch eine damit isotonische Lösung von salicylsaurem Natron ersetzt. In $11 \mathrm{cc}$ der auf diese Weise erhaltenen Aufschwemmung waren etwa $1,5 \mathrm{cc}$ Zellen vorhanden. $5 \mathrm{cc}$ wurden mit $10 \mathrm{cc} \mathrm{CO}_{2}$ geschüttelt, andere 5 cc nicht. Beide wurden centrifugirt und von der überstehenden Flüssig. keit je 4 cc zur Alkalinitätsbestimmung mittelst ${ }^{1} / 20$ normal $\mathrm{HNO}_{3}$ entnommen. 
Das Resultat war:

\begin{tabular}{c||c||c}
\hline \multicolumn{1}{c||}{} & II & III \\
\hline 4 cc Flüssigkeit & Alkalinität & $\begin{array}{c}\text { Flüssigkeit in gleichen } \\
\text { Volumen der Suspensionen }\end{array}$ \\
\hline \hline $\begin{array}{c}\text { der normalen Zellen } \\
\text { der mit } \mathrm{CO}_{2} \text { geschüttelten } \\
\text { Zellen }\end{array}$ & $0,23 \mathrm{cc} 1 / 20 \mathrm{n} . \mathrm{HNO}_{2}$ & 43,5 \\
$0,3, \ldots, \quad$, & 42,5
\end{tabular}

Nach Berücksichtigung der Empfindlichkeit des Lakmoidpapieres und der Volumverhältnisse für die Zahlen von Spalte II sind die Ergebnisse folgende:

\begin{tabular}{l||c}
\hline \multicolumn{1}{c||}{4 ce Flüssigkeit } & Alkaligehalt \\
\hline der normalen Zellen & $0,17 \mathrm{cc}{ }^{1 / 20} \mathrm{n} . \mathrm{HNO}_{3}$ \\
der mit $\mathrm{CO}_{2}$ geschüttelten Zellen & $0,23, \pi, \pi, \pi$
\end{tabular}

Aus dieser Versuchsgruppe geht hervor, dass unter Einfluss von $\mathrm{CO}_{2}$ Alkali die Lymphdrïsenzellen verlässt.

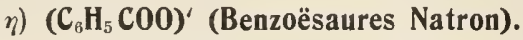

Lymphdrüsenzellen wurden wiederholte Male mit 4,15\% iger Glykoselösung ausgewaschen, bis eine reine Aufschwemmung der Zellen in der Flüssigkeit erhalten wurde. Diese wurde abcentrifugirt und durch eine isotonische Lösung von benzoësaurem Natron ersetzt. In 11 cc der auf diese Weise erhaltenen Aufschwemmung waren etwa 2 cc Kellen vorhanden. 5 cc wurden mit $15 \mathrm{cc} \mathrm{CO}_{2}$ geschüttelt, andere 5 cc nicht. Beide wurden centrifugirt und von der überstehenden Flüssigkeit je 5 cc für die Alkalinitätsbestimmung mittelst $1 / 20$ normal- $\mathrm{HNO}_{3}$ fortgenommen.

Das Resultat war:

\begin{tabular}{c||c||c}
\hline \multicolumn{1}{c||}{ I } & II & III \\
\hline 4 ce Flüssigkeit & Alkalinität & $\begin{array}{c}\text { Flüssigkeit in gleichen } \\
\text { Volumen der Suspensionen }\end{array}$ \\
\hline $\begin{array}{c}\text { der normalen Zellen } \\
\text { der mit } \mathrm{CO}_{2} \text { geschïttelten } \\
\text { \%ellen }\end{array}$ & 0,65 cc $1 / 20 \mathrm{n} . \mathrm{HNO}_{3}$ & 72 \\
0,85, &,
\end{tabular}

Nach Berücksichtigung der Lmpfindlichkeit des Lakmoidpapieres und der $\checkmark$ olumverhältnisse sind die Ergebnisse folgende:

\begin{tabular}{l||c}
\hline \multicolumn{1}{c||}{ ce Flüssigkeit } & Alkalinität \\
\hline der normalen Zellen & 0,59 cc ${ }^{1 / 20}$ n. $\mathrm{HNO}_{3}$ \\
der mit $\mathrm{CO}_{2}$ geschüttelten Zellen & 0,79 " " ,
\end{tabular}

Aus dieser Versuchsgruppe geht hervor, dass unter Einfluss von C(r., Alkali die Lymphdrïsenzellen verlässt. 


\section{e) Zusammenfassung und Schluss.}

Die hier beschriebenen Untersuchungen haben demnach in der Hauptsache Folgendes ergeben:

I. Wenn man kohlensäurehaltige Lymphdrüsenzellen mit einer neutralen Lösung von $\mathrm{NaCl}, \mathrm{Na}_{2} \mathrm{SO}_{4}$ oder $\mathrm{NaNO}_{3}$ versetzt, so werden die neutralen Lösungen alkalisch, während $\mathrm{Cl}^{\prime}$, bezw. $\mathrm{SO}_{4}$ " und $\mathrm{NO}_{3}$ ' aus der Flüssigkeit in die Zellen überwandern. Diese Erscheinungen treten in um so ausgiebigerem Maasse auf, je mehr Kohlensäure zur Wirkung gelangt. Hieraus geht hervor, dass die genannten Zellen für die betreffenden elektronegativen Ionen permeabel sind.

II. Diese Permeabilität muss, wie frïher auch für die Leukocyten betont wurde, auch für das Leben Gültigkeit besitzen, wie folgende Gründe mit grosser Wahrscheinlichkeit erkennen lassen.

1. Die Erscheinungen werden auch bei Behandlung der Zellen mit so geringen Mengen Kohlensäure beobachtet, wie die, um welche es sich im Leben handelt.

2. Die Erscheinungen sind gewöhnlich, wenn auch in schwachem Maasse, auch bei normalen, nicht mit $\mathrm{CO}_{2}$ behandelten weissen Blutkörperchen oder Lymphdrïsenzellen nachzuweisen.

3. Der durch $\mathrm{CO}_{2}$-Behandlung accentuirte osmotische Austausch geht bei Vertreibung der $\mathrm{CO}_{2}$ wieder zuriick; der Process ist also umkehrbar.

4. Nach einer gleich starken $\mathrm{CO}_{2}$-Behandlung behalten die we is s en Blutkörperchen noch die Fähigkeit, Kohlenpartikelchen in sich aufzunehmen.

III. Die Thatsache, dass bei der Einwirkung von Kohlensäure auf Suspensionen von Lymphdrüsenzellen in $\mathrm{NaCl}, \mathrm{Na}_{2} \mathrm{SO}_{4}$ und $\mathrm{NaNO}_{3}$ ein Alkalischwerden dieser Flüssigkeiten (durch Austritt von $\mathrm{CO}_{3}$ " aus den Zellen) mit dem durch quantitative chemische Analyse streng nachgewiesenen Eintritt von $\mathrm{Cl}_{3}{ }^{\prime}, \mathrm{SO}_{4}{ }^{\prime \prime}$ und $\mathrm{NO}_{3}{ }^{\prime}$ in die Zellen stets parallel geht, giebt ein einfaches Mittel an die Hand, um die Permeabilität dieser Zellen auch für diejenigen elektronegativen Ionen zu untersuchen, für welche keine so genauen quantitativen Methoden wie für $\mathrm{Cl}_{3}{ }^{\prime}, \mathrm{SO}_{4}$ " und $\mathrm{NO}_{3}{ }^{\prime}$ zur Verfügung stehen. Man braucht nur die Zellen mit Traubenzuckerlösung auszuwaschen, dann die zu untersuchende neutrale Salzlösung hinzuzufügen, mit Kohlensäure zu schütteln, die Flüssigkeit abzucentrifugiren und auf ihre Alkalinität zu prüfen. Ist die Flüssigkeit alkalisch geworden, so darf dies als Beweis dafür gelten, dass eine gewisse Menge 
des im Salze vorhandenen Anions in die Zellen eingedrungen sein muss. War die zu untersuchende Lösung bereits von Haus aus alkalisch, so wird eine Vermehrung der alkalischen Reaktion im gleichen Sinne beweisend sein, wie ein Auftreten alkalischer Reaction in neutralen Salzlösungen.

Diese Auffassung entspricht der Vorstellung, dass kein elektronegatives Ion die Lymphdrüsenzelle verlassen kann, wenn nicht eine äquivalente Menge eines anderen elektronegativen Ions aus der Umgebung einwandern und seine Stelle vertreten kann (Ko e p pe).

Nach diesen Gesichtspunkten wurden die Natriumsalze von Jodwasserstoffsäure, Bromwasserstoffsäure, Oxalsäure, Phosphorsäure, Salicylsäure, Benzoësäure, Arsensäure untersucht. Es zeigte sich ausnahmlos, dass die betreffenden neutralen Flüssigkeiten alkalisch wurden und die bereits alkalischen an Alkalinität zunahmen. Zum Ueberfluss wurde noch für $\mathrm{J}^{\prime}$ und $\mathrm{Br}^{\prime}$ mittelst quantitativer Analysen nachgewiesen, dass diese Ionen wirklich in die Zellen eindrangen.

Man darf also die weissen Blutkörperchen und die Lymphdrüsenzellen für permeabel halten für dieelektronegativen Ionen von Natrium-Chlorid, -Sulfat, -Nitrat, -Jodid, -Bromid, -Oxalat, -Phosphat, -Salicylat, -Benzoat und -Arsenat.

IV. Dass diese Thatsachen aus einem physiologischen Gesichtspunkte Bedeutung haben müssen, kann kaum bezweifelt werden. Die durch Oxydation entstandenen Säuren, wie Schwefelsäure, Milchsäure u. s. w. werden sich wohl an das Natrium (auch wohl andere Metalle) der alkalischen Gewebeflüssigkeiten binden und in den entstandenen Salzen als elektronegative Ionen auftreten. Wie wir nun gesehen haben, können dieselben unter dem Einfluss von Kohlensäure in die betreffenden Zellen eindringen und mit diesen weiter transportirt werden.

Zu gleicher Zeit wird die Gewebeflüssigkeit stärker alkalisch und damit nimmt ihre Oxydationsfähigkeit zu.

Auch ans einem pharmakologischen Gesichtspunkte scheinen mir die vorliegenden Untersuchungen nicht ohne Interesse, weil dieselben nachgewiesen haben, dass die Anionen von Stoffen, wie $\mathrm{KJ}$, KBr, salicylsaurem Natron u. s. w., welche als Arzneimittel gebraucht werden, wirklich in Lymplıdrüsenzellen eindringen können.

So giebt z. B. in Beziehung auf die bekannte antibakterielle Wirkung von KJ das Eindringungsvermögen ron $J^{\prime}$ zu denken.

Ich hebe schliesslich auch hier, wie es schon bei den Blutzellen geschah, mit Nachdruck hervor, dass die aus meinen Versuchen über die Permeabilität gewonnenen experimentellen Ergebnisse ihren Werth 
auch für diejenigen beibehalten, die nicht geneigt sind, die Auswechslung als Ionenaustausch anzusehen und die Vorstellung berorzugen, dass es sich um einen Austausch von Säureradicalen oder von Salzen als solchen handelt.

\section{Leber-, Milz- und Nierenparenchymzellen.}

Einfluss von Säuren und Alkalien auf deren Volumen.

Anwendung auf die parenchymatöse Schwellung.

Bekanntlich hat Virchow zuerst darauf hingewiesen, dass bei Infectionskrankheiten wiederholte Male an einem oder mehreren Organen parenchymatöse oder trübe Schwellung beobachtet werden kann. Nach Virchow handelt es sich hier um einen durch die Krankheit ausgeübten Reiz, der die Zelle zu einer vermehrten Nahrungsaufnahme anregt und dadurch eine Quellung herbeiführt.

Wie die mikroskopische Untersuchung lehrt, lagert sich hierbei in der Zelle eine kiörnige, eiweissartige Masse $a b$, die ihr das trübe Ansehen giebt. Virchow [6] beschreibt es als "eine Art acuter Hypertrophie mit Neigung zur Degeneration". In der That wissen wir, dass diese Degeneration sich darin äussert, dass die Eiweisskörnchen Fett bilden und dass letzteres die Zellen verlässt.

Nach den bahnbrechenden Untersuchungen J. Cohnheim's über die Entzündung musste die Lehre der nutritiven Irritation viel von ihrem Terrain preisgeben und Niemand wird sich darüber wundern, dass Cohnheim selbst wenig geneigt war, Virchow's Deutung der trüben Schwellung zu übernehmen und schliesslich lieber erklärte, dass „wir über die eigentliche Natur dieser Degeneration nichts Bestimmtes aussagen können" [13]. Seit dieser Aeusserung, die aus dem Jahre 1882 datirt. ist man nicht viel weiter gekommen. Die Lehrbücher über allgemeine Pathologie und pathologische Anatomie bringen keine Aufklärung; gewöhnlich schweigen sie über das Problem.

Tnter diesen Umständen erschien es mir nicht unwichtig den Gegenstand, der jetzt mehr als 20 Jahre geruht hat, auf's Neue auf die Tagesordnung zu bringen [14]. Die Veranlassung dazu bildeten die von mir und Anderen angestellten Untersuchungen über den Einfluss von $\mathrm{CO}_{2}$ und anderen Säuren auf rothe und weisse Blutkörperchen (vergl. B. 1, S. 299, 333, 402, 418). Nach den damals erhaltenen Ergebnissen führen die Säuren einen Austausch ron Bestandtheilen zwischen Blutzellen und Lmgebung herbei, an welchem auch das Wasser und 
zwar derart betheiligt ist, dass die Zellen auf Kosten des dem Serum gehörenden Wassers an Tolumen zunehmen. Vertreibt man die $\mathrm{CO}_{2}$ durch $\mathrm{O}_{2}$ oder ein anderes indifferentes Gas, so gehen die Teränderungen wieder zurück: das Tolumen der Blutkörperchen nimmt wieder ab.

Diese Beobachtungen wurden von vielen Seiten, u. A. von Kovács in A. v. Korányi's Kilinik bestätigt. (Vergl. unter Harnuntersuchung aus pathologischem Gesichtspunkt, Bd. II, S. 261). Bei Klappenfehlern mit Circulationsstörungen konnte er Quellung der Blutkörperchen und Eindickung des Blutplasma deutlich constatiren und dieser Zustand ging durch O-Inhalationen zurïck. Neuerdings hat Loewy nachgewiesen, dass das Gleiche durch Inhalation von anderen indifferenten Gasen zu erreichen ist. Dies stimmt auch mit meinen Beobachtungen in vitro ïberein [15]. Der quantitative Einfluss von $\mathrm{CO}_{2}$ und anderen Säuren erwies sich als sehr bedeutend. Eine Gabe von $0,0025 \% \mathrm{HCl}$ zu defibrinirtem Blute, wobei die Blutfliissigkeit selbstverständlich alkalisch bleibt, und nur in sehr geringem Maasse an Alkalinität abnimmt, liessen die genannten Erscheinungen deutlich zu Tage treten, während Hinzufügung von $0,00775 \%$ Alkali, d. h. $1 \mathrm{KOH}$ auf $12960^{\circ}$ Blut das Gegentheil, also Schrumpfung der Zellen und Steigerung des Wassergehaltes der Blutflüssigkeit, herbeiführte (Bd. I, S. 317).

Nun hat man wiederholt constatirt, dass bei fieberhaften Zuständen Säuren gebildet werden und die Alkalinität der Blutflüssigkeit abnimmt. Ich habe mich deshalb gefragt, ob Abnahme der Alkalinität, welche, wie gesagt, Quellung von rothen und weissen Blutkörperchen herbeiführt, nicht a uch eine Schwellung von a nderen Zellen, etwa denen der Leber, Milz, Nieren, und anderen Organen verursachen kann.

Es liat sich gezeigt, dass das in der That der Fall ist.

a) l.eberzellen.

Kleine Stücke Leber eines kurz zuvor durch Terblutung getödteten Pferdes wurden mit l'ferdeserum geschüttelt, wodurch eine grosse Menge Zellen sich ablöst. Nach Colirung durch ein feinmaschiges 'l'uch, erhält man eine trübe Flüssigkeit, welcho bei mikroskopischer Untersuchung nur schöne Leberzellen erkennen lässt.

lis wurden vier Mischungen angefertigt:

1. 25 cc Serum $+0,5$ cc Wasser

2. $25 \mathrm{cc}$ Serum $+0,5$ cc ${ }^{1 / 10}$ norm. $\mathrm{H}_{2} \mathrm{SO}_{4}$

3. 25 cc Serum $+0,5$ cc ${ }^{1 / 10}$ norm. KOH

4. 25 cc Serum $+0,5$ cc $\mathrm{H}_{2} \mathrm{O}$, geschüttelt mit 25 Tol.Proc. $\mathrm{CO}_{2}$. 
Von diesen vier Mischungen wurden je 2 cc in trichterförmige Röhrchen gebracht, deren capillarer, genau calibrirter Hals unten geschlossen ist.

In 2 cc jedes Gemisches wurden 0,08 cc der soeben angefertigten Leberzellensuspension in Serum hinzugefügt.

Nach halbstündiger Einwirkung wurde bis zu constantem Sediment-Volumen centrifugirt.

Die folgende Tabelle giebt die Resultate einer derartigen Versuchsreilıe wieder.

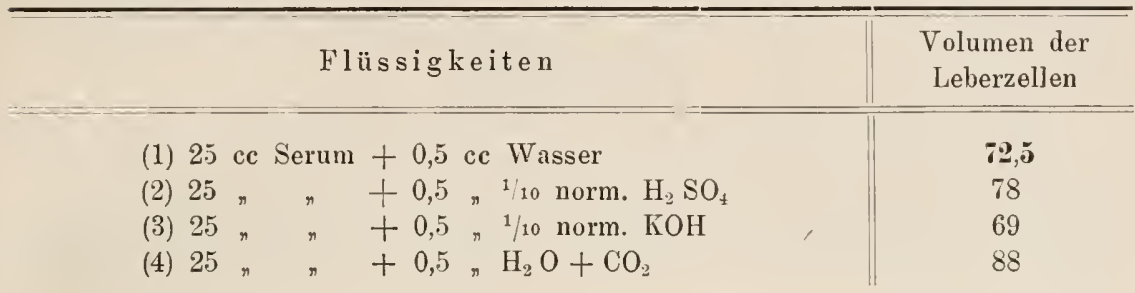

Vergleicht man die Volumine der Zellen in den Versuchen (2), (3). und (4) mit dem in Versuch (1), so stellt sich mit grosser Deutlichkeit heraus, dass durch Spuren $\mathrm{H}_{2} \mathrm{SO}_{4}$ ebenso wie durch $\mathrm{CO}_{2}$ das Volumen der Leberzellen zunimmt; dass abernach geringer Vermehrung der Alkalinität das Volumen der Leberzellen abnimmt.

Entsprechende Resultate wurden mit Leberblöckchen von $1 \mathrm{~cm}$ Länge, $1 \mathrm{~cm}$ Breite und 0,5 cm Höhe erzielt, die eine Stunde in den genannten Nischungen gelegen hatten und deren Volumen vor und nach der Einwirkuug gemessen wurde. Dies geschal durch Einsenkung in bekannte Volumina der betreffenden Fliissigkeiten, bezw. in Oel, und Ablesung der Tolumvermehrung in graduirten Cylindern.

Auffallend war es auch, dass die Stïckchen, die im mit Schwefelsäure oder mit $\mathrm{CO}_{2}$ bebandelten Serum gelegen hatten, die typischen stumpfen Ränder zeigten, während die Ränder im mit $\mathrm{KOH}$ oder $\mathrm{H}_{2} \mathrm{O}$ versetzten Serum sich schärfer abzeichneten, und zwar in dem mit $\mathrm{KOH}$ behandelten Serum entschieden am schärfsten.

Auch die Farbe der angeschwollenen Leberblöckchen stimmte mit der überein, welche bei trüber Schwellung beobachtet wird. Die Farbe erinnerte an das "weisse" "Bestäubte“, das man in diesem Falle walırzunehmen pflegt. Man hat allen Grund zu der Annahme, dass es sich hier um einen Absatz von Eiweisskörnchen handelt. So lösen sich z. B. die Körnchen leicht bei weiterer Zugabe von verdünnten Säuren oder Alkalien. 
Es ist nun wahrscheinlich, dass diese Körnchen sich aus dem Albuminat der Zellen gebildet haben. Ist es doch bekannt, dass beim Durchleiten von $\mathrm{CO}_{2}$ durch verdünntes Serum ein Eiweissniederschlag entsteht. Dasselbe geschieht, wenn man statt $\mathrm{CO}_{2}$ ein wenig verdünnter Säure hinzufügt. Man kann sich vorstellen, dass dem gelösten Albuminat durch die hinzugefügte Säıre etwas Metall entzogen wird, sodass Eiweiss präcipitirt wird.

Könnte Aehnliches nicht auch in den Leberzellen stattfinden?

\section{b) Milzzellen.}

Nicht weniger deutlich als die isolirten Leberzellen zeigten auch die isolirten Vilzzellen eine Scliwellung, wenn durch Spuren einer Säure die Alkalinität des Serums vermindert, und eine Schrumpfung, wenn durch Hinzufügung einer Spur Alkali die Alkalinität ein wenig vermehrt wurde.

Dies geht aus folgender Tabelle hervor:

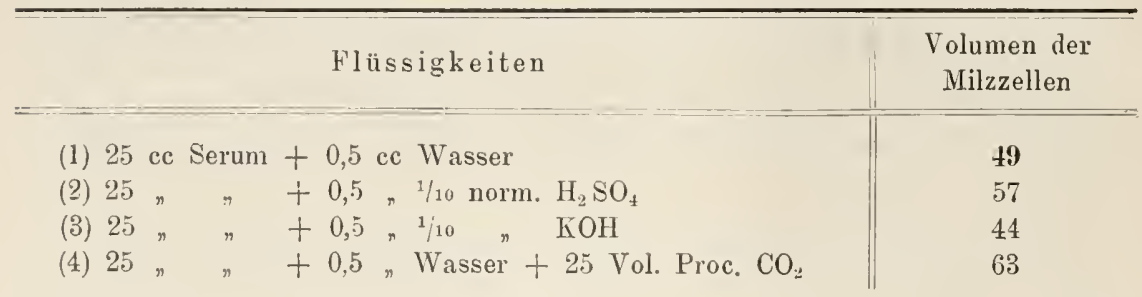

Die Versuchsergebnisse lassen kieinen Zweifel darüber, dass durch $\mathrm{H}_{2} \mathrm{SO}_{4}$ (2) und durch $\mathrm{CO}_{2}$ (4) Schwellung und durch $\mathrm{KOH}(3)$ Schrumpfung hervorgerufen wurde.

In demselben Sinne änderten sich auch die Tolumina von Milzblöckchen.

\section{c) Nierenzellen.}

Eine frische eben aus dem Körper entfernte Niere wurde auf ein Brett gelegt und in körperwarmes Oel gebracht. Dann wurde durch die A. renalis unter constantem Druck Serum hindurcligeleitet.

Als der Strom ans der V. renalis regelmässig geworden war, wurde nach 5 Dimensionen a, b, c, d und e die Giösse ermittelt. Um die Messstellen genau zu fixiren, wurden Bündchen in verschiedenen Richtungen über die Niere gespannt und an Nägeln befestigt, die in das Brett geschlagen waren.

Dann wurde, unter demselben Druck wie soeben, Serum hindurchgeleitet, denz cin wenig KOH hinzugefügt war. Wieder wurden die 5 Dimensionen ermittelt.

Endlich wurde, wieder unter demselben Druck, Serum hindurchgeleitet, dem. ein wenig Säure zıgesctzt war. Auch nun wurden die 5 Dimensionen gemessen. 
Un den Einfluss des Wassers bei der Vermischung mit Alkali und Säure $z u$ eliminiren, wurden in allen drei Fällen eine gleiche Flüssigkeitsmenge hinzugesetzt und zwar auf 1500 cc Serum jedesmal 30 cc Flüssigkeit. Es ist dies noch weiter aus der folgenden Tabelle ersichtlich, in welcher die Versuchsresultate aufgenommen sind.

\begin{tabular}{|c|c|c|c|c|c|}
\hline \multirow[t]{2}{*}{ Hindurchgeleitete Flüssigkeiten } & \multicolumn{5}{|c|}{ Dimensionen in Centimeter } \\
\hline & a & $b$ & $\mathrm{c}$ & $d$ & e \\
\hline 1. 1500 ce Serum +30 ec Wasser & 18,7 & 13,8 & 18,0 & 18,8 & 7,5 \\
\hline 2. 1500 cc Serum +30 ce $^{1 / 10}$ norm. KOH & 18,4 & 13,6 & 17,6 & 18,7 & 7,5 \\
\hline 3. $1500 \mathrm{cc}$ Serum $+30 \mathrm{cc}^{1 /} / 8$ norm. $\mathrm{H}_{2} \mathrm{SO}_{4}$ & 19 & 14,0 & 18,2 & 18,9 & 7,6 \\
\hline
\end{tabular}

Die Dimensionen a, b, c, d und e der Nierenahmen also durch Steigerung der Alkalinität des Serums ab, und durch Herabsetzung derselben $z u$.

Die Veränderungen sind allerdings nicht gross. Man bedenke jedoch, dass bloss die linearen Veränderungen gemessen wurden und nicht die räumlichen. Ferner sind auch die herbeigeführten Aenderungen der Alkalinität nach beiden Pichtungen sehr klein.

Versuche über den Einfluss von $\mathrm{CO}_{2}$, Säuren und Alkali auf is olirte Nierenparenchymzellen wurden damals nicht angestellt, weil es schwer schien dieselben zu bekommen. In letzterer Zeit aber haben die Herren Mesdag und Sypkens Smit in meinem Laboratorium behufs anderer Untersuchungen die Zellen der Nierencorticalis isolirt. Es wurde ein Stuickchen der frischen Niere zerhackt und in Blutserum des betreffenden Thieres (Schwein) suspendirt und geschüttelt. Dann wurde durch ein Tuch colirt, um die gröberen Partikel zurückzuhalten. Das Filtrat enthielt nun die Zellen isolirt oder doch nur zu wenigen vereinigt. Ausserdem waren aber Körnchen von zerfallenen Gewebspartikelchen vorhanden. Durch kurzdauerndes, nicht kräftiges Centrifugiren gelang es die Suspension in zwei Theile zu trennen. Was sich schnell zu Boden setzte, enthielt hauptsächlich die erwünschten Zellen; die darüberstehende trübe Flüssigkeit bestand hauptsächlich aus Zellenpartikelchen und Gewebsfetzen. Diese Manipulation wurde so oft als nöthig wiederholt.

Lang dauerndes oder kräftiges Centrifugiren muss vermieden werden, weil sonst die Zellen zu einem festen Kuchen zusammenbacken können.

Die so erhaltenen Zellen zeigten Quellung in hyp is o ton is cher und Schrumpfung in hyperisotonischer Salzlösung. 
So wurden z. B. zwei gleiche Volumina $(0,08$ cc) einer Nierenparenchymsuspension mit relativ grossen Mengen $(3 \mathrm{cc})$ NaCl-Lösung ron $0,6 \%$ und $1,5 \%$ versetzt. Die Volumina waren nach dem Centrifugiren 33 und 25,5 Skalentheile. In einem anderen Versuch mit einer anderen Niere ergaben sich 33 und 24,5.

Weiter führte $\mathrm{CO}_{2}$ eine erhebliche Quellung herbei

Dass auch die isolirten Leberzellen durch hypisotonische Lösungen quellen und durch hyperisotonische schrumpfen, möge aus folgender Tabelle hervorgehen.

\section{Isolirte Leberzellen des Frosches.}

Gleiche Mengen einer Suspension von Leberzellen in $\mathrm{NaCl}$ von $0,7 \%$ wurden mit relativ grossen Mengen NaCl-Lösung von $0,35 \%, 0,5 \%, 0,7 \%$ und $1 \%$ versetzt.

\begin{tabular}{|c|c|c|c|c|}
\hline Flüssigkeit & \multicolumn{4}{|c|}{ Volumen des Sediments in Skalentheilen } \\
\hline $\mathrm{NaCl} 0,35 \%$ & 26,5 & 27 & 26 & 26 \\
\hline ๓ 0,5 , & 24 & 25 & 22,5 & 22,5 \\
\hline " 0,7 \% & 18,5 & 21 & 19 & 19 \\
\hline$n 1 n$ & 13,5 & 13,5 & 11,5 & 11,5 \\
\hline
\end{tabular}

Man sieht, dass die Volumina der Leberzellen, welche in einer $0,7 \%$ igen NaCl-Lösung sich ungefähr in osmotischen Gleichgewicht befinden, durch $\mathrm{NaCl}$ von 0,5 , noch mehr durch $\mathrm{NaCl}$ von $0,35 \%$ quellen, aber durch $\mathrm{XaCl}$ von $1 \%$ schrumpfen.

Indessen scheint mir doch wohl das vorwaltende Interesse unter den Versuchsergebnissen mit den Zellen von Leber, Milz und Niere, in der Quellung durch $\mathrm{CO}_{2}$ und $\mathrm{HCl} z u$ liegen, weil sie auf das Wesen der bis jetzt für uns noch wenig aufgeklärten trüben Schwellung Licht wirft.

\section{Froscheier in Salzlösungen.}

Diese Untersuchungen stammen ebenso wie die genamnten über die Optimum-Lösungen für die Spermatozoenbewegung (vergl, oben S. 3) aus jener Zeit (1884), zu der ich erforschen wollte, wo die isotonische Coëfficienten ausser bei den rothen Blutkörperchen noch weiter zum Ausdruck kamen. Sie sind nicht veröffentlicht worden.

Eier eines paarenden, also geschlechtsreifen Frosches wurden in eine grosse Menge Salzlösung von verschiedener Concentration gebracht. 
In dieser blieben sie etwa 26 Stunden; dann wurden sie herausgenommen mit Filtrirpapier möglichst sorgfältig abgetrocknet und in Messcylinder gebracht, die bis zu einer bekannten Marke mit derselben Flüssigkeit gefüllt waren, der die Eier ausgesetzt gewesen waren. Die Zunahme des Flüssigkeitsniveaus wurde aufgezeichnet und auf diese Weise das Gesammtvolumen der Eier ermittelt. Durch Division dieses Volumens durch die Anzahl erhielt man das mittlere Tolumen des einzelnen Eies.

Einfluss der Concentration von NaCl-Lösmngen auf das Volumen von Froscheiern.

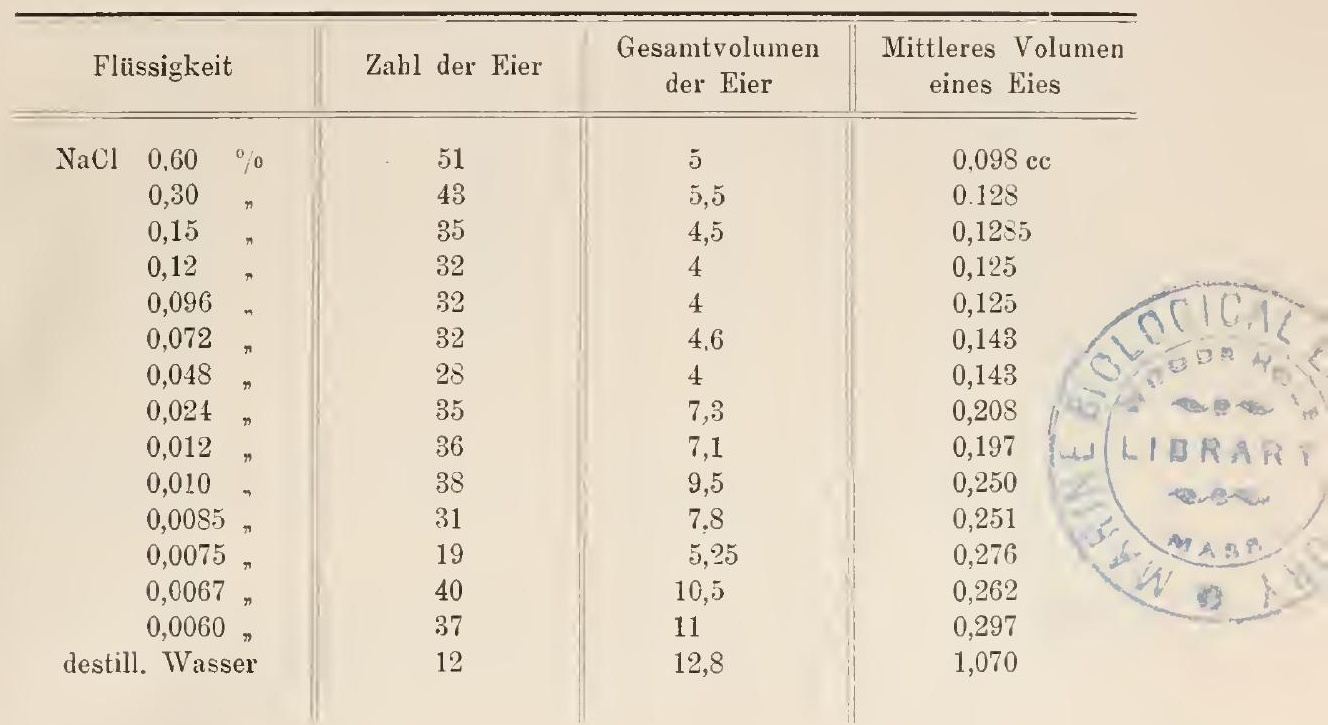

Man sielit, dass bei Abnahme der liochsalzconcentration das Volumen der Eier langsam aber allmählich zunimmt. In lıohem Maasse ist es aber auffallend, dass das Volumen beim Uebergang ron der doch schon sehr schwachen $0,006^{\circ}$ \% igen Kochsalzlösung zu destillirtem Wasser, plötzlich sehr erheblich ansteigt.

Was ich hier gemessen habe, sind indessen nicht die Eier allein, sondern die Eier mitsammt ihrer durch die Flïssigkeit zur Quellung gebrachten, ursprïnglich sehr dïnne Schleimschieht.

Auffallend ist, dass die Eier, oder besser gesagt, die umbüllenden Kugeln, an einander kleben und nicht leicht ron einander zu entfernen sind. Dies ist aber wohl der Fall, wenn sie in destillirtem Wasser liegen. 
Ich gebe nunmehr eine Versuchsreihe mit Kalisalipeter wieder.

In der letzten Spalte ist noch das mittlere Eivolumen in der mit der angewandten $\mathrm{KNO}_{3}$-Lösung isosmotischen NaCl-Lösung angegeben. Diese Zahlen stammen aus der vorigen Tabelle und beziehen sich auf einen anderen Frosch.

Einfluss der Concentration von $\mathrm{KNO}_{3}$-Lösungen auf das Volum von Froscheiern.

\begin{tabular}{|c|c|c|c|c|}
\hline Flüssigkeit & $\begin{array}{c}\text { Zahl } \\
\text { der Eier }\end{array}$ & $\begin{array}{l}\text { Gesammt- } \\
\text { volumen } \\
\text { der Eier }\end{array}$ & $\begin{array}{c}\text { Mittleres Volumen } \\
\text { eines Eies } \\
\text { in Kalisalpeter }\end{array}$ & $\begin{array}{l}\text { Mittleres Volumen eines Eies } \\
\text { in der mit der } \mathrm{KNO}_{3}- \\
\text { Lösung isosmot. } \mathrm{NaCl-Lösung} \\
\text { (vorige Tabelle) }\end{array}$ \\
\hline 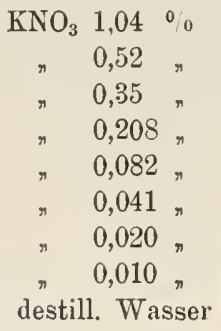 & $\begin{array}{l}34 \\
33 \\
24 \\
32 \\
37 \\
50 \\
47 \\
24 \\
11\end{array}$ & $\begin{array}{l}3,65 \text { ce } \\
3,3 \\
2,7 \\
3,4 \\
4,4 \\
7,2 \\
11,1 \\
8,5 \\
12,4\end{array}$ & $\begin{array}{l}0,107 \text { ce } \\
0,100 \\
0,102 \\
0,106 \\
0,119 \\
0,144 \\
0,236 \\
0,354 \\
1,12\end{array}$ & $\begin{array}{l}0,098 \\
0,128 \\
\\
0,125 \\
0,143 \\
0,208 \\
0,197 \\
0,297 \\
1,070\end{array}$ \\
\hline
\end{tabular}

Auch durch $\mathrm{KNO}_{3}$ entsteht also bei Abnahme der Concentration eine allmähliche Volumzunahme, die schliesslich beim Uebergang zu destillirtem Wasser steil ansteigt.

Die Eier des $\mathrm{KNO}_{3}$-Versuchs stammten von einem anderen Frosch als die des vorigen $\mathrm{NaCl}-\mathrm{Versuchs.} \mathrm{Der} \mathrm{Verlauf} \mathrm{der} \mathrm{Volumzunahme} \mathrm{in}$ den beiden Fällen zeigt nur einen leidlichen Parallelismus.

In der mit 1,04\%iger $\mathrm{KNO}_{3}$ - und $0,6 \%$ iger $\mathrm{NaCl}$-Lösung isotonischen KBr-Lösung (von 0,81\%) hatte das Ei ein mittleres Volumen von 0,112 cc.

Es interessirte mich zu untersuchen, bei welcher Verdünnung des Salzes die schnelle Volumvermehrung anfing.

Hierzu wurden auch stärkere Verdünnungen angefertigt.

\begin{tabular}{|c|c|c|c|}
\hline Flüssigkeit & Zahl der Eier & $\begin{array}{l}\text { Gesammtvolum } \\
\text { der Eier }\end{array}$ & $\begin{array}{l}\text { Mittleres Volum } \\
\text { eines Eies in ce }\end{array}$ \\
\hline $\mathrm{NaCl} \quad 0,6$ & 26 & 2.3 & 0,0885 \\
\hline r 0,003 & 16 & 7,15 & 0,45 \\
\hline r 0,0015 & 15 & 7,9 & 0,526 \\
\hline$\pi 0,0007$ & 12 & 8,1 & 0,675 \\
\hline " 0,00035 & 13 & 8,5 & 0,655 \\
\hline Destill. Wasser & 9 & 10,2 & 1,133 \\
\hline
\end{tabular}


Man sieht einen wie grossen Sprung im Volumen, der Uebergang von $\mathrm{NaCl} 0,00035 \%$ auf destillirtes Wasser, noch hervorzurufen im Stande ist.

Diese Untersuchungen sind nicht weiter geführt worden. Sie eröffnen aber manche wichtige Frage. Vor allem ist natürlich festzustellen, welchen Antheil das $\mathrm{Ei}$ selbst, und welchen Antheil die gequollene Hülle an der Volumzunahme hat. 


\section{Zweites Kapitel.}

\section{Bemerkungen über Colloide und Fermente.}

\section{Litteratur.}

1. Zsigmondy, Zeitschr. f. physikal. Chemie. 33. 1900. S. 63.

2. Stoeckl und Vanino, Zeitschr. f. physikal. Chemie. 30. 1899. S. 98; 34. 1900 S. 378.

3. Bredig, Anorganische Fermente Leipzig W. Engelmann 1901.

4. Picton und Linder, Journal of the Chem. Soc. 61. 1892. p. 148, ref. nach $\mathrm{H}$ a rdy.

5. Bodländer, Nachrichten d. kgl. Gesellsch. d. Wissensch. Göttingen 1893. S. 267.

6. Spring, Bulletin de l'Acad. Royale de Belgique 1900. p. 483.

7. Hardy, Journal of Physiol. 24. 1899. p. 301.

8. O. Wiener, Wiedem. Annalen. 31. 1887. S. 666.

9. C. Eykman, Centralbl. f. Bacteriol. 29. 1901. S. 841.

10. Lobry de Briyn, Recueil de trav. chim. des Pays Bas et de Belgique. 19. 1900. p. 251.

11. Zsigmondy, Liebig's Ann. 301. S. 29.

12. Picton und Linder, Journal of the chemic. Society 70. 1897. p. 568.

13. Ifardy, Journal of Physiol. 24. 1899. p. 288.

14. Coehn, Zeitschr. f. Elektrochemie 4. S. 65.

15. Schulze, Journal f. prakt. Chemie 25. 1882. S. 435.

16. Prost, Bullet. de l'Acad. Royale de Belgique (3) 14. 1887. p. 312.

17. Pieton und Iinder, Journal of the Chemic. Soc. 67. 1895. p. 65.

18. Rodländer, Neues Jahrbuch f. Mineralogie 3. 1893. S. 147.

19. Whetham, Journal of Physiol. 24. 1899. p. 288; Philosoph. Magazine Nov. 1899.

20. Hardy, Proceedings of the Royal Soc. 66. 1900. p. 110.

21. Nerust, Zeitschr. f. physik. Chemie 9. 1892. S. 139; 13. 1894. S. 532.

22. Spiro und Pemsel, Zeitschr. f. physiol. Chemie 26. S. 233.

23. Bredig, Zeitschr. f. Elektrochemie 5. 1899. S. 33.

24. Panli und Rona, Hofmeister's Beiträge zur chem. Physiol. und allgem. Pathol. 2. 1902. S. 1. 
25. Pauli, Hof me is ter's Beiträge zur chem. Physiol. und allgem. Pathol. :3. 1902. S. 22.5.

26. Lobry de Bruyn. Zittingsverslag d. Koninkl. Akad v. Wetensch. te Amsterdam 30. Jan. - 27. Febr. 1904. p. 778.

27. Freundlich, Zeitschr. f. physik. Chemie 44. 1903. S. 129.

28. Billitzer, Zeitschr. f. physik. Chemie 45, 1903. S. 307.

29. C. Ludwig, Lehrbuch d. Physiologie 2. Aufl. 1. S. 50.

30. Ostwald, Zeitschr. f. physik. Chemie 24. 1897. S. 723; 99. 1899. S. 190; 34. 1900. S. 510.

31. Bredig und Miiller vol Berneck, Zeitschr. f. physik. Chemie 31. 1899. S. 258.

32. Carey Lea, Philos. Magazine (5) 31. 1889. p. 238 u. 320.

33. Lottermoser, Therapeutische Monatshefte 1899. S. 159.

34. Bredig und Ikeda und Reinder's, Zeitschr. f. physik. Chemie 37. 1901. S. 1 und 323 .

35. Galeotti, Biologisches Centralblatt 21. 1901. S. 321.

36. Lobry de Briyı. Zittingsverslag d. Koninkl. Akad. v. Wetensch. Amsterdam 28. Juni 1898. p. 61. Recueil de trav. chim. des Pays Bas et de Belgique 19. 1900. p. 236.

37. Einst Cohen, Eder's Jahrb. f. Photographie 1895.

38. O. Sullivau und Tompsou, Journal of the chem. Soc. Trans. 57. 1890. p. 926.

39. Tammaun, Zeitschr. f. physik. Chemie 3. 1889. S. 35; 1S. 1895. S. 436. Zeitschrift f. physiol. Chemie 16. 1892. S. 28.

40. Duclaux, Traité de Microbiologie Paris 1899.

41. V. Hell'i, Zeitschr. f. physik. Chemie 39. 1901. S. 194.

42. V. Heuri, Lois générales de l'action des diastases. Thèses Paris Février 1903.

45. Helzog, Zittingsverslag der Koninkl. Academie v. Wetensch. Amsterdam 31. Oetober 1903. p. 486.

44. Senter, Zeitschr. f. physik. Chemie 44. 1903. S. 257.

45. Visser, Zittingsverslag d. Koninkl. Academie v. Wetensch. Amsterdam 30. Jan. 1904. p. 766.

46. Jacobson, Zeitschr. f. physiol. Chemie 16. 1892. S. 340.

47. Bredig, Ergebnisse der Physiologie, herausgeg. v. A sher und S piro 1. Jahrg. 1. Abth. 1902. S. 134.

48. Croft Hill, Journal of chem. Soc. 73. 1898. S. 634.

49. Kastle und Loewenthart, Americ. Chem. Journ. 26. 1901. p. 533.

50. Hanriot, Compt. rend, 132. 1901. p. 212.

51. C'remer, Ber. d. deutschen chem. Gesellsch. 32. 1899. S. 2062.

52. E. Fischer und Frankland Armstron⿺, Ber. der deutschen chem. Gesellsch. 3.5. 1902. S. 3151.

53. van Bemmelen, Zeitschr. f. anorg. Chemie 2:3. 1900. S. 360. Da auch ausführlich angegebene Litteratur.

54. Schoorl, Recueil des Travaux Chim. des Pays Bas et de Belgique 22. 1902. p. 31.

55. Höber, Zeitschr. f. physik. Chemie 34. 1900. S. 515.

56. Höber', P fl üger's Archiv \$2. 1900. S. 631.

57. V. Henri, Archivio di Fisiologia. 1. 1904. p. 299.

57. C. Oppenleimer, Die Fermente und ihre Wirkungen. 2. Aufl. 1903. Leipzig. F. C. W. Vogel. 
Die grosse Bedeutung, die das Studium der Eigenschaften von Colloiden für die Biologie besitzt, macht es wünschenswerth in einem besonderen Kapitel einige Thatsachen hervorzuheben, die an anderen Stellen in nicht genügender Weise zu ihrem Rechte gelangen können.

Ich muss mich aber darauf beschränken aus der reichhaltigen, überaus interessanten Litteratur Einzelnes fragmentarisch herauszugreifen und werde dabei insbesondere auf diejenigen Thatsachen und Ausführungen die Aufmerksamkeit lenken, auf welche die Ionenlehre ihren Einfluss geltend gemacht hat.

Zunächst möchte ich einige Bemerkungen über die Natur der Colloide vorausschicken.

\section{Die Natur der Colloide. (Lösung oder Suspension?)}

Ich brauche kaum zu erwähnen, dass Colloide in zwei Zuständen vorkommen, als Sol und als Gel. Ist das Colloid flüssig, so spricht man von Sol; ist es fest geworden, so bezeichnet man es mit Gel. Diese beiden Zustände werden am sinnfälligsten repräsentirt durch warmflüssigen und durch erstarrten Leim. Ist die Flüssigkeit, in der das Colloid vertheilt ist, Wasser, so spricht man von Hydrosol und Hydrogel. Ist die betreffende Flüssigkeit z. B. Alkohol, so spricht man von Alkoholsol und Alkoholgel.

Ich muss noch hinzufügen, dass nicht nur erstarrte, sondern auch ausgeflockte Colloide zu den Gelen gerechnet werden, so z. B. die mittelst Salzlösung gefällten.

Ist nun das in Solform sich befindende Colloid als eine Lösung (Zsigmondy [1]) oder als eine Suspension (Stoeckl und Vanino [2], Bredig [3]) auf zufassen?

Ueber diese Frage ist viel discutirt worden; zu einer Entscheidung ist man aber noch nicht gelangt. Es sind bei der Discussion verschiedene Erwägungen zur Sprache gekommen, ron denen ich hier einige folgen lassen will.

1. Es ist die Frage, ob man, um die Hydrosole als Suspensionen auffassen zu dürfen, die Forderung stellen muss, dass die suspendirten Theilchen auch als solche direct sichtbar sind.

Es wäre das höchst willkürlich; denn die Entscheidung würde dann von der augenblicklichen Potenz unserer Mikroskope abhängen. Ausserdem scheint es, dass dieselbe chemische Verbindung sich in dieser Hinsicht verschieden verhalten kann. So z. B. kann eine Lösung ron $\mathrm{As}_{2} \mathrm{~S}_{3}$ bei Betrachtung mit unbewaffnetem Auge homogen erscheinen, 
aber unter dem Mikroskop sieht man Partikel in Brownscher Molekularbewegung, während sich, wie Picton und Linder [4] in ihrer Abhandlung "Solution und Pseudosolution" ausgefïhrt haben, andererseits Lösungen von $\mathrm{As}_{2} \mathrm{~S}_{3}$ leerstellen lassen, die bei keiner Vergrösserung mehr Discontinuität erkennen lassen.

2. Der Uebergang von Hydrosol aus Hydrogel durch Ausflockung.

Nan hat gemeint, diese Erscheinung als ein Argument dafür anführen zu dürfen, dass das Hydrosol eine Lösung ist. Das Argument hat aber keinen Grund: denn auch bei echten Aufschwemmungen, bei denen der Charakter einer Suspension keinem Zweifel unterliegt, so z. B. von Kaolin in Wasser, können äusserst geringe Zusätze löslicher Stoffe ein Ausflocken herbeiführen. So hat Bodländer [5] gezeigt, dass Spuren von Säuren ( $1 \mathrm{~g} \mathrm{HCl}$ in $1500000 \mathrm{~g}$ Wasser) hierzu im Stande sind. Spring [6] hat sogar die Vermuthung ausgesprochen, dass die Deltabilidung bei Flüssen zum Theil auf die Vermischung des schlammigen Süsswassers an der Strommündnng mit den Elektrolyten des Meerwassers zuriickzuführen ist.

Es ist auffallend, dass bloss Elektrolyte im Stande sind Kaolinaufschwemmungen auszuflocken. Mit Nicht-Elektrolyten geht es nicht. Vollkommen Gleiches findet man bei Hlüssigen Colloiden. Nan darf hieraus schliessen, dass bei der Ausflockung die Ionen die Hauptrolle spielen. Das geht u. A. aus den Zahlen von Hardy[7] für die Ausflockung von Mastix hervor, wo die erforderlichen Mengen mit der $\mathrm{H}$-Ionenconcentration proportional sind. Man ersieht das aus folgender Tabelle, nach der eine Vastixlösung durch Säurelösungen von derselben specifischen Leitfähigkeit ausgeflockt wurde.

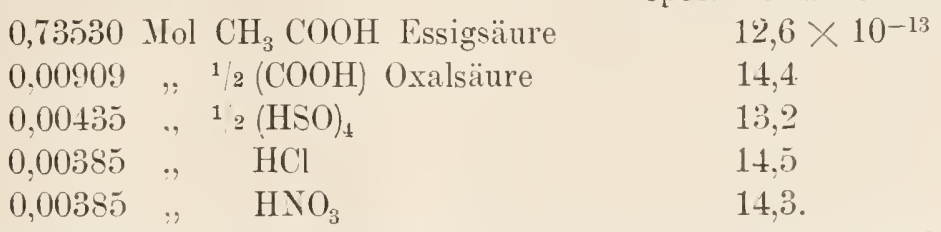

Ueberhaupt haben bezüglich der Ausflockung durch Elektrolyte die Hydrosole und die unzweifelhaften Suspensionen keinen Unterschied gezeigt.

3. Unzweifelhafte Suspensionen (wie z. B. Schwefel oder Graphit in Wasser oder in Terpentinöl) erfahren Kataphorese, d. h. sie werden 
durch den galranischen Strom mitgeführt, bei Hydrosolen sieht man dasselbe. (Vergl. Bd. II S. 433, auch diesen Band S. 67 ff.).

4. Mit Recht wird ron Bredig als ein weiteres Argument für die suspensionsartige Natur ron Hydrosolen die ron ihm gefundene Thatsache angefiihrt, dass man die letzteren durch elektrische Kathodenzerstäubung von Metalldrähten unter Wasser bereiten kann. Dass in der That unter dem Einfluss eines galvanischen Stroms Zerstäubung von Metall stattfinden kann. war bereits früher aus Versuchen von 0 . Wiener [8] hervorgegangen. Dieser Forscher wies nach, dass man durch elektrische Zerstäubung einer Silberkathode im Vacuum auf einer Glimmerplatte noch Silberschichten von der Dicke $0,00014 \mu$ erhält, also etwa von der Nolekulardicke.

5. Sehr beachtenswerth ist. wie Picton und Linder gefunden haben [4]. das Verhalten gegenüber Licht. Sie wiesen nach. dass die colloidalen Lösungen einfallendes Licht zerstreuen und polarisieren. Es müssen also in den Colloiden, Theilchen vorhanden sein, an denen die Aetherwellen reflectirt werden. Von dem polarisirten Zustande des reflectirten Lichtes kann man sich in einfacher Weise überzeugen, indem man es mit einem Nicol betrachtet, dessen Achse senkrecht zur Richtung der austretenden Lichtstrahlen gestellt ist. Dieses Tyndallphänomen zeigen echte Lösungen nicht, wohl aber feine Suspensionen. Bedenkt man, dass man mit den besten Mikroskopen noch $0,14 \mu$ erkennen kann und das Tyndallphänomen bei Hydrosolen beobachtet wird, die unter dem Mikroskop vollkommen homogen aussehen, so hat man darin ein einfaches Mittel die Gegenwart von Theilchen, die kleiner als 0,14 "थ. zu entdecken.

Diese Anffassung schien in den Untersuchungen ron Spring (Recueil d. Trav. chim. d. Pays-Bas et de Belgique. 18. 1899. p. 153) eine kräftige Stütze zu finden. Es war ihm gelungen "optisch leere“ Lösungen zn bereiten, d. h. Lösungen in denen kein Licht durch etwa darin schwebenden Theilchen reflectirt wurde: ein Bündel in die Lösung geworfenes Licht war unsichtbar. Dieser Zustand wurde dadurch erzielt, dass Spring colloidales Metalllydroxyd in der Flïssigkeit entstehen liess, das bei Senkung ohne Luftzutritt, alle Staubtheilchen mit zum Boden führte. Auf diese Weise hat der Autor aus einer Anzahl Lösungen die Staubtheilchen entfernt. Sei der Untersuchung mittelst Licht stellte sich mun herans, dass bei den organischen Colloiden doch noch Lichtreflex und Polarisation des Lichtes bestehen blieb; das 
Gleiche war der Fall mit einigen stark verdünnten Lösungen von schweren Metallsalzen.

Später aber lhat Spring (Recueil 19. 1900. p. 339) bei seinen Untersuchungen iiber das Verhalten von gefärbtem Glas gegenüber Licht auf die Möglichkeit hingewiesen, dass den .optisch leeren“ Lösungen Reflexerscheinungen deshalb fehlten, weil er Licht von zu geringer Intensität angewendet hatte. Es schien ihm nicht unmöglich, dass intensiveres Licht wohl reflectirt werden könnten, und zwar durch die gelösten Moleküle selbst.

In der That ist es Lobry de Bruyn, unabhängig von diesen Ausfïhrungen Spring's auch gelungen [26], bei Lösungen ron Rohrzucker, Raffinose und anderen Stoffen, deren Krystalloid-Natur man niemals bezweifelt hat, Reflexion und Polarisation des Lichtes nachsilweisen. Die Lösungen waren zuvor mittelst Zinkhydroxyd von Staub befreit.

Ian sieht, dass auch das Tyndall-Phänomen kein zuverlässiges Nerkmal für Colloide ist.

6. Das scheint auch mit einer anderen bekannten und in manch anderer Hinsicht wichtigen Eigenscliaft der Colloide, nicht der Fall zu sein, mit der Eigenschaft nämlich, anderen Colloiden den Durchgang zu verweigern. Denn C. Eykmann hat gefunden, dass eine Leimlösung auf eine Agar-Agarplatte gebracht in kurzer Zeit in die selbe hineindiffundirt, wenn nur für eine geeignete Temperatur Sorge getragen wird, damit die Lösung nicht erstarrt [19].

Ian sieht, eine absolute Entscheidung darüber, ob es sich bei den Hydrosolen um eine Lösung oder um eine Suspension äusserst feiner Theilchen handelt, haben die erwähnten Untersuchungen nicht gebracht.

7. Auch die Gefrierpunkterniedrigung giebt keine entscheidende Auskunft, ob Hydrosole Lösingen sind oder feine Suspensionen. Beim ersten Anblick erscheint das befremdend, denn man könnte meinen, dass bei Suspensionen die festen Theilchen an der Depression nicht betheiligt sein könnten und die Gefrierpunkterniedrigung also 0 sein mïsste, während eine Erniedrigung gefunden werden muss, wenn es sich um eine wahre Lösung handelt; freilich mag auch diese Gefrierpunkterniedrigung nur geringfügig sein, weil die Moleküle sehr gross sind und also in geringer molecularer Concentration vorhanden sein können. 
Doch kann man auch bei Annahme der ersten Möglichkeit, nämlich, dass das Sol eine Suspension ist, das thatsächliche Bestehen einer Gefrierpunkterniedrigung wohl deuten.

Ich sehe hierbei von der Möglichkeit ab, dass es sich um Verunreinigung mit Krystalloiden handelt. Obgleich zugegeben werden muss, dass es äusserst schwierig, vielleicht kaum möglich ist, flüssiges Eiweiss ohne gelöste Krystalloide, resp. Salze zu erhalten, so kann diese Ueberlegung doch bei Starling's Verfalıren zur Bestimmung des osmotischen Drucks von Serumeiweiss (Vergl. Bd. II, S. 398) kaum in Betracht kommen und doch wird da ein osmotischer Druck gefunden.

Es kann aber ein osmotischer Druck bei fein vertheilten Suspensionen wohl in anderer Weise erklärt werden.

a) Dadurch, dass die festen Theilchen die Flüssigkeitstheilchen durch Adsorption festhalten und es also Arbeit kostet dieselben zu trennen (so findet man z. B. dass feste Theilchen den Dampfdruck des Wassers beträchtlich vermindern). Diese Kraft wird um so intensiver zum Ausdruck kommen, wo, wie hier, durch die Ḱleinheit der Theilchen die Berührungsoberfläche von festen Theilchen und Flüssigkeit so enorm gross ist.

b) Wie Bredig bemerkt, (vergl. anch unten bei den Ausführungen Hardy's) besitzen die festen Theilchen einer Suspension eine elektrische Ladung. Die gleichnamig geladenen Theilchen stossen einander ab. Es besteht somit in feinen Suspensionen ein Bestreben der Theilchen sich von einander zu entfernen, ebenso wie das für die Theilchen in Krystalloidlösungen angenommen wird. Man wird sich erinnern, dass gerade dieses Bestreben der Theilchen den osmotischen Druck zur Folge hat. Den analogen in Colloiden, durch die feinen suspendirten Partikel ausgeübten Druck nennt Bredig „pseudoosmotischen Druck".

Ich halte diese soeben wiedergegebenen Vorstellungen für uns von Wichtigkeit, weil bereits bei manchen Betrachtungen, so z. B. über die Riesorption (Bd. II, S. 162), über die Glomerulusfliissigkeit (Bd. II, S. 397) dem osmotischen Druck des Eiweisses eine bedeutsame Rolle zuzuschreiben war.

Darf also angenommen werden, dass nicht nur wahre Lösungen, sondern anch äusserst feine Suspensionen einen osmotischen Druck ausïben, so kann die I'liysiologie den Streit über die Frage, ob eine Eiweisslösung eine Suspension sei oder nicht, ruhig währen lassen. Dennoch ist die lirage für sie nicht ganz gleichgiltig, demn wenn die unter a und b gemachten Amahmen richtig sind, so muss die wasseranziehende Kraft oder der pseudoosmotische Druck mit dem Vertheilungsgrad der 
Colloidpartikelchen wachsen. $\mathrm{Da}$, wie noch weiter ausgeführt werden wird, dieser Vertheilungsgrad, also die Grösse der Partikelchen, durch mancherlei Factoren beeinflusst wird, so z. B. durch den Säure- oder Alkoholgehalt des Hydrosols, so würde die wasseranziehende Kraft oder der pseudoosmotische Druck von Colloidlösungen eine veränderliche Grösse sein.

Dass Colloidlösungen eine Wasseranziehung oder eine Art osmotischen Druck ausüben, gewinnt an Wahrscheinlichkeit durch Versuche mit Stärkelösungen. Brown und Millar, sowie Rodenwald und Kattein fanden für die lösliche Stärke (also ein Hydrosol) auf rein chemischem Wege dasselbe Molekulargewicht, das bereits zuror auf kryoskopischem Wege ermittelt worden war.

Berechnet man daraus weiter mit Lobry de Bruyn annähernd die Grösse des gelösten Stärkemoleküls [10], so gelangt man zu dem Werthe von etwa $5 \mu \mu$. Ein gleicher Werth ergiebt sich, wenn man die Grösse der Theilchen ermittelt, die erforderlich sind, um das TyndallPhänomen hervorzurufen, d. h. Licht zu polarisiren.

Lobry de Bruyn meint denn auch, und seine bereits oben genannten Untersuchungen gewähren eine kräftige Bestätigung, dass eine scharfe Grenze zwischen colloidalen und wahren Lösungen nicht zu ziehen ist. Neuerdings ist auch Billitzer [28] auf ganz anderem Wege zu der Schlussfolgerung gelangt, dass zwischen Suspension, colloidaler Lösung und wahrer Lösung Continuität besteht.

\section{Zustandänderungen organischer Colloide.}

Die Bedingungen, unter welchen Hydrosole (wie Eiweiss-, Gelatineund andere derartige Lösungen) in die entsprechenden Gele übergehen, sind in den letzten Jahren vielfach studirt worden. Wiederholte Male hat man in den betreffenden Abhandlungen hervorgehoben, dass diese Untersuchungen von grosser Wichtigkeit für die Biologie seien, ohne jemals einen anderen Grund anzufïhren, als dass auch das Protoplasma als colloidaler Stoff zu betrachten ist. Ich muss gestehen, dass ich die Wichtigkeit dieses Grundes niemals recht verstanden habe. Was kann es schliesslich für die Kenntniss des Protoplasma nützen, dass man weiss, durch welche Salzlösungen Eiweiss ausgeflockt und das Erstarren von Gelatine befördert oder verzögert wird? Es liommt doch im lebenden Protoplasma niemals zu einer Ausflockung oder Erstarrung!

Seit ich aber mit den Ausführungen von Picton und Linder bekannt geworden bin, haben derartige Untersuchungen auch ans 
biologischem Gesichtspunkt für mich ein directes und lebhaftes Interesse gewonnen. Picton und Linder haben nämlich hervorgehoben, dass ein Salz, auch wenn seine Concentration nicht ausreicht, Hydrosol in Hydrogel zu verwandeln, doch nicht ganz ohne Wirkung ist. Die Partikel nehmen dureh Agglutination an Grösse zu und das Hydrosol bekonunt andere physikalisehe Eigensehaften: andere Viscositait U. S. w.

Das Grösserwerden der Partikel konnte Hardy unter dem Mikroskop verfolgen. (Vergl. das Kiapitel „Histologisches“.)

In geistreicher Weise hat $\mathrm{Loeb}$ diese Aenderung physikalischer Eigenschaften herangezogen, um den Einfluss der Ionen auf die Zelltheilung bei der Eifurchung, und auf die Zuckung bei Muskelreizung zu erklären. Wie unten erörtert werden wird, kann man durch Hinzufügung von Ionen zu Colloiden Ausflockung herbeifülıren. Setzt man wenig hinzu, so kommt es zwar nicht zur Ausflockung, doch ändert sich jedenfalls die Viscosität. Dadurch wird, wenn es sich um Protoplasma handelt, die Beweglichkeit der Protoplasmatheilchen beeinflusst und damit auch die Geschwindigkeit der Zelltheilung bei der Eifurchung, und der Zuckung bei der Muskelreizung.

Ich bespreche nunmehr die Mittel zur Herbeiführung von Zustandsänderungen.

\section{a) Zustandänderung durch den galvanischen Strom.}

Wenn man eine verduinnte, durch Hitze opalisirend gewordene Eiweisslösung in ein U-förmiges Rohr bringt und einen elektrischen Strom hindurchleitet, so bewegen sich Eiweisspartikelchen nach der Anode. Das hat in so fern nichts Befremdendes, als Zsigmondy [11] bereits früher gefunden hat, dass auch colloidales Gold sich unter dem Einfluss eines galvanischen Stromes oder, genauer gesagt, im elektrischem Felde, nach der Anode bewegt. Picton und Linder [12] fïgten dem u. A. hinzu, dass die festen Colloid-Partikelchen auch wohl die ent. gegengesetzte Richtung, also nach der Kathode nehmen. Dies hängt von der chemischen Natur der Substanz ab.

Es ist ein Verdienst Hardy's, gefunden zu haben, dass auch die Eiweisspartikelchen sich in beiden Richtungen bewegen können, und und dass die Richtung nur von der Reaction der betreffenden Colloidlösung abhängt. So lange die Eiweisslösung alkalisch ist, bewegen sich die Eiweisspartikelchen zur Anode; macht man die Lösung schwach sauer, so gehen sie nach der Kathode. 
Man bereitet die Eiweisslösungen in folgender Weise:

Mit der Schere zerschnittenes Hühnereiweiss wird mit der neunfachen Wassermenge versetzt und filtrirt. Ein Theil des Filtrates wird in ein Reagensrohr gebracht (nach meiner Erfahrung besser in einem Wasserbade erhitzt). Dann setzt sich eine Eiweissschicht an der Wand ab. Man giesst die Flüssigkeit aus und ersetzt sie durch eine neue Menge des Filtrates, die man nunmehr erhitzt. Man wiederholt das so lange, bis die an der Wand des Reagensröhrchens abgesetzte Eiweissschicht so dick ist, dass eine weitere Einwirkung der Glaswand auf die zu kochende Eiweisslösung ausgeschlossen ist $\left.{ }^{1}\right)$. Dann sind die suspendirten Eiweisspartikelchen so fein, dass die Flüssigkeit eine bläuliche Farbe besitzt. Diese colloide Eiweisslösung hat $\mathrm{Hardy}$ zu verschiedenen $\mathrm{Z}$ wecken benutzt.

Will man in Fällen, wo die Anwesenheit von Salzen unerwünscht ist, diese entfernen, so dialysirt man während einiger Tage gegen destilliertes Wasser. Es entsteht dann im Dialysator ein Coagulum von Eiweiss, das durch Hinzufügung einer Spur Alkali oder einer Spur Säure flüssig wird. Brachte nun $\mathrm{Hardy}$ die so erhaltene Flüssigkeit in ein U-Rohr, senkte in jeden Schenkel eine Elektrode und liess einen Strom von 105 Volt durch die Lösung hindurchgehen [13], so setzte sich, wenn die Lösung alkalisch war, nach einiger Zeit ein EiweissCoagulum an der Anode (positive Elektrode) ab. Befand sich im U-Rohr angesäuerte Eiweisslösung, so setzte sich ein Coagulum an der Kathode $\left.a b^{2}\right)$. Offenbar wird in beiden Fällen das Eiweiss durch je eine der Elektroden angezogen und man ist wohl genöthigt anzunehmen, dass im ersten Fall die Eiweisspartikelchen (da sie sich am positiven Pol absetzen) selbst negativ waren, im zweiten Fall (wo die Auflösung durch Säure stattgefunden hatte) positiv.

Wie hat man sich nun vorzustellen, dass in einem Falle Eiweisspartikelchen positiv, im anderen Falle negativ elektrisch sind?

Hardy hat sich bei der Deutung dieser Erscheinung ganz auf dem Standpunkt von $\mathrm{H}$ e l $\mathrm{mhol} \mathrm{tz}-\mathrm{Qu}$ in cke gestellt, indem er annimmt, dass

1) Dass die Wand einen Einfluss ausübt, geht aus folgenden Daten hervor: Wenn man in einem Glasrohr in einiger Entfernung ein Paar Elektroden anbringt und einen galvanischen Strom hindurchleitet, so bewegt sich das im Glasrohr befindliche Wasser in der Richtung des Stromes, d. h. von der Anode nach der Kathode. Es verhält sich also selbst positiv und das Glas negativ. Terpentin bewegt sich in entgegengesetzter Richtung, ist also selbst negativ elektrisch. Luftbläschen in Wasser gehen auch mit dem negativen Strom.

2) Man kann, wie ich fand, die zu diesem Versuch erforderliche Eiweisslösung auch in der Weise anfertigen, dass man das zerschnittene und mit neunfacher Menge destillirtem Wasser verdünnte Hühnereiweiss, nach Filtration durch einen durchlöcherten Porzellantrichter, durch Filtrirpapier geben lässt; die Lösung wird dann direct in das U-förmige Rohr gebracht. 
auf der Grenze jedes Colloidpartikelchens und der dasselbe umgebenden Flüssigkeit eine elektrische Doppelschicht besteht ${ }^{1}$ ). Im Falle der schwach alkalischen Eiweisslösung ist das Eiweisspartikelchen negativ, das umgebende Wasser positiv. Deshalb geht das Eiweiss zu der Anode, die positiv wässerige Flüssigkeit zu der Kathode. Handelt es sich hingegen um eine angesäuerte Eiweisslösung, so sind die Eiweisspartikelchen positiv, das umgebende Wasser dagegen negativ elektrisch. (Vergl. auch Bd. II, S. 433 über Kataphorese.)

Die Proteidtheilchen haben demnach, wie Hardy fand, die merkwürdige Eigenschaft, dassihr elektrischer Charakter durch die Natur der Flüssigkeit bedingt wird.

Wenn es nun hiernach möglich ist durch Hinzufügung einer Spur Säure zu der schwach alkalischen Eiweisslösung die negative Natur der Eiweisspartikel in eine positive zu verwandeln, und zugleich das Menstruum (Wasser) jeweils umgekehrt zu beeinflussen, so muss es einen Punkt geben, an welchem Eiweisspartikel und Wasser keine Potentialdifferenz aufweisen. Sie sind dann, wie Hardy es nennt, "isoelektrisch" und die Colloidpartikelchen schlagen sich nieder, oder wie man es auch ausdrückt, das Hydrosol (d. h. die wässerige Colloidlösung) geht in Hydrogel (in Gallert- oder Präcipitatzustand) über. Der Solzustand geht immer mit einer elektrischen Ladung der Colloidpartikel einher; bei Abnahme der Ladung vergrössern sich die Agglomerate, bleiben jedoch unsichtbar, um bei fortgesetzter Abnahme erst als Opalescenz, dann als Flocken sichtbar zu werden. Haben sie die Ladung vollständig verloren, so ist die Ausflockung vollkommen (vergl. S. 75 und auch die Fussnote S. 89.

Man braucht aber nur die gecingste Spur Alkali hinzusetzen, um wieder etwas Eiweiss zur Auflösung zu bringen. Lässt man nunmehr einen Strom hindurchgehen, so wandert Eiweiss nach der Anode und flockt da aus. Hat man dagegen eine Spur Säure zugesetzt, so wandert es nach der Kathode, verliert dort seine positive elektrische Ladung und flockt aus.

Man hat also zwei Mittel das Eiweiss auszuflocken; den elektrischen Strom und die chemische Neutralisation durch Säure oder Alkali.

Wir werden sogleich noch andere Stoffe besprechen, welche AusHockung herbeizufïhren im Stande sind.

i) Bereits früher hatte auch Coehn [14] zur Erklärung von kataphoretischen Bewegungen in Colloiden die Helmholtz'sche Doppelschicht benutzt. 
Eigentlich kennt man diese Thatsachen über die Präcipitirung und Lösung von Eiweiss durch Alkali und Säure bereits lange. So hiess es immer: Das in Säure lösliche Syntonin hat die Eigenschaft bei sehr genauer Neutralisation durch Alkali niedergeschlagen zu werden. Fügt man ein wenig Alkali im Ueberschuss hinzu, so löst sich das Präcipitat wieder auf; es bildet sich Alkalialbuminat, während das ursprüngliche Syntonin als Acidalbumin zu betrachten ist. Jetzt kann man es so ausdrücken: Alkalialbuminat und Acidalbumin sind Hydrosole; bei genauer Neutralisation gehen diese in Hydrogel über.

Ein anderes Beispiel hat man in der Präcipitirung des Milchcasëins. Verdünnt man Milch mit der zehnfachen Wassermenge und fügt danz vorsichtig verdüınte Salzsäure oder Essigsäure hinzu, so wird das Casëin ausgeflockt und es lässt sich eine vollkommen klare Flüssigkeit abfiltriren. Das geringste Säureübermaass macht aber, dass das Filtrat sich trübe zeigt. Das rührt daher, dass die Ausflockung nicht mehr vollkommen ist, und dann gehen Eiweissaggregate, die zu klein sind, um durch das Filter zurückgehalten 7. u werden, aber doch gross genug, um der Flüssigkeit ein trübes Aussehen zu geben, durch das Filter hindurch.

Bei dieser Betrachtung muss es möglich und erklärlich erscheinen, dass auch ein klares Filtrat nicht vollkommen eiweissfrei zu sein braucht.

\section{b) Zustandänderung durch Hinzufïgung von Ioneu (in Sïuren, Basen oder Salzen).}

Nicht nur der elektrische Strom oder blosse Neutralisation mittelst Alkali oder Säure ist im Stande aus einer Eiweisslösung Eiweiss zur Ausflockung zu bringen, auch die Hinzufügung vieler anderen chemischen Verbindungen führt dasselbe herbei. Doch sind es ausschliesslich Elektrolyte, die diese Fähigkeit besitzen, Nichtleiter sind dazu nicht im Stande ${ }^{1}$ ). Es ist das auch ein kräftiges Argument dafür, dass es sich bei der Ausflockung oder Coagulation wirklich um elektrische Ladungen handelt.

Graham hatte bereits darauf hingewiesen, dass Salze Colloidlösungen zu „zersetzen“ vermögen. 1882 studirte Schulze[15̃] die Sachlage genauer, indem er von verschiedenen Salzen die Concentration aufsuchte, die ein gleiches präcipitirendes Vermögen auf das Hydrosol von Schwefelarsen ausübten.

Hierbei ergab sich, dass den Säurecomponenten der Salze nur ein geringfügiger Einfluss zukommt, und das Phänomen fast ausschliesslich von der Valenz der Metalle abhängt. Die Salze der bivalenten Metalle besassen ein viel grösseres Coagulationsvermögen als die der univalenten, und die Salze der trivalenten Metalle wieder ein bedeutend grösseres als die der bivalenten Metalle, m. a. W. man braucht von Metallsalzen mit trivalęntem Metall äusserst wenig, mehr von Metall-

1) Alkohol macht eine Ausnahme. Vergl, die Fussnote unter $3 \mathrm{c}$. 
salzen mit bivalentem Metall und am meisten von Metallsalzen mit uni. valentem Metall. Es ergab sich aus Schulzes Messungen, dass die Coagulationsvermögen der Chloride der 1-, 2- und 3-werthigen Metalle sich zu einander verhielten wie $1: 30: 1650$.

Zu gleichartigen Zahlen gelangten Prost [16] mit dem Hydrosol des Schwefelcadmiums und Picton und Linder [17] mit dem Hydrosol des Schwefelantimons. Letztere Autoren fügten die wichtige Thatsache hinzu, dass ein kleiner Theil des die Coagulation herbeiführenden Salzes zersetzt und in das Coagulum eingeschlossen wird.

Wie erklärt es sich nun, dass auch die Salze coagulirend wirken? Hardy liat sich, um dies zu erforschen, zunächst gefragt, ob es keine Grössen gab, deren Werthe mit dem Betrag des coagulirenden Vermögens parallel liefen, z. B. der osmotische Druck, die Oberflächespannung oder die Viscosität. Die Antwort fiel vollkommen negativ aus. Es lag nun im Zusammenhang mit dem bereits gefundenen auf der Hand, an das elektrische Verhalten der verschiedenen Metallsalze zu denken, zumal deshalb, weil nur Elektrolyte coagulirend wirken, Nichtleiter hingegen nicht. Ausserdem hatten Linder und Picton[17] bei Vergleichung des Ausflockungsvermögens von Salzen desselben Metalls mit verschiedenen Säuren gezeigt, dass der Dissociationsgrad von grossem Einfluss auf das Coagulationsvermögen war. Dies hatte bereits Bodländer [18] Veranlassung gegehen, die coagulirende Wirkung der Elektrolyte deren elektrischer Natur zuzuschreiben. Hardy glaubt daher, dass diecoagulirende Wirkung durch die elektrische Ladung der Metalle beherrscht wird.

Diese Vorstellung bringt aber eine grosse Schwierigkeit; denn in diesem Fall würde - entsprechend dem Faraday'schen Gesetz, nach dem ein zweiwerthiges Metall zweimal so viel Elektricität transportirt, wie ein einwerthiges - das Coagulationsvermögen der Salze bivalenter Metalle zweimal grösser sein müssen als dasjenige der einwerthigen Metalle. Das ist aber keineswegs der Fall, der Unterschied ist vielmehr grösser; denn, wie bereits gesagt, das Verhältniss zwischen dem coagulirenden Vermögen der Chloride der 1-, 2- und 3-werthigen Metalle ist gleich $1: 30: 1650$.

Whetham hat diesen Widerspruch durch eine einfache Hypothese aufgeklärt [19].

Er nimmt an, dass zur Herbeiführung einer gewissen Conglomeration von colloidalen Partikeln, wie sie sich beim Uebergang in den Gelzustand ereignet und 
eigentlich das Wesentliche dieses Ueberganges bildet (Vergl. oben, S. 66), als Minimum jedenfalls eine Ladung vorhanden sein muss, die einem dreiwerthigen Ion entspricht, dass also keine Agglomeration in Gegenwart einer kleineren Ladung möglich ist.

Da nun nach dem Faraday'schen Gesetz ein dreiwerthiges Ion eine dreimal so grosse Ladung besitzt, wie ein einwerthiges, so werden zu der genannten Agglomeration 3 einwerthige Ionen erforderlich sein, bezw. aus demselben Grund 2 oder eigentlich ${ }^{3 / 2}$ zweiwerthige Ionen.

Whetha $\mathrm{m}$ argumentirt dann folgendermaassen:

In einer Lösung, in der sich Ionen frei bewegen, kann die Wahrscheinlichkeit, dass ein Ion jeden Augenblick in das Bereich eines bestimmten Punktes (d. h. in den Bereich des colloidalen Partikelchens) gelangt, durch das Product AC ausgedrückt werden. Hierin bedeutet A eine Constante und $\mathrm{C}$ die Concentration der Lösung. In der That ist die Chance um so grösser, je concentrirter die Lösung ist. Das Product AC nimmt die Gestalt eines Bruches an, wenn die Gewissheit, dass das Ion den colloidalen Partikel jeden Augenblick erreicht, gleich 1 gesetzt wird.

Die Chance, dass zwei Ionen gleichzeitig in das Bereich des colloidalen Partikels gelangen, ist $(\mathrm{AC})^{2}$, d. h. sio gleicht dem Product der beiden Einzel-Chancen. Die Wahrscheinlichkeit, dass $\mathrm{dr} \theta \mathrm{i}$ Ionen gleichzeitig in das Bereich des colloidalen Partikelchens gelangen, ist gleich (AC) ${ }^{3}$.

Demnach ist die Wahrscheinlichkeit, dass drei einwerthige Ionen gleichzeitig in der Nähe des colloidalen Partikels zusammentreffen, sehr gering (ein Bruch in der dritten Potenz), und zwar viel geringer als diejenige für das Eintreffen eines einzelnen Ions. Soll die W ahrscheinlichkeit des gleichzeitigen Zusammentreffens dreier einwerthiger Ionen derjenigen für das Eintreffen eines einzelnen dreiwerthigen Ions gleichen, so muss eine sehr grosse Zahl einwerthiger Ionen vorhanden sein. Umgekehrt kann die Zahl der dreiwerthigen Ionen gegenüber der erforderlichen Zahl der einwerthigen sehr gering sein.

Die Bereclnnung der für die verschiedenwerthigen Ionen erforderlichen Concentrationen erfolgt nach $W$ hetham folgendermaassen:

Es seien die molecularen Concentrationen der dreiwerthigen Ionen $\mathrm{C}_{1}$, der zweiwerthigen $\mathrm{C}_{2}$ und der einwerthigen $\mathrm{C}_{3}$, bezw. die zugehörigen Wahrscheinlichkeiten $\mathrm{AC}_{1},\left(\mathrm{AC}_{2}\right)^{2}$ und $\left(\mathrm{AC}_{3}\right)^{3}$.

Besitzen die drei Lösungen ein äquicoagulatives Vermögen, so muss $\mathrm{AC}_{1}=$ $\mathrm{A}^{2} \mathrm{C}_{2}{ }^{2}=\mathrm{A}^{3} \mathrm{C}_{3}{ }^{3}=$ Const. $=\mathrm{B}$ (Bruch) sein.

$$
\begin{aligned}
& \text { Hieraus folgt } C_{1}=\frac{B}{A} ; C_{2}^{2}=\frac{B}{A^{2}} \text { oder } \\
& C_{2}=\frac{1 \bar{B}}{A} \text { und } C_{3}=\frac{\sqrt[3]{B}}{A} \text { oder } \\
& C_{1}: C_{2}: C_{3}=B: / \bar{B}: i^{3} \bar{B} .
\end{aligned}
$$

Diese Gleichung ist aber nur annähernd richtig, denn die Constanten $\mathrm{A}$ werden nicht in allen 3 Fällen genau dieselben sein. Ausserdem haben wir angenommen, dass zwei zweiwerthige Ionen die gleiche Ladung haben wie ein dreiwerthiges oder drei einwerthige. Das ist jedoch nicht streng richtig und es wäre genauer, zu sagen 
${ }^{3} / 2$ zweiwerthige Ionen besitzen dieselbe Ladung wie ein dreiwerthiges oder drei einwerthige. Mit dieser Verbesserung lautet die Gleichung

$$
\mathrm{C}_{1}: \mathrm{C}_{2}: \mathrm{C}_{3}=\mathrm{B}: 1^{3} \mathrm{~B}::^{3} 1^{3} \mathrm{~B}
$$

in welcher also $C_{1}$, die für ein dreiwerthiges lon, $C_{2}$ die für ${ }^{3} / 2$ zweiwerthigen Ionen and $\mathrm{C}_{3}$ die für drei einwerthige Ionen erforderliche Concentration bedeutet.

Untersuchen wir jetzt, ob dieser Ausdruck der Wirklichkeit entspricht! Nach übereinstimmenden Versuchsergebnissen von Schulze, Prost, Picton und Linder und von $\mathrm{H}$ ardy gilt die Gleichung $R_{1}: R_{2}: R_{3}=1: 30: 1650$. Hierin bedeuten $R_{1}$, das Coagulationsvermöge ı dos 1-, 2- und 3-werthigen Metallions.

$\mathrm{Da}$ das Coagulationsvermögen der zur Coagulation erforderlichen Menge proportional ist, so gilt auch: $\mathrm{C}_{1}: \mathrm{C}_{2}: \mathrm{C}_{3}=1: 30: 1650$.

Setzen wir $\mathrm{C}_{1}: \mathrm{C}_{3}=1: 1650$ als feststehend, was wird dann nach der oben

abgeleiteten Formel der Werth für $\mathrm{C}_{2}$ sein? Es war $\mathrm{B}: \mathrm{i}^{3} \mathrm{~B}=1: 1650$.

Hieraus ergiebt sich die $\log$ arithmische Gleichung: $\log \mathrm{B}-{ }^{1} / 3 \log \mathrm{B}=-\log 1650$, also ${ }^{2 / 3} \log \mathrm{B}=-\log 1650$, und aus dieser $\mathrm{B}=0,0,0001492$.

Man findet dann weiter $\mathrm{B}: \mathrm{l}^{\mathrm{2}} \mathrm{B}=1: 40,6$.

Demnach erhalten wir $\mathrm{C}_{1}: \mathrm{C}_{2}: \mathrm{C}_{3}=1: \mathbf{4 0 , 6}: 1650$ was von der empirisclien Gleichung $\mathrm{C}_{1}: \mathrm{C}_{2}: \mathrm{C}_{3}=1: 30: 1650$ _nur wenig abweicht.

Indessen hat $\mathrm{Hardy}$ in einer zweiten Abhandlung [20] nachgewiesen, dass im Allgemeinen nicht nur die positiven Metallionen, bezw. deren Valenzen das coagulative Vermögen des Salzes bedingen, sondern auch die negativen Säureionen, deren quantitative Thätigkeit ebenfalls von der Valenz abhängt. Welches der beiden Ionen, das positive oder das negative, das Uebergewicht hat, hängt davon ab, welches Zeichen das Colloidpartikel besitzt. Ist es negativ elektrisch, so ist es das positive Metallion des Salzes, ist das Colloidpartikel positiv, so ist es das negative Säureion des Salzes, das die Coagulation bedingt.

Ich finde bei Hardy folgende Beispiele:

a) Kieselsïure (negativ) ${ }^{1}$ )

wird coagulirt:

sofort durch: nach 10 Min. durch: nach 24 Std. durch:

$\begin{array}{rr}\mathrm{Al}_{2}\left(\mathrm{SO}_{4}\right)_{2}\left[\mathrm{Al}^{\cdots}\right] & \mathrm{K}_{2} \mathrm{SO}_{4}\left[\mathrm{~K}^{*}\right] \\ \mathrm{CuCl}_{2}\left[\mathrm{Cu} \cdot{ }^{*}\right] & \mathrm{Na}_{2} \mathrm{SO}_{4}\left[\mathrm{Na}^{*}\right] \\ \mathrm{Cd}\left(\mathrm{NO}_{3}\right)_{2}\left[\mathrm{Cd}{ }^{* *}\right] & \\ \mathrm{BaCl}_{2}\left[\mathrm{Ba}^{*}\right] & \end{array}$

1) Unter "Kieselsäure (negativ)“ ist zu verstehen, dass die in der Flüssigkeit vorhandenen Kieselsäuretheilchen elektronegativ sind. Die sie umgebende Flüssigkeit ist dann positiv. 
Wie ersichtlich sind es hier die positiven Metallionen, die die negative Kieselsäure zur Ausflockung bringen. Dies geht insbesondere daraus hervor, dass das dreiwerthige Kation viel kräftiger wirkt als das zweiwerthige, obgleich die coagulirenden Lösungen alle äquimolecular waren, nämlich 0,00833 Mol enthielten, und bei derselben Temperatur einwirkten.

Dagegen

b) Eisenoxyd (positiv)

wird coagulirt:

$\begin{array}{cr}\text { sofort durch } & \text { nicht durch } \\ \mathrm{Al}_{2}\left(\mathrm{SO}_{4}\right)_{3}\left[\mathrm{SO}_{4}{ }^{\prime \prime}\right] & \mathrm{CuCl}_{2}\left[\mathrm{Cl}^{\prime}\right] \\ \mathrm{CuSO}_{4}\left[\mathrm{SO}_{4}{ }^{\prime \prime}\right] & \mathrm{Cd}\left(\mathrm{NO}_{3}\right)_{2}\left[\mathrm{NO}_{3}{ }^{\prime}\right] \\ \mathrm{K}_{2} \mathrm{SO}_{4}\left[\mathrm{SO}_{4}{ }^{\prime \prime}\right] & \mathrm{BaCl}_{2}\left[\mathrm{Cl}^{\prime}\right] \\ \mathrm{Na}_{2} \mathrm{SO}_{4}\left[\mathrm{SO}_{4}{ }^{\prime \prime}\right] & \mathrm{NaCl}\left[\mathrm{Cl}^{\prime}\right]\end{array}$

Man erkennt deutlich, dass es hier die negativen Säureionen (Anionen) sind, die die Coagulation bedingen, denn es stellt sich heraus, dass in der ersten Reihe ebensowenig wie in der zweiten Reihe die Werthigkeit des Metalls irgend einen Einfluss ausübt. Dagegen zeigt sich, dass dies mit dem Anion sehr wohl der Fall ist: $\mathrm{SO}_{4}$ " führt unmittelbar Coagulation herbei, $\mathrm{Cl}^{\prime}$ und $\mathrm{NO}_{3}{ }^{\prime}$ sind wirkungslos. Alle Lösungen waren äquimolecular, und zwar enthielten sie 0,01 Mol.

Mancher Leser wird bei obigen Ausführungen einer fundamentalen Schwierigkeit begegnet sein. Wie sich Hardy vorstellt, müssen die elektrisch geladenen Colloidtheilchen entladen werden, damit sie ausgeflockt werden können. Diese Entladung kann nicht nur durch den galvanischen Strom, sondern auch durch Ionen geschehen.

Nehmen wir das ebengenannte Beispiel, dass $\mathrm{K}_{2} \mathrm{SO}_{4}$ durch seine $\mathrm{K}$-Ionen die negative Kieselsäure zur Coagulation brachte. Nan wird nun die Frage erheben können: Waren denn nicht gleichzeitig negative $\mathrm{SO}_{4}{ }^{\prime \prime}$-Ionen und zwar in äquivalenter Menge vorhanden? In dieser Frage kann ein zuerst von Nernst ausgesprochenes Prinzip Aufklärung geben [21]. Es ist hierzu nöthig, sich das Hydrosol als ein zweiphasiges System vorzustellen, und zwar als feine Partikel, die in einer Flüssigkeit suspendirt sind. Nach Nernst vertheilen sich, ebenso wie das bei Molekülen stattfindet, auch die Ionen in einem zweiphasigen System über beide Phasen. In unserem Beispiel vertheilen sich also die $\mathrm{K}$-Ionen über die Colloidtheilchen und das Wasser. Wie viel sich in den Colloidtheilchen anlıäuft und wie viel im Wasser, das hängt von der Löslich- 
keit des K-Ions in beiden Medien ab (Theilungsprincip). Aber nicht nur die K-Ionen vertheilen sich über die beiden Phasen, auch mit den $\mathrm{SO}_{4}$ "-Ionen geschieht das Gleiche. Es ist jedoch nicht zu erwarten, dass das Verhältniss oder - genauer ausgedrückt - der Theilungscoefficient hier genau derselbe sein wird. Lösen sich nun relativ mehr $\mathrm{K}$-Ionen als $\mathrm{SO}_{4}$ "-Ionen in den negativen Kieselsäuretheilchen, so nimmt die elektrische Ladung dieser Theilchen ab und die Bedingung zur Gelbildung ist gegeben. Es liegt nun weiter nichts Gezwungenes darin, anzunehmen, dass bei der Theilung sich mehr elektropositive $\mathrm{K}$-Ionen in den negativen Kieselsäuretheilchen anhäufen werden als im positiven Wasser. Dementsprechend ist es auch verständlich, dass bei positiver Ladung der festen Theilchen, wie im Beispiel des colloidalen Eisenoxydes, diese bei der Vertheilung die meisten negativen $\mathrm{SO}_{4}$ "-Ionen an sich ziehen werden.

Man begreift hiernach, warum nach $\mathrm{H}$ ardy's Befund, die elektronegativen Hydrosole gerade hauptsächlich durch positive Ionen und die elektropositiven durch negative beeinflusst werden.

Auch kann es jetzt nicht befremden, dass die Salzlösung, welche im Stande ist eine Eiweisslösung, die z. B. alkalisch auf Lackmus reagirte, auszuflocken, dazu nicht im Stande ist, wenn man die Lösung sauer gemacht hat. Nach den Ausführungen von Hardy haben ja die Eiweisspartikel durch die Hinzufügung von Säure eine entgegengesetzte Ladung erhalten.

Ein Beispiel mag dies erläutern.

a) Die Eiweisspartikel des Hydrosols sind positiv.

Es fand dann Coagulation statt s o f ort durch:

$\begin{array}{llll}\mathrm{Al}_{2}\left(\mathrm{SO}_{4}\right)_{3} & {\left[\mathrm{SO}_{4}{ }^{\prime \prime}\right]} & \mathrm{Cu} \mathrm{Cl}_{2} & {\left[\mathrm{Cl}^{\prime}\right]} \\ \mathrm{Cu} \mathrm{SO} \mathrm{H}_{4} & {\left[\mathrm{SO}_{4}{ }^{\prime \prime}\right]} & \mathrm{Cd}\left(\mathrm{NO}_{3}\right)_{2} & {\left[\mathrm{NO}_{3}{ }^{\prime}\right]} \\ \mathrm{K}_{2} \mathrm{SO}_{4} & {\left[\mathrm{SO}_{4}{ }^{\prime}\right]} & \mathrm{Ba} \mathrm{Cl} & {\left[\mathrm{Cl}^{\prime}\right]} \\ \mathrm{Na}_{2} \mathrm{SO}_{4} & {\left[\mathrm{SO}_{4}{ }^{\prime}\right]} & \mathrm{NaCl} & {\left[\mathrm{Cl}{ }^{\prime}\right]}\end{array}$

Man sieht hier deutlich: dass die negativen Anionen es sind, die die Coagulation bedingen. Die zweiwerthigen wirken viel kräftiger als die einwerthigen. Letztere waren offenbar nicht in genügender Concentration vorhanden.

b) Die Eiweisspartikel des Hydrosols sind negativ.

Es fand Coagulation statt $\mathrm{s}$ of ort durch:

$\begin{array}{llll}\mathrm{Al}_{2}\left(\mathrm{SO}_{4}\right)_{3} & {[\mathrm{Al} \cdots]} & \mathrm{Na}_{2} \mathrm{SO}_{4} & {[\mathrm{Na} \cdot]} \\ \mathrm{Cd}\left(\mathrm{NO}_{3}\right) & {[\mathrm{Cd} \cdot \cdot]} & \mathrm{K}_{2} \mathrm{SO}_{4} & {[\mathrm{~K} \cdot]} \\ \mathrm{Cu} \mathrm{SO} \mathrm{SO}_{4} & {[\mathrm{Cu} \cdot \cdot]} & \mathrm{Na} \mathrm{Cl} & {[\mathrm{Na} \cdot]} \\ \mathrm{Cu} \mathrm{Cl}{ }_{2} & {[\mathrm{Cu} \cdot \cdot]} & & \end{array}$


Hier sind es offenbar die positiven Metallionen, die den massgebenden Einfluss auf die Coagulation ausüben.

Dass Eiweiss hier zuweilen sauren, zuweilen auch alkalischen Charakter zeigt, kann nach den Versuchen von Spiro und Pemsel [22] nicht Wunder nehmen. Auch Bredig hat auf die amphotere Natur desselben hingewiesen [23]. ${ }^{1}$ )

Noch eine andere Aufklärung wird dem Leser willkommen sein. Sie betrifft das Wesen des Ausflockungsprocesses und stammt von Bredig her. Hierfür sei auf die Theorie des Capillarelektrometers erinnert, dessen Beschreibung man übrigens auf S. 357 des zweiten Bandes findet.

Auf der Grenze zwischen Quecksilbermeniscus und Schwefelsäure befindet sich bei dem genannten Instrument eine elektrische Doppelschicht, bestehend aus positiven Ionen an der Quecksilberseite und negativen auf der Seite der Schwefelsäure. Diese Potentialdifferenz beeinflusst die Form des Meniscus. Dies geht unmittelbar daraus hervor, dass geringe elektromotorische Kräfte, die hinzugebracht werden, die Stellung des Meniscus ändern, was wieder darauf zurückgeführt werden muss, dass zu jeder Stelle im conischen Capillarrohr eine bestimmte Meniscusform passt.

Wie hat man sich nun den Mechanismus dieser Formveränderung $\mathrm{zu}$ denken?

Abgesehen vom Bestehen einer elektrischen Doppelschicht, herrscht auf der Grenze zwischen Quecksilber und einer wässerigen Flüssigkeit eine Oberflächenspannung, d. h. eine Tendenz die gemeinschaftliche Oberfläche zu verkleinern ${ }^{2}$ ).

1) Vergl. über die Bedeutung des Theilungsprincips bei der Ausflockung von Colloiden auch eine Arbeit von Spiro in Hofmeister's Beiträgen z. chem. Physiol. u. Pathol. 4. 1903. S. 300. Ich kann dieselbe hier nicht mehr berücksichtigen. Derselbe Aufsatz enthält auch Untersuchungen über die Einwirkung verschiedener Alkohole und alkoholischer Salzlösungen auf die Eiweissfällung (vergl. Fussnote S. 89).

2) Man erkennt die Oberfächespannung z. B. bei folgendem Versuch. Man nimmt einen viereckigen Rahmen von Metalldraht und bringt ihn in eine Seifenlösung. Nach dem Herausheben ist der Kahmen ganz mit einer Seifenhaut gefüllt. Weiter denke man sich in der Mitte einer der vier Seiten des Rahmens einen Seidenfaden befestigt und legt diesen derart auf die Seifenhaut, dass der Faden über die angrenzende Seite des Rahmens zu liegen kommt. Das Ende des Fadens hängt vertikal ab, indem ein kleines Gewicht daran befestigt ist. Jetzt wird die Seifenhaut an einer beliebigen Stelle, innerhalb der Fadenbegrenzung, durchgestossen, wodurch die Schicht auf der Innenseite des Fadens ganz verschwindet. Vergrössert man jetzt die Belastung des Fadenendes, so senkt sich dasselbe und diese Senkung geht einher mit einer Vergrösserung der Seifen oberfläche. Mit jeder weiteren Gewichts- 
Im entgegengesetzten Sinne wirkt die soeben genannte elektrische Ladung des Quecksilbers. Da gleich geladene Ionen einander abstossen, so werden die an der Meniscusoberfläche gelegenen und positiv geladenen Quecksilberionen einander abstossen und so die Oberfläche des Quecksilbers zu vergrössern versuchen.

Führt man nun dem Quecksilber mittelst eines elektrischen Stromes eine negative Ladung $\mathrm{zl}$, so verringert sich seine eigene positive Ladung ${ }^{1}$ ). Sofort macht sich die Oberflächenspannung des Quecksilbers relativ stärker geltend; dem zufolge nimmt der Quecksilbermeniscus eine kleinere Oberfläche ein, womit eine Stellungsveränderung im Capillarrohr einhergeht.

Wird die positive Ladung der Quecksilbermeniscusoberfläche durch die hinzugebrachte negative Ladung gerade aufgehoben, so erreicht die Oberfläche ihre geringste Grösse. Denn durch weitere Ladung des Quecksilbers mit negativer Elektricität, wird die betreffende Meniscusoberfläche negativ geladen, die Lösung wird positir. Da an der betreffenden Seite durch den Strom auch eine entsprechende Nenge positiver Elektricität zugeführt wurde, hatte sich wieder auf's Neue eine Doppelschicht, aber mit umgekehrten Zeichen gebildet. Was hier insbesondere wichtig ist, ist, dass nunmehr die negativen Quecksilberionen versuchen die Oberfläche zu vergrössern und der Oberflächenspannung entgegenzuarbeiten.

Mit diesem Lippmann'schen capillarelektrischen Phänomen hat Bredig die Vorgänge in colloidalen Lösungen verglichen.

vermehrung und entsprechender Senkung des Gewichtes, nimmt die Grösse der Oberfläche zu. Hieraus gelıt hervor, dass zur Vergrösserung der Oberfläche der Seifenlösung Arbeit verwendet werden muss. Man kann dieselbe sogar berechnen. Hat man die Senkung h des Gewichtes beobachtet, so ist die durch die Gewichtsvermehrung $\mathrm{p}$ verrichtete Arbeit $\mathrm{ph}$. Hat man auch die dadurch herbeigeführte Flächenausdehnung der Seifenschicht gemessen, so kann man leicht berechnen, wie viel Arbeit man braucht, um die Schicht um eine Oberflächen-Einheit zu vergrössern.

Vermindert man das Gewicht, so verkleinert sich die Oberfläche wieder und das übriggebliebene Gewicht steigt.

Aus diesem Versuch erkennt man deutlich die Neigung einer Oberfläche sich zu verkleinern.

Aehnliches findet man auch, wenn man zwei verschiedene, wenig mischbare Flüssigkeiten auf einander schichtet. Aber dann kann es sich auch ereignen, dass dadurch die Neigung zu einer Vergrüsserung der gemeinschaftlichen Oberfläche statt zu einer Verkleinerung entsteht. Es kann dann eine Emulsion auftreten.

1) Ebenso auch die negative der Schwefelsäure um einen entsprechenden Betrag, da der Schwefelsäure positive Elektricität durch den Stromkreis hinzugeführt wird. 
Ist im Lippmannschen Phänomen die Quecksilberoberfläche am kleinsten, wenn durch Entladung dieser Obertläche die Elektricität weggenommen ist, so kann dasselbe auch in den Hydrosolen angenommen werden. Auch hier wird angenommen, dass das Colloidpartikel von Flüssigkeit umgeben ist und dass auf der Grenze eine elektrische Doppelschicht besteht. Neutralisiert man nun die elektrische Ladung der Colloidtheilchen, so werden sie ihre Oberfläche, d. h. ihre Berührungsfläche mit der Flüssigkeit zu verkleinern suchen, was auf die Bildung komplexer Theilchen, und schliesslich, wenn keine elektrische Ladung mehr entgegenwirkt, auf eine Ausflockung hinausläuft.

Wiederum drängt sich hier die Vorstellung auf, dass vor der Ausflockung eine allmähliche Grössenzunahme der Komplexen stattfindet, wenn dieselbe auch unter dem Mikroskope, jedenfalls im Anfangsstadium, nicht sichtbar ist. Der Fortfall der elektrischen Ladung entspricht Hardys „isoelektrischem" Punkt (vergl. oben S. 68).

Immerhin scheint aber die Deutung aller über die Ausflockung bekannten Erscheinungen noch nicht sichergestellt.

So haben Pauli und Rona ausgeführt [24], dass Nichtleiter eine hemmende Wirkung auf die Fällung der Colloide durch Elektrolyte ausiiben.

Vielleicht handelt es sich hier aber einfach nur um eine Herabsetzung der Leitfähigkeit der Elektrolyte durch Nichtleiter. Das wäre quantitativ zu untersuchen. Ebenso auch, ob die durch Alkohol herbeigeführte Fällung von Eiweiss vielleicht ebenfalls auf eine Zurückdrängung der Dissociation der das Eiweiss in Lösung haltenden Säure oder des Alkalis beruht.

Pauli glaubt den allgemeinen Satz aufstellen zu dürfen, dass die eiweissfällende Wiikung von Elektrolyten additiver Natur ist. Die Kationen wirken fördernd, die Anionen hemmend. Ob also ein Salzgemisch Fällungsverınögen besitzen wird und von welcher Grösse dieses eventuell sein wird, hängt von der algebraischen Summe der Fällungswerthe der betreffenden Kationen und der Hemmungswerthe der betreffenden Anionen ab [25].

Ich muss hierzu bemerken, dass Pauli die Richtigkeit dieses Salzes an den vielfachen Versuchsresultaten von $\mathrm{Hardy}$, von Picton und Linder und anderen über die Fällung von Colloide nicht geprüft hat. Es berührt dieses Thema ebensowenig, wie Hardy's Erklärung der Erscheinungen.

Nit Nachdruck laben $\mathrm{Pa}$ uli und Rona hervorgehoben, dass man die Fällung von Colloiden, namentlich der Gelatine, von der Gelatinirung (Erstarrung) unterscheiden muss. Beide Processe werden in verschiedener Weise durch Elektrolyte und Nicht-Elektrolyte beeinflusst.

In der letzten Zeit sind noch andere Thatsachen ans Licht getreten, die den Vorstellungen von $\mathrm{Hardy}$ und Bredig Schwierigkeiten bereiten. Freundlich [27] hat darauf hingewiesen, dass die Schnellig- 
keit, mit der die Salzlösung zum Sol zugesetzt wird, von grossem Einfluss auf die Fällungswerthe ist, m. a. W. die Menge der Salzlösung, welche zu dem Sol hinzugefügt werden muss um dieses auszuflocken, hängt auch von der Schnelligkeit ab, mit der das geschieht.

Hierzu bemerkt dann Freundliclı, dass diese Versuche sich nicht deuten lassen, wenn man annimmt, dass es auf das Vertheilungsgleichgewicht der Ionen oder ïberhaupt auf Gleichgewichtsverhältnisse ankommt; denn diese hängen bloss von der Concentration ab, und letztere ist doch nach raschem Zusatz des Elektrolyten ebenso gross wie nach langsamem. Es handelt sich hier also um einen Vorgang, bei dem der zeitliche Abla uf eine wesentliche Rolle spielt. Hier denkt Freundlich z. B. an eine Diffussion von Ionen in die Colloidtheilchen, die nicht in allen Fällen mit gleich grosser Geschwindigkeit vor sich geht.

Andere Einwände sind von Billitzer [28] erhoben worden. Diesem Verfasser gelang es eine Methode ausfindig zu machen, die Potentialdifferenz zwischen Colloidtheilchen und Lösung zu messen und also auch die Aenderung, welche die Potentialdifferenz beim Zusatz von Elektrolyten erfährt. Mit Hilfe dieses Verfahrens fand er, dass nicht selten eine Fällung durch Elektrolyte herbeigeführt wird, ohne dass eine Aenderung der Potentialdifferenz auftritt.

Doch nimmt Billitzer auf Grund von directen Messungen an, dass in Colloidlösungen die Colloidtheilchen elektrisch geladen sind; er hält aber die Annahme einer elektrischen Doppelschicht im Sinne von Helmholtz-Quincke für überflüssig. Der Verfasser stellt sich auf den Standpunkt ron Nernst's osmotischer Theorie der Stromerzeugung und glaubt, dass die Colloidtheilchen Ionen in die Flüssigkeit aussenden (elektrolytischer Lösungsdruck oder Dissociationsdruck). Werfen sie positive Ionen in die Flüssigkeit, so wird diese positiv geladen und die Theilchen selbst werden negativ (vergl. B. II S. 333). Auf diese Weise entsteht dann eine Potentialdifferenz. Ich folge dem Autor in seinen weiteren Ausführungen, wo er von diesem Standpunkt versucht, die Ausflockung durch Elektrolyte zu erklären, nicht. Ich erwähne nur, dass Billitzer genöthigt ist, dazu eine Hilfshypothese heranzuziehen. Ob jedoch alle bekannt gewordenen Thatsachen betreffs der Colloide zu seiner Vorstellung passen, ist nocl fraglich. Mich kann sie allerdings nicht ganz befriedigen. Damit will ich nicht aussagen, dass dies mit der Vorstellung von Hardy woll der Fall ist. So scheint mir bei ihm Folgendes nicht recht deutlich. Setzt man zu einem alkalischen Eiweisssol so viel Salzsäure hinzu, dass Colloidtheilchen und Flüssigkeit isoelektrisch werden, d. h. ihre Potentialdifferenz verlieren, so flockt es aus. Durch 
ein geringes Uebermaass löst sich das Eiweiss wieder, weil die $\mathrm{H}^{-}$-Ionen der $\mathrm{HCl}$ den Eiweisstheilchen neue positive Elektricität ertheilen und die $\mathrm{Cl}^{\prime}$-Ionen der die Eiweisstheilchen umgebende Flïssigkeit, negative. Es entsteht also wieder eine Potentialdifferenz und die Bedingung für den Uebergang in den Solzustand ist wieder vorhanden (Vergl. S. 67). Ich möchte nun aber fragen, warum sieht man diesen Uebergang dann auch nicht, wenn man Salze zu der Ausflockung angewandt hat? In diesem Falle führt doch ein Uebermaass keinen Uebergang zu dem Solzustand herbei.

Ueberhaupt scheint es mir ein Mangel in den Ausführungen Hardy's, dass er die Art und Weise, in welcher die elektrische Ladung die Beständigkeit der Sole bedingt, nicht näher definiert hat. Das hat dann Bredig übernommen, aber Bredigs Vorstellung bereitet Schwierigkeiten, wo es darauf ankommt, die allgemein anerkannte grosse Bedeutung der Werthigkeit von Kationen und Anionen bei der zur Ausflockung erforderlichen Mengen zu erklären.

Man sieht das letzte Wort in dieser Materie ist noch keineswegs gesprochen und der Biologe sieht mit grossem Interesse der weiteren Entwicklung der Ansichten über das Wesen der Zustandänderungen der Colloide entgegen.

Bei allem Zweifel, der hierüber noch bestehen mag, möchte ich aber Folgendes mit Nachdruck hervorheben:

1. Es kann als festgestellt angesehen werden, dass es sich beim Uebergang von Sol in Gel (dazu gehört auch der Zustand von Ausflockung) unter dem Einfluss von Elektrolyten um einen continuirli chen Process handelt, bei welchem die Conglomerate von Colloidtheilen stets grösser werden.

2. Diese Thatsache auf das lebende Protoplasma übertragen, sagt aus, dass unter Einwirkung geringer Mengen von Elektrolyten die Conglomeration der Protoplasmatheilchen Modificationen erfahren wird und damit die Viscosität, Beweglichkeit, in einem Wort gewisse Lebenseigenschaften beeinflusst werden muss. Einen schönen Hinweis in dieser Richtung geben bereits die Fxperimente von J. Loeb.

Die weitere Frage, auf welche Weise die Elektrolyte diese Aenderung in der Conglomeration bewirken, werden weitere Forschungen noch aufklären müssen. 


\section{Metallische Colloide.}

Wir betreten hier ein noch nicht besprochenes Gebiet der Colloide, namentlich die Colloide als Fermente.

Ptyalin, Pepsin, Trypsin sind eiweissartige Stoffe, die als Enzyme (Fermente) wirksam sind. Fermentwirkungen spielen im Leben eine äusserst wichtige Rolle.

Die im Thierkörper mit erstaunlicher Geschwindigkeit stattfindenden Umsetzungen für die im Laboratorium, soweit sie z. Z. daselbst ausführbar sind, so hohe Temperaturen und Einwirkung von so kräftigen Reagentien wie von starken Säuren und Alkalien erforderlich sind, dass deren Thätigkeit das Leben in kürzester Zeit zerstören würde, kommen im Organismus bei $37^{\circ} \mathrm{C}$. und bei fast neutraler Reaction durch Fermentwirkung zu Stande. Die Fermentwirkungen sind katalytischer Natur.

Der Name „Katalyse" rührt von Berzelius her. Nach dem berühmten schwedischen Chemiker handelt es sich bei ihr um eine Kraft, durch die ein Körper lediglich durch seine Gegenwart Reactionen auslöst, die sonst nicht stattfinden können.

Nach Berzelius ist es insbesondere Schönbein gewesen, der sich mit dem Problem der Katalyse beschäftigt hat. Eine besondere Aufmerksamkeit widmete er der Zersetzung von Wasserstoffsuperoxyd $\left(\mathrm{H}_{2} \mathrm{O}_{2}\right)$ durch Platinmohr. Spuren Platinschwarz waren im Stande grosse Mengen $\mathrm{H}_{2} \mathrm{O}_{2}$ zu zersetzen; das Platinmohr selbst erfuhr dabei keine merkbare Veränderung. Platinmohr wirkte hier als Katalysator. Aber nicht nur Platinmohr war im Stande $\mathrm{H}_{2} \mathrm{O}_{2}$ zu katalysiren, auch Spuren einer Anzahl eiweissartiger (Colloid-) Stoffe.

Der Physiologe Carl Ludwig war nach dieser Untersuchung dermassen von der grossen Bedeutung der katalytischen Wirkung durchdrungen, dass er in seinem Lehrbuch [29] schrieb: ., es dïrfte leicht dahin kommen, dass die physiologische Chemie ein Theil der katalytischen würde."

Es mag befremden, dass trotz dieser Aeusserung seitens einer so grossen Autorität, Jahrzehnte vorïbergegangen sind, olıne dass die Biologen dem Studium der Katalyse ihre Aufmerksamkeit widmeten. In Wahrheit lag das an der Definition, die durch Ostwald dahin modificirt wurde, dass nach ihm die Katalyse nicht eine Wirkung ist, welche ohne Katalysator nicht zu Stande kommt, sondern eine solche, die durch den Katalysator beschleunigt (zuweilen auch verzögert) wird [30]. 
Ein deutliches Beispiel besitzt man in der altbekannten Sauerstoffbereitung aus $\mathrm{KClO}_{3}$. Um aus dem reinen Salz das Gas zu bereiten, muss man eine sehr hohe Temperatur anwenden. Setzt man aber etwas $\mathrm{MnO}_{2}$ hinzu, so verläuft die 7ersetzung des $\mathrm{KClO}_{3}$ ganz regelmässig bei relativ niedriger Temperatur. Das $\mathrm{MnO}_{2}$ selbst wird nicht zersetzt; es wirkt als Katalysator.

Durch diese Auffassung der Katalyse erwuchs wie ron selbst die Aufgabe, den katalytischen Process messend zu verfolgen. So erhebt sich unmittelbar die Frage: in welchem Masse wird die Reaction durch die katalysirende Substanz beschleunigt, welchen Einfluss iibt die Menge des Katalysators, die Temperatur, die Anwesenheit anderer Substanzen aus. Es braucht kaum herrorgehoben zu werden, dass man nur auf Grund solcher Messungen, über den Reactionsverlauf und schliesslich über das Wesen der Katalyse sich ein Urteil bilden kann.

In dieser Richtung haben dann in $\mathrm{Os}$ twalds Laboratorium Bredig und Müller von Berneck[31] das Studium der Katalyse auf's Neue zur Hand genommen. Als Versuchsobject wählten sie die Katalyse von $\mathrm{H}_{2} \mathrm{O}_{2}$ durch Platin, welche Schönbein bereits „das Urbild aller Gährungen“" genannt hatte. Das Platinmohr war zu ihren Zwecken wenig geeignet, weil dasselbe schwer zu vertheilen ist. Empfehlenswerther erschien den Autoren das Metall in colloidalem Zustand.

Colloidale Metalllösungen sind schon lange bekannt. Bereits 1889 wurde das colloidale Silber von dem amerikanischen Chemiker Carey Lea [32] entdeckt und durch Reduction von Metallsalz bereitet. Nach demselben Princip wird auch jetzt noch das Argentum colloidale von Credé hergestellt.

$$
3 \mathrm{Ag} \mathrm{NO} \mathrm{N}_{3}+3 \mathrm{FeSO}_{4}=3 \mathrm{Ag}+\mathrm{Fe}\left(\mathrm{NO}_{3}\right)_{3}+\mathrm{Fe}_{2}\left(\mathrm{SO}_{4}\right)_{3} .
$$

Wie aus der Gleichung ersichtlich ist, wirkt das $\mathrm{Fe} \mathrm{SO}_{*}$ reducirend und es scheidet sich Silber ab. Dasselbe bildet einen schwarzen Niederschlag. Dieser wird, nachdem er sich abgesetzt hat und die überstehende Flüssigkeit abgehebert worden ist, mittelst eines porösen Thonfilters abgesaugt und endlich über $\mathrm{H}_{2} \mathrm{SO}_{4}$ in Vacuum getrocknet. In diesem Zustande stellt das colloidale Ag schwarze metallglänzende Stücke dar, welche mit Wasser eine tiefbraune Flüssigkeit geben, die schon bei sehr starker Verdünnung undurchsichtig ist.

In ähnlicher Weise kann auch colloidales Quecksilber bereitet werden, indem man z. B. auf Quecksilberoxydnitrat in der Kälte Zinnoxyduhnitrat einwirken lässt. (Lottermoser [33].

Bredig [3 u. 31] hat eine andere und einfachere Nethode zur Bereitung von colloidalen Metalllösungen entdeckt, die auch eine grössere Reinheit garantirt. Mit diesen Lösungen haben der Autor und seine Mitarbeiter eine Reihe interessanter Untersuchungen ausgeführt. Zunächst theile ich Einiges über die Bereitungsweise mit. 


\section{a) Herstellung von Metallsolen durch elektrische Zerstäubung.}

Zur Herstellung einer colloidalen Gold lösung benutzt man folgende Versuchsanordnung:

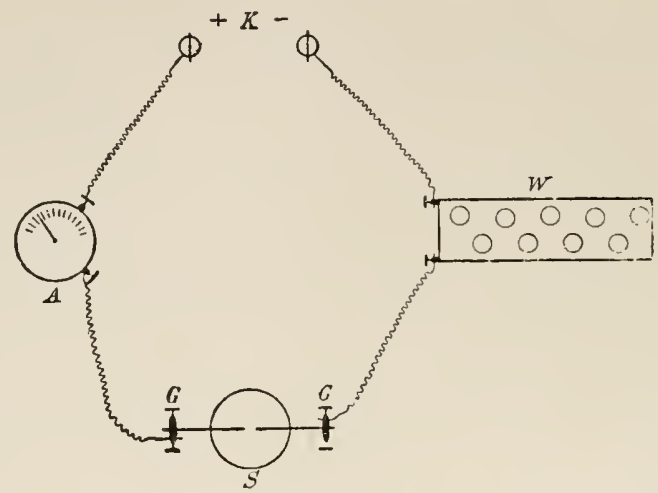

Fig. 1.

${ }_{n}$ An die Klemmen der Lichtleitung $K$ (110 Volt Gleichstrom) schaltet man hintereinander (Fig. 1) das Ampèremeter (A), einen Regulierwiderstand (W), der bei 110 Volt Klemmenspannung 4-12 Ampère giebt (Lampenbatterie oder Flüssigkeitswiderstand) und zwei Elektroden G, welche aus je einen etwa $1 \mathrm{mim}$ dicken und $6-8 \mathrm{~cm}$ langen Golddraht bestehen. Der eine Golddraht ist aurch ein enges Glasrohr (Fig. 2) gesteckt, damit man die Elektroden mit den Händen isolirt anfassen kann.

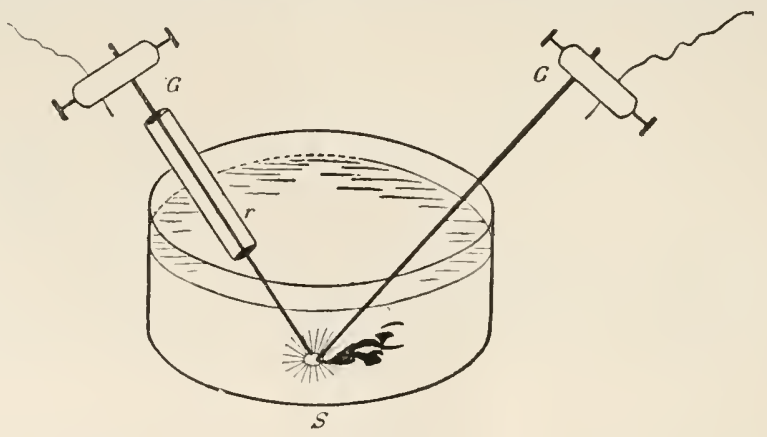

Fig. 2.

Der Regulirwiderstand wird so lange verstellt, bis man bei Kurzschluss und vorsichtigem Auseinanderziehen der Elektroden unter Wasser, wobei ein kleiner, etwa $1 \mathrm{~mm}$ langer Lichtbogen entsteht, ungefähr die gewünschte Stromstärke hat. Nunmehr schreitet man zum eigentlichen Versuch: Eine aussen mit Eis gekühlte Glasschale S. von ca. 50-100 cc Inhalt wird mit sehr reinem, kohlensäurefreiem, destillirtem Wasser von der specifischen Leitfähigkeit 2 bis $3 \times 10^{-6}$ gefüllt. Alsdann bringt man die mit den Händen gefassten Goldelektroden bei der obigen Schaltung 
in die in Fig. 2 dargestellte Lage, stellt zwischen ihren Spitzen $1-2 \mathrm{~cm}$ unterhalb des Wasserspiegels Kurzschluss her und entfernt die Spitzen alsdann langsam von einander um etwa 1 bis $2 \mathrm{~mm}$, wobei sich ein kleiner Lichtbogen herstellt. Solange dieser Lichtbogen ruhig zischt, sieht man nun das Gold in blauen oder purpurrothen dunklen Wolken aus der Kathode hervorschiessen und sich theils als Sol, theils als gröbere Theilchen in der umgebenden F'lüssigkeit verbreiten.

Der Bogen erlischt sehr leicht, man macht dann wieder Kurzschluss und wiederholt das Spiel von neuem unter zeitweiligem Umrühren, bis sich das Wasser in der Schale in eine tiefdunkle Flüssigkeit verwandelt hat. Zu starke Erwärmung ist zu vermeiden, auch darf der Versuch mit einer Wasserfüllung nicht zu lange fortgesetzt werden, weil sonst das Goldsol leicht coagulirt.

In reinem Wasser geht bei Gold die Zerstäubung bei einer Stromstärke von 5-7 Amp. mit $1 \mathrm{~mm}$ dicken Drähten ziemlich schlecht, und man erhält fast nur grobe, nicht filtrirbare Suspensionen, bei 10-12 Amp. geht die Zerstäubung besser, und nach Filtration durch Faltenfilter kann man dunkle, blaurothe Filtrate erhalten.

Eine ganz ausserordentliche Verbesserung der Zerstäubung erzielt man beim Golde durch Zusatz einer Spur Alkali (0,001 normal $\mathrm{NaOH})$. Man erhält dann bei einer Stromstärke von 9-10 Amp. unter den obigen Bedingungen eine tiefdunkelrothe colloidale Goldlösung, welche nur wenig grob zerstäubtes Gold auf dem Filter zurücklässt. In den ersten Tagen setzt das Filtrat meist noch etwas metallisches Gold ab, bleibt aber dann ziemlich constant."

Die Farbe des Sols ändert sich je nach der Bereitung in einigen Wochen oder Monaten in blauviolett, bei sorgfältiger Darstellung und besonderer Reinheit des destillierten Wassers aber kann man (auch mit weniger Alkalizusatz) Lösungen bekommen, welche ihre rubinrothe Farbe, wenn auch mit einem Stich in's Blaue, noch nach zwei Jahren besitzen."

Durch besondere Versuche hat Bredig festgestellt, dass bei obigem Verfahren im Wesentlichen nur die Kathode zerstäubt. Behufs Führung dieses Nachweises wurden Anode und Kathode vor und nach einer kurzen Zerstäubung gewogen.

$\begin{array}{ccc}\text { Versuch } 1 \text { Gewichtsänderung der Kathode }-0,079 \mathrm{~g} \\ \text { Versuch } 2 & " \text { " Anode }+0,039 " \\ & " & " \text { Kathode }-0,033 "\end{array}$

Die Herstellung des Platinsols und des Silbersols geschah in gleicher Weise wie die des Goldsols; nur war dabei der Zusatz von Alkali entbehrlich.

Bredig empfiehlt Platindrähte von $2 \mathrm{~mm}$ Durclımesser und eine Stromstärke von 5-6 Ampère anzuwenden. Silberdrähte von $1 \mathrm{~mm}$ Durchmesser zerstäuben bei Stromstärken von 4-8 Amp. (auch ohne Alkalizusatz) in reinem Wasser leicht und unter Entwicklung eines schönen grünen Bogenlichtes zu tiefdunkeln Solen, deren Farbe je nach Umständen dunkel rothbraun bis tief olivgrün ist. Die verdünnten Sole besitzen oft eine gelbe Farbe. 
Ich empfehle, die Elektroden behufs Zerstäubung nicht mit den Händen zu bewegen, wie es Bredig thut, sondern in je eine Klemme zu fassen. Man lässt die eine unbeweglich, während die andere durch eine Schraubenvorrichtung derart verstellbar ist, dass man die unter Wasser sich befindenden Spitzen der Elektroden auf willkürliche Entfernung von einander bringen kann.

Solche Stative mit bewegbarem Gestell besitzen die physiologischen Laboratorien in verschiedener Construction.

\section{b) Katalytische Wirkung der colloidalen Metalle.}

Ton den verschiedenen colloidalen Metallen haben Bredig und seine Mitarbeiter Müller von Berneck [31], Ikeda und W. Reinders [34] insbesondere das colloidale Platin in Beziehung auf seine katalytische Wirkung studirt und sie gelangten hierbei zu sehr interessanten Resultaten.

Es stellte sich heraus, dass Platinhydrosol, gleich vielen organischen Fermenten, die Fähigkeit besitzt, $\mathrm{H}_{2} \mathrm{O}_{2}$ lebhaft zu katalysieren. 1 g-Atom Metall aufgelöst in 70 Millionen Litern Wasser war noch im Stande die $\mathrm{H}_{2} \mathrm{O}_{2}$-Zersetzung, welche auch spontan, aber dann in äusserst schwachem Grad vor sich geht, in merklichem Maasse zu beschleunigen.

Es fragt sich nun, wie sich dabei der Reactionsverlauf gestaltet. Bredig und Müller von Berneck konnten durch das Experiment feststellen, dass es sich bei der Wirkung von Platinsol auf $\mathrm{H}_{2} \mathrm{O}_{2}$ um eine Reaction erster Ordnung (monomoleculare Reaction) handelt. Ich habe bereits früher gelegentlich der Inversion über derartige Reactionen gesprochen. (Vergl Bd. II, S. 494 und 467.)

Ist $\frac{d x}{d t}$ die Reactionsgeschwindigkeit (d. h. hier die in einem äusserst kurzen Zeitintervall, aber auf die Zeiteinheit berechnete, umgesetzte $\mathrm{Menge}_{\mathrm{H}} \mathrm{H}_{2} \mathrm{O}_{2}$ ), so ist diese proportional der im betreffenden Augenblick noch vorhandenen Substanz. Diese ist $(\mathrm{A}-\mathrm{x})$, wenn $\mathrm{A}$ die Anfangsconcentration und $\mathrm{x}$ die Concentration der bereits umgesetzten Menge ist. Weiter hängt die Reactionsgeschwindigkeit von der Temperatur und von anderen Umständen $a b$, die man unter $k$ (Reactions- oder Geschwindigkeits-Constante) zusammen zu fassen pflegt.

Folglich ist $\frac{d x}{d t}=k(A-x)$

Nach Integration wird diese Gleichung.

$$
\mathrm{k}=\frac{1}{\mathrm{t}} \log \frac{\mathrm{A}}{\mathrm{A}-\mathrm{x}} \text {. }
$$

Verfolgt man nun den Reactionsverlauf derart, dass man zu verschiedenen Zeiten $\mathrm{t}$ die umgesetzte Menge $\mathrm{x}$ ermittelt, so kann man $\mathrm{k}$ berechnen. Stellt sich hierbei heraus, dass $\mathrm{k}$ ziemlich konstant bleibt, so darf man mit grosser Wahrscheinlichkeit schliessen, dass die Formel die Reaction richtig angiebt. 
Man kann nun weiter mehrfache Modificationen anbringen. Man kann die Temperatur steigern oder herabsetzen und feststellen, wie sich k ändert. Man kann die Menge des Katalysators und die Concentration der umzuwandelnden Substanz variiren; man kann Umwandlungsprodukte und auch fremde Stoffe hinzufügen etc. Von allen diesen Modificationen muss der Einfluss auf $\mathrm{k}$ ermittelt werden ${ }^{1}$ ).

So fanden Bredig und Mïller von Berneck bei verschiedenen Temperaturen in zwei Versuchsreihen die folgenden Werthe: für $\mathrm{k}$ :

\begin{tabular}{ccc|ccc} 
& bei $25^{\circ}$ & bei $45^{\circ}$ & bei $45^{\circ}$ & bei $65^{\circ}$ & bei $85^{\circ}$ \\
k & 0,0039 & 0,013 & 0,0032 & 0,0085 & 0,024
\end{tabular}

Man sieht in Folge der Temperatursteigerung von $25^{\circ}$ auf $45^{\circ}$ die Geschwindigkeitsconstante schnell zunehmen. Dasselbe beobachtet man im Temperaturintervall $45^{\circ}-85^{\circ}$. Für dieses Intervall ist eine geringere Platinmenge angewendet worden, als für das Intervall $25^{\circ}-45^{\circ}$. Ich mache hierauf aufmerksam, weil das eine Mal bei $45^{\circ} \mathrm{k}=0,013$ und das andere Nal $\mathrm{k}=0,0032$ ist.

So fanden Bredig und Müller von Berneck bei Benutzung verschiedener Platinmengen folgende k-Werthe.

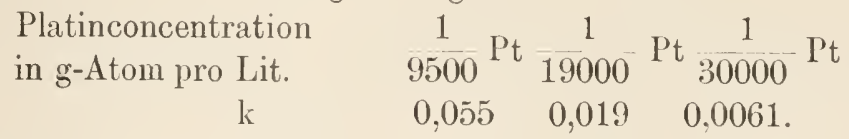

Man sieht, dass die Reactionsconstante bei Abnahme der Platinconcentration kleiner wird.

Die Autoren gelangten ganz allgemein zu dem Resultat, dass bei Verminderung der Concentration des Platins in geometrischer Progression, (z. B. 2:1) die Geschwindigkeitsconstante $\mathrm{k}_{1}$ der $\mathrm{H}_{2} \mathrm{O}_{2}-\mathrm{Kata}_{\text {a }}$ lyse progressiv sinkt ( $3: 1$ ungefähr).

Das lässt sich durch folgende empirische Formel ausdrücken:

$$
\frac{\mathrm{k}_{1}}{\mathrm{k}_{2}}=\left(\begin{array}{l}
\mathrm{C}_{1} \\
\mathrm{C}_{2}^{-}
\end{array}\right)^{\mathrm{b}}
$$

worin $k_{1}$ und $k_{2}$ die Geschwindigkeitsconstanten bei den verschiedenen bezüglichen Platinconcentrationen $\mathrm{C}_{1}$ und $\mathrm{C}_{2}$ bedeuten. $\mathrm{b}$ ist eine Constante, die von der Natur des Platinpräparates abhängt und zwischen 1,6 und 1,3 liegt.

Bei gleicher Platinconcentration haben nicht alle Platinpräparate dieselbe quantitative Wirkung. Das hängt ron ihrer Bereitungsweise, vom Alter, im Allgemeinen von der, ,Vorgeschichte" des Platinpräparates ab. Tan Bem melen hat die Eigenschaft der allmählichen Alteration der Colloide mit dem Namen ,Hysteresis“ bezeichnet [5̃3].

1) Lin gutes Beispiel einer derartigen systematisch durchgeführten Untersuchung findet man auch bei V. Henri [57]; diese bezieht sich auf die Zuckerinversion. 
Höchst interessant sind die Untersuchungen über die $\mathrm{L}$ ähmung (Vergiftung) der katalytischen Wirkung.

Schon Faraday beschreibt die interessante Thatsache, dass ein mit Schwefelwasserstoff oder Schwefelkohlenstoff verunreinigtes Knallgasgemisch durch Platinmetallbleche nicht mehr katalysirt wird (citirt nach Bredig). Ebenso fanden Bredig und Müller von Berneck, dass eine mit Spuren von $\mathrm{H}_{2} \mathrm{~S}$ versetzte Platinflüssigkeit die Fähigkeit verliert, Wasserstoffsuperoxyd zu katalysiren und Guajactinctur zu bläuen.

Es zeigte sich, dass $\mathrm{H}_{2} \mathrm{~S}$ nach einer Verdünnung von $0,000003 \mathrm{Mol}$. $\mathrm{H}_{2} \mathrm{~S}$ pro Liter stark verzögernd auf die Platinkatalyse von $\mathrm{H}_{2} \mathrm{O}_{2}$ wirkt.

Wurde das $\mathrm{H}_{2} \mathrm{~S}$ in schwach alkalischer Lösung angewandt, so machte sich $1 \mathrm{~g}$-Atom Schwefel in zehn Millionen Litern Wasser (also in einer Verdünnung von 1:300000000) noch deutlich durch seine verzögernde Wirkung auf die Metallkatalyse bemerklich (Bredig und Reinders).

Man könnte geneigt sein, dies auf eine Bildung von Schwefelmetall zurückzuführen, aber dazu sind die Giftmengen viel zu klein.

Ein anderes ausgezeichnetes Lähmungsbeispiel sieht man in dem Einfluss der Bla usäure.

1 Mol HCN in 20 Millionen Litern (also pro Liter 0,014 Milligramm) genügt, um die Geschwindigkeit der Katalyse (von $0,06 \mathrm{H}_{2} \mathrm{O}_{2}$ durch 0,00001 Pt) auf die Hälfte herabzusetzen (Bredig und Ikeda). In einem anderen Versuche setzte der Zusatz von 0,000000001 g Blausäure pro cc die intensive katalytische Wirkung von $0,000006 \mathrm{~g}$ colloidalem Platin bei der $\mathrm{H}_{2} \mathrm{O}_{2}$-Zersetzung um die Hälfte herab.

Ich gebe noch eine Tabelle, nach welcher der Verlauf der Vergiftung mit der Zeit und die Erholung hervorgeht.

Wie man sich erinnert, war in der Formel

$$
\mathrm{k}=\frac{1}{\mathrm{t}} \log \frac{\mathrm{A}}{\mathrm{A}-\mathrm{x}}
$$

$t$ die Reactionsdauer und $A-x$ die zur Zeit $t$ noch vorhandene unzersetzte Menge $\mathrm{H}_{2} \mathrm{O}_{2}$.

In vorliegendem Beispiel handelt es sich um ein Gemisch von $0,037 \mathrm{H}_{2} \mathrm{O}_{2}$ $+0,00003 \mathrm{Pt}+0,008 \mathrm{HCN}$.

\begin{tabular}{c|c|c|c|c|c|c|c|c}
\hline & $\begin{array}{c}\text { Zu } \\
\text { Beginn }\end{array}$ & $\begin{array}{c}\text { Nach } \\
40^{\circ}\end{array}$ & $\begin{array}{c}\text { Nach } \\
960^{\circ}\end{array}$ & $\begin{array}{c}\text { Nach } \\
1140^{\circ}\end{array}$ & $\begin{array}{c}\text { Nach } \\
1420^{\circ}\end{array}$ & $\begin{array}{c}\text { Nach } \\
2320^{\circ}\end{array}$ & $\begin{array}{c}\text { Nach } \\
2520^{\circ}\end{array}$ & $\begin{array}{c}\text { Nach } \\
2620^{\circ}\end{array}$ \\
\hline $\begin{array}{c}\text { Werthe von A-x } \\
\text { Werthe von: } \\
10^{6} \times 0,434 \mathrm{k}\end{array}$ & 19,5 & 19,5 & 18,6 & 18,2 & 17,7 & 11,0 & 8,9 & 6,7 \\
\hline
\end{tabular}


Aus dieser Tabelle ist ersichtlich.

1. dass nach 40 Minuten der Werth von $(A-x)$ unverändert, also noch die ursprüngliche $\mathrm{H}_{2} \mathrm{O}_{2}$-Menge vorhanden ist. Erst nach $960^{\prime}$ tritt die lähmende Wirkung der HCN ein wenig zurück und nimmt allmählich immer weiter ab. Man darf also sagen, dass die Wirkung der Blausäure allmählich verschwindet und das Platin sich von der Vergiftung erholt und wieder wirksam wird.

Es verdient Erwähnung, dass bei Abwesenheit von HCN, nach 40 Minuten mehr als die $\mathrm{Hälfte}$ des $\mathrm{H}_{2} \mathrm{O}_{2}$ umgesetzt war.

2. Der Werth von $0,434 \mathrm{k} \times 10^{6}$, also auch die Reactionsconstante $\mathrm{k}$ selbst, ist nach 40 Minuten noch 0 und fängt dann allmählich an zu steigen. Das entspricht dem soeben erwähnten Ergebniss, dass das Platin sich von der Vergiftung erholt.

Wirkt kein HCN ein, so bleibt, wie andere Versuche zeigten, $\mathrm{k}$ zu verschiedenen Zeiten unverändert.

Bredig und Ikeda haben noch die Giftigkeit einer Anzahl anderer Stoffe in Beziehung auf die Platinkatalyse untersucht, so von Jod, Br, Anilin, Amylnitrat, arseniger Säure, $\mathrm{P}, \mathrm{PH}_{3}, \mathrm{CO}$ etc.

Bredig fand hierbei, dass die lähmende Wirkung auf die Platinkatalyse noch sehr merklich ist:

\begin{tabular}{|c|c|c|c|c|c|c|c|c|}
\hline be & Zusatz & von & 0,00000005 & $\mathrm{~g}$ & Mol & JCN & pro & Liter \\
\hline$n$ & $n$ & $n$ & 0,0000001 & $\pi$ & $\pi$ & $\mathrm{J}_{2}$ & $n$ & $n$ \\
\hline$n$ & $\pi$ & $n$ & 0,00004 & r & $n$ & $\mathrm{Br}_{2}$ & n & $\eta$ \\
\hline$n$ & $\pi$ & , & 0,00004 & $\pi$ & $n$ & $\mathrm{NH}_{2} \mathrm{OH}$ & $n$ & $\eta$ \\
\hline$n$ & $n$ & $n$ & 0,00018 & $\pi$ & $\pi$ & $\mathrm{C}_{6} \mathrm{H}_{5} \mathrm{NH}_{2}$ & , & r \\
\hline$n$ & $n$ & $n$ & 0,00004 & $\pi$ & $\pi$ & $\mathrm{P}_{4}$ & , & $\pi$ \\
\hline$\eta$ & $n$ & n & 0,00024 & n & $\eta$ & $\mathrm{PH}_{3}$ & , & $n$ \\
\hline$n$ & $n$ & $n$ & 0,001 & & $\eta$ & $\mathrm{C}_{2} \mathrm{H}_{4} \mathrm{O}_{2}$ & $n$ & 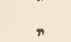 \\
\hline , & $n$ & $n$ & 0,000001 & $\pi$ & 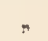 & $\mathrm{Hg} \mathrm{Cl}_{2}$ & $n$ & 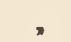 \\
\hline & $n$ & $n$ & 0,0048 & & $n$ & $\mathrm{Hg} \mathrm{Cy}_{2}$ & $n$ & $n$ \\
\hline & $n$ & $n$ & 0,002 & & $n$ & $\mathrm{Na}_{2} \mathrm{SO}_{3}$ & n & n \\
\hline & & & 0,0002 & & 川 & $\mathrm{Na}_{2} \mathrm{~S}_{2} \mathrm{O}_{3}$ & $n$ & $n$ \\
\hline & $n$ & , & 0,0003 & & $n$ & $\mathrm{HCl}$ & n & 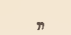 \\
\hline
\end{tabular}

In wie geringen Mengen colloidale Metallösungen wirksam sein können geht noch hervor aus Untersuchungen Galeotti's [35], der, weiter bauend auf den Untersuchungen Naegeli's über die oligodynamischen Erscheinungen in lebenden Zellen fand, dass eine colloidale Kupferlösung, die $1 \mathrm{~g}$ Atom Kupfer auf 20000000 Liter Wasser enthielt, im Stande war, die wandständigen Chlorophyllbänder in Spirogyrazellen zur Verkürzung und Zusammenballung zu veranlassen. In reinem destillierten Wasser war von dieser Erscheinung absolut nichts zu constatiren. 


\section{c) Eigenschaften des Silbersols (A rgentum colloidale).}

Die Eigenschaften der verschiedenen auf elektrischem Wege erhaltenen Metallsole stimmen in der Hauptsache mit einander überein. Vom medizinischen Standpunkt interessirt uns am meisten das Silbersol (Argentum colloidale, Collargol). Bekanntlich wird es zur Bekämpfung von Infectionskrankheiten (Bakteriämien) mit Erfolg angewandt. Ich bespreche dasselbe deshalb hier näher.

Das von Bredig hergestellte Argentum colloidale zeigte folgende Eigenschaften:

a) Beim Gefrieren und beim Zusatz ind ifferenter Elektrolyte lassen die Silbersole ihren Silbergehalt unlöslich ausfallen; hindert.

b) bei Gegenwart von Spuren Gelatine wird diese Fällung ver-

Ueber den Einfluss von Gelatine auf den Solzustand im Allgemeinen besitzen wir werthrolle Mittheilungen von Lobry de Bruyn [36].

Wenn man eine warme $10 \%$ ige wässerige Gelatinelösung mit dem gleichen Volumen von zwei Salzlösungen versetzt, die unter normalen Unıständen mit einander einen amorphen Niederschlag geben, z. B. $\mathrm{KCrO} \mathrm{O}_{4}$ und $\mathrm{Ag} \mathrm{NO} \mathrm{N}_{3}, \mathrm{NaCl}$ und $\mathrm{Ag} \mathrm{NO}_{3}$, oder den Componenten von Berliner Blau, Ferrocyankupfer u. s. w., so erweist sich das Gemisch sowolıl vor wie nach der Erstarrung als völlig transparent. Der sonst amorphe Niederschlag ist unter dem Einfluss der Gelatine in den Colloidzustand versetzt worden. In ähnlicher Weise lassen sich auch metallisches Silber, Gold, Quecksilber in colloidalem Zustand erhalten. Um z. B. in leichter Weise das von Lottermoser entdeckte colloidale Quecksilber zu gewinnen, hat man nur gelatinöse Lösungen von Sublimat und Zinnchlorür, oder von Quecksilbernitrat und Ammoniak mit einander zu versetzen: das durch Reduktion abgeschiedene Quecksilber wird und bleibt unter dem Einfluss der Gelatine colloidal.

Krystallinische Niederschläge waren auf diese Weise nicht in Solform $\mathrm{zu}$ bringen.

Wie Lobry de Bruyn mittheilt, hatte Ernst Colien bereits zuvor eine ähnliche Erscheinung studirt.

Gaedicke hatte nämlich behauptet, dass äquivalente Mengen $\mathrm{Ag} \mathrm{NO}_{3}$ und $\mathrm{K} \mathrm{Br}$ sich beim Zusammenbringen in einer $5 \%$ igen Gelatinelösung nur theilweise umsetzen, während die Reaction in Wasser, der ausserordentlich geringen Löslichkeit des $\mathrm{Ag} \mathrm{Br}$ wegen, vollständig verläuft. In der That, wenn man die Reaction in gelatinöser Lösung ausführt, sieht man keinen Niederschlag, sondern lediglich eine Opalescenz. auftreten. 
Cohen konnte aber durch Leitfähigkeitsbestimmungen mit Sicherheit feststellen [37], dass die Reaction in Gelatine vollständig verläuft, denn das Leitvermögen entsprach nur dem des entstandenen $\mathrm{K} \mathrm{NO}_{3}$. Wären $\mathrm{Ag} \mathrm{NO}_{3}$ und $\mathrm{K} \mathrm{Br}$ übrig geblieben, so hätten auch diese ihren Einfluss auf die Leitfähigkeit gelten machen müssen. AgBr ist an der Leitfähigkeit nicht betheiligt; es ist nicht in Ionen gespalten und war offenbar als solches zu einem Hydrosol aufgelöst.

Es kommt mir nicht unwahrscheinlich vor, dass die Wirkung therapeutisch angewandten colloidalen Silbers, trotz der im Serum vorhandenen Elektrolyte, durch die ebenfalls darin und in den Zellen vorhandenen Colloide (Eiweissstoffe) ermöglicht wird ${ }^{1}$ ).

c) Die Colloide-Metalllösungen zeigten deutlich das TyndallPhänomen (reflectirtes polarisirtes Licht).

Vergleicht man das auf elektrischem Wege bereitete mit dem auf chemischem Wege von Carey Lea, Prange, Lottermoser und E. von Me yer [38] hergestellten colloidalen Silber, so zeigt sich keine vollständige Identität. Bredig bemerkt, dass seine Präparate, im Gegensatz zu jenen, beim Eintrocknen keinen metallischen Spiegel geben, sondern einen mattschwarzen bis mattgrauen Rückstand. Lottermoser hebt hervor, dass im Bredig'schen Präparat die V'ertheilung nicht so fein ist. Demgegenüber ist Bredigs Silbersol viel haltbarer, was wohl mit seiner grossen Freiheit von elektrolytischen (coagulirenden) Verunreinigungen zusammenhängt. Bredig theilt mit, dass er Sole von Silber und Gold länger als zwei Jahre im Lichte aufbewahren konnte, während Lösungen von Argentum Credé (vergl. oben S. 81) schon nach einigen Wochen oder Monaten coagulirten.

Lottermoser und auch Bredig liaben die Frage erhoben, ob man es beim colloidalen Silber nun wirklich mit Metallpartikelchen zu thun hat oder ob es sich

1) In ihren neuerdings veröffentlichten ,Studien über Austlockungserscheinungen“ haben M. Neisser und U. Friedeman n (Münchener med. Wochenschr. 1903 Nr. 11) die Hemmung der Auslockung von Mastixlösungen durch Spuren Gelatine und durch Spuren Serum, darauf zurückgeführt, dass die äusserst feınen colloidalen Mastixtheilchen sich mit einer Gelatine- bezw. Eiweissschicht umbüllen. In analoger Weise könnte man sich meines Erachtens vielleicht auch den hemmenden Einfluss denken, den Serum auf die Ausflockung der colloidalen Silbertheilchen ausiabt.

Ich kann die einschlägigen Untersuchungen, die auch viele interessante neue Thatsachen bringen, hier nicht weiter berücksichtigen. Nur will ich noch erwähnen, dass die Autoren ausfülırlichere Mittheilungen, die sich auch auf die Agglutination beziehen, in die Zeitschrift für Hygiene in Aussicht gestellt haben. Auch wird, wie sie angeben, ein Aufsatz, der mehr speciell die physikalisch-chemische Seite der Ausflockungsfrage beleuchtet, von der Hand Bechhold's in der Zeitschrift für physik. Chemie veröffentlicht werden. 
vielleicht um Metalloxyde oder andere Verbindungen handelt. Dass es sich bloss um Metallpartikelchen handelt, wird dadurch wahrscheinlich, dass Salzsäure gleich allen anderen Säuren aus der colloidalen Flüssigkeit eine Ausfällung metallischen Silbers herbeiführt. Diesem Niederschlag sind auch bei grossem Ueberschusse nur ganz geringe Spuren von $\mathrm{Ag} \mathrm{Cl}$ beigemengt.

Ausserdem können im Bredig'schen Präparat höchstens Verbindungen mit Bestandtheilen des Wassers vorhanden sein.

Interessant ist weiter die Einwirkung der Halogene Chlor, Brom und Jod auf die Lösung des colloidalen $\mathrm{Ag}$ (und $\mathrm{Hg}$ ). Lässt man diese in gasförmigem oder gelöstem Zustande auf die colloidale Metallösung einwirken, so bilden sich die entsprechenden $\mathrm{Halogensalze}$ in colloidalem Zustande.

Aus dem colloidalen $\mathrm{Ag}$ entsteht $\mathrm{AgCl}, \mathrm{AgBr}$ und $\mathrm{AgJ}$. Es sind diese Lösungen weisse oder gelbe milchartige Flüssigkeiten, aus denen das Halogensilber durch jedes beliebige Salz in unlöslichem Zustand ausgefällt wird.

Ich erwähne schliesslich noch, dass Lottermoser und E. von Meyer die Ausfällung des colloidalen Silbers quantitativ verfolgt. Die meisten Fällungsversuche wurden mit verdünnter Säure angestellt. Dabei stellte sich $u$. A. heraus, dass die Säure-Menge, die nöthig war, um in gleicher Zeit Ausfällung zu erzielen, der Stärke der Säure umgekehrt proportional war. Weiter zeigte es sich, dass in demselben Maasse, in welchem eine und dieselbe Colloidlösung verdünnt wurde, auch die zur Ausfällung erforderliche Zeit caeteris paribus grösser wurde.

Ueber die Ursache der therapeutischen Wirkung des colloidalen Silbers bei septischen Zuständen ist man sich noch nicht im Klaren. Man hat die Ansicht ausgesprochen, es liege hier eine bactericide Wirkung vor. Andere und auch ich haben diese Meinung nicht bestätigen können

Ich habe mir dann die Frage vorgelegt, ob hier das colloidale Silbervielleicht die Rolle eines Katalysators spielt, durch den die Zersetzung der Toxine beschleunigt wird. Es schien mir nicht unmöglich, dass die durch die pathogenen Bakterien gebildeten Krankheitsproducte, welche in normalen Umständen allmählich durch den Sauerstoff des Blutes oxydirt werden, unter dem Einfluss von Argentum colloidale einer viel kräftigeren Oxydation anheimfallen wïrden.

Um diese Vorstellung zu prüfen, schien es mir erwünscht zu untersuchen, ob überhaupt das Argentum colloidale zu einer Katalyse organischer Substanzen im Stande ist. Zu diesem Zweck suchte ich eine toxische Substanz, deren Menge in leichter Weise dosirt werden konnte; dadurch war ich dann zu gleicher Zeit im Stande, den Process messend zu verfolgen. Ich wählte das Staphylotoxin, das nach den Untersuchungeu von Neisser und Wechsberg das Vermögen besitzt Hämolyse herbeizuführen, insbesondere von Kaninchenblutkörperchen. Die Autoren hatten es durch Impfung von Staphylococcus pyogen. aureus oder albus in Bouillon bereitet.

Ich cultivirte die Mikrobe in Kaninchenserum und beobachtete dann, dass in der That das nach Filtration durch $\mathrm{Ch}$ amberlandkerzen gewonnene klare Serum nunmehr im Stande war, Erythrocyten des Kaninchens zu zerstören. 
Ich erwartete nun, dass Hinzufügung von Ag colloidale zu dem toxin- und sanerstoffhaltenden Serum, dessen hämolytische Wirkung herabsetzen würde. Das Umgekehrte war der Fall; die hämolytische Wirkung wurde erheblich kräftiger und zwar konnte dieser Einfluss noch constatirt werden als ${ }^{1 / 4}$ cc einer 0,05-procentigen Lösung von Argentum Colloidale in destillirtem Wasser ${ }^{1}$ ) zu 2 ec Serum hinzugefügt wurde; das Serum enthielt also $0,0000625 \mathrm{~g}$, oder wie man es gewöhnlich auszudrücken pflegt, 0,00000058 Gramm-Atom colloidales Silber.

Später stellte sich heraus, dass grössere Mengen colloidalen Silbers die hämolytische Wirkung des Staphylotoxins wohl herabsetzten.

Beim Abdruck des vorliegenden Kapitels sind die Untersuchungen, die ich in Gemeinschaft mit Herr'n J. Hekman ausführe, noch im Gang. An einer anderen Stelle komme ich auf dieselben zurück. Dass hier eine katalytische Erscheinung vorliegt, kann nicht bezweifelt werden.

So hätte man dann hier das erste Beispiel katalytischer Wirkung eines anorganischen Colloids auf organische Stoffe.

\section{d) Vergleichnng der Katalyse durch Platin und Wasserstoff einerseits und durch organische Fermente anderseits.}

Dass organische Fermente in verschwindend kleinen Mengen im Stande sind $\mathrm{H}_{2} \mathrm{O}_{2} \mathrm{zu}$ zersetzen, hat bereits Schönbein dargethan.

Weiter sind es dann insbesondere O'Sullivan und Tompson, Tammann, Duclaux, Victor Henri und Jacobson gewesen, die den zeitlichen Verlauf dieser und anderer katalytischen Umsetzungen durch organische Fermente studirten. In unancher Hinsicht weisen die Resultate dieser Autoren auf eine Uebereinstimmung mit den bei der Katalyse durch Platin und anderen anorganischen Katalysatoren gewonnenen Ergebnissen hin; andererseits wurden wesentliche Abweichungen gefunden. Ich will lier einige Punkte erörtern.

1. O'Sullivan und Tompson [38] fanden, dass es sich bei der katalytischen Rohrzucker-Inversion durch das organische Enzym Invertase, im Wesentlichen um eine Reaction erster Ordnung (monomoleculare Reaction) handelt, wie das auch der Fall ist, wenn verdünnte Säuren die Umsetzung herbeiführen (vergl. Bd. II, S. 467 u. 493). Indessen wurden von Tammann [39] und auch von Duclaux [40] zwischen der Rohrzucker Inversion durch Invertase und derjenigen durch Säure wesentliche Unterschiede beobachtet.

Duclaux geht selbst so weit, auszusprechen, dass die Gesetze der physikalischen Chemie auf Enzymwirkungen nicht anwendbar sind. Dass in der That die Umsetzung durch organische Fermente nicht in gleicher Weise wie durch anorganische verlänft, hat auch Victor Henri durch

1) Es war bezogen von der Fabrik von $\mathrm{Heyden}$, Radebeul-Dresden. Käuflich in Röhrchen zu 1 à 5 Gramm. 
ausführliche IIntersuchungen nachgewiesen [41 u. 42]. Weder im System Saccharose-Invertase, noch im System Salicin-Emulsin erwies sich die "Geschwindigkeitsconstante $\mathrm{k}$ " wirklich als constant; im erstgenannten System nahm sie mit der Zeit zu, im zweiten System ab.

Bei der Umsetzung von Rohrzucker durch Invertase gilt also nicht die Gleichung, welche bei der Inversion durch $\mathrm{H} \mathrm{Cl}$ den Reactionsverlauf angibt, nämlich

$$
\left.\frac{\mathrm{dx}}{\mathrm{dt}}=\mathrm{k}(\mathrm{A}-\mathrm{x})^{1}\right)
$$

sondern für $\mathrm{k}$ ist $\mathrm{zu}$ setzen $\mathrm{k}_{1}\left(1+\frac{\mathrm{x}}{\mathrm{A}}\right)$

m. a. W. bei der Inversion mittelst organischer Fermente ist die Reactionsconstante veränderlich und zwar nimmt sie proportional dem relativen Inversionsgrad $\frac{\mathrm{x}}{\mathrm{A}} \mathrm{zu}$.

Diese Zunahme wäre nach älteren Ausführungen Ostwald's auf A utokatalys e zurïckzuführen.

1) Diese Gleichung scheint beim ersten Anblick eine andere zu sein als die Gleichung 1b (Bd. II, S. 469), welche ebenfalls die monomoleculare Reaction vorstellen soll und auch später (S. 495) für die Inversion von Rohrzucker mitteīst HCl benutzt wurde. Bei näherer Betrachtung stellt sich aber heraus, dass sie nun etwas anders geschrieben ist. Die Schreibweise wurde von Henri und wird von vielen anderen Autoren benutzt.

Der Ausdruck kann folgenderweise abgeleitet werden:

Ist $\mathrm{k}$ die Concentration der umgewandelten Menge zu einer bestimmten Zeit, so kann die äusserst geringe Vermehrung dieser Concentration vorgestellt werden durch $\mathrm{dx}$ (Differential $\mathrm{x}$ ). Diese Vermehrung hat in einem äusserst geringen Zeitintervall dt stattgefunden. Also kann die Concentrationsvermehrung der umgewandelten Menge in der Zeiteinheit, m. a. W. die Reactionsgeschwindigkeit vorgestellt werden durch $\frac{d x}{d t}$. Sie ist abbängig von einer Constante k (Geschwindigkeitsconstante) und von der noch vorhandenen Menge der umzuwandelnden Substanz. Es sei die Anfangsconcentration dieser Substanz A und die Concentration der umgewandelten Menge $\mathrm{x}$, so ist noch $\mathrm{A}-\mathrm{x}$ übrig, also

$$
\frac{\mathrm{dx}}{\mathrm{d} \mathrm{t}}=\mathrm{k}(\mathrm{A}-\mathrm{x}) \text {. }
$$

Wie bereits mehrmals gesagt, ist bei constanter Temperatur $\mathrm{k}$ abhängig von der Natur der umzuwandelnden Substanz und des Katalysators, und bleibt währeud des ganzen Reactionsverlaufs unverändert, wird also weder von der Concentration der noch umzuwandelnden Substanzmenge, noch von der der Unwandlungsproducte beeinflusst. So ist es bei del e infa $\mathrm{chen} \mathrm{monomolecularen}$ (irreversiblen) Reaction, auf die z. B. dic Inversion von Rohrzucker durch Salzsäure praktisch zurückgeführt werden kaun. 
Unter Autokatalyse versteht Ostwald die häufig vorkommende Erscheinung, dass durch die Reaction selbst und während derselben Stoffe, entstehen, welche als Beschleuniger der Reaction wirken und deren Nenge mit der Dauer der Reaction zunimmt. Die obige Formel $\frac{\mathrm{dx}}{\mathrm{dt}}=\mathrm{k}(\mathrm{A}-\mathrm{x})$ wird demnach $\frac{\mathrm{dx}}{\mathrm{dt}}=\left[\mathrm{k}_{1}\left(1+\frac{\mathrm{x}}{\mathrm{A}}\right)\right](\mathrm{A}-\mathrm{x})$.

Durch Integration erhält man

$$
2 k_{1}=\frac{1}{t} 1 \frac{A+x}{A-x}
$$

Fügt man nun die im Experiment für rerschiedene Zeiten erhaltenen Werthe ron $\mathrm{x}$, und den Werth von $\mathrm{A}$ in die Formel ein, so erhält man in der That constante Werthe für $k_{1}$, m. a. W. der $k_{1}-W$ erth bleibt während der Reaction constant. Für Zuckerlösungen von verschiedener Concentration ist $k_{1}$ von der Anfangsconcentration A, also vom osmotischen Druck der Lösung abhängig.

In ähnlicher Weise ist auch von Herzog [43] die Spaltung von Salicin in Saligenin und von Glukose unter dem Einfluss des Enzyms Emulsin studirt worden. Wie oben erwähnt, nimmt bei dieser Reaction die Reactionsgeschwindigkeit $k$ mit der Zeit ab. Hier würden, den Anschauungen 0 stwald's gemäss die Reactionsproducte einen hemmenden Einfluss (negative Autokatalyse) ausüben. Herzog hat diese Annahme an der Hand der zu diesem Zweck vo Ostwald gegebenen Formel geprüft und fand dann eine Constante $k_{1}$.

Auch die in Ostwald's Laboratorium ausgeführten Untersuchungen von Senter [44] haben ein gleichartiges Resultat ergeben. Senter konnte ein Enzym in ziemlich reinem Zustande aus dem Biut herstellen, das er mit „Hämase" bezeichnete und welches ebenso wie colloidales Platin, die Zersetzung von $\mathrm{H}_{2} \mathrm{O}_{2}$ kräftig katalysirte. Wurde eine verdünnte $\mathrm{H}_{2} \mathrm{O}_{2}$ Lösung gebraucht, so verlief die Katalyse genau nach dem Massenwirkungsgesetz.

Der oben genannte Satz von Duclaux ist also wenigsters für die von Henri, Herzog und Senter näher untersuchten Reactionen nicht mehr aufrecht zu halten.

$\mathrm{Zu}$ der gleichen Ansicht ist auch A. W. Visser [45] gelangt, ron dessen Untersuchungen unten die Rede sein wird. (Vergl. S. 97.)

Was den Grund für die von T a m mann gefundenen Abweichungen betrifft, so sind diese, wie Henri und Visser hervorgehoben haben, hauptsächlich auf durch Gährung verursachte Zersetzungen zurückzuführen. Wie Visser nachwies, sind diese zu vermeiden, wenn man 
unter möglichst aseptischen Cantelen und unter Hinzufügung von $0,5 \%$ $\mathrm{NaFl}$ arbeitet. Auf diese Weise hatte z. B. das Emulsin nach 12 Tagen noch seine unveränderte Stärke behalten.

2. Aus den Versuchen von $J$ acobson [46] über die katalytische Wirkung von Emulsin auf $\mathrm{H}_{2} \mathrm{O}_{2}$ geht hervor, dass die Umsetzungsgeschwindigkeit bei steigendem Zusatz von Alkali ( $\mathrm{OH}^{\prime}$-Ionen) zunimmt, ein Maximum erreicht, um bei weiter fortgesetztem Zusatz abzunehmen. Eine überraschend analoge Curve gewann Bredig bei Anwendung des colloidalen Platins. Was für Emulsin festgestellt wurde, galt auch für andere Enzyme, wie Pankreasauszug, Diastase, Pepsin etc.

Auch Salze modificiren die Katalyse durch Platin und organische Fermente in conformer Weise. $\mathrm{NaCl}$ und $\mathrm{HCl}$ z. B. verlangsamen, $\mathrm{K}_{2} \mathrm{SO}_{4}$ beschleunigt die $\mathrm{H}_{2} \mathrm{O}_{2}$-Zersetzung durch Platin, wie auch durch Emulsin und Pancreasextract.

3. Auch bei der Lähmung der katalytischen Wirkung durch gewisse Zusätze tritt die Analogie der colloidalen Metallsole mit den organischen Fermenten ganz auffallend hervor.

Bereits Schönbein hat für die organischen Fermente ebenfalls festgestellt, dass ihre katalytische Wirkung auf $\mathrm{H}_{2} \mathrm{O}_{2}$ durch geringe $\mathrm{H}_{2} \mathrm{~S}$-Zusätze gelähmt wird. J a cobson [46] hat diese Angaben quantitativ geprüft, bestätigt und erweitert. Er sah auch, dass Spuren HCN die Wirkung von Emulsin und ron Pankreas auf $\mathrm{H}_{2} \mathrm{O}_{2}$ lähmen, und beobachtete weiter, dass die organischen Fermente, ebenso wie auch das colloidale Platin, sich von der Giftwirkung erholen.

Kobert nahm wahr, dass die Katalyse von $\mathrm{H}_{2} \mathrm{O}_{2}$ durch Blut, durch Spuren HCN gehemmt wurde.

4. Bei der Platinkatalyse, wie bei derjenigen durch organische Fermente, besteht ein Temperaturoptimum und zwar insofern, als beide Arten Katalysatoren bei wachsender Temperatur zunächst kräftiger wirksam sind, bei fortgesetzter Temperatursteigerung aber geschädigt und schliesslich zersetzt werden.

5. Bei der Vergleichung von organischen und anorganischen Katalysatoren kommen noch andere Fragen in Betracht, u. A. diejenige, ob organische Katalysatoren reversibele Reactionen zu Stande bringen, oder, besser gesagt, beschleunigen können. Um nicht zu ausführlich zu 
werden, muss ich es mir versagen, auf diesen wichtigen Gegenstand hier allzu nahe einzugehen.

Von biologischem Gesichtspunkte aus besitzt diese Frage aber so hohe Wichtigkeit, dass es mir nothwendig erscheint ihr doch wenigstens einige Worte zu widmen, zumal weil damit zugleich ein Beispiel aus der für die Physiologie so wichtigen chemischen Kinetik gegeben wird ${ }^{1}$ ).

Wenn man Alkohol und Essigsäure auf einander einwirken lässt, so bilden sich Essigsäureaethylester und Wasser; die Reaction geht aber nicht zu Ende. Das rührt daher, dass der Essigsäureaethylester und Wasser auch wieder auf einander einwirken unter Zurückbildung von Alkohol und Fssigsäure. Es entsteht ein chemisches Gleichgewicht zwischen Essigsäureaethylester, Wasser, Alkohol und Essigsäure. Wie viel von dem Ester in Gemisch vorhanden sein wird, hängt von der relativen Geschwindigkeit der beiden entgegengesetzten Reactionen ab. Ist die Geschwindigkeitsconstante der ersteren Reaction die grösste, so prävalirt die erste Reaction. Wie bereits erwähnt (Bd. II, S. 476), kann man eine derartige reversible Reaction in folgender Weise zum Ausdruck bringen,

$$
\mathrm{C}_{2} \mathrm{H}_{5} \mathrm{OH}+\mathrm{CH}_{3} \mathrm{COOH} \rightleftarrows \mathrm{CH}_{3} \mathrm{COO}\left(\mathrm{C}_{2} \mathrm{H}_{5}\right)+\mathrm{H}_{2} \mathrm{O} \text {. }
$$

Ist $\mathrm{C}_{1}$ die Concentration des $\mathrm{C}_{2} \mathrm{H}_{5} \mathrm{OH}$,

$\mathrm{C}_{2}$, , der $\mathrm{OH}_{3} \mathrm{COOH}$, und

$k_{1}$, Geschwindigkeitsconstante,

so kann die Reactionsgeschwindigkeit $\mathrm{S}_{1}$ der ersteren Reaction durch die Formel $\mathrm{S}_{1}=\mathrm{k}_{1} \mathrm{C}_{1} \mathrm{C}_{2}$ dargestellt werden. Ist weiter $\mathrm{C}_{3}$ die Concentration des gebildeten Esters und $\mathrm{C}_{4}$ diejenige des Wassers, während $\mathrm{k}_{2}$ die Geschwindigkeitsconstante ist, womit die zweite, umgekehrte Reaction verläuft, so kann die Reactionsgeschwindigkeit $S_{2}$, der letzteren durch $\mathrm{S}_{2}=\mathrm{k}_{2} \mathrm{C}_{3} \mathrm{C}_{t}$ angegeben werden. Die Reactionsgeschwindigkeit in jedem Moment ist also $S_{1}-S_{2}$. Ist ein Gleichgewichtszustand eingetreten, in welchem also ebensoviel Moleküle Ester gebildet wie zersetzt werden, so ist $\mathrm{S}_{1}-\mathrm{S}_{2}=0$ oder $\mathrm{k}_{1} \mathrm{C}_{1} \mathrm{C}_{2}=\mathrm{k}_{2} \mathrm{C}_{3} \mathrm{C}_{4}$.

$$
\frac{\mathrm{k}_{1}}{\mathbf{k}_{2}}=\frac{\mathrm{C}_{3} \mathrm{C}_{1}}{\mathrm{C}_{1} \mathrm{C}_{2}} \text {. Das Verhältniss } \frac{\mathrm{k}_{1}}{\mathrm{k}_{2}}=\mathrm{K} \text { (Bd. II, s. 478). }
$$

nennt man die Gleichgewichtsconstante.

Nehmen wir einel Augenblick an, was in Wirklichkeit beim vorliegenden System nicht der Fall ist, dass $k_{1}$ gegenüber $k_{2}$ sehr gross ist, so kann ein Gleichgewichtszustand nur eintreten, wenn $\mathrm{C}_{1}$ und $\mathrm{C}_{2}$ im Vergleich zu $\mathrm{C}_{3}$ und $\mathrm{C}_{4}$ sehr klein sind. Im vorliegenden Fall würde das bedeuten: Wenn die Bildung von Ester aus Alkohol und Essigsäure in Vergleich zur Rückbildungsreaction äusserst schnell von statten geht, so ist, wenn ein Gleichgewichtszustand erreicht ist, die Concentration $\mathrm{C}_{1}$ und $\mathrm{C}_{2}$ von Alkohol und Essigsäure sehr klein, vielleicht unmessbar klein geworden. Bringt man Ester und Wasser zu einander, so bildet sich kaum eine Spur Alkohol und Essigsäure; denn wenn diese beiden gebildet worden sind, so findet wieder mit viel grösserer Geschwindigkeit eine Rückbildung zu Ester und Wasser statt, denn $k_{1}$ ist $\mathrm{sehr}$ viel mal grösser als $\mathrm{k}_{2}$ angenommen worden. Solch eine Reaction nennt man eine irreversible. In Wirklichkeit ist das übrigens, wie gesagt, beim genannten System Alkohol-Essigsäure nicht der Fall;

1) Vergl. übrigens den Artikel von Bredig [37]: Die Elemente der chemischen Kinetik mit besonderer Berücksichtigung der Katalyse (S. $160 \mathrm{ff}$ ). 
der Quotient $\frac{k_{1}}{k_{2}}$ hat hier nicht einen so hohen Werth. Ich setzte nur einen Augenblick diesen Fall, um an einem bekannten Beispiel die Sache zu verdeutlichen.

Nicht umkehrbare und umkehrbare Reactionen (letztere werden auch Gleichgewichtreactionen genannt) laufen oft sehr langsam ab, m. a. W. es dauert nicht selten sehr lange, bevor ein definitiver Gleichgewichtzustand erreicht ist. Unter dem Einfluss von bestimmten Ionen kann der Ablauf jedoch beträchtlich beschleunigt werden. Im täglichen Sprachgebrauch drückt man es nicht selten so aus, als ob die Reaction ganz dadurch zu Stande gebracht wird; das ist nicht ganz richtig, sie wird bloss durch dieselben beschleunigt (bisweilen auch verzögert) (vergl. S. 80). Im obengenannten Beispiel von Aethylacetat und Wasser (reversible Reaction) führen Säuren eine grosse Beschleunigung herbei und zwar ihrer Ionenconcentration proportional (vergl. hierzu Bd. II, S. 476 u. 496). Durch welchen Mechanismus diese Katalyse vor sich geht, ist noch unbekannt.

Es ist nun die Frage: Giebt es auch Enzyme, die reversible Reactionen beschleunigen?

Croft Hill [48] hat in der That ein solches Enzym nachgewiesen. Er liess Hefemaltase auf $40 \%$ ige Lösungen von Traubenzucker bei $30^{\circ}$ einwirken und stellte fest, dass dieselbe Maltase, die die Maltose in Traubenzucker spaltet, auch Maltose ${ }^{1}$ ) aus dem Traubenzucker zu regeneriren vermag. In gleicher Richtung liegen viele andere Untersuchungen. So fanden Kastle und Loewenthart [49] und später auch Hanriot [50], dass das fettspaltende Enzym, das Lipase, im Stande ist, Buttersäure-Aethylester in Buttersäure und Aethylalkohol zu spalten und umgekehrt aus den Spaltungsproducten den Ester zurückzubilden.

In gleicher Richtung liegt auch eine Beobachtung von Cremer (51), nach der im Buchner'schen Hefepresssaft das anfangs vorhandene Glykogen allmählich verschwindet und Traubenzucker an seine Stelle tritt. Zu jeder Zeit kann man aber Glykogen wieder erscheinen lassen, wenn man Traubenzucker- (oder Fruchtzucker-) Lösung zu dem Presssafte giebt. Es ist indessen auch möglich, dass hier zwei verschiedene Enzyme vorliegen ${ }^{2}$ ). Aber auch in diesem Falle ist die Beobachtung von Cremer noch interessant, insoweit sie wieder zeigen wïrde, dass es Enzyme giebt, die Synthesen beeinflussen können, was man lange verneint hat, aber nach den vielen späteren Untersuchungen $u$. A.

1) Eigentlich, wie Emmerling fand, Isomaltose; aber dann handelt es sich doch jedenfalls um ein Polysaccharid.

2) An diese Möglichkeit soll man, mit Hinsicht auf die grosse Schwierigkeit, organische Enzyme in reinem Zustande zu bekommen, beim Studium ihres Wirkungsmodus stets denken. 
von Emil Fischer und Frankland Armstrong [52] doch wohl nicht mehr verneinen wird.

Höchstwahrscheinlich gehört die Umsetzung von Zucker in Glykogen und von Glykogen in Zucker in der Leber zu derselben Kategorie von Erscheinungen.

Neulich hat Visser in einer vorläufigen Nittheilung betont [41], dass es sich bei der Umwandlung von Salicin in Saligenin und Glukose unter dem Einfluss von Emulsin, auch um eine reversible Reaction handelt, denn das Enzym ist auch im Stande Salicin aus Saligenin und Glukose zurück zu bilden.

Aehnliches ist höchstwahrscheinlich bei der Umwandlung von Rohrzucker in Glukose und Fructose (früher sprach man von der Umwandlung in "Dextrose und Lävulose") der Fall. Unter dem Einfluss derselben Invertase, welche diese Inversion herbeiführt, wird auch die Zurückbildung beider Komponenten in Rohrzucker veranlasst. (Vergl. unten S. 98).

Hier eröffnet sich ein vielversprechendes neues Untersuchungsgebiet, auf welchem auch manche andere Frage über Umwandlung von Nahrungsstoffen und Assimilationsproducten Klärung erfahren könnte. Dies wird umsomehr der Fall sein, wenn die Ansicht Visser's richtig ist, dass alle Enzyme umkehrbare Reactionen, sogenannte Gleichgewichtsreactionen, herbeiführen. Hiernach würden die Enzyme die Reaction in beide Richtungen beschleunigen, und zwar in dem Sinne, dass die Beschleunigung in der einen Richtung nicht von derselben Grösse zu sein braucht als in diejenige in der anderen.

Von diesem Standpunkt ausgehend, hat Visse r die Theorie der betreffenden Umsetzungen in anderer Weise aufgefasst, als dies bis jetzt geschah und Formeln abgeleitet, die den Zusammenhang zwischen Reactionsgeschwindigkeit und chemischem Gleichgewicht angeben. Obgleich die ausführliche Arbeit beim Abdruck dieses Kapitels noch nicht erschienen ist, kann ich doch Näheres über die interessanten Ausführungen mittheilen, da der Verfasser so liebenswürdig war, mir das Manuscript zur Einsicht zu überlassen.

\section{Ausführungen von Visser.}

Während Henri und Andere vor ihm von der Meinung ausgehen, dass die Umwandlung ron Saccharose in Glukose und Fructose unter dem Einfluss von Invertase nach einiger Zeit vollständig ist, so dass ebenso wie bei der Umwandlung unter dem Einfluss von Salzsäure schliesslich aller Rohrzucker verschwunden ist, glaubt $\mathrm{V}$ is ser nachgewiesen zu haben, dass bei Inversion einer 0,5 norm. Saccharoselösung durch Invertase, immer noch $1 \%$ der Saccharose zurückbleibt, was dadurch erklär- 
lich ist, dass mit der Spaltung von Saccharose eine Rückbildung aus den beiden Componenten einhergeht. Man kann sich, meiner Meinung nach, die Sache so vorstellen, dass beim Beginn der Reaction die Geschwindigkeit der Spaltung diejenige der Rückbildung übertrifft. Je weiter die Reaction fortgeschritten ist, um so weniger Saccharose und um so mehr Spaltungsproducte sind vorhanden. Da nun die Geschwindigkeit einer Reaction auch von der vorhandenen Menge der activen Substanz ablängig ist (Bd. II, S. 467), so wird eine Zeit kommen, zu welcher Spaltung und Rückbildung mit gleicher Geschwindigkeit einhergehen und dann besteht Gleichgewicht. Im vorliegenden Beispiel einer $0,5 \mathrm{n}$. Saccharoselösung ist dann in der Flüssigkeit $99 \%$ Invertzucker und $1 \%$ Rohrzucker vorhanden ${ }^{1}$ ).

Die Reaction entspricht der Bd II, S. 476 beschriebenen und lässt sich versinnlichen durch folgende Gleichung

$$
\text { Saccharose + Wasser } \rightleftarrows \text { Glukose + Fructose. }
$$

Die Reaction lässt sich in folgender Weise in eine Formel bringen:

Ist die Concentration der Saccharoselösung zu einer bestimmten Zeit $=\mathrm{C}$, so wird die Umwandlungsgeschwindigkeit $S_{1}$, mit der diese Saccharoselösung in Glukose und Fructose gespalten wird, vorgestellt werden durch $\mathrm{k}_{1} \mathrm{C}$, wenn $\mathrm{k}_{1}$ die entsprechende Geschwindigkeitsconstante ist; also $S_{1}=k_{1} \mathrm{C}$.

Die umgekehrte Reaction, also die von rechts nach links, verläuft mit einer Gesclıwindigkeit $\mathrm{S}_{2}$, die ebenfalls von einer Geschwindigkeitsconstante $\mathbf{k}_{2}$ abhängig ist, und weiter von den Concentrationen $\mathrm{C}_{1}$ und $\mathrm{C}_{2}$ der entstandenen Zuckerarten; also $\mathrm{S}_{2}=\mathrm{k}_{2} \mathrm{C}_{1} \mathrm{C}_{2}$. Da lier von diesen beiden Stoffen immer die gleiche Menge entsteht, ist $\mathrm{C}_{1}=\mathrm{C}_{2}$; deshalb $\mathrm{S}_{2}=\mathrm{k}_{2} \mathrm{C}_{1}{ }^{2}$.

So bald $\mathrm{S}_{2}$ so gross wie $\mathrm{S}_{1}$ geworden ist, besteht Gleichgewicht; es wird dann praktisch keine neue Saccharose mehr umgewandelt. So lange aber $S_{3}>S_{1}$ ist, ist dies wohl der Fall und dann giebt $\mathrm{S}_{1}-\mathrm{S}_{2}$ die Geschwindigkeit an, mit der die Concentration der vorhandenen Saccharose thatsächlich abnimmt.

Ist $\mathrm{dC}$ die äusserst geringe Concentrationsabnahme in einem äusserst geringen Zeitverlauf dt, so ist diese Abnahme in der Zeiteinheit $-\frac{d C}{d t}$ (Bd II, S. 468);

$$
\text { also } \mathrm{S}_{1}-\mathrm{S}_{2}=-\frac{\mathrm{dC}}{\mathrm{dt}}=\mathrm{k}_{1} \mathrm{C}-\mathrm{k}_{2} \mathrm{C}_{1}{ }^{2} \text {. }
$$

1) Von demselben Gesichtspunkt kann man auch die Inversion durch HCl betrachten, nur dass lier die nach Erreichung des Gleichgewichtzustandes zurückgeblebene Saccharosemenge so klein ist, dass wir diese mit den zur Verfügung stehenden Hülfsmitteln nicht nachweisen können (vergl. Bd. II, S. 467). Es wird auch unten gezeigt werdell, dass die von Visser für die sichtlich umkehrbare Reaction abgeleitete Formel auch für diejenige gilt, deren Umkehrbarkeit nicht sichtbar ist. Vereinfacht man diese Formel dadurch, dass man die Reaction von rechts nach links unberücksichtigt lässt (vergl. S. 100 u. 101), so enthält man die bereits Bd. II, S. 469 abgeleitete Gleichung für die einfache, nicht umkehrbare Reaction. Letztere kann also als ein specieller Fall der von Visser abgeleiteten Formel betrachtet werden. 
Nun lässt sich $C_{1}$ durch bekannte Werte ausdrücken. Wenn nämlich beim Beginn des Versuches die Concentration der Saccharose A war, und dieselbe ist zu einer Zeit $t$ gleich $\mathrm{C}$ geworden, so ist die Concentration der umgewandelten Menge $\left(A_{1}-\mathrm{C}\right)$ und das ist auch die Concentration des Invertzuckers; also $\mathrm{C}_{1}=\mathrm{A}-\mathrm{C}$.

Demnach

$$
-\frac{\mathrm{dC}}{\mathrm{dt}}=\mathrm{k}_{1} \mathrm{C}-\mathrm{k}_{2}(\mathrm{~A}-\mathrm{C})^{2}
$$

Wie Bd. II, S. 468 und 470 erörtert wurde, kann man solch' eine Differentialgleichung integriren. Auf S. 468 des zweiten Bandes wurde auf diese Weise eine Beziehung $z$ wischen $\mathrm{C}, \mathrm{k}$ und $\mathrm{t}$ erhalten. So gewinnt man auch hier eine Beziehung $\mathrm{zwischen}$ $\mathrm{C}, \mathrm{k}_{1}, \mathrm{k}_{2}, \mathrm{~A}$ und t. Diese Beziehung ist, wie die Integralrechnung lehrt, folgende: $=1\left(\mathrm{C}-\frac{\mathrm{k}_{1}+2 \mathrm{k}_{2} \mathrm{~A}+1 \overline{\mathrm{k}_{1}{ }^{2}+4 \mathrm{k}_{1} \mathrm{k}_{2} \mathrm{~A}}}{2 \mathrm{k}_{2}}\right)-1\left(\mathrm{C}-\frac{\mathrm{k}_{1}+2 \mathrm{k}_{2} \mathrm{~A}-\sqrt{\mathrm{k}_{1}{ }^{2}+4 \mathrm{k}_{1} \mathrm{k}_{2} \mathrm{~A}}}{2 \mathrm{k}_{2}}\right)+$ Const.

Fis seien:

$$
\mathrm{l} \overline{\mathrm{k}_{1}^{2}+4 \mathrm{k}_{1} \mathrm{k}_{2} \mathrm{~A}}=\gamma
$$

$$
\begin{aligned}
& \frac{1}{2 k_{2}}\left(k_{1}+2 k_{2} A+\sqrt{k_{1}{ }^{2}+4 k_{1} k_{2} A}\right)=\alpha \\
& \frac{1}{2 k_{2}}\left(k_{1}+2 k_{2} A-\sqrt{k_{1}{ }^{2}+4 k_{1} k_{2} A}\right)=\beta
\end{aligned}
$$

so wird die Gleichung: $\gamma t=1 \frac{\mathrm{C}-\alpha}{\mathrm{C}-\beta}+$ Constans.

Um diese Constante zu berechnen, muss man sich fragen, wie die Formel sich gestaltet, wenn $\mathrm{t}=0, \mathrm{~d}$. h. wenn die Reaction beginnt; in diesem Fall ist $\mathrm{C}=\mathrm{A}$

$$
\text { also } \gamma t=1 \frac{\mathrm{A}-\alpha}{\mathrm{A}-\beta}+\text { Constans }
$$

und da $t=0$

$$
\begin{aligned}
& 0=1 \frac{A-\alpha}{A-\beta}+\text { Constans } \\
& \text { Constans }=-1 \frac{A-\alpha}{A-\beta} .
\end{aligned}
$$

Bringt man diese Constante in die Formel: $\gamma \mathrm{t}=1 \frac{\mathrm{A}-\alpha}{A-\beta}+$ Constans so wird $\gamma \mathrm{t}=1 \frac{\mathrm{C}-\alpha}{\mathrm{C}-\beta}-1 \frac{\mathrm{A}-\alpha}{\mathrm{A}-\beta}$

oder, da die Differenzen der Logarithmen gleich dem Logarithmus der Quotienten ist,

$$
\begin{gathered}
\gamma t=1 \frac{\mathrm{C}-\alpha}{\frac{\mathrm{C}-\beta}{\mathrm{A}-\alpha}}=1 \quad \begin{array}{l}
(\mathrm{A}-\beta)(\mathrm{C}-\alpha) \\
(\mathrm{A}-\alpha)(\mathrm{C}-\beta)
\end{array} \\
\gamma=\frac{1}{\mathrm{t}} \operatorname{l} \frac{(\mathrm{A}-\beta)(\mathrm{C}-\alpha)}{(\mathrm{A}-\alpha)(\mathrm{C}-\beta)} . . .
\end{gathered}
$$

Visser hat nun aus verschiedenen Versuchsergebnissen von ihm selbst und von $\mathrm{Henri}$ die $\gamma$-Werthe berechnet,

Wie gesayt, stellt $\gamma$ eine Beziehung vor $z$ wischen den Geschwindigkeitsconstanten $k_{1}$ und $k_{2}$, und der Anfangsconcentration, kann somit als ein Reactionscoefficient angesehen werden. 
Der Leser wird die Bemerkung machen, dass diese $k_{1}$ und $k_{2}$ auch noch im zweiten Glied der Formel (1) sich befinden, denn $\alpha$ und $\beta$ sind abgekürzte Ausdrucksweisen für Formeln, in denen $k_{1}$ und $k_{2}$ vorkommen. Sie können aber leicht aus den Formeln eliminiert, resp. entfernt werden.

Zunächst stellt sich heraus, dass wenn man die thatsächlichen Werthe von $\alpha$ und $\beta$ mit einander multipliciert, folgender einfacher Ausdruck resultiert:

$$
\begin{aligned}
\alpha \beta & =\mathrm{A}^{2} \\
\text { also } \alpha & =\frac{\mathrm{A}^{2}}{\beta .}
\end{aligned}
$$

Und was den Werth von $\beta$ selbst betrifft, so lässt sich dieser aus folgender Betrachtung ableiten:

Wenn der Umwandlungsprozess zur Ruhe gekommen ist, so ist:

$$
\begin{gathered}
\frac{\mathrm{dC}}{\mathrm{dt}}=0, \text { also } \\
\mathrm{k}_{1} \mathrm{C}-\mathrm{k}_{2}(\mathrm{~A}-\mathrm{C})^{2}=0 .
\end{gathered}
$$

Die Concentration $\mathrm{C}$ der Saccharose ist dann ihre Endconcentration. Nennen wir diese $\mathrm{CE}_{\mathrm{E}}$, so wird die Formel

$$
\mathrm{k}_{1} \mathrm{C}_{\mathrm{E}}-\mathrm{k}_{2}\left(\mathrm{~A}-\mathrm{C}_{\mathrm{E}}\right)^{2}=0 .
$$

Berechnet man aus dieser Gleichung $\mathrm{C}_{\mathrm{E}}$, so ergiebt sich

$$
\mathrm{C}_{\mathrm{E}}=\frac{1}{2 \mathrm{k}_{2}}\left(\mathrm{k}_{1}+2 \mathrm{k}_{2} \mathrm{~A}-\sqrt{\mathrm{k}_{1}{ }^{2}+4 \mathrm{k}_{1} \mathrm{k}_{2} \mathrm{~A}}\right) \text {. }
$$

Und das ist gerade auch der eigentliche Werth von $\beta$. (Vergl. oben S. 99). Somit ist $\mathrm{C}_{\mathrm{E}}=\beta$.

Von der Gleichung (1) ist demnach das zweite Glied ganz bekannt; A ist die Anfangsconcentration der umzuwandelnden Substan $z, \beta$ die Endconcentration und

$$
\alpha=\frac{\mathrm{A}^{2}}{\text { Endconcentration }} \text {. }
$$

Beiläufig mache ich darauf aufmerksam, dass die Formel (1) a uch für die sogenannte irreversible Reaction giltig ist. Denn in diesem Fall war in $\gamma=\sqrt{k_{1}{ }^{2}+4 k_{1} k_{2} A}$ der Werth $k_{2}=0$; denn man geht ja von der Annahme aus, dass die Reaction von rechts nach links nicht stattfindet, bezw. zu vernachlässigen ist, also die entsprechende Geschwindigkeitskonstante gleich 0 gesetzt werden muss. Somit wird $\gamma=\sqrt{\mathrm{k}_{1}{ }^{2}}=\mathrm{k}_{1}$ und das ist gerade die Geschwindigkeitsconstante für die Reaction von links nach rechts.

Weiter ist $\beta$ die Endconcentration der umzuwandelnden Substanz. Bei der Annahme, dass die Reaction ganz zu Ende geht, (bei der Rohrzuckerinversion, dass am Ende kein Rohrzucker mehr vorhanden) ist $\beta=\mathrm{C}_{\mathrm{E}}=0$. 
Danach wird, da $\alpha=\frac{\mathrm{A}^{2}}{\beta}$, die Gleichung (1)

$$
\begin{aligned}
& k_{1}=\frac{1}{t} l \frac{(A-0)\left(C-\frac{A^{2}}{\beta}\right)}{\left(A-\frac{A^{2}}{\beta}\right)(C-0)} \\
& k_{1}=\frac{1}{t} l \frac{A\left(c-\frac{A^{2}}{\beta}\right)}{\left(A-\frac{A^{2}}{\beta}\right) C}=\frac{1}{t} 1 \frac{A\left(C \beta-A^{2}\right)}{C\left(A \beta-A^{2}\right)} \text {, und da } \beta=0 \\
& \mathrm{k}_{1}=\frac{1}{\mathrm{t}} \mathrm{l} \frac{\mathrm{A}\left(0-\mathrm{A}^{2}\right)}{\mathrm{C}\left(0-\mathrm{A}^{2}\right)}=\frac{1}{\mathrm{t}}+\frac{\mathrm{A}}{\mathrm{C}}
\end{aligned}
$$

Diese Formel ist genau dieselbe, welche früher für die monomoleculare Reaction ${ }^{1}$ ) abgeleitet wurde (Bd. II, S. 469) und die auch für die Inversion von Rohrzucker mittelst $\mathrm{HCl}$ benutzt wurde (Bd. II, S. 495).

Denn $\mathrm{C}$ ist die Concentration der noch rorhandenen Substanz, und diese ist gleich $(\mathrm{A}-\mathrm{x})$, wenn $\mathrm{A}$ die Anfangsconcentration dieser Substanz und $\mathrm{x}$ die der umgewandelten Menge ist,

$$
\text { demnach } k_{1}=\frac{1}{t} l \frac{A}{A-x} \text {. }
$$

Verfolgen wir jetzt wieder die Ausführungen Visser's. Wie ich bemerkte, hat er aus verschiedenen Versuchsergebnissen von ihm selbst und von Henri die $\gamma$-Werthe berechnet. Ich entnehme seiner Arbeit ein Beispiel, das in der nächten Tabelle (S. 102) zusammengestellt wird.

In dieser Tabelle ist auch die Geschwindigkeits-Constante $\mathrm{k}_{1}$ berechnet, als ob es sich bei der Inversion durch Invertase um eine regelmässige monomoleculare Reaction, wie bei der Inversion durch $\mathrm{HCl}$ handelte (Spalte III). In Spalte IV ist die Geschwindigkeitsconstante nach der Formel von Henri berechnet, in Spalte V der $\gamma \cdot$ Werth nach Visser.

Aus der Tabelle auf Seite 102 geht hervor, dass die k-Werthe von Spalte III wenig Uebereinstimmung zeigen. Das war dann auch der Grund, dass Henri unter Zugrundelegung des Begriffes der Autokatalyse, die einfache logarithmische Gleichung von Spalte III in die von Spalte IV änderte (Vergl. S. 92). Wie ersichtlich, gewährt letztere in der That übereinstimmende Werthe. Trotzdem hat Visser die Richtigkeit von Henri's Formel aus Gründen, die ich nicht näher erörtern werde, in Abrede gestellt und, wie mir scheint, mit Recht.

Leider aber giebt Viss er's eigene Formel (1), whe aus Spalte V hervorgeht, $\gamma$-Werthe, die nicht übereinstimmen.

1) D. h. im Allgemeinen für nicht umkehrbare Reactionen und auch für umkehrbare, deren Producte entfernt werden, so dass sie sich nicht mehr zu der ursprünglichen Substanz verbinden können. 
Umwandlung einer 0,25 norm. Saccharoselösung durch Invertase. $\mathrm{A}=$ Anfangsconcentration $=0,25 ; \beta=$ Endconcentration der Saccharose $=0,0027$

$$
\alpha=\frac{\mathrm{A}^{2}}{\beta}=23,148 \text {. }
$$

\begin{tabular}{c|c|r|r|r}
\hline I & II & III & IV & V \\
\hline \multirow{2}{*}{ in Minuten } & $\begin{array}{c}\text { Concentr. Zucker } \\
\mathrm{C}\end{array}$ & $\mathrm{k}={ }_{\mathrm{t}}^{1} \mathrm{l} \frac{\mathrm{A}}{\mathrm{C}}$ & $2 \mathrm{k}_{1}=\frac{1}{\mathrm{t}} \mathrm{l} \frac{\left.2 \mathrm{~A}-\mathrm{C}^{1}\right)}{\mathrm{C}}$ & $\gamma=\frac{(\mathrm{A}-\beta)(\mathrm{C}-\alpha)}{(\mathrm{A}-\alpha)(\mathrm{C}-\beta)}$ \\
\hline \hline 75 & 0,2337 & 0,00039 & 0,00075 & 0,00040 \\
150 & 0,2161 & 42 & 79 & 43 \\
240 & 0,1964 & 44 & 70 & 45 \\
690 & 0,1079 & 53 & 81 & 54 \\
1620 & 0,0232 & 64 & 81 & 67 \\
2875 & 0,0061 & 56 & 66 & 65 \\
$\infty$ & 0,0027 & & &
\end{tabular}

Man könnte geneigt sein, eine Modification des Enzyms dafür verantwortlich zu machen. Es stellte sich aber heraus, dass wenn unter möglichst aseptischen Cautelen gearbeitet wurde und ausserdem $0,5 \% \mathrm{NaFl}$ hinzugefügt war, sowohl Invertase wie Emulsin - mit diesen beiden Enzymen arbeitete $\mathrm{V}$ isser - eine lange Reihe von Tagen unverändert blieben.

Der Autor hat nun, um bei dem Mangel an Uebereinstimmung zwischen den $\gamma$-Werthen eine bessere Reactionsconstante zu bekommen, einen neuen Begriff eingeführt, denjenigen der ,Enzymintensitït66, „I". Er stellt sich vor, dass die Intensität der Enzymwirkung von der Concentrationsgrösse des umzuwandelnden Stoffes und weiter von einer Constante $k_{3}$ abhängig ist, die mit der Natur des Enzyms, mit ihrer "Vorgeschichte" (S. 85) in Zusammenhang steht.

Man darf annehmen, dass die Umwandlungsgeschwindigkeit $\frac{\mathrm{dC}}{\mathrm{dt}}$ jeden Augenblick der Intensität I, mit der das Enzym seine Wirkung entfaltet, proportional ist.

$\left.{ }^{1}\right)$ Eigentlich hat Hen ri seiner Formel eine andere Form gegeben:

$$
2 \mathrm{k}_{1}=\frac{1}{t} \mathrm{l} \frac{\mathrm{A}+\mathrm{x}}{\mathrm{A}-\mathrm{x}} \text {. (Vergl. S. 92). }
$$

- In dieser Formel ist $\mathrm{x}$ die Concentration der umgewandelten Menge; diese ist gleich der Anfangsconcentration A, minus der Concentration C der noch zurückgebliebenen Menge der noch umzuwandelnden Substanz: also $\mathrm{x}=\mathrm{A}-\mathrm{C}$.

Demnach wird die Gleichung:

$$
\begin{aligned}
& 2 \mathrm{k}_{1}=\frac{1}{\mathrm{t}} \mathrm{l} \frac{\mathrm{A}+\mathrm{A}-\mathrm{C}}{\mathrm{A}-\mathrm{A}+\mathrm{C}} \\
& 2 \mathrm{k}_{1}=\frac{1}{\mathrm{t}} \mathrm{l}^{\frac{2 \mathrm{~A}-\mathrm{C}}{\mathrm{C}}}
\end{aligned}
$$


Also

$$
-\frac{\mathrm{dC}}{\mathrm{dt}}=\left\{\mathrm{k}_{1} \mathrm{C}-\mathrm{k}_{2}(\mathrm{~A}-\mathrm{C})^{2}\right\} \mathrm{I}
$$

Wann wird nun nach dieser Gleichung die Umwandlung den Endzustand erreicht haben, bezw. wann wird $\frac{d C}{d t}=0$ sein? Natürlich, wenn

$$
\left\{\mathrm{k}_{1} \mathrm{C}-\mathrm{k}_{2}(\mathrm{~A}-\mathrm{C})^{2}\right\} \mathrm{I}=0 \text { wird. }
$$

Dieser Bedingung wird Genüge geleist, entweder, wenn

$$
\left\{\mathrm{k}_{1} \mathrm{C}-\mathrm{k}_{2}(\mathrm{~A}-\mathrm{C})^{2}\right\}=0 \text {, oder } \mathrm{I}=0 \text {. }
$$

Wie aber der Versuch lehrt, wird I nicht 0 ; denn wenn nach dem Eintritt des Gleichgewichtes eine neue Saccharosemenge hinzugefügt wird, so findet auch noch Umsetzung dieser Saccharose statt.

Also wird der endgültige Gleichgewichtszustand lediglich von der Formel $\left\{\mathrm{k}_{1} \mathrm{C}^{\cdot}-\mathrm{k}_{2}(\mathrm{~A}-\mathrm{C})^{2}\right\}=0$ bedingt, d. h. von dem reinen Ausdruck des Massenwirkungsgesetzes, aus dem sie abgeleitet wurde. Von dem nenen Begriff ,Enzymintensität" ist der Gleichgewichtszustand dem nach unabhängig.

Den neuen Begriff braucht man aber wohl, um den Zustand zu jedem beliebigen A ugenblick zu kennen.

Visser hat den I-Werth anf empirischem Wege festgestellt. Derselbe ist eine Function der Concentration A des umzuwandelnden Stoffes und einer Constante $k_{3}$, die von der Natur des Enzyms abhängig ist.

Für Saccharose-Invertase fand er: $I=\frac{\mathrm{k}_{3}}{4 \mathrm{~A}+2 \mathrm{AC}+\mathrm{C}^{2}}$

Demnaclı wird die Umsetzungsgeschwindigkeit $\frac{\mathrm{dC}}{\mathrm{dt}}$

$$
-\frac{\mathrm{dC}}{\mathrm{dt}}=\left\{\mathrm{k}_{1} \mathrm{C}-\mathrm{k}_{2}(\mathrm{~A}-\mathrm{C})^{2}\right\} \frac{\mathrm{k}_{3}}{4 \mathrm{~A}+2 \mathrm{AC}+\mathrm{C}^{2}} .
$$

Diese Formel wird integrirt und liefert dam einen Werth für $k_{2} k_{3}$.

Im Gegensatz zu den oben erhaltenen Werthen von $\gamma$ ist dieses Product constant. Dividirt man beide Producte durch einander so bekommt man $\frac{k_{1} k_{3}}{k_{2} k_{3}}=\frac{k_{1}}{k_{2}}$. (Vergl. Bd. II, S. 478.)

Es stellte sich nun heraus, dass bei Versuchen mit verschiedenen Saccharose-Concentrationen die Werthe ron $k_{k_{2}}$ dieselben waren. Und 
das galt nicht nur für die aus seinen eigenen Versuchsergebnissen erhaltenen Werthe von $\frac{k_{1}}{k_{2}}$, sondern auch für die aus Henri's Versuchen berechneten. Man darfdaraus schliessen, dass die ron Visser gegebene Vorstellung den Reactionsverlauf in richtiger Weise wiedergiebt.

Visser hat auch einen Ausdruck für I abgeleitet, der zu der Reaction von Emulsin auf Salcin gehört. Die dadurch erhaltene Formel für $\frac{\mathrm{dC}}{\mathrm{dt}}$ wurde integrirt und gab dann Werthe für $\frac{k_{1}}{k_{2}}$, welche sehr gut mit einander ïbereinstimmten. Der ron Herzog benutzte Begriff der negativen Autokatalyse (S. 93) erwies sich als rollkommen überflüssig.

Ferner passten zu den Resultaten von Visser's Ausführungen die von Schoorl erhaltenen Zahlen bei der Einwirkung von Glukose auf Harustoff [54]. Auch diese Reaction ist eine Gleichgewichtsreaction und kann versinnlicht werden durch:

Glukose + Harnstoff $\rightleftarrows$ Glukoseharnstoff.

Weiter will ich nicht auf diesen Gegenstand eingehen. Ich glaube, dass diese Ausführungen genügen werden, die für Chemiker geschriebene Arbeit für Mediciner verständlich zu machen.

\section{e) Ansichten iiber das Wesen der Katalyse.}

Ich werde hier die verschiedenen älteren Hypothesen zur Erklärung der Katalyse nicht besprechen. Man findet sie in der bekannten Abhandlung von Bredig und Mïller von Berneck und auch in Bredig's interessanter Monographie „Die anorganischen Fermente“. Ich entnehme letzterer Arbeit nur die Hypothese, die sich nach Bredig den gegenwärtigen Anschauungen am besten anpasst, und die auch mir viel Verlockendes zu haben scheint.

Bereits F a ra da y wies darauf hin, dass alle porösen Körper, auch Metalle, eine grosse Menge von Gasen auf ihrer Oberfläche verdichten können und dass diese Wirkung auch bei der Katalyse stattfindet, in dem Sinne, dass der Katalysator durch ein auswählendes Vermögen katalysirte Substanz auf sich verdichten und dadurch die Reaction begünstigen kann.

Dementsprechend meint Bodländer, dass fein vertheilte Metalltheilchen und Mangansuperoxyd Sauerstoffatome auf ihrer Oberfläche condensiren und auf diese Weise zur Oxydation des Wasserstoffs von $\mathrm{H}_{2} \mathrm{O}_{2}$ Veranlassung geben. 
Was nun die Aufnahme des Sauerstoffes durch die Metalltheilchen betrifft, so weist Bredig, wie auch Euler, darauf hin, dass im Allgemeinen die Kratalysatoren gerade diejenige Reactionscomponenten absorbiren, deren Abspaltung oder Uebertragung sie beschleunigen. Im vorliegenden Fall des Platins würde also das colloidale Metall die Rolle eines Mediums spielen, in welchem der Vorgang wegen der höheren Concentration der reagirenden Stofte und besonders wegen einer eventuell grösseren Reactionsgeschwindigkeit, in diesem Medium schneller verliefe, als ohne dieses Medium.

B redig hat versucht einen solchen einfachen messbaren Fall experimentell zu construiren. Man hätte also eine Reaction zu finden, welche im Medium A sehr vielmal schneller verläuft als in einem mit A nicht mischbaren Medium B. Ausserdem sollen die Theilungscoëfficienten (vergl. S. 73 und im Kapitel Pharmakologisches unter 4a a) der reagirenden Stoffe solche Werthe haben, dass diese Stoffe im Medium A vielmal leichter löslich sind als in Medium B. Dagegen sollen womöglich die Reactionsproducte in B leichter löslich sein als in A. Löst man nun die reagirenden Stoffe im Medium B auf, so wird die Reaction langsam verlaufen. Setzt man nun aber eine Spur des Lösungsmittels A als Emulsion hinzu, so wird diese Emulsion von A die Rolle eines, Fermentes ${ }^{2}$ spielen, d. h. die Reactionkatalytisch enorm beschleunigen.

Es ist Bredig aber nicht gelungen, einen Fall, der obigen idealen Anforderungen $\mathrm{g}$ a $\mathrm{nz}$ entspricht, $\mathrm{zu}$ finden.

Ein weiteres Moment, das hier noch zu berücksichtigen ist, ist

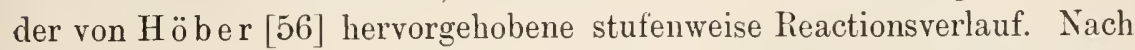
diesem Autor, dem sich Bredig anschliesst, erfolgt die Katalyse des $\mathrm{H}_{2} \mathrm{O}_{2}$ durch Platin in zwei Stufen:

1. Das Platin entnimmt dem $\mathrm{H}_{2} \mathrm{O}_{2}$ Sauerstoff; es bildet sich eine Platinsauerstoffphase; das $\mathrm{H}_{2} \mathrm{O}_{2}$ wird reducirt.

2. Der Platinsauerstoff geht mit dem noch vorhandenen $\mathrm{H}_{2} \mathrm{O}_{2}$ eine Umsetzung an, wobei $\mathrm{H}_{2}$ des $\mathrm{H}_{2} \mathrm{O}_{2}$ oxydirt wird $\mathrm{zu}_{2} \mathrm{O}$ und $\mathrm{O}_{2}$ frei wird.

Es findet also erst eine Reduction, dann eine Oxydation des $\mathrm{H}_{2} \mathrm{O}_{2}$ statt.

In der That fand Euler, dass sorgfältig von Sauerstoff befreites Platin im ersten Theile des Versuchs viel langsamere Katalyse für $\mathrm{H}_{2} \mathrm{O}_{2}$ ergab als sauerstoffhaltiges Platin.

Bei der ausserordentlichen Fähigkeit des Platins, Sauerstoff aufzunehmen und bei der feinen Vertheilung der Metalltheilchen im Hydrosol, in Folge deren eine ausserordentlich grosse Oberflächenentwicklung stattfindet, muss die Reaction äusserst schnell verlaufen.

Es erhebt sich nun weiterdie Frage, ob man diekatalytische Wirkung der organischen Fermente ingleicher Weise erklären kann. 
Zunächst sei bemerkt, dass die organischen Fermente colloider Natur sind. Insofern besteht keine Schwierigkeit, die auf das ebenfalls colloidale Platin bezüglichen Anschauungen auf die organischen Fermente zu ïbertragen. Auch bei diesen kann also die enorme Oberflächenentwicklung der Theilchen als eine günstige Bedingung für die schnell ablaufende Reaction gelten.

Indessen muss hervorgehoben werden, dass der colloidale Zustand allein für das Zustandekommen einer katalytischen Wirkung nicht genügt, denn die colloidale Kieselsäure, das colloidale Eisenoxydhydrat und noch andere Colloide katalysieren nicht.

Nach der beim Platin ausgesprochenen Anschauung muss noch dazu kommen, dass eine Substanz, die im Stande sein soll den zu katalysirenden Stoff zu zersetzen, resp. aufzubauen, im Katalysator sehr löslich ist. Diese Substanz würde für die Oxydasen Sauerstoff sein. Van hätte sich dann vorzustellen, dass das Ferment viel Sauerstoff aufnimmt und diesen dann ebenso wie beim colloidalen Platin auf die zu katalysirenden Stoffe überträgt.

Nach Höber [57] hat man dann weiter die lähmende Wirkung ron HCN und anderen Stoffen, auf die Bildung einer Verbindung dieses Giftes mit dem Platin, bezw. der Oxydase zurückzuführen. in dem Sinne, dass das Bindungsvermögen für 0 dadurch herabgesetzt wird.

Diese Hypothese bedarf natürlich einer weiteren eingehenden experimentellen Bearbeitung.

Uebrigens hat sich aus den Untersuchungen von Emil Fischer mit grosser Deutlichkeit herausgestellt, dass ein bestimmtes Enzym nur wirksam ist gegenüber einer Verbindung von bestimmter Configuration, ja selbst aus stereoisomeren Verbindungen eine Auswahl zu treffen weiss. Der Schlïssel „Ferment" muss zu dem Schlosse "Substrat" passen.

Ich gehe auf den Mechanismus der Katalyse organischer Fermente nicht weiter ein, und verweise hierfür, sowie für manch andere auf die Fermente bezügliche Frage auf das bereits citirte ausgezeichnete Werk von C. Oppenheimer [58]: Die Fermente und ihre Wirkungen. 


\section{Drittes Kapitel.}

\section{Zur Muskel- und Nervenphysiologie.}

\section{Litteratur.}

1. Nasse, Pflüg er's Archiv. 2. 1869. S. 114; 11. 1875. S. 140.

2. Tamman, Zeitschrift f. physik. Chemie. S. 1891. S. 685 .

3. Kahlenberg und True, The Botanical Gazette. 22. 1896. p. 81.

4. J. Loeb, P flüger's Archiv. 69. 1898. S. 1.

5. J. Loeb, P flü ger's Archiv. 71. 1898. S. 457.

6. J. Loeb, Pflüger's Archiv. 56. 1894. S. 270.

7. J. Loeb, Pflü ger's Archiv. 75. 1899. S. 303.

8. W. Pauli, Ueber die physiologischen Zustandsänderungen der Eiweisskörper. Wiener akad. Anzeiger. 12. Oktober 1899.

8a. W. Panli, Ueber physikalisch-chemische Methoden und Probleme in der Medicin. Wien 1900.

8b. W. Pauli, P fl ü ger's Archiv. 78. 1899. S. 315.

9. J. Loeb, Ueber Ionen, welche rhythmische Zuckungen der Skelettmuskeln hervorrufen. Festschrift für Ad. Fick, Braunschweig 1899.

10. J. Loeb, American Journal of Physiol. 5. 1901. p. 362.

11. J. Loeb, American Journal of Physiol. 3. 1900. p. 327.

12. J. Loeb, American Journal of Physiol. 3. 1900. p. 383.

13. J. Loeb, Pflüg er's Archiv. 80. 1900. S. 229.

14. Lingle, American Journal of Physiol. 4. 1900. p. 265.

15. Miss Moore, American Journal of Physiol. 4. 1900. p. 386.

16. Howell, American Journal of Physiol. 2. 1898. p. 47.

17. Sidney Ringer, Journal of Physiol. 3. p. 380 ; 4. p. 29; 8. p. 15; Papers by Sidney Ringer London 1897.

18. Langendorff und Hueck, Pflüger's Archiv. 96. 1903. S. 473.

19. Howell, American Journal of Physiol. 6. 1901/1902. p. 181.

20. J. Loeb. American Journal of Physiol. 6. 1902. p 411.

21. Hardy, Journal of Physiol. 24. 1899. p. 288.

22. Hardy, Proceedings of the Royal Society. 66. 1900. p. 110.

23. J. Loeb. Pflüg er's Archiv. 85. 1901. S. 68. 
24. Overton, Pflüger's Archiv. 92. 1902. S. 115.

25. Overton, Pflüger's Archiv. 92. 1902. S. 346.

26. Tschagowetz, Zeitschr. d. russ. Gesellschaft f. physik. Chemie (russisch). 27. 1897. S. 430. Ref. bei Oker-B lom. Pflüger's Archiv. 84. 1901. S. 194.

27. Hermann, Untersuchungen über den Stoffwechsel der Muskeln. 1867. S. 125.

28. Aıg. D. Waller, Thierische Elektricität. Leipzig 1899 (Deutsche Uebersetzung).

29. Oker-Blom, Pflüge r's Archiv. \$4. 1901. S. 191.

30. Walden, Zeitschr. f. physik. Chemie. 1899. S. 699.

31. Hir'schmamn, Pflüger's Archiv. 49. 1891. S. 301.

32. Griitzner, Pf] ü ger's Archiv. 53. 1893. S. 83.

33. Grïtzner, Pflüger's Archiv. 55. 1894. S. 69.

34. Weinland, P flüg er's Archiv. 5S. 1894. S. 105.

35. Posternak, Annales de l'Instit. Pasteur. 15. 1901. p. 84.

36. von Zeynek, Nachrichten der Königl. Gesellschaft d. Wissensch. in Göttingen. Physik. Mathem. Classe. 1899. S. 94.

37. Nernst, Nachrichten der Königl. Gesellschaft d. Wissensch. in Göttingen. Physik. Mathem. Classe 1899. S. 104.

38. Bor'uttau, P flüge r's Archiv. 76. 1899. S. 626; Internal Physiologen-Congress in Cambridge. Supplementheft zum Journal of Physiol. 1899.

39. Bornttau, P flüger's Archiv. 90. 1902. S. 233.

\section{Verhalten von Froschmuskeln in Salzlösungen.}

a) Untersuchungen von Nasse.

O. Nasse hat zuerst untersucht, ob ein Zusammenhang zwischen den Concentrationen verschiedener Salze bestand, in welchen der Froschmuskel am längsten reizbar blieb. Bringt man vorsichtig und sorgfältig abpräparirte Froschmuskeln mit dem 100-fachen ihrer Volumina von Kochsalzlösung verschiedener Concentrationen zusammen, so bemerkt man, dass die Froschmuskeln ihre Fähigkeit auf elektrische Reize zu reagiren, in Lösungen die mehr und weniger als $0,6 \% \mathrm{NaCl}$ enthalten, schneller verlieren als in der $0,6 \%$ igen Lösung. Je verdünnter, bezw. je concentrirter die Salzlösungen sind, um so schneller verlieren die Muskeln ihre Reactionsfähigkeit.

Wie für Kochsalzlösungen eine bestimmte Concentration für die Erhaltung der Lebensäusserungen des Froschmuskels besonders günstig ist, so ergiebt sich nach Nasse für jedes Salz eine bestimmte Lösung, in der die Muskeln länger verweilen können als in concentrirteren oder verdünnteren Lösungen, ohne die Fähigkeit einzubüssen auf Reize zu reagiren.

Nasse verglich diese Optimum-Concentrationen verschiedener Salze mit einander, doch führten die Untersuchuıgen nicht zur Erkemntniss eines gesetzmässigen Zusammenhanges. 
Unmittelbar nachdem ich 1883 gefunden hatte, dass rothe Blutkörperchen dem Gesetze der isotonischen Coëfficienten gehorchten, untersuchte ich auf rechnerischem Wege, ob das auch mit $N$ asse's Optimumlösungen für Froschmuskeln der Fall war. Es ergab sich, dass viele und grosse Abweichungen vorhanden waren, also neben der einfachen Wasseranziehung unzweifelhaft noch andere Factoren eine Rolle spielen mussten. Ich wendete mich daher, da es zunächst nur in meiner Absicht lag, zu erforschen bei welchen Lebenserscheinungen die isotonischen Coëfficienten deutlich zu Tage treten, bis auf Weiteres von diesem Gegenstande ab und veröffentlichte auch das Resultat nicht.

Später hat Tamman dasselbe unternommen und das Resultat mitgetheilt [2]. Er drückte die von Nasse erhaltenen Zahlen in Gefrierpunkterniedrigungswerthen aus.

Die Optimum-Concentrationen lassen sich in drei Gruppen einreihen.

\section{I.}

\begin{tabular}{|c|c|c|c|}
\hline $\mathrm{TaCl}$ & $0,6 \%$ & $0,103 \mathrm{Mc}$ & (Grammmolekül pro Liter) \\
\hline $\mathrm{NaBr}$ & 1,2 & 0,116 & \\
\hline $\mathrm{NaJ}$ & 1,75 & 0,116 & \\
\hline $\begin{array}{l}\mathrm{CH}_{3} \mathrm{COO} \mathrm{Na} \\
\text { (Natriumacetat) }\end{array}$ & 0,95, & 0,116 & \\
\hline $\mathrm{SO}_{4}$ & $\mathbf{1}, 86$ & 0,155 & \\
\hline
\end{tabular}

Die Gefrierpunkterniedrigung all dieser Salzlösungen ist dieselbe und schwankt innerhalb naheliegender Grenzen um - $\mathbf{0 , 3 6 4}^{\circ}$.

Die zweite Gruppe ist

$\begin{array}{llll}\mathrm{Na}_{2} \mathrm{SO}_{4} & 1,44 \% & 0,099 \mathrm{Mol} \\ \mathrm{Na}_{2} \mathrm{HPO}_{4} & 1,55 & 0,109{ }^{n} \\ \mathrm{MgCl} \mathrm{Cl}_{2} & 0,87 & \pi & 0,092{ }^{n} \\ \mathrm{~B}_{2} \mathrm{O}_{3} & 2,5 & \pi & 0,357\end{array}$

Bei dieser Gruppe ist der Werth von $\Delta$ höher; für $\mathrm{Na}_{2} \mathrm{SO}_{4}$ liegt er bei $-\mathbf{0 , 4 3 0}{ }^{\circ}$ und für $\mathrm{MgCl}_{2}$ bei $-\mathbf{0 , 4 5 4 ^ { \circ }}$.

Die dritte Gruppe ist

\begin{tabular}{|c|c|c|c|c|c|c|c|c|}
\hline $\mathrm{rCl}$ & 0,7 & $\%$ & 0,093 & Mol & $\mathrm{Mg}\left(\mathrm{NO}_{3}\right)_{2}$ & 0,74 & & 0,050 \\
\hline $\mathrm{KNO}_{3}$ & 0,7 & $\pi$ & 0,068 & $\pi$ & $\mathrm{Ca} \mathrm{Cl}_{2}$ & 0,28 & $\pi$ & 0,025 \\
\hline $\mathrm{KBr}$ & 0,35 & $\pi$ & 0,029 & $\pi$ & $\mathrm{Ca}\left(\mathrm{NO}_{3}\right)_{2}$ & 0,83 & $\pi$ & 0,056 \\
\hline $\mathrm{SO}_{4}$ & 0,25 & , & 0,014 & n, & $\mathrm{SrCl}_{2}$ & 0,50 & $\pi$ & 0,031 \\
\hline $\left.\mathrm{H}_{4}\right) \mathrm{Cl}$ & 0,35 & , & 0,065 & ， & $\mathrm{Sr}\left(\mathrm{NO}_{3}\right)_{2}$ & 0,64 & $\pi$ & 0,030 \\
\hline $\left.\mathrm{H}_{4}\right) \mathrm{NO}_{3}$ & 0,2 & $n$ & 0,025 & , & $\mathrm{Ba} \mathrm{Cl}_{2}$ & 0,54 & $\pi$ & 0,023 \\
\hline $\left.\mathrm{H}_{4}\right) \mathrm{Br}$ & 0,4 & , & 0,040 & $n$ & $\mathrm{Ba}\left(\mathrm{NO}_{3}\right)_{2}$ & 0,64 & $\pi$ & 0,024 \\
\hline $\left.\mathrm{H}_{4}\right)_{2} \mathrm{SO}_{4}$ & 0,25 & , & 0,018 & x & $\mathrm{As}_{2} \mathrm{O}_{3}$ & 2,00 & » & 0,100 \\
\hline
\end{tabular}

Diese Lösungen sind nicht isosmotisch, stimmen aber darin unter einander überein, dass die Gefrierpunkterniedrigungen kleiner sind als 
bei den beiden anderen Gruppen; so ist z. B. für $\mathrm{CaCl}_{2} \Delta=-\mathbf{0 , 1 2 4}{ }^{\circ}$, für $\mathrm{SrCl}_{2}-\mathbf{0 , 1 8 3}{ }^{\circ}$, für $\mathrm{Ca}\left(\mathrm{NO}_{3}\right)_{2}-\mathbf{0 , 2 3 8 ^ { \circ }}$.

Zur Beurtheilung dieser Zahlen sei noch hervorgehoben, dass in $0,6 \%$ Chlornatriumlösung die Froschmuskeln längere Zeit ihre Reizbarkeit behalten als in den Optimumlösungen anderer Salze.

Ich habe die Zahlen hier mitgetheilt, nicht weil etwa daraus der Einfluss des osmotischen Druckes auf die Haltbarkeit der Muskeln besonders deutlich hervorgeht, sondern weil man hier ein relativ grosses Thatsachenmaterial vor sich hat, das als Grundlage für weitere Untersuchungen über Eindringen und Wirkung von Salzen und deren Ionen dienen kann.

Denn dass es sich hier nicht um eine blosse Wasseranziehung handelt, braucht nicht hervorgehoben zu werden. Man werfe nur einen Blick auf die Differenzen der Gefrierpunkterniedrigung.

Dass hier wirklich ausser osmotischem Druck noch andere Factoren in Betracht kommen, geht auch aus den weiteren Untersuchungen von Loeb und Overton hervor, von denen jetzt die Rede sein wird.

\section{b) Untersuchungen von J. Loeb.}

Jacques Loeb hat eine Reihe von Arbeiten ausgeführt, welche bezweckten die Wirkung der Ionen bei verschiedenen physiologischen Processen zu untersuchen.

Kiahlenberg und True [3] waren ihm darin vorangegangen, indem sie von verschiedenen Säuren, $\mathrm{HBr}, \mathrm{HCl}, \mathrm{HNO}_{3}$ und $\mathrm{H}_{2} \mathrm{SO}_{4}$ diejenige Concentration ermittelten, welche Lupinenkeimlingen noch eben erlaubte, 16-24 Stunden zu wachsen. Es stellte sich heraus, dass diese Concentrationen gerade so gross sein mussten, dass die Concentration der $\mathrm{H}^{-}$-Ionen bei allen dieselbe war. Hiergegen erhebt Loeb aber den Einwand [4], dass, wenn Jemand behauptete, die betreffenden Säuren haben in diesen Versuchen nicht nach der Zahl der H-Ionen, sondern nach der Zahl der Säuremoleküle gewirkt, sich ein solcher Einwand aus den Zahlen von Kahlenberg und True nicht wiederlegen liesse. Das rïhrt daher, dass die Reactionsgrenzen nicht mit genügender Genauigkeit zu ermitteln waren. Um diesem Einwand zu entgehen, benutzte Loeb solche Reactionen, die eine exacte quantitative Bestimmung der Wirkung zuliessen [4]. Als solche Reactioneu wählte er aus:

Erstens die Wasseraufnahme des Muskels unter dem Einfluss von Elektrolyten. Der Autor hatte nümlich gefunden, dass der Wadenmuskel des Frosches, der bekanntlich im Allgemeinen ungefähr 
den osmotischen Druck einer 0,7\% igen Kochsalzlösung besitzt, bei Zusatz einer Spur einer Säure oder Base zu dieser Kochsalzlösung, beträchtlich an Gewicht zunimmt und zwar in Folge von Wasseraufnahme.

Die zweite Reaction, die er auswählte, war der Einfluss der Elektrolyte auf die Reizschwelle.

Als Reizquelle dienten Inductionschläge und als Maass der Reizschwelle der grösste Rollenabstand, bei dem noch eben eine merkbare Contraction stattfindet. Diese Methode besitzt aber nach dem Verfasser nicht den gleichen Grad von Genauigkeit wie die erste Methode.

a) Ueber den Wassergehalt der Muskelsubstanz unter dem Einfluss von Säuren.

Es wurden $1 / 10$ normal Säurelösungen angefertigt, also z. B. von $\mathrm{HCl}(1+35,5)$ $=36,5 \mathrm{~g}$ pro 10 Liter; von $\mathrm{H}_{2} \mathrm{SO}_{4}{ }^{1 / 2} \mathrm{Mol}={ }^{1 / 2}(2+32+64)=49 \mathrm{~g}$ pro 10 Liter. Von diesen Lösungen wurden je $5,10,15$ oder 20 cc zu 100 cc einer $0,7 \%$ igen

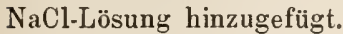

Ein Gastrocnemius des Frosches wurde u n ve rlet $\mathrm{z}$ t herauspräparirt, rasch zwischen zwei Blättern Filtrirpapier an der Oberfläche abgetrocknet, von der Sehne befreit, zwischen zwei Uhrgläser gebracht, gewogen und dann in die oben erwähnte Lösung gelegt.

Nachdem der Muskel einige Zeit darin verweilt hatte, wurde derselbe wieder zwischen Filtrirpapier sorgfältig an der Oberfläche getrocknet und wieder gewogen. Nach Loeb ist die Methode auf $5 \mathrm{mg}$ genau.

Bei Anwendung dieser Methode waren folgende Umstände zu berücksichtigen: Da der Austausch der Stoffe zwischen Muskel und Lösung an der Oberfläche stattfindet, so ist es nöthig für dieselbe Versuchsreibe nur Muskeln von nahezu gleichem Gewicht und folglich auch gleicher Oberfläche auszuwählen. Ferner ist zu beachten, dass der osmotische Druck des Froschgastrocnemius nicht unbeträchtlichen Schwankungen unterliegt, je nachdem das Thier vorher unruhig war oder geruht hatte. Will man also die Wirkung verschiedener Stoffe vergleichen, so muss man darauf achten, dass man Frösche benutzt, die seit 24 Stunden möglichst unter den gleichen Bedingungen (Licht, Wasser, Temperatur, Sauerstoffversorgung) gewesen sind. Selbst dann bleiben noch individuelle Verschiedenheiten bestehen. Dieser Schwierigkeit kann man nur durch Anstellung einer grösseren Zahl von Versuchen begegnen. Ich gebe nunmehr einige Versuche mit Salpetersäure, Salzsäure und Schwefelsäure wieder.

Es wurden von den betreffenden $1 / 10$ normalen Lösungen je 5 cc zu 100 cc $\mathrm{NaCl} 0,7 \%$ hinzugesetzt. Die Säuren waren also in einer Verdïnnung $(\mathrm{V})$ von $1 / 200$ Normalität vorhanden.

Es ergab sich nun, dass die Muskeln innerhalb einer Stunde $i_{1}^{\&}$ Mittel um $5,7 \%, 6,1 \%$ und $6,5 \%$ an Gewicht zugenommen 
hatten, während in der nicht mit Säureversetzten 0,70\% igen NaCl-Lösung, das Gewicht der Muskeln immer unverändert blieb, ja sogar eher ein wenig abnahm.

Loeb legte sich nun die Frage vor, ob dieser Einfluss der Säuren auf Ionenwirkung zurïckzuführen sei. Dazu ermittelte er zuerst, in welchem Grad die Säuren bei der genannten Verdünnung dissociirt sind.

Ich will die Berechnung für Salzsäure bei $25^{\circ} \mathrm{C}$. vorführen. Die Dissociationscoëfficient $\alpha$, d. h. der Procentgehalt der dissociirten Moleküle ist $\frac{\Lambda_{\mathbf{v}}}{\Lambda_{\infty}} \cdot \Lambda_{\mathrm{v}}$ ist die Leitfähigkeit der Salzsäure bei der Verdünnung V (200). Diese beträgt nach Ostwald 377 .

Um die Leitfäligkeit $\Lambda_{\infty}$, bei unendlicher Verdünnung, zu berechnen, nimmt man die Summe der Leitfähigkeit des Wasserstoffions $l_{\mathrm{H}} \cdot$ und der des Chlorions $\mathrm{l}_{\mathrm{Cl}}{ }^{\circ}$; diese sind bei $25^{\circ} 325$ bezw. 70,2.

Somit ist $\alpha=\frac{377}{395,2}=0,95$.

$$
\Lambda_{\mathrm{V}}=\mathrm{l}_{\mathrm{H}} \cdot+\mathrm{l}_{\mathrm{Cl}^{\prime}}=325+70,2=395,2 .
$$

Man sieht, die $\mathrm{HCl}$ ist bei der Verdünnung $\mathrm{V}=200$ fast vollständig in ihre Ionen dissociirt. Das Gleiche ist bei der äquimolecularen $\mathrm{HNO}_{3}$-Lösung $(0,96)$ der Fall, während für $\mathrm{H}_{2} \mathrm{SO}_{4}$ eine etwas schwächere Dissociation gefunden wird.

Loeb folgert hieraus, dass die Gewichtszunahme des Muskels eine Ionenwirkung sei, und dass die wirksamen Ionen die Wassertoffionen sein müssen.

Es ist nun die Frage, auf welche Weise die letzteren die Gewichtszunahme herbeiführen. Einfach dadurch, dass sie in den Muskel eindringen? Es lässt sich berechnen, dass selbst, wenn die ganze Säuremenge einträte, kaum eine nennenswerthe Gewichtsvermehrung des Muskels stattfinden würde. Die Gewichtszunahme ist also keinesfalls auf ein direktes Eindringen von $\mathrm{H}^{-}$-Ionen in den Muskel zurückzuführen. Man muss also an eine Wasseraufnahme denken, denn das Trockengewicht eines derartigen mit Säure behandelten Muskels gleicht genau demjenigen eines nicht mit Säure behandelten. Es entsteht also die weitere Frage, wie die eingedrungenen Wasserstoffionen Wasseraufnahme herbeiführen können. Loeb stellt sich vor, đass die Wasserstoffionen durch eine Art Fermentation (Katalyse) Säurebildung herbeiführen. Die Säure steigert den osmotischen Druck innerhalb des Muskels und es tritt Wasser ein. Gleiche Wasserstoffmengen werden somit eine gleiche Gewichtsvermehrung des Muskels veranlassen.

Diese Erklärung für die Wasseraufnahme kann mich nicht recht befriedigen. Wohl kann man zugeben, dass Fermentation eine Steigerung 
des osmotischen Drucks herbeiführen kann; aber Loebs Versuche berechtigen nicht zu der Annahme, dass die Säuren durch ihre $\mathrm{H}^{-}$-Ionen hier wirken, zumal der Autor findet, dass die organischen Säuren grosse Abweichungen zeigen $[2,3]$.

In der folgenden Tabelle stelle ich die bei organischen Säuren erzielten Ergebnisse zusammen, und füge zu gleicher Zeit die Dissociationsgrade der benutzten Säuren bei der angewandten Verdünnung hinzu. Diese Verdünnung war ${ }^{1 / 10}$.

\begin{tabular}{|c|c|c|c|}
\hline$S \ddot{a} u r$ e $\mathrm{n}$ & & $\begin{array}{c}\text { Mittlere Gewichtszunahme } \\
\text { des Muskels }\end{array}$ & $\begin{array}{c}\text { Dissociationsgrad } \alpha \\
\text { der gebrauchten Säuren }\end{array}$ \\
\hline Ameisensäure . . & . . & $5,0 \%$ & 0,14 \\
\hline Essigsäure . . . & .. & 3,9 & 0,04 \\
\hline Trichloressigsäure & . . & 7,1 & 0,94 \\
\hline Milchsäure . . . & . & 7,2 & 0,11 \\
\hline Valeriansäure . . & . & 5 & 0,04 \\
\hline Mandelsäure . & . . & 7,2 & 0,19 \\
\hline${ }_{1 / 2}^{1 / 2}$ Oxalsäure . . & .. & 6,9 & 0,87 \\
\hline${ }^{1}, 2$ Bernsteinsäure . & • & 5,6 & 0,08 \\
\hline${ }^{1 / 2}$ Aepfelsäure . & • & 5,1 & 0,18 \\
\hline${ }^{1}{ }_{2}$ Rechts-Weinsäure & e & 6,3 & 0,27 \\
\hline${ }^{1 / 2}$ Traubensäure. & . . & 6,2 & 0,27 \\
\hline
\end{tabular}

Aus dieser Tabelle geht hervor, dass die Gewicht.(Wasser-)zunahmen des Muskels keineswegs mit dem Dissociationsgrade (der Con-

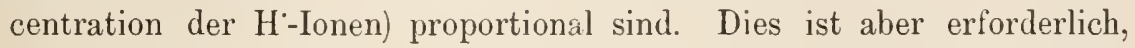
wenn man diese Wasseraufnahme auf einen katalytischen Vorgang zurïckführen will, und hat sich z. B. auch bei der Zuckerinversion und bei der Zerlegung ron Methylacetat durch die verschiedenartigsten Säuren mit aller Schärfe ergeben.

Loeb hat die Abweichungen dadurch zu deuten gesucht, dass in seinen Fällen auch die Anionen der betreffenden Säuren (Ameisen-, Essig-, Milch-, Valerian-, Mandel-, Bernstein-, Wein-, Traubensäure) directe oder indirecte Einflüsse auf den Muskel ausüben, in Folge deren der osmotische Druck und auch die Wasseraufnahme sich ändern.

Hierfür sprechen nach Loeb folgende Thatsachen. Wenn man einen Froschmuskel eine Stunde in 0,7\% iger NaCl-Lösung verweilen lässt, so bleibt das Gewicht unverändert. Nach 18-stündigem Verweilen hat der Gastrocnemius der $1,239 \mathrm{~g}$ wog, um $88 \mathrm{mg}$, also um $7^{0} 0$ seines Anfanggewichtes, zugenommen. Dabei war der Muskel nicht abgestorben und unerregbar geworden, sondern er zeigte noch eine relativ hohe Er.

H a mburger, Osmot. Druek. 11I. Band. 
grebarkeit. Während seine Reizschwelle Anfangs zu etwas über $420 \mathrm{~mm}$ Rollenabstand gefunden wurde, war der Muskel nach 18-stündigem Verweilen in $0,7 \%$ iger $\mathrm{NaCl}-L o ̈$ sung noch bei $330 \mathrm{~mm}$ Rollenabstand erregbar. Der Verfasser nimmt an, dass Säurebildung im Muskel die Ursache einer Steigerung des osmotischen Drucks und folglich auch der Wasseraufnahme ist.

$\mathrm{Ja}$ selbst in hyperisotonischen Lösungen ( $\mathrm{NaCl}$ von sogar $4,9 \%$ ) kann noch eine Wasseraufnahme stattfinden. Erst ninumt das Gewicht des Muskels ab, aber nach mehreren Stunden macht die Abnahme einer Gewichtzunahme Platz. Diese rührt nach dem Autor nicht etwa von einer NaCl-Aufnahme her, demn die Trockensubstanz des Muskels bleibt nahezu unverändert. Es liegt also eine Wasseraufnahme vor und diese wird dadurch verursacht, dass im Muskel Säure gebildet wird, die den osmotischen Druck steigert. In der That konnte der Verfasser eine Säurebildung auf qualitativem Wege nachweisen.

Ich bezweifle keinen Augenblick, dass Säurebildung im Muskel stattfinden kann und dass dadurch der osmotische Druck ansteigt, ebensowenig wie ich bezweifle, dass auch bei Hypertrophie des Muskels eine Steigerung des osmotischen Druckes im Zellinnern stattfinden muss, wie der Verfasser früher hervorhob [6]. Etwas Anderes ist es aber, ob die in lyyperisotonischen $\mathrm{NaCl}$-Lösungen auftretende Quellıng lediglich einer Zunahme des osmotischen Druckes zugeschrieben werden muss. Ich halte es für nicht unmöglich, dass zwar Säurebildung eine Steigerung der wasseranziehenden Kraft herbeifübrt, aber dass diese doch nicht der Hauptfactor der Wasseraufnahme ist. Denn erstens hat Loeb nicht nachgewiesen, dass, sobald die Gewichtabnalıme des Muskels ab$z u f a l l e n$ anfängt, Säurebildung eingetreten ist; zweitens hat er auch nicht gezeigt, dass die Menge der gebildeten Säure, bezw. deren osmotischen Druck, wirklich so bedeutend ist, dass der in der ersten Stunde beobachtete Wasserverlust des Gastrocnemius von 17,4\% des Anfanggewichts, einer Wasseraufnahme von $20 \%$ Platz machen könnte.

Ich verneine die Möglichkeit nicht, ich halte Loeb's Annahme nur nicht für erwiesen. Unter diesen Umständen scheint es mir bereclitigt eine andere Deutung vorzulegen. Wäre es nicht möglich, dass es sich hier in der Hauptsache um Diffusion und Imbibition handelt?

Legt man einen Froschmuskel in $4.9^{\circ} 0$ ige Koclısalzlösung, so wird derselbe durch Wasserabgabe sehr bald erheblich an Gewicht verlieren; aber während dies geschielte, findet Diffusion von $\mathrm{NaCl}$ in den Muskel statt, 
weil der Kochsalzgehalt ausserhalb des Muskels ein grösserer ist als innerhalb. Zwar hat Loeb keine Gewichtvermehrung der Trockensubstanz beobachtet. Aber hat er denn nachgewiesen, dass der Muskel absolut keine festen Bestandteile an die Flüssigkeit abgegeben hat? Aus seiner Arbeit geht das nicht herror; und wie leicht können nicht auch etwas mehr Kochsalzmoleküle in den Muskel hineindiffundiren, als andere Moleküle ihn verlassen, ohne dass es bei der Bestimmung des Trockenrïckstandes bemerkbar wird. Und gerade das liochsalz hat eine relativ grosse wasseranziehende Kraft. Es kann also die Differenz im osmotischen Druck von Muskelinhalt und Umgebung sich durch Diffusion zu Gunsten des Muskels verschieben.

Weiter kann noch die Imbibition von Flïssigkeit sich geltend machen, die doch bei lebenden Geweben niemals vermisst wird.

Ist es nicht denkbar, dass $\mathrm{NaCl}$-Lösung, bezw. Wasser, imbibirt wird, und dass Säuren diese Imbibition beeinflussen, sowie schliesslich dass der Grad dieser Imbibition nicht lediglich von der $\mathrm{H}$-Ionenconcentration, sondern auch von der Permeabilität der Muskelsubstanz für die Anionen und ungespaltenen Molecüle abhängt?

Nach Beendigung dieses Abschnittes wurde eine Arbeit ron Overton reröffentlicht, in welcher gleichartige Einwände gegen die Loeb'sche Auffassung erhoben werden. (Vergl. unten S. 133.)

\section{B) Einfluss von Basen.}

Loeb hat gleichartige Versuche, wie er sie mit Säuren anstellte, auch mit Basen ausgefuihrt. Es wurden hauptsächlich berücksichtigt $\mathrm{LiOH}, \mathrm{NaOH}$ und $\mathrm{KOH}$. Ferner wurden einige Versuchreihen mit $1 / 2 \mathrm{Ba}(\mathrm{OH})_{2}$ und $1 / 2 \mathrm{Sr}(\mathrm{OH})_{2}$ angestellt. Die Versuche ergaben, dass die erwähnten Basen alle den gleichen Einfluss auf die Wasseranfnahme des Huskels hatten, wenn sie in solchen Concentrationen angewendet wurden, dass die gleiche Zahl von Hydroxylgruppen im gleichen Volumen der Lösung enthalten waren.

Ein Paar Beispiele:

Verdünnung 200 (d. l. $1 \mathrm{~g}$-Aequivalent in $2001 \mathrm{NaCl} 0,7^{\circ} \circ$ aufgelöst).

$\begin{array}{lc}\text { Basen } & \begin{array}{r}\text { Gewichtzunahme } \\ \text { des Muskels. }\end{array} \\ \mathrm{LiOH} & 8,2 \% \\ \mathrm{NaOH} & 8,5 \\ \mathrm{~K} \mathrm{OH} & -\quad 6,5\end{array}$




\begin{tabular}{lc|lc}
\multicolumn{2}{r|}{ Verdünnung 100.} & \multicolumn{2}{c}{ Verdünnung 50.} \\
$\mathrm{Li} \mathrm{OH}$ & $15,5 \%$ & $\mathrm{Li} \mathrm{OH}$ & $25,5 \%$ \\
$\mathrm{Na} \mathrm{OH}$ & 15,8 & $\mathrm{Na} \mathrm{OH}$ & 27,1 \\
$\mathrm{~K} \mathrm{OH}$ & 15,6 & $\mathrm{~K} \mathrm{OH}$ & 23,5 \\
$1 / 2 \mathrm{Ba}(\mathrm{OH})_{2}$ & 18,1 & $1 / 2 \mathrm{Ba}(\mathrm{OH})_{2}$ & 27,2 \\
$1 / 2 \mathrm{Sr}(\mathrm{OH})_{2}$ & 15,4 & $1 / 2 \mathrm{Sr}(\mathrm{OH})_{2}$ & 25,8
\end{tabular}

Aus diesen Daten geht hervor, dass wenn man zu einer 0,7 prozentigen NaCl-Lösung äquimoleculare Mengen Li OH, $\mathrm{NaOH}$ und $\mathrm{KOH}$ $1 / 2 \mathrm{Ba}(\mathrm{OH})_{2}$ und ${ }^{1 / 2} \mathrm{Sr}(\mathrm{OH})_{2}$ hinzugefügt, die Gewichtzunahme der Muskeln dieselbe ist. Weiter zeigt sich, dass bei grösserer Laugeconcentration auch die (iewichtzunahme eine grössere ist.

Loeb legt den Nachdruck darauf, dass in den angewandten Verdünnungen die Dissociation eine so vollständige ist, dass es sich hier lediglich um Ionenwirkungen handelt, und zwar - wie er hinzufügt ausschliesslich um Wirkungen der Hydroxylionen. Dieser letzte Theil der Schlussfolgerung fordert zum Nachdenken auf, nicht nur, weil man sich fragen muss, auf welche Weise die $\mathrm{OH}^{\prime}$-Ionen zur Wasseraufnahme Veranlassung geben, sondern auch, wie es kommt, dass die Metallionen, die doch sonst, wie L o eb weiter nachgewiesen hat, einen so verschiedenartigen und kräftigen Einfluss auf den Muskel ausüben, hier ganz in den Hintergrund treten.

Es scheint sehr erwünscht, dass man noch eine grössere Anzahl gleichconcentrirte aber in verschiedenen Graden dissociirte Lösungen von verschiedenen Basen in dieser Richtung untersucht, um zu prüfen, ob auch bei diesen die Wasseraufnahme immer mit der Hydroxylionen-Concentration parallel geht.

\section{ү) Die Wirkung einfacher Salzlösungen.}

In einer dritten Arbeit über die Wasseraufnahme des Muskels hat der Verfasser [7] auf die merkwürdige Thatsache aufmerksam gemacht, dass ein Froschmuskel nach dem Einbringen in verschiedenartige Salzlösungen, die mit einer 0,7\% \% igen NaCl-Lösung äquimolecular sind, in einigen Salzen nach längerer Zeit (18 Stunden) Wasser aufnimmt, in andern abgiebt.

Es geht dies aus der folgenden Tabelle hervor. (Gewichtzunahmen in Prozenten des Anfanggewichts des Muskels sind mit + , Gewichtabnahmen mit - bezeichnet.

\begin{tabular}{l|l|l|l}
$\mathrm{LiCl}-1 \% \%$ & $\mathrm{NaCl}+6 \%$ & $\mathrm{~K} \mathrm{Cl}+45,7 \%$ & $\mathrm{CaCl} 2-20 \%$ \\
$\mathrm{LiBr}-10 \%$ & $\mathrm{NaBr}+7 \%$ & $\mathrm{~K} \mathrm{Br}+41^{\circ} \%$ & \\
$\mathrm{LiJ}-3 \%$ & $\mathrm{NaJ}+10 \%$ & $\mathrm{~K} \mathrm{~J}+45 \%$ &
\end{tabular}


Nun hatte, wie oben erwähnt, der Verfasser gefunden, dass der Muskel eine erhebliche Wassermenge aufnimmt, wenn man zu einer $0,7 \%$ igen $\mathrm{NaCl}-\mathrm{L} o ̈ s u n g$ ein wenig Säure hinzufügt. Es war die Frage, was geschehen würde, wenn man statt einer $0,7 \%$ igen $\mathrm{NaCl}$-Lösung eine äquimoleculare $\mathrm{K} \mathrm{Cl}$ - und $\mathrm{Ca} \mathrm{Cl}_{2}$-Lösung mit etwas Säure versetzte und auf den Muskel einwirken liess. Es ergab sich aus diesen Versuchen das merkwürdige Resultat, dass Säuren die Flüssigkeitsaufnahme des Muskels in Kaliumsalzen erheblich verringerten und in $\mathrm{Chlor}$ calcium-Lösungen bedeutend förderten. In einem Versuche nahm ein Muskel in einer isotonischen KI-Lösung in 18 Stunden $35 \%$ seines Gewichtes zu, in derselben KI-Lösung mit dem erwähnten Säurezusatz nur $6,2 \%$ !

So verlor der Muskel in einer isotonischen $\mathrm{CaCl}_{2}$-Lösung in 18 Stunden ca. $20 \%$ seines Gewichtes, wenn man zu 100 cc der $\mathrm{Ca} \mathrm{Cl}_{2}$-Lösung 10 cc einer ${ }^{1} / 10 \mathrm{n}$. $\mathrm{H} \mathrm{NO}_{3}$-Lösung zugefügt hatte.

Kalium- und Calciumsalze haben hier also eine entgegengesetzte Wirkung. Auffallend ist es, dass sie auch gegenüber Seifen einen entgegengesetzten Charakter zeigen. Ersetzt man in einer Natriumseife das Natrium durch Calcium, so findet dabei im Allgemeinen eine Wasserabgabe statt. Ersetzt man umgekehrt das Natrium durch Kálium, so zeigt sich eine Wasseraufnahme. Die Ursache dieser Erscheinungen ist darin zu suchen, dass Seifen mit Wasser feste Lösungen ${ }^{1}$ ) bilden und die Löslichkeit von Wasser indiesen drei Seifen sehr verschieden ist. In Kaliumseifen ist Wasser sehr löslich. Das kommt u. A. darin zum Ausdruck, dass diese Seifen soviel Wasser aus der Luft aufnehmen, dass sie schliesslich zerfliessen. Die Natronseifen nehmen auch Wasser auf, aber erheblich weniger als die Kaliseifen. Calciumseifen noch weniger. Sie sind daher auch wegen ihrer äusserst geringen Aufnahmefähigkeit für Wasser zum Waschen unbrauchbar.

So stellt Loeb sich auch vor, dass die Metallionen mit im Muskel vorhandenen Proteïden Verbindungen bilden, die ebenso wie die verschiedenen Seifen eine ungleiche Löslichkeit für Wasser besitzen.

1) Der Begriff "feste Lösung " stammt von van 't Hoff (s. w. das Kapitel „Histologisches"). Es löst sich z. B. Kohle in Porzellan, Silber in geschmolzenem Jodsilber; wenn man ein Stück Zinn auf ein Stück Blei legt und man hämmert kräftig, so verbreitet sich Zinn in das Blei. In ähnlicher Weise vertheilt sich Wasser in Seife. Es sind das alle feste Lösungen. 
In einer weiteren Reihe von Arbeiten hat der Verfasser die grosse Bedeutung derartiger Ionen eiweissverbindungen für das Leben, deren Existenz gleichzeitig aus ganz anderen Gründen von W. Pauli [8, 8a, 8 b] betont war, nachgewiesen, indem er zeigte, dass bei Ersatz eines Ions durch ein anderes die Eigenschaften der lebenden Zelle sich in weitgehendem Naasse änderten.

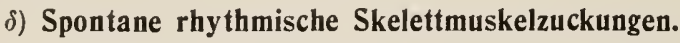

So fand er [9], dass Skelettmuskeln nach dem Verbringen in Salzlösuugen spontan rhythmische $Z$ uck ungen zeigen, die 24 bis 48 Stunden anhalten können. Das geschieht lediglich in Lösungen von Elektrolyten, nicht in solchen von Nicht-Elektrolyten. Sie finden deshalb in Harnstoff- und in Zuckerlösungen nicht statt, wohl aber in verschiedenartigen Na-Salzlösungen. Bei Vergleichung dieser Salze stellte sich heraus, dass in einer 0,7\% igen NaCl-Lösung die Zuckungen später anfingen und minder kräftig waren, als in einer äquimolecularen NaBr-Lösung. Daraus folgert Loeb, dass nicht lediglich das Metallion die Eigenschaften der Ionen-Proteide beeinflusst, sondern auch das Anion. Allerdings giebt es auch Gründe für die Annahme, dass das Proteidmoleciul gleichzeitig und an verschiedenen Stellen ein Kation und ein Anion festhalten kann.

Indessen tritt für das Zustandekommen der Skelettmuskelzuckungen in Na-Salzlösungen als weitere Bedingung hinzu, dass der Muskel eine geniigende Menge $\mathrm{Ca} "-$ und $\mathrm{K}$-Ionen enthält. Man darf hieraus nicht schliessen, dass $\mathrm{H}$ in z u füg ung von Ca- und K-Salz zu der NaCl-Lösung auf die rhythmischen Zuckungen der Skelettmuskeln befördernd wirken wird. Im Gegentheil, vielmehr hören die Zuckungen nach Zugabe von Ca- und K-Salzen auf.

I)ie Erklärung dieser Erscheinungen findet Loeb darin, dass gerade der Austritt von $\mathrm{Ca}^{*}$ - und $\mathrm{K}$-Ionen aus dem Muskel die Zuckung herbeiführt. Enthält die $\mathrm{NaCl}-\mathrm{Lösung}$ eine genügende Menge Ca"*-oder $\mathrm{K}$-Ionen, so giebt es keine Veranlassung für die $\mathrm{Ca}^{\prime}$ - oder $\mathrm{K}$-Ionen den IIuskel zu verlassen. Enthält die NaCl-Lösung gar keine $\mathrm{Ca}^{\prime \prime}$ - oder $\mathrm{K}$-Ionen und giebt folglich der Muskel diese beiden Ionenarten ab, so kommt schliesslich eine Zeit, in der er zu wenig davon enthält und er verliert die Erregbarkeit.

D) as (ileichgewicht zwischen $\mathrm{Ca}^{\prime \prime}$ - (und $\mathrm{K}$-) Ionen in Blut and lluskeln ist nach Loeb auch die Ursache, dass unsere Muskeln sich nicht spontan rhythmisch zusammenziehen. 


\section{ह) Reizbarkeit durch Contact (Contact-irritability).}

Beiläufig sei lier darauf hingewiesen, dass man diese rhythmischen Zuckungen von Skelettınuskeln in reinen Natriumsalzlösungen nicht mit den Zuckungen identificiren darf, welche durch eine ebenfalls von Lo e b neuentdeckte Form der Erregung entstehen [10]. Wenn man einen lebenden Froschmuskel in eine Natriumsalzlösung gehalten hat, so sieht man deu Muskel nach Entfernung aus der Lösung zucken. Die Salzlösung muss unbedingt eine Natrium-Salzlösung sein und zwar mus die betreffende Säure mit Calcium eine unlösliche Verbindung bilden. Es kommen also in Betracht: Natriumcitrat, Fluornatrium, Natriumoxalat, Natriumcarbonat, Natriumtartrat (1 g Mol. in 8 bis 10 Liter Wasser).

Loeb hat sich viel Mühe gegeben, die Ursache dieser Erscheinung zu erklären, und ist schliesslich zu dem Resultat gelangt, dass man es hier wahrscheinlich mit einer Erscheinung zu thun hat, die mit durch Berührung ausgelösten amöboiden Bewegungen von Leukocyten vergleichbar ist. Die Zuckungen finden nicht nur beim Verbringen des Muskels aus einer der genannten Flüssigkeiten in $\mathrm{Luft}$ statt, sondern auch in $\mathrm{CO}_{2}$, Chloroform, Toluol und Quecksilber. Der Verfasser bezeichnet diese Erscheinung als "Contact-irritability“. Dass der Muskel erst in einer der genanntell Natriumlösungen verweilt haben muss, weist nach Loeb darauf hin, dass für das Auftreten des Effectes die (äusseren) Muskelfibrillen derart verändert sein müssen, dass sie Caliumionen verloren und statt deren $\mathrm{Na}$-Ionen aufgenommen haben $[10]$.

Mit curarisirten Muskeln gelangen die Versuche nicht. Das gab Loeb Veranlassung, statt des Muskels den Nerv in die Lösungen einzusenken und wieder daraus zu entfernen. Es ergab sich hierbei die merkwürdige Thatsache, dass der Nerv, im Gegensatz zu dem beim Muskel beobachteten, während der Eiusenkung in die Flüssigkeit gereizt wurde, so dass der damit verbundene aber ausserhalb der Flüssigkeit sich befindende Muskel zu zucken anfing und in Tetanus gerieth. Wurde der Nerv aus der Flüssigkeit entfernt, so hörte die Zuckung auf. Man könnte nun meinen, dass die Na-Salze oder deren Ionen den Nerv direct reizen. Dies ist aber nicht ohne weiteres der Fall, denn wenn man den Ncerv nach Entfernung aus der Flüssigkeit mit einem beliebigen festen oder flüssigen Körper in Berïhrung bringt, so fangen die Muskelcontractionen wioder an. Die Thatsache, dass gewisse Ionen im Stande sind, Erregbarkeitsformen in Nerven und Muskeln hervorzurufen, die in normalen Umständen nicht bestehen, kann nach Loeb vielleicht einer Anzahl krankhaften Erscheinungen (Neurosen, Hysterie) erklären, in welchen die motorischen und sensorischen Reactionen des Patienten geändert sind.

Wenn es also richtig ist, dass die Lebenserscheinungen von der Anwesenheit verschiedener Metallproteide ( $\mathrm{Na}, \mathrm{Ca}, \mathrm{K}$ und $\mathrm{Mg}$ ) in bestimmten Verhältnissen ablı̈̈ngig sind, so müssen Lösungen, die nur eine Art von Metallionen enthalten, als Gifte wirken. Denn wenn die lebende Zelle in solch einer einfachen Salzlösung liegt, wird ein Austausch von Metall- 
ionen stattfinden und das ursprüngliche Verhältniss der in der Zelle vorhandenen Ionen erfährt eine Aenderung. So muss selbst eine

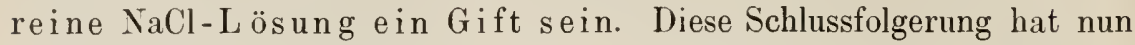
in der That eine mehrfache experimentelle Bestätigung gefunden.

\section{$\eta$ ) Ionenproteide und ihre Bedeutung. Giftigkeit einfacher reiner Salzlösungen.}

\section{Fïr Fundulıs.}

Zunächst experimentirte L oeb mit jungen, frisch ausgeschlüpften Exemplaren von Fundulus, einem Seefisch, der eine sehr bedeutende Steigerung der osmotischen Concentration des Seewassers ohne Schaden erträgt [11]. Bringt man dieses Thier in reine NaCl-Lösung, die mit dem Seewasser isotonisch ist, so stirbt es in sehr kurzer Zeit. Je schwächer die reine $\mathrm{NaCl}$-Lösung ist, um so weniger giftig ist sie. Selbst in destillirtem Wasser lebten die jungen Fische beliebiglange ${ }^{1}$. Vielleicht wird man hier die Bemerkung entgegenhalten, dass im letzteren Fall doch Metallionen in das Wasser hinüberwandern können. Dem ist jedoch nicht so, denn soll ein Austritt von Metallionen stattfinden, so müssen andere an ihre Stelle treten und diese sind im destillirten Wasser selbstverständlich nicht vorhanden.

Ich lasse hier eine von Loeb gegebene Zusanmenstellung folgen, die das obige in deutlicher Weise illustrirt.

Mittlere Lebsnsdauer von jungen Fundulus in reinen NaCl-Lösungen verschiedener Concentration.

\begin{tabular}{|c|c|c|c|c|c|c|c|}
\hline \multicolumn{7}{|c|}{$\mathrm{L} \ddot{0} \mathrm{~s} u \mathrm{ng}$ e $\mathrm{n}$} & Lebensdauer \\
\hline 100 & $\mathrm{ce}^{5}$ & orm. & & $(3,65 \%)$ & & & weniger als 12 Stunden \\
\hline 90 & $n$ & n & n & $+10 \mathrm{cc}$ & sti & assers & Ungefähr $\quad 24$ \\
\hline 80 & $n$ & $n$ & $n$ & +20 & n & $n$ & , \\
\hline 50 & $n$ & $n$ & $n$ & +50 & 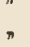 & $n$ & 40 \\
\hline 20 & $n$ & $n$ & $n$ & +80 & $n$ & $n$ & 60 \\
\hline 10 & " & " & $n$ & +90 & 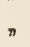 & $n$ & , $\quad 72 \quad$, \\
\hline 0 & $n$ & $n$ & n & +100 & $n$ & $n$ & $\begin{array}{l}\text { Noch nach } 10 \text { Tagen am } \\
\text { Leben. }\end{array}$ \\
\hline
\end{tabular}

1) Eine Quellung konnte Loeb nicht beobachten, was er darauf zurückführt, dass verschiedene lonen einen verschiedenen und oft entgegengesetzten Einfluss auf die Flüssigkeitsaufnahme ausüben (vergl. das auf S. 117 für die Muskeln mitgetheilte: $\mathrm{KCl}$ verursachte eine Wasseraufnahme von $46 \%$ und $\mathrm{CaCl}_{2}$ eine Wasserabgabe von $20 \%$ ). 
Fügte Loeb nun zu der reinen NaCl-Lösung andere Metall-Ionen hinzu, so wurde die Giftigkeit vermindert.

Der Verfasser bereitete folgende Lösungen:

(1) 96 cc $5 / 8 \mathrm{n} \cdot \mathrm{NaCl}+4$ cc ${ }^{10} / 8 \mathrm{n} \cdot \mathrm{MgCl}_{2}$

(2) " $"+4 \mathrm{cc}^{5 / 8}$ n. $\mathrm{KCl}$

(3) $\quad, \quad+4 \mathrm{cc}^{10} / 8 \mathrm{n} \cdot \mathrm{CaCl}_{2}$

In jeder dieser Lösungen starben die Fische innerhalb 24 Stunden. Dann wurden andere Gemische mit $\mathrm{NaCl}$ angefertigt.

(1) $96 \mathrm{cc} 5 / 8 \mathrm{n}$. $\mathrm{NaCl}+2$ cc ${ }^{10} / 8 \mathrm{MgCl}_{2}+2 \mathrm{cc}^{10} / 8 \mathrm{CaCl}_{2}$

(2) $", \quad+, \quad, \quad, \quad{ }^{5 / 8} \mathrm{KCl}$

(3) $\quad, \quad+,{ }^{10 / 8} \mathrm{CaCl}_{2}+,, \quad$,

In den ersten zwei Lösungen lebten die Thiere etwa 30 Stunden, in der dritten Lösungwaren sie nach 10 Tagen noch am Leben, womit der Versuch abgebrochen wurde.

Man sieht also, dass die Giftigkeit der NaCl-Lösung verschwindet, wenn man einen kleinen Betrag an $K$ - und Ca“-I onen lıinzuge fügt.

\section{Fiir Gonionemus.}

Gleichartige Versuche wurden bei G on i onemus angestellt. Diese Medusen bewegen sich durch rhythmische Zusammenziehung einer Art Schwimmblase. Diese Bewegungen hören auf, wenn man das Thier in eine $5 / 8 \mathrm{n}$. NaCl-Lösung bringt, und beginnen wieder, wenn man das Thier in Seewasser oder auch in die genannte NaCl-Lösung wirft, der etwas $\mathrm{K}$ - und $\mathrm{Ca}$-Ionen hinzugefügt sind. Im Gegensatz zu Fundulus, ist Gonionemus gegen destillirtes Wasser nicht immun.

Auch Cilien bewegungen gehorchen dieser Regel. Hierzu wurden Blastulalarven benutzt. Indessen fiel es hierbei auf, dass in bestimmten Gemischen (z. B. 20 ce $5 / 8$ n. $\mathrm{NaCl}+80$ ce $5 / 8$ n. KCl) die Cilienbewegungen viel länger anhielten als die Schwimmblasenbewegungen von Gonionemus. Nicht alle contractilen Geweben verhalten sich demnach aus quantitativem Gesichtspunkt in vollkommen gleicher Weise. Es wäre auch gewagt anzunehmen, dass die Ionenproteide in allen contractilen Elementen von gleicher Zusammensetzung wären. So fand Loeb [12] für frisch befruchtete Fier von Fundulus eine ${ }^{5,8}$ n. KCl-Lösung viel weniger schädlich als eine $5 / 8 \mathrm{n}$. NaCl-Lösung. In der ersten Lösung gelangen viel mehr Eier zur Entwicklung als in der zweiten. Für das Herz aber ist KCl viel schädlicher als NaCl. Daraus erklärt sich, dass später, wenn die Eier von Fundulus sich so weit entwickelt haben, dass das Herz pulsirt, KCl schädlicher ist als $\mathrm{NaCl}$. 


\section{Für das Herz.}

Ebenso wie die obengenannten Objecte verhält sich auch das Herz $[13,14]$ und das Lymphherz des Frosches [15]. Das Schildkrötenherz hört in einer reinen $\mathrm{NaCl}-\mathrm{Lösung}$ zu schlagen auf, und beginnt wieder, wenn der $\mathrm{NaCl}-\mathrm{Lösung}$ etwas $\mathrm{KCl}$ und $\mathrm{CaCl}_{2}$ hinzugefügt werden. Die beiden letzteren Salze haben auch hier wieder keine andere Wirkung, als dass sie die ,giftige Wirkung" der reinen NaCl-Lösung verhindern. Sie sind, rerstehe ich Loeb richtig, nach ihm nur in so weit für die Herzcontraction erforderlich, als sie dafür sorgen, dass keine $\mathrm{Ca}$ - und $\mathrm{K}-$ Ionen aus der Herzmuskelsubstanz a ustreten.

Es giebt Untersuchungen von $\mathrm{Howell}[16]$, aus denen hervorzugehen scheint, dass das Herz für seine Contractionen wirklich $\mathrm{Ca}$ * braucht und in diesem Sinne ist das auch, wie Loeb meint, von Howell gedeutet. Wenn ein Herz in Ringer's Lösung nach langer Zeit zu schlagen aufgehört hat, und man fügt nun $\mathrm{CaCl}_{2}$ hinzı, so fängt es (allerdings nur für eine kurze Zeit) wieder zu pulsiren an. Loeb hebt hervor, dass hier nichts Specifisches für das Herz vorliegt; denn Gleichartiges wird auch bei Gonionemus beobachtet. Die Erscheinung ist darauf zurückzuführen, dass durch die Hinzufügung von Ca"-Ionen eine gewisse Menge $\mathrm{Na} \cdot-$ Ionen in den Herzmuskelzellen durch $\mathrm{Ca}$ "-Ionen ersetzt wird. Dieser $\mathrm{Na}^{\prime}$-Ionenverlust, der natürlich einige Zeit anhält, bedeutet einen Reiz und auf diesen Reiz folgen Pulsationen (vergl. auf S. 118 über die rhythmische Contraction ron Skelettmuskeln in reinen NaCl-Lösungen, wo der Austritt ron $\mathrm{Ca}^{*}$ - und $\mathrm{K}$-Ionen den Reiz bilden).

Ich muss mich beschränken, und darf mir nicht erlauben, näher auf den wichtigen Gegenstand einzugehen, zumal zwischen den Autoren mancherlei Missverständniss herrscht.

Auf e ine Angelegenheit, die zu Missverständnissen bereits Veranlassung gegeben hat und in der nächsten Zeit, wie ich fürchte, noch weitere Veranlassung geben wird, will ich aber die Aufmerksamkeit lenken.

Loeb spricht wiederholte Male von der „Giftigkeit ron reinen NaCl-Lösungen" und von der ..Giftigkeit von Na-Ionen“. Man bekommt dadurch den Eindruck, dass das $\mathrm{Na}$ eine specifisch toxische Wirkung besitzt. Ich glaube, wie ich bereits sagte, nicht, dass Loeb dieser Meinung ist. Vielmehr halte ich dafür, dass er in prägnanter Form liervorheben wollte, dass die sogenannte physiologische Kochsalzlösung, 
o hne anderweitigen / us a tz angewandt, schädlich wirken kann ${ }^{1}$ ), sich als ein Gift documentirt. Aus Loeb's Ausführungen scheint hervorzugehen, dass nach ihm auch andere einfache Salzlösungen giftig wirken, und zwar weil sie das für die normale Thätigkeit erforderliche Gleichgewicht der verschiedenen Ionenproteïde stören.

Schliesslich noch einige Bemerkungen!

Alle neueren Autoren sind darüber einig, dass, wie bereits Sidney Ringer [17] fand, die Anwesenheit ron Kalk in der das Froschherz speisenden Flüssigkeit zur Erhaltung der Leistungsfähigkeit nothwendig ist. Unter diesen Autoren hebe ich hier insbesondere Langendorff und Hueck [18] hervor, die nicht nur mit Fröschen experimentirten und die Anwesenheit von Ca* in der Nährflüssigkeit des Herzens als eine Conditio sine qua non für die Leistungsfähigkeit betrachten ${ }^{2}$ ), sondern auch Versuche mit Säugethierherzen anstellten. Sie fanden, dass durch Hinzufügung von $3 \mathrm{cc}$ einer $1 \%$ igen $\mathrm{CaCl}_{2}$-Lösung zu $150 \mathrm{cc}$ defibrinirtem Katzenblut (also $0,05 \% \mathrm{CaCl}_{2}$ ) die Contractionstärke des isolirten Herzens sogar erheblich gesteigert wurde. Das Gleiche fanden sie beim lebenden Thier. Durch Einspritzung von $0,1 \mathrm{gr} \mathrm{CaCl}_{2}$ bei einem chloroformirten und curarisirten Kater, erzielten sie einen bleibenden bedeutend gesteigerten Blutdruck, der auf eine gesteigerte Contractionskraft des Herzens zurückzuführen war. Ringer hatte auf Grund seiner Versuche am Froschherzen darauf hingewiesen, dass diese Eigenschatt des $\mathrm{CaCl}_{2}$ die Herzkraft anzuregen, eine therapeutische Verwendung finden könnte. Langendorff und $\mathrm{Hueck}$ wiederholen diesen Vorschlag noch einmal auf Grund ihrer Versuche an Warmblütern. Man soll bei Salzwasserinfusionen bei gesunkener Herzenergie

1) Nach diesen Anschauungen ist es also nicht gestattet, selbst diejenige Kochsalzlösung, welche das Volumen der Zellen ganz unverändert lässt, als eine physiol o gis che Salzlösung zu bezeichnen. Ich habe das für die rothen Blutkörperchen bereits früher streng nachgewiesen (Bd. I, S. 197). Am meisten genügt noch dieser Auforderung ein Salzgemisch, wie sich das im natürlichen Medium der Zellen vorfindet. Für rothe und weisse Blutkörperchen z. B. wäre enteiweisstes Serum am meisten geeignet.

Von Poehl hat ein solches Salz ("Sal physiologicum Prof. Poehl“) bereitet. Dasselbe soll alle mineralen Bestandtheile des Serums in den richtigen Verhältnissen enthalten; sogar soll ein Theil der Phosphorsäure als Glycerinphosphorsäure im Salze vorhanden sein. Die Gefrierpunkterniedrigung einer $1,5 \%$ igen Lösung beträgt $-0,709^{\circ}$. Das Salz soll demnach in $1-1,5^{\circ}$ o iger Lösung benutzt werden. (Zeitschr. f. Diät. u. physik. Therapie. 4. 1900. H. 1.

2) Sie empfehlen für das Froschherz das folgende Ringer'sche Gemisch: $0,7 \% \mathrm{NaCl}, 0,02^{\circ}, \mathrm{CaCl}_{2}, 0,01 \% \mathrm{KCl}$ und $0,01 \% \mathrm{NaHCO}_{3}$ in $100 \mathrm{cc}$ destillirtem Wasser. Weniger $\mathrm{CaCl}_{2}$ macht die Herzcontractionen schwächer. 
des Menschen, weiterhin kalkhaltige Flüssigkeiten nehmen, a $m$ bestenein Ringer'sches Gemisch.

Weiter will ich hier noch auf eine sehr lesenswerthe Arbeit How ell's aufmerksam machen, welche Langendorff und $\mathrm{Hueck}$ bei ihrer Kritik der Ansichten Howell's entgangen ist: An analysis of the influence of the sodium, potassium and calcium salts of the blood on the automatic contractions of heartmuscle [19]. Er findet u. A., dass das Calciumion den Rhythmus verlangsamt oder das refractäre Stadium verlängert.

Schliesslich möchte ich hervorheben, dass die von Quinton nachgewiesene günstige Wirkung intravenöser Injectionen von Seewasser (B. II. S. 2), im Lichte der oben besprochenen Versuche nicht mehr befremdend erscheinen.

Loeb scheint von seiner Ansicht, dass einfache reine Salzlösungen schädigend wirken, weil die Ionenproteïde der Zelle nicht mehr ihre ursprüngliche Zusammensetzung behalten und deren Metallionen theilweise durch das der umgebenden Salzlösung ersetzt werden, zurückgekommen zu sein. Freilich hat er jene Auffassung eigentlich niemals in voller Schärfe formulirt. Aber beim aufmerksamen Lesen und Wiederlesen bekam ich den Eindruck, dass des Autors Ansicht doch dahin ging. Jedoch vermisst man dabei den Versuch des Nachweises, dass es sich wirklich um einen Kationen-A ustausch handelt, der doch so leicht auszuführen gewesen wäre. Wenn z. B. die giftige Wirkung einer reinen NaCl-Lösung auf den Vuskel, wirklich darauf berult, dass Calciumionen der Muskelsubstanz durch $\mathrm{Na}$-Ionen des $\mathrm{NaCl}$ ersetzt werden, so muss nach einiger Zeit $\mathrm{Ca}$ * in der diese Muskel umgebenden $\mathrm{NaCl}$-Lösung nachzuweisen sein ${ }^{1}$ ).

Es giebt aber auch Stelien, wo man den Eindruck bekommt, dass Loeb nicht an einen Austausch denkt.

So denkt er z. B. bei dem Versuch der Erklärung der antitoxischen Wirksamkeit von $\mathrm{Ca}$ "-Ionen bei der giftigen Wirkung von $\mathrm{NaCl}-$ Lösungen auf den Muskel, etwa an eine „Bindung" des „giftigen $\mathrm{Na}$ Ions" durch das Ca"-Ion. Er verwirft aber diese Erklärung, weil Kationen

1) Aus nicht veröffentlichten Untersuchungen über die Permeabilitä von Froschmuskelı, die ich in Oktober 1890 kurz nach meiner ersten Arbeit über die Permeabilität der rothen Blutkörperchen anstellte, geht in der That hervor, dass eine Auswechslung stattfindet. Lebende Froschmuskeln wurden in $\mathrm{KNO}_{3}$-Lösungen von $1,2 \%$ und $3 \%$ gelegt. Es stellte sich dann nicht nur heraus, dass die Salzlösung nach einiger Zeit $\mathrm{Cl}$ enthielt, sondern auch dass die Menge in der stärkern $\mathrm{KNO}_{3}$ Lösung grösser war als in der schwachen. 
sich ja nicht mit einander verbinden können. Ind doch wäre nichts einfacher gewesen, als die antitoxische Wirkung der $\mathrm{Ca}$ "Ionen dadurch zu erklären, dass die Hinzufügung derselben zu der umgebenden $\mathrm{NaCl}$ Lösung das Gleichgewicht wieder herstellt, welches durch den Verlust der Metallproteïde der Muskelsubstanz an Ca* und dem Ersatz derselben durch Na gestört war. Damit wären zwei Thatsachen erklärt worden, deren Deutung man bei dem Verfasser vergeblich sucht: 1. Wenn man zu der NaCl-Lösung bereits so viel ('aCl, hinzugesetzt hat, dass das Herz nunmelır in normaler Weise weiter pulsirt, so wirkt weitere Hinzufügung von $\mathrm{CaCl}_{2}$ schädlich. Das scheint mir leicht verständlich, denn wenn der Ca"-Gehalt der Umgebung grösser ist als der der Muskelzellen, werden $\mathrm{Na}$ oder $\mathrm{K}$-Ionen ausgetrieben werden und auch dadurch wird die contractile Substanz der Muskelzelle alterirt. 2. Loeb findet, dass eine quantitative Beziehung zwischen der Menge der giftigen einwerthigen Kationen und der zu ihrer Entgiftung nöthigen Menge zweiwerthiger Kationen besteht. Je höher die Concentration einer reinen NaCl-Lösung ist, um so grösser ist die minimale Nenge des zweiwerthigen Kations, die gerade ausreicht, um die Entgiftung herbeizuführen. Das leuchtet nach der Austauschhypothese ein; denn je grösser die Concentration der $\mathrm{Na}$-Ionen der umgebenden Lösung ist, um so mehr $\mathrm{Ca}^{\prime}$ "-Ionen werden aus der Zelle ausgetrieben werden und um so grösser ist die Concentration der in der NaCl-Lösung erforderlichen Ca"-Ionen, um deren Austritt hintanzuhalten (vergl. aber über die Beziehung zwischen den betreffenden Quantitäten S. 70 und 131).

\section{Ђ) Erklärung der unter $\eta$ erwähnten Giftwirkungen und deren Aufhebung mittelst der elektrischen Ladung der lonen.}

Wie dem auch sei, ob Loeb die oben entwickelte AustauschHypothese in seinen früheren Schriften in Wirklichkeit vertreten hat oder nicht, in seinen neueren Arbeiten $[13,20]$ huldigt er derselben entschieden nicht. Er stellt sich nunmehr vor, dass bei der giftigen Wirkung einer reinen NaCl-Lösung nicht die NaIonen, sondern die Cl-Ionen den toxischen Einfluss ansüben und dass dies durch ihre negativ-elektrische Ladung geschieht, während das Kation Ca", indem es durch seine positive Ladung die negative Elektricität neutralisiert, antitoxisch wirkt.

Zu der Ansicht, dass nicht die Kationen es sind, die bei der Einwirkung einer einfachen Salzlösung den toxischen 
Effect a usüben, sondern die Anionen, sieht der Verfasser sich durch folgende Versuche genöthigt.

Dieselben wurden mit Funduluseiern angestellt und es wurde untersucht, wie viel frisch befruchtete Eier in verschiedenen Lösungen zu Embryonen auskeimten.

So ermittelte $\mathrm{Loeb}$ die $\mathrm{CaCl}_{2}$-Mengen, welche erforderlich waren, um den toxischen Effect von Natriumsalzen mit verschiedenwerthigen Anionen aufzuheben. Hierzu verwendete er Natriumacetat, Sulfat und Citrat, also eine Verbindung von $\mathrm{Na}$ mit einem 1-, 2- und 3-werthigen Anion. Es stellte sich heraus, dass in einem Fall, wo in einer $\frac{m_{1}}{8}$ ) Natriumacetat-Lösung der Muskel seine faradische Erregbarkeit nach 24 Stunden verlor, nach Hinzufügung von 1-4 cc einer $\frac{\mathrm{m}}{32} \mathrm{CaCl}_{2}$-Lösung zu 100 cc der Acetatlösung die Dauer der Erregbarkeit auf 48-51 Stunden verlängert wurde.

So lebte in einer $\frac{\mathrm{m}}{8} \mathrm{Na}_{2} \mathrm{SO}_{4}$-Lösung der Muskel 17-19 Stunden. Um die Lebensdauer auf 36 Stunden zu verlängern, mussten $1-4$ cc einer $\frac{\mathrm{m}}{8} \mathrm{CaCl}_{2}$-Lösung zu 100 cc der $\mathrm{NaSO}_{4}$-Lösung zugesetzt werden. Die $\mathrm{CaCl}_{2}$-Menge also, welche in Stande war, die giftige Wirkung der Natriumacetatlösung aufzuheben, war unwirksam, wenn sie zu einer $\mathrm{Na}_{2} \mathrm{SO}_{4}$-Lösung linzugefügt wurde; die für die $\mathrm{Na}_{2} \mathrm{SO}_{4}$ Lösung günstige $\mathrm{CaCl}_{2}-\mathrm{Menge}\left(\frac{\mathrm{m}}{8}\right.$ statt $\left.\frac{\mathrm{m}}{32}\right)$ wirkte sehr schädlich, wenn sie zu einer Acetatlösung hinzugefügt war.

In einer $\frac{m}{8}$-Natriumcitratlösung verlor der Muskel seine Irritabilität innerhalb 3 Stunden. Hinzufügung von $1 / 2-2$ cc einer normalen $\mathrm{CaCl}_{2}$-Lösung brachte die Erregbarkeitsdauer auf 7 Stunden.

Die antitoxische Dosis $\mathrm{CaCl}_{2}$ für das Acetat, Sulfat und Citrat verhalten sich also als $1: 4: 16$.

"These figures leave no room for doubt, that the calcium in this case serves to do away with the poisonous effects of the anions and not of the sodiumions. In the poisonous effects of a sodiumchloridsolution we must therefore, in all probability consider the $\mathrm{Cl}^{\prime}$-ions as poisonons and not the $\mathrm{Na}$-Ions as I stated in my former papers."

Diese Auftassung wird nach Loeb noch dadurch bestätigt, dass auch die Chloride anderer Metalle der Baryumgruppe, also Ba", selbst Sr." und Mg" als Antitoxica dienen können. Ja es stellte sich sogar die merkwürdige 'Thatsache heraus, dass auch das zweiwerthige Zn“*, Kobalt und das an sich giftige Blei hier treffliche Dienste als Antitoxica leisten können: auch das dreiwerthige Metallion Aluminium zeigte sich wirksam.

1) $\mathrm{m}=$ Granımmolekül pro Liter. 
Man sieht, es ist gleichgültig, welches mehrwerthige Metall man als Salzverbindung hinzusetzt, es darf sogar ein an sich giftiges Metallsalz sein. In der Überlegung, dass also die chemische Natur des Metalles nicht in Betracht kommt, erblickt der Verfasser ein Argument für die Vorstellung, dass es sich hier um etwas handelt, was alle Metallionen gemeinsam haben, nämlich um eine positiv elektrische Ladung. Diese positiv elektrische Ladung würde dann die durch das Anion auf das Protoplasmagebrachte und toxisch wirkende negative Ladung, neutralisiren.

Dass nun in der That eine negativ elektrische Ladung toxisch, und eine Ladung mit entgegengesetztem Zeichen antitoxisch wirken kann, wird nach Loeb wahrscheinlich durch die Untersuchungen von $\mathrm{Hardy}$ $[21,22]$ über die ich an dieser Stelle nicht ausführlich sprechen werde, um den Gedankengang Loeb's nicht zu sehr zu stören. Ich habe die betreffenden Untersuchungen in ein besonderes Kapitel verwiesen, zumal sie auch für andere biologische Probleme von grosser Wichtigkeit sind und bitte den Leser behufs des richtigen Begriffs ron Loeb's Auffassungen, die betreffenden Ausführungen Hardy's nebst denjenigen von Picton und Linder zu berücksichtigen (diesen Band S. $70 \mathrm{ff.}$.).

Aus den betreffenden Untersuchungen will ich hier folgendes herrorheben.

Die Colloidpartikelchen haben eine elektrische Ladung. Welches Zeichen die Ladung besitzt, hängt in hohem Maasse von der Flüssigkeit ab, in welcher die Partikelchen liegen. Ist die Flüssigkeit eine Säure, so ist das Colloidpartikelchen positiv elektrisch und die Flüssigkeitschicht, die das Partikelchen umgiebt, negativ. Macht man die Flüssigkeit schwach alkalisch, so kehrt sich das Zeichen um, das heisst, die Colloidpartikelchen werden negativ elektrisch. Es lässt sich nun erwarten, dass wenn die Flüssigkeit weder sauer noch alkalisch ist, ke ine Potentialdifferenz zwischen Colloidpartıkelchen und umgebender Flüssigkeitschicht bestehen wird. Unter diesen Umständen vereinigen sich die Colloidpartikelchen zu grossen Aggregaten; es findet Ausflockung statt.

Können Säuren und Basen den Colloidpartikelchen eine gewisse elektrische Ladung ertheilen, so müssen auch Salze dazu im Stande sein bezw. deren Ionen. Wenn dem so ist, so ist es verständlich, dass durch Zusatz eines Salzes zu einer sauren Colloidlösung ebenso gut eine Ausfällung von Colloidpartikelchen erreicht werden kann, wie durch eine Base. Ob ein Salz dazu im Stande sein wird, hängt davon $a b$, welches Ion des Salzes, das Kation oder das Anion, sich am kräftigsten geltend macht. Im Allgemeinen haben die zweiwerthigen Ionen einen sehr grossell Einfluss. So wirkt z. B. in $\mathrm{CaCl}_{2}$ die positive Ladung von $\mathrm{Ca}$. viel krätiger als die gleich grosse negative Ladung der beiden $\mathrm{Cl}^{\prime}$-Ionen (wie das zu erklären ist, darüber $v \in$ rgleiche man im zweiten Kapitel S. 70 die Ausführungen Whetham's). Haben Colloidpartikelchen also eine negative Ladung bekommen, so genügen Spurell $\mathrm{CaCl}_{2}$ um dieselbe zu neutralisiren. 
Von sehr grosser Wichtigkeit ist es nun, dass, wenn Hinzufügung einer Substanz zu einer Colloidlösung noch nicht im Stande ist, Ausflockung herbeizuführen, m. a. W. die elektrische Ladung der Colloidtheilchen ganz zu neutralisiren, eine Verminderung der Ladung darum nicht ohne Wirkung ist. Picton und Linder haben an anorganischen und $\mathrm{Hardy}$ an organischen Colloiden gezeigt, dass Abnahme der elektrischen Ladung Verkleinerung der Gesammtobertläche der Colloidtheilchen zur Folge hat, m. a. W. Vergrösserung, d. i. Aggregation der Partikelchen. Es entsteht dadurch eine grössere Viscosität der Colloidlösung. Diese muss, wenn diese Colloidlösung Protoplasma ist, auf dessen Lebensäusserungen, wie Eifurchung, Muskelzuckung, u. s. w. Einfluss ausüben.

Kehren wir jetzt zu unserem Ausgangspunkt, der giftigen Wirkung einer reinen NaCl-Lösung zurück, so haben wir uns nach Loeb vorzustellen, dass das Protoplasma, das ein Hydrosol, d. i. colloidale Lösung ist, seitens der $\mathrm{Cl}^{\prime}$-Ionen eine negative Ladung empfängt. Durch diese Ladung ändert sich die Grösse der Colloidtheilchen, sowie ihre Viscosität. Diese Aenderungen können durch Hinzufügung von Salzen wieder rückgängig gemacht werden, deren positiv geladene Ionen den ungünstigen Einfluss der negativen neutralisiren können. Hierzu eignet sich $\mathrm{Ca} \mathrm{Cl}_{2}$ besonders gut, da, wie gesagt, ein zweiwerthiges Metall einen relatir grossen Einfluss ausübt. So erklärt sich dann der günstige Einfluss von Spuren $\mathrm{Ca} \mathrm{Cl}_{2}$ (oder anderer Chloride ron zweiwerthigen Metallen) gegenüber der schädigenden Wirkung einer reinen NaCl-Lösung auf das Herz, auf die Muskelzuckung und auf die Entwickelung von Eiern.

Diese Vorstellung hat viel Verlockendes, zumal sie tiefer in das Wesen der intracellularen Vorgänge einzudringen versucht. Man stösst aber, wie ich glaube, auf Schwierigkeiten, wenn man sich genau an die Form hält, die ihr Loeb gegeben hat.

\section{Einige kritische Bemerkungen. Schluss.}

Dieselben betreffen zuı̈chst die ausschliessliche Giftigkeit der Anionen im Gegensatz zu den Kationen. Wenn es nur auf die Anionen ankäme, wie Loeb meint, so würden äquimoleculare Lösungen von $\mathrm{Li} \mathrm{Cl}, \mathrm{KCl}$ und $\mathrm{NaCl}$ dieselbe giftige Wirkung ausiiben mïssen. Đoch findet $\mathrm{Loeb}$ selbst, dass die Concentration der LiCl-Lösung, welche die Bildung eines Embryos bei Fundulus verhindert, niedriger ist, als diejenige der entsprechenden $\mathrm{NaCl}-\mathrm{L} \ddot{s}$ sung. Ferner sind reine $\mathrm{NH}_{4} \mathrm{Cl}-$ und KCl-Lösungen weniger giftig für die Entwickelung von Fundusembryonen, als $\mathrm{NaCl}$ - und Li Cl-Lösungen. Hieraus scheint mir doch unwiderlegbar 
hervorzugehen. 1. dass auch die Kationen an der giftigen Wirkung betheiligt sind, 2. dass deren elektrische Ladung nicht der einzige Factor ist, der hier in Betracht kommt; denn dieser wird bei äquimolecularen Lösungen ron Chloriden der Alkalimetalle wohl ungefähr derselbe sein ${ }^{1}$ ).

Auch machen es die Untersuchungen Overton's [26] an Muskeln höchst wahrscheinlich, dass bei der Thätigkeit derselben jedenfalls das Kation die Hauptrolle spielt. (Vergl. S. 146).

Eine zweite Schwierigkeit erwächst, wenn man die Natriumsalze verschiedener Halogenionen in Beziehung auf ihre schärdiche Wirkung auf Fischeier vergleicht. Käme es nur auf die elektrische Ladung der Anionen an, so würde die schädliche Wirkung äquimolecularer Lösungen ungefähr die gleiche sein müssen, weil die elektrolytische Dissociation dieser Salze in äquimolecularer Lösung nicht viel differirt.

Loeb findet "that the toxic effect of the sodiumsalts of the halogens upon fish-eggs increases in the following order: $\mathrm{NaCl}, \mathrm{NaBr}$, $\mathrm{NaJ}, \mathrm{NaFl} . "$

Wie ich unten noch mittheile, fand auch Grützner für die Natriumverbindungen verschiedener Halogenen nicht denselben Effect auf die Nerven.

Die genannten von mir geltend gemachten Schwierig. keiten fallen aber im Wesentlichen fort, wenn man, ebenso

1) Dass die Grösse der elektrischen Ladung nicht das einzige ist, auf welches es hier ankommt, geht noch aus den folgendell von Loeb selbst gemachten Erfahrungen hervor.

Zwar können nach Vergiftung der Eier von Fundulus durch NaCl-Lösung, selbst Zink, Blei und Chromionen für die Entgiftung benutzt werden; bei andern Formen jedoch, wie bei den Eiern von Seeigeln, ist man in der Auswahl der zweiwerthigen Ionen, welche benutzt werden können, mehr beschränkt. Hier haben bisher nur $\mathrm{Ca}^{*}$ und $\mathrm{Sr}^{*}$ antitoxische Wirkungen ergeben.

Zuweilen genügt der Zusa $\downarrow z$ eines zweiwerthigen Kations gar nicht. Wenn man z. B. frisch befruchtete Seeigel-Ejer in eine ${ }^{5 / 8} \mathrm{n}$. NaCl-Lösung bringt, so entwickeln sich die Eier nicht, meist tritt nicht einmal Furchung ein. Fügt man nun eine kleine Vlenge eines zweiwerthigen Kations, beispielsweise Calcium, hinzu, so vermag das die (iiftwirkung der Natriumionen nicht aufzuheben. Es entwickelt sich kein schwimmender Embryo, obwohl die Eier ihren Furchungsprocess beginnen können. Die Entgiftung tritt aber sofort ein, wenn man der Lösung eine kleine Menge Kaliumionen zusetzt. Dann bilden die Eier nicht nur schwimmende Embryonen, sondern die letzteren können die volle Lebensdauer der ceteris paribus in normalem Seewasser gezüchteten Larven erreichen. Setzt man die Kaliumionen allein (ohne die Calciumionen) zu, so vermag die Furchung eine Reihe von Stunden weiter zu gehen, aber dann kommt alles zum Stillstand.

$\mathrm{H}$ a m bu rger, Osmot. Druck. III. Band. 
wie Hardy für die Ausflockung von Colloidlösungen that (vergl. Kapitel I S. 73), a uch hier das Theilungsprincip in Anwendung bringt.

Danach wäre es erklärlich, dass bei bestimmten lebenden Objecten die Kationen, bei anderen die Anionen die Führung bei der Modification von Lebenseigenschaften haben. Man hat dann nur die Hilfshypothese heranzuziehen, dass im ersten Falle die Kationen, im zweiten die Anionen in den Colloidtheilchen leichter löslich sind, als in der diese Theilchen umgebenden Flüssigkeit. Nach demselben Princip wäre dann auch der quantitative Unterschied in der Wirkung verschiedener, aber doch ungefähr gleichgeladener Anionen, wie $\mathrm{Cl}^{\prime}, \mathrm{Br}^{\prime}$ und $\mathrm{J}^{\prime}$ verständlich. Man hat sich nur zu denken, dass auch diese sich nicht in gleichem Grade in den Colloidtheilchen lösen.

Aber mit dieser Hilfshypothese, die übrigens noch wohl weiterer experimenteller Stuitzen bedarf, scheinen mir noch nicht alle Einwände gegen die Ladungshypothese aus dem Wege geräumt.

Ich muss fragen, wie es unter dieser Annahme erklärlich ist, dass nach der Giftwirkung einer reinen NaCl-Lösung, also des negativen Cl-Ions, bloss ein zwei- (oder drei-) werthiges Kation entgiftend wirkt, ein einwerthiges aber dazu nicht im Stande ist, auch wenn man eine beliebig grosse Menge davon benutzt.

Die Austauschhypothese kann diese Erscheinung wohl erklären. Man hat sich nur vorzustellen, dass Ca"-Ionen durch die Einwirkung von $\mathrm{Na}$-Ionen aus den Ionenproteiden verdrängt werden und dass diesem Verlust durch Hinzubringen von $\mathrm{Ca}^{*}$ - oder anderen zweiwerthigen Ionen entgegengewirkt wird. Dies kann aber durch einwerthige Kationen nicht geschehen, ohne die Zusammensetzung des Ionenproteidgemisches wesentlich zu schädigen. Nach demselben Gedankengang wäre dann auch zu erklären, dass umgekehrt die giftige Wirkung von reinen $\mathrm{CaCl}_{2}$-Lösungen durch einwerthige Kationen wolıl aufgehoben werden kann; denn unter dem Einfluss ron $\mathrm{CaCl}_{2}$ treten einwerthige Kationen aus den Zellen aus. Um diesem Austritt entgegenzutreten, bezw. die ursprïngliche Zusammensetzung der intracellularen Proteide wieder herzustellen, ist der Zusatz eines einwerthigen Kations erforderlich.

Andererseits ist vielleicht auch die Austauschhypothese nicht genügend. Nach dieser würde man erwarten, dass zwischen der Concentration der entgiftenden Calciumlösung und der giftigen NaCl-Lösung Aequivalenz bestehen müsse, 1n. a. W., dass 1 Grammatom $\mathrm{Na} \cdot 1 / 2$ 
Grammatom Ca" zur Entgiftung brauchen würde. Das scheint aber nach den Versuchen Loeb's nicht der Fall zu sein. Nach diesem Verfasser ist zu dem genannten Zweck viel weniger als ${ }^{1 / 2}$ Grammatom $\mathrm{Ca}^{*}$ erforderlich.

Auch würde man erwarten, dass für die Entgiftung einer Natriumacetat-Lösurg dieselbe Menge Ca-Salz erforderlich sein würde, als für die Entgiftung einer äquivalenten Menge Natriumsulfat.

Und was ergaben die Experimente?

Um die giftige Wirkung einer Natrium a cetatlösung zu lindern, waren $1-4 \mathrm{cc}$ einer $\mathrm{CaCl}_{2}$-Lösung von ${ }^{1 / 32}$ Grammmolecül pro Liter erforderlich, während zur Linderung der giftigen Wirkung von 100 cc Natrium sulf at lösung, $1-4$ cc einer $\mathrm{CaCl}_{2}$ Lösung von $1 / 8$ Grammmolecül gebraucht wurden.

L o eb schliesst hieraus, dass man für die Sulfatlösung eine viermal grössere $\mathrm{CaCl}_{2} \cdot \mathrm{Menge}$ als Antitoxicum braucht als für die äquimolare Acetatlösung.

Dieses Resultat steht in Einklang mit dem, was $\mathrm{H}$ ardy und andere Autoren für die Ausflockung fanden, dass nämlich ein $z$ weiwerthiges Ion ein viel grösseres Ausflockungsvermögen als das zweifache eines einwerthigen besitzt.

Man könnte nun meinen, dass das genannte Resultat von Loeb mit der Austauschhypothese schwer vereinbar ist, dieselbe sogar ausschliesst. Bei näherer Betrachtung aber ist das nicht der Fall, denn man muss sich nicht fragen, wie viel $\mathrm{CaCl}_{2}$ braucht man, um die Wirkung einer bestimmten Natriumsalzlösung auf lebende Zellen aufzuheben, sondern um den darin festgelegten Theil des Salzes wieder zu entfernen und durch das ursprünglich ausgetriebene zu ersetzen. Nur letzterer Austausch muss nach der Austauschhypothese in äquivalenten Mengen stattfinden. Die Concentration der ursprünglichen Natriumsalzlösung ist hier Nebensache.

Mit diesen Bemerkungen will ich die Möglichkeit nicht in Ábrede stellen, dass es sich bei der Giftwirkung reiner Salzlösungen und bei deren Entgiftung um elektrochemische Verhältnisse handelt. Im Gegentheil, im Zusammenhang mit den Untersuchungen von $\mathrm{Hardy}$ und $\mathrm{Pa}$ uli glaube ich, dass dieselben hier eine wichtige Rolle spielen, und dass man Loeb zu Dank verpflichtet ist, dass er die Aufmerksamkeit hierauf gelenkt hat. Dass es aber bei der giftigen und entgiftenden Wirkung einfacher Salzlösungen lediglich auf die elektrischen Ladungen ankommt, diese Ansicht kann ich, selbst nach Heranziehung der auf dem Theilungsprincip beruhenden Hilfshypothese, unmöglich theilen. Eine Reihe von Thatsachen, die theilweise von Loeb selbst gefunden wurden, machen es unumgängig, auch der chemischen Natur der Zellenbestandtheile, ich meine der Ionenproteide, einen wesentlichen Einfluss einzuräumen. Ueber einen etwaigen Zusammenhang zwischen den beiden Einflïssen lässt sich bei dem gegenwärtigen Stand unserer Kenntnisse noch nichts aussagen. 
Vielleicht ist es Untersuchungen, wie sie neuerdings Galeotti ausgeführt hat, vorbehalten, die beiden Anschauungen zu überbrücken. Galeotti hat es nämlich an der Hand der Phasenlehre in hohem Maasse wahrscheinlich gemacht, dass es sich bei der Ausflockung von Eiweisslösungen - er experimentirte mit Eier- und Serumalbumin, $\mathrm{CuSO}_{4}$ und $\mathrm{AgNO}_{3}$ - um Gleichgewichtreactionen handelt. Es handelt sich um das Gleichgewicht einer festen Phase: Eiweiss-Kupfersalz und einer flüssigen Phase: Eiweiss-Kupfersalz-Wasser ${ }^{1}$ ). Ich habe bereits im Kapitel: „Bemerkungen über Colloide und Fermente" mit Nachdruck darauf hingewiesen, dass die Untersuchungen über die Ausflockungsbedingungen deshalb für die Biologie von so grosser Bedeutung sind, weil der Ausflockung ein unsichtbares Zusammenpacken von Colloidtheilchen, eine unsichtbare Bildung von grösseren Aggregaten in continuirlicher Weise vorangeht und weil mit dieser Bildung von grösseren Aggregaten von Colloid-(Protoplasma-)theilchen in der lebenden Zelle die Beweglichkeit und damit Zelltheilung und andere Lebensäusserungen sich ändern müssen. Auf Grund eingehender Untersuchungen hat nun Galeotti den Satz ausgesprochen, dass die Salze der Schwermetalle mit den Eiweisskörpern keine echten Verbindungen mit constanten Beziehungen im Sinne der Valenztheorie bilden, m. a. W., die sogenannten Ionenproteide sind nur als lockere Verbindungen der Eiweisskörper mit den Metallen nach veränderlichen Verhältnissen anzusehen.

Was hier für schwere Metalle ersichtlich ist, wird auch wohl für die Leichtmetalle Giltigkeit besitzen und so muss man dementsprechend annehmen, dass nach Einwirkung einer einfachen Salzlösung auf lebendige Zellen ein neuer Gleichgewichtzustand zwischen der nunmehr darin an-

1) Zur Bestimmung der Gleichgewichtbedingungen bediente sich Gale otti (Zeitschr. f. physiol. Chemie 40. 1904. S. 492) der von Gibbs angegebenen und zuerst von Bakhuis Roozeboom, dann von Schreinemakers und Anderen aus. gebauten geometrischen Methode, welche erlaubt, die thermodynamischen Eigenschaften eines mehrphasigen Systems so darzustellen, dass die Gleichgewichtzustände der Phasen durch graphische Methoden vollkommen bestimmt werden.

Ich bedaure, die Ausführungen Gale otti's hier nicht näher erörtern zu können, um so mehr, weil ich dann die Gelegenheit gehabt hätte, die Grundzüge der Phasenlehre zu entwickeln, die zweifellos berufen ist, auch in der Biologie eine bedeutende Rolle zu spielen. Dem in vorliegendem Buche befolgten Grundsatz getreu, lediglich diejenigen physikalisch-chemischen Gegenstände zu behandeln, die bereits Früchte für die Biologie getragen haben, fand ich im übrigen bisher keine Veranlassung die Phasenlehre einer Besprechung zu unterziehen. 
wesenden Lösung ron freien Salzen und Ionen-Proteiden zu Stande gekommen ist. Es hat sich ein anderes quantitatives Verhältniss zwischen der Menge der flüssigen und festen Phasen hergestellt; dadurch hat sich der physikalische Zustand des Zellinhaltes geändert. Auch ist die chemische Zusammensetzung der Colloidtheilchen in der Zelle ebensowenig unverändert geblieben wie diejenige der Eiweisslösuug, wenn das Kupfersalz auf dieselbe einwirkte; mag es dann sein, dass die gebildete Verbindung locker und die Reaction reversibel ist.

In dieser Beziehung darf es als zweckmässig angesehen werden, dass durch die Permeabilitätsverhältnisse der äusseren Zellbegrenzungen der Eintritt fremder Salzlösungen in hohem Maasse beschränkt ist. Dadurch sind im normalen Leben die Zellen gelegentlich vor grossen Aenderungen physikalischer Eigenschaften geschützt.

Man kann sich nun weiter die Frage vorlegen, durch welchen Mechanismus bildet sich die feste Phase (bezw. die unsichtbare Zusammenpackung der Colloidtheilchen). Hier dürfte dann die Hypothese der elektrischen Ladung erklärend eintreten.

\section{c) Untersuchungen von 0 verton.}

\section{a) Verhalten von Muskeln in Salzlösungen.}

In der allerletzten Zeit hat auch Overton ausführliche Untersuchungen über das Verhalten von Muskeln in verschiedenartigen Lösungen angestellt. So weit die Versuche Loeb's wiederholt wurden, erfuhren sie grösstentheils eine Bestätigung. Dies gilt aber nicht für ihre Deutung.

Die Methode war im wesentlichen dieselbe, die Loeb anwandte, $d . h$. die Muskeln wurden in Salzwasser gebracht und nach verschiedenen Zeiten gewogen. Ueber einige Einzelheiten spreche ich unten. Hier will ich nur erwähnen, dass der Verfasser den Sartorius dem von Lo eb angewandten Gastrocnemius vorzog, insbesondere weil ersterer Muskel dünner ist und deshalb schneller mit der Umgebung in Gleichgewicht kommt. In dieser Hinsicht leisteten der auch benutzte M. cutaneus pectoris und die Zehenmuskeln noch Besseres.

Loeb liess bei seinen Ausführungen die Hüllen des Muskelfleisches ausser Betracht. Orerton dagegen widmet denselben volle Aufmerksamkeit und macht einen Unterschied zwischen dem Perimysium externum, internum und Sarcolemma einerseits und der eigentlichen Muskelsubstanz andererseits. Während die erstere für Krrystalloide als völlig permeabel betrachtet werden, sind die Muskelfibrillen 
semipermeable Gebilde. Aus diesem Gegensatz werden viele neue Thatsachen auf ungezwungene Weise erklärt, $u$. A. auch der bereits von Loeb constatirte Befund, dass Froschmuskeln in $\mathrm{NaCl}$ von $0,7 \%$ in Gewicht weder zu- noch abnehmen, während das Blutplasma des Frosches mit einer $0,6 \%$ igen Kochsalzlösung isosmotisch ist.

\section{Die mit der Mnskelsubstanz isotonische NaCl-Lösung [24].}

Zunächst hat $\mathrm{O}$ vert on sich klar zu machen gesucht, warum der Froschsartorius in einer 0,7\% igen NaCl-Lösung an Gewicht unverändert bleibt, und in $\mathrm{NaCl}$ von $0,6 \%$ quillt, während doch die Blutkörperchen des Frosches mit einer 0,6\% igen Kochsalzlösung in osmotischem Gleichgewicht stehen.

Hierzu bemerkt $\mathrm{O}$ verton, dass zwischen dem Perimysium externum und internum einerseits und den Muskelfibrillen andererseits eine eiweisshaltige Flüssigkeit (Lymphe) angehäuft ist. Man denke sich, diese sei mit dem Blutplasma isotonisch. Was wird nun geschehen, wenn man den Muskel in eine sehr grosse Menge, ebenfalls damit isosmotischer Salzlösung - sei es NaCl-Lösung - legt? Da das Perimysium externum für Salze völlig permeabel ist, wird Diffusion stattfinden, bis die innerhalb des Perimysium externum gelegene Lösung von Krystalloiden dieselbe Zusammensetzung angenommen hat, wie die ausserhalb gelegene. Nun haben wir soeben angenommen, dass die Menge der umgebenden Salzlösung relativ sehr gross sei. Die innerhalb des Perimysium externum gelegene Krystalloidlösung wird somit eine $\mathrm{NaCl}$-Lösung von 0,6\% werden. Nun enthielt die ursprüngliche interstitielle Flüssigkeit (Lymphe) ausser Krystalloiden auch noch Eiweiss. Für diese ist das Perimysium nicht permeabel, so dass zu dem osmotischen Druck der $0,6 \%$ igen $\mathrm{NaCl}$-Lösung noch der der Colloide hinzu kommt. Die Folge ist, dass der osmotische Druck der Flüssigkeit zwischen Muskelsubstanz und Perimysium höher ist, als derjenige einer $0,6 \%$ igen NaCl-Lösung. Demzufolge nimmt die interstitielle Flüssigkeit Wasser aus der NaCl-Lösung auf. (Die Menge dieser äusseren NaCl-Lösung wird aber so gross angenommen, dass dies keinen merkbaren Einfluss auf ihre Concentration ausübt.)

Schliesslich nimmt also das Volumen der interstitiellen Flüssigkeit zu. Um das zu verhindern, muss die äussere 0,6\% ige $\mathrm{NaCl}$-Lösung durch eine etwas concentrirtere ersetzt werden und zwar muss ihre Concentration um soviel höher sein, als dem osmotischen Druck der Colloide in der interstitiellen Flüssigkeit entspricht. Je mehr Eiweiss diese Lymphe enthält, um so höher wird die erforderliche Concentration der $\mathrm{NaCl}-\mathrm{Lösung}$ sein, die das 
Volumen des Gesammtmuskels unverändert lässt. Dementsprechend sah Overton auch die Leber des Frosches, deren Lymphe bekanntlich viel eiweissreicher ist, als die IIuskellymphe, erst in einer 0,8\% igen NaCl-Lösung das ursprïngliche Volumen behalten. Ferner blieb das Volumen des Gesammtmuskels in einer $0,6 \%$ igen $\mathrm{NaCl}-\mathrm{L}$ ösung unverändert, weun derselben ein Colloid, oder ganz allgemein ein Stoff zugesetzt war, wie Dextrin, für den das Perimysium gleichfalls wenig durchlässig ist. So war es auch möglich durch Hinzufügung einer grösseren Menge dieses Stoffes, $d$. h. einer solchen Menge, deren osmotischer Druck den der interstitiellen Colloide überstieg, zu der $0,6 \%$ igen NaCl-Lösung, Schr umpfung des Gesammtmuskels herbeizuführen. Vielleicht liesse sich - so bemerkt $\mathrm{Overton}$ - hieraus eine einfache Methode ausarbeiten, den osmotischen Druck von Colloiden wenigstens annähernd zu ermitteln.

\section{Hypisotonische Lösungen.}

Um einen Einblick in Overton's Versuchsverfahren zu geben, erwähne ich ein Experiment.

Gewichtänderungen eines Sartorius bei seiner Ueberführung aus einer $0,6 \%$-igen in eine $0,4 \%$-ige Lösung und aus dieser in eine $0,3 \%$ ige Lösung.

An 2. October $19012 \mathrm{~h}, 47$ p. m. wurde der Sartorius einer kräftigen-Rana esculenta, der nach vierstündigem Verweilen in einer 0,6\%-igen NaCl.Lösung $271 / 4 \mathrm{cg}$ wog, in $0,4 \% \mathrm{NaCl}$ verbracht. Er wog

$$
\begin{aligned}
& \text { Um } 2 \text { h,57 p. m. } 28^{3 / 4} \text { cg. } \\
& \text { Um } 3 \text { h,07 p. m. } 29^{1 / 2}-29^{3 / 4} \text { cg. } \\
& \mathrm{Um} 3 \mathrm{~h}, 57 \text { p. m. } 31^{1} \mathrm{2}-31^{3 / 4} \mathrm{cg} \text {. } \\
& \text { Um } 5 \text { h,30 p. m. } 32^{1 / 2}-32^{3 / 4} \text { cg. } \\
& \text { Um } 8 \mathrm{~h}, 03 \text { p. m. } 33 \mathrm{cg} \text {. }
\end{aligned}
$$

Um 8 h,04 p. m. wurde er in $0,3 \% \mathrm{NaCl}$ übergeführt.

Um 9h,40 p. m. wog er 39 cg. Bei $8 \mathrm{~cm}$ Rollenabstand Contraction noch ziemlich lebhaft, bei $9 \mathrm{~cm}$ unerregbar.

Um 8 h,47 a. m. am folgenden Tage (3. October) war das Gewicht $40 \mathrm{cg}$; bei $6 \mathrm{~cm}$ Rollenabstand reizbar, aber selbst bei $3-4 \mathrm{~cm}$ Contraction nur schwach und ein Theil der Muskelfasern sicher todt.

Um $7 \mathrm{~h}, 50$ p. m. des 3 . Octobers $37 \frac{1}{2} \mathrm{cg}$; unerregbar, recht starr. Darauf in $0,6^{\circ}, 0 \mathrm{NaCl}$ zurückgebracht. Um 9 h, 50 p. m. $33 \mathrm{cg}$; unerregbar. Um $10^{\text {n }}, 15 \mathrm{a} . \mathrm{m}$ des 4. Octobers $30^{1 / 4} \mathrm{cg}$. Um $2 \mathrm{~h}, 10$ p. m. $31^{1} / 2 \mathrm{cg}$; um $8 \mathrm{~h}, 45$ a. m. des 5 . Octobers $34^{1} / 2$ cg. Versuchstemperatur $20-22^{\circ} \mathrm{C}$.

Aus diesen und anderen Versuchen geht zunächst hervor, dass lebende Mfuskeln bei ihrem Verweilen in hypisotonischen NaCl-Lösungen (hypisotonisch = niedriger als das Blutplasma) an Gewicht zunehmen. Der Vorgang spielt sich in folgender Weise ab: Wenu ein Muskel 
längere Zeit z. B. in einer $0,6 \%$ igen $\mathrm{NaCl}$-Lösung verweilt hat, so besteht die Lösung zwischen den Muskelfasern nach vollendetem Diffusionsaustausch ebenfalls im Wesentlichen aus $0,6 \%$ iger NaCl-Lösung. Wird hierauf der Muskel in $0,4 \% \mathrm{NaCl}$ übergeführt, so diffundirt $\mathrm{NaCl}$ aus dieser Zwischenflüssigkeit, bis ihre Concentration auf diejenige der den Muskel umgebenden Lösung gesunken ist. Die Muskelfasern selbst sind als semipermeabele Gebilde zu betrachten, die wohl für Wassermolecüle, nicht aber für die Molecüle resp. Ionen das Natriumchlorids und der Kaliumphosphate durchlässig sind, wie schon daraus hervorgeht, dass die Muskelfasern, trotzdem sie während des ganzen Lebens von einer NaCl-reichen Lösung umspült sind, dennoch höchstens Spuren von Na und $\mathrm{Cl}$ enthalten und auch ihrerseits an die Lymphe weder Kalium noch Phosphorsäure abgeben.

Weiter hat Overton gefunden, dass Froschmuskeln trotz der Quellung lange Zeit in $\mathrm{NaCl}$ von $0,6 \%, 0,5 \%$ und $0,4 \%$ lebensfähig bleiben. Nur sind sie empfindlicher gegen schädliche Eintlüsse als Muskeln von normalem Wassergehalt. In $0,3 \% \mathrm{NaCl}$ bleiben Sartorien unter denselben sonstigen Umständen, unter denen andere Sartorien in 0,4-7\% igen Kochsalzlösungen 40-48 Stundeu dem Tode widerstehen, nur ca. 20 Stunden erregbar. Eine $0,2 \%-\mathrm{NaCl}-$ Lösung zeigte sich für den Sartorius als unmittelbar schädlich; nachdem das Volumen (und Gewicht) einige Zeit zugenommen hat, fängt es an wieder abzunehmen. Overton schreibt das dem Umstande zu, dass die Muskelsubstanz für Salze durchlässig wird. So wird $\mathrm{K}_{2} \mathrm{HPO}_{4}$ die Muskelsubstanz verlassen; dadurch wird der Salzgehalt der Muskelsubstanz abnehmen und sie wird Wasser verlieren.

Overton hat weiter die Volumzunahme berechnet, die der Muskel erfahren müsste, wenn er aus einer mit verdünnter Salzlösung $(0,7 \% \mathrm{NaCl})$ gefïllten Blase bestünde, die in eine $0,35 \%$ ige $\mathrm{NaCl}-$ Lösung gelegt würde. Es würde sich dann das Volumen auf das Doppelte vergrössert haben. Thatsächlich ist das aber nicht der Fall, die Volumvergrösserung ist vielmehr erheblich geringer. Das rührt theilweise daher, dass die festen Bestandtheile ein so grosses Volumen einnehmen (vergl. S. 5). Dasselbe beträgt etwa $20 \%$. Aber auch bei Berücksichtigung desselben stimmt die berechnete Volumzunahme des Muskels noch nicht mit der thatsächlichen überein, so dass der Autor sich zu der Annahme genöthigt sieht, wenigstens zwei Phasen in der II uskelsubstanz anzunehmen. Die Muskelsubstanz wïrde danach aus einer wirklichen wässerigen Lösung von Krystal- 
loiden und Eiweisssubstanzen und aus einer oder mehreren festen Lösungen bestehen, d. h. aus eiweissartigen Stoffen, in denen Wasser gelöst ist. Letzteres Wasser will er der Einfachheit halber "Quellungswasser" nennen. Dieses Quellungswasser ist die Ursache des erwähnten Mangels an Uebereinstimmung zwischen Berechnung und thatsächlichem Befund. Der Gedanke an zwei verschiedene Phasen in der Zelle ist nicht neu. Ich glaube, dass er zuerst von Hardy ausgesprochen wurde. Dieser Forscher betrachtet die intracellulare Flüssigkeit als die flüssige Phase und das Gerüst als die feste Phase, wobei der feste Stoff Wasser in Lösung enthält. (Vergl. oben, S. 4); ausführlicher unter "Histologisches".

\section{Hyperisotonische Lösungen}

Wie zu erwarten war, zeigten die Muskeln in hyperisotonischen Lösungen eine Gewichtabnahme. Während sie aber, wie erwähnt, eine sehr bedeutende Menge Wasser aufnehmen können, ohne wesentliche Störungen in ihrer Function zu erleiden, ertragen sie eine partielle Wasserentziehung viel weniger gut, d. h. sie verlieren ihre Erregbarkeit früher. Diesem Verlust folgt bald eine Gewichtzunahme. Dieselbe hatte auch Loeb beobachtet und einer Säurebildung zugeschrieben. Die Säure sollte dann durch ihre $\mathrm{H}$-Ionen secundär auf katalytischem Wege eine chemische Wirkung im Muskel herbeiführen und zwar eine Vergrösserung der Molecülzahl und in deren Folge eine Wasseraufnahme. So giebt Loeb an, dass Gastrocnemien nach einiger Zeit selbst in $4,9 \%$ iger $\mathrm{NaCl}$-Lösung an Gewicht zunehmen (vergl. oben S. 114). Schon diese Thatsache - bemerkt Overton - genügt, um die Unhaltbarkeit von Loebs Erklärung darzuthun. Denn selbst, wenn das gesammte Glykogen der Muskeln in Traubenzucker und alle Proteïnverbindungen vollständig in Hexonbasen etc. zerfallen würden, bliebe der gesammte osmotische Druck dieser Verbindungen hinter dem einer $5 \%$ igen $\mathrm{NaCl}-\mathrm{Lösung}$ zurück. Kohlensäure und Milchsäure kommen hierbei nicht in Betracht, da die lebenden Muskelfasern für diese beiden Verbindungen sehr leicht durchlässig sind. Im Uebrigen kann natürlich von einer Spaltung der Proteïnverbindungen der Muskeln in diesem Maassstabe, selbst wenn eine solche in merklichem Grade überhaupt stattfinden sollte, nicht die Rede sein.

Overton will nicht in Abrede stellen, dass eine Säurewirkung stattfindet, aber er bestreitet, dass sie die Quellung herbeiführt. Die Hauptursache der Gewichtzunahme liegt nach ihm in etwas anderem, nämlich darin, dass die Muskelsubstanz beim Absterben des Muskels für 
Salze durchlässig wird und zwar in höherem Maasse für $\mathrm{NaCl}$ als für $\mathrm{K}_{2} \mathrm{HPO}_{4}$. Es wird also mehr $\mathrm{NaCl}$ in die Muskelfibrillen eindringen, als $\mathrm{K}_{2} \mathrm{HPO}_{4}$ dieselben verlässt. Demzufolge steigt der osmotische Druck der Muskelsubstanz, und dieselbe zieht Wasser an. Damit stimmt überein, dass der Muskel, wenn man ihn statt in eine reine hyperisotonische NaCl-Lösung, in eine Lösung von Traubenzucker, Milchzucker, Raffinose verbringt, zu der soviel $\mathrm{NaCl}$ hinzugefügt ist, als gerade für die Erhaltung der Erregbarkeit ausreicht, schliesslich abstirbt, ohne eine nachträgliche Gewichtvermehrung zu erfahren. Die genannten Stoffe dringen viel schwerer in die Muskelsubstanz ein, als $\mathrm{K}_{2} \mathrm{HPO}_{4}$ sie verlässt.

Mit dem Absterben einiger oder sämmtlicher Muskelfasern und der dadurch bewirkten Aenderung der Permeabilitätsverhältnisse der Fasern steht auch die zuerst von Loeb beobachtete, aber ganz anders gedeutete Thatsache in Zusammenhang, dass Muskeln in 0,7\% igen Kochsalzlösungen, $\mathrm{zu}$ denen eine geringe Menge Säure oder Alkali zugegeben wird, eine Gewichtzunahme erfahren (vergl. S. 111). Diese sehr verdünnten Säuren und Alkalien ändern nach Overton zugleich die Quellbarkeit der Muskelfasern. Diese vermehrte Quellung beruht aber nach Overton nicht auf einer durch Spaltung vergrösserten molecularen Concentration der in Wasser gelösten Bestandtheile der Muskelfasern, sondern ist vielmehr eine Erscheinung von derselben Art wie die starke Quellung von Blutfibrin in schwachen Säuren. Das Maass der Quellung von Muskeln in anderen angesänerten Lösungen ist ausserordentlich abhängig von der Natur der sonst anwesenden Verbindungen; sie ist z. B. in einer Lösung von $1: 1000 \mathrm{HCl}$ in $6-7 \%$ Rohrzucker oder Milchzucker viel grösser als in den isosmotischen Lösungen von $1: 1000 \mathrm{HCl}$ in $0,6-0,7 \% \mathrm{NaCl}$.

Gerade dieser Umstand wïrde jedoch meiner Meinung nach eher dafür sprechen, dass es sich hier um Ionenwirkung handelt, denn durch Anwesenheit von $\mathrm{NaCl}$ wird nach den Untersuchungen von Arrhenius u. A. die Dissociation von $\mathrm{HCl}$ zurïckgedrängt.

Indessen kann hier keine reine Ionenwirkung vorliegen, weil die viel weniger stark dissociirten organischen Säuren, wie z. B. Milchsäure, eine erheblichere Quellung herbeiführen als starke Säuren, wie $\mathrm{HCl}$. Diese Erscheinung erklärt Overton dadurch, dass die Muskelfasern und andere thierische und pflanzliche Zellen schon in völlig unversehrtem Zustande für die nicht gespaltenen Molecïle zahlreicher organischer Säuren, sehr leicht durclılässig sind, während sie Ionen erst im beschädigten Zustande oder unter ganz besonderen Umständen den Durchgang gestatten: 
$\beta$ ) Permeabilitätsverhältnisse der Iebenden Muskelfasern für die verschiedenen Gruppen organischer Verbindungen, sowie für einige anorganische Verbindungen.

Die Methode, welche 0 verton benutzte, um die Permeabilität von Muskelfasern zu untersuchen, lässt sich aus folgendem Beispiel entnehmen.

Bringt man einen Sartorius aus einer 0,7\% igen NaCl-Lösung, in der der Muskel 3 Stunden verweilt hatte, in eine 0,5\% ige NaCl-Lösung zu der 3 Gewichtprocent Methylalkohol hinzugefügt wurde, so ist 1 Stunde nachher das Gewicht von $281 / 4 \mathrm{cg}$ auf 31 , und wieder 1 Stunde nachher auf 32 gestiegen, um weitere 2 Stunden unverändert zu bleiben. Nun entspricht der osmotische Druck einer Mischung von $0,5 \% \mathrm{NaCl}$ $+3 \%$ Methylalkohol einer 3,6\% Muskel in eine derartige stark hyperisotonische $\mathrm{NaCl}$-Lösung, so würde er stark an Gewicht abnehmen und fast sofort getödtet werden. Und was geschieht hier? Die Lösung wirkt nicht als eine hyperisotonische, sondern als eine hypisotonische, denn der Muskel hat an Gewicht abgenommen, statt dass er daran zunahm und ist dabei noch reizbar geblieben. Das lässt sich nicht anders deuten als durch die Annahme, dass der Nethylalkohol keine oder kaum eine osmotische Wirksamkeit entfaltet, m. a. W. dass er sich gleichmässig über Muskelsubstanz und Umgebung vertheilt hat. Da, wie gesagt, sich ausserdem herausstellte, dass der Muskel noch reizbar blieb - die Reizbarkeit war nach vierstündiger Einwirkung des Gemisches unverändert geblieben - so durfte geschlossen werden, dass der eingedrungene Methylalkohol die Muskelsubstanz nicht geschädigt hatte.

Nach dieser Methode hat Overton für eine grosse Reihe anderer Stoffe die Permeabilitätsverhältnisse der Froschmuskeln ermittelt. Immer wurde zugleich untersucht, ob nach erreichter Gewichtconstanz die Reizbarkeit des Muskels unverändert geblieben oder herabgesetzt war.

In dieser Hinsicht wurden bei gleicher Permeabilität grosse Differenzen beobachtet. So zeigte sich z. B., dass auch Aethylalkohol in die Muskelsubstanz eindringt, dass er aber nicht, wie der Methylalkohol unschädlich für dieselbe ist.

Es liegt auf der Hand, dass es um so länger dauert, bis das Gewicht des Vuskels constant geworden ist, je langsamer der fremde Stoff eindringt. Auf diese Weise kann man also auch eine Vorstellung davon bekommen, ob eine Substanz schnell oder langsam eindringt. Weiter brauche ich kaum hinzuzufügen, dass, wenn die Substanz, die man zu der $0,5 \%$ igen Kochsalzlösung hinzusetzt, nicht in den Muskel eindringt, deren osmotischer Druck sich zu dem der 0,5\% igen NaCl-Lösung 
addirt, und dass das Volumen des Muskels dann entsprechend abnehmen wird.

\section{Ich gebe nunmehr einige der erhaltenen Resultate wieder;}

1. Ebenso schnell wie Methyl-und Aethylalkoholdringenalle übrigen untersuchten einwerthigen Alkohole in die lebenden Muskelfasern ein; die höhern Glieder der Reihe durchsetzen die Muskelfasern mindestens ebenso schnell wiedie Glieder von niedrigerem Moleculargewicht, wahrscheinlichsogar noch schneller.

2. Nicht minder leicht durchlässig als für die einwerthigen Alkohole erwiesen sich die Muskelfasern für alle geprüften Halogen-Kohlenwasserstoffe, Nitroparaffine und Nitrile, für Aethyläther, für die neutralen Ester der Mineralsäuren und die Ester der einwerthigen Fettsäuren, für die Urethane, für die einwerthigen Aldehyde und Ketone, sowie ihre Aldoxime und Ketoxime und ebenso für Lactone, diekeine Hydroxylgruppen im Molecülenthalten.

3. Etwas weniger leicht permeabel als für die unter 2 aufgezählten Classen von Verbindungen zeigen sich die Muskeln für die nicht-substituirten zweiwerthigen Alkohole. Dies ist einmal daran zu erkennen, dass bei der Ueberführung von Muskeln z. B. aus $0,7 \% \mathrm{NaCl}$ in $0,7 \% \mathrm{NaCl}+1 \%$ A ethylenoder Butylenglykol eine vor übergehende Gewichtabnahme der Muskeln stattfindet; dann auch daran, dass bei der Uebertragung von Muskeln aus $0,7 \% \mathrm{NaCl}$ in $0,2 \% \mathrm{NaCl}+1 \%$ Glykol Wasserstarre später eintritt, als in $0,2 \% \mathrm{NaCl}$ ohne diesen $\mathrm{Zusatz}$; ferner aus der bedeutend langsameren Wasseraufnahme von Muskeln, die aus $0,7 \% \mathrm{NaCl}$ in $0,4 \% \mathrm{NaCl}+1$ oder $2 \%$ eines zweiwerthigen Alkohols übertragen werden, gegenüber dem Verhalten bei der Uebertragung der Muskeln in $0,4 \% \mathrm{NaCl}$ ohne Zusatz der betreffenden Alkohole etc. Dagegen dringen viele Derivate der zweiwerthigen Verbindungen, wiez. B. deren Monohalogenhydrine, ferner Methylal, Acetal etc. ebenso schnell in die Muskelfasern ein als die unter 2 verzeichneten Verbindungen.

4. Langsamer als die zweiwerthigen Alkohole dringen die dreiwerthigen (z. B. Glycerin) und noch viel langsamer als letztere die vierwerthigen Alkohole (Erythrit) in die Muskelfasern ein. Viele Derivate der drei- und vierwerthigen Alkohole dagegen diffundiren schnell oder sogar sehr schnell in die Muskelfasern ein, soz. B. das Monochlorhydrin des Glycerins, das Monoacetin des Glycerins, der Diäthylester der Weinsäure und noch schneller (etwa so schnell wie die einwerthigen Alkuhole) das Dichlorhydrin des Glycerins, das Triacetin des Glycerins, das Diäthylin des Glycerins, der Triäthylester der Citrorensäure, das Dichlorhydrin des Erythrits etc.

5. Die A mide der einwerthigen Säuren dringen ungefähr ebenso schnell in die Muskelfasern ein, wie die zweiwerthigen Alkohole und zwar, wie bei den letzteren, die höheren Glieder der Reihe etwas schneller, als die 
Glieder mit einer geringeren Anzahl von Kohlenstoffatomen. Lact. amid dringt etwas langsamer ein als A cetamid oder Butyramid.

6. Für Harnstoff und Thioharnstoff sind die Muskelfasern sch í rer durchlässig als für Glycelin, aber leichter als für Erythrit. Die al. kylirten Harnstoffe dringen leichter in die Muskelfasern ein, als die einfachen Harnstoffe, und zwar um soleichter, je mehr Wasserstoffatome des Harnstoffs und des Thioharnstoffs durch Alkyle ersetzt werden. Phenyllarnstoff dringt fernerschnellor ein, als Methylharnstoff.

7. Für Aminosäuren sind Muskelfasern zum Theil nicht merklich, zum andern Theile sehr schwer durchlässig; ebenso sind sie nicht merklich durchlässig für Kreatin, Kreatinin und Allantoin. Dagegen sind die Muskelfasern höchstwahrscheinlich (nach Analogie mit Pflanzenzellen) für die Ester der Amidosäuren sehr leicht durchlässig. (Diese Ester waren in Folge ihrer stark basischen Natur zu giftig, um auf ihr Eindringen in die Muskelfasern mit Hülfe der in dieser Arbeit benutzten Methode direct geprüft zu werden).

8. Für die fünf- und sechswerthigen aliphatischen und allocyklischen Alkohole (Quercit, Inosit), für die Hexosen und Disaccharosen, sowie für die natürlich vorkommenden Glukoside sind die lebenden Muskelfasern nicht merklich durchlässig. Es ist zwar nicht unmöglich, dass eine gewisse Menge z. B. von Traubenzucker als solcher in die Muskelfasern übergeht; wenn aber dies der Fall sein sollte, so wird auf irgend eine Weise, sobald die Traubenzuckerconcentration in den Muskelfasern einen gewissen, recht niedrigen Werth erreicht hat, ein weiterer U e bertrit von Traubenzucker in die Muskelfasern ganz oder beinahe ganz auf. gehoben, selbst wenn die Traubenzuckerconcentration in der die Muskelfasern umspülenden Lösung einen zwanzig-oder dreissigfach höheren Werth besitzt. Wenn also Traubenzucker als solcher in die Muskelfasern übergeht, so muss der Mechanismus der Aufnahme ein gänzlich anderer sein als bei den unter 2-8 a fuezählten Verbindungen, wo die in die Muskelfasern übergehenden Mengen sich proportional den Concentrationen dieser. Verbindungen in der die Muskelfasern umgebenden Lösung verhalten.

9. Die Mehrzahl der aromatischen und heterocyklischen Verbindungen ist $\mathrm{zu}$ giftig oder in Wasser $\mathrm{zu}$ wenig löslich, um auf ihr Eindringungsvermögen, resp. auf die relative Schnelligkeit ihres Eindringeus in die noch unversehrten Muskelfasern mittelst der genannten Methode direct geprïft zu werden. Für einige der wichtigsten Reprïsentanten der verschiedenen Classen dieser. Verbindungen kann indessen die sehr leichte Durchlässigkeit der noch völlig gesunden oder nicht dauernd beschädigten Muskelfasern durch directe Versuche nachgewiesen werdel,, so z. B. für Phenol (Carbolsäure), für Resorcin, für Anilin unà Acetanilid, für Phenacetin, für Pyridin und für Antipyrin. Aus vergleichenden Beobachtungen lässt sich mit grosser Wahrscheinlichkeit folgern, dass die Muskelfasern in noch unversehrtem Zustande für die grosse 
Mehrzahl der aromatischen Verbindungen leicht durchlässig sein müssen. Für die Sulfosäuresalze der aromatischen und heterocyklischen Verbindungen sind die Muskelfasern indessen in normalem Zustande nicht merklich durchlässig, und - wenn überhaupt - sind sie auch jedenfalls äusserst wenig durchlässig für die Salze der einfachen aromatischen Säuren, während sie für die meisten freien aromatischen Säuren (Berzoësäure, Salicylsäure etc.) jedenfalls leicht durchlässig sein werden.

10. Für die Salze der basischen Anilinfarben sind die lebenden Muskelfasern sehr leicht durchlässig, wie an der Färbung intra vitam zu erkennen ist; für die sulfosauren Farbstoffe sind dagegen die lebenden Muskelfasern undurchlässig.

11. Bei $20^{\circ} \mathrm{C}$. dringen Glycerin und Harnstoff (die einzigen Verbindungen, die bisher in dieser Richtung untersucht worden sind) circa anderthalb Mal so schnell in die Muskelfasern ein als bei $0,5^{\circ} \mathrm{C}$.

12. Unter den anorganischen Verbindungen wurde die sehr leichte Durchlässigkeit der Muskelfasern für freie gelöste Kohlensäure durch directe Versuche nachgewiesen. Borsäure dringt in die Muskelfasern ungefähr so schnell ein, wie die zweiwerthigen Alkohole von riedrigen Moleculargewicht (z. B. Aethylenglykol). In geeigneten Lösungsgemischen von Chlornatrium und Borsäure bleiben Muskeln (und Nerven) ausserordentlich lange am Leben (einige Muskeln über $12 \mathrm{~T}$ age lang bei gew öhnlicher Zimmertemperatur, Nerven über 120 Stunden). - Nach Versuchen mit andern Zellarten kann mit grosser Wahrscheinlichkeit geschlossen werden, dass die Muskelfasern auch für Stickoxydul, für freies Ammoniak, für Schwefelwasserst off und für Wasserstoffsuperoxyd sich sehr leicht durchlässig zeigen werden. Auch für die Lösungen von Sauerstoff, Stickstoff, Argon, Schwefelkohlen. stoff, Jod und einzelne andere anorganische Verbindungen ist eine leichte Durchlässigkeit der Muskelfasern sehr wahrscheinlich.

Aus der Gesammtheit der Versuche ergiebt sich die Regel, dass a lle Verbindungen, die neben einer merklichen Löslichkeit in Wasser sich in Aethyläther, in den höheren Alkoholen, in Olivenöl und in ähnlichen organischen Lösungsmitteln leicht lösen oder wenigstens in den zuletzt genannten Lösungsmitteln nicht viel schwerer löslich sind als in Wasser, äusserst leicht in die lebenden Muskelfasern und in andere thierische und pflanzliche Zellen eindringen. Es ist also mit einem hohen Grade von Wahrscheinlichkeit vorauszusehen, dass die Muskelfasern etc. sich für weit über 80000 der ca. 100000 zur Zeit bekannten organischen Verbindungen als sehr leichtdurchlässig erweisen werden.

In welchem Grade die Muskeln aus wässerigen Lösungen verschiedener Substanzen letztere aufnehmen, hängt von dem Theilungs- 
coëfficienten ab. Was man darunter zu verstehen hat, ist an verschiedenen Stellen auseinander gesetzt. Man vergleiche die Untersuchungen von Me yer und Orerton über Narkose im Kapitel "Pharmakologisches"; auch unter "Histologisches" ist davon die Rede, etc.

Wenn die wässerige Lösung einer Substanz mit der Muskelsubstanz in Berührung gebracht wird, so kann nur dann ein Theil der Substanz in die Muskelsubstanz übergehen, wenn sich im Muskel ein Bestandtheil befindet, in welchem die zu untersuchende Substanz löslich ist. Ist diese Löslichkeit grösser als die in Wasser, so wird sich der Stoff bald in grösserer Concentration in der Muskelsubstanz als im Wasser befinden. Das Verhältniss der Löslichkeiten bestimmt also den Theilungscoëfficienten.

Nun ist es jedoch schwierig, die lösende Substanz im Muskel ausfindig zu machen. Aus den Untersuchnngen von $\mathrm{O}$ verton hat sich aber ergeben, dass gerade diejenigen Stoffe leicht in die Muskelsubstanz eindringen, die auch in Cholesterin, Lecithin, Aethyläther und höheren Alkoholen leicht löslich sind.

Diese Regel vereinfacht die Voraussage des Eindringens und des Grades des Eindringens von Stoffen in die Muskelsubstanz in ungemeinem IIaasse.

Indessen muss darauf hingewiesen werden, dass zuweilen auch Ausnahmen vorkommen. Die Salze der basischen Anilinfarbstoffe dringen sehr leicht in die Muskelfasern ein; ebenso in Lecithin und Cholesterin. Das stimmt mit der Regel, aber im Gegensatz zu derselben sind diese Anilinfarben in A ether und Olivenöl kaum löslich.

Man hat aber noch ein anderes Mittel die Permeabilität zu untersuchen, nämlich mittelst Pflanzen, wobei die Plasmolyse den Indicator bildet (vergl. Bd. I, S. 215). Overton fand die wichtige Thatsache, dass in sämmtlichen Fällen, in denen es möglich war, auch Pflanzenzellen auf ihre Durchlässigkeit für verschiedene Verbindungen zu untersuchen, sich eine vollständige Uebereinstimmung mit der Muskelsubstanz ergeben hat, die sich auch auf die relative Schnelligkeit des Eindringens erstreckt.

Es besteht sonach, wie Overton meint, eine grosse Wahrscheinlichkeit dafür, dass diese Uebereinstimmung sich auch auf solche Verbindungen erstrecken wird, die nur bei Pflanzenzellen, aber nicht bei den Muskelfasern genauer auf ihr Eindringungsvermögen geprüft werden können. Der Autor geht noch weiter und schreibt den Permeabilitätsverhältnissen, die er für Muskelfibrillen findet, auch für die anderen thierischen Zellen Geltung zu. 


\section{Kritische Bemerkung.}

Ich kann nicht unterlassen, ernsten Zweifel darüber zu äussern, ob dieser Satz in aller Strenge richtig ist und richtig sein kann.

Sehen wir nicht, um ein Beispiel zu nennen, dass die Magenschleimhaut ganz andere Permeabilitätsverhältnisse besitzt, als die Darmschleinıhaut und diese wieder ganz andere als die rothen Blutkörperchen? Ich glaube sogar, dass die Natur in den Permeabilitätsdifferenzen ein mächtiges Mittel zur Differenzirung der Functionen des Organismus besitzt. Ich will nicht in Abrede stellen, dass die meisten Zellenarten gegenüber einer und derselben Substanz im Grossen und Ganzen ähnliche Permeabilitätsverhältnisse zeigen, so \%. B. gegenüber Aethylalkohol, i m Detail gilt dies aber nicht. Um kleine Differenzen in der Durchlässigkeit, namentlich auch in der Schnelligkeit des Eindringens zu erkennen, gewährt weder die auf die Muskeln noch die auf die Pflanzenzellen von Overton angewendete Methode eine genügende Genauigkeit. Ein principieller Einwand ist ausserdem darin zu finden, dass die Methoden den Austausch nicht in genügendem Maasse würdigen können. Wenn eine Substanz in die von Overton untersuchte Zelle eindringt und eine ungefähr isosmotische Menge anderer Bestandtheile aus ihr austritt, so gelangt $\mathrm{Ov}_{\mathrm{v}} \mathrm{rton}$ zum Resultat, dass die Zelle für die erste Substanz impermeabel war. Dieser Schluss erfolgt zu Unrecht. Auf diese Weise ist $O$ verton die Permeabilität ron Pflanzenzellen (und also auch von Blutkörperchen) für Ionen entgangen. Es würde ihm auch schwer fallen, diese durch Plasmolyse, selbst nachträglich, nachzuweisen. Das rührt daher, dass der plasmolytischen Versuchsmethode ein osmotischer Austausch entgeht; andererseits daher, dass, wo der Austausch nicht in isosmotischen Verhältnissen stattfindet, die Methode nicht genügende Genauigkeit besitzt diese zu entdecken. Gleiches gilt auch für die bei den Muskeln geübte Methode.

\section{y) Bedeutung der $\mathrm{Na}^{-}$-Ionen für den Contractionsact des Muskels.}

In einer zweiten Abliandlung hat Overton die Bedentung der $\mathrm{Na}$-Ionen für den Contractionsact des Muskels studirt [25̃].

Auch hier weichen die Resultate theilweise von denen Loeb's ab. Ausgangspunkt war die Beobachtung, dass ein Sartorius nach dem Verbringen aus einer $0,6^{\circ} \%$ igen NaCl-Lösung in eine isosmotische Rohrzuckerlösung $\left(6^{\circ} \%\right)$, „spontane“ Zuckungen zeigte und danach bald wieder zur liuhe kam, ohne zunächst in seiner Erregbarkeit irgendwie gelitten zu haben. Kurze Zeit nachher wurde aber der Muskel völlig uner- 
regbar, obgleich er im Wesentlichen ein normales Aussehen behielt. Merkliche Mengen von Rohrzucker konnte er nicht in seine Fasern aufgenommen haben. Was war also die Ursache der Erscheinung?

Es war Overton aufgefallen, dass Hinzufügung von etwas Kochsalz zu der Zuckerlösung, die Erregbarkeit bald wiederherstellte. War dies nun eine Folge davon, dass die Zuckerlösung verdïnnt wurde und demzufolge der schädigende Einfluss abnabm, oder war es vielleicht das Kochsalz als solches, das restaurirend wirkte? Ier Versuch ergab, dass reine Rohrzuckerlösungen von geringerer Concentration $(5 \%$ und $4 \%$ ) ebenso schädlich wirkten; ferner dass nicht nur Rohrzucker, sondern auch isosmotische Lösungen anderer Nichtelektrolyte giftig waren, aber dass die toxische Wirkung all dieser Substanzen durch Hinzufügung von $\mathrm{NaCl}$ gelindert wurde ${ }^{1}$. Die Concentration an $\mathrm{NaCl}$, die diese NichtElektrolytlösungen bedürfen, um die Muskeln ungefähr ebenso lange erregbar zu halten wie in $0,6-0,7 \% \mathrm{NaCl}$ war $0,1-0,12 \%$, während der niedrigste Chlornatriumgehalt einer Lösung, die eben ausreichte um die Muskeln noch merklich erregbar zu halten $0,07 \% \pm 0,003 \%$ rund $0,05 \%$ o betrug. Die benutzten Muskeln waren: Sartorius, Cutaneus pectoris und Hinterfussmuskeln, zuweilen auch der Gastrocnemius. Aus diesen Versuchen geht hervor, dass beim Verweilen von Muskeln in $6 \%$ igen Rohrzuckerlösungen oder in mit diesen isosmotischen Lösungen von Traubenzucker, Fructose, Milchzucker, Mannit, Alanin etc., der bald eintretende unerregbare Zustand nur durch die Verarmung der Zw is chenflï s sigkeit der Muskeln an Chlornatrium bedingt sein kann, indem letzteres aus den Muskeln in die Rohrzuckeriösungen etc. exosmirt.

Diese Schlussfolgerung wurde noch dadurch bestätigt, dass Muskeln, die in einer $6 \%$ igen Rolirzuckerlösung behufs Entfernung der Lymphe gut abgespült waren, bei einem weiteren Aufenthalt in einer frischen Rohrzuckerlösung an diese soviel Chlor abgaben, dass dieses mit $\mathrm{Ag} \mathrm{NO}_{3}$ und $\mathrm{H} \mathrm{NO}_{3}$ leicht nachgewiesen werden konnte.

Weiter zeigte sich, dass durch den Chlornatriumverlust nicht nur die Erregbarkeit (das Contractionsvermögen), sondern auch die Erregungsleitung aufgehoben wird.

Ist somit für die Erhaltung beider Lebenseigenschaften die Anwesenheit einer gewissen NaCl-Menge nothwendig, so ergiebt sich die weitere Frage, ob es hierbei auf die Na-Ionen, oder auf die Cl'-Ionen, oder auf das ungespaltene $\mathrm{NaCl}$ an$\mathrm{k}$ om m t.

1) Howell [19] fand Aehnliches für das Froschherz.

H amburger, Osmot. Druck. III. Band. 
Um diese Frage zu beantworten, untersuchte $O$ verton verschiedene Natriumsalze (Natriumbromid, Nitrat, Sulfat, secundäres Phosphat $\left(\mathrm{Na}_{2} \mathrm{HPO}_{4}\right)$, Natriumbicarbonat $(\mathrm{Na} \mathrm{HCO})$, Chlorat $(\mathrm{NaCl} \mathrm{O})$, Natriumacetat, -benzoat, -salicylat, Ferrocyannatrium $\left(\mathrm{Na}_{4} \mathrm{Fe}(\mathrm{CN})_{6}+10 \mathrm{aq}\right)$ und Ferricyannatrium $\left(\mathrm{Na}_{3} \mathrm{Fe}(\mathrm{CN})_{6}+2 \mathrm{aq}\right)$. $\mathrm{Er}$ bereitete Lösungen, die neben $6 \%$ Rohrzucker, soviel von den einzelnen Natriumsalzen enthielten, als einer $0,1 \%$ igen NaCl-Lösung äquivalent war. In der ganzen Reihe von Versuchen blieb die Erregbarkeit regelmässig erhalten, bezw. sie wurde wiederhergestellt und war sogar in den ersten Stunden fast genau dieselbe wie in Lösungen von $6 \%$ Rohrzucker $+0,1 \% \mathrm{NaCl}$.

Es lässt sich also nach Overton mit höchster Wahrscheinlichkeit schliessen, dass für die Vorgänge der Erregungsleitung und Muskelconcentration nur die Natriumionen von Bedeutung sind, während die Anionen und die nicht dissociirten Molecüle dabei nicht betheiligt sind oder höchstens eine ganz nebensächliche Rolle spielen.

Overton untersuchte nun weiter, ob auch die Hinzufügung geringer Mengen von $\mathrm{Ca}$-, Sr- und $\mathrm{Hg}$-Salzen zu der 6\%-Rohrzuckerlösung die Erregbarkeit wieder herzustellen vermochte. Es zeigte sich, dass das nicht der Fall war. Nach Overton liegt gerade darin das stärkste Argument für den Satz; dass es die Natriumionen und nicht die den Säuren entsprechenden Anionen sind, die die günstige Wirkung ausüben. Selbst Kalium-, Rubidium- und Calciumsalze waren dazu nicht im Stande, wohl aber Lithiumsalze. Diese können also $\mathrm{Na}$-Salze ersetzen, wenn sie auch, freilich in etwas höheren Concentrationen, auf die Muskeln und noch mehr auf die Nerven allmählich schädlich einwwirken. Auch die Thatsache, ảass verschiedene Lithiumsalze, wie Lithium-Chlorid, Sulfat, Nitrat, Phosphat und Acetat, sämmtlich das $\mathrm{NaCl}$ vertreten können, spricht für die Annahme, dass die Kationen die Hauptrolle spielen.

Die Minimal-Concentrationen der Lithiumsalze, die eine Contraction ermöglichen, waren die gleichen wie bei den entsprechenden Natriumsalzen.

Eine ihn selbst befriedigende Erklärung für die Nothwendigkeit eines 'Zusatzes von Kochsaiz zu der Rohrzuckerlösung, ist der Autor schuldig geblieben. Deshalb wage ich den Versuch, auf eine solche hinzudeuten. 
Wenn es richtig ist, wie es aus den Versuchen hervorzugehen scheint, dass das Perimysium externum und internum, sowie auch das Sarcolemma, für Salze permeabel sind, so muss, nachdem der Muskel einige Zeit in einer $6 \%$ igen Zuckerlösung gelegen hat, die interstitielle Flüssigkeit auch nahezu eine $6 \%$ ige Rohrzuckerlösung und frei von Salzen sein. Nun ist die Frage, warum die Muskelsubstanz in einer salzfreien Umgebung ihre Functionsfähigkeit verliert. Von Ionenaustausch zwischen Muskelsubstanz und Umgebung kann nicht die Rede sein, denn in letzterer sind keine Ionen mehr vorhanden. Es scheint mir aber nicht unmöglich, dass die Muskelsubstanz $\mathrm{NaCl}$ als solches austreten lässt, und dass dieser Austritt unter normalen Verhältnissen deshalb nicht stattfindet, weil sich dann Kochsalz zwischen Muskelsubstanz und Perimysium befindet.

Aehnliches ist zu erreichen, wenn man zu der interstitiellen Zuckerlösung $\mathrm{NaCl}$ oder $\mathrm{LiCl}$ hinzufügt und zwar eine solche Menge, die mit dem Na-Gehalt der Ionenproteïde der Muskelsubstanz im Gleichgewicht steht.

Ich erwähne schliesslich noch, dass Nerven durch Verweilen in reinen Zuckerlösungen ihre Erregbarkeit nicht verlieren. Dies ist vielleicht darin begründet, dass die umgebende Zuckerlösung, die etwa zwischen Achsencylinder und Markscheide gelegene NaCl-Lösung, nicht so leicht austreibt, weil die Diffusion nur in der Nähe der Ranvier'schen Einschnürung stattfinden kann.

\section{Elektromotorische Erscheinungen am ruhenden Froschmuskel.}

Man geht wohl nicht fehl, wenn man annimmt, dass von den meisten Physiologen der von Hermann gegebenen Darstellung über den Ursprung der elektromotorischen Kraft an geschädigten und gereizten Muskeln beigestimmt wird. Nach dieser Vorstellung ist, wie auch Engelmann endgültig nachwies, der unversehrte, nicht gereizte Muskel stromlos und die geschädigte, bezw. gereizte Stelle negativ elektrisch gegenüber der nicht geschädigten, bezw. nicht gereizten ${ }^{1}$ ). Diese Ansicht hat eine grosse Anzahl älterer Thatsachen unter einem einheitlichen Gesichtspunkt gebracht und auch viele neue zu Tage gefördert.

1) Unter gewissen Bedingungen aber kann die alterirte Stelle gegenüber dem nicht geschädigten Theile auch positiv werden (E. Hering). 
Die Frage, warum eine alterirte Stelle negativ wird, konnte bei dem damaligen Stand der Wissenschaft nicht mit Aussicht auf Erfolg in Angriff genommen werden. Der erste Versuch hierzu wurde 1897 von Tschagowetz [26] unternommen.

\section{a) Demarkationsstrom bei küinstlichem Querschnitt (Tschagowetz).}

Der russische Forscher fasst die elekromotorischen Erscheinungen als Folge eines Diffusionsstromes von $\mathrm{CO}_{2}\left(\mathrm{H}_{2} \mathrm{CO}_{3}\right)$ auf. Bereits 1867 hatte Hermann festgestellt [27], dass die Kohlensäureentwicklung am künstlichen Querschnitt des ruhenden Muskels 6,5 mal grösser sei als im übrigen Theil derselben. Es handelt sich also um eine Concentrations-(Gas-) Kette, die dadurch gebildet wird, dass die Concentration der $\mathrm{H}$-Ionen am künstlichen Querschnitt, resp. an der gereizten Stelle grösser ist, als an den normalen. Stellen. (Vergl. über Concentrationsketten B. II S. 332 und auch unten S. 149 ff.) Berechnet man nun daraus die elektromotorische Kraft des Ruhestromes, d. h. des Stromes, den man erhält, wenn man den künstlichen Querschnitt und die unversehrte Oberfläche durch einen Kupferdraht mit einander verbindet, so ergiebt sich eine Zahl, die mit dem beobachteten Werth gut übereinstimmt. So berechnete Tschagowetz bei einem Sartorius des Frosches für die elektromotorische Kraft 0,038 Volt, während der Versuch 0,043 Volt ergab.

Tschagowetz hebt hervor, dass der berechnete Werth kaum eine Aenderung erfahren wïrde, wenn der Muskelstrom nicht von der entstandenen Kohlensäure, sondern von Milch- oder Phosphorsäure herrühren sollte.

Nach dem erwähnten Princip hat Tschagowetz auch die Neigungströme gedeutet. Man darf annehmen, dass die $\mathrm{CO}_{2}$-Entwicklung auf dem Querschnitt senkrecht auf die Muskelfasern, an allen Stellen von gleicher Intensität ist.

Legt man einen schrägen Schnitt an, so wird die Koblensäure sich am spitzen Winkel auf eine kleinere, am stumpfen aber auf eine grössere Oberfläche vertheilen. Demzufolge ist der osmotische 1)ruck an diesen Stellen, der Grösse der betreffenden Winkel umgekehrt proportional. Aus diesem Unterschied im osmotischen Druck am stumpfen und spitzen Winkel berechnet dann Tschagowetz die elektromotorische Kraft der Neigungströme. Lr erhielt folgende Werthe bei drei verschiedenen Neigungswinkeln.

$\begin{array}{lccc} & \alpha=30^{\circ} & 45^{\circ} & 60^{\circ} \\ \text { berechnet } & 0,033 \text { Volt } & 0,022 \text { Volt } & 0,014 \text { Volt } \\ \text { beobachtet } & 0,034, \pi & 0,021 \text { n } & 0,012,\end{array}$

Für eine Betheiligung der Kohlensäure bei den thierischen, elektrischen Erscheinungen hat sich auch Aug. D. Waller 1897 aus- 
gesprochen [29]. Waller hält es für sehr wahrscheinlich, dass der grösste Theil der Erscheinungen an lebenden Nerven und Muskeln einfache Erscheinungen physikalisch-chemischer Natur sind, eine Ansicht, die auch von Boruttau mit Bezielung auf die Erscheinungen der Nervenleitung energisch vertheidigt wurde (siehe unten).

In gleichem Sinne hat auch Oker-Blom vier Jahre später Versuche angestellt [29]. Dabei wurden erst die Potentialgefälle studirt, wenn chemische Agentien örtlich auf den Muskel applicirt wurden. Mit Hilfe der dadurch erworbenen Kenntnisse wurde dann weiter der durch künstlichen Querschnitt herbeigeführte Demarkationsstrom untersucht. In beiden Fällen handelt es sich um Concentrationsketten.

Zum Verständniss seiner Ausführungen, insbesondere aber mit Rücksicht auf die grosse Wichtigkeit dieser Ketten für eine Anzahl biologischer Erscheinungen, will ich noch einiges über die physikalisch-chemische Seite des Gegenstandes mittheilen. In zweiten Band, S. 332 ff. ist bereits ausführlich die Rede ron diesen Ketten gewesen.

\section{b) Allgemeine Bemerkungen iiber Concentrationsketten.}

\section{a) Wesen der Concentrationsketten.}

In jeder wässerigen Elektrolytlösung sind die Molecüle wenigstens theilweise in Kationen und Anionen gespalten. Die ersten sind mit positiver, die zweiten mit negativer Elektricität geladen. Dennoch weist eine solche Lösung für sich allein keine elektromotorische Kraft auf, weil in ihr die Zahl der Kationen und Anionen gleich ist. Diese sind mit gleich grossen, entgegengesetzten Elektricitätsmengen geladen, so dass die algebraische Summe der Ionenladungen $=$ Null ist.

Was wird nun geschehen, wenn zwei ver'schieden concentrirte Lösungen desselben Elektrolyten mit einander in Berührung gebracht, z. B. vorsichtig auf einander geschichtet werden?

Es wird eine Diffusion von nicht gespaltenen Molekïlen aus der concentrirten in die verdïnnte Lösung stattfinden. Aber auch die Ionen werden sich in Bewegung setzen, und zwar aus der Flüssigkeit, in der sie in grösseren Concentrationen vorhanden sind, nach der, in welcher ihre Concentration geringer ist. Nehmen wir einen Augenblick an, dass in einem bestimmten Fall die Kationen eine grössere Wanderungsgeschwindigkeit besitzen, als die Anionen. Dann werden in einer bestimmten Zeit mehr Kationen als Anionen in die rerdünnte Lösung hineindiffundirt sein: demzufolge wird die verdünnte Lösung positiv 
elektrisch, während durch das Zurückbleiben von Anionen die concentrirte Lösung negativ elektrisch wird. Diffundiren die Anionen schneller als die Kationen, so wird umgekehrt die verdünnte Lösung negativ elektrisch.

Ein Beispiel für den ersten Fall giebt das $\mathrm{HCl}$. Die Wanderungsgeschwindigkeit von $\mathrm{H}^{\prime}$ ist bei $18^{0} 318$, von $\mathrm{Cl}^{\prime}=65,9$. Bringt man eine verdünnte HCl-Lösung mit einer concentrirten in Berührung, so werden aus der letzteren positive $\mathrm{H}^{-}$-Ionen mit grösserer Geschwindigkeit in die verdünnte hinüberwandern als $\mathrm{Cl}^{\prime}$-Ionen. An der Grenzschicht wird also die der verdünnten Säure zugekehrten Seite positiv und die der concentrirten Säure zugekehrte negativ elektrisch. Bei KOH-Lösungen ist gerade das Umgekehrte der Fall, denn da haben die elektronegativen $\mathrm{OH}^{\prime}$-Ionen eine grössere Geschwindigkeit (174) als die elektropositiven $\mathrm{K}$ : Ionen $(65,3)$.

Es kann auch geschehen, dass die Wanderungsgeschwindigkeiten der Kationen und Anionen nahezu dieselben sind, wie z. B. in $\mathrm{KCl}$ (wo die von $\mathrm{K}^{\cdot}=65,3$ und von $\mathrm{Cl}^{\prime} 65,9$ ist). In diesem Fall wird keine Elektricitätstrennung beobachtet.

Ich führe hier einige Ketten an, deren elektromotorische Kraft $0 \mathrm{ker-Blom}$ ermittelt hat.

ß) Beispiel von Concentrationsketten und ihre elektromotorische Kraft.

0,1 n. $\mathrm{KCl} \mid 0,00001$ n. $\mathrm{NaCl} \mid 0,1$ n. $\mathrm{NaCl} \mid 0,1$ n. $\mathrm{KCl}$

(Vergl. bezüglich der Gefässe Bd. II S. $345 \mathrm{ff}$.

Hier grenzen also zwei verschiedene concentrirte $\mathrm{NaCl}-\mathrm{L}$ ösungen einander. Die dadurch entstandene Elektricität wird beiderseits mittelst einer $0,1 \mathrm{n}$. KCl-Lösung abgeleitet. Der Grund der Potentialdifferenz, die bei Berührung der zwei NaClJösungen auftritt, liegt darin, dass die Wanderungsgeschwindigkeit von $\mathrm{Na} \cdot 44,4$, die von $\mathrm{Cl}^{\prime} 65,9$ beträgt. Die negativen Chlorionen werden deshalb schneller in die verdünntere $\mathrm{NaCl}-\mathrm{L}$ ösung übergehen als die positive $\mathrm{Na} \cdot$ Ionen. Von der linken Seite der hette wird somit negative Elektricität abgeleitet werden können. Der Versuch lebrt, dass die Potentialdifferenz - 20 Millivolt beträgt.

War die schwächere $\mathrm{NaCl}$-Lösung statt 0,00001 normal 0,0001 normal, so war die Potentialdifferenz - 13 Millivolt; war sie $0,01 \mathrm{n}$. so war sie - 4 Millivolt.

Die folgende Kette ist nach dem oben gesagten stromlos.

$$
\text { I } 0,1 \mathrm{KCl} \mid 0,001 \text { n. } \mathrm{KCl} \mid 1 \mathrm{n} \text {. KCl } \mid 0,1 \mathrm{n} \text {. KCl II }
$$

denn Chlor- ma Kaliumionen besitzen die gleiche Wanderungsgeschwindigkeit.

Bringt man jedoch etwa 0,1 n. Salpetersäure zwischen die beiden mittleren KCl-Lösungen, so entsteht folgende Kette:

I $0,1 \mathrm{KCl} \mid 0,001 \mathrm{n}$. KCl| 0,1 n. $\mathrm{HNO}_{3} \mid 1 \mathrm{n}$. $\mathrm{KCl} \mid 0,1 \mathrm{n}$. $\mathrm{KCl}$ 
Diese Kette zeigt einen Strom in der Richtung II $\rightarrow$ I.

Die Wanderungsgeschwindigkeit der positiven $\mathrm{H}$-Ionen beträgt 318 und die der $\mathrm{NO}_{3}^{\prime}$-Ionen 60,8 . Es lässt sich erwarten, dass die $\mathrm{H}^{\prime}$-Ionen gegen die verdünnte KCl-Lösung einen grösseren Vorsprung vor den $\mathrm{NO}_{3}$-Ionen erhalten, als gegenüber der concentrirteren KCl-Lösung. Daher entsteht ein Strom in der Richtung von rechts nach links.

Noch einwandfreier dürte diese Ueberlegung erscheinen, wenn wir zwei Nicht-Elektrolyten einschalten, z. B. destillirtes Wasser mit Mannitlösung.

I $0,1 \mathrm{n} . \mathrm{KCl} \mid$ Destill. Wasser $\mid 0,1 \mathrm{n}$. Mannit $\mid 0,1 \mathrm{n}$. KCl. II ist stromlos.

Wird aber zwischen dem reinen Wasser und der Mannitlösung ein in $0,1 \mathrm{n}$. $\mathrm{HCl}$ getränkter Fliesspapierstreifen eingeschaltet, so kann an der linken Seite (I) +26 Millivolt abgeleitet werden. Wird dagegen eine in $0,1 \mathrm{n}$. $\mathrm{NaOH}$ getränkter Fliesspapierstreifen eingeschaltet, so entsteht ein Strom in entgegengesetzter Richtung, mit einer Potentialdifferenz von - 23 Millivolt.

Aus praktischem Gesichtspunkt will ich noch die folgende Kette erwähnen.

$$
0,00001 \text { n. KCl | 0,01 1.. HCl | 0,01 n. KOH | 0,00001 n. KCl }
$$

Diese Kette ergab $+7+$ Millivolt. Wurde aber zur Ableitung nicht $0.00001 \mathrm{n}$. $\mathrm{KCl}$ verwendet, sondern $0,001 \mathrm{n}$. KC'l, so betrug die gesammte Potentialdifferenz +22 Millivolt. Wurde $0,1 \mathrm{ll}$. KCl genommen, so war sie -9 Millivolt und wurde endlich 1 norm. KCl gebraucht, - 13 Millivolt. Man sieht, welchen grossen Einfluss in einem derartigen Fall die Ableitungsfliissigkeiten a uf die Grösse, ja selbst auf das Zeichen der Potentialdifferenz ausüben können. Die Ursache liegt darin, dass es sich hier nicht um eine Berührungstläche handelt, nämlich von $0,01 \mathrm{HCl} \mid 0,01 \mathrm{NaOH}$, sondern auch um die Berührungsflächen der HCl-Lösung mit der KCl-Lösung, und der NaOH-Lösung mit der KCl-Lösung. Nun ist die Potentialdifferenz von $0.01 \mathrm{n} \mathrm{HCl}$ mit verschiedenen $\mathrm{KCl}$-Lösungen nicht dieselbe und Gleiches gilt auch für die NaOH-Lösung; auch hier fallen die Ableitungsflüssigkeiten ins Gewicht. Was man misst, ist selbstverständlich die algebraische Summe der verschiedenen Potentialdifferenzen.

\section{7) Constanz der Concentrationsketten.}

Mit Beziehung auf die Schnelligkeit, mit der bei Berïhrung zweier Lösungen die elektromotorischen hräfte sich einstellen, constatirte Planck, dass sie ron der 
Grössenordnung der Geschwindigkeit des Lichtes, resp. der elektrischen Wellen in metallischen Leitern ist. Der Endzustand an der Berührungsfläche ist somit sehr schnell erreicht.

Wir haben uns hier den Fall vorgestellt, dass zwei Lösungen neben einander geschichtet sind. Es liegt auf der Hand, dass je nachdem die Diffusion fortschreitet, die Potentialdifferenz abnimmt. Will man die anfängliche Potentialdifferenz einige Zeit behufs quantitativer Bestimmungen constant erhalten, so empfiehlt es sich einen Wattebausch zwischen die verschieden concentrirten Flüssigkeiten zu legen oder Gelatinelösungen derselben herzustellen, die man nach dem Erstarren neben einander legt.

Um die Berührung gleichmässig und sicher zu erzielen, empfiehlt es sich dann weiter, die entsprechende Stelle mit einer erwärmten Messerschneide zu berühren, so dass die beiderseitigen Grenzschichten sich etwas verflüssigen.

Eine derartige Anordnung lehrt noch etwas Besonderes: Dass es nämlich gleichgültig ist, an welcher Stelle man die beiden Gelatinblöcke behufs Messung der Potentialdifferenz ableitet. Sie hat bei Ableitung in der unmittelbaren Nähe der Berührungstläche dieselbe Grösse wie bei Ableitung von mehr entfernten Stellen. Hi eraus geht hervor, dass die Differenz in der That an der Berührungsfläche entsteht.

\section{ઈ) Einfluss der Permeabilität der Berührungsfläche für Ionen auf die Constanz der Kette.}

Ein besonderer und aus biologischem Gesichtspunkt sehr wichtiger Zustand ergiebt sich, wenn zwei Verbindungen an einander grenzen, die eine semipermeable Niederschlagsmembran mit einander bilden, z. B. Ferrocyankalium und Kupfersulfat [30]. Die Membran von Ferrocyankupfer ist für Ferrocyan- oder $\mathrm{SO}_{4}$ "-Ionen, ebenso wenig permeabel, wie für Kupferionen und für die ungespaltenen Salze; wohl ist sie es aber für $\mathrm{K}$-Ionen. Diese werden sich bestreben durch die Ferrocyankupfermembran hindurch in die $\mathrm{CuSO}_{4}$-Lösung zu wandern. Sie werden aber durch die elektronegativen Ferrocyanionen, die selbst gar nicht hinüber wandern können, in erheblichem Maasse zurückgehalten werden, so dass nicht viele über die Grenze gelangen.

Wenn man nun den Unterschied nicht durch einen äusseren Schliessungsbogen ausgleicht, so hat die Hinüberwanderung der K-Ionen bald aufgehört. Es ist ein Gleichgewichtszustand erreicht und es ändert 
sich nichts. Dies erklärt die grosse Constanz der Kette $\mathrm{K}_{4} \mathrm{FeCy}_{6} \mid \mathrm{CuSO}_{4}$. Bei Schliessung des Schliessungsbogens zeigt sich ein Strom. Es ist das gerade eine charakteristische Eigenschaft einer constanten Zelle, dass dieselbe sich, während sie sich im Oeffnungszustande befindet, nicht ändert. Man denke z. B. an die Leclanché-Zelle.

Oker-Blom hat eine derartige Zelle angefertigt, indem er die beiden Salze in Gelatine löste. Die Potentialdifferenz wurde mittelst $0,1 \mathrm{n} \mathrm{KCl}$ abgeleitet.

Die Kette hatte also folgende Gestalt:

$0,1 \mathrm{n} \mathrm{KCl} \mathrm{|} \mathrm{Ferrocyankalium-Gelatine} \mathrm{|} \mathrm{CuSO}_{4}$-Gelatine | $0,1 \mathrm{n} \mathrm{KCl}$.

Dieselbe erwies sich jedoch nicht als constant. Die ursprüngliche Potentialdifferenz betrug - 56 Millivolt und sank nach 24, 48 und 72 Stunden auf resp. - 52, -44 und -34 Millivolt. Zwischen den Beobachtungszeiten war der Stromkreis geöffnet. Dass die Zelle nicht so constant ist, wie sich aus theoretischen Gründen erwarten lässt, ist den sonstigen verunreinigenden Elektrolyten, die schwer aus der Gelatine $\mathrm{zu}$ entfernen sind und eventuell die Ferrocyankupfermembran passiren können, zuzuschreiben.

Es braucht kaum hervorgehoben zu werden, von wie grosser Bedeutung die Permeabilität der lebenden Membranen für bestimmte Ionen im Hinblick auf das Entstehen elektromotorischer Kräfte ist.

\section{c) Demarkationstrom durch örtliche Application verschiedener Flïssig- keiten auf den Muskel (0ker-Blom).}

Oker-Blom hat nun die durch Berührung verschiedener Stoffe mit dem Muskel, herbeigeführte Potentialdifferenz nach folgendem Schema ermittelt.

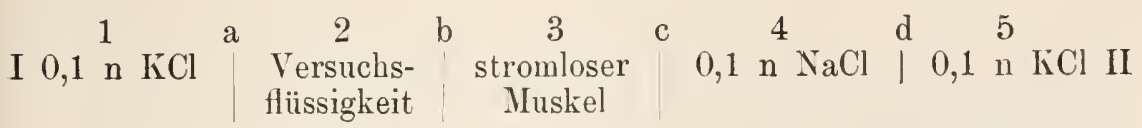

Für diese Anordnung wurden zwei Ostwald sche Normalelektroden benutzt. Diese haben die in Fig. 3 wiedergegebene Gestalt. (Die Abbildung ist in $1 / 2$ der natürlichen Grösse.)

In den Boden des Reservoirs A ist ein Platindraht eingeschmolzen. Dieser steckt im Quecksilber, mit welchem der Boden über eine möglichst grosse Oberfläche bedeckt ist. Auf dem Quecksilber befindet sich ein wenig Calomel. Ferner ist das Reservoir ganz oder theilweise mit der zuerst genannten Lösung der Kette angefüllt, also in dem zu besprechenden Falle, mit 0,1 n. KCl. Wenn man das Gummirohr mittelst Klemme abschliesst, kann die KCl-Lösung nicht aus dem Seitenrohr 
ausfliessen. Dennoch ist letzteres mit der KCl-Lösung gefüllt. In einem zweiten Reservoir B, das, wie ersichtlich, mit einer offenen Verjüngung endet, befindet sich die Versuchsflüssigkeit (2). Man sieht, dass die KCl-Lösung (1) mit dieser Ver-

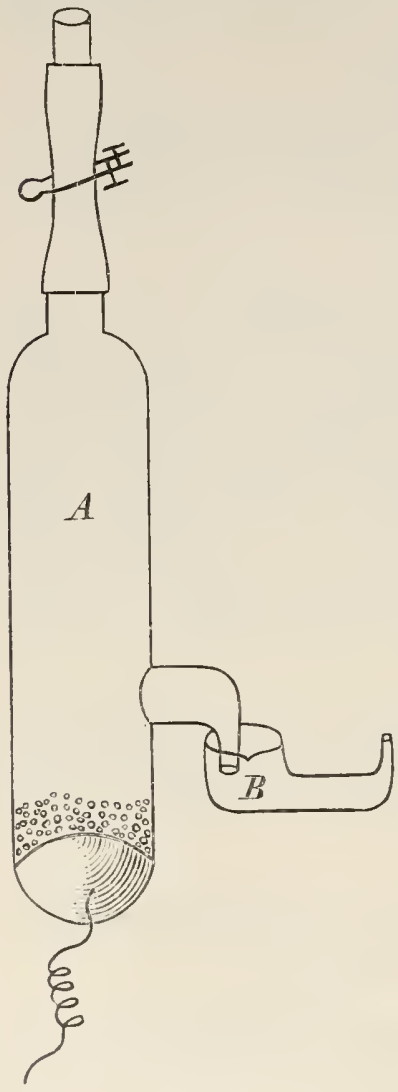

Fig. 3. suchungsflüssigkeit(2) in Contact steht. Neben dieser Vorrichtung wird eine zweite Normalelektrode aufgestellt, deren Reservoir A in gleicher Weise mit Quecksilber, Calomel und $0,1 \mathrm{n} . \mathrm{KCl}(5)$ angefüllt ist, und deren Reservoir B $0,1 \mathrm{n} . \mathrm{NaCl}$ (4) enthält. Der vorher stromlose Muskel wird vorsichtig auf die beiden offenen Verjüngungen gelegt. Dann wird der mittelst der Platindrähte (I und II) abzuleitende Strom gemessen.

Ich gebe einen Versuch wieder, bei dem die Versuchsflüssigkeit [2] destillirtes. Wasser war.

Frischer stromloser Sartorius eines curarisirten grossen Frosches im Frühjahr.

$$
\begin{array}{lrrrrrrr}
\text { Nach } & 0 & 2 & 4 & 9 & 14 & 17 & 19 \text { Minuten } \\
& -9 & -7 & -10 & -7 & -1 & -0 & +0 \text { Millivolt } \\
\text { Nach } & 23 & 25 & 29 & 33 & 35 & 36 \text { Minuten } \\
& +1 & +4 & +10 & +13 & +47 & +34 \text { Millivolt } \\
\text { Nach } & 37 & 38 & 39 & 40 & 41 & 43 \text { Minuten } \\
& +31 & +25 & +20 & +17 & +15 & +13 \text { Millivolt } \\
\text { Nach } & 46 & 51 & 58 & 63 & 69 & 76 & \text { Minuten } \\
& +10 & +6 & +4 & 0 & -3 & -7 \text { Millivolt } \\
\text { Nach } & 83 & 88 & 95 & 104 & 117 & 125 \text { Minuten } \\
& -11 & -13 & -17 & -20 & -30 & -32 \text { Millivolt } \\
\text { Nach } & 131 & 137 & \text { Minuten } \\
& -36 & -38 & & &
\end{array}
$$

Im Anfang des Versuchs zeigt die linke Seite eine Negativität, die allmählich abnimmt und verschwindet (1. Phase); dann entsteht Positivität, die schnell ansteigt und allmählich wieder abfällt um 0 zu werden (¿. Phase) und wieder in eine steigende Negativität überzugehen (3. Phase). Man kann also 3 Phasen unterscheiden. Diese Erscheinungen sind complicirt. Sie werden von Oker-Blom derart gedeutet, dass unter dem Einfluss des Wassers eine Gleichgewichitverschiebung von gelösten Stoffen, eine Ionenverschiebung, entsteht und demzufolge eine Concentrationskette vorliegt.

Fine derartige Kette entsteht auch, wenn der Muskel auf andere Weise geschädigt wird. z. B. ein kïnstlicher Querschnitt angelegt wird. Durch die ungleiche Wanderungsgeschwindigkeit der ans den Zerfallsstoffen entstandenen Ionen durch die Muskelsubstanz, wird dann eine Concentrationskette hervorgerufen.

Indessen werden diese Verhälnnisse dadurch complicirt, dass die Hiillen eigenthümliche Permeabilitätsverhältnisse zeigen. 
Oker-Blom hält unversehrte Hiillen für impermeabel für die Zerfallstoffe. $\mathrm{Ob}$ das, soweit die letzteren Krystalloide sind, wirklich der Fall ist, scheint mir, mit Rücksicht anf die grosse Permeabilität, die Overton den Hüllen vindicirt, einer näheren Untersuchung bedïrftig. Unter gewissen Umständen können sie nach $\mathrm{Oker-Blom}$ fïr elektropositive Ionen impermeabel werden; sind die Hüllen stark geschädigt, so werden sie für die Zerfallstoffe vollständig durchlässig.

Für eine andere längst bekannte Erscheinung weiss $\mathrm{Oker-Blom} \mathrm{keine} \mathrm{Er-}$ klärung. Wenn man an einem lebenden vorher stromlosen Muskel einen Querschnitt anlegt, findet man bekanntlich nicht nur Potentialunterschiede zwischen dem küustlichen Querschnitt und der unversehrten Oberfläche, sondern auch $\mathrm{zwischen}$ Punkten auf dieser, welche vom Querschnitt ungleich weit entfernt sind. Diese Potentialunterschiede zeigen sich schon nach einigen Minuten und $\mathrm{z}$ war auch an Punkten, die auf grossen Distanzen vom Querschnitt gelegen sind. Es ist kaum anzunehmen, dass die stromerzeugenden Zerfallproducte durch einfache Diffusion in so kurzer Zeit in die unverletzte Muskelsubstanz durch einfache Diffusion eingedrungen sein können. Wir stossen hier auf eine Erscheinung, durch welche das elektromotorische Verhalten des verletzten lebenden Muskels sich von einer einfachen chemischen Concentrationskette entschieden unterscheidet.

Auch abgesehen von der Thatsache, dass Oker-Blom die Erklärung des eben genannten Stromes schuldig geblieben ist, kann ich in seinen Ausführungen eine in jeder Hinsicht befriedigende Dentung des Hermann'schen Satzes ïber das Entstehen des Demarkationsstromes nicht finden. Auch fragt man sich, warum $\mathrm{Oker-Blom} \mathrm{die} \mathrm{Vorstellung}$ von Tschagowetz weder in bestätigendem noch in ablehnendem Sinne in den Kreis seiner Betrachtungen aufgenommen hat, um so mehr, als er dieselbe in seinen Litteraturangaben erwähnt.

Vielleicht rechnet $\mathrm{Oker-Blom} \mathrm{die} \mathrm{CO}_{2}$ stillschweigend zu den Zerfallsproducten. Dem ist in der That so; aber dieses Zerfallsproduct hat hier eine so grosse Bedeutung, dass Tschagowetz die ganze elektromotorische Kraft darauf zurïckführen konnte.

Jedenfalls hat Oker-Blom's Arbeit das Verdienst wiederum auf die Elektrochemie als Mittel zur Lösung physiologischer Probleme aufmerksam gemacht zu haben. Wie weit diese Arbeit auch in directer Weise dazu beigetragen hat, die Erkenntniss der Entstehung von Demarkations- und Actionsströmen zu vertiefen, müssen spätere Untersuchungen noch lehren ${ }^{1}$.

1) Ich mache noch auf zwei Arbeiten vou Brünings aufmerksam, die hier aber nicht mehr berücksichtigt werden können: „Ueber den Ruhestrom des Froschmuskels" (Pf üger's Archiv 9S. 1903. S. 241) und "Ueber Ruhestrom und Reizung " ebenda 100. 1903. S. 357). 
Gleiches gilt für die anderen oben besprochenen Untersuchungen auf dem Gebiete der Muskelphysiologie. So sind über das Verhalten der Muskeln in Lösungen verschiedener Agentien interessante Thatsachen aufgefunden worden; aber es ist noch nicht gelungen, daraus sichere Schlussfolgerungen über den chemischen Bau der Muskeln abzuleiten, insbesondere über die Form, in welcher die anorganischen Bestandtheile darin vorhanden sind. Aber auch für die Erreichung dieses Zieles scheint mir der neue Weg ein vielversprechender.

\section{Zur Kenntniss der Nervenreizung.}

Hirschmann [31] war der erste, der die Theorie des osmotischen Drucks zum Studium der Nervenreizung anwandte. Hirschmann untersuchte auf Vorschlag Heidenhain's, welches die Concentration verschiedener Salze war, die eben noch ausreichte, den Nerv zu einer Muskelzuckung zu veranlassen [23].

Er untersuchte Natrium-, Kalium- und Lithiumsalze und zwar mit einwerthigen und zweiwerthigen Säuren und fand, dass die eben wirksamen Concentrationen der Natriumsalze nahezu äquimolecular waren. Ich lasse eine zusammenfassende Tabelle folgen, die auch die Gewichtsprocente der Salze angiebt.

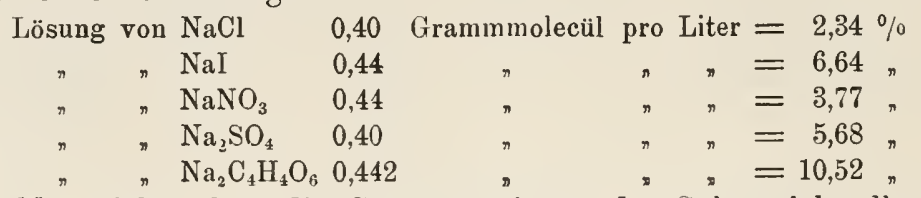

Man sieht, dass die Concentrationen der Salze sich alle um 0,40 Grammmolecüle pro Liter bewegen, obgleich die Concentrationen in Gewichtsprocenten grosse Unterschiede zeigen, Eigentlich sind aber diese Lösungen nicht genau isosmotisch; denn wir wissen, dass der Dissociationscoëfficient von $\mathrm{Na}_{2} \mathrm{SO}_{4}$ ein ganz anderer ist, als z. B. von $\mathrm{NaCl}$ (Bd. 1 S. 97). Hirschmann nimmt demnach an, dass die Lösungen isosmotisch (untereinander isotonisch) sind. Trotzdem glaubt er aber nicht, dass es sich um eine reine Wasserentziehung handelt, denn in diesem Falle müssten sich auch die molecularen Concentrationen der Lithiumsalze und der Kaliumsalze um 0,4 Grammmolecüle pro Liter bewegen. Für Lithiumsalze war das nicht der Fall und für Káaliumsalze noch weniger.

Für Lithiumsalze lag die Grenzconcentration höher.

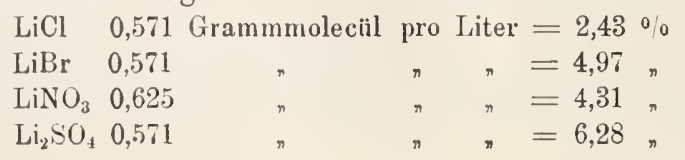


Mit Kaliumsalzen konnte absolut keine Reizwirkung erzielt werden, weder mit einer Lösung von 2,5, noch mit einer von 1 , noch mit einer von 0,4 Grammmolecuilen pro Liter. Hirschmann glaubt daher, dass es sich bei der Nervenreizung um eine specifische Wirkung der Salzbas is handet. Diese soll eine chemische Alteration der Nervensubstanz herbeiführen.

Demgegenüber haben Untersuchungen von Grützner nachgewiesen, dass a uch die Säureradicale oder, wie wir jetzt sagen, die Anionen einen bedeutenden Einfluss auf die Nerven ausuiben. Zunächst studirte Grützner, zum Theil mit Burginski, den Einfluss von äquimolecularen hyperisotonischen Lösungen von $\mathrm{NaJ}, \mathrm{NaBr}, \mathrm{NaCl}$ und $\mathrm{NaFl}$, auf motorische Nerven und fand ausnahmslos, dass das Jodnatrium am stärksten reizend wirkte; ihn folgte das Bromnatrium und, in der Regel diesem nahe stehend, das Chlornatrium.

Das Fluornatrium trat aus der Reihe herans, wie es ja auch in seinen rein chemischen Eigenschaften der Fall ist. Dieses reizte am stärksten von allen.

Der Unterschied gegenüber Hirschmann's Resultaten, der lediglich die Netalle für die von ihm gefundenen geringen Differenzen verantwortlich macht, ist, wie Grïtzner meint, dadurch bedingt, dass Hirschmann etwas ganz anderes untersucht hat als er. Hirschmann untersuchte, wie stark die Salzlösungen sein müssten, damit sie in der Regel den Nerven und seinen Muskel zu erregen anfangen, während Grützner die Wirkung je zweier äquimolecularer Lösungen eine Zeit lang mit einander verglichen hat. Ausserdem benutzte Hirschmann einen einfachen Muskel mit Nerven, Grützner den ganzen Unterschenkel mit Hüftnerv. Letzteres ist vielleicht nicht gleichgültig für die Zuverlässigkeit der Resultate.

Dieselbe Reihenfolge, die Grützner für die Intensität der Reizwirkung fand, beobachtete er auch für die Erregbarkeit.

Das Jod steigerte die Erregbarkeit schneller und bedeutender, als das Brom und dieses wieder mehr als das Chlor.

Dass es wirklich die Halogene als solche sind, die den Unterschied herbeiführen, geht noch besonders aus Versuchen mit äquivalenten Mengen der Halogene herror. Diese wurden alle je in derselben $\mathrm{NaCl}$ Lösung gelöst. Auch hier wurde wieder die stärkste Wirkung durch Jod, die schwächste durch Chlor hervorgerufen.

Indessen sei hervorgehoben, dass nach Grützner's Untersuchungen auch die Metalle (Kationen) specifische Einflüsse geltend machen. Bei der Vergleichung der Chloride des Kaliums, Rubidiums und Cäsiums 
schädigte das Kaliumsalz am meisten und schnellsten; weniger das Rubidium-, am wenigsten das Cäsiumsalz. Eine entsprechende Reihenfolge zeigten $\mathrm{Ba} *$, $\mathrm{Sr} *$ und $\mathrm{Ca} *$.

Aus diesen Versuchen geht also hervor, dass von den Salzen sowohl Kationen als auch Anionen ihren Einfluss auf die motorischen Nerven geltend machen.

In einer zweiten Abhandlung hat Grützner Untersuchungen über sensible Nerven veröffentlicht [33].

Die Versuche wurden derart angestellt, dass kleine Schnittwunden an den Händen beigebracht wurden, auf welche man mit einem feinen Haarpinsel die betreffenden Lösungen auftrug. Dann wurde die Zeit gemessen, welche von diesem Auftragen der Flüssigkeit bis zum Auftreten des Schmerzes verstrich.

Auch hier ergab sich wieder dieselbe Reihenfolge wie bei den motorischen Nerven.

Eine Lösung von Jodnatrium erzeugte bereits nach etwa 5 Secunden Schmerzempfindung, eine äquimoleculare Lösung von Bromnatrium nach 10 und eine solche von Chlornatrium nach 50 Secunden.

Grützner hat gleichartige Untersuchungen mit Säuren und Basen angestellt. Es wäre interessant $\mathrm{zu}$ berechnen wie weit hier die Concentration der $\mathrm{H}^{\text {; }}$ bezw. $\mathrm{OH}^{\prime}$-Ionen zum Ausdruck kommt.

An einem ganz anderen Object hat sein Schüler We inla nd [34] noch Versuche angestellt. Er benutzte Flimmerepithel von Fröschen. Am stärksten wurde die Thätigkeit durch die Jodide, am wenigsten durch die Chloride gehemmt. Es ergab sich also wieder dieselbe Reihenfolge, die bei den Nerven beobachtet wurde.

Es ist nun wohl merkwürdig, dass, wie in der letzten Zeit von Posternak [35] gefunden wurde, dieselbe Reihenfolge auch beim Verhalten der Colloide zum Ausdruck kommt. In schwachem Alkali aufgelöstes Eiweiss wird durch Chlorid leichter zur Ausflockung gebracht, als durch Bromid und durch dieses wieder leichter als durch Jodirl. Die Quellung von Gelatine wird durch Jodid mehr verstärkt als durch Bromid und Chlorid. In ähnlichem Sinne machen sich auch bei den Zustandänderungen der Colloide die Kationen geltend.

Ueberlegt man dies Alles, so ist man unwillkürlich geneigt, zwischen den besprochenen Modificationen von vitalen Processen und den durch dieselben Agentien erreichbaren $Z u$ standänderungen von Colloiden, einen causalen Zusammenhang zu vermuthen. 
Später hat Nernst versucht, das Wesen der Nervenreizung auf elektrischem Wege dem Verständniss näher zu bringen.

von Zeynek [36] hatte in Nernst's Laboratorium gefunden, dass bei Erregung der sensibeln Nerven der Fingerkuppe durch den Inductions-(Wechsel-)strom, die für die Reizschwelle erforderliche Stromintensität proportional der Quadratwurzel aus der Wechselzahl anstieg.

Nun fand Nernst [37] durch mathematische Ableitung, dass ganz m Allgemeinen bei Durchgang von Wechselströmen durch zwei Elektrolytlösungen, die durch eine semipermeable Membran getrennt sind, die durch die Wechselströme herbeigeführten Ionenconcentrationsänderungen ebenfalls der Quadratwurzel der Wechselzahl proportional sein müssen. Betrachtet man nun die Grenzflächen der Structurtheile lebender Organe als semipermeable Membranen, so ist der Versuch von Zeynek's durch rein physikalisch-chemische Principien erklärt und bildet ein weiteres Beispiel für den nach Nernst allgemein giultigen Satz, dass jede Nervenreizung auf eine durch den Strom herbeigeführte Ionenverschiebung zur ückzuführen ist.

Auch B orutta u [38] stellt sich bei der Erklärung der Nervenreizung auf physikalisch-chemischen Standpunkt und nimmt an, dass dabei Kohlensäure entsteht und zwar an der Grenzfläche der zwei Elektrolyte, aus welchen der Nerv als Kernleiter zusammengesetzt gedacht werden kann.

Diese Kohlensäure führt eine örtliche Aenderung des osmotischen Druckes herbei, und diese muss nach dem Princip der Concentrationskette einen Potentialunterschied zur Folge haben (vergl. Bd. II S. 332 und diesen Band S. 149). In dieser Weise denkt er sich eine wellenförmige Fortpflanzung der Erregung. Dass in der That $\mathrm{CO}_{2}$ bei der Nervenerregung betheiligt ist, wird, wie Bor utta u bemerkt, durch die Arbeiten Waller's und 'Tschagowetz wahrscheinlich gemacht.

Gegen Boruttau's Auffassung haben Hermann, Cybulski und Cremer Einwände erhoben. Letzterer hat ausgeführt, dass der durch eine Jocale Concentrationsänderung an der Grenzfläche des Kernleiters erzeugte Concentrationskette-Gegenstrom, bei langer Dauer zu extrapolaren Erscheinungen durch Diffusion Veranlassung geben muss, bei kurzer Dauer dagegen keine Wirkung auf die Nachbarschaft haben, oder höchstens "Pseudowellen" erzeugen wird.

Dagegen führte Boruttau aus, dass letzteres nur so lange gilt, als wir den sich bewegenden Ionen, den augenblicklichen Anschauungen 
in der physikalischen Chemie entsprechend, keine Trägheit zuschreiben. Sobald wir eine solche, sei es auf Grund irgend einer besonderen Constitution der den Kernleiter zusammensetzenden Substanzen, sei es nach genanerer Einsicht in die Eigenschaften der Ionen überhaupt, werden annehmen dürfen, ergiebt sich die wellenförmige Fortpflanzung einer localen Concentrationsänderung und damit elektromotorischer Kraft, also eines Actionsstromes, ganz im Sinne seines Schemas mit zwingender Nothwendigkeit. Dem Problem, durch welche genauer erkennbare Eigenschaften der den Kernleiter construirenden Substanzen diese Trägheit der Ionen herbeigeführt wird, wird man nach Boruttau mit den Fortschritten der physikalischen Chemie auf rein theoretischem Wege vielleicht näher kommen.

In einer späteren Abhandlung hat Boruttau [39] seine Ansichten weiter auseinander gesetzt.

Ich beherrsche die Litteratur der Nervenleitung nicht dermaassen, dass ich mir ein selbständiges Urtheil in dieser Streitfrage anmassen darf.

Schliesslich erwähne ich noch einen allgemeinen Gedanken Loeb's über die Nervenreizung, der für den Leser, der die Ausführungen auf S. 128 und auch Hardy's Ausführungen über Colloide (vergl. S. 66) kennt, leicht verständlich sein wird.

Die Zellen unseres Körpers und auch die Nerven bestehen grösstentheils aus Colloiden, die sich in gelöstem Zustande befinden (Hydrosol. Die Colloidtheilchen besitzen eine elektrische Ladung. Sobald nun ein elektrischer Strom zugeführt wird, ändert sich die Ladung der Colloide und damit die Grösse der Theilchen. Nimmt durch den hinzugeführten Strom die Ladung der Colloidtheilchen ab, so bilden sich grössere Aggregate, die Viscosität nimmt zu. Nimmt die Ladung zu, so geschieht das Umgekehrte. Es liegt auf der Hand, dass mit den Veränderungen des physikalischen Zustandes des Protoplasmas (Colloids) Lebensäusserungen einhergehen werden, wie Zuckungen etc., die in ihrer Verschiedenheit, auch von der Art des Protoplasmas abhängig sind, das durch den Reiz getroffen wurde.

Aus diesem Gesichtspunkte ist es verständlich, warum der elektrische Strom eine so allgemeine Reizform ist, und es leuchtet ein, warum auch Säuren und Basen reizen können. Führen ja auch diese eine Modification der Anordnung der Colloidtheilchen herbei und zwar ebenfalls durch Aenderung ihrer elektrischen Ladung. 


\title{
Viertes Kapitel.
}

\section{Ophthalmologisehes.}

\author{
Litteratur:
}

1. Massart, Archives de Biol. 9. 1889. p. 335.

2. Dreser, Archiv f. exp. Pathol. u. Pharmak. 29. 1892. S. 318.

3. Hamburger, Verhand. d. Koninkl. Akad. v. Wetensch. 3. Nr. 5. 1893.

4. J. J. Kunst, Beiträge zur Kenntniss der Farbenzerstreuung und des osmotischen Drucks einiger brechenden Medien des Auges. Inaug. Dissert. Freiburg. i. Br. Leiden 1895.

5. Manca et Deganello, Archives Ital. de Biol. 30. 1898. p. 172.

6. Manca, Archives Ital. de Biol. 30. 1898. p. 177.

7. Kunde, Zeitschr. f. wissensch. Zoologie. S. 1857. S. 466.

8. Mitchell, Americ. Journal of med. Science. 29. 1860. p. 106.

9. Guttmann, Berlin. klin. Wochensehr. 1865. S. 370 .

10. R. Dentschmann, Archiv f. Ophthalmologie. 23. 1877. S. 112.

11. Henbel. Pflü ger's Archiv. 20. 1879. S. $114 ;$ 21. 1880. S. 153; 23. 1880. S. 580.

12. R. Dentschmam, Pflüg er's Archiv. 20. 1879. S. 420, 22. 1880. S. 41.

13. R. Dentschmam, Archiv f. Ophthalmologie. 33. 1887. S. 229.

14. H. Magnus. Archiv f. Ophthalmologie. 34. 1890. S. 150.

15. Nanca et Ovio. Archivis di Ottalmologia. 4. fax 5/6 1896.

16. Nanca et Ovio, Archives Ital. de Biol. 99. 1898 p. 23. (Résumé). Ausführlich in Atti e Memorie della R. Accademia di scienze, lettere ed arti in Padova 13. 1897. p. 271.

Die Lehre vom osmotischen Druck hat bisher von ophtalmologischer Seite noch nicht das Maass von Aufmerksamkeit erfahren, das sie beanspruchen darf, obgleich ihre Bedeutung auf diesem Gebiete von Massart bereits 1889 an einem treffenden Beispiel dargethan wurde.

\section{Thränenflüssigkeit.}

Den Ausgangspunkt von M as sart's Untersuchung [1] bildete die bekannte Thatsache, dass die Berïhrung des Auges mit reinem Wasser, sowie mit einer starken Kochsalzlösung eine unangenehme Empfindung 
hervorruft. Zwischen beiden müsste also eine Salzlösung sich finden lassen, die das Auge ebensowenig wie die Thränendrüse reizt, und es liess sich erwarten, dass diese mit der Thränenflüssigkeit isotonisch sein würde.

In der That stellte sich heraus, dass solch eine Kochsalzlösung zu finden war. Bei einer der zwei Versuchspersonen war ihre Concentration $0,025 \mathrm{Mol}$ (d. h. 0,025 g-Molec. pro Liter), bei der anderen 0,0225, also im Mittel $0,02375 \mathrm{Mol}=0,02375 \times 58,5 \%=1,39 \%$. Diese Zahi stimmt mit dem ron $\mathrm{Lerch}$ gefundenen $\mathrm{NaCl}-\mathrm{Gehalt}$ der menschlichen Thränen, nämlich $1,3 \%$, gut überein, wenn man dabei in Betracht zieht, dass gerade das Kochsalz den Hauptbestandtheil der Flïssigkeit bildet. Sowohl schwächere, wie stärkere $\mathrm{NaCl}$-Lösungen verursachten eine unangenehme Empfindung, aber diese war in beiden Fällen nicht dieselbe.

Die hypisotonische Lösung (schwächer als $\mathrm{NaCl} 1,39 \%$ ) führte eine diffus unangenehme Empfindung herbei, ein Gefühl von Reibung; es war, als ob die Conjunctiva bulbi und palpebralis sich schwierig an einander vorbeibewegten. Dabei bestand Neigung, das Auge geöffnet zu halten. Die hyperisotonische Lösung (stärker als $\mathrm{XaCl} 1,39 \%$ ) dagegen veranlasste eine Reizung, die an der Stelle der Caruncula lacrymalis localisiert war, und, statt einer Neigung, die Augenlider offen zu halten, bestand eine lebhafte Tendenz, sie energisch zusammenzukneifen.

Der Unterschied der durch schwache und stärkere Lösungen hervorgerufenen Erscheinungen ist in folgender Weise zu erklären. Durch hypisotonische Lösungen erfahren die Epithelzellen der Conjunctiva bulbi und palpebrae eine Quellung, die sich an der offen liegenden Seite selbstverständlich am meisten ausspricht. Durch die Quellung bekommen die Zellen an dieser Seite kleine Erhebungen, so dass die Conjunctivae sich nicht mehr so glatt über einander bewegen und eine Reibung wahrgenommen wird. Um der unangenehmen Empfindung vorzubeugen, werden die Augenlider nicht bewegt: eine zweckmässige Einrichtung, weil dann ausserdem Flüssigkeit verdampfen kann, und dadurch die Schwellung zurückgeht.

Bei Einwirkung der hyperisotonischen Lösung findet eine Reizung und reflectorische Thränenabsonderung statt, und zwar wahrscheinlich durch die Reizung der zwischen den Corneazellen liegenden feinen Nervenendigungen, die nach J. Cohnh eim frei in die Thränenflüssigkeit hinausragen. Il assart wies mit Recht darauf hin, dass auch letztere Einrichtung sehr zweckmässig ist. Wenn das Auge für hyperisotonische Lösungen nicht empfindlich wäre, so würde die Conjunctiva durch die fortgesetzt stattfindende Verdampfung trocken werden; es würde Entzündung 
auftreten und schliesslich könnte das Auge zu Grunde gehen. Thatsächlich findet eine reflectorische Thränensecretion statt und die Bewegung der Augenlider sorgt für schnelle Ausbreitung über die Oberfläche.

Massart hat sich die Frage vorgelegt, ob das Auge inittelst Cocaïn, ebenso wie für Berührung auch für die Concentration unempfindlich gemacht werden kann.

Er tröpfelte erst eine einprocentige Cocainlösung, dann eine concentrirte (5,85\% ige) NaCl-Lösung ein. Unangenehme Empfindungen blieben dann aus. Ganz etwas anderes wurde wahrgenommen, wenn das Kochsalz gleichzeitig mit der Cocaïnlösung eingetröpfelt wurde, also eine Lösung von $1 \mathrm{~g}$ salzsaurem Cocain und $5,85 \mathrm{~g} \mathrm{NaCl}$ in $100 \mathrm{~g}$ Wasser. Zwar war unmittelbar nach der Eintröpfelung das Auge vollständig für $\mathrm{Be}$ rührung anästhesiert, wovon sich Massart mittelst eines Fremdlörpers überzeugte, andererseits aber wurde ein heftiger, fast unerträglicher spontaner Schmerz empfunden, der vollkommen jenem glich, der bei Anwendung einer lediglich $5,85 \% \mathrm{NaCl}$ enthaltenden Lösung wahrgenommen wird. Es scheint also, folgert Massart, dass die Nervenfasern, die die Concentrationsempfindung vermitteln, andere sind, als die, welche mit der Beriihrungsunterscheidung beauftragt sind.

Ich erwähne noch, dass Massart die meisten Versuche in gleicher Weise wie mit NaCl-Lösungen auch mit Natriumsulfat, Lithiumcitrat und Harnstoff wiederholt hat. Auch die Lösungen dieser Stoffe folgten dem Gesetze der isotonischen Coefficienten, d. h. die unwirksamen Concentrationen waren mit der $1,39 \%$ igen $\mathrm{NaCl}$-Lösung isosmotisch.

Auch von Humor aquaeus und vom Glaskörper sind Bestimmungen des osmotischen Druckes ausgeführt worden.

\section{Humor aquaeus.}

Als Dreser die Gefrierpunkterniedrigung einiger Körperflüssigkeiten ermittelte, hat er auch den Humor aquaeus bei seinen Untersuchungen herangezogen [2].

Er führte zwei Bestimmungen für das nach dem Tod exstirpirte Rinderauge aus und fand $A=-0,60^{\circ}$ und $-0,61^{\circ}$.

Wie ersichtlich, ist diese Depression grösser als die des Rinderblutserums, welche ungefähr $-0,58^{\circ}$ beträgt.

Dies stimınt mit den von mir ungefähr gleichzeitig und unabhängig von Dreser erhaltenen Zahlen beim lebenden Pferde [3] überein. 
Ich fand, dass der osmotische Druck grösser war als der des Blutserums desselben Thieres, selbst grösser, als der der entsprechenden Halslymphe. Die Bestimmung geschah mittelst meiner Blutkörperchenmethode (B. I S. 385; B. II S. 304).

Diese wurde auch von Kunst zu demselben Zwecke und mit demselben Resultat angewendet [4]. Als Mittelwerth aus zahlreichen Versuchen an Augen geschlachteter Rinder fand er einen osmotischen Druck, der einer NaCl-Lösung $\mathbf{0 , 9 9 5 \%} \%$ entsprach (grösster Werth 1,01\%, kleinster $0,94 \%$ ).

Daneben wurden von $\mathrm{Kunst}$ auch noch Gefrierpunktbestimmungen ausgeführt, und die dabei erhaltenen Zahlen auf NaCl-Lösung umgerechnet. Ich möchte bei dieser Gelegenheit hervorheben, dass Kunst zwei wichtige Vorsichtsmassregeln beachtet hat, die immer noch oft versäumt werden. Er stellte erstens vor und nach jeder Gefrierpunktbestimmung den Stand des Thermometers für destillirtes Wasser fest, ferner ermittelte er durch eigene Versuche die Depression einer reinen $1 \%$ igen $\mathrm{NaCl}$-Lösung, so dass der Einfluss des Apparates und der persönliche Fehler bei der Umrechnung möglichst vermindert waren.

Für eine $1 \%$ ige Kochsalzlösung fand er $I=-0,605^{\circ}$. Da die Gefrierpunkterniedrigung des Humor aquaeus $0,58^{0}$ betrug, war also das Humor aquaeus isotonisch mit einer NaCl-Lösung von $\frac{0,58}{0,605}=0,96 \%$.

Sowohl nach der Blutkörperchenmethode wie nach der Gefrierpunktsmethode findet man Zahlen für den Humor aquaeus, die grösser als die sind, welche man für das Blntserum zu finden pflegt. Für eine vollkommen brauchbare Vergleichung wäre es besser gewesen, Humor aquaeus und Serum desselben Thieres zu untersuchen. Wahrscheinlich hat Kunst das unterlassen, weil jedes Auge ihm nur 0,8 cc Flüssigkeit lieferte und er deshalb eine Mischung aus mehreren Augen verwenden musste.

Nach meinen späteren Untersuchungen und Erfahrungen ïber die Blutkörperchen-Vethode, genügen für sie 1,6 cc Humor aquaeus und eventuell noch weniger.

Man bringt in das trichterförmige Röhrchen ${ }^{1}$ ) 1,5 cc Humor aquaeus, setzt eine Wassermenge hinzu, die muthmasslich noch nicht im Stande sein wird, Blutfarb-

1) Vergl. Bd. 1. S. $379 \mathrm{ff}$. Die Röhrchen sind nicht mehr von der dort angegebenen Adresse zu beziehen, sondern von der Firma Franz Hugershoff zu Leipzig, oder auch rom Mechaniker meines Instituts Herrn J. J. Boom, der auch das Kästchen mit Zubehör liefert. 
stoffaustritt zu veranlassen und mischt Humor und Wasser gut mit einem Platindraht. Dann fügt man 0,06 cc defibrinirtes Blut hinzu, mischt, lässt eine Viertelstunde stehen, und centrifugirt. Die Blutkörperchen befinden sich dann im capillaren Theil, die Flüssigkeit im Trichter. Ist letztere farblos (Vergleichung mit Wasser gegen weisses Papier), so wird vorsichtig eine bekannte Menge Wasser hinzugefügt, mit der Flüssigkeit im Trichter gut gemischt (ohne die Blutkörperchen zu berühren) und nachher mit den Blutkörperchen gemischt. Wieder wird eine Viertelstunde gewartet, centrifugirt, u. s. w. bis die Flüssigkeit in Trichter nach der Centrifugirung roth erscheint. Die letzte und die vorletzte Verdünnung sind dann die gesuchten Grenzen.

Man sieht, dass man die Blutkörperchenmethode auch unter Verwendung äusserst kleiner Quantitäten benutzen kann.

Schliesslich sei noch erwähnt, dass auch Manca, ebenso wie ich, den osmotischen Druck des Humor aquaeus und des Serums desselben Thieres ermittelt hat. Er bediente sich der Blutkörperchenmethode [5] und der Hämatokritmethode [6].

Er fand als Ergebniss zahlreicher Untersuchungen, dass - wenn der osmotische Druck des Serums $100(0,824 \% \mathrm{NaCl})$ beträgt — der des Humor aquaeus $113(0,936 \% \mathrm{NaCl})$ ist.

Nach den erwähnten Versuchen unterliegt es keinem Zweifel, dass der Humor aquaeus einen höheren osmotischen Druck besitzt als das entsprechende Blutserum.

\section{Glaskörper.}

Der einzige, der, soweit mir bekannt, den osmotischen Druck des Glaskörpers ermittelte, war $\mathrm{K}$ unst.

Die Flüssigkeit wurde in folgender Weise erhalten:

Nach Entfernung der Cornea mit Hülfe von Pincette und Scheere, wurde der noch zurückgebliebene geringe Rest des Humor aquaeus mittelst eines Stückchens Filtrirpapier aufgesaugt und hierauf durch Spaltung der vorderen Linsenkapsel und Druck auf die Linse, letztere entfernt. Der Glaskörper liess sich dann leicht von den zurückbleibenden Augenhäuten trennen und in einem Tuche auffangen. Er wurde iu demselben ausgepresst, und die heraustriefende Flüssigkeit wurde filtrirt.

Auch hier wurde die Blutkörperchen- und die Gefrierpunktmethode benutzt.

Als Mittelwerth aus den Untersuchungen von \& Glaskörpern ergab die Blutkörperchenmethode einen osmotischen Druck von $0,96 \% \mathrm{NaCl}$.

Die Gefrierpunktmethode ergab folgende Mittelwerthe:

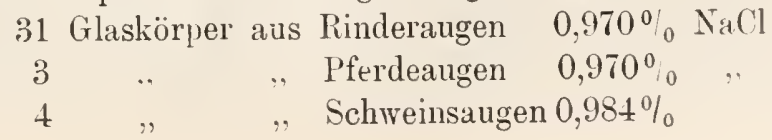


Es ist also insehrhohem Maasse wahrscheinlich, dass auch der Glaskörper einen höheren osmotischen Druck besitzt als das entsprechende Serum.

Humor aquaeus und Glaskörper scheinen etwa isosmotisch zu sein.

\section{Linse.}

Ausführliche Untersuchungen über das osmotische Verhalten der Linse verdanken wir Manca und $\mathrm{Orio.}$

Seit 1857 ist es durch Experimente von Kunde [7] bekannt, dass bei Fröschen die Krystallinse sich trübt, wenn man den Thieren starke Salzlösungen einverleibt. Diese Angaben wurden alsbald von mehreren Seiten bestätigt und vielfach erweitert. Ich nenne die Untersuchungen über die experimentelle Kataraktbildung von Mitchell [6], Guttmann [7], R. De utschmann $[10,12,13]$, Heubel [11] und H. II agnus [12]. Aus diesen geht wohl übereinstimmend hervor, dass Katarakt sich u. A. durch Wasserentziehung bilden kann. Manca und Ovio haben der Litteratur dieses Gegenstandes einen besonderen Aufsatz gewidmet [15], auf den ich hier verweise.

Ihre eigenen Experimentalarbeiten beziehen sich auf die Untersuchung der Linse verschiedener Thiere (Frosch, Rind, Kaninchen, Ratte) im Licht der neueren physikalisch-chemischen Lehre. Es wurden Untersuchungen in vivo und in vitro angestellt.

Die Untersuchungen in viro lehrten in Uebereinstimmung mit den Ergebnissen der anderen genannten Autoren:

dass beim $\mathrm{Frosch}$ durch Einbringen von $\mathrm{NaCl}, \mathrm{LiCl}, \mathrm{KCl}, \mathrm{MgSO}_{4}$, $\mathrm{Na}_{2} \mathrm{SO}_{4}$ und Glukose in den Conjunctivalsack (Methode Heubel) leicht Katarakt hervorgerufen werden konnte. Auch gelingt es bei diesem Thiere leicht, durch Einführung von $\mathrm{NaCl}$ in den Lymphsack Katarakt herbeizuführen.

Bei anderen Thieren begegneten sie jedoch Schwierigkeiten.

Bei weitem die meisten ihrer Untersuchungen stellten M a nca und Ovio in vitro an und sie gelangten dabei zu sehr interessanten Resultaten [16]. Sie fanden, dass die Krystallinse für Concentrationsunterschiede sehr empfindlich ist. Diese Empfindlichkeit äussert sich in einer Verminderung der Durchsichtigkeit und in einer Gewichtveränderung. Die Durchsichtigkeit wurde ermittelt, indem unter die Linse ein Stiick Papier mit feinen Buchstaben gelegt wurde, oder indem man sie auf schwarzen Sammet legte. Um die In- 
tensität der Trübung festzulegen, wurde die auf schwar'zem Sammet liegende opake Linse photographirt.

Die Autoren beobachteten nun Folgendes. Kurz nachdem die Linse in eine Lösung gebracht worden ist, die ilı gegeniiber anch nur schwach hyperisotonisch ist, wird sie trübe und nimmt an Gewicht ab. Ist die Flüssigkeit hypisotonisch, so verliert die Linse ebenfalls ihr normales transparentes Ansehen und nimmt dabei an Gewicht zu. Zwischen beiden Concentrationen liegt eine solche, in welcher die Linse an Aussehen und Gewicht unverändert bleibt. Es stellte sich heraus, dass die beiden ganz verschiedenen Methoden dieselbe Salzlösung als die indifferente erwiesen.

Für den Frosch liegt dieselbe in Mittel zwischen 0,135 und $0,14 \mathrm{Mol} \mathrm{NaCl}$, d. h. zwischen $0,79 \%$ und $0,82 \%$.

Für das Rind war die $\mathrm{NaCl}$-Lösung, in welcher die Linse ihr normales Aussehen behielt, im Mittel $1,15 \%$, und die in welcher ihr Gewicht weder zu- noch abnahm, ungefähr $1,25 \%$. Diese Uebereinstimmung ist nicht so gross wie beim Frosch; sie ist indessen ziemlich befriedigend. Nimmt man aus den beiden letzteren Zahlen den Mittelwerth, so erhält $\operatorname{man} 1,2 \%$.

Sowohl beim Frosch wie beim Rind, ist die indifferente Concentration gegenüber dem entsprechenden Blutserum hyperisotonisch und zwar bei beiden in gleicliem Grade:

$$
\frac{1,2}{0,9}=1,33 \text { (für das Rind), } \frac{0,801}{0,6}=1,33 \text { (für den Frosch). }
$$

Nicht nur mit NaCl-Lösungen haben II anca und Ovio Versuclie angestellt, sondern anch mit LiCl- und KCl-Lösungen. Es ergab sich, dass die LiCl- und die KCl-Lösung, welche die Linse unverändert liess, mit der entsprechenden $\mathrm{TaCl}$-Lösung isosmotisch war.

Doch verhalten sich diese drei Salze keineswegs in jeder Hinsicht der Linse gegenüber gleich, aber der Unterschied documentirt sich erst nach einigen Stunden.

Ianca und $\mathrm{Orio}$ fanden nämlich, dass bei allen drei Salzen das osmotische Gleichgewicht sich innerhalb 10 Minuten herstellt. Und dieses Gleichgewicht lässt sich sehr scharf beurtheilen. Wird die Linse in eine hyperisotonische Lösung gebracht, deren Concentration diejenige der isotonischen nur um 0,005 g-Nolec. übersteigt, so tritt eine deutlich wahrnehmbare Trübung ein, die nach Verbringen in eine genau isotonische Lösung vermisst wird. Bei längerem A ufenthalt in hyperisotonischen Lösungen nimmt man aber einen deutlichen Lnterschied war. In der 
hyperisotonischen KCl-Lösung fängt die Trübung bald an abzunehmen, um endlich ganz zu verschwinden; in der isosmotischen hyperisotonischen $\mathrm{NaCl}$ - und LiCl-Lösung bleibt die Trübung selbst 24 Stunden fast unvermindert fortbestehen. Dieser Unterschied lässt sich kaum anders erklären, als durch die Annahme, dass die Froschlinse für $\mathrm{Na} \cdot$ und $\mathrm{Li} \cdot$ nicht, für $\mathrm{K}^{*}$ dagegen leicht permeabel ist. Mit Recht weisen Manca und Ovio auf diese Thatsache als auf eine besonders interessante hin. Sie erweist mit grosser Deutlichkeit, dass gleichnamige Salze derselben Metallgruppe erheblich verschiedene Permeabilitätsverhältnisse zeigen können, eine Thatsache, die später auch bei den Untersuchungen ron L oeb und seinen Schülern über künstliche Parthenogenesis klar zu Tage getreten ist (S. 176).

Manca und Ovio untersuchten auch, wie sich die Linse in Blut und Serum verhält. Sie stellten die betreffenden Experimente am Rind an. Yon sieben Linsen zeigte nur eine nach 1/2-stündigem Aufenthalt in Serum ein wenig von der charakteristischen Opalescenz, die man auch beim Aufenthalt in Wasser oder in hypisotonischen Lösungen beobachtet. Die übrigen behielten ihre Transparenz und ihr normales Aussehen. Mit letzterer Beobachtung stimmt nicht überein, was bei der Gewichtbestimmung beobachtet wurde, die bei 5 Linsen eine Vermehrung um etwa $0,21 \%$ anzeigte. Nach diesem Versuch muss also das Serum gegenüber der Linse als schwach hypisotonisch angesehen werden. Das steht in der That auch mit dem Werth in Einklang, der beim Frosch für die der Linse gegenüber indifferente Kochsalzlösung gefunden wurde $(0,801 \%$ gegenüber dem Serum $\pm 0,6 \%)$.

Aus allen bis jetzt ausgeführten Untersuchungen scheint hervorzugehen, dass der Humor aquaeus eine gegenïber dem Blutserum desselben Individuums hyperisotonische Flüsigkeit ist und dass die Krystallinse, wie zu erwarten, sich mit diesem für sie natürlichen Medium, in osmotischem Gleichgewicht befindet.

Der Glaskörper scheint denselben osmotischen Druck zu besitzen, wie Hunor aquaeus und Krystallinse. $O b$ das in aller Strenge der Fall ist, wird erst festgestellt werden können, wenn man die beiden Flüssigkeiten eines und desselben Thieres untersucht bat. Solche Untersuchungen stehen noch aus (vergl. über die erforderlichen Quantitäten S. 164). 
Fiinftes Kapitel.

\section{Geschmack.}

\section{Litteratur.}

1. Kahlenberg, Bulletin of the University of Wisconsin Nr. 25; Science Series 2 . 1898. p. 1.

2. Richard, American chemic. Journal 20. 1898. p. 121.

3. Kahlenberg, Journal of physic. Chemistry 4. 1900. p. 33 u. 533.

4. Richard, Journal of physic. Chemistry 4.1900. p. 207.

5. Ostwald, Zeitschr. f. physik. Chemie 28. 1899. S. 174.

6. Noyes, Journal of the Americ. Chemic. Society 22. 1900. p. 73.

7. Höber und Kiesow, Zeitschr. f. physik. Chemie 27. 1898. S. 601.

8. G. Heymans, Zeitschrift für Psychologie und Physiologie der Sinnesorgane 21. 1899. S. 321.

\section{Säuren.}

1898 wurde von Kahlenberg die Frage behandelt, in wie fern der Geschmack verdünnter Lösungen mit der elektrolytischen Dissociation der darin gelösten Stoffe zusammenhängt [1].

Vergleicht man mit einer verdünnten Salzsäurelösung, die noch einen ausgeprägt sauern Geschmack hat, eine NaCl-Lösung von äquimolecularer Concentration, so stellt sich heraus, dass letztere ganz geschmacklos ist. So fand Ka h le nberg, dass 1/800 normale Salzsänre noch sauer schmeckte, 1/800 normal $\mathrm{NaCl}$ aber war geschmacklos. Beide Verbindungen sind in der angewandten Verdünnung so gut wie vollständig ionisirt; es lag also anf der Hand zu schliessen, dass die Wasserstoffionen den sauren Geschmack herbeiführen.

Diese Schlussfolgerung wurde durch die weiteren Beobachtungen desselben Autors an wässrigen Lösungen ron Schwefelsäure, Jodwasser- 
stoffsäure und Salpetersäure unterstützt. Auch diese Flüssigkeiten liessen sich, ebenso wie Salzsäure, in ${ }^{1 /} / 800$ normaler Lösung noch gerade durch den Geschmack von reinem destillirten Wasser unterscheiden. Nun sind in dieser Concentration die genannten Säuren gleich stark dissociirt und enthalten also im gleichen Volumen dieselbe Anzahl Wasserstoffionen.

Wie aber Kahlenberg und auch Richard fanden, gilt die genannte Regel nicht für alle Säuren. So scheint Essigsäure z. B. eine Ausnahme zu machen. Es stellte sich nämlich heraus, dass bereits eine ${ }_{1 / 200}$ normale Essigsäure sauren Geschmack besass. Nun ist eine derartige Lösung zu etwa $6 \%$ dissociirt, also ist die Concentration der Wasserstoffionen in derselben $6 / 100 \times 1 / 200=6 / 20000$ normal, während bei $\mathrm{HCl}, \mathrm{H}_{2} \mathrm{SO}_{4}, \mathrm{HNO}_{3}$, die $\mathrm{H}^{-}$-Ionen-Concentration etwa ${ }^{1 / 800}$ normal sein muss.

Behufs Ergründung der Ursache dieses abweichenden Verhaltens sind vielfache Untersuchungen angestellt worden, u. A. von Kahlenberg [3], Richard [4], Ostwald [5], Noyes [6], ohne jedoch bisher völlige Aufklärung zu bringen. Jedenfalls sind noch weitere Versuche erforderlich.

\section{Laugen.}

Gleichzeitig und unabhängig von Kahlenberg und von Richard wurden auch von Höber und Kiesow Untersuchungen in derselben Richtung angestellt, hauptsächlich ïber Laugen und Salze [7].

Höber und Kiesow fanden, dass alle Laugen bei grosser Verdünnung einen eigenthümlichen süssen Geschmack haben, der hauptsächlich am Zungenrand wahrgenommen wird. Es kam also nur darauf an zu prüfen, ob dieser Geschmack immer bei der gleichen $\mathrm{OH}^{\prime}$-IonenConcentration aufzutreten beginnt.

Die Resultate enthält folgende Tabelle:

Moleculare Concentration der $\mathrm{OH}^{\prime}$-Ionen

\begin{tabular}{|c|c|c|}
\hline $\mathrm{KOH}$ & & 0,009 \\
\hline $\mathrm{NaOH}$ & & $0,008-0,012$ \\
\hline $\mathrm{Ca}(\mathrm{OH})_{2}$ & & 0,008 \\
\hline $\mathrm{Ba}(\mathrm{OH})_{2}$ & & 0,006 \\
\hline $\left.\mathrm{Co}\left(\mathrm{NH}_{3}\right)_{6}\right](\mathrm{OH})_{3}$ & & 0,006 \\
\hline
\end{tabular}

$\begin{array}{ll}\text { Hexamincobalthydroxyd }\left[\mathrm{Co}\left(\mathrm{NH}_{3}\right)_{6}\right](\mathrm{OH})_{3} & 0,006 \\ \text { Nitropentamincobalthydroxyd }\left[\mathrm{Co}\left(\mathrm{NH}_{3}\right)_{5} \mathrm{NO}_{2}\right](\mathrm{OH})_{2} & 0,005 \overline{5}-0,007\end{array}$

Dihydroxylotetraminplatin-

$$
\text { hydroxyd } \quad\left[\mathrm{Pt}\left(\mathrm{NH}_{3}\right)_{4}(\mathrm{OH})_{2}\right](\mathrm{OH})_{2} \quad 0,005 \tilde{\Xi}-0,007
$$


Die moleculare Concentration der $\mathrm{OH}^{\prime}$-Ionen wurde einfach durch Titration mit $1 / 10 \mathrm{n}$. Säure ermittelt, da die Laugen in der angewendeten Concentration ganz dissociirt sind.

Die Tabelle lehrt, dass die Laugen bei annähernd gleicher Concentration an $\mathrm{OH}^{\prime}$-Ionen anfangen, siiss zu schmecken.

Als eine Eigenthümlichkeit des süssen Geschmacks der Laugen erwähnen die Autoren nocl, dass derselbe bei der Application der Schwellenlösung (Lösung, die die Reizsclıwelle eben iiberschreitet) mit grosser Deutlichkeit am hinteren Zungenrand aufritt und zwar nicht sofort, sondern erst nach Verlauf einiger Secunden. Er zeigt sich erst dann mit grosser Deutlichkeit, wenn die Lösung mit der Zunge hin und her bewegt wird. (Es wurden für alle Versuche, auch bei denen mit Salzlösungen, 2 cc der auf $25^{0}$ erwärmten Flüssigkeit mittelst Pipette auf die Zunge gebracht.) Ja manchmal beobachtet man die Süssigkeitsempfindung erst dann, wenn die Lösung aus dem Munde entfernt wird.

Weiter stellte sich heraus, dass Kali- und Natronlauge auch an der Zungenspitze schwach süss schmeckten, aber dass diese Süssigkeitsempfindung sich qualitativ ganz deutlich von der an dem hinteren Rande unterscheidet. Die Süssigkeitsempfindung an der Spitze ähnelt der der Kohlenhydrate, die an den hinteren Rändern ist genau dieselbe, wie sie auch der Bleizucker auslöst. Endlich unterscheiden sich die Laugen noch durch ihren jemaligen Nebengeschmack.

Man sieht, die Sache ist nicht so einfach, wie sie auf den ersten Anblick erscheint. Complicirter noch liegt sie bei den Salzen.

\section{Salze.}

Höber und Kiesow experimentirten hier in ähnlicher Weise wie bei Laugen.

Es wurde die schwächste Lösung eines Salzes ausfindig gemacht, die noch einen salzigen Geschmack hervorrief. Von dieser die Reizschwelle für die Salzempfindung repräsentirenden Lösung wurde dann der Gebalt an Ionen und undissociirten Molekiilen bestimmt. So konnte dann weiter durch Vergleich der gefundenen Werthe für die verschieden gleich schmeckenden Lösungen festgestellt werden, ob etwa die Anionen, Kationen oder die neutralen Molecüle den gemeinsamen Salzgeschmack bedingten.

Zunächst wurden Halogensalze: $\mathrm{KCl}, \mathrm{NaCl}, \mathrm{NaBr}$, Na.J untersucht. Es stellte sich dabei heraus, dass der Schwellenwerth für den Salzgeschmack 0,024-0,037 Mol. betrug. Unglücklicherweise aber sind alle Halogenalkalien annähernd gleich stark dissociirt, so dass in äquimolecu- 
laren Lösungen der procentische Gehalt an Anionen derselbe ist, desgleichen der an Kationen und an ungespaltenen Molecülen.

So war es also unmöglich zu sagen, von welchem der drei Bestandtheile der Salzgeschmack abhängt.

Desshalb wurden Salze zur Untersuchung herangezogen, deren Dissociation qualitativ von derjenigen der Halogenalkalien verschieden ist, wie z. B. $\mathrm{Na}_{2} \mathrm{SO}_{4}$. Dies geschah auf Grund folgender Ueberlegung:

Angenommen die Analyse der $\mathrm{Na}_{2} \mathrm{SO}_{4}$-Lösung, die eben eine Salzempfindung auslöst, ergebe eine gewisse molare Concentration $\mathrm{c}$ und einen Dissociationsgrad $\alpha=0,80$. Dies bedeutet, dass aus 100 Molekülen $\mathrm{Na}_{2} \mathrm{SO}_{4} 80 \mathrm{SO}_{4}{ }_{4}$-Ionen und $160 \mathrm{Na}$-Ionen entstanden, während 20 Moleküle unverändert geblieben sind. Die Concentrationen der Anionen, Kationen und ungespaltenen Moleküle können somit ausgedrückt werden durch $\frac{80 \mathrm{c}}{100}, \frac{160 \mathrm{c}}{100}$ und $\frac{20 \mathrm{c}}{100}$.

Denken wir uns nun, dass bei den Halogenalkalien die Schwellenlösung ebenfalls die Concentration c hatte und der Dissociationsgrad $\alpha$ ebenfalls 0,80 wäre, so könnte man daraus schliessen, dass entweder die neutralen Moleküle oder die Anionen den Salzgeschmack verursachen. Keinesfalls könnten es aber die Kationen sein, weil deren Concentrationswerth für $\mathrm{Na}_{2} \mathrm{SO}_{4} \frac{160 \mathrm{c}}{100}$ und für $\mathrm{NaCl} \frac{80 \mathrm{c}}{100}$ beträgt, also nicht derselbe ist.

Indessen sind die Salze mit zweiwerthigen Ionen, wie $\mathrm{Na}_{2} \mathrm{SO}_{4}$ schwächer dissociirt als die einfachen binären Elektrolyte. Dadurch gestaltet sich die Sache etwas complicirter, aber doch noch einfach genug, um die folgende Tabelle ohne weiteres verständlich erscheinen zu lassen.

\begin{tabular}{c|c|c|c|c|c|c|c}
\hline I & II & III & IV & V & VI & VII & VIII \\
\hline & $\begin{array}{c}\text { Molare } \\
\text { Concentra- } \\
\text { tion(g-Mol. } \\
\text { pro Liter) }\end{array}$ & $\begin{array}{c}\text { Leitver- } \\
\text { mögen } \mu_{\mathrm{V}} \\
\text { bei der Ver- } \\
\text { dünnung } \mathbf{v}\end{array}$ & $\begin{array}{c}\text { Leitver- } \\
\text { mögen } \mu_{\infty} \\
\text { bei unend- } \\
\text { licher Ver- } \\
\text { dünnung }\end{array}$ & $\begin{array}{c}\text { Dissocia- } \\
\text { tionsgrad } \\
\alpha=\frac{\mu_{\mathrm{V}}}{\mu_{\infty}}\end{array}$ & $\begin{array}{c}\text { Concen- } \\
\text { tration der } \\
\text { Anionen }\end{array}$ & $\begin{array}{c}\text { Concen- } \\
\text { tration der } \\
\text { Kationen }\end{array}$ & $\begin{array}{c}\text { Concen- } \\
\text { tration der } \\
\text { gespaltenen } \\
\text { Holeküle }\end{array}$ \\
\hline \hline $\mathrm{K}_{2} \mathrm{SO}_{4}$ & 0,043 & 208,9 & 292,1 & 0,724 & 0,031 & 0,062 & 0,012 \\
$\mathrm{Na}_{2} \mathrm{SO}_{4}$ & 0,034 & 178,4 & 240,7 & 0,741 & 0,025 & 0,051 & 0,009 \\
$\mathrm{MgCl}_{2}$ & 0,0175 & 210,2 & 252,0 & 0,834 & 0,029 & 0,015 & 0,003 \\
$\mathrm{CaCl}_{2}$ & 0,0355 & 200,2 & 266,0 & 0,753 & 0,053 & 0,027 & 0,009
\end{tabular}

1) Vergl. B. I S. 8. 
Die vier Salze erreichen in den vier genannten molaren Concentrationen (Spalte II) die Reizschwelle für die Salzempfindung.

Aus Spalte III und IV ist berechnet, wie gross der Dissociationsgrad $a$ der vier Salzlösungen ist. Multiplicirt man diese $a$ mit der entsprechenden molaren Concentration von Spalte II, so bekommt man die Concentration der Anionen (Spalte VI) für die beiden ersten Salze und, nach weiterer Multiplication mit 2, auch diejenige für die beiden anderen Salze. Um die Concentration der Kationen zu berechnen, multiplicirt man ebenfalls $\alpha$ mit den Werthen der Spalte II und dann weiter die betreffenden Werthe in den ersten beiden Fällen noch mit 2. Um die Concentration der nicht gespaltenen Moleküle zu erhalten (Spalte VIII), müssen die Zahlen von Spalte I jedesmal mit $(1+\alpha)$ multiplicirt werden.

Vergleicht man die Werthe der Spalte VI, VII und VIII, so ergiebt sich, dass noch am ehesten unter denjenigen der Syalte VI Uebereinstimmung herrscht, wenigstens soweit die drei ersten Salze in Frage kommen. Höber und Kiesow sind denn auch geneigt, den Anionen die salzige Geschmacksempfindung zuzuschreiben.

Demgegenüber macht das Calciumsalz eine Ausnahme. Vorläufig nehmen sie zur Erklärung an, dass die im Speichel rorkommende $\mathrm{CO}_{2}$ einen Theil des Calciums bindet.

So wenig wie bei den Langen die verschiedenen Schwellenwerthe eine röllig gleichartige Siissigkeit hervorrufen, ebenso wenig geben auch bei den Salzen die Schwellenlösungen genau dieselbe Geschmacksempfindung. Die Nebenempfindung muss man wohl den verschiedenen Kationen und unzersetzten Molekülen zuschreiben. In der That hat sich auch ein derartiges Verhältniss bei den Berylliumsalzen nachweisen lassen. Diese Salze haben einen süssen Geschmack, welcher von den Kationen herrührt; denn die molare Concentration der Schwellenlösungen verhält sich z. B. für $\mathrm{Be} \mathrm{Cl}_{2}$ und $\mathrm{BeSO}_{4}$ wie $1: 1$ und nicht wie 2:1, wie es sein müsste, wenn der betreffende Geschmack durch die Anionen bedingt würde. Man wird vielleicht die Bemerkung machen, dass hier noch eine andere Erklärung möglich ist, dass nämlich das unzersetzte Molekül den süssen Geschmack bedingt. Das ist sicher nicht der Fall, denn die Schwellenlösungen waren so verdünnt, dass die Salze als rollständig dissociirt betrachtet werden konnten.

So meinen Höber und Kiesow, dass die Magnesium- und Baryum-Ionen eine bittere Empfindung verursachen.

Im Allgemeinen sprechen sie den Satz aus, dass sich der Geschmack eines jeden Salzes additiv zusammensetzt aus dem Geschmackder Kationen und dem der Anionen; vielleicht sind auch die ungespaltenen Moleküle noch daran betheiligt. 
Indessen weichen die experimentellen Ergebnisse von Kahlenberg und von $\mathrm{Höber}$ und $\mathrm{Kies} \mathrm{ow}$ in mancher Hinsicht von einander ab, und es scheint, wie Cohen in seinen Vorträgen richtig bemerkt, fraglich, ob auf diesem Gebiete ohne Heranziehung der Lehre von der psychischen Hemmung weitere Erfolge zu erzielen sind. Bekanntlich sagt diese u. A. aus, dass ein Bewusstseininhalt durch die gleichzeitige Existenz eines anderen Bewusstseininhaltes einen Intensitätverlust erleidet, also entweder geschwächt oder vollständig aus dem Bewusstsein verdrängt wird (G. Heymans [8]). So müssen auch die durch Kationen ausgelösten Geschmackempfindungen die seitens der Anionen veranlassten beeinflussen. In welchem Maasse das geschieht, das wird u. A. von der Intensität des Reizes (Schwellenwerth) und von dem latenten Stadium (siehe oben) der beiden abhängen. Sind auch noch die ungespaltenen Salzmolecüle am Geschmack betheiligt, was wohl wahrscheinlich ist, so muss die Wechselwirkung noch viel verwickelter werden. 


\title{
Sechstes Kapitel.
}

\section{Embryologisches.}

\author{
Litteratur.
}

1. J. Loeb, American Journal of Physiol. :. 1899. p. 135.

2. J. Loeb, American Journal of Physiol. 3. 1900. p. 434.

3. J. Loeb, American Journal of Physiol. 4. 1900. p. 178.

4. J. Loeb, American Journal of Physiol. t. 1901. p. 423.

5. Morgan, Archiv f. d. Entwicklungsmechanik S. 1899. S. 448.

6. Hunter, American Journal of Physiol. 6. 1901. p. 177.

7. Loeb, Fischer und Neilson, P flüger's Archiv S7, 1901. S. 1.

8. Mathews, American Journal of Physiol. (6. 1902. p. 142.

9. Herbst, Archiv f. d. Entwicklungsmechanik 9. 1900. S. 424.

10. Morgan, Archiv f. d. Entwicklungsmechanik 2. 1895. S. 65.

11. Driesch, Archiv f. d. Entwicklungsmechanik 10. 1900. S. 411.

12. Zur Strassen, Archiv f. d. Entwicklungsmechanik 7. 1898. S. 642.

13. Hans Winkler, Nachr. d. Kgl. Gesellsch. d. Wissensch. zu Göttingen. 1900. S. 187.

14. Gies. Americ. Journ. of Physiol. 6. 1902. p. 305.

15. Loeb, Americ. Journal of Physiol. 6. 1902. p. 305.

16. Zanier, Gazetta degli ospedali 1895. Nr. 60. Ref. in Jahresber. f. Thierchemie über das Jahr 1895. S. 172.

17. Kriiger, Untersuchungen des fötalen Blutes im Moment der Geburt. Inaug.Diss. Dorpat. 1886.

18. Scherenziss, Untersuchungen des fötalen Blutes im Moment der Geburt. Inaug.Diss. Dorpat 1888.

19. J. Veit, Zeitschr, f. Geburtshülfe u. Gynäkologie 2. 1900. S. 2.

20. Krönig und Fueth, Zeitschr. f. Geburtshülfe u. Gynäkologie 13. 1901. S. 177.

21. D. G. Ubbels, Vergleichende Untersuchungea von mütterlichem Blute, fötalem Blute und Fruchtwasser. Inaug. Diss. Giessen (Utrecht) 1901.

22. Jacqué, Bulletin de l'Académie royale des sciences de Belgique. Nr. 4. Avril 1902. Résumé.

Ausführlich: in Mémoires couronnés et autres Mémoires $\left(8^{\circ}\right)$ publiés par l'Académie royale de Belgique 63. 1902.

23. Farkas und Scipiades, $\mathrm{P} f \mathrm{l}$ üger's Archiv 95. 1903. S. 551.

24. Pozzi, R. Accademia di Medicina de Torino. 13 luglio, 1900.

25. Bousquet, Recherches cryoscopiques sur le sérum sanguin. Paris. E. Bernard \& Cie, 1899. 


\section{Künstliche Parthenogenesis.}

In den letzten Jahren haben namentlich Loeb und seine Schüler eine Reihe interessanter Untersuchungen über künstliche Parthenogenesis ${ }^{1}$ ) veröffentlicht. Derartige Untersuchungen bei Seethieren sind auch viel versprechend für die Kenntniss der Entwickelungsmechanik der Eier bei höheren Thieren.

\section{a) Kiinstliche Parthenogenesis durch Steigerung des osmotischen Druckes.}

Zunächst gelang es durch Steigerung des osmotischen Druckes des Seewassers um 30-60\%, wenn nicht bei allen, so doch bei vielen Echinodermen die Eier parthenogenetisch zur Entwickelung zu bringen $[1,2,3,4,55]$.

Es schien dabei ganz gleichgültig, durch welche Stoffe der osmotische Druck des Seewassers erhöht wurde, so dass man nicht fehl geht, die künstliche Parthenogenesis hier auf einen Wasserverlust seitens des Eies zurïckzuführen. Diese Versuche wurden von einer Reihe anderer Autoren wiederholt und bestätigt, u. A. von Wils on und Curt Herbst, während Hunter [6] nachweisen konnte, dass gleiches auch bei Arbacia stattfand, wenn die Steigerung des osmotischen Druckes des Seewassers durch Einkochen erzielt wurde.

Der letzte Autor verfuhr derart, dass zwei Portionen von je 500 ce normalen Seewassers die eine auf $375 \mathrm{cc}$, die andere auf $250 \mathrm{cc}$ eingeengt und dann auf $22^{\circ} \mathrm{C}$ abgekühlt wurden. Um die beim Erhitzen ausgetriebene Luft zu ersetzen, wurde drei Mal Luft durchgeleitet. Jetzt wurde eine gleiche Eiermenge in die beiden Lösungen gebracht und darin zwei Stunden belassen. Nach Ueberführung in normales Seewasser zeigten die Eier aus der am wenigsten eingeengten Lösung bald Segmentation und viele später auch Locomotion; die aus der stärker eingeengten Lösung zeigten keine Entwickelung. Die genannte günstige Lösung ist, wie $\mathrm{Hunter}$ hervorhebt, gerade isotonisch mit dem Gemisch von normalem Seewasser und concentrirter NaCl-Lösung (25 ec bis $37^{1 / 2}$ ec NaCl-Lösung $2^{1}{ }_{2}$ normal, versetzt mit Seewasser zu $250 \mathrm{cc}$ ), durch das auch Loeb künstliche Parthenogenesis bei Arbacia hervorrief.

b) Kiinstliche Parthenogenesis durch Ionen.

Aber nicht nur durch Steigerung des osmotischen Druckes, auch durch Hinzufïgung kleiner Ionenmengen konnte Parthenogenesis erzeugt werden $[4]$.

Fügt man zu 100 cc Seewasser $1-2$ cc einer 2,5 n. KCl- (oder $\mathrm{KNO}_{3}-$ )Lösung zu, wodurch der osmotische Druck nicht in nennens-

1) Vergl. hierzu auch das dritte Kapitel sub 1 b $\eta$ und $\zeta$. (S. 120 ff.). 
werthem Maasse gesteigert wird, und bringt unbefruchtete Eier von Chaetopterus etwas länger als 3 Minuten in die Flüssigkeit, so bilden sich schwimmende, anscheinend normale Larren. Hierbei sind noch zwei Thatsachen interessant, erstens, dass solch eine Lösung auf unbefruchtete Seeigeleier ganz wirkungslos ist. zweitens, dass allein Kaliumionen die genannte Wirkung auf Chaetopterus-Eier auszuüben im Stande scheinen.

Andere Eier brauchen wieder andere Ionen. So konnten Loeb, Fischer und Neilson [7] bei einem Seestern (Asterias) künstliche Parthenogenese durch Wasserstoffionen herror'ufen, und zwar nur durch Wasserstoff- und nicht durch Kaliumionen.

Sie brauchten zu 100 cc Seewasser nur $3-5$ cc einer 1/10 n. anorganischen säure hinzuzusetzen und hierin die unbefruchteten Seesterneier 3-20 Minuten zu belassen. Nach Zurückbringen in normales Seewasser entwickelten sich dieselben dann zu Gastrulis.

Man muss bei derartigen Versuchen über künstliche Parthenogenesis dem $\mathrm{Zu}$ tritt von Spernatozoen mit grösster Sorgfalt vorbeugen [4]. Speziell bei Versuchen mit Seesterneiern hat man überdies noch darauf zu achten, dass man die Eier nicht schüttelt. Mathe $\mathrm{s}$ s hat nämlich gefunden [8], dass unbefruchtete Seesterneier, wenn sie in einem bestimmten Stadium der Reife geschüttelt wurden, sich zu Larven entwickeln konnten. Diese Larven entwickelten sich aber nicht weiter, als bis zur Gastrulaform. Weiter war für sie charakteristisch, dass sich eine dicke Membran um die Zelle bildete und die Keruwand verschwand.

Mit Rücksicht auf den parthenogenetischen Einfluss mechanischer Bewegungen wurde desshalb sicherheitshalber jeder Versuch von einem Controlversuch mit demselben Material begleitet, das mechanisch genau ebenso behandelt wurde, wie die mit Säure behandelten Eier.

In den Controlversuchen wurde keine Entwickelungr ron Larven beobachtet. Wohl aber geschah dies bei den SäureEiern und zwar in erheblichem Masse.

Auf Seeigeleier haben Wasserstoffionen keinen Einfluss. Bei wieder anderen Eiern, nämlich bei denen des marinen Ringelwurmes, A mphitrite, wirken zum Seewasser hinzugefügte Calciumionen befruchtend. $\mathrm{Mg} \mathrm{g}^{*}, \mathrm{Sr}, \mathrm{Li}, \mathrm{Na}$ und $\mathrm{K}$ erwiesen sich als wirkungslos.

Bei Tersuchen mit Amphitrite sund ähnliche Vorsichtsmaassregeln erforderlich, wie bei den Tersuchen mit Eiern von Seesternen. Es gelang nämlich unbefruchtete Amphitriteeier durch Uebertragen von einem Gefïs mit Seewasser in ein anleres zur Entwickelung zu bringen. Es schien aber, dass das nur dann möglich war, wenn die Eier eine Zeit lang in Seewasser gelegen hatten; aber auch dann konnte man nicht mit Sicherheit bei diesem Versuch auf Erfolg rechnen. I)agegen war H a mburger, Osmot. Druek III. Band. 
es mit voller Sicherheit möglich, unter allen Umständen, aus den unbefruchteten Amphitriteeiern schwimmende Larven zu züchten, wenn man, wie gesagt, dem Seewasser eine kleine aber bestimmte Menge Calcium zufügte [7].

\section{c) Vergleichung des Entwicklungsganges der Eier nach kiinstlicher Parthenogenesis und nach natiirlicher Befruchtung mit Spermatozoen.}

L oeb hat mittelst der Nikroskopes die morphologischen Veränderungen verfolgt, die ein $\mathrm{Ei}$ von Chaetopterus nach beiden Arten von Befruchtung durchmacht.

Zunächst findet man einen erheblichen Unterschied in Beziehung auf die erforderliche Zeit.

Die durch Spermatozoen befruchteten Eier entwickelten sich viel schneller, als die auf künstlichem Wege befruchteten. Um 12 Uhr 45 Minuten durch Spermatozoen befruchtet, zeigten die Eier bereits um 1 Uhr 20 Min. das 16.Zellenstadium, wälrend die fast gleichzeitig mit $\mathrm{K} \cdot$ - mentirung zeigten. Um 5 Uhr schwammen Larven der normal befruchteten Eier umher, während die $\mathrm{K}$-Eier erst zwischen 8 und 9 Uhr zu schwimmen anfingen. Die Larven beider Herkunft sehen gleich aus, doch sind die Bilder, welche sie durchlaufen, nicht ganz dieselben. Die durch Ionen zur Entwickelung gebrachten Eier lassen kaum Furchungskugeln sehen, während diese bei den durch Spermatozoen befruchteten sehr deutlich sichtbar sind.

Was die Lebensdauer betrifft, so gingen Chaetopterus-Larven beiderlei Herkunft nach zwei Tagen zu Grunde, was Loeb Bakterien zuschreibt. Da die natürliche Entwicklung schneller vor sich gegangen war, befanden sich die betreffenden Larven bei jhrem Tode auch in in einem weitergeförderten vorgeschrittenen Stadium, als die durch Salze zur Entwicklung gebrachten. Unter den gleichen Umständen hielten die parthenogenetischen Larven von Arbacia zehn Tage aus.

Zuweilen entwickeln sich bei der Befruchtung mit hyperisotonischen Lösungen Zw ergformen. Loeb fand, dass es sich hier nicht um reinen Zufall handelt, dass das vielmehr von der Art des zugesetzten Salzes abhängt. Wenn die nicht befruchteten Eier von Arbacia in Seewasser gebracht werden, dessen osmotischer Druck durch Hinzufügung eines Kaliumsalzes gesteigert ist (88 n. Seewasser +12 cc 2,5 n. $\mathrm{KCl}$ ) und zwei Stunden später in normales Seewasser zurückgebracht werden, so entwickeh sich schwimmende Embryonen. Aus jedem Ei hat sich nur e in Embryo gebildet und dieser hat die normale Grösse. Wenn aber statt $\mathrm{KCl}, \mathrm{NaCl}$ oder $\mathrm{MgCl}_{2}$ zu dem Seewasser hinzugefügt wird, so bilden sich aus einer Anzahl von Eiern je mehr als ein Embryo, und die so gebildeten Embryonen sind kleiner als norma!. Der Grund 
dieses Unterschiedes scheint in der Agglutination der Furchungskugeln zu liegen. Das durch Spermatozoen befruchtete Ei besitzt eine Membran, die die Furchungskugeln zusammenhält. Wird diese Membran zerstört, so können mehr Embryonen entstehen.

In einigen mittelst $\mathrm{KCl}$ befruchteten Eiern ist ebenfalls eine dünne Membran vorhanden, aber bei den meisten fehlt sie. Dennoch sehen wir nach Beliandlung von Eiern mit $\mathrm{KCl}$ aus einem $\mathrm{Ei}$ bloss ein e n Embryo entstehen. Man muss also wohl annehmen, dass die Furchungszellen unter dem Einfluss von K.Salz an einander kleben, agglutiniren, was unter dem Einfluss von $\mathrm{NaCl}$ oder $\mathrm{MgCl}_{2}$ nicht stattfindet. Desshalb können unter dem Einfluss dieser Salze aus einer Eizelle zwei oder mehr Zwerglarven entstehen.

Hiermit stimmt die Beobachtung von Herbst [9] überein. dass die Furchungszellen der durch Spermatozoen befruchteten Lier, in Ca-freiem Seewasser die Neigung besitzen, aus einander zu fallen.

Eine weitere Stütze erhält die Agglutinationsvorstellung durch die künstliche Herrorrufung von Riesenembryonen. Wenn KCl die Furchungszellen eines Eies aneinander zu kleben im Stande ist, so muss es auch zwei oder mehr Eier zu agglutiniren im Stande sein. In der That fanden Morgan [10] und Driesch [11] auf experimentellem Wege dass, wenn zwei Eier ron Seesternen an einander kleben, ein Embryo von grösserer Dimension entstehen kann und Zu r S tra s s en [12] konnte Gleiches auch für Ascariseier nachweisen. Loeb hat denn auch bei Eiern von Chaetopterus, die durch Hinzufügung von $\mathrm{KCl}$ zu Seewasser zur Entwickelung gebracht waren, wiederholte Male zwei oder mehr Trochophoren (mit Cilien versehene runde Körper mit dunklem Centrum) mit einander verklebt gesehen, und auch rollständig ausgebildete Riesenembryonen beobachtet. Letzteres ist besonders merkwürdig, weil die Chaetopteruseier im unbefruchteten Zustand eine Membran besitzen. Offenbar wird diese also an der Berührungsstelle zweier Eier verflüssigt.

Auch die durch Spermatozoen befruchteten Eier agglutiniren unter dem Einfluss von Kaliumsalz und bilden Riesenembryonen.

Ceber das Aneinanderkleben ron Froscheiern vergl. Inan diesen Band S. 55 .

\section{d) Bedeutung der kiinstlichen Parthenogenesis fiir die Auffassung der natiirlichen Befruchtung und der Lebenserscheinungen im All- gemeinew.}

Bereits lange Zeit ist es von einigen Thieren bekannt, dass die Eier sich parthenogenetisch entwickeln. Zu diesen gehören die Biene, Psyche, Daphnia, PHanzenläuse. Bei allen diesen Thieren können aber auch Spermatozoen die Refruchtung herbeiführen. 
Wie kommt es dann, dass sie sich unter bestimmten Umständen auch parthenogenetisch entwickeln können?

Loeb's Experimente zeigen, dass, wenn das Seewasser nur ein wenig Kali mehr enthalten würde, Chaetopterus zu den normal parthenogenetisch sich entwickelnden Thieren gehören wïrden.

Es giebt Thiere, bei welchen physikalische Factoren entscheiden, ob die Eier sich durch Spermatozoen oder parthenogenetisch entwickeln. Bei Pflanzenläusen ist die Parthenogenesis Regel, wenn die Temperatur hoch ist oder die Pflanze viel Wasser besitzt. Austrocknen der Pflanze, also Wasserverlust, veranlasst sexuelle Fortpflanzung. Derselbe Factor, Wasserverlust, ermöglicht die künstliche Parthenogenesis von Echinodermen und Chaetopterus. Bei Pflanzenläusen ist der Effect von der gleichen Art, aber von entgegengesetzter Richtung. Bei ihnen veranlasst Wasserverlust umgekehrt geschlechtliche Fortpflanzung.

Es ist nun sehr interessant, dass die Eier von Anneliden und Echinodermen, die unter normalen Umständen durch Spermatozoen befruchtet werden, im normalen Seewasser gewöhnlich das Zweizellenstadium erreichen, Chaetopterus entwickelt sich darin selbst zu 12 bis 16 Zellen. Wenn dann keine Spermatozoen hinzukommen, stirbt das Ei ab. Es besteht also auch im normalen Seewasser ohne Anwesenheit von Spermatozoen eine Neigung zur Entwicklung. Hertwig fand Gleiches anch bei einigen Crustaceen; ja Janosik fand selbst in Ovarien von Säugethieren Eier, die ohne Befruchtung bereits Furchung zeigten.

Nach Loeb besteht die Wirkung der Wasserentziehung bezw. der Ionen einfach darin, dass die Theilung, welche im normalen Seewasser so langsam ror sich geht, dass die Zellen nach den ersten Furchungen absterben, jetztkräftig beschleunigt wird. Die K-Ionen, um bei diesem Beisł,iel zu bleiben; wirken als Katalysator, d. h. sie beschleunigen einen Process, der sonst zu langsam verläuft. Der Einfluss der Wasserentziehung wäre dann darauf zurïckzuführen, dass bei der allgemeinen Einengung des löslichen Eiinhaltes, eine der Substanzen katalytisch zu wirken anfüngt. $O b$ auch die durch Schïtteln erzeugte Parthenogenesis ( $M$ at hews) auf einen katalytischen Process zurïckgeführt werden muss, darüber spricht Loeb nicht. Vielleicht löst das mechanische Schütteln eine chemische Umsetzung von sehr labilen Stoffen aus, wodurch ein Katalysator entsteht. Die Katalyse wïre indessen schwach, denn die in Folge schuittelns sich entwickelnden Eier bringen es nicht weiter als bis zur Gastrulaform. 
Die Auffassung der künstlichen Parthenogenesis als eines katalytischen Processes, legt den Gedanken nahe, dass es sich auch bei der Wirkung der Syermatozoen um einen katalytischen Process handelt. Es erhebt sich dann die weitere Frage, welche Substanz es ist, die bei den Spermatozoen als Katalysator fungirt. Hans Winkler [1:3] fertigte Extracte von Spermatozoen, an und fand, dass diese eine Furchung ron Seeigeleiern bis zun Vierzellen-Stadium veranlassten. Demgegenüber hat W. Gies es aber sehr wahrscheinlich gemacht, dass bei Winkler's Versuchen osmotische Einflüsse im Spiele waren [14].

Gies hat solche bei seinen Versuchen rermieden und konnte dann mit den nach den üblichen Methoden der Enzymbereitung angefertigten Extracten von Arbaciaspermatozoen keine Furchung bei den entsprechenden reifen Eizellen erzielen. Auch waren die Extracte nicht im Stande, die Bildung einer Vitellinmembran zu veranlassen, die bekanntlich um viele Eizellen - und auch um Arbaciaeier - entstehen, nachdem ein Spermatozoon eingedrungen ist. Diese Membran beugt bekanntlich dem Eindringen weiterer Spermatozoen vor.

Auf welche Weise und durch welche Substanz, die Spermatozoen katalytisch wirken, ist somit bis jetzt völlig unbekannt.

Wie oben erwähnt, rettet der Kiatalysator die Eizellen vom Tode. Loeb stellt sich das in folgender Weise ror. Er nimmt an, dass sich im reifen unbefruchteten $\mathrm{Ei}$, nachdem es das Orarium rerlassen hat, zwei Processe abspielen, die bis zu einem gewissen Maasse antagonistisch wirken. Der eine führt zur Bildung von Stoffen, die den Tod des Eies herbeizuführen geneigt sind, der andere hat die Bildung von Stoffen zur Folge, die Zelltheilung und Wachsthum ermöglichen.

Lo e b suchte nun in Femeinschaft mit Le w is einen Stoff ausfindig zu machen, der den activen Absterbungsprocess entgegenwirken und dadurch die Lebensdauer verlängern könnte. Ein solcher Stoff war Cyankalium [13].

Zunächst wurde festgestellt, wie lange reife, unbefruchtete Seeigeleier in normalem Seewasser liegen konnten ohne abzusterben. Der Indicator für das Leben war die Fähigkeit der Befruchtung durch Spermatozoen. Es zeigte sich, dass nach 23 stündigem Verweilen der Eier im Seewasser nur wenig noch befruchtet werden konnten; nach einer Zeitdauer von 32 Stunden keines mehr. Schlagend war nun der günstige Einfluss von KCN. Wurde zu 99 cc Seewasser 1 cc ${ }^{1}{ }_{10}$ normal KCN hinzugefügt, enthielt also das Seewasser ${ }^{1} 1000$ normal KCN, so waren die Eier nach 72 Stunden noch lebendig. Diese Experimente wurden in verschiedener Weise variirt und dabei zeigte es sich u. A, dass die Eier am längsten leben blieben, wenn man die KCN-Concentration allmählich abnehmen liess: von ${ }^{1} 750 \mathrm{n}$. KCN auf ${ }^{1 / 1400},{ }^{1}{ }_{2000}$, $1 / 2500$ n. KCN. 
Vollkommen gleichlautende Resultate ernielten die Verfasser, wenn die Lebensfähigkeit, statt durch Spermatozoen, durch KCl (künstliche Parthenogenesis) geprüft wurde. Anch dann zeigte sich, dass Hinzufügen von KCN zu Seewasser die Lebensdauer verlängerte.

\section{Intrauterine Verhältnisse.}

a) Osmotische und osmotisch chemische Analyse des Blutes bei Mutter und Frucht. Zur Kenntniss des Stoffaustausches zwischen beiden.

Unsere Kenntniss darüber, auf welche Weise das Blut des Fötus von dem der Mutter Nahrungsstoffe erhält und die Stoffwechselproducte dem Mutterthiere wieder zurïckgiebt, ist noch sehr mangelhaft. Sogar die erste Grundlage einer diesbezüglichen Erkenntniss, nämlich die Bekanntschaft mit dem Unterschiede in der Zusammensetzung der hier in Frage kommenden Blutarten, lässt noch viel zu wünschen übrig.

Es war ein guter Gedanke J. Veit's, unter diesen Umständen mit Hilfe der Lehre vom osmotischen Druck zu versuchen, die Aufklärung zu erhalten, die man bis dahin mittelst chemischer Untersuchung des Blutes vergeblich gesucht hatte. Zwar hatte der italienische Forscher Z a nier [16] bereits früher (1896) den ersten Schritt in dieser Richtung gethan, indem er das Verhalten von Mutterthier und Fötus gegen verdünnte Salzlösungen (die sogen. Resistenz der Blutkörperchen) nach der Methode von Hamburger-】osso untersuchte. Auf die Bedeutung seiner Resultate ist aber Zanier nicht eingegangen, was auch bei dem damaligen Stand unserer Kenntnisse allerdings schwer gefallen wäre. Anch über die Veranlassung zu der Cntersuchung spricht er nicht. Er theilt neben der von ibm befolgten Methode bloss das später von U bbels bestätigte Ergebniss mit, dass die Blutkörperchen von Iutterthier und Fötus (Rind) in derselben Salzlösung beginnenden Farbstoffaustritt zeigten, dass aber zur Zerstörung aller Blutkörperchen für das fötale Blut eine viel schwächere Salzlösung erforderlich ist als beim Mutterthier. Es befinden sich im fötalen Blute also auch Blutkörperchen, die viel resistenter gegenüber verdünnten Salzlösungen sinulals die im mütterlichen Blute vorhandenen.

Bevor ich zur Mitheilung der Untersuchungen V'eit's schreite, scheint es mir empfehlenswerth, den damaligen Stand der Kenutnisse in einigen \%eilen zusammenzufassen, zumal die betreffenden Arbeiten nicht für jeden leicht zugänglich sind. Unser früleres Wissen knüpft 
an zwei Dorpater Dissertationen an, die ron Krïger [17] (1886) und von Scherenziss [18] (188S) herrihren.

Kr ï ger fanà Folgendes:

1. Die Vermehrung des Gehaltes des fötalen Blutes an festen Bestandtheilen ist im Vergleich zu dem des Blutes Schwangerer, wie Becquerel und Rodier ermittelten, nur unbedeutend. Während Becquerel und Rodier im Blute Schwangerer $80,16^{\circ} \circ$ Wasser fanden, ergiebt sich aus 10 Bestimmungen $\mathrm{Kr}$ üger's für fütales Blut $78,932^{\circ} \circ$.

2. Der Fibringehalt des fötalen Blutes im Moment der Geburt ist gegenüber den des mütterlichen Blutes beträchtlich vermindert.

3. Der Haemoglobingehalt des fötalen Blutes kommt im Moment der Geburt dem des mütterlichen gleich, erreicht aber nie die Höhe, wie im Blute des Neugeborenen einige Zeit nach der Geburt.

4. Das Geschlecht des Fötus beeinflusst die Zusammensetzung nicht wesentlich; während bei den erwachsenen Individuen sich, je nach dem Geschlecht, deutliche quantitative Verschiedenheiten, namentlich im Haemoglobingehalt, zeigen.

5. Das Gewicht des Kindes zeigt keinen nennenswerthen kinfluss auf die quantitative Zusammensetzung des fötalen Blutes im Momente der Geburt.

6. Das fötale Blut besitzt im Momente der Geburt eine grosse Tendenz zur Gerinnung, gerinnt aber langsam, d. h. die Gerinnung tritt früh ein, dauert jedoch lange.

7. Der Grund der langsamen Gerinnung des Fötalblutes im Nomente der Geburt liegt in einer relativ geringeren Haltbarkeit der weissen Blutkörperchen desselben.

Die Resultate ron 5 cherenziss lassen sich in Folgendem resumiren:

1. Das fötale Blut besitzt etwas, das Serum desselben dagegen bedeutend niedrigeres spec. Gewicht als das Blut und das Serum des Erwachsenen.

2 Das Fötalblut ist bämoglobinarm, dagegen stromareich; das Verhältniss seines Hämoglobingehaltes zu dem im Blute des Erwacbsenen ist gleich 76,8:100.

3. Der Fibringehalt ist im Fötalblute verhältnissmässig gering und verhält sich zu dem des mütterlichen Blutes ungefähr wie $2: 7$.

4. Das Fötalblut eignet sich nicht zur quantitativen Analyse durch Auswaschen mit Salzlösungen; es gehen sehr viele Blutkörperchenbestandtheile, die locker gebunden sein müssen, insbesondere auch Hämoglobin, in die Waschfliissigkeit über.

5. Das Fötalblut jst salzieicher als das Blut Erwachsener; besonders auffallend ist der grössere Gehalt an unlöslichen Salzen im Gesammtblute des Neugeborenen im Momente der Geburt, gegenüber dem Blute des Erwachsenen. Aber auch das Ceberwiegen der unlöslichen Salze im Serum und dasjenige der Chloride im Gesammtblute und im Serum ist sehr dentlich bemerkbar.

6. Das fötale Blnt ist etwas natriumreicher, dagegen bedeutend kaliumärmer als das Blut Erwachsener.

7. Die Summe des an Chlor nicht gebundenen Kaliums und Natriums ist im Fötalblute beträchtlich kleiner als im Blute des Erwachsenen.

8. Das Geschlecht und Gewicht des Kindes scheinen die quantitative Zusammensetzung des Blutes des Neugeborenen in Momente der Cieburt nicht zu beeinflussen. 
Vergleicht man diese in demselben Laboratorium ausgeführten Untersuchungen, so findet man in Beziehung auf den Hämoglobingehalt Widerspriiche. Während Kir ïger findet, dass der Hämoglobingehalt ron fötalem und mütterlichem Blute gleich ist, betont Scherenziss, dass beim Fötus der Hämoglobingehalt beträchtlich geringer ist als bei Erwachsenen.

\section{a) Untersuchungen von Veit [19].}

Veit ermittelte die Gefrierpunkterniedrigung rom mütterlichen und fötalen Blutserum, sowie vom Fruchtwasser. Ueber letzteres spreche ich erst im folgenden Abschnitt.

\section{Blutgewinumng.}

Die Gewinnung des kindlichen Blutes war sehr einfach. Nabelt man das Kind früh $a b$, so bleibt in der Placenta Blut zurück. Diese übrigens recht wechselnde Menge, die beim Durchschneiden der Schuur aus dem placentaren Ende ausläuft, wurde aufgefangen. Das so gewonnene Blut dürfte, da mit voller Sicherheit jede fremde Beimengung ferngehalten wurde, als fötales Blut angesehen werden. Zur Controle wurde auch umgekehrt verfahren. Durch späte Abnabelung wurde dem Kinde alles Blut aus der Placenta zugeführt und dann die nöthige Menge von ca. 10 cc Blut aus dem fötalen Ende der Schnur entleert.

Endlich hat $V$ eit auch in einem Fall bei früher Abnabelung dem Kind die gleiche Menge aus seinem Nabelstrangende entzogen. Die Resultate dieser verschiedenen Versuche ergaben gegenüber der Mutter stets das gleiche Verhalten; die Differenzen der Bestimmungen untereinander waren unerheblich und überschritten nicht die sonstigen Schwankungen. In derselben Weise gewannen übrigens auch K r üger und Scherenziss das fötale Blut.

M ütterliches Blut gewann Veit auf verschiedene Weise; am einfachsten gelang es bei einem $\mathrm{K}$ aiserschnitt. Hier floss beim Einschneiden in den Uterusmuskel, weil die Placenta getroffen wurde, reichlich Blut aus, das olne jede fremde Beimengung in einem sterilen trockenen Gefäss aufgefangen wurde. Demnächst ist es genau so sicher; wenn man den retroplacentaren Bluterguss bei Schultze'schem Mechanismus benutzt; bei einiger Vorsicht kann man mit voller Sicherheit rein mütterliches Blut gewinneu. Am unsichersten ist das Auffangen beim Duncanschen Mechanismus oder bei Nachblutungen. Man muss dabei nit der Möglichkeit rechnen, dass Fruchtwasser, Cervix-Secret, Harn, Meconium und dergleichen sich dem Blut beimengt. Veit hat diese Methode desshalb auch nicht angewendet.

Aus einem Aderlass wurde das Blut nie genommen.

\section{Resultate.}

Die Gefrierpunkterniedrigungen waren in den Fällen, in denen sie für miitterliches und kindliches Blut gleichzeitig bestimmt werden konuten, folgende.

\begin{tabular}{c|ccc|c|c|c|c|c|c|c}
\hline & 1 & 2 & 3 & 4 & 5 & 6 & 7 & 8 & 9 & 10 \\
\hline \hline $\begin{array}{c}\text { Kindliches Blut } \\
\begin{array}{c}\text { Mütterliclies } \\
\text { Blut }\end{array}\end{array}$ & $-0,6025^{\circ}$ & $-0,542^{\circ}$ & $-0,5275^{0}$ & $-0,59^{0}$ & $-0,5625^{0}$ & $-0,58^{9}$ & $-0,553^{0}$ & $-0,6075^{0}$ & $-0,59^{0}$ & $-0,63^{0}$ \\
& $-0,5585^{0}$ & $-0,532^{\circ}$ & $-0,5) 1^{0}$ & $-0,57^{0}$ & $-0,605^{0}$ & $-0,57^{0}$ & $-0,541^{0}$ & $-0,555^{0}$ & $-0,60^{0}$ & $-0,585^{\circ}$ \\
\end{tabular}


Wie ersichtlich, ist mit Ausnahme ron Fall 5 und 9 stets die Gefrierpunkterniedrigung des fötalen Blutes grö̈ser als die des mütterlichen. Nun rerlief in Fall 5 und 9 die Geburt nicht normal; das eine Mal dauerte die Geburt 34 Stunden und wurde schliesslich mit Forceps beendet, das andere Mal musste das Krind exprimirt werden.

Der Durchschnitt beträgt bei den 8 übrigen Fällen $\Delta$ des künstlichen Blutes - $\mathbf{0 , 5 7 9}{ }^{\circ}$ und des mütterlichen - $\mathbf{0 , 5 5 1}{ }^{\circ}$. Die Differenz ist also $0,028^{\circ}$, was einer NaCl-Lösung von $0,045 \%$ entspricht.

Wie bereits gesagt, bestimmte Veit gleichzeitig auch die Gefrierpunkterniedrigung des Fruchtwassers. Hiervon wird noch weiter unten die Rede sein.

\section{ß) Untersuchungen von Krönig und Fueth [20].}

Den Untersuchungen Veit's folgten bald gleichartige ron Seiten Krönig's und Fueth's. Ihre Resultate stehen aber in schroffem Widerspruch mit denen Veit's. Auf Grund von 20 mit grosser Sorgfalt ausgeführten Bestimmungen erklären sie die Gefrierpunkterniedrigung des Ser ums von fötalem und mütterlichem Blute für gleich. Sie drücken sich folgendermassen aus:

„Das Blut einer Frau, gewomnen aus dem retroplacentaren Haematom oder aus einer Armvene durch Venaesectio, entweder in der Austreibungsperiode oder kurz post partum, und das aus der Nabelschnur entnommene Blut des neugeborenen Kindes sind isotonisch."

Bei mehr als 20 Bestimmungen am Blute der Kreissenden und der entsprechenden Neugeborenen fanden sie die folgenden Zahlen für die Gefrierpunkterniedrigung.

\begin{tabular}{|c|c|c|c|c|}
\hline 1 & $-0,4937$ & retroplac. & $-0,4945^{\circ}$ & belschnur \\
\hline 2 & $-0,5007$ & $n$ & $-0,5007$ & n \\
\hline 3 & $-0,4935$ & , & $-0,494$ & , \\
\hline 4 & $-0,490$ & n & -0.4877 & $\pi$ \\
\hline 5 & $-0,4955$ & $n$ & $-0,5042$ & , \\
\hline 6$\}$ & $\begin{array}{l}-0,505 \\
-0,4985\end{array}$ & Aderl. & \}$-0,4985$ & $\pi$ \\
\hline 7 & $-0,5025$ & $n$ & $-0,5007$ & $\pi$ \\
\hline 8 & $-0,5037$ & \% & $-0,5025$ & , \\
\hline 9 & $-0,5058$ & n & $-0,5078$ & $"$ \\
\hline 10 & $-0,502$ & retroplac. & $-0,4988$ & $\pi$ \\
\hline 11 & $-0,4975$ & , & $-0,4997$ & r \\
\hline 12 & $-0,5092$ & $r$ & $-0,5103$ & " \\
\hline 13 & $-0,4972$ & , & $-0,5020$ & n \\
\hline
\end{tabular}




$$
\begin{aligned}
& 14 \begin{array}{l}
-0,505^{\circ} \\
14
\end{array} \text { retroplac. } \\
& 15-0,4977 \text { aderl. }
\end{aligned}
$$

Die Verfasser meinen, dass diese Resultate den chemischen Analysen von Scherenziss nicht widersprechen; zwar hat letzterer Forscher im fötalen Blute einen höheren Salzgehalt gefunden als im mütterlichen Blute, aber Krönig und Fueth weisen auf die Möglichkeit hin, dass ein grösserer Theil dieser Salze im mütterlichen und fötalen Blute in verschiedener Form vorhanden sein könne. Sind die Mineralstoffe an Eiweiss gebunden, so kommen sie bei der Gefrierpunkterniedrigung nicht als solche zum Ausdruck, sondern tragen nur insofern zur Depression bei, als das Eiweiss selbst daran betheiligt ist. Im freien Zustande sind sie hingegen selbständig am osmotischen Druck betheiligt.

Nun bestimmte Scherenziss die Salze nach vorhergehender Veraschung und hierbei sind auch diejenigen Nineralstoffe frei geworden, die an Eiweiss gebunden waren. Somit ist nach Krönig und Fueth die Möglichkeit nicht ausgeschlossen, dass das fötale Serum desshalb den gleichen osmotischen Druck zeigt, wie das Serum der Mutter, weil darin viel Nineralstoffe an Eiweiss gebunden sind.

Bei diesem Sachverhalt schien es nicht überflüssig, das Thema nochmals von anderer Seite in Angriff zu nehmen.

\section{$\gamma$ ) Untersuchungen von $\mathrm{Hamb} \mathrm{u}$ rger und Ubbels.}

Ich habe desshalb mit Herrn Ubbels eine Reihe von Experimenten ausgeführt [21], die nicht nur den osmotischen Druck, sondern auch den Farbstoffaustritt (die sogen. Resistenz), die Tolumänderungen der Blutkörperchen durch Salzlösungen, das elektrische Leitvermögen und die Bestimmung des Gehaltes an Chlor, Alkalinität und festen Bestandtheilen zum Zweck hatten.

Um die geringfïgigen Differenzen, um welche es sich wahrscheinlich bei den beiden Blutsorten nur handeln kann, entdecken zu können, sind wir bei unseren Cntersuchungen darauf bedacht gewesen, für jede vergleichende Versuchsreihe dasselbe Thier zu nehmen. Bei vers chie- 
den en Thieren derselben Species kommen so mannigfache kleine Schwankungen in der Zusammensetzung des Blutes vor, dass der Werth desselben vielleicht noch über die Differenzen zwischen dem Blut der Mutter und des zugehörigen Fötus hinausgeht. Selbstverständlich waren wir bei dem geplanten Versuchsmodus, bei welchem das Blut in verschiedener Richtung untersucht werden sollte, auf grosse Hausthiere beschränkt. Am meisten empfiehlt sich das Rind, weil es am bequemsten ist, gerade von diesem Thiere Material zu bekommen.

Um eine Vorstellung von dem Stoffaustausch zwischen Mutter und Frucht zu bekommen, schienen uns die folgenden vier Blutsorten eines und desselben Thieres mit einander verglichen werden zu müssen.

1. Das Blut aus der Arteria uterina, also das Blut, das der Placenta materna zuströmt;

2. das Blut aus der Vena uterina, d. h. das Blut, welches die Placenta materna verlässt;

3. das arterielle Blut der Vena umbilicalis, also das Blut, welches lem Fötus zuströmt;

4. das venöse Blut aus der Arteria umbilicalis, d. h. das Blut, welches den Fötus verlässt.

Leider war es aus technischen und ökonomischen Gründen unmöglich, diesen Plan vollständig zur Ausführung zu bringen. Für die Gewinnung der gesammten Blutsorten wäre eine Sectio caesarea unumgänglich, was nahezu dem Tode des Thieres gleich kommt. Auch wenn man die erforderlichen Vorsichtsmassregeln möglichst genau beachtet, hat die Operation doch immer unglückliche Nachwirkungen für das Thier zur Folge. Aber auch abgesehen von den ökonomischen Schwierigkeiten, über welche wir uns in einem unserer Versuche hinwegsetzten, gelingt es doch nicht, alle die obengenannten Blutsorten in genügender Quantität zu gewinnen.

Einmal entleert sich beim Durchschneiden des Nabelstranges lediglich Blut aus der Vena umbilicalis; die Arteriae umbilicales liefern höchstens einige Tropfen des venösen Blutes des Fötus. Was ferner das Blut der Mutter betrifft, so ist es sehr schwer die Vena uterina zu entdecken. Wir mussten also das ursprünglich in Aussicht genommene eingehende Verfahren aufgeben und uns nach einer anderen Methode umsehen.

So erwuchs dann der Gedanke, venöses Blut des Fötus mit dem arteriellen Blute der Mutter zu vergleichen. weil zwischen diesen beiden Blutarten ein Stoffaustausch stattfinden muss. Für diesen Plan schien eine eingreifende Operation nicht notwendig, denn statt Blut der Arteria uterina kann man auch Blut einer anderen Arterie anwenden. Es konnte eine oberflächliche Arterie benutzt werden, als welche sich die mittlere untere Schwanzarterie am meisten empfahl. lch brauche kaum zu sagen, dass es für die Zusammensetzung gleich- 
gültig ist, ob das arterielle Blut aus der Arteria uterina oder aus einem anderen Theil des arteriellen Gefässsystems stammt.

Aber auch bei der Gewinnung ron Blut aus der Schwanzarterie begegnet man praktischen Schwierigkeiteu. Man findet den Viehhalter selten bereit, eine Operation des Schwanzes zu gestatten, so dass wir uns schliesslich mit durch Aderlass erhaltenem Blute aus der Vena jugılaris genügen lassen mussten. Wir waren uns aber vollständig dessen bewusst, dass es nicht gleichgültig ist, ob man das der Placenta zuströmende fötale Blut mit dem arteriellen Blute der Mutter vergleicht oder mit dem venösen Blut ihres Kopfes. Wir müssen das nachdrücklich hervorheben, weil es anderen Autoren gleich zu gelten scheint, ob man arterielles oder venöses Blut der Mutter zur Vergleichung hinanzieht. Zuweilen liest man, dass Blut aus der Armvene genommen wurde, andere Male, dass Blut aus einem retroplacentaren Hämatom benutzt wurde. Ich kann nicht beurtheiien, wie weit man es im letzten Falle mit reinem arteriellen Blute der Mutter $\mathrm{zu}$ thun hat und weiche Aenderungen nach dem Bluterguss stattgefunden haben. Veit hebt hervor, dass er kiein Blut durch Venaesectio erhalten hat. Dies sollte eigentlich auch niemals geschehen; denn es erscheint in der That absurd, dass man einerseits hofft, Unterschiede in der Zusammensetzung zwischen mütterlichem und fötalem Blute zu entdecken und - selbst, wenn diese nur gering sind - Schlüsse über den Stoffaustauschen zwischen Mutter und Frucht darauf aufbaut, während man andererseits bei der Wahl des zur Vergleichung dienenden mütterlichen Blutes keinen Unterschied zwischen arteriellem und venösem Bhut macht. Diese Blutsorten zeigen aber Differenzen von vielleicht demselben Grade, wie diejenigen, welche man eben nachzuweisen wünscht. Aus diesem Gesichtspunkte wären diejenigen unserer Untersuchungen, bei welchen das venöse Blut des Fötus mit Jugularisblut der Mutter verglichen wurde, statt mit arteriellen, ohne weiteres zu verurtheilen. Man könnte in diesem Falle immer fragen, ob das Jugularisblut der Mutter nicht in gleichen Sinne und vielleicht in etwa gleichem Grade sich von Carotisblut der Mutter untersclieidet wie das Jugularisblut (Arteria umbilicalis-Blut) des Fötus vom arteriellen Blute der Mutter. Bei unseren Schlussfolgerungen haben wir aber immer den Versuchsergebnissen, die der Eine von uns ${ }^{1}$ ) bei seinen vergleichenden Untersuchungen von arteriellem und venösem Blute gewonnen lat, Rechnung getragen (B. I s. 261 ff.).

1) Hamburger, Archiv für (Anat. u.) Physiol. Supplem. 1893 S. 157; 1894 S. 214. 


\section{Untersuchungsmethoden.}

1. Gewinnung des Materials.

Es wurde bei diesen Untersuchungen ansschliesslich Blut von Rindern verwendet. Das Blut der Mutter wurde, wie gesagt, in den meisten Fällen durch Aderlass aus der Vena jugularis gewonnen, am liebsten im Moment der Geburt. Zuweilen geschah dies aber auch einige Stunden vor der Geburt. mit Rücksicht auf die Eventualität, dass das Kalb unerwartet zur Welt kam, bevor man den Aderlass ausgeführt hatte.

Vom Kalbe wurde das Blut ebenfalls durch Aderlass der Vena jugularis gewonnen, und zwar stets innerhalb einer halben Stunde nach der Geburt. In einem Fall (sect. caesarea) haben wir auch das Blut aus der Vena umbilicalis untersucht.

Wir defibrinirten inmer in gut gefüllten geschlossenen Flasclien, weil sonst eine andere Vertheilung der Blutbestandtheile über Blutkörperchen und Blutserum stattfindet, als sie in circulirenden Blute auftritt. Wie Band I S. 271 mitgetheilt wurde, hatte sich bei früheren Untersuchungen gezeigt, dass beim Schütteln von Blut mit Luft Chlor die Blutkörperchen verlässt, während der Eiweissgehalt und die Alkalinität zunehmen. Diese Veränderungen treten bereits bei Behandlung mit einer geringen Quantität Luft ein.

Dann wurde das Blut durch nicht präparirte Gaze filtrirt, damit jedes Glasstïckchen und alles Fibrin als entfernt erachtet werden konnten. Das Blut wurde vor jedem Versuche umgerührt, weil die Blutkörperchen beim Stehen bald zu Boden sinken.

Ausserdem haben wir noch einige Versuche am Blute junger Kälbchen angestellt, ohne das Blut der entsprechenden Mutter damit vergleichen zu können.

\section{Farbstoffaustritt.}

Es wurde in folgender Weise verfahren: Eine Reihe gleichweiter Reagensröhrchen wurden mit je 3 cc Kochsalzlösung beschickt, deren Concentration um je $0,01^{\circ}{ }_{0}$ von einander differirte. $\mathrm{Zu}$ jeder Lösung wurden zwei Tropfen des zu untersuchenden Blutes hinzugefügt, mit der Flüssigkeit sorgfältig gemischt und die Mischungen sich selbst überlassen. Aeusserer Umstände halber konnten wir das Resultat erst 12 Stunden später beobachten. Die Untersuchung geschah bei auffallendem Lichte gegen einen weissen Schirm als Hintergrund.

Gewöhnlich war Folgendes zu constatiren: Zunächst eine Reihe Röhrchen, in der die überstehende Flüssigkeit absolut farblos war; dann folgte eine Reihe, in der eine schwach rothe Nuance ohne dentlichen Intensitäts-Unterschied sichthar war. Dann wurde mit abnehmender Concentration der Farbstoffaustritt stets intensiver, so dass schliesslich keine Differenz in der Rothfärbung mehr zu bemerken war. Das Sediment zeigte dann wohl noch Verschiedenheiten; diese wurden bei abnehmender Concentration stets geringer, um endich bei sehr schwacher Concentration ganz zu verschwinilen.

Wir haben nur drei Cincentrationen notirt. 1. Die NaCl-Lösung, welche unmittelbar derjenigen vorangeht, die eine schwache rothe Nuance herbeiführte. (Diese Lösung ist also absolut farblos und entspricht der sogenannten Minimum-Resistenz.) 2. Die letzte Lösung, welche eine schwach rothe Nuance besitzt und derjenigen vorangeht, bei welcher eine Steigerung des Farbstoffaustrittes beginnt. 
3. Die NaCl-Lösung, welche derjenigen vorangeht, in der alle Blutkörperchen zerstört sind. Es ist dies also die Lösung, in welcher noch eine Spur Sediment vorhanden ist, und sie entspricht der sogenannten M a i m u m-R es is tenz (B. I S. 362 ff.).

Die Resistenz der Blutkörperchen gegenüber Salzlösungen wurde nicht durch die Concentration der Salzlösung, sondern durch den reciproken Werth (vergl. Bd. I, S. 372) derselben ausgedrückt. Ist z. B. die der Minimum-Resistenz entsprechende NaCl-Lösung 0,66\% und die, welche der Maximum-Resistenz entspricht $0,45 \%$, so drücke ich die Minimun- und Maximum-Resistenz aus durch 1/0,66 bezw. 1/0,45. Derart wird die Minimum-Resistenz durch eine kleinere Zahl ausgedrückt als die Maximum-Resistenz, was sonst nicht der Fall wäre. Die Differenz: $1 / 0,45-1 / 0,66$ bezeichne ich als ., Resistenzbreite".

Ich füge hier noch hinzu, dass wir in einigen Fällen die Resistenzbestimmungen nach der in Band I, S. 379 angegebenen Methode mittelst trichterförmiger Capillarröhrchen ausführten und dabei dieselben Resultate erhielten wie mit den oben erwähnten Reagensröhrchen.

\section{Osmotischer Druck.}

Der osmotische Druck wurde in zweierlei Weise bestimmt: 1. durch meine Blutkörperchen-Methode 2 und 1: 2. durch die Gefrierpunkterniedrigung.

Um mittelst der Blutkörperchen-Methode den osmotischen Druck zu ermitteln, wurden 2,5 ce der zu untersuchenden Flüssigkeit mit verschiedenen Mengen Wasser $\{15 \%$ bis $60 \%$ je mit einer Differenz von $5 \%$ versetzt und zu den Gemischen, welche sich in gleich weiten Reagensröhrchen befanden, je zwei Tropfen Blut hinzugesetzt. Die Flüssigkeiten wurden wieder gut gemischt und sich selbst überlassen. In gleichartige Reagensröhrchen wurden je 3 cc NaCl-Lösung von abnehmender Concentration gebracht, wie ich es unter "Farbstoffaustritt" beschrieb. Nach einiger Zeit wurde untersucht, in welchem Serum-Wassergemisch Farbstoffaustritt sichtbar war. Die Kochsalzlösung; in welcher ein gleichgradiger Farbstoffanstritt sichtbar war, wal dann mit dem betreffenden Serum-Wassergemisch isotonisch. Es war nun einfach zu berechnen, mit welcher Kochsalzlösung das unverdünnte Serum isotonisch war. (Vergl. auch Bd. II S 304).

Nach dieser Methode haben wir leider das Serum wegen Mangel an Material nicht untersuchen können; die Allantois. und Amnionflussigkeiten aber sind fast imner nach genanuter Methode untersucht. Kin Beispiel, aus welchem die Berecllnungsweise hervorgeht, findet man in Versuch I mitgetheilt.

Die Bestimmung der Gefrierpunkterniedrigung gescliah mittelst des bekannten Beckmann'schen Apparates. Die $1 \%$ ige Kochsalzlösung zeigte nach der angewandten Methode eine Gefrierpunkterniedrigung von $-0,603^{\circ}$; danach sind die für Serum und Fruchtwasser gefundenen Gefrierpunkterniedrigungen zu beurtheilen. Leider kounten in Folge der vielen Bestimmungen, welche gleichzertig auszuführen waren, nicht für jede Versuchsreihe die Gefrierpunkterniedrigung einer $1 \%$ igen Kochsalzlösung untersucht werden. Wohl aber wurde jedes Mal der Stand des Quecksilbers für ausgekochtes destillirtes Wasser zu Beginn jeder Versuchsreihe festgelegt. 
4. Volumänderung der Blutkörperchen durch Salzlösungen.

Seit den Untersuchungen von inir selbst, Hedin, Koeppe und Gryns ist es bekannt, dass Blutkörperchen in hyperisotonischen Lösungen schrumpfen und in hypisotonischen Lösungen quellen. Später habe ich die procentische Ab- und $\mathrm{Zu}$. nahme des Blutkörperchenvolumen ermittelt, indem ich eine bestimmte Menge Blut $(0,06 \mathrm{cc})$ mit einer grossen Menge $(2 \mathrm{cc})$ Kochsalzlösung verschiedener Concentration versetzte und dann in Capillarröhrchen, welche unten geschlossen und oben trichterförmig erweitert waren, so lange centrifugirte, bis das Sedimentvolumen constant wurde.

Man stelle sich vor, dass die Blutkörperchen aus einem flüssigen Inhalt bestehen und in eine feine Membran eingeschlossen sind, welche semipermeabel ist. Dieser Inhait steht in osmotischem Gleichgewicht mit der Umgebung. IVenn nun die Zelle in eine Salzlösung von doppelt so grosser Concentration gebracht wird, so wird man erwarten, dass sie ungefähr bis zur Hälfte schrumpft. In der That sieht man aber, dass die Schrumpfung viel kleiner ist. Das kann nur daher rühren, dass das Blutkörperchen wenigstens aus zwei Stoffen besteht: aus einem, der an der Wasseranziehung nicht oder wenig betheiligt ist, und einem anderen, welcher das Wasseranziehungsvermögen herbeifülırt. Je kleiner die procentische Schrumpfung ist, welche durch eine gewisse hyperisotonische Kochsalzlösung herbeigeführt wird, um so grösser muss die relative Menge der Blutkörperchensubstanz sein, die an der Wasserentziehung nicht betheiligt ist. Die procentische Schrumpfung, welche durch eine bestiminte hyperisotonische Kochsalzlösnng veranlasst wird, ist also ein Maass für das Tolumen der in den Blutkörperchen vorhandenen, nicht oder kaum an der Wasseranziehung betheiligten Stoffe und indirect also auch für das Volumen der Flüssigkeit, welche daran betheiligt ist. Zu den ersten Stoffen müssen das colloidale Protoplasma und die eiweissartigen Stoffe, wie Hämoglobin etc. gerechnet werden. Das wasseranziehende Vermögen des letzteren kann vernachlässigt werden, so dass wir in der Bestimmung der procentischen Schrumpfung oder, was auf dasselbe hinauskommen muss, in der procentischen Quellung ein Maass für die relative Menge der intraglobularen Flüssigkeit besitzen, bezw. der Protoplasmasubstanz und der eiweissartigen Substanzen. (Vergl. hierzu diesen Band S. 4).

Es schien nun von Interesse, diese Grösse für die fötalen und mütterlichen Blutkörperchen zu vergleichen, um so mehr, weil Scherenziss für das fötale Blut einen so grossen Stromagehalt gefunden hatte.

Es wurden stets $0,06 \mathrm{cc}$ Blut mit 2 ec einer $0,8^{\circ} \%, 1^{\circ} \%$ und $1,5^{\circ} \% \mathrm{NaCl}$-Lösung versetzt, während in einem vierten Röhrchen 0,06 cc Blut ohne weiteren Zusatz blieben. Dann wurde centrifugirt bis das Sediment-Volumen constant war. Das Capillarröhrchen war genau graduirt, so dass jeder Theil 0,0004 ce Blut enthielt.

Diese Methode gab zu gleicher Zeit an, mit welcher NaCl-Lösung das Serum isotonisch war. Es war dies nämlich die Nacl-Lösung, in welcher das Sediment ebenso gross war, wie in unvermischtem Blute (B. I S. 188 u. S. 442). Auf diese Weise hatten wir eine Controle für den aus der Gefrierpunkterniedrigung ermittelten osmotischen Druck. Weiter diente dieser Versuch als Controle für die unten zu besprechenden Bestimmungen der relativen Menge der Blutkörperchen und des Serums im fötalen und mütterlichen Blute, die mit Hülfe des elektrischen Leitvermögens ausgeführt wurden. Bei jenem Versuche, bei dem 0,06 ec Blut gebraucht wurden, konnte inan das Blutkörperchensediment unmittelbar an der Theilung des Capillarröhrchen ablesen. In Versuch I findet man Beispiele der verschiedenen Anwendungen dieser Methode. 


\section{Elektrisches Leitvermögen von Serum und Blut.}

Mit dem elektrischen Leitvermögen des Serums und des Blutes beabsichtigten wir sowohl den Werth dieser Constanten als solchen, als auch das relative Volumen des im Blut vorhandenen Serums und der entsprechenden Blutkörperchen fest. zustellen.

Das elektrische Leitvermögen des Serums ist ein Maass für diejenigen Stoffe, welche den Strom leiten, d. h. für dịe Elektrolyte. Diese Elektrolyte werden im Serum fast ausschliesslich von den freien anorganischen Salzen gebildet. Ich sage voll den freien anorganischen Salzen, denn so weit die Salze an Eiweiss gebunden sind, leiten sie den Strom nicht.

Van wird sich aus der Kinleitung erinnern, dass, während Scherenziss den Salzgehalt des fötalen Blutes grösser gefunden hatte als den des mütterlichen Blutes. Krönig und Fueth die Gefrierpunkterniedrigung der beiden Blutsorten gleich fanden. Und doch sind es fast ausschliesslich die Salze, welche die Gefrierpunkterniedrigung verursachen. Die Verfasser wiesen desshalb auf die Möglichkeit hin, dass bei Scherenziss durch die Einäscherung Salze gebildet wurden, die in normalem Zustande mit dem Eiweiss ein einheitliches Molecül bildeten.

Mit Rücksicht auf diese Fraǵge beabsichtigten wir mittelst Leitfähigkeitsbestimmung des Serums zu untersuchen, ob der Gehalt an freien Salzen mit den Angaben von Scherenziss übereinstimmte. Was den zweiten Zwe ck der Leitfähigkeitsbestimmung anbetrifft, so ist schon von Stewart, von Bugarszky und Tangl sowie von Roth unabhängig ron einander festgestellt worden, dass an der elektrischen Stromleitung des Blutes die Blutkörperchen nicht betheiligt sind. Wenn also ein elektrischer Strom sich durch eine $1 \mathrm{~cm}$ dicke Blutschicht bewegt, so wird er um so grösseren Widerstand finden, je mehr Blutkörperchen darin vorhanden sind. Die Grösse des Widerstandes, die eine $1 \mathrm{~cm}$ dicke Blutschicht der Stromleitung darhietet, ist also ein Maass für das relative Mengenverhältniss zwischen Blutkörperchen und Serum. Eine genaue Proportionalität besteht in dieser Hinsicht zwar nicht; man kann aber durch Vermischung von Serum mit bekannten Quantitäten Blutköryerchen empirisch feststellen, auf welche relative Menge Blutkörperchen und Serum der gefundene Widerstand zurückzufühen ist; dabei muss natürlich das Leitrermögen des reinen Serums bekannt sein.

Oker Blom hatte bereits früher derartige Untersuchungen ausgeführt und die Resultate in einer Curve zum Ausdruck gebracht, aus der man unmittelbar entnehmen kann, welches Volumen an Blutkörperchen in 100 Raumtheilen Blut vorhanden ist, wenn das Leitvermögen des Serums und das des Blutes bekannt sind (B. I S. 522).

Die Leitfähigkeitsbestimmungen wurden mit Wechselstrom und Telephon ausgeführt. Der Brückendraht war von Platin-Iridium, $1 \mathrm{~m}$ lang, $0,14 \mathrm{~mm}$ dick, und hatte einen Widerstand von etwa 10 .. Der Kheostat, Hartmann \& Braun Nr. 2664, reichte von 0,01 bis $4000 \Omega$ und war nach Chaperon gewickelt. Seine Fehler sind kleinel als ${ }^{3} / 10000$. Das kleine Inductorium von Köhler wurde von 
einem ganz kleinen Chromsäure-Element getrieben; es gab den bekannten Mückenton, der jedoch durch Gummifüsse und einen dreifachen Pappdeckel ganz unhörbar gemacht wurde.

Das Thermometer, G. S. 1180, war in ${ }^{1}{ }_{20}$ Grade getheilt und war im September 1900 von der Physikalisch-Technischen Reichsanstalt in Ilmenau geprüft worden.

Die Einstellungen des Brückendrahtes wurden auf ${ }^{1 / 4} \mathrm{~mm}$ genau abgelesen. Nach der ersten orientirenden Einstellung wurde der Rheostat so gestöpselt, dass die folgenden Einstellungen immer in die Nähe von $500 \mathrm{~mm}$ fielen. Der Kalibrirungsfehler des Drahtes für 500 war unmerklich.

Aus der ausführlichen Beschreibung des ersten Versuches wird man sich ein Urtheil über die Genauigkeit bilden können, welche bei unseren Untersuchungen erreicht worden ist. Hier sei nur bemerkt, dass die Bestimmungen bei einer Temperatur von $18,35^{\circ}$ bis $18,60^{\circ}$ ausgeführt wurden. Es ist selbstverständlich gleichgiltig, ob man das bei dieser oder bei der üblichen 'Temperatur von $18^{\circ}$ thut, wenn man bloss da. für Sorge trägt, dass alle Resultate auf dieselbe Temperatur reducirt werden. (Vergleiche weiter betreffs Widerstandsgefäss und Anderes bei der Leitfähigkeitsbestimmung Bd. I, S. 98 ff. und S. 524 ff.)

\section{Chlorbestimmung.}

Die Chlorbestimmung wurde in folgender Weise ausgeführt. 10 cc Serum wurde mit 20 ce gesättigter chlorfreier $\left(\mathrm{NH}_{4}\right)_{2} \mathrm{SO}_{4}$-Lösung versetzt, und das Gemisch in einer geschlossenen Flasche im Wasserbade erhitzt. Nach erfolgter Abküllung wurde filtrirt und in dem nunmehr eiweissfreien Filtrat das Chlor nach der Methode von Vollhard bestimmt, indem $15 \mathrm{cc}$ mit $10 \mathrm{cc}{ }^{1}{ }_{10}$ normal $\mathrm{Ag} \mathrm{NO} \mathrm{N}_{3}$ und 5 cc concentrirter $\mathrm{HNO}_{3}$ versetzt wurden. Nach Filtration des gebildeten $\mathrm{AgCl}$ wurden $15 \mathrm{cc}$ des Filtrats mit ${ }^{1 / 10}$ normal KCNS bei Gegenwart von überschüssiger Salpetersäure und einigen Tropfen Ferrinitrat als Indicator titrirt.

Bei der Berechnung, wie viel $\mathrm{Ag} \mathrm{NO}_{3}$-Lösung dem Chlor des Serums entsprach, wurde der mit Ammoniumsulfat erhaltene Niederschlag als Flüssigkeit in Rechnung gebracht. Es wurde also, wie auch aus den Beispiele im ersten Versuch zu ersehen ist, die bei der Endtitration festgestellte $\mathrm{Ag} \mathrm{NO}_{3}$-Lösung mit 4 multiplicirt.

Streng genommen ist das aber nicht richtig, denn wenn $10 \mathrm{cc}$ Serum mit $20 \mathrm{cc}$ $\left(\mathrm{NH}_{4}\right)_{2} \mathrm{SO}_{4}$ versetzt werden, so bekommt man nicht $30 \mathrm{cc}$ Flïssigkeit. sondern das Chlor ist dann in einer geringeren Flüssigkeitsmenge entlıalten. Ermittelt man nun den Chlorgehalt in dieser Flüssigkeit unter der Voraussetzung, dass 30 cc dieser Flüssigkeit vorhanden wären, so fällt die Bestimmung zu hoch aus. Diese Erwägung hat aber keine Bedeutung, wenn zwei Sera, deren Eiweissgehalt nicht weit auseinander liegt, in Beziehung auf ihren Chlorgehalt mit einander verglichen werden, wie zum Beispiel das Serum vou Mutter und Fötus. Diese Erwägung ist dagegen dann von Bedeutung wenn zwei Flüssigkeiten verglichen werden, deren Eiweissgehalt einen grossen Unter schied zeigt, z. B. Amnion- oder Allantoisflüssigkeit mit Serum.

Von diesem Gesichtspunkte aus haben wir auch einige Chlorbestimmungen nach einer anderen Methode ausgeführt und die dabei gefundene Zahl mit der verglichen, welche mittelst der ersten Methode erhalten wurde. Die zweite Methode bestand darin, dass wir das Serum und die Amnion- und Allantoisflüssigkeiten bei 
$105^{\circ} \mathrm{C}$. eintrocknen liessen und dann einäscherten. Die Asche wurde sorgfältig unit heissem Wasser ausgezogen und in der Lösung nach der oben erwähnten Methode von Volhard der Chlorgehalt bestimmt. Ich lasse hier einige vergleichende Bestimmungen folgen.

\section{Methode.}

(Fällung des Eiweisses mittelst $\left.\left(\mathrm{NH}_{4}\right)_{2} \mathrm{SO}_{4}\right)$.

10 cc Flüssigkeit enthalten eine Menge Chlor, welche entspricht:

beim mütterlichen Serum, 10,8 cc ${ }^{1 / 10}$ normal $\mathrm{Ag} \mathrm{NO}_{3}$, beim fötalen Serum, 10,8 cc ${ }^{1 / 10}$ normal $\mathrm{Ag} \mathrm{NO}_{3}$, bei Allantoisflüssigkeit, $1,6 \mathrm{cc}^{1 / 10}$ normal $\mathrm{Ag} \mathrm{NO}_{3}$. beim mütterlichen Serum, 10,4 cc ${ }^{1 / 10}$ normal $\mathrm{Ag} \mathrm{NO}_{3}$, beim mütterlichen Serum, 9,2 cc ${ }^{1 / 10}$ normal $\mathrm{Ag} \mathrm{NO}_{3}$.

\section{Methode.}

(Entfernung des Eiweisses mittelst Einäscherung.)

10 cc Flüssigkeit enthalten eine Menge Chlor, welche entspricht: beim mütterlichen Serum, $9 \mathrm{cc}^{{ }^{2}}{ }_{10}$ normal $\mathrm{Ag} \mathrm{NO}_{3}$, beim fötalen Serum, $9 \mathrm{cc}^{1 / 10}$ normal $\mathrm{Ag} \mathrm{NO}_{3}$, bei Allantoisflüssigkeit, 1,5 cc ${ }^{1 / 10}$ normal $\mathrm{AgNO}_{3}$, beim mütterlichen Serum, 8,5 cc $1 / 10$ normal $\mathrm{Ag} \mathrm{NO}_{3}$, beim mütterlichen Serum, 8,5 cc ${ }^{1 / 10}$ normal $\mathrm{AgNO}_{3}$.

\section{Alkalinität.}

Nach den Untersuchungen von Loewy nnd Zuntz, sowie von mir selbst, kann man das in serösen F'lüssigkeiten vorkommende Alkali in diffusibles und nicht diffusibles Alkali unterscheiden (vergl. u. A. Bd. I, S. 280). Das erste ist in der Form anorganischer Salze vorhanden und zu diesen gehören $\mathrm{Na}_{2} \mathrm{CO}_{3}, \mathrm{Na}_{2} \mathrm{HPO}_{4}$ und $\mathrm{NaH}_{2} \mathrm{PO}_{4}$. Wenn man Serum in einen Pergamentschlauch bringt, der von Wasser umgeben ist, so dıffundiren die genannten Salze in das Wasser hinein; daher der Name diffusibles Alkali. Das nicht diffusible Alkali ist an Eiweiss gebunden und bildet damit Albuminate, die nicht in das Wasser hinein diffundiren. Ich habe nun eine Methode angegeben, um beide von einander zu trennen. Fügt man nämlich zu dem Serum die doppelte Nenge $96 \%$ igen Alkohols, so wird alles Eiweiss gefällt und mit ihm auch das nicht diffusible Alkali, während das diffusible abfiltrirt werden kann. Letzteres kann man mit Hilfe verschiedener Indicatoren titriren. Am meisten empfiehlt sich das Lakmoid, weil hierbei sowohl das an Phosphorsäure wie an Kohlensäure gebundene Natrium berücksichtigt wird. Wird also das Filtrat unter Anwendung dieses Indicators titrirt, so stellt man alles an Kohlensäure und Phosphorsäure gebundene Alkali fest. Mit demselben Indicator kann man auch die Menge des nicht diffusiblen Alkalis ermitteln, indem nämlich das ursprüngliche Serum titrirt wird und von der für das gesammte Alkali gefundenen Zahl die dem diffusiblen Alkali entsprechende abgezogen wird.

Ich verfuhr in folgender Weise: う cc der serösen Flüssigkeit wurden so lange mit ${ }^{1} / 20$ normal Weinsäure versetzt, bis ein Tropfen des entstandenen Gemisches, auf einen Streifen blauen Lakmoidpapier gebracht, einen Stich ins Rothe hervorrief. Dis gebrauchte Weinsäuremenge entspricht dann der Gesammtmenge von diffusiblem und nicht diffusiblem Alkali. In aller Strenge ist das aber nicht richtig, denn um 
die rothe Farbe auf Lakmoidpapier herbeizuführen, muss ein gewisser Ueberschuss von Säure vorhanden sein. Ich habe die Grösse desselben derart bestimmt, dass 5 cc Wasser (10 ec Alkohol) so lange mit Weinsäure versetzt wurden, bis die Grenzreaction auf Lakmoidpapier sichtbar wurde. Die verbrauchte Säuremenge, welche selbstverständlich von der Empfindlichkeit des Lakmoidpapiers abhängig ist, muss von der gefundenen Alkalescenz der serösen Flüssigkeit abgezogen werden, wenn man die wahre Alkalescenz kennen will.

Das diffusible Alkali wurde - wie gesagt - von dem nicht diffusiblen durch Hinzufügung der doppelten Alkoholmenge getrennt. In unseren Versuchen wurden 10 ec Flüssigkeit mit 20 ce Alkohol von $96 \%$ vermischt, dann filtrirt und 15 ec des Filtrats mit ${ }^{1 / 20}$ normal Weinsäure und Lakmoidpapier als Indicator titrirt.

Beim Serum mussten wir uns mit der Bestimmung der Gesammtalkalinität begnügen, beim Fruchtwasser, wo wir über grössere Quantitäten verfügten, konnten wir beide Formen der Alkalinität bestimmen.

\section{Feste Bestandtheile.}

Die festen Bestandtheile wurden in der üblichen Weise ermittelt. $10 \mathrm{cc}$ wurden in einem zuvor gewogenen Porzellan-Schälchen zur Trockne eingedampft und bei einer Temperatur von $100^{\circ}$ bis $105^{\circ} \mathrm{C}$. fertig getrocknet. Dieses wurde so lange fortgesetzt, bis keine Gewichtabnahme mehr erkennbar wal. Nach der Entfernung aus dem Trockenofen liessen wir das Schälchen in einem Exsiccator abkühlen. Dann wurde es sorgfältig gewogen.

Ich schreite jetzt zu der ausführlichen Beschreibung einer Versuchsreihe. Ueber die anderen kann ich mich dann kïrzer fassen. Sie sind nach der ersten zu beurtheilen.

\section{Versuche.}

Versuch 1.

Kuh 6 Jahre alt. Blut entnommen durch Aderlass 4 Stundell ante partem; Aderlass des Kalbes unmittelbar nach der Geburt.

\section{Farbstoffaustritt.}

a) ke in Farbstoffaustritt (sog. Minimum-Resistenz)

b) deutlicher Farbstoffaustritt, welcher von hier an bei abnehmender Concentration allmählich zunimmt

c) Farbstoffaustritt bei allen Blutkörperchen (sogen. Maximum-Resistenz)

$$
\begin{aligned}
& \text { Also Resistenzbreite bei der Kiuh } \frac{1}{0,42}-0,42 \% 0,25 \% \text {. } 1 \\
& 0,73=1,01 \\
&, \quad \text { beim Kialb } \frac{1}{0,25}-\frac{1}{0,73}=2,63
\end{aligned}
$$

Mutterthier Kalb $\mathrm{NaCl} 0,73 \% \quad 0,73 \%$$$
\text { л } 0,66 \% \quad 0,66 \%
$$

Riesultat: Das Widerstandvermögen der mindest resistenten Blutkörperchen gegenüber verdünnten Salzlösungen ist also beim Mutterthiere und Neugeborenen dasselbe. Nur ist beim Neugeborenen die 
Resistenzbreite grösser, indem bei demselben sich Blutkörperchen finden, welche noch viel verdünnteren Salzlösungen Widerstand bieten wie die im Blute des Mutterthieres enthaltenen.

$$
\begin{aligned}
& \text { Osmotischer Druck } \\
& \text { ermittelt durch Gefrierpunkterniedrigung. } \\
& \text { Blut Mutterthier Blut Kalb }
\end{aligned}
$$

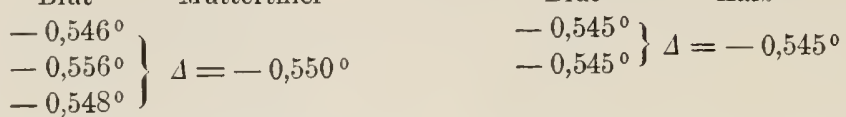

Resultat: Die Gefrierpunkterniedrigung des Jugularisserums des Mutterthieres ist ein wenig grösser als die des Jugularisblutes des Neugeborenen. Der Unterschied ist aber so gering, dass er noch innerhalb der Fehlergrenze der Nethode liegt.

Volumänderung der Blutkörperchen durch Salzlösungen.

0,06 cc Blut geben nach dem Centrifugiren ein Blutkörperchenvolumen

$\begin{array}{ccc} & \text { Mutterthier } & \text { Kalb } \\ \text { ursprüngliches Blut } & \left.63{ }^{\prime}\right) & 71 \\ \text { mit } 0,8 \% \text { NaCl-Lösung } & 62 \text { ? } & 74 \\ \pi 1,0 \% \text { " } & 53 & 73 \\ \pi 1,5 \% \text { " } & 46 & 58\end{array}$

Resultate: a) Das Blut des Mutterthieres enthält ein kleineres Blutkörperchenvolumen als dasjenige des Kalbes (63 und 71).

Das procentische Volumen an Blutkörperchen ist also:

$$
\begin{aligned}
& \text { beim Nutterthier }\left(\frac{63 \times 0.0004}{0,06}\right) \times 100=\mathbf{4 2} \% \\
& \text { beim Kalbe } \quad\left(\frac{71 \times 0,0004}{0,06}\right) \times 100=\mathbf{4 7 , 3} \% \text {. }
\end{aligned}
$$

b) Die procentische Schrumpfung, welche die Blutkörperchen erfahren, wenn dieselben aus dem Serum in eine $1,5 \%$ ige NaCl-Lösung hinübergebracht werden, ist folgende:

$$
\begin{aligned}
& \text { beim Nutterthiere }\left(\frac{63-46}{63}\right) \times 100=23,9 \% \\
& \text { beim Kalbe } \quad\left(\frac{71-58}{71}\right) \times 100=18,3 \% .
\end{aligned}
$$

IHiernach ist also das procentische Volumen der intraglobularen Flüssigkeit (Hämoglobin nicht mitgerechnet) bei den Blutkörperchen der Kuh bedeutend grösser als beim Kalbe.

1) Jeder 'l'heilstrich des Capillar-Röhrchens entspricht 0,0004 cc. (Vergleiche Bd. I, S. 379.) 
Elektrisches Leitvermögen von Serum und Blut.

Bestimmung der Capacität des Gefässes mittelst $1 / 10$ normal $\mathrm{KCl}$ bei einer Temperatur von $18.55^{\circ} \mathrm{C}$.

Gefüss. Rheostat. Finstellung der Brücke. Faktor. Widerstand. Mittel.

$\left.\begin{array}{lllll} & 170 \Omega \text { (internat. Ohm) } & 507 & 1,028 & 174,83 \\ \text { Nr. } 1 & 174 & 501.5 & 1,006 & 175,04 \\ & 175 & 500 & 1,000 & 175\end{array}\right\}$

Das Leitvermögen von $1 / 10$ normal $\mathrm{KCl}$ ist bei einer Temperatur von $18,55^{\circ} \mathrm{C}$. $=0,01132$. Da nun die Capacität des Gefässes dem Produkte aus Leitvermögen und gefundenem Widerstand entspricht, so ergiebt sich für diejenige des obengenannten Gefässes ( $\mathrm{Nl}$. 1)

$$
175 \times 0,01132=1,981 .
$$

Die anderen Gefässe hatten die folgenden Capacitäten:

$$
\begin{aligned}
& \text { Nr. } 2 \text {. . . . . . . } 2,067 \\
& \text { Nr. } 3 \text {. . . . . . } 1,970 \\
& \text { Nr. } 4 \text {. . . . . . } 1,981
\end{aligned}
$$

Bestimmung des Leitvermögens von Serum und Blut.

\begin{tabular}{lcccc|c} 
& Rheostat. & Einstellg. d. Brücke. & Factor. Widerstand. Mittel. \\
Serum vom Mutterthiere & $178 \Omega$ & 502 & 1,008 & 179,4 & \\
Temperatur $=18,60^{\circ} \mathrm{C}$. & 180 & 499,5 & 0,998 & 179,6 & 179,6 \\
Capac. des Gefässes $=1,970$ & 180 & 499,75 & 0,999 & 179,8 & \\
& & & & & \\
Blut vom Mutterthiere & 332 & 501 & 1,004 & 333,3 & \\
Temperatur $=18,55^{\circ} \mathrm{C}$. & 333 & 500 & 1,000 & 333,0 & \\
Capac. des Gefässes $=1,981$ & 333 & 500 & 1,000 & 333,0 & 333 \\
& 333 & 500 & 1,000 & 333,0 & \\
& 333 & 500 & 1,000 & 333,0
\end{tabular}

Das Leitvermögen von Serum bezw. Blut ist also in diesem Versuche $\frac{1,970}{179,6}=0,01097$, bezw. $\frac{1,981}{333}=0,005949$. Multipliciren wir die gefundenen Werthe mit $10^{6}$, so erhalten wir für das Leitverrnögen:

$$
\begin{aligned}
& \text { Serum } \begin{cases}\text { Muttertbier } 10970 \text { (bei } 18,60^{\circ} \mathrm{C} \text {.) } \\
\text { Kalb } & 11795 \text { (bei } 18,50^{\circ} \mathrm{C} \text {.) }\end{cases} \\
& \text { Blut \{ Mutterthier } 5949 \text { (bei } 18,55^{\circ} \mathrm{C} \text {.) }
\end{aligned}
$$

Aus unseren Untersuchungen über das Leitvermögen von Serum und Blut bei verschiedenen Temperaturen, geht hervor, dass mit jedem Grade Temperatur-Differenz das Leitvermögen sich um ungefähr $2 \%$ ändert. Wir haben nun in unseren Versuchen die gefundenen Werthe des Leitvermögens auf eine Temperatur von $18,50^{\circ} \mathrm{C}$. ungerechnet. Hierbei gewinnen wir folgendes Resultat:

Leitvermögen

$$
\begin{aligned}
& \text { Serum }\left\{\begin{array}{ll}
\text { Mutterthier } & 10948 \\
\text { Kalb } & 11795
\end{array} \text { bei } 18,50^{\circ} \mathrm{C} .\right. \\
& \text { Blut } \begin{cases}\text { Mutterthier } & 5943 \\
\text { Kalh } & 4904\end{cases}
\end{aligned}
$$


Resultat: Das elektrische Leitvermögen des Serums ist beim neugeborenen Kalbe grösser als beim Mutterthiere; beim Blute ist das Umgekehrte der Fall.

Berechnet man das Verhältniss zwischen dem Leitvermögen von Blut und Serum so bekommt man

$$
\begin{aligned}
& \text { beim Mutterthiere } \frac{10948}{5943}=1,842 \\
& \text { beim Kalbe } \quad \frac{11795}{4904}=2,405 .
\end{aligned}
$$

Hieraus geht hervor, dass das Blut des Mutterthieres ein geringeres Blutkörperchenvolumen enthält, als das des Kalbes. Nach der von Oker-Blom gegebenen Tabelle lässt sich aus obigen Zahlen berechnen für das Blutkörperchenvolumen (B. I, S. 521)

$$
\begin{aligned}
& \text { beim Iutterthiere . . . . . . } 30 \% \text {, } \\
& \text { beim neugeborenen Kalbe . . . 40\%. }
\end{aligned}
$$

\section{Chlorgehalt.}

10 cc Flüssigkeit enthalten eine Chlormenge, welche entspricht:

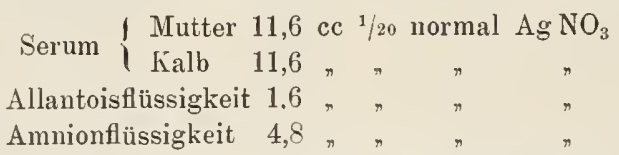

Hätten wir den Chlorgehalt nach Veraschung bestimmt, so wäre derselbe, wie aus den vergleichenden Untersuchungen (S. 194) zu ersehen ist, kleiner ausgefallen.

Resultat: Mütterliches und fötales Serum haben gleichen Chlorgehalt. Derselbe ist grösser als derjenige beider Fruchtwasserarten. Von den letzteren besitzt die Amnionflüssigkeit einen bedeutend höheren Chlorgehalt als die entsprechende Allantoisflüssigkeit.

\begin{tabular}{|c|c|c|c|c|}
\hline Serum \& Mutterthier & 5,5 & $\operatorname{cc}^{1 / 20}$ & normal & Weinsäure \\
\hline serum Kalb & 6,75 & $n$ & n & , \\
\hline Allantoisflüssigkeit & 2,3 & , & n & ᄁ \\
\hline Amnionflïssigkeit & 2,5 & $n$ & . & , \\
\hline
\end{tabular}

\section{Alkalinität.}

a) Gesammt-Alkalinität. (Bestimmung mittelst Lakmoidpapier.)

5 cc Flüssigkeit brauchen zur Süttigung:

b) Gehalt an diffusiblem Alkali.

10 cc Flüssigkeit wurden mit 20 ce Alkohol von $96 \%$ vermischt. Nach Filtration erfordern 15 cc des Filtrats bei der Titration mit ${ }^{1 / 20}$ normal Weinsäure: bei Allantoisflüssigkeit $1 \mathrm{cc}^{1} / 20$ normal Weinsäure, bei Amnionflüssigkeit 1,2 cc. 
Resultat: Aus den Versuchen geht hervor, dass die Gesammtalkalinität des renösen Blutes beim Mutterthier'e etwas kleiner ist, als beim Kalbe. Von beiden aber ist die Gesammtalkalinität bedeutend grösser als diejenige der entsprechenden Fruchtwasser. Von den beiden letzteren enthält die Allantoisflüssigkeit den niedrigsten Gehalt an Alkali.

Was den Gehalt an diffusiblem Akali betrifft, so wurde dieser beim Serum nicht ermittelt, bei Amnionfliussigkeit zeigte derselbe sich ebenso wie der Totalalkaligehalt grösser als bei Allantoisflüssigkeit.

Feste Bestandtheile.

10 cc Flüssigkeit enthalten:
a) Serum $\left\{\begin{array}{ll}\text { Mutterthier } & 0,869 \\ \text { Kalb } & 0,632\end{array}\right.$, Trockenrïckstand
b) Blut $\left\{\begin{array}{ll}\text { Mutterthier } 1,963 \\ \text { Kalb } & 1,913\end{array}\right.$,

Resultat: Beim Kalb ist der Gehalt des Serums an festen Bestandtheilen geringer als beim Mutterthier; das Gesammtblut beider zeigt dieselben Verhältnisse.

Nach den beschriebenen Methoden sind auch bei anderen gebärenden Kühen und entsprechenden Kälbern Versuche ausgeführt worden.

Ausser diesen Versuchen haben wir noch nach denselben Methoden eine Reihe anderer ausgeführt, bei denen lediglich das Blut des Neugeborenen, oder bloss die beiden Fruchtwasserarten zur Verfügung standen. Wir werden diese Experimente nicht beschreiben, sondern dieselben einfach in die Tabelle bringen, welche auch die oben mitgetheilten Versuche enthält. Sie enthält auch die Resultate der Untersuchung von Allantois- und Amnionflüssigkeit, über die in dem folgenden Abschnitt die Rede sein wird. Un Raum zu ersparen. sind die betreffenden Resultate hier mit eingefügt, zumal die Flüssigkeiten meistens von entsprechenden Thieren stammten.

Die Einrichtung der Tabelle auf Seite 200 und 201 brauche ich nicht im Einzelnen zu behandeln; sie ist einfach genug.

Nur auf Folgendes sei hingewiesen:

Spalte I benennt das Gefäss, aus welchem das Blut entnommeu wurde.

Spalte II. a bedeutet die Concentration der NaCl-Lösung, in welcher die Blutkörperchen beginnenden Farbstoffaustritt zeigen (Minimum-Resistenz). $\beta$ ist die Concentration, in welcher sie im Begriff stehen, an schwächere Salzlösungen mehr Farbstoff abzugeben. y führt die NaCl-Lösung an, in welcher fast alle Blutkörperchen ihren Farbstoff verloren haben, d. h. die 
Uebersichtliche Zusammenstellung

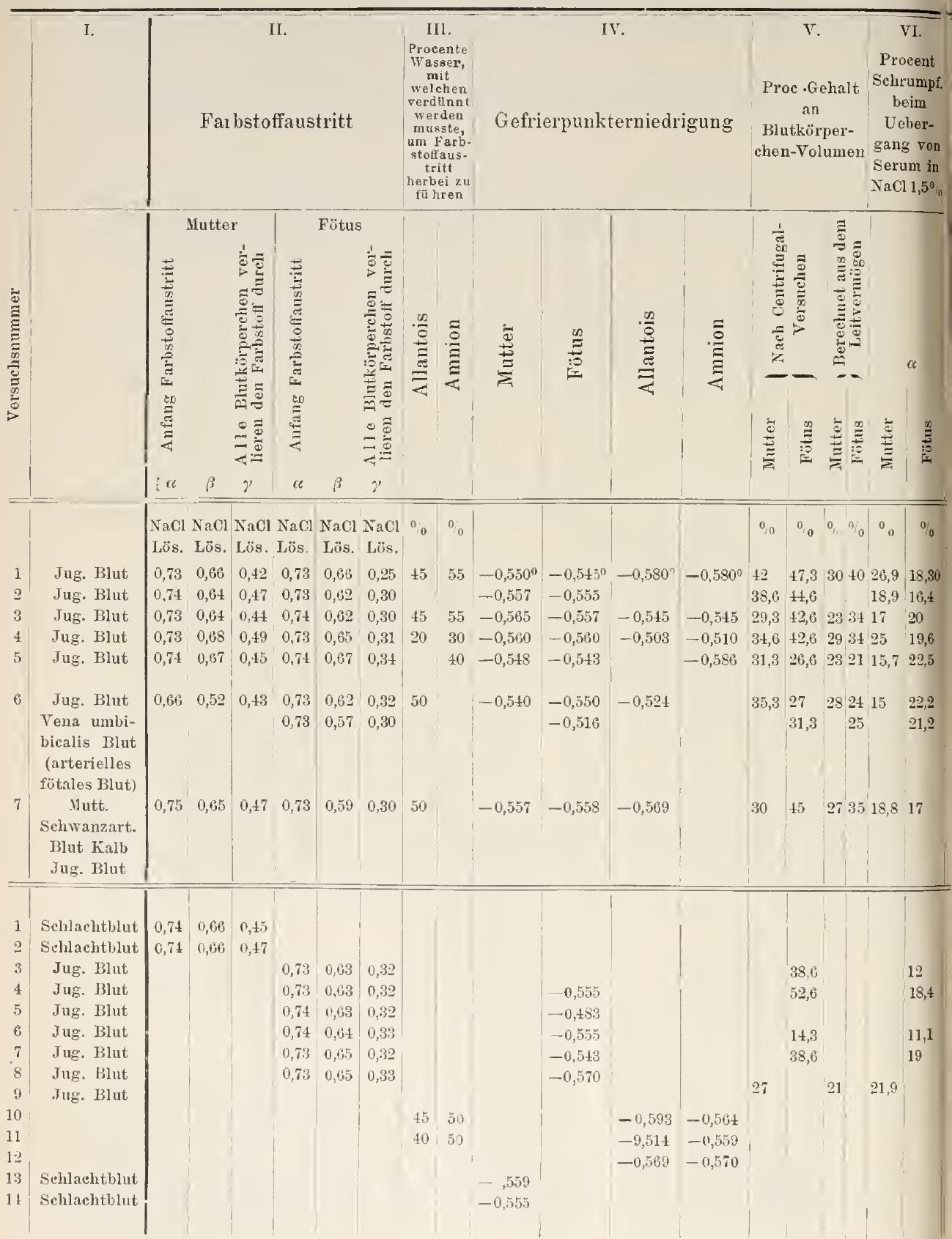


der gewomenen Resultate.

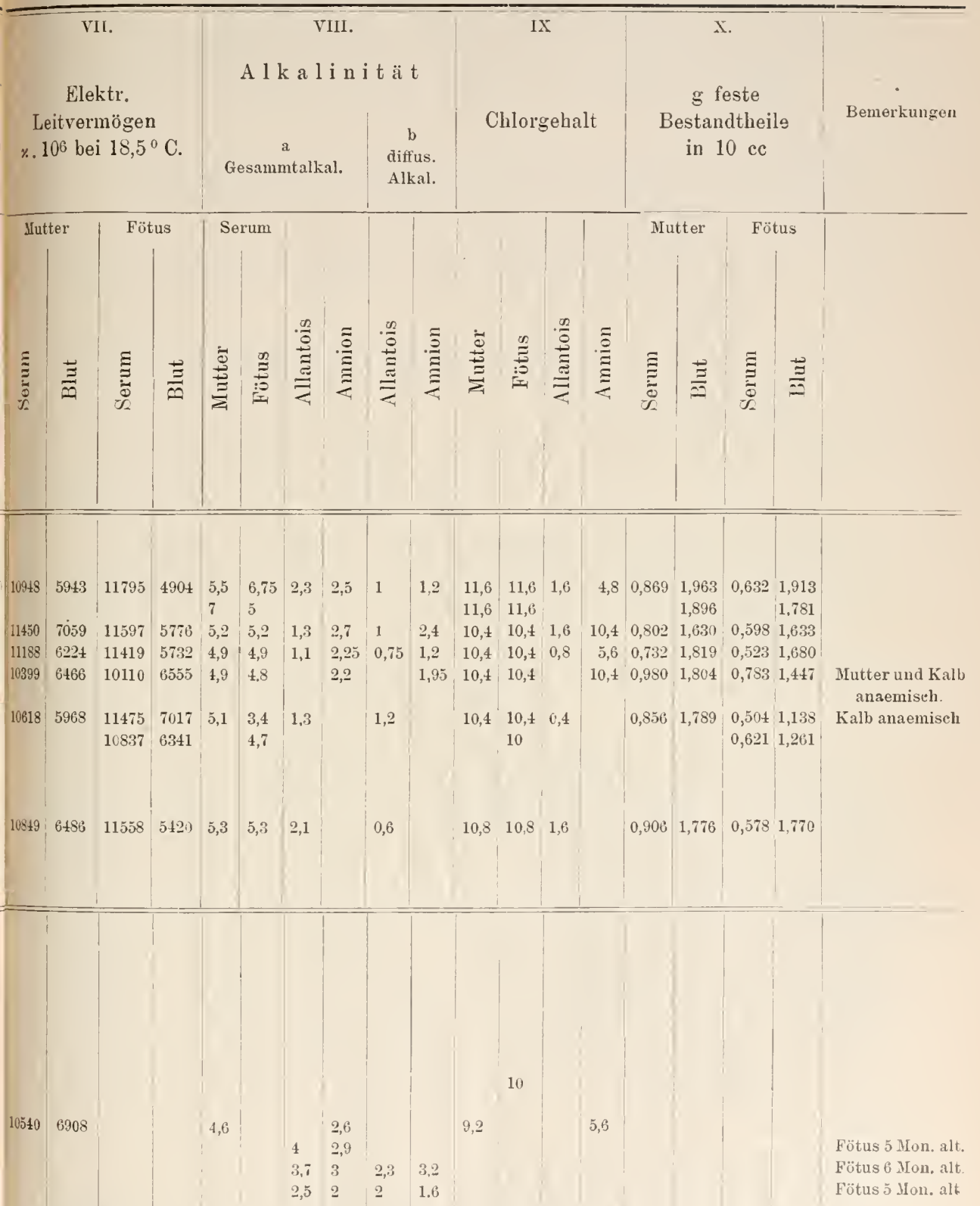


Lösung, in welcher auch die meist resistenten Blutkörperchen im Begriff stehen ibren Farbstoff abzugeben (Maximum-Resistenz).

Spalte III giebt an, mit wie viel Procent Wasser man Allantois- und Amnionflüssigkeit verdünnen kann, bevor das Gemisch in demselben Grad Farbstoffaustritt herbeiführt, wie die Kochsalzlösung $\beta$ im entsprechenden mütterlichen Blut.

Spalte IV enthält die Gefrierpunkterniedrigungen des mütterlichen und des fötalen Blutes, sowie auch die der Allantois- und Amnionflüssigkeit.

Spalte $V$ giebt das Volumen der Blutkörperchen in 100 cc Blut an:

a) erhalten durch einfaches Centrifugiren;

b) erhalten durch Bestimmung des elektrischen Leitvermögens von Blut und entsprechendem Serum, und Benutzung von Oker-Blom's Tabelle.

Spalte VI giebt die procentische Schrumpfung der Blutkörperchen an, welche entsteht, wenn die Blutkörperchen aus ihrem Serum in eine $1,5 \%$ ige NaClLösung verbracht werden.

Spalte VII enthält das elektrische Leitvermögen von Serum und Blut.

Spalte VIII enthält unter a die Zahlenwerthe für die Gesammtalkalinität und unter $b$ diejenigen für das diffusible Alkali.

Spalte IX enthält den Chiorgehalt von $10 \mathrm{cc}$ Flüssigkeit, ausgedrückt in cc $1 / 10$ normal $\mathrm{Ag} \mathrm{NO}_{3}$.

Spalte $\mathrm{X}$ gibt den Trockenrückstand in $10 \mathrm{cc}$ der untersuchten Flüssigkeiten an.

Discussion einiger in der Tabelle niedergelegten Resultate.

1. Ich bespreche zuerst die Ergebnisse von Versuch 1, 2, 3 und 4 .

Betrachten wir zunächst Spalte 11, so sieht man, dass die Blutkörperchen vom Mutterthiere und Neugeborenen in derselben Salzlösung

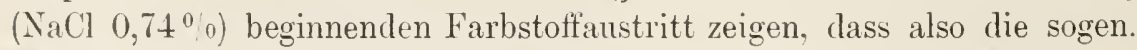
Minimum-Resistenz $\alpha$ dieselbe ist. Ias gilt nicht mehr für die MaximumResistenz $\gamma$; beim Neugeborenen sind offenbar noch Blutkörperchen vorhanden, die eine schwächere Salzlösuug ertragen als die des Mutterthieres. Während nämlich die Blutkörperchen des Mutterthieres, wie aus Spalte 11 ersichtlich, sämmtlich in einer $0,44 \%$ igen $\mathrm{NaCl}$-Lösung zu Grunde gehen, giebt es bei den Neugeborenen Blutkörperchen, die in einer derartigen $\mathrm{NaCl}$-Lösung noch ihren Farbstoff behalten. Dieses Resultat stimmt rollkommen mit dem Befunde \%anier's überein, welcher die Blutproben aus dem Herzen der Thiere entnonmen hatte.

Ich glaube diesen Befund in plausibler Weise deuten zu können. Hierzu bitte ich den Leser Spalte VI zu betrachten. Dort zeigt sich, dass die procentische Schrumpfung, die die gesamnten 
Blutkörperchen (đ. h. die Blutkörperchen aller Resistenzgrade) der Mutter erfahren, wenn dieselben aus ihrem eigenen Serum in eine $1,5 \%$ ige $\mathrm{NaCl}-L o ̈ s u n g ~ g e b r a c h t$ werden, grösser ist als die beim entsprechenden Blut des Neugeborenen (nur Versuch 3 scheint eine Ausnahme zu machen) ${ }^{\mathbf{1}}$.

Nun hängt der Betrag der procentischen Schrumpfung von zwei Factoren ab; erstens rom osmotischen Druck des Blutkörpercheninhaltes, zweitens von dem Volumen der intraglobularen Flüssigkeit. Wie sich bald ergeben wird, besteht zwischen dem osmotischen Druck des Blutkörpercheninhaltes bei Mutter und Neugeborenen kein nachweisharer Unterschied. Wir müssen also schliessen, dasśdie Blutkörperchen der Mutter ein grösseres Volumen intraglobularer Flüssigkeit enhalten als die Blutkörperchen der Neugeborenen. In den letzteren muss also ein relativ grösseres Volumen an Stroma + eiweissartigen Stoffen vorhanden sein, ein Resultat, das mit dem auf ganz andere Weise gewonmenen Ergebniss von Scherenziss im Einklang steht (Vergl. oben S. 183).

Nun habe ich früher ausgeführt, dass je geringer das Volumen der intraglobularen Flüssigkeit eines Blutkörperchens ist, um so geringer wird bei gleichbleibendem osmotischen Druck dieser Flüssigkeit die durch eine verdünnte Salzlösung herbeigeführte Volumzunahme sein; um so schwächer wird also die Salzlösung sein, die es ertragen kann ohne zerstört zu werden (Bd. I, S. 355).

Da nun bei beiden Blutsorten (von Nutter und Neugeborenem) der beginnende Farbstoffaustritt durch dieselbe Kochsalzlösung herbeigeführt wird, schliesse ich, dass gerade diejenigen Blutkörperchen der Neugeborenen, welche die schwächsten Concentrationen ertragen, es sind, die das grösste Quantum Stromat eiweissartige Stoffe enthalten. Diese sind es, die für die Thatsache verantwortlich sind, dass in den Gesammtblutkörperchen des Fötus mehr Stroma + eiweissartige Stoffe gefunden wird als in denen der Mutter (Scherenziss) und dass die procentische Schrumpfung bei Ueberführung in eine hyperisotonische Salzlösung das umgekehrte Verhalten zeigt.

1) Es muss hier ein Inthum vorliegen.

Nachträglich sehe ich in meinen Protokollen, dass man das zu centrifugirende Blut vergessen hat durch Filtrirpapier zu filtriren. Es bilden sich nämlich beim Defibriniren zuweilen sehr feine Pfröpfchen, die durch die Gaze schlüpfen. Ein einziges derartiges Pröpfchen kann einen Centrifugirversuch ganz verderben. 
Hierdurch gewinnen die sogen. Resistenzbestimmungen eine greifbare Bedeutung, die sie bis jetzt noch nicht hatten.

2. Nach zwei Methoden hat sich herausgestellt, dass das Volumen der Blutkörperchen im Blute des Neugeborenen grösser ist als im Blute des Mutterthieres (Spalte V) und zwar. sowohl durch einfaches Centrifugiren gleicher Mengen der betreffenden Blutarten, wie durch Bestimmung des elektrischen Leitvermögens des Gesammtblutes. Bei der letzteren Methode stellte sich immer heraus, dass das Blut des Neugeborenen ein beträchtlicheres Leitvermögen besass, als das des Mutterthieres (Spalte VII).

Dieses grosse Volumen der Blutkörperchen beim Neugeborenen war, wenn nicht ausschliesslich, so doch jedenfalls theilweise darauf zurïckzuführen, dass, wie vergleichende Zählungen lehrten, die Blutkörperchenzahl beim Neugeborenen vielgrösser war als beim Mutterthier.

3. Befremdend muss es, mit Rücksicht auf das sub 2 Erwähnte, auf den ersten Anblick erscheinen, dass in der Regel der Gehalt an festen Bestandtheilen beim Gesammtblut des Neugeborenen (Spalte X) kleiner gefunden wurde als der des Mutterthieres. Es ist ja bekannt, dass der Gesammtgehalt des Blutes an festen Bestandtheilen um so grösser ist, je mehr Blutkörperchen im Blute vorhanden sind. Dem steht aber im vorliegenden Fall entgegen, dass das Serum des Neugeborenen immer erheblich wasserreicher war als das Serum der Mutter (Spalte X). Offenbar ist letzterer Einfluss überwiegend.

4. Gefrierpunkterniedrigung. Spalte IV lehrt, dass die Gefrierpunkterniedrigung des miitterlichen Jugularis-Blutes mit derjenigen des Jugularis-Blutes des entsprechenden Neugeborenen übereinstimmtEs scheint dies nicht in Einklang mit dem Ergebniss ron Spalte III zu stelien, nach welchen das elektrische Leitvermögen des fötalen Serums stets grösser ist als dis des mütterlichen. Aber der Widerspruch ist nur scheinbar, denn wie Spalte $\mathrm{X}$ lehrt, ist das fötale Serum wasser'eicher als das miitterliche. Nun ist es seit den Untersuchungen von Tangl und Bugarsky (B. I, S. 490) bekannt, dass jedes Procent Eiweiss die Leitfähigkeit des Serums um etwa $2,5 \%$ herabsetzt. Nehmen wir den ersten Versuch, so sieht man, dass das mütterliche Serum 8,69\% und das fötale $6,32 \%$ feste Bestandtheile enthält. Betrachten wir den Unterschied 8,69-6,32=2.37\% als lediglich durch Eiweiss verursacht, so muss dieser die elektrische Leitfähigkeit des miitterlichen Serums um $2.5 \times 2,37=5,92 \%$ himablrieken. 
Aus Spalte VII geht herror, dass die Leitfähigkeit für mütterliches Serum 10948 und für fötales 11795 beträgt. Der Unterschied ist hiernach gleich $\frac{11795-10948}{11795}=7,1 \%$.

Hiernach würde nach Eliminirung des Einflusses oder Eiweisses die Leitfähigkeit des fötalen Serums doch noch etwas grösser sein als die des mütterlichen. Die anderen Versuche liefern bei gleicher Berechnung folgende Resultate.

\begin{tabular}{|c|c|c|}
\hline \multicolumn{2}{|c|}{$\begin{array}{l}\text { Differenz des elektrischen Leitvermögens } \\
\text { bei mütterlichem und fötalem Serum }\end{array}$} & $\begin{array}{l}\text { Hiervon kommt auf } \\
\text { Rechnung } \\
\text { des Eiweisses }\end{array}$ \\
\hline Versuch 1 & 7,1 Procent & 5,9 Procent \\
\hline 3 & 2,1 & $5,1 \quad$, \\
\hline 4 & 2 & 6,2 \\
\hline 5 & 2,8 & 4,9 \\
\hline 6 & 7,5 & 8,8 \\
\hline 7 & 6,1 & 8,2 \\
\hline
\end{tabular}

Man sieht, dass im Allgemeinen die geringere Leitfähigkeit des mütterlichen Serums durch den grossen Eiweissgehalt genügend erklärt, ja selbst noch übercompensirt wird.

Jedenfalls besteht demnach kein Grund, aus der Leitfähigkeit zu schliessen, dass das fötale Serum mehr Salz enthält als das mütterliche. Eine höhere Gefrierpunkterniedrigung kann also auf Grund der Leitfähigkeitbestimmungen nicht erwartet werden.

\section{b) Osmotische und osmotisch-chemische Analyse des Fruchtwassers.}

Teber den Ursprung der Amnionflüssigkeit sind die Meinungen getheilt: während Ahlfeld und Andere dieselbe als ein Transsudat, sei es mütterlichen oder fötalen Lrsprunges betrachtet, meint Prochownick, dass die Flüssigkeit durch die Haut und Nieren abgeschieden wird. Es braucht kaum hervorgehoben zu werden, von wie grosser Wichtigkeit es ist, über diesen Gegensatz ins Reine zu kommen, denn rlerselbe betrifft eine sehr wesentliche Angelegenheit in der Ernährung der Frucht.

Ist die Amnionflüssigkeit ein Transsudat, also ein Analogon der Lymphe, so ist sie als ernährende Flüssigkeit aufzufassen. Ist sie von renalem Ursprung, so ist sie ein Abfallproduct. (Vergl. S. 209 ff.)

Gusserow und auch Schröder haben die zwischen diesen beiden Extremen vermittelnde Meinung ausgesprochen, dass es sich je 
nach dem mehr oder minder vorgeschrittenen Stadium der Schwangerschaft um ein Gemisch von Transsudat und fötalem Harn handelt.

Unter denjenigen, die die Amnionflüssigkeit als Transsudat betrachten, besteht auch wieder Meinungsverschiedenheit über die Frage, ob die Placenta auch noch an der Nahrung der Frucht betheiligt ist, oder lediglich für den Gaswechsel Sorge trägt.

Die chemischen Analysen haben all diese Fragen nicht zur Entscheidung bringen können und so sehen wir Veit als Ersten versuchen, ob man nicht an der Hand der physikalischen Chemie weiterkommen könnte.

Eigentlich ist Bousquet [22] der Erste gewesen, der Gefrierpunktbestimmungen des Fruchtwassers ausgeführt hat. Ueber den Zweck seiner Versuche hat er aber nicht gesprochen und auch die Resultate nicht discutirt. Er fand einmal $\Delta=-0,51^{\circ}$, ein anderes Mal bei einem macerirten und 2 Monate retinirten Fötus, also in einem abnormen Fall $d=-0,585$. Nach Bousquet ist die Gefrierpunkterniedrigung der Amnionflüssigkeit geringer als die des Blutserums.

Zu einem ähnlichem Resultat gelangte Veit. Er findet für Amnionflüssigkeit $\Delta=-0,5$ : $-0,4925$ : $-0,503 ;-0,501 ;-0,485$; also im Mittel $\Delta=-\mathbf{0}, \mathbf{4 9 6}$, während er für das mütterliche Blutserum im Mittel $A=-\mathbf{0 , 5 5 1}$ (und für das kindliche eine noch höhere Zahl) fand

Wie bereits mitgetheilt wurde, ist auch von $\mathrm{Ubbels}$ das Frucht. wasser einer Untersuchung unterzogen worden, mit dem Unterschied, dass sich dieselbe auf dieselben Thiere bezog, die auch für die Blutuntersuchung benutzt wurden, und weiter, dass ausser der Gefrierpunkterniedrigung auch noch andere Werthe bestimmt wurden. Ausserdem sind aber noch Allantois- und Amnionflüssigkeit untersucht worden, die ron anderen Thieren, nämlich Schlachtthieren, stammte. Diese Flüssigkeiten entsprachen frïheren Entwicklungsstadien der Frucht. (Vergl. die Tabelle S. 200 und 201.)

Die Gewinnung des Fruchtwassers in unseren Versuchen erfolgte im Moment der Geburt. Sobald die Fruchtwasserblasen sichtbar waren, wurden sie mit einer Scheere geöffnet, der Inhalt in einer Schaale aufgefangen und durch Filtrirpapier filtrirt. Leider konnte nicht immer Allantois- und Amnionflüssigkeit erhalten werden, da zuweilen die Fruchthüllen schon zerrissen und das Fruchtwasser ausgelaufen war, bevor man noch etwas bemerkt hatte.

Ueber die Untersuchungsmethode habe ich nicht weiter zu.sprechen, da sie dieselbe war, wie die beim Blut geübte. Nur ein einziges Wort sei über die Bestimmung des osmotischen Druckes gestattet.

Für das Fruchtwasser wurde gewöhnlich sowohl die Blutkörperchenmethode wie die Gefrierpunkterniedrigung in Anwendung gebracht. Dadurch war es möglich, in diesen Flüssigkeiten die Menge derjenigen Stoffe zu ermitteln, welche in die Blut- 
körperchen einzudringen im Stande sind; zu diesen Stroffen gehört bekanntlich u. a. der Harnstoff.

Die Gefrierpunkterniedrigung ist ein Ausdruck für die Wasseranziehung aller in einer Flüssigkeit vorhandenen Stoffe; die Blutkörperchenmethode ermittelt nur diejenigen Stoffe, welche nicht in die Blutkörperchen eindringen. Harnstoff ist also ausgeschlossen. Man kann sich das in folgender Weise erklären: Fügt man eine Harnstofflösung den Blutkörperchen hinzu, so vertbeilt sich dieselbe gleichmässig über Blutkörperchen und Umgebung. Wenn man desshalb gefunden hat, dass Blutkörperchen beginnenden Farbstoffaustritt in einer $0,6 \%$ igen NaCl-Lösung zeigen, so wird man genau dasselbe finden, wenn man zu dieser NaCl-Lösung eine beliebige Quantität Harnstoff hinzufügt. Nimmt man aber statt Harnstoff Kochsalz oder Natriumsulfat oder irgend ein Alkalisalz in Substanz und fügt man dieses der $0,6^{\circ}{ }^{\prime}$ igen $\mathrm{NaCl}$ Lösung hinzu, so wird dies wohl Einfluss auf den Farbstoffaustritt ausüben. Es wird jetzt deutlich sein, dass man mittelst der Blutkörperchenmethode nur den osmo. tischen Druck derjenigen Stoffe bestimmt, für welche die Blutkörperchen impermeabel sind. Zielıt man nun den so gefundenen osmotischen Druck von demjenigen ab, welchen man aus der Gefrierpunkterniedrigung findet, so bekommt man den osmotischen Druck, welcher denjenigen Stoffen zugehört, für welche die Blutkörperchen permeabel sind. Diese Stoffe haben ein physiologisches Interesse, weil sie nicht alleiı durch die Blutkörperchen, sondern durch die meisten anderen Zellen hindurch gehen können. Es ist auffallend, dass diese Stoffe die hauptsächlichsten Stoffwechselprodukte des Eiweisses bilden. Es kann nun nichts zweckmässiger scheinen, als dass die Zellen sich leicht ron diesen Stoffwechselprodukten entlasten können und das ist nur durch die grosse Permeabilität derselben für diese Stoffe ermöglicht. (Vergl. B. II, S. 238, 298 und 306). In unserem speziellen Falle kann man durch die Combination von Gefrierpunkt. und Blutkörperchenmetlode sich ein Urtheil über die Frage bilden in wie weit die Allantoisflüssigkeit als eine Art fötalen Harns anzusehen ist.

Als Beispiel für die Bestimmung des osmotischen Druckes mittelst Gefrierpunkterniedrigung und Blutkörperchenmethode, wähle ich Versuch I.

A. Gefrierpunktmethode.

A l l a n to is fl ïs sigkeit.

$$
\left.\begin{array}{l}
-0.579 \\
-0,582 \\
-0,579
\end{array}\right\} J=-0,580 \text {. }
$$

A m n i onflüssigkeit.

$$
\begin{aligned}
& \text { (filtrirt) (nicht filtrirt) }
\end{aligned}
$$

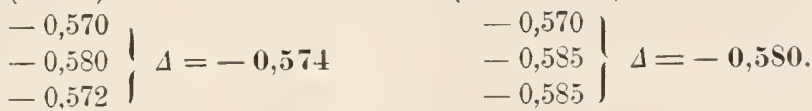

B. Blutkörperchenmethode.

a) Die Allantoisflïssigkeit muss mit $45^{\circ}, 0$ Wasser verdünnt werden, um einen gleichartigen Farbstoffaustritt wie eine 0,66\% ige NaCl-Lösung aus dem Blute der Kuh herbeizuführen. 
B) Amnionflüssigkeit muss mit $55 \%$ Wasser verdünnt werden, um einen gleichartigen Farbstoffaustritt aus dem Blute der Kuh herbeizuführen, wie eine $0,66 \%$ ige NaCl-Lösung.

Da die Gefrierpunkterniedrigungen von Allantois- und Amnionflüssigkeit sich als gleich erweisen, während andererseits die Allantoistlüssigkeit mit weniger Wasser als die Amnionflïssigkeit verdünnt werden muss, um Farbstoffaustritt aus den Blutkörperchen zu veranlassen, so müssen in der ersteren Flïssigkeit Substanzen vorhanden sein, welche gegenüber Blutkörperchen ihren osmotischen Druck nicht entfalten. Zu derartigen Stoffen gehört der Harnstoff, der sich bekanntlich gleichmässig auf Blutkörperchen und Umgebung vertheilt.

Dieses Ergebniss we ist darauf hin, dass die Allantoisflüssigkeit eine Art fötaler Urin ist.

$\mathrm{Zu}$ gleichlautenden Resultaten führen auch, wie Spalte III der Tabelle, S. 200 zeigt, die darauf folgenden Versuche 3 und 4. Was die Gefrierpunkterniedrigung der beiden Fruchtwassersorten in Vergleich zu der des Blutserums von Mutter und Neugeborenen betrifft, so hat sich im 1., 5. und 7. Versuch herausgestellt, dass die des Fruchtwassers über die des Blutserums hinausgeht, während in Versuch 3, 4 und 6 gerade das Umgekehrte der Fall ist.

Dieses Resultat gilt für das Ende der Schwangerschaft. Vergleichende Versuche von Amnion- und Allantoisflüssigkeit in früheren Perioden der Schwangerschaft ergaben einmal (Versuchsreihe 12) dieselbe Gefrierpunkterniedrigung und zweimal eine verschiedene (Versuchsreihen 10 und 11), aber in entgegengesetzter Richtung. Es scheint also, dass in dieser Zeit Wechsel vorkommen (Allantois- und Amnionflüssigkeit $-0,593^{\circ}$ und $-0,5064^{0}$; bezw. $-0,514^{0}$ und $\left.-0,559^{\circ}\right)$.

Die Gesammtalkalinität (nicht diffussibles - diffusibles Alkali) von Allantois- und Amnionflüssigkeit ist beträchtlich geringer als diejenige der entsprechenden Sera (Spalte VIIIa). Vergleicht man die Alkalinität der beiden Fruchtwasserarten mit einander, so findet man in der Amnionflüssigkeit mehr Alkali als in der Allantoisflüssigkeit; dasselbe gilt auch für das diffusible Alkali allein.

Was für den Alkaligelialt gefunden wurde, wurde auch, wenigstens für die Allantoisflüsigkeit, mit Beziehung auf das Chlor beobachtet (Spalte IX). Bei der Amnionflïssiglieit waren die Resultate wechselnd. Kweimal (Versuch 1 und 4) wurde ein geringerer, in zwei Fällen derselbe Chlorgehalt wie beim Serum ge- 
funden. Bei der Ammniontlüssigkeit einer jungen Frucht wurde ein Resultat gewonnen, welches mit Vers. 1 und 4 übereinstimmte.

Wie in der Einleitung mitgetheilt wurde, ist nach Veit die Gefrierpunkterniedrigung der Amnionfliissigkeit geringer als die des Serums Neugeborener.

Der geringe Gehalt der Allantoisflüssigkeit an Alkali und Chlor sollte die Erwartung erregen, dass auch die Gefrierpunkterniedrigung dieses Fruchtwassers weit geringer wäre, als die des Blutserums. Das ist aber bloss in drei Versuchen der Fall und selbst in diesen hätte man mit Recht erwarten dürfen, dass die Gefrierpunkterniedrigung noch kleiner ausgefallen wäre, als sie sich in Wirklichkeit zeigte. Vollkommen dasselbe gilt für die Amnionflüssigkeit, besonders da, wo sowohl Chlor wie Alkaligehalt sich geringer auswiesen, als beim Serum. Man würde danach immer eine Gefrierpunkterniedrigung erwarten müssen, wie sie thatsächlich $V$ eit auch gefunden hat. Wir haben bloss im Versuch 4 solch eine geringe Gefrierpunkterniedrigung beobachtet.

Ich habe hier noch eine ausfiuhrliche im Liitticher physiologischen Institut in sorgfältiger Weise ausgeführte Arbeit von Léon Jacqué zu erwähnen [22].

\section{c) Untersuchungen von Jacqué iiber die Genese von Fruchtwasser.}

Dieser Verfasser hat bei weitem die meisten Versuche beim Schaf, weitere aber auch beim Menschen, Kaninchen, Rind und Schwein angestellt. Beim Schaf und beim Menschen hat er auch noch das mütterliche und fötale Blut bei seinen Experimenten herangezogen.

\section{a) Schaf.}

Auf Seite 210 sind die beim Schaf erhaltenen Resultate in einer Tabelle zusammengefasst. Aus derselben geht hervor:

1. die Gefrierpunkterniedrigung des fötalen Blutes ist beim Schaf immer bedeutend grösser als die des mütterlichen.

Ich muss hinzufügen, dass, um den Einfluss der Kohlensäure auf die etwaigen Differenzen zu eliminiren, Jacqué das Blut immer mittelst Luftschüttelung künstlich arteriell machte.

Woher das fötale und miitterliche Blut stammt, habe ich nicht gelesen. (Vergl. oben S. 188.)

2. die Amnion- und Allantoisfliissigkeit besitzen stets eine kleinere Gefrierpunkterniedrigung als das Blutserum von Mutter und Frucht.

Es ergeben sich nun verschiedene Fragen:

ad 1. Zunächst, woher stammt die grössere Gefrierpunkterniedrigung des fötalen Blutes im Vergleich zu der des mütterlichen?

Rührt das von Salzen her? 
Gefrierpunkterniedrignng von Blnt mul Frnchtwasser beim Schat.

\begin{tabular}{|c|c|c|c|c|c|c|}
\hline \multirow{2}{*}{$\begin{array}{c}\text { Nummer } \\
\text { des } \\
\text { Versuches }\end{array}$} & \multirow{2}{*}{$\begin{array}{c}\text { Grösse des } \\
\text { Fötus } \\
\text { in cm }\end{array}$} & \multicolumn{2}{|c|}{\lrcorner} & \multicolumn{2}{|c|}{4} & \multirow{2}{*}{$\begin{array}{l}\text { Bemerk- } \\
\text { ungen }\end{array}$} \\
\hline & & $\begin{array}{c}\text { mütterliches } \\
\text { Blut }\end{array}$ & $\begin{array}{c}\text { fötales } \\
\text { Blut }\end{array}$ & $\begin{array}{l}\text { Amnion- } \\
\text { flüssigkeit }\end{array}$ & $\begin{array}{l}\text { Allantois- } \\
\text { flüssigkeit }\end{array}$ & \\
\hline \multirow{3}{*}{1} & 14 & & & $0,554^{\circ}$ & $0,494^{\circ}$ & \multirow{5}{*}{3 Fötus } \\
\hline & 15 & $0,597^{\circ}$ & $0,618^{\circ}$ & 0,552 & 0,510 & \\
\hline & 16 & & & 0,557 & 0,502 & \\
\hline 2 & 24 & 0,592 & 0,653 & 0,560 & 0,577 & \\
\hline 3 & 30 & $(0,631)$ & 0,637 & 0.590 & 0.565 & \\
\hline 4 & , 30 & \multirow{2}{*}{0,577} & 0,608 & 0,500 & 0.527 & \multirow{14}{*}{$\begin{array}{l}\text { Zwillinge } \\
\text { Zwillinge }\end{array}$} \\
\hline 5 & 31 & & 0,611 & $0,505 \hat{\jmath}$ & 0,327 & \\
\hline 6 & , 31 & \multirow{2}{*}{0,568} & 0,614 & 0,495 । & \multirow{2}{*}{0,540} & \\
\hline 7 & 31 & & 0,615 & $0,499 i$ & & \\
\hline 8 & 32 & 0,566 & 0,650 & 0,546 & $0,546^{\circ}$ & \\
\hline 9 & 32 & 0,573 & 0,624 & 0,527 & 0,547 & \\
\hline 10 & 35 & 0,581 & 0,616 & 0,475 & 0,526 & \\
\hline 11 & 35,5 & 0,596 & 0,630 & 0,512 & 0,551 & \\
\hline 12 & 36 & 0,574 & 0,602 & 0,510 & 0.538 & \\
\hline 13 & 36 & 0,565 & 0,592 & 0,527 & 0,544 & \\
\hline 14 & 37 & 0,579 & 0,594 & 0,543 & 0,548 & \\
\hline 15 & 39 & 0.599 & 0,646 & 0,524 & 0,542 & \\
\hline 16 & 41 & 0,553 & 0,638 & 0.523 & 0,547 & \\
\hline 17 & 46 & 0,569 & 0,650 & 0.463 & 0,543 & \\
\hline Mittelv & verthe & $-0,55^{\circ}$ & $-0,6: 33^{0}$ & $-0,5000$ & $-0, \operatorname{sins} 0$ & \\
\hline
\end{tabular}

Jacqué hat hierzu Serum eingeäschert und die Menge der in Wasser löslichen und der in Wasser unlöslichen Aschenbestandtheile ermittelt; ausserdem die $\mathrm{NaCl}$-ILenge.

Im Allgemeinen war der Salzgehalt beim Fötus grösser, aber die Differenz war nicht so gross, dass sie den grossen Unterschied der betreffenden Gefrierpunkterniedrigungen erklären konnte. Jacqué nahm deshalb an, dass auch organische Zerfallproducte im fötalen Blutserum in grösserer Menge vorhanden sind als im mütterlichen.

Letzteres lässt sich sehr gut durch den regen Stoffwechsel in Fötns erklären. Dann fragt es sich aber, warum nicht auch beim Menschen dasselbe beobachtet wird. Krönig und Fuetlı und auch Jacqué selbst (siehe unten) haben doch im Gegensatz zu Veit beim Menschen keinen Unterschied in der Gefrierpunkterniedrigung zwischen fötalem und mïtterlichem Blutserum gefunden. Jacqué macht zwei Ursachen für diesen Unterschied verantwortlich: erstens. dass die Berührungsfläche zwischen 
bei den Blutsorten, beim Meuschen grösser ist als beim Schaf, also die Gelegenheit für Austausch und Gleichgewichtbildung günstiger ist und zweitens, dass der Stoffwechsel beim Schaf reger ist als beim Menschen. Am Ende der Schwangerschaft wiegt der menschliche Fötus 3200 bis $3400 \mathrm{~g}$ und der Schaffötus $3300-3700 \mathrm{~g}$ und zur Erreichung dieses Gewichtes hat der erstere 280 Tage zur Verfügung; der Scliaffötus nur 150 .

Und wie ist dann der grössere Salzgehalt im fötalen Serum zu erklären? Veit denkt an eine secretorische Thätigkeit der Langhansschen Zellen, eine Hypothese, die kaum Unterstiutzung findet. Jacqué sieht die Ursache in der Abscheidung eines salzarmen fötalen Harns, dessen Depression im Mittel nur gleich $-0,255^{\circ}$ gefunden wurde. Hierdurclı würde der Salzgehalt im Blutserum des Fötus zunehmen.

ad 2. Die Gefrierpunkterniedrigungenvon Allantois und Amnionfluissigkeit sind beide viel kleiner als die vom Blutserum. Sie können also nach Jacqué keine Transsudate sein. Was sind sie dann? Besprechen wir erst die Allantoisflïssigkeit!

Jacqué hält die Allantoisflüssigkeit für einen fötalen Harn. Ein wichtiges Argument hierfür findet er in den starken Schwankungen des Verhältnisses zwischen dem Gehalt an $\mathrm{NaCl}$ und an löslichen Salzen. Dieselben bewegen sich zwischen 3 und 40. Aehnliches gilt auch fïr den fötalen Harn (16-70). Bei Transsudaten dagegen ist das Verhältniss sehr constant, ebenso wie im Blutserum.

Dazu kommt, dass die Gefrierpunkterniedrigung der Allantoisflüssigkeit, ebenso wie die des fötalen Harns, durch die anorganischen Stoffe nicht gedeckt erscheint. Es müssen somit auch noch organische darin rorkommen. Man erinnert sich, dass dies von mir und Ubbels durch die Blutkörperchenmethode direct nachgewiesen wurde. Aber wenn die Allantoisflüssigkeit fötaler Harn ist, warum ist dann die Gefrierpunkterniedrigung dieses Fruchtwassers dann noch immer um so Vieles grösser als - 0,25̃ $5^{\circ}$ (siehe oben)? Ja cq u é glaubt, dass diese Steigerung durch Resorption entsteht. Allanto is flüssigkeit ist also eingeengter fötaler Harn. Diese Einengung findet theilweise durch die in der Wand verlaufenden Blutgefässe statt, theilweise durch den begrenzenden semipermeablen Amnionsack. Dass die Gefrierpunkterniedrigung der Allantoisflïssigkeit dennoch immer unter der des Blutes bleibt, ist zunächst dadurch erklärlich, dass die Harnblase, obgleich in Zwischenpausen, so doch regelmässig in den Allantoissack entleert wird, und dann auch - Jacqué hebt das nicht hervor - weil der osmotische Aus- 
gleich in einer Blase, wo die Flïssigkeit nicht activ bewegt wird, langsam vor sich geht (Bd. II, S. 237). Aber wie steht es nun mit der Amnionflüssigkeit?

Wenn man die Zusammensetzung der Amnionflïssigkeit untersucht, so stellt sich heraus, dass deren Salzgehalt insbesondere der $\mathrm{NaCl}-$ Gehalt grosse Aehnlichkeit mit dem des Blutserums besitzt Dies hatte bereits früher Dö derle in Veranlassung gegeben, die Amnionfliissigkeit als Transsudat zu betrachten. Diese Ansicht wird von Jacqué bekämpft. Zwar wird von ihm anerkannt, dass der $\mathrm{NaCl}$-Gehalt vom mütterlichen Blut stammt, aber dass es durch einen Filtrationsprocess nach der Art der Lymphe in die Amnionflüssigkeit, oder besser als Amnionflüssigkeit, übergeführt wird, kann J a c qué nicht zugeben. Denn handelte es sich um ein Transsudat, so würde die Gefrierpunkterniedrigung der Amnionflüssigkeit nicht hinter der des mütterlichen Blutes zurïckbleiben, was thatsächlich stets der Fall ist. Jacqué stellt sich vor, dass an der Stelle, an welcher das Amnion die miitterliche Placenta begrenzt, $\mathrm{NaCl}$ durch Diffusion aus den mütterlichen Blutgefässen in die Amnionflïssigkeit eintritt. Dass trotzdem die Gefrierpunkterniedrigung der Amnionflüssigkeit kleiner bleibt als die des mütterlichen Blutes, rührt vom fötalen Harn her.

Jacqué entwirft folgendes Bild: In der ersten Schwangerschaftperiode, d. l. etwa von Anfang der Schwangerschaft bis zu der Zeit, in welcher der Fötus eine Länge von $20 \mathrm{~cm}$ erreicht hat, ergiesst sich der fötale Harn mittelst des Urachus in den Allantoissack. Die Gefrierpunktbestimmung lehrt aber, wie gesagt, dass die AllantoisHlüssigkeit viel concentrirter ist, als der fötale Harn. Sie muss deshalb Wasser verlieren, und dieser Wasserverlust geschieht nun theilweise durch die in der Wand verlaufenden Blutgefässe, grösstentheils aber durch die Fläche, in welcher Amnion uud Allantois einander berïhren. Auf diese Weise bleibt dann die Amnionflüssigkeit hypisotonisch, wälıend sie sonst unter dem Einfluss des Blutes der mütterlichen Placenta mit diesem isotonisch werden würde.

In der zweiten Schwangerschaftsperiode (der Zeit, während welcher die Länge des Schafembryos von 20 bis auf 30 Centimetern :ınwächst) ist die Hypisotonie der Amnionfliissigkeit noch dadurch gesichert, dass sich nunmehr fötaler Harn direct mittelst des Ureters in den Amnionsack ergiesst.

In der dritten und letzten schwangerschaftsperiode (von der Zeit, in welcher die Länge des Fötus 30 Centimeter betrïgt 
bis zum Ende), ist der Urachus undurchlässig geworden und der fötale Harn entleert sich lediglich in den Amnionsack.

Diese Vorstellung lässt es unter anderem begreiflich erscheinen, dass in der ersten Schwangerschaftsperiode die Allantoisflüssigkeit eine viel geringere Gefrierpunkterniedrigung als die Amnionflüssigkeit besitzt; ferner, dass beide in der zweiten Periode ungefähr gleich sind und dass in der dritten Periode die Amnionflüssigkeit einen kleineren Werth für $\Delta$ ausweist als die Allantoistlüssigkeit.

Von grosser Wichtigkeit sind die Beobachtungen ron Jacqué über die schnelle Veränderung ron Gefrierpunkterniedrigung und chemische Zusammensetzung des Fruchtwassers nach dem Tode. So nahm Jacqué wahr, dass bereits 2 Stunden nach dem Tode bei der Allantoisfliissigkeit $\Delta$ von $-0.555^{0}$ auf $-0,569^{\circ}$ zunahm; fünfzehn Stunden nach dem Tod wurde eine Zunahme um 0,066 bis $0,099^{\circ}$ beohachtet.

Die Amnionflüssigkeit zeigte Veränderungen in derselben Richtung, aber in geringerem Maasse.

Unerwartet schnell änderte sich der Salzgehalt. So fand Jacqué den NaCl-Gehalt von Allantoisflüssigkeit, der anfänglich 0,008\% betrug, 2 Stunden nach dem Tode auf das Doppelte und 15 Stunden nach dem Tode auf das Zelmfache angewachsen. In einem anderen Fall aber, wo der $\mathrm{NaCl}-G e h a l t$ der Allantoisflüssigkeit unmittelbar nach dem Tode ein hoher war, nämlich $0,36 \%$, änderte sich derselbe wenig. Grosse Veränderungen mit der Zeitdauer wurden auch im Werthe des Quotienten $\frac{\mathrm{NaCl}}{\text { lösliche Salze }}$ beobachtet.

Jacqué schliesst hieraus, dass jede Analyse, welche nicht mit dem frischen Fruchtwasser unternommen wurde, falsch ist. Sie ist um so unzuverlässiger, je längere Zeit seit dem Tode verstrichen war.

Es fragt sich nun, was ist die Ursache dieser Erscheinungen? In seinen Versuchen war der Embryo mit den Fruchtwassersäcken im schwangeren Uterus sich selbst überlassen. Es konnte also durch Verdampfung durch die Uteruswand in indirecter Weise Wasserverlust aus den Fruchtsäcken erfolgen. In der That stellte sich heraus, dass die Zunahme des Salzgehalts nicht so stark ausgesprochen war, wenn man den Uterus in einen feuchten Raum brachte, aber es zeigte sich doch, dass die Hauptursache eine andere sein musste.

Jacqué meint, dass die Eihäute nach dem Tode für Salze permeabel werden, und diese aus der Wand des Uterus aufnehmen. 
Dass die Eihänte während des Lebens nicht für Salz durchlässig sind, geht и. A. aus dem erheblichen Unterschied in der chemischen Zusammensetzung der Amnion- und der Allantoisflüssigkeit hervor. Nach dem Tode werden sie permeabel. Nach dieser Vorstellung ist es auch weiter verständlich, warum die Allantoisflüssigkeit eine grössere Zunahme der Gefrierpunkterniedrigung und des Salzgehaltes in derselben Zeit zeigt als die Amnionflüssigkeit. Jacqué erinnert nämlich daran, dass der Allantois gerade auf demjenigen Theil des Chorions liegt, der die grössten Cotyledonen besitzt, so dass die Gelegenheit zum Austausch da am grössten ist.

Eine Bedeutung der Amnionflüssigkeit für die Ernährung, meint Jacqué auf Grund des geringen Eiweissgehaltes in Abrede stellen zu müssen. Der Eiweissgehalt beträgt nur 0,023 bis $0,058 \%$ (in einem Fall $0,16 \%$ ).

Sogar die Allantoisflüssigkeit, die doch wohl von Niemandem für eine Nahrungsflüssigkeit gehalten wird, enthält mehr Eiweiss. Wenn der Fötus eine Länge von $32 \mathrm{~cm}$ besitzt, beträgt der Eiweissgehalt $2,84 \%$; dieser Gehalt nimmt ab und bleibt dann auf $0,5 \% \%$ stehen, was immer noch relativ viel mehr ist als das in der Amnionflüssigkeit gefundene. Dass indessen Amnionflüssigkeit in der letzten Schwangerschaftsperiode per os aufgenommen wird, will Jacqué nicht in Abrede stellen.

Er findet, dass die Flïssigkeit im Magen eine Concentrationssteigerung erfährt, was aus folgender Tabelle hervorgeht.

Verhalten der Amnionfliissigkeit im fötalen Magen.

\begin{tabular}{c|c|c|c}
\hline $\begin{array}{c}\text { Nummer } \\
\text { des } \\
\text { Versuches }\end{array}$ & $\begin{array}{c}\text { Länge des } \\
\text { Fötus in } \\
\text { Centimetern }\end{array}$ & Mageninhalt & Amnionflüssigkeit \\
\hline \hline 1 & 36 & $-0,557^{\circ}$ & $-0,520^{\circ}$ \\
2 & 38 & $-0,570$ & $-0,531$ \\
3 & 38 & $-0,541$ & $-0,497$ \\
4 & 41 & $-0,519$ & $-0,513$ \\
5 & 44 & $-0,533$ & $-0,493$ \\
6 & 46 & $-0,502$ & $-0,463$ \\
7 & 49 & $-0,515$ & $-0,482$ \\
& & &
\end{tabular}

Wenn man diese Zahlen graphisch in Form einer Curve aufträgt, sieht man die Gefrierpunkterniedrigung des Mageninhaltes derjenigen der Amnionflüssigkeit genau folgen. 


\section{ß) Kuh und Schwein.}

Der Autor stellte auch Untersuchungen über die Gefrierpunkterniedrigung von Allantois- und Amnionflüssigkeit des Rindes an. Wio aus der folgenden Tabelle hervorgeht, gehen die Depressionen nicht durch die ganze Schwangerschaft parallel. Anfänglich ist $\rfloor$ der Amnionflüssigkeit bedentend grösser; am Ende der Schwangerschaft sind die Werthe für beide Fliissigkeiten gleich. Eine Umkehrung des Verhältnisses, wie sie beim Schaf beobachtet wird, tritt hier nicht ein, d. h. $\Delta$ der Amnionflüssigkeit wird am Ende nicht kleiner als $\Delta$ der Allantoisflüssigkeit. Das hängt damit zusammen, dass bekanntlich beim Rinde der Urachus bis zum Ende der Schwangerschaft offen bleibt, wodurch also die Allantoisblase noch bis ans Ende fötalen Harn bekommt. Dieses Verhältniss scheint in der That als Stütze für $J$ ac qué's Anschauung aufgefasst werden zu können.

Gefrierpunkterniedrigung von Ammion- nnd Allautoisfliissigkeit bei der Kuh.

\begin{tabular}{cc|cc|c}
\hline $\begin{array}{c}\text { Versuchs. } \\
\text { nummer }\end{array}$ & $\begin{array}{c}\text { Länge } \\
\text { des } \\
\text { Fötus } \\
\text { in cm }\end{array}$ & $\begin{array}{c}\text { Amnion- } \\
\text { flüssigkeit }\end{array}$ & $\begin{array}{c}\text { Allantois- } \\
\text { flüssigkeit }\end{array}$ & Bemerkungen \\
\hline & 13 & $-0,544^{\circ}$ & $-0.456^{\circ}$ & - \\
\hline 1 & 17 & 0,551 & 0,428 & - \\
2 & 18 & 0,564 & 0,494 & - \\
3 & 29 & 0.557 & 0,484 & - \\
4 & 32 & 0,534 & 0,456 & Bedeutende Hydramnion \\
5 & 38 & 0,542 & 0,524 & - \\
6 & 43 & 0,523 & 0,491 & - \\
7 & 45 & 0,543 & 0,504 & - \\
8 & 46 & 0,514 & 0,490 & - \\
9 & 46 & 0,528 & 0,483 & - \\
10 & 48 & 0,534 & 0,521 & - \\
11 & 56 & 0,530 & 0,538 & - \\
13 & 60 & 0,522 & 0,531 & - \\
14 & 60 & 0,539 & 0,522 & - \\
15 & 80 & 0,525 & 0,525 & - \\
& & & & -
\end{tabular}

Jacqué hat das Blut der entsprechenden Thiere nicht untersucht, meint aber doch, dass die Gefrierpunkterniedrigung der Amnionflüssigkeit kleiner ist, als die des mütterlichen Blutes. Denn Nolf fand für das Blut der Kuh $J=-0,578^{\circ}$ (Kuchenserum) und $-0,566^{\circ}$ (defibrinirtes Blut). Die von Bugarszky und Tangl gefundene Zahl $\Delta=-0,611^{\circ}$ erscheint Jacqué zu hoch.

Die Thatsache, dass das Blut nicht von schwangeren Kühen stammte und die Gefrierpunkterniedrigung nicht von derselben Person mit demselben Apparat ermittelt wurde, wie die des Fruchtwassers, vermindert hier die Sicherheit von Jacqué's Schlussfolgerungen. Dennoch muss wohl zugegeben werden, dass $\lrcorner$ für die Amnionflüssigkeit geringer ist, als für Rinderblut im Allgemeinen gefunden wird. 
Grösser noch als bei der Kuh, ist der Unterschied zwischen Amnion- und Allantoisflüssigkeit beim Schwein.

Gefrierpunkterniedrignng der Amnion- und Allantoisfliissigkeit beim Schwein.

\begin{tabular}{c|c|c|c}
\hline \hline $\begin{array}{c}\text { Versuchs- } \\
\text { nummer }\end{array}$ & $\begin{array}{c}\text { Länge des } \\
\text { Fötus in } \\
\text { Centimetern }\end{array}$ & $\begin{array}{c}\text { Amnion- } \\
\text { flüssigkeit }\end{array}$ & $\begin{array}{c}\text { Allantois. } \\
\text { flüssigkeit }\end{array}$ \\
\hline \hline & 13 & $-0,522^{\circ}$ & $-0,365^{\circ}$ \\
2 & 16 & 0,511 & 0,391 \\
3 & 15 & 0,522 & 0,270 \\
4 & 16 & 0,537 & 0,313 \\
5 & 14 & 0,521 & 0,429 \\
& 23 & 0,535 & 0,434
\end{tabular}

\section{i) Mensch.}

Werthe.

Die folgende Tabelle enthält die beim Menschen gefundenen

Gefrierpunkterniedrigung ron Amnionfliissigkeit. miitterlichem und fötalem Blnte.

\begin{tabular}{|c|c|c|c|c|c|}
\hline \multirow{2}{*}{$\begin{array}{l}\text { Versucbs- } \\
\text { nummer }\end{array}$} & \multicolumn{3}{|c|}{\rfloor} & \multirow{2}{*}{$\begin{array}{c}\text { Zeit der } \\
\text { Schwanger- } \\
\text { schaft }\end{array}$} & \multirow[b]{2}{*}{ Bemerkungen } \\
\hline & $\begin{array}{l}\text { Amnion- } \\
\text { flüssigkeit }\end{array}$ & $\begin{array}{l}\text { Mütterliches } \\
\text { Blut }\end{array}$ & $\begin{array}{c}\text { Fötales } \\
\text { Blut }\end{array}$ & & \\
\hline 1 & $-0,520^{\circ}$ & - & $-0,531^{\circ}$ & 6 Monate & \\
\hline 2 & 0,508 & - & 0,536 & $8 \quad$, & Acute Hydramnion \\
\hline 3 & 0,471 & 0,520 & 0,535 & $8^{1 / 2}$ Monate & \\
\hline 4 & 0,499 & - & - & Schluss & Leichte Hydramnion \\
\hline 5 & 0,468 & - & $(0,632)$ & $n$ & \\
\hline 6 & - & 0,524 & 0,532 & $n$ & \\
\hline 7 & 0,477 & - & 0,548 & $n$ & \\
\hline 8 & 0,468 & - & - & $n$ & MässigeHydramnion \\
\hline 9 & 0,448 & - & - & $n$ & \\
\hline 10 & 0,481 & - & 0,542 & , & Leichte Hydramnion \\
\hline 11 & - & 0,530 & 0,530 & , & \\
\hline 12 & - & 0,553 & 0,553 & , & \\
\hline 13 & 0,485 & 0,530 & 0,581 & , & MässigeHydramnion \\
\hline 14 & - & 0,555 & 0,554 & r & \\
\hline 15 & - & 0,545 & 0,546 & 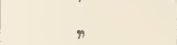 & \\
\hline 16 & 0,470 & 0,520 & 0,518 & , & \\
\hline 17 & - & 0,521 & 0,526 & $\pi$ & \\
\hline $\begin{array}{l}\text { Mittel- } \\
\text { werth }\end{array}$ & $-0,+75^{0}$ & $-0,53: 3^{\circ}$ & $-0.5835^{\circ}$ & & \\
\hline
\end{tabular}


Jacqué theilt mit, dass das fötale Blut aus dem Placentar-Ende des Nabelstranges stammte und das mütterliche Blut aus retroplacentarem Hämaton.

Aus der'Tabelle geht zunächst hervor, dass das mütterliche und fötale Blut keine nennenswerthe Differenz in der Gefrierpunkterniedrigung zeigen. Das stimmt mit dem Ergebniss ron Krönig und Fueth überein. Auffallend ist, wie Jacqué bemerkt, dass das mütterliche Blut der Gebärenden, sowohl bei ihm selbst, wie bei Krönig und Fueth eine so geringe Gefrierpunkterniedrigung hat (resp. $-0,533^{\circ}$ und $-0,520^{\circ}$ ) gegenüber dem Werth, den man bei normalen Menschen beobachtet $\left(-0.56^{\circ}\right)$. Gleichartiges wurde a uch beim Schaf und Rind gefunden.

Auch ist nach Untersuchungen. die Farkas und Scipiades [23] in Tangl's Laboratorium beim Menschen ausführten, die Depression des Blutserums während der Schwangerschaft geringer als unter normalen Umständen, um nach der Geburt im Wochenbette wieder die normale durchschnittliche Grösse zu erreichen, dieselbe sogar zu übersteigen.

Nach Farkas und Scipiades wird die Depressionsabnahme gegen Ende der Schwangerschaft durch Nicht-Elektrolyte herbeigeführt, denn die corrigirte elektrische Leitfähigkeit (Bd. I, S. 490) erleidet keine Veränderung, bleibt constant. Ton diesen Nicht-Elektrolyten ist aber das Eiweiss an der Abnahme nicht betheiligt; denn auch von dieser substanz bleibt die Concentration unverändert. Um welche NichtElektrolyte es hier dann wohl handelt, ist noch eine offene Frage.

Was mit den Ergebnissen von $V$ e it hingegen wohl übereinstimmt, ist die geringe Gefrierpunkterniedrigung der Allantoisflüssigkeit. In gleichen Sinne sprechen auch die Versuche von Farkas und Scipiades, die für das menschliche Fruchtwasser $\Delta=-0,475^{\circ}$ fanden. Die Autoren schliessen hieraus, dass das Fruchtwasser wenigstens am Ende der Schwangerschaft kein einfaches Transsudat sein kann.

Beiläufig erwähne ich noch, dass sie für die $\mathrm{OH}^{\prime}$-Ionen-Concentration $0,9 \times 10^{-7}$ fanden, einen Werth, der mit dem des Blutserums übereinstimmte. Beide Flüssigkeiten sind also im elektrochemischen Sinne neutral. (Vergl. Bd. II, S. 386 u. 486.)

Un die beim Schaf gewonnenen Resultate ganz mit den beim Menschen erzielten vergleichen zu können, hat Ja cqué berechnet, wie gross beim Schaf die Gefrierpunkterniedrigung des Gesammtfruchtwassers sein würde, die nach Mischung von Allantois- und Amnionflüssigkeit entstände. Hierfür mussten in den entsprechenden Schwangerschaftperioden nicht nu die Depressionen, sondern auch die Mengen- 
verhältnisse beider Flüssigkeiten berücksichtigt werden. So berechnete er für einen Fötus von $4,5 \mathrm{~cm}$, der $26 \mathrm{cc}$ Amnionflüssigkeit von $\Delta=-0,569^{\circ}$ und 45 cc Allantoisflüssigkeit von $\Delta=0,550^{\circ}$ enthielt, die Gefrierpunkterniedrigung der Mischflüssigkeit zu $-0,562^{\circ}$ und für einen Fötus von $14 \mathrm{~cm}-0,560^{\circ}$, von $32 \mathrm{~cm}-0,534^{\circ}$ und von 46 und $49 \mathrm{~cm}-0,507^{\circ}$ bezw. $-0,508^{\circ}$. Es ergiebt sich also eine Abnahme der Gefrierpunkterniedrigung der Mischflüssigkeit. Auch beim Fruchtwasser des Menschen, das als ein natüriches Gemisch betrachtet werden kann, nimmt man, wie aus der Tabelie ersichtlich, solch eine Abnahme wahr.

Jacqué hält also die Ausführungen über das Entstehen der Amnionflüssigkeit des Schafes, auch für den Menschen für gültig.

\section{d) Zusammenfassung und Schlussbetrachtung.}

Wenn es dem Leser so ergeht wie mir, so wird er, am Ende des Abschnittes ,intrauterine Verhältnisse" angelangt, wenig befriedigt sein; er wird sich fragen, was haben uns nun all diese Untersuchungen uiber die Lebensverhältnisse der Frucht gelehrt? Haben sie uns einen Einblick in den Mechanismus des Stoffaustausches zwischen Mutter und Frucht gewährt, oder die Lebensverhältnisse der Frucht im Wesentlichen aufgeklärt. Kann ich diese Frage auch nicht bejahen, so meine ich doch, dass diese Untersuchungen keineswegs nutzlos gewesen sind.

Es sind durch sie einige werthrolle neue Thatsachen festgestellt, andere sind wahrscheinlich gemacht worden und zwar an der Hand nener Untersuchungsmethoden, die bei weiterer Anwendung einen fruchtbaren Erfolg versprechen. Ich zähle zunächst die Thatsachen a uf, die als feststehend angesehen werden dürfen.

1. Das Blut des Nengeborenen enthält ein erheblich grösseres Volumen Blutkörperchen als das mütterliche Blut. Dies geht sowohl aus Centrifugirbestimmungen wie aus der Ermittelung der Leitfähigkeit hervor (S. 196 u. 198).

Blutkörperchenzählungen lehren, dass der betreffende Unterschied wenigstens theilweise in der Anzahl zu suchen ist (S. 204).

2. Die Gesammtmenge an festen Bestandtheilen ist beim fötalen Blut geringer als beim mütterlichen. Das wird nach dem sub 1 Gesagten befremden, weil doch im ersteren viel mehr Blutkörperchen enthalten sind. Die Versuche lehren, dass es daher rührt, dass das Serum der Neugeborenen erheblich wasserreicher ist (S. 199).

3. Die elektrische Leitfähigkeit des Jugularis-Serums rom Neugeborenen ist grösser als die des mütterlichen Jugularis-Seruims. In einigen Versuchen kann dies eben dadurch erklärt werden, dass letz- 
teres mehx Eiweiss enthält, das bekanntlich die Leitfähigkeit beeinträchtigt. In anderen Versuchen ist diese Beinträchtigung grösser als der wirkliche Leitfähigkeitsunterschied beträgt. In diesen Tersuchen ist demnach die Concentration der Elektrolyte im fötalen JugularisSerum grösser als im mütterlichen (S. 205).

4. Im Blut der Neugeborenen kommt noch eine grosse Zahl Blutkörperchen vor, die mehr stroma-eiweissartige Substanzen enthalten als die Blutkörperchen des mütterlichen Blutes. Diese stroma-eiweissreichen Blutkörperchen ermöglichen dem fötalen Blut, schwächere Salzlösungen als das mütterliche zu ertragen, ohne vollständig zerstört zu werden (S. 203).

Weiter verdienen folgende Punkte hervorgehoben zu we rden.

5. Beim Menschen scheint das kindliche Blut (das dem Kinde durch die V. umbilicalis zuströnt) keinen nennenswerth höheren osmotischen Druck zu besitzen als das mütterliche (das der Placenta durch die A. uterina zuströmt) (Krönig und Fueth und auch Jacqué gegenüber $\mathrm{V}$ eit).

Dagegen ist das nach Jacqué beim Schafwohl der Fall. Es ist aber schwierig dieses Resultat zu beurtheilen, da der Verfasser nicht mittleilt, welches Blut vom Mutterthier und welches vom Fötus er mit einander verglichen hat. Ausserdem kann seine Methode, das Blut vor der Gefrierpunktbestimmung künstlich arteriell zu machen, um den Eintluss der Kohlensäure auf die Depression zu eliminiren, nicht als einwandfrei angesehen werden, da durch die betreffende Behandlung osmotischer Austausch zwischen Blutkörperchen und Serum stattfindet, der bei den beiden zu vergleichenden Blutsorten nicht gleichartig sein dürfte.

Tehmen wir aber vorläufig an, dass beim Schaf sowohl das arterielle wie das venöse im Fötus kreisende Blut eine höhere Gefrierpunkterniedrigung besitzt als das entsprechende arterielle oder venöse Blut der Mutter, so erhebt sich die Frage nach der Deutung dieser Erscheinung. Nach Jacqué besteht im Schaffötus ein sehr reger Stoffwechsel, viel reger als im Menschenfötus. Dadurch wird eine grössere Molecülzahl im Blutserum zurïckbleiben, und die fötalen Nieren sind auf diese höhere Molecülzahl eingestellt.

6 Weiter ergiebt sich aus den Untersuchungen ron Veit und Jacqué - was sie selbst nicht hervorheben - dass, abgesehen von 
etwaigen Differenzen, das fötale Blntserum den Schwankungen im osmotischen Druck des mütterlichen Blutserums ziemlich regelmässig folgt. (S. 184 u. 216.) verzeichnen.

Was das Fruchtwasser betrifft, so wären folgende Ergebnisse zu

7. Beim Menschen ist die Gefrierpunkterniedrigung der Amnionflïssigkeit immer kleiner als die des Blutserums (Teit, Jacqué).

8. Beim Rind und Schaf ist dasselbe der Fall und zwar sowohl für die Allantoisflüssigkeit, wie für die Amnionflüssigkeit.

9. Indessen gehen die Gefrierpunktcurven der beiden Fliissigkeiten während der Schwangerschaft nicht parallel. Bei der Allantoisflüssigkeit ist die Depression erst gering und steigt später, bei der Amnionfliissigkeit ist das Entgegengesetzte der Fall.

Jacqué hat hierfür die folgende plausible Erklärung gegeben: Man kann beim Schaf die Schwangerschaft in drei Perioden eintheilen: In der ersten erhält die Allantoisblase mittelst des Urachus fötalen Harn, der einen sehr geringen Werth für $/$ besitzt. Dadurch ist die Gefrierpunkterniedrigung der Allantoisflüssigkeit auch klein, aber doch keineswegs so gering, wie die des fötalen Harns selbst. Es muss also eine Einengung stattfinden und diese erfolgt seitens der Amnionflüssigkeit, deren Salzgehalt in dieser Zeit in Folge Diffusion aus der miitterlichen Placenta hoch ist. Durch diese Diffusion würde die Amnionflüssigkeit denn auch zu dieser Zeit den osmotischen Druck des mütterlichen Blutserums besitzen, wenn sie nicht durch Wasserentziehung aus der Allantoisfliissigkeit fortwährend eine Verdünnung erfuihre. Dadurch bleibt sie hypisotonisch.

In der $\mathrm{z}$ we iten Periode der Schwangerschaft (die Zeit, in welcher der Fötus von 20 auf $30 \mathrm{~cm}$ Länge anwächst) bekommt die Amnionflüssigkeit auch direct fötalen Harn und zwar durch den Ureter. In dieser Periode beherrscht also der sehr dünne fötale Harn in beiden Fruchtblasen den osmotischen Druck und die Gefrierpunkterniedrigungen sind in Allantois- und Amnionflüssigkeit nahezu gleich.

In der dritten Schwangerschaftsperiode ist der Urachus undurchlässig geworden und es ist nummehr lediglich die Amnionblase, die in directer Weise fötalen Harn empfängt. Jetzt herrscht hier der kleinste osmotische Druck.

10. Dass die Allantoisflüssigkeit ein fötaler Harn ist, wurde durch die Untersuchung der Allantoisflüssigkeit mittelst der Blutkörperchenmethode in hohem Maasse wahrscheinlich gemacht. 
11. Dass auch die Amnionflüssigkeit ein fötaler Harn ist, hat Jacqué durch seine Ausführungen sehr wahrscheinlich gemacht. Den stricten Beweis hat er aber meines Erachtens noch nicht erbracht. Ausserdem scheint mir eine grosse Schwierigkeit gegen Jacqués Annahme in der Thatsache zu liegen, dass die Combination von Gefrierpunkt- und Blutkörperchenmethode (S. 208), die bei der Allantoisflüssigkeit keinen Zweifel darüber lässt, dass diese Flüssigkeit Stoffe enthält, für die die Erythrocyten permeabel sind (Harnstoff), bei der Amnionflüssigkeit ein derartiges Resultat nicht giebt. Man würde doch auch hier in der dritten Schwangerschaftsperiode relativ viel Harnstoff erwarten. Vielleicht geht der Harnstoff aber rasch in die mütterliche Placenta durch die Wand über, die auch $\mathrm{NaCl}$ und Alkali in die Amnionflüssigkeit eintreten liess! (S. 208.)

Bei diesen Anschauungen bleibt die Entstehung der ersten Allantois- und Amnionflüssigkeit unsicher.

Das Vorangehende giīt für physiologische Verhältnisse; die für pathologische Fälle gefundenen Zahlen kann man vorläufig noch gar nicht verwerthen. Sie müssen als werthvolles Naterial für später zurückgestellt werden. So z. B. die Zahlen von Pozzi [28] über die Isotonie des Bhutes von Frauen, deren Schwanger. schaft mit Krankheiten complicirt ist. In allen von ihm untersuchten Fällen war die "Isotonie", die der Verfasser nach der Methode von Mosso (Bd. I, S. 363) bestimmte und die in normalen Fällen $0,46-0,48^{\circ}{ }_{0} \mathrm{NaCl}$ war, herabgesetzt, durch Eklampsie auf $0,50 \%$ bis $0,62 \%$, durch Tuberculosa pulmonalis zu $0,58 \%$ bis $0,62 \%$ durch Anaemia perniciosa auf 0,80 . Vergleiche übrigens in der Tabelle über die Resistenz Vicarelli und Andere (Bd. 1, S. 364).

Die höhere Gefrierpunkterniedrigung $0,61^{\circ}, 0,60$ und 0,62 , die Bousquet [25] bei Eklampsie fand, scheint für ein Missverhältniss von Bildung und Abfuhr von Molecülen, für Retention (Druck auf die Ureteren?) zu sprechen.

Die Auffassung der beim Rind vielfach vorkommenden Hydrallantois als Transsudat scheint mir mit der von mir selbst gefundenen geringen Gefrierpunkterniedrigung von $-0,497^{\circ}$ schwer zu vereinigen. 


\section{Siebentes Kapitel.}

\section{Pharmakologisches.}

Wenn in irgend einem Zweig der medicinischen Wissenschaften, die physikalische Chemie berufen ist, Vieles zu erklären, was jetzt noch unverständlich ist und in verschiedenen Richtungen neue Thatsachen zu Tage zu fördern und Ausblicke zu eröftinen, so ist das auf dem Gebiet der Pharmakologie.

Die Aufgabe, dem Leser diese Ueberzeugung zu vermitteln, scheint mir nicht schwer, zumal bei frühern Gelegenheiten bereits Gegenstände erörtert wurden, die für den Pharmakologen und wissenschaftlichen Kliniker nicht weniger als für den Physiologen von Interesse sein dürften. Ich erinnere an die Ausführungen über die Resorption, z. B. über den Mechanismus der purgativen Mittelsalze und über die Aufnahme von Arzneistoffen: ich denke an die Ausführungen über den Wirkungsmodus der Diuretica u. s. w. Eigentlich dürfte kaum ein Gegenstand aus der Physiologie zu nennen sein, mit dem die Pharmakologie keine Rechnung zu halten hat. Das liegt auch auf der Hand, denn alle experimentellpharmakologischen Wirkungen sind schliesslich auf eine willkïrliche Störung des physiologischen Gleichgewichts oder auf eine Wiederherstellung desselben zurückzuführen.

Indessen giebt es Fragen, die mehr speciell dem Arbeitsgebiet des Pharmakologen und Klinikers angehören, und für den Physiologen ein entfernteres und indirectes Interesse haben. Ton einigen derselben wird hier die Rede sein. Dabei werde ich mich bestreben, diejenigen auszuwählen, die als Beispiel für die Behandlung verschiedener verwandter Themata dienen können.

Was die physikalische Chemie der Antiseptica betrifft, so liesse sich diese sowohl unter "Pharmakologisches" wie unter „Bakteriologisches" einreihen; ich bespreche sie in diesem Kapitel. 
Ueber das Argentum colloidale ist im Kapitel II (Bemerkungen über Colloide) auf Seite 81 die Rede gewesen.

Soweit mir bekannt, ist das erste Thema, mit dem die neuere physikalische Chemie auf pharmakologischem Gebiete sich beschäftigt hat, der Vergleiclı der diuretischen Wirkung verschiedener Salze gewesen. v. Limbeck zeigte, dass die durch verschiedene intravenös injicirten Salze herbeigeführte diuretische Wirkung im grossen Ganzen gleich war, wenn diese Salze in unter einander isotonischer (isosmo. tischer) Concentration angewandt wurden. (Arch. f. exp. Patl. u. Pharmak. 25, 1889, S. 69). Später hat dann auch Dreser (Arch. f. exp. Path. und Pharmak. 29, 1891, S. 303) den Mechanismus der Diurese ebenfalls mit physikalisch-chemischen Hilfsmitteln zu erforschen gesucht. Während v. Limbeck aber für die Bestimmung der wasseranziehenden Kraft, die Blutkörperchenmethode benutzte, verwendete Dreser die Gefrierpunkterniedrigungsmethode. Ich gehe hier auf die Diurese nicht weiter ein, da ich sie bereits bei Besprechung der Nierenthätigkeit ausführlich behandelte (vergl. Bd. II, S. 399); die vorstehende Bemerkung war lediglich eine historische Notiz.

Ich bespreche zuerst einige Untersuchungen allgemeiner Natur.

\section{Untersuchungen an Pflanzenzellen zu Erforschung der Ein- dringungsfähigkeit von Substanzen in das Protoplasma und zur Ermittelung von deren Giftigkeit.}

\section{Litteratur.}

1. Orerton, Zeitschr. f. physik. Chemie. 12. 1897. S. 189.

2. A. J. J. Vanderelde, Handelingen van het $3 e$ Vlaamsch Natuur- en Geneesk. Congres Antwerpen 24. Sept. 1899.

3. A. J. J. Vanderelile, Handelingen van het 4 e Vlaamsch Natuur- en Geneesk. Congres Brussel 30. Sept. 1900.

4. A. J. J. Vaudevelde, Handelingen van het 5e Vlaamsch Natuur-en Geneesk. Congres Brugge 29. Sept. 1901.

Wenn man einen Rückblick auf die Entwickelung der Toxikologie und Pharmakologie während der letzten 60 Jahre wirft, so sind zwei Forschungsergebnisse allgemeiner Natur besonders augenfällig. Das Erste besagt, dass die Wirkungen der salzartigen Verbindungen rein additiver Natur sind, d. h. aus zwei Componenten sich zusammensetzen, und zwar aus der specifischen Wirkung der Basis und der Säure, wobei es sich allerdings häufig ereignet, dass die Wirkung der einen Componente so sehr überwiegt, dass diejenige der andern daneben praktisch nicht in Betracht kommt. So ist es gleichgültig, ob man Chinin als Sulfat, Chlorid oder als Nitrat nimmt. So erscheint es weiter gleichgültig, ob man Cyanide als Kalium, Natrium oder $\mathrm{NH}_{4}$-Cyanid 
gebraucht, in allen Fällen tritt die Cyanwirkung hervor. Bei Anwendung des Chininsalicylats jedoch kommen die Wirkungen von Chinin und Salicylsäure beide zur Aeusserung.

Wenn in den verschiedenen Pharmakopoen dennoch häufig mehrere Salze einer und derselben wirksamen Base oder Säure aufgenommen sind, so beruht das gewöhnlich auf accessorischen Erwägungen. So ist es z. B. erwünscht, dass für intravenöse Injectionen die Lösungen neutral reagiren, während bei Einführung in den Verdauungscanal die Reaction irrelevant ist. So müssen weiter die Substanzen für die intravenöse Einspritzung leicht löslich sein, was wiederum für die Einverleibung per os gewöhnlich nicht ron so hervorragendem Interesse ist. Zuweilen wünscht man eine nur allmähliche Resorption des Medicamentes aus dem subcutanen Bindegerrebe. In diesem Falle ist die Anwendung eines schwerlöslichen Salzes am Platze.

Dass es nun wirklich gleiclgültig ist, ob man eine Base, deren Wirkung man zu Stande kommen zu lassen wünscht, in Foru eines wasserlöslichen Sulfats, Nitrats oder Chlorids u. s. f. anwendet, ist durch die Ionenlehre vollkommen begreiflich geworden. Denn die dem Salze zu Grunde liegende Base ist, in Folge der beträchtlichen Verdïnnung. in der das Salz sich wohl immer im Körper befindet, als freies Kation zugegen, was auch mit der Säure der Fall ist. Hieraus geht dann zugleich hervor, dass beide ihre specifische Wirkung ausüben könıen.

Das zweite allgemeine Versuchsergebniss betrifft die Wirkung eines Giftes oder Arzneimittels auf bestimmte Gewebselemente unter Ausschluss aller übrigen. Curare stört die peripheren Endigungen der motorischen Nerven in den quergestreiften Muskelfasern, Strychnin wirkt vorzugsweise in bestimmten Theilen des Riïckenmarks, $\mathrm{CO}$ auf die rothen Bluthörperchen.

Es ist nun die Frage, wie hat man sich die Verschiedenheit zu erklären!' Das von mir auf die Tagesordnnng gebrachte Permeabilitütsproblem (vergl. Bd. 1, S. 203) liess bald einen erfolgreichen Angriff möglich erscheinen. Durch Heranziehung dieses Problems liess sich nämlich die Frage derart präcisiren, dass nunmehr eine Beantwortung auf experimentellem Wege ausführbar wurde. Es eröffneten sich zwei Möglichkeiten. Entweder besitzen alle Zellenarten den verschiedenartigsten Merlicamenten gegenüber dieselhen Permeabilitätsverhältnisse, aber je nach der speciellen (chemischen) Natur der einzelnen Zellenarten einerseits, des Medicamentes resp. (riftes andererseits, findet eine Ver- 
änderung in der Zelle, somit in ihrer Lebensïusserung statt. Oder die Wahlwirkung eines bestimmten Arzneistofles fuir bestimmte Zellengattungen kamn auch noch darin begründet sein, dass die Permeabilität einer und derselben Zelle für verschiedene Stoffe sehr ungleich ist. Fiir die rothen Blutkörperchen wurde ausführlich gezeigt, dass letzteres wirklich der Fall ist. Für weisse Blutkörperchen und für verschiedene andere thierische Zellenarten, auch selbst für PHanzenzellen hat sich dasselbe herausgestellt. Es wäre vielleicht genügend, im Allgemeinen auf das Kapitel über die Permeabilität (Bd. I, S. 702, Zusammenfassung S. 252) zu verweisen. Doch scheint es mir zweckmässig, hier auf die da bereits besprochenen, von $\mathrm{Overton}$ angestellten Untersuchungen etwas näher einzugehen, als dies im Kapitel über die Permeabilitit der Fall war.

Freilich beziehen sich diese Untersuchungen fast ausschliesslich auf Pflanzenzellen. Ist es nun im Allgemeinen auch nicht berechtigt, das, was für Pflanzenzellen gilt, ohne weiteres auf thierische Zellen zu übertragen, so hat sich doch gezeigt, dass im Grossen und Ganzen die Permeabilitätsverhältnisse der in dieser Beziehung untersuchten thierischen Zellen, mit denen vieler Arten Pflanzenzellen parallel laufen.

Nun bieten die Pflanzenzellen für die Untersuchung der Permeabilitätsverhältnisse des Protoplasma in mancher Hinsicht ein ausgezeichnetes Object und wir wissen, ron wie grossem Werth es für den Biologen ist, seine Untersuchungen an dem meist geeigneten Object zu beginnen. Denn ist er an der Hand leicht ausführbarer und ausfïhrlicher Untersuchungen zur endgïltigen Feststellung einer Thatsache oder Erlilärung: gelangt, so wird es ihm, da er jetzt die richtigen Versuchsbedingungen kennen gelernt hat, häufig möglich sein, die Thatsache oder Erklärung an einem schwieriger zu untersuchenden Object, das ihn am meisten interessirt, zu prüfen. Wie viel Nutzen hat z. B. die Erforschung des Insektenmuskels für die Kenntniss der Structur und Contraction des schwierig zu untersuchenden Säugethiermuskels gebracht!

Aber nicht nur in diesem Sinne. d. h. für die Auffindung ron Thatsachen und Erklärungen, sondern auch für die Beurtheilung der neueren Untersuchungsmethoden dürfte die Anwendung anscheinend ferner stehender Objecte von Nutzen sein. Ich glaube somit, dass die Besprechung der ron Overton an Pflanzenzellen ausgefïhrten Untersuchungen, die sich ausserdem hauptsächlich auf die für die Pharmakologie wichtigen Alkaloide beziehen, keine weitere Rechtfertigung braucht. 


\section{a) Eindringungsfähigkeit von Substanzen in das Protoplasma von Pflanzenzellen.}

Overton hat zwei Methoden in Anwendung gebracht. Die erste bezeichnet er mit ,os motometris che". Besser hätte er sie die plasmolytische genannt. Die zweite beruht auf der Thatsache, dass es Pflanzenzellen giebt, die Tannin enthalten. Alkaloide und viele andere Stoffe geben mit Tannin einen Niederschlag. Haben nun in der That solche Stoffe das Vermögen in die Zelle einzudringen, so wird ras Präcipitat in der Zelle sichtbar werden. Es kommen hierbei noch andere Erwägungen in Betracht, von denen an der geeigneten Stelle die Rede sein wird. Zunächst will ich die erste Methode und die mit ihrer Hülfe erzielten Resultate mittheilen.

\section{a) Osmotometrische (plasmolytische) Methode.}

Der Verfasser beschreibt diese Methode folgendermaassen:

,Gesetzt wir wollen ermitteln, ob ein gelöster Körper A auf diosmotischem Wege in eine beliebige PHanzenzelle oder vielmehr in deren Protoplast (wenn im Folgenden bloss von dem Eindringen in die Zelle die Rede ist, so ist stets darunter zu verstehen, dass die betreffende Verbindung auch durch das Protoplasma hindurch in den Zellsaft gelangt) eindringt oder nicht, so bringen wir die betreffende Zelle zunächst in die Lösung einer Verbindung B, deren Moleculargewicht wir kennen und von der wir wissen, dass sie weder durch den Protoplast eindringt, noch auf denselben schädlich wirkt. Fs ist zweckmässig hierzu einen Nichtleiter, etwa Rohrzucker zu wählen.

Wir bestimmen nun, bei welcher Concentration von $B$, eine eben merkliche Abhebung des Protoplasts ron irgend einer Stelle der Cellulosemembran bewirkt, d. h. eine beginnende Plasmolyse eingeleitet wird. Wir wollen diese Concentration die plasmolytische Grenzlösung (de Vries) von B nennen und mit Bg bezeichnen.

Wir wollen nun zunächst annehmen, dass die Verbindung A ebenfalls ein Nichtleiter ist, ferner, dass sie leicht löslich und noch bei relativ hoher Concentration für die Zelle unschädlich sei. Wir bereiten in diesem Falle eine Lösung vou A, deren Concentration Ag sich so verhält zu der Concentration Bg, wie das Moleculargewicht des Körpers A zu dem des Körpers B (Ag ist dann isotonisch mit Bg). Es muss dann, nach dem Gesetz des osmotischen Druckes, wenn der Körper A nicht in die Zelle dringt, aucl diese Lösung eine eben merkliche und dauernde P'lasmolyse der Zelle bewirken. Dringt der Körper A dagegen ein, so 
wird entweder gar keine Plasmolyse der Zelle oder nur eine vorübergehende eintreten. Es müssen in diesem Falle noch eine Reihe von Versuchen angeführt werden, um die Schnelligkeit des Eindringens zu bestimmen."

Ist die Verbindung A nur wenig löshich in Wasser, oder wirkt dieselbe schon bei relativ niedriger Concentration auf die Zelle schädlich ein, so machen wir von dem Gesetz Anwendung, dass, wenn zwei Verbindungen, welche nicht chemisch auf einander einwirken, in einer und derselben Lösung sich befinden, der osmotische Druck dieser gemischten Lösung gleich ist der Summe der osmotischen Drucke beider Körper zusammen genommen.

Wir lösen also eine kleine Menge des Körpers $A$, welche noch nicht schädlich wirkt, in der Lösung $\mathrm{Bg}$ auf und untersuchen darauf, ob die Plasmolyse zunimmt oder nicht, und, im ersten Fall, ob die Zunahme der Plasmolyse eine dauernde oder nur vorübergehende ist. Findet ïberhaupt keine Zunahme der Plasmolyse statt, so dringt die Terbindung allmählich in den Protoplast ein. Das Eindringen ist ein um so schnelleres, je rascher die Plasmolyse auf den ursprünglichen Grad zurïckkehrt. Stellt sich eine dauernde Zunahme der Plasmolyse ein, so dringt der Körper A nicht merklich in den Protoplast ein.

Um ferner, im Falle ein gelöster Körper in den Protoplast ïbergeht, völlig sicher zu sein, dass die Aufnahme durch einen rein osmotischen Vorgang bewirkt wird, muss gezeigt werden, dass der betreffende Körper ebenso leicht aus der Zelle exosmirt. wie derselbe eingedrungen ist, und dass die Aufnahme und Abgabe auch bei Sauerstoffmangel und während der Narkose ungefähr gleich schnell wie bei der lebensthätigen Zelle geschieht.

Eine sehr ausgedehnte Untersuchung nach dieser Methode zeigte zunächst, dass die verschiedensten Pflanzenzellen (mit möglicher Ausnahme der Pilze, welche sich zu genauen Untersuchungen wenig eignen) im Wesentlichen in ihren osmotischen Eigenschaften übereinstimmen und dass die Fähigkeit өiner gelösten Verbinduug, in den Protoplast einzudringen, von der chemischen Constitution derselben abhängt. So hat sich ergeben, dass bei organischen Verbindungen nur die Anwesenheit bestimmter Atomgruppen im Molecül für die Aufhebung, resp. Herabsetzung der Fähigkeit der betreffenden Verbindung, in den Protoplast einzudringen massgebend ist, währeıd andere Atumgıuppen keinen merklichen: Einfluss auf die Geschwindigkeit des Eindringens ausüben. Bei den O-haltigen organischen Verbindungen kommt vor allen Dingen die Bindungsweise des 0 in Betracht.

Nach der Grösse des verzögernden Einflusses, den sie ausüben, kann man für die wichtigsten der wirksamen Atomgruppen nachstehende Reihenfolge aufstellen:

1. Die Amidosäuregruppe.

2. Die Carboxylgruppe. 
3. Die Säureamidgruppe.

4. Die alkoholische Hydroxylgruppe.

5. Die Aldehydgruppe.

Sind in einer Verbindung mehrere verzögerende Atomgruppen vorhanden, so nimmt die Grösse der verzögernden Wirkung mit der Anzahl dieser Gruppen in einer raschen geometrischen Progression zu.

Sclıon eine einzige Amidosäuregruppe in einem Molekül, auch olne Anwesenheit anderer wirksamen Gruppen, hebt die Fähigkeit der Verbindung, auf rein osmotischem Wege in die Zelle einzudringen, fast völlig auf. So dringen z. B. Glykocoll, Alanin, Leucin, Taurin etc. fast gar nicht merklich ein.

Der Eintluss der Carboxylgruppe (von den Amidosäuren abgesehen) scheint in verschiedenen Verbindungen ein veränderlicher zu seiı. Wegen der schädlichen Wirkung der Säuren auf die meisten Zellen schon in niedrigen Concentrationen, ist es sehr schwer, genauere Untersuchungen über den Einfluss dieser Gruppe auszuführen.

Die Säureamidgruppe übt eine viel geringere retardirende Wirkung aus, als eine Amidosäuregruppe; doch genügt schon eine einzige solche Gruppe, um in den nöthigen Concentrationen der betreffenden Verbindung eine allerdings rasch vorïbergehende Plasmolyse zu erzeugen. Bei Anwesenheit zweier solcher Gruppen im Molecül ist der Uebergang der Verbindung in die Zelle schon ein recht langsamer.

Ist in einer Verbindung bloss eine einzige alkoholische Hydroxyl. gruppe vorhanden und keine andere wirksame Atomgruppe im Molekül vertreten, so ist der verzögernde Einfluss dieser Gruppe zu klein, um auf osmotometrischem Wege überhaupt nachweisbar zu sein. Alle einwerthigen Alkohole diosmiren so schnell in den Protoplast, dass sie unter keinen Umständen eine Plasmolyse hervorrufen, resp. vermehren können. Enthält aber eine Verbindung ausser der Hydroxylgruppe noch eine andere wirksame Gruppe, so vermehrt die Hydroxylgruppe den verzögernden Einfluss der anderen wirksamen Gruppe. So dringt z. B. Lactamid

$$
\mathrm{CH}_{3}-\mathrm{CH}-\mathrm{CO} \mathrm{NH}_{2}
$$

langsamer in die Zelle ein als Acetamid oder Propionamid.

Enthält eine-Verbindung zwei alkoholische Hydroxyle, so ist de retardirende Wirkung der Hydroxylgruppe sehr deutlich. Solche Verbindungen, z. B. Aethylenglycol, Propylenglycol, Butylenglycol etc. können eine Plasmolyse herbeiführen, doch gelıt dieselbe ziemlich schnell zurïck. Zwei Hydroxyle üben eine etwas stärker verzögernde Wirkung aus, als eine einzige Säureamidgruppe. Bei Vorhandensein von drei alkoholischen Hydroxylen ist die Verzögerung schon sehr bedeutend, und eine Verbindung mit vier solchen Gruppen, z. B. Erythrit, dringt nur noch selır langsam in eine Zelle ein. Enthält endlich ein Körper fün $f$ oder mehr Hydroxylgruppen, so tritt derselbe überhaupt nicht mehr nachweisbar in den Protoplast ein.

Eine noch etwas geringere verzögernde Wirkung als die alkoholische Hydroxylgruppe scheint die Aldehydgruppe zu haben, wie der Vergleich von Glyoxal (welches Doppelmoleciule bildet) mit Erythrit, oder von Arabinose mit Quercit zeigt. 
Die Ketongruppe, die Dialkyloxyde (wahre Aetherarten), die Nitrilgruppe, die Lactonbindung u. s. f. üben, wenn überhaupt, ebenfalls nur einen sehr geringen retardirenden Einfluss aus.

Ueberhaupt keine verzögerude Wirkung in den organischen Verbindungen scheinen die Halogene zu besitzen. Ersetzt manz z. B. in Glycerin eine Hydroxylgruppe durch ein Chloratom, so dringt das entstehende Monochlorhydrin

$$
\mathrm{C}_{3} \mathrm{H}_{5} \underset{\mathrm{Cl}}{\stackrel{\mathrm{OH}}{\mathrm{OH}}}
$$

ebenso schnell in den Protoplast ein, wie ein einfacher zweiwerthiger Alkohol. Werden in Glycerin zwei Hydroxyle durch Chloratome ersetzt, so zeigen sich die Protoplasten tür die dadurch erhaltenen Dichlorhydrine ebenso leicht permeabel wie für einen nicht substituirten einwerthigen Alkohol. Auch die Verbindungen von der Form $\mathrm{C}_{\mathrm{n}} \mathrm{H}_{2 \mathrm{n}+1} \mathrm{X}, \mathrm{C}_{\mathrm{n}} \mathrm{H}_{2} \mathrm{n} \mathrm{X}_{2}, \mathrm{C}_{\mathrm{n}} \mathrm{H}_{2 \mathrm{n}-1} \mathrm{X}_{3}$ etc., wo $\mathrm{X}$ ein Halogenatom bedeutet, scheinen sämmtlich äusserst schnell die lebenden Protoplasten zu durchsetzen.

A ehnlich wiedie Ersetzungeiner Hydroxylgruppedurch ein Halogenatom, wirki a ch die Ersetzung durch eine Methoxylgruppe.

Ebenswenig wie die Halogenatome, üben Estergruppen irgend welchen verzögernden Einfluss auf das Eindringen der Verbindung aus. So geben z. B. der Triäthylester der Phosphorsäure $\mathrm{PO}\left(\mathrm{O}_{2} \mathrm{C}_{2} \mathrm{H}_{5}\right)_{3}$ und der neutrale Aethylester der Citronensäure $\mathrm{C}_{3} \mathrm{H}_{4} \cdot(\mathrm{OH}) \cdot\left(\mathrm{CO} . \mathrm{OC}_{2} \mathrm{H}_{5}\right)_{3}$ ebenso schnell durch die Protoplasten wie ein einwerthiger Alkohol. Dagegen sind die Protoplasten für den Methylester der Gallussäure $\mathrm{C}_{6} \mathrm{H}_{2}(\mathrm{OH})_{3} . \mathrm{CO} . \mathrm{OCH}_{3}$ nur ungefähr ebenso permeabel wie für das Glycerin.

Ueber Verbindungen, deren Verhalten aus den vorstehenden allgemeinen Regeln sich nicht ableiten lässt, möge noch angeführt werden, dass Blausäure und Kohlensäure die Protoplasten sofort durchdringen (Blausäure ist für Pflanzenzellen und viele undifferenzirte Thierzellen keineswegs ein sehr heftiges Gift). Borsäure diosmirt ebenfalls rasch in die Zelle ein (ungefähr so schnell wie ein zweiwerthiger Alkohol).

Es giebt Fälle, in denen die besprochene Methode den Dienst versagt, und für diese hat Overton noch ein anderes Verfahren in Anwendung gebracht. Derselbe beruht, wie bereits gesagt, auf der Eigenschaft des Gerbstoffes mit vielen Stoffen unlösliche Terbindungen zu bilden, so z. B. mit Coffeïn und Antipyrin.

Bevor ich zur Besprechung dieses Verfahrens übergehe, gestatte ich mir auf die Ausführungen in B. 1 S. 219 (Permeabilität) und in diesem Band S. 144 (Muskel- und Nervenphysiologie) hinzuweisen. wo ich meine Meinung über die 7urerlässigkeit und Tragweite der plasmolytischen Methode zur Beurtheilung und Messung der Permeabilität von thierischen Zellen auseinandergesetzt habe. 


\section{ß) Methode der gerbstoffhaltigen Zellen.}

Bringt man lebende gerbstofthaltige Zellen, etwa die Fäden einer geeigneten Spirogyra-Art in eine ca. 0,5 pro Mille-Lösung von Coffeïn, so entsteht im Zellsaft sofort ein Niederschlag in Form von kleinsten Tröpfchen. Bei genauem Studium der Reaction kommen eigenthümliche Erscheinungen zu Gesicht, die hauptsächlich auf Hydrolyse zurückzuführen sind und deren Analyse aus allgemein pharmakologischem Grunde von Wichtigkeit ist.

Schon kurze Zeit, nachdem die Tröpfchen sichtbar geworden sind, vermehrt sich der Niederschlag nicht mehr. Lässt man dann die Zellen weiter in der Lösung verweilen, so verschmelzen die kleinen Tröpfchen zu immer grösser werdenden Tropfen. Wenn man darauf die Zellen aus der 0,5 pro Mille-Lösung und eine solche von 1 pro Nille bringt, so entsteht ein erneuter Niederschlag, der zunächst wieder in der Form kleinster Tröpfchen sehr deutlich zu unterscheiden ist. Auch dieser sammelt sich mit der Zeit zu grossen Tropfen. Ueberführt man die Zellen nach gewissen Intervallen in immer concentrirtere Lösungen von Coffë̈n, so wiederholt sich das gleiche Spiel immer aufs Neue. Bringt man aber die Zellen umgekehrt in immer verdünntere Lösungen, so wird der Niederschlag kleiner und immer kleiner, his bei einer Concentration von circa 1:20000 derselbe vollkommen verschwindet, um bei Erhöhung der Concentration wieder aufzutreten. Der Niederschlag verschwindet zuerst bei den gerbstoffärmeren Zellen und bei gerbstoffreicheren Zellen, erst bei etwas verdünnten Coffë̈nlösungen. Die Erklärung für diese Erscheinungen fällt nicht schwer. Nach Overton haben wir es hier mit einer im Zustande der "hydrolytischen Dissociation" befindlichen Gerbstoff-Coffeïn-Verbindung zu thun ${ }^{1}$ ).

1) Offenbar denkt Overton hier an eine hydrolytische Spaltung der salzartigen Verbindung Gerbstoff-Coffeïn, in der der Gerbstoff die Säure und Coffeïn die Base ist. Versetzt man im Allgemeinen eine Säure mit einer Base, so bildet sich ein Salz unter Austritt von Wasser. Umgekehrt bildet sich, wenn man Wasser zu einem Salz hinzufügt, freie Base und freie Säure, so dass thatsächlich in jeder wässerigen Salzlösung ein Gleichgewicht zwischen freier Base, freier Säure und unzersetztem Salz besteht. Handelt es sich um ein Salz, das aus starker Base und starker Säure aufgebaut ist, beispielsweise $\mathrm{NaCl}$, so ist die Zersetzung unter dem Einfluss von Wasser in $\mathrm{NaOH}$ und $\mathrm{HCl}$ so gering, dass davon nichts zu beobachten ist. Ist eine der Componenten schwach, wie z. B. in $\mathrm{Na}_{2} \mathrm{CO}_{3}$, so ist die Spaltung in $2(\mathrm{NaOH})$ und $\mathrm{H}_{2} \mathrm{CO}_{3}$ wohl nachzuweisen (vergl. Bd. II, S. 481 u. 484).

Wenn Säure und Base beide schwach sind, so behalten diese Erwägungen, wie auch ohne weiteres Geltung, nur dass in Overton's Fall das Auftreten von basischer oder saurer Reaction unter Umständen ausfallen kann; nämlich dann, wenn der Dissociationsgrad der schwachen Base und der schwachen Säure genau der gleiche ist, oder, anders ausgedrückt, die Dissociationsconstante (Bd. II, S. 480) der Säure und der Base von gleicher Grösse sind. 
Um die Einzelheiten der Erscheinungen zu erklären, geht er von dem Gleichgewichtszustande in einer 1 pro Mille Coffeïnlösung aus.

Es befinden sich im Zellsaft:

1. ein Niederschlag von gerbsaurem Coffeïn,

2. gelöstes gerbsaures Coffeïn,

3. Lydrolytisch abgespaltenes Coffeïn und freie Gerbsäure.

Für all diese verschiedenen gelösten Bestandtheile ist die innere Grenzschicht des Protoplasmas (die Vacuolenhaut) undurchlässig, mit einziger Ausnahme des freien Coffeïns ${ }^{1}$ ). Die Concentration des abgespaltenen Coffeïns im Zellsaft muss, da laut Annahme Gleicligewicht herrscht, gleich derjenigen in der Aussenflüssigkeit sein; die Concentration der abgespaltenen Gerbsäure muss die Concentration der ursprünglich vorhandenen Gerbsäure im Zellsaft minus der im Niederschlag befindlichen Gerbsäure haben.

Wird nun die Concentration des Coffë̈ns in der Aussenflüssigkeit erhölt, so vermehrt sich auch der Gehalt an diesem Bestandtheil im Zellsaft. Nach einem allgemeinen Dissociationsgesetze drängt Zusatz von einem der Zersetzungsproducte bei constant bleibenden Volumen (dem Zellsaftraum) den Dissociationszustand zurück. (Vergl. dieses Kapitel S. 260.) Durch diesen Vorgang aber wird die Lösung des (hydrolytisch) nicht gespaltenen gerbsauren Coffeïns übersättigt; es scheidet sich aufs Neue ein Niederschlag aus, was so lange andauert, bis die durch die grössere Concentration des Coffeïns herabgesetzte Tendenz zu hydrolytischer Spaltung durch die entgegengesetzte Tendenz aufgehoben wird, welche durch die allmähliche Verarmung des Zellsaftes an freier Gerbsäure eingeleitet wird.

Wird dagegen die Concentration des Coffeïns in der Aussenflüssigkeit erniedrigt, so finden genau entgegengesetzte Vorgänge statt. Coffeïn tritt aus dem Zellsaft aus, die hydrolytische Spaltung wird dadurch vermehrt, die Lösung des gerbsauren Coffeïns wird ungesättigt, es löst sich ein Theil des Niederschlags auf, die Concentration der gelösten Gerbsäure im Zellsaft nimmt zu, was wieder zur Herabsetzung der Tendenz zur hydrolytischen Spaltung führt und es tritt wieder ein Gleichgewichtszustand ein.

Sinkt aber die Concentration des Coffeïns in der Aussenflussigkeit unter ein gewisses Minimum, so bleibt die ganze Menge des gebildeten gerbsauren Cuffeïns in Lösung und die Reaktion entzieht sich der Wahrnehmung.

Wenn man zu der Flïssigkeit Säure hinzufügt, kann eine Niederschlagsbildung vollständig ausbleiben, indem dadurch die hydrolytische Spaltung so weit zurückgedrängt wird, dass die Concentration der abgespaltenen Basen nicht mehr ausreichte, um eine gesättigte Lösung der gerbsauren Verbindungen im Zellsaft zu erzeugen.

Mit der Entscheidung dieses Punktes gewinnt man nach Overton zugleich eine Methode um den Betrag der hydrolytischen Spaltung der Ammoniaksalze, der Salze der Amine und der Alkaloidsalze zu bestimmen. (Dies gilt nur für die Salze mit stärkeren und mittelstarken Säuren, da die hydrolytisch abgespaltenen schwächern Säuren ebenfalls mehr oder weniger in die Protoplaste eindringen.) So bestimmte Overton die Concentration der Lösungen des freien Ammoniaks einerseits und des Salmiaks andererseits, die bei Zellen von demselben Gerbstoffgehalt eben noch hin-

1) Offenbar denkt Overton hier an das nicht-dissociirte Coffeïn; thatsächlich sind vom Coffeïn, wenn dasselbe als freie Base in Lösung auftritt, $\mathrm{OH}^{\prime}$-Ionen abgespalten. Da es aber eine sehr schwache Base ist, kann die Dissociation hier vernachlässigt werden und das Ganze als ungespaltenes Coffeïn betrachtet werden. 
reichten, um einen deutlichen Niederschlag zu erzeugen, und fand hieraus, dass (bei Zimmertemperatur) ca. ein Theil freies Ammoniak in der Lösung enthalten ist, wenn in 1000000 Gewichtstheilen Lösung 2000 Theile Ammoniumchlorid aufgelöst sind. Durch die Gegenwart von geringen Spuren Calciumcarbonat etc. in dem Lösungs. wasser wird natürlich die Menge des freien Ammoniaks stark vermehrt. Im Blutstrom aufgelöst ist die abgespaltene Menge freien Ammoniaks recht beträchtlich (Aehnliches gilt von den Salzen der Amine und Alkaloide).

Ich bespreche jetzt die nach dieser Methode erhaltenen Ergebnisse, betreffend die Permeabilitätsverhältnisse verschiedener Alkaloide.

Da die meisten Alkaloide von hydrirten oder auch nicht hydrirten Pyridin- und Chinolinbasen sich ableiten, schien es Overton erwünscht zunächst das Verhalten dieser Zellen gegen diese Basen selbst anzugeben.

Das Pyridin dringt ausserordentlich schnell in die Protoplasten ein, wie man dank seiner geringen Giftigkeit schon auf osmotischem Wege leicht und sicher bestimmen kann. Dasselbe gilt für das allerdings giftigere Chinolin. Die wässerigen Lösungen ihrer Salze (namentlich des Pyridins) sind hydrolytisch zersetzt und können deswegen starke Niederschläge in gerbstoffhaltigen Zellen bewirken.

Das Piperidin (Hexahydropyridin) ist mehr als hundertmal giftiger als Pyridin, da aber gerbstoffhaltige Zellen noch in Lösungen ron 1:2000000 Wasser Niederschläge in ihrem Zellsaft aufweisen, so ist es leicht zn zeigen. dass auch das Piperidin äusserst leicht durch die noch unbeschädigten Zellen eindringt. Die Lösungen seiner Salze sind nur mässig stark hydrolytisch zerlegt, jedoch stärker als die entsprechenden Ammoniaksalze.

\section{b) Giftigkeit ron Substanzen fiir das Protoplasma ron Pflanzenzellen.}

Untersuchungen ron Vanderelde.

Seit 1899 hat A. J. J. V anderelde eine Reihe von Untersuchungen veröffentlicht, in denen er die Giftigkeit ron verschiedenen Substanzen mittelst der Plasmolyse quantitativ zu bestimmen versuchte.

Er benützte dazu die anthocyanreichen Epidermiszellen einer unter dem Namen „Oignon rouge de Brunswick" bekannten rothen Varietät der gemeinen Zwiebel (Allium cepa). An meisten empfahlen sich die Epidermiszellen der inneren Schuppen [2]. Diese sind viel grösser und weit empfindlicher als die der zwei äusseren Schuppen und zeigen ausserdem unteremander grosse Tebereinstimmung in der Resistenz gegen die Gifte.

Wenn man solche Zellen in eine hyperisotonische Salzlösung (\%. B. $\mathrm{NaCl} 5^{\circ} \%$ ) legt, zieht sich der P'rotoplast von der Wand zurïck und hält 
dabei, ebenso wie man es bei Tradescantia discolor sieht (B. I, S. 437), den gefärben Inhalt umschlossen. Der Raum zwischen Protoplast und Zellmembran ist farblos. Versetzt man aber die NaCl-Lösung mit einer Substanz, die für den Protoplast giftig ist, jhn töltet, so ist derselbe für den rothen Farbstoft permeabel geworden. In Folge dessen wird der Raum zwischen Protoplast und Zellenmembran roth tingirt und das ganze Präparat sieht gleichmässig roth aus.

Vandevelde nahm nun 5 cc einer $10 \%$ igen NaCl-Lösung und verdünnte dieselbe mit 5 cc einer anderen Flüssigkeit, die je verschiedene Mengen von der zu untersuchenden Verbindung enthielt. Wenn er z. B. die Giftigkeit von Aethylalcohol bestimmen wollte, bestand sie aus: 2 cc Alkohol + 3 cc Wasser, 3 cc Alkohol + 2 ce Wasser, 4 cc Alkohol + 1 ce Wasser, etc.

Es wurde dann weiter untersucht, mit welchem Alkoholgemisch die 5 ec der $10 \%$ igen NaCl-Lösung verdünnt werden musste, um an der Hälfte der Zellen Plasmolyse herrorzurufen ${ }^{1}$ ) oder die Plasmolyse der Hälfte aller Zellen 5 Minuten andauern zu lassen. Diese Lösung bezeichnete er mit dem Namen ..Kritische Lösung“"

Ich lasse hier ein Beispiel folgen, aus welchem man beurtheilen kann, wie weit die Genauigkeit des Verfahrens geht.

\begin{tabular}{|c|c|c|c|c|}
\hline I & II & III & IV & $\mathrm{V}$ \\
\hline $\begin{array}{l}10^{\circ} \text { o ige } \\
\mathrm{NaCl}- \\
\text { Lösung }\end{array}$ & $\begin{array}{l}\text { Aethyl- } \\
\text { alkohol } \\
94^{\circ} \%\end{array}$ & Wasser & $\begin{array}{l}\text { Volumprocent } \\
\text { absol. Alkohol } \\
\text { berechnet } \\
\text { aus Spalte I, } \\
\text { II und III }\end{array}$ & $\begin{array}{c}\text { Resultate von verschiedenen } \\
\text { Versuchen }\end{array}$ \\
\hline $5 \mathrm{cc}$ & $2,0 \mathrm{ec}$ & $3,0 \mathrm{ce}$ & $18, \varepsilon 0$ & Plasmolyse, Plasmolyse \\
\hline 5, & 3,0 & 2,0 & 28,20 & Plasmolyse, Plasmolyse \\
\hline 5, & 4,0 & 1,0 & 37,60 & $\begin{array}{c}\text { Keine Plasm., keine Plasm., Plasm. } \\
\text { verschwindet }\end{array}$ \\
\hline 5, & 2,5 & 2,5 & 23,50 & Plasmolyse, Plasmolyse, Plasmolyse \\
\hline 5, & 2,9 & 2,1 & 27.26 & Plasmolyse, ${ }_{1 / 2}$ Plasmolyse. Plasmolyse \\
\hline 5, & 3,0 & 2,0 & $2 \varepsilon, 20$ & $\begin{array}{c}{ }^{1 / 2} \text { Plasm., Plasm., Plasm., 1/2 Plasm., } \\
\text { Plasmolyse, Plasmolyse }\end{array}$ \\
\hline 5, & 3,1 & 1,9 & 29,14 & $\begin{array}{c}\text { Keine Plasm., keine Plasm., }{ }^{1}{ }^{\prime 2} \text { Plasm., } \\
\text { keine Plasmolyse }\end{array}$ \\
\hline 5, & 3,2 & 1,8 & 30,08 & $\begin{array}{c}\text { Keine Plasm, Plasm. verschwindet } \\
\text { Plasmolyse verschwindet }\end{array}$ \\
\hline
\end{tabular}

1) Denselben Maassstab legte de Vries bei seinen plasmolytischen Versuchen an. (Vergl. B. I, S. 43T.) 
Man sieht, dass bei Anwendung eines Alkoholgemisches von:

2,9 cc Alkohol + 2,1 cc Wasser in zwei Versuchen alle Zellen plasmolysirt waren und in einem Versuch die Hälfte; dass bei Anwendung eines Gemisches von 3 cc Alkohol +2 cc Wasser in 4 Versuchen alle und in 2 Versuchen die Hälfte der Zellen plasmolysirt waren.

War die Mischung alkoholreicher, d. h. enthielt sie 3,1 Alkohol $+1,9$ cc Wasser, so war in drei Versuchen gar keine Plasmolyse zu erkennen, in einem vierten Versuch war die Hälfte plasmolysirt.

Vandevelde hält demnach 5 cc NaCl-Lösung von $10 \%$ +3 cc Alkohol von $94 \%+2$ cc Wasser für die kritische Lösung: sie enthält 28,2 Volnmprocent absoluten Aethylalkohol.

Auf diese Weise versuchte der Autor in seiner ersten Abhandlung die kritische Lösung auch von anderen Alkoholen festzustellen.

So fand er als kritische Lösung für Methylalkohol $40 \%$ und für Isopropylalkohol $21 \%$. Stellt man diese Resultate zusammen, so ergiebt sich:

$\begin{array}{ll}\text { Methylalkohol } \mathrm{CH}_{3} \cdot \mathrm{OH} & 40 \% \\ \text { Aethylalkohol } \mathrm{CH}_{3} \cdot \mathrm{CH}_{2} \cdot \mathrm{OH} & 28,2 \% \\ \text { Isopropylalkohol } \mathrm{CH}_{3} \cdot \mathrm{CH}(\mathrm{OH}) \cdot \mathrm{CH}_{3} & 21 \% .\end{array}$

Die Giftigkeit steigt also mit dem Moleculargewicht.

Diese im April unternommenen Versuche wurden im August wiederholt. Obgleich die absoluten Werthe nicht dieselben waren, zeigte sich doch eine grosse Aehnlichkeit in den Giftigkeitsverbältnissen. Die Augustversuche ergaben:

$\begin{array}{ll}\text { Methylalkohol } & 37 \% \\ \text { Aethylalkohol } & 24,44 \% \\ \text { Isopropylalkohol } & 16 \% \\ \text { (Normal-Propylalkohol) } & 11 \% .\end{array}$

Aus diesen procentischen Verhältnissen hat $V$ andevelde andere Zahlen berechnet, namentlich kritische Coëficienten.

$\mathrm{Zu}$ diesem Zweck bezeichnet er die Giftigkeit des absoluten Aethylalkolıols mit 100. Es ist dann der kritische Coëfficient des Methylalkohols (Aprilreihe) $=\frac{40}{28,3} \times 100=141,8$ und der des Isopropylalkohols $\frac{21}{28,2} \times 100=74,5$.

In einer zweiten Mittheilung [3] hat Vandevelde Untersuchungen über die Giftigkeit flü chtiger Oele (Essenzen) veröffentlicht. Das Versuchsverfahren war genau dasselbe. Ich beschränke mich auf die zusammenfassende Mittheilung der Resultate, nur möchte ich hinzufügen, dass die zu untersuchende Substanz gewöhnlich in absolutem Alkohol aufgelöst und der Einfluss des letzteren selbstverständlich in Abzug gebracht wurde.

I. Stoffemit einem kritischen Coëfficienten $<1$.

Diese sind also wenigstens $100 \mathrm{mal}$ giftiger als absoluter Alkohol (kritische Concentration bis zu 2500 mal kleiner giftiger als Aethylalkohol). 


\begin{tabular}{|c|c|c|}
\hline Thymol & . & \\
\hline Menthol & • & \\
\hline Zimmtsäurealdehyd & & \\
\hline Chinazimmtöl (Cassiaöl) & & \\
\hline Nelkenöl (Oleum Caryophy & yllorum) & \\
\hline Thymianöl (Oleun & m Thymi) & \\
\hline immtöl . . . . & 0 & \\
\hline Rothes Thymianöl & . & \\
\hline
\end{tabular}
sammengesetzt.

Diese Substanzen sind hauptsächlich aus Alkoholen und Aldehyden zu.

II. Kritischer Coëfficient $=1$ bis 5 (also Substanzen, die 100-bis 20mal giftiger sind als absoluter Alkohol).

Nitrobenzol . . . . . . . . . 1.25

Pfefferminzül . . . . . . . . . . 1,52

Macisöl (Oleum Nucis Moschati) . . . . . 1,77

Oleum Anisi Stellati . . . . . . . 1,81

Wermuthöl (Oleum Absynthii) . . . . . . 1,97

Kümmelöl (Oleum Carvi) . . . . . . . . 2,06

Bittermandelöl (Oleum Amygdalarum amarum) 2,26

Benzaldehyd . . . . . . . . . 2,26.

Diese Stoffe enthalten Phenole und Aldehyde; ausserdem Ketone und Terpene.

III. Kritischer Coëfficient $=5$ bis 10 (also Substanzen, die 20- bis 10 mal giftiger sind als absoluter Alkohol).

Kümmelessenz . . . . . . . . . . 5,40

Citronenöl . . . . . . . . . . . . . 6,45

Orangenblüthenöl (Oleum florum Aurantii) . 7,11

Ananasöl . . . . . . . . . . . . . . 7,29

Aprikosenessenz . . . . . . . . . . . 7,69

Angelicaöl . . . . . . . . . . . . 7,84

Pfirsichöl . . . . . . . . . . . 9,05.

Diese Stoffe enthalten Terpene und Aether. Der kritische Coëfficient der Fruchtöle weicht wenig von 10 ab.

IV. Kritischer Coëfficient $=10$ bis 20 (Stoffe, die 10-bis $5 \mathrm{mal}$ giftiger sind als absoluter Aethylalkohol).

Apfelöl = Apfelessenz . . . . . . . . 10,65

Birnenöl = Birnenessenz . . . . . . . . 10,68

Angelicasamenöl . . . . . . . . . . 10,31

Anisöl (Oleum Anisi) . . . . . . . . 10,33

Amylalkohol . . . . . . . . . . . . 12,66

Künstliches Cognacöl (Oleum Vitis viniferae) 14,80

Himbeeröl . . . . . . . . . . . . . 15,37

Anethol . . . . . . . . . . . . 17,08

Citronenöl . . . . . . . . . . . . . 18,55

Cognacöl . . . . . . . . . . . . . 18,89

Erdbeeröl . . . . . . . . . . . . . 19,92.

Diese Stoffe enthalten Terpene, Aether und Alkohole. 
V. Kritischer Coëfficient $\mathrm{z}$ wischen 20 und 50 (Stoffe also, die 5-bis 2 mal giftiger sind als absoluter Aethylalkohol).

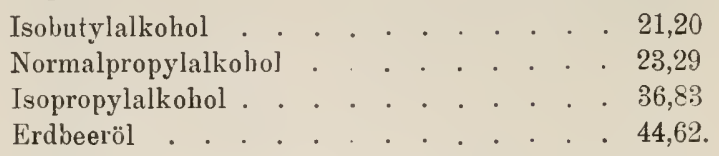

Vandevelde fügt diesen Resultaten die Bemerkung hinzu, dass die Phenole und die Aldehyde unter den untersuchten Stoffen, den höchsten Giftigkeitsgrad erreichen; dann folgen die Ketone und Terpene; dann die Aetber und endlich die Alkohole. Im Vergleich mit einigen ätherischen Oelen, wie Thymianöl und Zimmtöl, die sich im so oft benutzten Thymian und Zimmt befinden, ist sonach der als gefährlich bekannte Amylalkohol nur wenig schädlich. Und wie viele Nahrungs- und Genussmittel werden nicht mit Hïchtigen Oelen und Essenzen zubereitet!

Eine dritte Nitheilung Vandevelde's [6] befasst sich mit der Giftigkeit pflanzlicher und thierischer Extracte.

Zunächst wurde Kaffee untersucht, der in verschiedenen Graden gebrannt war. Es stellte sich heraus, dass die wässerigen Extracte für die Zellen von Allium unschädlich waren, wohl aber waren die alkoholischen Auszüge schädlich. Hieraus schliesst der Verfasser, dass erst durch den Alkohol die Gifte ausgezogen werden und wir also den Kaffee als wässrigen Aufguss, in zweckmässiger Weise, benutzen.

Gerade das Umgekehrte fand er bei Thee. Hier wurden mittelst Wasser Substanzen extrahirt, die für das Protoplasma ron Allium schädlich waren, während die durch Alkohol extrahirten Stoffe diese Eigenschaft nicht besassen.

Sehr wenig giftig zeigte sich Cacao, nicht nur in wässerigen, sondern auch in alkoholischen Extracten.

Bemerkenswerth ist, dass Tabak in wässeriger Lösung sehr wenig giftig ist.

Wurde der kritische Coëfficient des Kaffees zwischen 59,5 und 132,3 gefunden, so lag derselbe für Thee zwischen 90 und 115; für Tabak zwischen 1504,3 und 233, für Cichorie zwischen 233,3 und 377,9 und endlich betrug er für Cacao 1063,8.

Extracte in 50 Vol. Procent Alkohol ergaben folgende Zahlen für die kritischen Coëfficienten.

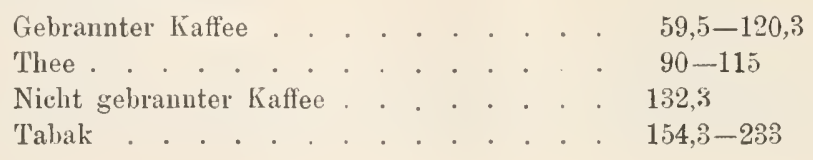




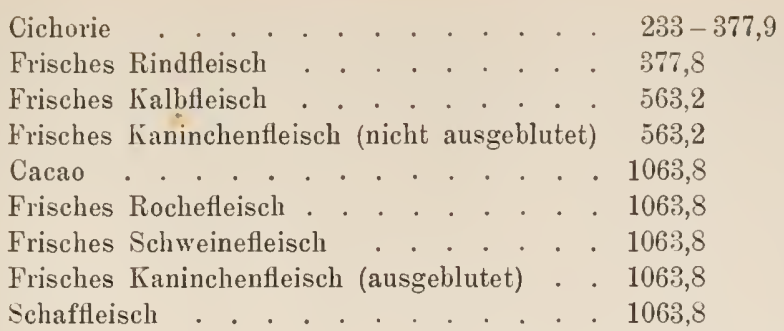

Es sind das die wichtigsten Resultate, die Vandevelde mittelst seiner Methode erzielt hat.

Man wird aber vorsichtig sein müssen und sie nicht ohne weiteres auf den thierischen Organismus iibertragen. Was für eine Zellenart giftig ist, ist es darum noch nicht für jede andere. Denn einmal ist die Permeabilität rerschiedener Zellen für eine und dieselbe Substanz nicht dieselbe, und weiter ist es fraglich, ob die Zusammensetzung des Protoplasma aller Zellen die gleiche ist. Indessen darf man wohl annehmen, dass im Grossen und Ganzen im Verhalten des Protoplasmas verschiedener Pflanzenzellen und thierischer Zelien gegenüber derselben chemischen Substanz vielfache Übereinstimmung besteht. Dafür sprechen auch die Untersuchungen Overton's.

\section{Dosirung von Medicamenten.}

Litteratur.

1. Juckuff, Versuche zur Auffindung eines Dosirungsgesetzes. Leipzig 1895.

2. Stokvis, Nederl. Tijdschrift v. Geneeskunde :2. (2). 1896. p. 105.

3. Bimmendijk, VI Congrès internat. des Sciences médic. Amsterdam 2. p. 370.

4. Stokvis, Deutsches Archiv f. klin. Medic. 73. 1892. S. 657. (K us smaul's Festschrift).

In den Pharmakopoeen pflegt man eine Tabelle der Iaximaldosen zu finden, welche die grössten Gaben der Arzneimittel für einen erwachsenen Menschen angiebt. Derartige Angaben werden nicht nur für die per os einzuverleibenden Medicamente rerzeiclınet, sondern auch für die, die in der Form einer subcutanen Injection, eines Ḱlystiers oder Suppositoriums rerabreicht werden. Eines der Principien, welches dieser Tabelle zu Grunde liegt, ist, dass die therapeutischen Wirkungen der darin genannten Nittel ihrem Gewichte proportional sind. Diese Annahme nun ist von Juckuff [1] und von Stokvis [2] bestritten wurden.

Der Einwurf Juckuff's lässt sich aus folgendem Versuche entnehmen. In einem Selbstversuch nahm Koppe 0,5 mg Digitoxin. Er bemerkte absolut nichts. 
Einige Zeit nachher nahm er ein weiteres mg. Es zeigte sich kaum einige Wirkung. Wieder einige Zeit später nahm er die doppelte Dosis: d. h. $2 \mathrm{mg}$, aber jetzt entwickelte sich eine so heftige Vergiftung, dass es den Anschein hatte, als ob er nicht zweimal $1 \mathrm{mg}$, sondern eine viel grössere Menge genommen habe. Vier Tage ist er sehr krank und erst nach 14 Tagen ist vollständige Gesundung eingetreten.

Was ist die Ursache dieser Disproportionalität?

Wie in der Sinnesphysiologie giebt es auch in der Toxicologie und Pharmakotherapie eine Reizschwelle. Juckuff spricht hier lieber von „Resistenzwerth", d. h. von einer Dosis, die absolut keinen Einfluss auszuüben vermag, die unwirksam ist. $0,5 \mathrm{mg}$ Digitoxin war ohne Effekt, $1 \mathrm{mg}$ verursachte kaum einige Wirkung, der Resistenzwerth mag $0,8 \mathrm{mg}$ gewesen sein. Als $1 \mathrm{mg}$ genommen wurde, war also die thatsächlich wirksame Quantität $1-0,8=0,2 \mathrm{mg}$. Bei $2 \mathrm{mg}$ war dann die thatsüchlich wirksame Quantität $2-0,8=1,2 \mathrm{mg}$, also sechs Mal so gross.

In Spencer's Versuchen hatte eine Dosis von 3,5 Volumprocent Aether in der atmosphärischen Luft, keinerlei Einfluss auf die Athmung; 4,45 Volumprocent führten eine deutliche Verlangsamung und 6 Volumprocent bereits den Tod herbei.

Die Einwände von Stokvis gegen die angebliche Proportionalität zwischen dem Gewicht der wirksamen Agens und dem therapentischen Effect wenden sich zunächst gegen die nicht berechtigte stillschweigende Annahme, dass die Wassermenge, in der das Medicament gelöst wird, ohne Einfluss ist. In der That ist die Concentration, in welcher ein Medicament gegeben wird, von nicht unbedeutendem Einfluss auf die Resorptionsgeschwindigkeit. So kann man sich den Fall denken, dass bei zu langsamer Resorption, der soeben genannte Resistenzwerth nicht erreicht wird. Steht namentlich den Nieren genügende Zeit zur Verfügung, trotz des anhaltenden Ueberganges des Medicamentes in die Blutbahn, das darin Zurückbleibende doch unter dem Resistenzwerth zu halten, so ist und bleibt der therapeutische Effect Null.

In zweiter Linie erhebt Stokvis den Einwand, dass genannte liegel der besonderen $\mathrm{X}$ atur der Flüssigkeit, in welcher das Medikament gelöst ist, keine Rechnung trägt. Hierzu macht er auf die von Binnendijk gefundene Thatsache aufmerksam, dass die Wirkung des in Wasser gelösten Phenols bei Zusatz von 20-30\% Glycerin bei Hunden und Kianinchen auf die Hälfte bis ein Fünftel herabgesetzt wurde, sowohl bei innerem wie bei äusserem Gebrauch. Spritzt man in Wasser gelöstes Phenol subcutan bei Kianinchen ein, so entsteht Hämoglobinurie; 
fügt man der Lösung etwas Glycerin hinzu, so bleibt die Hämoglobinurie wiederholte Male aus. Es handelt sich hier nicht um eine antagonistische oder antidotische Wirkung. Die Hinzufügung von Glycerin setzt einfach die Wirkung des Carbols herab. Gleichartiges beobachtete später (1893) Hallopea u bei Weinsäure: auch ron diesem Stoffe setzt Glycerin die Wirkung herab (citirt nach Stokvis). In allen diesen Fällen ich gehe unten bei der Besprechung der desinficirenden Wirkung anf den Grund der Sache näher ein - hat also eine Angabe der Maximaldose absolut keinen Werth, un so weniger, weil in der betreffenden Tabelle des Arzneibuches den Medien, in welchen die verschiedenen Stoffe gelöst sind, gar nicht Rechnung getragen wird. Eine eingehende Reform ist also auch auf diesem Gebiete auf physikalisch chemischer Grundlage zu erhoffen.

Ich mache schliesslich noch auf eine interessante Arbeit von Stokvis [4] über den Einfluss des Verdünnungsgrades von KBrLösungen auf den letalen und toxischen Effect beim Froschherzen aufmerksam. Bei den Experimenten wurde das mit Kronecker's Canüle rersehene isolirte Froschherz, frei in einer $0,6 \%$ igen NaCl-Lösnng pulsirend, mit verdünntem Pinderblut (200 cc Blut +600 cc $0,6 \%$ iger $\mathrm{NaCl}-\mathrm{Lösung}$ ) gespeist, in welchem verschiedene abgewogene KBr-Mengen aufgelöst wurden.

Der letale Effect wurde aus dem Stillstand des Herzens beurtheilt, der toxische aus der Blutmenge, die das Herz, vor und nach der Hinzufügung von $\mathrm{KBr}$ zu dem Blut, in einem bestimmten Zeitraum auszuwerfen im Stande war. In den angestellten Untersuchungen gelang es nun constant $100 \mathrm{mg}$ Froschherz durch $2-3 \mathrm{mg} \mathrm{KBr}$ zu tödten, d. h. das Herz seiner rhythmischen Thätigkeit völlig zu berauben, aber nur in geeigneter Concentration. In geringeren Concentrationen konnte Stokris viel grössere Mengen, selbst bis über $100 \mathrm{mg}$ dem Herzen zuführen, ohne dass es seine Thätigkeit einbüsste. Es wäre also ein grober Fehler 2-3 mg KBr als die letale Dosis zu bezeichnen, denn nicht diese Gewichtsmenge an und für sich, sondern die Concentration, in welcher sie mit dem Herzen in Berührung kommt, beherrscht den letalen Effect.

Die letale Concentration zeichnete sich scharf ab; eine KBr-Lösung von 1 Mol aufgelöst in 600 Liter Wasser, also ${ }^{1 ! 600}$ normal (in Gewichtsprocenten ausgedrückt $0,2{ }^{\circ}{ }_{0}$ ) hob fast unmittelbar die Herzthätigkeit auf; eine ${ }^{1 / 660}$ normal KBr-Lösung $(0,181 \% \mathrm{KBr})$ führte selbst bei einer 4-stündigen Dauer des Experimentes keinen letalen 
Effect herbei. Nur tritt bei letzterer Concentration ebenso wie bei schwächeren Lösungen (Stokvis untersuchte Verdünnungsgrade bis zu $1 / 1200$ norm.) ein toxischer Effect auf.

Die genannten Grenzwerthe, ${ }^{1 / 600}$ und $1 / 660$ normal, sind, in absolutem Sinne genommen, nicht richtig: denn aus Stokvis' Ausführungen geht hervor, dass er das verdünnte Rinderblut (200 cc Blut $+600 \mathrm{cc} \mathrm{NaCl-Lösung)} \mathrm{als} \mathrm{eine} \mathrm{Flüssigkeit} \mathrm{be}$ trachtet. Das ist nun natürlich nicht der Fall, denn es sind auch Blutkörperchen darin vorhanden und diese nehmen kaum $\mathrm{KBr}$ in sich auf. Die KBr-Lösungen sind daher concentrirter als ${ }^{1 / 600}$ normal und ${ }^{1 / 660}$ normal. Das lässt selbstverständlich die Schlussfolgerungen des Verfassers unberührt. Ich wollte'aber darauf aufmerksam machen, weil es sich ereignen könnte, dass man später absolute Zahlenwerthe braucht.

\section{Die Ionenlehre in der Homoöpathie.}

\section{Litteratur.}

1. van der Stempel, Geneeskundige Courant voor het Koninkryk der Nederlanden 14. April, 21. April, 5. Mai 1901.

2. Brand, Geneeskundige Courant 28 April, 12. Mei 1901.

3. Karl von Nïgeli, Neue Denkschriften der allgem. Schweiz. Gesellsch. f. d. gesammten Naturwissensch. 3i3. Abth. 1. 1893.

4. Galeotti, Biol. Centralblatt 21. 1901. S. 321.

5. Israël und Klingmanu, Virchow's Archiv 127. 1897. S. 430.

Von homöopathischer Seite ist die Ionenlehre herangezogen worden, um die besondere Heilkraft von gerade minimalen (infinitesimalen) Dosen verständlich zu machen. Hahnemann hatte den heilkräftigen Einfluss grosser Verdïnnungen einer vitalen „Dynamisirung“ zugeschrieben. V an der Stempel[1] meint, dass demselben eine Ionisirung zu Grunde liegt. Durch die Verdiinnung werden die Molecüle in ihre Ionen dissociirt und diese mit Elektricität geladenen Theilchen sind es, die sich mit Ionen der Kernsäfte (bezw. Zellsäfte) verbinden und die erwiinschte Wirkung entfalten. Die nicht dissociirten Molecüle üben einen ganz anderen Einfluss auf die Körpergewebe aus: sie wirken schädlich. Daher ist die Verdünnung nothwendig und je stärker sie ist, um so intensiver ist die heilsame Wirkung. gemacht

Gegen letztere Anschauung hat Brand [2] mit Recht geltend

1. dass alle elektrisch spaltbaren Medicamente, selbst in geringer Verdïnnung verabreicht, im thierischen Körper durch dessen grossen Wasserreichthum in Ionen zerlegt werden. Und wenn einmal die vollständige Spaltung statt- 
gefunden lat, so kann nach dem Massenwirkungsgesetz ${ }^{1}$ ) weitere Verdïnnung der Intensität der chemischen Wirkung nur schaden. In der That, wenn man sagt, dass bei Verdünnung einer Salzlösung in Folge Ionenbildung die Energie zunimmt, so folgt daraus nicht, dass durch zunehmende Verdünnung die Energie fortwährend weiter steigen muss. Es lommt eine Verdünnung vor, bei der alle Molecüle in Ionen gespalten sind. Wird dann die Verdünnung noch weiter fortgesetzt, so nimmt die Ionenconcentration ab und auf die absolute Ionenconcentration kommt es bei der Reaction an. Es kann sich sehr gut ereignen, dass die Ionenconcentration bei einer beschränkten Verdünnung grösser ist, als bei einer stärkeren. Das ist für jede Substanz rerschieden und hängt ron ciem Grade der Spaltung bei einem bestimmten Wasserzusatz ab.

2. Nicht alle Medicamente können in Ionen zerlegt werden. Das gilt nur für Salze, Basen und Säuren. Für die nicht in Ionen spaltbaren, für die Nicht-Elektrolyte also, lässt van der Stempel's Erklärung im Stich.

Dass ferner, wie van der Stempel meint, die ungespaltenen Molecüle den, ,primären" schädlichen und die entsprechenden Ionen den ,secundären“ heilkräftigen Einfluss ausüben, und weiter, dass letzterem Einfluss durch den ersten entgegen gearbeitet wird, dafür habe ich den thatsächlichen Beweis nirgendwo finden können. Ich muss hinzufügen, dass es mir auch unmöglich sein würde. eine solche Thatsache nach dem gegenwärtigen Standpunkt unseres Wissens zu deuten.

Ich glaube also nicht, dass die Ionenlehre im Stande ist, die angebliche kräftige Wirkung gerade der infinitesimalen Verdünnungen der Homöopathen zu erklären.

Immerhin hat die Wissenschaft der letzteren Jahre die biologische Bedeutung von äusserst geringen Dosen ausser Zweifel gesetzt und van der Stempel, sowie auch andere homöopathische derzte haben auch nicht rersäumt, hierauf besonderen Nachdruck zu legen. In der That ist z. B. die Empfindlichkeit von Spirogyra für minimale Ku upfermengen erstaunlich. Lösungen von 1 Kupfer auf 100000000 Wasser scheinen nach Untersuchungen von K $\mathrm{arl}$ von Nägeli [3] für Spirogyra tödtlich zu sein. Solch eine Ḱupferlösung entsteht, wenn man ein Stück Kupferblech einige Zeit in destillirtes Wasser hält.

1) Dieses sagt aus, dass die Intensität einer Reaktion mit der Anzahl der in Wirkung tretenden Theilchen proportional ist. (Vergl. Bd. II, S. 466.) 
Wie Galeotti fand [4], wirkt auch colloidales liupfer in äusserst verdünnten Lösungen (1 Cu auf 126000000 Liter Wasser) schädigend auf Algen und tödtet sie schliesslich. Durch Zusatz einer Spur NaCl wird diese Wirkung aufgehoben, offenbar weil dadurch der colloidale Zustand aufgehoben wird.

Auch an thierischen Zellen haben Israel und Kilingmann [5] ähnliche „oligodynamische Erscheinungen" beobachtet, wie sie Nägeli bei Spirogyra constatirte.

Die Beispiele über den Einfluss äısserst geringer Quantitäten lassen sich leicht um eine grosse Anzahl vermehren. Bei diesem Einfluss spielt das elective Termögen bestimmter Zellen für bestimmte Stoffe eine bedeutende Rolle. Dieses Vermögen besteht darin, dass bestimmte Körperzellen im Stande sind, bestimmte Verbindungen, obgleich in sehr grosser Verdünnung in den Körpersäften vorhanden, in relatir grosser Concentration aufzuspeichern ${ }^{1}$ ). Es ist eine Errungenschaft der letzten Jahre, nicht nur durch zahlreiche Experimente das Bestehen derartiger Selectionen näher begründet, sondern sie auch durch Anwendung des Theilungsprincipes, dem Verständniss näher gerückt zu haben ${ }^{1}{ }^{1}$.

Wie hat nun unter diesen Lmständen der I'nparteiische über die Thätigkeit der ausserordentlich kleinen Dosen im thierischen Organismus zu denken? Ich glaube, die Thatsache, dass weder bei physiologischen Experimenten noch auch in der thierärztlichen Praxis, die von der Homöopathie vorgeschriebenen infinitesimalen Dosen bis jetzt einen sichtbaren Effect zu rerzeichnen haben, mahnt bei voller Anerkennung der Wirkung erstaunlich geringer Ouantitäten, doch zu grosser Vorsicht. Mit dem praktischen Werth haben wir uns indessen an dieser Stelle nicht zu beschäftigen; es handelte sich nur um die Frage, ob in der Ionenlehre eine dem heutigen Standpunkt der Wissenschaft entsprechende befriedigende Deutung der Hahnemannschen Dynamisirung oder l'otenzirung gefunden worden ist. Die Antwort lautet rerneinend.

\section{Zum Mechanismus der Narkose.}

\section{Litteratur.}

1. Dastre, Les Anesthésiques. Paris 1890.

2. Overton, Studien ïber die Narkose, zugleich ein Beitrag zur allgemeinen Pharmakologie. Jena 1901.

3. Claule Bernard, Leçons sur les effets des substances toxiques et médicamenteux 1857. Leçons sur les Anesthésiques 1875.

1) Vergl. dieses Kapitel, S. 245 u. 246 und das Kapitel ,.Histologisches“ 2 b. 
4. R. Dubois, Compt. rend. de la Soc. de Biol. 1884. p. 583. Anesthésie physiologique. Paris 1894.

5. Hermanı, Archiv f. (Anat. u.) Physiol. 1866. S. 73.

6. H. Meyer, Archiv f. exp. Pathol. u. Pharmak. 42. 1899. S. 109.

7. Baum, Archiv f. exp. Pathol. u. Pharmak. 42. 1899. S. 123.

8. Jungfleisch und Berthelot, Ann. Chim. Phys. 26. 1872. p. 396. Berthelot Ibid. S. 408.

9. Nerust, Zeitschr. f. physik. Chemie S. 1891. S. 110.

10. Nernst, Theoretische Chemie. 3. Aufl. 1900. S. 454.

11. Overtoll, Jahrb. f. wissensch. Botanik 34. 1900. S. 669.

12. H. Meyer, Archiv f. exp. Path. u. Pharmak. 46. 1901. S. 338.

Nachdem Morton und Jackson 18-t8 den Aethyläther als Narkoticum erwiesen hatten, ist auf dem Gebiet der Narkose mit ununterbrochenem Eifer, und man darf sagen, mit reichem Erfolg fortgearbeitet worden. Es liegt selbstverständlich nicht in Plan dieses Buches hier eine historische Uebersicht über den Gegenstand zu geben, $\mathbf{m}$ so weniger, weil man in einer Arbeit Dastre's [1] und auch in einer Monographie, die Overton dem Gegenstand gewidmet hat [2], treffliche Zusammenstellungen findet. Hier darf nur von denjenigen Untersuchungen die Rede sein, bei welchen die physikalische Chemie zu Wort gekommen ist. Von den auf anderen Boden stehenden Forschungen erwähne ich liur folgendes.

\section{a) Aeltere Ansichten.}

Nachden die vasomotorischen Centra bekaunt geworden waren, wurden diese als der Angriffspunkt der Narkotica angesehen. Nan stellte sich vor, dass die Narkose auf einer Contraction der Gehirngefässe berubte. Dieser Hypothese wurde aber von $\mathrm{Claude}$ Bernard selbst, dem Entdecker der vasomotorischen Nerven, niemals gehuldigt, und mit Recht, denn bei Amphibien bleibt das Gehirn, selbst nach vollständiger Unterdrückung der Gehirncirculation, längere Zeit functionsfähig und dennoch lassen sie sich ebenso leicht narkotisiren wie die Säugethiere. Man ersieht hieraus, dass die Narkose mit dem Blutzufluss höchstens in einem entfernten Zusammenhang steht. Das wird durch den Befund an Insecten und Crustaceen bestätigt, die überhaupt keine besonderen Blutgefässe im Gehirn besitzen, sondern nur eine Art intercellularer Lymphe.

Claude Bernard hat deshalb auch eine ganz andere Hypothese über die Wirkungsweise der Narkotica aufgestellt [3] und führt sie auf eine S e mic o a g ulation des Ganglienzellenprotoplasma zurïck. Selbstverständlich muss er dann gleichzeitig annehmen, dass das Protoplasma nach Entfernung des Narkoticums wieder zu dem ursprünghichen Zustand zurückkehrt. Dieser Vorstellung hat sich Binz in seinen Vorlesungen über Pharmakologie angeschlossen, aber, wie Overton betont hat, aus ungenügenden Gründen. 


\section{b) Hypothese ron R. Dubois.}

Eine neue Hypothese ist von R. Dubois [4] aufgestellt worden. Nach diesem Verfasser bewirken die Anaesthetica eine partielle Entwässerung des Protoplasmas. In Folge dessen sollen die Zellen in einen Zustand latenten Lebens versetzt werden, analog demjenigen der ausgetrockneten Weizenälchen oder der ausgetrockneten Coniferen.

Der Hauptversuch, auf welchen diese Vorstellung sich stützt, ist folgender: Wenn man in einem geschlossenen Gefäss Fettpflanzen mit Aetherdampf in Berüllrung bringt, so treten nach einiger Zeit dicke Wassertropfen auf der kpidermisoberfläche aus. „Les oranges qui out séjourné assez longtemps dans une semblable atmosphère prennent l'aspect de fruits dégelés". Es ist interessant zu constatiren, sagt Dubois weiter; dass die wesentliche Wirkung der allgemeinen Anaesthetica derjenigen der Kälte in erheblichem Maasse entspricht, denn auch diese beschränkt oder verhindert die Imbibition und ruft in den gefrorenen Geweben die Trennung von Wasser und Protoplasma hervor. Nun ist die Kälte in der That auch ein Anaestheticum und Antisepticum.

Dieser Deutung ist Overton auf physikalisch-chemischen Grïnden entgegen getreten. Er betonte, dass die (behauptete) Wasserausscheidung bei anästhesirten Pflanzen mit Narkose als solcher gar nichts zu thun hat, aber auf eine Aenderung der osmotischen Eigenschaften der Zelle zurückzuführen ist. Nach Overton ist nämlich der Protoplast unter dem Einfluss des Aetherdampfes für den Zellsaft permeabel geworden, so dass letzterer, der immer unter einem gewissen Druck in den Vacuolen steht, mit Erfolg ausgepresst wird. Auch nacl Gefrieren und Aufthauen büsst die Zelle ihre Undurchlässigkeit für den in den Vacuolen vorhandenen Zellsaft ein. In den Versuchen von Dubo is stammt also das ausgepresste Wasser nicht aus dem Protoplasma, sondern aus dem Zellsafte.

Stellt man nach Overton den Versuch von Dubois mit der Iodification an, dass man die betreffenden Pflanzen nicht den Dämpfen des reinen Hüssigen Aethers oder Chloroforms, sondern den Dämpfen der wässerigen Lösungen dieser Verbindungen aussetzt, und zwar Lösungen von solchen Concentrationen (1,25-1,5 Gew.-Proc.), die gerade hinreichen, um z. B. eingebrachte Algenfäden zu narkotisiren, so tritt dnrchaus keine Wasserausscheidnng bei Fettpflanzen auf, oder doch erst nach langer Zeit, nachdem die Pflanzen bereits dauernd geschädigt worden sind, wie dies bei jeder zu lange dauernden Narkose schliesslich geschieht.

Nit Recht bemerkt Overton, dass anch der durch Aether und Chloroform herbeigeführte Austritt des flüssigen Inhaltes aus den rothen Blutkörperchen auf einer Störung der osmotischen Eigenschaften der äusseren Protoplasmabegrenzung beruht. 


\section{(c) Hypothese von II. Meyer und E. Overton.}

Ein ganz anderer Gredanke liegt einer Hypothese zu Grunde, die schon im Jahre 1847, also gleich nach der Entdeckung der anästhesirenden Eigenschaften des Aethers, von Bibra und Har less ausgesprochen wurle. Nach diesen Verfassern sollte die Wirkung des Aethers und und auch des Chloroforms darauf beruhen, dass diese Stoffe das ,Gehirnfett" auslaugten. Dementsprechenr hat auch später L. Hermaun die Frage aufgeworfen, ob nicht vielleicht die Lecithinkörper, Cholesterin und Fett der Ganglienzellen den gemeinsamen Angriffspunkt für die anästhesirenden Verbindungen darstellen [5].

Später wurde diese Torstellung ron H. Me yer [6] und unabhängig von ihm von $\mathrm{Overton}$ in folgender Weise geändert bezw. präcisirt. Auch nach ihnen beeinflussen die indifferenten ${ }^{1}$ ) Narkotica, wie Alkohol, Aether und Chloroform, in erster Linie die Cholesterinund lecithinartigen Bestandtheile der Zellen aber nicht in der von Bibra und Harless angenommenen Weise, sondern derart, dass sie den physikalischen Zustand, in dem diese Bestandtheile sich unter normalen Terhältnissen in den Zellen befinden, verändern, ohne aber das Austreten dieser Bestandtheile aus den Zellen zu veranlas sen.

,Zunächst mïssen also die indifferenten Narkotia in die lecithinund cholesterinartigen Bestandtheile der Zellen ïbergehen. Ist das geschehen, so verändern sie den physikalischen Zustand ${ }^{2}$ ) dieser Stoffe entweder dadurch, dass letztere ihre normalen Functionen innernalb der Zelle nicht mehr vollziehen kïnnen oder durch Störung der Functionen anderer Zellenbestandtheile wirken."

Der Kürze halber nemnt Overton die cholesterin- und lecithinartigen Bestandtheile der Zellen Gehirn-Lipoide.

Um die Stärke der verschiedenen Narkotica vergleichen zu können, war es zunächst erwïnscht zu untersuchen, wieviel von jedem Narkoticum in das Lipoid einzudringen im Stande war. Indessen werden unvermischte Narkotica wohl niemals gebraucht. So werden in der chirurgischen Praxis die Narkotica immer mit Luft vermischt. In den ron Meyer und seinem Schïler Baum [7] angestellten Versuchen, bei

1) Neben indifferenten Narkotica hat man noch basische, z. B. das Morphin zu unterscheiden. Hiervon später.

2) Bekanntlich kann z. B. ein Gemenge von Lecithin und Cholesterin unter Wasseraufnahme quellen. 
denen es sich hauptsächlich um die Narkotisirung von Kaulquappen und ron Wimperbewegungen handelte, wurden Lösungen von indifferenten Narkotica in Wasser gebraucht. Und eigentlich handelt es sich auch bei der Narkotisirung des Menschen um wässerige Lösungen, denn die Ganglienzellen müssen die Narkotica aus der sie umspülenden wässerigen Flüssigkeit (Lymphe) beziehen.

So ergiebt sich von selbst die Frage, wie viel von dem in Lymphe aufgelösten Narkoticum in dieGanglienzellen, resp. deren Lipoid übergeht.

Nehmen wir Aether als Beispiel: Der Patient hat Aether eingeathmet; bald enthält die die Ganglienzellen umspülende Lymphe eine gewisse Menge dieses Narkoticums gelöst. Wie viel nimmt die Ganglienzelle, resp. deren Lipoid davon auf? Der Aether vertheilt sich über Lymphe und Lipoid und dies geschieht nach einem bestimmten Gesetz, dem sogenannten Theilungsprincip. Von diesen Princip ist bereits in Bd. II S. 411 und in diesen Band S. 75 die Rede gewesen.

Wegen der allgemeinen Bedeutung dieses Gesetzes, insbesondere für die Pharmakologie, namentlich für die Vertheilung auch von anderen Arzneistoffen auf verschiedene Gewebstheile, erörtere ich diesen Begriff mit einigen Worten näher. Ich komme später unter „Bakteriologisches und Histologisches" nochmals auf den Gegenstand zurïck.

\section{a) Theorie der Theilungscoëfficienten.}

Wenn man einen Stoff mit zwei Flüssigkeiten schüttelt, in denen er in verchiedenem Grade löslich ist, so vertheilt er sich über beide Flüssigkeiten nicht in gleichem Maasse. Er wird in derjenigen Flüssigkeit in der grössten Concentration vorhanden sein, in der er am meisten löslich ist.

Der Quotient zwischen den Concentrationen des Stoffes in den beiden Flüssigkeiten, ist der Theilungscoëficient (Jungfleisch und Berthelot [8]). Wenn z. B. in einem Liter Wasser $1 \mathrm{~g}$ einer Verbindung löslich ist und in einem Liter Xylol bei derselben Temperatur $10 \mathrm{~g}$, so theilt sich die Verbindung zwischen dem Wasser und dem Xylol bei dieser Temperatur stets so, dass das Xylol zehnmal so viel enthält, als das gleiche Volumen Wasser. Der Theilungscoëfficient der Verbindung zwischen Wasser und Xylol ist also bei alle $\mathrm{n}$ Concentrationen, d. h. gleichviel also, ob die Menge der zu vertheilenden Substanz gegenüber dem Flüssigkeitsvolumen gross oder klein ist, $\frac{1}{10}=0,1$.

Wie Nernst gefunden hat, trifft diese einfache Regel aber nur unter bestimmten Bedingungen zu. Insbesondere muss die Verbindung sich in beiden Lösungsmitteln in demselben Molecularzustand befinden [9 und 10]. So fand Nernst, dass Benzoesäure sich über Wasser und Benzol nach einer ganz anderen Regel vertheilt. Dies rührt daher, dass die Benzoesäure in Benzol Doppelmolecüle bildet. 
Dementsprechend wird der Coëfficient nicht, wie im ersten Fall, ausgedrückt durch $\mathrm{C}_{1}$, worin $\mathrm{C}_{1}$ und $\mathrm{C}_{2}$ die Concentrationell sind, in welchen die Verbindung sich in den zwei Flüssigkeiten löst, sondern durch $\frac{\mathrm{C}_{1}}{\mathrm{VC}_{2}}$. (Vergleiche das Kapitel „Histolosisches" 2 b.)

Ferner gilt die Regel in ihrer einfachen Gestalt auch nicht, wenn die Substanz in der einen Flüssigkeit sich elektrolytisch dissociirt, in der andern nicht, oder nicht in gleichem Maasse.

Auch die Temperatur ist nicht ohne Einfluss. Wenn nämlich die Temperatur die Löslichkeit der Verbindung in einer der Flüssigkeiten in einem andern Grade beeinflusst, als in der zweiten Flüssigkeit, so kann der Theilungscoëfficient eines Systems nicht für alle Temperaturen derselbe sein. Endlich müssen, wenn die oben angegebene einfache Regel zutreffen soll, die beiden Lösungsmittel nur in äusserst geringem Maasse sich mit einander mischen lassen.

Wie steht es nun mit dem Theilungscoëfficienten von indifferenten Narkotica z. B. ron Aether und ron Chloroform, gegenüber Lymphe uud Lipoid?

\section{3) Ermittelung des Theilungscoëfficienten bei Narkotica.}

Um diesen Coëfficienten ermitteln zu können, muss man natürlich über Lipoid, d. i. Lecithin und Cholesterin rerfügen. Diese Stoffe sind in grossen Quantitäten schwierig zu erhalten. Darum und auch mit Hinsicht auf unsere mangelhafte Kenntniss betreffs der quantitativen Zusammensetzung der grauen Substanz haben Neyer und Baum, sowie auch Overton sich begnügt. statt Lipoid, Olivenöl zu nehmen und statt Lymphe Wasser zu benïtzen. So ermittelten sie dann den Theilungscoëfficienten der indifferenten Narkotica zwischen Olivenöl und Wasser. Orerton rerhehlt sich nicht, dass auf die genaue Uebereinstimmung zwischen Lipoid und Olivenöl kaum zu rechmen ist. Es sind z. B. die käuflichen Salze der basischen Anilinfarben in Olivenöl niclıt oder kaum löslich, im Gegensatz hierzu aber löslich in Cholesterin wie auch in Lecithin.

Es giebt verschiedene allgemeine Methoden den Theilungscoëfficienten zu bestimmen. Man kann sie in pliysikalische, chemische und physiologische eintheilen.

Die im Princip einfachste, aber nicht immer leicht ausführbare ist diejenige, der man eine bestimmte Gewichtsmenge des zu untersuchenden Stoffes in einer bekannten Menge der einen Flüssigkeit aufüst, die erhaltene Lösung mit einem bekannten Volumen der zweiten Flüssigkeit schüttelt, die Trennung beider Flüssigkeiten abwartet und in der ersten Flüssigkeit die Concentration der nunmehr noch gelösten Substanz ermittelt. Die Schwierigkeit liegt in der quantitativen Bestimmung. 
Die von Overton ausgedachte physiologische Methode ist im Gegensatze zu der eben genannten, nur für Narkotica verwendbar. Als Indicator benutzt Orerton am liebsten junge Kaulquappen von 9-14 mm Länge und verschiedene Entomostraken (Arten von Daphnia. Cyclopss etc.). Auch kann man Infusorien. Pflanzenzellen etc., nehmen. Man ermittelt erst die Concentration des betreffenden Narkoticums in wässeriger Lösung, welche gerade hinreicht, um die Organismen, die man als Indicatoren benutzen will, vollständig zu narkotisiren. Diese Concentration ist nicht nur für verschiedene Objecte verschieden, sondern differirt auch für Objecte derselben Art. Mit Rücksicht auf letztere Thatsache stellt man verschiedene Versuche an und berechnet Mittelwerthe.

Besitzt man diese Mittelconcentration a, so werden Olivenöl und Wasser in einem bekannten Verhältniss mit einer bestimmten Menge des zu untersuchenden indifferenten Narkoticums geschüttelt. Nach $\mathrm{Ab}$. setzen der wässerigen Lösung wird geprüft, ob letztere das object narkotisirt. Ist das der Fall, so fügt man zum Gemisch eine abgemessene Qnantität Wasser, prïft wieder und wiederholt bis in der wässerigen Lösung eine bestehende Narkose etwas zurückgeht. Auf diese Weise hat man somit eine wässerige Flüssigkeit gefunden, von der man sagen kann, dass die Concentration mit der von a übereinstimmt. Es ist num nicht schwer, den Theilungscoëfficient zu berechnen.

Man habe z. B. $1 \mathrm{~g}$ des Narkoticums in dem Flüssigkeitsgemisch gelöst. Nach wiederholter Wasserzugabe ergab sich, dass 10 ce Olivenöl mit 100 ce Wasser versetzt werden müssen, um die zur Narkose erforderliche wässrige Lösung zu bekommen. Hatte sich nun früher ergeben, dass im Nittel eine $0,3 \%$-Lösung des betreffenden Narkoticums zur Narkose himeichte, so darf man schliessen, dass nach dem Schütteln von $1 \mathrm{~g}$ des Narkoticums mit 10 ce Olivenöl und 100 ec Wasser, die wässrige Lösung $0,3^{\circ}$ o des Narkoticums enthielt, also in $100 \mathrm{cc} 0,3 \mathrm{~g}$. In $10 \mathrm{cc}$ Olivenöl befanden sich also $0,7 \mathrm{~g}$. In 100 ce Olivenöl würde das $7 \mathrm{~g}$ betragen haben. Der Theilungscoëfficient des bewussten Narkoticums zwischen Olivenöl und Wasser betring also $7: 0,3=23,3$.

Es ist das ein ganz willkürliches Beispiel, das ich znr Erläuterung supponirt habe. In der Monographie Orerton's findet man kein zahlenmässiges Beispiel erwähnt.

Die Methode hat unter andern den Tortheil, dass man nur sehr geringe Mengen des Narkoticums braucht; schon wenige ce der Lösung reichen für den Narkoseversuch aus, sofern man uur kileine Kaulquappen oder die kaum einige cm messenden Entomostraken als Indicatoren anwendet. 


\section{$\gamma$ ) Bedeutung der Theilungscoëfficienten für die Auffassung des Wirkungsmechanis- mus von indifferenten Narkotica.}

H. Neyer fand, dass die relativen narkotischen Kräfte vieler praktisch wichtiger Narkotica in der nämlichen Reihenfolge stehen, wie die Grösse ihrer Theilungscoëfficienten zwischen Oel und Wasser. Nach dem Gesagten lässt sich hier der Theilungscoëfficient ausdrücken durch den Quotient der Concentration des Narkoticums in Oel und der Concentration desselben in Wasser.

Der Theilungscoëfficient ist demnach um so grösser, je bedeutender

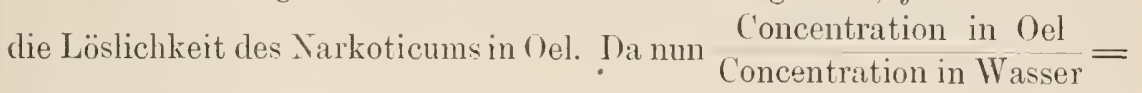
Concentration in Lipoid Concentration in Lymphe angenommen ist, kann man auch sagen: Ein Narkoticnm wirkt n so stärker je grösser die relative Löslichkeit in dem Gehirnlipoid ist $\left.{ }^{1}\right)$.

Hier schliesst sich unmittelbar die Frage an, ob verschiedene Narkotica, wenn sie in gleicher Menge im Gehirnlipoid anwesend sind, anch quantitativ dieselbe narkotische Wirkung ausüben, ob also die Natur der Narkotica (abgesehen somit ron ihrem Löslichkeits- und 'Theilungsverhältniss) für die Wirknng gleichgültig ist. las ist eine Frage, die man, solange die procentische Zusammensetzung des Gemisches der Gehirnlipoide in den Neuronen nicht bekannt ist, noch nicht entgïltig beantworten kann. denn hierfür ist es zunächst nöthig, gen a u zu wissen, wie viel des Narkoticums in die Zellen eingedrungen ist. Erst dann kann man ausfindig machen, ob gleiche Mengen denselben Effect haben.

Es ist uns noch eine Thatsache in gleicher Richtung bekannt geworden, die in hohem Maasse die Aufmerksamkeit beansprucht. Overton hat gefunden, dass die Concentration des Aethyläthers im Blutplasma eines Hundes, welche gerade hinreicht, um den Hund in vollständiger Narkose zu erhalten, fast genau die gleiche ist. wie die Aetherconcentration in dem Blutplasma *) einer Kaulquappe, die erforderlich ist, um letztere völlig zu narkotisiren. Da nun auch zur vollständigen Narkose des Menschen, wie von Paul Bert und Andern festgestellt

1) Hierbei wird die Löshichkeit des Narkoticums in Wasser und Lymphe als gleich angenommen.

2) Eigentlich die Aether-Concentration in dem wässerigen Medium, in dem die Kaulquappe sich befindet. 
worden ist, der Aethergehalt der Inspirationsluft, ebenso, wie beim Hunde, $20 \mathrm{~g}$ Aether pro Hektoliter betragen muss und da die Bluttemperatur des Menschen und des Hundes im wesentlichen gleich sind, so gelangt man zu dem unerwarteten Ergebniss, dass das Gehirn des höher entwickelten Menschen niclit empfindlicher gegen Aetler istals das Gehirn eines Hundes oder einer Kaulquappe, oder dass wenigstens bei allen dreien dieselbe Concentration des Aethers im Blutplasma zur vollständigen Gehirnnarkose erforderlich ist.

Auch Mäuse, Sperlinge und Insecten (es wurden Bienen, Wespen, Ameisen und Fliegen untersucht), mussten ein Luftgemisch von mindestens $20 \mathrm{~g}$ Aether pro Hektoliter einathmen, um vollständig narkotisirt $z u$ werden. Die Sperlinge bedurften sogar eines Luftgemisches, das etwas mehr Aether enthält. Dies hängt damit zusammen, dass die Körpertemperatur bei den Vögeln um einige Grade höher ist, als bei den Säugethieren. Das Blut absorbirt aber aus demselben Gemisch von Aether und Luft bei höherer Temperatur etwas weniger Aether.

Aehnliche Verhältnisse wurden anch bei Chloroform gefunden.

Es muss hervorgehoben werden, dass die Gleichheit der zur Narkose erforderlichen Concentration des Aethers in dem Blutplasma, nicht für alle Thierclassen gilt. Bei den verschiedenen Gruppen der Würmer ist eine mindestens doppelt so hohe Concentration des Aethers erforderlich, bei einigen noch höhere Concentrationen. Bei den Protozoen und Pflanzen sind etwa 6 mal höhere Concentrationen des Aethers zur Narkose erforderlich als bei den Kaulquappen.

Letzteres rïhrt vielleicht daher, dass die Protozoen und Pflanzenzellen weniger lipoidartige Stoffe (Lecithin, Cholesterin etc.) enthalten und sich bei der Theilung also einer geringeren Quantität des ihnen dargebotenen Narkoticums bemächtigen können ?

Meyer hat hervorgehoben, dass die Narkose eigentlich bei allen Zellen des Organismus möglich ist, wenn nur Fett und fettähnliche (oder wie wir mit Overton sagen lipoidartige) Substanzen darin vorkommen, in welchen sich die Narkotica lösen können. Dementsprechend wird die Wirkung an denjenigen Zellen am ersten und stärksten hervortreten müssen, in deren chemischen Baı jene fettähnlichen Stoffe vorwalten und in denen sie besonders wesentliche Träger der Zellfunction sind: in erster Linie also an den Nervenzellen.

In Uebereinstimmung damit steht, wie Overton noch nälier betont hat, dass diejenigen Verbindungen die stärksten Narkotica sind, die gleichzeitig eine sehr geringe Löslichkeit in Wasser mit einer sehr hohen Löslichkeit in Olivenöl, oder strenger in den Gehimlipoiden, combiniren. Phenanthren z. B., von dem 1 Theil erst in circa 200000 Theilen Wasser, das aber in Olivenöl leicht löslich ist. narkotisirt Kaulquappen noch in einer Concentration von 1: 1500000; (Chloroform thut es erst in einer Concentration von $1: 6000)$. 
Ebenfalls dem Verhalten der Theilungscoëfficienten entsprechend, nimmt in den verschiedenen homologen Reihen die narkotische Kraft einer Verbindung mit der Länge ihıer Kohlenstoffkette zunächst schnell zu. Wenn aber, wie das bei den höchsten Gliedern der Ketten der Fall ist, trotz einer hohen relativen Löslichkeit in den Gehirnlipoiden, die absolnte Löslichkeit unter ein bestimmtes Minimum sinkt, kann die Verbindung nicht mehr als Narkoticum dienen.

Weiter ist von den isomeren Alkoholen, Estern u. S. w. die Verbindung mit der am wenigsten verzweigten Kohlenstoffkette, das stärkste Narkoticum. Diese Verbindung ist auch viel löslicher in Olivenöl als die Verbindung mit der am meisten verzweigten Kohlenstoffkette.

Der Eintritt einer Hydroxylgruppe in ein Molecül an Stelle eines Wasserstoff- oder Halogen-Atoms setzt die narkotische Kraft der Verbindung stark herab. In noch stärkeren Maasse gilt dies für den Eintritt von zwei oder mehr Hydroxylgruppen in das Molekiil. Wird aber der Wasserstoff der Hydroxylgruppen durch eine Alkylgruppe ersetzt, so fungiren die entstehenden Verbindungen wieder als starke Narkotica. Auch die Phenoläther sind starke Narkotica.

Diese Aenderungen in der narkotischen Kraft einer Verbindung nach rerschiedenen Substitutionen gehen wieder parallel mit den Grössen der Theilungscoëfficienten.

Schliesslich sei es mir gestattet auf einen sehr schönen Beweis aufmerksam zu machen, den Meyer kürzlich füx das Gesetz der Theilungscoëfficienten erbracht hat [12].

Da der Einfluss der Temperatur auf die Löslichkeit in Wasser und Oel für verschiedene Verbindungen nicht der gleiche ist, so hat es nichts Befremdendes, dass mit dem Steigen der Temperatur, der Theilungscoëfficient zwischen Oel und Wasser bei manchen Stoffen abnimmt, bei manchen zunimmt. Dementsprechend muss die Concentration, bei welcher gerade Narkose eintritt, für Poikilotherme z. B. Froschlarven, bei den einen mit der Temperatur zumehmen, bei den andern mit derselben abnehmen.

Die Experimente genügen in vollkommenster Weise der theoretischen Forderung.

\begin{tabular}{|c|c|c|c|c|}
\hline \multirow[t]{2}{*}{ Narcoticum } & \multicolumn{2}{|c|}{$\begin{array}{c}\text { Concentration, bei welcher eben } \\
\text { Narkose eintritt }\end{array}$} & \multicolumn{2}{|c|}{$\begin{array}{c}\text { Theilungscoëfficient } \\
\text { Oel } \\
\text { Wasser }\end{array}$} \\
\hline & bei $3^{0}$ & bei $30^{\circ}$ & bei $3^{0}$ & bei $30^{\circ}$ \\
\hline Salicylamid & 1/1300 norm. & ${ }^{1 / 600}$ norm. & 22,232 & 14,002 \\
\hline Benzamid & ${ }^{1} ; 500 \quad$, & $1 / 200 \quad "$ & 0,672 & 0,437 \\
\hline Monoacetin & ${ }^{1} / 90$ & ${ }^{1 / 70}$ & 0,099 & 0,066 \\
\hline Aethylalkohol & $1 / 3$ & $1_{17}$ & 0,026 & 0,047 \\
\hline Chloralhydrat & $1 / 50$ & $1 / 250$ & 0,053 & 0,236 \\
\hline Aceton & $1 / 3$ & ${ }^{1 / 7}$ & 0,146 & 0,235 \\
\hline
\end{tabular}


Nehmen wir nun z. B. den Versuch mit Chloralhydrat. Eine 1/250 Normal-Chloralhydratlösung (1 Mol. Chloralhydrat auf $250 \mathrm{~L}$. Wasser) hebt hei $30^{\circ}$ die Bewegungen der Kaulquappen auf. Bei einer niedrigeren Temperatur ist die dazu erforderliche Concentration stärker (bei $3^{0}$ $1 / 50$ normal). Wenn man also die $1 / 250$ Normal-Chloralhydratlösung, in welcher die Froschlarven bei $30^{\circ}$ zum Stillstand gekommen sind, abkühlt, so fangen sie sich wieder zu bewegen an. Das steht in vollkommenem Einklang mit dem Theilungscoëfficienten. Durch Abkiihlung ron $30^{\circ}$ auf $3^{0}$ nimmt dieser von $0,236-0,053 \mathrm{ab}$, d. h. durch Abkühlung sinkt die relative Quantität des Chloralhydrates im Oel (Lipoid des Thieres) und reicht nicht mehr aus, um die Narkose herbeizuführen.

Man darfaus diesen Erörterungen wohl den Schluss ziehen, dass die narkotische Kraft eines indifferenten Narkoticums vorwiegend durch die Grösse seines Theilungscoëfficienten zwischen Gehirnlipoiden und Lymphe bestimmt wird.

() verton konnte diese Ansichten auch auf die organischen Antiseptica (Carbolsäure, Kresole, Thymol etc.) ausdehnen. Diese stimmen mit den indifferenten Narkotica darin überein, dass sie äusserst leicht in die lebenden Zellen ein- und austreten. Sie gehen auch zum Theil in die Gehirnlipoide über, besitzen aber a usserdem die Fähigkeit. mit den Zellproteïnen Verbindungen einzugehen. Uebrigens hängt es oft nur von der Concentration ab, ob eine Verbindung als Narkoticum oder Antisepticum zu bezeichnen ist. Dieselhe Substanz liann in geringeren Mengen als Narkoticun und in grösseren als Antisepticum wirken.

Bis jetzt war lediglich von den indifferenten Narkotica die Rede. Auch den basischen Narkotica, wie Morphin, hat Orerton die Aufmerksamkeit gewidmet.

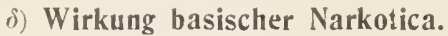

I)iese gehen höchstwahrscheinlich Verbindungen mit den Zellenproteïnen ein, die sich in der Zelle im Zustande der Dissociation befinden. Durch Herabsetzen der Concentration der betreffenden freien Basen im Protoplasma werden sie weiter dissociirt. Es handelt sich hier um einen ganz analogen Vorgang, wie bei den Versuchen mit tamninhaltigen Zellen (S. 230), auf welche ich deshalb nur zu verweisen brauche. Im rorliegenden Falle nimmt das Eiweiss die Stelle des Tannins ein. 
So ist durch das Studinm der osmotisclien Eigenscliaten der Zelle unsere Einsicht in den Mechanismus der Wirkung der Narkotica einen wesentliclen Schritt we it er ger ückt.

\section{Pharmakologische Bedeutung von complexen Salzen, erläutert an der therapeutischen Anwendung des Quecksilbers.}

\section{Litteratur.}

1. Drever, Archiv f. experim. Path. u. Pharmak. 32. 1893. S. 456.

2. Barth, Zeitschr. f. physik. Chemie 9. 1४92, S. 54.

Die therapeutische Anwendung des Quecksilbers ist mit mancherlei schwierigkeit verknüpft.

Wendet man es als solches in Form von grautr Salbe zur Inunctionscur an oder in der Gestalt einer wasserunlöslichen Verbindung (Calomel) zur subcutanen Einspritzung, so weiss man nicht, wie viel von dem im Uebermaass dargebotenen Medicament wirklich in rer Säftemasse circulirt. Wünscht man letzterer Schwierigkeit zn entgehen, so kann man eine wasserlösliche Terbindung benutzen. Aber in diesem Falle wirkt es, vermöge seiner besonders starken Affinität zum Eiweiss, stark ätzend an den Applicationstellen.

Um nun wieder diese localen Wirkungen thunlichst zu verhüten, lat man vorgeschlagen, das Quecksiber in einer bereits mit Eiweiss verbundenen Form (Quecksilberpeptonat) subcutan zu injiciren. Es stellte sich aber bald heraus, dass diese Verbindungen in Beziehung anf Reizwirkungen an der Injectionstelle nicht viel vor der Sublimatlösung: voraus hatten. Dies erscheint nicht wunderbar, denn es war eigentlich nicht zu erwarten, dass diese Verbindung sich nicht theilweise dissuciiren würde. Deshalb wurden dann andere lösliche Quecksilberverbindungen versucht, aus denen sich vielleicht keine $\mathrm{Hg} \cdot$-Ionen abspalten würden. Als solche wurden von Dreser (1) zwei schwe f el baltig e Verbindungen gewählt: Das Mercurisalz der Rhodanwasserstoffsäure $\mathrm{Y}=\mathrm{C}-\mathrm{SH}$, und der Unterschwefligsäure $\mathrm{HO}_{3} \mathrm{~S}$ - SH, also $\mathrm{Hg}(\mathrm{CNS})_{2}$ und $\mathrm{Hg}_{3} \mathrm{~S}_{2} \mathrm{O}_{3}$. Jiese salze bilden, nach den Untersuchungen von Dreser mit Rhodanka-

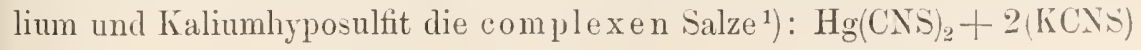

1) Dreser nennt dieselben irrthümlich Doppelsalze. Ueber den Unterschied beider Bezeichnungen vergl. unten S. 254. 
bezw. $3\left(\mathrm{Hg}_{3} \mathrm{~S}_{2} \mathrm{O}_{3}\right)+5\left(\mathrm{~K}_{2} \mathrm{~S}_{2} \mathrm{O}_{3}\right)$. Sie krystallisiren schön, geben mit Eiweiss keine Fällung und enthalten $39,31 \%$ bezw. $31,41 \%$ Quecksilber.

Um die Quecksilberwirkung dieser Salze kennen zu lernen, versetzte sie Dreser mit Zucker und Hefezellen und untersuchte, in welchem Maasse die Gährung durch die Salze beeinträchtigt wurde. Daneben wurden ähnliche Versuche mit einer Sublimatlösung angestellt, die dieselbe Quecksilbermenge enthielt. Während nun die Sublimatlösung und die Rhodansalzlösung die Zuckergährung verhinderten, war merkwïrdiger Weise die Lösung von Quecksilberhyposulfit hierzu nicht im Stande.

Das sonst so giftige Quecksilberwar also merkwürdiger Weise in der Form seines complexen unterschwefligsauren Kalisalzes ungiftig für die Hefezellen.

Dreser hat dafür die richtige Erklärung gegeben. Cm diese verständlich zu machen, will ich einige allgemeine pyhsikalisch-chemischen Bemerkungen vorausschicken, die ron grosser Tragweite sind.

Wenn man $\mathrm{AgNO}_{3}$ mit $\mathrm{NaCl}$ rersetzt, so entsteht bekanntlich $\mathrm{AgCl}$. In die Sprache der Ionenlehre übersetzt heisst dies: $\mathrm{AgNO}_{3}$ ist in die Ionen $\mathrm{Ag}^{\circ}$ und $\mathrm{NO}_{3}^{\prime}$ gespalten: $\mathrm{NaCl}$ ist in die Ionen $\mathrm{Na}^{\circ}$ und $\mathrm{Cl}^{\prime}$ gespalten und die Ionen $\mathrm{Ag}^{\circ}$ and $\mathrm{Cl}^{\prime}$ verbinden sich $\mathrm{zu} \mathrm{AgCl}$. Versetzt man aber $\mathrm{AgNO}_{3}$ mit $\mathrm{NaClO}_{3}$, so bildet sich kein $\mathrm{AgCl}$, weil bei der elektrolytischen Dissociation ron $\mathrm{NaClO}_{3}$ keine (hlorionen frei werden, denn diese Verbindung wird in $\mathrm{Na}$ und $\mathrm{ClO}_{3}{ }^{\prime}$ gespalten. Nur Ionen reagiren mit einander.

Ein schönes Beispiel für letzteren Satz finden wir in folgendem Versuch.

Leitet man trockenes $\mathrm{HCl}$ durch Chloroform, so erhält man eine Lüsung, welche keine Ionen enthält. Dies ergiebt sich daraus, dass sie den elektrischen Strom nicht leitet. Bringt man in diese Lösung ein Carbonat, so wird es nicht zersetzt. Fügt man aber weiter eine Spur Wasser hinzu, so dass ein Theil der $\mathrm{HCl}$ sich dissociiren kann, so findet unmittelbar Entwickelung von Kohlensïure statt.

Dasselbe Princip gelangt auch bei den complexen Salzen zum Ausdruck.

Beilüufig sei herrorgehoben, dass man die „complexen Salze“ wohl ron denen zu unterscheiden hat. die man Doppelsalze nemnt.

Ein Beispiel möge den (interschied klar legen.

Werden Kupfersulfat $\left(\mathrm{Cn} \mathrm{SO}_{4}\right)$ und Kaliumsulfat $\left(\mathrm{K}_{2} \mathrm{SO}_{4}\right)$ in Wasser gelöst und mischt man die entstandenen Lösungen mit einander, so wird bei Abkühlung aus dieser Lösung ein Salz auskrystallisiren, welches den Namen Kaliumkupfersulfat trägt 
und durch die Formel Cu SO $\mathrm{SO}_{4} \cdot \mathrm{K}_{2} \mathrm{SO}_{4} \cdot 6 \mathrm{H}_{2} \mathrm{O}$ dargestellt werden kann. Löst man dieses Salz auf's Neue in Wasser, so lässt sich die Gegeuwart von Kupferionen (mittelst $\mathrm{H}_{2} \mathrm{~S}$ ), Kaliumionen (mittelst $\mathrm{H}_{2} \mathrm{PtCl}_{6}$ ) und Sulfationen (mittelst $\mathrm{BaCl}_{2}$ ) nachweisen. Man nent nun das Salz $\mathrm{CnSO}_{4} \cdot \mathrm{K}_{2} \mathrm{SO}_{4} \cdot 6 \mathrm{H}_{2} \mathrm{O}$ ein Doppelsalz. Ein solches Salz giebt in seiner Lösung die Reactionen, welche die einzelnen I onen zeigen. Die Gefrierpunkterniedrigung einer Lösung des Doppelsalzes ist gleich der Summe der Gefrierpunkterniedrigungen seiner Componenten, hier von $\mathrm{CuSO}_{4}$ und $\mathrm{K}_{2} \mathrm{SO}_{4}$.

Betrachten wir dagegen die Lösung des Silbercyankalium AgCN. KCN, welches entsteht, wenn man AgCN in KCN-Lösung auflöst. Zusatz einer Lösung von $\mathrm{NaCl}$ erzeugt darin keinen Niederschlag̣ von $\mathrm{AgCl}$. Die Erklärung hierfür findet man in dem Ergebniss anderer Versuche, welche lehren, dass das Silbercyankalium in die Ionen K. und $\mathrm{Ag}(\mathrm{CN})_{2}$ zerfällt. Silberionen sind also darin nicht vorhanden und deshalb ist die Bildung von $\mathrm{AgCl}$ unmöglich. Ein solches Salz wie $\mathrm{KAg}(\mathrm{CN})_{2}$, in welchem die Eigenschaften der Componenten AgCN und KCN nicht unverändert geblieben sind, nenut man ein complexes Salz. Die Ionen, welche in den Lösungen der Componenten $\mathrm{AgCN}$ und $\mathrm{KCN}$ zugegen waren $\left(\mathrm{K}^{\circ}, \mathrm{C}^{\prime} \mathrm{N}^{\prime}, \mathrm{Ag} \mathrm{g}^{\circ}\right)$ findet man in der Lösung des complexen Salzes nicht unverändert wieder und hiermit längt die Thatsache zusammen, dass die Gefrierpunkterniedrigung einer derartigen Lösung nicht gleich der Summe derjenigen ist, welche die Componenten ergeben würden.

Durch diese Vorstellung erhalten zahllose Thatsachen, die seit Langem bekannt sind, eine ungezwungene Erklärung. Ich verweise wegen des Näheren auf Ostwald's wissenschaftliche Grundlagen der analytischen Chemie. $3 e$ Auflage. Leipzig 1901.

Gleichartige Ueberlegungen wie bei dem complexen Salz AgCN. KCY gelten auch für Dreser's unterschwefligsaures Quecksilbersalz.

Dieses entsteht z. B., wenn man gelbes $\mathrm{HgO}$ in Kaliumhyposulfit $\mathrm{K}_{2} \mathrm{~S}_{2} \mathrm{O}_{3}$ (gewöhnlich Kaliumthiosulfat genannt) einträgt, nach folgender Gleichung:

$$
\mathrm{HgO}+\mathrm{K}_{\mathrm{S}-\mathrm{SO}_{3} \mathrm{~K}}^{\mathrm{K}}=\mathrm{K}_{2} \mathrm{O}+\mathrm{Hg}_{3} / \mathrm{S}-\mathrm{SO}_{3} \mathrm{~K}
$$

Letzteres nun spaltet sich in die Ionen

$$
\left(\mathrm{Hg}_{\mathrm{S}} / \mathrm{S}-\mathrm{SO}_{3}\right)^{\prime} \text { und } 2 \mathrm{~K}
$$

Dass wirklich keine Hg"-I onen als solche, wohl aber K-Ionen sich abspalten, hat Dreser noch durch Elektrolyse weiter bewiesen. Er fand, dass Kíalium sich an der Kathode, Quecksilber aber an der Anode abschied ${ }^{1}$ ) Eine gleichartige Ionenspaltung hatte friiher

1) Man sieht, es war ein Irrthum Dreser's, hier von einem "Doppelsalz" zu sprechen. Der Irrthum bezieht sich bei dem Verfasser aber lediglich auf den Namen, denn die Deutung der Thatsachen war eine überaus richtige. 
Barth [29] in Ostwald s Laboratorium fiir das schwefligsaure $\mathrm{N}$ atriumquecksilbersalz gefunden.

War nach dieser Vorstellung die nichtgiftige Wirkung des complexen Salzes auf Hefezellen leicht zu verstehen, so musste es doch beim ersten Anblick befremden, dass es demgegenüber auf den Kaninchenorganismus einen sehr schädlichen Einfluss ausuibte, ja sogar eine eben so starle Giftwirkung entfaltete, als ob eine äquivalente Sublimatlösung angespritzt war. Offenbar aber zersetzt sich das $\left(\mathrm{Hg} / \mathrm{S}-\mathrm{SO}_{3}\right)^{-\mathrm{S}-\mathrm{SO}_{3}}$ im Körper dieses Thieres schnell unter Bildung von Quecksilberi onen. Auf diese Weise kann dann das Quecksilber auch im complexen Salz eine Giftwirkung ausüben.

Diese Zersetzung des complexen Ions findet bei niedriger Temperatur sehr langsam statt, denn bei Fischen und Fröschen blieb die Quecksilberwirkung sehr lange ans. Dreser hält also das unterschwetligsaure Quecksilbersalz für die praktische Terwerthung sehr geeignet, denn es gibt

1. keine Eiweissfällang,

2. keine Localerscheinungen

und 3. ermöglicht es eine exacte Dosirung.

\section{Die Lehre von der Desinfection im Lichte der Theorie der elektrolytischen Dissociation.}

\section{Litteratur.}

1. Paul und Krönig, Zeitschr. f. physik. Chemie 21. 1896. S. 414.

2. Paul und Krönig, Zeitschr. f. Hygiene und Infectionskrankh. 25. 1897. S. 1.

3. Paul, Entwurf zur einheitlichen Bestimmung chemischer Desinfectionsmittel. Berlin 1901.

4. Kahlenber Zeitschr. f. physik. Chemie S. 1891. S. 587 u. 608.

5. Scheurlen, Archiv f. exp. Path. u. Pharmak. 37. 1895. S. 74. Die Bedeutung des Molecularzustandes der wassergelösten Desinfectionsmittel für ihren Wirkungswerth. Strassburg 1895.

6. Wiardi Beekmann, Centralbl. f. Bact. u. Parasitenk. 20. 1896. S. 577.

7. Paul und Krönig, Münchener med. Wochenschr. 1897. Nr. 12.

8. Scheurlen und Spiro, München. med. Wochenschr. 1897. Nr. 12. S. 304

9. Spiro und Broms, Archiv f. exp. Path. u. Pharmak. 41. 1899. S. 355.

10. Römer, München. med. Wochenschr. 1898. S. 298.

11. Spiro, Physik. u. Physiol. Selection. Strassburg 1897. 
12. Setschenow, Zeitschr. f. physik. Chemio 4. 1889. S. 117.

13. Gordon, Zeitschr. f. physik. Chemie 1S. 1895. S. 1.

14. Roth, Zeitschr. f. physik. Chemie 24. 1897. S. 114.

15. Steiner, Wiedem. Ann. 52. 1894. S. 275.

16. II Intosh, Journal of physic. Chemistry 1. 1897. p. 474.

17. Enler, Zeitschr. f. physik. Chemie. 31. 1899. S. 360.

18. Rothmund, Zeitschr. f. physik. Chemie 33. 1900. S. 401.

19. Minervini, Zeitschr. f. Hygiene 29. 1899. S. 58.

20. Maillard, Compt. rend. Soc. de Biol. 4. Janv. 1899; Journal de Physiol. norm. et pathol. 1899. p. 130.

21. Eckardt, Ueber die Diffusion und ihre Beziehung zur Giftwirkung. Inaug.-Diss. Leipzig 1898.

22. Manfred Bial, Zeitschr. f. physik. Chemie 40. 1902. S. 513.

Im Jahre 1896 veröffentlichten Paul und Krönig Untersuchungen, welche bezweckten, das desinficirende Vermögen verschiedener Stoffe mit einander zu vergleichen. Sie studirten Salze, Basen, Säuren, Halogene, Oxydationsmittel und einige organische Verbindungen in wässeriger, alkoholischer und ätherischer Lösung bei verschiedenen Verdünnungen $\left[\begin{array}{lll}1 & \text { u. } 2\end{array}\right]$. Bei allen Untersuchungen wurde die Temperatur constant gehalten, da nur unter dieser Bedingung vergleichbare Resultate zu erzielen waren.

Als Versuchsobjecte benutzten die Verfasser meistens Milzbrandsporen oder Staphylococcus pyogenes aureus. Sie arbeiteten wenig mit den vegetativen Formen, sondern meist mit den Sporen des Milzbrandes, weil die regetative Form von Milzbrand - und dies gilt auch von Staphylococcus, der nur als regetative Form zu erhalten ist - gegen so verdünnte Lösungen vor Desinfectionsmitteln empfindlich ist, dass Unterschiede nicht mit genügender Deutlichkeit hervortreten können.

Die desinficirende Kraft der Lösungen wurde in der Weise untersucht, dass die Autoren sie auf eine annähernd gleiche Anzahl Sporen einwirken liessen. Dann wurden die Gifte auf chemischem Wege beseitigt - also etwa bei Anwendung von schweren Metallsalzen, durch Einwirkung von Schwefelammon oder bei Anwendung von Laugen bezw. Säuren durch Yeutralisation - und nunmehr geprüft, wieviele Sporen noch auf Agar auskeimten. Insbesondere haben sich Krönig und Paul bemüht festzustellen, ob und inwieweit die Desinfection (und Entwickelungshemmung), auf Ionen zurückzuführen sei.

\section{a) Salze.}

Von den Salzen kamen nur die der schweren Metalle zur Untersuchung. 
Die meisten Experimente wurden mit Quecksilberverbindungen angestellt. Verschiedene dieser Verbindungen wurden in äquivalenten Mengen abgewogep und in gleichen Volumen Wasser gelöst. Die Autoren hatten also gleich concentrirte Lösungen. Durch Bestimmung der Leitfähigkeit war bekannt, in welchem Grade diese äquivalenten Lösungen dissociirt waren. (Bd. I, S. 41, Methode.)

Folgende Tabelle enthält die Namen einiger dieser Verbindungen nach ihrem Dissociationsgrad geordnet.

1. Quecksilberchlorid $\mathrm{Hg} \mathrm{Cl}_{2}$.

2. Quecksilberbromid $\mathrm{HgBr}_{2}$.

3. Quecksilbercyanid $\mathrm{Hg}(\mathrm{CN})_{2}$.

Es liess sich nun erwarten, dass, wenn die desinficirende Wirkung der Anionen $\mathrm{Cl}^{\prime}, \mathrm{Br}^{\prime}$ und $(\mathrm{CN})^{\prime}$, sowie der nicht dissociirten Molecüle gegenüber der desinficirenden Wirkung des $\mathrm{Hg}^{*}$-Ions gering oder Null war, die Desinfectionswirkung der betreffenden Lösungen im Wesentlichen von der Concentration dieses $\mathrm{Hg}^{\prime}$-Ions abhängen, d. h. mit dem Dissociationsgrad der Salze parallel gehen würde.

Dass dies wirklich der Fall war, geht aus folgender Tabelle hervor, welche die Versuchsergebuisse an Sporen von B. Anthracis enthält.

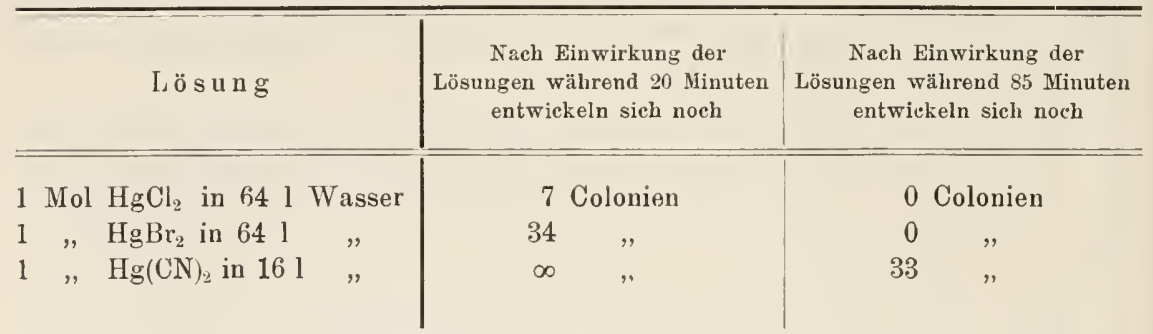

Es entwickelten sich also, nach 20 Minuten währender Einwirkung von 1 Grammmolecuil $\mathrm{HgCl}_{2}$ (271 g) aufgelöst in 64 Liter Wasser, 7 Colonien : nach Einwirkung von 1 Grammmolecül $\mathrm{HgBr}_{2}$ in 64 Liter Wasser dagegen 34 Colonien. Die $\mathrm{HgCl}_{2}$-Lösung wirkte also stärker desinficirend als die äquivalente $\mathrm{Hg}_{\mathrm{g}}-\mathrm{Br}_{2}$ - Lösung, und eine sogar concentrirtere $\mathrm{Hg}(\mathrm{CN})_{2}$ Lösung war die schwächste von allen. Ein entsprechendes Resultat erhielten die Verfasser auch nach längerer Einwirkung der betreffenden Lösungen.

Diese Abnahme der desinficirenden Wirkung ron oben nach unten entspricht ganz der gleichsinnigen Abnahme des Dissociationsgrades, m. a. W.: Je stärker die untersuchten Quecksilberverbindungen dissocirt sind, d. h. je mehr Quecksilberionen in der Volumeinheit der betreffenden Lösungen vorhanden sind, um so stärker ist die desinficirende Wirkung. 
Wie Paul und Krönig mittheilen [2], hat Ikeda eine einfache Beziehung zwischen Concentration und Giftwirkung der $\mathrm{Hg} \mathrm{Cl}_{2}$-Lösungen abgeleitet, die aber auch nach ihm selbst eine weitere experimentelle Nachprüfung bedarf. Der Verfasser hält es für wahrscheinlich, dass der Ausdruck ganz allgemein auf die Desinfectionsvorgänge angewendet werden kann.

$\mathrm{Zu}$ demselben Resultat wie bei den Quecksilbersalzen, gelangten Paul und Krönig auch bei Silber-, Gold- und Kupfersalzen, bei denen das Metallion gleichfalls giftige Wirkung hat. Insbesondere bei den Silberverbindungen haben sie aber weiter gefunden, dass neben dem Metallion auch das Säure-Ion (Anion) und vielleicht auch das unzersetzte Molecül an der desinficirenden Wirkung betheiligt ist.

Ich erwähne folgende Tabelle:

\begin{tabular}{|c|c|}
\hline Lösung & $\begin{array}{l}\text { Colonien nach } \\
60 \text { Minuten }\end{array}$ \\
\hline $\mathrm{AgNO}_{3}$ in $20 \mathrm{l}$ Wasser & 27 \\
\hline $\mathrm{AgClO}_{3}$ in $20 \mathrm{l} \quad$, & 42 \\
\hline $\mathrm{AgClO}_{4}$ in $20 \mathrm{l}$ & 219 \\
\hline $\begin{array}{l}\mathrm{CH}_{3} \mathrm{COOAg} \text { in } 20 \mathrm{I} \text { Wasser } \\
\text { (essigsaures Silber) }\end{array}$ & 1580 \\
\hline $\begin{array}{c}\mathrm{C}_{6} \mathrm{H}_{5} \cdot \mathrm{SO}_{2} \cdot \mathrm{OAg} \text { in } 20 \mathrm{l} \text { Wasser } \\
\text { (benzolsulfosaures Silber) }\end{array}$ & 800 \\
\hline 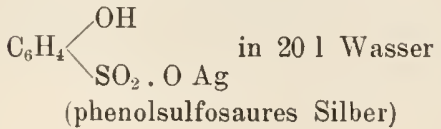 & $\begin{array}{l}1654 \\
1653\end{array}$ \\
\hline
\end{tabular}

Offenbar ist das desinficirende Vermögen dieser Lösungen verschieden stark, obgleich die Concentration der Silberionen dieselbe ist. Die Wirksamkeit dieser Lösungen hängt also auch von dem Säureion, rielleicht auch ron den undissociirten Molekülen ab.

Erwähnung verdient noch, dass das Silberthiosulfat (unterschwefligsaures Silber) sehr geringe desinficirende Wirkung zeigt, ebenso wie auch das entsprechende Quecksilbersalz. Beide sind eben complexe Salze, aus welcher nur wenige Metallionen abgespalten werden. (Vergl. oben S. 255 in dem rorigen Abschnitt.)

In vollkommener Uebereinstimmung damit steht, dass — während das Sulfat, Chlorid und Acetat des Kupfers das Wachsthum von Lupinenkeimlingen hemmen, ja dieselben bereits tödten, wenn nur 1/51200 Mol. in einem Liter Wasser enthalten sind - von der complexen, wenige 
$\mathrm{Cu}$ "-I o n en bildenden Verbindung, die der Zusammensetzung $1 \mathrm{Cu} \mathrm{SO}_{4}+$ $1 \mathrm{C}_{12} \mathrm{H}_{22} \mathrm{O}_{11}+3 \mathrm{KOH}$ entspricht, bis zu ${ }^{1 / 400}$ Mol. im Liter Lösung vorhanden sein kann, bevor sich eben Giftwirkungen bemerklich machen [4].

\section{๙) Abschwächung der desinficirenden Wirkung von Salzen durch Hinzufügung be- stimmter lonen.}

Nach dem soeben Gesagten wird jedes Mittel, das die elektrolytische Dissociation der $\mathrm{Hg}^{*}$-Salze, also die Concentration der wirksamen Ionen einschränkt, schwächend auf das desinficirende Vermögen wirken müssen. Zu den Mitteln nun, die den Grad der elektrolytischen Dissociation herabsetzen, gehört der Zusatz des entsprechenden Anions, so z. B. der Zusatz von $\mathrm{Cl}^{\prime}$-Ionen zu dem $\mathrm{HgCl}_{2}$. Es ist aber nicht möglich lediglich freie Anionen hinzuzusetzen; deshalb benutzt man zu diesem Zweck ein neutrales Chlorid, z. B. NaCl.

Der Grund dieser dissociationsvermindernden Beeinflussung ist. folgender:

Wir denken uns eine gesättigte $\mathrm{HgCl}_{2}$-Lösung theilweise in die Ionen $\mathrm{Hg}$ * und $\mathrm{Cl}^{\prime}+\mathrm{Cl}^{\prime}$ zerfallen. Bei constanter Temperatur besteht ein bewegliches Gleichgewicht zwischen den unzersetzten $\mathrm{HgCl}_{2}$ - Molekülen und den Ionen $\mathrm{Hg}^{*}$ und $\mathrm{Cl}^{*}$.

$$
\mathrm{HgCl}_{2} \rightleftarrows \mathrm{Hg}^{* *}+\left(\mathrm{Cl}^{\prime}+\mathrm{Cl}^{\prime}\right)
$$

Ist $\mathrm{k}_{1}$ die Geschwindigkeit, mit welcher $\mathrm{HgCl}_{2}$ in seine Ionen zerfällt und $\mathrm{k}_{2}$ diejenige, mit welcher die Ionen das undissociirte Salz zurückbilden, so ist nach dem Gesetz von Guldberg und $\mathrm{W}$ a age $\Theta$, wenn $\mathrm{CHgCl}_{2}, \mathrm{CHg}_{\mathrm{H} \cdot \cdot,} \mathrm{C}_{\mathrm{Cl}^{\prime}}{ }_{2}$ die Concentrationen von $\mathrm{HgCl}_{2}, \mathrm{Hg}^{*}$ und $\mathrm{Cl}_{2}{ }_{2}$ vorstellen (vergl. $\mathrm{Bd}$. II, S. 477),

$$
\begin{aligned}
& \mathrm{k}_{1} \mathrm{CHgCl}_{2}=\mathrm{k}_{2} \mathrm{CHg}_{\mathrm{Hg}} \times \mathrm{CCl}_{2} \\
& \text { also } \frac{\mathrm{k}_{1}}{\mathbf{k}_{2}}=\frac{\mathrm{CHg}^{*} \times \mathrm{CCl}_{2}}{\mathrm{CHgCl}_{2}} \\
& \text { Setzen wir für } \frac{k_{1}}{k_{2}}=K \\
& \text { so ist } \frac{\mathrm{CHg}^{*} \times \mathrm{CCl}_{2}}{\mathrm{CHgCl}_{2}}=\mathrm{K} \\
& \text { also } \mathrm{CHg}_{\mathrm{Hg}^{*}} \times \mathrm{C}_{\mathrm{Cl}_{2}^{\prime}}=\mathrm{K} \times \mathrm{C}_{\mathrm{HgCl}_{2}} \text {. }
\end{aligned}
$$

Da nun bei constanter Temperatur in einer gesättigten $\mathrm{HgCl}_{2}$-Lösung, $\mathrm{C}_{\mathrm{HgCl}_{2}}$ constant ist, so können wir für das letztere Glied eine andere constante $K^{\prime}$ schreiben.

Demnach: $\mathrm{C}_{\mathrm{Hg}} \cdot \times \mathrm{C}_{\mathrm{Cl}^{\prime} 2}=\mathrm{K}^{\prime}$

Also das Product der Concentrationen in der Lösung (Löslichkeitsproduct) ist constant.

Vergrössern wir nun durch Zusatz von Chlorionen den Werth von $\mathrm{C}_{\mathrm{Cl}^{\prime}}$, so wird, dader. Werth von $\mathrm{k}_{1}$ constant bleibt, $\mathrm{C}_{\mathrm{Hg}}$. dementsprechend abnehmen müssen, d. h. die Dissociation von $\mathrm{HgCl}_{2}$ geht etwas zurïck und je mehr $\mathrm{NaCl}$ man hinzufügt, um so grösser ist dieser Rückgang. 
Statt $\mathrm{NaCl}$ liann man, wie aus diesen Ausführungen und auch aus den Versuchen hervorgeht, auch andere Chloride wie $\mathrm{KCl}, \mathrm{CaCl}_{2}$ und selbst $\mathrm{HCl}$ anwenden, Paul und $\mathrm{Krönig} \mathrm{haben} \mathrm{nun} \mathrm{constatirt,} \mathrm{dass}$ durch alle diese Mittel auch die desinficirende Kraft abnimmt. Dementsprechend geschieht das auch, wenn man $\mathrm{zu} \mathrm{Hg}\left(\mathrm{NO}_{3}\right)_{2}$ ein Nitrat z. B. $\mathrm{NaNO}_{3}$ oder auch $\mathrm{HNO}_{3}$ hinzufügt.

Die folgende Tabelle enthält einige zalılenmässige Resultate. Das Object war Bac. anthracis (Sporen). Die Flüssigkeiten wirkten 9 Minuten auf die Sporen ein.

\section{Abnahme der desinficirenden Kraft durch Hinzufiigung von Ionen.}

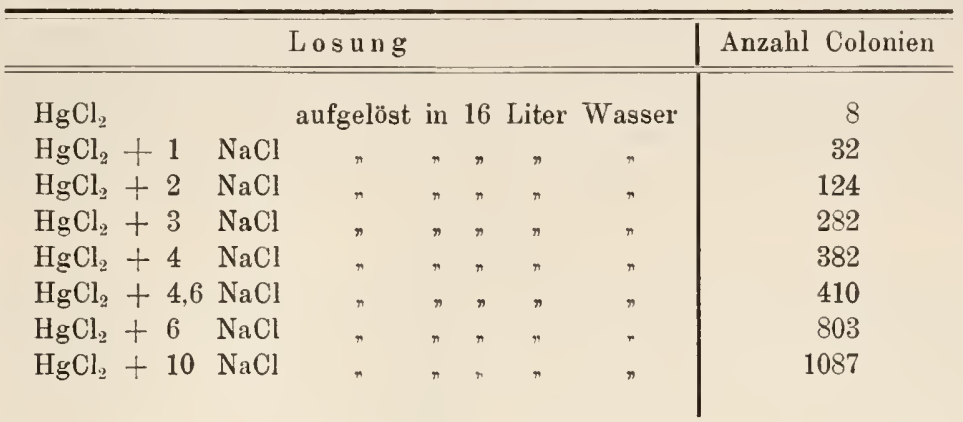

Diese Tabelle lehrt unzweideutig, dass je mehr Kochsalz zu dem Sublimat hinzugefügt wurde, sich um so mehr Colonienceteris paribus entwickelten, um so geringer also die desinficirende Kraft war.

Dieses Ergebniss ist auch deshalb von Interesse, weil in der medicinischen Praxis relativ oft mit Sublimatlösungen desinficirt wird und es hierbei üblich ist, die Schwerlöslichkeit des $\mathrm{HgCl}_{2}$ durch starken Zusatz von Kochsalz zu beseitigen. Das deutsche Arzneibuch hat in seiner neuesten Auflage Sublimatpastillen vorgeschrieben, welche $\mathrm{HgCl}_{2}$ und $\mathrm{NaCl}$ in gleichen Gewichtstheilen enthalten, was ungefähr der Zusammensetzung $\mathrm{HgCl}_{2}+4,6 \mathrm{NaCl}$ der 'Tabelle entspricht.

Man sieht aus der Tabelle, dass dieses Kochsalzquantum die desinficirende Kraft erheblich zurückdrängt. Indessen ist diese Zurückdrängung viel geringer, wenn es sich um grössere Verdünnungen handelt. Wenn man 1 Grammmolecül $\mathrm{HgCl}_{2}+4,6 \mathrm{NaCl}$ nicht in 17 , sondern in 256 Liter auflöst - und diese Verdünnung entspricht gerade der in der Praxis gebräuchlichen 1 pro Mille-Lösung — so fällt der Eintluss des $\mathrm{NaCl}$ fast ganz weg. Eine entsprechende Versuchsreihe, bei der in $256 \mathrm{l}$ Wasser einmal 1 Grammmolecül $\mathrm{HgCl}_{2}+2$ Gramm- 
moleciile $\mathrm{NaCl}$ aufgelöst wurden, lehrte, dass die während 20 Minuten lang mit diesen Flïssigkeiten behandelten Sporen, 10 bezw. 13 Colonien gaben (Das Verhältniss bei Verdünnung mit 161 Wasser war, wie oben ersichtlich, 8 und 124).

Obgleich also die Sublimatpastillen in der iiblichen Verdünnung keine erhebliche Einschränkung des dem vorhandenen $\mathrm{HgCl}_{2}$ entsprechenden Desinfectionsvermögens erleiden, geht doch aus diesen Versuchen deutlich hervor, dass es im Allgemeinen nicht gleichgültig ist, wie viel $\mathrm{NaCl}$ man hinzusetzt, um so weniger, weil $1 \mathrm{HgCl}_{2}+2 \mathrm{NaCl}$ ein complexes Salz $\mathrm{Na}_{2} \mathrm{HgCl}_{4}$ bildet, in dem das $\mathrm{Hg}^{*}$-Ion als solches nicht mehr vorhanden ist.

Paul und Krönig wiesen nach, dass auch andere Chlorverbindungen das Desinfectionsvermögen des Sublimats zurïckdrängen, dies aber in geringerem Maasse thun, je schwächer sie dissociirt sind, z. B. $\mathrm{CaCl}_{2}$ weniger als $\mathrm{NaCl}$. Es entspricht dies der oben gegebenen Erklärung.

\section{b) Säuren.}

Im Grossen und Ganzen geht die desinficirende Wirkung der Säurelösungen ihrem Dissociationsgrad parallel, d. i. also der Zahl der Wasserstoffionen pro Volumeinheit der Lösung. Ich sage, ,im Grossen und Ganzen", denn wenn man $\mathrm{HCl}, \mathrm{HBr}, \mathrm{HClO}_{4}$ und $\mathrm{HNO}_{3}$ in Concentrationen, bei denen sie gleich stark dissociirt sind, mit einander vergleicht, so ist ihre Desinfectionswirkung doch eine verschiedene. Dies rührt daher, dass die Säuren noch ätzende, oxydirende und andere Wirkungen anf die Bacterien ausiiben. Bei sehr starken Verdünnungen treten diese Wirkungen aber in den Hintergrund, so dass der oben genannte Parallelismus um so mehr der Wahrheit entspricht, je verdünnter die Lösungen sind.

Für höhere Pflanzen hat man gleichartige Thatsachen beobachtet. So fand z. B. $\mathrm{He}$ ald eine ${ }^{1 / 12800}$ normal Lösung von $\mathrm{HCl}, \mathrm{H}_{2} \mathrm{SO}_{4}, \mathrm{HNO}_{3}$ und $\mathrm{HBr}$ in gleichem Maasse giftig für die Keimlinge von Pisum sativum. Die äquinormalen Lösungen der genannten starken Säuren enthalten bei dieser grossen Verdünnung die gleiche $\mathrm{H}^{\cdot}$ Ionenconcentration. Gleichartiges fand er für Zea Mais, bei welcher die $1 / 3200$ Normallösungen giftig waren. Dass die Giftwirkung in der That von den $\mathrm{H}^{\prime}$-Ionen und nicht von den $\mathrm{Cl}^{\prime}, \mathrm{Br}^{\prime}, \mathrm{NO}_{3}^{\prime}$, $\mathrm{SO}^{\prime \prime}{ }_{4}$-Ionen herrührt, geht daraus hervor, dass die Natriumsalze der genannten Säuren in derselben Verdünnung keine Giftwirkung zeigen. Dagegen ertrugen Pisum sativum und Zea Mais viel stärkere Essigsäure-Lösungen. Das rührt dalıer, dass die $1 / 12800$ - und 1/3200 Normalessigsäurelösungen bei weitem nicht so stark in ihre Ionen dissociirt sind als die äquivalenten Lösungen der genannten starken Säuren. Demgegenüber wirken nach Kablenberg und True Propionsäure, Buttersäure und Valeriansäure, wenngleich sie nach Ostwald etwas weniger stark dissociirt sind als Essigsäure, doch viel stärker schädigend als diese. Man hat das dadurch zu erklären gesucht, dass hier auch die Anionen und vielleicht auch die unzersetzten Säuren nicht obne Einfluss sind, hat indessen den Factor 
„Zeit" nicht berücksichtigt (siehe unter g, S. 268). Weiter verweise ich auf die früher erörterten Ausführungen von J a cques Loeb (Muskeln).

Dass aber unter geeigneten Bedingungen die antiseptische Function von Säuren sehr deutlich als durch $\mathrm{H}^{\prime}$-Ionen herbeigeführt sich ergeben kann, lehren die sorgfältigen Versuche ron Ma n fred Bial [22]. Sie betreffen die antiseptische Wirkung verdünnter Säuren auf den Hefepilz und unterscheiden sich insbesondere dadurch von den Experimenten von $\mathrm{Paul}$ und Krönig, dass sie mit viel verdünnteren Säuren ausgeführt werden konnten, weil Hefepilze weit empfindlicher sind, als die ron Paul und Krönig benützten Milzbrandsporen. Die Anwendung sehr verdünnter Säuren hat den grossen Vortheil, dass man wenig ron Nebenwirkungen der Säuren zu fürchten hat.

Auch war Bial's Versuchsverfahren sehr einfach. Die Activität des Hefepilzes und also auch die Beinträchtigung durch Säure wurde durch Messung des aus Traubenzucker entwickelten Gases ermittelt; das Volumen drückte die Gährintensität aus.

Ich will hier eine Versuchsreihe mittheilen.

Vergleich von $\mathrm{HCl}, \mathrm{H}_{2} \mathrm{SO}_{4}, \mathrm{H}_{3} \mathrm{PO}_{4}, \mathrm{CH}_{3} \mathrm{COOH}$.

\begin{tabular}{|c|c|c|c|c|c|c|c|c|c|}
\hline Röhre & 1 & entlıaltend & 0,00083 & norm. & $\mathrm{HCl}$ & & 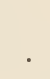 & G & $\begin{array}{l}\text { ährintensitä } \\
\left.\text {. } 57,60^{1}\right)\end{array}$ \\
\hline , & 2 &. & 0,00166 &., & ", & . . & & . & . 2060 \\
\hline , & 3 & , & 0,0025 & , & , & . . & & . & $3 / 60$ \\
\hline , & 4 & , & 0.0033 &, & , & . . & & . & . $2 / 60$ \\
\hline , & 5 & ,. & 0,005 & , & ., & . . & . & . & . 0 \\
\hline ,. & 6 & , & 0,0066 & .. & , & . . & 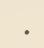 & . & . 0 \\
\hline , & 7 & ., & 0,00083 & , & $\mathrm{H}_{2} \mathrm{SO}_{4}$ & . . & 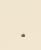 & . & . 5560 \\
\hline , & 8 & , & 0.00166 & ., & . & . . & $\cdot$ & . & . 3060 \\
\hline , & 9 & " & 0,0025 & , & , & . . & . & . & . 560 \\
\hline :" & 10 & , & 0,0033 & , & , & . . & 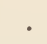 & . & . 260 \\
\hline , & 11 & , & 0,005 & , & ” & $\therefore$. & . & . & . 0 \\
\hline, & 12 & , & 0,0066 & ., & ,, & . . & 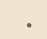 & . & . 0 \\
\hline , & 13 & ,. & 0,00083 &, & $\mathrm{H}_{3} \mathrm{PO}_{4}$ & . . & 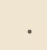 & 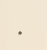 & . 56,60 \\
\hline , & 14 & , & 0.00166 &, & , & . . & . & - & . $56 / 60$ \\
\hline ., & 15 & , & 0,0033 & ,. & , & . . & . & . & . 2060 \\
\hline , & 16 & ,. & 0,005 & , & , & . . & . & - & 1260 \\
\hline ,. & 17 & , & 0,0066 & , & , & . . & . & . & 360 \\
\hline , & 18 &, & 0,0083 & $"$ & $"$ & . . & 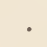 & . & $2 / 60$ \\
\hline ., & 19 & , & 0,01 & , & $"$ & . . & . & . & . 0 \\
\hline. & 20 & ", & 0,016 & , & $\mathrm{CH}_{3} \mathrm{COOH}$ & . . & 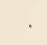 & . & . $\quad 57 / 60$ \\
\hline , & 21 & , & 0,025 & , &, & . . & . & . & - $\quad 56,60$ \\
\hline , & 22 & , & 0,033 & ,. &, & . . & . & . & . 5560 \\
\hline , & 23 & " & 0,05 & , & , & . . & 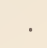 & . & . $3 / 60$ \\
\hline ,, & 24 & , & 0,066 & $"$ & " & . . & . & . & . 0 \\
\hline
\end{tabular}

1) d. h. also, dass 57,60 des Gefässes mit Gas gefüllt ist. 
Ich muss hier noch auf eine wichtige Sache aufmerksam machen. Wenn es richtig ist, dass die antiseptische Wirkung verdünnter Säuren von der $\mathrm{H}$-Ionenconcentration abhängig ist, so muss jedes Mittel, das die elektrolytische Dissociation der Säure herabsetzt, auch deren antiseptische Wirkung herabdrücken. Wie aus dem Obenerwähnten (S. 260) hervorgeht, wird die elektrolytische Dissociation von $\mathrm{HCl}$ durch $\mathrm{NaCl}$ zurückgedrängt. Trotzdem fand Bial das antiseptische Vermögen nicht verringert; im Gegentheil vermehrt. Der Autor erklärt das dadurch, dass die Chlorionen (des $\mathrm{NaCl}$ ) auf die $\mathrm{H}$-Ionen katalysirend wirken. Eine vollkommen gleiche Erscheinung beobachtet man bei der Zuckerinversion. Versetzt man $\mathrm{HCl}$ mit ein wenig $\mathrm{NaCl}$, so wird das Inversionsvermögen gesteigert. Was $\mathrm{NaCl}$ gegenüber $\mathrm{HCl}$ bewirkt, bewirkt $\mathrm{Na}_{2} \mathrm{SO}_{4}$ gegenüber $\mathrm{H}_{2} \mathrm{SO}_{4}$, Natriumacetat gegenüber Essigsäure. Grössere Mengen der entsprechenden Salze drücken aber das antiseptische Vermögen der Säuren herab, weil dann der Einfluss der Dissociationsabnahnie bedeutender ist als der der katalytischen Wirkung.

\section{c) Basen.}

Von diesen wurden $\mathrm{KOH}, \mathrm{NaOH}, \mathrm{LiOH}$ und $\mathrm{NH}_{4} \mathrm{OH}$ untersucht. Ihre desinficirende Wirkung geht dem Dissociationsgrad parallel, also auch der Anzahl freier Hydroxylionen pro Volumeinheit der Lösung. Dementsprechend ist auch die desinficirende Kraft des Ammoniaks sehr klein, da die elektrolytische Dissociation dieser Verbindung sogar bei erheblicher Verdünnung noch gering ist (vergl. Bd. 1 S. 43).

\section{d) Halogene.}

Die Halogene: $\mathrm{Cl}, \mathrm{Br}$ und $\mathrm{J}$ besitzen auch in sehr grossen Verdünnungen eine ganz ausserordentlich starke Desinfectionskraft. Nach einer Einwirkungszeit von 2 Minuten haben Chlor und Brom bei der Verdünnung von $1 \mathrm{Mol}$ auf 128 Liter die Sporen getödtet. Da sich das Jod erst in 571 Liter Wasser löst, konnte ein Vergleich der drei Halogene nur von dieser Verdünnung an vorgenommen werden. Es stellte sich dabei heraus, dass diese Elemente nach ihrer Desinfectionswirkung in derselben Reihenfolge - Chlor, Brom, Jod - stehen, welche sie auch in ihrem sonstigen chemischen Verhalten zeigen.

e) Phenol, lysol, Creolin und andere organische Desinfectionsmittel.

Bekanntlich bildet Phenol $\left(\mathrm{C}_{6} \mathrm{H}_{5} \mathrm{OH}\right)$ bei gemöhnlicher Temperatur farblose lírystalle, die sich mit 10\% Wasser zu einer Flïssigkeit, dem sogenannten "Acid. carbolicum liquefactum" verbinden. 
Es stellte sich nun die merkwïrdige Thatsache heraus, dass das Acid. carbolic. liquefactum nicht besser, eher etwas schwächer auf Milzbrandsporen einwirkt als die $5 \%$ ige wässerige Lösung, obgleich erstere fast $16 \mathrm{mal}$ so viel Phenol im selben Volumen der Flüssigkeit enthält.

Auf eine weitere merkwïrdige Thatsache hat Scheurlen die Aufmerksamkeit gelenkt. Wenn zu einer wässerigen Phenollösung ein Salz. z. B. NaCl hinzugesetzt wird, so wird die desinficirende Kraft der Lösung wesentlich verstärkt [5].

Diese Thatsache ist später ron Wiardi Beckmann [6], von Paul und Krönig [7], von Scheurlen und Spiro [8], von Spiro und Bruns [9] eingehend studirt und bestätigt worden. Die Verstärkung des Phenols geht der Concentration der Kochsalzlösung parallel und macht sich schon bei geringen Kochsalzconcentrationen bemerkbar, wie die folgenden Versuche von Römer beweisen [10].

Einfluss von NaCl anf die desinficirende Wirkung ron Phenol.

Tage der Finwirkung auf die Milzbrandsporen.

\begin{tabular}{|c|c|c|c|c|c|c|c|c|}
\hline & 0 & 1 & 3 & 7 & 9 & 11 & 13 & 15 \\
\hline $\begin{array}{l}3 \% \text { Phenol } ; \% \\
3 \% \text { Phenol }+1 \%\end{array}$ & 6300 & 1390 & 1260 & 950 & 810 & 530 & 560 & 530 Colonien \\
\hline $\mathrm{NaCl} \cdot .$. & 8640 & $\begin{array}{l}1450 \\
1480\end{array}$ & 2520 & 300 & - & 186 & 96 & 0 \\
\hline $\begin{array}{l}3 \% \text { Phenol }+8 \% \\
\mathrm{NaCl} .+.\end{array}$ & 2350 & 230 & 6 & 0 & - & - & - & - \\
\hline
\end{tabular}

An Stelle von Kochsalz kann man auch andere Verbindungen verwenden, nur müssen es Elektrolyte sein; fast undissociirte Salze, wie benzoesaures Natrium, nuitzen beinahe nichts. Indessen wirken gleich stark dissociirte Elektrolyte nicht gleich, sondern es herrscht doch eine ganz bestimmte Reihenfolge, die, nach absteigendem Effect geordnet, nach Spiro und Bruns, die folgende ist: $\mathrm{NaCl}$, KCl, NaBr, Na.J, $\mathrm{NaNO}_{3}$.

Was ist die Ursache dieser Erscheinung? Bekanntlich wird durch Elektrolyte die Löslichkeit organischer, oder richtiger gesagt, nichtleitender Verbindungen besonders nachdrücklich herabgesetzt. Phenol lässt sich, wie Spiro und Bruns gelegentlich ihrer Untersuchungen auch berichten, durch $\mathrm{NaCl}$ sogar ausfällen, ,aussalzen."

Denkt man sich nun Bacterien von einer wässerigen Phenollösung umgeben, so wird das Phenol sich über das Lipoid des Bacterienleibes 
und das umgebende Wasser vertheilen. Je löslicher das Phenol im Wasser ist, um so weniger häuft sich im Bacterienleib an, und umgekehrt ${ }^{1}$ ). Setzt man also die Löslichkeit von Phenol in der äusseren Flüssigkeit durch Hinzufügung von Salz herab, so ändert sich das Theilungsverhältniss zu Gunsten des Lipoids : es dringt mehr Phenol in den Bacterienleib ein, die desinficirende Wirkung hat somit durch Hinzufügung von Salz zu dem Phenol zugenommen (Spiro [11]). Diese Erklärung für die Verstärkung der Phenolwirkung durch Kochsalz gewinnt dadurch in hohem Maasse an Wahrscheinlichkeit, dass die Erscheinung nicht bloss an Phenol, sondern auch an anderen Nichtleitern beobachtet wird. Insbesondere wird sie ferner noch dadurch befestigt, dass die Verstärkung der desinficirenden Wirkung in derselben Reihenfoige zunimmt, wie die Löslichkeit der hinzugefïgten Elektrolyte in Phenol.

In gleichem Sinne sprechen auch die Ergebnisse verschiedener anderer Lös lichkeitsbestimmungen. Setschenow [12] bestimmte den Einfluss verschiedener Salze auf die Löslichkeit von Kohlenoxyd in Wasser. Gordon [10] und Roth [14] thaten dasselbe für Stickstoffoxydul, Steiner [15] für die Löslichkeit von Wasserstoff. Mc Intosh [16] von Alkohol, Euler [17] von Aethylacetat und Rothmund [18] von Phenylthiocarbamid. Alle fanden, dass die Löslichkeit der genannten, doch sehr verschiedenartigen Stoffe stets am ungünstigsten beeinflusst wird durch $\mathrm{SO}_{4}^{\prime \prime}$, dann durch $\mathrm{Cl}^{*}$, weniger durch $\mathrm{NO}_{3}^{\prime}$ und $\mathrm{Br}^{\prime}$ und am wenigsten durch $\mathrm{J}$. Von Kationen war es das $\mathrm{Na}$; das am stärksten beeinträchtigend auf die Löslichkeit wirkte; schwächer wirkten $\mathrm{K}$. und $\mathrm{NH}_{4}$. Warum die Ionen so verschieden und in erwähntem Sinne auf die Löslichkeit wirken, ist noch unbekannt.

\section{i) Alkohol und Aether als Lisungsmittel; ihr Einfluss auf das des- inficirende Vermögen.}

Paul und Kr rönig haben weiter auf die Thatsache aufmerksam gemacht, dass eine Lösung vou $\mathrm{HgCl}_{2}$ oder $\mathrm{AgNO}_{3}$ in absoluten Alkohol oder Aether, auch bei tagelanger Einwirkung, ohne jeden Einfluss auf Milzbrandsporen ist. Dies rührt daher, dass die betreffenden Substanzen in diesen Lösungsmitteln nur sehr wenig discociirt sind. Wird dann der Alkohol mit Wasser verdïnnt, so tritt auch die desinficirende Wirkung ein. Verfolgt man nun weiter, in welchem Grade dies bei Alkohollösungen verschiedenen Procentgehaltes der Fall ist, so gelangt man zu dem unerwarteten Resultat, dass Lösungen vou Sublimat und $\mathrm{AgNO}_{3}$ in Alkohol-Wassergemischen sogar viel stärker desinficirend wirken, als in Wasser allein.

1) Ueber das Theilungsprincip vergl. man Bd. II, S. 411 u. diesen Band S. 246; weiter das Kapitel Histologisches unter $2 \mathrm{~b}$. 
Vielleicht ist diese günstige Wirkung der Alkohol-Wassergemische auf eine Begünstigung des Eindringens von $\mathrm{Ag}^{*}$ - und $\mathrm{Hg}^{*}$-Ionen durch den Alkohol zurückzuführen.

Auch ist, wie Minervini bei seinen Untersuchungen über die Wirkung ron Desinfectionsmitteln in alkoholischer Lösung hervorgehoben hat, der Einfluss des Theilungscoëfficienten zwischen Lipoiden und Lösungsmittel nicht ausser Betracht zu lassen. Bei Ersatz von Alkohol durch Wasser findet zweifellos eine Verschiebung statt [19].

Paul und Krönig haben gefunden, dass die Verstärkung beim Silbernitrat eine viel bedeutendere ist wie beim Sublimat und weiter, dass ersteres in $50 \%$ igem und letzteres in $25 \%$ igem Alkohol am besten wirkt. Beim $\mathrm{AgNO}_{3}$ beginnt die Verstärkung schon bei einer alkoholischen Lösung von $10 \%$, während beim Sublimat zunächst eine Abschwächung der Desinfection eintritt und die Verstärkung erst bei $20 \%$ einsetzt.

\section{g) Anderweitige Abweichungen. Schlussbetrachtung.}

Der erörterte Satz, dass bei den Salzen, Säiren und Basen, die desinficirende Wirkung der Concentration der wirksamen Ionen proportional ist, welcher Satz noch eine schöne Bestätigung in der Beobachtung fand, dass die Vittel, welche nach den theoretischen Forderungen der Ionenlehre die Dissociation zurückdrängen, auch die desinficirende Wirkung hinabdrücken, dieser Satz scheint aber einige Ausnahmen zu erleiden.

So fanden Paul und Krönig, dass das Nitrat, Sulfat, Acetat des Quecksilbers, obgleich sie in äquimolecularen Lösungen viel stärker dissociirt sind als die entsprechende Sublimatlösung, viel schwächere Desinfectionsmittel sind als diese.

Dies mag aus folgender Tabelle hervorgehen.

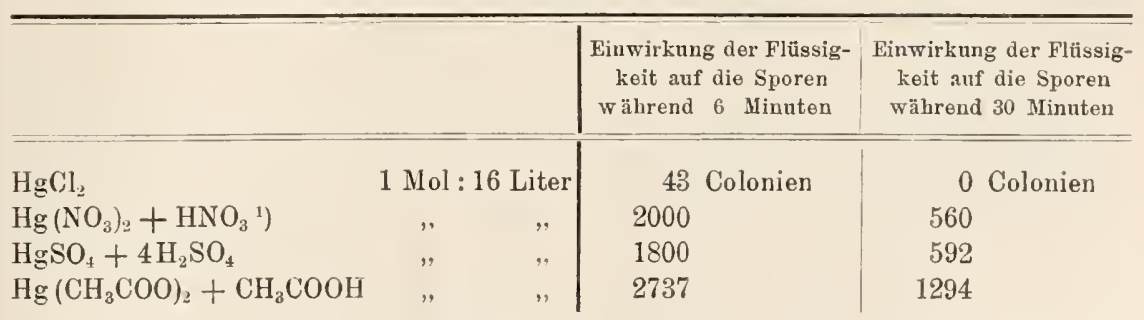

1) Die entsprechenden Säuren sind hinzugefügt wolden, weil sonst durclı Lösung in viel Wasser basische Salze ausfallen. Die entsprechende Säure als solche steigert aber die Wirksamkeit der freien Hy."-Ionen nicht, wie oben (S. 264) aus einander gesetzt wurde. Im Gegentheil! 
Wie ersichtlich, entwickeln sich nach Einwirkung von Sublimat viel weniger Colonien als nach Einwirkung der anderweitigen Quecksilberverbindungen. Das Sublimat hat also am kräftigsten desinficirend gewirkt.

Weiter fanden $\mathrm{Paul}$ und $\mathrm{Kr}$ önig, dass $\mathrm{HgCl}_{2}$ und $\mathrm{Hg}(\mathrm{CN})_{2}$ trotz der Versch i e denheit der D iss oc ia tions g r a d e einen gleichgradigen Einfluss auf die Entwickelungshemmung (ich spreche hier nicht von Abtödtung) von Milzbrandsporen ausübten.

Und so giebt es mehr Abweichungen. M a illa rd [20] betonte aber, dass man neben dem Einfluss der molecularen (osmotischen) Concentration, auch dem Einfluss der Einwirkungszeit Rechnung tragen soll. Wenn man Organismen nur sehr kurze Zeit mit giftigen Ionen in verschiedener Concentration in Berührung lässt, so kann es sich ereignen, dass trotz dieser Verschiedenheit in der Concentration, kein quantitativer Unterschied zu bemerken ist, weil dieser in der kurzen Zeit noch nicht genïgend zum Ausdruck gekommen ist. Erst nach längerer Einwirkung und zwar, nachdem die Ionenconcentration innerhalb und ausserhalb der Organismen ungefähr dieselbe geworden ist, kann man eigentlich das Facit aufstellen. Es kommt also a ch die Dif fussionsgeschwindigkeit in Betracht, die nicht bei allen Bacterienzellen dieselbe ist.

Bereits früher hatte aucl $\mathrm{Paul}$ vermuthet, dass die Diffusionsgeschwindigkeit bei der desinficirenden Wirkung verschiedener chemischer Agentien eine Rolle spielt und hatte dann Eckardt [21] veranlasst, die Diffusionsgeschwindigkeit verschiedener Desinfectionsmittel zu untersuchen. Dabei stellte sich heraus, dass zwischen dieser Diffusionsgeschwindigkeit und der Giftwirkung, welche sich gewissen Bacterien gegenüber zeigt, ein gewisser Parallelismus besteht.

\section{Verfolgen wir zunächst Maillard's Untersuchungen!}

Der Verfasser hatte sich zur Aufgabe gestellt, die Giftigkeit des Kupfersulfats rür Penicillium glaucum kennen zu lernen. Hierzu brachte er Culturen des genannten Pilzes in Glaskolben, die sich in einem Thermostat bei $18^{\circ}$ befanden. Dann wurden verschieden concentrirte Kupfersulfatlösungen eingetragen. Die Entwickelung der Pilze fand während etwa $f$ ü $\mathrm{n} f \mathrm{~W}^{\mathrm{o}} \mathrm{ch}$ e $\mathrm{n}$ statt, in welcher Zeit das osmotische Gleichgewicht $z$ wischen den Flüssigkeiten innerhalb und ausserhalb der organischen Zellen sich einstellen konnte. Sodann wurden die Flocken (Pilzanhäufungen), welche sich in der Flüssigkeit gebildet hatten, durch Filtration von derselben getrennt, getrocknet und gewogen. Die nachstehende Tabelle zeigt, in welcher Weise das Gewicht der Culturen mit der Concentration der Kupferionen zusaminenhängt. (Diese Concentration liess sich aus der Leitfähigkeit der betreffenden Lösungen bestimmen.) 
Anzahl der Grammionen Kupfer.

$$
\begin{aligned}
& 0,0803 \\
& 0,0647 \\
& 0,0554 \\
& 0,0329
\end{aligned}
$$

Gewicht der Culturen.

0,0166

0,0442

0,0505

0,0649

Je grösser die Zahl der Kupferionen in demselben Volumen, um so geringer ist das Gewicht der Culturen.

Wurde der Dissociationsgrad des vorhandenen Kupfersulfats durch Zusatz eines Salzes mit gleichartigem Anion (z. B. $\left(\mathrm{NH}_{4}\right)_{2} \mathrm{SO}_{4}$ oder $\mathrm{Na}_{2} \mathrm{SO}_{4}$ ) zurückgerrängt, so trat eine Herabsetzung der Giftigkeit der Kupfersulfatlösung ein, ein Beweis für die Richtigkeit der Annahme, dass die Giftigwirkung der Lösung der Gegenwart freier Kupferionen zuzuschreiben ist.

Man sieht, dass, wenn der Factor ,Ze it" genügend berücksichtigt wurde, die Giftigkeit in der That mit der Ionenconcentration Hand in Hand ging. Doch wäre es übertrieben zu erwarten, dass bei dieser Berïcksichtigung die betreffende Gesetzmässigkeit überall zu Tage treten würde.

Es giebt mehrere Gründe, die letzteres unwahrscheinlich machen.

1. Die Desinfectionswirkung hängt nicht nur von der Reaction des betreffenden Mittels mit dem Protoplasma ab, sondern auch von der Geschwindigkeit, mit der dieselbe eindringt. Obgleich nun Eckardt einen gewissen Parallelismus zwischen der Diffusionsgeschwindigkeit einiger Metallsalze durch todte Membranen und der Grösse der Giftwirkung auf Bacterien beobachtete, und sogar konstatiren konnte, dass Mittel, welche die Giftwirkung beeinträchtigen, auch die Diffusionsgeschwindigkeit durch todte Membranen herabsetzen (z. B. $\mathrm{NaCl}$ mit $\mathrm{HgCl}_{2}$ ), so wird doch Niemand wagen anzunehmen, dass Diffusibilität und chemische Protoplasmawirkung immer parallel gehen werden.

2. Es darf nicht erwartet werden, dass alle Zellenarten, wenn es sich um schwere Metallsalze oder Säuren handelt, lediglich für Metall-, bezw. H-Ionen, und wenn es sich um Basen handelt, lediglich für $\mathrm{OH}^{\prime}$-Ionen permeabel sein werden. Es scheint doch etwas gewagt anzunehmen, dass die anderen, die Terbindung zusammensetzenden Ionen mit entgegengesetzten Zeichen, ganz ohne Einfluss auf das Leben der Zellen sein werden.

3. Betreffs der Wirkungsweise derjenigen Ionen, von denen ein Eindringen wohl als sichergestellt erachtet werden darf, z. B. bei Quecksilbersalzen von $\mathrm{Hg}^{*}$, und bei Säuren von $\mathrm{H}^{*}$, tasten wir bei unserer weitgehenden Unkenntniss der chemischen Zusammensetzung der lebenden Zelle noch im Dunkeln. Unter diesen Umständen kann 
man auch nicht vorhersagen, dass der Tod resp. die Entwickelungshemmung der Organismen immer ausschliesslich die Fölge einer directen Wirkung der thätigen Ionen ist. Es ist auch möglich, dass es sich zuweilen um eine indirecte Wirkung handelt, die mit der Ionenconcentration vielleicht gar nicht in einem proportional-quantitativen $\mathrm{Zu}$ sammenhang steht.

4. Man muss annehmen, dass für jedes in die Zelle eindringende (giftige) Ion ein gleichnamiges Ion austritt. Es ist fraglich, ob diese Ionen immer unter den gegebenen Bedingungen in der erforderlichen Menge zur Verfügung stehen. Ist das nicht der Fall, so muss bereits dadurch die gesuchte Proportionalität zwischen Giftwirkung und Concentration der in der Flüssigkeit rorhandenen giftigen Ionen vermisst werden.

5. Bei Lösungen ron schweren Metallsalzen wird die Sache noch dadurch complicirt, dass man selbst ron rein chemisch-physikalischer Seite keineswegs ïber deren osmotische Zusammensetzung orientirt ist. Bei Lösungen von schweren Metallsalzen mangelt es selbst a $n$ genauen Daten über dieConcentration der Metallionen.

6. Auch sind die B eding ungen für die Bildung von c o m plexen Salzen noch keineswegs aufgeklärt. Dass diese complexen Salze, deren Ionen ganz abweichende toxische Eigenschaften besitzen, auch im Zellinnern sich bilden, kann kaum einem Zweifel unterliegen, denn in diesen Zellen sind verschiedenartige andere Salze wie $\mathrm{NaCl}, \mathrm{KCl}, \mathrm{K}_{2} \mathrm{CO}_{3}$ etc. zugegen. Dabei spreche ich noch nicht einmal von basischen Salzen, die sich unter dem Einfluss der alkalischen Reaction der intracellularen Flüssigkeit bilden können und die Concentration der schweren Metallionen beeinflussen.

Man sieht, die Sache liegt sehr complicirt und wen $\mathrm{n}$ man dennoch, nicht nur bei Bacterien, sondern auch bei höheren Pflanzen, Ionenconcentration und Giftigkeitsgrad bei lerselben Gruppe von Substanzen, in bei Weitem den meisten der untersuchten Fälle parallel la ufen sieht, so darf man mit grosser. Wahrscheinlichkeit daraus schliessen, dass dieser Parallelismus von fundamentaler Bedeutung ist. Diese Erkenntniss kann bei der Analyse der complicirten Erscheinungen als werthroller Mittel- oder Ausgangspunkt benutzt werden. 


\section{Löslichkeitsverhältnisse von Harnsäure und harnsauren Salzen, und ihre therapeutische Bedeutung für die Auflösung von Concrementen.}

\section{Litteratur.}

1. His und Paul, Zeitschr. f. physiol. Chemie 31. 1900. S. 1 u. 64.

2. His und Paul, Pharmaceutische Zeitung 1900.

3. Stokvis, Leçons de Pharmacothérapie 2. p. 117 ff. Paris 1898.

4. Ruidel, Archiv f. exp. Path. u. Pharmak. 30. 1892. S. 469

a) Löslichkeitsverhältnisse von Harnsäure und harnsauren Salzen.

Die zahllosen Widersprüche über die Löslichkeitsverhältnisse der Harnsäure gaben $\mathrm{H}$ is und Paul [1] Veranlassung, diese Substanz mittelst physikalisch-chemischer Metloden eingehend $\mathrm{zu}$ studiren. Zunächst wurde die Löslichkeit von Harnsäure in reinem Wasser ermittelt. Im Gegensatz zu den Angaben, nach denen das Löslichkeitsverhältniss der Harnsäure in Wasser, bei Zimmertemperatur 1: 10075 bis $1: 16700$ beträgt, konnten $\mathrm{His}$ und $\mathrm{Paul}$ feststellen, dass sich die Harnsäure in reinem Wasser bei $18^{0}$ im Terhältniss $1: 39480$ löst. In 1 Liter der gesättigten Lösung sind also $0,0253 \mathrm{~g}$ Harnsäure oder $\frac{0,25 \check{2}}{168,2} \mathrm{Mol}$.gelöst, da das Moleculargewicht derselben $\left(\mathrm{C}_{5} \mathrm{H}_{4} \mathrm{~N}_{4} \mathrm{O}_{3}\right)$ gleich 168,2 ist.

Nachdem dies in sorgfältiger Weise festgestellt war, stellten die Autoren sich zur Aufgabe, zu entscheiden, ob und in welchem Sinne die Löslichkeit der Harnsäure eine Aenderung durch Hinzufügung von Salzsäure erfährt. Diese Frage besass bereits deshalb einige Wichtigkeit, weil eine Methode zur quantitativen Bestimmung der Harnsänre im Harn gerade auf einer Abscheidung der Harnsäure aus Uraten mittelst Salzsäure beruht. Würde etwa die zur krystallinischen Abscheidung gelangte Harnsäure, durch überschüssige Salzsäure wieder gelöst, so wäre das für die Methode keine Empfehlung. In der Litteratur findet man sehr weit auseinander gehende Angaben. Während z. B. R üdel und auch Smale ohne Weiteres annehmen, dass ein derartiger Zusatz die Löslichkeit der Harnsäure erhöht, theilt Zabelin mit, dass derselbe keinen Einfluss ausübt. Nach physikalisch-chemischen Principien liess sich erwarten, dass die Salzsäure auf die Löslichkeit der Harnsäure in Wasser nicht einen fördernden, sondern einen beeinträchtigenden Einfluss haben würde, denn die freien Ionen der $\mathrm{HCl}$ müssen die elektrolytische Dissociation der Harnsäure zurückdrängen. (Tergl. oben in dem vorigen Paragraphen S. 260). Was ist nun der Fall? 
Wir denken uns eine gesättigte filtrirte Lösung von Harnsäure in Wasser. Diese Lösıng enthält: 1. undissociirte Harnsäuremolecüle $\mathrm{C}_{5} \mathrm{H}_{4} \mathrm{~N}_{4} \mathrm{O}_{3} ; 2$. primäre Säureionen, d. h. Harnsäuremolecüle, von denen je $1 \mathrm{H}$-Ion abgespalten ist, also Anionen von der Formel $\mathrm{C}_{3} \mathrm{H}_{3} \mathrm{~N}_{4} \mathrm{O}_{3}{ }^{\prime}$; 3. $\mathrm{H}$-Ionen.

Das primäre Säureion kann seinerseits auch wieder gespalten werden und zwar in ein secundäres Säureion und ein $\mathrm{H}^{\prime}$-Ion, denn die Harnsäure ist eine zweibasische Säure. Diese Spaltung zweiter Ordnung tritt aber derart in den Hintergrund, dass sie verachlässigt werden larf. Da Harnsäure eine zweibasische Säure ist, giebt es ein primäres oder saures Natriumsalz (in welchem $1 \mathrm{H}$ durch $\mathrm{Na}$ ersetzt ist) und ein secundäres Natriumsalz (in dem $2 \mathrm{H}$ durch $2 \mathrm{Na}$ ersetzt sind). Das primäre Salz spielt die Hauptrolle. Nach dem GuldbergW aage'schen Giesetz gilt für Harnsäure die folgende Gleichung

$$
\mathrm{k}_{1} \mathrm{C} \underset{\text { Harnsäure }}{\text { undis. }}=\mathrm{k}_{2} \mathrm{C}_{\text {Harnsäure-Ion }} \times \mathrm{C}_{\mathrm{H} \cdot \text {-Ion }}
$$

Diese Gleichung (vergl. Bd. II, S. 479) sagt aus: die Geschwindigkeit mit welcher die Harnsäure in ihre Ionen gespalten wird, multiplicirt mit der Concentration der undissociirten Harnsäure, ist gleich dem Product von der Concentration der beiden Ionen und der Geschwindigkeit, mit der diese sich vereinigen.

$$
\begin{array}{ll} 
& \frac{\mathrm{k}_{1}}{\mathrm{k}_{2}} \mathrm{C} \text { 站diss. } \\
\text { Setzt mansäre } & =\mathrm{C}_{\text {Harnsäure-Ion }} \times \mathrm{C}_{\mathrm{H}^{\cdot} \text {-Ion }} \\
& \frac{\mathrm{k}_{1}}{\mathrm{k}_{2}}=\mathrm{K} \text {, so ergiebt sich } \\
& \mathrm{K}_{\text {Harnsäure }}=\mathrm{C}_{\text {Harnsäure-Ion }} \times \mathrm{C}_{\mathrm{H}^{\prime} \text {-Ion }}
\end{array}
$$

$K$ ist die Affinitäts- oder Dissociationsconstante der Harnsäure (Vergl. Bd. II, S. 480 ff.).

Um die Schreibweise zu vereinfachen, wollen wir setzen $\mathrm{K} \mathrm{C}_{\mathrm{ur}}=$ $\mathrm{C}_{1} \times \mathrm{C}_{2}$.

Setzt man nun eine wässerige Salzsäurelösung zu der gesättigten Harnsäurelösung, so bringt man freie $\mathrm{H}^{\prime}$-Ionen in dieselbe hinein, da ja die Salzsäure als starke Säure noch bei ziemlich beträchtlicher Concentration nahezu ganz in ihre Ionen $\mathrm{H}^{-}$und $\mathrm{Cl}^{\prime}$ zerfallen ist. Ist die Concentration der Wasserstoffionen in der Harnsäurelösung um d gestiegen, so muss, nachdem das Gleichgewicht sich wieder eingestellt hat, folgende Gleichung gelten:

$$
\text { K } \mathrm{C}_{\mathrm{ur}}=\mathrm{C}_{1}\left(\mathrm{C}_{2}+\mathrm{d}\right) \text {. }
$$

Nun ist $\mathrm{K}$ eine Constante; Gleiches ist der Fall mit $\mathrm{C}_{\text {Harnsäure }}=\mathrm{C}_{\mathrm{ur}}$, da die Concentration des undissociirten Theiles in einer gesättigten 
Lösung bei constanter Temperatur eine unverïnderliche Grösse ist. Das erste Glied muss es demnach auch sein. $\mathrm{Da}$ jedoch die $\mathrm{H}$-Ionen-Concentration zugenommen hat, muss dementsprechend die Concentration $\mathrm{C}_{1}$ der Harnsäureionen abnehmen, m. a. W. der Dissocationsgrad der Harnsäure muss kleiner werden. Es bilden sich Harnsäuremolecüle in den nicht dissociirten Zustand zur ück, und da die ursprüngliche Harnsäurelösung bereits gesättigt war, muss die zurückgebildete Harnsäure niederschlagen werden.

Der Zusatz von Salzsäure zu der gesättigten Harnsäurelösung muss also zu einer Löslichkeitserniedrigung derselben führen.

$\mathrm{H}$ is und $\mathrm{Paul}$ haben diese auf theoretischem Wege berechnet und gefunden, dass während die Löslichkeit in reinem Wasser (bei 18²) $1: 39480$ beträgt, sie in einer Lösung, welche pro Liter $36, \tilde{\Xi} \mathrm{g} \mathrm{HCl}$

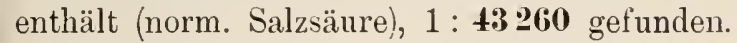

In guter Uebereinstimmung damit haben die Autoren auf experimentalem Wege für die Löslichkeit in Normal-Salzsäurelösung $1: \mathbf{4} \mathbf{4 3 0}$ gefunden.

Es erscheint mir nuitzlich die betreffende Berechnung hier vorzuführen, weil sie als Iuster für andere gleichartige dienen kann, und es sich hierbei um eine häufig vorkommende Angelegenheit handelt.

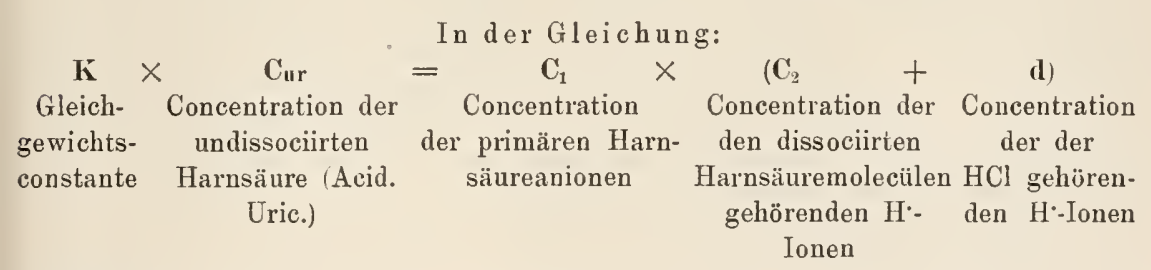

handelt es sich um vier Factoren, die wir jetzt besprechen werden.

1. K, die Affinitätsconstante der Harnsïure.

In Bd. II, S. 481 haben wir gesehen, dass

$\mathrm{K}=\frac{\left(\frac{\Lambda \mathrm{v}}{\Lambda \infty}\right)^{2}}{\mathrm{~V}\left(1-\frac{\Lambda v}{\Lambda \infty}\right)} \cdot$ In dieser Gleichung ist $\Lambda \mathrm{v}$ die äquivalente Leitfähigkeit der gesättigten Harnsäurelösung bei $18^{\circ}$, $\Lambda_{\text {oo }}$ die Leitfähigkeit bei unendlicher Verdüunung, V die Verdünnung, d. h. die Anzahl Liter Wasser, die erforderlich sind, um ein Molekül Harnsäure aufzulösen.

Aus $\Lambda \mathrm{v}, \mathrm{V}$ und $\Lambda_{\infty}$ können wir also $\mathrm{K}$ berechnen.

Zunächst spreche ich von $\mathrm{Iv}$.

H a mburger, Osmot. Druck. III. Band. 
$\mathrm{H}$ is und $\mathrm{Pa}$ a fanden mittelst der Methode von $\mathrm{K}$ oh $\mathrm{lr}$ a usch (vergleiche Bd. I, S. 118 u. 524) für $\Lambda \mathrm{v}$ bei $18^{\circ} \mathbf{3 2 , 2 4}$. Ich mache darauf aufmerksam, dass diese Zahl erhalten wurde, nachdem die Leitfähigkeit des Wassers von der der Harnsäurelösung abgezogen wurde (vergl. Bd. I, S. 110). Handelt es sich un Lösungen von grosser Leitfähigkeit, so vernachlässigt man die Leitfähigkeit des Wassers gewöhnlich, zumal wenn es möglichst rein ist. Hier aber ist die Leitfähigkeit der Lösung selbst bereits so geringfügig, dass eine Vernachlässigung zu erheblichen Fehlern Veranlass ung geben würde. In den meisten Versuchen betrug die Leitfähigkeit der Harn säurelösung etwa 39 und es musste ungeführ 6,30 für das Wasser in Abzug ge. bracht werden.

Ein zweiter Gegensiand, auf den ich hier die Aufmerksamkeit lenke, ist die merkwürdige, von $\mathrm{H}_{1 \mathrm{~S}}$ und $\mathrm{Paul}$ beobaclitete Thatsache, dass die Leitfähigkeit der Harnsäure im Widerstandgefäss allmähliclı abnahm, so dass es anfangs schwierig erschien, zuverlässige Werthe für die Leitfähigkeit zu erhalten. Die Autoren fanden, dass hier eine Zersetzung der Harnsäure durch das Platinschwarz der Elektroden vorlag. Eine aualoge Zersetzung findet auch, wenn auch vie] langsamer, statt, wenn Harnsäure lediglich mit Wasser in Berührung gelassen wird.

Nachdem sie dies erkanut hatten, beliessen $\mathrm{H}$ is und $\mathrm{Paul}$ die Harnsäurelösung nur möglichst kurze Zeit im Widerstandsgefässe.

Ich mache auf diese Erscheinung aufmerksam, damit man ganz allgemein bei allmählicher Aenderung der Leitfähigkeit einer Flüssigkeit im Widerstandsgefäss auf diese Möglichkeit gefasst sei.

$\Lambda \infty$. Harnsäure gehört zu den schwachen Säuren und sie ist folglich sehr schwach dissociirt. Die Ermittelung der Leitfähigkeit bei einer Concentration, in welcher alle Harnsäuremoleküle als dissociirt betrachtet werden können, würde eine so grosse Verdünnung erfordern, dass die Genauigkeit viel zu wünschen übrig lassen würde. In Bd. I, S. 43 habe jch bereits ein Mittel besprochen, welches diese Schwierigkeit zu umgehen gestattet. Die Leitfähigkeit eines Elektrolyten ist nämlich gleich der Leitfähigkeit des Kations $l_{k}+$ der Leitfähigkeit des Anions $l_{A}$.

Demnach ist die Leitfähigkeit der Harnsäure gleich der Leitfähigkeit des $\mathrm{H}$ Ions + derjenigen des primären Harnsäure-Ions.

Ersteres ist bekannt und letzteres lässt sich a us einer anderen Verbindung ableiten, die leichter dissociirt. Hierzu kann man das primäre harnsaure Natron und Kali wählen. Vom primären harnsauren Natriun wurde das Aequivalent-Leitvermögen bei $18^{\circ}$ und bei Verdünnungen von 1 Molecül pro 2315 und 2359 Liter zu $\Lambda_{2315}=63,0$ bezw. $\Lambda_{2359}=64,2$ gefunden.

\section{Mittel $\Lambda_{2337}=63,6$.}

Die Wanderungsgeschwindigkeit des Natrium-Ions bei derselben Verdünnung beträgt nach F. Kohlrausch (vergl. Bd. I, S. 137) 43,3; folglich bleiben für das primäre Harnsäure-Ion $\left(\mathrm{C}_{5} \mathrm{H}_{3} \mathrm{~N}_{4} \mathrm{O}_{3}\right.$-Ion $) \quad 63,6-43,3=\mathbf{2 0 , 3}$ bei einer Ver dünnung von ca. 2300 Liter.

Dieselbe Zahl für das Harnsïure-Ion bekommt man, wenn man von dem primären Kaliumurat ausgeht.

Vom primären harnsauren Kali wurde gefunden

$$
\begin{gathered}
\Lambda_{1259}=84,8, \quad \Lambda_{1253}=83,3 . \\
\text { Mittel } \Lambda_{1256}=84,1 .
\end{gathered}
$$


Die Wanderungsgeschwindigkeit des $\mathrm{K}$-Ions bei derselben Verdünnung beträgt nach F. Kohlrausch 63,8, folglich bleiben für das primäre Harnsäure-Ion $84,1-63,8=20,3$ bei einer Verdünnung von ca. 1250 Liter.

Da die Zunahme der Wanderungsgeschwindigkeit der Ionen von 1250 Liter zu 2300 Liter nur sehr gering ist, so ist die Uebereinstimmung der aus dem Natriumund Kaliumsalz berechneten Wanderungsgeschwindigkeiten für das prinäre Harnsäure-Ion eine ganz vorzügliche zu nennen.

Wie gross ist nun aber die Wanderungsgeschwindigkeit dieses Ions bei unendlicher. Verdünnung?

Die Zunahme der Wanderungsgeschwindigkeit des Essigsäure-Ions (Essigsäure ist auch eine schwache Säure) von einer Verdünnung von 2000 Liter bis zur unendlichen Verdünnung beträgt 0,9 Einheiten. Man wird daher der Wahrheit sehr nahe kommen, wenn man die Wanderungsgeschwindigkeit des primären Harnsäure-Ions bei $18^{\circ}$ und unendlicher Verdünnung (vollständiger Dissociation der Harnsäure) $=21$ setzt.

Nun ist nach Kohlrausch (Bd. I, S. 137) die Wanderungsgeschwindigkeit des $\mathrm{H}^{\cdot}$-Ions bei unendlicher Verdünnung und $18^{\circ} \mathrm{C}=318$. In Folge dessen ist $\mathrm{I} \infty$ für Harnsäure bei $18^{\circ}=318+21=\mathbf{3 3 9}$.

Hieraus ergiebt sich für $\mathbf{K}=$

$$
\frac{\left(\frac{\Lambda \nabla}{\Lambda_{\infty}}\right)^{2}}{\mathrm{~V}\left(1-\frac{\Lambda \nabla}{\Lambda_{\infty}}\right)}=\frac{\left(\frac{32,24}{339}\right)^{2}}{6640\left(1-\frac{32,24}{339}\right)}=0,000001 \mathrm{~s} 1 \text {. }
$$

உ. Cur (Molec. Concentration der undissociirten Harusäuremolekiile).

Die moleculare Concentration der Harnsäure in der gesättigten Lösung wurde, wie bereits erwähnt, von His und $\mathrm{Paul}$ zu $\frac{\mathbf{6 6 4 0}}{\mathbf{6}}$ ermittelt, d. h. ein Molecül ist in 6640 Litern Wasser gelöst.

Bevor wir nun daran gehen die moleculare Concentration der Harnsäure-Ionen nach Hinzufügung von $\mathrm{HCl}$ zu berechnen, wollen wir den Werth von d, das heisst, die durch diese Hinzufügung herbeigeführte Zunahme der $\mathrm{H}$-Ionen-Concentration ermitteln.

\section{3. d (Zunahme der molecularen Concentration der $\mathrm{H}$-Ionen).}

Um diese ausfindig zu machen, brauchen wir nur die $\mathrm{H}^{\cdot}$-Ionenconcentration der normalen HCl-Lösung festzustellen. Der Dissociationsgrad viner Lösung wird allgemein durch $a=\frac{1 \mathrm{v}}{L_{0}}$ ausgedrückt.

Nach den Versuchen von Kohlrausch beträgt bei Normal-Salzsäure von $18^{\circ} \mathrm{C} . \Lambda \mathrm{v}=301 ; \Lambda \infty=384 ;$ also $\alpha=\frac{301}{384}=0,78$.

In einer Normal-Salzsäurelösung sind also $78 \%$ der vorhandenen HCl-Moleküle in Ionen gespalten, mit anderen Worten: da die gesamintmoleculare Concentration der Normal-Lösung $=1$ ist, so ist die Concentration der $\mathrm{H}$-Ionen (und auch der Chlor-Ionen) $=0,78$, also $d=0,78$. 


\section{4. $\mathrm{C}_{1}$ (die gesuchte Concentration der primären Harnsäureionen).}

Diese lässt sich nunmehr aus 1,2 und 3 ableiten. Die Formel lautet nämlich: $\mathrm{K} \mathrm{Cur}=\mathrm{C}_{1}\left(\mathrm{C}_{2}+\mathrm{d}\right)$

$$
\text { oder } \mathrm{K} \mathrm{Cur}_{\mathrm{ur}}=\mathrm{C}_{1} \mathrm{C}_{2}+\mathrm{C}_{1} \mathrm{~d} \text {. }
$$

Da aber $\mathrm{C}_{1}$ (die Concentration der Harnsäure-Ionen) immer gleich der Concentration $\mathrm{C}_{2}$ der entsprechenden $\mathrm{H} \cdot$-Ionen ist, so dürfen wir schreiben

$$
\begin{array}{ll} 
& \mathrm{K} \mathrm{C}_{\mathrm{ur}}=\mathrm{C}_{1}{ }^{2}+\mathrm{C}_{1} \mathrm{~d} \\
\text { oder } & \mathrm{C}_{1}{ }^{2}+\mathrm{C}_{1} \mathrm{~d}-\mathrm{K} \mathrm{Cur}_{\mathrm{ur}}=\mathrm{O} \\
& \mathrm{C}_{1}=-\frac{\mathrm{d}}{2} \pm \sqrt{\left(\frac{\mathrm{d}}{2}\right)^{2}+K \mathrm{C}_{u r} .}
\end{array}
$$

Setzen wir die Werthe für $d=0,78, K=0,00000151$ und $\mathrm{Cur}_{\mathrm{ur}}=\frac{1}{6640}$ in die Formel ein, so bekommen wir für $\mathrm{C}_{1}$ einen Werth, der gegenüber dem Werth von $\mathrm{C}_{1}=0,0000143^{1}$ ) vor dem Salzsäurezusatz verschwindend klein ist.

Aus diesem Resultat geht also hervor, dass durch Hinzufügung von soviel $\mathrm{HCl}$ zu der Harnsäurelösung, dass die Flüssigkeit Normal-Salzsäure enthält, die Dissociation der Harnsäure vollständig zurückgedrängt wird. Da die Harnsäurelösung vor der Hinzufügung von Salzsäure bereits gesättigt war, so wird die aus den Ionen zurückgebildete Harnsäure in festem Zustand niedergeschlagen werden.

Es fragt sich nun, wie viel Harnsäure befand sich vor der Zufügung von $\mathrm{HCl}$ in dissociirtem Zustande?

-Das lässt sich aus der bekannten Formel $\alpha=\frac{\Lambda \mathrm{v}}{\Lambda \infty}$ berechnen, in welcher $\Lambda \mathrm{v}$ die Leitfähigkeit der gesättigten Harnsäurelösung (Verdünnung 6640) $=32,24$ und $\Lambda_{\infty}$ die Leitfähigkeit bei vollständiger Dissociation $=3 \vdots 9$ (siehe oben) bedeutet, folglich ist der Dissociationsgrad $a=\frac{32,24}{339}=0,095$. In einer bei $18^{\circ}$ ges ättigten Harnsäurelösung befindet sich als $9,5 \%$ der gelösten Harnsäure in dissociirtem Zustande.

Wie gesagt, geht diese dissociirte Harnsäure unter dem Einfluss von HCl in den nicht dissociirten, sogar in den festen Zustand über. Dies kommt darauf hinaus, dass die Löslichkeit der Harnsäure unter dem Einfluss von Salzsäure um 9,5\% zurückgeht.

1) Diese Zahl, welche die Concentration der Harnsäure-Ionen v o r der Zufügung von Salzsäure angeben muss, wird durch Multiplication der molecularen Concentration der Harnsäure mit dem Dissociationsgrad erhalten.

Die moleculare Concentration ist $\frac{1}{6640}$, während der Dissociationsgrad $\frac{\Lambda \mathrm{v}}{\Lambda_{\infty}}=\frac{32,24}{339}=0,095$ beträgt. Demnach wird $\mathrm{C}_{1}$ vor der Hinzufügung von Salzsäure $\underset{6640}{1} \times 0,095=0,0000143$. 
In reinem Wasser betrug die Löslichkeit $1: 39480$ (siehe oben). In normal. Salzsäure beträgt sie $9,5^{\circ} / 0$ weniger, d. h. $1: 39,480 \times 109, \overline{5}$ als $1: 43230$, was, wie bereits erwähnt wurde, mit dem auf experimentellem Wege gefundenen Verhältniss $1: \mathbf{4 2 4 3 0}$ gut übereinstimmt.

His und Paul haben gefunden, dass bereits $1 / 100$ Normal-Salzsäure die Dissociation der Harnsäure vollständig zurïckdrängt. Von praktischem Standpunkt wird also, wenn die Flüssigkeit einmal 1;100 n. Salzsäure enthält, durch weiteren Zusatz ron Säure die Zurückdrängung der Dissociation nicht gesteigert und die Löslichkeit nicht weiter herabgesetzt. Aehnliche Versuche wie mit Salzsäure, haben die Aautoren auch mit Schwefelsäure angestellt und gleichartige Resultate erhalten.

Ebenso wie die Löslichkeit der Harnsäure durch starke Säuren herabgesetzt wird, weil diese eine $\mathrm{H}^{\prime}$-Ion mit ihr gemein haben, ebenso muss auch die Löslichkeit des harnsauren Natrons im Blute durch $\mathrm{NaCl}$ und andere Natriumsalze erniedrigt werden, weil das $\mathrm{Na}$-Ion beiden gemeinsam ist. So wird z. B. die Löslichkeit des Natriumurats in einer NaCl-Lösung, die 1/128 Mol. NaCl pro Liter enthält $(=0,046 \%)$ bereits auf die Hälfte herabgesetzt.

Diese Thatsachen scheinen von praktischem Interesse.

\section{b) Bedeutung der erörterten Löslichkeitsverhältnisse lür die Auf- lösung von Concrementen im Organismus.}

Seit Langem hat man vorgeschlagen, die im Körper als gichtische Concremente zur Abscheidung gelangte Harnsäure und die Urate mittelst doppelkoblensauren Natrons in Lösung zu bringen. Die klinischen Erfahrungen und experimentellen Ergebnisse sind aber bis jetzt in zweifelhaftem Simne ausgefallen.

Die erwähnten Untersuchungen lassen für derartige Heilverfahren nur wenig Hoffnung, denn, wie die obigen Ausführungen gelehrt haben, müssen Natronsalze die Löslichkeit von Natronurat herabsetzen und nicht steigern.

Auch andere Mittel hat man zur Entfernung der meist aus primärem harnsaurem Natron bestehenden Concremente versucht, aber ebenso wenig mit eclatantem Erfolg wie Bicarbonate. Es waren dies Mittel, die auf die Ueberführung des schwer löslichen Natriumsalzes in ein leichtlösliches abzielten. Insbesondere sind die Lithiumsalze 
hierzu empfohlen worden, weil das saure harnsaure Lithium verhältnissmässig leicht löslich ist. Hiermit hängt die Verordnung von lithiumhaltigen Mineralwassern zusammen.

Das Irrationelle dieser Therapie lässt sich mit $\mathrm{H}$ is und $\mathrm{Paul}$ etwa in folgender Weise darlegen.

Die Gichtconcremente liegen so zu sagen in einer gesättigten Lösung von primärem Natriumurat. Wenn zu dieser Lösung geringe Mengen eines Lithiumsalzes hinzugefügt werden, wie es dem therapeutischen Vorgehen entspricht, so bedeutet das nur das Hinzukommen von einigen Lithiumionen, die nicht einmal auf die Bestandtheile der Lösung, noch weniger auf das Ungelöste irgend eine Wirkung haben. Es entspricht das ungefähr der Indifferenz zweier Lösungen stark dissociirter Elektrolyte, die völlig reactionslos sich mit einander vermischen. Wenn man z. B. sehr verdünnte Lösungen von $\mathrm{NaCl}$ und KJ zusammengiesst, so zeigt sich keine Spur einer Wärmetönung als Ausdruck eines chemischen Vorganges; es bleibt ja auch thatsächlieh alles beim Alten; die Ionen $\mathrm{Na}^{\prime}, \mathrm{Cl}^{\prime}, \mathrm{K}^{\prime}$ und $\mathrm{J}^{\prime}$ existiren nach wie vor frei neben einander. Früher wunderte man sich über diese "Thermoneutralität der Salzlösungen", nach der Ionentheorie ist sie selbstverstäudlich (vergl. Bd. I, S. 61).

Dagegen tritt dann eine Aenderung ein, wenn grosse Mengen von Lithiumsalz zu der Uratlösung hinzugesetzt werden, aber dann ist der Effect dem erwïnschten gerade entgegengesetzt. Ich gehe darauf hier nicht ein, zumal weil von der Einführung grosser Quantitäten Lithium in Folge der regulatorischen Thätigkeit der Nieren nicht die Rede sein kann. Aelınliches gilt auch für die Alkalien, die das Vermögen besitzen, das schwerlösliche primäre (saure) Natriumurat in das leichter lösliche secundäre Biurat umzusetzen. Auch hier würde, wie die physikalische Chemie lehrt, die Alkalinitätsteigerung so bedeutend sein müssen, wie das im Organismus kaum denkbar ist.

Wenn dennoch, wie viele Autoren meinen, die lithiumhaltigen und alkalischen Mineralwasser thatsächlich einen günstigen Einfluss gegen die Absetzung der Concremente von harnsaurem Natron oder auf deren Lösung ausüben, so ist für diese heilsame Wirkung eine andere Erklärung als die bis dahin gegebene zu suchen. So schreibt z. B. Stokvis [3] das litholytische Vermögen mancher Mineralwasser der stärkeren Diurese und der wenig sauren Reaction des Harns zu, welche der Gebrauch dieser Wasser zur Folge hat. Diese stärkere Diurese verlindert die Abscheidnng der Harnsäure und der Urate; aber eine thatsächliche Autlösung von Steinen im Thierkörper, oder von Tophi, welche sich in 
den Gelenken gebildet haben, kommt nach diesem Pharmakologen nicht zu Stande.

Aehnliches wie für die Kalium- resp. Lithiumsalze, gilt nach $\mathrm{H}$ is und Paul auch für die Anwendung des Piperazins und derartiger Präparate, insofern man deren Wirkung auf Rechnung der Bildung leichtlöslicher harnsaurer Salze schreibt.

Schliesslich erwähne ich noch ein anderes Vittel, das von Rüdel [4] als Litholyticum vorgeschlagen wurde, den Harnstoff. In concentrirter Lösung soll er Harnsäure und Urat lösen. Aus IIessungen ron $\mathrm{H}$ is und $\mathrm{Paul}$ hat sich aber ergeben, dass der Harnstoff gar keinen Finfluss auf die Löslichkeit der genannten Stoffe ausübt, so dass die auf Grund von Rüdel's Resultate vielfach befolgte Harnstofftherapie jetzt der wissenschaftlichen Grundlage entbehrt.

\section{Begünstigung der Bromwirkung durch Enthaltung von Chlor.}

\section{Litteratur.}

1. Richet et Toulouse, Effet d'une alimentation pauvre en chlorures sur le traitement de l'épilepsie par la bromure de sodium. Nouv. rem. 1900. p. 142. Toulouse Gaz. des Hôpitaux 25. Janv. 1900. Centralbl. f. d. med. Wissensch. 39. 1901. S. 413.

2. Roux, Centralbl. f. d. med. Wissensch. 39. 1901. S. 413 . Compt. rend. de la Soc. de Biol. 24 Mars 1900.

3. Toulouse, Gaz. des Hôpitaux 21 Juillet 1900. Centralbl. f. d. med. Wissenschaft 40. 1902. S. 206.

4. Stokvis, De vervanging van physiologische keukenzoutsoluties door äquimoleculaire oplossingen van Broomnatrium en Joodnatrium. Feestbundel Prof. D1: Rosenstein. Leiden 1902.; Nederl. Tijdschr. v. Geneeskunde 21. Juni 1902. p. 1428 .

5. van Leersum, Archiv f. experim. Pathol. u. Pharmakol. 49. 1902. S. 85.

Seit langer Zeit wird Bromkalium gegen Epilepsie angewendet und es ist wohl sicher, dass seine Wirkung auf derjenigen des Broms beruht. Richet und Toulouse stellten num die Vermuthung auf, dass bei Darreichung einer chlorarmen Nahrung an den Patienten [1] die Ganglienzellen - in denen wohl der Ausgangspunkt der Krankheit zu suchen sein wird - so zu sagen entchlort werden und eine geringere Bromsalzgabe als unter normalen Umständen genügen wuirde.

Diese Hypothese wurde durch die Erfahrung mehrfach bestütigt. Richet und Toulouse verordneten eine Diät, in welcher statt der gewohnten Menge ron 14 g Kochsalz nur 2 g enthalten waren. Diese 
Diät konnte ohne Schaden plötzlich eingeführt und 7 Monate durchgeführt werden. 20 Kranke im Alter von 17-49 Jahren wurden so behandelt. Alle litten an sogen. essentieller Epilepsie. Im Mittel hatten sie durchschnittlich alle Tage einen Anfall. Es wurden nun zuerst $4 \mathrm{~g}$ Bromnatrium, später 2 gegeben. Bei allen Krranken trat eine auffällige Verminderung der Krämpfe und Schwindelanfälle ein, jene verminderten sich un $92 \%$, diese um $70 \%$. Sobald aber zur gewöhnlichen Diät übergegangenwurde, tratendie Anfälle wieder ein.

Es zeigte sich weiter, dass grössere Brommengen bei normaler Diät nicht so gut wirkten wie kleinere Mengen bei der salzarmen Diät.

Roux [2] hat ebenfalls sehr günstige Resultate mit der Methode von Richet-Toulose bekommen. Er verordnete als kochsalzarme Diät ausschliessliche Milchnahrung. Bei 4 Litern pro Tag nimmt alsdann der Kranke statt $9 \mathrm{~g}$ Chlor $3,8 \mathrm{~g}$ zu sich. Auch hier brachten $3-4 \mathrm{~g}$ Bromnatrium erhebliche Besserung, die aber sofort in Verschlimmerung des Leidens umschlug, als die gewöhnliche Nahrung verabreicht wurde.

Später hat Toulouse [3] noch über 20 eigene Beobachtungel: betr. die Brombehandlung Epileptischer unter Kochsalzentziehung berichtet. Er benutzte eine Diät, die die Bromdose auf $2,5 \mathrm{~g}$ pro Tag herabzudrücken erlaubte. Sie bestand aus $1000 \mathrm{~g}$ Milch, $300 \mathrm{~g}$ Kartoffehn, 2 Eiern, $10 \mathrm{~g}$ Kaffee, $300 \mathrm{~g}$ Fleisch, $200 \mathrm{~g}$ Mehl, $50 \mathrm{~g}$ Zucker und $40 \mathrm{~g}$ Butter.

Es unterliegt also keinem Zweifel, dass man in Stande ist durch Entziehung ron Chlorionen, Br'-Ionen an deren Stelle treten zu lassen.

Man muss sich, wie ich denke, die Sache so vorstellen, dass eine grosse Menge Bromionen in der Ganglienzelle festgelegt werden muss, um einen therapeutischen Effect zu erzielen. Der Platz für diese Bromionen muss auf Kosten der vorhandenen Chlorionen erobert werden.

Verabreicht man einem Individuum, das eine normale Kochsal\%menge in Zellen und Blutfliussigkeit (resp. Lymphe) enthält, eine gewisse Menge NaBr, so wird eine gewisse Menge $\mathrm{Cl}^{\prime}$-Ionen aus den Zellen entfernt und durch $\mathrm{Br}^{\prime}$-Ionen ersetzt. Der Umfang dieser Ersetzung wird u. A. von der relativen Menge des im Blute kreisender $\mathrm{NaCl}$ und $\mathrm{NaBr}$ abhïngen. Lässt man das Individuum mehr Bromnatrium aufnehmen, so wird die Bedingung für das Eintreten von Brom in die Zellen günstiger. Man kann aber dasselbe erzielen, indem man die ursprünglich verabreichte Brommenge unverändert lässt und den Kochsalzgehalt herab- 
setzt. Denn auch in diesem Fall ist das relative Bromquantum, das die Zelle umspült, gesteigert.

Mit wie grosser Begierde die Zellen Brom- und auch Jod-Ionen aufnehmen können, lehren Experimente ron Stokvi s [4]. Dieser Autor untersuchte, ob es möglich wäre, fast zu Tode verblutete Kaninchen, statt durch intravenöse Einspritzung einer Kochsalzlösung (K ronecker), mittelst isotonischer Lösungen von Bromnatrium und Jodnatrium $\left(\alpha=0,56^{\circ}\right)$ zu retten. Gelegentlich dieser Untersuchungen, bemerkte Stokvis zu seinem grossen Erstamen, dass der Harn der Thiere wohl $\mathrm{Cl}$, aber keine Spur $\mathrm{Br}$ oder $J$ enthielt. Die Zellen hielten also $\mathrm{Br}$ und J zurïck.

Van Leersum hat dieses Ergebniss bestätigt [5].

Eine andere Frage ist es aber, ob die Lebensfunction der Zellen unter diesen Umständen normal bleibt. Für das Herz des Frosches scheint das nach Stokvis in der That der Fall zu sein [4]. Nährt man das ausgeschnittene Froschherz in der bekannten Kroneckerschen Versuchsanordnung mit Rinderblut, das statt mit $\mathrm{NaCl}$, mit einer isosmotischen $\mathrm{NaBr}$ - oder NaJ-Lösung versetzt worden ist (1 Vol. Rindsblut +3 Vol Salzlösung von $J=-0,43^{\circ}$ ), so arbeitet es mit normaler Kraft durch.

Ganz anders ist der Effect beim genannten Kaninchenversuch. Zwar wirken die NaBr- und NaJ-Lösung lebensrettend, aber das rührt daher, dass nunmehr das Herz ein normales Flüssigkeitsquantum durchzutreiben bekommt, denn wie van Leersum fand, erreicht man das Gleiche mit isosmotischen Lösungen von Natriumacetat, -sulfat, -nitrat, -formiat, -propionat und -citrat, sowie auch mit Traubenzucker, Rohrzucker und Milchzucker. Die Thiere blieben in den Versuchen von Stokvis schwach, deprimirt und paretisch, verweigerten Nahrung und rerendeten stets innerhalb 24 Stunden. Auch van Leersum konnte seine Thiere nicht am Leben erhalten. 


\section{Achtes Kapitel. \\ Balneologisehes.}

\section{Litteratur.}

1. C. von Thau, Ts chermak's mineralogische und petrogr. Mittheil. N. F. 11. 1890. S. 487.

2. Koeppe, Physikalische Chemie in der Medicin. Wien 1900. S. 131.

3. von Kostkewicz, Therapeutische Monatshefte 13. 1899. S. 577.

4. Hintz und Griinhnt, Chemische und physik.-chem. Untersuchung des Rhenser Sprudels. Wiesbaden. K reidel's Verlag 1902.

5. Griinhut, Zeitschr. f. angewandte Chemie. 1902. S. 648.

6. Hintz und Griiuhut, Chemische und physik.-chem. Untersuchung des grossen Sprudels zu Neuenahr. J. F. B ergma n n Wiesbaden 1902; Jahrbücher des N as s a u'schen Vereins f. Naturkunde. Jahrg. 55.

7. Roloff, Zeitschr. f. angewandte Chemie 1902. S. 964 u. 994.

8. Grïnhut, Vortrag f. die XI. Jahrversammlung des allgemeinen deutschen Badeverbandes über die neueren physik.-chem. Anschaungen in ihrer Anwendung auf Mineralwässer und deren Eintheilung. Balneol. Centralzeitung 1903.

9. Diiuschmann, Einfluss des Salzgehaltes der Trinkquellen auf die Blutbeschaffenheit. Berlin-Hirschwald 1901.

10. Rothsehild und Inghes, Einfluss der Mineralbäder auf den osmot. Druck des Blutes. Vortrag Balneol. Gesellsch. Frankfurt a M. März 1900.

11. Grube, Vortrag Balneol. Gesellsch. Stuttgart. März 1902; Deutsche Medicinalzeitung 1902. Nr. 36.

12. Fr. Engelmann, Vortrag Balneol. Gesellsch. Stuttgart. März 1902; Deutsche Medicinalzeitung 1902. Nr. 38.

13. Fr. Engelmann, Zeitschr. diätet. und physik. Therapie 6. H. 12. 1902/03.

14. H. Strauss, Deutsche med. Wochensclir. 1902. Nr. 37 und 38.

15. Grossinamn, Deutsche med. Wochenschr. 1902.

16. Strauss, Koeppe, Eugelmamu, Grube, Deutsche Medicinalzeitung. 11. Mai 1903. S. 421.

17. H. Strauss, Therap. Monatshefte 13. 1899. S. 582.

18. E. Beckmamm, Zeitschr. f. physik. Chemie 21. 1896. S. 240.

19. E. Beckmanu, Zeitschr. f. physik. Chemie. 44. 1908. S. 161

20. Hamburger, Zeitschr. f. physik. Chemie. 47. 1904. S. 495. 
In zweifacher Beziehung haben die Theorie vom osmotischen Druck und die Ionenlehre ihren Einfluss auf die Balneologie geltend gemacht, und zwar mit Bezug auf die Darstellung der chemischen Zusammensetzung der Mineralwässer und auf die Erkenntniss ihrer Wirkung.

Ich unterziehe die hauptsächlichsten in beiden Richtungen erzielten Errungenschaften einer kurzen Besprechung.

\section{Osmotische und osmotisch-chemische Untersuchung der Mineral- wässer.}

Durch die neue Theorie der Lösungen haben sich die Auffassungen über die Zusammensetzung der Nineralwässer wesentlich geändert. Während man früher meinte, dass sie aus einer Lösung von Salzen bestanden, die oft auch Gase enthielt, wissen wir jetzt, dass die gelösten Substanzen grösstentheils in Ionenform vorhanden sind. So kommen $\mathrm{Na}$ und $\mathrm{Cl}$ nicht allein als $\mathrm{NaCl}$ in Mineralwasser vor, sondern auch als elektropositive $\mathrm{Na}$ und elektronegative $\mathrm{Cl}^{\prime}$-Ionen ${ }^{1}$ ).

Dass im Mineralwasser thatsächlich Ionen vorhanden sind, wurde wohl zuerst von Carl von Than hervorgehoben. Reines Wasser leitet den elektrischen Strom kaum, ebenso wenig vermögen ungespaltene Molecuile dies zu thun. Findet man also, wie in den Mineralwïssern, ein Leitvermögen, das über $8 \times 10^{-6}$ reciproke $\mathrm{Ohm}$ (Leitvermögen des ausgekochten gewöhnlichen destillirten Wassers) hinausgeht, so darf man sagen, dass freie Ionen vorhanden sind. Ihre Nenge ist in den rerschiedenen Wässern sehr verschieden, wie aus folgender Tabelle der Leitfähigkeit hervorgeht, die ich $K$ o epp e entnehme.

a) Specifische Leitfähigkeit und Gefrierpunkterniedrigung einiger Mineralwäisser.

1. Absolut reines Wasser (berechnet von Kohlrausch Reciproke $\mathrm{Ohm}$ $\times 10^{6}$ ) bei $18^{\circ} \mathrm{C}$. und Heydweiller). . . . . . . . . . . . . . .

2. Reinstes Wasser (dargestellt von Kohlrausch und Heydweiller)

$$
0,038
$$

3. Wasser aus geschmolzenem Natureis (Kohlrausch und Heydweiller)

1) Vergl. auch Zusammenfassung und Schlussbetrachtung S. $306 \mathrm{ff}$."

2) Bei Ko eppe heisst es "Reciproke Ohm $\times 1010^{4}$. Doch benutzt der Autor eine andere Einheit für die specifische Leitfähigkeit, als andere Autoren zu benutzen pflegen, und die auch im vorliegenden Werke gebraucht wurde. Er definirt sie nämlich als die Leitfähigkeit eines Flüssigkeitfadens von $100 \mathrm{~cm}$ Länge und $1 \mathrm{qmm}$ Querschnitt. Behufs Ueberführung in $\mathrm{cm} / \mathrm{Ohm}$ sind also Koeppe's Werthe mit 10-4 zu multipliciren, was in obiger Tabelle geschehen ist. 
4. Wasser, nach Nernst durch Gefrieren gereinigt

Reciproke $\mathrm{Ohm}$

$\times 10^{6}$ bei $18^{\circ} \mathrm{C}$

6. Destillirtes Wasser gekocht . . . . . . . . . . . . . 10,0

7. Wasser der Gasteiner Ache (von Walte nh of fen) . . . . 31,8

8. Wasser des Gasteiner "Giftbrunnens" (v on Waltenhofen) 31,9

9. Wasser des Brunnens vom Gasteiner Curhaus (von Waltenh of en)

35,1

43,5

49,2

137,0

239,0

296,0

344,0

654,0

701,0

1142,0

1369,0

$19.52,0$

1979,0

3924,0

4965,0

5646,0

5750,0

7532,0

8200,0

10058,0

10400,0

10486,0

11042,0

11050,0

14697,0

15493,0

16863,0

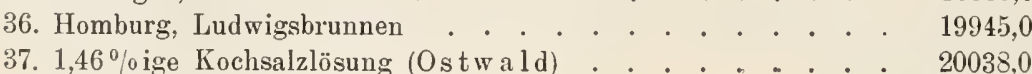

Nan sieht, der Unterschied der Leitfähigkeit verschiedener Wässer ist sehr gross.

Es fragt sich nun, kann man aus der Leitfähigkeit die Anzahl Ionen im Liter Fliissigkeit berechnen?

Wäre das der Fall, so würde man auch im Stande sein, die Zahl der Molecüle, die nicht in Ionen gespalten sind, festzustellen, da man die Gesammtzahl der in einem Liter Wasser vorhandenen Molecüle + Ionen (Molionen $\left.{ }^{1}\right)$ ) leicht durch Bestimmung der Gefrierpunkterniedrigung

1) Vergl. Bd. II, S. 456. 
ermitteln kann. Letzteres beruht bekanntlich darauf, dass jedes 'Theilchen, sei es ein Molecül oder ein Ion, in Grammen ausgedrückt und in einem Liter Wasser aufgelöst, eine Gefrierpunkterniedrigung von $1,85^{\circ}$ herbeiführt. Verursacht demnach eine Lösung eine Gefrierpunkterniedrigung $J$, so sind $\frac{d}{1,85}$ Theilchen (Molecuile + Ionen) im Liter Wasser aufgelöst. Eine analoge Berechnungsweise ist aber für das Leitvermögen, bezw. für die Feststellung der Ionenzahl nicht statthaft, weil das Leitrermögen der rerschiedenen Ionen keineswegs dasselbe ist.

Man hat darum, um den Grad der Ionenspaltung in sinnfälliger Weise auszudrücken, ein anderes Hilfsmittel gewählt, das ich weiter unten bei der osmotisch-chemischen Analyse der bis jetzt in dieser betreffenden Richtung untersuchten Mineralwässer, zugleich mit anderen dabei erhaltenen Ergebnissen, erörtern werde.

Ich werde bei dieser Besprechung der drei Mineralwässer, die bis jetzt Gegenstand einer eingehenden osmotisch-chemischen Analyse geworden sind, Gelegenheit haben, auch noch andere Punkte, wie die Nethodik der Gefrierpunkterniedrigungsbestimmung zu berühren.

Zuvor will ich aber noch eine Zusammenstellung der Gefrierpunktbestimmungen an einer Anzahl von Mineralwässern geben, die von v. Kostkewicz [3] und H. Strauss [17] ermittelt worden sind.

von Kostkewicz hat von jedem Mineralwasser vier Bestimmungen ausgeführt. Für je zwei Versuche benutzte er immer den Inhalt einer besonderen Flasche. Von den vier Bestimmungen wurde das arithmetische Mittel genonmen. Jeden Tag wurde der Gefrierpunkt von destillirtem Wasser festgestellt. Andere weiter unten noch zu behandelnde Vorsichtsmassregeln sind offenbar nicht eingehalten worden Dennoch sind die Zahlen zu vielen Zwecken sehr gut anwendbar.

Die Quellen sind in absteigender Ordnung der Gefrierpunkterniedrigung gruppirt. Weiter findet man in der Tabelle die Gesammtınenge der festen Bestandtheile angegeben und auch die Menge der wichtigeren mineralischen Bestandtheile jeder Quelle. Diese Zahlen hat von Kostkewicz nicht selbst ermittelt; sie sind, wie er mittheilt, theils dem Buche von Rosemann: „Die Mineraltrinkquellen Deutschlands“, theils anderen Lehrbüchern der Balneotherapie; Flechsig, Handbuch der Balneotherapie, Berlin 1892: Glax, Lehrbuch der Balneotherapie, Stuttgart 1897, entnommen.

Was in hohem Maasse die Aufmerksamkeit fesselt, ist die Thatsache, dass die Menge an festen Bestandtheilen mit der Gefrierpunkterniedrigung keineswegs parallel geht und eigentlich damit auch nicht in einem brauchbaren Zusammenhang steht.

Von der Bedeutung der Gefrierpunkterniedrigung der Mineralwässer wird erst unten bei den Ausfülırungen von Strauss die Rede sein. 
Balneologisches.

\begin{tabular}{|c|c|c|c|c|c|c|c|c|c|c|c|}
\hline \multirow[b]{2}{*}{ Name, Quelle } & \multirow[b]{2}{*}{$\Delta$} & \multirow{2}{*}{$\begin{array}{c}\text { Feste } \\
\text { Bestand- } \\
\text { theile } \\
\text { in \&1 } \\
\text { Wasser }\end{array}$} & \multicolumn{9}{|c|}{ Gehalt pro 11 Wasser an } \\
\hline & & & $\begin{array}{c}\mathrm{g} \\
\mathrm{Na}_{2}- \\
\mathrm{SO}_{4} \\
\end{array}$ & $\left|\begin{array}{c}\mathrm{g} \\
\mathrm{Mg}- \\
\mathrm{SO}_{4}\end{array}\right|$ & \begin{tabular}{|c|}
$\mathrm{g}$ \\
$\mathrm{Na}-$ \\
$\mathrm{Cl}$
\end{tabular} & $\begin{array}{c}\mathrm{g} \\
\mathrm{Na}_{2}- \\
\mathrm{CO}_{3} \\
\end{array}$ & \begin{tabular}{|c|}
$\mathrm{g}$ \\
Bicar- \\
bonate \\
v. Mg \\
und Ca \\
\end{tabular} & $\mid$\begin{tabular}{c|}
$\mathrm{g}$ \\
\\
$\mathrm{Igg}-$ \\
$\mathrm{Cl}_{2}$
\end{tabular} & \begin{tabular}{c|}
$\mathrm{g}$ \\
\\
$\mathrm{Fe}_{2}-$ \\
$\left(\mathrm{SO}_{4}\right)_{3}$ \\
\end{tabular} & $\left|\begin{array}{c}\mathrm{g} \\
\mathrm{CaSO}_{4} \\
+ \\
\mathrm{MgSO}_{4}\end{array}\right|$ & $\begin{array}{c}\mathrm{g} \\
\mathrm{As}_{\mathrm{g}^{-}} \\
\mathrm{O}_{3}\end{array}$ \\
\hline Kissinger Bitterwasser & $-1,11^{\circ}$ & 25,2 & 5,8 & 5,0 & 7,6 & - & - & 3,8 & - & - & - \\
\hline $\begin{array}{l}\text { Friedrichshaller Bitter- } \\
\text { wasser }\end{array}$ & 1,08 & 25,6 & 5,9 & 5,9 & 7,3 & & - & 4,7 & - & - & - \\
\hline Franz Joseph-Bitterwasser & 1,047 & 52,2 & 23,1 & 24,7 & - & - & - & 1,7 & - & - & - \\
\hline $\begin{array}{c}\text { Lunyadi-Janos-Bitter- } \\
\text { wasser }\end{array}$ & 1,015 & 41,7 & & 18,4 & 1,4 & - & - & - & - & - & - \\
\hline Apenta-Bitterwasser & 1,015 & 43,8 & 15,4 & 24,4 & 1,8 & - & - & - & - & - & - \\
\hline $\begin{array}{l}\text { Sodener Soolbrunnen } \\
\text { Salzschlirfer Bonifacius. }\end{array}$ & 0,945 & 16,9 & - & - & 14,2 & - & - & - & - & - & - \\
\hline brunnen & 0,892 & 14,2 & - & - & 10,2 & - & - & - & - & - & - \\
\hline $\begin{array}{c}\text { Kreuznacher Elisabeth- } \\
\text { brunnen }\end{array}$ & 0,797 & 11,7 & - & - & 9,4 & - & - & - & - & - & - \\
\hline Sodener Wiesenbrunnen & 0,765 & 12,9 & - & - & 11,2 & - & - & - & - & - & 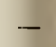 \\
\hline $\begin{array}{c}\text { Boemenstorfer Bitter- } \\
\text { wasser }\end{array}$ & 0,752 & 31,0 & 7,0 & 22,0 & - & - & - & - & - & - & - \\
\hline Saidschützer Bitterwasser & 0,750 & 23,2 & 6,0 & 10,9 & - & - & - & - & - & - & - \\
\hline $\begin{array}{l}\text { Tarasper Luciusquelle } \\
\text { Homburger Elisabeth- }\end{array}$ & 0,680 & 14,7 & 2,1 & - & 3,6 & 4,8 & 3,4 & - & - & - & - \\
\hline brunnen & 0,627 & 13,9 & - & - & 9,8 & - & - & - & - & - & - \\
\hline Püllnaer Bitterwasser & 0,585 & 25,4 & 9,5 & 10,8 & 2,5 & - & - & - & - & - & - \\
\hline Sodener Champagnerquelle & 0,515 & 7,7 & - & - & 6,5 & - & - & - & - & - & - \\
\hline Wiesbadener Kochbrunnen & 0,483 & 8,2 & - & - & 6,8 & - & - & - & - & - & - \\
\hline Pyrmonter Salzquelle & 0,472 & 10,7 & - & - & 7,0 & - & - & - & - & - & - \\
\hline Kissinger Rakoczy & 0,470 & 8,5 & - & - & 5,8 & - & - & - & - & - & - \\
\hline Marienbader Ferdinands. & & & & & & & & & & & \\
\hline brunnen & 0,460 & 10,6 & 5,0 & - & 2,0 & 1,8 & 1,4 & - & - & - & - \\
\hline Kissinger Pandur & 0,435 & 7,9 & - & - & 5,5 & - & - & - & - & - & - \\
\hline Marienbader Kreuzbrunnen & 0,435 & 11,0 & 4,9 & - & 1,7 & 1,6 & 1,4 & - & - & - & - \\
\hline Gleichenberger Constan- & & & & & & & & & & & 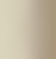 \\
\hline $\begin{array}{c}\text { tinquelle } \\
\text { Kissinger Maxbrun }\end{array}$ & $\begin{array}{l}0,400 \\
0,340\end{array}$ & 5,4 & - & - & $\overline{2} 3$ & 2,5 & - & - & - & - & - \\
\hline Vichy Grand-Grille & 0,330 & 7,0 & 0,2 & - & $\begin{array}{l}, 0 \\
0,5\end{array}$ & 4,8 & - & - & - & - & - \\
\hline Vichy-Hospital & 0,320 & 7,1 & 0,2 & - & 0,5 & 5,0 & - & - & - & - & 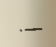 \\
\hline Sodener Warmbrunnen & 0,290 & 4,5 & - & - & 3,4 & - & - & - & - & - & - \\
\hline Karlsbader Sprudel & 0,275 & 5,5 & 2,4 & - & 1,0 & 1,9 & 0,7 & - & - & - & - \\
\hline Mühlbrunnen & 0,270 & 5,4 & 2,3 & - & 1,0 & 2,0 & - & - & - & - & 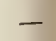 \\
\hline Marktbrunnen & 0,255 & 5,9 & 2,3 & - & 1,0 & - & - & - & - & - & - \\
\hline Schlossbrunnen & 0,255 & 5,3 & 2,3 & - & 1,0 & 1,7 & - & - & - & - & 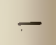 \\
\hline Neubrunnen & 0,250 & 5,4 & 2,3 & - & 1,0 & - & - & - & - & - & - \\
\hline $\begin{array}{c}\text { ranzensbader Wiesen- } \\
\text { quelle }\end{array}$ & 0,250 & 6,6 & 3,3 & - & 1,2 & 1,6 & - & - & - & - & - \\
\hline
\end{tabular}




\begin{tabular}{|c|c|c|c|c|c|c|c|c|c|c|c|}
\hline \multirow[b]{2}{*}{ Name, Quelle } & \multirow[b]{2}{*}{$\Delta$} & \multirow[b]{2}{*}{$\begin{array}{c}\text { Feste } \\
\text { Bestand- } \\
\text { theile } \\
\text { in } 11 \\
\text { Wasser }\end{array}$} & \multicolumn{9}{|c|}{ Gehalt pro $1 \mathrm{l}$ Wasser an } \\
\hline & & & $\begin{array}{c}\mathrm{g} \\
\mathrm{Na}^{-} \\
\mathrm{SO}_{4} \\
\end{array}$ & \begin{tabular}{|c|}
$\mathrm{g}$ \\
$\mathrm{Mg}-$ \\
$\mathrm{SO}_{4}$ \\
\end{tabular} & $\begin{array}{c}\mathrm{g} \\
\mathrm{Na}- \\
\mathrm{Cl}\end{array}$ & $\begin{array}{c}\mathrm{g} \\
\mathrm{Na}_{2}-1 \\
\mathrm{CO}_{3}\end{array}$ & $\begin{array}{c}\mathrm{g} \\
\text { Bicar- } \\
\text { bonate } \\
\text { v. Mg } \\
\text { und Ca }\end{array}$ & $\begin{array}{c}\mathrm{g} \\
\mathrm{Mg}- \\
\mathrm{Cl}_{2} \\
\end{array}$ & $\begin{array}{c}\mathrm{g} \\
\mathrm{Te}_{2-} \\
\left(\mathrm{SO}_{4}\right)_{3} \\
\end{array}$ & $\begin{array}{c}\mathrm{g} \\
\mathrm{CaSO}_{4} \\
+ \\
\mathrm{IgSO}_{4} \\
\end{array}$ & $\begin{array}{c}\mathrm{g} \\
\mathrm{As}_{2^{-}} \\
\mathrm{O}_{3} \\
\end{array}$ \\
\hline Karlsbader Felsenquelle & 0,245 & 5,4 & 2,3 & - & 1,0 & -1 & - & - & - & - & - \\
\hline $\begin{array}{l}\text { Theresien- } \\
\text { brunnen }\end{array}$ & 0,245 & 5,4 & 2,3 & - & 1,0 & - & - & - & - & - & - \\
\hline Apollinaris & 0,240 & 2,2 & 0,2 & - & 0,3 & 0,9 & - & - & - & - & - \\
\hline Wildunger Helenenquelle & 0,230 & 4.6 & - & - & 1,0 & - & 2,6 & - & - & - & - \\
\hline Rilmer Wasser & 0,230 & 5,2 & 0,6 & - & - & 4,6 & - & - & 一 & - & - \\
\hline Rhenser Mineralwasser & 0,230 & 3,9 & - & - & - & - & - & - & - & - & - \\
\hline Aachener Kaiserquelle & 0.227 & 4,0 & - & - & 2,6 & 0,9 & - & 一 & - & - & - \\
\hline Offenbacher Kaiser- & & & & & & & & & & & \\
\hline Friedrichquelle & 0,220 & 4,2 & - & - & - & 2,4 & - & - & - & - & - \\
\hline Adelheidsquelle & 0,220 & 6,1 & - & - & 4,9 & 0,9 & - & - & - & - & - \\
\hline Homburger Luisenquelle & 0,217 & 4,5 & - & - & 3,1 & - & - & - & - & - & - \\
\hline Vichy Célestins & 0,200 & 7,1 & 0,2 & - & 0,5 & 5,1 & - & - & - & - & - \\
\hline Sodener Milchbrunnen & 0,200 & 3,3 & - & - & 2,4 & - & - & - & - & - & - \\
\hline Marienbader Waldquelle & 0,200 & 4,3 & 1,2 & - & 0,3 & 1,0 & 0,8 & - & - & - & - \\
\hline Franzensbader Salzquelle & 0,190 & 5,4 & 2,8 & - & 1,1 & 0,9 & - & - & - & - & - \\
\hline Obersalzbrunner Ober- & & & & & & & & & & & \\
\hline brunnen & 0,190 & 3,8 & 0,4 & - & 0,1 & 2,1 & - & - & - & - & - \\
\hline Emser Kränchen & 0,170 & 3,5 & - & - & 0,9 & 1,9 & - & - & - & - & - \\
\hline Victoriaquelle & 0,165 & 3,5 & - & - & 0,9 & 2,0 & - & - & - & - & - \\
\hline $\begin{array}{l}\text { Tarasper-Schulser Boni- } \\
\text { faciusquelle }\end{array}$ & 0,165 & 5,1 & 0,2 & - & 0,05 & 1,4 & - & - & - & - & - \\
\hline $\begin{array}{c}\text { Krondorf Kronprinz } \\
\text { Stephan }\end{array}$ & & & & & & & & & & & \\
\hline $\begin{array}{c}\text { Stephan } \\
\text { Franzensbader Franzens- }\end{array}$ & 0,165 & 2,4 & - & - & - & 1,1 & - & - & - & - & - \\
\hline quelle & 0,160 & 5,9 & 3,1 & - & 1,2 & 0,9 & - & - & - & - & - \\
\hline Emser Kesselbrunnen & 0,160 & 3,5 & - & - & 1,0 & 1,9 & - & - & - & - & - \\
\hline Fachinger Wasser & 0,155 & 5,5 & - & - & 0,6 & 3,6 & 1,2 & - & - & - & - \\
\hline Wildunger Königsquelle & 0,140 & 3,8 & - & -- & 1,3 & - & 2,2 & -1 & - & - & - \\
\hline $\begin{array}{c}\text { Obersalzbrunner Kronen- } \\
\text { quelle }\end{array}$ & & & & & & & & & & & - \\
\hline Pyrmonter Helenenquelle & $\begin{array}{l}0,130 \\
0,120\end{array}$ & $\begin{array}{l}2,3 \\
2,9\end{array}$ & $\frac{0,1}{-}$ & $\overline{0,4}$ & $\overline{0.1}$ & 0,8 & 1,1 & - & - & - & - \\
\hline Giesshübler Wasser & 0,120 & 1,4 & - & - & - & $\overline{0,8}$. & 1,0 & - & - & - & - \\
\hline Levico starkes Wasser & 0,112 & 6,2 & - & - & - & - & - & - & 2,5 & 2,5 & 0,008 \\
\hline Marienbader Rudolfsquelle & 0,09 & 3,2 & 0,1 & - & - & 0,1 & - & 1,7 & - & - & - \\
\hline Neuenahrer Sprudel & 0,087 & 2,0 & 0,1 & - & - & 0,1 & - & -1 & - & - & - \\
\hline Schwalbacher Wein- & & & & & & - & & & & & \\
\hline brunnen & 0,075 & 1,0 & - & - & 一 & - & - & - & 一 & - & 一 \\
\hline $\begin{array}{c}\text { Weilbacher Schwefel- } \\
\text { brunnen }\end{array}$ & 0,075 & 1,5 & - & - & - & - & - & - & - & - & 一 \\
\hline Pyrmonter Hauptquelle & 0,072 & 2,7 & - & 0,4 & 0,1 & - & 1,1 & - & - & - & 一 \\
\hline
\end{tabular}




\begin{tabular}{|c|c|c|c|c|c|c|c|c|c|c|c|}
\hline \multirow[b]{2}{*}{ Name, Quelle } & \multirow[b]{2}{*}{$d$} & \multirow{2}{*}{$\begin{array}{l}\text { Feste } \\
\text { Bestand- } \\
\text { theile } \\
\text { in } 11 \\
\text { Wasser }\end{array}$} & \multicolumn{9}{|c|}{ Gehalt pro 11 Wasser an } \\
\hline & & & $\begin{array}{c}\mathrm{g} \\
\mathrm{Na}_{2}- \\
\mathrm{SO}_{4}\end{array}$ & $\begin{array}{c}\mathrm{g} \\
\mathrm{Mg}- \\
\mathrm{SO}_{4} \\
\end{array}$ & $\left\{\begin{array}{c}\mathrm{g} \\
\mathrm{Na}- \\
\mathrm{Cl}\end{array}\right.$ & $\begin{array}{c}\mathrm{g} \\
\mathrm{Na}_{2}- \\
\mathrm{CO}_{3} \\
\end{array}$ & $\begin{array}{c}\mathrm{g} \\
\text { Bicar- } \\
\text { bonate } \\
\text { v. Mg } \\
\text { und Ca }\end{array}$ & $\begin{array}{c}\mathrm{g} \\
\mathrm{Mg}- \\
\mathrm{Cl}_{2}\end{array}$ & $\begin{array}{c}\mathrm{g} \\
\\
\mathrm{Fe}_{2}- \\
\left(\mathrm{SO}_{4} / 3\right.\end{array}$ & $\left|\begin{array}{c}\mathrm{g} \\
\mathrm{CaSO}_{4} \\
+ \\
\mathrm{MgSO}_{4}\end{array}\right|$ & $\begin{array}{c}\mathrm{g} \\
\mathrm{As}_{2}- \\
\mathrm{O}_{3} \\
\end{array}$ \\
\hline $\begin{array}{c}\text { Wildunger Georg-Victor- } \\
\text { quelle }\end{array}$ & 0,067 & 1,49 & - & - & - & - & 1,2 & - & - & - & 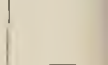 \\
\hline Teplitzer Stadtquelle & 0,060 & 7,2 & 0,7 & - & 0,7 & 4,2 & 0.8 & - & - & - & - \\
\hline Pystianer Wasser & 0,045 & 1,3 & - & - & - & - & - & - & - & - & - \\
\hline Assmannshäuser Wasser & 0,042 & 2,0 & - & - & 0,5 & 0,1 & - & - & - & - & - \\
\hline Roncegno-Wasser & 0,030 & 7,8 & - & - & - & - & - & - & 3,0 & 2,2 & 0,1 \\
\hline $\begin{array}{c}\text { Schwalbacher Stahl- } \\
\text { brunnen }\end{array}$ & 0,025 & 0,4 & $\begin{array}{l}0,08 \\
\text { Fer- } \\
\text { robi- } \\
\text { car- } \\
\text { bonat }\end{array}$ & - & - & - & - & - & -- & - & \\
\hline $\begin{array}{c}\text { Schlangenbader (Nassau) } \\
\text { Wasser }\end{array}$ & & & 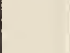 & . & 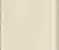 & - & 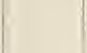 & - &.- & - & \\
\hline Bad Gasteiner Wasser & 0,010 & 0,3 & - & - & - & - & - & $\begin{array}{l}0,5 \\
\left(\mathrm{Fe}^{2}\right. \\
\left.\mathrm{SO}_{4}\right)\end{array}$ & 0,2 & - & 0,00095 \\
\hline $\begin{array}{l}\text { Levico schwaches Wasser } \\
\text { Wildbader Thermal- }\end{array}$ & 0,007 & 1,2 & - & - & - & - & - & - & - & - & - \\
\hline wasser & 0 & 0,5 & - & - & -- & - & - & - & - & - & - \\
\hline
\end{tabular}

Von Kostkewicz hat noch von den in den Handel gebrachten Salzen Dr. Sandow's die Gefrierpunkterniedrigung und die Trockensubstanz bestimmt, indem er dasjenige Quantum eines jeden Salzes, das in den, den Salzen beigefiigten Anweisungen angegeben ist, in 200 cc destillirten Wasser löste.

\begin{tabular}{|c|c|c|}
\hline $\begin{array}{l}\text { Name der Salze } \\
\text { von Dr. Sandow }\end{array}$ & \lrcorner & $\begin{array}{l}\text { Summe der festen } \\
\text { Bestandtheile in } 11\end{array}$ \\
\hline $\begin{array}{l}\text { Friedrichshaller } \\
\text { Kissinger } \\
\text { Marienbader } \\
\text { Karlsbader } \\
\text { Emser }\end{array}$ & $\begin{array}{l}0,890 \\
0,430 \\
0,380 \\
0,225 \\
0,215\end{array}$ & $\begin{array}{l}23,52 \\
8,075 \\
7,15 \\
4,5 \\
4,6\end{array}$ \\
\hline
\end{tabular}

Schliesslich erwähne ich noch einige Bestimmungen, die von Strauss an anderen Mineralwässern ausgeführt worden sind [17]. 


\begin{tabular}{l|c|c}
\hline \multicolumn{1}{c|}{ Name des Wassers } & $\Delta$ & $\begin{array}{c}\text { Summe der festen Lestand- } \\
\text { theile pro 1 l } \\
\text { (CO) und } \mathbf{H}_{2} \mathbf{S} \text { abgereclinet) }\end{array}$ \\
\hline \hline Harzburger Crodoquelle & 1,17 & 16,533 \\
Mergentheimer Carlsquelle & 0,90 & 20,489 \\
Elster Salzquelle & 0,39 & 8,305 \\
Vals Madeleine & 0,30 & 9,248 \\
Elster Marienquelle & 0,26 & 6,131 \\
Elster Moritzquelle & 0,26 & 2,282 \\
Selters & 0,23 & 3,827 \\
Rohitscher Tempelbrunnen & 0,20 & 7,774 \\
& & als saures kohlen- \\
Cudowaer Eugenquelle & & 2,757 \\
Reinerzer laue Quelle & 0,14 & 2,612 \\
Driburger Stahlquelle & 0,12 & 3,665 \\
Cudowaer Gottholdquelle & 0,11 & 1,888 \\
Lippspringer Arminiusquelle & 0,10 & 2,404 \\
Driburger Caspar Heinrichquelle & 0,08 & 1,359 \\
Nenndorfer Trinkquelle & 0,08 & 2,613 \\
Guberquelle & 0,08 & 0,760 \\
Evianer Wasser & 0,04 & 0,459 \\
& 0,02 &
\end{tabular}

\section{b) Eingehende Untersuchung von Irei Mineralwässern.}

\section{a) Das Liebensteiner Mineralwasser.}

Das erste Mineralwasser, das einer eingehenden Betrachtung aus physikalisch-chemischen Gesichtspunkten unterzogen wurde, war das Liebensteiner Stahlwasser der Quelle in Bad Liebenstein in Thüringen. Die Untersuchung wurde von $\mathrm{H}$. K o eppe ausgeführt.

1. Ge frierpunkterniedrigung.

Die Gefrierpunkterniedrigung bot der freien Kohlensäure wegen, eigenthümliche Schwierigkeiten dar.

Durch das bei der Depressionsbestimmung nothwendige Rühren treibt man Kohlensäure aus, insbesondere so lange die Temperatur noch relativ hoch ist. Da auch die Kohlensäure am Betrage des osmotischen Drucks betheiligt ist, sinkt die Gefrierpunkterniedrigung bei jeder Wiederholung des Versuches und diese Abnahmen sind nicht gering.

Um den Fehler möglichst herabzusetzen, wurde das Mineralwasser in verschlossener Flasche in einer Kältemischung soweit abgekühlt, 
dass der Nullpunkt annähernd erreicht wurde. Gleichzeitig wurden Gefrierröhre und Rührer auf $0^{0}$ abgekïhlt. Dann wurde die Flasche vorsichtig und langsam geöffnet und das Wasser ebenfalls vorsichtig in das schräg gehaltene Gefriergefäss übergefüllt. Es zeigte sich bei diesem Verfahren, selbst bei Mineralwässern mit hohem Gehalt an freier Kohlensäure, keine sichtbare Bläschenbildung. Ohne jede Erschütterung wurde jetzt die Gefrierröhre in den Gefrierapparat gebracht, dessen Kältemischung auf einer Temperatur wenig unterhalb des Gefrierpunktes des Mineralwassers gehalten wurde, damit die Unterkühlung nur gering ausfiel. Das Rï̈hren unterblieb bis die Unterkülılung beobachtet wurde, und erfolgte sodann auch nur so, dass der Rührer nie ganz aus dem Wasser herausgehoben wurde.

Auf diese Weise gelang es Ko eppe übereinstimmende Resultate zu erhalten (der Unterschied der Werthe aufeinander folgender Bestimmungen betrug $\left.0,005^{\circ}\right)$, vorausgesetzt, dass die einzelnen Proben gleichwerthig, d. h. nur die erste Probe aus den frisch geöffneten Flaschen waren.

Koeppe hat die Frage erhoben, ob es nicht möglich sei, auf eine bequemere Weise übereinstimmende Resultate zu erzielen, z. B. durch Verjagung der freien Kohlensäure. Auch das ist mit Schwierigkeiten verbunden. Denn die meisten Mineralwässer enthalten Kalk oder andere Stoffe, welche nur in Gegenwart freier Kohlensäure in Wasser gelöst bleiben, also ausfallen, wenn die freie Kiohlensäure entwichen ist. Es würde sich also noch mehr als die freie $\mathrm{CO}_{2}$ der Betheiligung an der Gefrierpunkterniedrigung entziehen.

K oeppe hat letzteres folgendermaassen zu umgehen gesucht. Lir bestimmte den Gefrierpunkt des Mineralwassers, olme aber die genannten Maassregeln zur Vorbeugung der $\mathrm{CO}_{2}$-Entweichung zu treffen. Diese Bestimmungen wurden einige Male an derselben Probe wiederholt, und die einzelnen Ablesungen notirt; jedesmal hatte die Gefrierpunkternierlrigung in Folge Entweichens von $\mathrm{CO}_{2}$ abgenommen. Hierbei war zunächst die Fliissigkeit stets nach dem Aufthauen klar geblieben, bis auf einmal nach dem Auftlıuen eine Trübung des Wassers beobachtet wurde. Der Werth, zwisclıen dem letzten für die nach dem Aufthauen noch klare Probe und dem ersten, für die nach dem Aufthanen trübe Probe ist nach Koeple der Crefrierpunlit des Wassers ohne die freie Kohlensäure.

Diese Behauptung kann aber 11. E. nicht in aller Strenge richtig sein, denn das Erscheinen einer Trübung sagt doch nicht aus, dass 
alle freie Kohlensäure vertrieben ist. „Häufig“, fügt der Autor hinzu, ,,besteht kein nennenswerther Unterschied zwischen beiden."

Unter diesen Kautelen hat K oeppe die Gefrierpunkterniedrigung des Liebensteiner Stahlwassers ermittelt.

a) Das der Erde entquellende Mineralwasser zeigte $\Delta=0,197^{\circ}$, was einer osmotischen Concentration $\left(\mathrm{C}_{0}\right)$ von $\frac{0,197}{1,85}=0,10648$ entspricht, oder anders gesagt: das Wasser enthielt pro Liter 0,10648 Molecüle + Ionen (Molionen).

ß) Das durch wiederholtes Gefrieren und Aufthauen an freier Kohlen. säure arm gemachte $W$ asser zeigte $A=0,095^{\circ}, d$. h. eine osmotische Concentration $\left(\mathrm{C}_{1}\right)$ von 0,05135 .

$\gamma)$ Das ausgekochte Mineralwasser, das also frei von $\mathrm{CO}_{2}$ war und aus dem die primären Carbonate von Eisen, Kalk, Mangan, Baryum, Strontium, Aluminium in die secundären umgewandelt und ausgefällt waren, zeigte $\Delta=0,045^{\circ} . \mathrm{C}_{0}$ war 0,0243 .

Die freie $\mathrm{CO}_{2}$ bedingte also eine Gefrierpunkterniedrigung von $0,197^{\circ}-0,095^{0}=0,102^{0}=0,055135$ Molecüle + Ionen.

Ich komme auf diese Zahlen noch zurïck.

\section{Elektrische Leitfähigkeit.}

a) Die specifische elektrische Leitfähigkeit des der Erde entquellenden Mineralwassers betrug bei $18^{0} 19,79 \times 10^{-4}$ reciproke $\mathrm{Ohm}^{1}$ ).

ß) Das an Kohlensäure arm gemachte Wasser hatte bei $18^{\circ}$ eine specifische Leitfähigkeit von $19,67 \times 10^{-4}$.

Aus diesem geringen Unterschied zwischen $\alpha$ und $\beta$ schliesst Koeppe, dass die freie Kohlensäure in dem Mineralwasser in der Form neutraler Moleciile vorhanden ist.

Koeppe hat versucht aus dem Leitfähigkeitswerth ein Bild über den Ionisirungsgrad zu gewinnen. Zu diesem Behufe suchte er die Chlornatriumlösung auf, die dieselbe Leitfähigkeit, wie die gefundene $19,67 \times 10^{-4}$, besitzt (vergl. über die Methode Bd. I, S. 491). Es stellte sich heraus, dass die Kochsalzlösung, die dieselbe Leitfälnigkeit besitzt wie das betreffende Mineralwasser, etwa 0,02 Molen oder $0,117 \% \mathrm{NaCl}$ enthält. Wird für diese Lösıng vollständige Dissociation angenommen, so wäre diese Leitfähigkeit bedingt durch $0,02 \times 2=0,04$ Ionen pro Liter.

1) Bei Koeppe heisst es: $19,79 \times 10-8$ reciproke Ohm. Auch die anderen von Ko ausgedrückt worden. Vergl, die Anmerkung S. 283. 
Im Ganzen sind vorhanden (vergl. $1 \alpha$ ) 0,10648 Molionen (Molecuile + Ionen $)^{1}$ ). Also sind etwa $0,10648-0,04=0,06648$ ungespaltene Nolecïle im Liter vorhanden.

\section{Vergleichung der chemischen mit der osmotischen Analyse.}

Nach der chemischen Analyse von B e y er lieferte $1 \mathrm{~kg}$ Liebensteiner Eisenwasser :

\begin{tabular}{|c|c|}
\hline 0391189 & $\mathrm{~g} \mathrm{FeO}$ \\
\hline 00302 & "Al $\mathrm{PO}_{4}$ \\
\hline $\begin{array}{l}0,292612 \\
0,4713255 \\
1,145923 \\
0,00009 \\
0,000209 \\
0,574483 \\
0,052974 \\
0,00707 \\
0,440457 \\
0,0002638 \\
0,000553 \\
0,0244 \\
0,00825 \\
3,204 \\
0,333296\end{array}$ & $\begin{array}{l}\Rightarrow \mathrm{CaO} \\
" \mathrm{Mg}_{2} \mathrm{P}_{2} \mathrm{O}_{7} \\
" \mathrm{Ag} \mathrm{Cl} \\
" \mathrm{Ba} \mathrm{SO}_{4} \\
" \mathrm{Sr} \mathrm{SO} \mathrm{SO}_{4} \\
" \mathrm{Ba} \mathrm{SO}_{4} \\
" \mathrm{~K}_{2} \mathrm{Pt} \mathrm{Cl}_{6} \\
" \mathrm{Li}_{3} \mathrm{PO}_{4} \\
" \mathrm{NaCl} \\
\mathrm{Mg}_{2} \mathrm{P}_{2} \mathrm{O}_{7} \\
" \mathrm{Mg}_{2} \mathrm{As}_{2} \mathrm{O}_{7} \\
" \mathrm{SiO}_{2} \\
" \mathrm{Mn} \mathrm{SO}_{4} \\
" \mathrm{CO}_{2} \text { gesammt } \\
\text { "CO gebunden }\end{array}$ \\
\hline
\end{tabular}

$$
\begin{aligned}
& =0,0005433 \mathrm{~g}-\mathrm{mol} . \mathrm{Fe} \cdot \\
& f=0,0000024, \quad, \quad \text {, Al } \cdots \\
& 1=0,0000024, \quad, \quad \mathrm{PO}_{4}{ }^{\prime \prime} \\
& =0,0052252, \quad, \quad, \quad \mathrm{Ca}^{*} \\
& =0,004232, \quad, \quad, \quad \mathrm{Mg}^{*} \\
& =0,0079911, . \quad, \quad \mathrm{Cl}^{\prime} \\
& =0,0000003, \quad, \quad \mathrm{Ba}^{\prime} \\
& =0,0000011, \quad, \quad, \quad \mathrm{Sr}^{*} \\
& =0,0024613, \quad, \quad \mathrm{SO}_{4}{ }^{\prime \prime} \\
& =0,0002176, \quad, \quad K^{\cdot} \\
& =0,000183,, \quad, \quad \mathrm{Li}^{\circ} \\
& =0,0075356 ., \quad, \quad \mathrm{Na} . \\
& =0,0000022, \quad, \quad \mathrm{PO}_{4}^{\prime \prime} \\
& =0,0000032, \quad, \quad \text { As } \mathrm{O}_{4}{ }^{\prime \prime} \\
& =0,0004030, \quad, \quad \text { Si O } \\
& =0,0000546, \quad, \quad, \quad \mathrm{Mn}^{*} \\
& =0,072818 \quad, \quad, \quad \mathrm{CO}_{2} \\
& \left.=0,007575 \quad \text { " } \quad, \quad \mathrm{CO}_{3}{ }^{\prime \prime}\right) \text {. }
\end{aligned}
$$

1) Es besteht, wie ich bereits früher (B. I, S. 13) bemerkte, eine Verwirrung in der Nomenclatur. Ko eppe sagt in vorliegenden Fall, es seien 'im Stahlwasser 0,10648 "Molen" vorhanden und versteht, wie viele andere, darunter: g.Molecüle + Ionen pro Liter. Dementsprechend würde dann unter "molarer Concentration" zu verstehen sein: die Anzahl Molecüle + Ionen pro Liter.

Indessen wird letzterer Ausdruck auch angewandt für die Concentration, die sich ergiebt, wenn man die Dissociation nicht berïcksichtigt. Ich habe nun vorgeschlagen die Ostwald'sche Bezeichnung für letztere Concentration festzuhalten und diese "molare“ zu benennen, dagegen diejenige Concentration, welche die Dissociation berücksichtigt, mit „osmotischer Concentration" $\mathrm{zu}$ bezeichnen. (Vergl. oben Bd. I, S. 14.) Ich habe daran consequent festgehalten, indem ich, wo die Anzahl Molecüle + Ionen angegeben werden sollte, niemals das Wort "Mol* gebrauchte, sondern: Moleküle + Ionen. Bei dem vielfältigen Gebrauch dieses Begriffes scheint es mir nachträglich sehr zweckmässig, dafür einen kürzeren Ausdruck zu suchen und schlage ich den Namen Molion [19] vor. Will man also z. B. ausagen: es kommen im Liebensteiner Mineralwasser 0,10648 Molecuile + Ionen pro Liter vor, so kann man das auch so ausdrücken, dass man sagt: es kommen im Liebensteiner Stahlwasser 0,10648 Nolionen vor, oder eventuell: die osmotische Concentration ist 0,10648 . 
An alyse in Ionen berechnet:

\begin{tabular}{|c|c|c|c|c|c|}
\hline \multicolumn{3}{|c|}{ Positive } & & \multicolumn{2}{|c|}{ Negative } \\
\hline & Molen & Valenzen & & Molen & Valenzen \\
\hline $\mathrm{Na} \cdot$ & 0,0075356 & $=0,0075356$ & $\mathrm{Cl}^{\prime}$ & 0,007991 & $=0,007991$ \\
\hline $\mathrm{K}$. & 0,0002176 & $=0,0002176$ & $\mathrm{Br}^{\prime}$ & 0,0000074 & $=0,0000074$ \\
\hline $\mathrm{Li} \cdot$ & 0,000183 & $=0,000183$ & $\mathrm{~J}^{\prime}$ & 0,0000029 & $=0,0000029$ \\
\hline $\mathrm{Ca} \cdot$ & 0,0052252 & $=0,010450$ & $\mathrm{SO}_{4}$ & 0,0024613 & $=0,004922$ \\
\hline $\mathrm{Mg} \cdot$. & 0,004232 & $=0,008464$ & $\mathrm{PO}_{4}$ & 0,0000024 & $=0,000007$ \\
\hline $\mathrm{Fe}^{*}$ & 0,0005433 & $=0,001086$ & $\mathrm{PO}_{4}^{\prime \prime}$ & 0,0000022 & $=0,000007$ \\
\hline$M n \cdot$ & 0,0000546 & $=0,000109$ & $\mathrm{AsO}^{\prime \prime \prime}{ }_{t}$ & 0,0000032 & $=0,0000095$ \\
\hline $\mathrm{Ba} \cdot$ & 0,0000003 & $=0,0000006$ & $\mathrm{SiO}_{2}^{\prime \prime}$ & 0,000403 & $=0,000806$ \\
\hline Sr." & 0,0000011 & $=0,0000022$ & $\mathrm{HCO}_{3}^{\prime}$ & 0,007575 & $=0,007575$ \\
\hline $\mathrm{Al} \cdots$ & 0,0000024 & $=0,0000072$ & $\mathrm{HCO}_{3}^{\prime}$ & 0,007575 & $=0,007575$ \\
\hline & & & & 0,026023 & 03 \\
\hline
\end{tabular}

Die chemische Analyse ergiebt somit eine Gesammtzahl an Molionen ron:

$$
\begin{aligned}
& 0,057668 \text { freie Kohlensäure } \\
& 0,017995 \text { positive Ionen (Kationen) } \\
& 0,026023 \text { negative Ionen (Anionen) } \\
& 0,101686
\end{aligned}
$$

Die Gefrierpunkterniedrigung aber ergab eine osmotische Concentration von 0,10648 Molionen. Das macht einen Unterschied von 0,00479 Molionen.

Eine solche Differenz ist in keiner Weise durch die Untersuchungsfehler, sei es der chemischen, sei es der physikalisch-chemischen Untersuchungen zu erklären. Es bleibt nach Koeppe nichts Anderes iibrig als zu schliessen:

In dem Liebensteiner Stahlwasser sind noch Stoffe vorhanden, welche durch die chemische, in der üblichen Weise ausgef ühte Analyse nicht mitbestimmt werden ${ }^{1}$ ).

In einem gleichlautenden Ergebniss führt die Vergleichung der chemischen und osmotischen Analyse des nach wiederholtem Gefrieren und Aufthauen an Kohlensäure arm gemachten Nineralwassers.

Die Gefrierpunkterniedrigung dieses Wassers ergab 0,05135 Molionen.

Die chemische Analyse

Also weist die chemische Analyse ein Deficit auf von 0,007332 Molionen.

Ein anderes Resultat dagegen gab das ausgekochte Mineralwasser.

1) Vergl. unten S. 300 . 
Nach dem Abkochen dürften im Mineralwasser vorhanden sein:

\begin{tabular}{ll}
0,007536 & $\mathrm{Na} \cdot$ \\
0,0002176 & $\mathrm{~K} \cdot$ \\
0,000183 & $\mathrm{Li}^{\cdot}$ \\
0,004232 & $\mathrm{Mg} \cdot$ \\
\hline 0,0121686 & Kationen.
\end{tabular}

Hierbei sind mehr Kationen als Anionen aufgezählt nnd ausserdem entspricht das zweiwerthige Kation Mg" zwei einwerthigen Kationen. Man darf daher so rechnen, als ob $0,012168+0,004232=0,0164$ einwerthige Kationen vorhanden wären. Diese brauchen zur Sättigung mehr als 0,0080013 Anionen, und zwar $0,0164-0,0080013=0,0083987$ Anionen mehr. $\mathrm{Zu}$ deren Bindung sind nach $\mathrm{Koeppe}$ noch zweiwerthige Ionen $\mathrm{SO}^{\prime \prime}{ }_{4}$ und $\mathrm{CO}_{3}{ }_{3}$ heranzuziehen. Diese entsprechen $0,0083987: 2=0,0041993$ Molionen.

Demnach wären im abgekochten Wasser vorhanden:

$$
\begin{aligned}
& 0,012168 \text { Kationen } \\
& 0,0080013 \text { einwerthige Anionen } \\
& 0,0041993 \text { zweiwerthige Kationen } \\
& \hline 0,0243686
\end{aligned}
$$

während aus der Gefrierpunkterniedrigung berechnet wurden 0,0243 Molionen.

Hier herrscht also Uebereinstimmung.

Koeppe gelangt also zu dem Schluss, dass die Stoffe, welche die durch chemische Analyse gefundene osmotische Concentration kleiner erscheinen lassen als die durch Gefrierpunktbestimmung ermittelte, beim Eindampfen entweichen, also flüchtiger Natur sind.

Stickstoffhaltige Verbindungen sind es nach Koeppe nicht, denn die Untersuchung auf Stickstoff fiel negativ aus. Die Untersuchung auf Schwefelwasserstoff war ebenfalls negativ. Für die Anwesenheit organischer Verbindungen sprach die Reaction des Wassers mit Silbernitrat. Quellwasser mit Silbernitratlösung versetzt, färbte sich beim Erwärmen blauviolett, bei weiterem Kochen schied sich ein schwarzes Pulver aus.

\section{ß) Rhenser Sprudel.}

Tom Rhenser Sprudel (zu Rhens bei Coblenz am Rhein) haben Hintz und Grïnhut eine sorgfältige chemische und physikalischchemische Untersuchung ausgeführt [4]. Sie wurde direct an der Quelle und an frisch entnommenem Mineralwasser angestellt.

\section{Gefrierpunkterniedrigung.}

Die Gefrierpunkterniedrigung erfolgte auf derselben Weise, also unter Einhaltung derselben Kautelen, die Ko ep pe angegeben hatte. 
Es kamen also, ebenso wie bei ihm, zur Untersuchung:

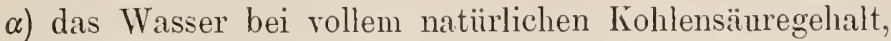

ß) das Wasser bei eben beginnender Trübung, also nach Entweichung der grössten Menge freier $\mathrm{CO}_{2}$.

$\left.\gamma^{\prime}\right)$ das ausgekochte Mineralwasser.

ad a) Das Wasser bei vollem Kohlensäuregehalt zeigte $\Delta=-0,334^{\circ}$.

ad $\beta$ ) das Wasser, aus dem die freie $\mathrm{CO}_{2}$ grösstentheils entwichen war, zeigte $\Delta=-0,200^{\circ}$.

Der freien $\mathrm{CO}_{2}$ wïrde nach Koeppe's Rechnungsweise also eine Gefrierpunkterniedrigung von $-(0,334-0,200)=0,134^{0}$ zukommen. Die Autoren bemerken hierzu mit Recht, dass dabei stillschweigend angenommen wird, der Zustand der in Lösung sich befindenden Salze sei durch die Austreibung der Kohlensäure nicht geändert worden. Hintz und Grünhut heben dann herror, dass das Rhenser Mineralwasser eine erhebliche Menge von Bicarbonaten enthält. Sobald sich neben diesen freie Kohlensäure in Lösung rorfindet, erfahren sie lediglich eine Dissociation in Ionen, d. h. das Natriumbicarbonat zerfällt nach dem Schema:

$$
\mathrm{NaHCO} \rightleftarrows \mathrm{Na}+\mathrm{HCO}_{3}{ }^{\prime} \text {. }
$$

Einem Salzmolecül entsprechen also zwei Ionen.

Fehlt jedoch die Kohlensäure in der Lösung der Bicarbonate, so erfährt ein erheblicher Antheil derselben durch Hydrolyse die folgende Umsetzung :

$$
\mathrm{NaHCO}_{3}+\mathrm{H}_{2} \mathrm{O} \rightleftarrows \mathrm{NaOH}+\mathrm{H}_{2} \mathrm{CO}_{3} \text {, }
$$

während das $\mathrm{NaOH}$ wieder zerfällt in $\mathrm{Na}^{\cdot}$ und $\mathrm{OH}^{\prime}$. Es entstehen also hier aus einem Salzmolecül $\mathrm{NaHCO}_{3}$, statt zwei, drei Theile: $\mathrm{Na}^{\circ}, \mathrm{OH}^{\prime}$ und $\mathrm{H}_{2} \mathrm{CO}_{3}{ }^{1}$ ).

Der durch Rühren herbeigeführte Kohlensäureverlust geht mit einer secundären Steigerung des osmotischen Druckes des Wassers einher. Es ist demnach nicht gestattet die der Kohlensäure entsprechende Depression einfach durch Abzug zu bestimmen. Die Gefrierpunkterniedrigung 0,200 ${ }^{\circ}$ hat durch Hydrolyse eine Erhöhung erfahren und die Gefrierpunkterniedrigung der Kohlensäure müsste also grösser als $0,334^{0}-0,200^{\circ}=0,134$ sein.

Dennoch stimmt diese Zahl mit der durch chemische Analyse ermittelten Menge freier Kohlensäure überein. Hintz und Grïnhut meinen daher, dass vielleicht mit dem Austreiben der freien Kohlensäure gleichzeitig noch andere, bisher unbekannte Reactionen sich abspielen, welche die durch Hydrolyse bedingte Vermehrung der Molenzahl gerade compensiren.

1) Diese ist als schwache Säure wenig dissociirt. 
Ich frage mich, ob letztere Annahme wohl erforderlich ist, denn, wie ich bereits hervorhob, ist man doch eigentlich nicht berechtigt anzunehmen, dass bei einer beginnenden Trübung alle freie Kohlensäure ausgetrieben ist.

Die Gefrierpunkterniedrigung des ausgekochten Wassers $(\gamma)$ betrug $\Delta=-0,160^{\circ}$.

2. Elektrische Leitfähigkeit.

Diese wurde in üblicher Weise ermittelt (vergl. B. I, S. 118). Die Temperatur des Wassers im Widerstandsgefäss betrug $22,1^{\circ} \mathrm{C}$; und wich von derjenigen der Quelle $\left(23,2^{\circ}\right)$ nur wenig ab.

Obgleich ich schon beim Blut und Serum Beispiele ron derartigen Leitfähigkeitsbestimmungen mitgetleilt habe (Bd. I, S. 524), will ich hier auch noch die von Hintz und Grünhut ausgeführte Bestimmung als Schema mittheilen.

\section{Capacität des Widerstandsgefässes.}

In h a lt: ${ }^{1 / 50}$ Normal-Chlorkalium-Lösung.

$$
\text { Temperatur: }+21,6^{\circ} \mathrm{C} \text {. }
$$

\begin{tabular}{|c|c|c|c|}
\hline $\begin{array}{c}\text { Widerstand } \mathrm{R} \\
\text { in Rheostat } \\
\Omega\end{array}$ & $\begin{array}{c}\text { Ablesung a auf } \\
\text { dem Brückendraht } \\
\mathrm{mm}\end{array}$ & $\frac{a}{1000-a}$ & $\begin{array}{c}\text { Gesuchter } \\
\text { Widerstand } \\
\Omega\end{array}$ \\
\hline 1000 & 505 & 1,02020 & 1020,2 \\
\hline 1010 & 502 & 1,00803 & 1018,1 \\
\hline 1030 & 497 & 0,98807 & 1017,7 \\
\hline 1020 & 499 & 0,99601 & 1015,9 \\
\hline 1010 & 502 & 1,00303 & 1018,1 \\
\hline 1000 & 506 & 1,02429 & 1024,3 \\
\hline 990 & 508 & 1,03252 & 1022,2 . \\
\hline $9=0$ & 511 & 1,04499 & 1024,1 \\
\hline
\end{tabular}

Specifische Leitfähigkeit $x_{21,6}{ }^{\circ}=0,002585$ (nach $\mathrm{Kohlrausch}$ ). Capacität des Gefässes C $=0,002585 \times 1020,1=\mathbf{2 , 6 3 6 9 6}$.

\section{Bestinmung der Leitfähigkeit.}

'T emperatur: $+22,1^{\circ} \mathrm{C}$.

Widerstand $\mathrm{R}$ Ablesung a auf in Rheostat dem Brückendraht

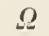

550

540

570

560

550

540 $\mathrm{mm}$

499

502

488

493

497

501 a

$1000-\mathrm{a}$

0.99600

1,00805

0,95313

0,97240

0,98808

1,00401
Gesuchter

Widerstand

$$
\Omega
$$

547,80

544,33

543,28

544,54

543,44

542,16

$x_{22,1^{\circ}}=\frac{\mathrm{C}}{544,3}=0,0048447$ reciproke Ohm. 
Die specifische Leitfähigkeit des Rhenser Mineralwassers bei $22,1^{\circ} \mathrm{C}$, d. h. die Leitfähigkeit einer Schicht von $1 \mathrm{~cm}$ Länge und 1 q cm Querschnitt, beträgt liernach 0,0048447 reciproke $\mathrm{Ohm}$.

Aus der Zusammenstellung auf S. 298 ergiebt sich, dass 1 Liter Rhenser Wasser sowohl $0,057455 \mathrm{~g}$-Aequivalente Kationen als auch $0,057455 \mathrm{~g}$-Aequivalente Anionen, folglich auch ebenso viele g-Aequivalente Salze enthält. Die Aequivalent-Concentration $\eta$ einer Cubikcentimeters Rhenser Wasser ist demnach $=0,000057455$. Nach der Formel

$$
\Lambda=\frac{x}{\eta} \text { (Bd. I, S. 121) }
$$

kann man hieraus die A equivalent-Leitfähigkeit $\Lambda$ bei $22,1^{\circ} \mathrm{C}$. berechnen und findet so für dieselbe, bezogen auf $\mathrm{cm} / \mathrm{Ohm}$ den Werth $84,3 \pm$.

Wie oben erwähnt wurde, hat Koeppe ein Bild von dem Ionisirungszustand zu entwerfen gesucht, indem er die NaCl-Lösung aufsuchte, die dieselbe Leitfähigkeit besass, wie das untersuchte Wasser. Von dieser NaCl-Lösung bestimmte er den Dissociationsgrad. Koeppe war sich dessen bewusst, dass dieses Verfahren bis zu einem gewissen Grade willkürlich war; denn das Mineralwasser enthält, obwohl in viel geringerer Menge, auch andere Bestandtheile, die einen ganz anderen Dissociationsgrad bei derselben Verdïnnung besitzen. So berechneten Hintz und Grünhut, dass, wenn man das Wasser, statt mit einer $\mathrm{NaCl}$-Lösung, mit einer $\mathrm{Na}_{2} \mathrm{SO}_{4}$-Lösung, von welchem das Rhenser Wasser ja gleichfalls erhebliche Mengen enthält, ron derselben Leit fähigkeit vergleicht, in einem Liter, bezw. statt $0,0812101^{1}$ ), 0,0588337 freie Ionen vorkommen würden.

Nach Grünhut [5] gelangt man zu einer exacteren Ableitung des Dissociationsgrades einer Salzlösung mit Hülfe des Gesetzes ron Kohlra us cll.

Bezeichnet man mit $\Lambda \varphi$ die Aequivalent-Leitfähigkeit einer Salzlösung von der Verdünnung $\varphi$, mit $l_{A}$ die Aequivalent-Leitfähigkeit ihres Anions und mit $l_{k}$ diejenige ihres Kations, so ist der Dissociationsgrad

$$
\alpha=\frac{\Lambda \varphi}{l_{\mathrm{A}}+\mathrm{l}_{\mathrm{k}}} .
$$

1) Ist die Aequivalent-Leitfähigkeit bei $22,1^{\circ} \mathrm{C} .84,32$ so lässt sie sich mittelst des Temperaturcoëfficienten 0,02 für $18^{\circ}$ umrechnen.

Es ergiebt sich dann für die specifische Leitfähigkeit bei $18^{\circ}, \%_{18}=0,0044775$.

Die gleiche specifische Leitfähigkeit besitzt eine 0,04656 normal NaCl-Liösung die andererseits einen Dissociationsgrad $\alpha=0,872$ aufweist.

Die osmotische Concentration einer solchen Lösung ist $=0,087160$ Molionen und hierunter befinden sich 0,0812101 freie Ionen. 
Für zusammengesetzte Salzlösungen, wie sie Mineralwasser darstellen, ist diese Formel offenbar dann anwendbar, wenn man für $l_{\mathrm{A}}$ und $\mathrm{l}_{\mathrm{k}}$ die mittlere Leitfähigkeiten aller vorhandenen Anionen, bezw. Kationen unter Berïcksichtigung ihrer relativen Menge einsetzt.

Man bezeichne mit \%t die specifische Leitfähigkeit des Mineralwassers bei $\mathrm{t}^{0} \mathrm{C}$, , bezogen auf $\mathrm{cm} \mathrm{Ohm}$, mit $\mathrm{a}_{1}, \mathrm{a}_{2}, \mathrm{a}_{3}$ etc. die Concentration der einzelnen Anionen (unter der Voraussetzung vollständiger Dissociation), in g-Aequivalenten pro Liter; mit $l_{\mathrm{A}_{1}}, l_{\mathrm{A}_{2}}, l_{\mathrm{A}_{3}}$ etc. die zugehı̈rigen Aequivalent-Leitfähigkeiten bei $18^{\circ} \mathrm{C}$. Ferner seiell $k_{1}, k_{2}, k_{3}$ etc. die entsprechenden Concentrationen und $l_{k_{1}}, l_{k_{2}}, l_{k_{3}}$ etc. die bei $18^{\circ}$ gemessenen Aequivalent-Leitfähigkeiten der einzelnen Kationen.

Setzt man endlich

$$
\text { nnd } \begin{aligned}
& a_{1} l_{A_{1}}+a_{2} l_{A_{2}}+a_{3} l_{A_{3}}+\ldots=\Sigma a l_{A} \\
& k_{1} l_{K_{1}}+k_{2} l_{K_{2}}+k_{3} l_{K_{3}}+\ldots=\Sigma k l_{K},
\end{aligned}
$$

so ergiebt sich unter der Annahme eines rnittleren Temperaturcoëfficienten von 0,02

$$
\alpha=\frac{1000 * \mathrm{t}}{\left(\Sigma \mathrm{a} l_{\mathrm{A}}+\Sigma \mathrm{k} \mathrm{l}_{\mathrm{K}}\right)(0,64+0,02 \mathrm{t}) .}
$$

Mit Hülfe dieser Formel, deren Ableitung Grünhut an anderer Stelle in Aussicht gestellt hat, ist $a$ zu berechnen, sobald man die Leitfähigkeiten aller einzelnen Anionen und Kationen $l_{A}$ und $l_{K}$ mit hinreichender Genauigkeit kennt. Das ist zur Zeit aber noch nicht für alle Ionen der Fall und die Ergebnisse können, wie Grünhut bemerkt, desshalb vorläufig nur als angenäherte gelten.

Unter dieser Einschränkung erhielt er dann für den Dissociationsgrad des Rhenser Mineralwassers annähernd 0,763.

Das heisst, von den im Rhenser Mineralwasser gelöst enthaltenen Salzmolecülen sind 76,3 Procent im Ionenzustand und 23,7 Procent als ungespaltene Molecüle vorhanden.

\begin{tabular}{|c|c|c|c|}
\hline Kationen in 1 I & Gramm & Molen & Gramm-A equivalent \\
\hline $\mathrm{H} \cdot$ & 0,000285 & $0,0002 \triangleleft 2$ & 0,000282 \\
\hline $\mathrm{Na}$ & 1,019652 & 0,044236 & 0,044236 \\
\hline $\mathrm{K} \cdot$ & 0,019210 & 0,000491 & 0,000491 \\
\hline $\mathrm{Li} \cdot$ & 0,001217 & 0.000173 & 0,000173 \\
\hline $\mathrm{NH}_{4}$ & 0,002518 & 0,000139 & 0.000139 \\
\hline $\mathrm{Ca}^{*}$ & 0,128928 & 0,003223 & 0,006446 \\
\hline $\mathrm{Sr} \cdot$ & 0,000147 & 0,000002 & 0,000003 \\
\hline $\mathrm{Mg} \cdot$ & 0,065502 & 0,002689 & 0,005378 \\
\hline Mn* & 0,000512 & 0,000009 & 0,000019 \\
\hline \multirow[t]{2}{*}{$\mathrm{Fe} \cdot$} & 0,008060 & 0,000144 & 0,000288 \\
\hline & & & 0.057455 \\
\hline
\end{tabular}

\section{Vergleichung der chemischen und osmotischen Analyse.}

Aus der chemischen Analyse wurde Folgendes berechnet: 
A nionen in 11

\begin{tabular}{llll}
$\mathrm{Cl}^{\prime}$ & 0,762721 & 0,021515 & 0,021515 \\
$\mathrm{Br}^{\prime}$ & 0,001135 & 0,000014 & 0,000014 \\
$\mathrm{~J}^{\prime}$ & 0,000014 & 0,0000001 & 0,0000001 \\
$\mathrm{HCO}_{3}^{\prime}$ & 1,484938 & 0,024339 & 0,024339 \\
$\mathrm{HSiO}^{\prime}$ & 0,021867 & 0,000282 & 0,000282 \\
$\mathrm{SO}_{3}^{\prime \prime}$ & 0,539484 & 0,005616 & 0,011232 \\
$\mathrm{~B}_{4} \mathrm{O}^{\prime \prime}{ }_{7}$ & 0,004432 & 0,000028 & 0,000057 \\
$\mathrm{HAsO}^{\prime \prime}$ & 0,000112 & 0,0000008 & 0,0000016 \\
$\mathrm{HPO}^{\prime \prime}$ & 0,000669 & 0,000007 & 0,000014 \\
\cline { 2 - 3 } & $\left.4,06140{ }^{1}\right)$ & 0,103190 &
\end{tabular}

Freie $\mathrm{CO}_{2}$ in $11 \frac{3,120484}{7,181887} \quad \frac{0,070920}{0,174110}$

Bei der vorstehenden Berechnung wurde angenommen, dass Borsäure in Form von Tetraboraten, Arsensäure und Phosphorsäure in Form einfach saurer Salze, beziehungsweise also in Form der zweiwerthigen Ionen $\mathrm{B}_{4} \mathrm{O}^{\prime \prime}, \mathrm{HAsO}^{\prime \prime}{ }_{4}$ und $\mathrm{HPO}^{\prime \prime}{ }_{4}$ vorhanden sind. Es schliesst sich das den Annahmen an, die sich auf Grund des Verhaltens der Salze genannter Säuren gegen freies Kohlendioxyd ergeben und steht somit auch in Uebereinstimmung mit dem üblichen Schema der Berechnung von Mineralwasseranalysen. Gleichfalls im Anschluss an letzteres wurde die Kieselsäure als freie in Rechnung gestellt. Die Autoren konnten sich hierbei jedoch insofern nicht an $\mathrm{H}$. Ko e p pe anschliessen, als sie die Kieselsäure nicht als $\mathrm{Si}_{2}$ anführten, sondern als $\mathrm{H}_{2} \mathrm{SiO}_{3}$, die sie in die Ionen $\mathrm{H}^{\cdot}$ und $\mathrm{HSiO}_{3}^{\prime}$ zerlegten.

Die Anionen $\mathrm{HAsO}_{t}, \mathrm{HPO}_{4}, \mathrm{HCO}_{3}$ und $\mathrm{HSiO}_{3}$ sind, wis $\mathrm{Hintz}$ und Grünhut bemerken, noch einer Dissociation zweiter Ordnung in $\mathrm{H}^{*}$ und As $\mathrm{O}^{\prime \prime \prime}{ }_{4}$, $\mathrm{H}^{*}$ und $\mathrm{PO}_{4}{ }_{4}, \mathrm{H} \cdot$ und $\mathrm{CO}_{3}{ }_{3}$ bezw. $\mathrm{H} \cdot$ und $\mathrm{SiO}^{\prime \prime}{ }_{3}$ fähig. Von einel Berücksichtigung dieser zweiten Dissociationstufe glaubten die Autoren bis auf Weiteres absehen zu dürfen, da sie einerseits bei so schwachen Säuren wie Kohlensäure und Kieselsäure unter normalen Verhältnissen praktisch kaum in Betracht kommt und andererseits bei den geringen Mengen $\mathrm{HAsO}^{\prime \prime}{ }_{4}$ und $\mathrm{HPO}_{4}{ }_{4}$ auf das Resultat keinen wesentlichen Einfluss ausübt.

Berechnet man aus der Gefrierpunkterniedrigung $-0,334^{\circ}$ des frischen natürlichen Wassers die osmotische Concentration, so ergiebt sich $\frac{0,334}{1,85}=0,180 \check{5} 4$ Nolionen, während die osmotisch-chemische Analyse 0,174110 Molionen aufweist.

Eine ebenso grosse Differenz erhält man, wenn man das an Kohlensäure arme $(\beta)$ und das ausgekochte Wasser $(\gamma)$ in Betracht zieht.

1) Diese Summe entspricht dem Gehalte eines Liters Rhenser Mineralwasser an gelösten Salzen. 
Die osmotische Concentration des auf die bekannte Weise an Kohlensäure arm gemachten Wassers war:

$$
\frac{0,200}{1,85}=0,108108 \text { Molionen, }
$$

während nach der chemischen Analyse, unter der Voraussetzung vollständiger Dissociation, die Zahl der Ionen in 1 Liter Rhenser Wasser 0,103190 betrug.

Die kryoskopische Untersuchung ergab somit ein Plus von 0,004918 Molionen.

In Wahrheit ist diese Differenz jedoch noch grösser, denn die Bestimmung der Leitfähigkeit hatte gelehrt, dass die Salzmolecüle im Mittel nur zu 76,3 Procent dissociirt sind. Die osmotische Concentration, welche der gefundenen chemischen Zusammensetzung entspricht, ist also thatsächlich geringer als 0,103190. Wie gross sie in Wirklichkeit ist, lässt sich nicht genau ermitteln, weil neben Moleciilen die in 2 Ionen zerfallen und auch noch solche vorhanden sind, die in 3 Ionen sich spalten

Nimmt man einen Augenblick an, dass jedes Salz sich in 2 Ionen spaltete, so ergiebt sich aus der chemischen Analyse von $\beta$ :

$$
\text { Gramm-Aequivalente } \times(1+\text { Dissociationsgrad })=\text { Anzahl Molionen }
$$

$$
0,057455 \times(1+0,763)=0,101293 .
$$

Demnach liefert die osmotisch-chemische Analyse 0,101293, und die osmotische Analyse, 0,108108 Molionen. Der Unterschied beträgt hiernach 0,006815 Molionen und entspricht einer Gefrierpunkterniedrigung von $-0,013^{\circ}$. Dieser Betrag liegt ausserhalb der Fehlerquellen.

Auch Ko eppe hatte beim Liebensteiner Stahlwasser eine Differenz in derselben Richtung gefunden und daraus geschlossen, dass noch unbekannte Stoffe im untersuchten Wasser vorhanden sein müssen, die die chemische Analyse nicht aufwies.

Hintz und Grünhut können diese Schlussfolgerung nicht als zwingend erachten; denn für die höhere Gefrierpunkterniedrigung des von der freien Kohlensäure befreiten Mineralwassers kann, jedenfalls theilweise, die nach $\mathrm{CO}_{2}$-Verlust eintretende Hydrolyse verantwortlich gemacht werden ${ }^{1}$ ).

Ich bin hierin mit den Autoren vollkommen einverstanden, füge aber doch noch hinzu, dass, wie ich bereits hervorhob, nicht anzunehmen ist, dass beim Auftreten einer sichtbaren Trübung bereits alle freie $\mathrm{CO}_{2}$ ausgetrieben sei. Wenn man dieselbe Fliussigkeit nun auch zur chemischen

1) Ueber den Begriff "Hydrolyse“ vergl. man Bd. II, S. $481 \mathrm{ff}$. 
Analyse benutzte, so könnte das Zurückbleiben von $\mathrm{CO}_{2}$ keinen Fehler bei der Vergleichung bedingen. Ueber eine derartige Untersuchung berichte auf S. 304.

Dass wirklich durch Hydrolyse eine Steigerung der osmotischen Concentration stattfindet, geht noch aus der Untersuchung des ausgekochten Mineralwassers hervor.

Wie Hintz und Grünhut bemerken, verliert das Wasser beim Auskochen die ganze freie Kohlensäure, die halbgebundene, sowie einen Theil der gebundenen Kohlensäure, unter Hinterlassung von Monocarbonaten; ferner einen Theil der Kieselsäure, alles Eisen, Mangan, allen Strontian, fast allen Kalk und einen Theil der Magnesia. Eine quantitative Bestimmung der Kieselsäure, des Kalks und der Magnesia in demselben ausgekochten Wasser, das zur Ermittlung der Gefrierpunkterniedrigung diente, gab folgende Resultate.

\section{Bestimmung der Kieselsäure.}

11 ausgekochtes Wasser lieferte $0,0054 \mathrm{~g}$ Siliciumdioxyd, entsprechend . . . . . . . . . . . . $0,000090 \mathrm{~g} \mathrm{H}^{*}$ $0,006921 \mathrm{~g} \mathrm{HSi} \mathrm{O}_{3}$.

\section{Bestimmung des Kalkes.}

Das in 1. erhaltene Filtrat wurde mit oxalsaurem Ammon gefällt und der Niederschlag durch Glühen in Aetzkalk überführt. Es wurde erhalten 0,0029 g Aetzkalk, entsprechend . . . . . . . . . . . $0,002071 \mathrm{~g} \mathrm{Ca*}$

\section{Bestimmung der Magnesia.}

Das Filtrat von 2. lieferte $0,1901 \mathrm{~g}$ pyrophosphorsaure Magnesia, entsprechend

$$
\text { - } 0,041584 \mathrm{~g} \mathrm{Mg} \cdot
$$

Berücksichtigt man, dass ausser diesen Bestandtheilen noch sämmtliches $\mathrm{Na}$, $\mathrm{K}$, $\mathrm{Li}, \mathrm{HN}_{4}^{\circ}, \mathrm{Cl}^{\prime}, \mathrm{Br}^{\prime}$, J' beim Auskochen zurückgeblieben sein muss, so ergiebt sich - abgesehen von den zweiwerthigen Anionen - folgende Zusammensetzung des ausgekochten Wassers.

\begin{tabular}{cccc} 
Katione n in 1 l & Gramm & Molen & Gramm-A equivalente \\
$\mathrm{H} \cdot$ & 0,000090 & 0,000089 & 0,000089 \\
$\mathrm{Na} \cdot$ & 1,019652 & 0,044236 & 0,044236 \\
$\mathrm{~K} \cdot$ & 0,019210 & 0,000491 & 0,000491 \\
$\mathrm{Li} \cdot$ & 0,001217 & 0,000173 & 0,000173 \\
$\mathrm{NH}^{*}$ & 0,002518 & 0,000139 & 0,000139 \\
$\mathrm{Ca} \cdot$ & 0,002071 & 0,000052 & 0,000104 \\
$\mathrm{Mg} \cdot *$ & 0,041584 & 0,001707 & 0,003414 \\
\cline { 2 - 3 } & & & 0,048646
\end{tabular}


Anionen in 11

\begin{tabular}{llll}
$\mathrm{Cl}^{\prime}$ & 0,762721 & 0,021515 & 0,021515 \\
$\mathrm{Br}^{\prime}$ & 0,001135 & 0,000014 & 0,000014 \\
$\mathrm{~J}^{\prime}$ & 0,000014 & 0,0000001 & 0,0000001 \\
$\mathrm{HSiO}^{\prime}$ & 0,006921 & 0,000089 & 0,000089 \\
\cline { 3 - 4 } & & 0,068505 & 0,021618
\end{tabular}

Da Kationen und Anionen in äquivalenter Menge vorhanden sein müssen, so können wir den Gehalt eines Liters ausgekochten Mineralwassers an den in vorstehender Aufstellung nicht mit berücksichtigten zweiwerthigen Anionen, aus der Differenz (0,048646--0,021618) zu $0,027028 \mathrm{~g}$-Aequivalenten $=0,013514$ Molen ermitteln.

Das ausgekochte Rhenser Mineralwasser enthält also unter der Voraussetzung vollständiger Dissociation im Liter $0,068505+0,013514$ $=0,082019$ Molen.

Die Bestimmung des Gefrierpunktes ergab in zwei vollständig übereinstimmenden Versuchen

$$
\Delta=-0,160^{\circ} \mathrm{C} \text {. }
$$

Diesem Werth entspricht eine osmotische Concentration von

$$
\frac{-0,160}{-1,85}=\mathbf{0 , 0 8 6 4 8 7} \text { Molionen. }
$$

In dem ausgekochten Wasser ergibt sich also für die osmotische Concentration ebenfalls ein höherer Werth, als ihn die chemische Analyse erwarten lüsst, wenn man lediglich die Ionenspaltung der Salze in Betracht zieht. Die Differenz erklärten Hintz und Grünhut auch hier zunächst auf dieselbe Art, wie bei dem von Kohlensäure befreiten Mineralwasser, durch die Hydrolyse, welche die zurïckbleibenden Monocarbonate in noch höherem Maasse erfalıren müssen, als die Bicarbonate im frïheren Falle. Die Hydrolyse führt auch hier zu einem Zerfall des Salzmoleciuls in mehr Molecülbruchstiicke, als sie bei der einfachen Dissociation in Ionen erhalten werden. So gilt z. B. bei $\mathrm{Na}_{2} \mathrm{CO}_{3}$ fuir die Dissociation die Gleichung

$$
\mathrm{Na}_{2} \mathrm{CO}_{3} \leftarrow \quad \rightarrow 2 \mathrm{Na}+\mathrm{CO}_{3}^{\prime \prime},
$$

während der Hydrolyse die Gleichung entspricht.

$$
\mathrm{Na}_{2} \mathrm{CO}_{3}+2 \mathrm{H}_{2} \mathrm{O} \longleftarrow 2 \mathrm{Na}+2 \mathrm{OH}^{\prime}+\mathrm{H}_{2} \mathrm{CO}_{3}
$$

Es braucht kaum hervorgehoben zu werden, dass auch beim frischen, kohlensäurereichem Mineralwasser $(\alpha)$ die sich aus der Gefrierpunkterniedrigung ergebende höhere osmotische Concentration wenigstens theilweise auf Hydrolyse zurückgebracht werden muss. 


\section{$\gamma$ ) Grosser Sprudel zu Bad Neuenahr.}

In vollkommen gleicher Weise haben Hintz und Grünhut auch das Wasser des grossen Sprudels zu Bad Neuenahr im Ahrthal untersucht [6]. Ich kann mich mit einer kưzen Erwähnung der Resultate begnïgen.

\begin{tabular}{|c|c|c|c|c|c|}
\hline & I & II & III & IV & V \\
\hline & $\begin{array}{c}\text { Gefrier- } \\
\text { punkter- } \\
\text { niedrigung }\end{array}$ & $\begin{array}{l}\text { Anzahl Mol- } \\
\text { ionen, berechnet } \\
\text { aus Spalte I }\end{array}$ & $\begin{array}{l}\text { Anzahl Molionen, } \\
\text { berechnet aus } \\
\text { der chemischen } \\
\text { Analyse }\end{array}$ & \begin{tabular}{|c|} 
Specifische \\
elektrische \\
Leitfähig- \\
keit bei \\
$3 \pm, 2^{\circ}$
\end{tabular} & $\begin{array}{c}\text { Mittlerer Disso- } \\
\text { ciationsgrad } \\
\text { der Fixa }\end{array}$ \\
\hline $\begin{array}{l}\text { a Frisches der Quelle } \\
\text { entnommenes } \\
\text { Wasser mit vollem } \\
\text { Kohlensäuregehalt }\end{array}$ & $-0,115^{0}$ & $\begin{array}{l}0,0621621 \\
\text { Milli Mol- } \\
\text { ionen }\end{array}$ & $\begin{array}{c}0,0772581 \\
\text { (unter Voraus- } \\
\text { setzung vollstän- } \\
\text { diger Disso- } \\
\text { ciation) }\end{array}$ & - & $\begin{array}{c}\text { unter Ein- } \\
\text { rechnung von } \\
\mathrm{H}_{2} \mathrm{SiO}_{3} \\
0,790 \\
\text { nach } \mathrm{Abzug} \\
\text { von } \mathrm{H}_{2} \mathrm{SiO}_{3} \\
0,837\end{array}$ \\
\hline $\begin{array}{l}\beta \text { Wasser, das soviel } \\
\text { freie Kohlensäure } \\
\text { verloren hat, dass } \\
\text { beginnende Trüb- } \\
\text { ung eintrat }\end{array}$ & $0,095^{\circ}$ & 0,051351 & $\begin{array}{c}0,05105 ّ 2 \\
\text { (unter Voraus- } \\
\text { setzung vollstän- } \\
\text { diger Disso- } \\
\text { ciation) }\end{array}$ & - & - \\
\hline $\begin{array}{l}\gamma \text { Ausgekochtes } \\
\text { Wasser }\end{array}$ & $0,063^{\circ}$ & 0,034054 & $\begin{array}{c}0,031679 \\
\text { (unter Voraus- } \\
\text { setzung vollstän- } \\
\text { diger Disso- } \\
\text { ciation) }\end{array}$ & - & - \\
\hline
\end{tabular}

Man steht hier wieder vor der Thatsache, dass die osmotische Concentration von $\beta$, aus der Gefrierpunkterniedigung abgeleitet $(0,0513551)$ grösser ist als die, welche aus der chemischen Analyse berechnet wurde $(0,051052)$ und eigentlich ist die Differenz noch grösser, denn letztere Zahl beruht auf der Annahme, dass die Spaltung in Ionen vollständig ist, was doch thatsächlich nicht der Fall ist. Hintz und Griinhut berechneten $\alpha=0,837$ und hieraus ergab sich ohne Einrechnung von $\mathrm{CO}_{2}$ die wahre osmotische Concentration von $\beta$ statt 0,051052 gleich $\mathbf{0 , 4 6 0 9 4}$. 
Die Autoren glauben - namentlich angesichts einer auch am Rhenser Wasser angestellten Berechnung - jetzt nicht mehr, dass die Hydrolyse allein den hohen Werth $(0,051351$ Spalte II) verursachen könne. Sie hatten - wie sie hervorheben - diesen Standpunkt bereits vor dem Erscheinen einer Nittleilung von Roloff [7] gewonnen. Roloff hebt in dieser Arbeit hervor, was sich auch mir bereits aufgedrängt hatte, dass das Wasser in dem Moment, in welchem durch Carbonatausscheidung Trübung eintritt, doch noch freie Kohlensäure enthalten könne.

In der That haben Hintz und Griinhut diese Ansicht auf experimentellem Wege bestätigen können, indem sie die freie Kohlensäure direct bestimmten, die nach der beginnenden Trübung noch im Wasser zurückgeblieben war. Diese Kohlensäuremenge $(0,004047$ Mol $)$ erklärt sogar die ganze Differenz zwischen dem Ergebniss der Gefrierpunktsbestimmung und der chemischen Analyse. Bei dieser näheren Betrachtung erwies sich also die Hydrolyse als irrelevant.

Eine zweite wichtige Thatsache, die Hintz und Grünhut bei der Besprechung des grossen Sprudels noch erwähnen, betrifft die initiale Gefrierpunkterniedrigung.

So wird von ihnen passend die Gefrierpunkterniedrigung des frischen, unter den von Koeppe vorgeschlagenen Kautelen in das Gefriergefäss gebrachten Wassers mit möglichst vollem Kohlensäuregehalt genannt.

Das Wasser des grossen Sprudels enthält nach chemischer Bestimmung 0,026206 Molen freie Kohlensïure. Wie soeben festgestellt wurde, bleiben bei beginnender Trübung noch 0,004047 Molen zurück. Es mïssen also durch das Rühren beim wiederholten Gefrieren und Aufthauen $0,026206-0,004047=0,022159$ Molen ausgetrieben sein. Auf Grund dieser Ueberlegung sollte man erwarten, dass die Differenz zwischen Initialgefrierpunkt und Gefrierpunkt bei eben beginnender Trübung, der letzten Molenzahl entsprechen würde, d. $\mathrm{h} .0,0-11^{\circ} \mathrm{C}$ betragen würde. Thatsächlich wurde aber $0,020^{\circ} \mathrm{C}$ gefunden.

Hieraus geht nach Hintz und Grünhut herror, dass bei dem erstmaligen Gefrieren des Wassers bereits eine erhebliche Menge der freienkohlensäure entwichen war.

Ich glaube hiernach, dass es besser ist die $\mathrm{CO}_{2}$-Entweichung bei der Gefrierpunktsbestimmung ganz zu verhüten, indem man den Versuch in einem vollkommen geschlossenen Gefäss vornimmt.

Zu diesem Zweck kann man ein von Beckmann vorgeschlagenes [18] Gefüss benutzen, in welchem der mit einem Eisenklotz versehene Rührer 
durch einen von aussen angebrachten Elektomagnet mit Hülfe eines Metronoms auf und nieder bewegt wird.

Neuerdings [19] hat dieser Autor die Vorrichtung in praktischer Weise geändert, indem er einen geeigneteren Elektromagnet angebracht und das Metronom durch ein Uhrwerk ersetzt hat ${ }^{1}$ ).

Seit einiger Zeit ist in meinem Laboratorium eine einfachere Methode im Gebrauch, die ebenfalls gestattet, im geschlossenen Gefäss zu arbeiten und auch mechanisch zu rühren. Der Glasstab des Rührers und das Glasröhrchen, in dem der Rührer sich bewegt, sind je mit einem verstellbaren cylindrischen Kupferstücke umgeben. Ueber diese Kupferstücke werden die beiden Enden eines sehr dünnwandigen und weiten Gummirohres luftdicht übergestreift. Das Gummirohr selbst wird aus Gummiplatte hergestellt, wie man sie zu Registrirzwecken für Cardiographen etc. zu benutzen pflegt; man hat nur zu kitten. Innerhalb des Gummirohres sind die Kupferstïcke mittelst einer Spirale verbunden. Hat man den Rührer gehoben, so wird derselbe durch die Spirale wieder nach unten gezogen.

Das Heben erfolgt sehr regelmässig mittelst eines kleinen Heissluftmotors von Heinrici und zwar derart, dass dessen rotirende Bewegungen auf eine Rolle übertragen werden, an der excentrisch ein Kupferstäbchen angebracht ist. Am Ende des Stäbchens ist eine Schnur befestigt, die iber eine zweite Rolle geht und in senkrechter Richtung den Rührer bewegt, an dem die Schnur gleichfalls befestigt ist. So hat man die drehende Bewegung des Motors in eine auf- und niedergehende umgesetzt. Die Geschwindigkeit lässt sich in einfacher Weise mittelst der Bremse regeln, die an dem Heinricischen Motor angebracht ist. Im Allgemeinen empfehlen sich 15 Hebungen jesp. Senkungen in 10 Secunden. Die Vorrichtung ist sehr befriedigend ${ }^{2}$ ) und hat grosse Vortheile.

1) In dieser Arbeit beklagt sich $B \theta \mathrm{ckmann}$ darüber, dass seine nachträglichen Ausführungen über Gebrauch und Construction seines Gefrierapparates von medicinischer Seite so wenig berücksichtigt worden sind. Ich glaube, das rührt daher, dass der Autor, der übrigens der Würdigung seiner betreffenden Arbeit auch von medicinischer Seite zufrieden sein darf, seine Ausführungen unter dem Titel: „Beiträge zur Bestimmung der Moleculargrösse" veröffentlicht hat. Wahrscheinlich sind sie dadurch denjenigen entgangen, die die Zeitschrift für physikalische Chemie nicht regelmässig lesen.

2) Man kann sich dieselbe selbst herstellen, auch liefert sie der Mechaniker meines Institutes, Herr J. J. B o o in. 
1. Man kann die Grösse der Hebung nach Willkür regeln.

2. Die Vorrichtung kann an jedem Beckmann'schen Apparat leicht angebracht und von demselben leicht entfernt werden, so dass auch dem Reinigen nach Beendigung eines Versuches nichts im Wege steht.

3. Die Heissluftmotoren laufen äusserst regelmässig, viel regelmässiger als die meisten Elektromotoren und Wassermotoren. Man kann, wenn erwünscht, denselben benützen, den man für den 'Thermostat (vergl. Tafel II in Band II), behufs Leitfähigkeiten und elektrochemischen Bestimmungen im Gebrauch hat, also ist die ganze neue Vorrichtung äusserst einfach und billig.

Aber auch bei vollkommenem Abschluss des Gefässes, wie denselben die Beckmann'sche Vorrichtung und die meinige gewähren und der vollständig genügt, so weit es darauf ankommt dem Ein- und Austritt von Aussenluft beim Rühren vorzubeugen, ist es nicht ganz zu vermeiden, dass bei dem Rïhren $\mathrm{CO}_{2}$ frei wird, wenn es sich um $\mathrm{CO}_{2}$-reiche Mineralwässer handelt. Diese Entweichung ist aber beendigt, sobald die Kohlensäure oberhalb des Fliissigkeitsniveaus eine gewisse Spannung erreicht hat.

Nöthigenfalls liesse sich aber auch diese Entweichung verhindern, wenn man das Gefriergefäss, bevor das Mineralwasser eingefüllt wird, mit einem Luft-Kohlensäuregemisch ron ungefähr derselben Spannung anfiillt, welche sich anderenfalls bei der Gefriertemperatur des Mineralwassers herausbilden würde. Auf den ersten Anblick scheint es, dass hierzu die Partialspannung der $\mathrm{CO}_{2}$ bekannt sein muss. Das ist jedoch nicht nöthig. Man kann das Gasgemisch, das sich in einem anderen und grösseren Reservoir oberhalb des bis Gefriertemperatur abgekühlten Mineralwassers befindet, in das Gefrierrohr saugen.

Weiter geht dann die Füllung des Gefriergefüsses unter denselben Kautelen vor sich, wie dieselben ron Koeppe beachtet worden sind.

\section{Zusammenfassung und Schlussbetrachtung.}

Bis vor kurzem wurde, in Uebereinstimmung mit der Yoraussetzung, dass die Heilwirkung der Mineralwässer eine Salzwirkung sei, die Zusammensetzung des Nineralwassers in Form ron Salzen ausgedrïckt. Das war für den Chemiker eine schwierige Aufgabe, denn man kann aus der chemischen Analyse direct nur ableiten, wieviel ron den verschiedenen Metalloxyden und den ver'schiedenen Säure-Anhydriden vorhanden ist. Welche Salze in der Flüssigleit zugegen sind und wieviel von jedem Salze, das lehren diese Analysen nicht. Die Erfahrung lehrte denn auch, dass die gleichen analytischen Ergebnisse nach der Umrechnung auf Salze, je nach der Ausführung derselben, ein sehr verschiedenartiges Bild gewährten, sodass eine Vergleichung und Classifi- 
cation der Mineralwässer, wie man sie doch wünschte, ernstlichen Schwierigkeiten begegnete.

Jetzt weiss man, dass bei weitem der grösste Theil der Salze in Ionen gespalten ist und die Frage, welche Salze diese bilden können, hat ihre Wichtigkeit theilweise rerloren. Indessen ist sie nicht völlig bedeutungslos geworden, denn die Permeabilitätsverhältnisse z. B. der Magenwand für Salze sind nicht dieselben, wie für Ionen. (Vergl. Bd. II, S. 439.)

Ob die Aufgabe des Chemikers bei den jetzigen Anschauungen erleichtert worden ist, mag dahingestellt bleiben, dankbarer ist sie sicher, denn er kann jetzt wesentlich tiefer in die moleculare Constitution des Mineralwassers eindringen, als es ihm bisher möglich war.

Zunächst gestattet ihm die Gefrierpunkterniedrigung zu ermitteln, wieviel Molecüle + Ionen im Liter Mineralwasser, oder kürzer ausgedriickt, wieviel Molione $\mathrm{n}^{1}$ ) darin vorhanden sind.

In zweiter Linie gewährt die elektrische Leitfähigkeit ein Maass für die Ionenzahl. Denn belianntlich sind es die Ionen und nicht die ungespaltenen Molecïle, die den Strom leiten. Leider aber ist die Rechnung hier nicht so einfach wie bei der Berechnung der Gesam intzahl ron Molecülen + Ionen aus der Depression. Während jedes Molecül oder Ion, welcher Natur es auch sein mag, in gleichem Maasse an der Gefrierpunkterniedrigung betheiligt ist, kann das von den Ionen mit Bezug auf die Leitfähigkeit nicht gesagt werden. Die rerschiedenen Ionen sind vielmehr an der Leitfähigkeit in sehr verschiedenem Grade betheiligt. K o eppe hat ein Mittel angegeben dieser Schwierigkeit gewissermassen zu begegnen, indem er berechnet, wie gross die Dissociation der NaCl-Lösung sein würde, die mit dem Mineralwasser isosmotisch ist.

Eine bessere Methode hat Grünhut vorgeschlagen (S. 297), aber auch diese ist, wie der Verfasser selbst hervorhebt, noch nicht vollkommen befriedigend.

Jedoch darf aus den angestellten Versuchen doch wohl entnommen werden, dass die Molecuile der bis jetzt in dieser Hinsicht untersuchten Mineralwässer zu ungefähr $80 \%$ in Ionen gespalten sind, wenn die Wasser ihren vollen Kohlensäuregehalt besitzen und zu ungefähr $90 \%$, wenn sie ihre freie Kohlensäure verloren haben. Der Unterschied rührt daher, dass die freie Kohlensäure als schwache Sänre nur zu einem äusserst geringen Theil in Ionen gespalten ist.

1) Un die grosse Nullenzahl zu beschränken, würde es sich empfehlen, im Zusammenhang mit dem Vorschlag von Hintz und Grünhut beim Mineralwasser von Millimolionen zu sprechen. 
Wenn so die Berechnung der osmotischen Concentration aus der Gefrierpunkterniedrigung keine Schwierigkeit bereitet, so findet man dennoch solche in der technischen Ausführung der Depressionsbestimmung. Das rührt von dem Kohlensäuregehalt her. Trotz aller bis jetzt eingehaltenen, von Koeppe vorgeschlagenen Kautelen, gelingt es, wie Hintz und Grünhut fanden, nicht immer, sogar bei der ersten Gefrierpunktbestimmung das Entweichen von Kohlensäure zu verhüten. Ich habe deshalb vorgeschlagen, die Bestimmung im geschlossenen Gefäss auszuführen und dabei auch noch einen Uebergang von $\mathrm{CO}_{2}$ in den geschlossen Raum oberhalb der Flüssigkeit zu verhüten (S. 304 u. 306).

Mit Recht hat man hervorgehoben, dass die Bestimmung von Gefrierpunkt und Leitfähigkeit nicht nur eine sehr erwünschte Ergänzung der rein chemischen Analyșe, sondern auch eine sehr werthvolle Controle derselben bilden. Wenn man aus der chemischen Analyse berechnet, wie viel Ionen höchstens, also bei vollständiger elektrolytischer Dissociation, vorhanden sein können, und man multiplicirt diese Zahl mit dem wirklichen aus der Leitfäliigkeit abgeleiteten Dissociationsgrad, so muss die also erhaltene Zahl dieselbe sein, wie sie sich in directer Weise aus der Gefrierpunkterniedigung ergiebt.

Ko e ppe hat, als ihm die Gefrierpunkterniedrigung eine grössere Concentration gab, wie die chemische Analyse erwies, geschlossen, dass das von ihm untersuchte Liebensteiner Wasser noch unbekannte Stoffe enthalten muss. Diese Schlussfolgerung scheint mir etwas übereilt, so lange die Versuchsanordnung bei der Bestimmung des Gefrierpunktes von kohlensäurereichen Wässern noch nicht einwandfrei ist. Immerhin darf man nicht ruhen, bevor die osmotische und chemisch-osmotische Analyse vollkommen übereinstimmende Resultate geben.

Damit will ich natürlicherweise keineswegs im Voraus in Abrede stellen, dass die Vergleichung doch nicht zur Aufsuchung und Auffindung von bis jetzt unbekannten Stoffen führen wird. Ich halte es deshalb auch schon allein aus diesem Grund neben mancherlei anderen Gründen, bei dem gegenwärtigen Stand unseres Wissens für durchaus unberechtigt, die natürlichen Mineralwasser für Heilzwecke ohne weiteres durch künstliche ersetzen zu wollen.

In seinem Vortrag für die XI. Jahresversammlung des Allgemeinen Deutschen Baderverbandes ïber die „neueren physikalisch-chemischen Anschauungen in ihrer Anwendung auf Nineralwässer und deren Eintheilung " hat Grünhut auf den Nachtheil hingewiesen, welcher aus der neuen Berechnungsweise der Vineralwasserzusammensetzung erwächst, 
wie dieselbe auch für die von einem Redactionsausschuss unter Mitwirkung des Kaiserlichen Gesundheitsamtes herauszugebende zweite Auflage des Werkes ïber Deutschlands Bäder und Heilquellen in Aussicht genommen ist [8].

Sie betrifft die Eintheilung der Mineralwässer. Wenn man bisher eine Gruppirung in Wildwasser, alkalische, muriatische, salinische Wasser, Kochsalzquellen, Soolen, Bitterwasser etc. vornahm, so stützte sich dieselbe auf die Salze, die man im Wasser voraussetzte. Sieht man nun von der Berechnung auf Salze ab und lässt man somit genanntes Eintheilungsprincip verschwinden, so muss doch mit Rïcksicht auf die verschiedenen Indicationen, etwas an die Stelle treten, was die Unterscheidung der Nineralwässer in übersichtlicherer Weise für den Arzt ermöglicht, als die einfache Aufzählung der darin vorhandenen Ionen, deren Zusammengehörigkeit man sich selbst zu construiren hat.

Um den praktischen Aerzten diese Arbeit und zugleich den Uebergang von der bisherigen Ausdrucksweise zu der neuen zu erleichtern, ist, wie Grünhut mittheilt, beschlossen worden, in dem erwähnten Werke über Deutschlands Bäder und Heilquellen dem neuen Analysenschema [Gramm-Ionen, Molen, Grammäquivalente (vergl. Tabelle S. 298), Gefrierpmkterniedrigung $\boldsymbol{L}$, specifische Leitfähigkeit $\boldsymbol{x}$ und daraus berechneter Dissociationsgrad $\alpha$ ] durchweg noch einmal die auf Salze berechnete Analyse beizufügen. Den Nothbehelf einer Salztabelle wird man aber in späterer Zeit verlassen müssen. Hintz und Grünhut haben deshalb schon jetzt versucht, einen Modus anfzufinden, der ohne Berechnung auf Saİze, aus der zeitgemässen Ionenanalyse die Zugehörigkeit zu einer bestimmten Gruppe erkennen lässt.

Sie stützen sich dabei auf dieselben Principien, die schon von Than zu gleichem Zwecke benutzt hat. Praktisch unterscheidet sich aber ihr Vorschlag sehr vortheilhaft von dem Than'schen, indem sie eine graphische Darstellung geben (siehe Tafel I).

Einige Worte mögen zur Erklärung genügen. Von jedem Mineralwasser wird die Anzahl der Kationen und daneben die der Anionen durch einen farbigen Streifen (oder, wie hier, durch einen Streifen von verschiedener Schraffirung) von entsprechender Länge vorgestellt. Eigentlich wird die Länge nicht angegeben durch die Zahl der Ionen, sondern durch die Zahl der Aequivalente. So werden für ein Ion Ba", weil es bivalent ist, zwei Einheiten aufgetragen, nämlich zwei Milligrammäquivalente (vergl. Tabelle S. 298). Selbstverständlich wird jedes Vineralwasser von Kationen und Anionen gleichviel Milligrammäquivalente enthalten. 
Ausserdem ist noch die freie Kohlensäure berücksichtigt, welche als grauer Strich die Linien der Kationen natürlich in seiner ganzen Länge überragt, denn sie ist ja nicht mit diesen verbunden (vergl. Tafel I).

„Betrachten wir zunächst die erste Darstellung, welche die Zusammensetzung des Grossen Sprudels zu Neuenahr versinnbildlicht. Der blaue Strich für $\mathrm{Cl}^{\circ}$ und der orange für $\mathrm{SO}^{\prime \prime}$ sind zusammen erheblich kürzer als der rothe für $\mathrm{Na}$; es muss also eine erhebliche Menge der $\mathrm{Na}$-Ionen noch durch $\mathrm{HCO}_{3}{ }_{3}$-Ionen gedeckt werden. Das entspricht dem Typus eines alkalis chen Wassers. Bei einem jeden solchen muss demnach der schwarze Strich für $\mathrm{HCO}_{3}^{\prime}$ erheblich nach links unter den rothen Strich für $\mathrm{Na}$ ' reichen.

So sehen wir sofort weiter, dass auch Ems, Karlsbad und Rhens alkalische Wässer sind. Aber bei Ems besitzt der blaue Strich für $\mathrm{Cl}^{`}$ bereits eine relativ beträchtliche Länge, es ist alkalisch-muriatisch. Die Länge des orange Striches für $\mathrm{SO}_{4}{ }_{4}$ verweist in gleicher Weise $\mathrm{Karlsbad}$ unter die alkalisch-salinischen Wässer, während wir in Rhenser Sprudel nun leicht einen Mischtypus, ein alkalisch-muriatisch-salinisches Wasser erkennen werden.

Wildungen hat gleichfalls alkalischen Charakter, aber die Länge der violetten und grünen Striche für $\mathrm{Ca}^{*}$ und $\mathrm{Mg}^{*}$ überwiegt diejenige des rothen $\mathrm{Na}$ * Striches derart, dass wir die Quelle um deswillen als erdige bezeichnen.

Wiesbaden zeigt keinen alkalischen Charakter mehr; die graphische Darstellung zeigt ferner sehr vorwaltend $\mathrm{Na}^{*}-$ und $\mathrm{Cl}^{\prime}$-Ionen: wir haben eine $\mathrm{Ko}$ chsalzquelle vor uns.

Bei Hunyadi János sehen wir, wie den Strichen für Ca" und Mg"vorwiegend der für $\mathrm{SO}_{4}{ }_{4}$ entspricht; das ist der Typus eines Bitterwassers. Wegen der grossen Menge gelöster Bestandtheile muss in Fällen, wie beim Hunyadi János-Wasser, der Längenmaassstab in der Darstellung auf ein Drittel reducirt werden. Damit das sofort kenntlich ist, wurde dementsprechend die Breite der betreffenden Striche verdreifacht.

Diese Darstellung der Milligramm-Aequivalente lässt keinen Schluss auf die Gramı-Concentration des Wassers zu. Um anch hierüber durch die graphische Darstellung zu orientiren, wurde jedem Mineralwasser oben eine feine schwarze Linie hinzugefügt, deren Länge der Summe aller gelösten Ionen, ausgedrückt in Grammen pro Liter, proportional ist.

Diese Linie gestattet weiter die Ausdehung der graphischen Darstellung auf diejenigen therapeutisch wichtigen Bestandtheile, welche in kleinen Mengen vorkommen, also z. B. auf $\mathrm{Li}^{*}, \mathrm{Fe}^{*}, \mathrm{Mn}^{*}, \mathrm{~J}^{\prime}, \mathrm{HAs}^{\prime \prime}{ }_{4}$. Man trägt ihre Mengen in (100 fach) vergrössertem Maassstabe auf dieser schwarzen Linie ab.

Das ist in vorliegender Tafel nur für das Eisen geschehen und zwar durch Anbringung kurzer rother (bezw. hier schwarzer) Querstriche. Die Entfernung derselben von dem Nullpunkte der schwarzen Linie ist dem Grammgehalt eines Liters Mineralwasser an Eisenionen proportional. Mau erkennt auf den ersten Blick, wie sich der Langenschwalbacher Stahlbrunnen durch hohen Eisengehalt vor dell anderen Quellen auszeichnet. Man ersieht weiter, dass er sich ausserdem dem Typus der erdigen Wässer einreiht. Der Schwalbacher Stahlbrunnen ist folglich ein erdiges Eisenwasser." 
Die Aufnahme dieser graphischen Darstellungen ist gleichfalls für die zweite Auflage von "Deutschlands Bäder und Heilquellen" in Aussicht genommen.

Noch in anderer Richtung wird die physikalische Chemie sich bei der chemischen Untersuchung der IIineralwässer geltend machen müssen, und zwar in Beziehung auf die quantitative Bestimmung ihres alkalischen und sauren Charakters.

Ich habe bereits wiederholt erörtert, dass unsere gebräuchlichen Titrirmethdoen die wahre Alkalität und Acidität einer Flïssigkeit nicht anzugeben im Stande sind (Bd. I, S. 508, Bd. II, S. 330), da sich dieselbe während der Titration in Folge der durch Reagentienzusatz bedingten Verschiebung des Gleichgewichtes ändert. Wir wissen jetzt, dass die Concentrationsketten diese Schwierigkeit zu beseitigen gestatten (vergl. Bd. II, S. 332 ff.)

Da der wirkliche Alkali-, bezw. Säuregehalt eines Mineralwassers im Augenblicke seiner Einverleibung für die Anwendung des betreffenden Wassers zu Heilzwecken nicht bedeutungslos ist, so müssen auch Untersuchungen in dieser Richtung ausgeführt werden und man kann in Zukunft wahrscheinlich bei der graphischen Darstellung noch eine Erweiterung behufs Berïcksichtigung der Concentration der $\mathrm{OH}^{\prime}-$ und $\mathrm{H}^{\circ}$-Ionen erwarten, als Hinweis darauf, wie gross der Gehalt an freiem Alkali, bezw. freier Säure ist.

Ein einziges Beispiel diene zur Erlätterung. Es betrifft den Neuenahrer Sprudel. Die Kette ist folgendermaassen zusammengesetzt

$\mathrm{H} \mid 0.01 \mathrm{n} \mathrm{HCl}, 0.2 \mathrm{n}$. NaCi | Neuenahrer Sprudel | H

Es handelt sich also hier um die Bestimmung der H'-Ionen-Concentration.

Ich bitte den Leser behufs Ausführung und Berechnung Bd. II, S. 353 ff. nachzusehen; Ausfülırlicheres findet man Bd. II, S. $367 \mathrm{ff}$.

Betreffs der Zusammenstellung der Kette, für die ich übrigens noch nach Bd. II, S. 380 verweise, bemerke ich noch, dass die Baumwolle des Verbindungsrohres (Fig. 19 in Bd. II, S. 347) mit derselben Flüssigkeit getränkt ist, die auch im zweiten $\mathrm{U}$-förmigen Rohr des Elementes vorhanden ist, nämlich $0,01 \mathrm{n} \mathrm{HCl}$, in der $0,2 \mathrm{n} \mathrm{NaCl}$, d. h. $1,17^{\circ} \% \mathrm{NaCl}$ gelöst ist.

Die Anfertigung erfolgte Abends $8 \mathrm{Chr}$; am folgenden Morgen $10 \mathrm{Uhr}$ erwies die Kette sich als constant. Um Entweichung von Gasen möglichst zu verhüten, wurden die Flüssigkeitsoberflächen mit einer Schicht Paraffinöl bedeckt. Vielleicht war dies, da der Apparat ja einen guten Verschluss verbürgt, überflüssig. Das ist noch nicht untersucht worden. Jedenfalls konnte es der Sicherheit halber geschehen, zuınal das Paraffinöl keinen nachtheiligen Einfluss auf den Versuch ausübt.

Die Temperatur des Thermostaten war $15^{\circ} \mathrm{C}$. 
1. Elektromotorische Kraft des Accumulators $\left(\mathrm{E}_{\mathrm{A}}\right)$.

Es müssen $5960 \Omega$ in das Stromgebiet des Normalelementes eingeschaltet werden, um das Galvanometer in Ruhe zu erhalten. Da die E. M. K. des Normalelements 1,0184 Volt betrug, ist

$$
\mathrm{E}_{\mathrm{A}}=\stackrel{1,0184 \times 11111,1}{5960}
$$

2. Elektromotorische Kraft des Gaselementes $(\pi)$.

Es müssen $1824 \Omega$ in das Stromgebiet des Gaselementes eingeschaltet werden, um das Galvanometer in Ruhe zu erhalten, also

$$
\pi=\frac{1824}{11111,1} \times \mathrm{E}_{\mathrm{A}}=\frac{1824}{11111,1} \times \frac{1,0184 \times 11111,1}{5960}=0,31168 \text { Volt. }
$$

3. Berechnung der $\mathrm{H} \cdot$-Ionen-Concentration $\left(\mathrm{C}_{\mathrm{H}}\right)$.

$$
\begin{aligned}
\pi & =\frac{0,0002}{\mathrm{n}} \mathrm{T} \log \frac{\mathrm{C}_{\prime \prime}}{\mathrm{C}_{\mathrm{H}}} \\
\text { hierin ist } \pi & =0,31168 \\
\mathrm{n} & =1 \\
\mathrm{~T} & =273+15=288 \\
\mathrm{C}_{\prime \prime} & =0,01 \\
\mathrm{C}_{\mathrm{H}^{\cdot}} & =\text { die gesuchte } \mathrm{H} \cdot \text {-Ionen-Concentration } \\
0,31168 & =0,0002 \times 288 \log \frac{0,01}{\mathrm{C}_{\mathrm{H}} .} \\
\mathrm{C}_{\mathrm{H}^{\cdot}} & =0,38837 \times 10-i .
\end{aligned}
$$

Die H'-Ionen-Concentration des untersuchten Neuenahrer Sprudels ist demnach geringer als die des reinen Wassers, welche bei $18^{\circ} 0,78 \times 10^{-7}$ beträgt (Bd. II, s. 386 und $4 ; 7)$. Da das Product der $\mathrm{H}^{-}$-Ionen- und $(\mathrm{OH})^{\prime}$-Ionen-Concentration constant ist, d. h. bei $18^{0} 0,61 \times 10^{-14}$ beträgt, ist die $(\mathrm{OH})^{\prime}$-Ionen-Concentration des Mineralwassers, wenn mall ausser Betracht lässt, dass dabei $\mathrm{C}_{\mathrm{H}}$. nicht bei $18^{\circ}$ sondern bei $15^{\circ}$ ermittelt wurde,

$$
0,61 \times 10^{-14}=1,571 \times 10^{-7} .
$$

Diese $(\mathrm{OH})^{\prime}$-Concentration kann selbstverständlich auch in directer Weise ermittelt werden, indem man dem Mineralwasser nicht Salzsäure, sondern ein Alkali z. B. $0,01 \mathrm{n} \mathrm{NaOH}$ gegenüberstellt. Zugleich wäre das eine gute Controle, oder umgekehrt. Wegen Zeitmangel musste diese directe $(\mathrm{OH})^{\prime}$-Ionen-Bestimmung unterlassen werden.

Die Titration des Sprudels mittels $0,1 \mathrm{n} \mathrm{KOH}$ und Phenolphtalein als Indicator ergab einen Säuregehalt von 0.234 Normal.

Um hieraus die $\mathrm{H}^{\circ}$-Ionen-Concentration zu berechnen, bedenke man, dass 0,234 Normalsäure 0,234 Grammatome Wasserstoff oder bei vollständiger Dissociation der Säure auch $0,234 \mathrm{H}^{\circ}$-Ionen pro Liter enthält. Man kann das auch in folgender Weise schreiben :

$$
2,34 \times 10^{-1} \text { oder } 2340000 \times 10^{-7} \text {. }
$$

Hieraus geht hervor, un wie viel grösser der durch Titration gefundene (potentielle) als der auf elektrochemischem Wege ermittelte (actuelle) Säuregehalt ist. 


\section{Einfluss der Mineralwässer auf die osmotisch-chemische Be- schaffenheit von Körperflüssigkeiten.}

Von dem Einfluss verschiedenartiger Flüssigkeiten im Allgemeinen auf die osmotisch-chemische Beschaffenheit von Körperflüssigkeiten, war früher schon oftmals die Rede. Ich erinnere an die Erörterungen über den osmotischen Druck des Blutes unter verschiedenen experimentellen Bedingungen, über die Resorption im Magen, im Darm, in der Bauchhöhle und anderen Körpertheilen, über die Physiologie und Pathologie der Harnabscheidung u. s. w. Wenn ich hier noch einmal auf den Gegenstand zurückkomme, so geschieht dies, um noch einige Dinge zu besprechen, die sich insbesondere auf den Einfluss von Mineralwässern beziehen und ron balneologischer Seite herrorgehoben sind. Es sind bis jetzt erst wenige Untersuchungen von dieser Seite ausgeführt worden.

\section{a) Einfluss auf das Blut.}

Abgesehen von den Untersuchungen Dünschmann's [9], die sich nur mit Kaninchen beschäftigten und die darin bestanden, dass er zweien dieser Thiere mit der Schlundsonde und einem mittelst intraperitonealer Einspritzung Homburger Elisabethbrunnen einverleibte und dann das Blut zu verschiedenen Zeiten untersuchte, beziehen sich alle einschlägigen Arbeiten auf menschliches Blut.

Rothschild und Hughes [10] fanden, dass Salzbäder, deren osmotischer Druck höher als derjenige des Blutes ist, eine Erhöhung des osmotischen Druckes des Blutes zu erzeugen vermögen, im Gegensatz zu Süsswasserbädern, bei welchen das Umgekehrte erfolgte.

Von den Untersuchungen Ko eppe's über den Einfluss verschiedenartiger Flüssigkeiten auf den osmotischen Druck des Blutes war schon früher bei der Besprechung des Hämatokrits die Rede (vergl. B. 1 S. 446$)$.

Weiter wurden von Grube Selbstrersuche mit Neuenahrer Sprudel ausgeführt [11].

Die Lebensweise war folgende:

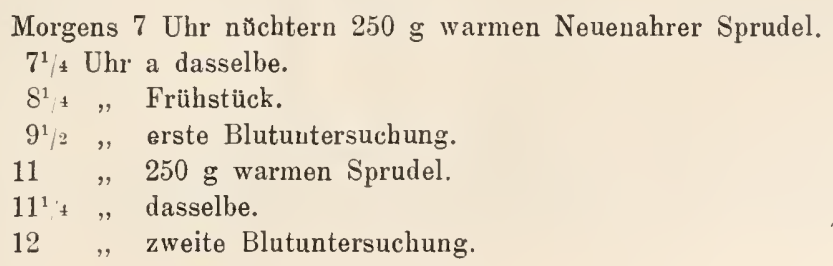


1 Uhr $p$ Mittagessen.

4 "Tasse Thee.

6 " dritte Blutuntersuchung.

$7^{1 / 2}$, Abendessen.

„Die Diät war denkbar einfach. Sie entsprach etwa derjenigen, die man einem Gallensteinkranken verordnen würde, also möglichst reizlos; abgesehen von 1 Glas Moselwein und ${ }^{1 /}$ * Liter Bier gar kein Alkohol".

Der osmotische Druck wurde mittels Koeppe's Haematokrit ermittelt (B. I, S. 446), und zwar derart, dass $\mathrm{Grube}$ die $\mathrm{MgSO}_{t}$-Lösung aufsuchte, die das Volumen der Blutkörperchen nicht veränderte.

Um den Einfluss des Wassers und sogar auch denjenigen der Temperatur zu eliminiren, stellte er Vorversuche mit warmem Wasser an, und zwar genau unter denselben Bedingungen, die auch später für den Sprudel eingehalten werden sollten. Den Vorversuchen mit warmem Wasser gingen wieder andere Vorversuche unter gewöhnlichen Lebensbedingungen voran.

Für diese drei Perioden gelangt Grube zu den folgenden Ergebnissen :

Periode des Vorversuches: Durchschnitt von 7 Tagen. Wassergehalt des Blutes 78,3\% $\%$ osmotischer Druck des Blutes $=\mathrm{MgSO}_{4}{ }^{-}$ Lösung von 0,233 Mol. $=5,8 \mathrm{~g}$ in $100 \mathrm{cc}$ Lösung.

Periode des warmen Wassers. Durchschnitt von 7 Tagen. Wassergehalt des Blutes 77,88\%; osmotischer Druck $=0,231$ Mol. $\mathrm{MgSO}_{4}$.

Periode des Neuenahrer Sprudels: Durchschnitt von 17 Tagen. Wassergehalt des Blutes $77,76 \%$; osmotischer Druck $=0,242 \mathrm{Mol}, \mathrm{MgSO}_{4}$.

Also hatte der regelmässige Genuss wamen Wassers eine Abnahme des Wassergehaltes des Blutes, sowie eine Abnahme des osmotischen Druckes zur Folge, während der regelmässige Genuss eines warmen Mineralwassers ebenfalls eine Abnahme des Wassergehaltes des Blutes, aber eine Zunahme des osmotischen Druckes zur Folge hatte.

Was den Einfluss zu verschiedenen Tageszeiten betrifft, so zeigt sich die V'eränderung der Blutbeschaffenheit bald nach der Aufnalime des betreffenden Wassers; während der folgenden drei Stunden wird sie ausgeprägter und klingt dann allmählich wieder ab.

Versuche von Hintz und Grünhut haben für $I$ des Wassers $-0,115^{\circ}$ ergeben.

Die Selbstversuche F. Engelmann's umfassen eine 19-tägige Trinkkur nit Kreuznacher Wasser [12].

Die Experimente wurden fast genau in derselben Weise, wie diejenigen Grube's ausgeführt. Mit Nachdruck sei aber hervorgehoben, 
dass das Mineralwasser, statt hypoisotonisch, erheblich hyperisotonisch gegeniiber dem Blutserum war, $d$ war nämlich $-1,03^{\circ}$. Der Gehalt an Chloriden betrug $1,60878 \%$

Es wurde ein Vorversuch von 10 Trgen angestellt, der Hauptrersuch dauerte 19 Tage, die Beobachtung der Nachwirkung 4 Tage. befolgt.

Während der ersten und dritten Periode wurde die gewöhnliche Lebınsweise

Ueber die Nahrung theilt der Verfasser nichts mit. Das ist sehr zu bedauern, da die Versuche mit grosser Sorgfalt angestellt sind.

Die Untersuchungen wurden dreimal während des Tages angestellt. Nach dem Frühstück um 9 Uhr, Nachmittags eine Stunde nach dem Essen um 3 Uhr, und um 6 Uhr.

Während des Hauptversuchs wurde statt der letzten Untersuchung eine solche nüchtern sogleich nach dem Aufstehen angestellt. Nach derselben wurden $500 \mathrm{~g}$ Soolwasser kurgemäss getrunken, dann gefrühstückt und eine Stunde nach Schluss des Trinkens der zweite Versuch gemacht.

Meistens erfolgte während des Frühstücks bereits ein ziemlich starker Stuhldrang. Der Stuhl war während der ganzen Dauer der Versuche diarrlı̈isch, doch nur einnal täglich.

Der osmotische Druck wurde mit dem Hämatokrit von Koeppe ernittelt, welche Methode Engelmann nach gewissenhafter Uebung als sehr zuverlässig und bequem preist [13]. Als Flüssigkeiten wurden dabei $\mathrm{MgSO}_{4}$-Lösungen benutzt und von derjenigen, welche das Blutkörperchenvolumen unverändert liess, die Depression ermittelt.

Die Torversuche ergaben für die mit dem Plasma isosmotische $\mathrm{MgSO}_{4}{ }^{-}$ Lösung eine Depression von etwa $-0,50^{\circ}$, was gewiss zu niedrig ist. Daraus geht wieder hervor, dass selbst ein Forscher, der sich lange Zeit auf die Koeppe'sche Methode eingeübt hat, nicht immer in absolutem Sinne richtige Resultate damit bekommt. Doch sind die erhaltenen Werthe, wie Engelmann in seiner oben genannten Schrift hervorhebt, als Vergleichswerthe sehr zuverlässig. Er fügt hinzu: „Will man sichere Resultate haben, so muss man dementsprechend recht lange (ich spatiire) centrifugiren. Dies ist unbequem, besonders bei Reihenuntersuchungen. Nun kommt es bei letzteren aber nicht so sehr auf absolut richtige Werthe an, sondern nur auf relative, die nach gleicher Methode gewonnen sind. Es genügt daher bei allen Versuchen mit derselben Kraft und Zeit zu centrifugiren, um verwendbare Zahlen zu bekommen. Durch die elektrische Centrifuge, die sich schneller dreht als Koeppe's Kreiselcentrifuge, werden all' diese Uebelstände Abstellung finden."

Wer sich für Koeppe's Hämatokrit besonders interessirt, den verweise ich auf die letztgenannte Arbeit F. Engelmann's. (Vergl. übrigens Bd. I, S. 452.) 
Ferner erwähne ich noch die von ihm erhaltenen Durchschnittszablen.

\begin{tabular}{|c|c|c|c|c|}
\hline Puls & Temperatur & Urin 4 & Hämoglobin & $\begin{array}{l}\text { Osmot. Druck } \\
\text { Plasma }\end{array}$ \\
\hline & & Vorversu & & \\
\hline 76,3 & 36,9 & $\begin{array}{l}10 \text { Uhr. } \\
-1,61^{\circ}\end{array}$ & 1,08 & $\Delta=-0,485^{\circ}$ \\
\hline 79,5 & 36,6 & $\begin{array}{l}3 \text { Uhr. } \\
-1,46\end{array}$ & 1,10 & $\Delta=-0,503^{\circ}$ \\
\hline
\end{tabular}

Uurchschuitt beider Versuchsreihen.

\begin{tabular}{lllll}
779 & 36,75 & $-1,53$ & 1,09 & $\Delta=-0,494^{\circ}$ \\
\hline
\end{tabular}

Während der Trinkkur.

$8^{1 / 2}$ Uhr (nüchtern).

64,2

35,7

$-1,80$

1,17

$\Delta=-0,518^{\circ}$

74

36,5

$10 \mathrm{Chr}$.

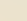

70.5

36,65

$-1,66$

1,137

$\Delta=-0,542^{\circ}$

$3 \mathrm{Uhr}$.

(1)

$-1,673$

1,04

$\Delta=-0,513^{\circ}$

Durchschnitt der drei Versuehsreihen.

69,6

$36,28-1,71$

1,12

$\Delta=-0,524^{\circ}$

Die Gefrierpunkterniedrigung des Harns ist durch die Trinkkur also im Mittel um $0,18^{\circ} \mathrm{C}$. und der osmotische Druck des Plasmas um $0,03^{\circ} \mathrm{C}$. gestiegen.

Auf Veranlassung von H. Strauss hat dann Grossmann [14] gleichartige Untersuchungen unternommen. Es war Strauss aufgefallen, in wie hohem Grade der menschliche Organismus die Fähigkeit besitzt den osmotischen Druck des Chylus alimentären Angriffen gegenüber constant zu erhalten. Er hatte z. B. einer Patientin mit einer Fistel des Ductus thoracicus 6 Uhr Morgens $500 \mathrm{~g}$ einer $2 \%$ igen $\mathrm{NaCl}-$ Lösung gegeben. In diesem Augenblick war der osmotische Druck des Chylus $\Delta=0,54^{0} \mathrm{C}$., und behielt trotz der Einverleibung der stark hyperisotonischen Lösung beständig denselben unveränderten Werth bis um 10 Uhr, wo der Werth auf $d=0,55^{0}$ stieg. 
Strauss hielt es deshalb für erforderlich, die Resultate von Grube und Engelmann, nach welchen der osmotische Druck des Blutes nach Aufnahme von Mineralwässern ziemlich grossen Schwankungen unterliegt, nach einer anderen Methode nachzuprïfen, da die Hämatokritmethode ihın kein Vertrauen erweckte. So fand z. B. Enge lmann morgens nüchtern, den osmotischen Druck meistens höher als nach dem Frübstïck und dem Gebrauch des hyperisotonischen Wassers. Engelmann glaubte dies damit erklären zu können, dass er ein nur geringes Nahrungsbedürfniss habe und wenig esse. Diese Erklürung ist aber nicht sehr wahrscheinlich.

Grossmann hat dann den osmotischen Druck des Blutes direct mit Hilfe des Beckmann'schen Apparates ermittelt, wozu er sich Venaepunctionen von 50 cc Blut machen liess.

Um sowohl den Einfluss eines hypisotonischen wie den eines hyperisotonischen Wassers zu studiren, nahm ex eine je 20-tägige Trinkkur mit Neuenahrer Sprudel $\left(\Delta=-0,11^{\circ} ; \mathrm{NaCl}=0,116^{\circ} \%\right)$ und nit Salzschlirfer Bonifaciusbrunnen $\left(\Delta=-0,90^{\circ} \mathrm{C} ; \mathrm{NaCl}=1,416^{\circ} \%\right)$ in der Weise vor, dass er täglich bei annähernd gleicher Nahrung Morgens um $7^{3 / 4}$ Uhr durchschnittlich $600 \mathrm{~g}$ des betreffenden Wassers zu sich nahın. Eine Stunde nachher nahm er das erste Frühstück ein. Zwischen beide Trinkkuren wurde eine Zwischenzeit von 15 T'agen eingeschoben. Sein Leben war ein sehr gleichmässiges. Vor Beginn der ersten Trinkperiode liess er sich eine Venenpunction machen und dieselbe je nach Abschluss der Neuenahrer Kur, sowie vor Beginn und nach Abschluss der Bonifaciuskur wiederholen. Das Blut wurde aufbewahrt und schied nach Gerinnung etwa 20 cc Serum ab.

Es stellte sich nun heraus, dass die Depression nach 20-tägigem Genuss vom Neuenahrer Sprudel unverändert $0,54^{\circ}$ blieb. Ein 20-tägiger Gennss von Salzschlirfer Bonifaciusbrunnen führte ebensowenig eine Veränderung der Gefrierpunkterniedrigung herbei.

Bedenkt man nun, dass die Blutentziehung immer 3-5 Stunden nach einer Wasseraufnahme stattfand, so darf man aus diesen Versuchen schliessen, dass 3-5 Stunden nach der Zufuhr der betreffenden Wässer keine Beeinflussung des osmotischen Druckes des Blutserums $\mathrm{zu}$ bemerken war, und dass auch eine lange dauernde Trinkkur darin keine Veränderung bringt.

Es ist erwïnscht, dass von anderer Seite noch Versuche angestellt werden, um in dem Widerstreit der Ergebnisse zwischen Grube und Engelmann einerseits und Grossmann andererseits zu entscheiden, der auch bei der Discussion zwischen Strauss, Koeppe, Engelmann und Grube in der letzten Sitzung der Balneologischen Gesellschaft nicht ganz aufgeklärt worden ist [16]. Hierbei erscheint die Einhaltung der in Bd. II, S. 279 und 281 aufgestellten Regeln erforderlich. 


\section{b) Einfluss auf den Harn.}

Grossmann hat, ebenso wie Engelmann, gleichzeitig den Einfluss der von ihm untersuchten Mineralwässer auf den Harn studirt.

Um 8 Uhr nahm er 500 cc des betreffenden Wassers $2 u$ sich und entleerte die Blase 4-5 Stunden lang in stündlichen Pausen.

Ich gebe hier die von Grossmann mitgetheilte Tabelle:

\begin{tabular}{|c|c|c|c|c|c|c|c|c|c|c|c|c|}
\hline \multirow[b]{2}{*}{ Stunde } & \multicolumn{4}{|c|}{ 25. Mai (Wasser) } & \multicolumn{4}{|c|}{$\begin{array}{l}\text { 15. Juni (Neuenahrer } \\
\text { Sprudel) }\end{array}$} & \multicolumn{4}{|c|}{ 20. Juli (Bonifaciusbrunnen) } \\
\hline & $\begin{array}{l}\text { Quan- } \\
\text { tum }\end{array}$ & $\begin{array}{l}\text { Spcc. } \\
\text { Gow. }\end{array}$ & $\Delta$ & $\begin{array}{c}\mathrm{NaCl} \\
\%\end{array}$ & $\begin{array}{l}\text { Quan- } \\
\text { tum }\end{array}$ & $\begin{array}{l}\text { Spee. } \\
\text { Gew. }\end{array}$ & $\Delta$ & $\begin{array}{l}\mathrm{NaCl} \\
\%\end{array}$ & $\begin{array}{l}\text { Quan- } \\
\text { tum }\end{array}$ & $\begin{array}{l}\text { Spec. } \\
\text { Gew. }\end{array}$ & $\Delta$ & $\begin{array}{c}\mathrm{NaCl} \\
\%\end{array}$ \\
\hline $8 \mathrm{Uhr}$ & 53 & 1024 & 1,80 & 1,40 & 60 & 1022 & 1,75 & 1,68 & 80 & 1022 & 1,68 & 1,56 \\
\hline 9 & 100 & 1020 & 1,55 & 1,38 & 83 & 1.013 & 1,59 & 1,77 & 100 & 1025 & 1,84 & 1,63 \\
\hline 10 & 90 & 1017 & 1,41 & 1,20 & 45 & 1021 & 1,37 & 1,45 & 115 & 1022 & 1,59 & 1,69 \\
\hline $11 "$ & 85 & 1017 & 1,50 & 1,39 & 44 & 1021 & 1,89 & 1,62 & 60 & 1020 & 1,24 & 1,20 \\
\hline 12, & 50 & 1024 & 2,00 & 1,60 & & & & & & & & \\
\hline
\end{tabular}

Aus diesen Versuchsergebnissen folgert Grossmann, dass unter dem Einfluss von Wasser und von dem relativ salzarmen Neuenahrer Sprudel, in der auf die Ingestion folgenden ersten Stunde bereits eine Erniedrigung des osmotischen Drucks stattfindet; eine Steigerung dagegen nach der Ingestion des hoch concentrirten Bonifaciusbrunnens.

\section{c) Mineralwäisser im Magen.}

Wichtige Untersuchungen über diesem Gegenstand verdanken wir H. Strauss [17]. Sie betreffen die Bedeutung der Gefrierpunkterniedrigung von Mineralwässern für die Motilität und Secretion des Magens und bilden eigentlich eine Fortsetzung von Untersuchungen, die der Autor früher theilweise mit $\mathrm{R} \cap \mathrm{th}$ anstellte und ron denen in Bd. II, S. 222 die Rede war. Es hatte sich damals ergeben, dass Salzlösungen von hohem osmotischen Druck sich im Magen rerdünnen, indem sie Wasser aus der Wand anziehen nnd das Volumen des Nageninhaltes vermehren und es wurde daran die praktische Bemerkung gelnüpft, dass man Patienten, die an motorischer Insufficienz des Magens leiden, keine Ingesta mit hohem osmotischen Druek geben soll.

Diese Bemerkung hat auch für die Mineralwässer volle Gïltigkeit.

Strauss hat in den Magen verschiedener Personen, mit dem Blut hypisotonische, isotonische und hyperisotonische Mineralwässer gebracht 
und den Rückstand nach 40, 20 oder 15 Minuten durch Expression entfernt. Es wurde immer $400 \mathrm{cc}$ eingefiihrt; die Versuchspersonen zeigten theils normale, theils erhölte, theils herabgesetzte Secretionsenergie, aber die Motilität war normal.

Ich erwähne als Beispiel drei Versuche, und zwar je einen mit hypisotonischem, isotonischem und hyperisotonischem Mineralwasser.

\begin{tabular}{c|c|c|c|c}
\hline \hline I & II & III & IV \\
\hline & Namen des Mineralwassers & $\begin{array}{c}\Delta \text { des } \\
\text { Mir eralwassers }\end{array}$ & $\begin{array}{c}\text { J des } \\
\text { Rüekstandes nach } \\
40 \text { Minuten }\end{array}$ & $\begin{array}{c}\text { Rüukstandes nach } \\
\text { 4j Minuten }\end{array}$ \\
\hline 1 & Neuenahrer Sprudel & $-0,10^{\circ}$ & $-0,24^{0}$ & $80 \mathrm{cc}$ \\
2 & Püllnaer Bitterwasser & 0,59 & 0,46 & $110, "$ \\
3 & Salzschlirfer Bonifacius & 0.92 & 0,70 & $210, "$
\end{tabular}

Wie bereits gesagt, wurden stets $400 \mathrm{cc}$ Mineralwasser einverleibt. Man sieht also, dass im ersten Fall, in welchem die Gefrierpunkterniedrigung gering war $\left(-0,10^{\circ}\right)$, nach 40 Minuten nur 80 cc Fliissigkeit im Magen vorhanden waren, wälrend im dritten Fall, in welchem das Mineralwasser hyperisotonisch war, nach dem genannten Zeitverlauf noch 210 cs rorzufinden waren. Das Püllnaer Bitterwasser mit $\Delta=-0,59^{\circ}$ stand entsprechend zwischen den beiden äussersten.

Ueber die Gefrierpunkterniedrigungsveränderungen spreche ich unten.

Zieht man num die Depressionswerthe heran, die auf Veranlassung ron Strauss ron von Kostkewicz ermittelt wurden (siehe oben S. 286), so stellt sich Folgendes heraus:

1. Die Mehrzahl der Eisenwässer, wie Homburger Luisenquelle, die Franzensbader Wässer, die Pyrmonter Helenenquelle, die Schwalbacher Wässer, sowie die Wässer von Levico und Roncegno zeichnen sich durch einen auffallend niedrigen Werth für $d\left(\Delta\right.$ zwischen $0,217^{\circ}$ und $\left.0,007^{\circ}\right)$ ans. Diese Eigenschaft, die, wie gesagt, ein rasches Schwinden aus dem Vaagen ermöglicht, ist besonders zweckmässig im Hinblick auf die bei Anämischen häufige Ityoparese und Hyperästhesie des Iagens, welche oft eine besondere Schonung des Magens, d. h. ein kurzes Verweilen des Inhalts erfordert;

2. Auch diejenigen Wässer, welche man im Allgemeinen als „Tafelwässer" bezeichnet, wie Apollinaris, Biliner, Rhenser, Giesshübler zeigen gleichfalls einen relatir niedrigen Werth für $I\left(I=-0,240^{\circ}\right.$ bis 
$\left.-0,120^{\circ}\right)$; Harzer Sauerbrunnen sogar nur $\Delta=0,06^{\circ}$. Diese Tafelwässer dienen unter Anderem dazu, den osmotischen Druck der Ingesta herabzusetzen.

Wie Strauss bemerkt, giebt es Weinsorten von hohem osmotischen Druck, die man dann auch gern mit solchen Tafelwässern verdünnt.

Rauenthaler Weisswein

Bordeaux (Château Giscours)

$$
\begin{aligned}
& \Delta=-5,04^{\circ} \\
& \Delta=-4,12^{\circ} \\
& \Delta=-3,71^{\circ} \\
& \Delta=-3,60^{\circ} \\
& \Delta=-2,94^{\circ} .
\end{aligned}
$$$$
\text { Zeltinger Weisswein }
$$

Frommscher Heidelbeerwein

Apfelwein

Uebrigens stellt sich bekanntlich das Bedürfniss nach Wasser nach reichlichem Weingenuss wohl von selbst ein.

In derselben Richtung scheint mir auch die Deutung der landläufigen Meinung zu liegen, dass man kein reines Gletscher- oder Bergwasser trinken soll; dass es aber mit etwas Alkolıol (Cognac etc.) versetzt, unschädlich wird. Bergwasser kann so rein sein, ja zuweilen noch reiner als das gewöhnliche destillirte Wasser ${ }^{1}$ ). Wer letzteres einmal getrunken hat, weiss, dass es schwer im Magen liegt. Wahrscheinlich ist die unangenehme Empfindung dadurch bedingt, dass die oberflächlichen Gewebelemente der Magenschleimhaut schwellen.

Nun repräsentiren, wie oben erwälnt, alkoholische Getränke einen sehr hohen osmotischen Druck (Cognac enthält etwa 50\% Alkohol). Ein wenig von letzterer Fliissigkeit wird also einen relativ bedeutenden osmotischen Druck herbeifïhren, wodurch der raschen Schwellung des Magenepithels rorgebeugt wird.

3. Auch die Wässer, die man als "Spülwässer" anzuwenden pflegt, so z. B. zum Lösen von Schleim bei der Gastritis mucipara, zu welchem Zweck ja eine nur wenige Minuten dauernde Anwesenheit eines Wassers im Magen geniigt, sollen ein niedriges $d$ haben. In der That ist das der Fall. So zeigen z. B. die alkalischen Säuerlinge: Vichy, Nenenahr, Fachingen, Obersalzbrunn Werthe für $l$, welche zwischen $0,330^{\circ}$ und $0,087^{\circ}$ schwanken, die alkalisch muriatischen Quellen Gleichenberg, Offenbach, Ems, Werthe für $A$, welche sich zwischen $-0,400^{\circ}$ und $-0,160^{\circ}$ bewegen. Von den alkalisch erdigen Quellen zeigt die

1) Es griebt auch Brunnen, deren Wasser reiner ist als destillirtes. Aus Tabelle S. 284 wird man ersehen, dass das Wasser (Nr. 8) des Gasteiner „Giftbrunneus" nach $\mathrm{v}$ on Waltenhofen eine Letfähigkeit von 31,9 besitzt, also eine geringere als gewöhnliches destillirtes Wasser (Nr. 11 der Tabelle). Ko eppe hat hervorgehoben, dass man von Giften niemals eine Spur entdeckt hat, sondern dass die grosse Schädlichkeit der ausserordentlich grossen Reinheit zuzuschreiben ist. 
Wildunger Königsquelle $\Delta=-0,140^{\circ}$ und die Georg-Victorquelle $I=-0,067^{\circ}$.

4. Den genannten Wässern, welche kurz im Magen verweilen und durch ihren schnellen Uebertritt in den Darm rasch in den Kreislanf gelangen, stehen schroff gegenüber die erdig sulfatischen Quellen, während die alkalisch-sulfatischen Quellen sich etwa in der Mitte zwischen beiden halten. Es gehören hierzı viele deutsche und ungarische Bitterwässer. Sie haben alle ein hohes $d$ und sollen bei Schwäche der Magenmuskulatur nicht gebraucht werden. In diesem Falle soll man, um denselben therapeutischen Effekt zu erreichen, gleichartige Wässer von geringerem osmotischen Druck anwenden. In solchen Fällen verdienen also Carlsbader und Marienbader Wasser weit den Vorzug vor den sogen. Bitterwässern, und unter den Bitterwässern wäre in solchen Fällen das Püllnaer Wasser, sowie die Tarasper Luciusquelle ror die anderen zu stellen.

Was die Gefrierpunkterniedrigung der im Magen zurückbleibenden INenge betrifft (Spalte III), so steigt die von 1, während die von 3 sinkt, ebenso wie auch die von 2. Es besteht hier also kein Bestreben des Mageninhalts, den osmotischen Druck des Blutserums zu behalten.

Wie früher bei der Untersuchung einfacher Salzlöstngen sich herausgestellt hat, ist die gastro-isotonische Lösung vielmehr eine solche, deren Gefrierpunkterniedrigung um 0,350 gelegen ist (Winter, Strauss). Das geht auch noch aus der auf Seite 322 abgedruckten Tabelle hervor, aus der man im Uebrigen ersehen wird, dass auch individuelle Schwankungen vorkommen.

Aus einem theoretischen Gesichtspunkt ist es wichtig, dass Magen, die nicht mehr im Stande waren, genügend Salzsäure zu produciren, sich bezüglich dieser Regelung des osmotischen Druckes kaum anders verhielten wie Magen mit gut erhaltener Salzsäureproduction. Es läge anderenfalls nahe, anzunehmen, dass auch im Magen, ebenso wie das für die anderen Höhlen bekannt ist, ursprïnglich das Bestreben besteht, den osmotischen Druck des Inhaltes demjenigen des Blutserums gleich zu machen, und dass vorwiegend die Salzsäureabscheidung eine Modifikation dieses osmotischen Druckes herbeiführte.

Nach den soeben genannten Erfahrungen von Strauss ist man nun wohl genöthigt entweder anzunehmen, dass eine mangelhafte Salzsäuresecretion zum Ausdruck kommen kann durch Abscheidung des normalen Volumens eines gegenüber dem Blutserum hypisotonischen Magensaftes von zu schwachem Salzsäuregehalt, oder die von mir gegebene Erklärung fallen zu lassen und mit Strauss an einen activ vitalen Process der Magenschleimhaut zu denken (Bd. II, S. 223 u. 230). 
Balneologisches.

\begin{tabular}{|c|c|c|c|c|}
\hline Mineralwasser & Versuehsperson & Versuchsdauer & $\begin{array}{c}\Delta \\
\text { des Mineral- } \\
\text { wassers }\end{array}$ & $\begin{array}{c}\lrcorner \\
\text { des Rück- } \\
\text { standes }\end{array}$ \\
\hline Püllnaer & Krämer & 40 Minuten & $-0,59^{\circ}$ & $-0,44^{0}$ \\
\hline & Braun & & 0,59 & 0,46 \\
\hline Friedrichshaller und & Handlos & & 0,58 & 0.35 \\
\hline & Mudrich & & 0,58 & 0,55 \\
\hline Kissinger Rakoczy & Handlos & 20 Minuten & 0,47 & 0,32 \\
\hline & I Mudrich & , & 0,47 & 0,33 \\
\hline Kissinger Maxbrunnen & ( Mudrich & & 0,35 & $0,3: 3$ \\
\hline Vichy-Grande-Grille & $\begin{array}{l}\text { Krämer } \\
\text { Mudrich }\end{array}$ & & $\begin{array}{l}0,35 \\
0,32\end{array}$ & 0,32 \\
\hline Carlsbader Schlossbrunnen & Lange & 40 Minuten & 0,26 & $\begin{array}{l}0,39 \\
0.32\end{array}$ \\
\hline \# Felsenquelle & Lange & & 0,25 & 0.33 \\
\hline Vichy Cólesting & f Krämer & 20 Minuten & 0,20 & 0,40 \\
\hline licny velestins & 1 Mudrich & $\pi \quad$, & 0,20 & 0,35 \\
\hline Nenenahrer Sprudel & Lange & 40 Minuten & 0,10 & 0,24 \\
\hline Assmannshäuser Wasser & Krämer & 15 & 0,08 & 0,26 \\
\hline Schwalbacher Stahlbrunnen & Mudrich & , & 0,05 & 0,15 \\
\hline$n$ & Mudrich & n & 0,05 & 0,11 \\
\hline
\end{tabular}

4. Einfluss auf die Mileh.

Gelegentlich seiner oben erwähnten Untersuchung hat Grossmann einer Sängenden $500 \mathrm{~g}$ Bonifaciusquelle verabreicht. 80 Minuten und zwei Stunden später wurden bei ihr mittelst Milchsaugers je $20 \mathrm{cc}$ Milch entnommen. Beide Proben ergaben bei der mit dem Beckmann'schen Apparate angestellten Bestimmung einen Werth $I=-0,54^{\circ}$. Vor der Verabreichung des Mineralwassers war $\Delta=-0,55^{\circ} \mathrm{C}$. Der Einfluss war somit gering. 


\section{Neuntes Kapitel.}

\section{Bacteriologisehes ${ }^{1}$ ).}

\section{L it teratur.}

1. Massart, Archives de Biologie 9. 18ะ9. p. 515.

2. Pfeffer, Unters, aus dem botanischen Institut zu Tübingen 1. 1884. S. 363; 2. 1888. S. 582.

3. Hugo de Vries, Botanische Zeitung 1888. Nr. 15 u. 16; 1889. Nr. 19 u. 20.

4. Janse, Verslagen en Mededeelingen d. Koninkl. Akad. v. Wetensch. Amsterdam 4. 1888. p. 332 (deutsch). Botanisches Centralblatt 32. 1887. Nr. 40.

5. voll Rysselber ghe, Réaction osmotique des cellules végétales à la concentration du milieu. Mémoires couronnés et autres Mémoires publiés par l'Académie royale de Belgique in $8^{\circ} .55 .1899$.

6. Léon Fr’édericı, Livre jubilaire de la Soc. de médec. de Grand 1884; La lutte pour l'existence chez les animaux marins. Paris 1889.

7. WIadimi rofl, Zeitschr. f. physik. Chemie 7. 1891. S. 529.

8. Alfred Fischer, Pringsheim's Jahrb. f. d. wissensch. Botanik 27. 1895. S. 1.

9. Alfred Fischer, Berichte der Künigl. sächs. Gesellsch. d. Wissensch. Mathem. physik. Klasse 1891. S. 52.

10. von Banmgarten, Arbeiten aus dem pathol. Institut zu Tübingen 3. 1899.

11. vou Baumgarten, Berl. klin. Wochenschr. 1900. Nr. 7-9.

12. Walz, Ueber die sogen. bactericide Eigensch. des Blutserums und über ihre Beziehungen zu Assimilations-Vorgängen und osmotischen Störungen. Habilitationsschrift Tübingen 1899; Münchener med. Wochenschr. 1899. Nr. 41.

13. Bnchner. Archiv f. Hyg. 10. 1890. S. 161.

14. Alfred Fischer. Zeitschr. f. Hyg. 3.5. 1900. S. 1.

15. Fokker, Versuch einer neuen Bacterienlehre. Untersuchungen aus dem hygienischen Institut in Groningen 1902. Nicht im Handel.

16. Fokker. Centralblatt f. Bacteriol. 31. 1902. S. 524.

17. A. Schwartz, Ueber die Wechselwirkung zwischen Hämoglobin und Protoplasma. G. Fischer Jena 1888.

18. Reiuhardt, Plasmolytische Studien zur Kenntniss des Wachsthums der Zellmembran. Festschrift f. Schwendener 1899. (Ref. aus Alfred Fischer).

1) Ueber Fixirung und Färbung von Bacterien vergleiche man das nächste Kapitel „Histologisches", 
19. Kobert, Lehrbuch der Intoxicationen. Stuttgart. 1893.

20. Ehrlich, Klinisches Jahrbuch 6. 1897.

21. Ransom, Deutsche med. Wochenschr. 1901. Nr. 16.

22. Stillmark, Arbeiten aus dem pharmacologischen Institut Dorpat 3. 1889.

23. Hellin, Der giftige Eiweisskörper Abrin und seine Wirkung auf das Blut. Inaug.-Diss. Dorpat 1891.

24. Kobert, Sitzungsber. der Natur f. Gesellsch. Rostock 25. Mai 1900.

25. Ehrlich, Deutsche med. Wochenschr. 1891. Nr. 12.

26. Ehrlich, Fortschritte d. Medicin 1897. Nr. 2.

27. Ehrlich, Deutsche med. Wochenschr. 1891. Nr. 14.

28. Hansmann, Hofmeister's Beiträge zur chemischen Physiol. 2. 1902.

29. Jacoby, Archiv f. exp. Path. und Pharmac. 46. 1901. S. 28.

30. van de Velde, La Cellule 10. 1894.

31. Neisser und Wechsberg, Zeitschr. f. Hyg. 36. 1901. S. 299.

32. Madsen, Zeitschr. f. Hyg. 32. 1899. S. 214 u. 239.

33. Krans und Ludwig. Wiener klin. Wochenschr. 1902. Nr. 15.

34. Todd, The Lancet, 14. December 1901.

35. Stepliens und Meyer's Journal of Pathol. and Bacteriol 5. 1898. p. 44.

36. Langer, Arch. f. exp. Pathol, u. Pharmak. 35. 1897. S. 381.

37. Kobert. Beitrag zur Kenntniss der Giftspinne. Stuttgart 1901.

38. H. Sachs, Hofmeister's Beiträge zur chem. Physiol. 2. 1902. S. 125.

39. Landois, T'ransfusion des Blutes. Leipzig 1875.

40. Daremberg, Archives de méd. expérim. et d' anat. patho]. 1891. p. 93.

41. Buchner, Archiv f. Hyg. 10. 1890. S. 84.

42. A. Mosso. Acad. der Lincei 4. 1888. Ref. Maly's Jahresber. f. Thierchemie. 1888.

43. Camus und Gley, Archives internat. de pharmacodyn. 5. 1898. p. 245.

44. Kossel, Berl. klin. Wochenschr. 1898. Nr. 7.

45. Weigert, Deutsche med. Wochenschr. 1896. Nr. 14.

46. Ehrlich, Klinisches Jahrbuch 6. 1897.

47. Ehrlich und Morgenroth, Berl. klin. Wochenschr. 1899. Nr. 1 u. 22.

48. Ehrlich und Morgenroth, Berl. klin. Wochenschr. 1900. Nr. 21 u. 31.

49. Ehrlich und Morgenroth, Berl. klin. Wochenschr. 1901. Nr. 10, 21 น. 22.

50. Ehrlich und Sachs, Berl. klin. Wochenschr. 1902. Nr. 21.

51 H. Sachs. Berl. klin. Wochenschr, 1902. Nr. 9 u. 10.

52. Pfeifler und Marx, Zeitschr. f. Hygiene 27. 1898.

53. Wassermann, Berl. klin. Wochenschr. 1898. S. 209.

54. Dentsch, Annales de l'Inst. Pas te ur 13. 1899.

55. Wassermam Zeitschr. f. Hyg. 37. 1901. S. 173.

56. von Dungern, Deutsche med. Wochenschr. 1900. Nr. 28.

57. Canns und Gley. Annales de l'Inst. Pasteur 13. 1899.

58. Kossel, Berl. klin. Wochenschr. 1898. Nr. 7.

59. Ehrlich, Croonian lecture; Proceedings of the Royal Society 66. 1900.

60. Koeppe, Pflüger's Archiv 99. 1903. S. 33.

61. Kyes und Sachs, Berl. klin. Wochenschr. 1903. Nr. 2-4.

62. Saclis, Centralblatt f. Bakerteriol. 34. 1903. S. 686 .

63. Metchnikofl. L’immunité dans les maladies infectieuses. 1901. Paris, Masson \& Cie.

64. Vou Banmgarten, Festschrift für Max J ffé 1901. S. 269.

65. von Baumgarten, Berl. klin. Wochenschr. 1901. Nr. 50. 
66. von Baumgarteu, Verhandl. d. deutschen pathol, Gesellsch. Sept. 1902. S. 46. G. R e i m e r Berlin 1903.

67. Ehrlieh, Berl. klin. Wochenschr. 1898. Nr. 12.

68. Neisser und Wechsberg, Münchener med. Wochenschr. 1901. Nr. 18.

69. Nolf, Annales de l'Inst. Past. 14. 1900. p. 297.

70. Gruber, Nünchener med. Wochenschr. 1901. Nr. 45.

71. H. Sachs, Die Hämolysine u. ihre Bedeutung für die Immunitätslehre in Lu ba r sc h' und Ostertag's Ergebnisse der Pathol. Anat. 7. 1902. Auch separat zu erhalten.

72. Asehhoff, Ehrlich's Seitenkettentheorie, Zusammenfassende Darstellung. Ver. worn's Zeitschr. f. allgem. Physiol. 1. 1902. S. 69. Auch separat zu erbalten.

73. von Dungern, Die Antikörper. G. Fischer, Jena 1903.

74. Dieudonné, Immunität, Schutzimpfung und Serumtherapie, zusanmenfassende Uebersicht über die Immunitätslehre. 3. Aufl. Leipzig, J. A. Barth 1903.

75. Arrhenius und Madsen, Physical chemistry applied to toxins and antitoxins. Festskrift ved indvielsen af Statens Serum Institut. (Edit. by Prof. C. J. Salomonsen). Kjsbenhavn 1902; Zeitschr. f. physik. Chemie 44. 1903. S. 7.

76. Madsen, Centralblatt f. Bakteriol. 34. 1903. S. 630.

77. Elırlielı, Berl. klin. Wochenschr. 1903. Nr. 35-37.

78. Arrhenius, Berl. klin. Wochenschr. 1904. Nr. 9.

79. Gruber (und Pirquet), Münchener med. Wochenschr. 1903. S. 1193 u. 1259; S. 1825 u. 2297.

80. von Dungerı, Iünchener med. Wochenschr. 1904. Nr. 8 und 9.

81. Arrhenius, Die Anwendung der physikalischen Chemie auf die Serumtherarie. Vortrag gehalten im Kaiserl. Gesundheitsamt zu Berlin am 22. Dez. 1903. Arbeiten aus dem Kaiserl. Gesundheitsamt. 20. 1903.

82. Arrhenins, Die Anwendung der physik. Chemie auf die serumtherapeutischen Fragen. Festschrift f. Boltzm ann. 1904. Leipzig, J. A. Barth.

83. Eisenber and Volk, Centralbl. f. Bakteriol, 34. 1903. S. 259.

84. Arrlenius, Zeitschr. f. physik. Chemie. 46. 1903. S. 415. (Ostwald-Band).

85. Arrhenius und Iradsen, The molecular weight of diphteria toxin. Festskrift Kjøbenhavn. 1902.

86. R. Sleeswyk, Der Kampf des thierischen Organismus mit der pflanzlichen ZelleAmsterdam, Sle esw y k. 1502.

\section{Die Beweglichkeit von Bacterien in Salzlösungen verschiedener Concentration.}

\section{a) Untersuchungen von Massart.}

Zu den ersten Untersuchungen, die nach Veröffentlichung von de Tries' Lehre von den isotonischen Coëfficienten und der Bestätigung ihrer Giltigkeit für die rothen Blutkörperchen in entsprechender Richtung angestellt wurden, gehört eine im Brüsseler botanischen Institut unternommene Arbeit von Massart [1]. Dieselbe bezweckte die Empfindlichkeit und Adaptirung von Organismen, insbesondere von Bacterien und Flagellaten, für die Concentration von Salzlösungen zu erforschen. 
Freilich hatte bereits Pfeffer [2] Untersuchungen über die Empfindlichkeit lebender Zellen (Spermatozoen von Kryptogamen) und niederer Organismen (Bacterien und Flagellaten) gegenïber concentrirten Salzlösungen angestellt und dabei constatirt, dass die Zellen eine Abstossung erfahren. Dieser Autor führte aber die Erscheinung nicht auf die Concentration, sondern auf die specifischen chemischen Eigenschaften der angewandten Verbindungen zurïck.

Am meisten interessiren uns hier Massart's Versuche mit Bacterien.

Die angewandte Methode entsprach in der Hauptsache Pfeffer's Verfahren.

Ein Tropfen der Bacteriencultur wurde auf ein Deckgläschen gebracht, dieses umgekehrt (Untersuchung im hängenden Tropfen) und auf ein Leistchen von Pappe gelegt. In den Tropfen wurden Glascapillaren gebracht, die mit der zu untersuchenden Flüssigkeit gefüllt waren. Diese enthielt in allen Versuchen auch eine Substanz, die eine grosse Anzielung auf die Bacterien ausübt, nämlich $\mathrm{K}_{2} \mathrm{CO}_{3}$. Doch war dasselbe in so geringer Menge vorhanden, dass es auf den osmotischen Druck keinen merklichen Einfluss ausüben konnte. Er war nämlich nur $0,00691 \% \mathrm{~K}_{2} \mathrm{CO}_{3}$ in die zu untersuchende Flüssigkeit eingeführt.

Dass bereits in dieser Verdünnung die Anziehungskraft des $\mathrm{K}_{2} \mathrm{CO}_{2}$ eine grössere war, zeigte sich, als man das Capillarröhrchen mit dieser Lösung füllte. Legte man es dann in den Culturtropfen, so traten die Bacterien in grosser Zahl hinein. Innerhalb 20-30 Minuten war das Capillarröhrchen strotzend damit gefüllt. Als Bacterien wurden Spirillum undula und Bacillus Megatherium benutzt.

Wenn nun weiter zu der $\mathrm{K}_{2} \mathrm{CO}_{3}$-Lösung steigende Mengen eines Salzes hinzugefügt wurden, so drangen immer weniger Bakterien ein. Schliesslich gelangte man zu einer Concentration, bei welcher der Eintritt von Bacterien ausblieb und dieselben sich am Eingang des Röhrchens anhäuften. Eine noch etwas stärkere Salzconcentration trieb die Bacterien sogar zurück.

Massart ermittelte nun die Concentration verschiedener Salze, welche den Bacterien erlaubte, das Capillarröhrchen vollständig anzufüllen, ferner die Concentration, die die Bacterien sich am Eingang ansammeln liess, und drittens die Concentration, die auch das nicht gestattete, bei der also die zurücktreibende Wirkung des Salzes vorwaltend war.

Von Salzen wurden untersucht:

$\mathrm{NH}_{4} \mathrm{Cl}, \mathrm{NaCl}, \mathrm{KCN}, \mathrm{KCl}, \mathrm{NaNO}_{3}, \mathrm{KNO}_{3}, \mathrm{KBr}, \mathrm{KClO}_{3}, \mathrm{KJ}$. 
Es stellte sich die merkwürdige Thatsache heraus, dass diese Salze, die alle den isotonischen Coëfficienten 3 besitzen (vergl. Bd. I, S. 3), also in äquimolecularer Lösung isosmotisch sind, auch die gleiche Wirkung auf die Bacterien ausiibten. Waren 0,004 Gramı-Molecüle des Salzes in 100 ce der $\mathrm{K}_{2} \mathrm{CO}_{3}$-Lösung aufgelöst, so wanderten Bacterien in das Capillarröhrchen ein; sie häuften sich aber am Eingang an, wenn 0,005 bis 0,006 Gramm-Molecüle in $100 \mathrm{cc}_{2} \mathrm{CO}_{3}$ gelöst waren. Hatte Massart 0.006 Gramm-Molecüle aufgelöst (d. i. also z. B. von $\mathrm{NaCl} 0,007 \times 58,5 \mathrm{~g}$ aufgelöst in $100 \mathrm{cc}$ der $\mathrm{K}_{2} \mathrm{CO}_{3}$-Lösung $=0,31 \% \mathrm{NaCl}$ ), so wurden die Bacterien vollständig zurïckgetrieben.

Es ist also nicht der chemische Character des Salzes, der hier die Bewegung beherrscht. Diese hängt vielmehr lediglich von der Molecülzahl, oder genauer gesagt, von der osmotischen Concentration ab. Nur das KCN machte eine Ausnahme, indem es in allen angewandten Concentrationen die Bacterien verhinderte einzuwandern.

Gleichlautende Resultate erhielt Massart mit anderen Salzen, die den isotonischen Coëfficienten 4 hatten, wie:

$\mathrm{Na}_{2} \mathrm{CO}_{3}, \mathrm{Na}_{2} \mathrm{SO}_{3},\left(\mathrm{NH}_{4}\right)_{2} \mathrm{SO}_{4},\left(\mathrm{NH}_{4}\right)_{2} \mathrm{HPO}_{4}$,

$\mathrm{K}_{2} \mathrm{CO}_{3}, \mathrm{Na}_{2} \mathrm{HPO}_{4}, \mathrm{Na}_{2} \mathrm{SO}_{4}, \mathrm{~K}_{2} \mathrm{HPO}_{4}$, Kaliumtartrat.

Ein abweichendes Resultat ergab Kaliumoxalat, das in sehr geringer Menge $(0,001$ Gramm-Molecüle in 100 cc) die Bacterien zurücktrieb. Dieses Salz hält Massart für giftig. Organische Substanzen zeigten geringe Uebereinstimmung. Glycerin zog in allen Concentrationen die Bacterien an; Harnstoff, Dextrose und Rohrzucker wirkten in gleichem Sinne, aber weniger stark, Lactose noch schwächer.

Indessen sind nicht alle Bacterien für kleine Concentrationsunterschiede empfindlich. B. termo wandert z. B. noch in das Capillarröhrchen ein, wenn dasselbe $20 \% \mathrm{KNO}_{3}$ oder $30 \%$ Saccharose enthält.

Auch ist für eine und dieselbe Bacterienart und für ein und dasselbe Salz die Concentration, durch welche diese Bacterienart abgestossen wird, nicht immer dieselbe. Dies hängt vielmehr, wie aus den Untersuchungen von Massart zu ersehen ist, von der Zusammensetzung des Nährbodens ab. So hat er seine Spirillen in flüssigen Nährböden (Düngerflüssigkeit) cultivirt, denen verschiedene $\mathrm{NaCl-Mengen} \mathrm{hin-}$ zugefügt waren. Es stellte sich nun heraus, dass diejenigen Bacterien, die in den kochsalzreichsten Medien gezüchtet waren, für die abstossende Wirkung des im Capillarröhrchen aufgelösten $\mathrm{NaCl}$ weniger empfindlich waren, d. h. sie ertrugen mehr von diesem Salz ohne zurückgestossen zu werden, als die im $\mathrm{NaCl}$-ärmeren Medium cultivirten. 
So drangen die aus gewöhnlicher Düngerflüssigkeit kommenden Spirillen kaum in das Capillarröhrchen ein, das $0,05 \mathrm{Mol} \mathrm{NaCl}$ enthielt; Spirillen aber die während 20 Stunden in Düngerflüssigkeit gezüchtet waren, der $0,03 \mathrm{Mol} \mathrm{NaCl}$ hinzugesetzt war, drangen in das $0,0.5 \mathrm{Mol} \mathrm{NaCl}$ enthaltende, ja sogar in ein $0.1 \mathrm{Mol}$ enthaltendes Capillarröhrchen ein. Spirillen, die während 20 Stunden in Nährflüssigkeit mit $0,09 \mathrm{Mol} \mathrm{NaCl}$ cultivirt waren, konnten noch in Capillarröhrchen einwandern, die $0,2 \mathrm{Mol} \mathrm{NaCl}$ enthielten.

Es liegt hier eine Gewöhnung (Adaptation) an concentrirte Salzlösungen vor, die bereits früher für Pflanzenzellen gefunden wurde und auch für höhere Wassertliere längst bekannt ist.

Wahrscheinlich steht die Erscheinung mit dem Eindringen des betreffenden Salzes in die Zelle in Zusammenhang. Wenn man Spirogyra in einer Salzlösung liegen lässt, die eben Plasmolyse hervorruft, so geht die Plasmolyse zurïck. Sie kann aber durch Ersatz der betreffenden Salzlösung durch eine concentrirtere wieder hervorgerufen werden. Auch darin rerschwindet dann wieder die Plasmolyse, um abermals durch eine stärkere Lösmng wieder herbeigeführt zu werden. Deutliche Beispiele dieser Art findet man für Ptlanzenzellen u. A. bei H. de V ries [3] und bei Janse [4] (vergl. besonders ron Rysselberghe [5]) und für Wasserthiere bei Lé on Fredericq [6].

Die leichte Adaptation von Mikrorganismen an den Wechsel der Zusammensetzung des Mediums ist für den Bacteriologen von herrorragender Bedeutung.

\section{b) Untersuchungen von Wadimiroff.}

Zwei Jahre später hat Wladimiroff [7] ohne, wie es scheint, die Massart'sche Arbeit zu kennen, Versuche mit dem gleichen Ziele aber nach einer ganz anderen Methode angestellt.

Wladimiroff wollte erforschen, in wie fern die Beweglichkeit ron Bacterien von dem osmotischen Druck der sie umgebenden Salzlösung beherrscht wird.

Anch hier wurden die Bacterien im hängenden Tropfen beobachtet, der aus einer Mischung ron Lösung und Nähr-Bouillon bestand.

Um die Lösungen möglichst wenig in ihrer Concentration zu alteriren, wurden dieselben in so grossen Tropfen an die Deckgläschen angehängt, als es die Höhlung in dem zu diesem Zweck gebräuchlichen Objectträger gestattete und darauf mit einer geraden Nadel, an der eine kaum wahrnehmbare Menge der Bouilloncultur haftete, geimpft. Genau 2 Minuten nach der Infection des Tropfens begann die Beobachtung. 
Ich will mit Hinsicht auf die etwaige Verwendung von beweglichen Bacterien für anderweitige Zwecke, Wladimiroff's Beobachtungen nahezu wörtlich wiedergeben.

„Schon in der Nährbonillon zeigen bekanntlich die verschiedenen beweglichen Bacterienarten gewisse Unterschiede in der Locomotion. Die Typhusbacillen schwimmen gleichmässig und ruhig, der Bacillus subtilis zeigt ein wackelndes Vor. wärtsstreben, die Koch'schen Choleravibrionen schwärmen hastig.

Aber auch die einzelnen Individuen derselben Art verhalten sich durchaus nicht alle gleich; im Allgemeinen kann man sagen, dass die grösseren Individuen, träger, die kleineren agiler sind und ferner, dass auch der Ort, an dem sie sich befinden, nicht ohne Einfluss ist, da die an Rande (resp. an der Oberfläche) des Tropfens befindlichen Bakterien wenig Neigung zeigen, ihre bezüglich der Sauerstoffversorgung günstige Position aufzugeben. Aus letzterem Umstande ergiebt sich die Nothwendigkeit, bei Untersuchungen über die Beweglichkeit sowohl den Rand als auch die inneren und tieferen Partien des Tropfens zu durchmustern.

Von Wichtigkeit ist es hier, das unter der Einwirkung von Lösungen verschiedener Concentration die charakteristische Eigenbewegung gewisse Teränderungen erleidet.

Verfolgt man letztere von den schwächeren Concentrationen zu den stärkeren, so kann man constatiren, dass zunächst sobald sich eine Einwirkung der Lösung geltend macht, die in Uebrigen normal erscheinende Schwimmbewegung etwas langsamer ausgeführt wird. Hand in Hand mit dem Stärkerwerden der Concentration nimmt die Verlangsamung $z u$, bis man das Bild erhält, als ob die Bacterien sich nur noch mühsam vorwärts arbeiten. Stets nimmt gleichzeitig die relative Zahl der Schwimmer ab, und es erscheinen von Stufe zu Stufe immer mehr Individuen. welche nur noch Vorstösse machen können, d. h. ihr Körper führt dieselben Bewegungen aus, wie beim unbehinderten Schwimmen, kommt dabei aber um wenige Körperlängen vorwärts. Darauf folgt eine Pause, dann wieder ein ebenso erfolgloser Vorstoss nach derselben, oder nach der entgegengesetzten Richtung und so fort."

Als ein weiterer Grad in der Schädigung der Eigenbewegung sind die Schwimmversuche $\mathrm{zu}$ bezeichnen. Auch hier macht das Individuum regelrechte Schwimmbewegungen, ist aber nicht mehr im Stande auch nur um die Länge seines Körpers vorwärts zu kommen. Sehliesslich kann man noch vor dem völligen Ellöschen der Kigenbewegung ein eigenthümliches Hin- und Herwerfen des Körpers beobachten, welches Wladimiroff der Kürze halber Fischwerfen nennen möchte, weil es lebhaft an das Gebahren eines Fisches auf dem Trocknen erinnert. Bei noch weiterer Steigerung der Concentration findet man an den Bacterien nur nur noch die sogenannten oscillatorische Molecularbewegung, welche sich in nichts von der Bewegung der zufällig vorhandenen unbelebten Partikelehen im Präparate unterscheidet.

Aus dieser Beschreibung geht hervor, dass man verschiedene Grade der Bewegungstörung als Maassstab benutzen kann.

Wladimiroff hat nun experimentell zu bestimmen gesucht, in welcher Lösung noch einige wenige, wenn anch langsame und mühselige 
Schwimmer zu finden sind. Ferner hat er die, etwas concentrirtere, Lösung aufgesucht, in welcher bloss noch Schwimmversuche, höchstens Vorstösse auftreten. Von dieser Concentration wurde das arithmetische Nittel genommen und diese entsprechende Lösung als Grenzlösung bezeichnet.

Nach dieser Methode wurde die Grenzlösung von zehn Neutralsalzen gesucht, nämlich von

$\begin{array}{ll}\mathrm{KCl} & \mathrm{NaCl} \\ \mathrm{KNO}_{3} & \mathrm{NaNO}_{3} \\ \mathrm{KBr} & \mathrm{NaBr} \\ \mathrm{K}_{2} \mathrm{SO}_{4} & \mathrm{Na}_{2} \mathrm{SO}_{4}\end{array}$

Als Bakterien wurden gewählt:

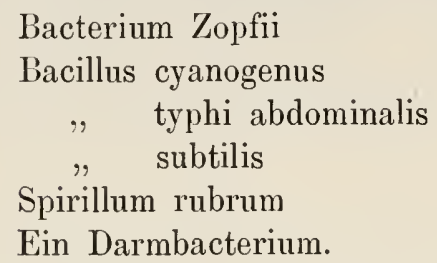

Die Resultate sind in der Tabelle auf Seite 331 zusammengefasst, deren Zusammenstellung ohne weitere Erörterung hegreiflich sein wird.

Wladimiroff war sich dessen bewusst, dass Spalte 5, die die moleculare Concentration der verschiedenen Salze darstellte, noch keinen Ausdruck für den osmotischen Druck bildete, denn er wusste, dass der Dissociationsgrad dieser Salzlösungen nicht derselbe war.

Damals waren die Gefrierpunkterniedrigungen erst von wenig Salzlösungen bekannt und die Möglichkeit, sie aus dem elektrischen Leitvermögen zu berechnen kaum durchgedrungen.

Wladimiroff versuchte daher auf Umwegen aus der Tabelle abzuleiten, wie weit die Gesetze des osmotisclien Druckes in den von ihm gefundenen Grenzlösungen zum Ausdruck kamen. Doch geht dies viel leichter, wenn man die Gefrierpunkterniedrigung der Grenzlösungen kennt. Ich habe desshalb diese Depressionen berechnet; sie sind in Spalte 6 aufgenommen.

Vergleicht man die gefundenen Grenzlösungen in Spalte 2 und 3, so ersieht man, dass die Genauigkeit der Versuchsmethode eine recht befriedigende ist, was noclı weiter in Spalte 4 zum Ausdruck kommt, wo die Concentrationsunterschiede von 2 und 3 in Procenten angegeben sind. 
Bacterium Zopfii.

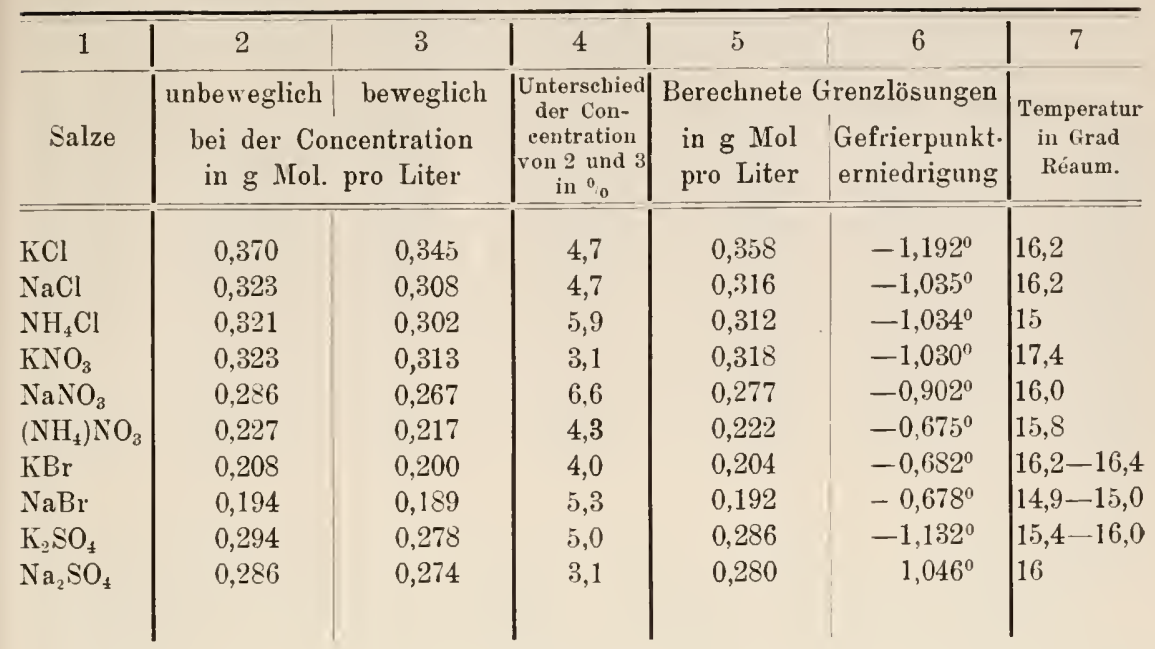

Bacillus Pyocyaneus.

\begin{tabular}{l|l|l|l|l|l|l}
$\mathrm{KCl}$ & 0,741 & 0,714 & 3,8 & 0,728 & $-2,357^{0}$ & $15,8-16,4$ \\
$\mathrm{NaCl}$ & 0,667 & 0,645 & 3,3 & 0,656 & $-2,063^{0}$ & $16,0-16,2$ \\
$\mathrm{NH}_{4} \mathrm{Cl}$ & 0,644 & 0,603 & 6,4 & 0,624 & $-2,060^{0}$ & $14,8-15,0$ \\
$\mathrm{KNO}_{3}$ & 0,645 & 0,625 & 3,1 & 0,635 & $-2,016^{0}$ & 16,0 \\
$\mathrm{NaNO}_{3}$ & 0,482 & 0,465 & 3,4 & 0,474 & $-1,615^{0}$ & 16,6 \\
$\left(\mathrm{NH}_{4}\right) \mathrm{NO}_{3}$ & 0,521 & 0,502 & 3,7 & 0,512 & $-1,774^{0}$ & 15,8 \\
$\mathrm{KBr}$ & 0,645 & 0,606 & 6,0 & 0,626 & $-1,944^{0}$ & 16,4 \\
$\mathrm{NaBr}$ & 0,606 & 0,588 & 2,9 & 0,597 & $-1,-10^{0}$ & 16,8 \\
$\mathrm{~K}_{2} \mathrm{SO}_{4}$ & 0,500 & 0,476 & 4,8 & 0,488 & $-1,689^{\circ}$ & $15,5-16,2$ \\
$\mathrm{Na}_{2} \mathrm{SO}_{4}$ & 0482 & 0.465 & 3,4 & 0,474 & $-1,474^{0}$ & 16,2
\end{tabular}

Wladimiroff gelangt zum Schluss, dass die von ihm beobachteten Erscheinungen der Bewegungshemmung, auf osmotische Vorgänge zur ückgeführt werden müssen. Dem kann ich nach Berechnung der entsprechenden Depressionen (Spalte 6) nicht beistimmen, um so weniger, als sich ähnliche Resultate auch für andere von Wladimir off untersuchten Bacterien ergeben.

Ich fasse alle Versuche in einer Tabelle auf Seite 332 zusammen:

Wie mir scheint, sind die Unterschiede der Gefrierpunkterniedrigungen in einer und derselben Verticalreihe zu gross, dass man berechtigt sein könnte, die Erscheinungen der Bewegungshemmung, ohne Weiteres auf osmotische Vorgänge zurïckzuführen. Es müssen hier auch andere Factoren im Spiele sein. 


\begin{tabular}{l|c|c|c|c|c|c}
\hline \multicolumn{1}{c|}{$\mathrm{Salz}$} & $\begin{array}{c}\text { Bacterium } \\
\text { Zopfii } \\
\Delta\end{array}$ & $\begin{array}{c}\text { Bacillus } \\
\text { cyanogenus } \\
\Delta\end{array}$ & $\begin{array}{c}\text { Bacillus } \\
\text { typhi } \\
\text { sacillus }\end{array}$ & $\begin{array}{c}\text { Spirillum } \\
\text { subtilis }\end{array}$ & $\begin{array}{c}\text { Darm- } \\
\text { bacterium } \\
\text { bubum }\end{array}$ \\
\hline $\mathrm{KCl}$ & $-1,192^{\circ}$ & $-2,357^{\circ}$ & $-2,357^{\circ}$ & $-2,116^{\circ}$ & $-2,461^{0}$ & $-2,340^{\circ}$ \\
$\mathrm{NaCl}$ & $-1,035$ & $-2,063$ & $-1,890$ & $-1,449$ & $-2,003$ & $-2,003$ \\
$\mathrm{NH}_{4} \mathrm{Cl}$ & $-1,039$ & $-2,060$ & $-1,896$ & $-1,506$ & $-1,805$ & $-1,405$ \\
$\mathrm{KNO}_{3}$ & $-1,030$ & $-2,016$ & $-1,918$ & $-1,848$ & $-2,072$ & $-2,216$ \\
$\mathrm{NaNO}_{3}$ & $-0,902$ & $-1,615$ & $-1,643$ & $-1,716$ & $-1,855$ & $-1,950$ \\
$\mathrm{NH}_{4} \mathrm{NO}_{3}$ & $-0,675$ & $-1,994$ & - & - & - & - \\
$\mathrm{KBr}_{\mathrm{NaBr}}$ & $-0,682$ & $-1,810$ & - & - & - & - \\
$\mathrm{K}_{2} \mathrm{SO}_{4}$ & $-0,678$ & $-1,689$ & - & - & - & - \\
$\mathrm{Na}_{2} \mathrm{SO}_{4}$ & $-1,132$ & $-1,689$ & $-1,663$ & $-1,168$ & $-1,500$ & $-1,276$ \\
& $-1,046$ & $-1,474$ & $-1,479$ & $-1,025$ & $-1,391$ & $-1,132$ \\
& & & & & &
\end{tabular}

Indessen giebt es anch nach Wladimir off einige Neutralsalze, die die Eigenbewegung gewisser Bacterien bereits in so rerdïnnten Lösungen lähmten, dass die Lähmung nicht auf Wasserentziehung zurïckgeführt werden kann. Hier muss nach ihm eine Giftwirkung angenommen werden.

In seiner ausführlichen Arbeit „.Untersuchungen über Bacterien“ hat Alfred Fischer nachdrücklich betont, dass Wladimir off's Versuche über die Beweglichkeit der Bacterien und Flagellaten ausschliesslich auf die Geisselfäden zu beziehen sind und mit osmotischen Vorgängen in der Bacterienzelle nichts zu thun haben. Wladimiroff's Grenzconcentrationen sind nicht Werthe für die Plasmolyse des Inhalts, wie der Autor vermuthet, sondern Werthe für die Geisselstarre in wasserentziehenden Salzlösungen. Lösungen von $\mathrm{KNO}_{3} 2,5 \%$, NaCl 1,25\% Rohrzucker $15 \%$ führten scharfe Plasmolyse von Typhusbacillen, Spirillum undula, Cholera und B. fluorescens herbei, liessen aber bald die Geisselwegung in voller Geschwindigkeit fortbestehen.

Die Bewegung der Geisseln bei den Flagellaten, der Cilien bei den Infusorien, der Wimpern an den Flimmerepithelien und die Geisselbewegung der Bacterien besteht noch fort, wenn der Zusammenhang z. B. durch Plasmolyse gestört ist. Im letzterem Fall wird der Zusammenhang zwischen Protoplast und Geissel aufgehoben. Das stimmt auch mit dem Befund Verworns, dass die Wimpern nach dem Zerdrücken der Infusorien weiter schlagen.

Dass ausser rein osmotischen Störungen noch weitere Momente hinzukommen, geht auch daraus hervor, dass in schlechten Nährlösungen 
gezüchtete unbewegliche Heubacillen die Geisselstarre sehr schnell verlieren, wenn ihnen ein besserer Nährstoff dargeboten wird. Es genügt hierfür schon $0,5 \%$ Asparagin. $\mathrm{F}$ is cher betrachtet deshalb die Geisseln nicht einfach als herausstreckbare und wieder einziehbare Protoplasmafäden. Die Substanz der Geisseln besitzt eigenes Leben, eigene Contractilität und Quellbarkeit, die durch gewisse Eingriffe gestört und durch tödtliche Eingriffe vernichtet werden können. Wohl hängen die Geisseln mit dem Protoplast, als dessen Theile sie zu betrachten sind, noch morphologisch, obgleich locker zusammen; das kleine Restchen, welches bei der Plasmolyse oft an der Geisselbasis hängen bleibt, ist sicher als ein Zeichen eines solchen morphologischen Zusammenhanges anzusehen.

\section{Morphologische Veränderungen der Bacterien in Salzlösungen verschiedener Concentration. Bekämpfung der Alexinlehre.}

Besitzt man in der Beweglichkeit von Bacterien ein Reagens um die Durchlässigkeit ihrer Geisseln für Salze, resp. Kationen, Anionen und Nicht-Elektrolyte zu studiren und somit die Lebenseigenschaften dieser niederen und für den Menschen so wichtigen Lebewesen näher zu erforschen, so bietet die mikroskopische Untersuchung der durch Salzlösungen herbeigeführten morphologischen Veränderungen ein weiteres Mittel hierfür.

Ausführliche Untersuchungen darüber verdanken wir dem Botaniker Alfred Fischer [9 u. 8]. Seine erste diesbezügliche Arbeit verfolgte fast ausschliesslich den Zweck, die Durchlässigkeitsgesetze der Bacterien zu untersuchen; eine spätere Arbeit war hauptsächlich darauf gerichtet die Lehre von der Alexinwirkung (Buchner) zu bekämpfen. Hiermit hatten bereits ron Baumgarten $[10,11]$ und dessen Schüler, insbesondere Jetter und Walz [12] begomen.

Buclner [13] selbst hatte gefunden, dass das gegen Wasser dialysirte Serum, welches keine Chlorreaction mehr gab, also salzfrei war, seine bactericiden Eigenschaften verloren hatte. Wurde dagegen, statt gegen Wasser, gegen $0,8 \%$ ige Kiochsalzlösung dialysirt, so dass also das Salz des Serums nur zu einem geringen Theil auswandern konnte, so blieb das Serum bactericid. Wurde das Serum mit entsprechenden Mengen destillirten Wassers verdünnt, so verlor es seine bactericide Wirkung, während eine Verdünnung mit 0,7\% NaCl-Lösung es nicht schwächte. Nach Buchner ist das Vorhandensein der Salze eine unerlässliche Bedingung für die normale Beschaffenheit der Albuminate 
des wirksamen Serums und die Albuminate sind die Träger der bactericiden Eigenschaften. Sie bilden ein proteolytisches Enzym.

Nach dieser Anschauung sind die Salze zwar unentbehrlich, aber sie sind doch nur sekundär an der Vernichtung der Bacterien betheiligt. Hiergegen gelang es Baumgarten's Schüler Jetter an eingeengtem Dialysat, das ganz vorwiegend aus Salzen bestand, bactericide Eigenschaften nachzuweisen. J a sogar eine reine $0,9 \%$ ige $\mathrm{NaCl}$ Lösung wirkte nicht selten bactericid.

Um diese Erscheinung zu erklären, führen $\mathrm{Baumgarten}$ und Jetter die Vernichtung von Bacterien auf einen Uebergang in einen fremden Nährbodenzurück, der für dieBedürfnisse des Bacteriums nicht chemisch abgestimmt ist; m. a. W. die Bacterien erhalten nicht genau das, was sie für ihre Assimilation brauchen (Assimilationstheorie). Später haben Baumgarten und Walz auch noch nachdrücklich auf eine andere Ursache für das Zugrundegehen in fremdem Nährboden hingewiesen, nämlich auf osmotische Störungen, welchen die Bacterien dabei anheimfallen würden.

Ich will hier nicht die ganze umfangreiche Controverse ïber die Frage vorführen, ob Alexine bestehen oder nicht, resp. bactericid wirken. Dazu besteht um so weniger Veranlassung, weil, wie aus den Ausführungen über die Hämolyse (vergl. unten S. 361) hervorgeht, von B a u mgarten vor Kurzem das Bestehen und die Giftwirkung ron Alexinen nach der heutigen Auffassung anerkannt hat. Ich sage "heutige" Auffassung, denn wie bereits Bd. 1 S. 398 erwähnt wurde, muss Buchner's Alexinlehre dahin ausgedehnt werden, dass nicht, wie man früher meinte, das Alexin allein im Stande ist, die Bacterien oder Blutkörperchen zu zerstören, sondern dass dazu noch die Mitwirkung eines „Sensibilisators" nothwendig ist.

Obgleich also der Streit zu Gunsten der Alexinlehre ausgefallen ist, so unterliegt es keinem Zweifel, dass ihre Bekämpfung durch ron Baumgarten und seine Schule der Wissenschaft viel Nutzen gebracht hat, denn einmal sind dadurch mehrere nene Thatsachen zu Tage gefördert worden, andererseits hat sich doch wohl mit Sicherheit ergeben, dass beim Uebergang der Bacterien in ein fremdes Medium, durch reränderte Nahrungsbedingungen, sowie anch durch osmotische Störungen. Abtödtung stattfinden kann.

Ueber die osmotischen Störungen habe ich zunächst hier einige Bemerkungen zu machen. 
Diese haben durch Alfred Fischer eine genauere Präcisirung erhalten [14]. Fischer unterscheidet zwei Gruppen von Bacterien, solche, die für Kochsalz sehr permeabel sind und solche, die nur eine geringe Iurchlässigkeit für das Salz zeigen. $\mathrm{Zu}$ den ersten gehören Bac. anthracis, Bac. subtilis, Bac. mesentericus, Bac. proteus. Sie werden durch starke NaCl-Lösungen nicht plasmolysirt. Zu der zweiten Gruppe gehören Vibrio cholerae, Bac. typhi, Bac. coli, Bac. pyocyaneus, fluoresc. liquefaciens, Micrococcus prodigiosus. Diese werden plasmolysirt, unterscheiden sich aber in ferneren Abstufungen dadurch, dass das Salz schneller oder langsamer, schliesslich doch noch aufgenommen wird. In Folge dessen verschwindet die Plasmolyse in der Salzlösung wieder, wie man das auch bei den Zellen höherer Pflanzen (de Tries, Janse, ron Rysselberghe etc.) sieht. Das Verschwinden der Plasmolyse hat darin seinen Grund, dass durch das allmähliche Eindringen von Salz der osmotische Druck des Zellinhalts zunimmt und folglich Wasser angezogen wird. Es ist nach Fischer nicht zu bezweifeln, dass dieselbe Bacterienart, je nach dem Alter der Cultur und der dargebotenen Nahrung und anderen einstweilen nicht zu erkennenden Gründen, das Salz bald schmeller, bald langsamer aufnimmt.

Besprechen wir nun, was mit den in hyperisotonischen $\mathrm{NaCl}$ Lösungen liegenden nicht-plasmolysirbaren Bakterien weiter geschieht und wählen als Beispiel Milzbrandbacillen!

Wir denken uns, dass sie aus Nährbouillon mit $0,8 \% \mathrm{NaCl}$ in eine 2\% ige $\mathrm{NaCl}-\mathrm{Lösung}$ gebracht werden. In Folge ihrer grossen Permeabilität für Kochsalz, geht $\mathrm{NaCl}$ in sie ïber und zwar so lange, bis die $\mathrm{NaCl}$-Concentration innerhalb der Bacterienzelle dieselbe ist, wie ausserhalb. In Folge dessen erhält die Bacterienzelle, da sie a uch andere Stoffe enthält, einen Ueberdruck; es findet eine Quellung statt und es kommt zum Austritt von Protoplasmakïgelchen, eine Erscheinung, die Fischer mit dem Namen Plasmoptyse bezeichnet hat.

Fischer cultivirte Choleravibrionen in salzarmem Nährboden: auf $100 \mathrm{cc}$ Wasser kamen $1 \mathrm{~g}$ Pepton (Albumose), $1 \mathrm{~g}$ Rohrzucker und 0,5 g Liebig's Fleischextract. Kochsalz wurde nicht besonders zugesetzt. Der osmotische Werth betrug nach Fischer also nicht mehr als 0,15 Procent $\mathrm{NaCl}$. Brachte er diese Vibrionen in das salzreichere und also hyperisotonische Rattenserum (Hängetropfen), so bildete sich an dem einen Ende eine kleine lichtbrechende Kugel, die bald grösser und dabei matter wurde.“ Wie kurze Stecknadeln mit recht dicken Köpfen sehen jetzt die Vibrionen aus."

Die Kugel ist nichts anderes als ein Theil des Protoplasmas, der in Folge des hohen, im Inneren herrschenden Druckes hervorgepresst, 
„ausgepieen“, wird. Daher der Name „Plasmoptyse“. Aber nicht nur im Rattenserum, auch in dem Serum vom Rind und Schwein findet die Plasmoptyse der Choleravibrionen statt.

Genau dieselben Erscheinungen wurden beobachtet, wenn die Bacterien erst in $0,75 \% \mathrm{NaCl}$ aufgeschwemmt und dann in eine $2-2,5 \%$ ige $\mathrm{NaCl-Lösung} \mathrm{eingeführt} \mathrm{wurden.} \mathrm{Innerhalb} \mathrm{der} \mathrm{ersten} \mathrm{Stunde} \mathrm{zeigte} \mathrm{sich}$ ein körniger Zerfall, "Plasmoptyse."

Die Versuche wurden mit folgenden Organismen angestellt. candicans.

1. Atriche (bewegungslose): Bacillus anthracis, Bacillus trunneus, Microcc.

2. Monotriche: Vibrio cholerae, Bacillus pyocyaneus.

3. Lophotriche: Bacillus fluorescens liquefaciens, Spirillum undula.

4. Pe ritriche: Bacillus proteus, Bacillus prodigiosus, Bacillus subtilis, Bacillus coli, Bacillus typhi.

Indessen ist der zeitliche Verlauf nicht bei allen Bacterien derselbe. Dies hängt hauptsächlich von der Permeabilität für $\mathrm{NaCl}$ ab.

Davon hängt es auch ab, ob die Bacterien in der $2 \%$ igen NaCl-Lösung Plasmolyse zeigen oder nicht. Ist, wie bei Choleravibrionen, Bac. typhi, Bac. coli, die Durchlässigkeit gering, so beobachtet man Plasmolyse. Dringt, wie bei Milzbrand, Bac. subtilis, Bac. proteus, das $\mathrm{NaCl}$ schnell ein, so wird die Plasmolyse vermisst.

Aber auch die Glieder je einer Gruppe verhalten sich nicht gleich, insbesondere hat das Alter der Cultur und besonders die dargebotene Nahrung Einfluss.

Es liegt auf der Hand, dass solch eine Plasmoptyse auch durch der Bacterienzelle gegenïber hypisotonische Lösungen wird stattfinden können. Durch genaue mikroskopische Untersuchungen in Hängetropfen hat Fischer festgestellt, dass die Abtödtung von Milzbrandbacillen im Serum in gleicher Weise geschieht und ebenfalls auf Plasmoptyse zurückzuführen ist. Dass auch durch Einwirkung von Wasser allein, Plasmoptyse auftreten muss, ist nach dem Gesagten selbstverständlich.

Wie steht es nun mitdenplasmolysirbaren Bacterien? Zunächst in hyperisotonischen Lösungen! Wie gesagt (S. 328), geht die durch hyperisotonische Lösungen verursachte Plasmolyse allmählich zurück. Dann kommt es sogar zu einem Ueberdruck, in Folge dessen Plasmoptyse eintritt. Selbstverständlich wird diese hier länger auf sich warten lassen als bei den Milzbrandbacillen, wo in Folge der grösseren Permeabilität für Salze diese rasch eindringen.

Hypisotonische Lösungen und Wasser rufen bei den plasmolysirbaren Bacterien direct Plasmoptyse hervor. 
Dieser Anschaung nach verfallen alle Bacterien, sowohl dieplasmolysirbaren, wie auch die nicht plasmolysirbaren Zellen, der Plasmoptyse, die ersteren nur später als die letzteren. Diese Plasmoptyse erfolgt sowohl durch hyper-wie durch hypisotonische Lösungen.

Die Plasmoptyse bedeutet nach A. Fischer den Tod der Bacterienzelle. Fischer hält schon den Ueberdruck als solchen, welcher der Plasmoptyse vorangeht, für gefährlich.

Die Plasmolyse als solche ist, wie $\mathrm{F}$ ischer in einer früheren Arbeit (Botan. Jahrb. 1895) nachdrücklich hervorgehoben hat, nicht geführlich, denn die plasmolysirten Bacterien bewegen sich so kräftig wie ganz normale; sie wird es aber, wenn ihr eine plötzliche Steigerung des Innendruckes folgt.

Diese Gefährdung des Protoplasmas, selbst bei schwacher Plasmolyse. beruht nach dem Autor darauf, dass es sich stellenweise von dem schützenden Widerlager der Zellwand loslöst und nun, sobald plötzlich der Innendruck steigt, unfellbar zerrissen werden muss, noch ehe es sich wieder an die Zellwand anlegen kann. So stirbt die Zelle ab, bei vollkommen intact bleibender Zellmembran. Es platzt nur der Protoplasmakörper. Das ist natïrlich bei den winzigen Bacterien nicht zu sehen.

Der Autor giebt zur Rechtfertigung dieser Behauptung einige Beispiele an Zellen höherer Pflanzen.

An den Epidermiszellen von Tradescantia discolor stellte de V ries fest, dass nach einstündiger schwacher Plasmolyse in $2 \%$ iger Kalisalpeter-Lösung (isotonisch mit etwa $1,1^{\circ} \%$ igem $\mathrm{NaCl}$ ) die Ueberführung in Wasser nicht vertragen wird. Alle Zellen sterben in Folge Platzens der contrahirten Protoplasmakörper innerhalb der Zellwände. Um dies zu vermeiden, mussten die Zellen aus $2 \%$ igem Salpeter erst 1 Stunde lang in $1 \%$ igen gelegt werden. Hatten aber die Zellen einen ganzen Tag in $2 \%$ igem Salpeter gelegen, so waren sie empfindlicher geworden. Sie vertrugen, trotz Einschaltung von $1 \%$ igem Salpeter die Ueberführung in Wasser nicht mehr.

Van Rysselberghe hat an demselben Object die Empfindlichkeit noch genauer bestimmt. Zellen, die 3 Tage in $2 \%$ igem Salpeter plasmolysirt worden waren, starben augenblicklich durch Platzen des Protoplasmas, als sie in 0,2, ja sogar als sie in $0,5 \%$ igem Salpeter eingelegt wurden. Hatten sie vorher in $1,6 \%$ igem Salpeter gelegen, so blieben sie beim 'Transport in $0,5 \%$ ige Lösung am Leben. Für Zuckerlösungen, die mit $2,2 \%$ iger Salpeterlösung isotonisch waren, and van Rysselberghe, dass die Zellen bei Uebergang in $1 / 3$ so starke Lösung starben, die also $0,7 \%$ igem Salpeter entsprach. His ergiebt sich hieraus, dass durch plötzliche Ueberführung in ${ }^{1 / 3}$ bis ${ }^{1 / 4}$ so dünne Lösungen, alle plasmolytisch contrahirten Protoplasmakörper, ohne sich vorher wieder ausgedehnt und der Zellwand angelegt zu haben, platzen. Das gilt für die kräftigeren Protoplaste der höheren Pflanzen, und die viel zarteren, unmessbar dünnen der Bacterien sind sicher noch 
empfindlicher. Eine Concentrationsdifferenz von $1 / 2$ oder $2 / 3$ wird sicherlich ausreichen, um das contrahirte Protoplasma zum Platzen zu bringen.

Die grosse Schädlichleit einer einmaligen Plasmolyse erkennt man auch aus Versuchen von Reinhardt [18] mit Keimptlanzen. „Alle Gewebe, die plasmolysirt waren, wuchsen nicht weiter, nachdem die Zellen wieder in normale Bedingungen gebracht waren."

Bedenkt man nach diesem Allem, wie der osmotische Druck der Bacterienzelle dem des Nährbodens folgt, sobald derjenige des letzteren wechselt, so liegt es auf der Hand, dass beim Uebergang in Serum, das gewöhnlich einen osmotischen Druck besitzen wird, der von dem der Bacterienzelle abweicht, osmotische Störung stattfinden wird.

Dieser Theorie Fischer's hat sich Fokker im Wesentlichen angeschlossen [15̃]. Derselbe hat eine grosse Zahl von Experimenten über die Einwirkung von Wasser auf Milzbrandbacillen angestellt. Ganz ähnlich wie man es nach Einführung von Milzbrandbacillen im Serum beobachtet, nämlich erst eine beträchtliche Abnahme, dann eine allmähliche Zunahme der Bacterienzahl, ganz so sieht man das nach der Einführung von Milzbrandbacillen in Wasser. Diese Erscheinungen, die Fokker auch beobachtete, als er Milzbrandbacillen dem Einfluss von $\mathrm{NaCl}-\mathrm{L}$ ösung von $2 \%$ und liöherer Concentration aussetzte, bilden gewiss keine Stütze für die Alexinlehre, die auch in Fokker immer einen entschiedenen Gegner gefunden hat [16]. Obgleich Fokker die von Fischer beschriebene Plasmoptyse nur in seltenen Fällen beobachten konnte (es wurde gewöhnlich nur ein Blasserwerden der Bacterien zu diffus contourirten unfärbbaren Schatten beobachtet), so besteht doch in sofern Uebereinstimmung, als auch Fokker annimmt, es entstehe durch Wasseraufnahme ein Ueberdruck, welcher einen Austritt von Plasma zur Folge hat.

Fokker geht nun weiter, und nimmt an, dass dieses Plasma in den entwickelungsunfähigen Schatten zurückkehrt und diesen wieder zu einem normalen Bacterium belebt.

Ein Analogon für eine derartige Regeneration findet man, worauf von Fokker nachträglich hingewiesen wurde, bei den rothen Blutkörperchen. A. Schwartz hat nämlich mitgetheilt [17], es sei ihm gelungen, Blutkörperchenscliatten mit dem ausgetretenen rothen Inhalte sich zu Erythrocyten regeneriren zu lassen.

Diese Plasmatheilchen hält Fokker für partielle Bionten, die zusammen den Bacterienleib bilden. Diese partiellen Bionten haben auch die Eigenschaft, chemische Umsetzungen herbeizuführen. Aus den 
Untersuchungen der letzten Jahre gehen derartige Wirkungen von Protoplasma genügend hervor. Auch findet die Ansicht Fokker's in soweit noch eine Stütze bei A. Fischer, als auch dieser es für möglich hält, dass die bei Plasmoptyse ausgetretene (Proto)plasmakugel, wenn ihr ein genügendes Nährmaterial zu Gebote steht, zu einem neuen Bacterium auswachsen kamn. Nach Fischer sollen sie dabei eine Membran bekommen.

\section{Die Hämolyse.}

In Band 1 S. 395 habe ich in aller Kürze über hämolytisches Serum gesprochen. Ich führte aus, dass nach Einverleibung des Blutes eines Thieres A bei einem Thiere B einer anderen Species, im Serum des letzteren ein Stoff entsteht, der für die Blutkörperchen von A giftig ist, d. h. Farbstoffaustritt (Hämolyse) bei denselben veranlasst. Bringt man Kaninchenblut in die Bauchhöhle eines Meerschweinchens und wiederholt diesen Versuch einige Male, entfernt etwas Blut aus der Carotis der Cavia und scheidet aus diesem Blut das Serum ab, so zeigt das letztere die Eigenschaft, die rothen Blutkörperchen eines beliebigen Kaninchens zu zerstören ${ }^{1}$ ). Es handelt sich hier um eine Erscheinung, ähnlich jener, die man beobachtet, wenn man statt Kaninchenblutkörperchen Choleravibrionen in die Bauchhöhle eines Meerschweinchens einverleibt. Auch dann entstehen Substanzen, die für Choleravibrionen giftig sind.

Tachdem dies festgestellt war, hat die Immunitätslehre ihre Aufmerksamkeit besonders auf die rothen Blutkörperchen gelenkt. Das kann nicht Wunder nehmen, denn sowohl durch Einbringung von fremden Blutkörperchen in den Thierkörper wie auch durch die Einverleibung von Vikroorganismen entstehen specifische Gifte, durch die der Körper sich gegen den fremden Eindringling zu vertheidigen sucht. Es lag nun nahe, für eine gründliche Erforschung des Kampfmechanismus die Blutkörperchen heran zu ziehen. Der Vorzug, den gerade diese Zellen bieten, ist in der That nicht gering. Es giebt vielleicht keine Zelle, die so scharf und sinnfällig auf geringfügige Veränderungen der U'mgebung und auf leichte Schädigungen reagirt wie die rothen Blutzellen. Ausserdem ist das Blutserum, das bei der Giftwirkung der Bacterien und bei der Entgiftung, als Vehikel fungirt, zugleich auch das natürliche Medium der Blutkörperchen.

1) von Baumgarten hat gefunden, dass das Meerschweinchenserum diese Eigenschaft oft bereits ohne die Einspritzung in geringem Maasse besitzt, aber durch dio Einspritungen sah er dieselbe immer kräftig angeregt. 
Auf diese Heranziehung der Blutkörperchen für das Studium der Immunität haben zweifellos die neueren osmotischen Untersuchungen über das Blut, namentlich die dabei gefundenen feinen Gesetzmässigkeiten beim Farbstoffaustritt, in nicht geringem Grade anregend gewirkt.

Es wäre ein Zeugniss von Einseitigkeit, wollte man behaupten, dass hierbei der Vortheil bloss auf der Seite der Bacteriologie lag. Die betreffenden Untersuchungen, die sich die Erforschung des Wesens der Immunität zum Ziel setzten, werden nicht verfehlen, das Verhalten des Zellprotoplasmas bei der Hämolyse zu beleuchten und damit auch ihrerseits dazu beitragen, den Mechanismus des Farbstoffaustrittes weiter aufzuklären.

Wie sich die gegenwärtigen Ansichten darüber gestalten, bespreche ich alsbald näher.

Zuvor gebe ich aber eine Uebersicht der verschiedenen hämolytischen Substanzen, die Ehrlich ganz allgemein mit dem Namen „Ḧ̈molysine"6 bezeichnet hat, weil sie Blutfarbstoft aus den Blutkörperchen herauslösen.

\section{a) Eintheilung der Hämolysine.}

Zunächst kann man sie in zwei grosse Gruppen (A und B) eintheilen.

A enthält eine Reihe scharf definirter chemischer Substanzen, z. B. Aether, Chloroform, Solanin, Saponin.

Sobald nur eine geringe Venge von diesen in einer dem Serum isosmotischen Salzlösung oder sogar in Serum selbst gelöst ist, verlieren die rothen Blutscheiben ihren Farbstoff. Saponinsubstanzen sind vielleicht am giftigsten. Schon Verdünnungen von 1:100000 oder noch stärkere bewirken das schnelle Lackfarbigwerden des Blutes.

Kobert [19] hat hervorgehoben, dass gerade diese chemisch gut bekannten Gifte, speciell auch die Alkaloide und Glykoside, nichtim Stande sind, die Bildung von Antitoxin im Organismus anzuregen.

Für Saponin trifft diese Regel aber scheinbar nicht zu, denn man kamn ein antitoxisches Serum für die Giitwirkung des Saponins bereiten. Durch die Intersuchungen Ransom's [21] hat sich aber herausgestellt, dass hier ein besonderer Sachverhalt vorliegt.

Ransom hat es nämlich wahrscheinlich gemacht, dass die Auflösung des Blutes durch Saponin durch den Cholesteringehalt der rothen 
Blutkörperchen vermittelt wird, indem das Cholesterin das Saponin in sich aufnimmt und auf diese Weise das Stroma der Giftwirkung aussetzt. Es stellt sich nun weiter heraus, dass das antitoxische Serum viel Cholesterin enthält. Man könnte also geneigt sein das Saponin als Gift und das Cholesterin als Gegengift zu betrachten. Doch liegt die Sache hier anders und es handelt sich rielmehr um das Theilungsprincip. Je mehr Cholesterin im Serum vorhanden ist, um so mehr wird sich das giftige Saponin im Serum und um so weniger in den Blutkörperchen anhäufen.

Die zweite Gruppe B ist die der Toxine.

Es sind das labile Substanzen complicirter Structur. Sie haben die Eigenschaft, nach Einführung in den Organismus die Auslösung ron Antikörpern zu veranlassen, was, wie gesagt. bei den Hämolysinen der ersten Gruppe nicht der Fall ist.

Diese Hämolysine können wieder eingetheilt werden

I in Hämolysine von höherem pflanzlichem Ursprung.

II $" \quad " \quad$ " thierischem Ursprung.

Zu I gehören: a) die Phytalbumosen (so z. B. Ricin, Abrin),

b) die Bacteriohämolysine (so z. B. Stofi'wechelproducte von Staphylococcus).

Zu II gehören: a) die Hämolysine bei niederen Thieren und in Drüsensecreten (so z. B. Schlangengift, Bienengift).

b) die Hämolysine des Blutserums (so z. B. das normale Aalserum für die rothen Blutkörperchen der Säugethiere).

Ich werde bei den Gruppen Ia und I b und II a nur je einige Augenblicke verweilen, um dann II b ausführlicher zu besprechen.

\section{ad I a. Phytalbumosen.}

Diese in höheren Pflanzen vorkommenden Stoffe scheinen zum Theil allerdings nicht hämolytisch, sonàern agglutinirend zu wirken (Kobert und dessen Schüler Stillmark [22], Hellin [23], Kobert [24]).

Bekanntlich besteht letztere Wirkung darin, dass die Blutkörperchen in ähnlicher Weise zu Haufen zusammenkleben, wie das besonders von Gruber, Durham und $\mathrm{W}$ id al bei Bacterien studirt wurde.

Vom praktischen, besonders vom theoretischen Gesichtspunkt ist es sehr wichtig, dass Ehrlich, nachden es ihm gelungen war, Mäuse gegen Ricin zu immunisiren [25], festgestellt hat, dass zwischen der Menge Antiricin, welche man 
braucht, um im Reagensglas das Ricin zu neutralisiren, und der Ricinmenge selbst, ein strenges zahlenmässiges Verhältnis besteht. Die Bindung von Toxin und Antitoxin ist hiernach als eine nach den Gesetzen der Chemie vor sich gehende anzu sehen [26] (Rochat).

Gleichartige Resultate erzielte Ehrlich [27] mit dem von Jequirity stam. menden Abrin. Die agglutinirende Wirkung desselben wurde wieder von Kobert und dessen Schüler $\mathrm{Hellin}$ entdeckt und $\mathrm{Hausmann}$ isolirte es in reinem Zustand aus dem käuflichen Präparat [28], was andererseits Jacoby mit Ricin bereits gelungen war [29].

Das Robin, Crotin und $\mathrm{Pl}$ allin gehören zu den Blutkörperchen agglutinirenden Substanzen. Auch diese geben nach Einverleibung in den Thierkörper Veranlassung zu der Bildung von Antikörpern, die anderen Thieren einverleibt, diese gegen grosse Dosen der genannten Gifte immunisiren.

Wenn auch bei diesen Pliytalbumosen in den meisten Fällen die Agglutination in den Vordergrund tritt und eine hämolytische Wirkung nicht selten vermisst wird, so ist es nach den Untersuchungen von Elırlich und von Baumgarten (siehe unten) doch sehr wahrscheinlich, dass beide Wirkungen durch denselben Stoff herbeigeführt werden. Die Hämolyse kommt zuweilen nur deshalb nicht zu Stande, weil in den agglutinirten Haufen die Bedingungen für eine Diffusion des Blutfarbstoffes ungünstig sind. In der That kann man sich gewöhnlich erst durch starkes Schütteln vom Austritt des Hämoglobins überzeugen.

\section{ad. I b. Bacteriohämolysine.}

Eine zweite Classe nach Art der Toxine wirkender Blutgifte bestelit aus Stoffwechselproducten der Bacterien. Vandevelde mag wohl der erste gewesen sein, der in keimfreien Bacterienfiltraten ein die Blutzellen zerstörendes Gift nachwies. Es waren Filtrate von Staphylococeus. Später haben Neisser und Wechsberg in einer ausfühılichen Arbeit das hämolytische Vermögen von Staphylococcenfiltraten systematisch untersucht [31] und dabei festgestellt, dass das entsprechende Hämolysin (Staphylolysin) ein constantes Merkmal des typischen Staphylococcus pyogenes aureus und albus darstellt. Die Staphylolysinproduction beginnt in der schwach alkalischen Bouilloncultur am 4. Tage und erreicht zwischen dem 9. und 14. Tage den Höhepunkt.

Es gelang beiden Autoren ein künstliches Antistaphylolysin durch Einspritzung kleiner Dosen der Cultur bei Kaninchen zu erhalten. Dieses Antistaphylolysin schützte Kaninchenblutkörperchen gegen die Auflösung durch Staphylolysin, nicht aber gegen die Auflösung durch ein anderes von Madsen eingehend studirtes Hämolysin, nämlich Tetanolysin [32]. Hierin liegt ein Beweis für die Verschiedenheit der Hämolysine. Früler hatte Ehrlich auch gesehen. dass das Antiricin die Stelle des Antiabrin nicht vertreten konnte.

Von verschiedenen anderen Bacterien sind Hämolysine bekannt geworden. Die Frage liegt nahe, ob diese in vitro so deutlich wirkenden Bacteriohämolysine auch im Organismus eine Rolle spielen. In der That ergab sich, besonders aus den Untersuchungen von Kraus und Ludwig [33], dass Bacteriohämolysine nicht nur in vitro, sondern auch in vivo Blutkörperchen zu schädigen im Stande sind. Dabei wirkte das Immunserum (Antistaphylolysin) ebenso specifisch auf das Staphylolysin im Organismus, wie in vitro. 
In guter Uebereinstimmung damit steht der Befund Todd's [34], wonach die Hämoglobinurie, die bei Meerschweinchen durch intravenöse Injection des Hämolysins von B. megatherium verursacht wird, bei gleichzeitiger Injection von Hämolysin und Immunserum ausbleibt. Diese Thatsachen legen den Gedanken nahe, dass die im Gefolge zahlreicher Infectionskrankleiten auftretenden anämischen Zustände, mit der blutkörperchenzerstörenden Wirkung der entsprechenden Bacteriohämolysine in causalem Zusammenhang stehen.

\section{ad II a. Hämolysine bei niederen Thieren und in Inrisensecreten.}

Das meist bekannte und auch am eingehendsten studirte Beispiel bildet das Schlangengift, das schon von Weir Mitchell und Relchert, Kanthack, Martin, Calmette, Physalix und Bertrand und Fraser untersucht wurde, dessen hämolytisches Vermögen in vitro aber zuerst von Stephens und Myers beobachtet wurde [35]. Diese Antoren constatirten zugleich, dass Gemische von Schlangen(Cobra)gift und Antitoxinserum, die nicht mehr im Stande waren, Blutkörperchen in vitro zu zerstören, sich auch im Thierversuch nicht mehr als giftig erwiesen. Auch hier handelt es sich demnach wiederum um eine Bindung von Toxin und Antitoxin.

Ausser Schlangengift kennt man Bienengift [36], Spinnengift [37]. Auch diese Gifte entfalten hämolytische Wirkung, wie es Pugliese für das Krötengift (Archives de Pharmacodyn. et de Thérapie, citirt nach H. Sachs), H. Sachs [38] für die Spinnen, speciell für die Kreuzspinne, nachwies und geben zur Bildung von Antihämolysinen Veranlassung.

\section{ad If b. Hämolysine des Blutserums.}

Dass die Sera vieler Thiere im Stande sind die rothen Blutkörperchen fremder Thierspecies aufzulösen, wissen wir seit Landois [39], dessen Untersuchungen später durch Darem berg [40] eine bedeutende Erweiterung erfuhren. Dieser stellte fest, dass die genannte globulicide Fähigkeit durch Erhitzen des Serums auf $50-60^{\circ}$ verloren geht, wie dies schon kurz zuvor von $H$. Buchner für die bactericide Kraft des Serums beschrieben war [41] und bald auch für die globulicide Wirkung bestätigt wurde. Ein frappantes Beispiel ist das Aalserum. Nachdem A. Mosso seine ausserordentliche Giftigkeit im Allgemeinen entdeckt hatte [42] wurde von Camus und Gley [43] und von Kossel [ $[4]$ die von ihuen zuerst beobachtete grosse hämolytische Kraft des Serums als die Hauptursache dieser Giftigkeit nachgewiesen.

Jetzt zweifelt wohl Niemand inehr daran, dass der ungünstige Erfolg von Transfusionen des Blutes anderer Thierspecies gewöhnlich der hämolytischen Wirkung des Serums auf die fremden Blutkörperchen zu zuschreiben ist, obgleich diese Wirkung in vitro gewöhnlich nicht so auffällig ist. Sie wird dies aber, wenn man den Versuch ron Belfante und Carbone ausführt. 
Nehmen wir ein Beispiel: Meerschweinchenserum ist nur wenig hämolytisch für Kaninchenblutkörperchen. Spritzt man jedoch einige Male ein wenig Kaninchenblut einem Meerschweinchen ein, so besitzt dessen Blutserum nach dieser Behandlung ein agglutinirendes und stark hämolytisches Vermögen gegenüber Kaninchenerythrocyten.

Dieser Versuch hat das Studium der Hämolyse in bedeutendem Maasse angeregt und deren Kenntniss vertieft.

Wie aber kaum anders bei einem so schwierigen Problem zu erwarten war, stimmen die Ansichten über den Mechanismus der Hämolyse nicht überein. Wir haben deren drei zu verzeichnen, die vor Bordet, von Ehrlich (und Morgenroth) und von von Baumgarten.

Ich bespreche dieselben in der entsprechenden Reihenfolge.

\section{b) Anschaungen iiber die Entstehung von Haimolysin durch Einver- leibung fremden Blutes und iiber den Mechanismus der Iämolyse. \\ ' $\alpha$ ) Die Theorie von Bordet.}

Im Wesentlichen habe ich diese bereits im ersten Bande mitgetheilt. Ich erwähne hier nur noch Folgendes und gehe dabei von dem obenerwähnten Meerschweinchenversuch aus.

Bordet stellt sich vor, dass beim Einspritzen des Kaninchenblutes in die Bauchhöhle des Meerschweinchens, sich im Serum des letzteren eine Substanz bildet, die er Sensibilisator nennt. Versetzt man nun das betreffende Serum mit frischem Kaninchenblut, so setzt sich der Sensibilisator auf die Kaninchenblutkörperchen fest. Dadurch sind sie für das immer im Serum vorhandene Alexin empfindlicher geworden. Dieses Alexin ist es, das die Hämolyse herbeiführt; der Sensibilisator an sich besitzt kein hämolytisches Vermögen.

Dass hier in der That zwei Stoffe zusammenwirken, geht aus folgendem Versuch hervor. Erhitzt man das Serum der vorbehandelten Cavia auf $55^{0}$, so verliert es das Vermögen, die durch Auswaschen mittelst NaCl-Iösung von Serum befreiten Kaninchenblutkörperchen zu zerstören. Das rührt daher, dass die Alexine bei dieser Temperatur zersetzt werden. Der Sensibilisator wird hiergegen bei dieser Temperatur nicht vernichtet, und erträgt viel höhere Temperaturen. Dass dieser Sensibilisator in der That noch wirksam geblieben ist, geht daraus hervor, dass man nach Zusatz von etwas frischem Kaninchenserum zu dem Gemisch des genannten bei $55^{\circ}$ erhitzten Caviaserum und ausgewaschenen Kaninchenblutkörperchen, sofort eine kräftige Hämolyse 
stattfindet. Fügt man aber statt frisches Kaninchenserum, das immer Alexin enthält, solches hinzu, das zur Zersetzung der Alexine auf $55^{\circ}$ erhitzt war, so bleibt die Hämolyse aus.

Bordet ist der Meinung, dass die Alexinwirkung nicht in einer chemischen Verbindung mit dem Blutkörperchenprotoplasma begründet ist, sondern dass es sich hier um ein plysikalisches Festhalten handelt, wie man es in der Färberei kennt.

\section{ß) Die Theorie von Ehrlich.}

Die Anschauung Ehrlich's gründet sich auf seine ursprünglich für die Erklärung der Antitoxinbildung aufgestellte Seitenkettentheorie, die ich hier erst in ihren Hauptzügen besprechen will.

\section{Die Seitenkettentheorie.}

Nach Elırlich besteht das Protoplasma aus dem Leistungskern und zahlreichen mit ihm rerbundenen Seitenketten. Der Leistungskern ist das eigentlich vitale Centrum, und seine Integrität Bedingung des normalen Zellenlebens. Die Seitenketten dagegen dienen den einzelnen Functionen, besonders der Ernährung der Zelie.

Die Ernährung wird dadurch ermöglicht, dass die Seitenketten Atomcomplexe darstellen, die durch ihre chemische Configuration befähigt sind, sich mit dem Nährstoff chemisch zu verbinden.

Dementsprechend müssen die Nahrungsstoffe auch ihrerseits Atomgruppen enthalten, um sich mit den entsprechenden Seitenketten verankern zu können. Solche an den Nahrungsstoffen vorkommende Atomgruppen hat Ehrlich "haptophore Gruppen" genannt.

Ehrlich stellt sich nun vor, ebenso wie sich Nahrungsstoffe an die Seitenkette anheften können, könne dies auch den Toxinen möglich sein. Dann müssen aber auch diese derartige haptophore Gruppen besitzen. Die chemische Verwandtschaft der Seitenketten zu den haptophoren Gruppen des Giftmolecüls ist eine zufällige und hat eben nur darin ihren Grund, dass durch ein für den Organismus verhängnissvolles Spiel des Zufalls die haptophoren Gruppen gewisser Toxine mit den haptophoren Gruppen der Nährstoffe identisch sind. Andererseits kann man auch sagen, dass Toxine nur dann eine Giftbindung (und Giftwirkung) werden zeigen können, wemn an den Körperzellen entsprechende Seitenketten vorhanden sind. Die Anwesenheit von geeigneten Seitenketten ist also die Vorbedingung für die Giftbindung und bedingt somit die Empfänglichkeit (Receptibilität) 
des Organismus. Die Seitenketten werden daher von Ehrlich auch als Receptoren bezeichnet.

Durch die partielle Inbeschlagnahme der Receptoren durch Toxine, ist die Gelegenheit, Nährstoffe aufzunehmen, herabgesetzt. Darauf antwortet aber der Leitungskern mit einer Neubildung von Receptoren und zwar mit einer Uebercompensation. Weigert hat ganz allgemein hervorgehoben, dass bei Schädigung von Gewebselementen immer eine übermässige Regeneration stattfindet [45]].

Auch in der Physiologie handelt es sich, wie mir scheint, zuweilen um derartige Uebercompensationen, so z. B. bei der Athmung während der Muskelarbeit. Das Blut ist dann, wie Geppert und Z untz fanden, trotz des grösseren $\mathrm{O}-\mathrm{V}$ er b rau clı es nicht ärmer, sondern sogar reicher an Sauerstoff.

So ist auch, wie ich selbst fand, unter normalen Umständen, das Blutplasma am Ende des Capillarsystems reicher an Nährstoffen als am Anfang, obgleich es doch aut seinem Weg den Geweben Nährstoffe abgegeben hat (vergl. B. 1 S. 278).

Nach Ehrlich werden nun, in Folge der Ueberproduction, soviel neue Receptoren gebildetwerden können, dass sie am Kern nicht mehr PJatz finden und in die Blutbahn abgestossen werden. Diese in der Blutbahn sich befindlichen Seitenketten oder Receptoren sind die Antitoxine; ebenso wie die an der Zelle sitzenden Receptoren sind die frei in der Blutbalm sich bewegenden befähigt, die Toxine chemisch zu verankern und dieselben darlurch vom Protoplasma abzulenken.

Später [45] lat Ehrlich sich auf Grund ausführlicher Untersuchungen veranlasst gesehen, im Toxinmolecül ausser der haptophoren Gruppe noch eine specifische. die Giftwirkung bedingende, toxophore Gruppe anzunehmen.

\section{Die Anwendung der Seitenkettentheorie anf die Erklärumg der Hämolysinwirkung.}

Ehrlich und Morgenroth haben nun versucht, Bildung und Wirkung des Serumhïmolysins vom Standpunkt der Seitenkettentheorie zu beleuchten [47,48, 49].

Ehrlich denkt sich den Vorgang in folgender Weise:

Injicirt man bei einem Meerschweinchen rothe Blutkörperchen eines Kaninchens, so werden diese theilweise zerstört und es werden dabei Atomcomplexe frei, welche mit bestimmten Seitenketten des Zell- 
protoplasmas des Meerschweinchens in Verbindung treten ${ }^{1}$ ), wie durch folgende Figur versinnlicht wird.

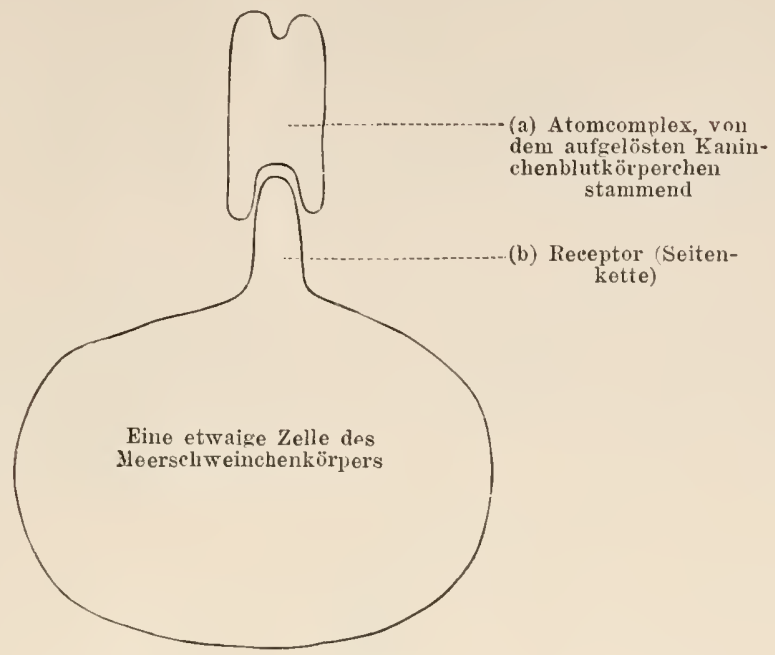

Fig. 4.

Werden viele Receptoren (Seitenketten) auf diese Weise besetzt, und deren Stelle also den Nahrungsmoleciilen vorenthalten, so bilden sich neue Receptoren (b) und zwar nach dem Weigert'schen Princip in Uebermass (ebenso wie das der Fall ist, wenn Toxinmoleküle die Receptoren besetzen [vergl. oben S. 346]) und ein Theil dieser Receptoren (b) gelangt in freiem Zustande in die Blutbahn. Es liegt nun nichts Gezwungenes darin, anzunehmen, dass diese freigewordenen Receptoren, die gerade von den lianinchenblutkörperchen ausgewählt waren, weil sie darauf passten, zu lianinchenblut gebracht, sich an die Blutkörperchen heften werden.

Was nun geschieht versinnlicht die folgende Figur 5, in welcher ersichtlich ist, dass sich der Receptor (b) von der Meerschweinchenzelle abgelöst (horizontaler Strich) und sich an den Receptor a des Kaninchenblutkörperchens befestigt hat.

1) Ehrlich hat für die meisten diesbezüglichen Versuche Hammelblut bei Ziegen eingespritzt, statt Kaninchenblut bei Meerschweinchen. Um den Gedankengang nicht zu stören, denken wir uns bei den Auseinandersetzungen die Experimente mit Kaninchenblut und Meerschweinchen angestellt. 
Dieser Receptor allein ist jedoch nicht im Stande das Kaninchenblutkörperchen zu zerstören. Dazu ist die Mitwirkung des Alexins, oder,

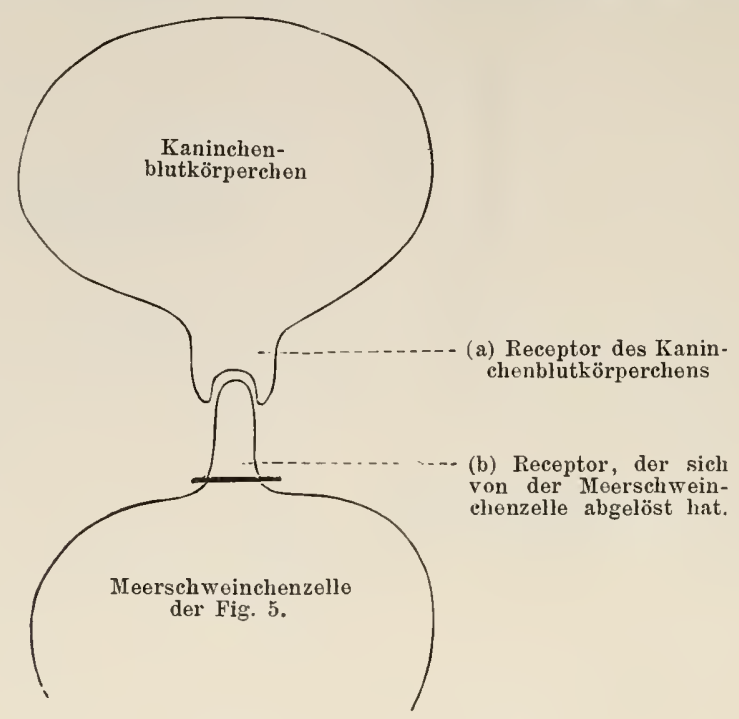

Fig. 5 .

wie Ehrlich es nennt, eines Complementes nöthig. Dasselbe ist bereits im Serum der unvorbereiteten Cavia vorhanden. Demnach wird die Configuration.

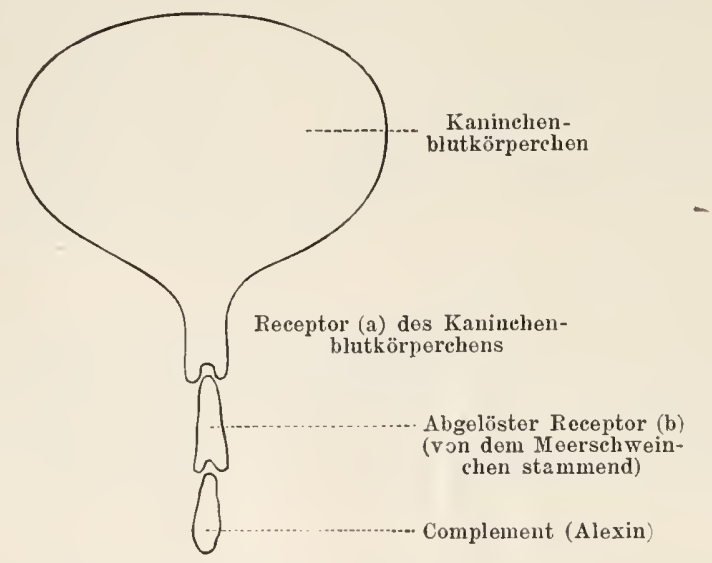

Fig. 6 .

Nach dieser Vorstellung passt das Complement nicht direct (Alexin) an das Blutkörperchen, sondern nur durch Vermittlung des Receptors (b). 
Dementsprechend kann das Alexin keine Giftwirkung auf das Blutkörperchen ausiiben, wenn nicht der Receptor dabei wirksam ist.

Receptor + Complement werden mit dem gemeinschaftlichen Namen Hämolysin bezeichnet oder, weil es aus zwei Componenten besteht, auch wohl complexes Hämolysingenannt.

Das ist die Grundlage der Anschauung über die Hämolyse, die Ehrlich und seine Schüler durch zahlreiche Versuche begründet haben.

Die jetzt folgende Figur 7 versinnlicht noch einige Einzelheiten, auf die ich noch die Aufmerksamkeit zu lenken habe. Sie bildet eine etwas detaillirte Fig. 6, ist aber, um derselben den Stand zu geben, in dem man sie gewöhnlich abgebildet sieht, mit dem unteren Theil nach oben gekehrt.

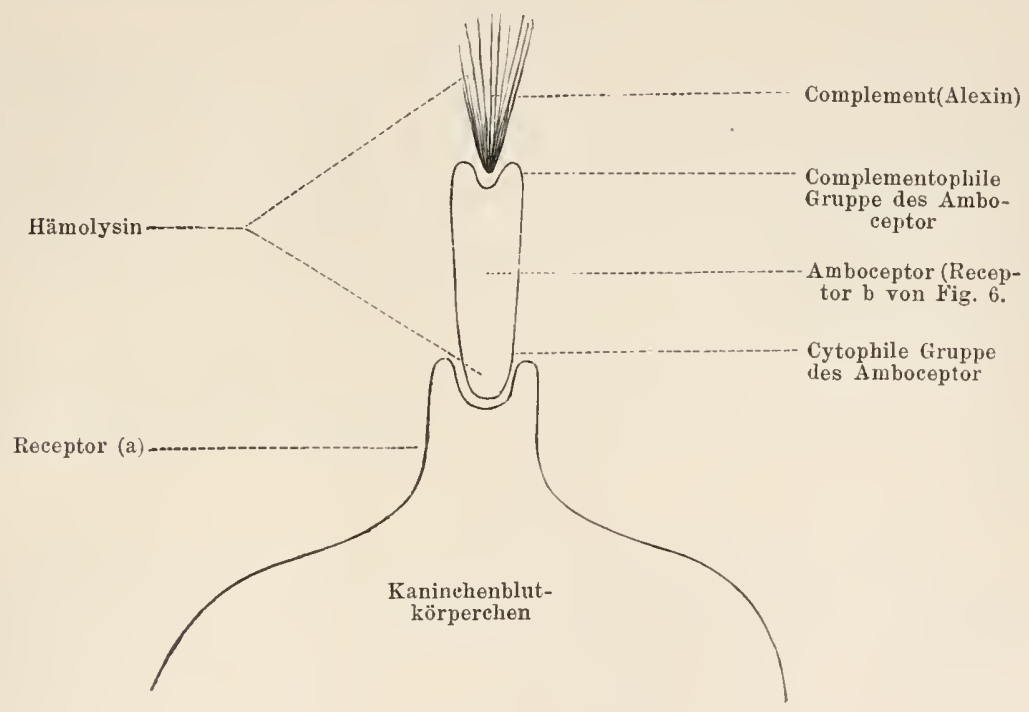

Fig. 7.

Zunächst sieht man in dieser Figur den Namen Amboceptor erscheinen. Mit diesem Namen haben Ehrlich und Morgenroth den Receptor (b) bezeichnet, weil derselbe $\mathrm{z}$ w e i Atomgruppen enthalten muss, eine, mittelst welcher derselbe am Blutkörperchen gebunden ist, (cytophile Gruppe) und eine andere, mittelst welcher er das Complement festhält (complementophile Gruppe). 
Während also nach Bordet das Hämolysin aus (thermostabilem) Sensibilisator und (thermolabilem) Alexin besteht, sind nach Ehrlich und II orgenroth der (thermostabile) Amboceptor und das (thermolabile) Complement die Theile des complexen Hämolysins.

Ein Paar grundlegende Versuche für die complexe Natur der Hämolysinen dürften dem Leser willkommen sein.

1. Der Beweis, dass der im injicirten Thiere (Meerschweinchen) freigewordene Amboceptor (Sensibilisator. Receptor (b)) von den mit ihm versetzten Blutkörperchen des Kaninchens gebunden wird.

Ehrlich und Morgenroth versetzten Hammelblutkörperchen mit dem bei $55^{\circ}$ erhitzten Serum der vorbereiteten Ziege. Durch diese Erhitzung war das Alexin zerstört, der Sensibilisator aber nicht. Die Hammelblutkörperchen wurden nicht gelöst. Nachdem das Gemisch $1 / 2$ Stunde bei $37^{\circ}$ sich selbst überlassen war, wurden Blutkörperchen und Zwischenflüssigkeit durch Centrifugiren von einander getrennt und Sediment und Abguss für sich untersucht.

Fügte man zu dem Blutkörperchensediment normales, also alexinhaltiges Ziegenserum, so lösten sich die Blutkörperchen. Die Hammelblutkörperchen mussten also aus dem inactiven Immunserum die thermostabile Substanz in sich aufgenommen, sie gebunden haben, gauz wie es der gehegten Erwartung entsprach.

Der Abguss dagegen war ganz frei von der Substance sensibilitrice, d. h. er entlielt keine freien Receptoren mehr. Denn wenn man zu diesem Serum normale Hammelblutkörperchen und normales Ziegenserum, also Alexin, hinzusetzte, so fand keine Hämolyse statt.

2. Es wurde der Beweis erbracht, dass das Complement (Alexin) im Gegensatz zu dem Amboceptor (Sensibilisator) nicht von den rothen Blutkörperchen gebunden wird, sondern dass dies erst geschieht, wenn der Sensibilisator einmal verankert ist.

Khrlich und Morgenroth kühlten Serum einer mit Hammelblut vorbehandelten Ziege auf $0^{0}$ bis $3^{0}$ ab. Die Flüssigkeit enthielt also das complexe Hämolysin, d. h. Sensibilisator und Alexin, Fügte man Hammelblutkörperchen hinzu, so erfolgte keine Hämolyse. Bei dieser niedrigen Temperatur nehmen die Hammelblutkörperchen lediglich den Sensibilisator aus dem Ziegenserum heraus; aber die Bindung von Sensibilisator und Alexin bleibt aus. Natürlich beruht diese Erscheinung auf einer differenten Affinität zwischen Sensibilisator und Alexin andererseits. Diese Differenz liegt zuweilen in umgekehrter Richtung; auch können sie sich be. einflussen (Ehrlich und Sachs [50]).

Es kann jetzt als feststehend betrachtet werden, dass die Hämolysine aus zwei Componenten bestehen und also complexer Natur sind. Buchner und Gruber meinten, dass anch Ausnahmen vorkämen. Doch wurde dies für die von ihnen angegebenen Fälle von H. Sachs endguiltig widerlegt [5 1$]$. 
Mit dem Fortschritt der Untersuchungen ergaben sich jedoch Complicationen, so dass Ehrlich und Morgenroth die Hypothese an verschiedenen Punkten ausbauen mussten. So z. B. erschien es erwünscht, sich an dem Amboceptor noch eine Gruppe zu denken, an die ein Nährmolecïl sich heften kann, was sich durch Fig. 8 schematisiren lässt.

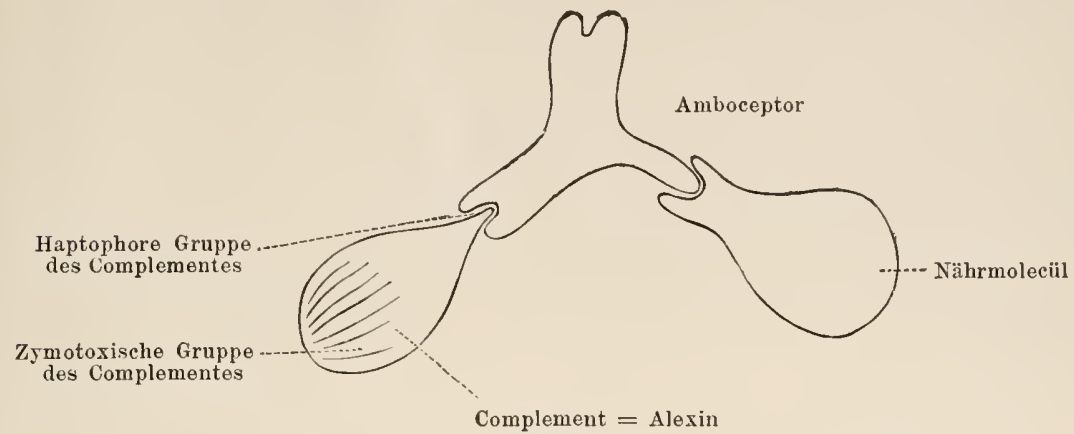

Fig. 8.

Aus dieser Figur sieht man auch, dass am Complement zwei Gruppen zu unterscheiden sind: eine haptophore, mittelst welcher sich das Complement an den Amboceptor haftet, und eine zymotoxische Gruppe, welche die giftige Eigenschaft des Hämolysins repräsentirt.

Es sinả nicht selten, um denselben Begriff anzudeuten, verschiedene Namen vorgeschlagen worden, die das Studium für den Nichteingeweihten nicht wenig erschweren.

Ich gebe deshalb unten ein Verzeichniss der Synonima für die beiden Hämolysincomponenten.

\section{Synonima.}

Thermostabile Substanz.

Subst. sensibilatrice (Bordet).

Immunkörper (Pfeiffer, Ehrlich und Morgenroth).

Zwischenkörper (ỉhlich und

Morgenroth).

Amboceptor.

Receptor III. Ordnung (Ehrlich und Morgenroth).
Thermolabile Substanz.

Alexin (Buchner, Bordet).

Addiment (Ehrlich und Morgenroth).

Complement (Ehrlich und Morgenroth).

Cytase (Metchnik off).

Haptin III. Ordnung (für den freien Amboceptor).

Fixateur (Metchnik off).

Copula (P. M ïller).

Desmon (London).

Präparator (Gruber). 
Was nun den Entstehungsort der Amboceptoren betrifft, so wissen wir aus den Untersuchungen von $\mathrm{Pfeiffer}$ und $\mathrm{Marx}$ über das Choleraserum [52] und aus denjenigen von Wassermann [53] und Deutsch [54] über das Typhusserum, dass die betreffenden bacteriolytischen Amboceptoren im wesentlichen in Knochenmark, Milz und Lymphdrüsen gebildet werden. Ueber die Bildungstätten der hämolytischen Amboceptoren sind wir roch im Unklaren. Wahrscheinlich muss der Bildungsort in den blutbereitenden Organen gesucht werden.

Besser sind wir über den Bestandtheil der injicirten rothen Blutkörperchen unterrichtet, durch den die Bildung von Amboceptoren ausgelöst wird. Aus den Untersuchungen von $\mathrm{B}$ ordet und $\mathrm{Nolf}$ weiss man, dass dies die Stromata sind. Denn die vom Hämoglobin befreiten Stromata sind ebenso, wie die intacten rothen Blutkörperchen, befähigt, die Bildung hämolytischer A mboceptoren zu veranlassen.

Dass hier die Stromata dasselbe thun, wie die rothen Blutkörperchen, stimmt mit den Anschauungen Ehrlich's überein, dass alle, Hämolyse bedingenden Gifte direct auf das Stroma abtödtend einwirken und es so für den Blutfarbstoff durchlässig machen.

Die Herkunft der Alexine glaubt Metchnik off durch Zerfall der Makrophagen erklären zu müssen. Buchner glaubt, dass sie als Secretionsproducte der lebenden Leukocyten aufzufassen sind. Wass ermann nimint an, dass auch andere Körperzellen Ursprungstellen von Alexinen darstellen [55].

Es ist anffallend, dass das bei Injection mit Blutkörperchen neugebildete Product der Hämolysinreaction lediglich der A mboceptor ist. Von Dungern hat quantitativ gezeigt, dass das Complement (Alexin) keine Vermelırung erfährt [56].

3. Immunisirung gegen die Hämolysinwirknng. Das Entstehen von Antikörpern (Antihämolysine, Antiamboceptor, Anticomplement).

Wenn man einem mit Kaninchenblut wiederholte Male injicirten Meerscheinchen Blut entzieht, so ist, wie bereits vielmals hervorgehoben wurde, das Meerschweinchenserum im Stande Kaninchenblutkörperchen zu zerstören. Bringt man das Serum in die Blutbahn des Kaninchens, so sieht man das Thier in kurzer Zeit verenden. Jedoch kann man das Thier gegen die Giftwirkung widerstandsfähig machen, wenn man wiederholte Nale langsam steigende Dosen des Meerschweinchenserums einverleibt. Das Thier ist dann gegen grosse Dosen des activirten Meerschweinchenserum immun geworden. Es hat sich ein Antilämolysin gebildet. Camus 
und Gley, sowie Kossel, sind die ersten gewesen, die Thiere gegen das giftige Blutserum immunisirten. Bei ihnen handelte es sich um Aalserum $[57,58]$.

Da, wie wir sahen, das Hämolysin complexer Natur ist, so fragt es sich, welcher 'Teil den Antikörper bildet, der Amboceptor orler das ('omplement. (Vergl. auch S. 382.)

Ehrlich hat darauf hingewiesen [59/, dass bei Injection von hämolytischem Serum theoretisch die Bildung von drei verschiedenen Antikörperı denkbar ist, da ja das complexe Hämolysin drei haptophore Gruppen enthält. \%wei sitzen am Amboceptor und zwei am Complement und jede dieser Gruppen kann im Organismus geeignete Receptoren vorfinden und deren Abstossung veranlassen. Antihämolysine können also Antiamboceptor oder Anticomplemente sein.

Es ist Bordet, sowie auch Ehrlich und Morgenroth gelungen, sowohl Antiamboceptoren, sowie Anticomplemente zu erzengen.

Die Wirkungsweise der ersteren besteht darin, dass sie in die cytophile Gruppe der Amboceptoren eingreifen und diese von den Blutkörperchen ablenken. Die Wirkungsweist der Anticomplemente besteht darin, dass sie durch Eingreifen in die haptophore Gruppe des Complementes seine Bindung an den Amboceptor, also die Yorbedingung der hämolytischen Wirkung, verhindern.

Da die Complemente Bestandtheile des normalen Serums sind, so kann man natürlich am leichtesten durch Immunisirung mit normalem Serum Anticomplemente erzielen.

Dass die Verschiedenheit der Amboceptoren (substance sensibilatrice) gross ist, daran wird nicht geweifelt. Das dem Meerschweinchen einverleibte Kaninchenblut macht das Meerschweinchenserum für Kaninchenblutkörperchen giftig, aber nicht für Blutkörperchen anderer 'Thiere. Man könnte einwesden, dass das nicht an den Amboceptoren, sonderr an den Complementen (Alexinen) liegt. Es stellt sich aber lieraus, dass das activirte Meerschweinchenserum mit vielen Serumarten, also mit Hülfe von Complementen von verschiedenen 'Thieren, Kaninchenblut zu zerstören im Stande ist.

Bordet hat nach dem Vorgange Buchner's die Ansicht rerfochten, dass in serum jeder 'Thierart nur eine Art von Alexinen rorkommt. In der Nomenclatur der Ehrlich-Morgenroth schen Theorie ausgedrückt, sollten somit die haptophoren Gruppen der Complemente von verschiedenen Thierspecies in einen und denselben Amboceptor passen miissen. Das ist bei der grossen Specificität der Amboceptoren liaum 
anzunehmen. Es wäre dann natürlich nothwendig, die toxophore Gruppe bei den meisten Amboceptoren als gleich vorauszusetzen. Ehrlich und Morgenroth sind denn auch der Meinung, dass in jedem Serum eine Vielheit von Alexinen vorkommt. (Sie werden darin, wie ich hervorhob, nicht durch Immunisirung neu gebildet, wie die Amboceptoren, sondern sind in normalen Serum vorhanden).

Für diese Auffassung sind mehrere Beweise sowohl von Ehrlich und seinen Schülern selbst, wie auch von anderen erbracht worden.

So konnten Ehrlich und Morgenroth im Ziegenserum ein Alexin (Complement) naclıweisen, das beim Erwärmen auf $56^{\circ}$ erhalten blieb, während die übrigen Alexine zerstört waren. Ehrlich und Sachs konnteu durch Combination verschiedener Methoden (Papainverdauung, Alkaliwirkung, Erhitzung auf $50^{\circ}$, Bindung durch Blutkörperchen) vier verschiedene hämolytische Alexine im Ziegenserum differenziren.

So konnte Wendelstadt im Serum einer Ziege, die mit Schweineblut und Hammelblut vorbehandelt war, durch Eingriffe thermischer und chemischer Art (Salzsäure), die für die entstandenen Amboceptoren passenden Complemente trenner.

Marshall und Morgenroth gelang es, zwei Complemente des Meerschweinchenserums zu differenziren, indem sie in einer Ascitesflüssigkeit ein Anticomplement fanden, welches nur in ein bestimmtes Complement des Meerschweinchenserums eingriff, ein anderes aber vollständig unbeeinflusst liess.

Auch Metchnikuff ist zu der Ammahme wenigstens zweier verschiedenen Complemente in demselben Serum gelangt [60]. Metchnik off fand, dass die an Makrophagen reichen Exsudate hämolytisch wirksam waren, dagegen keine bactericiden Functionen auszuüben vernochten.

Umgekehrt übten die im Wesentlichen Mikrophagen enthaltenden Exsudate eine bedeutende bactericide Kraft aus, erwiesen sich aber als unfähig, hämolytische Amboceptoren zu activiren. Metchnik off schliesst daraus, dass von den beiden Zellarten zwei verschiedene Complemente geliefert werden, die Mikrocytose, welche die bactericiden Wirkungen veranlasst, und die Makrocytose, welche Trägerin der die thierischen Zellen zerstörenden Functionen ist.

\section{y) Zusammenfassung. Discussion der Ansichten Bordet's und Ehrlich's.}

Zusammenfassend darf man sagen, dass nach der Ansicht von Ehrlich und seinen Schülern die Hämolyse darauf beruht, dass in das rothe Blutkörperchen ein Amboceptor eingreift und auf den Amboceptor ein Complement(Alexin) gepfropft wird. Durch Vermitthung des Amboceptors als Mittelglied wirkt also das Complement (Alexin) auf das Blutkörperchen ein. Ohne diese Vermitthng findet keine Alexinwirkung, keine Zerstörung statt. Letztere Einwirkung selbst hält Ehrlich für eine chemische, fermentative, wobei das Stroma eine Art Verdaunng erfälrt.

Offenbar weicht diese Ansicht von der Bordet's insofern ab, als nach ihm das Alexin unmittelhar die Blutkörperchen angreift. Der 
Sensibilisator hat den Zweck, diesen Angriff zu ermöglichen nud zwar nicht etwa dadurch, dass er wie das Glied einer liette functionirt, sondern .,wie der Schlüssel eines Sicherheitsschlosses, durch dessen Einführung erst diejenige des eigentlichen Hauptschlïssels (des Alexins) ermöglicht wird." Und was die Fixation des Alexins selbst am Blutkörperchen betrifft, ist diese, wie bereits erwähnt, nach Bordet nicht chemischer, sondern physikalischer Natur.

Dass das Alexin direct am Blutkörperchen seinen Angriffspunkt wählen sollte, ist u. A. ron Neisser und Wechsberg [68] bestritten worden und zwar gelegentlich ihrer Versuche mit Bacteriolysinen, die ja den Hämolysinen durchaus analog sind.

Gebrauchten sie in einer Versuchsreihe stets dieselbe Bacterienund Alexin(Complement-)menge, und setzten andererseits Sensibilisatoren (Amboceptoren) - die durch Erhitzung activen Serums auf $55^{0}$ gewonnen waren - in steigenden Mengen zu, so blieb bei einem gewissen Ueberschuss von Amboceptoren die zerstörende Wirkung der Bacterien völlig aus. Sie führen zur Erklärung dieses Resultates an, dass das Complement bei Gegenwart der überschüssigen und daher nicht von den Zellen gebundenen Amboceptorenmenge gerade diese frei gebliebenen Amboceptoren bevorzugt, also gewissermassen durch letztere von den Bacterien abgelenkt wird. Wirkte dagegen, wie Bordet meint, der Amboceptor als Sensibilisator, so müsste die Zelle durch eine grössere Menge derselben um so geeigneter werden, der sie direct ergreifenden sclä̈digenden Wirkung des Complementes zu unterliegen. Wenn wir dagegen den Amboceptor nach Elırlich und Morgenroth als ein Bindeglied zwischen Zelle und Complement (Alexin) auffassen, so wird die Vertheilung des Complementes bei einem Ueberschuss freier, nicht an die Zelle gebundener Amboceptoren davon abhängig sein, ob die Affinität der complementophilen Gruppe durch die Bindung des Amboceptors an die Zelle gleich bleibt, oder eine Erhöhung oder Verminderung erfährt. Im ersten Falle wird es ein Spiel des Zufalles sein, ob das Complement an die freien oder an die an der Zelle sitzenden Amboceptoren herangeht. Wird die Affinität erhöht, so werden die von der Zelle bereits verankerten Amboceptoren natürlich vom Complement bevorzngt werden, im umgekehrten Falle die freien Receptoren. Im letzteren Falle wird bei hinreichendem Amboceptorenüberschuss unter allen Umständen das Phänomen der Complementablenkung eintreten.

Iiese Vorstellung der Complementablenkung ist wieder ron Metchnik off und von Gruber bestritten worden. Lipstein hat aber die Einwände in, wie mir scheint, befriedigender Weise widerlegt. 
Noch durch andere Versuche ist Bordet's Sensibilisirungstheorie angefochten worden. Es ist nämlich gelungen, Combinationen aufzufinden, in denen der Amboceptor an und für sich, nicht von den Blutkörperchen gebunden, sondern erst durch Hinzufügung von Complement reactionsfähig gemacht wird [50].

Das ist mit der Anschauung Bordet's nicht vereinbar; wohl aber mit der Vorstellung von Ehrlich und Morgenroth.

Das alles betrifft die Frage, ob das Alexin direct an die Blutkörperchen gebunden wird (Bordet) oder nur unter Vermittlung eines 7wischengliedes (Ehrlich und Morgenroth).

Wie gesagt, ist die Art der Alexinfixation ein weiterer Punkt der Controverse. Bordet meint, dass hier eine physikalische Fixation vorliegt. Ehrlich und Morgenroth halten sie für eine chemische Bindung, die am besten durch ein Beispiel aus der Chemie versinnlicht wird. Plienol und Blausäure verbinden sich mit einander nicht, wohl geschieht dies aber mit Hülfe des Diazobenzaldehyds. Letzterer functionirt dann als Bindeglied zwischen Phenol und Blausüure. So ist auch der Amboceptor Bindeglied zwischen Zelle und Complement.

Ich habe bereits im ersten Band S. 400 den Versuch angeführt, auf den Bordet seine Ansicht über die pliysikalische Bindung stützt. Bordet versetzte eine bestimmte Menge hämolytischen Serums mit derjenigen Blutmenge, die gerade noch vollständig gelöst werden konnte. Wenn er nun den Versuch unter sonst gleichen Bedingungen wiederholte, nur mit dem Unterschiede, dass er die Blutmenge portionsweise zusetzte, so fand keine Lösung des Gesammtblutes statt. Daraus geht nach Bordet hervor, dass die ersten Antheile einen zu grossen 'Theil des Hämolysins aufgenommen haben und dies ist nur denkbar, wenn es sich dabei um eine Flächenanziehung handelt.

Man kann aber auch mit Ehrlich und Morgenroth annehmen, dass die Blutkörperchen ïber einen grossen Receptorenapparat verfïgen und nur ein geringer Theil ron den Blutgiften besetzt zn sein brancht, um die zur Hämolyse fïhrende Schädigung zu veranlassen. Unter diesen Umständen kann natürlich eine grössere Receptorenmenge verankert worden sein, als zur Hämolyse nöthig war.

In der That haben Ehrlich und Morgenroth in ihrer fünften Mittheilung über Hämolysine nachgewiesen (Berl. klin. Wochenschr. 1901 Nr. 10): dass die Bindungsfähigkeit der Bhutkörperchen ausserordentlich variirt. 
Ueber die Ansiclit von Arrhenius betreffs des Angriffsmodus des Hämolysins wird noch unten (\$. 385) die Rede sein. Hier erwähne ich nur, dass sich nach diesem Autor der Amboceptor ïber Blutkörperchen und Serum vertheilt und zwar in dem Sinne, dass die Blutkörperchen bei Weitem die grösste Nenge aufnehmen. duch das Complement vertheilt sich über beide Componenten, aber rom Complement bleibt die grösste Menge im Serum zuriick.

Nacl dieser Vorstellung, die wieder auf dem Theilungsprincip fusst, müssen in dem Blutkörperchen eine oder mehrere substanzen vorhanden sein, in denen die beiden Bestandtheile des Hämolysins und insbesondere der Amboceptor löslich ist. Als solche kommt vielleicht das Lecithin oder Cholesterin in Betracht, das von Ransom aus einem ähnlichen Grund bereits bei der hämolytischen Wirkung des Saponins herangezogen wurde (vergl. S. 340). In der That ist das Saponin in Lecithin leicht löslich.

Die Untersuchungen von Kyes und Sachs [61] und von H. Sachs allein [62] haben die Bedeutung des Lecithins für die Hämolyse durch Cobragift und durch Arachnolysin sichergestellt.

Auf welche Weise nun weiter das in den Blutkörperchen anwesende Hämolysin dieselben zum Farbstoffaustritt veranlasst, darüber äussert sich Arrlıenius nicht. Auch Koeppe hat bei seinem Versuch, dem Mechanismus der Hämolyse näher zu treten [60], die Trsache der Zerstörung durch Hämolysin unberührt gelassen. Dagegen behandelt er das Zugrundegehen ron solchen Blutkörperchen in anderen Flüssigkeiten. Indem der Autor annimmt, dass die halbdurchlässige Wand (äussere Begrenzung) der rothen Blutscheibe aus einer „fettähnlichen Substanz" besteht, wird die Wirkung der Agentien, die das Blut lackfarben machen, auf eine Zerstörung dieser fettähnlichen Substanz zurückgeführt, so z B. der hämolytische Einfluss von freien Säuren, auf Beschleunigung der Fettspaltung durch die H'-Ionen und die hämolytische Wirkung ron freiem Alkali auf Peschleunigung der Fettverseifung. Aether, Chloroform, Schwefelkohlenstoff wirken hämolytisch durch Lösung der fettähnlichen Substanz.

\section{ס) Die Ansichten von Baumgarten's.}

In der Festsclurift für .Jaffé hat von Baumgarten die Hämolyse auf ganz andere Weise zu erklären gesucht [64]. Diese Erklärung weicht von den Theorien von Buchner, Bordet und Ehrlich und Morgenroth wesentlich ab. Während diese Autoren sich vorstellen, dass das Blutkörperchenstroma einer Art verdauender Wirkung unterliegt und 
dadurch dem Hämoglobin den Durchgang gestattet, sieht von Baumgarten die primäre Ursache der Hämolyse in einer osmotischen Störung. Das heterogene Serum soll gegenüber dem fremden rothen Blutkörperchen hyperisotonisch sein und diese sollen darin, wie der Verfasser durch genaue mikroskopische Beobachtungen feststellte, dieselben Veränderungen erfahren, die man auch beobachtet, wenn beliebige Erythrocyten sich in einer hyperisotonischen NaCl-Lösung aufhalten. Nur geht der hämolytische Process im heterogenen Serum viel schneller vor sich, was von Bau ngarten darauf zurückführt, dass der Immunkörper (Sensibilisator, Amboceptor) die Resistenz der Blutkörperchen gegenüber osmotischen Störungen steigert.

In der Hauptsache beobachtet man sowohl in heterogenem Serum, wie in 2\% iger NaCl-Lösung erst Schrumpfung in Folge von Wasserentziehung, dann Quellung in Folge Eindringens von Salz und osmotischem Ueberdruck und endlich Austritt von Blutkörpercheninhalt in Gestalt von Kügelchen (Plasmoptyse A. Fischer, vergl. oben S. 335).

Dass das heterogene Serum nach $1 / 2$ stündiger Erhitzung bei $55^{0}$ das hämolysirende Vermögen verliert, glaubt von Baumgarten durch einen Uebergang des Serums aus dem hyperisotonischen in den isotonischen Zustand erklären zu können.

In einer zweiten Mitteilung [65] hat der Tübinger Forscher in Gemeinscliaft mit Dömény seine Ansichten näler begründet. Er wies unter anderem nach, dass die rothen Blutkörperchen im erhitzt gewesenen Serum ihr Volumen, d. h. ihre Breitedimensionen nicht änderten. Sie behielten ihre platten runden Conturen und verhielten sich darin wie in einer Conservirungsfluissigkeit. Es ist nun höchst interessant unter dem Mikroskop zu beobachten, wie die rothen Blutkörperchen trotz ihrer ganz glatten Ränder in dem erhitzt gewesenen Serum zu Haufen zusammentreten, agglutiniren und wie man in den Haufen jetzt jedes einzelne Kö̈rperchen wohlumschrieben erkennen kann, während bei der gewöhnlichen Agglutination, die an einandergelagerten Körperchen zu fast homogen erscheinenden Massen zusammensintern.

Weiter wird folgender Versuch mitgetheilt. Wenn man das gegen Kaninchenblut activirte Cariaserum auf $55^{0}$ erhitzt und dadurch wirkungslos gemacht hat, so kann man es, ebenso wie durch Hinzufügung ron normalem Serum, auch durch eine $4 \%$ ige NaCl-Lösung reactiviren. In diesem Versuche ist also das wirksame Addiment (Complement, Alexin) nichts anderes als eine hyperisotonische Kochsalzlösung.

Ein nicht unwesentlicher Theil der Arbeit beschäftigt sich weiter mit dem Agglutinin. 
Es würde den Rahmen dieses Buches überschreiten, wollte ich lier die betreffenden Ausführungen näher besprechen. Es sei nur erwähnt, dass das Zusammenkleben der Blutkörperchen, das gewöhnlich der Hämolyse durch heterogenes Serum vorangeht, nach von Baumgarten nicht, wie Ehrlich und Morgenroth meinen, durch eine selbstständlige Substanz herbeigeführt wird, die sie als "Hämagglutinin" bezeichnen und die in ähnlicher Weise entstehen soll, wie das Antitoxin und der Amboceptor, sondern dass diese Substanz der A mboceptor selbst ist. Obgleich ich es für wahrscheinlich halte, dass fortgesetzte Untersuchungen die Frage nach dem Wesen der Agglutination auf das Gebiet der physikalischen Chemie hinüber spielen werden, indem es sich dabei wohĩ um eine Zustandsänderung des Colloids handeln wird (vergl. S. 65), so will ich doch, um nicht ohne Nothwendigkeit, ausführlich zu werden, nicht weiter auf die Sache eingehen und auf das Original verweisen.

Dagegen spreche ich noch mit einigen Worten über die Hämolyse als Erscheinung osmotischer Auflösung und muss da zunächst hervorheben, dass mich von Bau m garten's Beweisführung nicht befriedigt lat.

1. Ich vermisse den Beweis, dass da, wo das heterogene Serum hämolytisch wirkte, auch wirklich Hyperisotonie gegenüber den zu zerstörenden Blutkörperchen bestand.

Allerdings hat der Verfasser Recht, wenn er bemerkt, dass Hyperisotonie bestehen kann, obne dass die Gefrierpunkterniedrigung oder selbst das elektrische Leitvermögen gesteigert erscheint. Unmöglich ist es auch nicht, dass eine durch diese Mittel nicht nachweisbare Aenderung doch noch schwer ins Gewicht fällt, wenn die Resistenz gegen osmotische Störungen durch (iifte (hier durch den Amboceptor) herabgedriickt wird. Dennoch erscheint es mir gewagt, auf Grund einer so wenig gestützten Hypothese eine osmotische Störung als Ursache anzunehmen.

Dass auf Hinzufügung einer erheblichen Menge $4 \%$-NaCl-Lösung zu inactivirtem Serum Hämolyse eintritt, scheint mir kein kräftiges Argument; denn an und für sich ist eine starke NaCl-Lösung bereits zur Herbeiführung von Hämolyse im Stande.

Der Versuch hätte grösseren Werth besessen, wenn der V'erfasser eine geringere, aber doch noch so grosse Menge $\mathrm{XaCl}$ hinzugefügt hätte, dass dieselbe durch Gefrierpunkterniedrigung nachweisbar gewesen wäre.

Ferner wäre noch ein anderes einfaches Experimentum crucis möglich gewesen. Wenn activirtes Meerschweinchenserum mit $5-10 \%$ Wasser verdünnt wird, was nachweislich eine dentliche Hypisotonie hervorzurufen im Stande ist, so muss, wenn die Auffassung ron Ba umgarten`s richtig ist, dieses serum keine hämolytische Wirkung auf Kaninchenblutkörperchen mehr ausïben. Ich lıabe mir aus wiederholt erwähnten Gründen versagt, diese Punkte experimentell zu bearbeiten, 
und deshalb auch diesen Versuch anzustellen, aber es würde mich in hohem Maasse wundern, wenn die Hämolyse ansbliebe. Dass sie durch das Wasser als solches veranlasst werden könnte, ist nicht denkbar; da das Serum mehr als 50 Volumprocent Wasser erträgt, bevor es so verdiinnt wird, dass es Farbstoffverlust herbeiführt.

Meine Ansicht über đie Dentung der mikroskopischen Untersuchungen von Ba nmgarten's geht rielmehr dahin, dass ich die osmotischen Störungen nicht als primär, sondern als secundär ansehe.

Ich glaube, dass unter dem Einfinss des Alexins das Stromaprotoplasma derart verändert wird, dass die Permeabilität modificirt wird. Das anfängliche, gewölnnlich vorkommende, aber auch nicht selten fehlende Schrumpfungsbild weist wahrscheinlich auf eine Structurveränderung des Stromas oder dessen äussere Begrenzung hin, wozu allerdings, wie aus der Agglutination ersichtlich ist, grosse Neigung besteht. Die nachherige Quellung rührt daher, dass die in das Blutkörperchen hineindiffundirten Substanzen einen grösseren osmotischen Druck repräsentiren als die daraus ausgewanderten. So wäre es z. B. denkbar, dass Chlornatrium in die Blutkörperchen hineindiffundirte und eine äquivalente Nenge $\mathrm{Na}_{2} \mathrm{CO}_{3}$ dieselben verliesse. In der That enthält das Serum viel mehr $\mathrm{Cl}^{\prime}$ als der Blutkörpercheninlıalt. Selbst wenn der Austausch in äquimolecularen Verhältnissen stattfindet, gehen $2 \mathrm{Cl}^{\prime}$ hinein und $1 \mathrm{CO}_{3}{ }^{\prime \prime}$ hinaus und in Folge dessen steigt der osmotische Druck innerhalb des Blutkörperchens. I)iese Vorstellung wäre experimentell durch quantitative Analysen zu prüfen ${ }^{1}$ ).

Als diese Zeilen geschrieben waren, kamen mir die gerade erschienenen Verhandlungen der deutschen pathologischen Gesellschaft [66] zu Händen, aus denen ich ersehe, dass der Autor auf Girund von Ver-

1) Ich muss indessen hervorheben, dass die Hämolyse nicht immer mit Volumvermehrung der rothen Blutkörperchen einhergeht. Auf meine Veranlassung lat nämlich van Me eteren Serum mit sehr geringen Aethermengen versetzt und diese Gemische auf die entsprechenden Blutkörperchen $(0,06$ ec Blut) einwirken lassen. Die Aethermengen waren so klein (auf 2 cc Serum resp. 1, 2, 3 und 4 Tropfen), dass die Gemische keinen Farbstoffaustritt veranlassten. Nach kräftigem Centrifugiren stellte sich in allen Versuchen heraus, das das Volumen der Blutkörperchen abgenommen liatte und zwar um so mehr, je mehr Aether hinzugefügt war.

Das Mittel vieler Versuche ergab für das Volumen der Blutkörperchen in:

2 cc Serum ohne 2 cc Serum n. 2 cc Serum n. 2 cc Serum u. 2 cc Serum u.

Aether 1 Tropfen Aether 2 Tropfen Aether 3 Tropfen Aether 4 'T'ropfen Aether

$47 \quad 46,5 \quad 44,5 \quad 43,5 \quad 42$

Hinzufügung von mehr Aetlıer veranlasst Zerstörung eines 'I'heils der Blut körperchen. Weil die Stromata ein kleineres Volumen als die hämoglobinhaltigen 
suchen zu der l'eberzeugung gelangt ist, dass seine Vorstellung nicht die richtige sein kann. Offenbar hat der Verfasser sich beeilen wollen, bald möglichst eine nummehr umö̈thig gewordene Controverse zu beendigen. Man ist ihm dafuir zu Dank rerptlichtet.

Zunächst führte nämlich auf von Baumgarten's Anregung, Dr. Dietrich Volumbestimmungen der Blutkörperchen aus, um die Resultate mit denjenigen der mikroskopischen Beobachtungen zu vergleichen. Derartige Volumbestimmungen waren nicht überflüssig, weil ich, wie auch ron Baumgarten bemerkt, früher gezeigt hatte, dass die rothen Blutkörperchen jedesmal eine Formänderung erleiden, wenn sie aus dem eigenen Blutserum in irgend eine andere isotonische, chemische indifferente Fliissigkeit ibertragen werden (Bd. I S. 197).

Diese Untersuchungen werden in einer noch zu veröffentlichenden ausführlichen Abhandlung von Dietrich beschrieben werden. Torläufig theilt von Baumgarten das Schlussergebniss in folgenden Worten mit.

„Die rothen Blutkörperchen erleiden auch bei Zimmertemperatur (bevor es noch zu Hämolyse gekommen ist) im heterogenen verdïnnten oder unverdünnten Serum eine rasche Volumveränderung, die in einigen Fällen in anfänglicher Quellung, in anderer in sofortiger Volumverminderung besteht." Im erhitzten (inactirirten) Serum constatirte er zwar eine anfängliche ganz geringe Tolumverminderung, aber keine Quellung, auch nicht nach längerer Dauer.

Im Zusammenhang mit diesen Resultaten sind auf seine Veranlassung Messungen der Gefrierpunkterniedrigungen, des elektrischen Leitvermögens und des Reibnngswiderstandes angestellt worden. Es fanden sich zwar, im Einklang mit diesbezüglichen Ermittelungen früherer Untersucher, zwischen den Sera verschiedener Thierspecies, z. B. Kaninchen und Meerschweinchen, welche bekanntlich auch ohne ent-

Blutkörperchen haben, sinkt bei diesen grössereu Aethergaben das Volumen relativ sehr stark.

Aehnliche Versuche wurden mit Saponin angestellt. Es zeigte sich, dass 2 cc Serum, in welchem ${ }^{1} 1200 \%$ Saponin vorhanden war, keine Blutkörperchen zerstörte. Dagegen trat dieses ein, wenn mehr Saponin hinzugefingt wurde. Der Versuch lehrte nun, dass das Blutkörperchenvolumen im Serum ohne Saponin 95 betrug; war jedoch ${ }^{1} / 1200^{\circ}$ " Saponin hinzugefügt, so war das Volumen nur 90,5 . Parallel mit diesen volumetrischen Versuchen wurden mikroskopische Beobachtungen angestellt. Messungen waren nicht möglich. Ueberall wo Aether oder Saponin hinzugesetzt war, wurden eckige, unregelmässige Gebilde gefunden, oft mit langen Ausläufern. Die Versuche betrafen Kaninchen-, Pferde- und Schweineblut. 
sprechende Vorbehandlung wechselseitig hämolytisch auf die rothen Blutkörperchen der anderen Thierart einwirken, bemerkenswerthe Differenzen der Gefrierpunkterniedrigung u. s. w., nicht aber solche zwischen dem erhitzten und unerhitzten Serum desselben Thieres. Differenzen wurden zwar auch hier beobachtet, aber nur so minimale, innerhalb der Versuchsfehlergrenzen liegende und noch dazu in den einzelnen Versuchen so wenig übereinstimmend, dass ein Riickschluss auf eine Constitutionsänderung des Serums durch die Erhitzung auf $55^{\circ}$ aus diesen Ergebnissen nicht stathaft erschien.

"Diese Resultate - bemerkt von Bau m garten - dienten der anfänglich von mir gehegten Annahme nicht zur Stütze."

Die Anisotonie ist also nach ihm nicht die primäre Ursache der Hämolyse im heterogenen Serum, wie er anfänglich meinte. Das entscheidende ursächliche Moment liegt in der Einwirkung der specifischen stoffe auf die rothen Blutzellen. Diese Stoffe alteriren nach ihm das Stroma und setzen deren Resistenz herab, äindern die I'ermeabilität. Verstehe ich den Verfasser recht, so denkt er sich den Vorgang so, wie ich ihn oben etwas schärfer präcisirt habe. Worauf es hier ankommt -- bemerkt er - das ist die Begründung der Ausicht, dass die Analyse im heterogenen Serum als ein osmotischer Process, als ein durch Störung des heterogenen Gleichgewichts zwischen Innendruck der Zelle und Aussendruck der umgebenden Flïssigkeit bedingter Austritt des Hämoglobins aus dem Zellgehäuse, nicht als das Resultat einer chemischen Auflösung der rothen Blutkörperchen durch ein fermentartig wirkendes Agens zu betrachten ist. Mlit Entschiedenheit kehrt er sich immer noch gegen die Auffassung Ehrlich's. dass die Veränderung des Stromas eine Art Verdaumng desselben sei, in Folge deren das Hämoglobin sich gewissermaassen in die Flüssigkeit vertheilt. Die Stromata bleiben erhalten. Von einer Verdaumg ist, wie sich aus vergleichenden und so ganz anders verlaufenden Versuchen mit Trypsin auf die Blutkörperchen ableiten lässt, nichts zu bemerken. Auch nach den Beobachtungen ron Nolf [69] und Gruber [70] entstehen bei der Auflösung von Blutkörperchen durch hämolytisches Serum durchaus keine Verdaungsproducte. Man wird daher bei der Wirkung der Complemente mehr an eigenartige Giftwirkungen denken miissen.

Berührt diese Differenz auch den Kern der Ehrlich'schen 'Theorie nicht, so ist sie doch in sofern nicht ohne allgemeine Bedeutung, als sie eine Verschiedenheit des Standpunktes in der Auffassung iiber das Wesen der I m m unität zum Ausdruck bringt. „Ich habe immer das 
Unerwiesene der Vorstellung betont, den Untergang eingedrungener pathogener Mikroorganismen im natürlich immunen oder kïnstlich immunisirten 'Thier oder Menschenkörper als das Resultat eines Verdaunngsprocesses aufzufassen. Das Studium der Hämolyse im häınlytischen Serum, welche allgemein als das klarste und iibersiclitlichste Beispiel einer Immunitätsreaction des Organismus angesehen wird, hat ergeben, dass dabei ron einer Verdauung der eingeführten Fremdzellen nichts nachzuweisen ist."

Indessen sei daran erinnert, dass Krompecher durch Einspritzen von Froschblut in Kaninchen ein Serum erhielt, welches auclı die Kerne der Froschblutkörperchen glatt zur Lösung brachte.

Uebrigens betont von Baumgarten wieder auf's Neue, dass das Agglutinin mit dem Amboceptor zusammenfalle. Doch fällt, wie gesagt, dieses Thema, so interessant es auch ist, ausserlialb des Rahmens dieses Buches.

Wer sich besonders dafür interessirt, den verweise ich auf die ausgezeichneten Zusammenstellungen von H. S a chs [71], A s ch h of f [72], von Dungern [73], Dieudonné [7t], wo man auch andere die Ilämolyse und Immunität betreffende Fragen behandelt findet.

In ähnlicher Weise wie von Baumgarten hat Nolf durch Experimente die rein osmotische Wirkung der Alexine zu beweisen versucht. El vergleicht den Vorgang, der sich bei Einwirkung des Amboceptors (Sensibilisators) und des Complements (Alexins) abspielt, im Sinne Bordet's mit der Beizung eines Gewebes, welches dadurch befühigt wird, eine Farbe, in diesem Falle das Alexin, leichter an sich zu reissen. Das in das Blutkörperchen abgelagerte Alexin wirkt nun wie ein Salz, wie Ammoniumchlorid, indem durch Wasseraufnahme das Hämoglobin gelöst wird. Bei $n^{0}$ verhält sich das Ammoniumchlorid ähnlich wie die Alexine, indem es in seiner Wirkung gehemmt ist. Aber es gelang Nolf nicht, durch irgend eine Salzlösung ein inactives Serum zu reactiviren. Auch das Entstehen ron Antiamboceptoren und Anticomplementen erscheint mir vom Standpunkt eines lediglich auf osmotischer Störung beruhenden Auffassung schwer verständlich.

v) Die Reactionsgeschwindigkeit bei der Hämolyse durch Bacteriengifte.

In einer ausführlichen Arbeit haben Arrhenius und Madsen [75] versucht, den Verlauf der Hämolyse mittelst physikalisch-chemischer Methoden zu verfolgen. 
Aus verschiedeneu Grïnden ist es für die Erkenntniss des Wesens eines Vorganges erwünscht, den Verlauf desselben und die Momente, die diesen Verlauf beeinflussen, kennen zu lernen. Man bestimmt hierzu die sogen. (Reactions-) Geschwindigkeitsconstante $k$, ron welcher bereits früher (Bd. II S. 467 ff.) die Rede war.

Ich theile Einiges aus dieser Arbeit mit, zumal sie als erster Versuch gelten kamn, einen durch Bacteriengifte verursacliten Process nach den in der physikalischen Chemie üblichen Methoden zu studiren. Die Untersuchung kann demmach als Muster für anderweitige derartige Forschungen dienen.

Die Verfasser bedienten sich eines Bacteriengiftes, dessen Concentration in vitro genau gemessen werden konnte, nämlich des Tetanolysins. Dieses Bakteriengift, dessen erythrocytenzerstörende Wirkung bereits 1599 ron Madsen [32] untersucht war, gehört, wie ich schon oben erwähnte, zu den Bacteriohämolysinen. Es wurde von Ehrlich [67] neben dem Tetanospasmin, das die Erscheinungen der tetanischen Contractur herbeiführt, in Tetanusbouillonculturen entdeckt.

Fügt man dieses Gift zu einer Suspension von rothen Blutkörperchen in Kochsalzlösung hinzı, so verlieren dieselben Farbstoff. Nach dem Centrifugiren giebt die Intensität der rothen Farbe der überstehenden Flüssigkeit ein Maass für den Umfang der Giftwirkung.

Die Versuche wurden in folgender Weise angestellt.

Pferdeblutkörperchen wurden centrifugirt und das Serum möglichst vollständig abgehoben. Dann wurde zu wiederholten Malen mit NaCl-Lösung von $0,85 \%$ ausgewaschen und endlich wurden $25 \mathrm{ce}$ des Sediments in $1000 \mathrm{ec} \mathrm{NaCl}-\mathrm{L}$ ösung von $0,85 \%$ suspendirt (in einigen Fällen auch in 1000 cc einer isosmotischen Rohrzuckerlösung von $7,79^{\circ} \%$ ). Von dieser Blutkörperchensuspension wurden stets $10 \mathrm{cc}$ in ein Reagirröhrchen gebracht und dann mit der Tetanolysinlösung versetzt. Diese entlielt $1 \mathrm{~g}$ auf gewöhnliche Weise durch Behandlung von Tetanuscultmren mit Ammoniumsulfat erlialtenes getrocknetes Tetanolysin auf $499 \mathrm{~g}$ Wasser, also $0,2 \%$ Teta $\mathrm{no}$ ly s in.

Das freigewordene Hämoglobin wurde durch Vergleiclıng mit Standardtlüssigkeiten colorimetrisch bestimmt. Behufs Herstellung derselben wurden 2,5 cc Blutkörperchensediment mit 97,5 cc Wasser versetzt. Hierbei entstand eine klare rothe Lösung, deren Intensität gleich 100 gesetzt wurde.

Durch Verdünnung mit Wasser auf das doppelte Volumen entsteht eine F'lüssigkeit, deren Intensität 50 beträgt; Verdünnung auf das vierfache Volumen bringt die Intensität der rothen Flïssigkeit auf $25 \%$ u. s. w. Wird also in das Röhrchen, das 10 ec der Blutkörperchensuspension in Kochsalz enthielt, Gift gebracht und stellt sich nach Sedimentirung der unzerstörten Blutkörperchen beim Vergleich mit den Blutlösungen lieraus, dass die überstehende Flüssigkeit eine 
Farbenintensität von 25 besitzt, so geht daraus hervor, dass $25 \%$ der Blutkörperchen hämolysirt sind 1).

Wir nehmen an, dass die Toxinmenge so gross ist, dass sie nicht nur alle in der Probe vorhandenen Bhntkörperchen zn zerstören im Stande ist. sondern wïhrend des ganzen Processes als constant betrachtet werden darf.

Es sei $d x$ die Menge der zerstörten Blutkörperchen in einem äusserst geringen \%eitintervall dt. Dann ist die Hämolyse in der \%eiteinheit $\frac{d x}{d t}$.

Diese Geschwindigkeit, mit der die Hämolyse innerhalb einer bestimmten \%eit verläuft (d. h. die zerstörte Erythrocytenmenge in der Zeiteinheit), ist proportional der in dieser Zeit noch vorhandenen Blutkörperchenmenge C.

In Uebrigen ist die Geschwindigkeit der Hämolyse von verschiedenen Umständen, wie Temperatur, Art des Giftes und Natur der Blutkörperchen ahhängig, also von der sogen. Geschwindigkeitsconstante k.

Es ist sonach $\frac{\mathrm{dx}}{\mathrm{dt}}=\mathrm{kC}$.

Ich habe diese Gleichung schon frïher bei der Besprechung der monomolecularen Reactionen angewendet (B. II S. 46!) und weiter entwickelt.

Nach Integration ergiebt sich

$$
\mathrm{k}=\frac{1}{\mathrm{t}_{1}-\mathrm{t}_{2}} \cdot \frac{\mathrm{C}_{1}}{\mathrm{C}_{2}}
$$

Hierin ist $C_{1}$ die Concentration der nach einer Zeit $t_{1}$ noch vorhandenen unzerstörten Blutkörperchen und $C_{z}$ die nach einer Zeit $t_{2}$ noch vorhandene Blutkörperchenconcentration(menge). Für $C_{1}$ kann man auch eineu anderen Werth setzen. Ist nämlich 100 die anfangs vorhandene Blutkörperchenmenge und ist eine Menge $x_{1}$ hämolysirt, so ist die Menge, die nach einer Zeit $t_{1}$ übrig ist, $100-\mathrm{x}$ also $C_{1}=100-\mathrm{x}_{1}$; dementsprechend ist $\mathrm{C}_{2}=100-\mathrm{x}_{2}$.

Die Gleichung wird somit

$$
\mathrm{k}=\frac{1}{\mathrm{t}_{1}-\mathrm{t}_{2}} \mathrm{l} \begin{aligned}
& \left.100-\mathrm{x}_{1}{ }^{2}\right) \\
& 100-\mathrm{x}_{2}
\end{aligned}
$$

$\mathrm{x}_{1}$ und $\mathrm{x}_{2}$ inisst man colorimetriscl.

1) Offenbar lassen die Verfasser ausser Betracht, dass die Suspension etwas weniger Blutkörperchen enthält als Lösung. Für die Suspension werden 25 cc Blutkörperchenbrei mit 1000 cc Salzlösung versetzt, für die Blutfarbstofflösung mit 975 cc Wasser. Ausserdem wird später bei der Berechnung auch nicht beriicksichtigt. dass die Flüssigkeit, also auch die entstandene Hämoglobinlösung, durch Hinzuftigung eines gewissen Voluınen Toxinlösung zu der Suspension eine Verdünnung erfährt.

2) Diese Gleichung ist dieselbe wie

A ist hier 100 gesetzt.

$$
\mathrm{k}=\frac{1}{\mathrm{t}_{1}-\mathrm{t}_{2}}+\frac{\mathrm{A}-\mathrm{x}_{1}}{\mathrm{~A}-\mathrm{x}_{2}} \text { (Bd. II, S. 469). }
$$


Da es vortheilhafter ist, statt natürlicher Logarithmen Brigg'sche zu ge. brauchen, so schreibt man die Gleichung lieber in einer diesen entsprechenden Form. Das ist sehr leicht. Da

so ist

$$
1 \frac{100-x_{1}}{100-x_{2}}=\frac{1}{2,3025} \log \frac{100-x_{1}}{100-x_{2}}
$$

$$
\begin{gathered}
\mathrm{k}_{1}=\frac{\mathrm{k}}{2,3025}=\frac{1}{\mathrm{t}_{1}-\mathrm{t}_{2}} \log \frac{100-\mathrm{x}_{1}}{100-\mathrm{x}_{2}} \\
\mathrm{k}_{1}=\frac{1}{\mathrm{t}_{1}-\mathrm{t}_{2}} \log \frac{100-\mathrm{x}_{1}}{100-\mathrm{x}_{2}}
\end{gathered}
$$

Man liann die Formel noch vereinfachen, wenn man $t^{\prime}=0$ setzt. In diesem Fall, also beim Beginn rer Hämolyse ist $x_{1}$ auch 0 ; also

$$
\mathrm{k}_{1}=\frac{1}{-\mathrm{t}_{2}} \log \frac{100}{100-\mathrm{x}_{2}} .
$$

Man hat nun zu jeder Zeit $t_{2}$ den entsprechenden Werth für $x_{2}$ zu beobachten und in die Formel einzulügen.

Ich gebe eine Versuchsreihe bei $20^{\circ}$ wieder.

10 cc Blutkörperchensuspension von $2,5 \%$ (d. h. 25 cc Blutkörperchen auf 1000 ce $\mathrm{NaCl}$-Lösung) wurden mit 0,6 ce $0,2 \%$ iger Tetanolysin versetzt und die umgesetzte Mengen $(\mathrm{x})$ nach einer Einwirkungsdauer von 5, 9, 11,5 und 15 Minuten ermittelt.

Damit die Hämolyse sich nach einer Einwirkungsdauer von 5 Minuten nicht fortsetzt, bringt man das Gemisch in eine Kältemischung, kühlt also auf $0^{\circ} \mathrm{ab}$. Entsprechend verfährt man auch bei den 3 anderen Versuchen.

Die Berechnung von $k_{1}$ gestaltet sich sehr einfach. Beträgt nach einer Einwirkung des Tetanolysins während 5 Minuten die hämolysirte Blutmenge $(x) 7^{\circ} \%$, so ergiebt sich die Formel:

$$
k_{1}=\frac{1}{5} \log \frac{100}{100-7}
$$

\begin{tabular}{c|cc|c}
\hline $\begin{array}{c}\text { Uämolyse (x) in } \\
\text { Procenten }\end{array}$ & Nachı & $\begin{array}{c}\text { Geschwindigkeits- } \\
\text { (Reactions) constante } \\
\mathrm{k}_{1}{ }^{1} \text { ) }\end{array}$ \\
\hline $7 \%$ & 5 & Minuten & 6,3 \\
$17 \%$ & 9 & $n$ & 8,99 \\
$24 \%$ & 11,5 & $n$ & 10,36 \\
30 & 24 & $n$ & 103,4
\end{tabular}

Man sieht, die Reactionsgeschwindigkeit nimmt mit der zeit zu.

1) Ich multiplicire alle Werthe von $k_{1}$ mit 1000 , um die grosse Anzahl von Nullen zu vermeiden; statt 0,0063 wird die erste Zahl also 6,3. 
Gleichartige Versuche haben die Verfasser statt mit 'Tetanolysin,

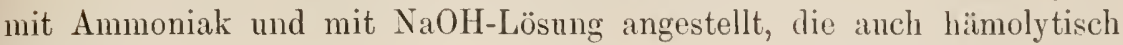
wirken.

Versuche mit Ammoniak.

\begin{tabular}{|c|c|c|c|}
\hline $\begin{array}{c}\text { Gemische von } 10 \mathrm{cc} \\
\text { Blutkörperchensuspension } \\
\text { von } 2,5 \% \text { und }\end{array}$ & $\begin{array}{l}\text { Hämolysirte } \\
\text { Mellge }(x) \text { in } \\
\text { Procenten }\end{array}$ & Nach & $\begin{array}{l}\text { Reactionsconstante } \\
\mathrm{k}_{1}\end{array}$ \\
\hline 0,75 cc $1 / 30$ n. $\mathrm{NH}_{3}$ & $\begin{array}{r}3 \\
11 \\
38 \\
75\end{array}$ & 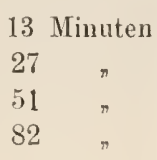 & $\begin{array}{l}1,0 \\
1,9 \\
4,7 \\
7,9\end{array}$ \\
\hline 0,5 ce $1 / 10$ n. $\mathrm{NH}_{3}$ & $\begin{array}{r}3 \\
18 \\
40 \\
65\end{array}$ & $\begin{array}{rr}6 & " \\
14 & \text { " } \\
23 & \text { " } \\
31 & \text { " }\end{array}$ & $\begin{array}{l}2,2 \\
6,2 \\
9,6 \\
9,7\end{array}$ \\
\hline 1 ce $1 / 10$ n. $\mathrm{NH}_{3}$ & $\begin{array}{l}-8,5 \\
20 \\
43 \\
56\end{array}$ & $\begin{array}{rr}5 & \text { " } \\
9 & \text { " } \\
15 & \text { " } \\
19 & \text { " }\end{array}$ & $\begin{array}{r}7,7 \\
10,7 \\
16,3 \\
18,7\end{array}$ \\
\hline
\end{tabular}

Auch hier sieht man, dass die Hämolyse um so schneller fortschreitet, je längere Zeit die hämolysirende Substanz mit den Blıtkürperchen in Beriihrung ist.

Aehnliches wurde bei der Anwendung von $\mathrm{NaOH}$ beobachtet.

\begin{tabular}{|c|c|c|c|}
\hline $\begin{array}{l}\text { Gemisch von } 10 \mathrm{cc} \\
\text { Blutkörperchensuspension }\end{array}$ & $\begin{array}{l}\text { Hämolysirte } \\
\text { Menge (x) in } \\
\text { Procenten }\end{array}$ & Nach & $\begin{array}{l}\text { Peactionsconstante } \\
\qquad k_{1}\end{array}$ \\
\hline $\begin{array}{c}\text { und } 0,3 \mathrm{ec} 1 / 20 \mathrm{n} \text {. NaOH- } \\
\text { Lüsung }\end{array}$ & $\begin{array}{r}7 \\
18 \\
35\end{array}$ & $\begin{array}{l}17 \text { Minuten } \\
22 \\
27 \pi\end{array}$ & $\begin{array}{l}1,85 \\
3,92 \\
6,99\end{array}$ \\
\hline
\end{tabular}

Das sclinelle Anwachsen der Hämolyse während der Einwirkungsdauer der Gifte, lässt sich auf ungezwungene Weise daraus erklären, dass nach liurzer Einwirkungsdauer des Giftes nur die am wenigsten resistenten Bhutkörperchen in Zerstörung begriffen sind. Während dieser 
Zeit hat aber das Stroma der resistenteren gleichfalls derart gelitten, dass anch sie allmählich der Hämolyse anleimfallen und der Zerfall beider sich summirt.

Arrhenius und Madsen haben mittelst derselben Methode den Einfluss der Concentration des Giftes, sowie den Einfluss der Temperatur, den Einfluss fremder Substanzen, wie Serum, Eiweiss, etc. aufdie Geschwindigkeit der Hämolyse studiert. Es würde hier zu weit führen, die betreffenden Ausfiihrungen mitzutheilen, zumal die Methode selbst bereits hinreichend erörtert ist. Es kommt nur darauf an, die k-Werthe unter den genannten Versuchsmodificationen festzustellen und mit einander zu vergleichen.

Ich wende mich jetzt zu einem anderen wichtigeren Punkt, den die genannten Autoren in der genannten Abhandlung untersucht haben.

\section{Die Bindungsverhältnisse bei der Neutralisirung von Toxin durch Antitoxin. Bekämpfung von Ehrlich's Giftspectrum.}

Wie bereits gesagt, hat Ehrlich gefunden, dass in der Tetanusbouilloncultur zwei Toxinformen rorkommen: das hämolytische Tetanolysin und das nicht hämolytische, aber 'Tetanus herbeiführende Tetanospasmin. Von beiden lässt sich durch Immunisirung ein Antikörper herstellen, das Antitetanolysin und das Antitetanospasmin. Uns interessirt hier nur das Antitetanolysin.

Kurz nach der Entdeckung dieses Antitoxins hatte Madsen im Ehrlichschen Seruminstitut eine Reilıe von Untersuchungen ausgeführt [32], um die Bindungsverhältnisse dieses Antitoxins mit dem entsprechenden Toxin messend zu verfolgen. Ehrlich hatte gleichartige Neutralisationsversuche bereits 1897 mit Diphtherietoxinen und -Antitoxinen ausgeführt, und zwar in der Weise, dass nach jedesmaliger partieller, aber immer fortschreitender Neutralisation des 'Toxins durch Antitoxin im Reagensglas, die resultirende Giftigkeit des Gemisches bei Thieren festgestellt wurde. Ehrlich war dabei zu höchst werthvollen Resultaten gelangt. Seine Untersuchungen erforderten jedoch viel mühevolle und kostspielige ' $\mathrm{T}$ h i e rexperimente.

Es war also ein guter Gedanken, auch die G iftigkeit in vitro zu ermitteln zu versuchen. Eigentlich war diese Methode bereits für Gifte nichtbacteriellen Ur. sprungs Ricin, Crotin, Cobragift und das hämolytische Aalserum angewendet worden war. Die Giftigkeit wurde durch den Betrag des Hämoglobinaustrittes aus gleichen Mengen rother Blutkörperchen gemessen.

Es ist hier nicht der Ort, die Ergebnisse der beiden genannten Arbeiten von Madsen ausfïhrlich zu besprechen. Nur sei hier erwähnt, dass Madsen durch 
partielle Sättigung des Giftes durch Antitoxill, so wie es Elrrlich zuerst mit Diphtheriegift gethan hatte, zu der Annabme verschiedener Componenten gelangt, so dass also das Tetanolysin aus verschiedenen Bestandtheilen von verschiedener Giftigkeit zusammengesetzt sei.

Der Versuch war etwa folgender: Wurde zu 2 cc der Giftmenge, die durch Hinzufügung von 1,3-1,4 cc Antitoxinlösung auf einmal neutralisirt werden konnte, zuerst nur $0,10 \mathrm{cc}$, also nur etwa der 13. Theil der neutralisirenden Menge hinzugesetzt, so verlor das Gift schondie Hälfteseiner Wirkung.

Fügte man 0,25 cc hinzu, also ungefähr den fünften Theil der neutralisirenden Antitoxinmenge, so verlor das Gift ${ }^{9_{1} / 10}$ seiner Wirkung. Fügte man $0,60 \mathrm{cc}$ zu, also ungefähr die Hälfte, so verlor das Gift $9: 100$ seiner Wirkung. Die toxische Kraft der übrigbleibenden Hälfte musste demnach wohl sehr gering sein, während, wie aus dem ersten Neutralisationsversuch hervorgeht, das zuerst gebundene Toxin höchst kräftig ist und die toxischen Eigenschaften zuerst verliert. Madsen war auf Grund dieser Ergebnisse, die vollkommen mit denen Ehrlich's übereinstimmten, geneigt, nach dem Vorgang Ehrlich's 4 Arten von Giften auch im Tetanolysin zu unterscheiden: Prototoxin, Deuterotoxin, Tritotoxin und Toxon.

E h r l i c h hat diese Verhältnisse in Gestalt eines Diagramms ('Toxinspectıum) versinnlicht, wonach z. B. das Toxon als äusserst schwach, und nur auf die empfindlichsten Blutkörperchen wirkendes Gift zu betrachten war.

Dem gegeniiber haben nun Arrhenius und Madsen|75|auf Grund physikalisch-chemischer V'ersuche und betrachtungen diese Neutralisationserscheinungen derart deuten kïmen, dass d i e An na h m e der vier genannten Varietäten überliussig ist und bloss ein einheitliclies Tetanolysin angenom men zu werden bra ucht.

Es wurde festgestellt, wieviel (n.) ce einer Antitetanolysinlösung von $0,04^{\%} \%$ zu einem Gemisch von 2 cc Tetanolysinlösung und $(2-n$.) cc Wasser limzugefügt werden muss, danit in einer $2.5 \%$ igen Pferdeblutkörperchensuspension (2.5 cc Pferdeblutkörpercheı +100 cc $\mathrm{NaCl}$ Lösung $0,85 \%$ ) ein Hämolyse von $20 \%$ aufträte ${ }^{1}$ ) (siehe oben).

Die Tabelle auf Seite 370 bringt die erhaltenen Zahlen.

/ur Verdeutlichung sei Folgendes bemerkt:

Die erste Spalte enthält die Anzahl (n) ce der zu der Tetanolysinlösung hinzugefügten Antitoxinlösung.

Die zweite Spalte giebt die Me nge $(x)$ des Gemisches von (2 cc $2 \%$ iger Giftlösung $(2-n)$ ec Wasser) und n ec Antitoxinlös-

1) Näheres über die Versuchsverhältnisse erwähnen die Autoren hier nicht. Im erstgenannten Artikel (Z. f. Hyg. :32 1899, S. 214) theilt M a d s e n mit, dass er Toxin und Antitoxin wälırend zwei Stunden auf einander einwirken liess, und dann das Gemisch mit der Blutsuspension versetzte. Die also erhaltene Masse wurde bei $37^{\circ}$ genau eine Stunde sich selbst überlassen und dann, zur Sedimentirung, wher Nacht bei niederer Temperatur in einen Eisschrank gesetzt. 
u ng, die Menge nämlich, die mit 10 ec der Blutsuspension versetzt werden muss, um $20 \%$ Hämolyse zu erzielen.

Die dritte Spalte bringt die Giftigkeit (G) der Toxin-Antitoxinbi I du ug von Spalte 2. Je geringer $x$ (zweite Spalte) zu sein braucht, um die $20 \%$ ige Hämolyse herbeizuführen, desto giftiger ist die Lösung. Die Giftigkeit ist also der Menge $x$ umgekehrt proportional: $G=\frac{1}{x}$. Indessen ist dieser Ausdruck nicht genau; denn wenn $\mathrm{x}$ zu den $10 \mathrm{cc}$ der Suspension hinzugesetzt ist, so beträgt das ganze Volumen $10+\mathrm{x}$; die noch giftiga Toxin-Antitoxinlösung ist verdünnt und muss eigentlich grösser angeschlagen werden, als sie dem Flüssigkeitszusat\% $\mathrm{x}$ zufolge geworden ist.

Demnach ist $\mathrm{G}=\frac{1}{\mathrm{x}} \times \frac{10+\mathrm{x}}{10}$.

Die vierte und fünfte Spalte enthalten die berechneten Werthe von $\mathbf{x}$ und G. Hiervon wird erst weiter unten die Rede sein; immerhin setze ich diese Wrerthe vorläufig in die Tabelle ein.

Giftigkeit von Mischungen von Tetanolysin und Antitetanolysin.

\begin{tabular}{|c|c|c|c|c|}
\hline 1 & 2 & 3 & 4 & 5 \\
\hline $\begin{array}{c}\mathrm{n} \\
\text { Anzahl ce Anti- } \\
\text { tetanolysin von } 1 /+n 0^{0} 0, \\
\text { die mit } \mathrm{x} \text { der zwoiten } \\
\text { Spalte } 20 \% \text { Hämolyse } \\
\text { geben }\end{array}$ & $\begin{array}{c}\mathrm{x} \\
\text { Anzahl ce eines } \\
\text { Gemisches von (2 cc } \\
\text { Tetanolysinlösung } 2 \% \\
+(2-\text { n) ce Wasser }) \\
\text { und n ce Antitetanolysin }\end{array}$ & $\begin{array}{c}\mathrm{G} \\
\text { Giftigkeit der } \\
\text { unter } 2 \text { er- } \\
\text { wïhnten Teta- } \\
\text { nolysinlösung }\end{array}$ & $\mathrm{x}$ (ber'echnet) & $\mathrm{G}$ (berechnet) \\
\hline 0 & 0,23 & 4,45 & 0,23 & $(4,45)$ \\
\hline 0,05 & 0,28 & 3,67 & 0,28 & 3,67 \\
\hline 0,1 & 0,33 & 3,13 & 0,35 & 2,95 \\
\hline 0,15 & 0,45 & 2,32 & 0,46 & 2,29 \\
\hline 0,20 & 0,66 & 1,62 & 0,60 & 1,76 \\
\hline 0,30 & $\left.1,15^{1}\right)$ & 0,97 & 1,05 & 1,03 \\
\hline 0,40 & 1,6 & 0,63 & 1,64 & 0,62 \\
\hline 0,50 & 2.3 & 0,45 & 2,21 & 0,46 \\
\hline 0,70 & 3,8 & 0,27 & 3,7 & 0,28 \\
\hline 1 & 6,0 & 0,18 & 5,9 & 0,18 \\
\hline 1,3 & 9 & 0,12 & 8,0 & 0,13 \\
\hline 1,6 & 12,5 & 0,09 & 10,2 & 0,11 \\
\hline 2 & 14 & 0,08 & 13,0 & 0,09 \\
\hline
\end{tabular}

Aus dieser 'labelle geht hervor, dass, wenn man kein Antitetanolysin ( $n=0)$ zu der Giftlösung hinzufügt, nur 0,23 ce nöthig sind, um

1) Wo, wie hier und in den folgenden Versuchen, eine grössere Menge als 1 cc des Giftes hinzugefügt werden sollte, haben die Autoren, um die Rechnung zu vereinfachen, eine zehıfach stärkere Lösuıg, aber dann natürlich ein Zehntel hiervon hinzugefügt, also hier, statt 1,15 nur 0,115 . 
$20 \%$ Hämolyse hervorzurufen. War 0.05 ce Antilösung benützt, so braucht man 0,28 ec des Gemisches ron Toxin und Antitoxin. Weiter wird es ersichtlich, dass bei Benutzung von mehr Antilösung die Menge des erforderlichen Gemisches nicht proportional, sondern viel stärker ansteigt, so dass man also schliesslich sehr grosser Mengen des Gemisches bedarf, un die 20\% ige Hämolyse herbeizuführen, und zwar vielmehr als der relativ geringere Zufuhrvermehrung von Antitoxin zu entsprechen scheint. Demnach scheint die Giftigkeit des Genisches, also auch des nicht neutralisirten Gifttheils schnell abzunelmen und man empfängt auch hier den Eindruck, dass der erst gesättigte Theil des Giftes der am meisten toxische sei. Die Verfasser haben diese Giftigkeit $(G)$ in Zahlen ausgedrückt. Sie ist, wie gesagt, der zur Hämolyse erforderlichen Menge ungekehrt proportional.

$$
\mathrm{G}=\frac{1}{\mathrm{x}} \times \frac{10+\mathrm{x}}{\mathrm{x}}
$$

Nach dieser Formel ist G in der dritten Spalte berechnet.

Trägt man nun die Antitetanolysinmengen (n.) als Abcissen und die entsprechenden Toxicitäten als Ordinaten auf, so kann man eine Curve construiren, die in frappanter Weise das Gleichgewicht e ines Körpers repräsentirt, der in partieller Dissociation verkehrt'). Ein solches Gleichgewicht wird durch das Massengesetz von Guldberg und Waage beherrscht (B. II S. 466 und 479). Auf das Toxin und Antitoxin angewendet, gestaltet sich dasselbe in folgender Weise:

$\mathbf{C}_{\text {freies }}$ roxin $\times \mathbf{C}_{\text {freies Antitoxin }}=\mathbf{K} \times \mathbf{C}^{2}{ }_{\text {Terbindung Toxiu-A }}$ titoxin.

Das heisst: das Product der Concentration von freiem Toxin und freiem Antitoxin, ist gleich einer Constante $\mathrm{K}$, multiplicirt mit dem Quadrat der Concentration der entstandenen Verbindung.

Vielleicht wird es manchem Leser angenehm sein, wenn ich versuche, die hier gebrauchte Formel abzuleiten.

Nach dem Guldber.g-Wage'schen Massenwirkungsgesetz wird die Geschwindigkeit S, mit der sich freies Toxin und freies Antitoxin mit einander verbinden, zunächst von den Concentrationen der beiden Stoffe abhängig sein, die der Uebursichtlichkeit halber mit $\mathrm{C}_{\text {freies Toxin }}$ und $\mathrm{C}_{\text {freies Antitoxin bezeichnet werden. }}$

1) Um dem Leser, der das Original in der Zeitschr. für physik. Chemie 4 , 1903. S. 1 studiren will, vergebliche Mühe zu ersparen, mache ich darauf aufmerksam, dass die auf S. 43 gegebene Curve nicht zu Zahlenwerthen gehört, die in der Abhandlung mitgetheilt worden sind, also auch nicht zu der Tabelle 19, auf die sie sich beziehen soll. Auch an anderen Stellen entsprechen die Curven dem Text nicht. 


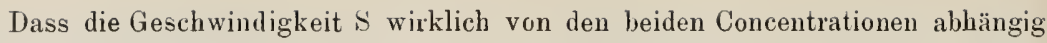
sein muss, kann nicht befremden, denn je grösser die Concentrationen, desto grösser ist die Chance des Zusammentreffens der Molecüle beider Substanzen.

Weiter ist die Verbindungsgeschwindigkeit noch abhängig von einer Constante k, die man Geschwindigkeits- oder Reactionsconstante nennt und deren Grösse von der Natur der beiden Stoffe, von der Temperatur, von der Anwesenheit anderer Substanzen u. s. w. abhängt.

Also $\mathrm{S}=\mathrm{kC}_{\text {freies }}$ Toxin $\times \mathrm{C}_{\text {freies }}$ Antitoxin.

Gleichzeitig mit der Bindung von Toxin und Antitoxin hat auch eine Zersetzung der bereits gebildeten Verbindung zu einem gewissen Grade statt. Das ist eben der Character von Gleichgewichtsreactionen. Man kann das hier einem Vorschlag van't Hoff's gemäss, in folgender Weise zum Ausdruck bringen.

Freies Toxin + freies Antitoxin $\rightleftarrows$ Verbindung 'Toxin-Antitoxin.

Die Geschwindigkeit $S_{1}$ mit der die Zersetzung vor sich geht, m. a. W. die Menge, welche in der Zeiteinheit zersetzt wird, ist zunächst abhängig von einer Geschwindigkeitsconstante $\mathrm{k}^{\prime}$ und weiter von der Concentration der entstandenen Verbindung, also von

$$
\text { CVerbindung Toxin-Antitoxin: }
$$

Somit wird $\mathrm{S}_{1}=\mathrm{k}^{\prime} \mathrm{C}$ Verbindung Toxin-Antitosin.

Besteht Gleichgewicht ${ }^{1}$ ), so ist $\mathrm{S}=\mathrm{S}_{1}$ demnach

$\mathrm{k} \times \mathrm{C}_{\text {freies }}$ Toxin $\times \mathrm{C}_{\text {freies Antitoxin }}=\mathrm{k}^{\prime} \mathrm{C}_{\text {Verbindung Toxin }- \text { Antitoxin }}$ oder Cfreies Toxin $\times \mathrm{C}_{\text {freies Antitoxin }}={ }_{\mathrm{k}}^{\mathrm{k}^{\prime}}$ CVerbindung Toxin-Antitoxin.

Statt $\frac{k^{*}}{k}$ kann man auch die einfache Grösse $K$ setzen, die man auch Gleicl. gewichts- oder Dissociationsconstante nennt (Bd. II S. 478). Die Formel wird also

\section{C freies Toxin $\times$ C freies Antitoxin $=\mathrm{KC}$ Verhindung Toxin-Antitoxin.}

Dem aufmerksamen Leser wird es aber auffallen, dass die hier abgeleitete (ileichung nicht der oben von Arrhenius und Madsen gebrauchten entspricht. Da handelt es sich im zweiten Glied um ein Quadrat.

Was ist die Ursache dieser Differenz?

Um diese zu begreifen, denken wir uns einen Augenblick, dass durch die Wechselwirkung von freiem Toxin und freiem Antitoxin nicht ein einleitliches

1) Bei beweglichen Gleichgewichtsvorgängen, wo Bildung und Rückbildung mit einander einhergehen, wie auch hier, überwiegt im Beginn der Reaction die Bildungsgeschwindigkeit $S$ über die Rückbildungsgeschwindigkeit $S_{1}$, was daher ruihrt, dass im ersten Fall die Concentrationen der beiden auf einander einwirkenden Substanzen noch relativ gross sind und die des gebildeten Productes klein; in Verlauf der Reaction nehmen die Concentrationen der Anfangssubstanzen ab, während dagegen die Concentration, und damit auch die Menge, ${ }^{\circ}$ die in der Zeiteinheit wieder zersetzt wird, also die Rückbildungsgeschwindigkeit $S_{1}$ zunimmt. In einem gewissen Zeitpunkt wird $S=S_{1}$; es wird dann ebenso viel gebildet wie zersetzt: es besteht ein hewegliches Gleichgewicht (vergl. hierzn oben S. 98 und unten 376,377 ). 
Moleciil, sondern zwei verschiedene entstehen, so wie das eigentlich bei den meisten Reactionen stattfindet, z. B. $\mathrm{KCl}+\mathrm{NaNO}_{3}=\mathrm{KNO}_{3}+\mathrm{NaCl}$.

Denken wir uns weiter, dass die Concentrationen der entstandenen Verbindungen $\mathrm{C}_{1}$ und $\mathrm{C}_{2}$ sind, so wird $\mathrm{S}_{1}=\mathrm{k}^{\prime} \mathrm{C}_{1} \times \mathrm{C}_{2}$ sein. Sind die Concentrationen, in denen die beiden Reactionsproducte entstehen, eirander gleich, so wird $\mathrm{S}_{1}=\mathrm{k}^{\prime} \mathrm{C}_{1}{ }^{2}$.

Nan kann sich nun weiter den Fall vorstellen, und das haben Arrhenius und Madsell offenbar stillschweigend gethan ${ }^{1}$ ), dass aus je einem Molecül freies Toxin und Antitoxin, $z$ we i Molec üle der Verbindung entstehen, also dass eigentlich die folgende Reaction stattfindet

$1 \mathrm{Mol}$ freies Toxin +1 Mol freies Antitoxin $\rightleftarrows 2$ Mol ('Toxin-Antitoxin).

Es bleibt danı natürlich, da jedes der zwei nunmelır gleichen Molecüle eine Concentration $\mathrm{C}_{1}$ besitzt: $\mathrm{S}_{1}=\mathrm{k}^{\prime} \mathrm{C}_{1}{ }^{2}$. Hiernach wird die Formel

$$
\mathrm{C}_{\text {freies }} \text { roxin } \times \mathbf{C}_{\text {freies Autitoxin }}=\mathbf{K}\left({ }^{2}\right. \text { Terbindung Toxin-Antitoxin }
$$

A r r enius und Madsen haben in ihrer Abhandlung die Coucentration ansgedrückt durch den Quotient aus der Menge der Substanz und dem Flüssigkeitsvolum in welchem sie gelöst ist. Ihre f'ormel lautet demnach

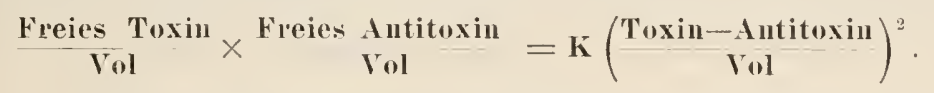

Weil auch bei allen anderen bezüglichen Ausführungen von Arrhenius und von M a d s o n die der Formel 1 a und nicht der Formel 1 entsprechende Schreibweise gebraucht worden ist, schien es mir empfehlenswerth, auch letztere hier vorzuführen.

Tach diesen mehr allgemeinen Betrachtungen kehren wir wieder zu den speciellen Untersuchungen über die Bindung von Tetanolysin zurïick.

'/unächst handelt es sich darum, die Versuchswerthe in die Formel 1 oder 1 a einzusetzen.

Wie aus der Tabelle hervorgeht, waren im ersten Versuche 0,23 cc T'oxin vorhanden und somit anch in den anderen, da stets gerade soviel von den Gemischen genommen wurde, dass in 10 cc der Blutsuspension die gleiche Hämolyse eintrat; also befindet sich in $1 \mathrm{cc}$ Flüssigkeit $\frac{0,23}{10+0,23}$ cc Toxin, und zwar von einer $1^{\%} \%$ igen Toxinlösung ${ }^{2}$ ).

Also $\quad \mathrm{C}_{\text {freies Toxin }}=\begin{array}{r}0,23 \\ 10,23\end{array}$

1) Vergl. die Fussnote auf S. 378.

2) Sie muss deshalb als eine $1 \%$ ige angesehen werden, weil 2 cc der $2^{\circ}{ }_{0}$ igen Tetanolysinlösung mit $(2-n)$ cc Wasser versetzt sind (Spalte 2). Nun ist im ersten Versuch $\mathrm{n}=0$; die zugefügte Wassermenge ist demnach 2. Und wenn man 2 cc einer $2^{\circ}$ oigen Tetanolysinlösung mit 2 ce Wasser versetzt, so bekommt man 4 cc einer $1^{\circ}$ oigen. 
Dieser Werth muss, wie gesagt, in allen Gemischen derselbe sein, weil in allen Versuchen eine gleichgradige (20\% ige) Hämolyse in $10 \mathrm{cc}$ derselben Suspension herbeigeführt wurde.

Mit Hilfe dieses Werthes ist der letzte Factor, d. h. die Concentration der Verbindung Toxin und Antitoxin zu berechnen. Denn diese ist gleich der Concentration des Gemisches von Toxin und Antitoxin (Spalte 2), vermindert um die Concentration des freien Toxins. Das leuchtet ein, wenn man bedenkt, dass nicht nur die ganze Antitoxinmenge durch dasselbe gebunden wird, sondern noch ein Theil des freien Toxins übrig bleibt.

Wie kann man nun die Concentration der Toxin-AntitoxinVerbindung ausdrücken?

$\mathrm{x}$ ist die Gesammtmenge des toxischen Gemisches (Spalte 2); nach Versetzung mit $10 \mathrm{cc}$ Blutsuspension ist dasselbe vertheilt auf $(10+x)$ Flüssigkeit; demnach ist die eigentliche Concentration des Gemisches von Toxin und Antitoxin $\frac{x}{10+x}$. Folglich wird

$$
\mathrm{C}_{\text {Verbindung Toxin und Antitoxin }}=\frac{\mathrm{x}}{10+\mathrm{x}}-\frac{0,23}{10,23} .
$$

Jetzt fehlt nur noch der zweite Factor $\mathrm{C}_{\text {freies Antitoxin. }}$

Dieser wird dadurch berechnet, dass von der Concentration der Gesammtmenge des Antitoxins die des gebundenen in Abzug gebracht wird. Die Concentration des gebundenen wird durch denselben Werth ausgedrückt, der bereits für die Verbindung T'oxin-Antitoxin gefunden wurde, d. h. $\frac{x}{10+x}-\frac{0,23}{10,23}$.

Es bleibt demnach noch die Berechnung der Concentration der totalen Antitoxinmenge ïbrig.

Wie aus Spalte 1 und 2 der Tabelle ersichtlich, sind n. cc Antitoxinlösung zu 2 cc $2 \%$ iger T'oxinlösung hinzugesetzt worden; es kommen also auf jede Einheit Toxin $\frac{\mathrm{n}}{4}$ cc Antitoxinlösung (die Einheit Toxin ist die Quantität Toxin, welclee in 1 cc einer $1 \%$ igen Toxinlösung vorhanden ist).

Wenn uun weiter ein cc der gebrauchten Antitoxinlösung äquivalent ist mit p. cc einer $1 \%$ igen Toxinlösung, so sind $\frac{n}{4}$ cc Antitoxinlösung äquivalent mit $\frac{x}{4}+p$ Toxineinheiten. Da aber eine Verdünnung. 
stattgefunden hat. die $\frac{x}{10+x}$ entspricht, so wird die Concentration der zugefügten n. ce Antitoxinlösung ausgedrückt durch $\begin{aligned} & n \\ & 4\end{aligned} x_{10+x} \mathrm{x}$. Von diesem Betrag muss. wie gesagt, der Betrag des gebundenen ToxinAntitoxins angezogen werden, um die Concentration des freien Antitoxins zu bekommen.

Somit wird die Gleichung:

$$
\begin{gathered}
\left(\frac{0,23}{10,23}\right)\left\{\frac{\mathrm{n}}{4} \times \frac{\mathrm{x}}{10+\mathrm{x}}-\left(\frac{\mathrm{x}}{10+\mathrm{x}}-0.23\right)\right\} \\
\mathrm{K}\left(\frac{\mathrm{x}}{10+\mathrm{x}}-\frac{0.23}{10,23}\right)^{2} .
\end{gathered}
$$

Fügt man aus zwei Versuchen die Werthe von $n$ und $x$ ein, so bekommt man zwei Gleichungen, aus denen man $p$ und $K$ berechnen kann. Es stellt sich dann heraus, dass $\mathrm{p}=14,55$ und $\mathrm{K}=0,115$ ist ${ }^{1}$ ). Die Temperatur war, wie gesagt, $37^{\circ}$.

Setzt man diese beiden Constanten in die Gleichung ein, so kann man andererseits für die verschiedenen 11 , die $x$-Werthe und auch die G-Werthe berechnen und wie die Tabelle lehrt (Spalte 4 und 5), stimmen diese sehr gut mit den gefundenen (Spalte 2 und 3) überein.

Sonach erscheint die Anschaung, dass es sich bei der Neutralisation von Tetanolysin und Antitetanolysin um einen einfachen chemischen Gleichgewichtsvorgang handelt, bei welchem das II assengesetzgültig ist, rollkommen berechtigt.

Arrhenius und II adsen haben, um diese Anschauung noch weiter zu illustriren, Gemische von Ammoniaklösung und Borsäurelösung auf dieselbe Weise auf Blutkörperchensuspension einwirken lassen, wie Tetanolysinlösung und Antitetanolysinlösung. Die Versuchsanordnung entsprach genau der in der Tabelle S. 370 versinnlichten. Bekanntlich ist Ammoniak eine stark hämolytische Substanz, spielt hier also die Rolle des Tetanolysins (Toxins); Borsäure wirkt neutralisirend auf den hämolytischen Finfluss von Ammoniak, fungirt also als Antitetanolysin (Antitoxin).

1) $p=14,55$ sagt also aus, dass $1 \mathrm{cc}$ des gebranchten Antitoxins (voll ${ }^{1} 400^{\circ} \%$ ) äquivalent ist mit $14,55 \mathrm{cc}$ der oben willkürlich angenommenen Toxineinheit, oder m. a. W. Die gebrauchte Toxineinheit stimmt überein mit $\frac{1}{p}=0,069$ cc des angewandten Antitoxins. 
Sie untersuchten nun bei steigenden Quantitäten Borsäurelösung: (Antitoxinlösung; vergl. Spalte 1 der Tabelle), wie viel cc des Gemisches von der Borsäure Ammoniali-lösmng (Spalte 2) jedesmal erforderlich war, um stets denselben Grad von Hämolyse herbeizufülıren.

Es stellte sich nun folgendes heraus:

Borsäure (Antitoxin) in einer (puantität 1 zu einer bestimmten Ammoniak- ('loxin-) Menge hinzugefiigt ${ }^{1}$ ) neutralisirt $50 \%$ dieser Base; in einer (Quantität 2, 66,7\%: in einer (Quantität :3, $75 \%$ und in einer Quantität 4, $80 \%$. Also neutralisirt die erste Quantität Borsäure $50 \%$ des Ammoniaks; die zweite gleiche (vuantität Borsäure 16,7; die dritte und vierte gleiche Quantität. Borsäiure 8,3 und $5 \%$ des Ammoniaks.

Auf die Hämolyse angewandt, wiirde es also heissen, dass das beim vierten Neutralisationsact unsclı̈dlich gemachte Ammoniak 10 mal weniger toxisch war als der beim ersten unschiddich gemachte! Also würde Ammoniak kein einfacher Körper sein, sondern zusammengesetzt aus Bestandtheilen verscliedener Toxic it ät!

Weiter wurde, ebenso wie das beim 'Toxin und Antitoxin geschehen war', muter '/ugrundelegung der Gleichung

$$
C_{\text {freies Ammoniak }} \times C_{\text {freie Borsäure }}=K^{\prime} C^{12} \text { Borsaures Ammuniak }
$$

Werthe für $x$ und $G$ abgeleitet. die eine 'Toxicitätscurve ergaben, welche vollkommen mit der empirisch a ufgefundenen übereinstimm te.

Durch diese Teberlegungen erlält die Ansicht eine kräftige Stütze, dass es sich bei der Neutralisirung von Toxin und Antitoxin um eine allmahlich verlanfende Bindung ohne unvermitelte Spriinge handelt. Die Erscheinung kann auf ein chem isches Gileichgewicht yur ückgefïhrt werden.

Jenn $11 \mathrm{~m}$ was handelt es sich hier eigentlich?

Wenn man. um beim Borsänre-Ammoniak-Beispiel zu bleiben, zu einer bestimmten Ammoniakmenge so viel liorsäure hinzugefügt hat, dass, laut des lämolytischen V'ermögens des Gemisches, j00/0 des freien Ammoniaks gesättigt ist und man fügt abermals die gleiche Borsäuremenge hinzu, so wird diese Borsäme sich wohl mit dem zurïckgebliebenen Ammoniak rerbinden, aber zn gleicher \%eit findet auch eine Spaltung eines 'Theiles des gebildeten Ammonimmborats in Borsäure und Ammoniak statt, sodass durcl die genannte abermalige Hinzufuigung der gleichen

1) Hierbei wird angenommen, dass auch in acidimetrischom Sinne die Borsäure noch nicht genügt, um alles Ammoniak zu sättigen. 
Borsäuremenge praktisch keine vollkommene Absättigung der übriggebliebenen Ammoniaks stattfindet. Fs bleibt noch freies Amoniak, allerdings neben freier Borsäure bestehen. Fïgt man dam wieder neue Borsäure hinzu, so wird, da in der (ileiclung (S. 372), S durch \%unalıme des Borsäure- (Antitoxin-) Gehalts wächst, die Bildung von Ammoninmborat zunehmen. Selbstverständlich nimmt anch $S_{1}$ zn, da die Concentration des Ammoniumborats zunimmin, nicht aber in gleichem Grade, denn $S_{1}$ hängt auch von $k^{\prime} a b$, ebenso wie $S$ von $k$ abhängig ist. Offenbar wird denn auch die ganze Gleichgewichtsreaction in hohem Maasse von ${ }_{k}^{\prime}=K$ der Dissociationsconstante beherrscht, die für jedes System eine andere ist. In ganz ïhnlicher Weise geht es mit der Sättigung von 'Toxin durch Antitoxin. Wenn man sich zu 'Toxin eine aquivalente Menge Antitoxin hinzugefügt denkt, so wird das Gemisch dennoch toxisch sein, weil die Verbindung Toxin-Antitoxin sich theilweise dissociirt in freies 'Toxin und Antitoxin. Fährt man mit der Hinzufügung ron Antitoxin fort, so wird die Dissociation der Verbindung stets mehr zurïckgedrängt, oder, wie man in solch einem Fall zu sagen pflegt, das Gleichgewicht wird nach rechts verschoben (siehe die Gleichgewichtsgleichung S. 373).

Eine vollständige Absättigung des freien loxins erfolgt nie, denn stets wird nach fortgesetzter /ufügung ron Antitoxin, sich etwas von der Verbindung Toxin-Antitoxin dissociuren ${ }^{1}$ ). Praktisch ist aber dennoch eine sichtbare Aufhebuug der Toxicität zu erreichen. Wenn sie nur unter dem schwellenwerth der Reaction (Hämolyse oder Krankheitssymptom) bleibt, pflegen wir zu sagen, dass vollständige Neutralisation statigefunden liat.

Die Verfasser heben noch hervor, dass aus der Aehnlichkeit zwischen den Gleichgewichtzuständen von Ammoniak, Borsäure und Ammoniumborat (und deren Ionen) auf der einen Seite, und den Gleichgewichtzuständen von Toxin, Antitoxin und der Verbindung Toxin-Antitoxin auf der anderen Seite, nicht der Schluss gezogen werden darf, dass das Toxin.Antitoxin elektrolytisch dissociirt sei, oder auch dass Toxin eine Base und dass Antitoxin eine Säure und dementsprechend die Verbindung ein Salz sei. Es liegt hier offenbar, a case of common dissociation" vor.

In ganz ähnlicher Weise lat dann Madsen die bindungsverbältnisse von Diphtheriet ox in und Diphtherieantitox in studirt $|76|$. Yur musste hier die Giftigkeit durch das Thierexperiment ermittelt

1) Eine schöne experimentelle Bestïtigung dieser Anschauung findet man in der zweiten Fussnote auf Seite $380 \mathrm{ff}$. erwähnt. 
werden. Hierzu stellte Madsen fest, wie viel von Gemischen einer bestimmten Menge Toxin mit verschiedenen Mengen von Antitoxin erforderlich waren, um eine Cavia von $250 \mathrm{~g}$ noch gerade $\mathrm{zu}$ tödten; in ähnlicher Weise war beim Tetanolysin festgestellt, wie viel ron einem Gemische einer bestimmten Menge Toxin mit verschiedenen Mengen Antitoxin erforderlich war, um in einem bestimmten Blutkörperchengemisch $20 \%$ Hämolyse herbeizuführen.

Je mehr man ron den Gemischen braucht (die Anzahl cc wurde $\mathrm{x}$ genannt), um die kritische Reaction auszulösen, desto geringer ist die Giftigkeit $G$ dieses Gemisches (vergl. die Tabelle S. 370 und auch die folgende Tabelle). Es stellte sich nun heraus, dass die beobachtete Giftigkeit in sehr befriedigender Weise übereinstimmte mit der, welche sich berechnen liess auf Grund der Annahme, dass die Bindung von Diphtherietoxin und Diphtherieantitoxin nach der Formel 1 oder $1 \mathrm{a}$ erfolgt $\left.{ }^{1}\right)$.

$\mathrm{C}_{\text {freies Toxin }} \times \mathrm{C}_{\text {freies Antitoxin }}=\mathrm{KC}^{2}$ Toxin-Antitoxin-Verbindung.

Ich gebe eine Tabelle, aus welcher die Versuchsresultate hervorgehen. Sie ist in derselben Weise angeordnet, wie die beim Tetanolysin mitgetheilte. Nur sei noch bemerkt, dass die Toxinmenge hier stets 0,1 cc betrug.

Biudungsverhältuisse von Diphtherietoxin und Diphtherieantitoxin.

\begin{tabular}{|c|c|c|c|c|}
\hline I & II & III & IV & $\mathrm{V}$ \\
\hline $\begin{array}{l}\text { n (Anzahl cc antitoxi- } \\
\text { sehes Serum, ausge- } \\
\text { drückt in Immunisir- } \\
\text { ungseinheiten, welche } \\
\text { zu } 0,1 \text { ce Toxinlösung } \\
\text { hinzugefügt wurden) }\end{array}$ & $\begin{array}{c}x \text { (Anzahl ec der } \\
\text { Gemische von Spalte 1, } \\
\text { welche gerade noch } \\
\text { im Stande sind, eine } \\
\text { Cavia zu tödten) }\end{array}$ & $\begin{array}{c}\text { G (Giftigkeit der } \\
\text { Gemische von Spalte 1, } \\
\text { d. h. wie viel letale } \\
\text { Dosen in (n+ }+0,1 \text { ce) } \\
\text { des Gemisches von } \\
\text { Spalte } 1 \text { noch vorhanden } \\
\text { sind }\end{array}$ & $\begin{array}{c}\mathrm{x} \\
\text { berechnet } \\
\text { (Vergl. } \\
\text { S. } 375)\end{array}$ & $\begin{array}{l}\text { G } \\
\text { berechnet } \\
\text { (Vergl. } \\
\text { S. } 375)\end{array}$ \\
\hline 0 & 0,002 & 50 & 0,0015 & 66,67 \\
\hline 0,05 & 0,002 & 50 & 0,00173 & 57,8 \\
\hline 0,1 & 0,0022 & 45 & 0,00207 & 48 \\
\hline 0,15 & 0,0022 & 40 & 0,0025 & 40 \\
\hline 0,2 & 0,0033 & 30 & 0,0032 & 31 \\
\hline 0,25 & 0,005 & 20 & 0,0044 & 22,9 \\
\hline 0,3 & 0,0067 & 15 & 0,0066 & 15,3 \\
\hline 0,35 & $0,01-0,012$ & $10-8$ & 0,011 & 9,1 \\
\hline 0,4 & 0,017 & 6 & 0,019 & 5,3 \\
\hline 0,45 & 0,013 & 3 & 0,03 & 3,4 \\
\hline
\end{tabular}

1) Aus noch nicht veröffentlichten Untersuchungen hat sich herausgestellt, dass hier die beiden neuen Molecüle, welche bei der Einwirkung von Toxin auf Antitoxin entstehen, nicht dieselben, sondern verschiedene sind. Sie werden des- 
Ist $n=0$, d. h. wird kein Antitoxin z, 0,1 ec Toxin hinzugefingt, so sind also nur $0,002 \mathrm{cc}$ erforderlich, um das Thier zu tödten und die Giftigkeit ist in Einheiten ausgedriickt, $\frac{0,1}{0,002}=50$.

Ist $n=0,05, d$. h. werden 0,05 cc Antitoxin zu 0,1 ce Toxin hinzugefügt, so sind 0,002 des Gemisches erforderlich, um das 'Thier zu tödten.

Ist $\mathrm{n}=0,2, \mathrm{~d}$. $\mathrm{h}$. werden 0,2 cc Antitoxin zu $0,1 \mathrm{cc}$ Toxin hinzugefügt, so sind 0,0033 ce des Gemisches erforderlich.

Ist $n=0,4$, d. h. werden 0,4 ce Antitoxin zu 0,1 ce Toxin hinzugefügt, so sind 0,017 cc des Gemisches erforderlich.

Hieraus geht hervor, dass man eine grössere Menge des Gemisches braucht, um das Thier z.u tödten, wenn mehr Antitoxin im Gemisch rorkommt: aber diese Menge steigt in viel bedeutenderem IIasse als mit der Vermehrung der Antitoxinzufuhr übereinstimmt (vergl. S. 369). Dementsprechend scheint auch die Giftigkeit der Gemische sehr schnell abzunehmen (Spalte III) und man empfängt auch hier den Eindruck, dass der bereits gesätigte Theil des Toxins der giftigste ist.

Also auch hier könnte man beim ersten Anblick mit Ehrlich geneigt sein, anzunehmen, dass im Diphtherieserum Toxine verschiedener Giftigkeit vorkommen. Die grosse Uebereinstimmung zwischen den Zahlen von Spalte IV mit Spalte II, und von Spalte $V$ mit Spalte III ${ }^{1}$ ), m. a. W. die Uebereinstimmung zwischen den Werthen, die sich unter Zugrundelegung der Annahme berechnen lassen, dass eine reversible Reaction vorliegt einerseits, und den rein experimentell gefundenen Werthen andererseits, berechtigen aber zu der Vorstellung, dass es sich hier um ein bewegliches Gleichgewicht zwischen freiem Toxin, freiem

halb mit Toxinan und Titoxin bezeichnet. (Briefliche Mittheilung von Prof. Arrhenius.) Sonach wird die Gleichung:

$\mathrm{C}_{\text {Toxin }} \times \mathrm{C}_{\text {Antitoxin }}=\mathrm{KC}_{\text {Toxinan }} \times \mathrm{C}_{\text {Titoxin }}$

oder, da die Concentrationen der beiden Producte die gleichen sind,

$\mathrm{C}_{\text {Toxin }} \times \mathrm{C}_{\text {Antitoxin }}=\mathrm{KC}^{2}$ Toxinan.

Es ist nach Prof. Arrhenius wahrscheinlich, dass die Verhältnisse beim T'etanolysin ähnlich liegen.

1) Für die Berechnung von $x$ und $G$ verweise ich nach $S .371$ u. 375. Nur sei hier bemerkt, dass die minimale letale Dosis des unvermischten Toxins 0,015 cc betrug. In $0,1 \mathrm{cc}$ dieses Toxins waren also $\frac{0,1}{0,015}=66,67$ tödtlichen Dosen vorhanden, wie auch in der ersten Horizontalreihe der Tabelle angegeben ist. 
Antitoxin und der Verbindung von Toxin und Antitoxin handelt, gatuz ähnlich wie beim System Tetanolysin-Antitetanolysin und beim System Borsäure-Ammoniak (vergl. S. 376). Sonach erscheint die Annalrme von verschiedenartigen Toxinen, von einem sogenannten Toxinspectrum, im Diphtherieserum, ganz überflüssig ${ }^{1}$ ).

Ehrlich hat diese Ansicht, welche er tïr das Tetanusgift anerkennt, für das Diphtheriegift kräftig bestritten [77]. Der Autor hegt die Ueberzeugung, dass das Diphtheriegift aus mindestens drei Giftvarietäten besteht.

1. Das Toxin.

2. Das Toxon, das Kaninchen acut, Meerschweinchen unter Lälımung tödtet.

3. Toxonoide, bei Kaninchen Lähmungen erzengend, für Meerschweinchen unschädlich.

Arrhenius ist ihm die Antwort nicht schuldig geblieben [78].

Ich kann auf die interessante Discussion, an der sich auch namentlich Gruber [79] und von Dungern [80] betheiligt luaben, der erste zur Bekïmpfung, der zweite zur Tertheidigung von Ehrlich's Anschauung, nicht eingehen. ohne zu ausführlich zu werden. Ausserdem besteht dazu um so weniger Veranlassung, weil sie noch nicht zum Abschluss gelangt scheint und ich die physikalisch-chemischen Principien, die der Discussion zn Grunde liegen, wie ich meine, in genügendem Maasse klar gelegt habe, so dass man dem Weiteren ohne Schwierigkeit wird folgen können ${ }^{2}$ ).

1) Das Bestehen von Prototoxoiden, die beim Aufbewahren des Giftes entstehen sollen, giebt Madsen aus Gründen, die ich hier nicht näher erörtern kann, in der vorliegenden Abhandhung zu. Wie aber Arrhenius neuerdings mitgetheilt hat (Berl. klin. Wochenschr. 1904. Nr. 9) ist nach neueren Untersuchungen von Madsen und Arrhenius die Existenz derselben höchst zweifelhaft.

2) Nur scheint es mir crwïnscht, noch mit einigen Worten auf eine gerade vor dem Abdrucken des vorliegenden Bogens erschienene wichtige Arbeit von Madsen und Walbaum (Centralbl. f. Bacteriol. :36. 1904. S. 242) linzuweisen, zumal ich dadurch die Gelegenheit habe, auf eine Methode aufmerksam zu machen, die die Beachtung in hohen Maasse beansprucht. Eigentlich war dieselbe bereits früher von Arrhenius und Madsen zu einem anderen Zweck benutzt (vergl. unten S. 336 unter 7.).

Madsen und W albanm experimentirten folgender Weise:

Sie versetzten eine gewisse Menge Diphtherietoxin mit soviel Diphtherieantitoxin, dass das Gemisch keinen toxischen Effect bei Meerschweinchen mehr zeigte. Wurde nun ein derartiges Gemisch auf erstarrte Gelatine geschichtet, so zeigte sich nach längerer Zeit in der oberen Schicht der Gelatine ein Uebermaass von Antitoxin 
Noch sei hier erwähnt, dass Arrhenius nicht nur die Bindung von Toxin und Antitoxin, sondern auch die damit veroleichbare Hämolysinbildung auf das Massenwirkungsgesetz zurïckgeführt hat [81,82]. Indem er sich nämlich auf den Standpunkt Ehrlich's stellt, dass das Hämolysin aus einer chemischen Bindung von Amboceptor und Complement entsteht (vergl. S. 349), die nach dem Gesetze des Theilungsprincipes in die Blutkörperchen eindringen (vergl. unten S. 385), stellt er sich vor, dass die Bildung des Hämolysins aus den zwei Componenten nach einer ähnlichen Gleichung vor sich geht, die auch bei der Sättigung ron Gift und Gegengift obwaltet.

$$
\mathrm{C}_{\text {Amboceptor }} \times \mathrm{C}_{\text {Complement }}=\mathrm{KC}_{\text {Hämolysin }}
$$

oder allgemeiner, nach der Gleichung:

$$
\mathbf{C}^{\mathrm{a}}{ }_{\text {Auboceptor }} \times \mathbf{C}_{\text {'omplement }}=\mathbf{K C}_{\text {Hämolysin }}
$$

und in den unteren Schichten von Toxin. Offenbar war also im ursprüngliclien Gemisch noch freies Antitoxin und freies Toxin vorhanden gewesen, von dem das Antitoxin langsamer in die Gelatine diffundirte als das Toxin.

Die Autoren beschreiben den Versuch etwa folgendermaassen:

Man versetzt 2 cc Diphtherietoxin mit einer Antitoxinmenge von 12 Immunisationseinheiten. Dieses Gemiscl hat absolut keinen toxischen Effekt auf Meerschweinchen. Es sind eine Reihe Eprouvetten aufgestellt worden, die alle eine erstarrte $10^{\circ} \%$ ige Gelatinelösung enthalten. Auf je eine Gelatineoberfläche bringt man 2 cc des eben genannten Toxin-Antitoxingemisches und überlässt daun die Röhrchen sich selbst bei $2^{\circ}$ à $3^{\circ} \mathrm{C}$. Nach einiger Keit entfernt man die Flüssigkeit, wäscht die Gelatineoberfläche mit einer sterilen NaCl-Lösung ab, zerschneidet die Gelatinesäule in Würfel, schmilzt dieselben und ermittelt den Gehalt an Antitoxin resp. an Toxin.

Beispiel: Nach einer Versuchsdauer von 66 Tagen entfernt man ${ }^{3} / 2$ ce der oberen Gelatineschicht, versetzt mit 0,0035 cc Toxin, eine auf sich selbst zweifellos letale Dosis; das Thier bleibt unversehrt.

Hieraus geht hervor, dass sich in der oberen Gelatineschicht freies Antitoxin hefand.

Ferner schmilzt man die weiter nach unten gelegenen 10 cc Gelatine. Die eine Hälfte tödtet Meerschweinchen innerhalb $4^{1 / 2}$ Tagen. Die andere Hälfte wird mit 400 Inınunisationseinheiten versetzt. Jetzt entsteht nach der Infektion bloss ein vorübergehendes Hautödem.

Aus diesem Versuche - andere gaben ein gleichlautendes Resultat - erhellt, dass nach Sättigung von Diphtherietoxin durch Diphtherieantitoxin, die, nach dem Thierexperiment $\mathrm{zu}$ urtheilen, eine vollständige Inactivirung des Giftes zur Folge hat, dennoch freies Toxin und freies Antitoxin vorhanden bleibt (S. 377). Das kanu kaum anders als dadurch erklärt werden, dass hier eine partielle Dissociation der Verbindung Toxin-Antrtoxin vorliegt. Es handelt sich also um denselben Fall, wie wenn äquivalente Nengen Borsäure und Ammoniak mit einander vermischt sind. Fs bleiben dann noch freies Ammoniak und freie Borsäure neben borsaurem Ammoniak in der Flïssigkeit bestehen. 
Mit dieser exponentiellen Form $\mathrm{C}^{\mathrm{a}}$ Amboceptor will Arrhenius offenbar aussagen, dass a Molecüle des Amboceptors mit einem Molecül des Complementes sich zu einem Molekïl Hämolysin verbinden. Arrhenius bemerkt, dass in den von ihm untersuchten Fällen, der Exponent a gewöhnlich den Werth 1 oder $2 / 3$, seltener $1 / 3$ annahm.

Ist demnach a, z. B. ${ }^{2 / 3}$, so lantet die Formel

oder

$$
\mathrm{C}^{2} /{ }^{\text {Amboceptor }} \times \mathrm{C}_{\text {Complement }}=\mathrm{C}_{\text {Hämolysin }}
$$

$$
\mathrm{C}^{2} \text { amboceptor } \times \mathrm{C}^{3} \text { Complement }=\mathrm{C}^{3} \text { Hämolysin . }
$$

Es müssen hier also doppel- und dreifache Moleküle gebildet sein (vergl. oben S. 373 und unten S. 384).

Gelegentlich dieser Untersuchungen hat der Autor noch gefunden, dass das bei der Immunisirung von Thieren gegen den hämolytischen Einfluss fremdartigen Blutes das fertige Hämolysin als ganzes und nicht das freie Complement bei der Immunisirung gebildeten Anticomplement gebunden, und also unschädlich gemacht wird (vergl. S. 353). Besser wäre es demnach das Anticomplement mit Antihämolysin zu bezeichnen.

Die Mittheilung aller dieser der Hämolysinbildung betreffenden Experimente steht augenblicklich noch aus. Der Autor hat dieselben in Aussicht gestellt.

\section{Bindungsverhältnisse des Agglutinins (und des Hämolysins) vom Standpunkt des Theilungsprincips.}

Wenn eine Bacteriencultur einem 'Thier einverleibt wird, so bekommt bekanntlich das Blutserum dieses Thieres die Eigenschaft die Bacterien einer gleichnamigen Cultur zusammenzukleben, zu agglutiniren. Iie im genannten Serum entstandene Substanz, welche diese Zusammenklebung vermittelt, bezeichnet man mit dem Namen Agglutinin.

Eisenberg und Tolk [83] haben eine grosse Zah] von quantitativen Versuchen angestellt, um die Bindungsverhältnisse des Agglutinins gegenüber den Bacterien zu ermitteln.

Die Versuche wurden so ausgeführt, dass zu einer bestimmten Menge von Bacterien eine gegebene Menge agglutinirendes Serum zugesetzt wurde. Nachdem die Mischung zwei Stunden im Thermostat bei $37^{\circ}$ und danach 24 Stunden bei Zimmertemperatur gestanden hatte, war der Gleichgewichtszustand längst eingetreten -- eigentlich war das schon nach weniger als fünf Minuten, selbst bei $0^{0}$ eingetreten - und die Bacterien hatten sich am Boden unter einer klaren Flïssigkeit zusammengepackt. 
Um dann die im Serum zurïckgebliebene Agglutininmenge zu ermitteln, wurde von der Flüssigkeit ein wenig abpipettirt und es wurde untersucht, in welcher Verdünnung sie noch eine eben deutliche Agglutination der betreffenden Bacterien hervorzurufen vermochte.

In derselben Weise war die Stärke des ursprünglich zugesetzten agglutinirenden Serums bestimmt. Durch Subtraction der eben erwähnten Agglutininmenge von der im Serum ursprünglich vorhandenen, konnte dann ermittelt werden, wie viel voll dem zugegebenen Agglutinin in die Bacterienleiber eingedrungen war.

Der Agglutiningehalt wurde folgendermaassen ausgedrückt. Wenn man z. B. 40000 Wasser zu 1 cc der zu untersuchenden Flüssigkeit hinzusetzen müsste, damit die agglutinirende Wirkung auf noch nicht agglutinirte Bakterien eben bemerkbar blieb, so war der Agglutiningehalt der Flüssigkeit 40000 Einheiten.

Es ist Arrhenius nun gelungen [84] zwischen der in die Bacterien aufgenommenen und der in der Flüssigkeit gebliebenen Agglutininmenge eine Gesetzmässigkeit zu entdecken. Es stellt sich nämlich heraus, dass das Agglutinin sich über Bacterien und umgebende Flüsigkeit nach dem Gesetze des Theilungsprincipes rertheilt.

Von diesem Princip ist bereits mehrmals die Rede gewesen. Ich verweise nach Bd. II, S. $411 \mathrm{ff}$., diesen Band S. 73, 246 und auch besonder's im letzten Kapitel wird noch darïber gehandelt. Bei der Nachlesung wird man bemerken, dass, wenn eine Substanz mit zwei nicht mischbaren Flüssigkeiten geschïttelt wird, dieselbe sich über die beiden Flüssigkeiten nach dem Verhältniss der Löslichkeiten vertheilt. Ob man wenig oder viel von dieser Substanz nimmt ist dabei gleichgiiltig. Das Verhältniss der gelösten Mengen, das man hier mit dem Namen Theilungscoëfficient berechnet, ist davon unabhängig; bei unveränderter Temperatur ist der Theilungscoëfficient ein constanter Werth.

Aehnliche Gesetzmässigkeit gilt, wenn die Substanz sich nicht über zwei Flüssigkeiten, sondern über eine Flüssigkeit und einen festen Körper vertheilt. Nach van't Hoff's Ausführungen giebt es ja Auflösungen ron Substanzen in festen liörpern, sogenannte feste Lösungen. Und so kann man sich hier vorstellen, dass in einer Bacteriensuspension das Agglutinin sich vertheilt über die Bacterienleiber und der umgebenden Fliissigkeit, und zwar wenn das Theilungsprincip hier gültig ist, stets nach einem einfachen festen, constanten Verhältniss. Wenn z. B. in einem Tersuch die Bacterien 5 mal mehr von einer Agglutininmenge aufgenommen haben als die Flüssigkeit, so muss dis in einem anderen Versuch, wo ceteris paribus ¿ cc Agglutinin zur Verfügung stand, auch der Fall sein.

Jedoch lehrt die Umrechnung ron Eisenberg und Volk's Versuchen, dass das nicht zutrifft. 
Nun hat Nernst darauf hingewiesen, dass der Molecularzustand chemischer Verbindungen nicht in allen Medien derselbe ist. So z. B. ist Benzoësäure, in Wasser gelöst $\mathrm{C}_{6} \mathrm{H}_{5} \mathrm{COOH}$, in Benzol gelöst ist rie Substanz als Doppelmoleciil vorhanden, also als $2 \mathrm{C}_{6} \mathrm{H}_{5} \mathrm{COOH}$. Unter diesen Umständen ist das Verhältniss

Concentration von Benzoësäure in Wasser $\left(\mathrm{C}_{1}\right)$
C'oncentration von Benzoësäure in Benzol $\left(\mathrm{C}_{2}\right)$ sondern es gilt, wie ich unter „Histologisches“ $2 \mathrm{~b}$ erörtert habe,

$$
\left.\frac{\mathrm{C}_{1}}{\sqrt{\mathrm{C}_{2}}}=\text { constans, orler } \frac{\mathrm{C}_{1}{ }^{2}}{\mathrm{C}_{2}}=\text { constans. }{ }^{1}\right)
$$

Dem entsprechend hat Arrhenius auf empirischem Wege gefunden

\section{(Concentration des Agglutinins in den Bakterienleibern) ${ }^{3}$ (Concentration des Agghtinins in (ulturllïssigkeit)2 \\ = constans. $(3)$}

In Analogie mit dem bei Benzoësäure Erörterten könnte man hier sagen: das Agglutinin in der Fliissigkeit (freies Agglutinin) hat ein anderthalb Mal so grosses Moleculargewicht. wie das in den Bacterienleib a ugenommene Agglutinin, m. a. W. besteht in der Fliissigkeit das Agglutininmolekiil aus einem Polymeren von 3 einfachen Molecülen, so besteht das Agglutinin in Bacterienleib nur aus einem Doppelmolecül.

Aus folgendem Beispiel möge hervorgehen, wie sich der ebengenannte Quotient wirklich als Constante documentirt.

Es handelt sich hier um das Serum eines Pferdes, das mit Typhus bacillen geimpft worden ist. Das Serum hat dadurch das Vermögen crlialten, in Aufschwemmungen von Typhusmikroben in $0.82 \%$ iger $\mathrm{NaCl}$ Lösmg, die Bacillen zu agghntiniren.

\begin{tabular}{|c|c|c|}
\hline $\begin{array}{l}\text { C } \\
\text { Concentration des } \\
\text { Agglutinins in den } \\
\text { Bacterienleibern }\end{array}$ & $\begin{array}{c}\text { B } \\
\text { Concentration des Agglutinins } \\
\text { in der Flüssigkeit } \\
\text { der Bacteriensuspension }\end{array}$ & $\begin{array}{c}\text { Constante, } \\
\text { mittelst der } \\
\text { Formel (3) aus } \\
\mathrm{O} \text { und B be- } \\
\text { rechnet }\end{array}$ \\
\hline 180 & 20 & 24,4 \\
\hline 340 & 60 & 22,6 \\
\hline 1500 & 500 & 23,7 \\
\hline 6500 & 3500 & 28,8 \\
\hline 11000 & 9000 & 25,4 \\
\hline
\end{tabular}

1) Diese Con-tante hat sellostverstämlich cinen andren Werth wir die vorige. 
Man sieht, dass trot\% Anwendung ron weit auseinander gehenden Agglutininmengen. der ()notient in sehr befriedigender Weise constant ist.

Ich habe hier die Bezeichnungen "C" und "B* von Arrhenius ïbernommen, um dem Leser noch mit einigen Worten klar zu machen, wie der Autor zu der von ihm in der ursprünglichen Abhandlung angewandten, aber nicht näher erörterten Formel $\mathrm{C}=$ const. $\mathrm{B}{ }^{2 / 3}$ gelangt ist.

Entsprechend der in der Tabelle gegebenen Bezeichnung der Buchstaben kann nämlich Formel (3) geschrieben werden:

$$
\begin{aligned}
\mathrm{C}^{3} & =\text { Constans } \\
\mathrm{B}^{2} & =\text { also } \mathrm{C}^{3}=\text { Constans } \times \mathrm{B}^{9} .
\end{aligned}
$$

Zieht man aus dieser Gleichung die Cubikwurzel, so bekommt man

$$
\left.\mathbf{C}=\text { Constans }^{1}\right) \times \mathbf{B}^{2 / 3} \text {. . . . . . . . . . (3a). }
$$

Diese Untersuchungen zeigen u. A.. dass die Agglutinine wirklich ron dem Bacterienleib aufgenommen werden und nicht, wie man sich friiher, besonders nach Bordet's Untersuchungen vorstellte, auf der Oberfläche condensirt werden. Einmal in den Bacterienleib aufgenommen, können die Agglutinine in demselben Veränderungen herbeiführen ${ }^{2}$ ).

Eine ganz älınliche Ansicht vertritt nun Arrenius mit Bezug auf das Hämolysin. Der Amboceptor rertheilt sich über Blutkörperchen und umgebende Fliissigkeit und zwar in dem Sinne, dass die Blutkörperchen bei weitem den grössten Theil in sich aufnehmen. Auch das Complement vertheilt sich über Blutkörperchen und Umgebung, aber von dieser Substanz geht nur ein relativ kleiner 'Theil in die Blutkörperchen über. Was hinein geht, verbindet sich num mit dem Amboceptor zu Hämolysin. Von einer Sensibilisirung des Alexins (Complementes) wie es sich Bordet rorstellt (S. 344), ist also nach Arrhenius nicht die Rede.

Ich kann hier die Versuche, welche den Ansichten von Arrhenius bezüglich der Hämolysinbildung zu Grunde liegen, nicht anführen, weil diese augenblicklich noch nicht veröffentlicht sind. A r'penius hat bis jetzt bloss die Resultate dieser auf Wunsch von Ehrlich rorgenommenen Untersuchungen mitgetheilt [82].

1) Dieser Constans ist wieder ein anderer als der Vorige; er ist die Cubikwurzel aus der vorigen Constante. Aber wenn ein Werth constant ist, so ist aucl seine Cubikwurzeln eine Constante.

2) Es kommt mir wahrscheinlich vor, dass diese in einer Zustandsänderung (einer Art Ausflockung) der Collö̈de in den Bacterien bestehen. 


\section{Verbindungswärme von Tetanolysin und Antitetanolysin.}

Arrhenius und Madsen haben den aus der Gleichung (1) oder (1 a) von S. 373 abgeleiteten Factor K (Gleicbgewichtsonstante) auch benutzt, um die Wärmetönung (W) bei der Verbindung von 1 Grammmoleciil Tetanolysin und 1 Grammmolecuil Antitetanolysin zu ermitteln.

Sie haben hierzu die von van't $\mathrm{H}$ off angegebene Formel benutzt:

$$
\frac{\text { d. } \log \text { nat. } K}{\mathrm{dt}}=\frac{\mathrm{W}}{1,99 \mathrm{~T}^{2}}
$$

Hier ist $t$ die Temperatur, 'T die absolute Temperatur, W die gesuchte Wärmemenge.

Sie haben die Grösse von $\mathrm{K}$ bei zwei Temperaturen ermittelt (vergl. S. 375). Bei $\mathrm{t}^{\prime}=37,25^{\circ}$ war $\mathrm{K}=1,18$ und bei $\mathrm{t}^{\prime \prime}=20^{\circ}$ war $\mathrm{K}\left(\mathrm{K}^{\prime}\right)=0,25$.

Die Formel lässt sich nun in folgender Weise schreiben:

$$
\begin{aligned}
& \frac{\log \text { nat. } K-\log \text { nat. } K^{\prime}}{t^{\prime}-t^{\prime \prime}}=\frac{W}{1,99 \cdot\left(t^{\prime}+273\right)\left(t^{\prime \prime}+273\right)} \\
& W=\frac{\log \text { nat. } K-\log \text { nat. } K^{\prime}}{t^{\prime}-t^{\prime \prime}} \times 1,99\left(t^{\prime}=273\right)\left(t^{\prime \prime}+273\right) \\
& W=\frac{\log \text { nat. } 1,18-\log \text { nat. } K^{\prime}}{37,25-20} \times 1,99 \times 310.25 \times 293= \\
& 1,99 \times 310,25 \times 293=6600 \text { Cal. }
\end{aligned}
$$

$2,3035 \log 1,18-2,3025 \log 0,25$

Hiernach werden also bei der Verbindung von 1 Grammmolecuil Tetanolysin mit 1 Grammmoleciil Antitetanolysin annähernd 6600 Calorien frei. Diese Wärmeentwickelung ist erheblich, wenn man bedenkt, dass bei der Neutralisation eines Gramnmolecüls einer starken Säure und einer starken Base nur, die doppelte Wärmemenge (13700 Calorien bei $\left.18^{\circ}\right)$ frei wird.

\section{Moleculargewicht von Diphtherietoxin.}

Da es bis jetzt noch nicht gelungen ist, Toxin- und Antitoxinpräparate von Diphtherie von hinreichender Reinheit herzustellen und es also niclıt möglich ist, durch directe Methoden, wie Gefrierpunktoder Dampfspannungermittelung das Moleculargewicht zu bestimmen, so haben Arrlıenius und Madsen eine indirecte Methode versucht [85]. Diese berulıt auf ler grösseren Diffusionsgeschwindigkeit, die Stoffe mit kleinerem Holecül gegenüher solchen mit grösserem Molecül anfweisen. Bekanntlich ist bei Gasen die Diffusionsgeschwindigkeit der Quadrat- 
wurzel des Moleculargewichtes umgekehrt proportional, also wenn D die Diffusionsgeschwindigkeit und in das Moleculargewicht bedeuten, ist D $\sqrt{\mathrm{m}}$ constant. Bei wässerigen Lösungen von festen Stofien ist das nach Hüfner und Euler nur in beschränktem Maass der Fall. Bei $12^{\circ}$ C. schwankt das Product D $\sqrt{\mathrm{m}}$ um 5,4 (für Rohrzucker $=5,3$ für Mannit 5,4, für Citronensäure 5,7, für Weinsïure 5,4, Aethylalkolıol 5,0 und Ammoniak 5,8$)$.

Arrlenius und Madsen haben nun die Diffusionsgeschwindig. keit von Toxinen, mit der bekannten Diffusionsgeschwindigkeit von Kochsalz rerglichen. Hierzu wurde eine $5^{0}$ oige neutralisirte Lösung volı feiner Gelatine in einem Reagensröhrchen sterilisirt und abgekühlt. Aul die Oberfläche wurden dann 2 cc einer wässerigen Lösung der zu untersuchenden Substanz geschichtet. Nach einiger Zeit wurde das Röhrchen vorsichtig zerbrochen und von dem oberflächlich schnell abgewaschenen Gelatinecylinder Stückchen von bestimmter Dimension ausgeschnitten und deren Toxitität ermittelt. Es geschah dies bei Diphtherietoxin durch das Thierexperiment. Die Minimum letale Dosis für Meerschweinchen von $250 \mathrm{~g}$ betrug, wenn die ursprïngliche Toxinlösung gebraucht wurde, $0,0027 \mathrm{cc}$; von der Flüssigkeit, welche nach dem Versuch die Gelatine noch bedeckte $0,00 t \mathrm{cc}$; von der oberen Gelatineschichte $0,01 \mathrm{cc}$; ron der darauffolgenden Schichte 0,048 ce und vou der dritten Schichte 2 ce.

Die darunterliegenden Schichten waren gar nicht toxisch.

Gleichartige Experimente wurden mit Diphtherieantitoxin, Tetanolysin und Antitetanolysin ausgefiihrt.

Aus diesen Experimenten wurden die folgenden Diffusionsconstanten D berechnet:

\begin{tabular}{|c|c|}
\hline Für Diphtherietoxin & 0,0142 \\
\hline Diphtherieantitoxin & 0,00149 \\
\hline Tetanolysin & 0,0366 \\
\hline Antitetanolysin & 0,00205 \\
\hline
\end{tabular}

Man sieht dass die Diffusionsconstanten für die beiden Antitoxine viel kleiner sind als für die betreffenden Toxinen, woraus herrorgeht, dass die Moleculargewiclte der Antitoxinen riel grösser sind als die der 'T'oxinen.

Wie die Verfasser mit Recht hervorleben, kann diese Metlode nicht zu gena ue n Moleculargewichtsbestimmungen dienen, weil die Gleichung $\mathrm{K} \sqrt{\mathrm{m}}=5,+$ keineswegs allgemeine Giltigkeit hat. Bei abnehmendem Moleculargewicht, oder besser gesagt, bei V'ereinfachung des Molecularbaues steigt der Werth von $\mathrm{K} \sqrt{\mathrm{m}}$. Vielleicht findet man spüter statt $\mathrm{K} / \mathrm{m}$ einen Ausdruck, der allgemeinere Gültigkeit besitzt. 


\section{Ansichten von R. Sleeswyk über das Wesen von Infection und Immunität.}

Im vorigen Jahre erschien eine merkwürdige Schrift [86], die in den Bïcherbesprechungen der medicinischen Zeitschriften nur oberflächliche Erwähnung gefunden hat. Vielleicht trägt der Verfasser selbst theilweise die Schuld hieran, weil das Büchlein nicht in sehr übersichtlicher Weise geschrieben ist; zum anderen, nicht geringen Theil mag die Ursache sicher auch darin liegen, dass der Autor über verschiedene fundamentale Probleme, auch auf rein physikalischem Gebiete, Auffassungen hat, die von den gangbaren Vorstellungen so sehr abweichen, dass ein eingehendes und zeitraubendes Studium erforderlich ist, um ihm folgen zu können.

Ich möchte versuchen, hier das Wesentliche mitzutheilen.

Der Verfasser stellt sich auf den Standpunkt der Neuronenlehre, d. h. auch nach ihm besitzen die Ganglienzellen zwei Arten von Ausläufern: Dendrieten und Neurieten, die mit der Ganglienzelle das Neuron bilden. Der Neuriet (früher Deiter'sche Ausläufer genannt) ist, sofern es sich um ein motorisches Neuron handelt, der Nerv, der zum Muskel geht und sich darin zu feinen Fibrillen verzweigt.

Hier begegnet man bereits einer Abweichung von der gangbaren Meinung. Während nämlich allgemein angenommen wird, dass der Achsencylinder des Neurieten in die Muskelsubstanz (d. h. in die Zwischenscheiben) continuirlich übergeht, liegt derselbe nach Sleeswyk der IIuskelsubstanz nicht an. Zwischen beiden befindet sich vielmehr noch ein wenig Lymphe. Der den Nuskel zur Contraction bringende Reiz muss nach dem Autor durch die Lymphe ïbertragen werden. Auch die Ganglienzelle mit ihren Ausläufern (Dendrieten) liegt in Lymphe.

Es handelt sich hier also um eine galvanische Kette (vergl. Bd. II S. 332); die eine Elektrode ist die Ganglienzelle, mit den feinen Dendrieten; die andere Elektrode wird von den feinen Fibrillen gebildet, die dem Muskel fast anliegen. Die Flüssigkeiten, in denen die Elektroden liegen, ist die beiderseitige Lymphe; den Verbindungsdralit bildet der Achsencylinder.

Sobald chemische und damit osmotische Veränderungen an der Ganglienzellenseite stattfinden, entsteht ein elektrischer Strom, der den Muskel zur Contraction bringt. Die Leitung des Stroms zur Muskelsubstanz wird, wie bereits gesagt, durch die Lymphe vermittelt; sie ist dazu im Stande, weil sie eine Elektrolytlösung ist.

Ein starkes Argument für seine Anschauung erblickt der Verser in der Wirkung ron Curare. Wenn man einem Thiere Curare 
einverleiht, so kann bekauntlich der Muskel nicht mehr willkïrlich bewegt werden. Was ist die Ursache hiervon! Der periphere Nerv ist reizbar geblieben, der Muskel als solcher ebenso. Das Hinderniss findet sich also im Nervenhügel. Sleeswyk glaubt, dass die Wirkung des Pfeilgiftes darauf zur ückzufülren ist. dass dasselbe die Leitfähigkeit der zwischen Nervenfibrillen und Muskel gelegenen Lymphe beeinträchtigt resp. aufhebt.

Auf welche Weise hat man sich aber. nach dem Autor, diese Beeinträchtigung oder Aufhebung des Leitvermögens seitens Curare vorzustellen?

Die Beantwortung dieser lirage findet man in einer ganz neuen Hypothese über das Leitvermögen der Elektrolyte.

Aus den bekannten Versuchen von $\mathrm{Hertz}$ hat sich ergeben, dass elektrische Wellen existiren und dass diese den gleichen Gesetzen der Brechung, Reflexion. Interferenz gehorchen, wie die Schall-, Lichtund Wärmewellen. Aber ebenso wie es Schall-, Licht- und Wärmewellen von verschiedener Wellenlänge giebt, so haben auch die elektrischen Wellen nicht sämmtlich die gleiche Wellenlänge.

Diese Sachlage lässt sich nach Sleesw yk durch folgendes spectrumartige Schema versinnlichen, aus dem gleichzeitig die relative Grösse der Wellenlänge ron elektrischen Strahlen, Wärme-, Licht-. chemischen und Röntgenstrahlen herrorgeht. Demnach besitzen die elektrischen Wellen eine relativ grosse Wellenlänge, bezw. geringe Schwingungsgeschwindigkeit.

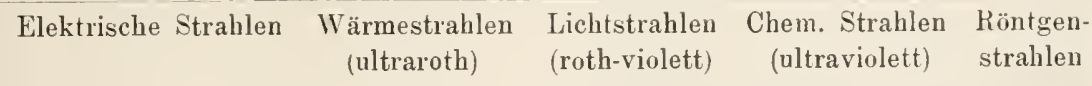

Ein elektrischer Strom besteht aus einer grossen Zahl elektrischer Wellen von rerschiedener Länge, resp. verschiedener Schwingungsgeschwindigkeit, ebenso wie das nit einem Bündel weissen Lichtes der Fall ist.

Welches Gemisch von Elektricitätsstrahlen in einem Strom vorhanden ist. das hängt ron der Elektricitätsquelle ab. Sind sie aus chemischer Wirkung geboren, so wird die qualitative und quantitative Zusammensetzung des Gemisches durch die Art der Substanzen bedingt, die miteinander in chemische Wechselwirkung getreten sind. (Ob umgekehrt ein elektrischer Strom chemische Umsetzung herbeiführt, hängt von dem Umstand $a b$, ob darin Strahlen vorhanden sind, mit deren Schwingungen die betreffenden Theile der chemischen Verbindung resoniren können. Da der Strom eine sehr grosse Mannigfaltigkeit von Elek- 
tricitätsstrahlen enthält, so wird er wohl immer zu chemischen Umsetzungen geeignet sein. So erklärt es Sleeswyk auch, dass ein e inzelne r Elektricitätsstrahl, also ein Strahl von gewisser Wellenlänge in chemischem Sinne für gewöhnlich unwirksam ist.

Bei dieser Anschauung lässt sich nach dem Autor auch der Leitungswiderstand verstehen. Diejenigen Elektricitätsstrahlen, die den Schwingungen der Stoffe entsprechen, aus welchen der Schliessungsdraht zusammengesetzt ist, bleiben im Draht zurück (und erzeugen Wärme). Was nicht mitschwingt, kann den Draht verlassen.

Verstehe ich den Verfasser recht, so führt seine Anschaumng zu der Consequenz, dass der Widerstand nicht nur von der Zusammensetzung des Drahtes, sondern anch von der Elektricitätsquelle abhängig ist. Was nun für einen Draht gilt, ist auch für eine Elektrolytlösung wahr. Die Leitfähigkeit wird hier bedingt durch die Frage, ob, und wie weit die Ionen mit den Elektricitätsstrahlen mitschwingen können. Die resonirenden Strahlen bleiben zurïck, die nicht resonirenden verlassen die Elektrolytlösung. Je umfangreicher die Mitschwingung, um so grösser ist das Leitvermögen. Auch das Leitvermögen der Elelitrolyte ist demnach, wie mir aus Sleeswyk's Ausführungen hervorzugehen scheint, keine constante Grösse, ebensowenig wie das Leitvermögen eines Metalldrahtes, sondern hängt auch von der Natur der Elektricitätsquelle ab.

Und nun zur Anwendung auf die Curarewirkung! Diese beruht alsdann darauf, dass die Elektricitätswellen, die durch den Nerv dem Muskel zugeführt werden, seitens des in der perimuscularen Lymphe angehäuften Pfeilgiftes zurückgelıalten werden.

Als ein vollkommen gleichartiger Vorgang wird die Toxinwirkung gedeutet.

Ebenso wie das Curare sich in der zwischen Nervenfibrillen und II uskelsubstanz sich befindenden Lymphe anhäuft, so setzt sich das Toxin in der Gewebflüssigkeit ab, die zwischen anderen Zellen und zugehörigen Nervenfibrillen gelegen ist. Das Toxin hat nun weiter das Vermögen eine Schirmwirkung auf Elektricitätswellen auszuiiben: d. h. bestimmten, von Neuronen kommenden Elektricitätstrahlen (Reizen) wird der Durchgang verweigert.

Sleeswyk unterscheidet die rom Neuron stammenden Reize nach ihrer Wirkung in assimilative und dissimilative.

Die assimilativen Reize sind Elektricitätschwingungen, die Synthesen in der Zelle herbeiführen; die dissimilativen solche. die den Abbau besorgen. 
Bringt die chemische /usammensetzung des Toxins es mit sich, dass dissimilative Reize durch dasselbe zurückgelıalten werden, so kann Dissimilation in der Zelle nur in mangelhaftem Grade stattfinden und so bilden sich aus dem Protoplasma Prodncte, die eine weniger weitgehende Spaltung erfahren haben, als sonst unter normalen Iimstiinden stattfindet. Diese Protoplasmaproducte von beschränktem Spaltungsgrad sind nach Sleeswyk die Antitoxine.

Werden, wie das bei anderen Toxinen der Fall ist, die assimilativen Reize von letzteren zurïckgehalten, so ist die synthetische Thätigkeit der Zelle mangelhaft, wenn auch durch sogen. "altruistische“ Zellenthätigkeit eine grössere Menge anderwärts assimilirte Nahrung von anderen Stellen zugeführt werden möchte.

Wie ist nun die erworbene Immunität, „das Giftfestwerden“ des Organismus nach stattgehabter spontaner Infection und nach lïinstlicher Immunisirung aufzufassen?

Slees wy denkt sich diesen Process folgendermaassen: Normaliter besteht zwischen den assimilativen und dissimilativen Reizen, die wie gesagt, vom Neuron der Zelle zugeführt werden, ein linetisches Gleichgewicht. Dieses wird nun durch die Schirmwirkung eines Toxins unmittelbar gestört, sei es, dass dasselbe die assimilativen, sei es, dass es die dissimilativen Reize absorbirt. Demzufolge können Neuron und zugehörige Zelle sich nicht die Wage halten. Demnoch offenbart sich eine Neigung zur Wiederherstellung des Gleichgewichts, indem mehr von der absorbirten Reizart durch das Neuron producirt wird.

Nehmen wir, um den Gedanken näher zu erörtern, an, dass es sich hier um eine Absorption des dissimilativen Reizes handelt, so wird nach Sleeswyk von dieser Reizart in Folge eines Compensationsactes mehr producirt werden. Diese Mehrproduction ist von der chemischen Thätigkeit in der Zelle selbst unabhängig.

Weil also bei dieser Annahme die Reguhrung des Abbaues in der Zelle von Seiten des Neurons bis zu gewisser Höhe fortfällt, findet eine Anhäufung von Dissinilationswellen statt, wodurch hinwiederum die assimilativen Reize, die Gleichgewicht mit den dissimilativen anstreben, zunehmen. Auch die rom Neuron ausgehenden synthetischen Reize erfahren deshalb eine Zunahme.

Auf diese Weise erhöht die Toxinwirkung die Leistung, .. den specifisch osmotischen Tonus", des Neurons und der zugehörigen Zelle und wenn dieser" "Reiz" imnerhalb gewisser Grenzen bleibt, also nicht zur Erlahmung führt, muss genannter Complex aus dieser erhöhten 
Function, aus dieser "Uebung “, eine ..Emenerung" aufbewahren, so dass bei einer folgenden Infection, der lieiz des Toxins eine viel grössere Antitoxinproduction aus der geübten Zelle bewirkt als vor stattgehabter natürlicher und künstlicher Infection ${ }^{1}$ ).

Die natürliche Immunität lässt sich nach Sleesw yk aus seiner Hypothese ebenfalls sehr leicht erklären, indem die Toxine nirgendwo im Körper elektromagnetischen Molecularbewegungen begegnen, die ihren eigenen entsprechen, so dass die Schirmwirkung ausbleibt, oder indem durch Anlage oder Vererbung die getroffenen Zellen im Stande sind, in der oben angedenteten Weise kräftig auf den durch Toxin hervorgerufenen Reiz zu antworten. .,Je hïher der specifische osmotische Tonus in den afficirten Zellen und den entsprechenden Neuronen ist, und je mehr derselbe der Steigerung in Folge Zufuhr osmotischer Druckwellen seitens des Totalorganismus fähig ist, desto später wird die toxische Schirmwirkung einen solchen (irad erreichen, dass die Zellen und damit das Individuum der Krankheit erliegt."

So hat Sleeswyk den ganzen V'organg der Infection und deren Bekämpfung auf „osmotische Druckwellen“ zurïickgeführt.

Der Autor stellt sich nämlich vor, dass ein Reiz, der eine thierische Zelle trift', in derselben eine osmotische störung veranlasst. Diese beschränkt sich jedoch nicht anf diese Zelle selbst, sondern pflanzt sich durch „osmotische Druckwellen" auf die iibrigen Zellen des Organismus fort. Die thierische Zelle ist also bei der Neutralisirung schällicher Einflüsse nicht auf sich selbst angewiesen, der ganze Körper betheiligt sich an der Reaction.

Was die osmotischen Drnckwellen selbst betrifft, so sind das nichts anderes als elektromagnetische Schwingungen. Reiz und Reizwirkung sind demnach energetischer Natur.

Ich will Sleeswyk's Ausführmugen, die sich nicht nur anf Bacterienwirkung beziehen, sondern eigentlich die Grundziige der ganzen Lebensthätigkeit zum Gegenstand haben, ja sogar, wie man bemerkt hat, eine Umwälzung der ganzen Elektricitätslehre einschliessen, nicht weiter wiedergeben.

Nur erlaube ich mir noch ein Paar Bemerkungen.

Wenn es dem Leser ergeht wie mir, so wird er fast auf jeder Seite von Sleeswyk's Schrift dem Antor die Fragen vorzulegen haben,

1) Die sechs Zeilen, die ich wörtlich von dem Verfasser übernehme, sind mir nicht recht klar. 
durch welche Thatsachen er seine Meinung stützen könne und welche Einwände er gegen die herrschende ind immer noch fruchtbare Hypothese habe. Ferner wird man fragen, ob die neue Hypothese auch mit denjenigen Haupterscheinungen in Einklang steht, von denen in Sleeswyks Schrift nicht die Rede ist.

Diese Fragen bedïrfen keiner lechtfertigung, zumal es sich hier um die Grundlagen unserer Vorstellungen handelt.

So fragt man z. B., welchen Beweis kann Sleeswyk für den Satz anführen, dass die Leitfähigkeit eines Metalldrahtes ausser von dem Material, ans welchem er angefertigt ist, auch wesentlich von der $\mathrm{Natur}$ der Elektricitätsquelle abhängig ist.

Das Gleiche soll nach ihm mit Elektrolytlösungen der Fall sein. Auch hier ist die Elektricitätsquelle von wesentlicher Bedeutung; nach Sleeswyk wird die Leitfähigkeit einer Elektrolytlösung einfach dadurch beherrscht, ob und in welchem Grade die Theilchen (Elektronen) der Elektrolytlösung mit den der Elektricitätsquelle eigenen und von denselben abgegebenen elektromagnetischen Wellen, mitschwingen können. Durch die Beweglichkeit der Ionen, wie man jetzt allgemein annimmt, wird sie nicht bedingt. Wie mir scheint, hätte Sleeswyk Gründe, und zwar triftige Gründe anführen müssen. um diese vielfach erprobte Theorie der Leitfähigkeit der Elektrolyte verwerfen zu dïrfen.

Auch für einen anderen fundamentalen Begriff hätte man gern einen Beweis oder jedenfalls einen Wahrscheinlichkeitgrund gehört: ich meine für die "Schirmwirkung". Setzt z. B. Curare oder Toxin die Leitfähigkeit der Lymphe in Wirklichkeit herab:

Weiter wird in Sleeswyk's Ausführungen Bacterienwirkung, 'wie auch Immunität lediglich auf Neuronenwirkung zurïckführt: alles wird von einem durch den ganzen Körper hinziehenden Netz von Neuronen und Gewebszellen besorgt. Es ist auffallend, und nicht ohne Bedenken, dass dem Blute dabei gar keine Bethätigung eingeräumt wird.

Ich könnte diese Bemerkungen erheblich vermehren, und ich bin davon iiberzengt, dass der Leser ebenso wie ich, bei den oben wiedergegebenen Ansichten des Verfassers auf eine Anzahl Schwierigkeiten gestossen ist rnd beim Studium der Original-Arbeit die Zahl derselben erheblich vermehrt sehen wird.

Dennoch hat die nur 139 Seiten enthaltende. aber doch umfassende und von grosser Gelehrsamkeit Zeugniss ablegende Schrift viel Anlockendes. Sie darf als ein kühner Versuch betrachtet werden, alle 
Lebenserscheinungen, inclusive Reiz und Reizwirkung, selbst auch die Katalyse, unter einem einheitlichen Gesichtspunkt zu vereinigen.

Zweifellos hätte die Arbeit ungemein an Werth und auch an Interesse gewonnen, wenn der Autor für ein einzelnes Kapitel der Biologie seine Anschauungen bis in Einzelheiten durchgeführt und mit Erfolg an den bekannten Thatsachen gepriift hätte. Durch äussere Umstände ist das dem Autor bis jetzt nicht möglich gewesen. Doch meinte ich auf die Schrift die Aufmerksamkeit lenken zu muissen, weil sie, wie mir scheint, zn denjenigen gehören könnte, die, bei nicht weiterer experimenteller Bearbeitung, in Vergessenheit gerathen und Jahrzehnte später von dem Historiker aus dem Staub hervorgeholt werden, um zu zeigen, dass dieser oder jener bedeutende Gedanke bereits ausgesprochen war, aber beim damaligen Standpunkt der Wissenschaft keine geniigende Stiitze seitens der bekannten Thatsachen fand, oder auch durch nebensächliche Anschauungen, die wirklich falsch waren, nicht zu seinem Recht gelangen konnte. 


\section{Elftes Kapitel.}

\section{His tologisehes.}

\section{Lit teratur.}

1. Flemming. Zellsubstanz, Kem- und Zelltheilnng Leipzig 1882. S. 51.

2. A. Fischer. Anat. Anzeiger 9. 1894. S. 678; 10. 1895. S. 769.

3. Biitschli, Untersuchungen über mikroskopische Schäume und iiber das Protoplasma. Leipzig 1882.

4. Hardy, Journal of Physiol. 24. 1899. p. 301.

5. van Bemmelen, Ber. d. deutschen chem. Gesellsch. 1:3. 1880. S. 1467.

5a van Bemmelen. Journ. f. prakt. Chemie @3. 1881. S 324 u. 379; 46. 1892. S. 497.

5b. van Bemmelen, Zeitschr. f. anorg. Chemie 5. 1893. S. 467; 13. 18.6. S. 233.

6. Hardy. Pruceed, of the royal Society 66. 1900. p. 110.

7. Marcano, Compt. rend. de la Soc. de Biol. 31 Mars 1900. p. 317. Travaux du laborat. d'Histologie du Collège de France, Année 1900. p. 175.

8. Gierke, Zeitschr. f. wissensch. Mikrosk. 1. 1884 ; S. 74 ; 2. 1885. S. 105.

9. Otto N. Witt, Färberzeitung 1890/91 Nr. 1 citirt nach Spiro und M. Heidenhain (Siehe unten).

10. Spiro, Ueber physikalische und physiologische Selection. Habilitationsschrift. Strassburg 1897.

11. van't Hoff, Zeitschr. für physik. Chemie 5. 1890. S. 322.

12. Martin Heidenhain, Theorie der histologischen Färbungen. Artikel in der Encyclopädie der mikroskopischen Technik mit besonderer Berücksichtigung der Färbelehre, herausgegeben von Ehrlich, Krause, Mosser, Rosin und Weigert, Berlin, Wien 1903. S. 335.

12. Martin Heidenhain, P flu ge er's Archiv 90. 1902. S. 115; 96. 1903. S. 440.

14. C. (O. Weber, Färberzeitung 5. 1894. S.S. 161, 184, 201, 204 (citirt nach Spiro).

15. v. Georgievicz. Monatshefte f. Chemie 15. 1894. S. 715.

16. Berthelot und Jungfleisch. Ann. chim. phys. (4). 26. 1872. p. 396.

17. Nernst, Zeitschr. f. physik. Chemie S. 1891. S. 110: verg]. auch Theoretische Chemie. 2. Aufl. S. 455 .

18. Paterno, Zeitschr. f. physik. Chemie 4. 1889. S. 45.

19. Auwers, Zeitschr. f. physik. Chemie 12. 1893. S. 689; 15. 1894. S. 33; 1s. 1895. S. $595 ;$ 21. 1896. S. 337.

20. F. Hofmeister, Archiv f. exp. Path. u. Pharmak. 28. 1891. S. 210. 
21. v. Geolgievics und Löwy, Monatshefte f. Chemie 16. 1895. S. 345

22. A. Fischer, Fixirung, Färbung und Bau des Protoplasmas. Jena. G. Fis cher. 1902.

23. Pappenheim, Grundriss der Farbchemie. Berlin-Hirschwald 1901.

24. Overton, Vierteljahrschr. d. natur. f. Versanml. in Zürich 44. 1899. S. 88.

25. Orerton, Jahrb. f. d. wissensch. Botanik 34. 1900. S. 669.

26. Ehrlich. Therapeutische Monatshefte. März 1887.

27. Jores, Centralblatt f allgem. Pathologie 7. 1896. S. 44.

28. Dekhnyzen, Comptes rend. 17 Aôut, 3̉1 Aôut 1903; Byvoegsel tot de Nederlandsche Staatscourant 1904. Nr. 19.

In den letzten Jahren sind einige Arbeiten veröffentlicht worden, die sich mit Fragen beschäftigen, die für die Histologie und damit auch für die Biologie überhaupt, von grundlegender Bedeutung sind. Sie betreffen die Zellfixirung und das Verhalten von todten und lebenden Zellen gegenüber Farbstoffen und zielen somit auf die Kenntniss der Structur intra vitam hin. Obgleich die Wichtigkeit des Gegenstandes eine Besprechung an dieser Stelle völlig rechtfertigt, habe ich doch gezögert eine solche zu bringen, weil die betreffenden Erörterungen sich nur theilweise auf dem Gebiete des osmotischen Druckes und der Ionenlehre bewegen. Es handelt sich hier vielmehr um zwei andere Gebiete der physikalischen Chemie, um die Lehre von den Zustandveränderungen der Colloide und die Lehre von den Theilungscoëfficienten. Da aber auch hier insbesondere die Ionenlehre sich von hervorragender Bedeutung erwiesen hat und zweifelsohne in Zukunft noch mehr herangezogen werden wird, um die Erscheinungen verständlich zu macheu, schien es mir doch nicht erlaubt, an den betreffenden Untersuchungen mit Stillschweigen vorüberzugehen, um so weniger, wo ron berufener Seite darüber geklagt wird, dass unsere Kenntnisse iiber die theoretischen Grundlagen der mikroskopischen T'echnik noch ausserordentlich mangelhaft $\operatorname{sind}^{1}$ ).

1) "Von einer "Mikrochemie“ der organischen Gewebe im strengen Sinne könıen wir augenblicklich noch nicht reden, " sagt W. Spalteholz in einer soeben erschienenen Schrift: Mikroskopie und Mikrochemie, Betrachtullgen über die Grundlagen der mikroskopischen Untersuchungsmethoden. Leipzig. S. Hirzel 1904. „Wir kennen wohl ein par mikrochemische Reactionen, aber nicht mehr,"

nDie Ursache dafür, dass unsere Kenntuisse vielfach so wenig tief eindringen, liegt zweifellos darin, dass die Mikroskopiker, in deren Hände die Beantwortung der Frage gelegt war, häufig eine gründliche Kenntniss der Nachbarwissenschaften vermissen liessen. Und gerade diese, vor allem aber die Chemie und physikalische Chemie, scheinen berufen, um bei den interessantesten und wichtigsten Fragen Wegweiser zu sein, nicht etwa nur in der Mikrochenie, sondern auch in der genannten Mikroskopie!" 


\section{Fixirung der Gewebe.}

Seit längerer Zeit haben einige Autoren anf die Möglichkeit hingewiesen. dass die bei der mikroskopischen Untersuchung der Gewebe z.ur Beobachtıng gelangenden Structuren Artefacte seien, die hauptsächlich dem sogenannten Fixirungsprocess ihre kntstehung verdanken, theilweise anch postmortalen Veränderungen zugeschrieben werden müssen.

Bereits 1882 hob dies Flem ming als erster hervor. Dieser Forscher wies nach, dass bei Fixation von Pflanzenzellensaft mit Osmiumsäure eine feine Netzstructur erscheint, die vor dieser Behandlung nicht bestand.

Der Botaniker Berthold sah durch Einwirkung von Pikrinsäure auf Hühnereiweiss ein schönes netzförmiges Gerüst entstehen (1886). Ein anderer Botaniker, Schwarz, konnte ein gleichartiges Gerüst auch in Gelatine und Pepton hervorrufen und war aus diesem Grund geneigt, das Bestelıen eines Gerüstes im lebenden Zellprotoplasma ganz in Abrede zu stellen (1887). Wieder ein anderer Botaniker, A. F is cher [2], geht noch weiter und verurtheilt u. A. auch die bekannten, von Flemming als Chromatolysis zusammengefassten Erscheinungen als Kunstproducte.

Nun hat Fischer in der That äusserst auffallende 'Thatsachen gefunden. Er liess 2-10\% ige Peptonlösungen von Hämoglobin, Nnclein, Serumalbumin, Paraglobulin in Hollundermark imbibiren, fixirte mittelst Flemming's Gemisch, oder mittelst derselben Flüssigkeit, die Altmann benutzt hatte, um Granula nachzuweisen, fertigte nach der üblichen Iethode feine Schnitte an und konnte darin einen Kern mit feinen Fäden und grossen und kleinen Granula beobachten ${ }^{1}$ ). Weiter gelang es ihm bei Anwendung ron Mischungen zweier Colloide, z. B. von Pepton und Serumalbumin, diese beiden im Präparat zu differenziren. So konnte er noch durch Anwendung von Altmann's Fixirungs- und Färbungsmethode, im Serumalbumin als Grundsubstanz Peptongranula fürben. Diese Thatsache ist sehr wichtig, denn bekanntlich mischen sich Serumalbumin und Pepton in jedem Verhältniss. Während also vor der Fixirung ein homogenes System bestand, wurde dieses nacliher in zwei Systeme differenzirt, die deutlich von einander getrennt und selbst durch Färbung zu unterscheiden waren.

Auf dem Gebiet der thierischen Zelle wurden von Bütschli (1892) ausgedehnte Untersuchungen angestellt [3]. Auch dieser Autor

1) Mit dieser Angabe Fischer's soll man sehr vorsichtig sein. Ilein verehrter College der Botanik, Herr Prof. J. W. Moll theilt mir mit, dass nach seinen Untersuchungen, die von $\mathrm{F}$ ischer beobachteten Kerne mit feinen Fäden $\mathrm{dem}$ Hollundermark selbst angehören. 
konnte in Lösungen von Pepton, Gelatine etc., Structuren nachweisen und war deshalb ebenso, wie die genannten Forscher, geneigt, die an fixirten Gewebezellen beobachteten Structuren als Artefacte zu betrachten, kam jedoch später zur Ueberzeugung, dass die gefundenen Wabenstructuren vielfach auch an lebenden Zellen vorkamen.

Der letzte Autor, der sich, soweit mir bekannt, bis jetzt mit dem Gegenstande beschäftigt hat, ist Hardy. Nit Recht war Hardy der Ansicht, dass man, um einen guten Einblick in den Fixirungsprocess zu gewinnen, den Vorgang erst an Colloidlösungen systematisch untersuchen sollte. Ich werde aus dieser wichtigen Arbeit [4], die leider wenig Beachtung zu finden scheint und selbst in Centralblättern kaum besprochen worden ist, einige Punkte hervorheben.

Zunächst will ich den Versuch beschreiben, bei welchem es Hardy gelang, die Structurbildung in einer Colloidlösung unter dem Mikroskope zu verfolgen.

\section{i) Structurbildung in Colloidlösungen beim Uebergang von Ifydrosol in Iydrogel.}

Ein dünner Seidenfaden wird mit einer $2 \%$ igen $\mathrm{CaCl}_{2}$-Lösung getränkt und auf einen Objectträger gelegt. Nachdem man diesen mit einem Deckgläschen bedeckt hat, wird einem Tropfen eines Hydrosols, nämlich einer verdünnten Eiereiweisslösung ') Gelegenheit gegeben, durch Capillarität in den Raum zwischen Objectträger und Deckglas zu gelangen. Wo das Hydrosol (gelöstes Eiweiss) mit dem $\mathrm{CaCl}_{2}$ in Berïhrung kommt, geht es allmählich in den festen Zustand (Hydrogel) über.

Während anfänglich die ganze Fliissigkeit, auch die, welche zunïchst dem Seidenfaden sich betindet, frei von sichtbaren kleinen Partikelchen ist, bilden sich in der Nähe des Fadens allmählich weisse Wölkchen, die, wie eine 500 malige Vergrösserung lehrt, aus kleinen Körnchen bestehen. Die Körnchen wachsen zu Aggregaten 2), die in Maximo eine Grösse von 0,75-1 $\mu$ erreichen. Während dieser Aggregation ordnen die Körnchen sich zu einem offenen Netz mit polygonalen Maschen, deren Diagonalen etwa $6 \mu$ betragen.

Dieses Stadium ist nicht von bleibender Natur; das Netz schrumpit und die Maschen werden kleiner, wahrscheinlich weil die Theilchen der

I) Ueber die Herstellung dieser Eiweisslösung vergleiche man oben, S. 67, unter "Collö̈de und Fermente".

2) Die Kräfte, welche hierbei thätig sind, scheinen elektrischer Natur zu sein und werden auf lonenwirkung zurückgeführt (vergl. S. 69 ff.). 
Agregate sich dichter an einander reihen. Schliesslich sind sie nicht mehr als solche zu unterscheiden und bilden ein feines Fadengerüst, und nur an dem Schnittpunkt der Fäden zeigen sich Verdickungen.

Fin gleichartiges Schlussbild erzielt man, wenn man statt des Clılorcalciums die üblichen Fixationsmittel nimmt, wie Osminmsäure, Hitze, KCNS, Kaliumbichromat, Sublimat, Formalin. Zn diesem Zweck bringt Hardy ein wenig von der Eiweisslösung in eine von einem Seidenfaden gebildete kleine Oese und setzt diese Oese dem Fixationsmittel aus; dann wird mit Alkohol, Xylol behandelt, in Paraffin eingeschlossen und das Präparat mittelst Mikrotom in äusserst feine Schnitte zerlegt. Es ist deutlich eine Netzstructur zu erkennen. Jedoch ist diese nicht unter allen Umständen genau dieselbe. Sie hängt zunächst von der Natur des Fixirmittels ab. So fand Hardy für den Durchmesser der Maschen bei Fixirung einer $13 \%$ igen Eiereiweisslösung mittelst

$\begin{array}{lr}\text { Osmiumsäuredampf } & 0,5-0,7 \mu, \\ \text { heissen Wasserdampfes } & 1 \mu, \\ \text { KCNS-Lösung } & 1 \mu, \\ \text { Kaliumbichromat } & 1,3 \mu, \\ \text { Sublimat (gesättigte Lösung in } 0,6 \% \mathrm{NaCl} \text { ) } 1,7 \mu \text {. }\end{array}$

In zweiter Linie hängt die Maschengrösse bei Anwendung desselben Fixirungsmittels von der Concentration des Eiweisses ab.

Schliesslich ist auch die Natur des Colloids für das Bild nicht gleichgültig. Wenn z. B. Gelatine statt Eiereiweiss benutzt wird und man coagulirt (fixirt) mit Sublimat, so entsteht kein offenes Netzgerüst, wie bei Eiereiweiss, sondern es bilden sich geschlossene Maschen. Dies geht aus der mikroskopischen Betrachtung sehr dünner Schnitte (von $1 \mu$ und weniger) hervor und zeigt sich auch, wenn man die Gelatine einem mechanischen Druck und der Centrifugalkraft unterwirft. Handelt es sich um ein offenes Netz, so ist nämlich mittelst Centrifugirung leicht Flïssigkeit hinauszupressen. Sind es geschlossene Maschen (Wabenstructur), so gelingt das unter sonst gleichen Unständen nur bei ausserordentlich hohen Drucken.

Auffallend ist nun wieder, dass wenn die Concentration der Sublimatlösung weniger als $4 \%$ beträgt, das mit Gelatine gebildete Netz ein offenes wird. Sonst ist es ein geschlossenes. Formalin bildet mit Gelatine unter allen Umständen ein offenes Netz.

Es hat sich nun ergeben, dass nicht nur die erwähnten bei Eiereiweiss und Gelatine beobachteten offenen und geschlossenen Netzstructuren, auch bei verschiedenartigen $\%$ ellen erscheinen, sondern dass aluch bei 
diesen die Grösse der Maschen ebenfalls von der Art und Concentration der Fixirungsmittel abhängt. Dieser Befund legt den Geranken nahe, dass die nach Fixung zur Beobachtung gelangenden Protoplasmastructuren Artefacte seien ${ }^{1}$.

Das soll, nach Hardy, nicht nur für die in den Zellen sichtbaren Gerüste gelten, sondern in vielen Füllen anch für die Granula. Hardy hat nämlich beobachtet, dass es unter bestimmten Umständen, z. B. wenn die Colloidlösung sehr verdünnt ist, bei der Bildung von Aggregaten bleibt, d. h. dass diese sich nicht zu Netzen anordnen. So kann auch bei der Fixirung des Protoplasma hier und da Netzbildung vermisst werden und es bei der Bildung von grösseren Aggregaten (Granula) bleiben.

Damit ist selbstverständlich nicht gesagt, dass alle Granula auf diese Weise, also als bleibendes Uebergangstadium zu der Netzbildung aufzufassen seien. Theilweise sind sie, wie Hardy bemerkt, auch Producte der Zellenfunction, also nicht unter dem Einfluss der Fixirung entstanden.

Wie steht es nun mit den Netzstructuren, die man einfach post mortem beobachtet, olne dass künstliche Fixirung stattgefunden hat.

Hier macht Hardy zunächst auf die bekannten Untersuchungen von Langley über die Speicheldrüsen aufmerksam. Langley fand. dass die Secret-Granula in den betreffenden sichleimzellen post mortem derart quellen, dass das dazwischen liegende Protoplasma zu einem dünnen Blättchen ausgepresst wird. Auf diese Weise entsteht ein schönes schwammiges Protoplasmagebilde.

In zweiter Linie soll, bei den übrigen Zellen, die postmortale Structur sich durch eine mit dem Alsterben einhergehende Coagulation ausbilden; es würde sich um einen ähnlichen Process handeln, wie wenn ein warmes Hydrosol durch Abkühlung in Hydrogel übergeht. Lässt man eine warme Gelatinelösung sich abkiihlen, so bildet sich bekanntlich ein Gel. Hardy fand, dass dieses Gel aus einem Netzwerk aufgebaut ist,

1) Hardy citirt bei dieser Gelegeuheit einen Passus aus Henneguy (Leçons sur la cellule), wo dieser Verfasser die Beobachtungen der L ouva in'schen Schule einer strengen Kritik unterwirft, weil dort immer Sublimat als Fixirmittel gebraucht werde. Wenn man die Tafeln der Zestschrift "La Cellule“ durchisieht, so ist man betroffen "par l'uniformité de structure que revêtiraient les cellules les plus diverses; und Heıneguy fragt, si celle-ci n'est point due à l'uniformité de la methode. Henneguy hält das Sublimat für das Studium der Protoplasmastructur für unge eignet (citirt nach $\mathrm{H}$ ardy). 
in dessen Maschen sich Fliissigkeit befindet; das Gel weist also zwei Phasen auf: eine feste und eine Hiissige l'hase. Die feste l'lase wird rom Gerüst gebildet und bestelit ans einer festen Lösung von Wasser in Gelatine, die fliissige Phase ist die Maschentlïssigkeit und besteht ans einer Lösung von Grelatine in Wasser.

Wenn Bütschli meint solch eine Structur auch bei lebenden Zellen gesehen zu haben, so glaubt Hardy zu dem Zweifel berechtigt zu sein, ob die betreffenden Zellen nicht bereits im Absterben begriffen waren.

Indessen fällt das Hauptgewicht der vorliegenden Ausfiihrungen auf den Einfluss der Fixirungsfliissigkeiten auf die zur mikroskopisclıen Beobachtung gelangenden Bilder, weil bei weitem die meisten histologischen Untersuchungen an fixirten ['räparaten ansgeführt werden.

Aus diesem Gesichtspunkt diirfte es wohl gestattet sein noch einen Augenblick auf das Wesen der Fixirung zurückzukommen ${ }^{1}$ ).

\section{b) Weiteres iiber den Uebergang ron Hydrosol in Hydrogel.}

Dieser Uebergang besteht im wesentlichen darin, dass, wie ganz im Allgemeinen bei jedem Uebergang von Hydrosol zu Hydrogel, eine Trennung von festem Stoffe unl Fliissigkeit stattfindet, die mit einer zuvor nicht bestehenden Structurbildung einhergelıt.

Bereits im Anfange der Besprechung von Hardy's Ausführungen theilte ich mit, wie die Zustandänderung vor sich geht. Die Hauptsache ist eine Association von Colloidtheilen zu Aggregaten, worauf eine weitere Anordnung dieser Aggregate zu einem Netz erfolgt.

Hardy theilt die Colloide in solche ein, die, wie Gelatine und Agar, nach erfolgter Coagulation durch Hitze wieder in Lösung gehen (heat-reversible), und in solche, denen diese Eigenschaft abgeht (heatirreversible). Zu letzteren gehören Kieselsäure, Eiweiss, Protoplasma.

\section{(a) Colloide, deren Hydrogele durch Hitze umkehrbar sind.}

Besonders schön lassen sich nach Hardy die Vorgänge bei Gelatine oder Agar-Wassergemischen verfolgen. Es war hereits oben davon die Rede. Ich will die Erscheinungen hier etwas ausfïhrlicher besprechen und mit einigen Zahlen illustrieren.

Man bringe z. B. $13,5 \mathrm{~g}$ Gelatine in ein Gemisch von $50 \mathrm{cc}$ Wasser und $50 \mathrm{cc}$ Alkohol und erhitze auf eine 'Temperatur oberhalb $17^{\circ}$. Man erhält dann eine homogene F'lüssigkeit. Bei Abkühlung bis eben unter $17^{\circ}$ sieht man nun unter dem

1) Vergl, auch S. $65 \mathrm{ff}$.

Hamburger, Osmot. Druck. III Band. 
Mikroskop (Vergrösserung 500) kleine Tröpfchen von $3 \mu$ erscheinen. Bei weiterer Temperaturerniedrigung kleben sie an einander und bilden ein Netzwerk, das bei $12^{\circ}$ anastomosirende Fäden bildet.

Es ist nicht schwer in diesem Gel Gerüst und Flüssigkeit durch Centrifugiren ron einander zu trennen. Es zeigt sich danu, dass es sich hier um zwei Phasen handelt; das Gerüst besteht aus Gelatine, die Wasser gelöst enthält; die Flüssigkeit besteht aus Wasser, das Gelatine gelöst enthält. Die /usammensetzung dieser Phasen ist ron der Temperatur abhängig. Bei $14^{0}$ enthielt die feste Phase $18^{\%} / 0$ Gelatine und die flüssige $5,5 \%$ Gelatine.

Wie gross der Einfluss der Temperatur auf die Zusammensetzung der Phasen ist, geht aus folgendem herror.

Löst man 2,5 $\mathrm{g}$ Agar in $100 \mathrm{cc}$ Wasser in der Hitze auf, so bildet sich bei Abkïhlung ein Hydrogel. Centrifugirt man dann, so scheidet sich eine Flüssigkeit ab, die

$$
\begin{aligned}
& \text { bei } \quad 0^{0} \quad 0,35^{\circ} \div 0 \text { Agar enthält } \\
& \text { n } 10,5^{\circ} 0,42_{n} \text { n n } \\
& \text { " } 15^{\circ} 0,45 \text {, n n } \\
& \text { " } 32^{\circ} 1 \text { " n " } \\
& \text { n } 42^{\circ} 1,66 \text {, \#, }
\end{aligned}
$$

Es ist nun von Wichtigkeit, dasses ganzgleichgültig ist, ob man eine $1 \%$, oder eine $2,5 \%$, oder eine $3,5 \%$ ige Agarlösung nimmt, stets enthält die flüsige Phase bei $15^{0} 0,45^{\circ} \%$ A g a r.

Diese zwei Beispiele betrafen Hydrogele, die durch Erhitzung wieder zu IIydrosolen zurïckgebildet werden können, also, wie man es nennt, reversibel sind.

\section{ß) Colloide, deren Hydrogele durch Hitze nicht umkehrbar sind.}

Die zweite Gruppe, die bei Erhitzung nicht reversiblen Colloide, zu welchen die Kieselsäure und auch das Eiweiss gehört, bilden in dem Gelzustand gleichfalls zwei Phasen. Tan Bemmelen [5] hat Kieselsäure und andere anorganische Hydrogele eingehend studirt und gelangte zu dem Resultate, dass die betrefienden Hydrogele nicht, wie man immer meinte, aus einem homogenen Gemisch von rerschiedenen Hydraten bestehen kömnen, sondern aus einem Netzwerk, in dessen Maschen sich Flüssigkeit von verschiedener Zusammensetzung befindet.

Eine entsprechencle 'Trennung in flüssige und feste Phase findet nun a uch nach Hardy statt, wenn eine Colloidlösıng der zweiten Gruppe wie Eiweiss, lebendes Zellprotoplasma durch die sogenannte Fixirnng in den Gelzustanil übergeht. Auch dann 
tritt eine Trennung auf: die festen Partikelchen orinen sich erst zu Aggregaten [6], diese wieder zu Fäden; die Fäden bilden ein Netzwerk.

Wie oben im Kapitel "Bemerkungen über Colloide" S. 69 auseinandergesetzt wurde, thun Salze mit dreiwerthigen Ionen das bereits in viel geringerer Quantität als die mit zweiwerthigen, und die letzteren wieder viel kräftiger als die mit einwerthigen Ionen.

Die Unwandlungsvermögen der dreiwerthigen, zweiwerthigen und einwerthigen Tonen verhalten sich zu einander wie $1600: 30: 1$.

Wegen alles Näheren über die Bedeutung der lonen in dieser Angelegenheit verweise ich auf das Kapitel Colloide (S. 69 ff.).

Die Maschenflüssigkeit kann selbstrerständlich bei der Fixirung durcl Fixirflïssigkeiten nicht von so constanter Zusammensetzung sein, wie bei der einfachen Coagulation durch Abkühlung oder Absterben. denn hier kommt die Zusammensetzung der Fixirungstliissigkeit in Betracht und neben dieser auch noch die Nenge. Wo das Fixirmittel in grosser Menge vorhanden ist, muss die Flüssigkeit in den Maschen der Zusammensetzung des Fixirmittels sehr nahe kommen. Später bei der weiteren Behandlung des Präparates wird diese Maschentlüssigkeit durch Alkohol ersetzt, dann durch Xylol, etc.

Von praktischem Standpunkt ist die Beobachtung von Hardy sehr wichtig, dass die Diagonale der einmal gebildeten Maschen sich bei Ersatz der ursprïnglichen Maschenflïssigkeit durch eine andere ändern kann.

Im Allgemeinen geht aus den Intersuchungen Hardy's hervor, dass die Grösse der Maschen von vielen Umständen abhängig ist. Dieselbe wird sowohl durch die Natur und die Concentration des Fixirmittels, wie durch die der Colloidlösung beeinflusst.

Ich will noch zwei andere wichtige Momente hinzufügen, die die Gestalt der Fixirungsfigur beeinflussen können.

Das erste Moment, das ich noch erwähnen will, betrifft den EinHuss der Anwesenheit ron festen Partikelchen in der Colloidlïsung, das zweite Moment den Eintluss der Lagerung der Colloidtheilchen vor der Fixirung.

Ueber die Anwesenheit ron festen Partikelchen hat Hardy einen interessanten Versuch mitgetheit. Wenn man in einer Eiweisslösung Carminpartikelchen suspendirt, und dann mit Sublimat fixirt, so bilden die Partikelchen die Knoten des Netzes und man liat es in der Hand durch Variation von Grösse und Menge der Partikelchen die Grösse der Maschen his zu einer gewissen Höhe nach Willkür zı regeh. 
Mit Beziehung auf das zweite Moment bringt Hardy einen Versuch B ïtschli's in Erinnerung. Wenn man eine filtrirte Eiweisslösung mittelst einer Bürste in einen Tropfen einer Mischung von Pikrinsäure, Schwefelsäure und Osmiumsäure einwirft, so sieht man in den nunmehr coagulirten Fibrinstreifen eine fibrilläre Structur.

Hardy hat ähuliche Versuche angestellt.

Er nahm einen durchlöcherten Kochring und verschloss das Loch mit einer dünnen Schicht einer Eiweisslösung, in derselben Weise wie man das bei Versuchen mit Seifenlösungen zu thun pflegt. In die Mitte der Eiweissschicht wurde ein Tröpfchen Quecksilber gebracht. Wurde die Schicht nun fixirt, so zeigten sich radiäre Streifen. Offenbar hatte die Schwere des Quecksilbertropfens einen Zug nach der Mitte ausgeübt. Das fixirte Bild machte den Eindruck, dass es sich hier um eine Structur handelte, die aus zwei verschiedenen Substanzen aufgebaut war; dennoch bildete die ursprüngliche Colloidlösung eine homogene Masse.

So denkt Hardy sich auch, dass die Kerntheilungsfiguren vielleicht bloss Aeusserungen dynamischer Natur sind. In bestimmten Richtungen wird in der homogenen Substanz ein Zug oder 1)ruck ausgeübt, welcher eine gewisse Lagerung der zähflïssigen Colloidtheilchen zur Folge hat. Wenn dieser Zustand durch ein Fixationsmittel festgelegt wird, bekommt man den Eindruck, dass die Kerntheilungsfiguren aus einer anderen Substanz bestehen. Und doch stammen sie aus der homogenen Flüssigkeit.

Indessen wird es, diinkt mich, befriedigen, dass man auf diese Weise die während des Lebens obwaltenden Zustände, seien es auch dynamische Aeusserungen, festzulegen im Stande ist!

Man könnte nun geneigt sein, zu denken, dass überhaupt in den Zellen, bei denen man nach der Fixation eine Netzstructur beobachtet, auch diese einen festgelegten Ausdruck eines Druckes oder Zuges in bestimmten Richtungen versinnlicht, der bereits in der lebenden \%elle bestanden hat. Unmöglich ist das allerdings nicht, obgleich die vollkommen analogen Structuren, die man aus homogener Agar-Gelatine und aus Eiweisslösungen entstehen sieht, wohl dagegen sprechen und das Bestehen einer intravitalen Net\%structur in dyuamischem Sinne, sehr 7weifelhaft machen. Indessen muss wiederlolt werden, dass B ütsclıli angiebt, die Netz- und Wabenstructuren zuweilen auch bei lebenden \%ellen gesehen zu haben. Hardy entgegnet hierauf, dass Bütschli wahrscheinlich Zellen, die im Absterben begriffen waren, unter Händen hatte. Er verspricht, daraut zurickzukommen, doch ist das seit 1899 noch nicht geschehen.

Ich erwähne schliesslich, dass Schäfer an Leukocyten, die durch Hitze fixirt waren, zwei dentliche Theile unterscheiden konnte, nämlich dünne pseudo. podienartige Gebilde, die keine Netzstructm zeigten und auch nicht färbhar waren 
und die übrige dickere Zellmasse, die eine Netzstructur zeigte nnd sich auch färben liess. Daraus schloss Schäfer, dass die Lenkocyten aus verschiedcnem Material bestehen, aus einem festen Gerüst und aus Hyaloplasma, das aus dem spongioplasmatischen Netz des Zellkörpers ausgeflossen ist. Hardy konnte aber aus Eiereiweiss eine gleichartige Figur herstellen.

Die Erscheinung ist wahrscheinlich derart zu deuten, dass bei der durch Hitze herbeigeführten Trennung des Colloids in zwei Phasen eine dünne Schicht der flüssigen Phase die Netzstructur begrenzt.

Wo das Ganze selır dünn ist, sieht man also lediglich die flüssige Phase.

\section{c) Volumverhältnisse bei Fixirung durch Formalin und andere Mittel.}

Bei der vielfachen Anwendung des Formalins zur Fixirung habe ich mir die Frage vorgelegt, wie weit die Zellen dabei ihre normale Grösse behalten. Diese Versuche sind mit rothen Blutkörperchen, als dem für diesen Zweck am meisten geeigneten Object, angestellt worden.

Dieses Object bietet deshalb noch besonderes Interesse, weil von M a reano vorgeschlagen wurde, Volumbestimmungen der Blutkörperchen für klinische Zwecke mit Hülfe von Formol auszuführen [7]. Dieser Verfasser hatte bemerkt, dass Blutkörperchen in Formollösungen spontan zu Boden sinken, ohne dass das Blut gerinnt.

II a r cano versetzt 100 ec $\mathrm{Na}_{2} \mathrm{SO}_{4}$-Lösung von 1,020 spec. Gew. (Serum von $\mathrm{M}$ al a sse z) mit 10 bis 15 ce käuflichem Formol. In dieses Gemisch wird ein bestimmtes Quantum Blut gebracht. Die Blutkörperchen senken sich spontan und man kann nach 24 Stunden das Volumen ablesen. Zahlen werden nicht gegeben.

Es fragt sich, welchen Einfluss derartige Formollösungen auf das Tolumen der Blutkörperchen ausüben.

Als Fixirungsflüssigkeit wählte ich das folgende, vielseitig gelobte Gemisch von Melnikow-Raswedenkow, modifizirt von Jores [27] $\left(\mathrm{NaCl} 5 \mathrm{~g} . \mathrm{NgSO}_{4} 10 \mathrm{~g}, \mathrm{Na}_{2} \mathrm{SO}_{4} 10 \mathrm{~g}, \mathrm{H}_{2} \mathrm{O} 500 \mathrm{~g}\right.$, Formalin (des Handels) $\left.50 \mathrm{~g}^{1}\right)$.

Es wurden 0,06 ce Kaninchenblut in 4 trichterförmige Röhrchen 1, 2, 3 und 4 (Bd. I S. 379) gebracht $^{2}$ ), in 2 und 4 wurden 2 ce Formalingemisch zugesetzt und nach einstündigem Stehen zugleich mit 1 und 3 centrifugirt, in welch letztere das Blut erst unmittelbar vor dem Centrifugiren gebracht wurde. Es wurde so lange centrifugirt, bis das Volumen des Sedimentes ${ }^{1 / 4}$ Stunde constant blieb.

Volumen der Blutkörperchen nach der Einwirkung des Formalingemisches.

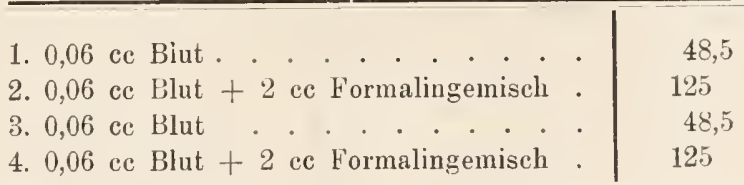

1) Die Zahlen für das Magnesiumsulfat und Natriumsulfat beziehen sich auf die krystallwasserhaltigen Salze.

2) Jetzt zu bezieben von der Firma Franz Hugersboff in Leipzig. 
Mansieht, dass das Volumen der Blutkörperchen durch Behandlung mit Formalingemisch bedeutend zugenommen hat, obgleich die Lösung stark hyperisotonisch war.

Dann wurde in den vier Röhrchen die überstehende Flüssigkeit entfernt und das Sediment mit 2 ce Alkohol von $96 \%$ vermischt, wie das bei der Formalinfixirung üblich ist. Der Alkohol wirkte eine Stunde ein, dann wurde bis zu constantem Volumen centrifugirt.

\section{Behandlung mit Alkohol $96 \%$.}

1. $0,06 \mathrm{cc}$ Blut +2 ec Allkohol $96 \%$

2. 0,06 ce Blut nach vorheriger Behandlung mit 2 ec Formalin, nunmelır mit

2 ce Alkohol $96 \%$ behandelt

3. 0,06 cc Blut +2 ce Alkohol $96 \%$

4. $0,06 \mathrm{cc}$ Blut (nach vorheriger Belrandlung mit 2 ec Formalin, dann mit 2 ce Alkohol $96 \%$ ) . . . . . . . . . . . . . . . . . . . . . . . .

Offenbar haben die normalen Blutkörperchen durch Behandlung mit Alkohol allein, an Volumen zugenommen. die Formalinblutkörperchen dagegen abgenommen.

Endlich wurde, wie bei der Formalinfixirung üblich, der Alkohol entfernt und durch eine Mischumg ron Glycerin und Wasser (zu gleichen Theilen) ersetzt. Nach einstïndiger Finwirkung wurde wiederum bis zu constantem Volum centrifugirt.

Behandlung mit Glycerin-Wasser (1:1).

1. 0,06 ce Blut, nach Behandlung mit Alkohol $96 \%$.

2. 0,06 cc Blut, nach Behandlung mit 2 cc Formalin, nachher mit Alkohol

3. 0,06 ce Blut, nach Behandlung mit Alkohol . . . . . . . . . . .

4. 0,06 ce Blut, nach Behandlung mit Formalin, nachher mit Alkohol . . 107,5

Man sieht, dass die durch Formalingemisch gequollenen Blutkörperchen (2 und 4), auch noch nach Behandlung mit Glycerin viel grösser erscheinen als die einfach in ihrem Serum sedimentirten Erythrocyten (die Volumina sind 107 und 107,5 gegen 48,5 geworden).

Ferner erhellt aus den Tabellen, dass auch die nicht mit Formalingemisch behandelten Blutkörperchen durch Alkohol und Glycerin Volumveränderungen erfahren. Das ist hier aber Nebensache. Ich habe diese Versuche nur zur Vergleichung angestellt und limzugefügt. Uebrigens liönnen sie als eine Bestätigung des auf S. 403 Erwähnten, betreffs der 
Aenderung der Maschengrösse fixirter \%ellen, bei Ersatz des Masclıeninlaltes durch eine andere Flüssigkeit gelten.

Ferner habe ich mir die Frage vorgelegt, wie sich die Tolumina verhalten würden, wenn bloss die $\mathrm{Hälfte} \mathrm{der} \mathrm{Salzmengen} \mathrm{in} \mathrm{der} \mathrm{Formahin-}$ lösung vorhanden wären.

Es wurde also mit der folgenden formalinlösung experimentirt: $\mathrm{NaCl} 2,5 \mathrm{~g}, \mathrm{MgSO}_{4} 5 \mathrm{~g}, \mathrm{Na}_{2} \mathrm{SO}_{4} 5 \mathrm{~g}$ Aqua 500, Formalin 50.

Auch diese Lösung ist noch bedeutend hyperisotonisch.

Ich fasse die Versuchsergebnisse in eine Tabelle zusammen, die ohne weitere Erklärung verständlich sein wird.

\begin{tabular}{|c|c|c|c|}
\hline & Volumen & $\begin{array}{c}\text { Nael } \mathrm{Be}- \\
\text { handl. mit } \\
\text { Alkohol } 96 \%\end{array}$ & $\begin{array}{c}\text { Nach Be- } \\
\text { handl. nit } \\
\text { Glycerin }\end{array}$ \\
\hline 1. 0,06 cc Blut, $\mathrm{n}$ icht mit Formalingemisch behandelt & 48,5 & 70 & 62 \\
\hline 2. 0,06 ce Blut, mit 2 ec Formalingemisch behandelt & 115 & 108 & 105 \\
\hline 3. 0,06 ce Plut, nicht mit Formalingemisch behandelt & 48,5 & 70 & 63 \\
\hline 4. 0,06 cc Blut, mit 2 ec Formalingemisch behandelt & 115 & 106 & 103 \\
\hline
\end{tabular}

Die durch die Formalinlösung herbeigeführte Quellung der Blutlörperchen ist auch hier sehr bedeutend, obgleich etwas geringer als bei der ersten Formalinlösung, die mehr Salz enthielt. Alkohol und Glycerin geben entsprechende Resultate, wie in der vorigen Versuchsreihe, in der ein salzärmeres Formalingemisch benutzt wurde.

Auch der Gebrauch von Kochsalz statt des Salzgemisches führte keine wesentliche Aenderung der Resultate herbei. So wurden in einer Lösung von $50 \mathrm{~g}$ Formalin in 500 Wasser statt der genannten Salze bloss $4,5 \mathrm{~g}$ Kochsalz gelöst, also eine $0,9 \%$ ige NaCl-Lösung in einer sogen. $10 \%$ igen Formalinlösung verwendet. Auch hier war die Quellung der rothen Blutkörperchen sehr bedeutend.

Auf den ersten Anblick muss die Quellung befremden, denn das Formol besitzt gerade die Eigenschaft rasch einzudringen. Man würde also erwarten, dass die Substanzen sicl ebenso wie Harnstoff, über Blutkörperchen und Umgebung gleichmässig vertheilen wïrden und demnach die Anwesenheit ron Formol in einer 0,9\% igen NaCl-Lösung. das Volumen der Blutkörperchen unverändert lassen würde (vergl. Bd. I, S. 208 und Bd. II, S. 238 u. 241).

Nachdem ich einige Zeit ror dem Problem gestanden hatte, kam ich auf den Gedanken, dass vielleicht die Ameisensäure hierfür verantwortlich zi machen wäre, die als Oxydationsproduct des 
Formols ${ }^{1}$ ) gewöhnlich im käuflichen Präparat vorkommt. Wie ich früher gefunden hatte, führen Säuren eine Quellung der Blutkörperchen hervor (vergl. Bd. I S. 330).

Es wurden deshalb einige Versuche mit ne utralisirter Formollösung angestellt.

Zu diesem Zweck wurde das käufliche Präparat mit $\mathrm{CaCO}_{3}$ geschüttelt, so dass die abfiltrirte klare Lösung gegenüber Lackmus neutral reagirte. Das mit dieser Lösung angefertigte Formalin-Salzgemisch ergab num in der That nur eine geringfügige Quellung.

Folgende Lösungen wurden mit einander verglichen : eine Lösung von $0,9 \% \mathrm{NaCl}$ in Wasser, in neutralisirter und in nicht neutralisirter Formollösung 1:50.

Einfluss der Neutralisirung des kïuflichen Formols anf das Volumen der rothen Blutkörperchen.

\begin{tabular}{|c|c|}
\hline Flüs sigkeiten & $\begin{array}{l}\text { Volumen der } \\
\text { Blutkörperchen }\end{array}$ \\
\hline 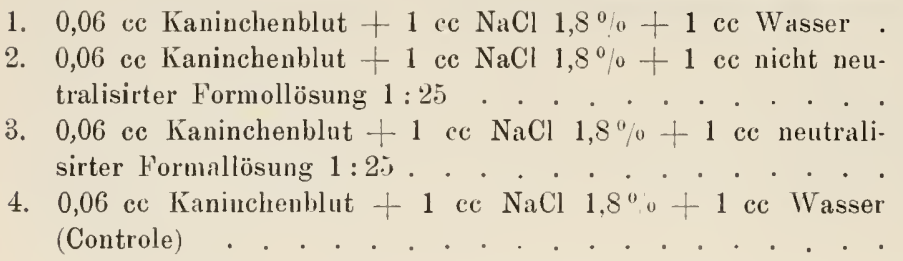 & $\begin{array}{l}67 \\
59 \\
55\end{array}$ \\
\hline
\end{tabular}

Wie ersichtlich, ist die durch neutralisirte Formollösung herbeigeführte Quellung weit geringer als die durch die saure Lösung veranlasste; aber dennoch ist eine Quellung bestehengeblieben. Vielleicht - so meinte ich - ist diese der $\mathrm{CO}_{2}$ zuzuschreiben, die bei der Neutralisation aus dem kohlensauren Kalk entsteht und in der Flïssigkeit zurückbleibt.

Aus diesem Grund wurde statt nit $\mathrm{CaCO}_{3}$ mit einer reinen 1/10 n. KOH-Lösung neutralisirt. Das schien auch deshalb empfehlenswerth, weil bei der nachträglichen Behandlung mit dem in der ersten Weise nentralisirten Formalingemisch die Blutkörperchen so hart wurden, dass sie katum aus dem capillaren Theil des trichterförmigen Riöhrchens zu entfernen waren. Diese Firscheinung wïrde auch in der l'raxis der Neutralisirung mittels $\mathrm{CaCO}_{3}$ im Wege stehen, denn dadurch würde die Anfertigung von Schnitten unmöglich werden. I)ie Ursache der Er-

1) Bekanntlich ist Formol der Aldehyd des Methylalkohols. Das weitere Oxydationsproduct ist Ameisensäure, und in Säuren quellen Blutkörperchen wie auch andere Zellen. 
härtung liegt hier offenbar in der Unlöslichkeit des bei der Neutralisation gebildeten Calciumformiats in Alkohol ${ }^{1}$ ).

Um die zur Neutralisation des Formols erforderliche KOH-Menge kiennen zu lernen, wurde mit der KoH-Lösung titrirt; Thenolphtalein diente als Indicator. $10 \mathrm{cc}$ Formollösung (Schering) aus einer frisch geöffneten Flasche erforderten 1,05 ‘c ${ }^{1 / 10} \mathrm{n}$. KOH-Lösung. (Obgleich die Flasche unmittelbar nach dem Gebrauch geschlossen wurde, war am folgenden Tag der 'Titer schon auf 1,1 cc angestiegen.)

Es wurden nun ähnliche Versuche angestellt, wie sie ausgeführt waren, um den Einfluss der durclı $\mathrm{CaCO}_{3}$ erzielten Neutralisation zu erforschen. Es stellte sich aber heraus, dass auch noch nach Neutralisation mittelst KOH-Lösung eine Quellung der Blutkörperchen hervorgerufen wurde.

Iclı lıabe keine Gelegenlieit mehr gelıabt, diese Untersuchungen weiter zu führen, so dass mir die noch nach der Neutralisation zurückgebliebene Quellung unbekannt geblieben ist.

Vielleicht liegt die Ursache in einer durch das Formaldehyd herbeigeführten Zustandänderung des Colloids (vergl. S. 398, 399).

In derselben Richtung ist vielleicht, jedenfalls theilweise, die Erklärung der Volumänderungen zu suchen, die sich bei der nachträglichen Einwirkung von Alkohol und von Glycerin kundgibt. Man erinnert sich die Ausführungen von Hardy über die Aenderungen, die die Maschen fixirter Zellen bei nachträglicher Tränkung mit differenten Flüssigkeiten erfähren (S. 403).

Indessen ist. wie mall auch ïberdie Erklärungdenken möge, bereits jetzt das Eine aus den oben erwähnten V'ersuchen zu folgern, dass nämlich gegenüber der Annahme, die Formalinfixirung habe auf die Grösse der Gewebelemente keinen Einfluss, Vorsicht geboten ist.

Auch die feinere Struktur wird zweifellos von derselben beeinflusst, da nicht anzunehmen ist, dass alle Gewebelemente eine gleichgradige Volumvermehrung erfahren werden.

Im Lichte dieser Untersuchungen sind auch die Angaben von Dekhuyzen [28] über die Fixirung und Conservirung von Geweben zu beurtheilen.

1) Ich balte es nicht für unmöglich, dass aus einem ähnlichen trrund, die nach Formalin-Alkohol-Xylol- (Terpentin-) Behandlung in Paraffin eingeschlossenen Präparate oft dermaassen erhärtet sind, dass eine Zerlegung in feine Schnitte geradezu unmöglich ist. Auch hier ist an ein Unlöslichwerden von Calciumformiat zu denken zumal diese Erscheinung insbesondere an kalkreichen Geweben (Rind) vorkommt. 
Dekhuyzen hatte bemerkt, dass die delomorphen Zellen der Säugethiere im bekannten Flemming'schen Gemisch bedeutende Schrumpfungen erleiden und meinte das dem zuschreiben zu müssen, dass diese Flüssigkeit einen dreifach grösseren osmotischen Druck als das Blut der Warmblüter besitzt ${ }^{1}$ ).

Von dieser Erfahrung ausgehend, hat er für die Fixirung und Conservirung von niederen Seethieren Fluissigkeiten bereitet, welche dieselbe Gefrierpunkterniedrigung besassen, wie ihr natürliches Medium, das Seewasser, m. a. W. damit isotonisch waren.

Als Flüssigkeit A bezeichnet der Autor ein Gemisch von Kaliumbichromat, Osmiumsäure und Salpetersäure, das in folgender Weise angefertigt wurde:

250 cc einer Lösung, die $2,5 \mathrm{~g}$ Kaliumbichromat in je 100 cc filtrirten Meereswassers entlıält, wird mit 25 cc Normal-Salpetersäure und ferner mit 54 cc einer $2 \%$ igen Osmiumsäurelösung versetzt. Von dieser Flüssigkeit war $\Delta=-2,042^{\circ}$.

Das Seewasser selbst stammte von Roscoff (Atlantischer Ocean bei Arcachon) und hatte in Juli eine Depression zwischen $-2,005^{\circ}$ und $-2,099^{\circ}$. Man sieht, der Unterschied der Gefrierpunkterniedrigung von Fixirungsflüssigkeit und Seewasser ist recht gering. Auch konnte seine Flüssigkeit sogar mit dem zweifachen Volumen des Seewassers verdünnt werden, ohne dass die Depression sich änderte. Die Flüssig. keit erwies sich sehr geeignet für die Fixirung von Sipunculus nudus und für Cydippen.

Als Fliissigkeit B bezeichnet Dekhuyzen ein anderes Gemisch, das er für diejenigen Objecte vorschlägt, in denen man die Kalkausscheidungen unversehrt lassen will. Deshalb lässt er die Salpetersäure fort.

Sie besteht aus einem Gemisch von 26,9 cc 2\% iger Osmiumsäure und $173,1 \mathrm{cc}$ einer $2,5 \%$ igen Lösung von Kaliumbichromat in Neereswasser. Auch von dieser Flüssigkeit B war $\lrcorner=-2,040^{\prime \prime}$. Der Verfasser theilt mit, dass Y. Delage die Flüssigkeiten $\mathrm{A}$ und $\mathrm{B}$ für die winzigen Asterienlarven angewandt und mit keiner anderen Flüssigkeit solche gute Resultate erzielt hat.

Ferner hat Dekhuyzen für Seethiere der zoologischen Station in Neapel zwei Fliissigkeiten $\mathrm{H}$ und $\mathbf{J}$ bereitet.

Fliissigkeit $\mathrm{H}$ ist folgende:

1 Liter einer 2,5\% igen Kaliumbichromatlösung in Seewasser

80 cc normal Salpetersäure

228 cc Wasser.

Fłüssigkeit $J$ wird aus zwei Standardflüssigkeiten bereitet:

a) Formollösung von $3,3 \%$ (isotonisch mit Seewasser)

b) Salpetersäurelösung von $3,58 \%$ (isotonisch mit Seewasser).

1) Eine älnliche Beobachtung hatte Bottazzi bereits 1097 bei Selacliergehirn gemacht. Er sah, dass nach Aufenthalt dieses Organs in M ïller'scher Flüssigkeit dasseibe quoll und sogar an verschiedenen Punkten zerplatzte. Botta z zi schrieb diese Erscheinung dem zu geringen osmotischen Druck der Fixirungsflüssigkeit zu: diese Ansicht wurde noch dadurch bestätigt, dass Hinzufügung von Salz der Quellung vorbeugen konnte (vergl. Bd. I S. 463). 
Diese beiden können nach dem Autor in jedem Verhältniss mit einander vermischt werden, ohne dass die Isotonie mit dem Meereswasser gestürt wird. IVie viel von jeder Standardflüssigkeit a und b angewandt werden muss, hängt von der Natur der Thiere und der Organe ab. In der Flüssigkeit $J$ ist das Formol herangezogen, um eine Substanz zu haben, die rasch in die Zellen eindringt.

Ob die von D ek h u y ze n vorgeschlagenen Flüssigkeiten die Volumina der betreffenden Zellen wirklich unverändert lassen, wie der Autor stillschweigend annimmt, verdient noch untersucht zu werden; nach den Ergebnissen meiner Experimente ist das keineswegs überflüssig.

Die stillschweigende Annahme Dekhuyzen's kann nur richtig sein, wenn die Zellen bei der Fixirung sich als semipermeable Gebilde verhalten, d. h. lediglich für Wasser permeabel sind. Das ist kaum anzunehmen. Im Gegentheil! Es unterliegt wohl keinem Zweifel, dass Osmiumsäure, Salpetersäure und Kaliumbichromat in die Zelle eindringen und auch die Colloidsubstanz sowohl in chemischem, wie auch in physikalischem Sinne modificiren. Ist in Folge dessen die äussere Begrenzung der Zelle durchlässig geworden, so ist es nicht mehr lediglich der osmotische Druck der Fixirungsfliissigkeit, der das Volumen der Zelle bedingt, sondern es macht sich auch die Diffusion geltend. Besitzen die Stoffe, die die Zellen verlassen, einen geringeren osmotischen Druck, als die, welche eintreten, so nimint der osmotische Druck und demzufolge auch das Volumen des Zellinhalts zu (vergl. Bd. II, S. 151, 398, diesen Band S. 114, 134, 335), im umgekehrten Falle nimmt dasselbe ab.

Aber abgesehen von dieser Erwägung ist auch aus einem anderen Grunde nicht ohne Weiteres anzunehmen, dass das Volumen der Zellen in isosmotischen Fixirungsmitteln unverändert bleiben wird. Man vergesse doch nicht, dass das colloidale Gerüst der Zellen unter dem Einfluss von Fixirungsmitteln eine Zustandänderung und damit eine Modification in der Anordnung der Colloidtheilchen erfährt, eine feinere Vertheilung desselben oder eine Conglomeration (S. 398), eine Modification, die sich sogar nach dem Fixirungsvorgang durch verschiedenartige Flüssigkeiten vielfach ändern lässt. Ich erinnere an die Ausführungen Hardy's über die Maschendimensionen (S. 403).

Wenn diese Modification nicht bei allen Elementen eines Gewebes die gleiche ist, so muss sich das auch auf die Configuration des feineren Structurbildes geltend machen.

Es liegt hier ein ganz ähnlicher Sachverhalt ror, wie er oben beim Formalin erörtert wurde.

Wenn Dekhuyzen und mit ihm I. Delage behaupten, dass die genannten isosmotischen Fixirungsflüssigkeiten bei Seethieren bessere Resultate geben als bis jetzt durch andere Fixirungsflüssigkeiten erreicht 
wurde, so muss man das vorläufig als richtig annehmen. (Vergl. auch die Fussnote von S. 410).

Ob jedoch diese Flïssigkeiten das Zellenvolumen und die Configuration des feinen Structurbildes unverändert lassen, mag, wie ich schon bemerkte, dahingestellt bleiben.

Ich gehe noch weiter und behaupte, dass inan, un dieses etwa zu erzielen, die Flüssigkeit gerade nicht mit dem natürlichen Medium isotonisch im Sinne Dekhuyzen's machen soll.

Ein Beispiel möge das erläutern.

Wenn man Kaninchenblutkörperchen mit einem Formalin-Kochsalzgemisch ${ }^{1}$ ) versetzt, das dieselbe Gefrierpunkterniedrigung besitzt, wie das entsprechende Blutserum $\left(-0,58^{\circ}\right)$, so findet eine Quellung statt, die um so bedeutender ist, je geringer der NaCl-Gehalt des Gemisches ist. Beträgt der Procentgehalt an $\mathrm{NaCl}$ weniger als $0,45 \%$, so verlieren die Blutkörperchen sogar Farbstoff. Das rührt daher, dass das Formaldehyd sich gleichmässig zwischen Blutlörperchen und Umgebung vertheilt und also dem Blutkörperchen gegenüber nicht am osmotischen Druck betheiligt ist. Es ist also das Kochsalz gleichsam einfach in $\mathrm{W}$ asser aufgelöst, und in einer Lösung ron $\mathrm{NaCl}$ in Wasser verlieren sie Farbstoff. Regelt man es so, dass das Formalin-Kochsalzgemisch (von $\left.I=-0,58^{\circ}\right) 0,6 \% \mathrm{NaCl}$ entlält, so quellen die Blutkörperchen zwar noch erheblich, aber Farbstoff verlieren sie nicht mehr.

Enthält also eine Fixirungsflüssigkeit eine oder mehrere Substanzen, die in die Zellen eindringen, so ist es gerade felllerhaft, wie es l)ekhuyzen gethan hat, diese Substanz sich ebenso an der Gefrierpunkterniedrigung betheiligen zu lassen, wie jene Stoffe für die die Zellen impermeabel waren. Aus diesem Grund nahm ich denn auch bei deı oben mitgetheilten Versuchen eine Formalinlösung, in der $0,9 \%$ NaCl aufgelöst war. Diese Lösung (5 cc NaCl-Lösung $1,8 \%$ +5 cc Formol 1:25) hatte eine Depression von - 1,159 ${ }^{\circ}$, also höher als die des Serums $(-0,58 \%$. Dennoch trat keine Schrumpfung ein, wie man nach Dekhuyzens Anschauungen erwarten sollte, vielmehr noch eine geringe Quellung!

\section{Theorie der Färbung fixirter Gewebe.}

Zur Erklärung der bei der histologischen Tinction fixirter Gewebe zur lieobachtung gelangenden Farbstoffaufnalme sind drei Theorien aufgestellt worden.

1) Neutralisirtes Formalin. 
1. Eine physikalische 'T' heorie, die besonders von Gierke|8| verfochten wurde. Danach handelt es sich um eine "Adsorptionse rscheinung“. Bekanntlich bedecken sich feste Körper, die mit der Luft in Berihrung stehen, mit einer dichten Gasschicht, die aus den Bestandtheilen der Luft besteht, aber in ganz anderen Verhältnissen als sie darin vorhanden sind. In analoger Weise soll sich auch der F a rbst off durch Oberflächenattraction auf die \%ellenbestandtheile absetzen.

2. Eine chemische Theorie, die sich vorstellt, dass eine chemische Reaction zwischen Gewebesubstrat und Farbstoff zu Stancle kommt und dass das Product dieser Reaction eine gefärbte chemische Verbindung sei. Diese Anschauung wird besonders durch die Arbeiten von Ehrlich und Weigert gestützt und wurde in der allerletzten Zeit von Martin Heidenhain kräftig rertheidigt.

3. Eine physikalisch-chemiscle 'l'heorie. Nach dieser Theorie, die zuerst ron 0 tto $\mathrm{N}$. Witt ${ }^{1}$ ) für die teclmische Färbung ausgesprochen [9] und später in modificirter Form von Spiro [10] auf die histologische Tinction in Anwendung gebracht wurde, löst die Faser den Farbstoff als solchen auf. Es handelt sich also um eine ,feste $\mathrm{L}$ ös $u n g$ ".

Bekanntliclı hat van't $\mathrm{H}$ of $\mathrm{f}$ auf das Bestehen delartiger Lösungen aufmerksam gemacht (vergl diesen Band S. 117). Bringt man ein Stückchen Silber in geschmolzenes Jodid und leitet nach Erstarrung des Jodids einen elektrischen Strom durch, so wird Silber in dem festen Jodid bewegt (Le h mann).

Als ein anderes Beispiel nennt $v$ an't $\mathrm{H}$ off das Eindringen von Kohlenstoff in Porzellan (Violle). Verkupfert man Platin, so dringt das Kupfer in das Platin ein (Gore), ebenso Gold in Blei.

In ähnlicher. Weise denkt sich Witt, dass sich Farbstoff in der Faser löst.

Von den Ausführungen Spiro's wird unten die Rede sein.

Ich werde nun diese drei Theorien ein wenig ausführlicher besprechen, werde aber aus redactionellen Grïnden die dritte (physikalischchemische) der zweiten (chemischen) vorangehen lassen, obgleich diese Reilienfolge nicht der chronologischen entspricht.

\section{a) Physikalische Theorie (Adsorption).}

Gegen diese Theorie ist unter anderem anzuführen, dass sie höchstens im Stande ist, die Schnittfärbung zu erklären. Fragt man nämlich, wie es kommt, dass auch grössere Gewebestïcke durchgefärbt werden, so entstehen Schwierigkeiten, denen man, wie mir scheint, nur

1) Färberzeitung 189091, N1. 1. Citirt nach Spiro und nach N. Heidenhain, der auch selhst nach einem Anderen eitirt. 
entgehen kann, wenn zu gleicher Zeit angenommen wird, dass der Farbstoff durch capillare Wirkung in die Interstitien weiterbefördert wird. Jedoch reicht diese Hilfshypothese für die Durchfärbung von homogenen Gelatineblöckchen nur in dem Falle aus, dass dann bei der Fixation der Gelatine ein offenes Netz entsteht. Nur dann kann man sich vorstellen, dass die Farblösung durch capillare Imbibition aufgenommen wird. Handelt es sich aber um eine Wabenstructur, so kann ron capillarer Imbibition nicht die Rede sein.

In seinem Artikel "Theorie der histologischen Färbungen" [12] hat auch Martin Heidenhain die Adsorptionstheorie, jedoch aus anderen Gründen für ungenügend erklärt.

Um die Adsorptionshypothese näher zu verfolgen, experimentirte Heidenhain mit Körpern von grosser Oberfläche. Hierzu nahm er Thierkohle und verschiedene "total wasserunlösliche weisse Pulver".

Bei den Versuchen mit Thierkohle fand er, dass sie Farbstoffe, olme Rücksicht auf deren chemischen Charakter aus den Lösungen herausnimmt. Sie adsorbirt sowohl saure wie basische Anilinfarbstoffe, ja sogar freie Säuren (Indigoschwefelsäure, etc.) und zeigt folglich keine chemische Wahlverwandtschaft zu den adsorbirten Stoffen. Aus diesem Grunde kann man die bei der Kohle gewonnenen Resultate nicht auf die Erklärung der Färbungsvorgänge in den Geweben anwenden.

Ferner experimentirte $\mathrm{Heidenhain,} \mathrm{wie} \mathrm{erwähnt,} \mathrm{mit} \mathrm{ver-}$ schiedenen unlöslichen Pulvern; dieselben wurden mit Lösungen von Anilinfarbstoffen geschüttelt Hier zeigte sich nun eine einfache Beziehung zwischen dem chem is chen Character von Pulver und Farbstoff.

Als ein Beispiel sei das folgende hier wiedergegeben [13]. Gewöhnlicher reiner Töpferthon, der medicinische Bolus, der, chemisch gesprochen, ein saures Polysilicat des Aluminiums ist, condensirt z. B. basische Anilinfarbstoffe; dieselben lassen sich vermittelst des Bolus aus ihren Lösungen ausschütteln. Mit sauren Anilinfarbstoffell gelingt das aber nicht.

Umgekehrt condensiren jene unlöslichen basischen Wismuthsalze, die der alten Medicin unter dem Namen Magisterium Bismuthi geläufig waren, die sauren Anilinfarbstoffe, während ihre Wirkung auf basische Farbstoffe gering ist.

Da die Alizarine sauren Character besitzen, so ist man demzufolge in der Lage, diese unlöslichen basischen Pulver im Tone der Alizarinsalze anzufärben; das gelbe Alizarinroth z. B. verleiht den Pulvern die schöne rothe Farbe des Alizarinsalzes.

Diese Anfärbungen unlöslicher Pulver sind also nach Heidenhain chemischer Natur und haben mit der sogenannten Adsorption der Farbstoffe durch Thierliolle nichts zu thun.

Dass die auf Beizung bernhenden Färbungen theilweise physikalischer Natur sind, liegt auf der Hand. 


\section{b) Physikalisch-chemische Theorie. Ias Theilungsprincip.}

Wie bereits erwähnt, löst sich nach Witt der Farbstoff' in der Faser und bildet mit dieser also eine feste Lösung. Das kann aber, wie C. 0 . Weber liervorhob, nicht in aller Strenge richtig sein $|1+|$. denn er fand, dass auch die Flissigkeit, mit welcher die Faser getrïint ist, für die Farbstoftaufnahme in Betracht kommt. Wenu man z. B. die Faser mit Aceton behandelt hat, so ist sie unfähig Farbstoff aufzunehmen.

Spiro lıat aus diesem Grunde die Vorstellung Witt's derart modificirt, dass auch der die Gewebesubstanz tränkenden Flüssigkeit Rechnung getragen wird. Er hat nämlich hierbei das Theilungsprincip herangezogen. Schon früher hatte von Georgievicz $\lfloor 15 \mid$, bei den Färbungserscheinungen mit Indigocarmin und Methyleublau. die Aufmerksamkeit auf dasselbe gelenkt.

Was versteht man unter dem 'Theilungsprincip?

Es scheint mir empfehlenswerth, dasselbe an einem Beispiel zu erläutern.

Bringt man überschüssiges festes Jod in Wasser, so löst sich nach langem Schütteln nur eine geringe Menge, denn Jod ist in Wasser wenig löslich. Filtrirt man das feste Jod ab, schichtet das klare braune Filtrat auf Schwefelkohlenstoff und schiittelt wieder, so wird der Schwefelkohlenstoff durch Aufnahme des Jods violett, während die wässrige Jodlösung so gut wie entfärbt wird. Die Ursache der Erscheinung ist darin zu suchen, dass Jod in $\mathrm{CS}_{2}$ viel löslicher ist als in Wasser. Das wird noch dadurch bestätigt, dass, wenn man eine violette Lösung von Jod in $\mathrm{CS}_{2}$ mit reinem Wasser überschichtet und dann schüttelt, kaum etwas Jod in das Wasser übergeht.

Berthelot und Jungfleisch [16] haben gefunden, dass die Concentrationen des Jods in Wasser und in Schwefelkohlenstoff sich nach dem Schütteln wie die Löslichkeit des Jods in den beiden Medien verhalten.

Das Verhältniss zwischen der Concentration des Jods im Wasser und im Schwefelkohlenstoff $\frac{\mathrm{C}_{1}}{\mathrm{C}_{2}}$ ist demnach eine constante Grösse. Ob viel oder wenig Jod zwischen den beiden Flüssigkeiten zu vertheilen ist, ist gleichgïltig, das Verhält n iss zwischen den Jodconcentrationen ist inmer dasselbe. Dieses Verhältn iss wird mit dem Namen T'heil-ungscoëfficient bezeichnet. 
Später hat Nernst auf manche Abweichungen von diesem Gesetz lingewiesen [17], konnte dieselben aber in befriedigender Weise erklären.

Es geschieht nämlich nicht selten, dass der in einem bestimmten Lösungsmittel gelöste Stoff in diesem ein anderes Moleculargewicht besitzt als in einem anderen. Dies rührt daher, dass in dem einen Fall die Molecüle sich theilweise zu Doppelmoleciilen oder grösseren Moleciilgattungen associiren. Nun ist $\frac{\mathrm{C}_{1}}{\mathrm{C}_{2}^{\prime}}$ nur constant für eine und dieselbe Moleciilgattung.

Ich nenne ein Paar Beispiele einer solchen Molecülassociation. Essigsäure erfährt in ätherischer Lösung keine Dissociation. Löst man $1 \mathrm{Mol}$ Essigsäure in Aether auf, so ist - ebenso wie bei der Lösung von 1 Mol. Zucker in $1 \mathrm{l}$ Wasser der osmotische Druck bei $0^{0}$ 22,34 Atmosphären. Löst man aber 1 Nol. Essigsäure in Benzol auf, so beträgt der osmotische Druck etwa die Hälfte des vorigen. Es ist also bei der Auflösung in Benzol eine kleinere Molekülzahl im Liter vorhanden, folglich müssen sich Doppelmolecüle $\left(\mathrm{CH}_{3} \cdot \mathrm{COOH}\right)_{2}$ gebildet haben.

Ebenso folgt aus der Gefrierpunkterniedrigung des in Eisessig gelösten Tannins, dass letzterer Stoff ein Moleculargewicht von 326 besitzen muss. Das entspricht der richtigen Formel $\mathrm{C}_{14} \mathrm{H}_{10} \mathrm{O}_{9}$. Wird aber das 'Tamnin in Wasser gelöst, so geht, wie Paternò fand, aus der Gefrierpunkterniedrigung ein Moleculargewicht zwischen 2643 und 3700 hervor [18]. In Wasser findet also eine erhebliche Association von Molecülen statt. Die wässrige Tanninlösung erscheint sogar als Colloid.

Auwers hat mit seinen Schülern die Association von Molecülen eingehend studirt [19].

Ich bringe noch ein Beispiel und verwerthe dasselbe fuir die nähere Erörterung des Theilungsprincipss.

Benzoesäure besitzt in Wasser die normale Moleculargrösse, entsprechend der Formel $\mathrm{C}_{6} \mathrm{H}_{5} \cdot \mathrm{COOH}$; in Benzol aber ist sie vorwiegend als Doppelmoleciil vorhanden. Ich sage "vorwiegend", denn theilweise findet sich die Säure auch in Benzol als $\mathrm{C}_{6} \mathrm{H}_{5} \cdot \mathrm{COOH}$. Man kann den Sachverhalt nun auch so auffassen, dass man annimmt, die Doppelmolecüle seien in Benzol theilweise in Einzelmolecüle gespalten, und kann dann den von Nernst ausgesprochenen Satz in Anwendung bringen, dass bei liegenwart mehrerer gelösten Stoffe, jede einzelne Molecülgattung sich so vertheilt, als ob die andern Molecülgattungen nicht zugegen wären. Die in Wasser und in Benzol vorhandenen Moleeïle $\mathrm{C}_{6} \mathrm{H}_{5} . \mathrm{COOH}$ vertheilen sich also nach dem gewöhnlichen Gesetz:

$\mathrm{C}_{1}$ (Concentration der $\mathrm{C}_{6} \mathrm{H}_{5} \mathrm{COOH}$ in Wasser)

$\mathrm{C}_{2}$ (Concentration der $\mathrm{C}_{6} \mathrm{H}_{5} \mathrm{COOH}$ in Benzol) = Constans =

Theilungscoëfficient von $\mathrm{C}_{6} \mathrm{H}_{5} \mathrm{COOH}$ in Wasser und Benzol.

Lässt man die geringfügige elektrolytische Dissociation der Benzö̈säıre in Wasser ausser Betracht, so lässt sich $C_{1}$ ohne weiteres durclı die Menge der im Wasser gelösten Säure ausdriicken. 
Eine andere Frage ist aber, wie gross ist die Concentration $\mathrm{C}_{2}^{\prime}$ der einfachen Benzoësäuremolecüle $\mathrm{C}_{6} \mathrm{H}_{5} \cdot \mathrm{COOH}$ in $\mathrm{Benzol}$ ? Hier sind doch nicht, wie in der wässerigen Losung ausschliesslich $\mathrm{C}_{5} \mathrm{H}_{5}$. $\mathrm{COOH}-$ Molecuile vorhanden, sondern daneben finden sich auch viele Doppelmoleciile. Nach den Dissociationsgesetzen ist die Concentration dieser einfachen Molecüle der Quadratwurzel der Gesammtconcentration $\mathrm{C}_{2}$ der in Benzol gelösten Benzoësäure proportional. Folglich ist $\mathrm{C}_{2}^{\prime}=\sqrt{\mathrm{C}_{2}}$ und die obige Formel wird $\frac{\mathrm{C}_{1}}{\sqrt{\mathrm{C}_{2}}}=$ constans ${ }^{1}$ ).

1) Ich werde diesen, ebenfalls von Nernst ausgesprochenen Satz (Vergl. Zeitschr. f physik. Chemie 8. 1891. S. 110; oder Nernst "Theoret. Chemie" 2. Aufl. S. 426) klar zu legen versuchen. Hierzu bitte ich die Lecture der Ausführungen in Bd. II, S. 479-480 über das Gleichgewicht einer theilweise dissociirten Verbindung vorangehen zu lassen.

Beim gegebenen Beispiel handelte es sich um einen Ausdruck für das Gleichgewicht in einer wässerigen Essigsäurelösung. In solch einer Lösung befinden sich ungespaltene $\mathrm{CH}_{3} \mathrm{COOH}-\mathrm{Molecüle}$, $\mathrm{H} \cdot$ Ionen und $\mathrm{CH}_{3} \mathrm{COO}^{\prime}$-Ionen. Nernst hat nun diese Verhältnisse auf die theilweise Dissociation von Doppelmolecülen übertragen, indem er sich vorstellt, dass auch - um beim obengenannten Beispiel zu bleiben ein Gleichgewichtzustand zwischen ungespaltenen Doppelmolecülen $\left(\mathrm{C}_{6} \mathrm{H}_{5} \mathrm{COOH}\right)_{2}$ und Einzelmolekülen im Benzolmedium sich herstellt. Ist diese Annahme zutreffend, so muss auch hier die Formel (4) von Bd. II Seite 480 Gültigkeit besitzen

$$
\mathrm{KV}=\frac{\alpha^{2}}{1-\alpha}
$$

In dieser Formel ist $\mathrm{K}$ die Dissociationsconstante von $\left(\mathrm{C}_{6} \mathrm{H}_{5} \mathrm{COOH}\right)_{2}$ in Benzol; $\mathrm{V}$ die Verdünnung, d. h. die Anzahl Liter Benzol, in der 1 Grammmolecül $\left(\mathrm{C}_{6} \mathrm{H}_{5} \mathrm{COOH}\right)_{2}$ aufgelöst wurde; $\alpha$ ist der dissociirte Theil der aufgelösten Doppelmolecüle.

Die Formel vereinfacht sich in erheblıclıem Maasse, wenn diese Doppelmolecüle in sehr weitgehendem oder in sebr geringem Umfang dissociirt sind. Im ersten Falle ist $\alpha$ nahezu $=1$, im zweiten Falle $=0$.

Im vorliegenden Benzoesäure-Benzol-Beispiel ist $\alpha$ klein. Demnach ist die Formel annähernd

$$
\begin{aligned}
\mathrm{KV} & =\frac{\alpha^{2}}{1-\overline{0}}=\alpha^{2}, \text { gleichzusetzen, } \\
\text { oder } \quad \frac{\alpha^{2}}{\mathrm{~V}} & =\mathrm{K} .
\end{aligned}
$$

Da $\alpha$ der dissociirte Theil und $\mathrm{V}$ die Literzahl ist, in der dieser Theil gelöst ist, kann durch $\frac{a}{\mathrm{~V}}$ die Concentration des dissociirten Theiles ausgedrückt werden. Da K eine Constante ist, ist $\frac{\alpha}{\mathrm{V}}$ also, bei geringfügiger Dissociation mit $\frac{1}{\sqrt{\mathrm{V}}}$, d. h. der Quadratwurzel der in die Benzol gelöste Substanz proportional. ${ }_{\mathrm{V}}^{\alpha}$ wurde im Texte mit $\mathrm{C}_{2}^{\prime}$ und $\mathrm{V}$ mit $\mathrm{C}_{2}$ bezeichnet. Demnach ist $\mathrm{C}_{2}^{\prime}$ mit $\frac{1}{\sqrt{\mathrm{C}_{2}}}$ proportional. 
Aus folgender Tabelle geht deutlich hervor, dass der Versuch diese Vorstellung bestätigt.

\begin{tabular}{c|c|c|c}
\hline $\begin{array}{c}\mathrm{C}_{1} \text { (Anzahl g in } \\
100 \text { ce Wasser) }\end{array}$ & $\begin{array}{c}\mathrm{C}_{2} \text { (Anzahl g in } \\
100 \text { ce Benzol) }\end{array}$ & $\begin{array}{c}\mathrm{C}_{1} \\
\mathrm{C}_{2}\end{array}$ & $\frac{\mathrm{C}_{1}}{\sqrt{\mathrm{C}_{2}}}$ \\
\hline \hline 0,0150 & 0,242 & 0,062 & 0,0305 \\
0,0195 & 0,412 & 0,048 & 0,0304 \\
0,0289 & 0,970 & 0,030 & 0,0293 \\
& & &
\end{tabular}

Wie ersichtlich sind die Zahlen der dritten Spalte ungleich, die der vierten stimmen unter einander überein.

Fassen wir die Gesetze des Theilungsprincips noch einmal zusammen, so lassen sie sich folgender Weise zum Ausdruck bringen.

Wenn eine Substanz sich über zwei Flüssigkeiten vertheilen kann und die Molecülgattung ist in beiden Flüssigkeiten dieselbe, so gilt $\frac{\mathrm{C}_{1}}{\mathrm{C}_{2}}=$ Constans.

Ist in einer der beiden Flüssigkeiten, z. B. in der $\mathrm{C}_{2}$ entsprechenden, die Molecülgattung theilweise auch eine andere, so muss diese in Abzug gebracht werden, wenn das Gesetz $\frac{\mathrm{C}_{1}}{\mathrm{C}_{2}}=$ Constans noch gültig bleiben soll. Denn es gilt nur für je eine und dieselbe Molecülgattung.

Nungiebt es, wie Nernst hervorhob, eine einfache Beziehung, um die Concentration der letztgenannten Molecülgattung aus der Gesammtconcentration abzuleiten; sie ist nämlich der Quadratwurzel der Gesammtconcentration proportional.

Ich kehre jetzt zu den Ausführungen Spiro's zurïck.

In einer Reihe von Untersuchungen hat bekanntlich Franz Hofmeister die Anfnahme von Farbstoffen durch Gelatineplatten studirt. Es ist nun Spiro gewesen, der die Ergebnisse dieser Untersuchungen unter Heranziehung des Theilungsprincipes gedeutet hat.

Da die betreffenden Versuche Hofmeister's auch aus anderen Gesichtspunkten wichtig sind, will ich hier Einiges darüber mittlıeilen.

Hofmeister [20] zeigte an der Hand eigener Versuche, sowie solcher seines Schülers Linnemann, dass z. B. dïnne Leimplatten aus 
einer $0,00125 \%$ Methylviolettlösung soviel Farhstoff aufnalınen, dass nach $3 \times 24$ Stunden die Concentration der nunmehr in der Leimplatte rorhandenen Farbstofflösung $36 \mathrm{mal}$ grösser war als die der ursprünglichen Farbstofflösung (Farbstoffflotte). Noch schlagender tritt diese Farbstoffaufnahme durch Gelatineplatten leervor, wenn man sie in eine Lösung von Methylenblau in Chloroform legt. Unter günstigen Umständen kommt es dann in wenigen Ninuten zu einer nahezu gänzlichen Entfärbung der blaten Chloroformlösung.

Um einen chemischen Vorgang handelt es sich lier nicht; denn die absoluten a ufgenommenen Farbstoffquantitäten nelımen für gleichdicke Leimplatten mit der Verdünnung der Farbstofflösung (Flotte) ab. Das ist mit dem Begrifi einer chemischen Bindung schwer zu vereinigen.

Weiter gelang es auch Spiro, derartig gefärbte Platten durch das Lösungsmittel allmählich zu entfärben.

Spiro kam nun auf den Gedanken, dass es sich hier vielleicht um eine Vertheilung von Farbstoff $z$ wischen Leim einerseits und Lösungsmittel der Flotte andererseits handelt. Berechnete er dann bei jedem Versuch das Verhältniss der Farbstoffconcentrationen in diesen beiden Medien, so erhielt er eine constante Grösse. $\mathrm{Zu}$ einem gleichlautenden Resultat war, wie Spiro mittheilt, auch v. Georgievicz bei der Färbung ron Seide mit Indigosulfosäure gelangt und ebenso v. Georgievicz mit E. Löwy [21] bei der Färbung von Cellulose mit Methylenblau. Auch da zeigte sich ein constantes Verhältniss zwischen der Concentration der aufgenommenen Farbstofflösung und derjenigen der ursprünglichen Flotte. Sie fanden

$$
\frac{\sqrt{\text { Concentration der Flotte }}}{\text { Concentration der Faser }}=\text { Constans. }
$$

In Uebereinstimmuug mit diesen Ergebnissen stellte sich heraus, dass die verschiedenen Farbstoffe sich derselben Leimplatte gegenüber ganz verschieden verhalten. Für rerschiedene Farbstoffe war also caeteris paribus die Constante (der Theilungscoëfficient) ein anderer. So ist der Theilungscoëfficient für Bismarckbraun ein ganz anderer wie für Methylenblau.

Aber auch bei einem und demselben Farbstoff bedingen die verschiedenen Lösungsmittel verschiedene Theilungscoëfficienten. Während z. B. die Leimplatten aus Lösungen von Methylenblau in Chloroform den Farbstoff leicht aufnehmen, wird aus alkoholischer oder AcetonLösung kein oder nur sehr wenig Farbstoff aufgenommen. 
Ganz andere Resultate erhält man mit anderen Colloidkörpern. Agarplatten z. B. nehmen aus Methylenblaulösungen, gleichgiiltig, welches Lösungsmittel man anwendet, stets Farbstoff in ziemlich reichlicher Menge auf, was, wie wir soeben sahen, bei Leimplatten nicht der Fall ist. Auch bei der Färbung von Bacterien z. B. kann man nur mit gewissen Lösungsmitteln eine Vertheilung erzielen, mit anderen dagegen nicht.

Von wie grosser Bedeutung somit die Art des Colloids für den Theilungscoëfficient ist, so ist andererseits auch das Quellwasser von nicht geringer Wichtigkeit. Beraubt man Leim, ohne seine chemische Beschaffenheit zu ändern, des colloidalen Wassers, indem man ihn vorsichtig eintrocknet, so beraubt man ihn auch der Fähigkeit in MethylenblauChloroformlösung gefärbt zu werden. Diese Fähigkeit erlangt der getrocknete Leim mit seiner Quellung im Wasser sofort wieder. Diese Thatsache lässt im Zusammenhang mil dem, was über die Verschiedenheit im Verhalten der Colloide als solcher gesagt wurde, nur die eine Deutung zu, dass bei der Färbung des Colloids eine Vertheilung zwischen dem Lösungsmittel (Flotte) einerseits und dem Colloid plus Wasser andererseits stattfindet.

Nachdem wir jetzt wissen, dass Colloide im Gelzustand aus einer festen und einer flüssigen Phase bestehen, und dass erstere netzförmig angeordnet ist, und die Flüssigkeit sich in den Maschen des Netzes befindet, müssen wir fragen, wo nun der Farbstoff zu finden ist, in den Maschen oder in der Netzsubstanz. Soweit mir bekannt. ist diese Frage gelegentlich anderer Erörterungen nur von $\mathrm{Hardy}$ beantwortet worden, aber bloss für fixirte Colloide. Es ergab sich, dass eine Färbung lediglich in der Netzsubstanz sichtbar war. Wahrscheinlich war sie in der wässerigen Maschenflüssigkeit nicht intensiv genug, um bei der ausserordentlichen Dünne des Schnittes zur Beobachtung zu gelangen. Jedenfalls geht aber hieraus lierror, dass das Hydrogel seine intensive Farbstoffaufnalume besondersder festen Phase (Lösung von Wasser in Colloid) verdankt.

In derselben Arbeit wandte Spiro, wie erwähnt, das Theilungsprincip auf die Theorie der histologischen Färbung an. Obgleich er nicht in Abrede stellen will, dass sich zuweilen Adsorption geltend macht und auch chemische Affinitäten zwischen Kellsubstanz und Farbstoff hier und da eine Rolle spielen, meint er doch, dass auf das Theilungsgesetz das Hauptgewicht gelegt werden muss. 
Allerdings wird man anerkennen müssen, dass viele in der Histologie und Bacteriologie bei der Färbung zum Ausdruck kommenden Erscheinungen, in dem oben geschilderten Verhalten von Colloiden gegenüber Farbstoffen und Lösungsmitteln eine befriedigende Erklärung finden. So wird es bei der Heranziehung des Theilungsprincipes dentlich, dass z. B. Malachitgrün und Methylviolett den Milzbrandbacillen und den Kommabacillen der asiatischen Cholera gegenüber, ungefähr $100 \mathrm{mal}$ mehr leisten als gegenüber den Typhusbacillen, wenn man annimmt, dass es sich bei den genannten Bacterien um verschiedenartige Colloidlösungen handelt.

Täglich sieht man in der Histologie, dass man durch Hinzıfügung von Reagentien in einem Fall Farbstoff wieder entziehen kann, in einem anderen Fall nicht. Analoge Erscheinungen beobachtet man bei Gelatine-, Agar- und anderen Colloidlösungen.

Wenn auch Spiro nicht so weit geht wie A. Fischer [22], der jede chemische Wirkung bei der Tinction einfach in Abrede stellt, so scheint er doch meines Erachtens deren Bedeutung zu unterschätzen.

Vielleicht wird der Autor aber, den die Untersuchungen von Weigert, Ehrlich, Unna und Anderen nicht befriedigt zu haben scheinen, nach den jüngst erschienenen Arbeiten von Martin Heidenhain, der Bethätigung chemischer Affinitäten bei der Tinction grössere Bedeutung beizumessen geneigt sein.

\section{c) Chemische Theorie.}

In zwei ausführlichen Arbeiten, die Martin Heidenhain als eine Ergänzung der wichtigen Pappenheim'schen Untersuchungen angesehen haben will, hat dieser Autor vor kurzem die chemischen T'msetzungen zwischen Eiweisskörpern und einer grossen Anzahl Anilinfarben eingehend studirt [13] und ist dabei zu Resultaten gelangt, die das Auftreten chemischer Wirkungen sicher stellen.

Es liegt nicht in dem Rahmen dieses Buches, die Arbeit Heide nhain's hier ausfülurlich zu behandeln. Wer sich mit histologischen und bacteriologischen Färbungen beschäftigt, dem kann ich dieselbe auch um der vielen, aus praktischen Gesichtspunkten wichtigen Einzelheiten sehr empfehlen. Nur möchte ich hier betreffs Heidenhain's Anschauungen Folgendes hervorheben.

Ich stimme dem Autor vollständig bei, wenn er in seinem Encyclopädieartikel [12] sagt: „Unsere hesten histologischen Methoden sind 
allein auf Grund tiichtiger chemischer Kenntnisse entstanden. Vorbildlich vor Allem sind die technischen Arbeiten von Ehrlich und Weigert. Wer da glaubt, er könne ohne chemische Kenntniss der Farbstoffe, und ohne Kenntniss des chemischen Verhaltens der Eiweisskörper ein guter Techniker sein, der unterliegt einer schweren Täuschung."

Wenn er aber weiter sagt: „Durch Diffusion allein kann kein Schnitt gefärbt werden", so muss ich ihm auf Grund der Ausführungen ron $\mathrm{Hofmeister}$ und Spiro entgegentreten.

Damit will ich keineswegs die grosse Bedeutung chemischer Wirkungen bei der Färbung in Abrede stellen. An der Hand Heidenhain's will ich vielmehr einige Beispiele vorführen, wo eine chemische Färbung auch mir unanfechtbar scheint.

Bekanntlich sind die Eiweisskörper, gleichgültig, ob sie ursprünglich in flïssigem Zustand oder in festem Zustand sich befinden, im Stande sowohl Basen wie Säuren zu binden. Was die Anilinfarbstoffe betrifft, so kommen diese meist als Salze in den Handel. Sie haben, wie man es unrichtig auszudriicken pflegt, einen sauren oder einen basischen Charakter, womit man eigentlich aussagen will, dass im ersten Fall die Säure und im zweiten Fall die Base das färbende Agens bildet. Diese Agentia nennt man dementsprechend Farbsäure bezw. Farbbase. Es leuchtet nun ein, dass im Zusammenhang mit den basischen und sauren Eigenschaften von Eiweiss und dessen Modificationen, der Möglichkeit chemischer Wirkung Raum genug geboten ist.

Ein markantes Beispiel einer unbestreitbar chemischen Färbung ist folgendes. Die chemisch reine Lösung der Rosanilinbase, welche man durch Kochen mit $\operatorname{Ag}_{2} \mathrm{O}$ aus dem salzsauren Salze (Fuchsin) erhält, ist klar und farblos, färbt aber den mikroskopischen Schnitt roth, d. h. im Tone der Salze des Rosanilins. Das Salz ist hier Rosanilinalbuminat.

Ist die Farbsäure anders gefärbt wie das Salz, so wird, wie M. Heidenliain ausfübrt, das Eiweiss immer in der Farbe des Salzes ausgefällt. Auch diese Thatsache kann als Stütze für das Stattfinden eines Chemismus gelten. Die Farbsäuren sind in den Farbsalzen meist an $\mathrm{Na}$ oder $\mathrm{K}$ gebunden. Wünscht man dann auch die Farbsäure an die alkalische Affinität des Eiweisses zu binden, so ist es empfehlenswerth durch Hinzufügung von Essigsäure die Farbsäure erst aus dem Na-Salz frei zu machen. Es sind das denn auch Färbungen, die man in Gegenwart von Essigsäure auszuführen pflegt.

Für Alizarine und ihre Verwandten, die ausnahmsweise nicht wie die meisten anderen Anilinfarbstoffe als Salz, sondern als Säure in den Handel kommen, ist diese Behandlung mit Essigsäure überflüssig. Das Eiweiss bildet mit denselben direct gefärbte Salze (S. 414).

M. Heidenha in ist auf Grund seiner Untersuchungen ïber die Bindung von Anilinfarben durch Eiweiss zu der Ueberzeugung gelangt, 
dass „die physikalischen Kräfte der Osmose, der Adsorption und der specifischen Natur des lösenden Mediums (wahrscheinlich denkt er hier an das Theilungsprincip) im Allgemeinen nur Hilfskräfte seien, welche den Uebergang des Farbstoffes aus der Lösung in das färbbare Substrat vermitteln".

Sonach würden nach $\mathrm{H}$ eidenhain auch die Hof un eister'schen Färbungen von Gelatine und Agar im Wesentlichen ebenfalls auf eine chemische Reaction zuriickzuführen sein. Heid enhain hat sich speciell hierüber nicht ausgesprochen; offenbar sind die betreffenden Ausfülırungen von $\mathrm{H}$ ofmeister and Spiro ilm nicht bekannt. Aber besonders die ron Spiro hervorgehobene Abnahme der Gelfärbung bei Abnahme der Farbstoffconcentration einerseits und auch die allmähliche Entfärbung des Gels andererseits scheinen mir mit der Anschauung, es sei hier ein Chemismus im Spiel, sich schwer zu vereinigen.

Ich glaube, dass hier ein Experimentum crucis anzustellen ist.

Man nehme eine Lösung des zu untersuchenden Anilinfarbstoffes und bestimme die Gefrierpunkterniedrigurg. Man löse darin eine gewisse Menge des Colloids (Gelatine, Agar, Eiweiss) auf und bestimme wieder die Gefrierpunkteruiedrigung. Kennt man nun auch die Depression der gleichprocentigen Lösung des Colloids in Wasser, so ist leicht festzustellen, ob der Anilinfarbstoff gebunden wird oder nicht. Wegen des Princips und der Ausführung verweise ich auf Bd. II, S. 508.

In Erwartung des Versuchsergebnisses ${ }^{1}$ ) glaube ich aber vorläufig, dass es besser ist den Satz zu unterschreiben, mit dem Heidenhain seinen Encyclopädieartikel eröffnet:

.Eine einheitliche, für alle Fälle passende Theorie der histologischen Färbungen giebt es nicht und kann es nicht geben. Einmal sind die in Betracht kommenden Farbkörper physikalisch und chemisch ungemein verschiedene Dinge, ebenso sind zweitens die Bestandtheile der Gewebe in physikalischer und chemischer Beziehung von ungemein verschiedener Art.“

1) Neuerdıngs haben auf meine Veranlassung die Herren J. Versteeg und J. de Vries Versuche in dieser Richtung ausgeführt und zwar mit dem erwarteten Resultat.

Als Farbstoff wurde Neutralroth, und als Colloid käufliches, im Vacuum getrocknetes Liereiweiss benützt.

Es wurden drei Flüssigkeiten bereitet:

1. Die bei Zimmertemperatur gesättigte Neutralrothlösung, von der 5 cc mit 5 cc ausgekochtem, destillirtem Wasser versetzt wurden.

2. Die Eiweisslösung. Diese enthielt $12,8 \mathrm{~g}$ Eiweiss auf $100 \mathrm{ce}$ ausgekochtes destillirtes Wasser. Das im Handel käufliche Liereiweisspulver enthält bekanntlich auch etwas Salz. Das ist hier aber nicht von Belang. 


\section{Färbung lebender Zellen (Intravitale Färbung).}

Wie aus früheren Mittheilungen hervorgeht, hat Overton die Meinung ansgesprochen, dass die äussere Begrenzung des Zellprotoplasma nur dann für eine Substanz permeabel ist, wenn diese in einem Gemisch von Cholesterin $\left.{ }^{1}\right)$ und Lecithin löslich ist, das nach ihm in keiner protoplasmatischen Zellbegrenzung fehlt. Dieses Gemisch hat der Verfasser der Kürze halber Lipoid genannt.

Von diesem Gesichtspunkt aus studirte er das Eindringen und die Thätigkeit der Narkotica (vergl. unter Pharmakologisches S. $245 \mathrm{ff}$.) und gelangte dabei gleichzeitig und unabhängig zu dem nämlichen Resultat wie der Pharmakologe Hans Meyer. Insbesondere haben Höber und Gurwitch (vergl. die Nierenthätigkeit Bd. II S 411) sich zu dieser Anschaung von der Ursache der Permeabilität bekannt.

3. Das Gemisch. Dieses wird bereitet durch Versetzung von 5 cc der gesättigten Farbstofflösung mit 5 cc der Eiweisslösung.

Die folgende Tabelle entbält die Versuchsresultate.

Gefrierpunkterniedrigung

\begin{tabular}{c|c|c}
\hline $\begin{array}{c}\text { von } 5 \text { ce gesättigter Neutral- } \\
\text { rothlösung } \begin{array}{c}5 \text { ce destillirtem } \\
\text { Wasser }\end{array}\end{array}$ & der Eiweisslösung \\
$-0,048^{\circ}$ & $-0,207^{\circ}$ & $\begin{array}{c}\text { des Gemisches von } 5 \text { ec } \\
\text { gesättigter Neutralrothlösung } \\
+5 \text { ce der Eiweisslösung }\end{array}$ \\
\hline$-0,256^{\circ}$
\end{tabular}

Man sieht, dass die Depression des Gemisches $\left(-0,256^{\circ}\right)$ nicht weniger beträgt als die Summe der Depressionen von Farbstoff- und Eiweisslösung

$$
-\left(0,048^{\circ}+0,207\right)=-0,255^{\circ} \text {. }
$$

Was durch Vermischung entstanden ist, darf demnach nicht als eine chemische Verbindung angesehen werden. Es bleibt ein Gemisch.

In gleichem Sinne wie Neutralroth verhielten sich Fuchsin, Blue-black und Anilinschwarz (Salz). Dagegen ergab sich bei Vermischung von Eiweisslösung mit Methylenblau und mit Vesuvin eine deutliche Depressionsabnahme. Mit diesen Farbstoffen bildete demnach das Eiweiss chemische Verbindungen.

1) Vielleicht handelt es sich nach ihm auch um Cholesterinester; auch diese Substanzen sind ebenso wie Gemische von Cholesterin und Lecithin im Stande, viel Wasser aufzunehmen, woraus sich dann die Durchlässigkeit für Wasser erklären liesse. Ein solches Gemisch von Cholesterinestern bildet z. B. das Lanolin, das mehr als das doppelte Gewicht an Wasser aufnehmen kann. 
Vollkommen dieselbe Ansicht vertritt Overton auch angesichts der Durchlässigkeit lebender Zellen fürbasische Anilinfarbstoffe [24].

Wie oben gesagt wurde, kommen die basischen Anilinfarbstoffe meist als Salze (schwefelsaure, salpetersaure, salzsaure Salze etc.) in den Handel. Overton meinte anfänglich, dass die Salze nicht als solche, sondern als Basen in die Zellen eindringen. Diese Annahme schien aus mehreren Gründen berechtigt, und für das Freiwerden der Base war hydrolytische Spaltung als Ursache heranzuziehen.

Man denke hierbei z. B. an $\mathrm{ZnCl}_{2}$, das sauer reagirt, weil die folgende Hydrolyse stattfindet

$$
\mathrm{Zn} \mathrm{Cl}_{2}+2 \mathrm{H}_{2} \mathrm{O} \rightleftarrows \mathrm{Zn}(\mathrm{OH})_{2}+2 \mathrm{HCl}
$$

Zinkhydroxyd ist eine schwache Base, Salzsäure eine starke Säure, so dass die $\mathrm{H}^{\cdot}$-Ionen-Concentration grösser ist als die $\mathrm{OH}^{\prime}$-Ionenconcentration (Bd. II S. 484 und diesen Band S. 230).

Auch eine 1\%-ige Lösung von salzsaurem Anilin reagirt auf Grund analoger Reactionen sauer. Diese Ansicht wurde durch die Thatsache gestützt, dass das salzsaure, salpetersaure und schwefelsaure Rosanilin die lebenden Zellen ungefähr gleich schnell färbten, wenn sie in äquivalenter Concentration angewandt wurden. Salzsäure, Salpetersäure und Schwefelsäure sind ungefähr gleich starke Säuren und die Hydrolyse der von ihnen gebildete Salze dementsprechend ungefähr gleich gross [24].

Es liess sich hiernach erwarten, dass das in äquivalenter Concentration angewandte essigsaure Rosanilin schneller färben würde, denn Essigsäure ist eine schwache Säure und demnach die hydrolytische Spaltung eine grössere. Es stellte sich aber heraus, dass die Färbung nicht schneller erfolgte.

Gleiche Verhältnisse wurden auch bei andern basischen Anilinfarben bei der Vergleichung des Acetats und des salzsauren Salzes beobachtet.

Nach erneuten Untersuchungen kam $O$ v e r to n zu der Ueberzeugung, dass sein Satz, es wandere lediglich die durch Hydrolyse freigewordene Farbstoffbase in die Zelle ein, in so allgemeiner Fassung nicht richtig sei und dass in vielen Fällen (bei den Triphenylmethan- und Chinonimidfarbstoffen s. unten) die basischen Anilinfarben in Form ron $\mathrm{nich}$ tzersetzten (nicht-hydrolysirten) Salzen aufgenommen werden [25].

Fr konnte sogar feststellen, dass sämmtliche basische Anilinfarben in der Form ihrer käuflichen Salze, von lebenden PHanzen- und Thierzellen äusserst leicht aufgenommen werden, und dass alle diese Salze in Cholesterin, oder in Lösungen von Cholesterin oder Lecithin in organischen Flüssigkeiten leicht löslich waren, auch wenn letztere an sich kein Lösungsvermögen für die betreffenden Farbstoffe besitzen. Ein Beispiel hierfür ist Terpentinöl, in welchem die basischen Anilinfarbsalze unlöslich sind. Lüst man aber Cholesterin in Terpentinöl auf, 
so entsteht eine Flüssigkeit, die die basischen Anilinfarbstoffe sehr wohl in sich aufzunehmen vermag ${ }^{1}$ ).

Es wurden 4 Gruppen untersucht ${ }^{2}$.

I. Gruppe: Triph en ylme than f a r bs t of fe.

Rosanilin (Chlorhydrat, Nitrat und Sulfat), Gentianaviolett, Methylviolett, Dahlia, spritlösliches Anilinblau, Toluidinblau, Victoriablau, Malachitgrün, Jodgrüin und Rhodamin.

II. Gruppe: Chinonimidfarbst of fe.

Thionin, Methylenblau, Methylengrün, Safranin, Toluylenroth (Neutralroth), spritlösliches Nigrosin und Indulin.

III. Gruppe: A z o f a rbst of fe.

Clirysoidin, Vesuvin und Bismarckbraun (letzere beiden Farbstoffe sind wahrscheinlich identisch).

IV. Gruppe: Akridinfarbstoffe.

Chrysanilin.

Hiergegen sind nicht löslich in Cholesterin und Lecithin und dringen dementsprechend auch nicht in die lebende Zelle ein: carminsaures Natrium und die meisten Sulfosäure-Farbstoffe. Von diesen wurden untersucht:

I. Gruppe: Triphenylmeth anfarbst of e.

Säurefuchsin, Säuregrün, Säureviolett, wasserlösliches Anilinblau.

II. Gruppe: Chinonimidfarbstoffe.

Wasserlösliches Nigrosin, wasserlösliches Indulin.

III. Gruppe: A zof arbsto ffe.

Congoroth, Ponceau R., Bordeauxroth und Biebricher Scharlach.

IV. Gruppe: Indigocarmin.

Eine langsame Aufnahme erfahren Methylorange und die Tropäoline 00 und 000. Dieselben sind Sulfosäure-Farbstoffe aus der Gruppe der Azofarbstoffe.

Ganz entsprechend seinen Ausführungen iiber die Permeabilität der Zellen für Narkotica (S. 249) stellt Overton sich auch hier bei der Durchlässigkeit der Zellen für Anilinfarbstoffe vor, dass der Farbstoff sich zwischen der Farbstofflösung und der Plasmahaut vertheilt. Je grössere Löslichkeit diese Plasmahaut für den Farbstoff besitzt, um so mehr wird relativ in dieselbe eindringen. Die Bestandtheile der Plasma-

1) Hierdurch erklärt sich auf ungezwungene Weise, dass, während es nicht gelingt, fixirte Zellen durch Farbstofflösung zu färben, Tinction zuweilen wohl erfolgt, wenn man die Zelle mit einer anderen Flüssigkeit tränkt.

2) Ueber die chemische Structur der Anilinfarben nach den neuesten Ansicliten, vergl. man Nietzki, Chemie der organischen Farbstoffe. 3. Aufl. 1 S97. 
haut, auf die es hier ankomınt, sind Cholesterin, Lecithin, Protagon, Cerebrin.

Es gilt hier also das mehrfach besprochene Theilungsprincip.

Für diese Auffassung spricht auch die folgende interessante Thatsache: Werden Lecithin, Protagon oder Cerebrin in sehr verdünnten wässerigen Lösungen ron basischen Anilinfarben (1:100000) suspendirt, so speichern sich diese Farbstoffe sehr reichlich in den Partikelchen auf, d. h. die Partikelchen werden stark gefärbt. Führt man denselben Versuch mit Sulfosäure-Farbstoffen, selbst in viel grösseren Concentrationen aus, so färben genannte Partikelchen sich nicht, weil diese Farbstoffe sich darin nicht lösen.

Die Aufspeicherung ist somit nichts Anderes als die Folge einer Theilung der Farbstoffe zwischen einem flüssigen und festen Lösungsmittel, wobei das Letztere das viel grössere Lösungsvermögen für die betreffenden Farbstoffe besitzt.

Nach diesen Ausführungen müsste man erwarten, dass bei Anwendung derjenigen basischen Anilinfarbstoffe, die, wie Methylenblau, sehr leicht in die lebende Zelle eindringen, auch die intravitale Färbung kräftig sein würde. Das ist jedoch meist nicht der Fall. Overton führt dies darauf zurück, dass die absolute Lecithin-, resp. Protogon- und Cerebrinmenge der dünnen Zellenbegrenzung im Allgemeinen sehr gering ist, und im Zelleninnern, wo diese Stoffe gequollen sind, relativ noch geringer ist. Besser gestaltet sich deshalb der Grad der Farbstoffaufnahme im Nervensystem. Bekanntlich sind die Elemente des Nervensystems viel reicher an Lecithin und Cholesterin als die andern Gewebe des Körpers. Ehrlich hat schon vor langer Zeit nachgewiesen (26], dass gewisse organische Farbstoffe, nach Einspritzung in die Blutbahn, vorwiegend im Nervensystem aufgespeichert werden. Eine solche Färbung des Nervensystems sah Ehrlich namentlich nach Einspritzung von basischen Anilinfarbstoffen eintreten, so z. B. nach Einspritzung von Methylenblau, Aethylenblau, Auramin, Chrysoidin, Bismarckbraun, Neutralroth, dagegen niemals nach Einspritzung von Sulfosäure-Farbstoffen. Die intravitale Färbung des Nervensystems durch Methylenblau liat in der Folge, wie allgemein bekannt, eine grosse Bedeutung erlangt.

Indessen liönnte, wie auch 0 rerton bemerkt, nicht mit Unrecht gegen die Hypothese, dass die Aufspeicherung des Methylenblaus etc. im Nervensystem, auf dessen hohem Gehalt an Lecithin und Cholesterin beruht, eingewendet werden, dass fast a usschliesslich die Ganglienzellen und Achsencylinder tingirt werden, während das Nervenmark fast farblos bleibt. Nun scheint das Nervenmark allerdings nur wenig Lecithin zu enthalten. Dafür enthält es aber grosse Mengen von Protagon, dessen Anfspeicherungsvermögen für Methylenblau ebenso gross ist als dasjenige des Lecithins. Zur Erklärung dieser Erscheinung 
müssen Hilfshypothesen herangezogen werden. Es bleibt weiterer Forschung vorbehalten, diesen Gegenstand genügend zu beleuchten.

Die Sache liegt auch hier wieder complicirt. Heidenhain hob in seinem Artikel iiber vitale Färbung hervor, dass nicht alles, was intra vitam gefärbt wird, deshalb lebend zu sein braucht, so z. B. die durch den Stoffwechsel in der Zelle entstandenen Körnchen.

Zweifellos werden sich auch, wenn der Farbstoff einmal in die Zelle gelangt ist, chemische Processe abspielen. Aber wie dem auch sei, man wird erkennen müssen, dass Overton durch Heranziehung des Theilungsprincipes und der Theorie der festen Lösungen, das Eindringen von Farbstoffen und dessen Bedingungen dem Verständniss wesentlich näher gerïckt hat. 


\section{Autoren-Register.}

Die fetten Ziffern bedeuten die Stellen, an welchen die Autoren in den Litteraturverzeichnissen vorkommen.

A.

Abderhalden I 358, 486, 507, 508.

Abegg I 50, 55, 57, 63, 64, 65, 66, 68, $69,71,75-82,84,95,96,108,454$; II $\mathbf{2 4 9}, 382$.

Abeles I 265.

Ach II 393, 412.

Adami II 393, 410.

Adler II 92, 99, 101.

Agostini I 360, 364, 366.

Ahlfeld III 205.

Alapy II ஃ:24, 245.

Albanese II 393, 412.

Albarran II 248, 279, 239, 311, 317.

Albu II $\mathbf{2 4 8}, 328$.

Alexandrow I 486, 488.

Altmann III 397.

v. Anrep II $\mathbf{2 2 1}, 222$.

Anten II 398, 412.

Argutinsky I 292.

Arloing I 281.

Armstrong, Frankl. 1II 59, 97.

Aindt II 148.

Arrhenius I 4-8, 10,11, 13, 14, 27, 28, $36-38,40,41,48,50,51,52,55,56$, $59,65,76-79,81,82,102,107,134$, $191,225,226,230,237,475,480,491$, 492. - II 240, 386, 414, 460, 464, 465,
$472,473,481,488,493,501,504 .-$ III 138, 395, 357, 363, 368, 369, 372, $373,375,379-587$.

Arrous II 392, 400 .

d'Arsonval II 359.

Aschhoff III 325, 363.

Asher II :31, 48, 51, 55-61, 64, 98, 148, 153, 158, 421, 422, 426, 431-434.

Auwers III, 395, 416.

Avogadro I $5,10,17,29,33-36,50$, 54,55 .

B.

Bainbridge II 31, 56, 57.

Bakhuis Roozeboom III 132.

Balthazard II $\mathbf{2 4 7}, 249,273-275,283$, $289,318,322,323$.

Bamberger I 289.

Barbèra II 31, 48, 51, 56-59, 93, 153.

Barfurth II 244.

Barlow, s. u. Lazarus-Barlow.

Bartels II $\mathbf{6 7}, 79,80$.

Barth III 253, 256.

Bauer II 166, 167.

Baum III 24:, 245, 247.

v. Baumgarten I 282, 396. - III 3:9, 325, 333, 334, 339, 342, 344, 357-365.

Bayliss II 31, 44, 52.

Bazy II 234. 
Bechhold III, 89.

Becker I, 359, 361.

v. Becker II, 126, 166, 179, 184.

Beckmann, E. Y 68, 64-66, 70, 71, 75, 77, 89-91, 93, 95-97, 385, 454, 455, 472, 479, 493. - II 36, 242, 277, 284, 293, 301, 448, 449, 452, 453. - III $\mathbf{2 8 2}$, 304, 305.

Becquerel III 183.

Beddard II 393, 410.

v. Behring I 271, 281.

Belfante I 394, 395. - III 343.

Bell I 118.

Beltwood I 131.

van Bemmelen III 59, 85, 395, 402.

Bergmann II 466.

Bernard, Claude I \$36, 460, 462. - III 242, 243.

Bernard, L. II 311.

Bernstein I 359, 361. - II 39.

Bert, Paul III 249.

Berthelot II 466. - III 243, 246, 395, 415.

Berthold III 397.

Bertrand III 343.

Berzelius III 80.

Besnier II 82.

Beyer III 29'.

Beyerinck II 4633, 474.

Bial, Manfred III 257, 263, 264.

Bianchi-Mariotti I 360, 367.

Bibra III 245.

Bickel II 248, 288.

Bier I 272, 289, 290.

Biernacki I 184, 199, 200.

Billitzer III 59, 65, 78.

Binnendijk III @37, 238.

Binz III 243.

Bleibtreu, L. 183, 188, 292, 512, 513-515. - M. I 183, 188-190, 292, 512, 513-515.

Boddaert II :31, 49, 67, 68.

Bodländer III 55, 61, 70, 104.

Boer I 972, 281.

Bönninger II 221, 227, 229.

Börnstein I 78 .

du Bois-Reymond, E. I 101. - II 421, $434,435$.

Bonanni I 436, 457. - II 443, 444, 445.

Bordas II 448, 452.
Bordet, J. I 285, 395, 396-399. - 344, $345,350-357,363,385$.

Boruttau III 108, 149, 159, 160.

Bose II 249, 355, 382.

Botkin II 31, 43.

Bottazzi I 261, 266, 291, 360, 365, 436, 458, 460, 462-467. - II $\mathbf{2 2 1 , ~ 2 2 5 , ~ 4 2 1 , ~}$ 422. $430,431$.

Bouchard I 69. - II 247, 248, 249, 303, 3 7-329.

Bousquet I 69, 436, 455, 456, 470, 472, 486, 502, 503. - II 248, 289, 303, 311, 443, 444. - III 175, 206, 221.

Bowman II 392, 393, 408, 413.

Boyd II 393, 407.

Boyer II 2:31, 245.

Boyle I 5, 6, 29, 30, 78. - II, 414.

Brand II 443, 444-447. - III 240.

v. Brasol II, 1, 2, 30, 32, 47 .

Braun, H. II 93, 148. - III 192.

Bredig I 37, 42, 44-46, 48, 124, 126, 131, 132, 142. - II 167, 207, 216, 374, 463, 465, 481. - III 5S, 59, 60, 62, 64, 75, 77, 79, 81, 83-90, 94, 95, 104, 105.

Brigg II 469, 516 .

Bright II 79.

Brown III 61, 65.

Brücke I 164, 169, 170. - II 437, 439.

Brünings III 155.

Brun II 350.

Bruns III ๑56, 265.

Buchner, H. I 272, 285, 290, 397, 398. III $96,323,324,333,343,350,352$, $353,357$.

Bütschli I 337, 340, 355, 356. - III 1, 4, 29, 395, 397, 401, 404.

Bugarszky, St. I 202, 221, 255, 349, 436, 456-458, 474, 475-478, 481-483, 486, 487, 489-491, 493, 495, 497, 499-502, 504, 512, 517-519. - II 247- 49, 293 $-297,317,324,325,332,345,346,382$, 447, 464, 503, 508-510. - III 192, 204, 215.

v. Bunge I 301. - II 437-439, 456.

Bunsen I 101. - II 349, 368, 380.

Burginski III 157.

Busch II 31, 56, 59.

Buyniewicz II 247, 272, 398, 408. 
C.

Cahn II 437, 441.

Calabrese I 271, 281.

Calmette III 343.

Camus III 324, 343, 352.

Cantani $1 \mathbf{2 \pi} \mathbf{7}, 281$.

Carbone I 394, 395. - - III 343.

Carey Lea III 59, 81, 89.

Carlinfante II $\mathbf{4 4 8 ,} 452$.

Carrara II 1, 19.

Caspar II 248, 283, 316.

Castellino I 359, 361, 364, 366.

Cavazzani I 360, 367.

Ceconi II 248, 287.

Chambers I $\mathbf{0} 0,56$.

Chanel I 359, 361-363, 365-367.

Chaperon I 113. - III 192.

Chroustchoff I 50, 56, 63, 70.

Clark, Cotimer I 510. - II 351, 352, 380.

Claude II $\mathbf{2 4 7}, \mathbf{2} \pm 8,249,273-275,283$, $289,291,318,322,323$.

Clausius I 37. 40.

Coehn III 58, 68.

Cohen, E. I 111. - II $\mathbf{2 4 9}, \mathbf{3 5 4}, \mathbf{4 6 3}, \mathbf{4 6 4}$, 474, 495, 496. - III 59, 88, 89, 174.

Cohnheim, J. II $56, \mathbf{6 7}, 68,77,79-84$, $86-88,90,91,392,399,433$. - III 1 , $49,162$.

Cohnheim, O II 92, 97, 133, 167, 202$209,212,215-217,219,220,222,231$, 235, 236, 464, 503, 506, 509.

Cohnstein, J. I 271, 277, 291, 298.

Cohnstein, W. I 272, 281, 282. - II 1, $12,30,37-43,46,47,49,51,53-56$, $59,62-65,67,83,89,90,92,9 \%, 99$, $152,157,163,164,418$.

Coletti II 443, 444, 446, 447.

Colin II 35.

de Coppet I 21, 25.

Cornevin I 281.

Couvée II 248, 287, 288, 312, 313.

Credé III 81.

Cremer III 59, 96, 159.

Croft Hill III 59, 96.

Cuénot I 461.

Cupron II 380.

Cushny, A. II 166, 197-199. 218, 392. 401, 404-406.
Cutore I :360, 367.

Cutter II 4:1, 422, 426, 431-434.

Cybulski III 159.

Czermak II 123.

Czerny II 93, 162.

D.

Daniell II 380, 435.

Danilewsky II $\mathbf{4 6} \pm, 503$.

Daremberg III 324, 343.

Dastre, A. I 68, 69, 74. - II 1, 2. III ㄴ2, 243.

Deganello III 161.

Déguisue I 135.

Dekhuyzen III 396, 409-412.

Delage, Y. III 410, 411.

Deutsch III 3:4.

Deutschmann, R. III 161, 166.

Diesselhorst I 98, 122, 124, 128.

Dietrich III 361.

Dieudonné III 395, 363.

Dieulafoy II 183.

Döderlein III 212.

Dömeny III 358.

Dohrmann II 448, 452.

Donders II 175.

Dourdouffi II 30, 32.

Dreser I 436, 453, 456, 458. - II \$1, 41 . 392, 395, 396, 412, 415, $443,444,448$, 460. - III 161, 163, 223, ㅃ58, 254-256.

Driesch III 175, 179.

Dubois, R. III 243, 244.

Ducceschi I 436, 460.

Duclaux II 463, 475. - III 59, 91, 93.

Dünschmann III 282, 313.

Dufonot II 514.

Duncan, J. I 359, 361.

v. Dungern III 324, 325, 352, 363, 380.

Durham III 341.

Durig, A. II 1, 23, 24.

Dybkowski II 92, 94, 96, 142.

E.

Eckardt III 257, 268, 269.

Ehrlich I 285, 295, 396-398. - III 824, 325, 340-342, 344-357, 359, 362, 364, 
$368,369,379-381,385,396,413,421$, $422,427$.

Eisenberg III 325, 382, 383.

Elb, K. II 379.

Ellinger II 31, 57, 58.

Emmerling III 96.

Emminghaus II 30, 32.

Engelmann, Fritz II 247, 282, 283, 287, 288, 318, 330. - III 282, 314, 315, $317,318$.

Engelmann, Th. W. I 403. - II 421, 422, 434, 435. - III 147.

Enriquez II 221, 225, 421, 430.

Ericson I 118.

Euler III 105, 257, 266, 387.

Ewald II 463, 492, 501.

Eykman, C. I 183, 189, 200, 202, 210, 234, 291, 296, 344, 360, 385, 386, 435, $442-446,453,472,512,513-515$. III 5S, 63 .

Eykman, J. F. I 64, 65.

F.

Falck II 442.

Fano I 436, 458, 466, 467. - II 421, 422.

Faraday I 7, 38, 511. - II 335. - III $70,71,86,104$.

Farkas II 442. - III 175, 217.

Fechner I 510.

Fehling I 265.

Fick, Ad. II 92, 108, 112, 113, 117, 160.

Fisch I 486, 457. - II 253, 254, 319.

Fischer, A. III 393, 332, 333, 335-339, 358, 395, 396, 397, 421.

Fischer, E. III 59, 97, 106.

Fischer, F. II 249, 365.

Fischer, M. III 175, 177.

v. Fitzen-Hennig I 37, 49.

Flechsig III 285.

Flemming III :395, 397, 410.

Fletcher II 230, 421, 423, 424, 429, 432.

Flügge I $\mathbf{2 7 1}, 277$.

v. Fodor I 271, 272, 281.

Fokker III 393, 338, 339.

Fraenkel, A. II 442.

Fraenkel, P. I 272, 290.

Fraser III 343.
Frazer I 50, 56.

Fredericq, L. I. 299, 436, 463. - III $\mathbf{3 2 3}$, 328.

Frerichs I $\mathbf{2 7 2}, 289$.

Freund, E. I 267. - II 406.

Freundlich III 59, 77, 78.

Friedemann, U. III 89

Friedenthal II 24, 160, 166, 194, 201, 202, $217,220,442$.

Fueth I 436, 456. - III 175, 185, 186, $192,210,217,219$.

Funk II 353, 354.

Funke II 126, 166, 179, 184, 249.

Fusari III 1, 15.

G.

Gaedicke III 88.

Gärtner I 379, 444. - II 67, 76, 80, 258. Galeotti II 167, 219, 220. - III 1, 3, 59, 87, 132, 240, 242.

Gallenkamp II 399.

Gallerani I $\mathbf{3 6 0}, 364$.

Gans, E. II 464, 513, 514 .

Gaule I 453.

Gay-Lussac I 5, 6, 29, 32-34.

Génin II 448, 452.

v. Georgievicz III 395, 396, 415, 419.

Geppert II 52, $\mathbf{2 4 8 , 3 1 3 . ~ - ~ I I I ~} 346$.

Gerota II 231, 232-234, 236-238, 243245.

Géza Kövesi II 166, 197, 201.

Gibbs III 132.

Gierke III 395, 412.

Gies, W. II 31, 60. - III. 175, 181.

Glax III 285.

Gley II 31, 58. - III 324, 343, 453.

Goldschmidt II 238.

Gordon III 257, 266.

Gore III 413.

Gottlieb II :39:, 397, 399, 402, 416.

Grab I 272, 281.

Graham II 112, 475. - III 69.

Grainger-Stewart II 79.

Gregory I 191.

Grober II 248, 329.

Grossmann III 282, 316-318, 322.

Grove II $\lesssim \ngtr 0$. 
Grube III 202, 313, 314, 317.

Gruber II 442. - III 32.5, 341, 350, 351, $355,362,380$.

Grünbaum II 421. 427, 430.

Grünhut III 2\$2, 294-304, 307-309, 314. Grützner II 393, 409. - III 108, 129, 157, 158.

van Gruting, D. II 449.

Gryns I 183, 189, 196, 200, 202, 206-209, 217-220, 234, 253, 256, 360, 385, 435, 436, 442, 443, 445, 446, 453, 457, 458, 513, 529-532. - II 200, 238, 300. III 191.

Günzburg II 464, 491, 492, 505.

Gürber I 202, 228, 229, 235, 256, 257. $\mathbf{2 6 1}, \mathbf{2 6 6}, \mathbf{2 7 1}, 280, \mathbf{2 9 1}, 296, \mathbf{2 9 9}, 300-$ 302, 307, 402, 403, 456, 499.

Guinard II $\mathbf{2 8 1}, 245$.

Guldberg I 21, 25, 26. - II 468, 466, 467, 477. - III 260, 371.

Gumprecht II 85, 90.

Gurwitsch II 398, 410, 411, 414. - III 424.

Gusserow III 205.

Guttmann III 161, 166 .

\section{H.}

Haake II 1, 2, 392, 400.

Haga II 362,364 .

Hahnemann III 240.

Hallopeau III 239.

Halter I $\mathbf{2} \mathbf{7}, 281$.

Hamburger I 4. 14, 21, 27, 25, 31, 32, 37, 155, 164, 173, 174, 177, 15:, 154, 187, 200, $\mathbf{2 0 2}, \mathbf{2 0 3}, 234-240, \mathbf{2 6 1}, \mathbf{2 6 6}, \mathbf{2 7 1}$, 280, 291, 299, 311, 317, 330, 339, 337, $341,351,35 \%, 358,359,360,368,369$, $378,385,402,403,405,409,413,415$, 419, 423, 435, 436, 440, 442, 453, 456

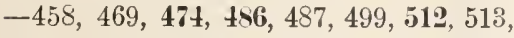
528. - II 1, 30, 31, 35, 37, 59, 67, 69, $71,77,92,93,96,103,114,117,119$, $121,122,125-128,130,131,148,157$, $158,160,164,166,170,171,173,183$, 188, 200, 201, 218, 222, 2:31, 244, 247, 245, 249, 300, 327, 348, 387, 393, 421, 427, 437, 444, 445. - III 1, 3, 49, 50, Hamburger, Osniot, Druek. III. Band.
53, 91，144，161，182，186-188, 191, 202, 203, 229, ㄴo?, 360, 405-409, 423.

Hammarsten II $\mathbf{4 4 3}, 446$.

Hammerschlag I 296, 514 .

Hammerschmidt I $\mathbf{2 7 1}, 276$.

Hanriot III 59, 96.

Hardy III 4, 5, 29, js, 61, 64, 66-68, $70,72-74,77-79,107,127,128,130$, 131, 137, 160, :395, 398-405, 409, 411, 420.

Harless III 245.

van Harrevelt, H. G. II 148, 158.

Hartmann III 192.

Hay, M. III 13.

Hayem I 859, 378.

Hausmann III 3:4, 342.

Heald III 262.

Hedin I 1St, 189-193, 195-197, 200, 202, 206, 210-215, 217-222, 226, 227, $238,253-256,344, \mathbf{3 6 0}, 385,386, \mathbf{4 3 6}$, 453, 456, 457, 459, 4\$6, 499, 512, 515. - II 200, 238, 241, 300. - III 191.

Hédon II 166, 200, 392, 400.

Heidenhain, M. III 395, 413, 414, 421423.

Heidenhain, R. I 436, 458, 4S6, 499. II 30, 31, 32-34, 36, 37, 39-48, 51, $53,55-58,61,62,66,67,68,82,88$, 92, 99, 101, 126, 132, 133, 141, 142, 144, $145,153,159,1666,167-172,174-176$, $190,193,197,203,205,210,213,216$, $220,222,230,244,392,393-395,397$, 408, 409, 413-415, 421, 422, 423, 425, 426, 429, 436, 437. - III 1, 18, 156.

Heinricius II 92, 131.

Heinz II 98.

Heinze II 148.

Hekmann, J. II 348, 387. - III 91.

Hellin II 39:3, 412. - III 324, 341, 342.

Helmholtz I 37, 40. - II 333. - III 68.

Henle II 394, 395, 408.

Henneguy III 400.

Henri. V. III 59, 85, 91-93， 99, 101 102, 104.

Hensen I 164, 170.

Herbst, C. III 175, 176, 179.

Hering, E. III 147.

Hermann III 10S, 147, 148, 155, 159. 
Hermann L. III $\mathbf{2 4 3}, 245$.

Herrmann, M. II 392, 397, 405.

Hertwig III 180.

Hertz III 389.

Herzfeld II 464, 496, 498.

Herzog III 59, 93, 104.

Hess I 413.

Heubel III 161, 166.

Heydweiller II 386, 387, 481, 487, 488. - III 283.

Heymans, G. III 169, 174.

Hill III 59, 96.

Hintz III 282, 294-297, 299-304, 307309,314 .

Hirschmann III 108, 156, 157.

His, W. II $\mathbf{2 4 9}, 389$. - III 271, 273$275,277-279$.

Hittorf I 7, 39, 42 .

Hitzig II 441.

Höber, R. I 62, 64, 96, 508, 509-512.-II 166, 195-201，204，205，216-218, 222, 248, $\mathbf{2 4 9}, 332,345,346,382,388$, 390, 442. - III 1, 21, 59, 105, 106, 169, 170, 171, 173, 174.

Hoensch II 495.

Hösselin II 463, 492.

van't Hoff I 4-7, 10, 11, 13, 2s, 27-29, $31,32,35,36,40,50,51,54-56,76$, 191. - II 335, 414, 463, 467, 472, 473, $476,488,493$. - III $117,372,383$, $386,395,413$.

Hoffmann, F. A. II 463, 464, 492-494. 497-499, 501-503, 511.

Hofmeister, F. II 166, 167, 198, 199, 212, 218, 392, 404, 407. - III 395, 418, $422,423$.

Holborn I 39, 98, 100, 101, 103-105, 109, $114,117,118,120,122,124-128,135$.

Hoppe-Seyler I 520. - II 166, 175, 190, 193.

Howell III 107, 122, 124, 145.

Hueck III 107, 123, 124.

Hüfner 1 346. - II. 277. - III. 387.

Hühnefeld I 164, 170.

Hugershoff, F. I 448.

Hughes III 282. 313.

Hulett II $\mathbf{2 4 9} 354$.

Hunter III 175, 176.
Hutchinson II 18.

Hyde, Ida II 421, 430.

Hymans van den Bergh II 1, 10, 17, 18, 24S, 328, 329.

\section{I.}

Ikeda II 463. - III 59, 84, 86, 87, 259. Mc Intosh III $\mathbf{2 5 \pi} 266$.

Israël II $\mathbf{2 4 8 , 2 8 3 . ~ - ~ I I I ~} \mathbf{2 4 0 ,} 242$.

J.

Jackson III 243.

Jacoangeli I 4:36, 457, 458.

Jacobson III 59, 91, 94.

Jacoby III $32 \pm, 342$.

Jacqué, L. III 175, 209-221.

Jacquet I 346, 453.

Jaeger II 351.

Jäger II 249, 356 .

Jahn I 50, 55.

v. Jaksch I 292. - II 464, 492, 511, 512. Jankowsky II 388, 390.

Janosik IIl 180.

Janse I 161, 162. - II 24. - III 393, $328,335$.

Jaworski II 221, 223, 231, 440.

Jetter III 333, 334.

Jona I 183, 187, 365.

Jones I 50, 56, 64, 77, 96.

Jores III 396, 404.

Juckuff III $\mathbf{2 3 7}, 238$.

Julia II 1, 2.

Julius, W. H. II $249,360$.

Jungfleisch III 243, 246, 415.

Justesen II 4:37, 443.

K.

Kahlbaum II 353.

Kahlenberg III 107, 110, 169, 170, 174, உ56, 262.

Kamerlingh Onnes II $249,362$.

Kanthack III 343.

Kast II $\mathbf{6 7}, \mathbf{7 5}, 81,87,88$.

Kastle III 59, 96.

Kattein III 65. 
Kaufmann II 31, 36, 50.

Keating-Stok I 292.

Kiesow III 169), 170, 171, 173, 174.

Kirchhoff I 139.

Kjeldahl I 246, 292.

Klein, A. I 272, 284.

Klemensiewicz II 93, 150, 151.

Klikowicz I 202, 238. - II 1, 2.

Klingmann III $\mathbf{2} \mathbf{1 0}, 242$.

Knox I 106. - III 284.

Kobert II 420. - III 94, 324, 340-342.

Koch, R. II 76.

Koelichen II 463, 485, 486.

Koelliker III 1, 2.

König II 456.

Koeppe [ 153, 189, 191, 196, 202, 206, $221,224-232,235,237,238,240,250$, 252, 256, 257, 99, 301-304, 306, 337, $346-351,330,379,387,423,435,436$, 442, 446, 450-452, 459, 469, 472, 483, 486, 493, 499, 508, 512, 514, 515. II $300,311,387,437,438-443,445$, 452, 456-461. - III 48, 191, 282, 283, $289-295,297,299,300,304,307,308$, 313-315, 317, 320, 324, 357.

Kövesi I 473. - II 166, 197, 201, 222, 245, 290, 312.

Kohlrausch, F. I 7-9, 37, 39-45, 49, $85,98,100-105,107,109,113-118$, 120-130, 133, 135, 142, 191, 482, 491, 492. - II 219, 293, 386, 387, 452, 481, 487, 488. - III 274, 275, 283, 296, 297.

Kohnstamm II $\mathbf{2 4 9}, 354$.

Kolossow II 92, 95.

Koppe III 237.

v. Korányi, A. I 436, 456, 457, 470, 472, $473, \mathbf{4 5 6}, 488,504$. - II $60, \mathbf{2 4 7}, 249-$ $253,255-276,278,279,288,289,292$. 293, 295, 308-312, 314, 315, 317-323, $326,327,393,408,419$. -- III 50.

Kossel III 324, 343, 353.

Kossler II 464, 511.

v. Kostkewicz III 252, 285, 288, 319.

Kovács II 253, 260, 261，263，264, 314, 319, 326, 327. - III 50.

Kramer, R. II 92, 118-120, 194.

Krannhals I 137.

Kraus III 324, 342 .
Kroenig II 289.

Krönig I 436, 456. - II 248. - III 175, 185, 186, 192, 210, 217, 219, 256, 257, $259,261-263,265-268$.

Krompecher III 363.

Kronecker II 131. - III 281.

Krüger, F. I 271, 277, 278. - III 175, $183,184$.

Kübel II 464, 513.

Kühne II 421, 435, 491.

Külz II 514 .

Kümmel, H. I 503. - II $247,276-279$, 281, 283, 284, 310, 315-318, 326.

Kumagawa II 464, 511.

Kunde III 161, 166.

Kunst, J. J. III 161, 164, 165.

Kurlbaum I 9S, 102, 105.

Kyes III 324, 357.

L.

van der Laan, R. II 448, 452-455, 459, 460.

Laennec I $485,486$.

Lafayette Mendel II $\mathbf{3 1}, 39$.

Laker I 359, 361, 370.

Lam II 448, $45 \mathcal{E}$.

Landois I 359, 362. - III 324, 343.

Landolt I 78.

Langendorff III 107, 123, 124.

Langer III 324.

Langgaard II :393, 412.

Langley II 230, 421, 423, 424, 429, 432, 433. - III 400.

Lannois II 166, 181.

Laptschinsky I 164, 170.

Laudenheimer II 18.

Laurent II 495.

Lautenschläger I 441. - II 307.

Lazarus-Barlow I 63, 158, 159, 436, 456, 457. - II 1, 14, 31, 48, 49, 66, 67, 77, 93, 149, 152, 157.

Lea, Carey III 59, 81, 89.

Leathes II 1, 14, 15, 31, 47, 51, 92, 142, 144-146, 157.

Leclanché II 341, 380.

van Leersum III 279 , 281.

Lehmann, C. I 235, 261, 266, உ71, 279, 291, 499. - III 413. 
Leo II 464, 512.

Lépine II 67, 75, 166, 181, 392, 404.

Leube II 501.

Leubuscher II 126, 166, 176, 177, 179, 181, 184, 193.

Leverrier II 439.

Lewin II 233.

Lewis III 181.

Lichtheim II $\mathbf{6 7}, 80,81,433$.

Lieberkühn II 15, 25, 174, 176, 207, 217.

Liebermann II 248, 332, 345, 346, 464, 503, 508-510.

van Lier, G. A. I 203, 206, 210, 240, 251, 258.

v. Limbeck I 183, 184, 187, 189, 202, 203, 205, 232, 261，266, 268, 271, 280, 91, 295, 296, 301, 3599, 362, 367, 402, 403, 436, 452, 469, 486, 499. - II 18, 314, 392, 395, 399, 415. - III 223.

Lindemann, L. I 473 . - II $\mathbf{2 4 7}, 249,250$, 266-270, 279, 288, 289, 312, 317.

Lindemann, W II 392, 404.

Linder III 58, 61, 62, 65, 66, 70, 72, 77, $127,128$.

v. Lingelsheim I $\mathbf{2 7 9}, 281$.

Lingle III 107.

Linnemann III 418.

Lippmann II 358. - III 76, 77.

Lipstein III 355.

Lobry de Bruyn III 58, $\mathbf{5 9}, 63,65,88$.

Loeb, J. I 37, 42. - II 2. - III 66, 79, 107, 110-116, 118-129, 131, 133, 134, $137,138,144,160,168,175,176-181,263$.

Loeper II 1, 29.

Loewenhardt II $\mathbf{2 4 8 ,} 283$.

Löwenherz, R. II $248,345,386,488$.

Loewenthart III 59, 96.

Löwit II 31, 43.

Loewy, A. I 271, 280, 299, 306-308, 333 336, 408, 499. - IlI 1, 50, 194.

Löwy, E. III 396, 419.

London III 351.

Loomis I 19, 55, 63, 64, 65, 68-70, 76, $77,82,83,85,87,88,95,96,130,454$. Lottermoser II 463, 475. - III 59, 81, $88-90$.

Loye II 1, 2.

Lubarsch II 83.
Ludwig, C. JI 31, 32, 61-63, 92, 94, 153, 158, 250, 252, 271, 392, 393-396, 404, 413, 419, 424, 430, 465. - III 59, 80 , 324, 342.

Lummer I 98, 102, 105.

Luther II 245, 341, 352.

Luys II 316.

\section{II.}

Madsen III 324, 395, 363, 364, 368, 369 , $372,373,375,377,378,380,386,387$.

Magendie II 76, 93, 148, 158.

Magnus, H. 1, 2, 10, 12, 18, 67, 87, 392 , 397, 399-402, 416. - III 161, 166.

Maillard III $\mathbf{2 5 7}, 268$.

Malassez I 154, 198, 359, 361, 362, 367, 378. - II 14. - III 404.

Mall II 31, 49.

Maltby I 98, 122.

Maly Il 439.

Manasseïn I 311, 317.

Manca I 164, 176, 177, 261, 266, 291, 360, 365, 367. - III 161, 165-168.

Manté II ะ48, 291.

Maragliano I 359, 361, 364-367.

Marcano III 395, 405.

Marfells II 166, 175.

Marfori III 1, 15.

Mariotte I 5, 29, 30.

Marshall III 354.

Martin III 343.

Marx III 324, 352.

Massart III 161, 162, 163, 328, 325-327. athews III 175, 177, 180.

Mathieu I 299.

Maxwell I 37, 49.

Mc Intosh III $\mathbf{2 5} \mathbf{7}, 266$.

Meade-Smith II $\mathbf{2 2 1}, 222$.

Meckel II 393.

Meerburg I 27.

van Meeteren III 360.

Melnikow III 404.

Melzer II 92, 99, 101, 121.

Menschutkin II 463, 474.

Mensonides II $\mathbf{3 0}, 32$.

v. Mering II $\mathbf{2} \mathbf{2 1}, 222,224,229, \mathbf{4 3 7}$, $440-442$. 
Messadaglia II 443, 444, 446, 147.

Mesdag III 53.

Metchnikoff I 398. - III 324, 351, 352, $354,355$.

Meyer, H. III 143, -43, 245, 247, 249 $-251,424$.

v. Meyer, E. 89, 90.

Meyerberg I 104.

v. Mikulicz I $\mathbf{2 7 1 .}$

Miller I 272. - III 65.

Minervini III $\mathbf{2 5 7}, 267$.

Mitchell III 161, 166.

Mitscherlich I 21.

Mörner, C. Th. II 464, 512.

Mohr I 298.

Moleschott II 166, 175. - III 1, 2.

Moll, J. W. III 397.

Monod II 67, 75.

Moore III 107.

v. Moraczewski II 18.

Morgan III 175, 179.

Morgenroth I $\mathbf{3 9 5}$, 396-398. - III 324, 344, 346, 349-351, 353-356, 359.

v. Noricz I 436, 457. - II 254.

Moritz II 221, 224, 229, 248, 289, 291.

Morton III 243.

Mosso, A. I 164, 177, 182, 360, 363, 364, 436. - III 182, 221, :24, 343.

Moussu II \$1, 51, 52, 54, 57, 77.

Müller, J. I 189, 190, 463, 464, 515.

Müller v. Berneck II 167, 207, 216, 4608. III \$.9. 81, 84-86, 104.

Müller, P. III 351.

Muencke I 441, 444, 453, 515. - II 304, 307.

Münzer II 392, 400.

Mulder, G. J. II 44:3, 448.

Munk, H. Il $421,435$.

Munk, J. II 93, 153, 393, 412, 420.

Murri I 360, 366.

Muscatello II 92, 95.

Myers III :324, 343.

Mylius II 249, 353, 354.

x.

v. Nägeli, C. I 21, 22. - III \$7, 240, $241,242$.
Nagano II 166; 200.

Nagelschmidt II 287, 290.

Nasse, O. I 15:3, 188. - III 107, 108, 109.

Naumann II 439.

Neeff I 100.

Neilson III 175, 177.

Neisser, M. III 89, 90, :3누, 3925, 342, 355.

Nernst I $\mathbf{3 7}, 39,42,45,50,55,60,62$, $63,65,66,68,69,71,74-76,82,95$, 96, 124, 454, 509, 510. - II $\mathbf{2 4 8 ,} 332$ -334, 377, 488. - III 58, 63, 78, 108, 159, 243, 246, 284, 384, 395, 416, 416, 418.

Newton II 439.

Niementowski I, 132, 133.

Nietzki III 426.

Nocard I 271, 281.

Noetzel, W. I 272, 290.

Nolf I $\mathbf{3 9 5}, 397$. - II 230, 421, 422, 426, 427, 430. - III 215, 32.5, 352, 362, 363.

Novi, Ivo II 421, 424, 425, 429.

Noyes III 169, 170.

Nussbaum, M. II 393, 409, 410.

\section{0.}

Obach I 119, 127, 139-141.

Oertel II 262.

Ohm II 378, 380.

Oker-Blom I 37, 49, 123, 171, 202, 206, $221-224,255,256,474,477,480,481$, 512, 520, 521, 523, 528, 537, 539. II 421, 422, 430, 435, 436. - III 108, 149, 150, 153-155, 192, 198, 202.

Oppenheim, H. II $\mathbf{2 4 5}, 291$.

Oppenheimer, C. II 463, 475. - III. 59, 106.

Orlow II 92, 96, 101, 102, 132, 142, 145 . $153,159,244$.

Ostertag II 83.

Ostroumouff II 32.

Ostwald I 8, 9, 14, 26, 37, 38, 41, 42, 45 $-47,49,50,59,60,98,100,102,111$, $115,118,120,126,131-133,142,149$,

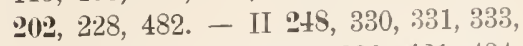
$341,352,354,358,366,386,421,434$, $440,441,456,46 * 3,464,469,480,481$, $484,488,489,493,494,496.498-501$. - 
III 59, 80, 92, 93, 112, 153, 169, 170, $255,262,284$.

Overton, E. I 202, 206, 215-220, 256. - II 248, 301, 393, 411. - III 108, $110,115,129,133-139.143-146,155$, 223, 225, 226, 229-232, 237, 242. 243, $244,245,247-250,252$, 396, 424-428. Ovio III 161, 166-168.

\section{P.}

Pace II 248, 278, 279, 283, 292.

Palmaer I 463, 475.

Paneth II 393, 419.

Pappenheim III 396, 421.

Pascheles II 166, 199, 218.

Paschutin II 30, 32. 35

Paternó III 395, 416.

Paul, Th. II 249, 389. - III 2566, 257, 259, 261-263, 265 - 268, 971, 273275, 277-279.

Pauli, W. III 55, 59, 77, 107, 118, 131. Pawlow II 437, 443.

Pekelharing II 30, 32.

Pemsel I 333, 335. - 56, 75.

Pfaundler II 247, 271, 272, 392, 406, 407.

Pfeffer I 6, 17, 21, 26, 27, 28, 30-32, $34,35,50,54,77$. - II 113. - III 32:3, 326.

Pfeiffer, Th. I 110, 183, 189, 396. - II 221, 226-229. - III 324, 351, 352.

Physalix III 343.

Pickering I 65, 472.

Picton III 55, 61, 62, 65, 66, 70, 72, 77, $127,128$.

Pirquet III 325.

van der Plaats, J. D. I. 101, 104, 108, 113, 117-119.

Planck I 37. - III. 151.

v. Poehl II थ48, 289. -- III. 123.

Poggendorff II 338, 339.

Pohl Il 339, 344.

Ponsot I 27, 50, 55, 6:3, 69, 73, 77, 95. Popoff II 31, 43, 46.

Porteret II 392, 404, 434.

Posternak III 10S, 158 .

Potain I 361.

Pott II 74.
Pouchon II 231, 245.

Pozzi III 175, 221.

Prange III 89.

Pringsheim I 21, 22.

Prochownick III 205.

Prost III 5S, 70, 72.

Pugliese III 343.

Pulfrich II 329.

Q.

Quincke I 289. - II 434. - III 67, 78. Quinton II 1, 2. - III 124.

R.

Ramon y Cajal II 430.

Ransom III 324, 340, 357.

Renvier III 147.

Raoult I 6, 14, 17, $\mathbf{2 1}, 25,26, \mathbf{2 8}, 35$, $55,56,58,68,64,65,68-71,73,76-$ $84,95,96,191,225,226,230,237,454$, 472.

Raswendenkow III 404.

Ravaut II 30, 36, 67, 74.

v. Recklinghausen II $\mathbf{6 7}, 80,9 \mathbf{9} .94,100$, 158.

Redtenbacher II 17.

Reformatsky II 463, 474.

Reicher I 191.

Reichert III 343.

Reindeıs, W. II 59, 84, 86.

Reinhardt III 32:3, 338.

Renaut I 359, 362.

Retzius II 430.

Reuss II 434.

Reychler I 28, 29.

Ribbert II 398, 407, 408.

Richard III 169, 170.

Ricchetti III 1, 2.

Richet III $\mathbf{2 7 9}, 280$.

Richter I $\mathbf{2 7}, 290 .-$ II $\mathbf{2} \mathbf{7}, \mathbf{2 4 5}, \mathbf{2 7 6}$, $283,292,311,315,316$.

Rigler I $272,281$.

Ringer, Sidney II 208. - III 107, 122 $-124$.

Ritter, C. Il 93, 146-148, 434. 
Rochat III 342.

Rodenwald III 65.

Rodier I 164, 178, 436, 462, 465, 466. III. 183.

Römer II 67, 76. - உこ6, 265.

Rogowicz II 30, 32, 35.

v. Rohrer II $\mathbf{2} \pm \mathbf{S}, 332,345,349,382$, 383, 388, 390.

Rokitansky I 272, 289.

Rollett I 164. 169-171, 383;, 344, 347, 353, 3อ99, 361, 399, 474, 478, 513, 533, 536,539 .

Roloff III 28:, 304.

Rona III 58, 77.

Rosemann III 285.

Rosenstein, S. S. II $\mathbf{6 7}, 80$.

Rosenstein, A. II 93, 153.

Rosetti I 96.

Roszkowski I 132, 133.

Roth, W. I 202, 221, 255, 349, 473, $\mathbf{4 7}$, 512, 517, 518. - II 31, 57, 60, 64, 93, 97, 156, 157, 163, 166, 197, 221, 222, 224, $-229.247,249,276,292,293,295-$ 297, 311, 315, 317, 324, 440. - III 192, 957, 266, 318.

Roth-Schulz I 473. - II ㅃs, 290, 312

Rothmund III 5\%, 266.

Rothschild III 2S2, 313.

Roux I 971, 281. - III 979, 280.

Roy II 392, 399.

Rudel II 39:3, 412.

Rïdel III $\mathbf{2 7 1 ,} 279$.

Rüdorff I 64 .

Rumpel II „4S, 288, 289.

Runeberg II 18.

v. Rysselberghe III 32:, 328, 335, 337.

\section{S.}

Sabbatani II :30, 36 .

Sabanejew I 456, 488.

Sabatier II 234.

Sachs, H. III :324, 325, 343, 350, 354, $357,363$.

Salkowski I 292. - II 464, 511.

Salzer II 69.

Santesson II 32.

Schäfer II 156. - III 404, 405.
Scharffenroth I 359), 361.

Scherenziss III 175, 183, 184, 186, 191, 192, 203.

Scheurlen III @56, 265.

Schmidt, Alex. I 299. - II 495.

Schmidt-Mühlheim II 93, 153.

Schmiedeberg II 412.

Schönbein III 80, 81, 91, 94.

Schöndorff II 200, 238, 245, 300.

Schoorl III 59, 104.

Schoute, D. II 1, 24, 25, 247, 279, 310, 311.

Schreinemakers III 132.

v. Schröder II 393, 398, 411, 412.

Schröder III 205.

van der Schroeff, H. J. I @03, 206, 240, 258, 403, 408, 493, 425, 432. - III 1, 37.

Schüler II 2:1, 226 .

Schulze II 244. - III 5̊s, 69, 70, 72.

Schwartz, A. IIl 393, 338.

Sehwarz III, 397.

Schweigger-Seldell II 92, 94, 95, 158.

Scipiades III, 175, 217.

Ségalas II 921, 245.

Senator, H. II $\mathbf{6 7}, 80,81, \mathbf{2 4 7}, 311,420$.

Senator, M. II 245, 278, 283, 288, 289, $311,312$.

Senter III ธั9, 93.

Setschenow I 299. - III 257, 266.

Shields I 474, 482. - II 463, 484-486, 488.

Sicard II 30, 36, 67, 74, 75 .

Siemens I :9, 113, 114.

Sjöqvist II 464, 502-506, 509, 512.

Sleeswyk, R. III 32j, 388-393.

Smale II 377. - III 271.

Smith II $\mathbf{2 * 2 1}, 222$.

Simits I 50, 56 .

v. Sobieranski II $\mathbf{3 9 3}, 409,412$.

Söldner II 456, 460.

Sollmaun II $\mathbf{3 9} \mathbf{2}, 400$.

Sommer II $\mathbf{2 2 1}, 226-229$.

Spalteholz, IV. III 396.

Spencer III 238.

Spina II 175.

Spiro I 33:3, 335. - II 1, 2, 392, 39:3, 400. 412. - III jS, 75, „5(;, 265, 266, 895, 413, 415, 418-423. 
Spohr II 464, 501.

Sprengel I 296.

Spring III 5\$, 61-63.

Starling I 436, 458, 486, 488. - II 1, $12, \mathbf{3 1}, 37,40-60,62-65, \mathbf{6 7}, 75,80$, $82-90,92,95,96,101,120,142,144$ $-146,149-158,162-164,244,392$, 398-403, 408, 415-417. - III 64.

Steiner III $\mathbf{2 5 7}, 266$.

Stejskal II 18.

van der Stempel III 240, 241.

Stewart I 171, 202, 221, 255, 349, 474, $476, \mathbf{5 1 2}, \mathbf{5 1 3}, 517,520,521,523,530$, 532-536, 539. - III 192.

Stephens III 324, 343.

Steyrer II 248, 272, 291, 296, 297, 325, 392, 406, 407.

Stillmark III :324, 341.

Stintzing II 85, 90.

Stoeckl III jS, 60.

Stokvis I II $\mathbf{2 3 1}, 236,245$.

zur Strassen III 175, 179.

Strauss, H. II $\mathbf{2 2 1}, 222-229,231, \mathbf{2 4 7}$, 248, 249, 250, 273, 279, 284-287, 289 $-292,311,318,327,329,330,440, \mathbf{4 4 3}$, 444, 445, 446, 447. - III 2\$2, 285, 288, $316,317,318,319,320,321$.

Stricker I 177, 183. - II 437, 441.

Strübell II $\mathbf{2 4 5}, 329$.

Succi II 254.

Sullivan, O' III 59), 91.

Surányi I 473.

Sypkens Smit III 53.

Szıli, A. II 248, 288, 289, 311.

T.

Talma II 67, 69, 71, 72, 75, 77, 82, 287, 464,501

Tammann, G. I $17,26,50,54,55,58$, $65,436,455,457,459,4 \times 6,488$. II :31, 41, 113, :39:2, 396-398, 415, 420, 46:3, 476. - III 59, 91, 93, 107. 109.

Tangl F. I 202, 221, 255, 349, 4:36, 457, $458,474,475-478,481-483,486,487$, 489-491, 493, 495, 497, 499-502, 504, 512, 517-519. - II 447. - Ill 192, 204, 215.
Tappeiner II 126, 166, 179, 181, 184, 185. v. Than, C. III 282, 283, 309.

Thörner II 448, 452, 453.

Thoma I 292.

Thomas I 281.

Thomassen II 313.

Thompson II 400, 401.

Tigerstedt II $\mathbf{3 0}, 32$.

Todd III 324, 343.

Tompson III 59, 91.

Toulouse III 279, 280.

Trappe II 487, 442.

Traube I 21, 26, 65, 289.

Treskin II $\mathbf{2 3 1 , ~ 2 3 4 , ~ 2 3 5 , ~} 237$.

True III 107, 110, 262.

Tschagowetz III 10S, 148, 155, 159.

Tschirwinsky II $\mathbf{3 1}, 43,46$.

Tubby II 92, 95, 96, 101, 142, 158, 244.

Turner II 283, 318.

\section{U.}

Ubbels, D. G. I 358, 360, 364, 383, $\mathbf{4 3 6}$, 456, 474, 478, 513, 516, 524. - III 175, 182, 186, 187, 206.

Ulsch I 246, 247.

Unna III 421.

Urbain I 299.

Urcelay I 360, 364-366, 368.

\section{V.}

Vandevelde, A. J. J. III 298, 232-237, 324, 342.

Vanino III 5s, 60.

Vaquez I 164, 176, 271, 280, 360, 366, 378.

Veit, J. I 436, 456. - III 175, 182, 184, 185, 188, 206, 209-211, 217, 219, 220.

Van der Velden II $\mathbf{4 6}, 503$.

Vella II 202.

Verhaegen II 437, 443.

Versteeg, J. III 423.

Verworn III 332.

Vicarelli I :360, 364. - III 221.

Viola I 153, 187, :360, 368, 365, 367, 436, $451,456,474,478,483-485,456$, 503-505, 508. - II 310, 311 . 
Violle III 413.

Virchow III 1, 49.

Visser, A. W. IIT 5!, 93, 97-99, 101-104.

Voigtländer III 46:3, 475.

Voit II 166, 167.

Volhard I 244, 292, 425, 426. - III 193, 194.

Volk III 325, 382, 383.

Vries, Hugo de I $2-4,11-13,21,22$, $23,25-27$, 2s, 31, 58, 59, 161, 162, $163,165-167,176,177,181,191,215$, 253, 43.), 437, 438. - II 238, 245, 301.III 2, 226, 233, 3:3, 325, 328, 335, 337. Vries, J. de III 423.

\section{W.}

Waage II 463, 466, 467, 477. - III 260, 371.

van der Waals I 7S, 79.

Wachsinuth II 352.

Wagner I 272.

Walbaum III 380 .

Walden, P. I 27, 37, 45, 46, 50, 55, 131 -133, 482. - III 108.

Walker II 464, 505.

Wallace II 166, 197-199, 218.

Waller, A. D. III 10S, 148, 149, 159.

v. Waltenhofen III 284, 320 .

Walz I 272, 282, 283, 285. - III 3:3, $333,334$.

Warder II 46:, 472.

Wassermann III $\mathbf{3 2 4} 352$.

Waymouth-Reid II 166, 167, 172, 174, 202, 207-212, 216, 219-221.

Weber, C. O. III 395, 415.

Wechsber'g III 90, 324, 325, 342, 355.

Wegner II 92, 120.

Weigert II 59. - III 3*4, 346, 347, 413, $421,422$.

Weinland III 108, 158.

Weir Mitchell III 343 .
Weiss II 35.

Wendelstadt III 354.

Werther II $4 * 1,423$.

Wesselly II 49.

Weston II $351-356,380$.

Westphal-Reimann I 513.

Westphal II 293.

Wettendorf II 1, 23.

Wheatstone I 98, 99, 121, 139.

Whethain III 5s, 70, 71, 127.

Wiardi Beckman III 956, 265.

Widal II 30, 36, 67, 74, 75. - III 341.

Wiedemann I 128. - II 434.

Wien I 9S, 101.

Wiener, O. III 58, 62.

Wijs II 386, 387, 481, 488.

Wildenstein I 243.

Wilhelmy II 464, 493, 495, 499.

Willerding I 20:2, 231-234, 237, 256.

Wilson III 176.

Winkler, H. III 175, 181.

Winter, J. I 436, 455-459. - II 448, 449, 452. - III 321 .

Winterberg I $\mathbf{9 7 2}, 284$.

Witt, O. N. III 395, 413, 415.

Witte II 57.

IVladimiroff III 323, 328-332.

Wooldridge II $67,77$.

IVundt II 397.

\section{Z.}

Zabelin III 271.

Zanier I 360, 363, 383. - II 30, 36, 74. - III 175, 182, 202.

v. Zeynek III 10S, 159.

Zickel, H. II 248, 272, 290.

Zsigmondy III $\mathbf{5 s}, 60,66$.

Zuntz, N. I 261, 271, 277, 280, 291, 298, 299, 300, 306, 3:3;, 336, 408, 456, 499. - II 52, 248, 313. - III 194, 346. 


\section{Sach-Register.}

A.

A a ls erum, Giftigkeit wegen des hämolytischen Vermögens III 343.

A c cumulator, Capacität Il 379 ; elektromotorische Kraft, Entladung, II 380.

A cetaldehyd, Permeab. d. r. Blutkörperchen I 215;

Permeab. von Pflanzenzellen I 216.

A ceta mid, Permeab. d. r. Blutkörperchen I 207, 215.

Permeab. d. r. Blutkörperchen und Pflanzenzellen I 219.

Acetanilid, Permeab. von Pflanzenzellen I 217.

Aceton, Permeab. d. r. Blutkörperchen I 215;

Permeab. d. Pflanzenzellen I 216.

A cetylendikarbonsäureanion, Leitfähigkeit I 150.

A chloride des Serums I 492.

A cidität, Begriff nach der Ionentheorie I 59.

Aciditätsbestimmung II 330 ff.; mittelst Inversion II 331;

mittelst Esterkatalyse II 332;

mittelst Concentrationskette II 332, 367;

Beispiel der Versuchsausführung; Berechnung und Controllirung des Versuches II 367;
Aciditätsbestimmung des Harns, auf elektrochemischem Wege, Bau der Concentrationskette II 380 ;

Beispiel f. d. Ausführung und Berechnung eines Vel'suches II 383;

Controlle der Bestimmung II 386 ;

Beispiel einer Bestimmung mittelst Concentrationskette II 388 ;

Vergl. mit dem durch Titration gefundenen Riesultate II 389;

Elektrochem. Acidität einiger Harne bei Nieren- und anderen Krankheiten II 390 ;

von Mineralwasser auf elektrochemivergl. auch "Sïuren";

schem Wege III 312.

A c onitin, Leitfähigkeit I 45.

A c onitsäureanion, Leitfähigkeit I 156.

Acrylsäure, Leitfähigkeit I 150.

Active Molecüle I 40, 52 .

Activitätscoëfficient ( $\alpha$ ) I $8,41,44$, Berechnung I 9;

als Maass für die Affinitätsgrösse I 9; zur Berechnung des osmotischen Drucks von Elektrolyten I 10 ;

Berechnung nach Arrhenius I 52; Berechnung mittelst Bredig's Tabelle

I 45 . - II 480;

siehe übrigens "Dissociationsgrad ". Actuelle Ionen II 331, 484. 
Adaptation von Bacterien an den Wechsel des Mediums III 328.

Ad diment III 351 .

A d ditive Natur der Leitfähigkeit (Wanderungsgeschwindigkeit) I $7,39,46$; der Ausflockung von Colloiden durch Elektrolyte III 77.

der pharmakol. Wirkung salzartiger Verbindungen III $2 \cdot 23$.

Additivität, convergente I 47.

A d i p insäureanion, Leitfähigkeit. I 155.

Adsorption, Bedeutung für die Darmresorption II 212;

als Ursache der histologischen Färbung III 409.

A epfelsäure, Leitfähigkeit I 152.

A epfelsäureanion, Leitfähigkeit I 155.

A equivalentleitfähigkeit I 120.

A ether, als Lösungsinittel von $\mathrm{HgCl}_{2}$ oder $\mathrm{AgNO}_{3}$, Einfluss auf das desinficirende Vermögen III 267 ;

Volumänderung d. r. Blutkörperchen III 360 .

A etherarten, Permeab. d. r. Blutkörperchen I 215;

Pormeab. d. r. Blutkörperchen und Pflanzenzellen I 219.

Aethylacetat, Permeab. d. r. Blutkörperchen I 207.

A ethylacetatzersetzung II 470 .

A ethyläther, Permeab. d. r. Blutkörperchen I 207, 215.

Permeab. d. Pflanzenzellen I 216.

A ethylalkohol, Activitäts- und Dissociationscoëfficient I 53 ;

Permeab. d. r. Blutkörperchen I 207, 215. Permeab. d. Pflanzenzellen I 216.

A ethylcy anid, Permeab. d. Pflanzenzellen I 216.

A ethylengly kol, Permeab. d. r. Blutköperchen I 213;

Permeab. d. Pflanzenzellen I 216;

Pernieab. d. r. Blutkörperchen und Pflanzenzellen I 218.

A ethylenhexaphenyldiphosphonium, Leitfähigkeit I 153.
A ethylmalonsäureanion, Leitfähigkeit I 155.

A e thy ls chw ef els äu re, Leitfähigkeit I 152.

A ethylurethan, Permeab. d. Pflanzenzellen I 216.

Af finität, nach physikalisch-chemischem Begriff I 59;

von Protoplasma zu Wasser II 24.

Affinitätsconstante (K) II 481; der Harnsäure III 272;

Beispiel einer Bestimmung III 273.

Affinitätsgrösse von Säuren I 9.

Agglutination von Lacterien bei Plattenculturen 1 283;

von Froscheiern nach Behandlung mit Salzlösungen III 55, 66, 89;। von Colloidtheilchen unter dem Einfluss von Elektrolyten (Ionen) III 123.

Siehe auch unter "Ausflockung " und unter "Colloïde".

A g g l ut in in, Vertheilung über Bacterien und umgebende Flüssigkeit III 38\%;

Fixationsmodus seitens der Bacterien III 385.

Agglutinirungsverhältnisse der rothen Blutkörperchen in erhitztem Serum III 358.

A l b u n o s e n, Säurebindungsvermögen II 506; siehe weiter unter Pepton.

A ldehy de, Permeab. d. r. Blutkörperchen I 215;

Permeab. d. r. Blutkörperchen und Pflanzenzellen I 219.

Alexin I 397;

Bindungsweise I 399, 400. - III 350;

Zusammenwirkung mit dem Sensibilisator III 344 ;

Einfluss der Temperatur III 344 ;

Natur des Angriffs auf das Blutkörperchen III 345 ;

Herkunft III 352;

Vielheit der Alexine III 353, 354;

Directer oder indirecter Angriff des Blutkörperchens III 355, 357;

Natur der Fixation an die Blutk. (chemische oder physikalische) III 356. 
Alexinlehre Buchner's, Bekämpfung derselben III 333, 338;

Ausbreitung durch die Untersuchungen von Bordet u. A. III 334 .

Alkalescenzbestimmung des Serums auf elektrochemischem Wege 1508-512, II 442.

Alkali, Beförderung der Oxydation in Geweben I 279;

Einfluss auf Farbstoffaustritt aus Blutk. I 321 ;

auf Chlorgehalt und feste Bestandtheile des Serums I 322;

Bindungsvermögen für Eiweiss IlI 75 .

Alkalinität des Serums. Beeinflussung durch Einwirkung von $\mathrm{CO}_{2}$ und $\mathrm{O}$ auf das Blut I 264, 280;

Einfluss auf antibacterielles Vermögen I 281, 291;

Steigerung bei Infectionen und Ricinusgaben 281;

Abnahme durch Diphtherietoxin I 281; bei Pflanzennahrung I 281;

bei Fleischmahrung I 282;

der serösen Flüssigkeit von Leukocytenaufschwemmungen nach Einwirkung von $\mathrm{CO}_{2}$ I $406-408$.

des Blutes bei fieberhaften Krankheiten III 50.

Alkalisalze, Permeab. d. r. Blutkörperchen und Pflanzenzellen I 217.

Alkali und Säure, Einfluss auf die Vertheilung der Blutbestandtheile zwischen Körperchen und Serum I 317-330. Siehe übrigens unter „Säure und Alkali".

Alkaloï de, Permeabilität von Pflanzenzellen für dieselben (Giftigkeit) III 230.

Alkohol, Moleculardepression wach Raoult. Siehe Aethylalkohol.

Alk ohole, Permeab. d. r. Blutkörperchen I 215 ;

(einwerthige), Permeab. d.r. Blutkörperchen und Pflanzenzellen I 219;

Einfluss von Alkoholen und alkoholischen Salzlüsungen auf die Eiweissfällung III 75 ;

Giftigkeit für das Protoplasma III 234;
A $1 \mathrm{k}$ o hole, Einfluss der Alkohole als Lösungsmittel von $\mathrm{HgCl}_{2}$ oder $\mathrm{AgNO}_{3}$ auf deren desinficirendes Vermögen III 267; s. auch osmotisch. Druck.

Allantoisflüssigkeit, Herkunft III 211, 217;

Beziehung zur Anınionflüssigkeit III 212; Gefrierpunkterniedrigung III 217; siehe weiter unter Fruchtwasser.

Allylalkohol, Permeab. d. r. Blutkörperchen I 215;

Permeab. d. Pflanzenzellen I 216.

A lum in iumi on, Leitfähigkeit I 156.

A mboceptor III 349 ;

Bindungsweise desselben III 350 ;

Entstehungsort III 352;

Auslösung der Bildung III 352;

Verschiedenheit d. A mboceptoren IlI 353. A meisensä ure, leeitfähigkeit I 149.

m-A mid o benzoesäure, Leitfähigkeit I 151.

o- A mid obe nz o e sä u r $\theta$, Leitfähigkeit I 151.

A midosäuren, Permeab. d. r. Blutkörperchen I 213;

Permeab. d. Pflanzenzellen I 216;

Permeab. d. roth. Blutkörperchen und Pflanzenzellen I 217.

A mmoniak, Leitfähigkeit bei verschiedenen Verdünnungen I 48, 131;

Activitäts-u.DissociationscoëfficientI 5s; Permeabilität d. Pflanzenzellen I 217.

A mmoniaksalze, Permeab. d. r. Blutkörperchen I 215.

A m moniumace tat, Permeab. d. r. Blutkörperchen I 207.

A mmoniuma crylat, Permeab. d. r. Blutkörperchen I 217.

Ammoniumbenzoat, Permeab. d. r. Blutkörperchen I 207.

A mm on iumborat, Permeab. d. r. Blutkörperchen I 207.

A mmoniumcarbonat, Mikroskopische Veränderungen der rothen Blutkörperchen durch dasselbe I 170 .

Ammoniumchlorid, Permeab. d. r. Blutkörperchen I 207.

Siehe Chlorammonium. 
A mmonium citrat, Permeab. d, roth. Blutkörperchen I 209.

A m moniumferricy anid, Permeab. d. r. Blutkörperchen I 208.

A m moniumfluorid, Permeab. d. rotl. Blutkörperchen I 207;

Ammonium hippurat, Permeab. d. r. Blutkörperchen I 207.

A mmoniumbydrocinnamat, Permeabilität der rothen Blutkörperchen I 207.

A m moniumion, Wanderungsgeschwindigkeit (Leitfähigkeit) I 9, 42, 137.

Permeabilität der rothen Blutkörperchen I 231.

A m monium jo did, Permeab. d. r. Blut. körperchen I 207.

A m m on iumlactat, Permeab. d. r. Blutkörperchen I 208.

A m m oniu mmal at, Permeab. d. r. Blutkörperchen I 209.

Ammoniummalonat, Permeab. d. r. Blutkörperchen I 207.

A mmoniumnitratlösungen, Gefrier. punkterniedrigung I 37.

Amnoniumnitrat, Permeab. d. r. Blutkörperchen I 208.

Ammoniumoxalat, Permeab. der r. Blutkörperchen I 207.

A minonium phenyla ce tat, Permeab. d. r. Blutkörperchen I 207.

A m monium phos phat, Permeab. d. r. Blutkörperchen I 208.

A mmoniumplatin dia $m$ mon i $\mathrm{m}$. $\mathrm{k}$ ation, Leitfähigkeit I 157.

Ammoniumpropionat, Permeab. der r. Blutkörperchon I 207.

Ammoniums alicylat, Permeab. d. r. Blutkörperchen I 207.

A mmoniumsuccinat, Permeab. d. r. Blutkörperchen I 209.

Ammoniumsulfat, Permeabilität der rothen Blutkörperchen I 208, 222, 223, 231;

Permeab. d. rothen Blutkörperchen und Pflanzenzellen I 218.

Ammoniumsulfatlösungen, $\Delta$ und i, I 97 .
A mmoniumtartrat, Permeab. der r. Blutkörperchen I 208.

A $m$ m onium thi ocyan at, Permeab. d. r. Blutkörperchen I 208.

A m moniumverbind ungen(organische). Leitfähigkeit von:

Ammonium, Methylammonium, Guanidin, Aethylammonium, Dimethylanmonium I 142;

Bromäthylammonium, Propylammonium, Isopropylammonium, Allylammonium, Trimetlylammonium, Isobutylammonium, Methyläthylkarbinammonium, Trimethylkarbinammonium, Diäthylammoniuı, Tetramethylammonium, Jodmethyltrimethylammonium, Isoamylammonium, Piperidinum, Methyldiäthylammonium, Vinyltrimethylammonium, Trimethyläthylammonium, $\beta$ Chloräthyltrimethylammonium, $\beta$ Bromäthyltrimethylammonium, Dipropylammonium, Trimethylammonium, Pyridinmethylium, Trinethylallylammonium, Trimethylpropylammonium, Dimethyläthylammoniuın, Benzylammonium, Pyridinäthylium I 143;

Picolinmethylium, Trimethylisobutylammonium, Methyltrimethylammonium, Jodmethyltriäthylammonium, a Lutidinmethylium, a Picolinäthylium, Coniin, Diisobutylammonium, Trimethylisoamylammonium, Teträthylammonium, Trimethylphenylammonium, Tripropylammonium, Triäthylallylammoniuın, Triäthylpropylammonium, Chinolinmethylium, Isochinolinmethylium, Dimethyläthylphenylammonium, Phenocoll, Menthylammonium, Diisoamylammonium, Triäthylisobutylammonium, Triäthylisoanyl. ammonium, 'Trimethyl- $\alpha$-Naphtylammonium, Trimethyl- $\beta \cdot$ Naphtylaminonium I 144;

Morphin, Cocain, Rechtscocain, Morphin-methylium, Codein, Aconitin I 145 . 
Ammoniumverbindungen: (organische, mit zweiwerthigem Kation). Leitfähigkeit :

Aethylendiammonium, Trimethylendiammonium, $\beta$ Chlortrimethylendiammonium, Tetramethylendiammonium, Diäthylendiammonium, Pentamethylendiammonium, $\beta$ Metlyyltetramethylendiammonium I 153.

Ammonplatotrichlorwasserstoffs äur eanion, Leitfähigkeit I 149.

Amnionflüssigke it, Herkunft III 212;

Beziehung zur Allantoisflüssigkeit III 212;

Verhalten von $\Delta$ der Amnionflüssigkeit im fötalen Magen III 214.

Siehe weiter unter Fruchtwasser.

A mpère II 378 .

A m phitrites, Künstliche Parthenogenesis III 177.

A myla lkohol, Permeab. d. r. Blutkörperchen I 215.

Permeab. d. Pflanzenzellen I 216.

A nä mi e, Osmotischer Druck und specifisches Gewicht des Blutserums I 447 , 451.

Anasarca, II 89.

Anfangsgrösse der Osmose (rinitial rate") I 158.

An hy drä m i e, Osmot. Druck, Eiweissgehalt und Chlorgehalt des Blutplasma bei derselben II $22-25$.

Farbstoffaustritt aus den r. Blutk. bei derselben II 25.

Angelicasäure, Leitfähigkeit I 150.

Anilin, Activitäts- und Dissociationscoëfficient I 53.

Leitfähigkeit I 147.

Permeab. d. Pflanzenzellen I 217.

A nilinfarbsalze, hydrolytische Spaltung III 425.

Anilinfarbstoffe, basische, bei der intravitalen Färbung III 420.

A nionen I 8.

Bedeutung bei der giftigen Wirkung einfacher Salzlösungen III $125 \mathrm{ff}$.

Anissäure, Leitfähigkeit I 151.

Antiamboceptor, Entstehen III 352.
Antibacterielles Vermögen von Blutserum, gesteigert durch Einwirkung von $\mathrm{CO}_{2}$ auf Blut I 280 .

Siehe auch unter "Serum".

des Serums von Leukocyten-aufschwemmungen und von Exsudat, Steigerung durch $\mathrm{CO}_{2}$ I 409, 410 .

Steigerung mit der relativen Leukocytenzahl I $411,412$.

S. auch "bactericide Wirkung".

Anticomplement, Entstehen III 352.

Antihämolysin III 381 ;

Entstehen 352.

Antiphon I 118.

Antipyrin, Permeab. der r. Blutkörperchen I 215.

Permeab. d. Pflanzenzellen I 217.

Permeab. d. rothen Blutkörperchen und Pflanzenzellen I 218.

Antiseptica, Beziehung zu Narkotica III 252.

Antiseptische Wirkung; Siehe desinficirende ${ }^{\circ}$ Wirkung.

Antitoxin, Gifte, welche die Bildung desselben im Organismus nicht anregen III 340 ;

Gifte, welche die Bildung desselben im Organismus wohl anregen III 341;

Bildungsweise nach Ehrlich's Seitenkettentheorie III 346 ;

Bindung an Toxin nach Arrhenius und Madsen III 368;

Bildung nach Sleeswyk III 391.

A plysia depilans, $\Delta$ des Manteldrüsensecretes II 431.

Aplysia 1 im a cina, $\Delta$ des Manteldrüsensecretes II 431.

A plysien, Osmotische Eigenschaften der Magenwand II 225.

A poplexie, Osmotischer Druck des Blutes I 470.

Osmot. chem. Anal. des Blutserums I 502 .

A r a b in ose, Permeab. d. r. Blutkörperchen I 213.

Permeab. d. Pflanzenzellen I 216.

Arabit, Permeab. d. r. Blutkörperchen I 213. 
A r b a cia, Künstliche Parthenogenesis III 176.

A rgentum colloidale, siehe colloidales Silber.

Arsen, Einfluss auf Bildung und Zusammensetzung der Lymphe II 60 .

Arsensäure, Beziehung zwischen Dissociationsgrad und Eiweissverdauung II 502 .

Arsensäureanion, Leitfähigkeit I 154.

Siehe Orthoarsensäureanion.

Arsonium verbindungen, Leitfähigkeit, Tetramethylarsonium, Tetraäthylarsonium I 145.

Arterielles Blut, Osmot. Druck bei Ertrunkenen II 19.

Arterielles und venöses Blut, Grenzlösungen für den Farbstoffaustritt aus den rothen Blutkörperchen I 268.

Vergleichung d. Zusammensetzung des Serums I 268.

Volumen der rothen Blutkörperchen I 296-299.

Arterielle Hyperämie, Einfluss auf antibacterielles Vermögen und auf Alkalescenz des Serums I 288.

Ascites, Osmotischer Druck d. Blutes I 471 .

A scites-Flüs sigke it, Durchmesser der Säugethierblutkörperchen in derselben I 199.

Osmot. Druck in Beziehung zu dem des Serums II 50 .

A s paragin, Permeab. der r. Blutkörperchen I 209.

A sparaginam moniak, Permeab. d. r. Blutkörperchen I 209.

Asphyxie, Osmot. Druck des Blutes I $467,469$.

Assimilative Reize III 389 .

A thmung als Factor bei Erzeugung des intraintest. Druckes II 191.

Atropasäure, Leitfähigkeit I 151.

$\mathrm{A} u \mathrm{fb}$ ew a h $\mathrm{r}$ n $\mathrm{g}$ von Flüssigkeiten I 106.
A ufbewahrung des Blutes, Einfluss auf den Hämoglobinaustritt durch Salzlösungen I 176.

Einfluss auf dessen osmotischen Druck I 177.

A u fnahmefähigkeit der Pliagocyten für Partikelchen; Einfluss von $\mathrm{CO}_{2}$ darauf I $416-448$.

A u ge, siehe Conjunctiva und andere Theile. A usflockung von Colloiden III 61 ; von Kaolinsuspension durch SpurenElektrolytlösung III 61 ;

Proportionalität mit $\mathrm{der} \mathrm{H}$-Ionen-Concentration von Säuren III 61;

von Eiweiss durch Alkohole und alkoholische Salzlösungen III 75;

der Colloide durch Elektrolyte, Hemmung durch Nicht-Elektrolyte III 77; von Colloiden, durch Elektrolyte, additive Natur III 77;

Einfluss der Schnelligkeit des Salzzusatzes auf die Fällungswerthe III 78; Erklärung der Ausflockung durch elektrischen Lösungsdruck III 78; von Colloiden durch Elektrolyte III 127; Siehe auch Colloide.

A usflockungserscheinungen, Bedeutung für die Biologie III 132.

Ausflockungsprocess, Wesen desselben III 75 .

A usflockungsvermögen von Halogenen gegenüber Colloiden, Beziehung zu ihrem Erregungsvermögen motorischer und sensibeler Nerven III 158.

Autokatalyse III 92, 93.

Autolysin I 398.

Avogadro-van't Hoff'scher Satz für Lösungen I 33, 50; Experimentelle Prüfungen I 34, 35; Abweichung bei Elektrolyten I 35, 51.

B.

B a ctericide Wirkung, siehe antibacterielle Wirkung und Desinfection. 
Bacterien, Beweglichkeit und Adaptirung in Salzlösungen verschiedener Concentration; Beziehung zum osmotischen Druck; Massarts Verfahren III 325;

Unterschied in der Empfindlichkeit verschiedener Bacterien für Concentrationsdifferenzen III 327;

Beweglichkeit in Salzlösungen verschiedener Concentration. Beziehung zum osmotischen Druck. Wladimi r of f's Verfahren III 328;

Zurückführung der Beweglichkeit auf die der Geisselfäden III 331;

Functionelle Selbstständigkeit der Geisselfäden III 332 ;

Morphologische Veränderungen in Salzlösungen verschiedener Concentration III 333 ;

Bekämpfung der Alexinlehre III 333;

Permeabilität für $\mathrm{NaCl}$; Unterscheidung nach diesem Merkmal in plasmolysirbare und nicht plasmolysirbare III 335 .

Bacterienfärbung, Nothwendigkeit der Berücksichtigung des Theilungsprincips III $415 \mathrm{ff}$.

Siehe auch Färbung.

Bacteriohämolysine III 342 ;

Verschiedenheit derselben III 342.

Bacteriologisches, neuntes Kapitel III 323.

Bact. Jymphag ogon II $37,50,71$.

Balneologisches, achtes Kapitel III 282.

Barym chlorid, siehe Chlorbaryum.

B a ry u mhydroxyd, Activitätscoëfficient, Dissociationscoëfficient I 53.

B a r y u m - I o n, Wanderungsgeschwindigkeit (Leitfähigkeit) I 9, 42, 137, 138, 153.

Baryumnitrat lösungen, Leitfähigkeit I 130.

Basen, Desinficirende Wirkung. Beziehung zu ihrem Dissociationsgrad III 264.

Basische Narkotica. Wirkungsmechanismus III 252.
Bauchhöhle, Resorption in derselben II 93;

Regelung des osmotischen Druckes Il 93; Resorptionsbahnen II 94;

siehe auch unter ${ }_{n}$ Resorption in der Bauchböhle".

Beckmanns Gefrierapparat I 64; Beschreibung des Apparates I 89;

Ausführung der Bestimmung I 90. III 305 ;

Schwierigkeiten I 93;

Beurtheilung der Ergebnisse I 95;

Siehe auch Gefrierpunkt.

Begonia manicata I 162.

Beizung, Färbung durch III 414.

Benzoesäure, Leitfähigkeit I 150.

Benzosulfonsäure, Leitfähigkeit I 152.

Benzylalkohol, Permeabilität der rothen Blutkörperchen I 215.

Bergwasser, Schädlichkeit III 320.

Beri-Beri, Osmotischer Druck und specifisches Gewicht des Serums I 447.

Bernsteinsäureanion, Leitfähigkeit I 155.

Beweglicbkeit der Ionen; Bedeutung für die Physiologie I 46.

Biconcave Gestalt der SäugethierbIutkörperchen. Zustreben zur Kugelform durch Salzlösungen, verdünntes Serum, normale und pathologische Lymphe I 197.

Bienengift III 343 .

Bimoleculare Reaction II 470 ; Geschwindigkeitsconstante (k) dabei II 471.

Bindegewebespalten, s. Resorption in Bindegewebespalten.

Bindungsverhältnisse bei der Neutralisirung von Toxin durch Antitoxin vom physikalisch-chemischen Gesichtspunkt III 368, 378;

Desgleichen bei der Bindung von Borsäure und Ammoniak III 376.

Bionten III 338 .

Blas enepithel, III 24; siebe auch Epithel der Blase

Blut des Menschen. Osmotischer Druck I 472 ; 
Blut von Rind, Stier, Sclıaf, Ziege, Pferd. Schwein, Kaninchen, Hund, Katze, Zusammensetzung I 506 ;

Physiol. Leitfähigkeit I 537;

Dissociationsgrad I 538, 539;

bei Nierenkrankheiten II 264;

$\Delta$ bei Anämie II 265;

$\Delta$ bei fieberhaften Krankheiten II 266 ;

$\Delta$ bei Herzfehlern II 266;

$\triangle$ für die Differentialdiagnose von Typhus und Pneumonie II 266;

$\triangle$ bei Urämie II 268;

$₫$ bei Milch-Eierdiät II 279;

Kautelen für die Erbaltung einer brauchbaren $\Delta$ II 279 ;

Beeinflussung des osmotischen Druckes durch das Trinken von Mineral wässern III 313 ; von warmem Wasser III 314; siehe auch "Blutserum" und "Serum". Blutdruck in der Carotis bei Arbeit von Rumpf und Extremitäten II 36 ;

in A. femoralis, V. porta und V. femoralis vor und nach Obstruction der V. cava II 45 ;

in den Leber-Capillaren, vasomot. Einfluss II 49;

in den Capillaren, Beziehung zu dem in der entsprechenden Arterie und Vena II 44, 50;

in der V. jugularis beim Gehen II 51 .

Blutegelextrakt, Jymphstrombeschleunigende Wirkung nach Heidenhain Il 34, nach Starling und Cohn. stein II 43.

Blutentzielıung, Osmot. Druck des Blutes I 452, 468.

Blutgefässe, Verhalten bei der Resorption in der Bauchhöhle II 95.

Blutkörperchen (rotbe), Volumen in Carotis- und Jugularisblut I 296-299; Zusammensetzung bei Rind, Stier, Schaf, Ziege, Pferd, Schwein, Kaninchen, Hund, Katze I 507;

Bedeutung für das Studium der Immunität IIl 339;

Volumverhältnisse bei und nach Behandlung mit Formalingemischen III $405 \mathrm{ff}$; ; Siehe auch unter Formalin.

H a m burger, Osmot, Druck. III. Band.
Blutkörpercheninhalt, Physikalisclıchemisches Verhalten I 528-539;

Dissociationsfäligkeit I 537.

Blutkörperchenmetlode I 4.31, 32,164 ff., 360 ff.;

Bestimmung der wasseranziehenden Kraft (des osmot. Druckes) durch dieselbe I 189, 439;

Bestätigung durch die Gefrierpunkterniedrigungsmethode I 189 ;

Kritik der Methode I 439-440;

inodificirtes Verfahren I 440-442;

Anwendung auf die Bestimmung des osmot. Druckes von Humor aquaeus III 164;

Anwendung auf die Harnuntersuchung II 298;

und Gefrierpunktmethode zur Erforschung der Herkunft der Allantoisflüssigkeit III 207.

Blutkörperchenstructur nach Rol. lett I 169.

Blutkörperchenvolumen im Blute I 512;

Bestimmung mittelst specif. Gewicht I 513-514; durch Centrifugalkraft 1 514-517; durch Leitfähigkeit I 517 -524. - I11 192.

Blutlymphe und Giewebelymphe II 40 .

Blutserum, Einfluss der Nahrungsaufnahme auf diø Leitfähigkeit II 202;

Gefrierpunkt, $\mathrm{NaCl}, \mathrm{N}$ bei chronischinterst. und chronisch-parenchym. Nephritis II 285;

$\triangle$ bei Urämie II 287, 312;

\lrcorner bei Nierensufficienz II 309 ;

\lrcorner bei Circulationstörungen II 314 ;

\lrcorner Sauerstoffinhalationen II 315 ;

\lrcorner für die Indication der Nierenexstirpation II 315 ;

Beeinflussung von $A$ durch Nahrungsbedingungen II 310 ;

$\triangle$ bei Eklampsie II 313 ;

Siehe auch "Blut" und "Serum".

Blutstrom in den Venen, Einfluss des extravasculären Druckes II 155.

Borax, Permeabilität der rothen Blutkörperchen für das Anion I 251. 
B orsä u re, Activitäts- und Dissociationscoëfficient I 53 .

Bouillonprobe zur Magensaftuntersuchung II 501.

Boyle-Mariotte'sches Gesetz fïr Lösungen J 30 ; experimentelle Prüfungen I $30,31$.

Brenzschleimsäure, Leitfähigkeit I 150.

Brenzweinsä ure, Leitfähigkeit I 152.

Brom, Begünstigung der Bromwirkung durch Enthaltung von Chlor III 279;

Festlegung von Brom bei Injection von Bromiden nach Verblutung III 281 ;

Verhalten des Herzens III 281.

$m$ - Brombenz oesäure, Leitfähigkeit I 151.

Bromessigsäure, Leitfähigkeit I 150.

Bromion, Leitfähigkeit I 148.

Bromka lium, Permeab. der r. Blutkörperchen I 208, 212.

Bromkalinmlösungen, Leitfähigkeit I 132 ;

Einfluss auf den Hämoglobinaustritt aus rothen Blutkörperchen I 166.

Brommagnesi um lösungen, Leitfähigkeit I 133.

Bromnatrium, Permeab. der r. Blutkörperchen I 208.

Bromnatriumlösungen, $\Delta$ und i I 97;

Leitfähigkeit I 132;

Einfluss auf den Hämoglobinaustritt aus rothen Blutkörperchen I 166.

Bromopurpureokobaltion, Leitfähigkeit I 153.

Bromsäureanion, Leitfähigkeit I 148.

Brucin, Leitfähigkeit I 146.

Brïcke, Wheatst one'sche I 99;

Vergl. auch Messbrücke.

Brückenwalze I 99, 115;

Siehe ïbrigens Messbrücke.

Biuret, Permeab. der r. Blutkörperchen I 207.

Bunsen-Element, Elektromotorische Kraft II 380.
Buttersäure, Leitfähigkeit I 150.

Butylmethyläther, Permeab. der r. Blutkörperchen I 207.

C.

$\mathrm{Ca} d \mathrm{~m}$ i u m i on, Wanderungsgeschwindigkeit (Leitfähigkeit) I 138, 153.

$\mathrm{C}$ a $\mathrm{l}$ c i u $\mathrm{mi}$ on, Wanderungsgeschwindig. keit (Leitfähigkeit) I 9, 42, 138, 153;

Bedeutung für die Herzthätigkeit III 122, 123, 124.

Siehe weiter unter Muskeln, Fundulus, Gonionemus, Cilienbewegung.

Ca lc i umnitrat, Activitäts- und Dissociationscoëfficient I 53.

Capacität des Widerstandsgefässes I 120.

Capillarelektrometer. II 357.

Capill a re nd ot he 1 , Secretorische Thätigkeit bei der Regelung der Zusammensetzung des Blutes II 34 .

Capronsäure, Leitfähigkeit I 150.

Carbonate des Blutes, Verhalten bei Injection hyperisotonischer Lösungen II 7, hypisotonischer Lösungen II 11.

Carbonatokobalttetramon, Leitfähigkeit I 142.

Carcinoma pylori, Osmot. Druck des Blutes I 452.

C a r o t is - und Jugularisblut, Volum der rothen Blutkörperchen I 296-299.

Ca s e ïn, Erklärung der Ausfällung durch Aufhebung der elektrischen Ladung III 69.

Cäsiumion, Leitfähigkeit I 142.

Cellularplys iologische Lymphbildungstheorie II 58 .

Centrifugalkraft bei der Bestimmung des Blutkörperchenvolumens I 188, 190.

Centrifuge I 453;

Einfluss der Umdrehungsgeschwindigkeit auf Volumen des Blutkörperchensedimentes I $343-345$.

Cerebrospinalflüssigkeit, Osmot. Druck beim Ochsen, Beziehung zu dem des Blutserums II 36 ; 
Cerebrospinalflüssigkeit, Osmot. Druck beim ITenschen im normalen und krankhaften Zustande II 74; als Diagnosticum tuberculöser Meningitis II 75 .

Chaetopterus, Künstliche Parthenogenesis III 177.

Chaperon'sche Wickelung in Rheostaten I 113.

Chem ot axi s, Einfluss von venöser Stauung (Kohlensäure) auf dieselbe I 413 -416 .

Chinin, Leitfähigkeit I 146.

Chinolin, Permeabilität der Pflanzenzellen für dasselbe III 232.

Chinolinsäureanion, Leitfähigkeit I 155.

Chlor, Permeab. d. r. Blutkörperchen I 206, 210;

im Harn bei Fieber II 18;

im Blutserum bei Pneumonie II 18;

im Blutserum bei Febris recurrens II 18;

im Harne bei Malaria II 18;

s. w. bei den Chlorverbindungen und bei "Halogenen."

Chloralhydrat, Permeab. d. r. Blutkörperchen I 215;

Permeab. d. Pflanzenzellen 1 216;

- Einfluss der Temperatur auf die narkotische Wirkung III 252.

Chlor a mm oni um, Activitäts- und Dissociationscoëfficient I 53 ;

$\Delta$ und i I 97 ;

Leitfähigkeit I 129, 132;

Einfluss auf den Hämoglobinaustritt aus rothen Blutkörperchen I 169;

Mikroskopische Veränderungen der roth. Blutkörperchen durch dasselbeI 170;

Permeab. d. r. Blutkörperchen und Pflanzenzellen I 218;

Permeab. d. r. Blutkörperchen I 222, 223.

Chlorbaryum, Permeab. d. r. Blutkörperchen I 208.

Chlorbaryumlösungen, $\triangle$ und i I 86, 97;

Leitfähigkeit I 130 ;

Einfluss auf den Hämoglobinaustritt aus rothen Blutkörperchen I 166.
a-Chlorbenzoesäure, Leitfähigkeit I 150.

Chlorcalcium, Permeab. d. r. Blutkörperchen I 203.

Chlorcalciumlösungen, 」 und i I 97 ;

Einfluss auf deu Häınoglobinaustritt aus rothen Blutkörperchen 1165.

$\beta$-Chlorcrotonsäure, Leitfähigkeit I 100.

Chloride, Verhalten bei Injection hyperisotonischer Lösungen II 71; von hypisotonischen Lösungen II 11.

Chl orgehalt des Serums, Beeinflussung durch Einwirkung von $\mathrm{CO}_{2}$ und $\mathrm{O}$ auf Blut I 263, 266.

Chlorhydride (hydrolytisch spaltbare) Leitfähigkeit;

Pyridin, Anilin, a-Picolin, Dimethylpyridin, Aethylpyridin, Methylanilin, o-Toluidin, m-Toluidin, $\mathrm{p}$ - Toluidin. asymmetr. m. Xylidin, Aethylanilin, Dimethylanilin, Collidin, Isochinolin, Chinolin, $\psi$-Cumidin, Methyläthy]anilin, Chinaldin, Lepidin, Diäthylanilin, Hydroxylamin I 147.

Chlorion, Leitfähigkeit I 9, 42, 138, 148;

Permeab. d. r. Blutkörperchen I 229, $232-235$.

$\alpha$-Chlorisocrotonsä ure, Leitfähigkeit I 150.

$\beta$ - Chloris o crotonsäure, Leitfähig. keit I 150.

Chlo rka lium, Permeab. d. r. Blutkörp. I 208, 212, 222, 223, 225.

Chlorkalinmlösungen, Dissociationsund Activitätscoëfficient I 53;

\lrcorner und i I 84, 85, 97;

Bereitung reiner Lüsungen I 122;

Leitfähigkeit I 122, 129, 131;

Specif. Leitvermögen zur Bestimmung der Widerstandscapacität von Ge. fässen 1128 .

Chlorlithiumlösung, 」 und i I 97; Leitfähigkeit I 123, 133.

Chlormagnesium, Permeab. d. r. Blutkörperchen I 208. 
Chl ormagnesiumlösungen, Gefrierpunkterniedrigung I 86.

$\Delta$ und i I 97.

Leitfähigkeit I 130, 133.

Einfluss auf den Hämoglobinaustritt aus rothen Blutkörperchen I 165.

Chlornatrium, Permeab. d. r. Blutkörperchen I 208, 335;

Gehalt im Serum I 495-499.

ChIornatriumlösungen, Activitätsund Dissociationscoëfficient I 53.

$\Delta$ und i I $82,83,86$.

Leitfähigkeit I 129, 132.

Kinfluss auf den Hämoglobinaustritt aus rothen Blutkörperchen I 165.

Intravenöse Injection II 7.

Chlorplatindia m moniumion, Leitfähigkeit I 153.

Chlorretention II 17.

Ch lorsäur e i on, Wanderungsgeschwindigkeit (Leitfähigkeit) I 42, 130, 138, 148.

$\mathrm{C}_{2} \mathrm{H}_{3} \mathrm{O}_{2} \mathrm{i} \circ \mathrm{n}$, Wanderungsgeschwindigkeit (Leitfähigkeit) I 138.

Cholesterin, Bedeutung des Gehaltes der Zelle für die intravitale Färbung III 424.

Chorioretinitis, Mensch, osmot. chem. Anal. des Blutserums I 502.

Chromicyanwasserstoffsäure. a ni on, Leitfähigkeit I 156.

Chromion, Leitfähigkeit I 156.

Chromioxalsäureanion, Leitfähigkeit I 156.

Chromsäure-EI e ment, Elektromot. liraft II 380.

Chromsä ureion, Leitfähigkeit I 154.

Cliylus. Osmot. Druck bei alimentären Eingriffen III 318.

Cili e nbew egungen, Giftigkeit einer reinen $\mathrm{NaCl}$-Lösung f. dieselben III 121.

Circulationstörungen, $\Delta$ des Blutserums II 314 ;

Einfluss von O-Inlaalationen iI 315.

Circulirendes Blut, Osmotische Verhältnisse unter experimentellen Eingriffen II 1.

Citraconsäure, Leitfähigkeit I 152.
Citrac onsäureani on, Leitfähig. keit I 155.

Citronensäure, Beziehung zwischen Dissociationsgrad und Eiweissverdauung II 502.

Citron ensäureani on, Leitfähigkeit I 156.

$\mathrm{Cl}$ arke-El ement, Elektromotorische Kraft II 380.

Cobragift III 343 .

Cocaïn, Leitfähigkeit I 145.

Codein, Leitfähigkeit I 145.

Coëfficienten, is otonische I 3:

Gesetz I 4, 58, 160;

Berechnung isotonischer Lösungen mittelst derselben I 4, 19, 163;

Giltigkeit für die Blutkörperchen I 4, $31,166$.

C o f fe ïn, Permeab. d. Pflanzenzellen I 216; als Diureticum II 402, 411.

Collo ïde und Fermente, zweites Kapitel III 58 ff.;

Natur der Colloïde (Lösung oder Suspension?) IIl $60 \mathrm{ff}$;

Bedentung dieser Frage für die Constanz des osmotischen Druckes von Colloïden II 40, 41, IIl 65;

Einfluss auf das Licht (Tyndallphänomen) III 62 ;

Durchlässigkeit für andere Colloïde III 63 ;

Gefrierpunkterniedrigung III 63;

Elektrische Ladung III 64 ;

Zustandändcrungen, Bedeutung der $\mathrm{Zu}$ standänderungen organischer Colloüde für die Biologie III 65;

Zustandänderungen durch den galvanischen Strom III 66;

Beeinflussung d. Stromwirkungen durch Säure und Alkali III 66;

Zustandänderung durch Hinzufügung von Ionen (in Säuren, Basen oder Salzen) III 69;

Verhalten von Nichtleitern III 69;

Einfluss der Valenz der Metalle bei der Ausflockung III 69;

Einschluss von Spuren des coagulirenden Salzes in das Coagulum III 70 ; 
Colloïde, Erklïrung des coagulirenden Vermögens von Salzen III 70 ;

Erklärung des Unterschiedes im Coagulationsvermögen bei Anwendung von Salzen mit ein-, zwei- und dreiwerthigen Metallionen III 70 ;

Desgleichen mit ein-, zwei- und dreiwerthigen Säuren III 73 ;

Erklärung des Ausflockungsprocesses durch das Princip des Capillarelektrometers III 75 ;

Grössezunahme der Theilchen durch Abnahme der elektrischen Ladung III 66, 68, 77, 79;

Kritik von Hardy's elektrischer Ladungshypothese zur Erklärung d. Ausflockung von Colloïden III 77 ff.;

metallische Colloïde III 80 ;

Ausflockung durch Elektrolyte III 127;

Bestimmung des osmotischen Druckes III 135 ;

Siehe auch Agglutination, Ausflock ung, Collö̈dlösungen und Colloïdtheilchen.

Colloïdales Metall, Verhalten von Kathode und Anode bei der elektrischen Zerstäubung III $\$ 3$;

Gold III 82;

Kupfer, Wirkung auf Spirogyra III 87; Giftigkeit von Spuren für Spirogyra III 242;

Platin, Katalyse von $\mathrm{H}_{2} \mathrm{O}_{2}$, Reactionsverlauf III 84 ;

Quecksilber III 88;

Silber III 81;

Bereitung auf chemischem Wege III 81; durch elektrische Zerstäubung III 83; Eigenschaften gegenüberGefrieren, Elektrolyte und andere Colloïde wie Gelatine und Eiweissstoffe III 88, 89;

Haltbarkeit des auf chemischem und auf elektrischen Weg bereiteten Präparates III 89 ;

Einfluss von $\mathrm{Cl}, \mathrm{Br}$ und J. III 90; Therapeutische Wirkung III 90; Katalyse von Staphylotoxin III 90;

Collo ̈ d lösung en, Structurbildung beim Uebergang von $\mathrm{Hydrosul}$ in $\mathrm{Hy}$ drogel III 397 ,
Colloïdlösungen, Bildung von zwei Phasen beim Erstarren (Gelbildung) durch Abkühlung III 401:

bei Ausfällung oder Fixirung durch chemische Agentien III 402.

Colloidtli eilchen, Beeinflussung des Zeichens der elektrischen Ladung durch die Natur der Flüssigkeit III 68 .

Colloïd-Zustand von Niederschlägen III 88.

Complement I 398;

in der Seitenkettentheorie III 348;

Bindungsweise III 350 ;

Directer oder indirecter Angriff an das Blutkörperchen III 355, 357;

Natur der Fixation an das Blutkörperchen (chemische oder physikalische) III 356.

Complementablenkung III 355.

Complementophile Gruppe des Am. boceptors IIl 349.

Complexe Kupfersalze, Giftigkeit für Lupinenkeimlinge III 259.

Complexe Salze, Unterscheidung von Doppelsalzen III 253, 254;

Gefrierpunkterniedrigung III 255;

Verhalten gegenüber dem elektrischen Strom III 255.

Concentration, Angabe nach Raoult und nach Arrhenius [ 6. - III 292; Umreclinung I 14;

Angabe in Molionen III 292.

Concentrationskette I 62. - II $332 \mathrm{ff}$. - III $149 \mathrm{ff}$., 311 ;

zur Bestimmung der $\mathrm{OH}^{\prime}$-lonen-Concentration im Serum I 510 ;

Princip II 332. - III 149.

Formel für die elektromotorische $\mathrm{Kraft}$ II 334 ;

Ausfülrrung der Methode II 338; Apparate hierfür II 341 ;

Accumulator II 341;

Messbrücke (zwei Kheostaten, Compensationsapparat mit Kurbelschaltung, Commutator) II 344:

Gefässe II 345; Platinirung der Elek. troden II 348, 368; Reinigung der (iefässe II 349 ; 
Concentrationskette:

Beschickung der Elektr. mit Wasserstoff II 349 ;

Normalelement II 351 ;

Capillarelektrometer II 357;

Galvanometer II 359; Aufstellung II 360 ; Ablesung II 362;

Telephon als Nullinstrument II 365;

Stromtaster II 366 ;

Beispiel der I'ersuchausfuihrung, Berechnung und Controlirung des Versuches II 367 ;

Die Concentrationskette zur Ermittlung des Grades der Hydrolyse II 485;

als Ursache des Demarcationsstromes III 148;

Beispiele von Concentrationsketten und ihrer elektromotorischen Kraft III 150;

Constanz der Concentrationsketten III 151;

Anfertigung von Concentrationsketten mittelst Gelatine III 152;

Einfluss der Permeabilität der Berührungsfläche auf die Constanz der Kette III 152;

Bestimmung der Acidität von Mineralwässern III 311;

Zurückführung des Neurons auf dieselbe III 387.

Coniin, Leitvermögen I 144.

Conjunctiva, Verhalten gegenüber Flüssigkeiten, die nit der Thränenfliissigkeit hyper- und hypisotonisch sind III 161;

Empfindlichkeit für Concentrationsunterschiede nach Cocaïnisirung III 163;

Contact-irritability III 119.

Contraction der Muskeln. Bedeutung von $\mathrm{Na}$-Ionen III 144; von $\mathrm{Li}^{-}$-Ionen III 146;

Erklärung der Erscheinungen III 146. Convergente, Additivität I 47.

Convergenztemperatur I 66.

Copula III 351.

Coulomb II 380 .

$\alpha$-Crotonsäure, Leitfähigkeit I 150.
$\beta$-Crotonsäure, Leitfähigkeit I 150 .

C u - I o n, Wanderungsgeschwindigkeit (Leitfähigkeit) I 138.

$\psi$-Cumolsulfonsäure, Leitfähigkeit I 152.

Cupron-Element, Elektromotorische Kraft III 380.

Curare, Schirmwirkung III 387.

Curcuma rubricaulis I 162.

Cy a ni on, Leitfähigkeit I 148.

Cyanka li um, Verlängerung des Lebens von Seeigeleiern durch Hinzufügung von KCN zu Seewasser III 181.

Cyanose, Farbstoffaustritt aus den betr. Blutkörperchen in Salzlösungen I 280; Resistenz der rothen Blutkörperchen dabei I 366, 368;

Osmotischer Druck des Blutes I 471.

C y a $\mathrm{n}$ wasserstoff als Lähmungsmittel der Platin- $\mathrm{H}_{2} \mathrm{O}_{2}$-Katalyse III 86 .

Cytase III 351 .

Cytophile Gruppe des Amboceptors III 349.

D.

Daniell-Element, Elektromotorische Kraft II 380.

Darm, siehe unter Resorption im Darme.

Darm epithel, sielıe Epithel der Darmmucosa.

Darmzotten, Pumpwirkung bei der Resorption in Darme II 195.

D e fä c a t $\mathrm{i}$ o $\mathrm{n}$ bei künstlicher hydrämischer Plethora II 17.

Defibriniren I 267;

Bedeutung der Art des Defibrinirens anf die Vertheilung der Blutbestandteile I 272;

Einfluss der Temperatur auf die Vertheilung der Blutbestandtheile I 276;

Bedeutung für vergleichende Blutuntersuchungen I 276.

Defribinirtes und nichtdefibrinirtes Blut, Farbstoffaustritt I 171.

Dekaden.Rheostat I 11 .

Deltabildung von Flüssen III 61 . 
Demarcationstrom, Bedeutung der Kohlensäure III 148, 155;

bei künstlichem Querschnitt III 14s, 155 ;

durch örtliche Application verschiedener Flüssigkeiten auf den Muskel III 153.

Depression, siehe Gefrierpunkterniedrigung.

Desinfection, im Lichte der Theorie der elektrischen Dissociation III $256 \mathrm{ff}$.

Desinficirende Wirkung von (juceksilbersalzen. Beziehung zu ihrem Dissociationsgrad III 257, 258;

von Silber-, Gold- und Kupfersalzen:

Beziehung zu ihrem Dissociationgrad III 259;

Betheiligung des Säureions III 259;

von Salien $\left(\mathrm{HgCl}_{2}\right)$ : Abschwächung durch Hinzufügung bestimmter Ionen (Cl') III 260;

Praktische Bedeutung für den Gebrauch von Sublimatpastillen III 261;

von Süuren: Beziehung zu der H-Ionenconcentration III 262 ff.;

Verstärkung durch Zurückdrängung der Dissociation III 264;

von Halogenen III 264;

von Basen: Beziehung zu ihrem Dissociationsgrad III 264;

von Phenol: Verstärkung durch NaCI und andere Elektrolyte III 265; Er-

klärung durch das Theilungsprincip III 266 ;

Beeinflussung der desinf. Wirk. von $\mathrm{HgCl}_{2}$ und $\mathrm{AgNO}_{3}$ durch das Lösungsinittel (Wasser, Alkohol oder Aether) III 266;

theilweise Zurückführung auf Ionenwirkung III 26i:

Schlussbetrachtung III 267 ff;

Parallelismus der desinf. Wirk. von Salzen, Säuren und Basen mit ihrem Dissociatıonsgrad. Abweichungen von diesem Satz III 267;

Bedeutung der Diffusionsgeschwindig. keit der Desinfectantia in die Bacterienzellen III 268;
Desinficireude Wirkung:

Berücksichtigung der Eimwirkungszeit für vergleiclıende Bestimmungen III 268 ;

Desmon III 351.

Destillirtes Wasser: Leitfähigkeit I 106;

Verunreinigungen I 106, 107;

Bereitung I 106;

Verbesserung I 107;

Brauchbarkeit des elektrochemisch nicht reinen I 110.

Deuterotoxin III 369.

Dextrose. Permeab. d. r. Blutkörperchen I 209. Siehe iibrigens Trauben. zucker.

Dextroselösungen, Gefrierpunkterniedrigung (Tabelle) I $\varepsilon 0$.

D i a betes, Osmot. Druck des Blutes I 452,470 .

Diacetonalkohol, Umwandlung zur Bestimınug des Grades der Hydrolyse II 485.

D i a $\mathrm{mm}$ on i u mi on e $\mathrm{n}$. Lcitfähigkeit: Hydrazin, Aethylendiammonium, Cinchonin, Cinchonidin, Chinin, Strychnin, Strychninbromaethilium, Brucinaethylium I 146;

Brucinbromaethylium, Brucinisoamylium $I 147$.

Dibrombernsteinsäureanion, Leitfähigkeit I 155.

Dichloressigsäure, Leittähigkeit I 154.

Diffusibles Alkali, Zunahme durch $\mathrm{CO}_{2}$ I 280 ;

Methode zur quantitativen Bestimmung I 307 ;

Vermehrung in Leukocytenaufschwemmungen durch $\mathrm{CO}_{2}$ I 406-408.

Diffusion bei hydrämischer Plethora II 15:

bei der Lymphbildumg II 64;

Betheiligung bei der Resorption II 109; Betheiligung bei der Resorption in der Bauchnöhle II 133;

Bedeutung für die Resorption II 161; 
Diffusiou:

Bedeutung für die Resorption im Darne II 195;

von Pepton und Glukose, gegeniiber Serum (durch Pergamentpapier) II 209 ;

von Maltose gegenüber Serum II 210;

Bethätigung bei der Magenresorption II 223, 227, 229;

in Kapselraum, in den Harnkanälchen, Bedeutung für die Zusammensetzung des Harns II 418;

Bedeutung bei der Speichelbildung II 429;

bei der Wasseraufnahme der Muskelsubstanz durch Säuren III 114;

s. w. Diffusionsgeschwindigkeit.

Diffusionscoëfficient II 197.

Diffusionsgeschwindigkeit von

Ionen, Beziehung zur Resorption in Darnı II 197;

in Gallerten II 475;

in Bacterien, Bedeutung für das desinficierende Vermögen III 268;

von Diphtherietoxin und Diphtherieantitoxin, von Tetanolysin und Antitetanolysin: Anwendung auf die Bindungsverhältnisse von Diphtherietoxin und Antitoxin III 380; auf die Bestimmung des relativen Moleculargewichtes III 386.

Diglykolsäureanion, Leitfähigkeit I 155.

Dilatometer II 485.

Dimensionen der rothen Blutkörperchen, Finfluss von isotonischen Salzlösungen und von Lymph I 197; von Kohlensäure I 311; vou Säure und Alkali I 330 ; in erhitzten Serum III 358 ;

s. übrigens unter Kohlensäure.

Dinatriumphosphatlösungen, Leitfähigkeit I 133.

Diphterietoxin, Bindung durch Diphterieantitoxin, als Gleichgewichtsreaction betrachtet III 378;

Frage der Vielheit d. Toxine III 379; Moleculargewicht III 385.
Dissimilative Reize III 389.

D iss ociation (elektrolytische), Beeinflussung durch einen Nichtleiter II 240; von Salzen $\left(\mathrm{HgCl}_{2}\right)$, Zurückdrängung durch Ionen $\left(\mathrm{Cl}^{\prime}\right)$ III 260 ;

von Säuren, Zurückdrängung durch Ionen III 264.

Dissociationscoëfficient (i) I 51; des Serums I 480, 481;

des unverdünnten Blutes I 538, 539.

Siehe übrigens unter i;

Dissociatiousconstante (K) II 480 ; des Wassers II 386, 481, 486 ff.;

von Harnsäure III 272;

Beispiel einer Bestimmung III 273;

von Toxin-Antitoxin III 375;

Dissociationsfähigkeit des Blutkörpercheninhalts I 537, 539.

Dissociationsgrad $(\alpha)$, oder Activi. tätscoëfficieut, Einwände gegen dessen Berechnung aus der Leitfähigkeit I 55 ;

Controversen bei dessen Ableitung aus der Gefrierpunkterniedrigung I 56 ;

des Serums I 479-486;

Einfluss des kiweisses auf den Dissociationsgrad des Serums I 475;

Einfluss der Verdünnung auf denselbell I 479 ;

Berechnung II 480;

von Säuren, Beziehung zur Rohrzuckerinversion II 494; zur Eiweissverdauung II 502; Beziehung zur Giftigkeit für höhere Pflanzen II 262;

von Mineralwässern III 291, 297, 307. Siehe auch unter „Activitätscoëffi. cient $(\alpha)_{\text {. }}$

Dissociirte Verbindung, Anwendung des Massenwirkungsgesetzes anf das Gleichgewicht II 479.

Dithionsäurean i on, Leitfähigkeit I 154. Diurese, Beeinflussung durch O-Inhalationen II 263;

Beziehung zur Niereuschwellung II 399, 402;

Beziehung zum osmot. Druck der injicirten Salzlösungen II 399, 415; 
Diurese:

Beziehung zur kirweiterung der Nierengefässe II 400 ;

Beziehung z. Blutdruck II 401, 416, 417;

Wirkungsweise des Coffeïns auf dieselbe Il $402,411$.

Diuretische Wirkung von Salzen, Beziehung zu ihrem osmot. Druck III 223.

Doppelsalze, Unterscheidung von complexen Salzen III 253, 254.

Doppelschicht, Siehe elektrische Doppelschicht.

Dosirung von Medicamenten III 237;

Einwände gegen die angebliche Proportionalität $z$ wischen Gewicht des wirksamen Agens u. therapeutischem Effect III 238;

Einfluss der Wassermenge $u$. der Natır des Lösungsmittels auf den Effect III 238;

Einfluss des Verdünnungsgrades von KBr-Lösungen auf den letalen und toxischen Effect III 239.

Druck, Einfluss d. atm. Dr. auf den Hämoglobinaustritt durch Salz- und Zuckerlösungen I 173;

Einfluss auf die Resorption II 164.

Drüsenthätigkeit bei der Regelung d. osmot. Drucks nach Einverleibung hyperisot. Lösungen II 15 .

Ductus thor a cicus, Unterbindung, Einfluss auf den osmotischen Druck des Blutes I 470.

Durchlässigkeit der Magenwand von Aplysien II 225;

der Blasenwand für verschiedene Substanzen II 236, 238.

Siehe auch Permeabilität.

Durchmesser der Säugethierblutkörperchen in verschiedenartigen Salzlösungen und serösen Flüssigkeiten I 197.

Durst, Beziehung zum osmotischen Druck des Blutplasma II 23;

nach Weingenuss III 320.

Dynamisirung in der Homöopathie III 240.
⿷.

Eier des Froschos, Beemflussung des Volumens durch anisotonische Salzlösungen III 54;

Agglutination der Eier III 55 .

Einheiten bei der Leitfähigkeitbestimmung I 124- 127.

Eis für die Bereitung destillirten Wassers I 107.

Eiweiss, Begünstigung der Oxydation durch Austausch v. Blutbestandtheilen in Folge des respiratorischen Gaswechsels I 279 ;

osmotischer Druck, I 487-489, II 6, 40-41, 152;

des Blutes in fieberh. Krankheiten II 18; des Blutplasma, Verhalten bei Injection

hyperisot. Lösungen II 7, 12, 14, 16 ; hypisotonischer Lösungen II 11.

der Lymphe, Bedeutung f. d. Entstehung von Hydrops II 84, 89.

Bedeutung dieses osmotischen Druckes für die Resorption von Salzlösungen in serösen Höhlen II 152, 153, 162;

bei der Darmresorption II 220 ;

bei der Bildung und Zusammensetzung des Glomerulusfiltrats II 397, 398, 403, 415, 417;

Bindung ron Eiw. an Salzsïure u. andere Säuren II 503;

Untersucht mittelst Leitfähigkeit II 504: mittelst Inversion II 506; mittelst Gefrierpunkterniedrig. II 508; mittelst der Gaskette II 510;

Bindung an $\mathrm{NaCl}$ II 510, 511;

Bindung an NaOII II 509;

Bindungsvermögen für säure und für Alkali (anphotere Natur) III 7.5;

Bedeutung des usmotischen Druck:s für die Concentration der mit der Muskelsubstanz isotonischen Salzlösung III 134; siehe auch "Colloide".

Eiwe isskörnchen, Absatz bei trüber Schwellung III 51.

Eiweissverdaung durch Pepsin und Säuren, Einfluss der Concentration der $\mathrm{H} \cdot$-Ionen II $50 \%$. 
Eiweisszerfall, Factor bei d. Lymphbildung II 64 .

Eklampsie, Osmot. Druck des Blutes I 470 , II 288 ;

osmot. chem. Analyse des Blutserums dabei I 502 ;

Farbstoffaustritt aus den rothen Blutkörperchen III 221.

Electives Vermögen bestimmter Zellen für bestimmte Stoffe III 242.

Elektrische Doppelschicht II 333 , III 68,75 .

Elektrische Ladung der Colloid. theilchen III 64;

für die Erklärung der Wirkung des galvanischen Stromes IlI 66;

der Ionen für die Erklärung der Giftwirkung reiner Salzlösungen III 125.

Elektrische 0 smose II 434 ff.;

s. a. Kataphorese.

Elektrische Reizung, Wesen derselben IIl 159.

Elektrischer Strom, Zusammensetzung aus elektrischen Wellen III 389.

Elektroden für Widerstandsyefüisse, Platinirung I 102, 104:

Grösse I 102, 105;

Aufbewahrung I 105;

Austrocknung I 105;

Polarisation der Elektroden I 105;

für Gasketten, Platinirung II 348;

Beschickung mit Wasserstoff II 351.

Elektrolyte I 7.

Elektrolytengehalt des Serums I 490,493 ;

Siehe übrigens bei den verschiedenen Thieren.

Elektrolytische Dissociation, physikalisch-chemisches, übersichtliche Zusammenfassung I 1;

Theorie I 7, 37-50;

Zunahme mit der Verdünnung I 8;

Bedenken gegen dieselbe I 38;

Bedeutung für die Physiologie u. Pathologie des Blutes I 161.

Beeinflussung durch einen Nichtleiter II 240.
Elektrolytischer Lösungsdruck zur Erklärung der Concentrationskette II 333 ;

zur Erklärung der Ausfällung von Colloïden III 78 .

Elektromotorische $\mathrm{Kraft}$ einiger Säure-Wasserstoffketten II 377 ;

d. Weston-, Clarke-, Cupron-, Leclanché-, Daniell-, Chromsäure, Grove-, Bunsenelementes II 380.

Embryologisches, Sechstes Kapitel III 175.

Emerythrin I 461.

Empfindlichkeit von Bacterien für Concentrationsunterschiede III 327.

Em p y e m a, osmotischer Druck des Blutes I 471.

Endgrösse der Osmose („final osmotic pressure $^{\text {") }}$ I 158.

Endosoma I 169, 399.

En zy me, Beschleuniger reversibler Reactionen, Beispiele III 96;

Beziehung der Thätigkeit zur Configuration der Verbindung III 106.

Enzymintensität III 102.

Enzym wirkungen, aufgefasst als reversible Reactionen III 97.

Epilepsie, Begünstigung der Bromwirkung durch Enthaltung von Chlor III 279 .

Epithel der Darmucosa, Volumänderungen durch anisotonische Salzlösungen III 8,18 .

Einfluss des physiologischen Zustandes des Epithels III 11, 18;

künstliche Modification des Permeabilitätzustandes III 13, 16;

Discussion der Resultate III 18;

Volumänderung der Kerne durch anisotonische Salzlösungen III 19, 35 .

Epithel der Harnblase, Permeabilität für Harnstoff II 241;

Volumänderungen durch anisotonische Salzlösungen IlI 24, 34 ;

Vergleichung mit den Volumänderungen der rothen Blutkörperchen III 25, 35;

Dimensionänderungen der Kerne III 26,56 ; 
Epithel der Harnblase:

Einfluss des Hackens auf die Volumänderungen durch anisotonische Salzlösungen III 29 ;

Bedeutung dieses Einflusses für die Waben- oder Netzstructurhypothese III 29.

Epithel des Oesophagus, Volumänderungen durch anisotouische Salzlösungen III $30 ; 34$.

Vergleichung mit den durch rothe Blutkörperchen hervorgerufenen III 31, 35; Ablagerungen in den Zellen III 32.

Epithel der Trachea, Volumänderungen durch anisotonische Salzlösungen III 21,34 .

Erregbarkeit motorischer und sensibler Nerven sowie von Flimmerepithel durch Halogene III 158;

Beziehung zu ihrem Ausflockungsvermögen von Colloïden III 158.

Erstarrung, Beeinflussung durch Elektrolyte und Nicht-Elektrolyte; Unterscheidung von Ausflockung III 77.

Ertrinken, Osmot. Druck d. Blutes in d. r. und l. Herzhälfte II 19 ;

Einfluss d. osmot. Dr. d. Wassers dabei II 19.

Erythrit, Permeab. d. r. Blutkörperchen I 213 ;

Permeab. d. Pflanzenzellen I 216;

Permeab. d. roth. Blutkörperchen und Pflanzeuzellen I 218.

Essenzen, Giftigkeit für des Protoplasma III 234.

Essigsäure, Leitfähigkeit I 149.

Essigsäureanıon $=\mathrm{C}_{2} \mathrm{H}_{3} \mathrm{O}_{2}$. Wanderungsgeschwindigkeit (Leitfähigkeit) I $42,138$.

Essigsäureäthylester, Permeab. d. r. Blutkörperchen I 215;

Permeabilitit der Pflanzenzellen I 216.

Essigsäurelös ungen, Leitfähigkeit I 131.

Fssigsäuremethylester, Permeab. d. r. Blutkörperchen I 215.

Essigsaures Kali siehe Kaliumacetat.
Essigsaures Natron siehe Natriumacetat.

Ester, Permeab d. r. Blutkörperchen I 215 ;

Permeab. d. roth. Blutkörperchen und Pflanzenzellen I 219.

Esterzersetzung If 470 ;

siehe auch Methylacetat.

Exsudat, Peritoneales und pleuritic ches, Einfluss von $\mathrm{CO}_{2}$ auf das diffusible Alkali I 407; auf die antibacterielle Wirkung der Exsudatfliussigkeit I 410; Osmotischer Druck II 147.

Extracte (pflanzliche und thierische), Giftigkeit für das Protoplasma III 236.

Extrameabel I 162. - II 24.

Extravascularer Druck, Einfluss auf Blutstrom in den Venen II 155.

F.

F äc es, nach der Injection hyperisotonischer Lösungen II 12.

Färbung fixirter Gewebe, drei Theorien III 412 :

physikalische Theorie (Adsorption) III 413 ;

physikalisch-chemische Theorie III 415. Einfluss der Natur der Flüssigkeit, in der Farbstuff gelöst ist und der Natur der zu fürbenden Substanz selbst III 419 ;

von Bacterien. Nothwendigkeit der Berücksichtigung des Theilungsprincips III 421 ;

chemische Theorie III 421;

Experimentum crucis für die physikalisch-chemische Färbung III 428;

lebender Zellen. Bedingung III 424;

Unfähigkeit der Sulfosäure-Farbstoffe, intravitale Färbung herbeizufülıren III 426;

des Nervensystems mittelst basischer Anilinfarbstoffe III $42 \overline{7}$.

Farbstuff a ufnahme, Vertheilung iiber Geriistsubstanz und Waschenflüssigkeit III 420 . 
Farbst of faustritt aus r. Blutkörperchen, Beeinflussung durch Kohlensäure I 261;

bei venösem u. arteriellem Blute I 262; nach Erzeugung hydrämischer Pletbora,

Hydrämie und Anhydrämie II 25-29; aus den Blutkörperchen während der

Schwangerschaft III 221;

bei Eklampsie III 221;

Mechanismus des Farbstoffaustrittes III 357;

siehe iibrigens unter "Blutkörperchenmethode" und unter "Resistenz".

Febris typhoidea, osinot. Druck des Blutes I 471;

Febris recurrens, Gehalt des Blutserums an Chlor, Eiweiss und Wasser II 18.

Fermente, III 80 ;

Complicationen bei der katalytischen Wirkung II 475;

Vergleichung ihrer katalytischen Wirkung mit der des colloidalen Platins und der Wasserttoffionen III $91 \mathrm{ff}$.

Siehe auch unter "Colloïde u. Fermente".

Fericyanwasserstoffsäureanion, Leitfähigkeit I 156.

Ferri oxalsäurea ni on, Leitfähigkeit I 156.

Ferrocyanwasserstoffsäureanion, Leitfähigkeit I 157.

Feste Lösungen III 117, 383 ;

in der Muskelsubstanz III 137;

Bedeutung für die Färbung von Geweben III 420 .

F ett, Begünstigung der Oxydation durch Austausch von Blutbestandtheilen durch den respiratorischen Gaswechsel I 279.

Fettgelıalt des Serums, Beeinflussung durch Einwirkung von $\mathrm{CO}_{2}$ und $\mathrm{O}$ auf das Blut I 265.

F i e b e r, Resistenz der rothen Blutkörperchen I $365,368$.

Filtration in Luft, Unterschied gegenüber der in Flüssigkeit II 38.

Filtrationshypothese bei der Lymphbildung, Einwände II 32; siehe auch unter Nierentlıätigkeit.
Fixateur III 351.

Fixirung der Gewebe, Kunstprodukte durch Anwendung von Fixationsmitteln III 397 ff.; beim Absterben III 400; nachträglicher Einfluss anderer Flüssigkeiten auf das fixirte Object III 403; durch Formalin III 405 ff.;

Berücksichtigung des osmot. Druckes der Fixirungsflüssigkeiten I 190, 463. - III 410-412.

Fixirungsflüssigkeiten isotonisch mit Seewasser III 410.

Flimmerepithel, Erregbarkeit durch Halogensalze III 158;

Beziehung zu ihrem Ausflockungsvermögen für Colloïde III 158.

Flotte III 419.

Flüchtige Oele, Giftigkeit für das Protoplasma III 234.

Fluorion, Leitfähigkeit I 148.

Flu orka liu mlösungen, Leitfähigkeit I 132.

Fluornatrium, Permeab. d. r. Blutkörperchen I 208.

Fluornatriumlösungen, Leitfähigkeit I 132.

Flüssigkeitsketten I 62; siehe übrigens Concentrationsketten.

Fo etus, Leltfähigkeit des Serums, ver. glichen mit der des Mutterthieres I 478; III 201.

Form der rothen Blutkörperchen in fremden Medien I, 178, 197;

unter dem Einfluss von Kohlensäure I 311 ;

unter dem Einfluss von Säure und Alkali I 332 ;

in erhitztem Serum III 358.

Formaldehyd, Permeab. d. r. Blutkörperchen I 215;

Permeab, der Pflanzenzellen I 216, 217.

Formalin als Fixationsmittel III 399 ;

Volumverhältnisse bei und nach Behandlung mit diesem Fixiermittel III 405;

Einfluss des Säuregebalts der Formalinpräparate III 407. 
Fötales Blut, siehe ${ }_{n}$ mütterliches und fötales Blut".

Frictionsphänomen II 504.

Froschblut, Hämoglobinaustritt durch Salzlösungen I 178.

Froscheier siehe Eier des Frosches.

Froschmuskeln in Salzlösungen. Zusammenhang zwischen Concentration und Reizbarkeit III 108;

Quellung in $\mathrm{NaCl} 0,6 \%$ III 134.

Fruchtwasser, osmotische und osmo. tisch-chemische Analyse III 205;

Gewinnung III 206;

osmotischer Druck III 206, 209, 211, 215,216 ;

Combination von Gefrierpunkt- und Blutkörperchenmethode III 207;

Alkalinität III 208;

in verschiedenen Schwangerschaftsperioden III 212;

Veränderungen nach dem Tode III 213;

$\mathrm{OH}^{\prime}$-Ionen-Concentration III 217;

Vergleichung der beim Schaf und beim Menschen gew onnenen Resultate. Einheitliche Erklärung der Genese des Fruchtwassers III 217;

Zusammenfassung und Schlussbetrachtung III 220.

F um a r säureanion, Leitfähigkeit I 155 .

F' un d u l u s, Verhalten gegenüber Steigerung der osmotischen Concentration des Seewassers III 120; gegenüber einer dem Seewasser isotomorischen reinen $\mathrm{NaCl-Lösung} \mathrm{III} \mathrm{120,} 122$.

F u r f u r o l, Permeabilität der rothen Blutkörperchen I 215;

Permeabilität der Pflanzenzellen I 216.

G.

Gährung, Einfluss auf den Verlauf von katalytischen Processen III 93.

Galactose, Permeabilität der rothen Blutikörperchen I 213.

Galle II 443;
Galle:

Gefrierpunkterniedrigung von Blasenund Fistelgalle II 444, 445;

feste Bestandteile II 44.5;

Veränderung von $\perp$ der Leichengalle II 446;

Einfluss von Salz- und Wassereinnalune auf $\lrcorner$ beim Menschen II 447;

elektrisches Leitvermögen II 447.

Galvanischer Strom, Einfluss der Wand auf die Fortbewegungsrichtung der Flüssigkeit durch den galvanischen Strom III 67;

Einfluss der Ladung der Flüssigkeittheilchen III 67;

siehe auch unter Kataphorese.

Galvanometer II 359 ;

Aufstellung II 360 ;

Ablesung II 362.'

Gans, Leitfähigkeit des Serums I 476.

Gaskettes. u. Concentrationskette.

G ast 0 -is o to nische, hyper-und hypisotonische Lösungen II 225, 228. III 321.

G a y - Lu s s a c'sches Gesetz für Lösungen I 32 ;

experimentelle Prüfungen I $32-33$.

Gebärende, Gefrierpunkt des Blutes bei denselben III 217.

Gef färbtes Glas, Verhalten gegenüber Licht III 63.

Gefrierpunkterniedrigung, Berechnung aus dem Leitvermögen I 17;

Beziehung zum osmotischen Druck I 35 ;

von Gemischen : zwei Nichtelektrolyten, zwei Ėlektolyten, einem Elektrolyt mit einem Nichtelektrolyt I 57;

Bestimmung I 63-98; III 305;

ungleiche Werthe bei verschiedenen Experimentatoren I 65;

Einfluss der Kältemischung I 65;

Einfluss des Rührens I 65;

theoretische Betrachtung des Gefrierprocesses nach $\mathrm{Nernst}$ und $\mathrm{Abeg} g$ I 66 ;

das Impfen I 67;

Verfahren von Raoult I 6869 
Gefrierpunkterniedrigung:

Verfahren von Loomis I 69;

Wärmeentwicklung beim Rühren I 69; verschiedene Abkühlungsmittel I 69;

Klopfen des Thermometers I 69;

Unterkühlung I 70;

Genauigkeitsgrenzen I 70, 71;

Linfluss der Concentration (des Volumens der aufyelösten Substanz) I 77 -79 ;

Einfluss des Kühlbades (Tabelle) I 83 ;

Vergleichung der Werthe, erhalten durch directe Beobachtung und durch Berechnung aus dem elektrischen Leitvermögen I $85-88$;

$\Delta$ einer 1 procentigen Kochsalzlösung I 96,472 ;

des Serums, Bestimmung in Blut oder von Serum selbst I 453;

Mangel an Uebereinstimmung der Resultate verschiedener Autoren I 454;

Vorschlag, un dazu zu gerathen I 455;

$\Delta$ des Scrums

beim Menschen I 456, 503, 504;

Rind I 456, 459, 494, 498;

Pferd I 457, 459, 494, 498;

Kaninchen I 457, 459;

Schaf I 457, 459, 494, 498;

Schwein I 457, 459, 495, 498;

Hund I 458, 459, 460, 498;

Katze I 458, 459, 495, 498;

Huhn I 458, 459;

Gallus bankiva, Emys Europaea, Bufo viridis, Rana esculenta. Vergleichende Bestimmungen I 460 ;

Seethiere I 460-466;

wirbellose Seethiere I 462 ;

Alcyonium palmatum I 460; Asteropecten aurantiacus, Asterias glacialis, Holothuria tubulosa, Sipuncnlus nudus, Maja Squinado, Homarus vulgaris, Aplysia limacina, Aplysia depilans, Octopus macropus, Octopus vulgaris I 461;

Wirbelthiere (marine) I 462-466;

Torpedo marmorata Risso, Mustelus vulgaris, Trygon violacea I 463 ;
Gefrierpunkterniedrigung:

$\Delta$ des Serums, Einfluss der Verdünnung I 479;

$\mathrm{CO}_{2}$-reichen Blutserums I 531, 532;

Beziehung von $\Delta$ des Serums zur Leitfähigkeit I 500, 502;

Vorsichtsmaassregel bei der Bestimmung von $\Delta$ I 95. - II 444;

des lackfarbenen Blutes

Pferd I 529;

Schwein I 530;

nach NaCl-Hinzufügung I 531, 532;

der Gewebefliissigkeit in Gehirn, Muskel,

Leber, Niere, Lunge, Milz II 37;

der Cerebro-Spinalfiussigkeit zur Diagnose von tuberculöser Meningitis II 75;

zur Untersuchung des Säure- und Alkalibindungsvermögens von Eiweiss, Pepton und Pepsin II 508;

$\Delta$ von Colloïden III 63 ;

zahlreicher natürlicher Mineralwässer III 286;

einiger künstlicher Mineralwässer III 288:

Kautelen bei der Bestimmung der $\rfloor$ von Mineralwässern, mit Rücksicht auf den $\mathrm{CO}_{2}$-Gehalt III 289, 295, 304, 308;

Initiale Gefrierpunkterniedrigung von Mineralwässern III 304;

Neuere Verbesserungen der Methodik von Gefrierpunktsbestimıung III 304 ff.;

Siehe übrigens unter Beckmann's Gefrierapparat, weiter unter ,Blut" und auderen Substanzen und auch unter "Osmotischer Druck".

Gehirn-Lipoid IJI 245.

Geisselbewegung, Fortbestehen bei Aufhebung des Zusammenhanges der Geisseln mit den Protoplast (bei Flagellaten, Infusorien und Flimmerepithelien) III 332.

Geisselfäden, Ursache der Bewegung der Bacterien III 331.

Geisselstarre durch concentrirte Salzlösungen, unabhängig von Plasmolyse der Zelle III 331. 
Gel III 60 .

Gel at in ir ung, Beeinflussung durclı Ionen II 199;

Siehe Erstarrung III 77.

Gemische, Leitfähigkeit I 48;

von zwei oder mehr Nicht-Elektrolyten,

Gefrierpunkterniedrigung I 57;

von zwei Elektrolyten, Gefrierpunkterniedrigung I 57 ;

von Elektrolyt und Nicht-Elektrolyt, Gefrierpunkterniedrigung I 57.

Gerbsäure, Untersuchung der Permeabilität von Pflanzenzellen für Alkaloüde mittelst derselben III 230.

Ger üst der rothen Blutkörperchen, quantit. Bestimmung I 337-359;

Kritik der Methode I 343. - III 4;

Übereinstimmung mit weissen Blutkörperchen I 338, 339;

Gerüstvolumen der rothen Blutkörperchen beim Pferd I 352, 358; Kaninchen I 353, 358; Frosch I 354, 358; Huhn I 353, 358.

Bestimmung in den weissen Blutkörperchen I 429-422;

der Zellen, ein Kunstproduct III 4;

Künstliche Bildung in Colloidlösung: Studium des Bildungsvorganges unter dem Mikroskop IIL 398;

Einflüsse auf die Grösse der Maschen III 399 ;

auf ihr Offen- und Geschlossensein III 399 ;

Siehe auch Netzstructur und Maschen.

Geschmack, fünftes Kapitel III 169;

von Säuren, Beziehung zur Concentration der $\mathrm{H}$-Ionen III 169;

von Laugen, Bezielnung zur Concentration der $\mathrm{OH}^{\prime}$-Ionen III 170;

von Salzen, Beziehung zum Dissociationsgrad III 171;

Betheiligung von Kationen und von Anionen III 172;

Einfluss der psychischen Hemmung III 174.

Gescliwindigkeit der Osmose I 158.
Geschwindigkeitsconstante (k) bei der monomolecularen Reaction II 467 469 ;

bei der bimolecularen Reaction II 471; Einfluss der 'Temperatur auf diesolbe II 471:

Ostwald 's Tabelle zur leichteren Borechnung II 489;

bei der Katalyse durch colloidale Metalle III $85 \mathrm{ff}$;

der Rohrzuckerinversion mittelst Invertase II 92;

bei der Hämolyse durch Tetanolysin III 364 ;

bei der Hämolyse durch Ammoniak und $\mathrm{NaOH}$ III 367;

Einfluss verschiedener Momente auf $k$ III 368 .

Ge stalt rother Blutkörperchen, Linfluss fremder isotonischer Lösungen I 197 ;

Einfluss des respirator. Gaswechsels I 311 ;

Beeinflussung durch Säure und Alkali I 332-333.

Gew e beflüssigk $\theta$ it, Gefrierpunkterniedrigung in verschiedenen Organen II 36 ;

Abnahme der Gefrierpunkterniedrigung uach dem T'ode II 37 ;

Steigerung des osmotischen Druckes durch Zerfallprodukte, ein Faktor bei der Bildung der Gewebeflüssigkeit II 60 .

Siehe übrigens unter Lymphe.

Gewebelymphe, Unterscheidung von Blutlymphe II 40.

Gew e bespalten, Osmot. Druckregelung in denselben II 146;

Resorption in denselben II 148.

Gewebespannung in Pflanzenzellen, Methode zur Bestimmung des osmot. Diuckes I 164.

Gewicht des Darmes, Factor bei der Erzeugung des intraintestinalen Drucks II 191.

G iftigke it von reinen Kochsalzlösungen und von Na-Ionen III 123; siehe weiter unter Kochsalzlösung; 
Giftigkeit:

von Substanzen für das Protoplasma, untersucht nittelst der Permeabilität von Pflanzenzellen III 223;

für das Protoplasma von Pflanzenzellen (nach Vandevelde) III 232;

von Alkoholen; Steigung der Giftigkeit mit ihrem Moleculargewicht III 234; von fiüchtigen Oelen (Essenzen) III 234; von pflanzlichen und thierischen Extracten III 236;

von Spuren Kupfer für Spirogyra III 241.

Giftspectrum nach Ehrlich, Bekämpfung III $368,380$.

Glas, Löslichkeit I 107, 108;

Beurtheilung des Löslichkeitsgrades I 108, 109;

Reinigung der Gefässe I 108.

G l a skörper, Osmotischer Druck III 165;

Beziehung zu dem des Serums III 166.

Gleichgewicht bei umkehrbaren Reactionen II 476 ;

bei einer theilweise dissociirten Verbindung II 479;

bei einer theilweise hydrolytisch ge. spaltenen Verbindung II 481;

bei Toxin-Antitoxingemischen III 369 .

Gleichgewichtreaction, Auffassung der Enzymwirkungen als -- III 97;

Auffassung der Bindung von Toxin und Antitoxin als - III 371, 378;

Desgleichen bei der Bindung von Borsäure und Ammoniak III 376.

Gletscherwasser, Schädlichkeit III 320.

Glomerulusepithelschicht, Permeabilität II 397, 403.

Glukose, Siehe Traubenzucker.

Glukoseharnst off III 104 .

Glu t arsäu re ani on, Leitfähigkeit I 155.

G lyc erin, Activitäts- und Dissociationscoëfficient I 53 ;

Einfluss auf den Hämoglobinaustritt aus rothen Blutkörperchen I 169;

Permeabilität der rothen Blutkörperchen I 207, 213;

Permeab. d. Pflanzenzellen I 216;
Gly cerin :

Permeab. d. roth. Blutkörperchen und Pflanzenzellen I 218.

G ly c e r ill lösu n gen , Gefrierpunkterniedrigung I 81.

Glykocoll, Permeab. d. r. Blutkörperclien I 209.

Glykogen, Beeinflussung der Umsetzungsgeschwindigkeit durch Alkalien II 514 ; Synthese zu Glukose III 97.

Glykolsäure, Leitfähigkeit I 150.

Glykose, siehe Traubenzucker.

Goldsalze, Desinficirende Wirkung ihrer Kationen bezw. Anionen III 259.

Gonionemus, Giftigkeit einer reinen NaCl-Lösung für denselben III 121.

Granula, als Kunstproducte bei der Fixirung III 400 .

Grove-Element, Elektromotorische Kraft II 380.

H.

Halslymphfistel beim Pferd. Operationstechnik II 35 ;

Hämagglutinin III 359.

Hämase III 93.

Hämatokrit I 226, 515 ; III 315,317 ; trichterförmige Röhrchen I 379;

siehe übrigens Centrifugalkraft und Resistenz gegenüber Salzlösungen.

Hämatokritmethode I 188, 442;

Verfahren und Versuchsergebnisse bei Menschen von C. Eykman I 443 -446 ;

Verfahren und Versuchsergebnisse bei Jenschen von Koeppe I 446-453.

Hämoglobin, Einfluss auf Gallen- und Lymphabsonderung II 57.

$\mathrm{H}$ ä mog lobina stritt aus rothen Blutkorperchen,

Einfluss der Concentration von Salzund Zuckerlösungen auf denselben I 164 ;

Giltigkeit der isotonischen Coëfficienten dabei I 4, 165; 
Hämoglobinaustritt:

Hypothese zur Erklärung der Gesetzmässigkeit bei demselben I 167;

durch Salz- und Rohrzuckerlösungen hoher Concentration I 169;

Vergleichung beim defibrinirten und nicht defibrinirten Blut I 171;

Einfluss der Temperatur auf denselben I 172 ;

Einfluss des äusseren Druckes auf denselben I 173;

Bedeutung vom physikalisch-chemischen Gesichtspunkt I 4, 32;

Einfluss des Aufbewahrens des Blutes auf denselben I 176;

aus Rinderblut I 165-172;

aus Schweineblut I 175;

aus Vogelblut I 175;

aus Fischblut I 177;

aus Amphibienblut I 178;

Grenzlösungen nach Behandlung der Blutk. mit Salzlösungen I 204-206, 236 ;

Beziehung zu der Permeabilität für Ionen I 231;

Gefrierpunkt der Grenzlösungen I 237; durch Bacteriengifte I 261;

durch Saponin I 261;

s. w. u. Farbstoffaustritt, Hänolyse und Ricsistenz.

H ämoglobinurie, Osmotischer Druck des Blutes I 471.

Ḧ̈moIyse, Gefrierpunkt und Leitvermögen des Blutes nach derselben durch fremdes Serum I 533;

durch StehenIassen I 535;

durch Gefrieren und Aufthauen, Saponin, Hitze I 535;

durch Condensatorentladungen I 536;

durch Ascitesflüssigkeit II 73;

Bedeutung für die Immunitätslehre III 339 ;

Mechanismus derselben, Theorie von Bordet I 395 . - III 344;

Theorie von Ehrlich III 345 ;

Beziehung zum Gehalt eines Exsudats an Makro- und Mikrophagen III 354; Bedeutung des Lecithins III 357;

$\mathrm{H}$ a m burger, Osmot. Druek. III. Band.
Haimolyse in heterogenem Serum, veranlasst durch osmotische Störung (v. Baumgarten) III 358, 363;

Volumänderung der Blutkörperchen durch hïmolytische Agentien und in heterogenem Serum IlI 360, 362, 363; Reactionsgeschwindigkeit bei der Hämolyse durch Bacteriengifte III 36 ? ff.; durch Ammoniak und $\mathrm{NaOH}$ III 367.

Häm ol y s in bildung, vom Standpunkte des Massenwirkungsgesetzes III 380.

$\mathrm{H}$ äm oly s in componenten, Synonima III 351.

Hä molysine, Eintheilung III 340 ; bei niederen Thieren und in Drüsensecreten III 343 ;

des Blutserums III 343;

Complexe Natur derselben (Receptor + Complement) III 349, 350;

Zusammensetzung aus thermostabiler und thermolabiler Substanz III 350; Bindung durch Antihämolysin III 382 ; Fixationsmodus seitens der Blutkörperchen III 385 .

Hämoly sinw ir kung, Immunisirung gegen dieselbe III 352.

Hämolytisches Serum I 394-400;

Bereitung I 395;

Vergleichung zwischen hämolytischer und antibacterieller Wirkung I 396 , 397 ;

Zusammenfassung und Diseussion der Ansichten Bordet's und Ehrlich's über den Wirkungsmechanismus III 354.

Haptin III 351.

Haptophore Gruppen (Seitenkettentheorie) III 345 ;

des Complementes III 351 .

Harn, Bcziehung zwischen Gefrierpunliterniedrigung und Kochsalzgehalt $\left(\begin{array}{c}\lrcorner \\ \mathrm{Y}_{\mathrm{C}} \mathrm{Cl}\end{array}\right)$

II 250, 268, 271;

viät II 250,256 ;

Incompensirte Herzfehler II 251;

Nach Digitalis- u. Diuretingabe II 252;

Tagesschwankungen II 253;

Muskelarbeit II 25:3, 255; 
$\mathrm{H}$ a I n :

Nahrungsaufnahme II 254;

Atmosphärische Einflüsse II 254;

bei Herzkranken II 257, 262 ;

bei Nierenkrankheiten II 264, 292 ;

bei beschleunigter Nierencirculation II 265 ;

bei fieberh. Krankheiten II 265;

$\Delta$ und $\frac{\Delta}{\mathrm{NaCl}}$ bei Stauungsharn II 272 ;

$\Delta$ und $\frac{\Delta}{\mathrm{NaCl}}$, Abhängigkeit von der

Nahrung II 272;

\section{Gefrierpunkternicdrigung}

bei normalen Personen II 279, 297, 317; Einfluss der Urate bei der Gefrierpunktbestimmung II 303 ;

Grenzen für $₫$ II 317 ;

des Harlus beider Nieren II 283 ;

Bedeutung der Nalıung bei der Untersuchung II 273;

Untersuchungen von $\mathrm{Cl}$ a $\mathrm{ude}$ u. Baltha z a r d über Diagnose der Niereninsufficienz II 273, 323;

bei Anämie und Nephritis II 265;

bei Cystitis und Pyelitis II 267 ;

bei chronisch interstit. und chronisch parenchymat. Nephritis II 289 ;

bei Nierenentziindungen, Einfluss der Nahrungsbedingungen II 290 ;

bei acuten Nephritiden II 292;

Lcitfähigkeit II 318;

Leitfähigkeit des Harns beider Nieren II 283;

Parallellismus zwischen Gefrierpunkterniedrigung und Leitfähigkeit II 283 ;

$$
\begin{aligned}
& \frac{1}{\text { spec. Gew. }-1} \text { II 294, 296, 324 ; } \\
& \text { specif. Leitfähigk. } \\
& \text { Aschengehalt }
\end{aligned}
$$

Concentr. organ. Molec.

Concentr: anorg. Molec. II 295 ;

$$
\frac{\Delta}{\text { Leitfäligkeit }} \text { II 295, 323, 325; }
$$

H a r' $n$ :

Concentr. d. Elektrolyte

Collcentr. d. org. Molec. II 297 ;

Untersuchung durch Gefrierpunkt- und Blutkörperchenmethode II 298, 325;

Zusammenfassung der Errungenschaften der Kryoskopie und Leitfähigkeitbestimmung für die Pathol. d. Nierentlütigkeit II 308-236; Schlussbetrachtung II 326;

Urotoxischer Coefficient II 327 ;

Refractometrische Untersuchung II 329;

Elektrochemische Aciditätsbestimmung II $330 \mathrm{ff}$;

Aenderung in der Zusammensetzung des Harns bei Harnstauung II 406, 419;

Herbeiführung alkalisch. Reaction durch NaCl-Gabe II 442.

Siehe die Behandlungsweise des Harns aus pathologischem Gesichtspunkt in Inhaltsverzeichniss zu Bd. II, S. VII und über den Harll aus physiologischem Gesichtspunkt, unter "Nierenthätigkeit".

Haru unà Blut, Untersucliungen von von Korány i II 250 ff.;

Untersuchungen von L. Linde mi nn II $266 \mathrm{ff}$.

Harnabsonderung bei hydrämischer Plethora II 17 ;

bei venöser Stauung II 419.

$\mathrm{H}$ a $\mathrm{r}$ n a $\mathrm{c}$ i d i ä t, siehe Acidität des Harns.

H a rnblasenepit hel (isolirtes), Permeabilität für Harnstoff II 241.

$H$ a $r$ u l u th bei intravenöser Injection hyperisotonischer Lösungen II 12;

$\mathrm{S}$. übrigens Harn und Diurese.

H a r n s ä u r*e, Löslichkeitsverhältnisse, Beeinflussung durch hinzugefïgte H.Ionen III 272;

und harnsaures Natron, Bedeutung der Löslichkeitsverhältnisse für die Auflösung von Concrementen III 277;

Beeinflussung d. Löslichkeit durch Hinzufügung voll $\mathrm{NaCl}$ III 277.

Harnstau ng, Einfluss auf die Zusammeusetzung II 406. 
Ha r n st o f f, Kinfluss auf den Hämoglobinaustritt aus rotlien Blutkörperchen I 169;

Permeab. der rothen Blutkörperchen I 207, 208, 215;

Permeab. der Pflanzenzellen I 216;

Permeab. d. rothen Blutkörperchen und Pflanzenzellen I 218, 220;

Resorption im Darm II 201;

Permeabilität der Harnblasenschleimhaut II 238;

Einfluss auf den osmotisclıen Druck von $\mathrm{NaCl}$-Lösungen II 240 ;

Permeabilität des isolirten Harnblasenepithels II 241;

Anwendung für die Auflösung von Concrementen III 279 ;

Haut von Fröschen, Permeab. II 24.

Ha utöde un II 87; s. auch Anasarca.

Hefepresssaft III 96.

$\mathrm{Herz}$, Giftigkeit einer reinen $\mathrm{NaCl}$ -

Lösung III 122;

Bedeutung der $\mathrm{Ca} \cdots$-Ionen für die normale Thätigkeit IlI 122; bei den therapeutischen Salzwasserinfusionen III 123 ;

Giftigkeit von Rohrzucker und auderen Nicht-Elektrolyten, Linderung der Toxicität durch Hinzufügung von $\mathrm{NaCl}$ III 145 ;

Ersatz von $\mathrm{Cl}^{\prime}$ durch $\mathrm{Br}^{\star}$ und $\mathrm{I}^{\prime}$ beim isolirten Froschberzen III 2s1; Verhalten des Kaninchenherzens dabei III 282.

Herzkrankheiten, Osmot. Druck des Blutes I 470, 471, II 260.

NaCl-Gehalt des Blutserums II 260;

Entscheidung über die Frage, ob die Zunahme von $\Delta$ und Abnahme von $\mathrm{NaCl}$ von einer Nierenerkrankung oder von einem incompensirten Herzfehler herrührt II 264;

$\Delta$ und $\mathrm{Cl}$ des Blutserums II 265.

Histologische Fixirung von Selachiergehirn in Müller'scher Flüssigkeit I 463.

Histologisches, Zehntes Kapitel III 395.
Halogene, Desinficirende Wirkung III 264.

Hom og ene $\mathrm{N}$ e mbranen (künstliche), Nachahmung der Resorption mittelst derselben II 110 ;

Apparat zum Studium der Gesetze von

Filtration und Osinose strömender Flüssigkeiten II 113; siehe auch Bd. II, Tafel I.

Ho in ö op a th ie, Heranziehung der Ionenlehre zur Erklärung der „Dynamisirung III 240.

Homotonisch II 195.

Humor aquaeus, Osmotischer Druck III 163 ;

Beziehung zu dem des Blutserums III 165.

Hund, Leitfähigkeit des Serums I 476,477;

Osmotische Concentration des Serums I 492;

Gefrierpunkterniedrigung, specifisches Gewicht, Leitfähigkeit, Eiweiss-, NaClGehalt des Serums I 495;

Concentration der Nicht-Elektrolyte, Elektrolyte, Achloride des Serums I 497, 498;

chemische Zusammensetzung von Blut, Serum und Blutkörperchen I 506, 507.

Hydrämie, Regelung des osmotischen Druckes und Aenderung des Blutplasma bei $\mathrm{H}$. II $20-22$;

Farbstoffaustritt aus den rothen Blutkörperchen bei H. II 25-28.

Hydrämische Plethora bei Niereninsufficienz I 473;

Regelung des osmotischen Druckes und Aenderung des Blutplasma II 3;

Betheiligung der Nieren, Speichel- und Thränendrüsen II 15;

Regelung des osmotischen Druckes bei Unterbindung der Nierenarterien II 14, 15;

Zusammenfassung II 16;

Farbstoffaustritt aus deu rothen Blutkörperchen II 25;

als Ursache von Oedem und Hydropss II 85. 
Hyaloplasma III 403 .

Hydrallanto isf 1 ü s sigke it, Gefrierpunkterniedrigung III 221.

Hydrogel III 60.

$\mathrm{Hydrolyse}$ II 481 ;

Ermittelung des Grades der Hydrolyse II 484;

bei der osmotischen Analyse des Mineralwassers III $301 \mathrm{ff}$.

Hydrolytische Spaltung IlI 230;

im Serum I 482;

von $\mathrm{KCN}$ II $4 \varepsilon 1$;

von $\mathrm{Na}_{2} \mathrm{CO}_{3}$ II 483 ;

von stearinsaurem Natron II 484;

von $\mathrm{ZnCl}_{2}$ II 484 . - III 425;

von Gerbstoff-Coffein III 230;

von Anilinfarbsalzen III 425.

Hy drops, siehe Oedem.

Hydrops cachecticus II 78 .

Hydrops inflammatorius II 75.

Hydropsie cardiaque II 75.

Hydrosol III 60.

H y dros or bi n s ä u re, Leitfähigkeit I 150 .

Hy drox y l-Gr u p pe, Einfluss deren Zahl in Alkoholen auf die Permeabilität von Blutkörperchen für dieselben I 216.

Hy droxyli on, Wanderungsgeschwindigkeit (Leitfähigkeit) I 9, 42, 138, 148;

Concentration im Serum. Bestimmung durch die Concentrationskette I 510; Controle der Bestimmung mittelst der $\mathrm{H} \cdot-$ Ionen-Concentration II 386 ;

Beispiel einer Bestimmung der $\mathrm{OH}$ Ionen-Concentration II 387;

Siehe unter Concentrationskette.

Hyperacidität, Bekämpfung auf osmotischem Wege II 224, 231.

Hyperisotonisch I 187.

Hyperisotonische Ingesta bei Hyperacidität und bei motorischer Insufficienz des Magens II 224, 231.

Hyperisotonische Lösungen, Intravenöse Injection II 3,16 ;

Läsion von Zellen und Kernen durch hohe Concentrationen III 27.

Hyperosmotisch I 472 .
Hypersthenurie II 256, 321.

Hypertrophie des Muskels. Steigerung des osmotischen Druckes in der Muskelsubstanz III 114.

Hypisotonisch I 187.

Hypisotonische Lösungen, Intravenöse Injection II 10, 16.

Hyposmotisch I 472.

Hyposthenurie II 256, 321.

$\mathrm{Hy}$ steresis III 85.

Hysterie, Osmotischer Druck des Blutes I 451.

I.

i, Ableitung aus dem Activitätscoëfficient (a) I 10 ;

Ableitung aus der Gefrierpunkterniedrigung I 10;

Berechnung aus dem Leitvermögen I 52;

Berechnung aus dem osmotischen Druck I 54 ;

Anwendung bei der Untersuchung der Permeabilität der rothen Blutkörperchen I 225, 226, 230.

I m bibiti on, Thätigkeit bei der Resorption II 108, 164;

von Flüssigkeit durch Agarplättchen II 212 ;

bei der Wasseraufnahme der Muskelsubstanz durch Säuren III 114.

Imidi onen, Leitfähigkeit. Succinimid, Acetylcyanamid, Cyanimidokohleusäureäther, Benzoylcyanamid, Azimid I 148.

I $m$ m un is i rung gegen Hämolysinwirkung III 352.

Immunität, Ansichten von Sleeswyk über ihr Wesen III 387 ff.

I mm unkörper III 351.

I nactive Molecüle I 40, 52 .

Indicat oren, Theorie I 60.

Indifferente und basische Narkotica III 245.

Induct orium für die Leitfähigkeitsbestimmung I 100 ;

Stromunterbrecher I 101; 
Inductorium:

Tonhöhe I 101;

Stromquelle I 101;

Aufstellung I 118.

Infection, Ansichten von Sleeswyk über ihr Wesen III 388 ff.

Initiale Gefrierpunktserniedrigung III 304.

Inosit, Permeabilität der rothen Blutkörperchen I 209.

Inotagmen I 403.

In sufficientia aortae, osmot. Druck des Blutes I 471;

Mitralis, osmotisch. Druck des Blutes I 471.

Interepitheliale Kittsubstanz bei der Darmresorption II 217.

Intra abdominaler Druck, Einfluss auf intraperitoneale Resorption II 118.

Intraglobulare Krystallbildung in rothen Blutkörperchen I 170;

Krystallisation von Hämoglobin in Fischblntkörperchen I 182.

Intraintes t in a le r Druck, Einfluss auf die Resorption im Darm II 174, 193; negativer intraintestinaler Druck II 188 , 194 ;

Factoren zur Erzeugung des intraintest. Drucks im normalen Leben II 191.

Intrameabel I 162. - II 28.

Intraperito neale Injection hyperisot. Lösungen. Osmotischer Druck der Blutflüssigkeit nach Unterbindung der Nierenarterien II 15;

Siehe unter Resorption in der Bauchhöhle.

Intrauterine Verhältnisse des Stoffaustausches zwischen Mutter und Frucht III 182.

Intravenöse Injection von Seewasser II 2. - III 124.

von Traubenzucker II 2;

von Natriumsulfat, Kochsalzlösung II 2; Verschwinden aus der Blutbahn II 2.

Intravitale Färbung. Bedingung III 424.

Inversion von Saccharose als Methode zur Ermittelung des Grades der Hydrolyse II 4\&6;
Inversion:

zur Ermittelung der freien Säure im Magensaft II 493 ;

Beeinflussung durch die Gegenwart neutraler Salze Il 501;

durch Säuren, Proportionalität zwischen Inversionsgrad und Concentration der H-Ionen II 494, 502 ;

Methode II 494.

Anwendung auf die Untersucirung des Säurebindungvermögens von Eiweiss und Pepton II 506;

Geschwindigkeitsconstante bei der Inversion durch Invertase III 92;

Auffassung der Rohrzuckerinversion als reversible Raction III $97 \mathrm{ff}$;

Prüfung von H e n ri's Zahlen aus diesem Gesichtspunkt III 99, 102.

Inversionsconstante (k) II 495; vergleichende Zahlen für Salzsäure, Salpetersäure, Chlorsäure, Schwefelsäure, Benzolsulfosäure, Trichloressigsäure, Dichloressigsäure, Monochloressigsäure, Ameisensäure, Essigsäure II 500.

Ionen I 7 ;

Unterscheidung in actuelle und potentielle II 494 (siehe weiter unter actuell und potentiell);

lonen bei complexen Salzen und bei Doppelsalzen III 254.

Leitfähigkeit einiger Ionen I 9;

siehe weiter unter Leitfähigkeit und unter den verschiedenen Ionen.

I onenacidität II 383,390 .

I onenaustaush bei Ionenproteïden III 124;

bei der giftigen Wirkung reiner Salzlösungen III 130.

I o nen-Geschwindigkeit, Abhängigkeit von ilırer Natur und Zusammensetzung I 46 ;

Bedeutung bei der Lymphbildung Il 65.

I o nenlehre, siehe electrolytische Dissociation;

in der Homöopathie, siehe Homöopathie.

Ionen proteïde III 118;

ihre Bedeutung III 120 ff.; 
Ionenproteïde:

Austausch von Kationen bei Einwirkung reiner Salzlösungen IIl 124;

aufgefasst als lockere Verbindungen nach veränderlichen Verhältnissen (vom Standpunkte der Phasenlehre) III 132 .

I o n i s ir u $\mathrm{ng} \mathrm{s} g \mathrm{r}$ a d von Mineralwässern III 291, 297, 307.

Is o butte rsäure, Leitfähigkeit I 150 .

Isobutylaldehyd, Permeabilität der Pflanzenzellen I 216.

lsobutylalkohol, Permeabilität der rothen Blutkörperchen I 215;

Permeabilität der Pflanzenzellen I 216.

Is obutylschwefelsäure, Leitfähigkeit I 152.

Isoelektrisch III 68.

Isoelektrischer Punkt III 77.

Is olirte Zellen, osmotisches Verhalten

III 1 ;

Kritik, Zusammenfassung und Discussion der Ausführungen über Epithelzellen III 33 ;

siehe weiter unter den betreffenden Zellen.

Is olysin I 398.

I s o m e re I o ne n, Wanderungsgeschwindigkeit I 46.

Is opropylalkohol, Permeabilität der roten Blutkörperchen I 215;

Permeabilität der Pflanzenzellen I 216.

Is o smotisch, Aufsuchen einer Lösung, die isosmotisch oder isotonisch mit einer anderen ist I 97; siehe isotonisch.

I s o smo tische Lösungen verschiedener Concentration. Einfluss auf das Volumen der Blutkörperchen I 191-196.

Is otonisch, Berechnung der Concentration einer Lösung, die mit einer anderen isotonisch ist I 19;

mikroskopisclies Verhalten von Froseh. blutkörperchen in mit dem Serum isotonischen Lösungen I 179, 182.

Isotonische Coëfficienten I 3, 23, 161, 163;

Gesetz I 4, 24;
Isotonische Coëfficienten:

Berechnung isotonischer Lösungen mittelst derselben I 4;

Giltigkeit bei deu rothen Blutkörperchen I 4, 27;

von organischen metallfreien Verhindungen, von Alkalisalzen der einbasischen Säuren, von neutralen Alkalisalzen der zweibasischen und dreibasischen Säuren, von Erdkalisalzen der einbasischen Säuren I 3, 24;

Beziehung zum osmotischen Druck oder zur wasseranziehenden Kraft oder zur Gefrierpunkterniedrigung I 11;

Anwendungsweise I 19, 24;

Bestätigung I 25;

ansführlichere Behandlung I 21-28;

Beziehung zur Dampfspannung I 25, 58 ;

Beziehung zur Gefrierpunkterniedrigung I 25, 58;

historische Bedeutung I 28;

Deutung durch die Theorie des osmotischen Drucks und der elektrolytischen Dissociation I 58, 59;

Hypothese zur Erklärung der Gültigkeit bei den roten Blutkörperchen I 167.

Isotonische Concentrationen, Berechnung mittelst der isotonischen Coëfficienten I 163;

Berechnung mittelst der Blutkörperchenmethode (Farbstoffaustritt) I 166.

Itaconsäureanion, Leitfähigkeit I 155 .

J.

Jod, Festlegung von Jod bei Injection von Jodiden nach Verblutung III 281;

$\mathrm{J}$ o d i o $\mathrm{n}$, Wanderungsgeschwindigkeit (Leitfähigkeit) I 42, 138, 148.

Jodka lium, Activitäts- und Dissociationscoëfficient I 53;

Permeabilität der rothen Blutkörperchen I 208. 
Jodka lium lösungen, Leitfähigkeit I 129, 132;

Einfluss auf den Hämoglobinaustritt aus rothen Blutkörperchen I 166.

Jodnatrium] ösung, 」 und i I 97;

Leitfälrigkeit I 132;

Einfluss auf den Hämoglobinaustritt aus rothen Blutkörperchen I 166.

$\beta$ - Jodpropionsäure, Leitfäligkeit I 150.

Jodsäureanion, Leitfähigkeit I 149.

Jod wasserst of f, Activitäts- und Dissociationscoëfficient I 53 .

Joule II 300.

J ugularis - und Carotisblut. Volumen der rothen Blutkörperchen I 296-299; Vergl. von 4 des Jugul.-Bl. mit der aus der comprimirten Jugularis und der Carotis I 467.

k.

Kachektisches Oedem II 88 .

Kakodylsäure, Leitfähigkeit I 152.

Kalbskrankheit II 313.

K a li um, Permeab. d. r. Blutkörperchen I 228.

Ka liuma cetatlösungen, Leitfahigkeit I 130.

Einfluss auf den Hämoglobinaustritt aus rothen Blutkörperchen I 165.

Ka liumbichromatlösung, Einfluss auf das Volumen der Blutkörperchen I $190,224$.

Kaliumbisulfat $l o ̈ s u n g e n$, Leitfähigkeit I 132.

Kaliumbromid, siehe Bromkalium.

Ka lium carbonat, Activitäts- und Dissociationscoëfficient I 53 ;

Permeab. d. roth. Blutkörperchen für I 226.

Ka liumcarbonatlösungen, Gefrierpunkterniedrigung I 87 ;

Leitfähigkeit I 130.

Ka liumchloratlösungen, Leitfähigkeit I 130, 131.
Ka liumchlorid siehe Chlorkalium.

líaliumby droxydlösungen, Gefrierpunkterniedrigung I 88 :

Leitfähigkeit I 131.

Kaliumion, Wanderungsgeschwindigkeit (Leitfähigkeit) I 9, 42, 137, 142.

Kalium jodid siehe Jodkalium.

Kaliumnitrat, Activitäts- und Dissociationscoëfficient I 53 ;

Permeab. d. r. Blutkörperchen I 212, $224,225$.

Kaliumnitratlösungen, Gefrierpunkterniedrigung I 87;

Leitfähigkelt I 129, 132;

Einfluss auf den Hämoglobinaustritt aus rothen Blutkörperchen I 165;

Ka liumnitritlösungen, Leitfäligkeit I 132.

Kaliumpermanganat $t$ ös ungen, Leitfähigkeit I 132 .

Kaliumphosphat-(secundäres)lösunge n, Gefrierpunkterniedrigung I 88 .

Kaliumsulfat, Permeabilitait der rothen Blutkörperchen I 212, 222, 223, 225 ;

Activitäts- und Dissociationscoëfficient I 53.

Kaliumsulfatlösungen, Gefrierpunkterniedrigung I 86 ;

$\triangle$ und $\mathrm{i}$, I 97 ;

Leitfähigkeit I 130, 132;

Ëinfluss auf den Hämoglobinaustritt aus rothen Blutkörperchen I 165.

Kan inch $\theta$, Leitfähigkeit des Serums I 476 ;

chemische Zusammensetzung von Blut, Serum, Blutkörperchen I 506, 507;

Katalyse II 465 . - III 80 .

bei organischen Fermenten II 475;

Ostwald's Definition III 80;

von $\mathrm{H}_{2} \mathrm{O}_{2}$ durch colloidales Platin, Reactionsverlauf III 84;

Einfluss von Temperatur und Menge des Katalysators auf Reactionsgeschwindigkeit III 85;

Lähmung der Katalyse III 86; 
Katalyse:

durch Platin und durch Wasserstoffionen, verghichen mit der durch organische Fermente III 91 ff.;

Einfluss der Gährung III 93;

Reversibilität der Reaction III 94;

Ansichten über das Wesen derselben III 104;

bei der künstlichen Parthenogenesis III 180 ;

bei der Befruchtung durch Spermato. zoen III 181.

Katalytische Wirkung von Emulsin auf Salicin III 93;

Beeinflussung durch Alkali und andere Stoffe III 94.

Kataphorese II 434 ff. - III 61; bei deì Magensaftbildung II 443.

K a t a r a t, durch Einführung von Salzlösungen in den Conjunctivalsack III 166.

Kationen I 8.

Katze, Leitfähigkeit des Serums I 476, 477 ;

osmotische Concentration des Serums I 492;

Gefrierpunkterniedrigung, specifisches

Gewicht, Leitfähigkeit, Eiweissgehalt,

$\mathrm{NaCl}$-Gehalt I 495 ;

Concentration der Elektrolyte, Nicht-

Elektrolyte, Achloride I 497, 498;

chemische Zusamınensełzung von Blut,

Serum und Blutkörperchen I 506, 507.

Kerne, Volumänderung durch anisotonische Lösungen I 359.

des Darmepithels:

Dimensionsänderungen durch anisototonische Salzlösungen (mikroskopische Messungen) III 19, 36;

des Tracheaepithcls:

Dimensionsänderungen durch anisotonische Salzlösungen (mikrosk. Messungen) III 23, 36 ;

des Harnepithels:

Dimensionsänderungen durch anisotonische Salzlösungen III 26, 36 ;

Läsion durch stark hyperisotonische Lösungen III 27.
Kerntheilungsfiguren als eine Aeusserung dynamischer Natur III 402.

Ke to ne, Permeab. d. r. Blutkörperchen 1215.

Permeab. d, roth. Blutkörperchen und Pflanzenzellen I 219.

K ind li ch es Blut, siehe mütterliches und fötales Blut.

Kittsubstanz, Verhalten bei der Resorption II 200;

bei der Darmresorption II 217;

Bedeutung für die Impermeabilität der Schleimhaut des Blasenepithels II 244 ;

des Darmepithels; verschiedenes Verhalten an verschiedenen Theilen des Darmes III 18.

Kobalt c y a nwasserst of fsäurea ni o n, Leitfähigkeit I 156.

Kochsalzäquivalent II 257.

K ochsalz lösung, Gefrierpunkterniedrigung einer einprocentigen I 96, 472; ein Gift für den Muskel III 120:

für Fundulus III 120, 122;

für Gonionemus IIl 121;

für Cilienbewegungen III 121;

für das Herz III 122;

für das Lymphherz des Frosches IlI 122 ;

s. w. u. Chlornatriumlösung.

Ko ohlensäure als Verunreinigung destillirten Wassers. Einfluss auf dessen Leitfähigkeit I 107;

Einfluss anf die Vertheilung der Blutbestandtleile auf Körperchen und Flüssigkeit I 261; auf den Farbstoffaustritt I 261, 295; anf die Zusammensetzung des Serums I 262 295; auf das Volumen der rothen Blutkörperchen I 291-299;

Umkehrbarkeit des Prozesses 1 263;

Einfluss auf das antibacterielle Vermögen des Serums I 286;

Bindungsvermögen von Cruor und Serum für Kohlensäure I 299;

Erklärung der durch $\mathrm{CO}_{2}$ im Blute herbeigeführten Erscheinungen 1 299310 ; 
Kohlensäure:

Einfluss auf das Volumen der Blutkörperchen. Erklärung von K o e p pe I 301-304; von $\mathrm{Ha} \mathrm{mburger}$ I 304 $-306,309,310$;

Einfluss auf die Alkalinität des Blutserums I 300; Erklärung von Zun tz I 300; von Gürber I 300; von Koeppe I 301-304; von Hamburger I 304-306, 309, 310;

Einfluss auf den Chlorgehalt des Serums; Erklärung von $G \ddot{u r b e r}$ I 300; von Koeppe I 301-304; von Hain burger I 306-309, 310;

Einfluss auf Gestalt der rothen Blutkörperchen I 311 ; sichtbar bei Carotis- und Jugularisblut und bei venöser Stauung I 312 ; bei Vogelblut 1 313; scheinbarer Gegensatz zwischen den Resultaten von Volumbestimmung und mikroskopischer Messung I 315;

Einfluss auf Volumen und Dimensionen der weissen Blutkörperchen I 403-405;

Einfluss auf die Alkalinität der serösen Flüssigkeit von Leukocytenaufschwemmungen I 405-408;

auf deren antibacterielle Wirkung I 409; Einfluss auf Chemotaxis I $413-416$;

Einfluss auf die Aufnahmefähigkeit der Phagocyten I 416-418;

Einfluss auf die Vertheilung der Blutbestandtheile über Blutkörper'chen und Serum; Umkelırbarkeit durch O-Inhalatationen II 261;

Einfluss auf das Volumen des Nierenepithels II 419;

der Mineralwasser, Berücksichtigung bei der Depressionsbestimmung III 289, 295, 304, 308.

Kohlensäureanion $\left(\mathrm{CO}_{3}^{\prime \prime}\right)$ Wanderungsgeschwindigkeit (Leitfähigkeit) I 138, 154;

Permeabilität der rothen Blutkörperchen I 229.

Korksäureanion, Leitfähigkeit I 155. Kostma as bei der Untersuchung von $\Delta$ des Harns u. des Blutes II 270.
Krebsm uskelextract, Beschleunigende Wirkung auf Lymphstrom II 43.

Kiritische Concentration I 193;

- Lösung III 233;

- Coëfficienten Ill 234.

Kryohydrat I 69.

Kryoskopie, Siehe Gefrierpunkterniedrigungsmethode.

Krystallbildung, intraglobulare, in rothen Blutkörperchen I 170.

K ünstliche Parthenogenesis, siehe Parthenogenesis.

Kupferdraht, Widerstandsgr. I 114.

Kupferion, Leitfähigkeit I 153;

lí upfersalze, Giftigkeit für Lupinenkeimlinge III 258;

Desinficirende Wirkung ihrer Kationen, bezw. Anionen III 258;

Parallelismus zwischen Giftigkeit für Penicillium glaucum und Concentra. tion der Kupferionen III 268.

Kupfersulfatlösungen, Leitfähigkeit I 130

Kurzschluss II 379.

L.

Lackfarbenes Blut, Gefrierpunkteiniedrigung.

von Blut, das lackfarben gemacht ist durch Gefrieren und Autthauen I 529, 530 ;

desgleichen nach vorheriger Behandlung mit $\mathrm{CO}_{2}$ I 530,531 .

Leitiermögen und Gefrierpunkterniedrigung von Blut, das lackfarben gemacht ist durch fremdes Serum I 533 ;

durch Stehenlassen I 535;

durch Gefrieren und Authauen I 535; durch Saponin I 535;

durch Hitze I 535;

durch Condensatorentladungen I 536;

La ct o se, Permeab. d. rothen Blutkörperchen I 209.

L a d ung, s. elektrische Ladung IlI 125.

$\mathrm{L}$ a h m ung d. Platin- $\mathrm{H}_{2} \mathrm{O}_{2}$-Katalyse III $₫ 6$; bei organischen u. anorganischen Katalysatoren III 94. 
L ävuloselösungen, Gefrierpunkterniedrigung (Tabelle) I 81.

Lebensdauer, Verlängerung d. Cyankalium III 182.

Leberparencliymzellen, Volumzunahme durch Kohlensäure und andere Säuren und Volumabnalıme durch Alkali III 50 ;

Volumänderungen durch anisotonische Salzlösungen III 54 .

Lecithin, Bedeutung für die Nierenthätigkeit II 411;

Bedeutung für die Narkose III 245;

Bedeutung für die Hämolyse III 357;

Bedeutung des Gehalts der Zelle f. die intravitale Färbung III 425.

L e clan ch é - E l e ment, Elektromotorische Kraft II 380 .

Lei mplatten, Farbstoffaufnahme nach dem Theilungsprincip III 418.

Leitfähigkeit der meist vorkommenden Ionen I $137 \mathrm{ff}$;

S. für die meist vorkommenden Ionen und thierischen Flüssigkeiten auch unter den Namen der Iunen und Flüssigkeiten selbst;

siehe auch unter Wanderungsgeschwindigkeit

a) einwerthiger anorganischer Kotionen: Lithium I 142;

Natrium I 142;

Kalium I 142;

Rubidium I 142;

Cäsium I 142;

Silber I 142;

Thallium I 142 :

Carbonatokobalttetrammonium I 142.

b) einwerth. orgunischer Ammoniumionen:

Ammonium I 142;

Methylainmonium I 142;

Guanidin I 142;

Athylammonium I 142;

Dimetliylammonium I 142;

$\beta$-Bromäthylammonium I 143 ;

Propylammonium I 143;

Isopropylammonium I 143;

Allylammonium I 143 ;

T'rimethylammonium I 143;
Leitfähigkeit:

Isobutylammonium I 143;

Methylätliylkarbinammonium I 143 ;

Trimethylkarbinammonium I 143;

Diäthylammonium I 143;

Tetramethylammonium I 143;

Jodmethyltrimethylammonium I 143;

Isoamylammonium I 143;

Piperidinum I 143;

Methyldiäthylanmonium I 143;

Vinyltrinethylammonium I 143;

Trimethyläthylammonium I 143;

$\beta$-Chloräthyltrimethylammonium I

143 ;

$\beta$-Bromäthyltrimethylammonium I

143 ;

Dipropylammonium I 143;

Triäthylammonium J. 143:

Pyridinmethylium I 143;

Trimethylallylammonium I 143;

Trimethylpropylammonium I 143;

Dimethyldiäthylammonium I 143;

Benzylammonium I 143;

Pyridinäthylium I 143;

Picolinmethylium I 144;

Trimethylisobutylammonium I 144;

Nethyltriäthylammonium I 144;

Jodmethylitriäthylammonium 1 144;

a-Lutidinmethylium I 144;

$\alpha$-Picolinäthylium I 144;

Coniin I 144;

Diisobutylammonium I 144;

Trimethylisoamylammonium I 144;

'Tetraäthylammonium I 144;

'Trimethylphen ylammonium I 144;

Tripropylammonium I 144;

Triäthylallylammonium I 144;

Triäthylpropylammonium I 144;

Chinolinmethylium I 144;

Isochinolinmethylium I 144;

Dimethyläthylphenylammonium I 144;

Phenocoll I 144;

Nenthylammonium I 144;

Diisoamylammonium 1 144;

Triäthylisobutylammonium I 144;

Triäthylisoamylammonium I 144;

Trimethyl- $\alpha$-Naphtylammonium I 144;

Trimethyl- $\beta$-Naphtylammonium I 144; 
Leitfähigkeit:

Morphin I 145;

Cocaïn I 145;

Rechtscocaïn I 145;

Morphinmethylium I 145;

Lodeïn I 145;

Akonitin I 145 ;

c) Phosphoniumionen:

(einwerthige Kationen):

Tetramäthylphosphonium I 145;

Teträthylphosphonium I 145;

Methyltriphenylphosphouium I 145;

Aethyltriphenylphosphonium I 145;

Propyltriphenylphosphonium I 145;

Isoamyltriphenylphosphonium I 145;

Triphenylbenzylphosphonium I 145;

Tetrabenzylphosphonium I 145;

d) Arsoniumionen:

(einwerthige Kationen);

Tetramethylarsonium I 145;

Teträthylarsonium I 145;

e) Stiboniumionen:

Tetramethylstibonium I 145;

Teträthylstibonium I 145 ;

f) Sulfiniumionen:

(einwerthige Kationen);

Trimethylsulfinium I 146 ;

Triäthylsulfinium I 146;

g) Telluriniumionen;

Trimethyltellurinium I 146;

Triäthyltellurinium I 146 ;

einwerthige Diam on iu mi o $n$ en:

Hydrazin I 146;

Aethylendiammonium I 146;

Cinchonin I 146;

Cinchonidin I 146;

Chinin I 146;

Strychnin I 146;

Brucin I 146;

Strychninäthylium I 146;

Strychninbromäthylium I 146;

Brucinäthylium I 146 ;

Brucinbromäthylium I 147;

Brucinisoamylium I 147.

i) Kationen der hydrolytisch spaltbaren

Chlorhydride.

Pyridin I 147;
Leitfähigkeit:

Anilin I 147;

a-Picolin I 147;

Dimethylpyridin I 147;

Aethylpyridin 1 147;

Methylanilin I 147:

o-Toluidin I 147;

m-Toluidin I 147;

p-Toluidin I 147;

asym. m-Xylidin I 147;

Aethylanilin I 147;

Dimethylanilin I 147;

Kollidin I 147;

Isochinolin I 147;

Chinolin I 147;

\%.Cumidin I 147;

Methyläthylanilin I 147;

Chinaldin I 147;

Lepidin I 147;

Diäthylanilin I 147;

Hydroxylamin I 147.

Einwerthige Anionen.

a) Imidionen:

Succinimid I 148;

Acetylcyanamid I 148;

Cyanamidokohlensäureäther 1 148;

Benzoylcyanamid I 148;

Azimid I 148.

b) anorganische einwerthige Anionen:

Hydroxyl I 148;

Fluor I 148;

Chlor I 148;

Brom J 148;

Jod I 148;

Cyan I 148;

salpetrige Säure I 148;

Salpetersäure I 148;

Chlorsäure I 148;

Bromsäure I 148;

Jodsäure I 149;

Perchlorsäure I 149;

Perjodsäure I 149;

Permangansäure I 149;

unterphosphorige Säure I 149;

Orthophosphorsäure I 149;

Orthoarsensäure I 149;

(Trijodwasserstoftsäure) I 149 ;

Silbercyanwasserstoffsäure I 149 ; 
Leitfähigkeit:

Ammonplatotrichlorwasserstoffsäure I 419;

des Erdmann'schen Co-Salzes I 149.

c) organisehe emwerthige Anionen: Anion der Ameisensäure I 149;

Essigsäure I 149;

Monochloressigsäure I 149;

Dichloressigsäure I 150;

Trichloressigsäure I 150;

Bromessigsäure I 150;

Thiacetsäure I 150 ;

Glykolsäure I 150;

Propionsäure I 150;

$\beta$-Jodpropionsäure I 150;

Akrylsäure I 150;

Milchsäure I 151;

Trichlormilchsäure I 150 ;

Buttersäure I 150;

Isobuttersäure I 150 ;

$\alpha$-Krotonsäure I 150;

$\beta$-Krotonsäure I 150;

Tetrolsäure I 150 ;

$a$-Chlorisokrotonsäure I 150;

$\beta$-Chlorkrotonsäure I 150;

$\beta$-Chlorisokrotonsäure I 150;

Valeriansäure I 150;

Angelikasäure I 1:0;

Tiglinsäure I 150;

Brenzschleimsäure I 150;

Succinursäure I 150;

Kapronsäure I 150;

Hydrosorbinsäure I 150;

Nikotinsäure I 150;

Pikrinsäure I 150;

Benzoësäure I 150 ;

o-Chlorbenzoësäure I 150 ;

m-Brombenzoësäure I 151;

o-Amidobenzoësäure I 151;

m-Amidobenzoësäure I 151 ;

o Nitrobenzoësäure I 151;

p-Nitrobenzoësäure I 151;

Salicylsäure I 151;

o-Toluylsäure I 151;

m-Toluylsäure I 151;

p-Toluylsäure 1 151;

a-Toluỵlsäure I 151;
Leitfähigkeit:

Anissäure I 151;

Mandelsäure I 151;

Phenylglykolsäure I 151;

Oxydehydracetsäure I 151;

Zimmtsäure I 151;

Atropasäure I 151;

Phenylpropiolsäure I 151;

Phtolursäure I 151;

Phtolanilsäure I 151;

des Laktons der Anilido- $\beta$-Isobuttersäure I 151 ;

des Laktons der O-Toluido- $\beta$-Isobuttersäure I 151;

des Laktons- $\beta$-Isobuttersäure I 151.

d) einwerthige Anionen zweiwerth. organ.

Süuren:

Weinsäure I 152;

Traubensäure I 152;

Aepfelsäure I 152;

Citraconsäure I 152;

Brenzweinsäure I 152;

Malonsäure I 152;

Oxalsäure 1 152;

o-Nitrophtalsäure I 152.

e) Anionen der Alkylsulfate und Sulfosüuren:

Methylschwefelsäure I 152;

Aethylschwefelsäure I 152;

Propylschwefelsäure I 152;

Isobutylschwefelsäure I 152 ;

Benzolsulfosäure I 152;

Nitrobenzolsulfosäure I 152 ;

Naphthalinsulfosäure J 152;

$\psi$-Cumolsulfosäure I 152;

Kakodylsäure I 152.

(C. Zweiwerthige Kationen.

a) Anorganische:

Magnesium I 153:

Calcium I 153:

Strontium I 153;

Baryum I 153;

Kupfer I 153;

Zink I 153;

hadmium I 153;

Platodiammon I 153;

Chlorplatindiarnmonium I 153 ; 
Leitf ähigkeit:

Bromopurpureokobalt I 153 ;

Xanthokobalt I 153.

b) Organische:

Aethylendianumonium Y 153;

Trimethylendiammonium I 153;

$\beta$-Chlortrimethylendiammonium I 153;

Tetramethylendiammonium I 153;

Diäthylendiammonium I 153;

Pentamethylendiammonium I 153;

$\beta$-Methyltetramethylendiammonium I 153 ;

Aethylenhexaphenyldiphosphonium I 153.

D. Zweiwerthige Anionen.

a) Anorganische Anionen:

Schweflige Säure I 154;

Schwefelsäure I 154;

Selensäure I 154;

('hromsäure I 154;

Molybdänsäure I 154;

Volframsäure I 154;

Thioschwefelsäure I 1.54;

Dithionsäure I 154;

Perschwefelsäure I 154;

Mercurisulfosäure I 154;

Methylendisulfosäure I 154;

Pyroschweflige Säure I 154;

Dichromsäure I 154;

Metaborsäure I 154;

Kohlensäure I 154;

Perjodsäure I 154;

Metaarsenige Säure I 154;

Phosphorsäure I 154;

Arsensäure I 151;

Nickelcyanwasserstoffsäure I 154;

Platocyanwasserstoffsäure I 154;

Platochlorwasserstoffsäure I 155;

Platinchlorwasserstoffsäure I 15.5.

b) Organische Anionen:

Oxalsäure I 155;

Malonsäure I 155;

Bernsteinsäure I 155;

Monobrombernsteinsäure I 155 ;

Dibrombernsteinsäure I 155 ;

Aepfelsäure I 155;

Diglykolsäure I 1.55;

Thiodiglykolsäure I 155;
Leitfähigkeit:

Veinsäure I 155;

Acetylendikarbonsäure I 155;

Fumarsäure I 155;

Maleïnsäure I 155;

Glutarsäure I 155;

Aetlılmalonsäure I 155;

Pyroweinsäure I 155;

Itaconsäure I 155;

Mesaconsäure I 155;

Citraconsäure I 15.5;

Adipinsäure I 155;

Pimelinsäure I 155;

Chinolinsäure I 155;

Korksäure I 155;

Phtalsäure I 155;

o-Nitrophtalsäure I 155;

Sebacylsäure I 156;

Phenylpyridinikarbonsäure I 156;

c-Truxillsäure I 156;

$\beta$-Truxiilsäure I 156.

E. Dreiwerthige Kationen.

Aluminium I 156;

Chrom I 156;

Luteokobalt I 156;

Roseokubalt I 156;

Tetraminroseokobalt I 156.

F. Dreimerthige Anionen.

Ferricyanwasserstoffsäure I 156 ;

Kobaltcyanwasserstoffsäure I 156 ;

Chromicyanwasserstoffsäure I 156;

Ferrioxalsäure I 156;

Chromioxalsäure I 156;

$\psi$-Aconitsäure I 156 ;

Citronensäure I 156;

Pyridintrikarbonsäure (1:2:3) I 156;

Pyridintrikarbonsäure (1:2:4) I 15้6;

Methylpyridintrikarbonsäure I 157.

G. Vierwerthige Kationen.

Ammonplatindiammonium 1157 ;

H. Vierwerthige Anionen.

Pyrophosphorsäure I 157;

Ferrocyanwasserstoffsäure [ 157;

Propargylentetracarbonsäure I 157 ;

Pyridintetracarbonsäure I 157.

I. Fiinfwertlige Inionen.

Pyridiupentacarbonsäure I $15 \overline{\text {. }}$ 
Leitfähigkeit:

K. Sechswerthige Anionen.

Mellithsäure I 157.

Leitfähigkeit von $\mathrm{K}, \mathrm{Na}^{*}, \mathrm{NH}_{4}{ }^{\circ}, \mathrm{Ag}$, $\mathrm{Ba}{ }^{*}, \mathrm{Sr}^{*}, \mathrm{Ca}{ }^{*}, \mathrm{Mg}{ }^{*}, \mathrm{H}^{*}, \mathrm{Cl}^{\prime}, \mathrm{NO}_{3}{ }^{\prime}, \mathrm{SO}_{4}{ }^{\prime \prime}$, $\mathrm{OH}^{\prime} \mathrm{I} 9$;

von $\mathrm{K}^{*}, \mathrm{Na}{ }^{*}, \mathrm{Li}^{\circ}, \mathrm{NH}_{+}{ }^{*}, \mathrm{Ag}^{*}, \mathrm{Ba}^{*}, \mathrm{Sr}^{*}$, $\mathrm{Ca}{ }^{*}, \mathrm{Mg}^{*}, \mathrm{Zn}{ }^{*}, \mathrm{H} \cdot \mathrm{Cl}^{\prime}, \mathrm{J}^{\prime}, \mathrm{NO}_{3}{ }^{\prime}, \mathrm{ClO}_{3}{ }^{\prime}$, $\mathrm{C}_{2} \mathrm{H}_{3} \mathrm{O}_{2}^{\prime}, \mathrm{SO}_{4}^{\prime \prime}, \mathrm{C}_{2} \mathrm{O}_{4}^{\prime \prime}, \mathrm{OH}^{\prime} \mathrm{I} 42$;

eine Function von lonenbeweglichkeit und Dissociationsgrad I 40;

additive Natur I 7, 39;

bei unendlicher Verdünnung I 43;

Berechnung der - einer Verbindung aus der der Jonen I 43;

Berechnung der - bei unendlicher Verdünnung I 44;

der Elektrolyte. Herabsetzung durch Nicht-Elektrolyte I 48, 475;

Methode der Bestimmung I 98-158;

Princip und Schema I 98-100;

Apparate I 100-117; II 383;

Messung I 117-124;

Tabellen f. d. Leitfähigkeit I 124-158; specifische I 120 ;

äquivalente I 120 ;

moleculare I 121;

Formel für die Berechnung, ausgedrückt in alten und in neuen Einheiten I 126;

ausführliches Beispiel einer Bestimm. ung I 127, 524-528, III 197, 296;

zur Untersuchung der Permeabilität $d$. rothen Blutkörperchen I 221;

des Serums I 474-486;

Beeinflussung durch Eiweiss I 475; durch die Temperatur I 476;

bei verschied. Thierspecies I 476,477 ; corrigirte - des Serums I 475-477; von Serum, Blutkörperchen und defibrin.

Blut I 477; beim Stehen I 477; physiologische - des Serums I 480; Einfluss der Verdünnung des Serums auf die Leitfähigkeit I 480;

des Serums des Menschen I 483-486; Einfluss der Verdünnung darauf I 484; physiologische Leitfähigkeit $d$. menschlicheu Serums I 484;
Luitfähigkeit:

des Serums bei kranken Menschen I $484-486$;

des Serums beim Pferd, Rind, Schaf I 494, 498;

von Schwein, Hund, Katze I 495, 498; Beziehung d. Leitf. d. Serums zur Gefrierpunkterniedrigung I 500, 502; Beziehung zum Chlorgehalt I 504; des menschlichen Blutserums, Einfluss von Nahrung und Kochsalzaufnahme I 508. - II 282;

des Blutes z. Bestimmung d. Volumens an körperl. Elementen I 517-524; detaillirte Beispiele für die Bestimmung an Serum und Blut I 127, 524528, III 197;

von Rinderserum und Rinderblut I 525 -528 , IIl 201;

von Serum und Blut d. neugeborenen Kalbes I 525-528, III 201; von lackfarbenem Blute l 532-536;

Beeinflussung d. Leitfähigkeit d. Serums durch Hämoglobin I 534; s. a. unter lackfarbenes Blut;

des Harns beider Nieren II 283;

der Galle II 447;

der Milch II $452 \mathrm{ff}$., (Sieh weiter unter Milch);

"physiologische" - der Milch II 459; der Milch, Beziehung z. Nahrung II 461; von absolut reinem Wasser III 283;

von Wasser aus Natureis III 284 ;

von verschied. Mineralwässern III 284; Ausführliches Beispiel einer Leitfähig-

keitsbestimmung v. Rhenser Sprudel III 296 ;

Neue Hypothese Sleesw yks über ihr Wesen der - III 390.

Leitfähigkeitsbest im mung (Beispiel) I 127, 524, III 197, 296.

Leitfähigkeits tabellen, Erklärung der - 1 129, 130.

Leuk olyse, lymphstrombeschleunigende Wirkung II 43.

L e u k o c y t e n, Dimensionsänderungen durch Kohlensäure I 402;

durch Alkali und Säure I 418; 
Leukocyten:

Zerstörung durch Pepton II 43;

Permeab. für die Anionen von Natriumsalzen III 47;

Mikroskopischer Bau III 404;

s. übrigens weisse Blutkörperchen.

Liebensteiner Stahlwasser, Eingelıende Untersuchung III $289 \mathrm{ff}$.

Linse, Trübung durch Einführung von Salzen und von Glukose in den Conjunctivalsack III 166, 167 ;

Empfindlichkeit f. Concentrationsunterschiede III 166 ;

verschiedene Permeabilitätsverhä]tnisse für gleichnamige Salze III 163 .

Lipoïd III 245;

Bedeutung für die Nierenthätigkeit III 411.

Bedeutung für das Zustandekommen der Narkose III 250;

Bedeutung für die intravitale Färbung III 424.

Lithiumehlorid, Permeab. d. r. Blutkörperchen I 208;

Sieh Chlorlithium.

Lithiu in lı altige Mineralwässer zur Auflösung von Concrementen III 278.

Lith i u h h y r oxyd, Activitäts-u. Dissociationscoëfficient I 53 .

Lithi umi on, Wanderungsgeschwindig. keit (Leitfähigkeit) I 43, 137.

Lith i u mulf a tlösungen, Leitfähigkeit I 130.

Li thol y ti ca, Sielie unter Lithiumsalzen, Piperazin und Harnstoff.

Löslichkeit des Glases, Bedeutung für die Leitfähigkeit I 107;

Steigerung mit der Temperatur I 10s; (Sieh übrigens Glas).

Löslichkeit von Substanzen, Beeinflussung derselben durch verschiedenartige Ionen III 266.

Löslichkeitsproduct III 260 .

Löslichkeitsverhältnissed. Harnsäure III 271;

Beeinflussung durch hinzugefügte $H$ Ionen III 272;
Löslichkeitsverh ïltnisse:

des harnsauren Natrons, Beeinflussung durch $\mathrm{NaCl} \mathrm{III} \mathrm{277;}$

von Harusäure und harnsaurem Natron,

Bedeutung für die Auflösung von Concrementen III 277.

Lösungen, Aufbewahrung. Siehe destillirtes Wasser.

L u p i n e zwischen Waclisthum und $\mathrm{H} \cdot-$ Ionen-Concentration der Säuren III 110.

Luteocobaltion, Leitfähigkeit I 156.

L y m p h a g o g a I. ınd II. Ordnung II $34,42,46,47,57$;

I. und III. Ordnung II 57;

in patholog. Flüssigkeiteu II 69; in Blutserum eines Nierenkranken II 75; bei Urämie II 75 ;

bei Stauung II 75 ;

bei chron. Nierenkrankheiten II 76;

Entfernung bei Venaesection II 76;

Einfluss auf die Permeabilität der Gefässwand II 90.

Wirkung von Tuberkulin und anderen Bacterienextracteu II 76 ;

Ly in phagoges Bacteriun II 71;

als Ursache von Oedem und Hydrops II 88.

Lymphbildung II 30 ;

$\mathrm{H} \theta \mathrm{i} d \mathrm{enhains}$ Secretionslehre II 31,61 ;

Argumente $\mathrm{H}$ a m b u r ge r's zu Gunsten dieser Lehre II 36, 66;

Cohnheims Ausf. gegen Heidenhains Schlussfolgerungen II 37,63 ;

Starling's Ausführungen gegen $\mathrm{Hei}$ de $n$ ha ins Schlussfolgerungen II 44,62 ;

Einwände von L a z a rus-B a r l o w dagegen II 48 ;

Einwände von Starling und Cohnstein gegen Hamburgers Schlussfolgerungen II 49 ;

Ausführungen von A $\mathrm{sh} \in \mathrm{r}$ (cellularphysiologische Lymphtheorie II 55;

Beziehung z. Speichelabscheidung II 56; Beziehung z. Gallenabscheidung II 56 ; 
Lymphbildung:

bedingt durch die Arbeit der Organe II 55 .

Untersuchungen $\mathrm{R}$ oths II 60;

Zusammenfassung und Schluss II 61 ;

L y $m p h d r$ üse $n z e l l e n$, Gewinnung III 37;

Permeab. für Chlorionen III 38;

Bewegung von Chlor und Alkali unter dem Einfluss von Kohlensäure III 38 ;

Umkehrbarkeit der Bewegung III 39;

Schlussfolgerung III 40;

Permeab. für $\mathrm{SO}^{\prime \prime}$-Ionen III 40 ;

Bewegung von $\mathrm{Cl}$ und Alkali unter dem Einfluss von $\mathrm{CO}_{2}$ III 40, 41;

Umkehrbarkeit der Bewegung III 41, 42;

Permeabilität für $\mathrm{NO}_{3}{ }^{-}$-Ionen III 41 ;

Permeabilität für anderweitige Anionen: I' III 43;

$\mathrm{PO}_{4}{ }^{\prime \prime}$ III 43;

$\mathrm{Br}^{\prime}$ III 44;

$(\mathrm{COO})_{2}$ " (Oxalsäureanion) III 45;

$\left(\mathrm{C}_{6} \mathrm{H}_{4}(\mathrm{OH}) \mathrm{COO}\right)^{\prime}$-Salicylsäureanion III 45 ;

$\left(\mathrm{C}_{6} \mathrm{H}_{5} \mathrm{COO}\right)^{-}$-Benzoesäureanion III 46 ;

Permeabilität für die Anionen von $\mathrm{Na}$ triumsalzen, Zusammenfassung und Schluss III 47; Bedingungen und Mechanismus III 47; Bedeutung aus physiologischem und pharmakologischem Gesichtspunkt III 48.

L y mphe, Durchmesser der Säugethier-

blutkörperchen in derselben I 199;

Osmotischer Druck II 36;

nach Injection hyperisotonischer Lösungen II 15;

Osmotischer Druck der Halslymphe des Pferdes beim Essen, Essen mit comprimirter Jugularis, bei Compression der Carotis, beim Gehen II 37;

Vergleichung mitdem osmotischenDruck des Jugularisserums II 36, 54;

und Bhutserum. Vergleichbarkeit des Zuckergehalts beider nach intravenöser Zuckerinjection II 42;

Eiweissgehalt der - II 45;
L y $m p$ li e :

Beziehung des osmotischen Drucks zu dem des Blutserums II 50 ;

Unabhängigkeit der Zusammensetzung von der des Blutserums II 50;

Alkaligehalt der Halslymphe in Beziehung zu dem des Jugularisserums II 52; in der Leber; osmotischer Druck II 40. - III 135;

von Fröschen; osmotischer Druck III 135;

Siehe weiter auch unter Gewebefliissigkeit.

Lymphfistel am Halse des Pferdes, Operationstechnik II 35;

$\mathrm{L} y \mathrm{mph}$ h $\in \mathrm{rz}$, Giftigkeit einer reinen $\mathrm{NaCl}$ Lösung III 122.

Ly mphocyten I 402 .

Lymphstrom, Einfluss von Obturation dèr Aorta thoracica auf denselben II 34,44 ;

Einfluss von Obturation der Vena porta II 45 .

Kinfluss des Verschlusses der Vena cava inf. unterhalb des Zwerchfells II 45 ;

am Halse, bei Arbeit von Rumpf- und Extremitätmuskeln II 36, 49;

nach Sympathicusdurchschneidung und Reizung II 52;

bei Compression der Vena jugularis und der Art. carotis II 37;

Einfluss der Lymphagoga 1. u. 2. Klasse II 34, 3. Klasse II 57;

siehe übrigens unter "Lymphagoga".

L y m phreibende Stoffe, vergl. Lymhpagoga.

II.

11 a assytem bei elektrochemischen Messungen II 378.

M a gen, Verhalten der Amniontlüssigkeit im fütalen Magen III 214;

Verhalten von Mineralwässern im Magen III 318 ;

Regelung des osmotischen Druckes im Magen III 321. 
Magen leiden (Anacidität), Osmotischer Druck des Blutes bei - I 451.

M agensaft II 437 ;

Osmotischer Druck II 225, 227, 228;

Bildung der Salzsäure II 438 ff.;

Kataphorese bei der Bildung des Magensaftes II 443.

M a ge n wand, Permeabilität für $\mathrm{NaCl}$, $\mathrm{Cl}^{\prime}$-Ionen und $\mathrm{H}^{-}$-Ionen II 440.

M agnesiumbromid Iösungen, Leitfähigkeit I 133.

Magnesiumchlorid, siehe Chlor. magnesium.

M a gnesi u mi on, Wanderungsgeschwindigkeit (Leitfähigkeit) I 9, 42, 137, 138, 153.

Magnesiumnitratlösungen, Leitfähigkeit I 133.

Magnesiumsalze, Dissociation I 45.

M agnesiumsulfat, Activitäts- und Dissociationscoëfficient I 53.

Permeabilität der rothen Blutkörperchen I 222, 223;

Permeabilität der rothen Blutkörperchen für das Anion I 251;

Purgative Wirkung II 217 ;

Einfluss auf die Permeabilität des Darmepithels für Salze III 13.

Magnesiumsulfat lösungen, Gefrierpunkterniedrigung (Tabelle) I 85;

\lrcorner und i I 97 ;

Leitfäligkeit I 130, 133;

Einfluss auf den Hämoglobinaustritt aus rothen Blutkörperchen I 165, 206.

M a krocytose III 354 .

Malaria, Osmotischer Druck des Blutes I 471;

ChIorgehalt des Harns II 18.

Maleinsäureanion, Leitfähigkeit I 155.

Ma lonsäure, Leitfähigkeit I 152.

Ma l onsäureani on, Leitfähigkeit I 155.

Maltase III 96 .

Mandelsäure, Leitfähigkeit I 151.

Mannit, Activitäts- und Dissociationscoëfficient I 53;

Permeabilität der rothen Blutkörperchen und Pflanzenzellen I 207;

H a mburger, Osmot. Druck. III. Band.
Manuit:

Permeabilität der rotheu Blutkörperchen I 209, 213;

Permeabilität der Pflanzenzelleu I 216. M a chell, Grösse derselben, Beeinflussung durch Fixirmittel III 399; bei Ersatz der letzteren durch andere Fliissigkeiten III 403; durch Anwesenheit fester Partikelchen III 403; durch mechanische Einflüsse III 404;

Siehe auch Netzstructur und Gerïst.

Massenwirkungsgesetz II 466 ;

Giltigkeit bei der Inversion voll Saccharose durch Invertase III 103;

Anwendung auf die Bindung von Toxin und Antitoxin III 371, 378;

von Borsäure und Ammoniak III 376; Anwendung auf die Hämolysinbildung III 380 .

Mastix, Ausflockung durch Säuren gleicher Leitfähigkeit III 61 .

Mastzellen I 402.

M a ximum-Resistenz I 381, 388; bei fötalem Blut III 191, 195, 202; Siehe übrigens unter Resistenz.

Medium, Einfluss auf die Reactionsgeschwindigkeit II 474.

Meerwasser, Intravenöse Injection II 2.

Mellithsäureanion, Leitfähigkeit I 157.

Membranen von Kalbsperitoneum I 158; von Ferrocyankupfer I 158;

Permeabilität von - für Ionen I 228. Durchlässigkeitsunterschiede für Ionen unter verschiedenen Bedingungen II 220 ;

Meningitis tuberculosa. Diagnose mittelst Gefrierpunkterniedrigung II 75.

Mensch, Leitfühigkeit des Serums I 483, 504,505 .

Zunahme mit der Verdünnung, Dissuciationsgrad ( c) I 483-486;

bei Krankheiten: Uraemia gravis, Muskelrheumatismus, Pleuropneumonie, Nephritis, Carcinom I 484, 486;

Pleuritis, Polysarca, Nephritis, Laennecsche Cirrhose, chron. Pleuritis I 48.;, 486 ; 
Mensch:

Osmotisch-chemische Analyse d. Serums b.

Krankheiten I 502; b. Gesunden I 503;

Osmotischer Druck des Serums I 472 , 503, 504,

osmotische Concentration I 505; Ein-

fluss der Nahrungsaufnahme und der

$\mathrm{NaCl}-A u f n a h m e$ auf dieselbe I 505;

s. w. unter "Blut", ${ }_{\text {SSerum" }}$ etc.

Mercurisulfonsäureanion, Leitfähigkeit I 154.

Mesa c onsäureanion, Leitfähigkeit I 155.

Messbrücke I 114;

Wahl zwischen gestrecktem Draht und

Walzenbrücke I 115;

Calibrirung I 116;

Controlle der Calibrirung I 117.

Messung des elektrischen Widerstandes I 117-124;

Fehlerquellen bei der Messung I 1i7;

Ausführung der Messungen I 118;

Beispiel I 119;

Berechnung der Leitfähigkeit aus den Messungen I 120-124;

Siehe übrigens Leitfähigkeit,Messbrücke,

Telephon, Tonminimum.

Metarsenige Säureanion, Leitfähigkeit I 154.

Metaborsäureanion, Leitfähigkeit I 154.

Metallische Collö̈de III 80 .

Metallsole, Siehe die betreffenden colloidalen Metalle : colloidales Silber, Gold, Platin etc.

Metamere Ionen I 48.

M e thyla cetat, Umwandlung durch Säure als Mittel zur Bestimmung der $\mathrm{H}$-Ionen-Concentration im Magensaft etc. II 498;

Beeinflussung der Umwandlung durch Neutral-Salze II 500.

Met hylal, Permeabilität der rothen Blutkörperchen I 215;

Permeabilität der Pffanzenzellen I 216.

Methylalk oho l, Permeab. der rothen Blutkörperchen I 207, 215;

Permeab. der Pflanzenzellen I 216.
Methyläthylketon, Permeab. der r. Blutkörperchen I 215.

Methylcyanid, Permeab. der Pflanzenzellen I 216.

Methylendisulfosäureanion, Leitfähigkeit I 154.

Methylpyridintricarbous ä urea ni o n, Leitfähigkeit I 157.

Methyls c hwef el sä ure, Leitfähig. keit I 152.

Mikrocytose III 354 .

Mikroskopisches Verbalten d. rothen Blutkörperchen von Frosch, Fisch und Vogel in Salz- und Zuckerlösungen verschiedener Concentration I 178-183.

Milch, Beziehung von Eiweiss- u. Kalkgehalt zum Lymphbildungsproblem II 33, 39, 448;

Osmotischer Druck, Bestimınung durch Tradescantia II 448;

Gefrierpunkt beim Beginn und Schluss des Melkens II 449;

Morgen- und Abendmilch II 450;

Volle und abgerahmte II 450;

Gefrierpunkt des Rahms II 451;

Nittelwerth der Gefrierpunkterniedrigung II 451 ;

Leitfähigkeit II 452 ;

Beziehung zwischen Aschengehalt und Leitfähigkeit II 453;

Einfluss des suspendirten Fettes auf die Leitfähigkeit II 453 ;

Einfluss des Sauerwerdens auf d. Leitfähigkeit II 454;

Entdeckung von Wasserverfälschung durch Gefrierpunkt- u. Leitfähigkeitsbestimmung II 455 ;

Beziehung von $\Delta$ und $\lambda$ zur Nahrung II 455;

Einfluss der Verdünnung auf $\Delta$ und Leitfähigkeit II 455 ;

Osmotisch-chemische Analyse II 456; K oeppes irrthümliche Schlussfolgerung II 458;

Physiolog. Leitfähigkeit II 459;

Beziehung zwischen $\Delta$ der Milch und des Blutserums II 460 ; 
Milch, Beziehung zwischen Milchzuckerund Aschegehalt II 461;

Beeinflussung des osmot. Druckes der Milch durch Mineralwasser III 322.

Milchsäure, Activitäts- und Dissociationscoëfficiont I 53;

Leitfähigkeit I 150;

Beziehung zwischen Dissociationsgrad und Eiweissverdauung II 502.

Milieu interne, Beziehung zwischen dessen osmotischem Druck und dem der Umgebung I 466.

Millimolion III 307.

Milzexstirpation, (Ismotischer Druck des Blutes I 467.

Milzparenchymzellen, Zunahmed. Volumens durch $\mathrm{CO}_{2} \mathrm{u}$. andere Säuren. Abnahme durch Alkali III 52.

Mineralsalze, Pormeab. der Pflanzenzellen I 216.

Mineralwasser, Einfluss auf den osmotischen Druck der Galle II 447;

Leitfähigkeit verschied. Sorten III 284; Vergleichung von Gefrierpunkterniedrigung und Gehalt an festen Bestandtheilen IIi 285 ;

Gefrierpunkterniedrigung verschiedener natürlicher Mineralwässer III 286; verschiedener künstlicher Mineralwässer II 288;

Ionisirungs- (Dissociations-) grad III 291, 297, 307 ;

Eingehende Untersuchung des Liebensteiner Stahlwassers III 289;

des Rhenser Sprudels III 294;

des grossen Sprudels Bad-Neuenabr IlI 303;

Kautelen bei der Depressionsbestimmung mit Rücksicht auf den $\mathrm{CO}_{2}$-Gehalt III $289,295,304,308$;

Dissociationsgrad III 291, 297;

Osmotische und osmotisch chemische Analyse des Liebensteiner Wassers. Schlussfolgerung aus dem Mangel an Uebereinstimmung III 294;

desgleichen b. Rhenser Sprudel III 300; dosgleichen b. grossen Sprudel Neuenahr III 303;
Mineralwasser:

Zusammenfassung und Schlussbetrachtung betr. osmotische und osmotischclremische Untersuchung von Mineralwässern III 306;

Classification der Mineral wässer III 307, 309; graphische Darstellung III 309; elektrochemische Aciditätsbestimmung III 311; Vergleichung mit der titrimetrischen III 312 ;

Einfluss auf den osmotischen Druck d. Blutes III 313;

Einfluss auf den Hämoglobingehalt des Blutes III 316 ;

Einfluss auf $\perp$ des Harns III 316,318 ;

Bedeutung des osmotischen Drucks für die Praxis III 319;

Regelung des osmotischen Druckes im Magen III 318, 322;

Einfluss auf den osmotischen Druck d. Milch III 322;

Minimum-Resistenz I 381, 388;

Einfluss von $\mathrm{NH}_{4} \mathrm{Cl}$ auf dieselbe I 358;

Einfluss von taurocholsaurem Natron darauf I 389 ;

bei fötalem Blut III 191. 195, 202.

Siehe übrigens u. Resistenz;

Mitschleppende Wirkung d. Blutstromes II 111, 118, 161;

bei der Resorption in Darme II 19.5.

Molare Concentration I 14.

Mo leculardepression mittelst Präcisionskryoskopie I 77 ;

von Rohrzuckerlösungen bei verschiedenen, aberstarken Verdünnungen I79; bei Steigerung der Concentration:

Rohrzucker und Dextrose I 80, 82;

Lävulose, Glycerin I 81 ;

Chlorkalium, Abnahme mit d. Concentration (Tabelle) I 84;

Magnesiumsulfat, Abnahme mit der Concentration I 85.

Moleculardicke III 62.

Moleculare Concentration I 13;

Moleculare Leitfähigkeit I 121.

Moleculare Gofrierpunkterniedrigung, abweichende Werthe b. verschiedenen Autoren I $7 \%$. 
Moleculargew icht von Diphtherietoxin, Beziehung zu dem des Antitoxins III $380,386$.

Molecularzust and, Verschiedenheit in verschiedenen Medien III 384.

Molion II 456, III 292.

M o l y b dän s äurea n i o n, Leitfähigkeit I 154.

Monobrombernsteinsäureanion, Leitfälirgkeit I 154.

Monochloressigsäure, Leitfähigkeit I 149.

Monomoleculare Reaction II 467.

Mononatriumarseniatlösungen, Leitfähigkeit I 133.

Mononatriumphosphatlösungen, Leitfähigkeit I 133.

Morbus Brightii, Osmotischer Druck des Blutes I 470;

osmotisch-chemische Analyse d. menschlichen Blutserums I 502.

M orphin, Leitfähigkeit I 145 .

Motorische Insufficienzd. Magens. Vermeidung hyperisotonischer Ingesta II 224 ;

ll ot oris che Nerven, Erregbarkeit III 158.

Mückenton des Inductoriums I 101.

Müllers Flỉssigkeit, Einfluss auf d. Volumen der Blutkörperclıen I 189; als Fixirungsflüssigkeit I 463 ;

Siehe auch Kaliumbichromat.

Muskel, Rhythmische Zuckungen in Natriumsalzlösungen III 118; Bedeutung von $\mathrm{Ca}^{*}$ und $\mathrm{K}$-Ionen hierbei III 118;

Reizbarkeit durch Contact (Contactirritability) III 119;

Permeabilitätsverhältnisse der Muskelbüllen III 133;

Osmotischer Druck der interstitiellen Flïssigkeit IlI 134;

Wasseraufnalıme и. Lebensfähigkeit in hypisotonischen Lösungen III 135;

Bedeutung der Na.Ionen für den Colltractionsact III 144; Günstige Wirkung von $\mathrm{Li}^{\cdot}$-Ionen IlI 146 ;
Muskel:

Giftigkeit von Rohrzucker und anderen Nichtelektrolyten; Linderung d. Toxicität durch Hinzufügung von $\mathrm{NaCl}$ III 145 , und von Lithiumsalz III 146 ; Erklärungsversuch III 146;

S. auch Froschmuskeln, Muskelhüllen, Muskelsubstanzu. Demarcationsstrom.

Muskelhüllen, Einfluss der Permeabilität auf die Grösse des Demarcationsstromes III 154.

M uskelsubstan z, Wasseraufnahme unter d. Einfluss von Säureı III 111; Zurückführung d. Erscheinung auf Ionenwirkung III 112; Heranziehung von Diffusion und Imbibition III 114;

Wasseraufnalıme unter dem Einfluss von Basen IlI 115 ;

Verhalten gegenüber einfachen Salzlösungen III 116; Zurückfülırung der hierbei gefundenen Erscheinungen auf d. Löslichkeit von Wasser in den verschiedenen Ionenproteiden III 118;

Zusammensetzung der - aus zwei Phasen III 136;

Lebensfähigkeit $u$. Wasserverlust bezw . Wass eraufnahme in hyperisotonischen Lösungerı IlI 137;

Verhalten gegenüber Säuren III 139;

Permeab. für d. verschiedenen Gruppen organischer, sowie für einige anorganische Verbindungen III 139:

Bedingungen für den Grad der Permeabilität III 142 ;

Uebereinstimmung d. Permeabilität mit der von Pflanzenzellen $u$. thierischen Zellen im Allgemeinen III 143; Kritische Bemerkungen dazu III 144.

Muskel-und Nervenphysiologie, drittes Kapitel III 107.

Mutterliches und Fötales Blut, Osmotische und osmotisch chemische Analyse IlI 182 ff.;

Gewinnung d. Blut. III 184, 185, 189, 217 ; Osmotischer Druck III 184, 185, 190, $196,200,219,216$;

Farbstoffaustritt, Resistenzbreite III $189,195,200$; 
Mütterliches und fötales Blut:

Volumetrische Verhältnisse nach Einwirkung von Salzlösungen III 191, 196, 200 ;

Beziehung zwischen dem Volumen der intraglobularen Flüssigkeit und des Stroma + eiweissartige Stoffe IlI 203;

Blektrisches Leitvermögen von Serum und Blut I 478, III 192, 197, 201 ;

Chlorbestimmung III 193, 198, 201;

Alkalinitätsbestimmung III 194, 198, 201 ;

Bestimmung der festen Bestandtheile III 195, 199, 201 ;

Wesen des Resistenzunterschiedes der beiden Blutkörperchenarten III 204;

Blutkörperchenzahl III 204;

Unterschied d. Gefrierpunktverhältnisse zwischen Schaf u. Nenschen III 211;

Zusammenfassung und Schlussbetrachtung 218 III.

\section{N.}

Nahrungsbedingungen, Einfl. anf $\Delta$ d. Blutserums II $310 ; \Delta$ des Harns II 317.

N ahrungsenthaltung, osmotischer Druck des Blutes dabei - I 468.

Naphtalinsulfosäure, Leitfähigkeit I 152.

Narkose, Aeltere Ansichten über den Mechanismus III 243;

Hypothese der partiellen Entwässerung des Protoplasmas (R. Dubois) III 244 ;

Hypothese des Theilungsprincips(M e y $\mathrm{r} \mathrm{r}^{\circ}$ und Overton) III 245;

Bedingung für ihr Zustandekommen in Zellen III 250;

Gleichheit der für die Narkose von Kaulquappe, Hund und Menschen erforderlichen Concentration von Chloroform und Aether III 250; Abweichung für andere Thierarten III 250 ;

Beziehung zwischen Grad der Narkose und chemischer Constitution von Verbindungen III 251;
Narkose:

Einfluss der Temperatur als neuer Beweis für die Giltigkeit des 'Theilungsgesetzes bei der Narkose III 251.

Narkotica, Unterscheidung in indifferente und basische III 245;

Beziehung zu Antiseptica III 252;

Wirkungsmechanismus der basischen Narkotica III 252.

N atriu m, Permeabilität der rothen Blutkörperchen I 228.

$\mathrm{N}$ a tr iu m a cetat, Permeabilität der rothen Blutkörperchen I 209.

Natriumacetatlösungen, Leitfähigkeit I 130.

Natrium ammoniumphosphat $10 \ddot{s}$ u n ge n, Gefrierpunkterniedrigung I 88.

Natriumarseniat, Permeabilität der rothen Blutkörperchen für das Anion I 251.

Natriumbicarbonat, Permeabilität der rothen Blutkörperchen I 226.

Natriumbromid, Permeabilität der rothen Blutkörperchen für das Anion I 251.

Natriumcarbonat, Activitäts- und Dissociationscoëfficient I 53 ;

hydrolytische Spaltung im Serum I 482.

Natriumcarbonatlösungen, Gefrierpunkterniedrigung I 87;

Leitfähigkeit I 130.

Natriumchloratlösungen, Leitfähigkeit I 132.

Natriumchlorid, Siehe Chlornatrium.

Natrium citrat, Permeabilität der rothen Blutkörperchen für das Anion I 251.

Natriumhydroxyd. Activitäts. und Dissociationscoëfficient I 53 .

Natriumbydroxydlösungen, Gefrierpunkterniedrigung I 88 ; Leitvermögen I 131.

Natriumion, Wanderungsgeschwindigkeit (Leitfähigkeit) I 9, 42, 137, 142.

Natriumjod atlö sunge n, Leitfähigkeit I 132.

$\mathrm{N}$ a trium jo did, Permeabilitait der rotheu Blutkörperchen für das Anion I 251. 
N atriuml a ct at, Permeabilität der roth. Blutkörperchen für das Anion I 251.

Natriummalonat, Permeabilität der rothen Blutkörperchen I 209.

Natriumnitrat, Permeabilität der roth. Blutkörperchen I 208, 212.

Natriumnitratlösungen, Gefrierpunkterniedrigung I 87 ;

$\Delta$ und i I 97;

Leitfähigkeit I 129, 133.

Natriumnitritlösungen, Leitfähigkeit I 133.

Natriumoxalat, Permeabilität der rothen Blutkörperchen für das Anion I 251.

N a triumphosphat, Permeabilität der rothen Blutkörperchen für das Anion I 251.

N atrium phosphat-(secundäres)lösunge n, Gefrierpunkterniedrigung I 88.

Natriumphosphat-(tertiäres) lös ungen, Gefrierpunkterniedrigung I 88.

Natriumpropionat, Permeabilität der rothen Blutkörperchen I 209.

Natriumpyrophosphatlösungen, I 133.

Natriumsalicylat, Permeabilität der rothen Blutkörperchen für das Anion I 251.

Natriumsilicatlösungen, Leitfähigkeit I 130.

Natriumsulfat, Activitäts- und Dissociationscoëfficient I 53 ;

Permeabilität der rothen Blutkörperchen I 208, 226;

Natriumsulfatlösungen, Gefrierpunkterniedrigung I 86 ;

$\Delta$ und i I 97;

Intravenöse Injection II 4, 7.

Neigungstrom III 148.

Neovitalismus Il 438.

Nephritis, Osmotischer Druck des Blutes I 452, 471;

Siehe auch Harn.

Nephritische Oedeme II 88 ; Siehe auch unter Nierenwassersucht.

Nerven, Erregbarkeit in Saccharoselösungen III 147.
Nervenerregbarkeit, Verhaiten der Anionen und Kationen III 157.

Nervenerregung, Beziehung zwischen Erregung sensibler Nerven und Wechselzahl des Inductionsstromes III 159; Zurückführung auf Ionenverschiebung III 159 ;

Wesen der Erregung III 159, 160.

Nervenreizung durch Salzlösungen.

Beziehıng zum osmotischen Druck derselben III 156;

Einfluss der Kationen und der Anionen III 157.

Netzstructur III 29, 34 ;

Künstliche Bildung in Colloidlösungen, Studium des Bildungsvorganges unter dem Mikroskop III 397;

Einfluss von Flüssigkeiten, festen Partikelchen, mechanischen Kräften auf die Grösse del Maschen III 399 ff., 403 ff.; auf ihr Offen- und Geschlossensein III 399 ;

durch einfaches Absterben von Geweben III 400;

Immer ein Kunstproduct? III 404;

Siehe auch Gerüst und Maschen.

Neuenahrer Sprudel, Chemische und physikalisch-chemische Analyse III 303;

Elektrochemische Aciditätsbestimmung .III 311.

Neurasthenie, Osmotischer Druck des Blutes I 452, 470;

Osmot. chem. Analyse des Blutserums I 502.

Neuron als Concentrationskette aufgefasst III 388 ;

Bedeutung bei der Bacterienwirkung III 398.

Neutralisationswärmetönung, Gesetz der -, erklärt durch die Ionenlehre I 61.

Neutralrothfärbung von Eiweiss, kein chemischer Vorgang III 423.

Nicht-Elektrolyte I 7;

Einfluss von - auf die Leitfähigkeit (Dissociationsgrad) von Elektrolyten I 475 . 
Nicht-Elektrolyte:

Verhalten gegenüber Colloüden III 69, 75; hemmender Einfluss auf die Ausflockung durch Elektrolyte III 77.

Nickelcyanwasserst of fäureanion, Beweglichkeit I 154.

Niedersch lagsmembranen, Permeabilität I 26 ;

Nieren, Bedeutung bei der Regelung des osmotischen Drucks II 12, 15, 29, 114 ; s. w. u. Harn.

Nierenarterien-Unterbindung, Einfluss auf Resorption in der Bauchhöhle II 97.

$\mathrm{N}$ i er en ent z ï ndu n ge n siehe Harn und Blut.

Niereuexstirpation, Bestimmung von $\Delta$ von Blut und Harn zur Indication derselben II $276,315$.

Niereninsufficienz, I 473 ;

$\checkmark$ des Blutserums II 309;

s. w. unter Harm.

Nierenkranke, Behandlung II 474.

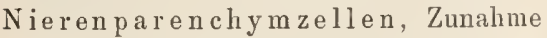
des Volumens durch $\mathrm{CO}_{2}$ und auch durch hypisotonische Salzlösungen anderer Säuren. Abnahme durch Alkali und durch hyperisotonische Salzlösungen II 419. - IlI 53.

Nierenschwellung, Beziehung zur Diurese II 399.

Ni ere n th ätigkeit aus physiologischem Gesichtspunkt II 392;

Theorie von Bow man II 393, 413;

Theorie von $\mathrm{Ludwig}$ II 394, 413:

Ansichten von Heidenhain II 394, 413;

in Lichte der Theorie des osmotischen Diucks II $395 \mathrm{ff}$.;

Arbeit der Nieren bei der Thätigkeit II 395 , 415;

Permeabilität der Glomerulusepithelschicht II 397,403 ;

Resorptionsvermögen der Harnkanälchen II 403, 416;

Beziehung zwischen Blutdruck und osmotischem Druck des Glomerulusfiltrats II $397,403,415,417$;
Nierenthätigkeit:

Bedeutung des osmotischen Drucks des Eiweisses dabei II 397, 398, 415, 417;

Beziehung zwischen Diurese und Nierellschwellung II 399, 402;

Beziehung zwischen Diurese und osmotischen Druck der injicirten Salzlösungen II 399, 415;

Beziehung zwischen Dimrese und (iefässerweiterung II 400 ;

Beziehung zwischen Blutdruck und Diurese III 401, 416, 417;

Schwierigkeiten bei Starling's Vorstellung II 402, 416;

Resorption von Glomeruluswasser II 402;

Verhatten der Nieren gegenüber'Traubenzucker II 402;

Discussion der Bowman-Heidenhain'schen Secretionslehre II 108;

Indigoversuch II 409, 414;

Nussbaum's Versuch am Frosehe II 409, 414;

Anwendung des Theilungsprincips bei der Harnsecretion II 411, 414;

Coffënwirkung II 411;

Zusammenfassung und Schluss II 413;

Eindickung der intracapsularen Flüssigkeit II 418;

Bedeutung der Diffusion für die Harnabsonderung II 418;

Beeinflussung der Harnabs. durch venöse Stauung II 419.

Siehe für die Nierenthätigk. aus patlıol. Gesichtsp. unter Ham etc.

Nierenwassersucht II 78;

s. a. nephritisches Oedem.

Nitratanion, Wanderungsgeschwindigkeit (Leitfähigkeit) I 9, 42, 138, 148;

Permeabilität der rothen Blutkörperchen I 230, 236-252; der Leukocyten I 428; der Lymphdruisenzellen für das Nitratanion $\left(\mathrm{NO}_{3}{ }^{\prime}\right)$ III 41.

o-Nitrobenzoes äure, Leitfähigkeit I 151.

p-Nitrobenzoesäure, Leitfahigkeit

I 151.

0 -Nitrophtals äure, Leitfäligkeit I 152. 
o- Nitrophtalsäureanio n, Leitfähigkeit I 155.

Nomenclatur, alte und neue, bei der

Leitfähigkeitsbestimmung I 126.

Normalelektroden III 153.

Normalelement II 351 ;

Herstellung des Cadmium. (Weston-) elementes II 352.

Normallösungen für die Bestimmung der Capacität des Widerstandsgefässes I 121.

\section{0.}

Obach's TabeIle zur. Wheatstone. Kirchhoff'schen Brücke I 119, 139 -141 .

Oberflächenspannung III 75 .

Octopus macropus, $\Delta$ des Speichels und osmotisches Verhalten der Drüse II 431.

Oedem und Hydrops. Ursachen II 68,76 ;

durch Unterbrechung der Lymphgefässe II 68;

durch Circulationsstörungen II 77, 82.85;

bei Nierenwassersucht II $78,81,83$;

bei Infektionskrankheiten, Erkältung etc. II 81 ;

durch schlechte Ernährung d.Gefässwand II 82;

vom Standpunkt der Sekretionslehre II 69 ;

rom Standpunkt der mechanischen Lymphbildungstheorie JI 83;

Zusammenfassung und Schluss II 87.

Oedem der Haut II 87.

Oertel's Kur, vom Standpunkt ron Koranyi's Ausführungen II 263.

Oesophagusepithel, siehe Epithel des Oesophagus.

$\mathrm{Ohm}$, Beziehung zur Siemens - Einheit I 39, 125. - II 378, 380.

Oligochlorurie II 257,321 .

Oligodynamische Erscheinungen an kebenden Zellen III 87, 242.

Oligurie II 257. 321.
Ophth almologisches, viertes Kapitel III 161.

Optisch leer III 62.

Or cin, Permeab. d. Pflanzenzellen I 217.

Orthoarsensäureanion, Leitfähigkeit I 140.

Orthophosphorsäureanion, Leitfähigkeit I 149.

Osmose, Geschwindigkeit I 158; Anfangsgrösse („initial rate") I 158; Endgrösse (final osmotic pressure) I 158; bei der Resorption im Darme II 195.

Osmotische Analyse des Serums bei Pferd, Rind, Schaf I 491, 492, 494, 496, 498;

Schwein, Hund, Katze I 495, 497, 498; Kritik I 500-502.

Osmotisch-chemische Analyse des Blutserums beim Menschen;

bei Krankheiten I 502 ;

bei Gesunden I 503.

Osmotische und osmotisch-chemisclıe Analyse des Blutserums I 486-508; des mütterlichen u. fötalen Blutes siehe "Mütterliches und fötales Blut".

Osmotische Concentration I 141; - des Serums I 489;

des Serums von Pferd, Rind, Schaf, Schwein, Hund, Katze I 493; von Menschen I 505;

Einfluss von Nahrung und NaCl-Aufnahme auf dieselbe I 508; s. a. u. osmot. Druck.

Osmotische Druckwellen III 392.

Osmotische Störungen, als Ursache der bactericiden Wirkung III 335; als Ursache der Hämolyse in heterogenem Serum III 358, 363 .

Osmotische TV e chselwirkung. Thätigkeit bei der Resorption II 109.

Os motis cher D r u c k, physikalischchemisches, übersichtliche Zusammenfassung I 1 ;

Van't Hoff's Theorie I 4;

Berechnung des o. Dr. einer beliebigen Lösung I 4;

Berechnung in Atmosphären I 15; 
Osmotischer Druck:

Begründung der $\nabla$ a n't $H$ of f 'schen Theorie des osmotischen Drucks I 29-37;

Beziehung zur Gefrierpunkterniedrigung I 35 ;

Directe Messung mittelst Niederschlagsmembranen I 55;

Bedeutung für die Physiologie u. Pathologie des Blutes I 161;

des Serums bei verschiedenen Thierspecies I 185;

des Blitkörpercheninhalts I 384-387; des Serums I 435-474;

Methoden zur Bestimmıng I 437-456:

Pflanzenzellenmethode I 437; Blutkörperchennethode I 439; Hämatokritniethode I 442; Gefrierpunktmethode I 453 ;

Zahleuwerthe fiir den osmot. Druck des Blutes beim normalen Menschen I 472. - II 276, 278:

Schwankungen bei gleicher Diät II 25; von gesunden Europäern und Eingeborenen is den Tropen I 445, 446; von Anämischen daselbst I 447 ;

Tagesschwankungen, Einfl. der Nahrungsaufnahme b. gesunden Menschen I $450-451$;

bei Krankheiten :

Hysterie, Anämie, Magenleiden (Anacidität) I 451; Carcinoma pylori, Diabetes Nephritis lev., Neurasthenie, Reconvalescenz, Pleuritis, Recouvalescenz-Pneun onie I 452 ;

II. Brightii, Apoplexie, Neurasthenie, Chorioretinitis Ischias, Herzkrank heit, Eklampsie, Diabetes I 470;

Insuff. Mitralis, fettige Degeneration des Herzens, Insuff. Aortae, Congenitale Cyanose, Herzkrankheit, Urämie, Nephritis, Hämoglobinurie, Febris typhoidea, Malaria, Pneumonie, Ascites, Kmpyema I 471;

hei acutem Fieberanfall II 17;

Blutentziehungen I 452 ;

bei wirbellosen Seethieren I 462;
Osmotisclier Druck:

bei vertslraten Secthieren T 462-466;

Knorpelfische (Selachier), Torpedo marmorata Risso I 463;

Mustelus vulgaris I 463, 465;

Trygon Violacea I 463;

Scyllium canicula u. Catulus 1465 ;

Centrina, Galeus canis, Raja undulata I 465 ;

Knochenfische (Teleostier), Charax puntazzo, Cerna (Serranus) gigas I 464;

Thalassochelys Caretta I 465;

Lophius piscatorius, Orthagoriscus Mola I 466 ;

bei Seereptilien Chelonea Cavuana I 466; bei Seesäugethieren:

Delphinius Phocaena (Braunfisch) I 466; Beziehung zum Milieu interne I 466; unter versehiedenen erperimentellen Einflüssen I 466-474;

Milzexstirpation, Asphyxie; Compressio Jugularis; v, porta und v. hepatica I 467 ;

Nahrungsenthaltung, Blutentziehung I 468;

Peptoneinspritzung I 469;

Phosphor I 469;

Durchschneidung d. verlängerten Marks I 469 ;

Unterbindung des Duct. Thorac. I 470;

Osınot. Druck des Eiweisses im Serum I 487-489. - II 6, 52; siehe übrigens unter "Collo:̈de".

Tiegelung d. osmot. Drueks bei hydrämischer Plethora durch hyperisotonische Lösungen II 3, 19; durch hypisotonische Lïsungen II 10, 19;

Betheiligung der Nieren II 12, 14;

der Speichel-, Thränen- u. Li eber $k$ ü hnschen Drüsen und der Diffusion II 1.j; des Blutes in der r. und 1. Herzhälfte bei Ertrinken II 19;

des Frosches nach Austrocknem II 23; bei Durst II 23;

Regelung bei Hydrimie und Anhydramie II 20, 22 25;

Regrelung d. osm. Dr. d. Bl. bei Nieren-, Herz- u. Infectionskrankheiten II 29; 
Osmotischer Druck:

Regelung des osmotischen Drucks nach intravenösen Injectionen bei Nierenausschaltung II 14, 15, 100;

osmotischer Druck d. Lymphe aus dem Duct. thoracicus hierbei II 14;

Regclung in der Bauchliöhle auch bei todten Thieren II 93, 105;

Regelung in der Pericardialhöhle bei lehenden Thieren II 135;

bei todten Thieren II 139;

Regelung in der Pleurahöhle II 143;

Osmotischer Druck von Exsudaten II 147;

Osmot. Druck von Eiweiss I 487-4\$9. - II 6, 152; Bedeutung für die Resorption von Salzlösungen II 152, 162 ; Einfluss bei der Darmresorption II 220; Bedeutung für die Bildung und Zusammensetzung des Gilomerulusfiltrats II 397, 398, 403, 415, 417; siehe auch unter "Colloïde“.

Osinot. Druck v. Rauenthaler Wein, Bordeaux, Schulttheiss Versandtbier, Fleischsaft, Brühsuppe, Kaffee II 224;

Regclung im Magen II 224, 227, 228. - III 321;

Regelung in der Magenwand von Aplysien II 225;

des Magensaftes II 225, 228 ;

Regelung in der Harnblase. II 234;

eines Leiters, Beeinflussung durch einen Nichtleiter II 240;

des Blutserums nach einseitiger Nierenexstirpation II 276 ;

Kautelen für ein constantes $\Delta$ des Blutes II 279;

Blutserum, Einfluss der Nahrungsaufnahme II 282 ;

des Harns beider Nieren II 283;

Bestimmung durch die Blutkörperchenmethode (Farbstoffaustritt) II $304 \mathrm{ff}$; der Lymphe aus dem Halslymphgefässe II 36 ;

der Leberlymphe II 40 ;

des Drüsensecretes von Oetopus macropus, Sepia officinalis, Aplysia limacina, Aplysia depilans II 431;
Osmotischer Druck:

der Galle II 444 ff.; nach Salz- und Wassergaben II 447;

Beziehung zu dem des Blutserums II 446 ;

der Milch unter verschiedenen Umständen II $448 \mathrm{ff}$. (siehe weiter unter Milch);

Beziehung des osmotischen Druckes der Milch zu dem des Blutserums II 460; Beziehung zur Nahrung II 461;

Widerstandsfähigkeit von Spermatozoen und Protoplasma gegen Aenderungen des osmotischen Druckes III 3 ;

von Colloiden, Bedeutung für die Re. sorption und aie Nierenthätigkeit III 64 ;

Bedeutung für die Concentration der mit der Muskelsubstanz isotonisclien Salzlösung III 134;

von Suspensionen III 64;

von Lymphe der Froschleber III 135;

von Colloiden II 40;

Methode zur Bestimmung des osmotischen Druckes von Colloiden III 135; von Humor aquaeus III 163; Beziehung zu dem des Blutserums III 165;

des Glaskörpers III 165;

der Linse III 166; Beziehung zu dem des Blutserums III 167, 168;

Künstliche Parthenogenesis durch Steigerung des osmotischen Druckes des Seewassers III 176;

des Blutserums bei Gebärenden und in der Schwangerschaft im Vergleich mit normalem III 217;

des Blutserums durch das Trinken von Mineralwässern III $313 \mathrm{ff}$; von warmem Wasser III 314;

des Chylus bei alimentären Eingriffen III 316 ;

des Harns nach Mineralwassergenuss III 316,318 ;

von Mineralwässern. Bedeutung für die Praxis III 319;

Berücksichtigung des osmot. Druckes bei der Fixirung von Zellen und Geweben I 463. - III 405, 410; 
Osmotischer D r uck:

von mütterlichem und fötalem Blut und Fruchtwasser, siehe unter Mütterliches und fötales Blut ${ }^{*}$ und unter "Fruchtwasser";

des Speichels, siehe unter, Speichel": voll Ascitesflüssigkeit II 73 ;

phylogenetische Entwicklung des osmotischen Drucks II 24.

Osmotisches Verhalten isolirter Zellen III 1;

Siehe weiter unter den verschiedenen Zellen.

Osmotische Verhältnisse des circulirenden Blutes unter experimentellen Eingriffen Il 1; siehe weiter unter, Osmotischer Druck“. Osmotometrische Methode zur Untersuchung der Permeabilität von Pflanzenzellen III 226.

Ostwald's Verdünnungsgesetz II 480 . Oxa lsäure, Leitfähigkeit I 152.

$\mathrm{Oxa}$ Is äurean ion $=\mathrm{C}_{2} \mathrm{O}^{\prime \prime}{ }_{4}$, Wandernngsgeschwindigkeit (Leitfähigkeit) I 42, 138,155 .

Oxydationsketten I 62.

Oxy dehy dra c etsäure, Leitfähigkeit I 151.

P.

Parald ehyd, Permeabilität der rothen Blutkörperchen I 215;

Permeabilität der Pflanzenzellen I 216. Parenchymatöse Schwellung von Leber-, Milz- und Nierenparenchymzellen III 49 ;

durch Abnahme der Alkalinität des Blutserums III 50 ;

Siehe weiter unter "Leber-, Milz- und Nierenparenchymzellen".

Parthenogenesis, künstliche, durch Steigerung des osmotischen Drucks des Seewassers III 176; durch Ionen III 176; durch Schütteln der Eier III 177;
Parthenogenesis:

Vergleichung des Entwicklungranges der Eier mit dem nach natïlicher Befruchtung mit Spermatozoen III 178;

kïnstliche Zwergformen III 178;

Agglutination der Furchungskugeln, Riesenembryonen III 179;

Bedentung der künstlichen Parthenogenesis für die Auffassung der natürlichen Befruchtung und der Lebenselscheinungen im Allgemeinen III 179;

Neigung zur parthenogenetischen Entwicklung bei Eiern von Crustaceen und Säugethieren III 180.

Pepton, Osmotischer Druck des Blutes nach Einspritzung von - I 469:

zerstörende Wirkung auf Leukocyten II 43 ;

lymphagoge Wirkung, Erklärungen von Starling und Colnstein II 45; Bindung an Salzsïure und andere Süuren II 503 ;

untel'sucht mittelst Leitfähigkeit II 504; untersucht mittelst der Inversion II 506 ; untersucht mittelst Gefrierpunkterniedrigung II 508;

Bindung an $\mathrm{NaOH}$ II 509 ;

untersucht mittelst der Gaskette II 510 .

Perchlorsäureanion, Leitfähigkeit I 149.

Pericardialhöhle, siehe unter Resorption und osmotischer Druckregelung in der Pericardialhöhle.

Perimysium, externum und internum, Permeabilitätsverhältnisse III 133.

Peristaltik als Factor bei Erzeugung des intraintestinalen Druckes II 191.

Perjodsäure, Leitfähigkeit I 154.

Perjodsäureanion, Leitfähigkeit I 149.

Permangansäurean ion, Leitfähigkeit I 149.

Permeahilität I 26 ;

tabellarische Uebersicht über die Permeabilität von Blutkörperchen und Pflanzenzellen für verschiedeno Stoffe I 217-219; 
Permeabilität:

kritische Bemerkungen über die Untersuchungsmethoden von Gryns, $\mathrm{He}$ din und Overton I 219-221;

der Blasenschleimhaut für Harnstoff II 238 ;

der Blutcapillaren II 157 ;

$\operatorname{der} G$ efässwand bei der normalen Lymphbildung II 62, 64;

bei der Einwirkung von Lymphagoga II 84,90 ;

der Haut bei Fröschen II 23, 24;

der rothen Blutkörperehen I 202-261;

für Chlor (Ha mburger) I 206, 210;

Anschauungen von Gi yns I 206-210:

Permeab. für Ammoniumifluorid, -chlorid, -jodid, -borat, -acetat, -propionat, -butyrat, -capronat, -oxalat, -malonat, -benzoat, -phenylacetat, -hydrocinna. mat ( $\beta$-phenylpropionat), -hippurat, -salicylat, -acrylat, Methylalkohol, Aethylalkolıol, Glycerin, Aetlıy äther, Butylmethyläther, A ethylacetat, Acetamid, Propionamid, Harnstoff, Biuret, Pyridin I 207;

Ammoniumnitrat, -sulfat, -thiocyanid, -phosphat, Lithiumchlorid, Natriumchlorid, -bromid, -fluorid, sulfat, -nitrat, Kaliumchlorid, -bromid, -jodid, Calciumchlorid, Strontiumchlorid, Baryumchlorid, Magnesiumchlorid, Ammoniumferrocyanid, -ferricyanid, -lactat, -tartrat I 208;

Ammoniumsuccinat, -citrat, -malat, Glykocoll, Asparagin, Asparaginammo. niak, Natriumacetat, -propionat, -malonat, Phenylacetat, -oxalat, -hippurat, Dextrose, Mannit, Inosit, Saccharose, Lactose I 209;

Untersuchungen von Hedin I 210215:

Princip seiner Untersuchungsmethoden I $210-212$;

Permeab, für Chlorkalium, Kaliumnitrat, Natriumnitrat, Bromkalium, Kaliumsulfat I 2i2;

Amidosäuren, Zuckerarten (Rohrzucker, 'l'raubenzucker, Galactose,
Arabinose), für mehrwerthige Alkohole (Mannit, Arabit, Erythrit, Glycerin, Aethylenglykol) I 213;

Ammoniaksalze, Antipyrin, Harnstoff, Urethan, Acetamid I 215;

einwerthige Alkohole (Methyl-, Aethyl-, Propyl-, Isopropyl-, Isobutyl-, Amyl-, Benzyl-, Allylalkohol), für Paraldehyd I 215;

Aldehyde, Ketone, Aetherarten und Ester (Formaldehyd, Acetaldehyd, Propylaldehyd, C'hloralhydrat, Furfurol, Aceton, Methyläthylketon, Aethyläther, Methylal, Essigsäuremethylester, Essigsäureäthylester I 215;

Untersuchungen von Oke - B l o m I 221 :

Permeabilität für $\mathrm{KCl}, \mathrm{K}_{2} \mathrm{SO}_{4}, \mathrm{NH}_{4} \mathrm{Cl}$, $\left(\mathrm{NH}_{4}\right)_{2} \mathrm{SO}_{4}, \mathrm{MgSO}_{4} \mathrm{I} 222,223$;

kritische Bemerkungen $\mathrm{zu}$ der Methode I 223, 224;

Untersuchungen von $\mathrm{K}$ oeppe $\mathrm{I} 224$ :

Permeab. für $\mathrm{KNO}_{3} \mathrm{I} 224,225$;

$\mathrm{KCl}, \mathrm{NaCl}, \mathrm{K}_{2} \mathrm{SO}_{4} \mathrm{I} 225$;

$\mathrm{Na}_{2} \mathrm{SO}_{4}, \mathrm{~K}_{2} \mathrm{CO}_{3}, \mathrm{NaHCO}_{3}$ I 226 ;

$\mathrm{K}, \mathrm{Na} \cdot \mathrm{I} 228$;

$\mathrm{Cl}^{\prime}, \mathrm{CO}_{3}{ }^{\prime \prime} \mathrm{I} 229$;

$\mathrm{SO}_{4}{ }^{\prime \prime}$ und $\mathrm{NO}_{3}{ }^{\prime} \mathrm{I} 230$;

$\left(\mathrm{NH}_{4}\right)^{\circ}$ und $\left(\mathrm{NH}_{4}\right)_{2} \mathrm{SO}_{4} \mathrm{I} 231$;

Kritik I 227-230;

Untersuchungen von Willerding für $\mathrm{Cl}^{\prime}$ - und $\mathrm{SO}_{4}$ "-Ionen I 232-234;

Neue Versuche von Hamburger mit van Lier und van der Schroeff I 234-25\%:

Permeab. für $\mathrm{Cl}^{\prime} \mathrm{I} 235$;

für $\mathrm{NO}_{3}{ }^{\prime}$ und $\mathrm{SO}_{4}{ }^{\prime \prime} \mathrm{I} 236-252$;

für die Anionen von Jodnatrium, Bromnatrium, milchsaurem, citronensaurem, salicylsaurem, oxalsaurem, phosphorsaurem, arsensaurem Natron, Borax und $\mathrm{MgSO}_{4}$ I 251;

Zusammenfassung I 252;

der weissen Blutkörperchen, Permeab. für $\mathrm{Cl}^{\prime}, \mathrm{NO}_{3}{ }^{\prime}, \mathrm{CO}_{3}{ }^{\prime \prime}, \mathrm{CO}_{4}{ }^{\prime \prime}$-Ionen I 423429 ;

für die Anionen von Natriumphosphat, -oxalat, -salicylat, -jodid, -bromid, -benzoat, -arseniat I 429-432; 
Permeabilität des Darmepithcls, Künstliche Modification III 13, 16;

des Darmes für Ionen II 196;

der Glomerulusepithclschicht II 397, 403;

des Harnblasenepithels III 24, 30, 34;

der Kerne II 20. - III 26, 30, 35;

der Kiemen II 23, 225;

der Lymphdrüsenzellen für die Anionen von Natriumsalzen III 37;

Siehe weiter unter Lymphdrüsenzellen; der Magenwand für $\mathrm{NaCl}, \mathrm{Cl}^{\prime}-$ Ionen, $\mathrm{H}^{-}$Ionen II 440;

von Membranen für Ionen, unter verschiedenen Bedingungen II 220; ihre Bedeutung für die E.M.K. der Concentrationskette III 153;

der. Muskielhïllen, Einfluss auf die Grösse des Demarcationsstromes III 154;

der. Iuskelsubstanz für die verschiedenen Gruppen organischer, sowie für einige anorganische Verbindungen III 139;

Bedingungen für den Grad der Permeabilität III 142 ;

Uebereinstimmung mit der von anderen thierischen Zellen und mit der von Pflanzenzeilen III 143;

Kritische Bemerkungen dazu III 144; des Oesophagusepithels III 23;

ron Pflanzenzellen, Untersuchungen von Overton I 215:

Permeab. für Mineralsalze, Zuckerarten, Amidosäuren I 216;

mohrwerthige Alkohole (Aethylenglykol, Glycerin, Arabinose, Erythrit, Mannit), Harnstoff, Methylalkohol, Aethylalkohol, Isopropylalkohol, Isobutylalkohol, Amylalkohol, Allylalkohol, Aethyläther; Essigsäure-Aethylester, Phosphorsä ure-Aethylester, Aethyl-Urethan, Formaldehyd, Acetaldehyd, Paraldehyd, Propylaldehyd, Isobutylaldehyd, Chloralhydrat, Aceton, Sulfonal, Methylal, Methylcyanid, Aethylcyanid, Furfurol, Coffeïn I 216;

Aromatische Verbindungen: Anilin, Formanilid, Acetanilid, Phenol, Resorcin, Orcin, Phloroglucin, Antipyrin, Ammoniak, Alkaloide I 217;
Permeabilit it:

Untersuchung der Permeal. v. Pflanzenzellen mittelst Gerbs:iure I 217;

zur Untersuchung der Giftigkeit von Substanzen für das thierische Protoplasma III 223, 22\%;

Siehe weiter die Unters. v. V andevelde III 232 u. unter "Plasmolyt. Methode" und "Tanninmethode". der Blutkörperehenschatten I 399;

des Tracheaepithels III 21;

der Zellkerne III 23 ;

zon Zellen für basische Anilinfarbstotte.

Bedeutung für die intravitale Färbung III 426.

Permeabilitätsunterschied in zwei Richtungen II 216.

Perschwef $\theta$ ls ä ureanion, Leitfăhigkeit I 154.

Pharmakologisches, siebentes Kapitel III 222;

Wirkung eines Giftes oder Arzneimittels auf bestimmte Gewebelemente, mit Ausschluss aller übrigen III 224.

Phasen, Bildung von zwei - bei Erstarrung von Gelatine III 402;

Zusammensetzung der Muskelsubstanz aus zwei - III 136;

siehe auch das Kapitel "Colloide".

Phasenlehre III 132;

Anwendung auf die Zusammensetzung der Ionenproteide III 132.

Pferd, Serum, Leitfähigkeit I 476, 477: Osmot. Analyse I 491, 492, 494;

Gefrierpunkterniedrigung ; specifisches Gewicht, Leitfähigkeit, Eiweissgehalt, NaCl-Gehalt I 494;

Concentration d. Elektrolyte, Nicht-Elektrolyte, Aclıloride I 496, 498;

Zusammensetzung von Blut, Blutkörperchen, Serum I 506, 507.

Phagocyten I 400, 402.

Plienol, Permeabilität der Pflanzenzellen I 217;

Desinficirende Wirkung, Beeinflussung durch $\mathrm{NaCl}$ und andere Elektrolyte III 265 .

Phenolphtaleïn I 60, 61 . 
Phenylacetat, Permeab. der rothen Blutkörperchen I 209.

Pheny lglyko] säure, Leitfähigk. I 151.

Phenylhippurat, Permeab. d. rothen Blutkörperchen I 209.

Phenyloxalat, Permeab. der rothen Blutkörperchen I 209.

Phenylpropi o lsä ure. Leitfähigk. I 151.

Phenylpyridindicarbonsäureanion Leitfähigkeit I 156.

Phlor ogluc in, Permeab. der Pflanzenzellen I 217.

Phloroglucin-Vanillin II 492, 595.

Phosphoniumverbindungen, Leitfähigkeit :

Tetramethylphosphonium, Teträthyl. phosphonium, Methyltriphenylphosphonium, Äthyltriphenylphosphonium, Propyltriphenylphosphonium, Isoamyltriphenylphosphonium, Triphenylbenzylphosphonium, Tetrabenzylphosphonium I 145.

Phosphor, Osmot. Druck des Blutes nach Einverleibung I 469.

Phosphorsäure, Beziehung zwischen Dissociationsgrad und Eiweissverdauung II 502.

Phosphorsäure-A etliylester, Permeabilität der Pflanzenzellen I 216.

Phosphorsäureanion, Leitfähigkeit; Siehe Orthophosphorsäureanion.

Phosphorsäurelösungen, Gefrierpunkterniedrigung I 87;

Leitfähigkeit I 131.

Phtalanilsäure, Leitfähigkeit I 151;

Phtalsä ureani o n, Leitfähigk. I 155.

Phtalursäure, Leitfähigkeit I 151.

Physikalisch-technische Reichsanstalt, Prüfung v. Rlieostaten I 113; Prüfung von Normal-Elementen II 356.

Physiologische Kochsalzlösung I $179,182,183,187,189,196$;

Discussion zwischen Bleibtre u, Hamburger, Hedin und Anderen über dieselbe I 188, 189;

und Wasseraufnahmefähigkeit I 200 ; mit Bezug auf das Leitvermögen I 482; Vergl. auch III 120, 123.
Physiologische Leitfähigkeit des Serums I 480;

des Serums von gesunden und kranken

Menschen I 484-486;

von Blut und Serum I 537, 539.

Physiologische Selection III 395.

Phytalbumosen III 341 ;

Agglutinitirendes Vermögen III 341 ;

Hämolytisches Vermögen III 342 ;

Beziehung zwischen beiden III 342 .

Pikrinsäure, Leitfähigkeit I 150.

Pimelinsäureani on, Leitfähigk. I 155.

Piperazin zur Auflösung von Concrementen III 279.

Piperidin, Permeabilität der Pflanzenzellen für dasselbe III 232.

Plasma, Gewinnung I 267.

$\mathrm{Pl}$ asmolyse, v. Zellen höherer Pflanzen I 22,162 ;

von Typhusbacillen, Spirillum Undula,

Cholera, B. fluorescens mit einhergehender kräftiger Geisselbewegung III 331 ;

Gefahr derselben III 337.

Plasmolyseartige Erscheinungen bei Frosch-, Fisch- u. Vogelblutkörperchen I $178-183$.

Plasmolytische Methode zur Bestimmung des osmotischen Druckes von Flüssigkeiten I 437, 438;

zur Untersuchung der Permeab. von Pflanzenzellen III 226, 232:

Zuver]ässigkeit und Tragweite $d . \mathrm{Me}^{-}$ thode I 219, III 144, 237 ;

Verhalten der Amidosäuregruppe, Carboxylgruppe, Säureamidgruppe, alkoholischen Hydroxylgruppe, Aldehydgruppe III 228.

Plasmoptyse bei Bacterien, Ursache III 335 ;

weiteres Verhalten nacin Plasmoptyse III 336 ;

durch Einwirkung von Wasser auf Milzbrandbacillen III 338.

Platinchlor wasserstoff fä urea nion, Leitfähigkeit I 155.

Platinirung von Elektroden d. Widerstandsgefässe I 104; 
Platinirung von Elektroden der Gaskette II $34 \mathrm{~S}$.

Plat ochlorwasserstoffs äu reanion, Leitfähigkeit I 155 .

Platocy anwasserstoffsäu reanion, Leitfähigkeit I 154 .

Plat od i a m on $\mathrm{m}$ m i on, Leitfähig. keit I 153.

Plattenverfa hre $\mathbf{l}$, Fehler bei der Zählung der Colonien I 283.

Pleurahöhle, Siehe unter Resorption und osmotische Durchregelung.

Ple uritis, Gsmotischer Druck des Blutes I 4.52 .

Pne u m o i e, Osmotischer Druck des Blutes I 452, 471;

Gehalt des Blutserums an Chlor, Ki. weiss, Wasser II 18;

Polarisation der Hiektroden I 105; des Lichtes, durch Colloïde III 62; durch gefärbtes Glas III 63; durch Zuckerlösuugen III 63.

Polychlorurie II 257.

Polymere Ionen I 48; Wanderungsgeschwindigkeit I 48.

Polymerisation v. Molecillen in verschiedenen Medien III 246, 384, 416.

Polyurie II 257.

Potentielle I o nen II 331, 484.

Potenzirung III 242.

Präcisionskryoskopie, Apparat v. R a o lt I 71;

Genauigkeit der Resultate mit diesem Apparat I 73 ;

Modificat. v. Ponsot am Apparat I 73; Apparat v. Nernst und Abegg I 74; Genauigkeit der Resultate mit diesem Apparat I 76;

Numerische Ergebnisse I 76-89.

Präparator III 351 .

Propargylentetra carbonsäurea n i o n, Leitfähigkeit I 157.

Propionamid, Permeabilität d. rothen Blutkörperchen I 207.

Propionsäure, Leitfähigkeit I 150.

Propylaldehyd, Permeab. der rothen Blutkörperchen I 215;

Permeab. der Pflanzenzellen I 216.
Propylalkohol, Permeab. der rothen Blutkörperchen I 215.

Propy ls ch we fe ls ä u re, Leitfahigkeit I 152

Prototoxin III 369 .

Prototoxoid III 330 .

Pseudoosm otischer Druck III 64.

Psychische Hemmung, Einfluss b. der Geschmackempfindung III 174.

Pus bonum et laudabile I 412. - II 415. Pyridin, Leitfảhigkeit I 147 ;

Permeab. d. 1. Blutkörperchen I 207;

Permeabilität d. Pflanzenzellen für dasselbe III 232.

Pyridinpentacarbons äurea $n$ i o n, Leitfähigkeit I 157.

Pyridintetracarbons ä urea $n$ i o $n$, Leitfähigkeit I 157.

P y r idintricarbons ä urea n i o n, Leitfähigkeit I 156, 157.

Pyrophosphorsä n reanion, Leitfähigkeit I 157.

Pyroschweflige Säureanion, Beweglichkeit I 154;

Leitfähigkeit I 154.

P y r o we ins ä u rea n i on, Leitfähigkeit I 155.

(2.

Quecksilber, therapeutische Anwendung III 253 ff.;

Ungiftigk eit d. (complexen) unterschwefligsauren Kalisalzes für Hefezellen III 254;

desgl. für den Menschen III 255;

Verhalten im Körper III 256.

Quecksilberegulator I 112.

Quecksilbersalze, Desinficirende Wirkung ihrer Kationen III 257;

ihrer Anionen III 258.

Quellung der rothen Blutkörperchen in hypisotonischen Lösungen, quantitative Bestimmung beim Pferd I 352;

beim Kaninchen I 353;

beim Frosch I 354;

beim Huhn I 355 ;

Beeinflussung durch Ionen II 199. 
Quellungswasser in der Muskelsubstanz III 137;

des Colloïds, Bedeutung für die Färbung III 415.

\section{R.}

Reactionsconstante (k) siehe Geschwindigkeitsconstante (k).

Reactionsgeschwindigkeit I 43, II 467 ;

in Gallerten II 475;

bei reversiblen Vorgängen III 95;

bei der Hämolyse durch Bacteriengifte III $363 \mathrm{ff}$;

bei der Hämolyse durch Ammoniak und $\mathrm{NaOH}$ III 367;

Einfluss verschiedener Momente auf die Geschwindigkeit der Hämolyse III 368.

Reactionsgleichgewicht II 466.

Reactionsverlauf II 466 ;

bei katalytischen Processen III 85; in colloidalen Medien III 89.

Receptoren in der Seitenkettentheorie III 346.

Reductionsketten I 62 .

Refractäres Stadium des Herzens, Beeinflussung durch Ca*-Ionen III 124.

Refractometrische Untersuchung des Harns II 329.

Regeneration von Bacterien nach Plasmophyse III 338;

von rothen Blutkörperchen nach Farbstoffverlust III 338.

R eizung, Wesen der elektrischen Reizung III 159.

Resistenz der rothen Blutkörperchen I 359-394, III 204;

gegenüber verschiedener Agentien I 361 ; gegeniiber Salzlösungen, nach M a l a s s e z

I 361; nach Chanel I 362; nach

Lando is I 362 ; nach Hambur ger

I 362; Analyse der Factoren I 369 -378 .

Minimum- und Maximumresistenz I $362-363,388-389$;
Resistenz der rothen Blutkörperchen:

Relative Resistenz I 372;

Einflïsse von:

Alter I 363,364 ;

Geschlecht, Schwangerschaft, Wochen. bett, Lactation, Menstruation, Hunger I 364 ;

Hunger, MuskeIarbeit, Milzexstirpation, Fieber, Aderlass, Blutung, Febris typhoidea, Pneumonie, Pleuritis, Erysipelas Faciei I 365 ;

paroxystische Hämoglobinurie, Tuberculosis pulmonum, Dyspnoea, Cyanose, Chlorose, perniciöse Anämie, Carcinom, atrophische Lebercirrhose, Melancholie, Neurasthenie, Epilepsie, Dementia posthaemioplegica, Paralysis von alkoholischem und syphilitischem Ursprung, Idiotie, Hysterie, Dementia senilis I 366 ;

Icterus, Malariafieber, Anaemia Saturnina, Toxine, Sublimat, Cocain, Chinin, Chloroform I 368;

fötalen und mütterlichen Blutes I 383 ; neue Methode zur Bestimmung der Resistenz, bei welcher Einheit der Angaben gesichert ist I 378-382;

Anwendung trichterförmiger Röhrchen bei derselben I 379;

Angabe der Resistenz I 382;

Resistenzbreite I 383 ;

Zusammenfassung der Ausfïhrungen ïber dic liesistenz I 390-394;

Resistenzbreite bei fötalem Blut III 191, 195, 202;

Wesen der Resistenz III 204;

Resorcin, Permeabilität der Pflanzenzellen I 217.

Resorption in der Bauchhöhle bei Unterbindung der Nierenarterien JI 97; Einfl. d. Cireulation auf dieselbe II 99; Einfluss der mitschleppenden Wirkung des Blutstroms II 111, 118, 161;

Betheiligung der Lymphgefässe II 101 ; bei chemischer und thermischer Schädigung des Peritoneums II 102; 
Resorption in der ba ch chöhle: bei todten Thieren II 105; physikalische Erklärung II 108; Einfluss des intra-abdominalen Druckes II 118;

Einfluss der Strömungsgeschwindigkeit des Blutes II 119;

Diffusionserscheinungen II 133 ;

Bedeutung des osmotischen Druckes des Eiweisses II 162.

Resorption in den Gewebespalten II 146 ;

Betheiligung der Blutgefässe II 148;

Einfluss des Druckes II 151;

Bedeutung des Eiweissgehaltes des Blutserums II 151.

Resorption in der Pericardialhöhle II 134;

bei lebenden Thieren II 134;

bei todten Thieren II 139;

Resorption in der Pleurahöhle II 142;

bei Schädigung mittels NaFl II 144.

Resorption in serösen Höhlen und Bindegewebespalten II 92;

Zusammenfassung und Schluss II 158;

siehe ïbrigens unter Resorption in

Bauch-, Pericardial-, Pleurahöhle und Gew ebespalten.

Resorption im Darme II 167; physiologische Triebkräfte II 168;

Einfluss von NaFl II 169;

Resorptionsvermögen in verschiedenen

Theilen des Darmes II 169, 181;

verschiedener Salze II 170;

bei todten Thieren II 171;

Einfluss des intraintestinalen Druckes II 174,193 ;

Abnahme derselben bei längerem Aufenthalt von Flïssigketen in Darme II 183; Ursache dieser Erscheinung II 184 ;

Verfahren zur Untersuchung des negativen intratestinalen Druckes II 188, 194;

Bedeutung der Lebensthätigkeit bei der physikalischen Auffassung II 190;

H a mburger, Osmot. Druck. III. Band.
Resorption im Darme:

Factoren bei der Erzeugung des intratestinalen Druckes II 191;

Bedeutung der Strömungsgeschwindig. keit des Blutes II 194;

physikalische Eactoren II 195, 201;

Permeabilitätsverhältnisse für Ionen II 196 ;

Beziehung zur Diffusionsgeschwindig. keit der Ionen II 197, 210;

Einfluss physikalischer und chemischer

- Factoren auf die Resorptionsgeschwindigkeit II 198;

Einfluss der Bildung unlöslicher und anderer Verbindungen im Darmepithel II 199;

von stereosisomeren Zuckerarten II 200; Betheiligung der Lympbahnen II 201; capillare Imbibition I1 201;

Einwände gegen die physikalische Auffassung II 202 ;

Unterschiede der Resorptionsverbältnisse im lebenden und todten Darme II 202;

Pesorptionsverhältnisse bei Schädigung durch NaFl und Arsenik II 205;

im überlebenden Darm (in Blut und Ringer'scher Flüssigkeit) II 207;

von Pepton und Glukose II 209, 213; von Maltose II 210;

von $\mathrm{NaCl}$ II 213;

Einfluss von Anämie (durch Aderlass, Reizung d. Mesenterialnerven, Ligatur der Gefässe) und von Giften II 210; von Blutserum II 210;

als eine Lebensthätigkeit II 209, 211, 216, 219;

Thätigkeit der Darmzotten II 211, 220. Bedeutung der Adsorption II 212;

Bedeutung der Imbibition II 212;

Zusammenfassung und. Schluss II 213. ff;

Untersuchungen Heidenlıain's über das Verhalten isotonischer und anisotonischer Lösungen in normalen und geschädigten Darmsclılingen II 213;

Verhalten in todten Darusclilingen II 213 ; 
Resorption im Darme:

intraintestinaler Druck II 214;

Athmung, Peristaltik, Gewiclit des Darmes II 214;

Einfluss der Imbibition II 214;

Kinfluss des Blutstromes II 214, 215; Einfluss des Filtrationsdruckes II 215;

Regelung des osmotischen Druckes im Darm II 215;

Verhalten des lebenden und todten Darmes gegenüber Zucker II 215;

Bethatigung der Kittsubstanz II 217;

Verhalten des lebenden und todten Darmes II 217;

Resorptionsgeschwindigkeit verschiedener Salze II 217;

Resorptionsgeschwindigkeit verschiedener Ionen II 217;

Beziehung zur purgativen Wirkung von $\mathrm{MgSO}_{4}$ II 217 ;

Einfluss der Diffusionsgeschwindigkeit auf die Resorption II 217 ;

Parallelismus zwischen Resorption und Diffusionsgeschwindigkeit II 218;

Einfluss der Membran auf die Resorption II 218;

Einwände gegen die mechanische Auffassung II 219 ;

Einfluss des osmotischen Druckes des Eiweisses II 220.

Resorption in der Harnblase II 231 ;

Historisch-kritische Bemerkungen II 232 ;

Teclınische Fehier und Schwierigkeiten bei der Untersuchung II 233;

Regelung des osmotischen Druckes II 234;

Permeabilitätsverhältnisse verschiede. ner Stoffe II 236; von Harnstoff II 238; von Traubenzucker II 235;

Bedeutung der Kittsubstanz II 244;

Bedeutung der melirfachen EpithelzellenSchicht II 246;

Zusammenfassung II 246.

Resorption im Magen II 221;

von Wasser und gelösten Substanzen II 221, 222, 224;
Resorption im Magen:

Untersucbungen von R oth und Strauss über die Resorption von Traubenzucker- und Kochsalzlösungen II 222 ;

Betheiligung der Diffusion II 223, 228 ;

Regelung des osmotischen Druckes beim Menschen II 224;

bei Aplysien II 225;

Untersuchungen von $\mathrm{Pfeiffer}$ und Sommer über das osmotische und resorptive Verhalten des Magens gegenüber $\mathrm{Na}_{2} \mathrm{SO}_{4}, \mathrm{NaCl}$ und $\mathrm{MgSO}_{4}$ Lösungen II 226;

Diffusion II 227;

Zusammenfassung und Schluss II 228;

Regelung des osmotischen Druckes II 228 ;

Diffusion II 228;

Vergleichung dieser Regelung mit der in serösen Höhlen II 230.

Resorption in den Harnkanälchen II 403, 416, 419;

im intracapsulären Raum des Corpusc. Malpighii II 418;

Resorption seitens der Tracheaschleimhaut III 23.

Resorptionsbahnen in der Bauch. hölle II 93.

Respiratorischer Gaswechsel, Einfluss auf die Vertheilung der Blutbestand theile über Körperchen und Flüssigkeit I 261; auf die Grenzlösungen für den Farbstoffaustritt aus rothen Blutkörperchen I 261; auf die Zusammensetzung des Serums I 262;

Unkehrbarkeit der durch den respiratorischen Gaswechsel herbeigeführten Veränderungen I 263;

Einfluss der Vertheilung der Blutbestandtheile für die Oxydation und die Ernährung der Gewebe I 278;

linfluss des respiratorisch. Gaswechsels auf die Gestalt der rothen Blutkörperchen I 311 ;

Einfluss auf Volumen und Dimensionen der weissen Blutkörperchen I 402405. 
Reversible Reaction, Auffassung der Enzymwirkung als - III 97;

Betrachitung der Umsetzung vou Saccharose durch Invertase von diesem Gesichtspunkt III 98; s. W. unter. „Gleichgewicht" und ,Gleichgewichtsreactionen".

Rhenser Sprudel, Chemische und physikalisch-chemische Analyse III 294.

Rhe ochord, Siehe Messbrücke.

Rheostat I 113;

Prüfung I 113;

Reinigung und Ëinsetzen der Stöpsel I 113;

für die elektrochemische Bestimmung der Acidität und Alkalität mittelst des Compensat. Verfahrens II 344 ff.

Rhythmus der Herzcontraction, Beeinflussung durch Ca*-lonen III 124.

Ric in III 341.

Riesenembryonen bei künstlicher Parthenogenesis III 179.

R ind, Serum, Leitfähigkeit I 476, 477; Osmotische Concentration I 492; Gefrierpunkterniedrigung, specifisches Gewicht, Leittahigkeit, Eiweissgehalt, NaClGehalt I 494; Concentration der Elektrolyte, NichtElektrolyte, Achloride I 496, 498;

Zusammensetzung von Blut, Blutkörperchen und Serum I 506, 507.

Rinderserum, Leitfähigkeit bei Mutterthier und Fötus I 478.

Ringer'sche Lösung II 207. - III 123.

Rohrzucker, Dissociations- und Activitätscoëfficient I 53 ;

1 einer $1^{\circ}, 0$-igen Lösung mittelst Präcisionskryoskopie I 77;

Permeabilität der rothen Blutkörperchen I 213;

Siehe auch Saccharose.

Rohrzuckerinversion, siehe Inversion und Inversionsconstante.

Rohrzucker lösungen, Gefrierpunkterniedrigung (Tabellen) I $80-82$;

Einfluss auf deu Hämoglobinaustritt aus rothen Blutkörperchen I 165.

Rose o c obaltion, Leitfähigkeit I 156.
Rothe Blutkörperchen I 161 .

Rubidiumion, Leitfäligkeit I 142.

$\mathrm{Rulestrom}$ III 155 ;

Sielie auch Demarcatiousstron.

Saccharose, Permeabilität der rothen Blutkörperchen I 209;

Siehe auch Rohrzucker.

Salicinspaltung durch Emulsiu III 93. Sali cy lsäure, Leitfähigkeit I 151 .

Salpetersäurea nion, s. Nitratanion.

Salpetersä ur e lösu ngen, Gefrierpunkterniedrigung I 88 .

salpetrigesäureanion, Leitfähigkeit I 148.

Sal physiologicum, Prof. Poehl III 123.

Sal zs äure, Activitäts- u. Dissociationscoëfficient I 53 ;

Bildung im Magen II 438 ff.;

Bestimmung der ,freien * Salzsäure im Magensaft II 464;

qualitativer Nachweis II 491;

quantitative Bestimmung II 492 ;

durch Inversion II 493; Methodik im

Allgemeinen II 494; Ausfülırung für

d. Magensaft II 497;

durch Methylacetat II 49s;

Kritik der Nethoden II 499;

Einfluss des Stehens des Magensaftes in der Wärme II 501;

Wahl zwischen Zuckerinversions- und Methylacetatmethode II 501 :

T a lma's Bouillonprobe II 501;

"freie" und gebundene" salzsäure im

Magensaft II j11;

Schlussbemerkungen II 511 ;

Vergl. auclı "Säuren " und Aciditatsbestimmung.

Salzsäurelösungen, Gefrierpunkterniedrigung I 86 ;

Leitvermögen I 131.

S a p o n i n, Blutkörperchenzerstörende Wirkung III 340 ;

Antitoxin für dasselbe III $3 \pm 0$. 
Saponin:

Mechanismus der hämolytischen Wirkung des Saponins III 341;

Volumänderung der rothen Blutkörperchen in Saponin III 361.

S a r k o l e m ma, Permeabiiitätsverhältnisse III 133.

Sauerst offinhalatio nen, Einfluss auf Zusammensetzung d. Blutes II 261; auf Diurese II 263;

Einfluss auf Blutbeschaffenheit, Diurese und $\frac{\Delta}{\mathrm{NaCl}}$ v. Blut und Harn II 263.

Säuren, Einfluss auf den Hämoglobinaustritt aus r. Blutkörperchen I 168;

Einfl. auf Farbstoffaustritt I 318, 319; auf Chlorgehalt $u$. feste Bestandtheile des Serums I 319, 320;

Beziehung zwischen Dissociationsgrad und Rohrzuckerinversion II 494;

zwischen Dissociationsgrad u. kiweissverdauung II 502;

Elektrochemisches Verhalten bei der usflockung v. Eiweiss III 68, 69, 78.

Beziehung zwischen Dissociationsgrad und giftiger Wirkung bei höheren Pflanzen und bei Bacterien III 262; beim Hefepilz III 263;

Verstärkender Einfluss des desinficirenden Vermögens durch Zurückdrängung der Dissociation III 264;

Siehe auch Salzsäure und Acidlitütsbestimmung.

Säure und AIkali, Einfluss auf d. Vertheilung der Blutbestandtheile zwischen Körperchen und Serum I 317-330;

Umkehrbark. d. dadurchịm Blute herbeigeführten Veränderungen I 323-326;

Giltigkeit der Veränderungen für nichtdefibrinirtes Blut I 326 ;

für das circulirende Blut I 329;

Einfluss auf das Volumen u. die Form der rothen Blutkörperchen I 330337 ;

Zusammenfassung und Erklärung der Erscheinungen I 333-337;

Einfluss auf Durchmesser der Leukocyten I 418, 419.
Säur ebindungsve r m ög e n von Eiweiss und Pepton II 503;

Siehe weiter unter Säuren, Eiweiss u. Pepton.

Sch a f, Serum, Leitfähigkeit I 477 ;

Osmotische Concentration I 492;

Gefrierpunkterniedrigung, specifisches Gewicht, Leitfähigkeit, Eiweissgehalt, $\mathrm{NaCl}$-Gehalt I 494;

Concentration der Elektrolyte, NichtElektrolyte, Achloride I 496, 498;

Zusammensetzung von Blut, Serum, Blutkörperchen I 506, 507.

Schatten, Permeabilität I 399.

Schlangengift III 343 .

Schmerz, Beziehung zum osmotischen Druck II 146.

Schrumpfung der rothen Blutkörperchen in hyperisotonischen Lösungen, quantitative Bestimmung derselben beim Pferd I 352; beim Kaninchen I 353; beim Frosch I 354; beim Huln I 355;

Vergl. Bestimmung dieser Schrumpfung bei Blutkörperchen von Mutter und Neugeborenen I 383, III 200.

$\mathrm{Sch}$ an gersch aft, Osmot. Druck (Gefrierpunkt) des Blutes III 217;

Ursache der Abweichung mit normalen Individuen III 217;

Grenzen für den Farbstoffaustritt aus den r. Biutkörperchen III 221.

Schwefelsäure, Activitäts- und Dissociationscoëfficient I 53 ;

Leitfähigkeit I 131;

Beziehung zwischen Dissociationsgrad und Eiweissverdauung II 502.

$\mathrm{Sch}$ we fels äu rei on, Wanderungsgeschwindigkeit (Leitfähigkeit) I 9, 42, 138, 154;

Permeab. der rothen Blutkörperchen I $230,232-234,236-252$.

$\mathrm{Sch}$ e fligesäureanion, Leitfähigkeit I 154.

Sc hw e in, Serum Leitfähigkeit I 476, 477;

Osmotische Concentration I 492;

Gefrierpunkterniedrigung, specifisches Gewicht, Leitfähigkeit, Eiweissgehalt, $\mathrm{NaCl}-G$ ehalt I 495 ; 
Schwein:

Concentration der Elektrolyte, NichtElektrolyte, Achloride I 497, 498;

Zusammensetzung von Blut, Blutkörperchen, Serum I 506, 507.

Se ba cylsäurea nion, Leitfähigkeit I 156.

Se cretionslehre der Lymphbildung II 32 .

Seif en, Löslichkeit v. Wasser in Seifen (feste Lösungen) III 117.

Seitenkettentheorie III 345 :

Anwendung derselben auf die Erklärung der Hämolysinwirkung III 346.

Selection (physiologische) III 395.

S elensäure an i on, Leitfähigkeit I 154.

Semipermeabel I 162.

Sensibilisator I 397 , III 334 ;

Betheiligung bei der Alexinwirkung III 344 ;

Temperaturverhältnisse III 344 ;

Bindungsweise III 350 .

Sensible Nerven, Erregbark. III 158.

Sepia officinalis, $\Delta$ der Tinte II 431.

Seröse Höhlen, s, unter Resorption in serösen Höhlen.

Serum, Wassermenge, die hinzugesetzt werden kann, ohne dass Hämoglobin aus den betreffenden Blutkörperchen austritt I 184;

Ermittlung d. wasseranziehenden Kraft durch die Blıtkörperchenmethode I 185;

Ermittlung der mit demselben isotonischen Salzlösung I 185;

Zusammensetzung bei Einwirkung von $\mathrm{CO}_{2}$ auf das Blut, Umkehrbarkeit b. Austreibung der $\mathrm{CO}_{2}$ I 262-266;

von Carotis und Jugularis, Unterschied, im antibacteriellem Vermögen I 284, 286 ;

Unterschied des Serums vom Blutkuchen und vom defibrinirten Blute I '287, $888,427,477$;

Antibacterielles Vermögen b. arterieller, bei venöser Hyperämie I 288;

Osmot. Druck [ $435-447 \mathrm{ff}$;
Sorum :

Methoden z. Bestimmung I 437-4.i6; Pflauzenzellenmethode I 4:37;

Blutkörperclıenmethode I 43?;

Hämatokritmetlode I 442;

Gefrierpunktmethode I 453 ;

Leitfihigkeit I 474-479;

Beeinflussung durch Eiweiss 1475 ;

durch die Temperatur I 476;

Ionen im Serum I 476;

Nicht-Elektrolyte darin I 476 ;

corrigirte Leitfähigkeit I 475-477;

physiologische Leitfähigkeit, I 480, 537, 539 ;

Einfluss des Stehenlassens auf d. Leitfähigkeit des Serums I 477;

Leitfähigkeit bei verschiedenen Thierspecies I 476, 477;

Vergleichung der Leitfähigkeit von Mutterthier und Foetus I 478;

Dissociationsgrad I 479-486; Einfluss d. Verdünnung auf deuselben I 479;

Einfluss d. Verdürnung auf die Gefrierpunkterniedrigung I 479 ;

des Mcnschen, Leitfähigkeit, I 483-486, 594.

Einfluss der Verdünnung I 484; physiologische Leitfähigkeit I 484;

Leitfähigkeit bei kranken Menschen I 484-486;

Osmotische und osmotisch-clemische Analyse I 486-508;

Osmotische Concentration I 489, 505; Einfl. d. Nahrung auf dieselbe I 505; Einfl. von NaCl-Aufnahme I 505;

Gefrierpunkterniedrigung I 503, 504.

Schwankungen derselben bei gleicher Diät II 25;

Gelialt an Elektrolyten und Nicht-Elektrolyten I 490 ;

des Pferdes, osmotische Analyse I 491, 492 ;

Osmotische Concentration bei Pferd, Rind, Schaf, Schwein, Hund, Katze I 493 ;

von Pferd, Rind, Schaf I 494, 496, 498; voll Schrein, Hund, Katze I 495, 497. 498; 
Serum:

Siehe iubrigens bei den verschiedenen Thieren;

Kritik der osmot. Analyse I 500-502;

Chemische Zusammensetzung bei Rind, Stier, Schaf, Ziege, Pferd, Schwein, Kaninchen, Hund, Katze I 506, 507;

Einfluss der Nahrung und NaCl-Aufnahme auf Leitfähigkeit und osmotische Concentration I 508;

Elektrochemische Methode zur Alkalescenzbestimmung I 508-512. - II 442;

Gefrierpunkterniedrigung des Serums nach Behandlung mit $\mathrm{CO}_{2}$ I 530 ;

Siehe auch unter ,Blut" und ,Blutserum".

Serumgehalt des Blutes. Bestimmung durch Leitfähigkeit I 517-524.

Sie in ens-Einheit I 39, 124 ;

Beziehung zum Ohm I 39.

Silbercyankalium als complexes Salz III 255.

Silber cyanwassers to f f säurean i on, Leitfähigkeit I 149.

Silberion, Wanderungsgeschwindigkeit (Leitfähigkeit) I 9, 42, 137;

Silbernitratlösungen, Leitfähigkeit I 29.

Silbersalze, Desinficirende Wirkung ihrer Kationen und Anionen IlI 258.

Sol III 60.

Specifische Leitfähigkeit I 120 .

Speichel II 421;

Gefrierpunkterniedrigung II 422;

$\Delta$ der Gld. submaxill. bei Sympathicusund Chordareizung il 422;

Beziehung zwischen Zunalıme der Absonderungsgeschwindigkeit und Procentgehalt an Salzen (H eiden ha in's Gesetz) II 422 ff.;

Einfluss intravenöser Salzinjection auf Menge und Zusammensetzung II 424;

Einfluss von Traubenzucker - Harnstoff - und Kochsalzinjection auf IIenge und Zusammensetzung II 426;

$I$ bei Uctopus macropus, Sepia officinalis, Aplysia limacina, Aplysia depilans II 431;
Speichel:

Osmotisches Verhalten der Drüsensubstanz II 431;

Einfluss von Gegendruck auf die $\mathrm{Zu}$ sammensetzung und $\Delta$ II 426 ;

Pliysikalische Erklärung des Absonderungsinechanismus II 427;

Speichelmenge nach intravenöser Injection liyperisotonischer Lösungen II 431 ;

Abhängigkeit der Speichelabsonderung von Nervenreizung II 432;

Wirkungsweise des Pilocarpins und Atropins II 433;

Bedeutung der Kataphorese II 433;

Schlussletrachtung II 436;

Speicheldrüsen bei hydrämischer Ple-

thora II 15.

Einfluss verschiedener Stoffe auf die Thätigkeit II 513.

Spermatozoen, Volumänderung durch

anisotonische Lösungen I 359;

Beeinflussung der Beweglichkeit durch Salze III 2;

Widerstandsfähigkeit gegen Aenderungen des osmotischen Druckes III 3;

Volumänderungen durch Salzlösungen III 4;

Bestimmung der procentischen Volumänderling (des Gerüstvolumens) III 5;

Vergleichung mit dem Gerïstvolumen der rothen Blutkörperchen derselben Thierart III 6 ;

Spinnengift III 343 .

Staphylolysin III 342 .

Stärkelösungen, Osınotischer Druck und Grösse des Molecüls III 65.

Staung, Farbstoffaustritt aus Blutkörperchen durch Salzlösungen I 280; Oertliche und allgemeine - als Ursache von Oedem und Hydrops II 88.

Staungshyperämie, Siehe venöse Stauung.

Stereoisomerer Zucker, Resorption seitens des Darmes II 200.

St tiboni umverbindungen, Leitfähigkeit, Tetramethylstibonium, Teträthylstibonium I 145. 
Stier, Zusammensetzung von Blut, Blutkörperchen und Serum I 506, 507.

St of f a u s ta u s : h z wischem mïtterlichem und fötalen Blut III 182.

Strömungsgeschwindigkeit des Blutes, Einfluss auf die Resorption II 111, 118, 194, 201.

Stroma der rothen Blutkörperchen. Verhalten gegenüber Wasser I 529;

Bindungsvermögen für $\mathrm{NaCl}$ I 531, 532; Biudung von Elektrolyten I 5s6;

Verhalten bei der Hämolyse III 354 , 362.

Stromtaster II 366.

Strontiumion, Wanderungsgeschwindigkeit (Leitfähigkeit) I 9, 42, 137, 138, 153.

Structur der Gewebezellen nach einfachem Absterben III 400;

bei nachträglicher Fixirung und Weiterbehandlung III $400,403$.

Structurbildung in Colloïdlösungen beim Uebergang von Hydrosol in $\mathrm{Hy}$ drogel III 398.

Strychnin, Leitfähigkeit I 146.

Stump fe Ränder bei trüber Schwellung III 51.

Sublimat als Fixationsmittel III 399.

Sublimatpastillen, Beeinflussung des desinficirenden Vermögens durch Hinzufügung von $\mathrm{NaCl}$ III 261.

Substance sensibilatrice III 351.

Succinursäure, Leitfähigkeit I 150.

Sulfiniumverbindungen, Leitfähigkeit von Trimethylsulfinium, T'riäthylsulfinium I 146.

Sulfonal, Permeabilität der Pflanzenzellen I 216.

Sulf os ä ure-Farbst of fe, Ursache der Unfähigkeit, intravitale Färbung herbeizuführen III 426 .

Suspensionen, Leitfähigkeit I 48;

Osmotischer Druck derselben III 64.

Synthesen, durch Enzyme beschleunigt III 96.

Syntonin, Erklärung der Präcipitirung durch Aufbebung der elektrischen Ladung III 69 .
$\mathrm{T}$.

Tanninmethode zur Untersuchung der Permeabilität von Pflanzenzellen für Alkaloïle, Pyridin etc. Uebertragung auf die thierische Zelle III 230.

Taurocholsaures Natron, Einfluss auf Gallen- und Lymphabscheidung II כ̌6.

Teleplon bei Widerstandbestinunungen I 118 ;

als Nullinstrument beim Compensationsverfahren II 365.

Telluriniumverbindungen, Leitfähigkeit, Trimethyltellurinium, 'Lriäthyltellurinium I 146.

Temperatur, Einfluss auf den Hämoglobinaustritt durch Salz- und Zuckerlösungen I 172;

Einfluss auf die Reactionsgeschwindigkeit II 471.

Temperaturcoëfficient I $42 ; 123$; bei der Leitfähigkeit.

der Lösungen von:

$\mathrm{KCl}, \mathrm{NH}_{4} \mathrm{Cl}, \mathrm{NaCl}, \mathrm{LiCl}, \mathrm{BaCl}_{2}, \mathrm{ZnCl}_{2}$, $\lg \mathrm{Cl}_{2}, \mathrm{KJ}, \mathrm{KNO}_{3}, \mathrm{NaNO}_{3}, \mathrm{AgNO}_{3}$, $\mathrm{Ba}\left(\mathrm{NO}_{3}\right)_{2}, \quad \mathrm{KClO} \mathrm{K}_{3}, \quad \mathrm{KC}_{2} \mathrm{H}_{3} \mathrm{O}_{2}, \mathrm{Li}_{2} \mathrm{SO}_{4}$, $\mathrm{Na}_{2}, \mathrm{SO}_{4}, \mathrm{Li}_{2} \mathrm{SO}_{4}, \mathrm{MgSO} \mathrm{SO}_{4}, \mathrm{ZnSO}_{4}, \mathrm{CuSO}_{4}$, $\mathrm{K}_{2} \mathrm{CO}_{3}, \mathrm{Na}_{2} \mathrm{CO}_{3}, \mathrm{KOH}, \mathrm{HCl}, \mathrm{HNO}_{3}$, $\mathrm{H}_{2} \mathrm{SO}_{4}$ I 133 ;

zwischen $26^{\circ}$ und $40^{\circ}$ bei verschiedenen Concentrationen von:

$\mathrm{KCl}, \mathrm{KJ}, \mathrm{KBr}, \mathrm{KNO}_{3}, \mathrm{NaCl}, \mathrm{LiCl}$, $\mathrm{BaCl}_{2}, \quad{ }_{2} \mathrm{IgCl}_{2}, \quad \mathrm{CuSO}_{4}, \quad \mathrm{NaCH}_{3} \mathrm{COO}$, $\mathrm{NaC} \mathrm{H}_{5} \mathrm{COO}, \mathrm{NaC}_{3} \mathrm{H}_{7} \mathrm{COO}, \mathrm{NaCHCl}_{2}-$ $\mathrm{COO}, \mathrm{Na}_{2}\left(\mathrm{C}_{2} \mathrm{H}_{4}\right)\left(\mathrm{CO}_{2}\right)_{2}: \mathrm{NaH}_{2} \mathrm{PO}_{2} \cdot \mathrm{NaOH}$, $\mathrm{HCl}, \mathrm{HBr}, \mathrm{HNO}_{3}, \mathrm{H}_{3} \mathrm{PO}_{4}, \mathrm{H}_{3} \mathrm{PO}_{2}$, $\mathrm{NaEl}, \mathrm{CH}_{3} \mathrm{COOH}, \mathrm{C}_{3} \mathrm{H}_{5} \mathrm{COOH}, \mathrm{C}_{2} \mathrm{H}_{7}-$ $\mathrm{COOH}, \mathrm{C}_{2} \mathrm{H}_{4}(\mathrm{COOH})_{2}, \quad \mathrm{CHCl}_{2} \mathrm{COOH}$, HEl I 134;

zwischen $2^{\circ}$ und $34^{\circ}$ bei verschiedenen Concentrationen ron:

$\mathrm{HCl}, \mathrm{HNO}_{3}, \mathrm{H}_{2} \mathrm{SO}_{4},\left(\mathrm{NH}_{4} \mathrm{Cl}, \mathrm{KCl}\right.$, $\mathrm{KNO}_{3}, \mathrm{~K}_{2} \mathrm{SO}_{4}, \mathrm{KJ}, \mathrm{NaCl}, \mathrm{NaNO}_{3}, \mathrm{Na}_{2}$ $\mathrm{SO}_{4}, \mathrm{AgNO}_{3}$ I 135

$\mathrm{BaCl}_{2}, \mathrm{BaNO}_{3}, \mathrm{IIgSO}_{4}, \mathrm{Na}_{2} \mathrm{CO}_{2}, \mathrm{H}_{3} \mathrm{PO}_{4}$, $\mathrm{C}_{2} \mathrm{H}_{4} \mathrm{O}_{2}, \mathrm{C}_{2} \mathrm{H}_{4} \mathrm{O}_{2}, \mathrm{C}_{2} \mathrm{H}_{4}(\mathrm{COOH})_{2}, \mathrm{C}_{2} \mathrm{H}_{2} \mathrm{O}_{4}$, $\mathrm{NaH}_{2} \mathrm{PO}_{4}, \mathrm{NaC}_{5} \mathrm{H}_{3} \mathrm{O}_{2}, \mathrm{NaC}_{4} \mathrm{H}_{5} \mathrm{O}_{4}, \mathrm{KOH}$ I 135 ; 
Temperaturcoëfficient:

zwischen $18^{\circ}$ und $99,4^{\circ}$ bei verschiedenen Concentrationen von:

$\mathrm{KCl}, \mathrm{KBr}, \mathrm{KNO}_{3}, \mathrm{KClO}_{3}, \mathrm{NaCl}, \mathrm{NaNO}_{3}$, $\mathrm{Na}_{2} \mathrm{SO}_{4}, \quad \mathrm{BaCl}_{2}, \quad \mathrm{Ba}\left(\mathrm{NO}_{3}\right)_{2}, \quad \mathrm{MgSO}_{4}$, $\mathrm{K}_{4} \mathrm{Fe}(\mathrm{CN})_{6}, \mathrm{HCl} \mathrm{I} 137$.

Temperaturoptimum bei der hatalyse durch organische und anorganische Katalysatoren III 94.

Testlösung I 232.

Tetanolysin III 342 ;

Geschwindigkeitsconstante (k) der Hämolyse durch dasselbe III 364;

Bindung durch Antitetanolysin, als eine Gleichgewichtsreaction aufgefasst; einheitliche Natur des Toxins III $369 \mathrm{ff}$;

Verbindungswärme bei "Neutralisation" durch Antitetanolysin III 386.

Tetraminroseocobaltion, Leitfähig. keit I 156.

Tetrathionsäureanion, Leitfähigkeit I 154

Tetrolsäure, Leitfähigkeit I 150 .

Thallium i on, Leitfähigkeit I 142.

Theilungsprincip, (Theorie d. Theilungscoëfficienten) III 246;

Beriicksichtigung d. Molecularzustandes der Substanz in beiden Medien III 246, 416; der elektrolytischen Dissociation III 247; der Temperatur III 247;

Bedeutung für die Narkose von poikilothermen Thieren III 251;

Methoden z. Ermittlung des Theilungs. coëffic. III 247;

Anwendung zur Kenntniss des Wirkungsmechanismus von indifferenten Narkotica III 249;

Beziehung zwischen narkotischer Kraft und Theilungscoüfficienten bei verschiedenen Substitutionsproducten III 251, 252;

Bedeutung der Art und der Menge des Quellungswassers des Colloïds für die Grösse des Theilungscoëfficienten III 415 .

Anwendung auf d. Harnsecretion II 411;
Theilungsprincip:

zur Erklärung der Thatsache, dass einmal die positiven (Metall-)Ionen, dann wieder die negativen (Säure-)Ionen des Salzes die Führung bei der Coagulation von Colloïden besitzen III 74,75 ;

bei der Erklärung der giftigen Wirkung reiner Salzlösungen und deren Entgiftung mittelst der elektrischen Ladung der Ionen III 130;

für den Grad der Permeab. d. Muskelsubstanz III 142;

Anwendung auf d. Desinfection IlI 252; zur Erklärung des günstigen Einflusses von $\mathrm{NaCl}$ auf d, desinficirende IVirkung von Phenol III 266;

Bedentung heim Einfluss des Lösungsmittels auf das desinficirende Vermögen von Sublimat und Silbernitrat III 267;

Anwendung auf die hämolytische Wirkung von Saponin III 341;

Anwendung auf den Angriffsmodus des Hämolysins III 357 ;

Anwendung bei der Hämolysinwirkung III $380,381,385$;

Anwendung bei der Agglutininbindung III 381,384 ;

Anwendung auf die Farbung von Gelatineplatten und auf die histologische Färbung III 419;

Berücksichtigung bei der Bacterienfärbung III 421 ;

Bedeutung für die intravitale Färbung III 426.

Thermoneutralität, Gesetz ner -, erklärt durch die Ionenlehre I 61 .

Thermostabile Substanz, Synonima III $351,352$.

Thermostat I 110.

Thiacetsäure, Leitfähigkeit I 150.

Thiodiglykolsäureanion, Leitfähigkeit I 155 .

Thioschwefelsä ureanion, Leitfähigkeit I 154.

Tliränendrüisen, Thätigkeit bei hydrämischer Plethora. 
Thräuen f l üs s igke it, Osmotischer Druck III 162;

Erscheinungen im Auge, durch Flüssigkeiten die gegenüber der Thrïmenflüssigkeit liyper- und hypisotonisch sind III 162.

Tiglinsä ure, Leitfähigkeit I 150

Titoxin III 379.

Toluolregulator I 111.

a.Toluylsäure, Leitfähigkeit I 151. m-Toluylsäure, Leitfähigkeit I 151. o-Toluylsäure, Leitfähigkeit I 151. p-Toluylsäure, Leitfähigkeit I 151.

Tonminimum des Telephons I 119;

Undeutlichwerden d. Tonminimums I119;

Genauigkeitsgrenze I 119.

Toxin an III 379.

Toxine, Eintheilung III 341;

Bindung durch Antitoxin III 368 ff.;

Beziehung zu ihrem Mleculargewicht und dem der entsprechenden Antitoxine III 386 ;

Schirmwirkung III 390.

Toxinspectrum, Siehe Giftspectrum.

Tox on III 369.

'Toxophore Gruppe des Amboceptors III 354.

Trach ea e pithel, Siehe Epithel der Trachea.

Tradescantia discolor I 162, II 3.

Transfusion fremden Blutes, Ursache der ungünstıgen Wirkung III 343.

Transsudat II 38 ; ل, N-, NaCl-Gelalt bei chron. interst. Nephritis und chron. parenchym. Nephritis II 286.

Transsudation II 63 .

Traubensäure, Leitfähigkeit I 152.

Traubenzucker, Permeab. der rothen Blutkörperchen I 213;

Begünstigung d. Oxydation durch Austausch von Blutbestandtheilen durch respiratorischen Gaswechsel I 279;

Lymphmenge nach intravenöser Injection II 3 ;

Resorption in der Bauchhöhle II 133;

Verhalten bei der normalen Nierenthätigkeit II 402, 416.

Siehe auch Dextrose.
Traubenzuckergelıalt des Serums, Beeinflussung durch Einwirkung v. $\mathrm{CO}_{2}$ und $\mathrm{O}$ auf das Blut I 265.

Trichloressigsäure, Leitfähigk. I 150.

Trichlormilchsäure, Leitfähigk. I 150.

Trichterförmige Rölırchen, Siehe Hämatokrit.

Trijodwasserst of f sä ureanion, Leitfähigkeit I 149.

Trinatriumphosphat $l$ os ungen, Leitfäbigkeit I 133.

Trinken bei ausgetrockneten Fröschen II 23.

Trinkw asser, Tauchelektroden f. Leitfähigkeitsbestimmung I 104.

Tritotoxin III 369 .

Trübe Schwellung III 49;

Siehe weiter unter "parenchymatöse Schwellung".

a-Truxillsäureanion, Leitfähigkeit I 156.

$\beta$-Truxillsäureanion, Leitfähigkeit I 156.

T u berkul ose bei Kalkarbeitern und bei Kartoffelnahrung I 281;

Vorkommen bei Klappenfehlern I 289; bei Kranklieiten der Pulmonalarterie I 289 ;

der Gliedmassen, behandelt mit venöser Stauung I 289.

Turgor I 161.

Tyndallphänomen III 62 .

U.

Uebercompensation(Uebərproduction). Weigert's Princip III 346.

Ueberführungszahlen I $39,42,71$.

Umkehrbare Reactionen. Gleichgewicht bei denselben II 476 .

Siehe auch unter "Gleichgewicht" und „Gleichgewichtsreactionen".

Umkehrbarkeit der Reaction bei der Wirkung organischer und anorganischer Kiatalysatoren III 94 ff.;

der Zustandänderung von Colloïden III 401; 
Un terk ü h l ung bei Gefrierpunkterniedrigung I 67,70 ;

Einfluss auf die Gefrierpunkterniedrigrigung (Tabelle) I 84.

Unterphosplorsäureanion, Leit. fähigkeit I 149.

Urämie I 473 ;

Osmotischer Druck des Blutes I 471; lymphtreibende Substanzen im Blute II 75 ;

$\Delta$ des Blutes II 268 287, 312.

Urate, Beeinflussung von $\Delta$ bei der Kryoskopie des Harns II 303.

Urethan, Permeabilität der rothen Blut körperchen I 215.

Urotoxischer Coëfficient des Harns II 327.

\section{V.}

Vacuolen in den rothen Blutkörperchen I 171.

V a lenz der Metalle, Einfluss auf das Coagulationsvermögen von Salzen III 69, 70;

der Säuren auf das coagulative Vermögen von Salzen III 72 ;

der Kationen bei der Entgiftung III 12 ; der Anionen bei der Entgiftung III $125 \mathrm{ff}$;

der Ionen, Bedeutung für die Entgiftung III 130 .

Valeriansäure, Leitfähigkeit I 150 ;

V asomotorische Einflüsse auf die Lymphabsonderung II 49;

Vena hepatica, Osmotischer Druck des Blutes I 467.

Vena porta, osmotischer Druck des Blutes I 467.

Ven ös e Stau ung, Einfluss auf das antibacterielle Vermögeu des Serums I 288; Behandlung der Tuberkulose der Glied. massen I 289; von syphilitischen, gonorrhoisclien, eitrigen Entziindungen, bei acutem Gelenkrheumatis. mus I 290; Erklärung der gïnstigen Wirkung I 290;
Venöse Stauung:

Einfluss auf die Gestalt der rothen Blutkörperchen I 312 ;

Einfluss auf die Chemotaxis I $413-416$; Einfluss auf die Nierentlıätigkeit II 419;

Ven̈̈ses und arterielles Blut, Grenzlösungen für den Farbstoffaustritt aus den rothen Blutkörperchen I 268; Vergleichung der chemischen Zusammensetzung des Serums I 268;

Venöses Blut, mit $\mathrm{O}$ behandelt. Einfluss auf Zusammensetzung des Serums und Plasmas I 269-271;

Osinotischer Druck nach dem Ertrinken II 19 ;

Verbindungswärme vou Tetanolysin und Antitetanolysin III 385.

Verdau ungs processe, Physikalischchemische Untersuchung II 463.

V erdünnung von Blut und Serum, Einfluss auf die Leitfähigkeit I 537, 539.

V erdünnungsgesetz Ostwald's II 480.

V e rdünnung s gra d von KBr-Lösungen, Einfluss auf letalen und toxischen Effect beim Froschlerzen III 239.

Vergleichende Blutuntersuchungen. Einfluss der Vertheilung der Blutbestandtheile auf dieselben in Folge der Eiuwirkung von $\mathrm{CO}_{2}$ und $\mathrm{O}$ I 276.

Verlängertes Mark, Einfluss der J) urchschneidung auf den osmotischen Druck des Blutes I 469.

Verseifung, Einfluss der Temperatur auf die Geschwindigkeitsconstante (k). II 473 .

Verseifungsm ethode zur Ermittelung des Grades der Hydrolyse II 485.

Vertheilung der Blutbestandtheile auf Körperchen und Serum (Plasnia) unter dem Einfluss des respiratorischeu Gaswechsels I 261, 266;

unter dem Einfluss der Temperatur I 275.

$\mathrm{V}$ iscosität III 66 ;

Aeuderung durch Elektrolyte (Ionen). III 128.

Volt II 378,380 . 
Volumändernngen der rothen Blutkörperchen durch hyper- und hypisoto. nische Lösungen; quantitative Bestimmung I 337-อิ59;

Uebereinstimmung mit weissen Blutkörperchen I 338, 339;

der woissen Blutkörperchen durch hyperu. hypisotonische Lösungen I $419-422$; der rothen Blutkörperchen bei der Hämolyse III 360;

in heterogenem Serum III 361.

Volum- und Dimensionsänder ungen der weissen Blutkörperchen durch $\mathrm{CO}_{2}$ und $\mathrm{O} 1402-405$.

$\mathrm{V}$ olumen der Blutkörperchen in mit dem Blutserum isotonischen und nicht-iso. tonischen Salzlösungen I 188;

der Blutkörperchen unter dem Einfluss isosmotischer Lösungen von verschiedener Concentration I 191-196; der rothen Blutkörperchen unter dem Einfluss von Säuren I $330-331$; voll Alkali I 332;

des Blutkörperchensedimentes. Einfluss der Undrehungsgeschwindigkeit der Centrifuge I 343-345;

der sämmtlichen Blutkörperchen im Blnte. Bestimmung durch Leitfähigkeit von Blut und Serum III 192.

Vorgeschichte von Colloïden III 85.

\section{IV.}

Wabenstructur III 29, 34, 398 ff.; Immer ein Kunstproduct? III 404.

Wahl des geeigneten Objectes bei biologischen Untersuchungen III 225.

W a lzen brücke I 115;

Siehe übrigens Messlurïcke.

W anderungsgeschwindigkeit isomerer Ionen I 46 ;

Verlangsamung durch bestimmte Additionen und Substitutionen I 4i;

Beschleunigung durch bestimmte Substitutionen I 47 ;

Siehe Leitfähigkeit; siehe auch die betreffendeu Ionen.

W anderungsahlen I 42.
IV a sser, Leitfäligkeit von reinem und gereinigtem destillirtem Wasser III 283 , 2\&4; siehe auch .,destillirtes WVasser".

VVasseranziehende Kraft I 13, 29; Ausfiilurlichere Behandlung I 21-2?.

W assera u fna hon efäh igke it der roth. Blutkörperchen, Grösse und Bedentung I 183-202;

und physiologische Kochsalzlösung I 187 ff.;

Zusammenfussung I 200; vergl. auch III 123.

Wassergehalt des Blutserums bei fieberhaften Krankheiten II 18.

IV asserretention bei Niereninsufficienz I 473.

Wa s serst of fio $n$, Wanderungsgeschwindigkeit (Leitfähigkeit) I 9, 42, 137, 142.

Wasserst offionen-Concentration, Controle der Bestimmung mittelst der OH'-Ionen-Concentration II $3 \triangleleft 6$.

Wasserst offsuperoxyd, Katalyse durch colloidales Platin, Reactionsverlauf III 84.

IV assersucht I 475 ; Behandlung I 474.

Watt II 379,380 .

Weigert's Princip der Uebercompensation III 346.

We in, Osmotischer Druck verschiedener Sorten; praktische Bedeutung III 320 .

We insä ure, Leitfähigkeit I 152 .

Weinsäureanion, Leitfähigkeit I 155 .

Weisse Blutkörperchen I 400-435; Siehe übrigens unter Leukocyten;

Beurtheilung ihrer Lebensfähigkeit I 400 ; Methoden der Gewinnung von Blutleukocyten aus Pferdeblut I 401; ans künstlichem und̄ natürlichem Exsudat I 402 ;

Einfluss des respiratorischen Craswechsels auf das Volumen I 402-405̃;

Einfluss von $\mathrm{CO}_{2}$, auf die Alkalinität von Leukocytenaufschwemmungen I 405 -409 ;

Einfluss von $\mathrm{CO}_{2}$ auf die antibacterielle Wirkung der Exsudatflüssigkeit I 409 -413 ; 
Weisse Blutkörperchen:

Einfluss von $\mathrm{CO}_{2}$ auf Chemotaxis und Aufnahmefähigkeit I 413-418;

Einfluss von Alkali und Säure auf den Durchmesser I 418, 419;

Volumänderungen durch hyper- und hypisotonische Lösungen I 419-423:

Permeabilität für Anionen I 423-432;

Zusammenfassung der gewonnenen Pie. sultate I $432-435$.

Worthigkeit, Siehe Valenz.

Weston-EI em ent, Elektromotorische liraft II 352.

Wheatstone'sche Brücke I 99.

Obach's Tabelle dazu I 139-141.

Widerstand, Siehe Leitfähigkeit.

Widerstandsca p a c it ät des Gefässes I 120 .

Widerstandsgefäss I 102 ;

für schlecht leitende Flüssigkeiten nach Ostwald I 102 ;

f. besser leitende $\mathrm{n}$. Kohlraus ch I 102 ; für Blut und andere Suspensionen nach

H a m burger I 103;

mit veränderlicher Capacität I 103;

Gefässe mit Tauchelektroden I 104;

für die Leitfähigkeitsbestimmung im

Thermostat II 383.

Siehe übrigens Elektroden;

WT o lf r a m s ä urean i on. Leitfähigkeit J 15 s.
Z.

Ze it d. Einwirkung, Nothwendigkeit ihrer Berücksichtigung b. vergleichenden Bestimmungen d. desinf. Vermögens III 268.

Zerstäubung v. Silbertheilchen IUI 62 .

Ziege, Zusammensetzung von Blutserum und Blutkörperchen I 506, 507.

Z i m m ts äur $\theta$, Leitfähigkeit I 151 .

Zinkchlorid, Siehe Cllorzink.

$\mathrm{Z}$ i n $\mathrm{k}$ i o $\mathrm{n}$, Wanderungsgeschwindigkeit (Leitfähigkeit) I 42, 138, 153.

Zinksulfat 1 ösung e n, Leitfähig. keit I 130

Zooid I 169.

Z u ckerarten, Permeabilität d. rothen Blutkörperchen I 213;

Permeab. der Pflanzenzellen I 216;

Permeab. d. rothen Bhutkörperchen und Pflanzenzellen I 217.

Zuckerinversion, Ostwald's Tabelle II 489 .

Zuleitwiderstände bei der Leitfähigkeitshestimmung I 113;

Berechnung von deren Grösse I 114.

Zust a ndänder u n g e n der Colloïde, Bedeutung für die Biologie III 65;

Siehe weiter unter "Colloïde".

Z w e r g f orm en b. künstlicher Parthenogenesis III 178.

Zwischenkör per III 351 .

Z y motoxis ch a Gruppe des Complementes III 351. 
In dieser Tabelle sind an Stelle der vom Autor ursprünglich gewäh!ten Farben die in der Heraldik üblichen Schraffirungen gesetzt und zwar

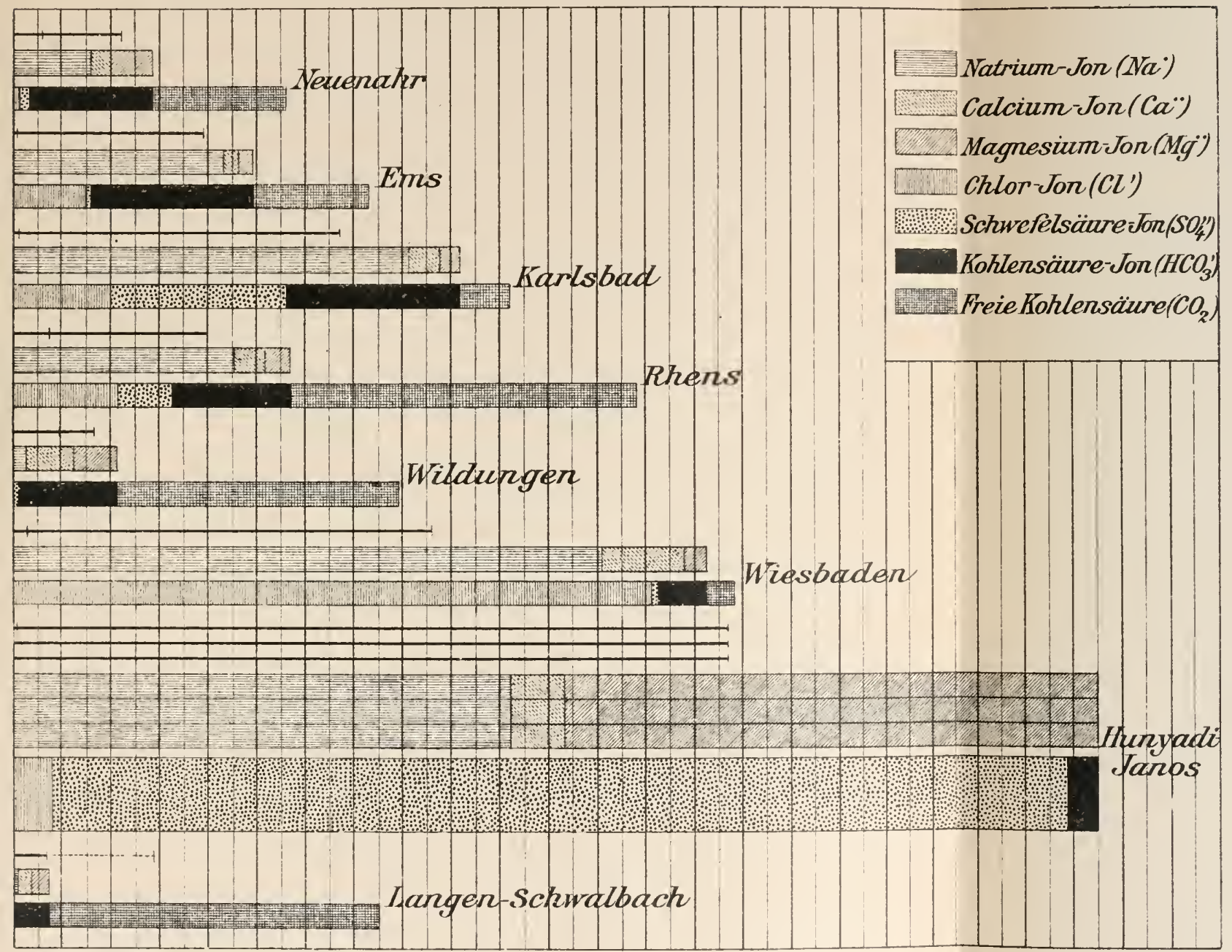

$\mathrm{Na}$ roth - $\mathrm{Ca} \cdot$ violett -- $\mathrm{Mg} *$ grün $-\mathrm{Cl}^{\prime}$ blau $-\mathrm{SO}_{4}$ " orange $-\mathrm{HCO}_{3}{ }^{\prime}$ schwarz $-\mathrm{CO}_{2}$ grau.

Fig. 4. 



\section{Ergebnisse der Physiologie.}

Erster Jahrgang, I. Abteilung.

Biochemie.

\section{Bearbeitet von}

Ferdinand Blumenthal, Berlin; G. Bredig, Heidelberg; M. Cremer, München; Friedr. Czapek, Prag; A lexander El I inger, Königsberg i. I'; E. Friedmann, Strassburg; O tto v on Fürth, Strassburg; E. Fuld, Halle; Ul of II a m marsten, Upsala; A. I effter, Bern; F. Hofmeister, strassburg; Martin J acoby, Heidelberg; Leo Langstein, Wien; l m manuel II unk, Berlin; W. Pauli, Wien; J. P. Pawlow, St. Petersburg; G. Rosenfeld, Breslau; Fr. N. Schulz, Jena; E. Schulze, Zürich; K. Spiro, Strassburg; H. Vogt, Strassburg; F r itzVoit, München; S i egfried W e b e r, Strassburg; Hugo Wi ever, Prag; E. Winterstein, Zürici.

\begin{tabular}{lcc}
\multicolumn{3}{c}{ Herausgegeben von } \\
L. Asher & und & K. Spiro \\
Bern. & & Strassburg i. E.
\end{tabular}

Preis llk. 22.60.

A uszug aus dem $\operatorname{lnhaltsverzeichnis.~}$

I. Allgemeine Physiko-Chemie der Zellen und Gewebe. Von W. Pauli, Wien.

Ia. Allgemeine Chemie der Eiweiss-Körper. Von F. H o f m e is ter, Strassburg.

II. Der Kreislauf des Schwefels in der organischen Natur. Von E. Friedmann, Strassburg i. E.

III. Uber die bei der Spaltung der Eiweisssubstanzen entstehenden basischen Produkte. Von E. S e hulze und E. Winterstein, Zürich.

IV. Die Bildung von Kohlehydraten aus Eiweiss. Von L. Langs te in, Wien.

V. Zur Gewebschemie des Muskels. Von Otto von Fürth, Strassburg.

VI. Die Elemente der chemischen Kinetik, mit besonderer Berücksichtigung der Katalyse und der Fermentwirkung. Von G. B redig, Heidelberg.

VII. Über die Bedeutung der intracellularen Fermente für die Physiologie und Pathologie. Von M a r t in J a coby, Heidelberg.

VIII. Die physiologische Chirurgie des Verdauungskanals. Von J. P. Paw low, si. Petersburg.

1X. Über Cerebrospinalflüssigkeit. Von Ferd. B l u menthal, Berlin.

X. Resorption. Von Immanuel II unk, Berlin.

XI. Über die Eiweissstoffe des Blutserums. Von O. H a m marsten, Upsala.

XI!. Die Bildung der Lymphe. Lon A lex. Ellinger, Königsberg i. Pr.

XIII. Chemische Physiologie der Nierensekretio niederer Tlere. Von Otto von Fürth, strassburg.

XIV. Physiologie der Harnabsonderung. Vou K. S pirou. H. Vogt, Strassurg

XV. Chemie des Harns. Von A. Hetfter, Bern.

XVI. Über Milchgerinnung. Von E. Fuld, Halle.

XVIa. Kohlehydratstoffwechsel. Von M. Cremer, München.

XVII. Die physiologische Farbstofibildung beim höheren Tiere. Vou Fr. N. c c hulz. Jena.

XVIII. Uber die Harnstofibildung im Organismus. Von M. J a coby, Heidelberg.

IIX. Die Harnsäure. Von Hugo Wiener, Prag.

XX. Fettbildung. Von Gr. liosenfeld, Breslau.

XXI. Nahrungsstoffe. Von F ritz Voit, Mïnchen.

XXII. Tber Hungerstoffwechsel. Ton Siegfried Weber, Strassburg.

XXII. Über einige bemerkenswerte Fortschritte auf dem Gebiete der PflanzenBiochemie im Jahre 1901. Von Friedrich C'zapek, Prag. 


\section{Ergebnisse der Physiologie.}

Erster Jahrgang, II. Abteilung.

\section{Biophysik und Psychophysik.}

\section{Bearbeitet von}

L. Asher, Bern; W. Bi edermann, Jena; R. du Bois-Reymond, Berlin; H. Boruttau, Göttingen; W. Eintboven, Leiden; R. Gottlieb, Heidelberg; P. Grützner, Tübingen; V. II ensen, Kiel; H. E. Hering, Prag; F. B. H ofmann, Leipzig; P. Jeusen, Breslau; O. Langendorff, Rostock; R. M agnus, Heidelberg; H. Meyer, Marburg; G. v. Monakow, Zürich; H. Przibram, Wien; E. H. Starling, London; R. Tigerstedt, Helsingfors (Finnland); A. 'T's chermak. Halle a. S.; J. vo n Uexküll, Neapel; H. $\mathrm{Z}$ wa a r d e maker, Utrecht.

\begin{tabular}{lcc}
\multicolumn{3}{c}{ Herausgegeben von } \\
L. Asher & und & K. Spiro \\
Bern. & & Strassburg i. E.
\end{tabular}

Preis Mk. 25.-

A uszug aus dem Inhaltsverzeichnis.

I. Die Protoplasmabewegung. Von P. Jensen, Breslau.

II. Regeneration. Von H. Przi bram, Wien.

III Elektrophysiologie. Von W. Biedermann, Jena.

IV. Nerv- und Muskelgifte. Von H. Me y er, Marburg.

V. Physiologie und Biologie in ihrer Stellung zur Tierseele. Von J. v. U exküIl, Neapel.

VI. Intrakardialer Druck und Herzstoss. Von R. Tigerstedt, Helsiugfors.

VII. Herzmuskel und intrakardiale Innervation. Von O. L angendorf, Riostock.

VIII. Die Innervation der Gefässe. Von L. A s her, Bern.

IX. Mechanik der Atmung. Von R. du Bois-Reymond, Berlin.

$\mathrm{X}$. Innervation der Atmung. Von H. Boruttau, Göttingen.

II. Pharmakologie der Atemmechanik. Ton R. M a g n u s, Heidelberg.

XII. Überblick über den gegenwärtigen Stand der Kenntnisse über die Bewegungen und Innervation des Verdauungskanals. Von E. H. St a rling, Londou.

XIII. Stimme und Sprache. Von P. Grützı er, Tübingen.

XIV. Die intrazentralen Hemmungsvorgänge in ihrer Beziehung zur Skelettmuskulatur. Ton H. E. Hering, l'rag.

XV. Über den gegenwärtigen Stand der Frage nach der Lokalisation im Grosshirn. Ion C. von $M 0 \mathrm{nakow}$, Zürıch.

XVI. Theorie der Narkose. Von R. Got tli eb, Heidelberg.

XVil. Die Akkommodation des menschlichen Auges. Von W. Einthoven, L,eiden.

XYIII. Die Hell-Dunkeladaptation des Auges und die Funktion der Stäbchen und Zapfen. Vim A. Tsclierma.., Halle.

XIX. Die neueren Untersuchungen über das Sehen der Schielenden Von F. 1). Hot in a n $n$, Leipzig.

XX. Die Fortschritte in einigen Teilen der Physiologie des Gehörs. Von V. Heus eu, Kiel.

XX1. Geruch. Von II. Zw a a r demaker, Utrecht. 


\section{Ergebnisse der Physiologie.}

\section{Zweiter Jahrgang, I. Abteilung. Biochemie.}

Bearbeitet von

K. Basch, Prag, O. Cohnheim, Heidelberg, F. Czapek, Prag, O.v. Fii tr t, Strassburg, A. Hefter, Bern, A. Jaquet, Basel, A. Loewy, Berlin, A. Noll, Jena, R. W. Raudritz, Prag, G. Rosenfeld, Breslau, Tr. N. Schulz, Jena, C. Speck, Dillenburg, H. W i en er, Prag.

$\begin{array}{lcr} & \text { Herausgegeben von } \\ \text { L. Asher } & \text { und } & \text { K. S pi ro } \\ \text { Bern. } & & \text { Strassburg i. E. }\end{array}$

Preis M. 18.60 .

In halt $\mathrm{s}-\mathrm{V}$ er ze i c h $\mathrm{n}$ is.

I. Über Kraft- und Ernährungsstoffwechsel. Von $($. s s e ck, Dillenburg.

II. Fettbildung (II. Teil). Von ( e o r g $R$ os en feld, Breslau.

III. Die Ausscheidung körperfremder Substanzen im Harn. I. Teil: Anorgauische Verbindungen. Von A. Hefter, Bern.

IV. Neuere Untersuchungen zur Physiologie der Geschlechtsorgane. Ton A. Loew y, Berlin.

V. Über einige Farbstoffe des Harns, ihre Entstehung und Bedeutung. Vou Fr. N. Schuiz, Jena.

VI. Bestandteile, Eigenschaften und Veränderungen der Milch. Von R. W. Ra u d n it $z$, Prag.

VIJ. Die Physiologie der Milchabsonderung. Von K. Bas c h, Prag.

VIII. Die Harnsäure in ihrer Bedeutung für die Pathologie. Ton II ugo Wi ener, Prag.

IX. Bildung und Regeneration der roten Blutkörperchen. Ton A. Noll Jeua.

X. Der respiratorische Gaswechsel. Von A. Jaquet, Basel.

XI. Über chemische Zustandsänderungen des Muskels. Von O. v. F ürth, strassburg.

XII. Physiologie des Alpinismus. Von O, Cohnheim, Heidelberg.

XIII. Der Stickstoff im Stoffwechsel der Pflanze. Von F. Czapek, Prag.

Nekrolog. - A utoren-Register.

.. Aus dieser Übersicht geht hervor, dass das bereits augedeutete Programm auch bereits sehr glücklich verwirklicht worden ist: Die sämtlichen genannten Kapitel sind Forschern übertragen, welche selbst zum Ausbau des einschlägigen Gebietes durch eigene Arbeit sehr wesentlich beigetragen haben. Die heutige wissenschaftliche Produktion, die gute und die schlechte, nehmen für jeden, der zum ganzen strebt, einen geradezu unheimlichen Umfang an. Gerade wir etwas Fernsteheuden können doppelt dankbar sein, wenn uns das so stark zerstreute physiologische Material in einem solchen, allen Anforderungen genügenden Zusammonhang geboten wird. Mag es sich um einen forschenden oder um einen praktischen Ar'zt handeln, wer diesen Band als Ratgeber berangezogen hat, wird für sein Denken und Tun wirklich Vorteil gewinnen. Geh.-R. Prof. F. Kraus-Berlin i. d. Deutsch, med. Wochenschr. 


\section{Ergebnisse der Physiologie. Zweiter Jahrgang, II. Abteilung. Biophysik und Psychophysik.}

\section{Bearbeitet von}

W. Biedermann, Jena; R. du Bois-lieymond, Berlin; F. B. H ofmann, Leipzig; O. Langendolff, Rostock; J. N. Langley, Cambridge; R. Magnus, Heidelberg; G. E. M üller, Göttingen; A. P ït 1 er, Göttingen; R. Som mer, Giessen; R. Tiegerstedt, Helsingfors; A. Tschermak, Halle;

H. Z wa ardema ker, Utrecht.

$\begin{array}{ccc}\text { Herausgegeben von } & \text { und } \\ \text { (Bern) } & & \text { K. Spiro } \\ \text { (Strassburg i. E.) }\end{array}$

Picis Mk. 2t.-

Inhalt :

I. Die Flimmerbewegung. Von A. Pütter in Göttingen.

II. Elektrophysiologie. Von W. B i ed erm a n n, Jena.

III. Die Gesichtspunkte und die Tatsachen der psychophysischen Methodik. Von G. E. M ïll er, Göttingen.

IV. Über den Einfluss verschiedener Temperaturen auf die Herztätigkeit. Von O. Lang e u d o r f $\mathrm{f}$, Rostock.

V. Der kleine Kreislauf. Von R. T i g e r st edt, Helsingfors.

VI. Gelenkbewegung. Spezielle Muskelphysiologie. Stehen und Gehen. Von R. du bois-Reymund, Berlin.

VII. Pharmakologie der Magen- und Darmbewegungen. Von R. Magnus, Heidelberg.

VIII. Die Messung der Zeit bei psychophysischen Versuchen. Von R. Sommer, Giessen.

IX. Geschmack. Von H. Z w a a r demaker, Utrecht.

$\mathrm{X}$. Über Kontrast und Irradiation. Von A. Ts e hermak, Halle.

XI. Einige Fragen der Augenmuskelinnervation. Von F. B. Hofmann, Leipzig.

XII. Das sympathische und verwandte nervöse System der Wirbeltiere (autonomes nervöses System). Von J. N. Langley, Cambridge.

A utoren-Register.

Der Plan des Werkes ist breit angelegt worden. Es wurden nicht nur die Ergebnisse der experimentellen Physiologie im engeren Siune des Wortes berücksichtigt, sondern die experimentelle Pathologie, die Pharmakologie, die klinische Medizin und die Entwickelungsgeschichte insofern herangezogen, als auf diesen Gebieten Tatsachen zutage gefördert wurden, die zur Aufklärung unserer Kenutnisse der tierischen Lebensvorgänge beigetragen haben. Auf diese Art bilden die Ergebnisse eine wirkliche Gruudlage der gesamteu medizinischen Experimentalforschung; der Kliniker und der experimentelle Patho$\log \theta$, der Augenarzt und der Otologe, ja selbst der praktische Arzt, der im Kontakt mit der wissenschaftlichen Forschung zu bleiben wïnscht, können das Werk ebensowenig entbehren, als der Physiologe cder der Pharmakologe. Der Rahmen eines Referates gestattet mir nicht, auf die einzelnen Essays einzugehen, die vielfach hervorragende Leistungen sind. Welche Fülle von Arbeit in diesem Band kondensiert wurde, geht hervor aus den umfangreichen Literaturverzeichnissen; so führt $\mathrm{Przibram}^{\circ}$ nicht weniger als 968 Nummern an, L, angendorff 322 , von Monakow 846.

Prof. Jaquet i. Korrespondenzbl. f. Schweiz. Ärzte. 
Verlag von J. F. Bergmann in Wiesbaden.

\section{Ergebnisse der Physiologie. \\ Dritter Jahrgang, I. Abteilung. Bioehemie.}

Bearbeitet von

W. O. Atwater, Middletown; R. Burian, Leipzig; W. Connstein, Berlin; F. Czapek, Prag; S. Fränkel, Wien; D. Gerhardt, Erlangen; L. Langstein, Berlin; O. Loewi, Marburg; C. Neuberg, Berlin; W. P a u li, Wieu;

J. P. Pawlow, St. Petersburg; J. Seemann, Marburg; S. Weber, Köln.

L. Asher, $\begin{aligned} & \text { Herausgegeben von } \\ & \text { Bern. }\end{aligned} \quad$ und

Inhalt:

Preis Mk. 18.60 .

I. Untersuchungen über Kraft- und Stoffwechsel am Respirationskalorimeter. Von IW. O. A t w a ter, Middletown.

II. Chemie der Spermatozoen. Vou R. B urian, Leipzig.

III. Über fermentative Fettspaltung. Von W. Connstein, Berlin.

IV. Der Stickstoff im Stoffwechsel der Pflanze. Von F. Czapek, Prag.

V. Stereochemisch bedingte Wirkungsdifferenzen und identische Wirkungen. Von s. Fr änkel, IVien.

VI. Über Darmfäulnis. Von D. Gerhar d t, Erlangen.

VII. Die Kohlehydratbildung aus Eiweiss. Von L. Langstein, Berlin.

VIIl. Pharmakologie des Wärmehaushalts. Von O. Loewi, Marburg.

IX. Pentosen und Glykuronsäuren. Vou C. Neuberg, Berlin.

X. Allgemeine Physiko-Chemie der Zellen im Gewebe. Von W. Pauli, Wien.

XI. Psychische Erregung der Speicheldrüse. Von J. P a w low, St. Petersburg.

XII. Die blutbildenden Organe. Von J. S e e mann, Marburg.

XIII. Der allgemeine Stoffwechsel unter dem Einfluss pharmakologisch wirksamer Substanzen. Vou S. W e ber, Cölı.

Lehrbuch der Haut- u. Geschlechtskrankheiten.

Von Professor Dr. Ed. Lang in Wien.

I. Band: Hautkrankheiten. Mit 87 Abbildungen. Mk. 14.60

II. Band: Geschlechtskrankheiten. Mit 85 Abbildnngen. Mk. 10.40

Handbuch der allgemeinen u. speziellen Hydro-

therapie. Von Dr. L. Schweinburg. Nebst einem Beitrage vou logie und Geburtshülfe. $\quad$ Ik. 6.-, gebunden Mk. 7.-

Chirurgie der Notfälle. Darstelluug der dringenden chirurgischen Eingriffe. Von Dr. H. Kaposi.

Geb. Ml. 5.30

Grundriss zum Studium der Geburtshülfe. In 28

lesungen und 578 bild I chen Darstell ungen. Vou Prof. Dr. E. Bumm in Halle. $Z$ weite vermehrte Auflage. 
Soeben neu erschienen :

\section{Lehrbuch}

\section{der \\ Physiologischen Chemie \\ von}

\section{Olof Hammarsten,}

o. ö. Professor der medizinischen und physiologischen Chemie an der Universität Upsala.

Fïnfte völlig umgearbeitete Anflage.

Preis Mk. 17.-, geb. Mk. 19.-.

Inhalt: I. Einleitung. - II. Die Proteïnstoffe. - III. Die Kohlehydrate. -- IV. Das Tierfett. - V. Die tierische Zelle. VI. Das Blut. - VII Chylus, Lymphe, Transsudate und Exsudate. - VIII. Die Leber. - IX. Die Verdauung. - X. Gewebe und Bindesubstanzgruppe. - XI. Die Muskeln. - XII. Gehirn und Nerven. - XIII. Die Fortpflanzungsorgane. - XIV. Die Milch. - XV. Der Harn. - XVI. Die Haut und ihre Ausscheidungen. - XVII. Chemie der Atmung. - XVIII. Der Stoffwechsel bei verschiedener Nahrung und der Bedarf des Menschen an Nahrungsstoffen. - Nachträge. - Sachregister.

... Es ist ein Vergnügen, sich au der Hand eines so klar geschriebenen Buches, wie das vorliegende, über behiebige physiologisch-chemische Fragen zu orientieren. Selbst so komplizierte Vorgänge, wie die Blutgerinnung, über welche die verschiedensten Meinungen bestehen, werden so klar und ruhig auseinandergesetzt, dass Jeder danach eine Vorstellung der wirklich feststehenden Tatsachen bekommt. Möge das Buch zu den Frounden, welche es schon hat, noch recht viele neue hinzuerwerben.

Chemiker-Zeitung.

... Zweifellos wird sich das treffliche Werk auch in seiner neuen, erweiterten Form eines grossen Leserkrises er freuen.

Münehener med. Wochenschrift.

... Rasch folgen die Auflagen dieses unter Ärzten so beliebten Werkes aufeinander. Und mit Recht! Greifen doch die Kenntnisse, die hier dargestellt werden, ebenso in die letzten Fragen des Lebens ein, wie sie Anweisungen geben, von denen der Praktiker täglich Gebrauch machen muss. In lichtvoller Schilderung findet man diese Materien hier wiedergegeben und nirgends vermisst man den Eindruck der meisterhaften Beherrschung des Stoffes.

Deutsche Medizinal-Zeitung. 
Verlag von J. F. Bergmann in Wiesbaden.

Soeben erschien:

Die

Anwendung der physikalischenn C'hemie auf die Physiologie und Pathologie.

Von

\section{Dr. Richard Brasch,}

Bad Kissingen.

Preis Mk. 4.80.

A uszug aus dem Inlaltsverzeichnis:

\section{Physikalische Chemie der Salze.}

I. Die Elemente, ihre physikalischen und chemischen Eigenschaften in bezug auf den menschlichen Organismus.

H. Die anorganischen Salzlösungen im menschlichen Organismus:

1. Die anorganischen Salzlösungen im allgemeinen.

2. Berechnung der Ionen und Salze einiger Lösungen anorganischer Salze im menschlichen Organismus.

3. Die Erhaltung der Alkaleszenz des Blutes.

4. Die anorganischen Salzlösungen als Leiter der Elektrizität.

III. Die Beziehungen der anorganischen Salze zu den verschiedenen Zellensystemen:

1. Die Beziehungen der anorganischen Salze zu den Zellen im allgemeinen.

2. Die Resorption der anorganischen Salze.

3. Die anorganischen Salze in den Blutzellen.

4. Die anorganischen Salze der Knochenzellen.

5. Die anorganischen Salze in den Nieren.

6. Die Funktionen der anorganischen Salze in den Zellen.

7. Der osmotisclie Druck.

8. Die physikalisch-chemische Beschaffenheit der Zellenmembran.

II. Die Oxydationsprozesse im menschlichen Organismus.

1. Einleitung.

2. Der Meclianismus der Oxydation.

3. Die Ausscheidung der Oxydationsprodukte.

4. Die Intensität des Oxydationsprozesses.

5. Die Oxydation der organischen Stoffe.

6. Die Oxydation der anorganischen Stoffe,

\section{Die Energetik des menschlichen Organismus.}

1. Die Bildungswärme, die Reaktionswärme und der Brennwert im allgemeinen.

2. Berechnung und Vergleich der Energieentwickelung aus den einzelnen Nahrungsstoffen.

3. Die Energieverluste.

4. Die Umwandlung der chemischen Energie in mechanische Arbeit.

5. Die direkt von aussen zugeführte Energie.

6. Dis physikalische Chemie des Gesamtstoff wechsels.

7. Die physikalische Chemie der Ernährung.

8. Die physikalische Chemie der Fettsucht.

9. Die physikalische Chemie des Fiebers. 
Verlag von J. F. Bergmann in Wiesbaden.

\title{
Osmotischer Druck und Ionenlehre
}

in den

\author{
medizinischen Wissenschaften. \\ Zugleich Lehrbuch physikalisch-chemischer Methoden. \\ Vou
}

Dr. chem. et med. H. J. Hamburger,

Professor der Physiologie an der Reichsuniversität Groningen.

Rand I: Physikalisch-chemisches uiber osmotischen Druck und elektrolytische Dissoziation. - Bedentung des osmotischen Drucks und der elektrolytischen Dissoziation für die Plıysiologie und Pathologie des Blutes.

Band II: Zirkulierendes Blut. Lymphbildung. - Ödem und HydropsResorption. - Harn und sonstige Sekrete. Elektrochemische Aziditätsbestimmung. Reaktions-Verlauf. Preis Mk. 16.-.

Die Bedentung der physikalischen Chemie für die medizinischen Wissenschaften ist in den letzten Jahren gelegentlich vou Rezensionen in diesem Blatte öfters hervorgehoben worden. Professor $\mathrm{Hamburger}$ steht in der vordersten Reihe vou denjenigen Forschern, welche durch umfassende und kritische Anwendung der physikalisch-chemischen Methoden und Lehren der mediziuischen Wissenschaft neue Wege gehahnt haben. Die Erwartung, dass ein solcher Forscher für ein zusammenfassendes Lehrbuch der geeignetste Nann sei, wird durch das vorliegende schöne Werk erfüllt. Die neueren physikalisch-chemischen Lehren sind darin mit grosser Klarheit und in sehr erschöpfender Weise dargestellt. Mit ganz besonderer Sorgfalt sind die mannigfaltigen, zum Teil schwierigen Methoden beschrieben, so dass jeder, der in die Lage kommt, praktiscl mit denselben arbeiten zu müssen, alles was nötig ist, vorfindet. Trotz der Klarheit und Leichtfasslichkeit sind aber, was hervorgehoben $\mathrm{zu}$ werden verdient, überall eingehend und kritisch, erstens die nicht zu entbehrende strenge Exaktheit, zweitens die etwas tiefer eindringenden theoretischen Fragen berücksichtigt. Soweit die beiden wichtigen Lehreu von dem osmotischen Druck und den Ionen in Frage kommen, ist Hamburgers Buch für den Mediziner, welcher sich gründliche Kenntnisse verschaffen will, wohl zur Zeit das beste Werk.

Der zweite Hauptteil des vorliegenden Bandes behaudelt die Bedeutung des osmotischen Drucks und der elektrolytischen Dissoziation für die Physiologie und Pathologie des Blutes, ein Kapitel von Beziehungeu, welches recht eigentlich durch $\mathrm{H}$ a m b u rer zu einem anschaulichen und selbständigen Lehrgebäude gestaltet worden ist. Eine schier erdrückende Fülle von Tatsachen sind hier niedergelegt und die zahlreichen Ausblicke auf wichtige praktische Fragen lehren, dass kein müssiger Ballast von Gelelırsamkeit aufgestapelt wurde. Theorie, Tatsachen und Methoden sind gleichmässig berücksichtigt. Die zahlreichen Tabellen, welche dem Buche beigegeben sind, machen dasselbe zu einem unschätzharen Nachschlagewerk.

Professor L. Asher (Beru) i. Korrespondenzblatt f. Schweizer Ärzte.

Mit diesem Werk ist der Groninger Physiologe, dem wir eine Reihe wertvoller physikalisch-chemischer Arbeiten über das Blut verdanken, einem wahren Bedürfnis entgegengekommen ....

.... In meisterhafter Weise hat es $\mathrm{H}$ a m bur ger verstanden, das ausgezeichnete Gebiet so zu bearbeiten, dass jede eiuzelne Frage für sich in objektivkritischer Weise gesichtet und für den Leser, der sich rascl zu orientieren wünscht, in zusammenfassender Weise heantwortet ist. Es ist überraschend, wie die wichtigsten Fragen der physiologischen und klinischen Hämatologie unter dem Einfluss der physikalischen Chemie in neue Beleuchtung gerückt sind . ...

.... Sehr wertvoll ist auch die Aufnalime aller für den Laboratoriumsgebrauch wichtigen Zahlen in Tahellenform. Das Buch wird allen, die sich mit diesen Fragen beschäftigen, unentbelırlich sein. Münehn. med. Wochenschr.

Das Manuskript des dritten (Scliluss-) Bandes befindet sich bereits in der. Druckerei und erscheint derselbe in aller Ḱürze. Dieser schlussband wird enthalten: Sonstige isolierte Zellen, Kolloide und Fermente, Muskelund Nervenphysiologie, Pharmakologisches, Bakteriologisches. Balneologisches, Histologisclies. 
